\title{
Which of the (mixed) halogenated n-alkanes are likely to be persistent organic pollutants?
}

\author{
Xiaolei Li ${ }^{1}$, Tannia Chevez ${ }^{1}$, Amila O. De Silva ${ }^{1,2}$, Derek C. G. Muir ${ }^{2}$, \\ Sonya Kleywegt ${ }^{3}$, Andre Simpson ${ }^{4}$, Myrna J. Simpson ${ }^{4}$, Karl J. Jobst ${ }^{1, *}$
}

${ }^{I}$ Department of Chemistry, Memorial University of Newfoundland, St. John's, NL, Canada A1B $3 X 7$

${ }^{2}$ Canada Centre for Inland Waters, Environment and Climate Change Canada, Burlington, ON,

Canada L7S $1 A 1$

${ }^{3}$ Technical Assessment and Standards Development Branch, Ontario Ministry of the Environment, Conservation and Parks, Toronto, ON, Canada M4V $1 M 2$

${ }^{4}$ Departments of Chemistry and Physical \& Environmental Sciences, University of Toronto, ON, Canada MIC $1 A 4$

*Corresponding author: kjobst@mun.ca

Table of Contents

Figure S1. Partitioning space for 184,600 PXAs with fluoride, chloride and bromine atom number as a color bar

Table S1. The physical-chemical properties of all $\mathrm{C}_{10} \mathrm{H}_{18} \mathrm{Cl}_{4}$ isomers predicted by EPISuite

Table S2. Partitioning coefficients computed using DFT(MO6-2X) and experimentally determined values of available halogenated n-alkanes, with the statistics shown

Table S3. The breakdown of screened compositions using experimental and DFT correction.

Table S4. Different categories of screened PXAs number separated against categories of 184,600 PXA under different resolution 

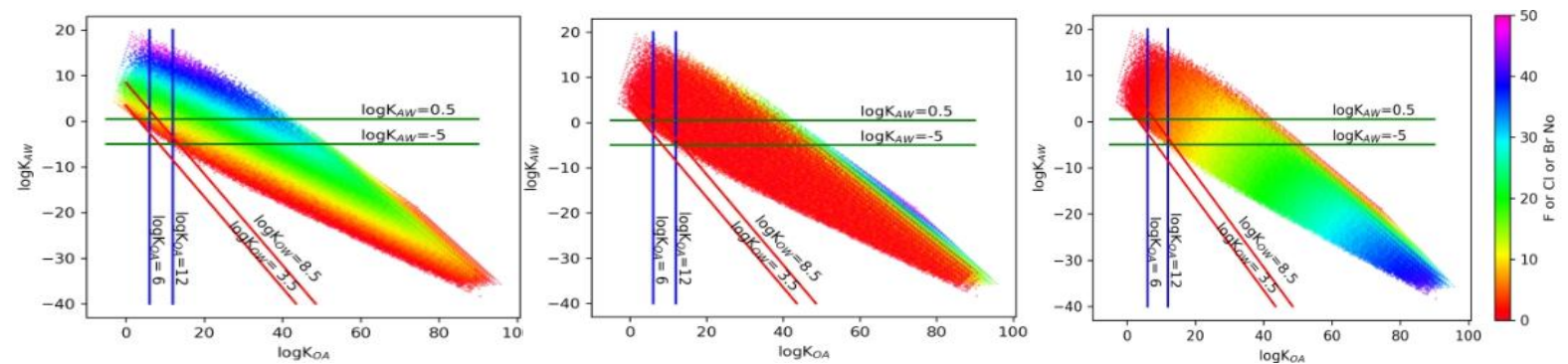

Figure S1. Partitioning space for 184,600 PXAs

(a)Color bar: the number of fluorine atoms in the composition; (b) Color bar: the number of chloride atoms in the composition; (c) Color bar: the number of bromine atoms in the composition

Note: blue line: the log $\mathrm{K}_{\mathrm{OA}}$ range in Brown and Wania criteria; Green line: the log $\mathrm{K}_{\mathrm{AW}}$ range in Brown and Wania criteria; Red line: the log $\mathrm{K}_{\mathrm{ow}}$ range derived from log $\mathrm{K}_{\mathrm{OW}}=\log \mathrm{K}_{\mathrm{OA}}+\log$ $\mathrm{K}_{\mathrm{AW}}$ in Brown and Wania criteria. 
Table S1. The physical-chemical properties and statics of all $\mathrm{C}_{10} \mathrm{H}_{18} \mathrm{Cl}_{4}$ isomers predicted by EPISuite

\begin{tabular}{|c|c|c|c|c|c|c|c|c|c|}
\hline & logKow & $\log K_{O A}$ & $\log K_{A W}$ & $\begin{array}{l}\text { Water_H } \\
\text { (days) }\end{array}$ & $\begin{array}{l}\text { Water_HL } \\
\text { (hours) }\end{array}$ & $\mathrm{BCF}$ & $\begin{array}{l}\text { Fish_HL } \\
\text { (days) }\end{array}$ & BAF & $\begin{array}{l}\text { Atmos_HL } \\
\text { (days) }\end{array}$ \\
\hline Min & 5.82 & 6.047 & -0.227 & 92.2 & 2212.5 & 202.7 & 6.48 & 4757 & 0.94 \\
\hline Max & 7.46 & 7.687 & -0.227 & 913.6 & 21927.2 & 14000.0 & 48.70 & 1162598 & 14.51 \\
\hline Mean & 6.23 & 6.45 & -0.227 & 291.5 & 6997.1 & 6589.4 & 12.50 & 60536 & 2.36 \\
\hline \multirow[t]{2}{*}{ SD } & 0.361 & 0.361 & 0 & 109.2 & 2620.1 & 3631.5 & 5.42 & 93125 & 1.04 \\
\hline & & slope ir & intercept & $\mathrm{R}^{2}$ & $\mathrm{R}$ & MAE & MSE & RMSE & MAPE \\
\hline \multicolumn{2}{|c|}{$\log K_{O W}, \log K_{\mathrm{OA}}$} & 1.15250 & & 0.9498 & 0.974577 & 0.7026 & 0.7397 & 0.8600 & 0.7343 \\
\hline \multicolumn{2}{|c|}{$\log K_{o w}$} & & & & & 0.5046 & 0.3911 & 0.6254 & 0.2284 \\
\hline \multicolumn{2}{|c|}{$\log K_{O A}$} & & & & & 0.9532 & 1.2694 & 1.1267 & 0.3618 \\
\hline \multicolumn{2}{|l|}{$\log K_{A W}$} & & & & & 0.9763 & 0.6136 & 0.7833 & 0.6018 \\
\hline
\end{tabular}


Table S2. Partitioning coefficients computed using DFT(MO6-2X) and experimentally determined values of available halogenated $n$-alkanes, with the statistics shown below

\begin{tabular}{|c|c|c|c|c|c|c|}
\hline SMILE & $\begin{array}{l}\text { logKow_ } \\
\text { Experimental }\end{array}$ & $\begin{array}{l}\operatorname{logK}_{\mathrm{OA}_{-}} \\
\text {Experimental }\end{array}$ & $\begin{array}{l}\log \mathrm{K}_{\mathrm{AW}}- \\
\text { Experimental }\end{array}$ & $\begin{array}{l}\text { logKow_ } \\
\text { DFT }\end{array}$ & $\begin{array}{l}\log _{\mathrm{OA}_{-}} \\
\mathrm{DFT}\end{array}$ & $\begin{array}{l}\log _{\mathrm{AW}} \\
\text { DFT }\end{array}$ \\
\hline $\begin{array}{l}\mathrm{C}(\mathrm{CC}(\mathrm{CC}(\mathrm{CC}(\mathrm{CC}(\mathrm{C}(\mathrm{C}(\mathrm{C}(\mathrm{C}(\mathrm{C}) \mathrm{Cl}) \\
\mathrm{Cl}) \mathrm{Cl}) \mathrm{Cl}) \mathrm{Cl}) \mathrm{Cl}) \mathrm{Cl}) \mathrm{Cl})(\mathrm{CC}) \mathrm{Cl}\end{array}$ & 6.81 & & & 8.74 & 19.01 & -10.28 \\
\hline $\begin{array}{l}\mathrm{C}(\mathrm{C}(\mathrm{CC}(\mathrm{CCCC}(\mathrm{C}(\mathrm{CC}(\mathrm{CCCC}) \mathrm{Cl}) \mathrm{C} \\
\mathrm{I}) \mathrm{Cl}) \mathrm{Cl}) \mathrm{Cl}) \mathrm{CC}\end{array}$ & 8.21 & & & 7.93 & 13.07 & -5.14 \\
\hline $\begin{array}{l}\mathrm{C}(\mathrm{C}(\mathrm{C}(\mathrm{C}(\mathrm{CCCC}(\mathrm{C}(\mathrm{CC}(\mathrm{CCCC}) \mathrm{Cl}) \\
\mathrm{Cl}) \mathrm{Cl}) \mathrm{Cl}) \mathrm{Cl}) \mathrm{Cl})(\mathrm{CC}) \mathrm{Cl}\end{array}$ & 8.01 & & & 8.10 & 15.63 & -7.52 \\
\hline $\mathrm{ClC}(\mathrm{F})(\mathrm{F}) \mathrm{C}(\mathrm{Cl})(\mathrm{Cl}) \mathrm{F}$ & 3.16 & 2.04 & 1.12 & 3.36 & 1.55 & 1.82 \\
\hline $\mathrm{C}(\mathrm{Br}) \mathrm{Br}$ & 2.50 & 3.96 & -1.46 & 2.06 & 3.91 & -1.85 \\
\hline $\mathrm{C}(\mathrm{Br})(\mathrm{Br}) \mathrm{Br}$ & 2.38 & 4.11 & -1.73 & 2.75 & 4.41 & -1.68 \\
\hline $\mathrm{C}(\mathrm{Br})(\mathrm{Cl}) \mathrm{Cl}$ & 2.10 & 3.28 & -1.18 & 2.55 & 3.79 & -1.23 \\
\hline $\mathrm{C}(\mathrm{Br})(\mathrm{Br}) \mathrm{Cl}$ & 2.24 & 3.70 & -1.46 & 2.66 & 4.10 & -1.44 \\
\hline $\mathrm{C}(\mathrm{Cl})(\mathrm{Cl})(\mathrm{Cl}) \mathrm{F}$ & 2.53 & 1.91 & 0.62 & 2.86 & 1.78 & 1.08 \\
\hline $\mathrm{C}(\mathrm{Cl})$ & 0.91 & 1.35 & -0.44 & 1.40 & 2.22 & -0.83 \\
\hline $\mathrm{C}(\mathrm{Cl})(\mathrm{Cl})$ & 1.25 & 2.17 & -0.92 & 1.83 & 3.58 & -1.74 \\
\hline $\mathrm{C}(\mathrm{Cl})(\mathrm{Cl})(\mathrm{Cl})$ & 1.97 & 2.73 & -0.76 & 2.46 & 3.56 & -1.10 \\
\hline $\mathrm{C}(\mathrm{Cl})(\mathrm{Cl})(\mathrm{Cl})(\mathrm{Cl})$ & 2.83 & 2.75 & 0.08 & 3.25 & 2.54 & 0.71 \\
\hline $\mathrm{CC}(\mathrm{Cl})$ & 1.43 & 1.81 & -0.38 & 1.93 & 3.07 & -1.14 \\
\hline $\mathrm{CC}(\mathrm{Cl})(\mathrm{Cl})$ & 1.79 & 2.43 & -0.64 & 2.31 & 4.09 & -1.78 \\
\hline $\mathrm{C}(\mathrm{Cl}) \mathrm{C}(\mathrm{Cl})$ & 1.48 & 2.72 & -1.24 & 2.32 & 4.46 & -2.14 \\
\hline $\mathrm{CC}(\mathrm{Cl})(\mathrm{Cl})(\mathrm{Cl})$ & 2.49 & 2.64 & -0.15 & 2.85 & 3.86 & -1.01 \\
\hline $\mathrm{C}(\mathrm{Cl})(\mathrm{Cl}) \mathrm{C}(\mathrm{Cl})$ & 2.38 & 3.81 & -1.43 & 2.67 & 5.23 & -2.56 \\
\hline $\mathrm{C}(\mathrm{Cl})(\mathrm{Cl}) \mathrm{C}(\mathrm{Cl})(\mathrm{Cl})$ & 2.39 & 3.37 & -0.98 & 3.33 & 5.50 & -2.18 \\
\hline $\mathrm{C}(\mathrm{Cl})(\mathrm{Cl})(\mathrm{Cl}) \mathrm{C}(\mathrm{Cl})(\mathrm{Cl})(\mathrm{Cl})$ & 4.14 & 4.61 & -0.47 & 4.33 & 3.52 & 0.82 \\
\hline $\mathrm{C}(\mathrm{Cl}) \mathrm{C}(\mathrm{Cl}) \mathrm{C}$ & 2.00 & 2.94 & -0.94 & 2.74 & 4.61 & -1.87 \\
\hline $\mathrm{C}(\mathrm{Cl}) \mathrm{CC}$ & 2.64 & 2.85 & -0.21 & 2.42 & 3.53 & -1.12 \\
\hline
\end{tabular}


Table S3. The breakdown of screened compositions using experimental and DFT correction. $\mathrm{n}_{\mathrm{C}}=10$ and Compositions No. $=172$ means that 172 compositions with a carbon chain length of 10 are screened. The weight percent is reported as to the nearest half unit. The median value is shown in bold.

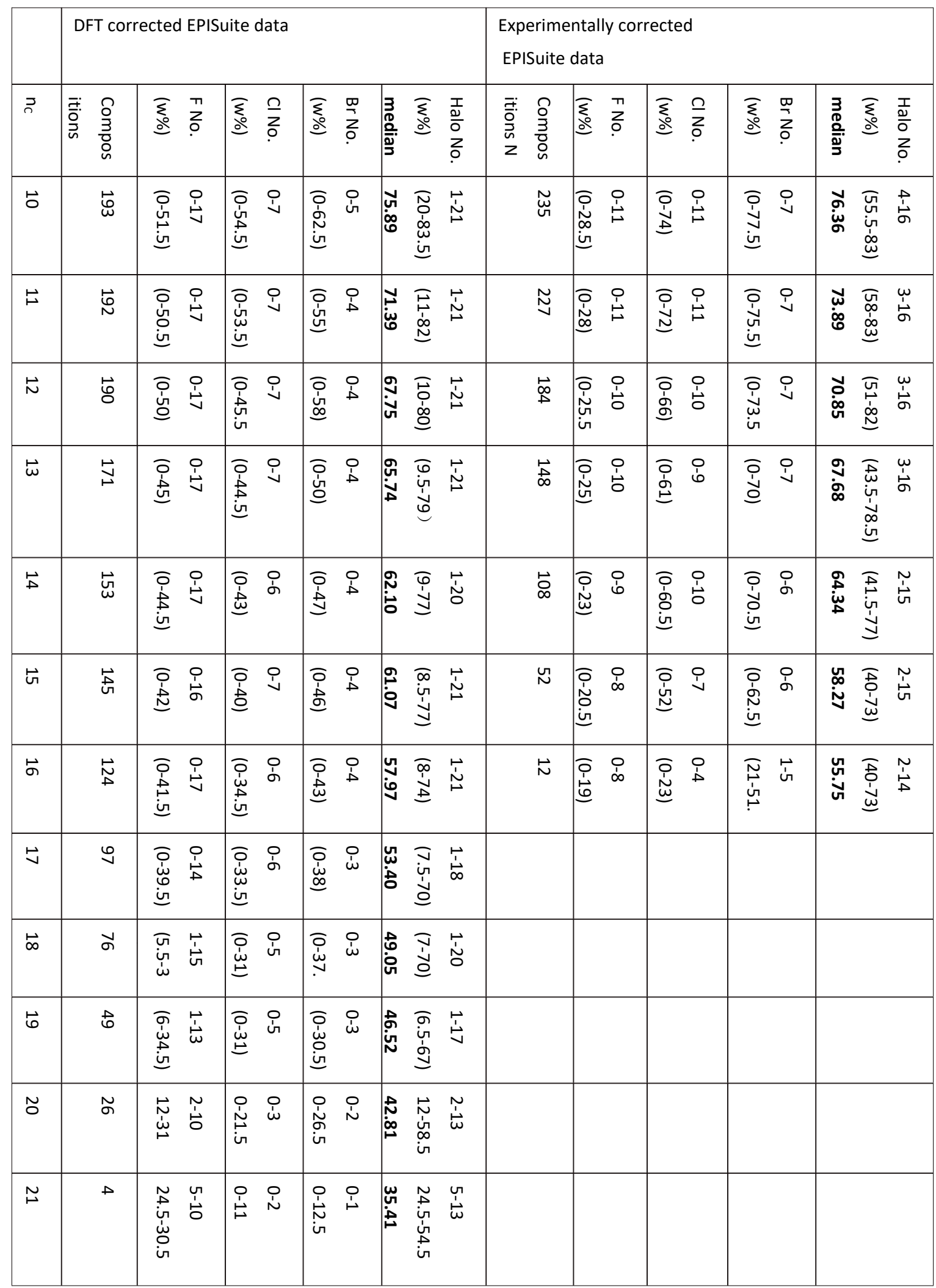


Table S4. Different categories of screened PXAs number separated against categories of 184,600 PXA under different resolution

numerator: the composition number separated; denominator: the total number in the screened category.

\begin{tabular}{|c|c|c|c|c|c|c|c|c|c|c|}
\hline & \multicolumn{10}{|c|}{ Categories in 184,600 PXAs } \\
\hline & $\mathrm{F}$ & $\mathrm{Cl}$ & $\mathrm{Br}$ & $\mathrm{ClF}$ & $\mathrm{BrF}$ & $\mathrm{BrCl}$ & $\mathrm{BrClF}$ & All ${ }^{*}$ & $w / o^{*}$ & $R$ \\
\hline & & & & & & & & & $\mathrm{BrClF}$ & $\left(10^{4}\right)$ \\
\hline \multirow[t]{7}{*}{$\mathrm{Cl}$} & $24 / 27$ & $27 / 27$ & $18 / 27$ & $0 / 27$ & $9 / 27$ & $1 / 27$ & $1 / 27$ & $0 / 27$ & $0 / 27$ & 1 \\
\hline & $27 / 27$ & & $23 / 27$ & $16 / 27$ & $23 / 27$ & $18 / 27$ & $20 / 27$ & $6 / 27$ & $6 / 27$ & 6 \\
\hline & & & $23 / 27$ & $27 / 27$ & $25 / 27$ & $18 / 27$ & $21 / 27$ & $11 / 27$ & $14 / 27$ & 10 \\
\hline & & & $23 / 27$ & & $27 / 27$ & $18 / 27$ & $22 / 27$ & $11 / 27$ & $14 / 27$ & 20 \\
\hline & & & $27 / 27$ & & & $21 / 27$ & $23 / 27$ & $18 / 27$ & $21 / 27$ & 50 \\
\hline & & & & & & $21 / 27$ & $26 / 27$ & $20 / 27$ & $21 / 27$ & 80 \\
\hline & & & & & & $21 / 27$ & $26 / 27$ & $20 / 27$ & $21 / 27$ & 100 \\
\hline \multirow[t]{7}{*}{$\mathrm{Br}$} & $22 / 23$ & $6 / 23$ & $23 / 23$ & $0 / 23$ & $3 / 23$ & $3 / 23$ & $0 / 23$ & $0 / 23$ & $0 / 23$ & 1 \\
\hline & $23 / 23$ & $17 / 23$ & & $11 / 23$ & $7 / 23$ & $8 / 23$ & $4 / 23$ & $0 / 23$ & $1 / 23$ & 6 \\
\hline & & $17 / 23$ & & $13 / 23$ & $9 / 23$ & $8 / 23$ & $6 / 23$ & $2 / 23$ & $3 / 23$ & 10 \\
\hline & & $23 / 23$ & & $15 / 23$ & $23 / 23$ & $8 / 23$ & $6 / 23$ & $3 / 23$ & $8 / 23$ & 20 \\
\hline & & & & $16 / 23$ & & $8 / 23$ & $16 / 23$ & $8 / 23$ & $8 / 23$ & 50 \\
\hline & & & & $18 / 23$ & & $8 / 23$ & $16 / 23$ & $8 / 23$ & $8 / 23$ & 80 \\
\hline & & & & $18 / 23$ & & $8 / 23$ & $16 / 23$ & $8 / 23$ & $8 / 23$ & 100 \\
\hline \multirow[t]{7}{*}{$\mathrm{ClF}$} & $83 / 83$ & $1 / 83$ & $48 / 83$ & $0 / 83$ & $9 / 83$ & $0 / 83$ & $0 / 83$ & $0 / 83$ & $0 / 83$ & 1 \\
\hline & & $68 / 83$ & $76 / 83$ & $40 / 83$ & $47 / 83$ & $53 / 83$ & $34 / 83$ & $7 / 83$ & $16 / 83$ & 6 \\
\hline & & $68 / 83$ & $76 / 83$ & $54 / 83$ & $47 / 83$ & $67 / 83$ & $37 / 83$ & $13 / 83$ & $28 / 83$ & 10 \\
\hline & & $83 / 83$ & $79 / 83$ & $83 / 83$ & $55 / 83$ & $75 / 83$ & $37 / 83$ & $20 / 83$ & $47 / 83$ & 20 \\
\hline & & & $79 / 83$ & & $73 / 83$ & $76 / 83$ & $48 / 83$ & $44 / 83$ & $66 / 83$ & 50 \\
\hline & & & $79 / 83$ & & $73 / 83$ & $80 / 83$ & $57 / 83$ & $45 / 83$ & $66 / 83$ & 80 \\
\hline & & & $79 / 83$ & & $73 / 83$ & $80 / 83$ & $59 / 83$ & $45 / 83$ & $66 / 83$ & 100 \\
\hline \multirow[t]{7}{*}{$\mathrm{BrF}$} & $122 / 127$ & $1 / 127$ & $55 / 127$ & $0 / 127$ & $3 / 127$ & $0 / 127$ & $0 / 127$ & $0 / 127$ & $0 / 127$ & 1 \\
\hline & $127 / 127$ & $89 / 127$ & $117 / 127$ & $15 / 127$ & $41 / 127$ & $38 / 127$ & $0 / 127$ & $0 / 127$ & $2 / 127$ & 6 \\
\hline & & $105 / 127$ & $117 / 127$ & $22 / 127$ & $41 / 127$ & $59 / 127$ & $0 / 127$ & $0 / 127$ & $7 / 127$ & 10 \\
\hline & & $119 / 127$ & $126 / 127$ & $41 / 127$ & $116 / 127$ & $92 / 127$ & $0 / 127$ & $0 / 127$ & $28 / 127$ & 20 \\
\hline & & $127 / 127$ & $127 / 127$ & $74 / 127$ & $127 / 127$ & $115 / 127$ & $14 / 127$ & $14 / 127$ & $65 / 127$ & 50 \\
\hline & & & & $96 / 127$ & & $127 / 127$ & $14 / 127$ & $14 / 127$ & $96 / 127$ & 80 \\
\hline & & & & $96 / 127$ & & & $14 / 127$ & $14 / 127$ & $96 / 127$ & 100 \\
\hline \multirow[t]{5}{*}{$\mathrm{BrCl}$} & $116 / 119$ & $20 / 119$ & $71 / 119$ & $1 / 119$ & $14 / 119$ & $16 / 119$ & $5 / 119$ & $0 / 119$ & $0 / 119$ & 1 \\
\hline & $119 / 119$ & $82 / 119$ & $112 / 119$ & $48 / 119$ & $91 / 119$ & $63 / 119$ & $33 / 119$ & $6 / 119$ & $23 / 119$ & 6 \\
\hline & & $82 / 119$ & $112 / 119$ & $57 / 119$ & $110 / 119$ & $63 / 119$ & $43 / 119$ & $6 / 119$ & $31 / 119$ & 10 \\
\hline & & $109 / 119$ & $112 / 119$ & $69 / 119$ & $115 / 119$ & 71/119 & $46 / 119$ & $8 / 119$ & $39 / 119$ & 20 \\
\hline & & 109/119 & 119/119 & 73/119 & $115 / 119$ & $85 / 119$ & $48 / 119$ & $14 / 119$ & $50 / 119$ & 50 \\
\hline
\end{tabular}




\begin{tabular}{|c|c|c|c|c|c|c|c|c|c|c|}
\hline & & $110 / 119$ & & 100/119 & 117/119 & $85 / 119$ & $62 / 119$ & $45 / 119$ & $72 / 119$ & 80 \\
\hline & & $119 / 119$ & & $101 / 119$ & 117/119 & $85 / 119$ & $63 / 119$ & $48 / 119$ & $80 / 119$ & 100 \\
\hline \multirow[t]{7}{*}{$\mathrm{BrClF}$} & $587 / 587$ & $19 / 587$ & $256 / 587$ & $0 / 587$ & $9 / 587$ & $0 / 587$ & $1 / 587$ & $0 / 587$ & $0 / 587$ & 1 \\
\hline & & $431 / 587$ & $532 / 587$ & $62 / 587$ & $345 / 587$ & $223 / 587$ & $44 / 587$ & $6 / 587$ & $23 / 587$ & 6 \\
\hline & & $501 / 587$ & $560 / 587$ & $120 / 587$ & $466 / 587$ & $307 / 587$ & $56 / 587$ & $10 / 587$ & 70/587 & 10 \\
\hline & & $565 / 587$ & $570 / 587$ & $284 / 587$ & $494 / 587$ & $466 / 587$ & $106 / 587$ & $25 / 587$ & $212 / 587$ & 20 \\
\hline & & $587 / 587$ & $584 / 587$ & $335 / 587$ & $558 / 587$ & $566 / 587$ & $149 / 587$ & $62 / 587$ & $307 / 587$ & 50 \\
\hline & & & $584 / 587$ & $429 / 587$ & $579 / 587$ & $584 / 587$ & $177 / 587$ & $153 / 587$ & $423 / 587$ & 80 \\
\hline & & & $584 / 587$ & $482 / 587$ & $580 / 587$ & $587 / 587$ & $189 / 587$ & $180 / 587$ & $472 / 587$ & 100 \\
\hline
\end{tabular}

*all: all the 184,600 PXAs; w/o BrClF: BrClF PXAs not included in the pool 
SMILE Generated

$\mathrm{C}(\mathrm{C}(\mathrm{C}(\mathrm{C}(\mathrm{C}(\mathrm{C}(\mathrm{C}(\mathrm{C}(\mathrm{C}(\mathrm{C}(\mathrm{Br})(\mathrm{F}) \mathrm{Br})(\mathrm{Br}) \mathrm{H})(\mathrm{H}) \mathrm{H})(\mathrm{H}) \mathrm{F})(\mathrm{H}) \mathrm{F})(\mathrm{F}) \mathrm{Br})(\mathrm{H}) \mathrm{H})(\mathrm{F}) \mathrm{F})(\mathrm{H}) \mathrm{F})(\mathrm{H})(\mathrm{F}) \mathrm{H}$ $\mathrm{C}(\mathrm{C}(\mathrm{C}(\mathrm{C}(\mathrm{C}(\mathrm{C}(\mathrm{C}(\mathrm{C}(\mathrm{C}(\mathrm{C}(\mathrm{F})(\mathrm{F}) \mathrm{Br})(\mathrm{H}) \mathrm{H})(\mathrm{Br}) \mathrm{H})(\mathrm{F}) \mathrm{F})(\mathrm{H}) \mathrm{H})(\mathrm{H}) \mathrm{H})(\mathrm{Br}) \mathrm{F})(\mathrm{Br}) \mathrm{H})(\mathrm{F}) \mathrm{H})(\mathrm{H})(\mathrm{Br}) \mathrm{F}$ $\mathrm{C}(\mathrm{C}(\mathrm{C}(\mathrm{C}(\mathrm{C}(\mathrm{C}(\mathrm{C}(\mathrm{C}(\mathrm{C}(\mathrm{C}(\mathrm{H})(\mathrm{F}) \mathrm{Br})(\mathrm{H}) \mathrm{Br})(\mathrm{H}) \mathrm{Br})(\mathrm{H}) \mathrm{F})(\mathrm{H}) \mathrm{Br})(\mathrm{H}) \mathrm{F})(\mathrm{F}) \mathrm{Br})(\mathrm{F}) \mathrm{F})(\mathrm{Br}) \mathrm{H})(\mathrm{H})(\mathrm{H}) \mathrm{H}$ $\mathrm{C}(\mathrm{C}(\mathrm{C}(\mathrm{C}(\mathrm{C}(\mathrm{C}(\mathrm{C}(\mathrm{C}(\mathrm{C}(\mathrm{C}(\mathrm{H})(\mathrm{F}) \mathrm{Br})(\mathrm{F}) \mathrm{H})(\mathrm{H}) \mathrm{H})(\mathrm{Br}) \mathrm{Br})(\mathrm{H}) \mathrm{Br})(\mathrm{H}) \mathrm{H})(\mathrm{H}) \mathrm{F})(\mathrm{Br}) \mathrm{H})(\mathrm{Br}) \mathrm{H})(\mathrm{Br})(\mathrm{F}) \mathrm{F}$ $\mathrm{C}(\mathrm{C}(\mathrm{C}(\mathrm{C}(\mathrm{C}(\mathrm{C}(\mathrm{C}(\mathrm{C}(\mathrm{C}(\mathrm{C}(\mathrm{Br})(\mathrm{H}) \mathrm{Cl})(\mathrm{H}) \mathrm{F})(\mathrm{Cl}) \mathrm{Cl})(\mathrm{H}) \mathrm{H})(\mathrm{H}) \mathrm{Cl})(\mathrm{H}) \mathrm{Cl})(\mathrm{H}) \mathrm{Cl})(\mathrm{Cl}) \mathrm{H})(\mathrm{Cl}) \mathrm{H})(\mathrm{Cl})(\mathrm{Cl}) \mathrm{H}$ $\mathrm{C}(\mathrm{C}(\mathrm{C}(\mathrm{C}(\mathrm{C}(\mathrm{C}(\mathrm{C}(\mathrm{C}(\mathrm{C}(\mathrm{C}(\mathrm{H})(\mathrm{Cl}) \mathrm{Cl})(\mathrm{H}) \mathrm{Cl})(\mathrm{H}) \mathrm{Cl})(\mathrm{H}) \mathrm{H})(\mathrm{Cl}) \mathrm{Cl})(\mathrm{Cl}) \mathrm{H})(\mathrm{Cl}) \mathrm{H})(\mathrm{F}) \mathrm{Cl})(\mathrm{H}) \mathrm{F})(\mathrm{Cl})(\mathrm{H}) \mathrm{H}$ $\mathrm{C}(\mathrm{C}(\mathrm{C}(\mathrm{C}(\mathrm{C}(\mathrm{C}(\mathrm{C}(\mathrm{C}(\mathrm{C}(\mathrm{C}(\mathrm{Cl})(\mathrm{H}) \mathrm{H})(\mathrm{Cl}) \mathrm{H})(\mathrm{H}) \mathrm{Cl})(\mathrm{Cl}) \mathrm{Cl})(\mathrm{Cl}) \mathrm{H})(\mathrm{F}) \mathrm{H})(\mathrm{H}) \mathrm{Cl})(\mathrm{H}) \mathrm{Cl})(\mathrm{Cl}) \mathrm{H})(\mathrm{Cl})(\mathrm{H}) \mathrm{Cl}$ $\mathrm{C}(\mathrm{C}(\mathrm{C}(\mathrm{C}(\mathrm{C}(\mathrm{C}(\mathrm{C}(\mathrm{C}(\mathrm{C}(\mathrm{C}(\mathrm{H})(\mathrm{H}) \mathrm{H})(\mathrm{H}) \mathrm{H})(\mathrm{H}) \mathrm{F})(\mathrm{Br}) \mathrm{F})(\mathrm{Br}) \mathrm{Br})(\mathrm{H}) \mathrm{F})(\mathrm{H}) \mathrm{F})(\mathrm{H}) \mathrm{F})(\mathrm{F}) \mathrm{Cl})(\mathrm{Cl})(\mathrm{F}) \mathrm{H}$ $\mathrm{C}(\mathrm{C}(\mathrm{C}(\mathrm{C}(\mathrm{C}(\mathrm{C}(\mathrm{C}(\mathrm{C}(\mathrm{C}(\mathrm{C}(\mathrm{F})(\mathrm{H}) \mathrm{Cl})(\mathrm{H}) \mathrm{H})(\mathrm{F}) \mathrm{Cl})(\mathrm{H}) \mathrm{Br})(\mathrm{H}) \mathrm{H})(\mathrm{H}) \mathrm{F})(\mathrm{F}) \mathrm{H})(\mathrm{H}) \mathrm{Br})(\mathrm{H}) \mathrm{Br})(\mathrm{Br})(\mathrm{F}) \mathrm{F}$ $\mathrm{C}(\mathrm{C}(\mathrm{C}(\mathrm{C}(\mathrm{C}(\mathrm{C}(\mathrm{C}(\mathrm{C}(\mathrm{C}(\mathrm{C}(\mathrm{Br})(\mathrm{F}) \mathrm{H})(\mathrm{Cl}) \mathrm{H})(\mathrm{H}) \mathrm{Br})(\mathrm{Cl}) \mathrm{H})(\mathrm{Br}) \mathrm{F})(\mathrm{H}) \mathrm{H})(\mathrm{F}) \mathrm{H})(\mathrm{H}) \mathrm{F})(\mathrm{H}) \mathrm{H})(\mathrm{F})(\mathrm{Br}) \mathrm{Br}$ $\mathrm{C}(\mathrm{C}(\mathrm{C}(\mathrm{C}(\mathrm{C}(\mathrm{C}(\mathrm{C}(\mathrm{C}(\mathrm{C}(\mathrm{C}(\mathrm{H})(\mathrm{Br}) \mathrm{F})(\mathrm{Cl}) \mathrm{H})(\mathrm{H}) \mathrm{H})(\mathrm{Cl}) \mathrm{H})(\mathrm{F}) \mathrm{Br})(\mathrm{H}) \mathrm{F})(\mathrm{F}) \mathrm{Cl})(\mathrm{H}) \mathrm{H})(\mathrm{Br}) \mathrm{F})(\mathrm{H})(\mathrm{F}) \mathrm{H}$ $\mathrm{C}(\mathrm{C}(\mathrm{C}(\mathrm{C}(\mathrm{C}(\mathrm{C}(\mathrm{C}(\mathrm{C}(\mathrm{C}(\mathrm{C}(\mathrm{H})(\mathrm{H}) \mathrm{F})(\mathrm{Br}) \mathrm{Cl})(\mathrm{F}) \mathrm{H})(\mathrm{H}) \mathrm{F})(\mathrm{H}) \mathrm{F})(\mathrm{Cl}) \mathrm{F})(\mathrm{Cl}) \mathrm{H})(\mathrm{H}) \mathrm{Br})(\mathrm{H}) \mathrm{Br})(\mathrm{H})(\mathrm{Br}) \mathrm{H}$ $\mathrm{C}(\mathrm{C}(\mathrm{C}(\mathrm{C}(\mathrm{C}(\mathrm{C}(\mathrm{C}(\mathrm{C}(\mathrm{C}(\mathrm{C}(\mathrm{H})(\mathrm{Br}) \mathrm{F})(\mathrm{F}) \mathrm{Cl})(\mathrm{H}) \mathrm{F})(\mathrm{H}) \mathrm{F})(\mathrm{H}) \mathrm{H})(\mathrm{Br}) \mathrm{Cl})(\mathrm{Br}) \mathrm{H})(\mathrm{Br}) \mathrm{H})(\mathrm{H}) \mathrm{Cl})(\mathrm{H})(\mathrm{Br}) \mathrm{H}$ $\mathrm{C}(\mathrm{C}(\mathrm{C}(\mathrm{C}(\mathrm{C}(\mathrm{C}(\mathrm{C}(\mathrm{C}(\mathrm{C}(\mathrm{C}(\mathrm{H})(\mathrm{H}) \mathrm{F})(\mathrm{F}) \mathrm{F})(\mathrm{Br}) \mathrm{H})(\mathrm{H}) \mathrm{Br})(\mathrm{Cl}) \mathrm{F})(\mathrm{H}) \mathrm{F})(\mathrm{H}) \mathrm{H})(\mathrm{F}) \mathrm{H})(\mathrm{Cl}) \mathrm{Cl})(\mathrm{H})(\mathrm{Cl}) \mathrm{H}$ $\mathrm{C}(\mathrm{C}(\mathrm{C}(\mathrm{C}(\mathrm{C}(\mathrm{C}(\mathrm{C}(\mathrm{C}(\mathrm{C}(\mathrm{C}(\mathrm{H})(\mathrm{H}) \mathrm{H})(\mathrm{F}) \mathrm{H})(\mathrm{Br}) \mathrm{H})(\mathrm{Br}) \mathrm{H})(\mathrm{Cl}) \mathrm{Br})(\mathrm{Cl}) \mathrm{H})(\mathrm{H}) \mathrm{F})(\mathrm{F}) \mathrm{H})(\mathrm{F}) \mathrm{H})(\mathrm{Br})(\mathrm{Cl}) \mathrm{C}$ $\mathrm{C}(\mathrm{C}(\mathrm{C}(\mathrm{C}(\mathrm{C}(\mathrm{C}(\mathrm{C}(\mathrm{C}(\mathrm{C}(\mathrm{C}(\mathrm{H})(\mathrm{F}) \mathrm{Cl})(\mathrm{F}) \mathrm{H})(\mathrm{Cl}) \mathrm{H})(\mathrm{H}) \mathrm{H})(\mathrm{Cl}) \mathrm{Cl})(\mathrm{H}) \mathrm{H})(\mathrm{Cl}) \mathrm{H})(\mathrm{Br}) \mathrm{F})(\mathrm{H}) \mathrm{H})(\mathrm{F})(\mathrm{Br}) \mathrm{F}$ $\mathrm{C}(\mathrm{C}(\mathrm{C}(\mathrm{C}(\mathrm{C}(\mathrm{C}(\mathrm{C}(\mathrm{C}(\mathrm{C}(\mathrm{C}(\mathrm{Cl})(\mathrm{F}) \mathrm{F})(\mathrm{Cl}) \mathrm{H})(\mathrm{H}) \mathrm{H})(\mathrm{F}) \mathrm{H})(\mathrm{Br}) \mathrm{H})(\mathrm{Cl}) \mathrm{Cl})(\mathrm{H}) \mathrm{Br})(\mathrm{Br}) \mathrm{H})(\mathrm{H}) \mathrm{H})(\mathrm{F})(\mathrm{Cl}) \mathrm{H}$ $\mathrm{C}(\mathrm{C}(\mathrm{C}(\mathrm{C}(\mathrm{C}(\mathrm{C}(\mathrm{C}(\mathrm{C}(\mathrm{C}(\mathrm{C}(\mathrm{H})(\mathrm{H}) \mathrm{F})(\mathrm{H}) \mathrm{F})(\mathrm{H}) \mathrm{Cl})(\mathrm{Cl}) \mathrm{H})(\mathrm{F}) \mathrm{H})(\mathrm{H}) \mathrm{Cl})(\mathrm{Cl}) \mathrm{Br})(\mathrm{Cl}) \mathrm{F})(\mathrm{F}) \mathrm{Cl})(\mathrm{H})(\mathrm{H}) \mathrm{H}$ $\mathrm{C}(\mathrm{C}(\mathrm{C}(\mathrm{C}(\mathrm{C}(\mathrm{C}(\mathrm{C}(\mathrm{C}(\mathrm{C}(\mathrm{C}(\mathrm{H})(\mathrm{Br}) \mathrm{Cl})(\mathrm{H}) \mathrm{Cl})(\mathrm{Cl}) \mathrm{Cl})(\mathrm{F}) \mathrm{F})(\mathrm{H}) \mathrm{H})(\mathrm{H}) \mathrm{F})(\mathrm{Cl}) \mathrm{H})(\mathrm{Cl}) \mathrm{Cl})(\mathrm{H}) \mathrm{F})(\mathrm{H})(\mathrm{H}) \mathrm{H}$ $\mathrm{C}(\mathrm{C}(\mathrm{C}(\mathrm{C}(\mathrm{C}(\mathrm{C}(\mathrm{C}(\mathrm{C}(\mathrm{C}(\mathrm{C}(\mathrm{H})(\mathrm{Cl}) \mathrm{Br})(\mathrm{Br}) \mathrm{H})(\mathrm{H}) \mathrm{Cl})(\mathrm{Br}) \mathrm{H})(\mathrm{Cl}) \mathrm{H})(\mathrm{H}) \mathrm{Cl})(\mathrm{Cl}) \mathrm{H})(\mathrm{H}) \mathrm{Cl})(\mathrm{Cl}) \mathrm{H})(\mathrm{H})(\mathrm{F}) \mathrm{C}$ $\mathrm{C}(\mathrm{C}(\mathrm{C}(\mathrm{C}(\mathrm{C}(\mathrm{C}(\mathrm{C}(\mathrm{C}(\mathrm{C}(\mathrm{C}(\mathrm{H})(\mathrm{Cl}) \mathrm{Cl})(\mathrm{Cl}) \mathrm{H})(\mathrm{H}) \mathrm{Cl})(\mathrm{F}) \mathrm{H})(\mathrm{H}) \mathrm{Cl})(\mathrm{F}) \mathrm{Cl})(\mathrm{H}) \mathrm{Cl})(\mathrm{H}) \mathrm{F})(\mathrm{Cl}) \mathrm{H})(\mathrm{Br})(\mathrm{H}) \mathrm{H}$ $\mathrm{C}(\mathrm{C}(\mathrm{C}(\mathrm{C}(\mathrm{C}(\mathrm{C}(\mathrm{C}(\mathrm{C}(\mathrm{C}(\mathrm{C}(\mathrm{Cl})(\mathrm{Cl}) \mathrm{H})(\mathrm{H}) \mathrm{Cl})(\mathrm{H}) \mathrm{Cl})(\mathrm{F}) \mathrm{H})(\mathrm{F}) \mathrm{H})(\mathrm{Cl}) \mathrm{F})(\mathrm{H}) \mathrm{H})(\mathrm{H}) \mathrm{Cl})(\mathrm{Cl}) \mathrm{H})(\mathrm{F})(\mathrm{Cl}) \mathrm{H}$ $\mathrm{C}(\mathrm{C}(\mathrm{C}(\mathrm{C}(\mathrm{C}(\mathrm{C}(\mathrm{C}(\mathrm{C}(\mathrm{C}(\mathrm{C}(\mathrm{H})(\mathrm{F}) \mathrm{H})(\mathrm{H}) \mathrm{H})(\mathrm{H}) \mathrm{Cl})(\mathrm{Cl}) \mathrm{H})(\mathrm{F}) \mathrm{H})(\mathrm{Cl}) \mathrm{Cl})(\mathrm{Cl}) \mathrm{Cl})(\mathrm{Cl}) \mathrm{F})(\mathrm{H}) \mathrm{H})(\mathrm{Cl})(\mathrm{H}) \mathrm{Cl}$ $\mathrm{C}(\mathrm{C}(\mathrm{C}(\mathrm{C}(\mathrm{C}(\mathrm{C}(\mathrm{C}(\mathrm{C}(\mathrm{C}(\mathrm{C}(\mathrm{H})(\mathrm{Cl}) \mathrm{F})(\mathrm{Br}) \mathrm{F})(\mathrm{H}) \mathrm{H})(\mathrm{H}) \mathrm{H})(\mathrm{F}) \mathrm{F})(\mathrm{H}) \mathrm{F})(\mathrm{Br}) \mathrm{H})(\mathrm{F}) \mathrm{H})(\mathrm{Br}) \mathrm{F})(\mathrm{H})(\mathrm{H}) \mathrm{Br}$ $\mathrm{C}(\mathrm{C}(\mathrm{C}(\mathrm{C}(\mathrm{C}(\mathrm{C}(\mathrm{C}(\mathrm{C}(\mathrm{C}(\mathrm{C}(\mathrm{H})(\mathrm{F}) \mathrm{H})(\mathrm{H}) \mathrm{H})(\mathrm{F}) \mathrm{F})(\mathrm{F}) \mathrm{H})(\mathrm{F}) \mathrm{H})(\mathrm{H}) \mathrm{Br})(\mathrm{H}) \mathrm{Br})(\mathrm{Br}) \mathrm{H})(\mathrm{F}) \mathrm{Cl})(\mathrm{Br})(\mathrm{H}) \mathrm{Br}$ $\mathrm{C}(\mathrm{C}(\mathrm{C}(\mathrm{C}(\mathrm{C}(\mathrm{C}(\mathrm{C}(\mathrm{C}(\mathrm{C}(\mathrm{C}(\mathrm{Br})(\mathrm{F}) \mathrm{H})(\mathrm{F}) \mathrm{Br})(\mathrm{F}) \mathrm{H})(\mathrm{Cl}) \mathrm{F})(\mathrm{H}) \mathrm{H})(\mathrm{Br}) \mathrm{H})(\mathrm{H}) \mathrm{H})(\mathrm{H}) \mathrm{Br})(\mathrm{H}) \mathrm{Br})(\mathrm{H})(\mathrm{Br}) \mathrm{Br}$ $\mathrm{C}(\mathrm{C}(\mathrm{C}(\mathrm{C}(\mathrm{C}(\mathrm{C}(\mathrm{C}(\mathrm{C}(\mathrm{C}(\mathrm{C}(\mathrm{H})(\mathrm{H}) \mathrm{H})(\mathrm{F}) \mathrm{F})(\mathrm{Br}) \mathrm{Br})(\mathrm{H}) \mathrm{Br})(\mathrm{Br}) \mathrm{F})(\mathrm{H}) \mathrm{H})(\mathrm{F}) \mathrm{Br})(\mathrm{H}) \mathrm{H})(\mathrm{F}) \mathrm{H})(\mathrm{F})(\mathrm{H}) \mathrm{H}$ $\mathrm{C}(\mathrm{C}(\mathrm{C}(\mathrm{C}(\mathrm{C}(\mathrm{C}(\mathrm{C}(\mathrm{C}(\mathrm{C}(\mathrm{C}(\mathrm{Br})(\mathrm{Br}) \mathrm{H})(\mathrm{F}) \mathrm{Br})(\mathrm{H}) \mathrm{Br})(\mathrm{F}) \mathrm{H})(\mathrm{H}) \mathrm{Br})(\mathrm{H}) \mathrm{F})(\mathrm{Br}) \mathrm{F})(\mathrm{H}) \mathrm{F})(\mathrm{H}) \mathrm{H})(\mathrm{H})(\mathrm{H}) \mathrm{H}$ $\mathrm{C}(\mathrm{C}(\mathrm{C}(\mathrm{C}(\mathrm{C}(\mathrm{C}(\mathrm{C}(\mathrm{C}(\mathrm{C}(\mathrm{C}(\mathrm{H})(\mathrm{H}) \mathrm{H})(\mathrm{H}) \mathrm{Br})(\mathrm{H}) \mathrm{Br})(\mathrm{H}) \mathrm{F})(\mathrm{Br}) \mathrm{Br})(\mathrm{F}) \mathrm{H})(\mathrm{H}) \mathrm{F})(\mathrm{Br}) \mathrm{F})(\mathrm{H}) \mathrm{Br})(\mathrm{H})(\mathrm{Br}) \mathrm{H}$ $\mathrm{C}(\mathrm{C}(\mathrm{C}(\mathrm{C}(\mathrm{C}(\mathrm{C}(\mathrm{C}(\mathrm{C}(\mathrm{C}(\mathrm{C}(\mathrm{Cl})(\mathrm{Cl}) \mathrm{H})(\mathrm{H}) \mathrm{Cl})(\mathrm{H}) \mathrm{H})(\mathrm{F}) \mathrm{H})(\mathrm{Cl}) \mathrm{Cl})(\mathrm{Cl}) \mathrm{Cl})(\mathrm{H}) \mathrm{H})(\mathrm{H}) \mathrm{Cl})(\mathrm{Cl}) \mathrm{H})(\mathrm{Cl})(\mathrm{H}) \mathrm{H}$ $\mathrm{C}(\mathrm{C}(\mathrm{C}(\mathrm{C}(\mathrm{C}(\mathrm{C}(\mathrm{C}(\mathrm{C}(\mathrm{C}(\mathrm{C}(\mathrm{Cl})(\mathrm{Cl}) \mathrm{H})(\mathrm{Cl}) \mathrm{H})(\mathrm{H}) \mathrm{Cl})(\mathrm{Cl}) \mathrm{H})(\mathrm{H}) \mathrm{H})(\mathrm{Cl}) \mathrm{Cl})(\mathrm{Cl}) \mathrm{H})(\mathrm{Cl}) \mathrm{H})(\mathrm{H}) \mathrm{H})(\mathrm{H})(\mathrm{Cl}) \mathrm{Cl}$ $\mathrm{C}(\mathrm{C}(\mathrm{C}(\mathrm{C}(\mathrm{C}(\mathrm{C}(\mathrm{C}(\mathrm{C}(\mathrm{C}(\mathrm{C}(\mathrm{H})(\mathrm{H}) \mathrm{H})(\mathrm{Br}) \mathrm{F})(\mathrm{H}) \mathrm{F})(\mathrm{H}) \mathrm{H})(\mathrm{H}) \mathrm{H})(\mathrm{Cl}) \mathrm{Br})(\mathrm{Cl}) \mathrm{F})(\mathrm{F}) \mathrm{H})(\mathrm{Br}) \mathrm{F})(\mathrm{H})(\mathrm{F}) \mathrm{H}$ $\mathrm{C}(\mathrm{C}(\mathrm{C}(\mathrm{C}(\mathrm{C}(\mathrm{C}(\mathrm{C}(\mathrm{C}(\mathrm{C}(\mathrm{C}(\mathrm{F})(\mathrm{Br}) \mathrm{H})(\mathrm{F}) \mathrm{Br})(\mathrm{H}) \mathrm{H})(\mathrm{Br}) \mathrm{H})(\mathrm{F}) \mathrm{H})(\mathrm{Br}) \mathrm{H})(\mathrm{H}) \mathrm{H})(\mathrm{Cl}) \mathrm{F})(\mathrm{H}) \mathrm{Cl})(\mathrm{F})(\mathrm{H}) \mathrm{H}$ $\mathrm{C}(\mathrm{C}(\mathrm{C}(\mathrm{C}(\mathrm{C}(\mathrm{C}(\mathrm{C}(\mathrm{C}(\mathrm{C}(\mathrm{C}(\mathrm{Br})(\mathrm{Br}) \mathrm{H})(\mathrm{H}) \mathrm{H})(\mathrm{F}) \mathrm{Br})(\mathrm{F}) \mathrm{H})(\mathrm{H}) \mathrm{H})(\mathrm{F}) \mathrm{Cl})(\mathrm{Br}) \mathrm{H})(\mathrm{Br}) \mathrm{Cl})(\mathrm{F}) \mathrm{H})(\mathrm{H})(\mathrm{H}) \mathrm{H}$ $\mathrm{C}(\mathrm{C}(\mathrm{C}(\mathrm{C}(\mathrm{C}(\mathrm{C}(\mathrm{C}(\mathrm{C}(\mathrm{C}(\mathrm{C}(\mathrm{Br})(\mathrm{Cl}) \mathrm{H})(\mathrm{H}) \mathrm{H})(\mathrm{H}) \mathrm{H})(\mathrm{H}) \mathrm{Cl})(\mathrm{F}) \mathrm{H})(\mathrm{H}) \mathrm{Cl})(\mathrm{H}) \mathrm{F})(\mathrm{Br}) \mathrm{F})(\mathrm{F}) \mathrm{H})(\mathrm{Br})(\mathrm{H}) \mathrm{F}$ $\mathrm{C}(\mathrm{C}(\mathrm{C}(\mathrm{C}(\mathrm{C}(\mathrm{C}(\mathrm{C}(\mathrm{C}(\mathrm{C}(\mathrm{C}(\mathrm{F})(\mathrm{F}) \mathrm{H})(\mathrm{Br}) \mathrm{Cl})(\mathrm{Br}) \mathrm{H})(\mathrm{H}) \mathrm{H})(\mathrm{Br}) \mathrm{H})(\mathrm{H}) \mathrm{H})(\mathrm{Cl}) \mathrm{Cl})(\mathrm{H}) \mathrm{H})(\mathrm{H}) \mathrm{F})(\mathrm{F})(\mathrm{H}) \mathrm{Br}$ $\mathrm{C}(\mathrm{C}(\mathrm{C}(\mathrm{C}(\mathrm{C}(\mathrm{C}(\mathrm{C}(\mathrm{C}(\mathrm{C}(\mathrm{C}(\mathrm{H})(\mathrm{H}) \mathrm{H})(\mathrm{F}) \mathrm{Cl})(\mathrm{H}) \mathrm{F})(\mathrm{H}) \mathrm{F})(\mathrm{H}) \mathrm{Cl})(\mathrm{Br}) \mathrm{Cl})(\mathrm{H}) \mathrm{Br})(\mathrm{H}) \mathrm{F})(\mathrm{Cl}) \mathrm{H})(\mathrm{H})(\mathrm{H}) \mathrm{F}$ $\mathrm{C}(\mathrm{C}(\mathrm{C}(\mathrm{C}(\mathrm{C}(\mathrm{C}(\mathrm{C}(\mathrm{C}(\mathrm{C}(\mathrm{C}(\mathrm{Br})(\mathrm{H}) \mathrm{Cl})(\mathrm{F}) \mathrm{H})(\mathrm{Cl}) \mathrm{F})(\mathrm{Cl}) \mathrm{H})(\mathrm{H}) \mathrm{Cl})(\mathrm{F}) \mathrm{H})(\mathrm{Br}) \mathrm{H})(\mathrm{H}) \mathrm{H})(\mathrm{H}) \mathrm{F})(\mathrm{H})(\mathrm{H}) \mathrm{Br}$ $\mathrm{C}(\mathrm{C}(\mathrm{C}(\mathrm{C}(\mathrm{C}(\mathrm{C}(\mathrm{C}(\mathrm{C}(\mathrm{C}(\mathrm{C}(\mathrm{H})(\mathrm{H}) \mathrm{Br})(\mathrm{H}) \mathrm{Cl})(\mathrm{Cl}) \mathrm{H})(\mathrm{F}) \mathrm{H})(\mathrm{H}) \mathrm{H})(\mathrm{Br}) \mathrm{Br})(\mathrm{Cl}) \mathrm{H})(\mathrm{H}) \mathrm{F})(\mathrm{H}) \mathrm{Br})(\mathrm{Cl})(\mathrm{H}) \mathrm{F}$ $\mathrm{C}(\mathrm{C}(\mathrm{C}(\mathrm{C}(\mathrm{C}(\mathrm{C}(\mathrm{C}(\mathrm{C}(\mathrm{C}(\mathrm{C}(\mathrm{H})(\mathrm{H}) \mathrm{Cl})(\mathrm{H}) \mathrm{F})(\mathrm{H}) \mathrm{H})(\mathrm{Br}) \mathrm{F})(\mathrm{H}) \mathrm{F})(\mathrm{Cl}) \mathrm{H})(\mathrm{H}) \mathrm{Cl})(\mathrm{F}) \mathrm{H})(\mathrm{Br}) \mathrm{Cl})(\mathrm{H})(\mathrm{Cl}) \mathrm{H}$ $\mathrm{C}(\mathrm{C}(\mathrm{C}(\mathrm{C}(\mathrm{C}(\mathrm{C}(\mathrm{C}(\mathrm{C}(\mathrm{C}(\mathrm{C}(\mathrm{H})(\mathrm{H}) \mathrm{Br})(\mathrm{Cl}) \mathrm{H})(\mathrm{Br}) \mathrm{H})(\mathrm{Cl}) \mathrm{Br})(\mathrm{F}) \mathrm{Cl})(\mathrm{H}) \mathrm{H})(\mathrm{H}) \mathrm{H})(\mathrm{H}) \mathrm{H})(\mathrm{Cl}) \mathrm{F})(\mathrm{F})(\mathrm{Cl}) \mathrm{H}$ $\mathrm{C}(\mathrm{C}(\mathrm{C}(\mathrm{C}(\mathrm{C}(\mathrm{C}(\mathrm{C}(\mathrm{C}(\mathrm{C}(\mathrm{C}(\mathrm{Cl})(\mathrm{Br}) \mathrm{Cl})(\mathrm{F}) \mathrm{H})(\mathrm{H}) \mathrm{F})(\mathrm{H}) \mathrm{Cl})(\mathrm{H}) \mathrm{H})(\mathrm{H}) \mathrm{Cl})(\mathrm{Br}) \mathrm{H})(\mathrm{H}) \mathrm{H})(\mathrm{Cl}) \mathrm{Br})(\mathrm{H})(\mathrm{H}) \mathrm{Br}$ $\mathrm{C}(\mathrm{C}(\mathrm{C}(\mathrm{C}(\mathrm{C}(\mathrm{C}(\mathrm{C}(\mathrm{C}(\mathrm{C}(\mathrm{C}(\mathrm{Cl})(\mathrm{F}) \mathrm{H})(\mathrm{H}) \mathrm{H})(\mathrm{Cl}) \mathrm{Cl})(\mathrm{H}) \mathrm{Cl})(\mathrm{H}) \mathrm{H})(\mathrm{H}) \mathrm{Br})(\mathrm{H}) \mathrm{F})(\mathrm{Cl}) \mathrm{F})(\mathrm{H}) \mathrm{F})(\mathrm{H})(\mathrm{F}) \mathrm{H}$ $\mathrm{C}(\mathrm{C}(\mathrm{C}(\mathrm{C}(\mathrm{C}(\mathrm{C}(\mathrm{C}(\mathrm{C}(\mathrm{C}(\mathrm{C}(\mathrm{Cl})(\mathrm{Br}) \mathrm{Cl})(\mathrm{Br}) \mathrm{H})(\mathrm{Cl}) \mathrm{H})(\mathrm{H}) \mathrm{H})(\mathrm{H}) \mathrm{F})(\mathrm{F}) \mathrm{H})(\mathrm{H}) \mathrm{Cl})(\mathrm{H}) \mathrm{H})(\mathrm{Cl}) \mathrm{H})(\mathrm{Cl})(\mathrm{H}) \mathrm{F}$ $\mathrm{C}(\mathrm{C}(\mathrm{C}(\mathrm{C}(\mathrm{C}(\mathrm{C}(\mathrm{C}(\mathrm{C}(\mathrm{C}(\mathrm{C}(\mathrm{Br})(\mathrm{H}) \mathrm{Cl})(\mathrm{Cl}) \mathrm{H})(\mathrm{Cl}) \mathrm{Cl})(\mathrm{H}) \mathrm{H})(\mathrm{H}) \mathrm{H})(\mathrm{H}) \mathrm{H})(\mathrm{Br}) \mathrm{Cl})(\mathrm{F}) \mathrm{H})(\mathrm{H}) \mathrm{F})(\mathrm{H})(\mathrm{Cl}) \mathrm{Br}$ $\mathrm{C}(\mathrm{C}(\mathrm{C}(\mathrm{C}(\mathrm{C}(\mathrm{C}(\mathrm{C}(\mathrm{C}(\mathrm{C}(\mathrm{C}(\mathrm{H})(\mathrm{H}) \mathrm{Br})(\mathrm{H}) \mathrm{Cl})(\mathrm{Cl}) \mathrm{H})(\mathrm{Br}) \mathrm{Cl})(\mathrm{Cl}) \mathrm{H})(\mathrm{Cl}) \mathrm{H})(\mathrm{H}) \mathrm{H})(\mathrm{H}) \mathrm{Br})(\mathrm{H}) \mathrm{F})(\mathrm{Br})(\mathrm{Cl}) \mathrm{H}$ $\mathrm{C}(\mathrm{C}(\mathrm{C}(\mathrm{C}(\mathrm{C}(\mathrm{C}(\mathrm{C}(\mathrm{C}(\mathrm{C}(\mathrm{C}(\mathrm{H})(\mathrm{F}) \mathrm{H})(\mathrm{F}) \mathrm{H})(\mathrm{H}) \mathrm{H})(\mathrm{F}) \mathrm{Cl})(\mathrm{Br}) \mathrm{H})(\mathrm{Cl}) \mathrm{H})(\mathrm{Cl}) \mathrm{H})(\mathrm{H}) \mathrm{H})(\mathrm{Cl}) \mathrm{Cl})(\mathrm{Cl})(\mathrm{H}) \mathrm{F}$ $\mathrm{C}(\mathrm{C}(\mathrm{C}(\mathrm{C}(\mathrm{C}(\mathrm{C}(\mathrm{C}(\mathrm{C}(\mathrm{C}(\mathrm{C}(\mathrm{Cl})(\mathrm{Cl}) \mathrm{Cl})(\mathrm{F}) \mathrm{F})(\mathrm{F}) \mathrm{Cl})(\mathrm{Cl}) \mathrm{H})(\mathrm{F}) \mathrm{H})(\mathrm{H}) \mathrm{H})(\mathrm{H}) \mathrm{Cl})(\mathrm{F}) \mathrm{H})(\mathrm{H}) \mathrm{H})(\mathrm{H})(\mathrm{H}) \mathrm{H}$ $\mathrm{C}(\mathrm{C}(\mathrm{C}(\mathrm{C}(\mathrm{C}(\mathrm{C}(\mathrm{C}(\mathrm{C}(\mathrm{C}(\mathrm{C}(\mathrm{Cl})(\mathrm{H}) \mathrm{H})(\mathrm{H}) \mathrm{F})(\mathrm{Cl}) \mathrm{H})(\mathrm{Cl}) \mathrm{Cl})(\mathrm{H}) \mathrm{F})(\mathrm{Cl}) \mathrm{H})(\mathrm{H}) \mathrm{H})(\mathrm{H}) \mathrm{H})(\mathrm{Cl}) \mathrm{H})(\mathrm{Cl})(\mathrm{Br}) \mathrm{Br}$ $\mathrm{C}(\mathrm{C}(\mathrm{C}(\mathrm{C}(\mathrm{C}(\mathrm{C}(\mathrm{C}(\mathrm{C}(\mathrm{C}(\mathrm{C}(\mathrm{H})(\mathrm{H}) \mathrm{Cl})(\mathrm{H}) \mathrm{H})(\mathrm{F}) \mathrm{H})(\mathrm{F}) \mathrm{Br})(\mathrm{H}) \mathrm{Cl})(\mathrm{H}) \mathrm{H})(\mathrm{F}) \mathrm{Cl})(\mathrm{H}) \mathrm{H})(\mathrm{Cl}) \mathrm{Cl})(\mathrm{H})(\mathrm{Cl}) \mathrm{Cl}$ $\mathrm{C}(\mathrm{C}(\mathrm{C}(\mathrm{C}(\mathrm{C}(\mathrm{C}(\mathrm{C}(\mathrm{C}(\mathrm{C}(\mathrm{C}(\mathrm{H})(\mathrm{F}) \mathrm{Br})(\mathrm{Cl}) \mathrm{Cl})(\mathrm{H}) \mathrm{H})(\mathrm{Cl}) \mathrm{H})(\mathrm{Cl}) \mathrm{Cl})(\mathrm{Cl}) \mathrm{H})(\mathrm{Cl}) \mathrm{H})(\mathrm{F}) \mathrm{H})(\mathrm{H}) \mathrm{H})(\mathrm{H})(\mathrm{Cl}) \mathrm{H}$ $\mathrm{C}(\mathrm{C}(\mathrm{C}(\mathrm{C}(\mathrm{C}(\mathrm{C}(\mathrm{C}(\mathrm{C}(\mathrm{C}(\mathrm{C}(\mathrm{H})(\mathrm{H}) \mathrm{Cl})(\mathrm{Cl}) \mathrm{Cl})(\mathrm{H}) \mathrm{Cl})(\mathrm{H}) \mathrm{F})(\mathrm{H}) \mathrm{Cl})(\mathrm{H}) \mathrm{Cl})(\mathrm{H}) \mathrm{F})(\mathrm{H}) \mathrm{F})(\mathrm{H}) \mathrm{H})(\mathrm{H})(\mathrm{Cl}) \mathrm{Cl}$ $\mathrm{C}(\mathrm{C}(\mathrm{C}(\mathrm{C}(\mathrm{C}(\mathrm{C}(\mathrm{C}(\mathrm{C}(\mathrm{C}(\mathrm{C}(\mathrm{H})(\mathrm{H}) \mathrm{Cl})(\mathrm{H}) \mathrm{H})(\mathrm{F}) \mathrm{F})(\mathrm{H}) \mathrm{H})(\mathrm{Cl}) \mathrm{Cl})(\mathrm{Cl}) \mathrm{H})(\mathrm{Cl}) \mathrm{Cl})(\mathrm{H}) \mathrm{Cl})(\mathrm{H}) \mathrm{Cl})(\mathrm{H})(\mathrm{Cl}) \mathrm{H}$ $\mathrm{C}(\mathrm{C}(\mathrm{C}(\mathrm{C}(\mathrm{C}(\mathrm{C}(\mathrm{C}(\mathrm{C}(\mathrm{C}(\mathrm{C}(\mathrm{H})(\mathrm{Br}) \mathrm{F})(\mathrm{F}) \mathrm{Br})(\mathrm{F}) \mathrm{H})(\mathrm{Br}) \mathrm{H})(\mathrm{H}) \mathrm{F})(\mathrm{H}) \mathrm{Br})(\mathrm{F}) \mathrm{Cl})(\mathrm{H}) \mathrm{H})(\mathrm{H}) \mathrm{H})(\mathrm{H})(\mathrm{H}) \mathrm{F}$ $\mathrm{C}(\mathrm{C}(\mathrm{C}(\mathrm{C}(\mathrm{C}(\mathrm{C}(\mathrm{C}(\mathrm{C}(\mathrm{C}(\mathrm{C}(\mathrm{Br})(\mathrm{H}) \mathrm{F})(\mathrm{H}) \mathrm{F})(\mathrm{Br}) \mathrm{F})(\mathrm{H}) \mathrm{Br})(\mathrm{H}) \mathrm{F})(\mathrm{H}) \mathrm{Cl})(\mathrm{Br}) \mathrm{H})(\mathrm{H}) \mathrm{H})(\mathrm{H}) \mathrm{Br})(\mathrm{H})(\mathrm{H}) \mathrm{F}$ $\mathrm{C}(\mathrm{C}(\mathrm{C}(\mathrm{C}(\mathrm{C}(\mathrm{C}(\mathrm{C}(\mathrm{C}(\mathrm{C}(\mathrm{C}(\mathrm{F})(\mathrm{H}) \mathrm{H})(\mathrm{H}) \mathrm{F})(\mathrm{Cl}) \mathrm{Br})(\mathrm{Br}) \mathrm{F})(\mathrm{H}) \mathrm{Br})(\mathrm{Br}) \mathrm{H})(\mathrm{H}) \mathrm{Br})(\mathrm{H}) \mathrm{H})(\mathrm{H}) \mathrm{H})(\mathrm{F})(\mathrm{Br}) \mathrm{H}$ $\mathrm{C}(\mathrm{C}(\mathrm{C}(\mathrm{C}(\mathrm{C}(\mathrm{C}(\mathrm{C}(\mathrm{C}(\mathrm{C}(\mathrm{C}(\mathrm{Br})(\mathrm{F}) \mathrm{H})(\mathrm{Br}) \mathrm{H})(\mathrm{H}) \mathrm{Br})(\mathrm{H}) \mathrm{H})(\mathrm{Br}) \mathrm{H})(\mathrm{H}) \mathrm{Cl})(\mathrm{H}) \mathrm{Br})(\mathrm{F}) \mathrm{Br})(\mathrm{H}) \mathrm{H})(\mathrm{Br})(\mathrm{H}) \mathrm{F}$ $\mathrm{C}(\mathrm{C}(\mathrm{C}(\mathrm{C}(\mathrm{C}(\mathrm{C}(\mathrm{C}(\mathrm{C}(\mathrm{C}(\mathrm{C}(\mathrm{H})(\mathrm{H}) \mathrm{Br})(\mathrm{Br}) \mathrm{Br})(\mathrm{F}) \mathrm{H})(\mathrm{H}) \mathrm{H})(\mathrm{F}) \mathrm{F})(\mathrm{F}) \mathrm{H})(\mathrm{H}) \mathrm{H})(\mathrm{F}) \mathrm{Br})(\mathrm{F}) \mathrm{H})(\mathrm{H})(\mathrm{H}) \mathrm{H}$ $\mathrm{C}(\mathrm{C}(\mathrm{C}(\mathrm{C}(\mathrm{C}(\mathrm{C}(\mathrm{C}(\mathrm{C}(\mathrm{C}(\mathrm{C}(\mathrm{F})(\mathrm{F}) \mathrm{F})(\mathrm{Br}) \mathrm{Br})(\mathrm{H}) \mathrm{H})(\mathrm{F}) \mathrm{F})(\mathrm{H}) \mathrm{H})(\mathrm{H}) \mathrm{Br})(\mathrm{H}) \mathrm{H})(\mathrm{H}) \mathrm{H})(\mathrm{Br}) \mathrm{H})(\mathrm{H})(\mathrm{Br}) \mathrm{H}$
$\mathrm{C}(\mathrm{C}(\mathrm{C}(\mathrm{C}(\mathrm{C}(\mathrm{C}(\mathrm{C}(\mathrm{C}(\mathrm{C}(\mathrm{C}(\mathrm{H})(\mathrm{H}) \mathrm{F})(\mathrm{H}) \mathrm{H})(\mathrm{F}) \mathrm{Br})(\mathrm{F}) \mathrm{H})(\mathrm{H}) \mathrm{H})(\mathrm{Br}) \mathrm{H})(\mathrm{Br}) \mathrm{H})(\mathrm{H}) \mathrm{F})(\mathrm{Br}) \mathrm{Br})(\mathrm{H})(\mathrm{H}) \mathrm{Br}$ $\mathrm{C}(\mathrm{C}(\mathrm{C}(\mathrm{C}(\mathrm{C}(\mathrm{C}(\mathrm{C}(\mathrm{C}(\mathrm{C}(\mathrm{C}(\mathrm{Br})(\mathrm{Br}) \mathrm{H})(\mathrm{H}) \mathrm{Br})(\mathrm{F}) \mathrm{Br})(\mathrm{H}) \mathrm{H})(\mathrm{H}) \mathrm{H})(\mathrm{Br}) \mathrm{H})(\mathrm{Br}) \mathrm{H})(\mathrm{H}) \mathrm{H})(\mathrm{F}) \mathrm{F})(\mathrm{H})(\mathrm{Br}) \mathrm{H}$ $\mathrm{C}(\mathrm{C}(\mathrm{C}(\mathrm{C}(\mathrm{C}(\mathrm{C}(\mathrm{C}(\mathrm{C}(\mathrm{C}(\mathrm{C}(\mathrm{H})(\mathrm{H}) \mathrm{H})(\mathrm{Cl}) \mathrm{Cl})(\mathrm{Cl}) \mathrm{H})(\mathrm{H}) \mathrm{H})(\mathrm{H}) \mathrm{H})(\mathrm{Cl}) \mathrm{Cl}(\mathrm{Cl}) \mathrm{H})(\mathrm{Cl}) \mathrm{H})(\mathrm{Cl}) \mathrm{H})(\mathrm{Cl})(\mathrm{H}) \mathrm{Cl}$ $\mathrm{C}(\mathrm{C}(\mathrm{C}(\mathrm{C}(\mathrm{C}(\mathrm{C}(\mathrm{C}(\mathrm{C}(\mathrm{C}(\mathrm{C}(\mathrm{Cl})(\mathrm{H}) \mathrm{Br})(\mathrm{H}) \mathrm{H})(\mathrm{H}) \mathrm{F})(\mathrm{F}) \mathrm{H})(\mathrm{H}) \mathrm{H})(\mathrm{H}) \mathrm{F})(\mathrm{H}) \mathrm{H})(\mathrm{H}) \mathrm{Br})(\mathrm{Br}) \mathrm{F})(\mathrm{Cl})(\mathrm{H}) \mathrm{Br}$ $\mathrm{C}(\mathrm{C}(\mathrm{C}(\mathrm{C}(\mathrm{C}(\mathrm{C}(\mathrm{C}(\mathrm{C}(\mathrm{C}(\mathrm{C}(\mathrm{Br})(\mathrm{Cl}) \mathrm{F})(\mathrm{Br}) \mathrm{H})(\mathrm{H}) \mathrm{F})(\mathrm{H}) \mathrm{H})(\mathrm{H}) \mathrm{Cl})(\mathrm{Br}) \mathrm{F})(\mathrm{H}) \mathrm{H})(\mathrm{Br}) \mathrm{H})(\mathrm{H}) \mathrm{H})(\mathrm{H})(\mathrm{H}) \mathrm{Br}$ $\mathrm{C}(\mathrm{C}(\mathrm{C}(\mathrm{C}(\mathrm{C}(\mathrm{C}(\mathrm{C}(\mathrm{C}(\mathrm{C}(\mathrm{C}(\mathrm{Cl})(\mathrm{Br}) \mathrm{H})(\mathrm{F}) \mathrm{Br})(\mathrm{H}) \mathrm{H})(\mathrm{H}) \mathrm{Cl})(\mathrm{H}) \mathrm{Br})(\mathrm{H}) \mathrm{Br})(\mathrm{H}) \mathrm{H})(\mathrm{Br}) \mathrm{H})(\mathrm{H}) \mathrm{H})(\mathrm{H})(\mathrm{F}) \mathrm{B}$ $\mathrm{C}(\mathrm{C}(\mathrm{C}(\mathrm{C}(\mathrm{C}(\mathrm{C}(\mathrm{C}(\mathrm{C}(\mathrm{C}(\mathrm{C}(\mathrm{F})(\mathrm{H}) \mathrm{H})(\mathrm{H}) \mathrm{H})(\mathrm{H}) \mathrm{H})(\mathrm{F}) \mathrm{Br})(\mathrm{H}) \mathrm{Cl})(\mathrm{H}) \mathrm{H})(\mathrm{F}) \mathrm{Cl})(\mathrm{H}) \mathrm{Br})(\mathrm{H}) \mathrm{H})(\mathrm{F})(\mathrm{Cl}) \mathrm{F}$ $\mathrm{C}(\mathrm{C}(\mathrm{C}(\mathrm{C}(\mathrm{C}(\mathrm{C}(\mathrm{C}(\mathrm{C}(\mathrm{C}(\mathrm{C}(\mathrm{H})(\mathrm{H}) \mathrm{Br})(\mathrm{H}) \mathrm{Br})(\mathrm{Cl}) \mathrm{Cl})(\mathrm{Cl}) \mathrm{Br})(\mathrm{H}) \mathrm{H})(\mathrm{H}) \mathrm{F})(\mathrm{H}) \mathrm{H})(\mathrm{F}) \mathrm{H})(\mathrm{F}) \mathrm{H})(\mathrm{H})(\mathrm{F}) \mathrm{H}$ $\mathrm{C}(\mathrm{C}(\mathrm{C}(\mathrm{C}(\mathrm{C}(\mathrm{C}(\mathrm{C}(\mathrm{C}(\mathrm{C}(\mathrm{C}(\mathrm{Cl})(\mathrm{H}) \mathrm{H})(\mathrm{Br}) \mathrm{H})(\mathrm{Br}) \mathrm{Br})(\mathrm{F}) \mathrm{Cl})(\mathrm{H}) \mathrm{H})(\mathrm{Cl}) \mathrm{H})(\mathrm{Br}) \mathrm{H})(\mathrm{H}) \mathrm{H})(\mathrm{F}) \mathrm{H})(\mathrm{H})(\mathrm{H}) \mathrm{F}$ $\mathrm{C}(\mathrm{C}(\mathrm{C}(\mathrm{C}(\mathrm{C}(\mathrm{C}(\mathrm{C}(\mathrm{C}(\mathrm{C}(\mathrm{C}(\mathrm{Cl})(\mathrm{H}) \mathrm{H})(\mathrm{Br}) \mathrm{Br})(\mathrm{H}) \mathrm{Cl})(\mathrm{H}) \mathrm{H})(\mathrm{H}) \mathrm{Cl})(\mathrm{H}) \mathrm{Br})(\mathrm{H}) \mathrm{H})(\mathrm{Br}) \mathrm{H})(\mathrm{Br}) \mathrm{F})(\mathrm{F})(\mathrm{H}) \mathrm{H}$ $\mathrm{C}(\mathrm{C}(\mathrm{C}(\mathrm{C}(\mathrm{C}(\mathrm{C}(\mathrm{C}(\mathrm{C}(\mathrm{C}(\mathrm{C}(\mathrm{H})(\mathrm{H}) \mathrm{F})(\mathrm{H}) \mathrm{Br})(\mathrm{H}) \mathrm{H})(\mathrm{H}) \mathrm{Br})(\mathrm{F}) \mathrm{Cl})(\mathrm{H}) \mathrm{Cl})(\mathrm{Cl}) \mathrm{H})(\mathrm{H}) \mathrm{H})(\mathrm{Br}) \mathrm{Cl})(\mathrm{F})(\mathrm{H}) \mathrm{H}$ $\mathrm{C}(\mathrm{C}(\mathrm{C}(\mathrm{C}(\mathrm{C}(\mathrm{C}(\mathrm{C}(\mathrm{C}(\mathrm{C}(\mathrm{C}(\mathrm{F})(\mathrm{H}) \mathrm{Cl})(\mathrm{Br}) \mathrm{H})(\mathrm{H}) \mathrm{H})(\mathrm{Br}) \mathrm{H})(\mathrm{Cl}) \mathrm{H})(\mathrm{Cl}) \mathrm{H})(\mathrm{Br}) \mathrm{Br})(\mathrm{H}) \mathrm{H})(\mathrm{Cl}) \mathrm{F})(\mathrm{H})(\mathrm{H}) \mathrm{H}$ $\mathrm{C}(\mathrm{C}(\mathrm{C}(\mathrm{C}(\mathrm{C}(\mathrm{C}(\mathrm{C}(\mathrm{C}(\mathrm{C}(\mathrm{C}(\mathrm{Cl})(\mathrm{H}) \mathrm{H})(\mathrm{H}) \mathrm{H})(\mathrm{H}) \mathrm{Cl})(\mathrm{H}) \mathrm{H})(\mathrm{Cl}) \mathrm{F})(\mathrm{Cl}) \mathrm{F})(\mathrm{H}) \mathrm{Br})(\mathrm{H}) \mathrm{H})(\mathrm{F}) \mathrm{H})(\mathrm{H})(\mathrm{Br}) \mathrm{Cl}$ $\mathrm{C}(\mathrm{C}(\mathrm{C}(\mathrm{C}(\mathrm{C}(\mathrm{C}(\mathrm{C}(\mathrm{C}(\mathrm{C}(\mathrm{C}(\mathrm{H})(\mathrm{Cl}) \mathrm{H})(\mathrm{F}) \mathrm{Cl})(\mathrm{H}) \mathrm{Br})(\mathrm{H}) \mathrm{Br})(\mathrm{H}) \mathrm{H})(\mathrm{H}) \mathrm{Cl})(\mathrm{H}) \mathrm{Cl})(\mathrm{H}) \mathrm{H})(\mathrm{Cl}) \mathrm{Br})(\mathrm{F})(\mathrm{H}) \mathrm{H}$ $\mathrm{C}(\mathrm{C}(\mathrm{C}(\mathrm{C}(\mathrm{C}(\mathrm{C}(\mathrm{C}(\mathrm{C}(\mathrm{C}(\mathrm{C}(\mathrm{Cl})(\mathrm{H}) \mathrm{H})(\mathrm{H}) \mathrm{H})(\mathrm{Cl}) \mathrm{F})(\mathrm{H}) \mathrm{Br})(\mathrm{H}) \mathrm{H})(\mathrm{F}) \mathrm{Cl})(\mathrm{F}) \mathrm{H})(\mathrm{H}) \mathrm{H})(\mathrm{F}) \mathrm{Cl})(\mathrm{Cl})(\mathrm{H}) \mathrm{H}$ $\mathrm{C}(\mathrm{C}(\mathrm{C}(\mathrm{C}(\mathrm{C}(\mathrm{C}(\mathrm{C}(\mathrm{C}(\mathrm{C}(\mathrm{C}(\mathrm{Br})(\mathrm{Cl}) \mathrm{H})(\mathrm{Cl}) \mathrm{H})(\mathrm{H}) \mathrm{Cl})(\mathrm{H}) \mathrm{Cl})(\mathrm{F}) \mathrm{Br})(\mathrm{Cl}) \mathrm{H})(\mathrm{F}) \mathrm{H})(\mathrm{H}) \mathrm{H})(\mathrm{Cl}) \mathrm{H})(\mathrm{H})(\mathrm{H}) \mathrm{H}$ $\mathrm{C}(\mathrm{C}(\mathrm{C}(\mathrm{C}(\mathrm{C}(\mathrm{C}(\mathrm{C}(\mathrm{C}(\mathrm{C}(\mathrm{C}(\mathrm{Br})(\mathrm{H}) \mathrm{Cl})(\mathrm{H}) \mathrm{H})(\mathrm{Cl}) \mathrm{Br})(\mathrm{H}) \mathrm{Cl})(\mathrm{Cl}) \mathrm{H})(\mathrm{Br}) \mathrm{H})(\mathrm{H}) \mathrm{H})(\mathrm{H}) \mathrm{H})(\mathrm{Cl}) \mathrm{Cl})(\mathrm{F})(\mathrm{H}) \mathrm{H}$ $\mathrm{C}(\mathrm{C}(\mathrm{C}(\mathrm{C}(\mathrm{C}(\mathrm{C}(\mathrm{C}(\mathrm{C}(\mathrm{C}(\mathrm{C}(\mathrm{Cl})(\mathrm{H}) \mathrm{H})(\mathrm{H}) \mathrm{F})(\mathrm{H}) \mathrm{H})(\mathrm{Cl}) \mathrm{Cl})(\mathrm{H}) \mathrm{F})(\mathrm{Br}) \mathrm{H})(\mathrm{Cl}) \mathrm{H})(\mathrm{F}) \mathrm{H})(\mathrm{Cl}) \mathrm{H})(\mathrm{H})(\mathrm{Cl}) \mathrm{H}$ $\mathrm{C}(\mathrm{C}(\mathrm{C}(\mathrm{C}(\mathrm{C}(\mathrm{C}(\mathrm{C}(\mathrm{C}(\mathrm{C}(\mathrm{C}(\mathrm{H})(\mathrm{Cl}) \mathrm{H})(\mathrm{H}) \mathrm{Cl})(\mathrm{Cl}) \mathrm{H})(\mathrm{F}) \mathrm{H})(\mathrm{Cl}) \mathrm{H})(\mathrm{H}) \mathrm{H})(\mathrm{H}) \mathrm{H})(\mathrm{Cl}) \mathrm{F})(\mathrm{F}) \mathrm{F})(\mathrm{H})(\mathrm{H}) \mathrm{Cl}$ $\mathrm{C}(\mathrm{C}(\mathrm{C}(\mathrm{C}(\mathrm{C}(\mathrm{C}(\mathrm{C}(\mathrm{C}(\mathrm{C}(\mathrm{C}(\mathrm{Cl})(\mathrm{H}) \mathrm{Cl})(\mathrm{F}) \mathrm{H})(\mathrm{H}) \mathrm{Cl})(\mathrm{H}) \mathrm{H})(\mathrm{Cl}) \mathrm{H})(\mathrm{H}) \mathrm{H})(\mathrm{Br}) \mathrm{H})(\mathrm{Br}) \mathrm{H})(\mathrm{Cl}) \mathrm{Cl})(\mathrm{H})(\mathrm{Cl}) \mathrm{H}$ $\mathrm{C}(\mathrm{C}(\mathrm{C}(\mathrm{C}(\mathrm{C}(\mathrm{C}(\mathrm{C}(\mathrm{C}(\mathrm{C}(\mathrm{C}(\mathrm{H})(\mathrm{H}) \mathrm{H})(\mathrm{Cl}) \mathrm{Cl})(\mathrm{H}) \mathrm{Cl})(\mathrm{H}) \mathrm{H})(\mathrm{Cl}) \mathrm{F})(\mathrm{Cl}) \mathrm{H})(\mathrm{H}) \mathrm{Cl})(\mathrm{H}) \mathrm{H})(\mathrm{F}) \mathrm{Br})(\mathrm{H})(\mathrm{Cl}) \mathrm{H}$ $\mathrm{C}(\mathrm{C}(\mathrm{C}(\mathrm{C}(\mathrm{C}(\mathrm{C}(\mathrm{C}(\mathrm{C}(\mathrm{C}(\mathrm{C}(\mathrm{H})(\mathrm{H}) \mathrm{H})(\mathrm{H}) \mathrm{Cl})(\mathrm{H}) \mathrm{Cl})(\mathrm{Cl}) \mathrm{H})(\mathrm{H}) \mathrm{Cl})(\mathrm{F}) \mathrm{Cl})(\mathrm{F}) \mathrm{Cl})(\mathrm{H}) \mathrm{H})(\mathrm{H}) \mathrm{F})(\mathrm{Cl})(\mathrm{H}) \mathrm{H}$ $\mathrm{C}(\mathrm{C}(\mathrm{C}(\mathrm{C}(\mathrm{C}(\mathrm{C}(\mathrm{C}(\mathrm{C}(\mathrm{C}(\mathrm{C}(\mathrm{Cl})(\mathrm{H}) \mathrm{F})(\mathrm{F}) \mathrm{Cl})(\mathrm{H}) \mathrm{Cl})(\mathrm{H}) \mathrm{H})(\mathrm{H}) \mathrm{H})(\mathrm{H}) \mathrm{H})(\mathrm{Cl}) \mathrm{H})(\mathrm{Cl}) \mathrm{Cl})(\mathrm{H}) \mathrm{H})(\mathrm{Cl})(\mathrm{H}) \mathrm{Cl}$ $\mathrm{C}(\mathrm{C}(\mathrm{C}(\mathrm{C}(\mathrm{C}(\mathrm{C}(\mathrm{C}(\mathrm{C}(\mathrm{C}(\mathrm{C}(\mathrm{H})(\mathrm{Cl}) \mathrm{Cl})(\mathrm{H}) \mathrm{Cl})(\mathrm{Cl}) \mathrm{H})(\mathrm{H}) \mathrm{Cl})(\mathrm{H}) \mathrm{H})(\mathrm{Br}) \mathrm{H})(\mathrm{H}) \mathrm{Cl})(\mathrm{H}) \mathrm{Cl})(\mathrm{H}) \mathrm{H})(\mathrm{Cl})(\mathrm{H}) \mathrm{Cl}$ $\mathrm{C}(\mathrm{C}(\mathrm{C}(\mathrm{C}(\mathrm{C}(\mathrm{C}(\mathrm{C}(\mathrm{C}(\mathrm{C}(\mathrm{C}(\mathrm{H})(\mathrm{H}) \mathrm{H})(\mathrm{F}) \mathrm{Cl})(\mathrm{Cl}) \mathrm{H})(\mathrm{Cl}) \mathrm{H})(\mathrm{Cl}) \mathrm{Cl})(\mathrm{H}) \mathrm{H})(\mathrm{H}) \mathrm{H})(\mathrm{Cl}) \mathrm{H})(\mathrm{Cl}) \mathrm{H})(\mathrm{H})(\mathrm{Cl}) \mathrm{Cl}$

\section{Formula}

$\mathrm{C} 10 \mathrm{H} 10 \mathrm{Br} 4 \mathrm{~F} 8$

C10H10Br5F7

C10H10Br6F6

$\mathrm{C} 10 \mathrm{H} 10 \mathrm{Br} 7 \mathrm{~F} 5$

$\mathrm{C} 10 \mathrm{H} 10 \mathrm{Cl10BrF}$

C10H10Cl10F2

C10H10Cl11F

$\mathrm{C} 10 \mathrm{H} 10 \mathrm{Cl} 2 \mathrm{Br} 3 \mathrm{~F} 7$

$\mathrm{C} 10 \mathrm{H} 10 \mathrm{Cl} 2 \mathrm{Br} 4 \mathrm{~F} 6$

C10H10Cl2Br5F5

C10H10Cl3Br3F6

$\mathrm{C} 10 \mathrm{H} 10 \mathrm{Cl} 3 \mathrm{Br} 4 \mathrm{~F} 5$

C10H10Cl3Br5F4

C10H10Cl4Br2F6

$\mathrm{C} 10 \mathrm{H} 10 \mathrm{Cl} 4 \mathrm{Br} 4 \mathrm{~F} 4$

$\mathrm{C} 10 \mathrm{H} 10 \mathrm{Cl} 5 \mathrm{Br} 2 \mathrm{~F} 5$

$\mathrm{C} 10 \mathrm{H} 10 \mathrm{Cl} 5 \mathrm{Br} 3 \mathrm{~F} 4$

C10H10Cl6BrF5

$\mathrm{C} 10 \mathrm{H} 10 \mathrm{Cl} 1 \mathrm{BrF} 4$

$\mathrm{C} 10 \mathrm{H} 10 \mathrm{Cl} 8 \mathrm{Br} 3 \mathrm{~F}$

$\mathrm{C} 10 \mathrm{H} 10 \mathrm{Cl} 8 \mathrm{BrF} 3$

$\mathrm{C} 10 \mathrm{H} 10 \mathrm{Cl} 18 \mathrm{~F} 4$

$\mathrm{C} 10 \mathrm{H} 10 \mathrm{Cl} 19 \mathrm{~F} 3$

$\mathrm{C} 10 \mathrm{H} 10 \mathrm{ClBr} 4 \mathrm{~F} 7$

$\mathrm{C} 10 \mathrm{H} 10 \mathrm{ClBr} 5 \mathrm{~F} 6$

$\mathrm{C} 10 \mathrm{H} 10 \mathrm{ClBr} 7 \mathrm{~F} 4$

$\mathrm{C} 10 \mathrm{H} 11 \mathrm{Br} 5 \mathrm{~F} 6$

C10H11Br6F5

C10H11Br7F4

$\mathrm{C} 10 \mathrm{H} 11 \mathrm{Cl10F}$

C10H11Cl1

$\mathrm{C} 10 \mathrm{H} 11 \mathrm{Cl} 2 \mathrm{Br} 3 \mathrm{~F} 6$

C10H11Cl2Br4F5

$\mathrm{C} 10 \mathrm{H} 11 \mathrm{Cl} 2 \mathrm{Br} 5 \mathrm{~F} 4$

$\mathrm{C} 10 \mathrm{H} 11 \mathrm{Cl} 3 \mathrm{Br} 3 \mathrm{~F} 5$

$\mathrm{C} 10 \mathrm{H} 11 \mathrm{Cl} 3 \mathrm{Br} 4 \mathrm{~F} 4$

$\mathrm{C} 10 \mathrm{H} 11 \mathrm{Cl} 4 \mathrm{Br} 2 \mathrm{~F} 5$

C10H11Cl4Br3F4

$\mathrm{C} 10 \mathrm{H} 11 \mathrm{Cl} 4 \mathrm{Br} 4 \mathrm{~F} 3$

$\mathrm{C} 10 \mathrm{H} 11 \mathrm{Cl} 5 \mathrm{Br} 2 \mathrm{~F} 4$

$\mathrm{C} 10 \mathrm{H} 11 \mathrm{Cl} 5 \mathrm{Br} 3 \mathrm{~F} 3$

C10H11Cl5Br4F2

$\mathrm{C} 10 \mathrm{H} 11 \mathrm{Cl} 15 \mathrm{BrF} 5$

$\mathrm{C} 10 \mathrm{H} 11 \mathrm{Cl} 6 \mathrm{Br} 2 \mathrm{~F} 3$

$\mathrm{C} 10 \mathrm{H} 11 \mathrm{Cl} 6 \mathrm{Br} 3 \mathrm{~F} 2$

C10H11Cl6Br4F

$\mathrm{C} 10 \mathrm{H} 11 \mathrm{Cl6BrF} 4$

C10H11Cl6F5

$\mathrm{C} 10 \mathrm{H} 11 \mathrm{Cl} 7 \mathrm{Br} 2 \mathrm{~F} 2$

$\mathrm{C} 10 \mathrm{H} 11 \mathrm{Cl} 7 \mathrm{BrF} 3$

C10H11Cl8BrF2

$\mathrm{C} 10 \mathrm{H} 11 \mathrm{Cl} 8 \mathrm{~F} 3$

$\mathrm{C} 10 \mathrm{H} 11 \mathrm{Cl} 19 \mathrm{~F} 2$

C10H11ClBr4F6

$\mathrm{C} 10 \mathrm{H} 11 \mathrm{ClBr} 5 \mathrm{~F} 5$

$\mathrm{C} 10 \mathrm{H} 11 \mathrm{ClBr} 6 \mathrm{~F} 4$

$\mathrm{C} 10 \mathrm{H} 11 \mathrm{ClBr} 7 \mathrm{~F} 3$

$\mathrm{C} 10 \mathrm{H} 12 \mathrm{Br} 4 \mathrm{~F} 6$

$\mathrm{C} 10 \mathrm{H} 12 \mathrm{Br} 5 \mathrm{~F}$

C10H12Br6F4

$\mathrm{C} 10 \mathrm{H} 12 \mathrm{Br} 7 \mathrm{~F} 3$

$\mathrm{C} 10 \mathrm{H} 12 \mathrm{Cl} 10$

$\mathrm{C} 10 \mathrm{H} 12 \mathrm{Cl} 2 \mathrm{Br} 4 \mathrm{~F} 4$

$\mathrm{C} 10 \mathrm{H} 12 \mathrm{Cl} 2 \mathrm{Br} 5 \mathrm{~F} 3$

$\mathrm{C} 10 \mathrm{H} 12 \mathrm{Cl} 2 \mathrm{Br} 6 \mathrm{~F} 2$

$\mathrm{C} 10 \mathrm{H} 12 \mathrm{Cl} 3 \mathrm{Br} 2 \mathrm{~F} 5$

$\mathrm{C} 10 \mathrm{H} 12 \mathrm{Cl} 3 \mathrm{Br} 3 \mathrm{~F} 4$

$\mathrm{C} 10 \mathrm{H} 12 \mathrm{Cl} 3 \mathrm{Br} 4 \mathrm{~F} 3$

$\mathrm{C} 10 \mathrm{H} 12 \mathrm{Cl} 3 \mathrm{Br} 5 \mathrm{~F} 2$

$\mathrm{C} 10 \mathrm{H} 12 \mathrm{Cl} 4 \mathrm{Br} 3 \mathrm{~F} 3$

$\mathrm{C} 10 \mathrm{H} 12 \mathrm{Cl} 4 \mathrm{Br} 4 \mathrm{~F} 2$

$\mathrm{C} 10 \mathrm{H} 12 \mathrm{Cl} 15 \mathrm{Br} 2 \mathrm{~F} 3$

C10H12Cl5Br3F2

$\mathrm{C} 10 \mathrm{H} 12 \mathrm{Cl} 5 \mathrm{BrF} 4$

$\mathrm{C} 10 \mathrm{H} 12 \mathrm{Cl} 6 \mathrm{Br} 2 \mathrm{~F} 2$

C10H12Cl6Br3F

$\mathrm{C} 10 \mathrm{H} 12 \mathrm{C} 16 \mathrm{BrF} 3$

$\mathrm{C} 10 \mathrm{H} 12 \mathrm{Cl} 16 \mathrm{~F} 4$

C10H12Cl7Br2F

C10H12Cl7BrF2

$\mathrm{C} 10 \mathrm{H} 12 \mathrm{Cl} 7 \mathrm{~F} 3$

$\mathrm{C} 10 \mathrm{H} 12 \mathrm{Cl} 8 \mathrm{~F} 2$

$\mathrm{C} 10 \mathrm{H} 12 \mathrm{C} 19 \mathrm{Br}$

$\mathrm{C} 10 \mathrm{H} 12 \mathrm{C} 19 \mathrm{~F}$
gKoa lgKow lgKaw lgKow lgKoa lgKaw lgKow lgKoa lgKaw EPI_EPI_EPI_Exp__Exp__Exp__DFT_DFT_DFT Suite Suite Suite corr corr corr corr corr corr $\begin{array}{llllllllll}7.42 & 7.64 & 0.22 & 6.48 & 6.25 & 0.22 & 6.63 & 11.64 & -5.0\end{array}$ $\begin{array}{llllllllll}7.42 & 7.64 & 0.22 & 6.48 & 6.25 & 0.22 & 6.63 & 11.64 & -5.01 \\ 9.05 & 8.04 & -1.01 & 7.07 & 8.09 & -1.01 & 6.94 & 14.64 & -7.71\end{array}$ $\begin{array}{llllllllll}9.88 & 7.63 & -2.25 & 6.46 & 8.71 & -2.25 & 6.62 & 16.16 & -9.54\end{array}$ $\begin{array}{rrrrrrrrr}11.6 & 8.11 & -3.49 & 7.18 & 10.67 & -3.49 & 6.99 & 19.32 & -12.33\end{array}$ $\begin{array}{llllllllll}11.6 & 8.11 & -3.49 & 7.18 & 10.67 & -3.49 & 6.99 & 19.32 & -12.33 \\ 11.7 & 8.08 & -3.59 & 7.13 & 10.72 & -3.59 & 6.97 & 19.44 & -12.47 \\ 10.8 & 8.42 & -2.35 & 7.64 & 9.99 & -2.35 & 7.23 & 17.79 & -10.56\end{array}$ $\begin{array}{llllllllll}1.7 & 8.08 & -3.59 & 7.13 & 10.72 & -3.59 & 6.97 & 19.44 & -12.47\end{array}$ $\begin{array}{lllllllll}1.1 & 7.99 & -3.10 & 7.00 & 10.10 & -3.10 & 6.90 & 18.39 & -11.49\end{array}$ $\begin{array}{llllllllll}7.83 & 7.79 & -0.04 & 6.70 & 6.75 & -0.04 & 6.75 & 12.40 & -5.66\end{array}$ $\begin{array}{llllllllll}8.8 & 7.52 & -1.28 & 6.30 & 7.58 & -1.28 & 6.54 & 14.18 & -7.64\end{array}$ $\begin{array}{rrrrrrrrrr}8.8 & 7.52 & -1.28 & 6.30 & 7.58 & -1.28 & 6.54 & 14.18 & -7.64 \\ 10.4 & 7.93 & -2.52 & 6.91 & 9.43 & -2.52 & 6.85 & 17.20 & -10.35\end{array}$ $\begin{array}{llllllllll}8.98 & 8.18 & -0.80 & 7.28 & 8.08 & -0.80 & 7.04 & 14.50 & -7.46\end{array}$ $\begin{array}{lllllllll}9.87 & 7.84 & -2.03 & 6.78 & 8.81 & -2.03 & 6.78 & 16.15 & -9.36\end{array}$ $\begin{array}{lllllllll}1.5 & 8.24 & -3.27 & 7.37 & 10.64 & -3.27 & 7.09 & 19.16 & -12.07\end{array}$ $\begin{array}{lllllllll}8.4 & 8.09 & -0.31 & 7.15 & 7.46 & -0.31 & 6.98 & 13.44 & -6.47\end{array}$ $\begin{array}{lllllllll}10.9 & 8.08 & -2.79 & 7.13 & 9.92 & -2.79 & 6.97 & 17.97 & -11.00\end{array}$ $\begin{array}{llllllllll}9.46 & 8.4 & -1.06 & 7.61 & 8.67 & -1.06 & 7.21 & 15.39 & -8.18\end{array}$ $\begin{array}{lllllllll}10.4 & 8.06 & -2.30 & 7.10 & 9.40 & -2.30 & 6.95 & 17.04 & -10.09\end{array}$ $\begin{array}{lllllllll}8.82 & 8.24 & -0.58 & 7.37 & 7.95 & -0.58 & 7.09 & 14.21 & -7.12\end{array}$ $\begin{array}{llllllllll}9.88 & 8.55 & -1.33 & 7.84 & 9.16 & -1.33 & 7.33 & 16.16 & -8.83\end{array}$ $\begin{array}{llllllllll}12.1 & 7.52 & -4.56 & 6.30 & 10.85 & -4.56 & 6.54 & 20.19 & -13.66\end{array}$ $\begin{array}{llllllllll}9.54 & 7.46 & -2.08 & 6.21 & 8.29 & -2.08 & 6.49 & 15.54 & -9.05\end{array}$ $\begin{array}{llllllllll}9.89 & 7.46 & -2.08 & 6.21 & 8.29 & -2.08 & 6.49 & 15.54 & -9.05\end{array}$

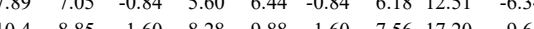
$\begin{array}{llllllll}0.4 & 8.85 & -1.60 & 8.28 & 9.88 & -\end{array}$ $\begin{array}{llllllllll}8.48 & 7.95 & -0.53 & 6.94 & 7.47 & -0.53 & 6.87 & 13.59 & -6.72\end{array}$ $\begin{array}{lllllllll}9.38 & 7.61 & -1.77 & 6.43 & 8.20 & -1.77 & 6.61 & 15.24 & -8.63\end{array}$ $\begin{array}{lllllllll}12.7 & 8.42 & -4.24 & 7.64 & 11.88 & -4.24 & 7.23 & 21.27 & -14.04\end{array}$ $\begin{array}{lllllllll}10.2 & 8.84 & -1.31 & 8.27 & 9.58 & -1.31 & 7.55 & 16.66 & -9.11\end{array}$ $\begin{array}{lllllllll}10.3 & 7.76 & -2.55 & 6.66 & 9.21 & -2.55 & 6.72 & 16.95 & -10.23\end{array}$ $\begin{array}{lllllllll}12 & 8.17 & -3.79 & 7.27 & 11.06 & -3.79 & 7.04 & 19.98 & -12.94\end{array}$ $\begin{array}{lllllllll}11.2 & 8.55 & -2.65 & 7.84 & 10.48 & -2.65 & 7.33 & 18.58 & -11.25\end{array}$ $\begin{array}{lllllllll}11.5 & 8.13 & -3.40 & 7.21 & 10.61 & -3.40 & 7.01 & 19.19 & -12.18\end{array}$ $\begin{array}{lllllllll}9 & 8.66 & -0.34 & 8.00 & 8.34 & -0.34 & 7.41 & 14.55 & -7.14\end{array}$ $\begin{array}{llllllllll}9.24 & 7.66 & -1.58 & 6.51 & 8.09 & -1.58 & 6.65 & 14.99 & -8.34\end{array}$ $\begin{array}{lllllllll}11.5 & 8.73 & -2.82 & 8.10 & 10.92 & -2.82 & 7.47 & 19.22 & -11.76\end{array}$ $\begin{array}{llllllllll}7.92 & 6.83 & -1.09 & 5.27 & 6.36 & -1.09 & 6.01 & 12.57 & -6.56\end{array}$ $\begin{array}{llllllllll}10.3 & 7.97 & -2.33 & 6.97 & 9.30 & -2.33 & 6.88 & 16.94 & -10.05\end{array}$ $\begin{array}{llllllllll}8.02 & 7.41 & -0.61 & 6.13 & 6.74 & -0.61 & 6.45 & 12.74 & -6.29\end{array}$ $\begin{array}{lllllllll}8.99 & 7.14 & -1.85 & 5.73 & 7.58 & -1.85 & 6.25 & 14.52 & -8.28\end{array}$ $\begin{array}{lllllllll}10.6 & 7.54 & -3.08 & 6.33 & 9.41 & -3.08 & 6.55 & 17.53 & -10.97\end{array}$ $\begin{array}{lllllllll}9.15 & 7.79 & -1.36 & 6.70 & 8.06 & -1.36 & 6.75 & 14.83 & -8.08\end{array}$ $\begin{array}{llllllllll}11.5 & 8.94 & -2.60 & 8.42 & 11.02 & -2.60 & 7.63 & 19.21 & -11.58\end{array}$ $\begin{array}{lllllllll}12.4 & 8.6 & -3.84 & 7.91 & 11.75 & -3.84 & 7.37 & 20.86 & -13.49\end{array}$ $\begin{array}{lllllllll}7.51 & 7.39 & -0.12 & 6.10 & 6.23 & -0.12 & 6.44 & 11.82 & -5.38\end{array}$ $\begin{array}{lllllllll}9.47 & 7.36 & -2.11 & 6.06 & 8.17 & -2.11 & 6.41 & 15.41 & -9.00\end{array}$ $\begin{array}{llllllllll}11.9 & 8.51 & -3.35 & 7.78 & 11.13 & -3.35 & 7.30 & 19.80 & -12.50\end{array}$ $\begin{array}{lllllllll}12.8 & 8.17 & -4.59 & 7.27 & 11.86 & -4.59 & 7.04 & 21.45 & -14.41\end{array}$ $\begin{array}{llllllllll}8.58 & 7.7 & -0.88 & 6.57 & 7.44 & -0.88 & 6.68 & 13.77 & -7.09\end{array}$ $\begin{array}{llllllllll}7.61 & 7.97 & 0.36 & 6.97 & 6.61 & 0.36 & 6.88 & 11.99 & -5.11\end{array}$ $\begin{array}{llllllllll}11.3 & 8.42 & -2.86 & 7.64 & 10.51 & -2.86 & 7.23 & 18.74 & -11.5\end{array}$ $\begin{array}{llllllllll}10.4 & 8.76 & -1.63 & 8.15 & 9.78 & -1.63 & 7.49 & 17.09 & -9.60\end{array}$ $\begin{array}{lllllllll}10.7 & 8.33 & -2.38 & 7.51 & 9.89 & -2.38 & 7.16 & 17.69 & -10.53\end{array}$ $\begin{array}{llllllllll}8.33 & 7.19 & -1.14 & 5.81 & 6.95 & -1.14 & 6.28 & 13.32 & -7.04\end{array}$ $\begin{array}{llllllllll}10.9 & 8.98 & -1.89 & 8.48 & 10.37 & -1.89 & 7.66 & 17.99 & -10.33\end{array}$ $\begin{array}{llllllllll}8.17 & 7.34 & -0.83 & 6.03 & 6.86 & -0.83 & 6.40 & 13.01 & -6.62\end{array}$ $\begin{array}{llllllllll}9.07 & 7.01 & -2.06 & 5.54 & 7.60 & -2.06 & 6.15 & 14.68 & -8.53\end{array}$ $\begin{array}{lllllllll}11.5 & 8.15 & -3.30 & 7.24 & 10.54 & -3.30 & 7.02 & 19.05 & -12.03\end{array}$ $\begin{array}{lllllllll}12.3 & 7.81 & -4.54 & 6.73 & 11.27 & -4.54 & 6.76 & 20.70 & -13.94\end{array}$ $\begin{array}{lllllllll}8.21 & 7.83 & -0.38 & 6.76 & 7.14 & -0.38 & 6.78 & 13.09 & -6.31\end{array}$ $\begin{array}{llllllllll}9.92 & 8.31 & -1.61 & 7.48 & 9.09 & -1.61 & 7.14 & 16.24 & -9.09\end{array}$ $\begin{array}{llllllllll}10.8 & 7.97 & -2.85 & 6.97 & 9.82 & -2.85 & 6.88 & 17.89 & -11.00\end{array}$ $\begin{array}{lllllllll}12.5 & 8.37 & -4.09 & 7.57 & 11.65 & -4.09 & 7.19 & 20.89 & -13.70\end{array}$ $\begin{array}{lllllllll}11.6 & 8.61 & -2.95 & 7.93 & 10.87 & -2.95 & 7.38 & 19.24 & -11.86\end{array}$ $\begin{array}{lllllllll}8.93 & 7.05 & -1.88 & 5.60 & 7.48 & -1.88 & 6.18 & 14.41 & -8.24\end{array}$ $\begin{array}{lllllllll}11.3 & 8.19 & -3.12 & 7.30 & 10.42 & -3.12 & 7.05 & 18.78 & -11.73\end{array}$ $\begin{array}{llllllllll}12.2 & 7.86 & -4.35 & 6.81 & 11.16 & -4.35 & 6.80 & 20.44 & -13.64\end{array}$ $\begin{array}{lllllllll}8.2 & 8.04 & -0.16 & 7.07 & 7.23 & -0.16 & 6.94 & 13.07 & -6.13\end{array}$ $\begin{array}{llllllllll}9.09 & 7.7 & -1.39 & 6.57 & 7.96 & -1.39 & 6.68 & 14.72 & -8.04\end{array}$ $\begin{array}{lllllllll}10.7 & 8.1 & -2.63 & 7.16 & 9.79 & -2.63 & 6.98 & 17.72 & -10.74\end{array}$ $\begin{array}{lllllllll}12.4 & 8.51 & -3.87 & 7.78 & 11.64 & -3.87 & 7.30 & 20.75 & -13.45\end{array}$ $\begin{array}{llllllllll}10.2 & 8.01 & -2.15 & 7.03 & 9.18 & -2.15 & 6.91 & 16.67 & -9.75\end{array}$ $\begin{array}{lllllllll}11.7 & 8.34 & -3.38 & 7.52 & 10.91 & -3.38 & 7.17 & 19.55 & -12.38\end{array}$ $\begin{array}{lllllllll}9.58 & 7.92 & -1.66 & 6.90 & 8.56 & -1.66 & 6.84 & 15.61 & -8.77\end{array}$ $\begin{array}{lllllllll}11.2 & 8.33 & -2.90 & 7.51 & 10.40 & -2.90 & 7.16 & 18.64 & -11.48\end{array}$ $\begin{array}{llllllllll}8.68 & 8.26 & -0.42 & 7.40 & 7.83 & -0.42 & 7.11 & 13.96 & -6.86\end{array}$ $\begin{array}{llllllllll}9.83 & 7.42 & -2.41 & 6.15 & 8.56 & -2.41 & 6.46 & 16.07 & -9.6\end{array}$ $\begin{array}{lllllllll}12.3 & 8.64 & -3.65 & 7.97 & 11.62 & -3.65 & 7.40 & 20.59 & -13.19\end{array}$ $\begin{array}{lllllllll}8.26 & 7.09 & -1.17 & 5.66 & 6.83 & -1.17 & 6.21 & 13.19 & -6.99\end{array}$ $\begin{array}{llllllllll}7.37 & 7.43 & 0.06 & 6.16 & 6.10 & 0.06 & 6.47 & 11.55 & -5.08\end{array}$ $\begin{array}{llllllllll}11 & 7.81 & -3.16 & 6.73 & 9.89 & -3.16 & 6.76 & 18.17 & -11.41\end{array}$ $\begin{array}{lllllllll}10.7 & 8.82 & -1.93 & 8.24 & 10.16 & -1.93 & 7.54 & 17.75 & -10.22\end{array}$ $\begin{array}{lllllllll}8.36 & 7.67 & -0.69 & 6.52 & 7.21 & -0.69 & 6.65 & 13.37 & -6.71\end{array}$ $\begin{array}{lllllllll}9.5 & 8.06 & -1.44 & 7.10 & 8.55 & -1.44 & 6.95 & 15.47 & -8.51\end{array}$ $\begin{array}{llllllllll}10.7 & 7.29 & -3.43 & 5.96 & 9.39 & -3.43 & 6.36 & 17.70 & -11.34\end{array}$ $\begin{array}{rrrrrrrrr}10.5 & 8.3 & -2.19 & 7.46 & 9.66 & -2.19 & 7.14 & 17.29 & -10.15\end{array}$ 
$\mathrm{C}(\mathrm{C}(\mathrm{C}(\mathrm{C}(\mathrm{C}(\mathrm{C}(\mathrm{C}(\mathrm{C}(\mathrm{C}(\mathrm{C}(\mathrm{Br})(\mathrm{H}) \mathrm{H})(\mathrm{H}) \mathrm{H})(\mathrm{Br}) \mathrm{Br})(\mathrm{H}) \mathrm{F})(\mathrm{F}) \mathrm{H})(\mathrm{F}) \mathrm{H})(\mathrm{H}) \mathrm{F})(\mathrm{Cl}) \mathrm{H})(\mathrm{Br}) \mathrm{H})(\mathrm{H})(\mathrm{F}) \mathrm{H}$ $\mathrm{C}(\mathrm{C}(\mathrm{C}(\mathrm{C}(\mathrm{C}(\mathrm{C}(\mathrm{C}(\mathrm{C}(\mathrm{C}(\mathrm{C}(\mathrm{H})(\mathrm{H}) \mathrm{H})(\mathrm{F}) \mathrm{Br})(\mathrm{F}) \mathrm{Cl})(\mathrm{H}) \mathrm{F})(\mathrm{H}) \mathrm{Br})(\mathrm{H}) \mathrm{H})(\mathrm{H}) \mathrm{H})(\mathrm{H}) \mathrm{Br})(\mathrm{H}) \mathrm{F})(\mathrm{Br})(\mathrm{Br}) \mathrm{H}$ $\mathrm{C}(\mathrm{C}(\mathrm{C}(\mathrm{C}(\mathrm{C}(\mathrm{C}(\mathrm{C}(\mathrm{C}(\mathrm{C}(\mathrm{C}(\mathrm{F})(\mathrm{H}) \mathrm{H})(\mathrm{F}) \mathrm{H})(\mathrm{H}) \mathrm{Br})(\mathrm{H}) \mathrm{H})(\mathrm{Br}) \mathrm{Br})(\mathrm{H}) \mathrm{H})(\mathrm{H}) \mathrm{F})(\mathrm{H}) \mathrm{Br})(\mathrm{Br}) \mathrm{Cl})(\mathrm{H})(\mathrm{Br}) \mathrm{H}$ $\mathrm{C}(\mathrm{C}(\mathrm{C}(\mathrm{C}(\mathrm{C}(\mathrm{C}(\mathrm{C}(\mathrm{C}(\mathrm{C}(\mathrm{C}(\mathrm{Br})(\mathrm{F}) \mathrm{H})(\mathrm{F}) \mathrm{Br})(\mathrm{H}) \mathrm{H})(\mathrm{H}) \mathrm{F})(\mathrm{F}) \mathrm{H})(\mathrm{H}) \mathrm{F})(\mathrm{H}) \mathrm{H})(\mathrm{H}) \mathrm{H})(\mathrm{Br}) \mathrm{Br})(\mathrm{H})(\mathrm{H}) \mathrm{H}$ $\mathrm{C}(\mathrm{C}(\mathrm{C}(\mathrm{C}(\mathrm{C}(\mathrm{C}(\mathrm{C}(\mathrm{C}(\mathrm{C}(\mathrm{C}(\mathrm{F})(\mathrm{H}) \mathrm{Br})(\mathrm{Br}) \mathrm{H})(\mathrm{Br}) \mathrm{F})(\mathrm{Br}) \mathrm{H})(\mathrm{H}) \mathrm{H})(\mathrm{H}) \mathrm{H})(\mathrm{F}) \mathrm{Br})(\mathrm{H}) \mathrm{F})(\mathrm{H}) \mathrm{H})(\mathrm{H})(\mathrm{H}) \mathrm{H}$ $\mathrm{C}(\mathrm{C}(\mathrm{C}(\mathrm{C}(\mathrm{C}(\mathrm{C}(\mathrm{C}(\mathrm{C}(\mathrm{C}(\mathrm{C}(\mathrm{H})(\mathrm{Br}) \mathrm{H})(\mathrm{H}) \mathrm{H})(\mathrm{F}) \mathrm{H})(\mathrm{H}) \mathrm{Br})(\mathrm{H}) \mathrm{F})(\mathrm{Br}) \mathrm{H})(\mathrm{H}) \mathrm{H})(\mathrm{Br}) \mathrm{H})(\mathrm{H}) \mathrm{H})(\mathrm{Br})(\mathrm{Br}) \mathrm{F}$ $\mathrm{C}(\mathrm{C}(\mathrm{C}(\mathrm{C}(\mathrm{C}(\mathrm{C}(\mathrm{C}(\mathrm{C}(\mathrm{C}(\mathrm{C}(\mathrm{Br})(\mathrm{F}) \mathrm{H})(\mathrm{Br}) \mathrm{H})(\mathrm{Br}) \mathrm{H})(\mathrm{F}) \mathrm{H})(\mathrm{H}) \mathrm{H})(\mathrm{Br}) \mathrm{H})(\mathrm{Br}) \mathrm{Br})(\mathrm{H}) \mathrm{H})(\mathrm{H}) \mathrm{H})(\mathrm{H})(\mathrm{H}) \mathrm{Br}$ $\mathrm{C}(\mathrm{C}(\mathrm{C}(\mathrm{C}(\mathrm{C}(\mathrm{C}(\mathrm{C}(\mathrm{C}(\mathrm{C}(\mathrm{C}(\mathrm{H})(\mathrm{H}) \mathrm{H})(\mathrm{H}) \mathrm{H})(\mathrm{F}) \mathrm{F})(\mathrm{H}) \mathrm{H})(\mathrm{H}) \mathrm{Cl})(\mathrm{Br}) \mathrm{F})(\mathrm{F}) \mathrm{Cl})(\mathrm{F}) \mathrm{H})(\mathrm{H}) \mathrm{Br})(\mathrm{H})(\mathrm{H}) \mathrm{H}$ $\mathrm{C}(\mathrm{C}(\mathrm{C}(\mathrm{C}(\mathrm{C}(\mathrm{C}(\mathrm{C}(\mathrm{C}(\mathrm{C}(\mathrm{C}(\mathrm{H})(\mathrm{H}) \mathrm{H})(\mathrm{Br}) \mathrm{H})(\mathrm{Cl}) \mathrm{H})(\mathrm{Cl}) \mathrm{F})(\mathrm{Br}) \mathrm{H})(\mathrm{F}) \mathrm{H})(\mathrm{F}) \mathrm{Br})(\mathrm{H}) \mathrm{H})(\mathrm{F}) \mathrm{H})(\mathrm{H})(\mathrm{H}) \mathrm{H}$ $\mathrm{C}(\mathrm{C}(\mathrm{C}(\mathrm{C}(\mathrm{C}(\mathrm{C}(\mathrm{C}(\mathrm{C}(\mathrm{C}(\mathrm{C}(\mathrm{H})(\mathrm{H}) \mathrm{Cl})(\mathrm{H}) \mathrm{Cl})(\mathrm{H}) \mathrm{H})(\mathrm{Br}) \mathrm{H})(\mathrm{F}) \mathrm{H})(\mathrm{H}) \mathrm{Br})(\mathrm{F}) \mathrm{H})(\mathrm{F}) \mathrm{Br})(\mathrm{H}) \mathrm{H})(\mathrm{Br})(\mathrm{H}) \mathrm{H}$ $\mathrm{C}(\mathrm{C}(\mathrm{C}(\mathrm{C}(\mathrm{C}(\mathrm{C}(\mathrm{C}(\mathrm{C}(\mathrm{C}(\mathrm{C}(\mathrm{Br})(\mathrm{H}) \mathrm{H})(\mathrm{Cl}) \mathrm{H})(\mathrm{H}) \mathrm{H})(\mathrm{H}) \mathrm{Cl})(\mathrm{H}) \mathrm{H})(\mathrm{H}) \mathrm{H})(\mathrm{H}) \mathrm{Br})(\mathrm{F}) \mathrm{H})(\mathrm{Br}) \mathrm{H})(\mathrm{F})(\mathrm{Br}) \mathrm{Br}$ $\mathrm{C}(\mathrm{C}(\mathrm{C}(\mathrm{C}(\mathrm{C}(\mathrm{C}(\mathrm{C}(\mathrm{C}(\mathrm{C}(\mathrm{C}(\mathrm{H})(\mathrm{Br}) \mathrm{H})(\mathrm{H}) \mathrm{Br})(\mathrm{Br}) \mathrm{F})(\mathrm{Br}) \mathrm{H})(\mathrm{H}) \mathrm{Br})(\mathrm{H}) \mathrm{H})(\mathrm{H}) \mathrm{H})(\mathrm{H}) \mathrm{H})(\mathrm{H}) \mathrm{Cl})(\mathrm{Cl})(\mathrm{Br}) \mathrm{H}$ $\mathrm{C}(\mathrm{C}(\mathrm{C}(\mathrm{C}(\mathrm{C}(\mathrm{C}(\mathrm{C}(\mathrm{C}(\mathrm{C}(\mathrm{C}(\mathrm{H})(\mathrm{H}) \mathrm{H})(\mathrm{F}) \mathrm{Cl})(\mathrm{H}) \mathrm{F})(\mathrm{H}) \mathrm{F})(\mathrm{H}) \mathrm{H})(\mathrm{Cl}) \mathrm{H})(\mathrm{H}) \mathrm{H})(\mathrm{Cl}) \mathrm{Br})(\mathrm{H}) \mathrm{H})(\mathrm{H})(\mathrm{Br}) \mathrm{F}$ $\mathrm{C}(\mathrm{C}(\mathrm{C}(\mathrm{C}(\mathrm{C}(\mathrm{C}(\mathrm{C}(\mathrm{C}(\mathrm{C}(\mathrm{C}(\mathrm{F})(\mathrm{Cl}) \mathrm{H})(\mathrm{Cl}) \mathrm{H})(\mathrm{H}) \mathrm{F})(\mathrm{H}) \mathrm{H})(\mathrm{Br}) \mathrm{Br})(\mathrm{H}) \mathrm{H})(\mathrm{H}) \mathrm{Br})(\mathrm{H}) \mathrm{Cl})(\mathrm{H}) \mathrm{H})(\mathrm{F})(\mathrm{H}) \mathrm{H}$ $\mathrm{C}(\mathrm{C}(\mathrm{C}(\mathrm{C}(\mathrm{C}(\mathrm{C}(\mathrm{C}(\mathrm{C}(\mathrm{C}(\mathrm{C}(\mathrm{Cl})(\mathrm{Br}) \mathrm{H})(\mathrm{H}) \mathrm{H})(\mathrm{F}) \mathrm{H})(\mathrm{H}) \mathrm{H})(\mathrm{H}) \mathrm{H})(\mathrm{H}) \mathrm{H})(\mathrm{Br}) \mathrm{Cl})(\mathrm{Br}) \mathrm{H})(\mathrm{H}) \mathrm{H})(\mathrm{Cl})(\mathrm{Br}) \mathrm{F}$ $\mathrm{C}(\mathrm{C}(\mathrm{C}(\mathrm{C}(\mathrm{C}(\mathrm{C}(\mathrm{C}(\mathrm{C}(\mathrm{C}(\mathrm{C}(\mathrm{H})(\mathrm{H}) \mathrm{Cl})(\mathrm{H}) \mathrm{Cl})(\mathrm{Br}) \mathrm{H})(\mathrm{Br}) \mathrm{H})(\mathrm{H}) \mathrm{H})(\mathrm{H}) \mathrm{H})(\mathrm{H}) \mathrm{F})(\mathrm{Br}) \mathrm{H})(\mathrm{Br}) \mathrm{Cl})(\mathrm{Br})(\mathrm{H}) \mathrm{H}$ $\mathrm{C}(\mathrm{C}(\mathrm{C}(\mathrm{C}(\mathrm{C}(\mathrm{C}(\mathrm{C}(\mathrm{C}(\mathrm{C}(\mathrm{C}(\mathrm{H})(\mathrm{Cl}) \mathrm{F})(\mathrm{Cl}) \mathrm{H})(\mathrm{H}) \mathrm{H})(\mathrm{H}) \mathrm{H})(\mathrm{H}) \mathrm{H})(\mathrm{Br}) \mathrm{Br})(\mathrm{H}) \mathrm{H})(\mathrm{F}) \mathrm{H})(\mathrm{H}) \mathrm{F})(\mathrm{Cl})(\mathrm{H}) \mathrm{Cl}$ $\mathrm{C}(\mathrm{C}(\mathrm{C}(\mathrm{C}(\mathrm{C}(\mathrm{C}(\mathrm{C}(\mathrm{C}(\mathrm{C}(\mathrm{C}(\mathrm{F})(\mathrm{H}) \mathrm{H})(\mathrm{Br}) \mathrm{H})(\mathrm{H}) \mathrm{H})(\mathrm{Cl}) \mathrm{F})(\mathrm{Br}) \mathrm{H})(\mathrm{H}) \mathrm{Br})(\mathrm{H}) \mathrm{H})(\mathrm{H}) \mathrm{H})(\mathrm{H}) \mathrm{H})(\mathrm{Cl})(\mathrm{Cl}) \mathrm{Cl}$ $\mathrm{C}(\mathrm{C}(\mathrm{C}(\mathrm{C}(\mathrm{C}(\mathrm{C}(\mathrm{C}(\mathrm{C}(\mathrm{C}(\mathrm{C}(\mathrm{Br})(\mathrm{Cl}) \mathrm{H})(\mathrm{F}) \mathrm{H})(\mathrm{H}) \mathrm{H})(\mathrm{Br}) \mathrm{Br})(\mathrm{H}) \mathrm{H})(\mathrm{H}) \mathrm{Cl})(\mathrm{H}) \mathrm{H})(\mathrm{H}) \mathrm{H})(\mathrm{Cl}) \mathrm{Cl})(\mathrm{H})(\mathrm{H}) \mathrm{Br}$ $\mathrm{C}(\mathrm{C}(\mathrm{C}(\mathrm{C}(\mathrm{C}(\mathrm{C}(\mathrm{C}(\mathrm{C}(\mathrm{C}(\mathrm{C}(\mathrm{Cl})(\mathrm{Br}) \mathrm{H})(\mathrm{H}) \mathrm{H})(\mathrm{Cl}) \mathrm{F})(\mathrm{H}) \mathrm{F})(\mathrm{Cl}) \mathrm{Cl})(\mathrm{H}) \mathrm{H})(\mathrm{H}) \mathrm{H})(\mathrm{H}) \mathrm{H})(\mathrm{H}) \mathrm{Br})(\mathrm{H})(\mathrm{Cl}) \mathrm{H}$ $\mathrm{C}(\mathrm{C}(\mathrm{C}(\mathrm{C}(\mathrm{C}(\mathrm{C}(\mathrm{C}(\mathrm{C}(\mathrm{C}(\mathrm{C}(\mathrm{Cl})(\mathrm{H}) \mathrm{Br})(\mathrm{Br}) \mathrm{H})(\mathrm{H}) \mathrm{H})(\mathrm{H}) \mathrm{H})(\mathrm{H}) \mathrm{H})(\mathrm{Br}) \mathrm{H})(\mathrm{H}) \mathrm{H})(\mathrm{Cl}) \mathrm{Cl})(\mathrm{H}) \mathrm{H})(\mathrm{F})(\mathrm{Cl}) \mathrm{Cl}$ $\mathrm{C}(\mathrm{C}(\mathrm{C}(\mathrm{C}(\mathrm{C}(\mathrm{C}(\mathrm{C}(\mathrm{C}(\mathrm{C}(\mathrm{C}(\mathrm{H})(\mathrm{H}) \mathrm{H})(\mathrm{Cl}) \mathrm{H})(\mathrm{H}) \mathrm{Br})(\mathrm{Cl}) \mathrm{Br})(\mathrm{H}) \mathrm{Cl})(\mathrm{Cl}) \mathrm{H})(\mathrm{Br}) \mathrm{H})(\mathrm{H}) \mathrm{H})(\mathrm{H}) \mathrm{H})(\mathrm{H})(\mathrm{Br}) \mathrm{Cl}$ $\mathrm{C}(\mathrm{C}(\mathrm{C}(\mathrm{C}(\mathrm{C}(\mathrm{C}(\mathrm{C}(\mathrm{C}(\mathrm{C}(\mathrm{C}(\mathrm{H})(\mathrm{F}) \mathrm{H})(\mathrm{H}) \mathrm{H})(\mathrm{H}) \mathrm{H})(\mathrm{Cl}) \mathrm{H})(\mathrm{Cl}) \mathrm{H})(\mathrm{H}) \mathrm{H})(\mathrm{Br}) \mathrm{F})(\mathrm{Cl}) \mathrm{Cl})(\mathrm{H}) \mathrm{Cl})(\mathrm{H})(\mathrm{F}) \mathrm{H}$ $\mathrm{C}(\mathrm{C}(\mathrm{C}(\mathrm{C}(\mathrm{C}(\mathrm{C}(\mathrm{C}(\mathrm{C}(\mathrm{C}(\mathrm{C}(\mathrm{H})(\mathrm{H}) \mathrm{Cl})(\mathrm{Cl}) \mathrm{H})(\mathrm{H}) \mathrm{H})(\mathrm{Cl}) \mathrm{H})(\mathrm{H}) \mathrm{Cl})(\mathrm{H}) \mathrm{H})(\mathrm{H}) \mathrm{H})(\mathrm{F}) \mathrm{Br})(\mathrm{Cl}) \mathrm{Br})(\mathrm{H})(\mathrm{H}) \mathrm{Cl}$ $\mathrm{C}(\mathrm{C}(\mathrm{C}(\mathrm{C}(\mathrm{C}(\mathrm{C}(\mathrm{C}(\mathrm{C}(\mathrm{C}(\mathrm{C}(\mathrm{H})(\mathrm{Cl}) \mathrm{H})(\mathrm{H}) \mathrm{H})(\mathrm{H}) \mathrm{Cl})(\mathrm{Br}) \mathrm{H})(\mathrm{Cl}) \mathrm{Cl})(\mathrm{Br}) \mathrm{H})(\mathrm{Br}) \mathrm{H})(\mathrm{Cl}) \mathrm{H})(\mathrm{H}) \mathrm{Cl})(\mathrm{H})(\mathrm{H}) \mathrm{H}$ $\mathrm{C}(\mathrm{C}(\mathrm{C}(\mathrm{C}(\mathrm{C}(\mathrm{C}(\mathrm{C}(\mathrm{C}(\mathrm{C}(\mathrm{C}(\mathrm{H})(\mathrm{Cl}) \mathrm{H})(\mathrm{H}) \mathrm{Cl})(\mathrm{H}) \mathrm{H})(\mathrm{Cl}) \mathrm{F})(\mathrm{H}) \mathrm{H})(\mathrm{H}) \mathrm{H})(\mathrm{Cl}) \mathrm{H})(\mathrm{H}) \mathrm{Cl})(\mathrm{H}) \mathrm{H})(\mathrm{F})(\mathrm{Br}) \mathrm{Cl}$ $\mathrm{C}(\mathrm{C}(\mathrm{C}(\mathrm{C}(\mathrm{C}(\mathrm{C}(\mathrm{C}(\mathrm{C}(\mathrm{C}(\mathrm{C}(\mathrm{H})(\mathrm{Cl}) \mathrm{Cl})(\mathrm{H}) \mathrm{Cl})(\mathrm{H}) \mathrm{H})(\mathrm{H}) \mathrm{Br})(\mathrm{Cl}) \mathrm{H})(\mathrm{H}) \mathrm{Cl})(\mathrm{H}) \mathrm{H})(\mathrm{Cl}) \mathrm{Br})(\mathrm{H}) \mathrm{H})(\mathrm{Cl})(\mathrm{H}) \mathrm{H}$ $\mathrm{C}(\mathrm{C}(\mathrm{C}(\mathrm{C}(\mathrm{C}(\mathrm{C}(\mathrm{C}(\mathrm{C}(\mathrm{C}(\mathrm{C}(\mathrm{H})(\mathrm{H}) \mathrm{Cl})(\mathrm{H}) \mathrm{H})(\mathrm{H}) \mathrm{Cl})(\mathrm{H}) \mathrm{H})(\mathrm{Cl}) \mathrm{Cl})(\mathrm{Cl}) \mathrm{H})(\mathrm{Br}) \mathrm{H})(\mathrm{H}) \mathrm{Cl})(\mathrm{F}) \mathrm{H})(\mathrm{Cl})(\mathrm{H}) \mathrm{H}$ $\mathrm{C}(\mathrm{C}(\mathrm{C}(\mathrm{C}(\mathrm{C}(\mathrm{C}(\mathrm{C}(\mathrm{C}(\mathrm{C}(\mathrm{C}(\mathrm{F})(\mathrm{H}) \mathrm{H})(\mathrm{Cl}) \mathrm{H})(\mathrm{Cl}) \mathrm{F})(\mathrm{H}) \mathrm{H})(\mathrm{H}) \mathrm{Cl})(\mathrm{H}) \mathrm{Cl})(\mathrm{Cl}) \mathrm{H})(\mathrm{H}) \mathrm{H})(\mathrm{Cl}) \mathrm{Cl})(\mathrm{H})(\mathrm{H}) \mathrm{H}$ $\mathrm{C}(\mathrm{C}(\mathrm{C}(\mathrm{C}(\mathrm{C}(\mathrm{C}(\mathrm{C}(\mathrm{C}(\mathrm{C}(\mathrm{C}(\mathrm{Cl})(\mathrm{Cl}) \mathrm{H})(\mathrm{Cl}) \mathrm{Cl})(\mathrm{H}) \mathrm{Cl})(\mathrm{H}) \mathrm{H})(\mathrm{H}) \mathrm{H})(\mathrm{H}) \mathrm{H})(\mathrm{Cl}) \mathrm{H})(\mathrm{Cl}) \mathrm{H})(\mathrm{Br}) \mathrm{Cl})(\mathrm{H})(\mathrm{H}) \mathrm{H}$ $\mathrm{C}(\mathrm{C}(\mathrm{C}(\mathrm{C}(\mathrm{C}(\mathrm{C}(\mathrm{C}(\mathrm{C}(\mathrm{C}(\mathrm{C}(\mathrm{F})(\mathrm{H}) \mathrm{Cl})(\mathrm{Cl}) \mathrm{Cl})(\mathrm{Cl}) \mathrm{H})(\mathrm{H}) \mathrm{H})(\mathrm{H}) \mathrm{H})(\mathrm{Cl}) \mathrm{Cl})(\mathrm{H}) \mathrm{H})(\mathrm{H}) \mathrm{H})(\mathrm{Cl}) \mathrm{H})(\mathrm{H})(\mathrm{H}) \mathrm{Cl}$ $\mathrm{C}(\mathrm{C}(\mathrm{C}(\mathrm{C}(\mathrm{C}(\mathrm{C}(\mathrm{C}(\mathrm{C}(\mathrm{C}(\mathrm{C}(\mathrm{H})(\mathrm{H}) \mathrm{H})(\mathrm{Cl}) \mathrm{Cl})(\mathrm{Cl}) \mathrm{H})(\mathrm{H}) \mathrm{H})(\mathrm{Cl}) \mathrm{Cl})(\mathrm{H}) \mathrm{H})(\mathrm{H}) \mathrm{Cl})(\mathrm{Cl}) \mathrm{H})(\mathrm{Cl}) \mathrm{H})(\mathrm{H})(\mathrm{H}) \mathrm{Cl}$ $\mathrm{C}(\mathrm{C}(\mathrm{C}(\mathrm{C}(\mathrm{C}(\mathrm{C}(\mathrm{C}(\mathrm{C}(\mathrm{C}(\mathrm{C}(\mathrm{F})(\mathrm{H}) \mathrm{Br})(\mathrm{F}) \mathrm{H})(\mathrm{H}) \mathrm{H})(\mathrm{Br}) \mathrm{H})(\mathrm{Br}) \mathrm{F})(\mathrm{H}) \mathrm{Br})(\mathrm{Cl}) \mathrm{F})(\mathrm{H}) \mathrm{H})(\mathrm{H}) \mathrm{H})(\mathrm{H})(\mathrm{H}) \mathrm{H}$ $\mathrm{C}(\mathrm{C}(\mathrm{C}(\mathrm{C}(\mathrm{C}(\mathrm{C}(\mathrm{C}(\mathrm{C}(\mathrm{C}(\mathrm{C}(\mathrm{H})(\mathrm{H}) \mathrm{H})(\mathrm{Br}) \mathrm{H})(\mathrm{H}) \mathrm{H})(\mathrm{Br}) \mathrm{H})(\mathrm{H}) \mathrm{H})(\mathrm{Cl}) \mathrm{H})(\mathrm{F}) \mathrm{Br})(\mathrm{Br}) \mathrm{H})(\mathrm{F}) \mathrm{H})(\mathrm{H})(\mathrm{F}) \mathrm{Br}$ $\mathrm{C}(\mathrm{C}(\mathrm{C}(\mathrm{C}(\mathrm{C}(\mathrm{C}(\mathrm{C}(\mathrm{C}(\mathrm{C}(\mathrm{C}(\mathrm{Br})(\mathrm{Br}) \mathrm{H})(\mathrm{Br}) \mathrm{H})(\mathrm{H}) \mathrm{H})(\mathrm{F}) \mathrm{H})(\mathrm{H}) \mathrm{Br})(\mathrm{Br}) \mathrm{H})(\mathrm{Br}) \mathrm{H})(\mathrm{H}) \mathrm{H})(\mathrm{F}) \mathrm{Cl})(\mathrm{H})(\mathrm{H}) \mathrm{H}$ $\mathrm{C}(\mathrm{C}(\mathrm{C}(\mathrm{C}(\mathrm{C}(\mathrm{C}(\mathrm{C}(\mathrm{C}(\mathrm{C}(\mathrm{C}(\mathrm{H})(\mathrm{F}) \mathrm{H})(\mathrm{Br}) \mathrm{H})(\mathrm{Br}) \mathrm{H})(\mathrm{H}) \mathrm{H})(\mathrm{H}) \mathrm{H})(\mathrm{F}) \mathrm{F})(\mathrm{Br}) \mathrm{H})(\mathrm{H}) \mathrm{H})(\mathrm{F}) \mathrm{H})(\mathrm{H})(\mathrm{H}) \mathrm{Br}$ $\mathrm{C}(\mathrm{C}(\mathrm{C}(\mathrm{C}(\mathrm{C}(\mathrm{C}(\mathrm{C}(\mathrm{C}(\mathrm{C}(\mathrm{C}(\mathrm{F})(\mathrm{H}) \mathrm{H})(\mathrm{H}) \mathrm{H})(\mathrm{H}) \mathrm{Br})(\mathrm{Br}) \mathrm{H})(\mathrm{H}) \mathrm{H})(\mathrm{H}) \mathrm{Br})(\mathrm{Br}) \mathrm{H})(\mathrm{F}) \mathrm{H})(\mathrm{Br}) \mathrm{H})(\mathrm{F})(\mathrm{H}) \mathrm{H}$ $\mathrm{C}(\mathrm{C}(\mathrm{C}(\mathrm{C}(\mathrm{C}(\mathrm{C}(\mathrm{C}(\mathrm{C}(\mathrm{C}(\mathrm{C}(\mathrm{H})(\mathrm{H}) \mathrm{Br})(\mathrm{Br}) \mathrm{Br})(\mathrm{H}) \mathrm{Br})(\mathrm{H}) \mathrm{H})(\mathrm{H}) \mathrm{H})(\mathrm{H}) \mathrm{H})(\mathrm{F}) \mathrm{Br})(\mathrm{H}) \mathrm{H})(\mathrm{H}) \mathrm{H})(\mathrm{F})(\mathrm{Br}) \mathrm{H}$ $\mathrm{C}(\mathrm{C}(\mathrm{C}(\mathrm{C}(\mathrm{C}(\mathrm{C}(\mathrm{C}(\mathrm{C}(\mathrm{C}(\mathrm{C}(\mathrm{Br})(\mathrm{Br}) \mathrm{H})(\mathrm{H}) \mathrm{H})(\mathrm{H}) \mathrm{Br})(\mathrm{Br}) \mathrm{Br})(\mathrm{H}) \mathrm{H})(\mathrm{F}) \mathrm{H})(\mathrm{Br}) \mathrm{H})(\mathrm{H}) \mathrm{H})(\mathrm{H}) \mathrm{Br})(\mathrm{H})(\mathrm{H}) \mathrm{H}$ $\mathrm{C}(\mathrm{C}(\mathrm{C}(\mathrm{C}(\mathrm{C}(\mathrm{C}(\mathrm{C}(\mathrm{C}(\mathrm{C}(\mathrm{C}(\mathrm{Br})(\mathrm{H}) \mathrm{H})(\mathrm{H}) \mathrm{H})(\mathrm{H}) \mathrm{H})(\mathrm{Br}) \mathrm{H})(\mathrm{F}) \mathrm{H})(\mathrm{Cl}) \mathrm{H})(\mathrm{H}) \mathrm{H})(\mathrm{H}) \mathrm{H})(\mathrm{H}) \mathrm{Br})(\mathrm{F})(\mathrm{Cl}) \mathrm{F}$ $\mathrm{C}(\mathrm{C}(\mathrm{C}(\mathrm{C}(\mathrm{C}(\mathrm{C}(\mathrm{C}(\mathrm{C}(\mathrm{C}(\mathrm{C}(\mathrm{H})(\mathrm{H}) \mathrm{H})(\mathrm{H}) \mathrm{H})(\mathrm{H}) \mathrm{Br})(\mathrm{F}) \mathrm{Cl})(\mathrm{Br}) \mathrm{H})(\mathrm{H}) \mathrm{Cl})(\mathrm{H}) \mathrm{H})(\mathrm{Br}) \mathrm{F})(\mathrm{H}) \mathrm{Br})(\mathrm{H})(\mathrm{H}) \mathrm{H}$ $\mathrm{C}(\mathrm{C}(\mathrm{C}(\mathrm{C}(\mathrm{C}(\mathrm{C}(\mathrm{C}(\mathrm{C}(\mathrm{C}(\mathrm{C}(\mathrm{H})(\mathrm{Br}) \mathrm{Cl})(\mathrm{H}) \mathrm{H})(\mathrm{H}) \mathrm{H})(\mathrm{F}) \mathrm{Br})(\mathrm{H}) \mathrm{H})(\mathrm{H}) \mathrm{H})(\mathrm{H}) \mathrm{Cl})(\mathrm{Br}) \mathrm{H})(\mathrm{H}) \mathrm{Br})(\mathrm{H})(\mathrm{H}) \mathrm{Br}$ $\mathrm{C}(\mathrm{C}(\mathrm{C}(\mathrm{C}(\mathrm{C}(\mathrm{C}(\mathrm{C}(\mathrm{C}(\mathrm{C}(\mathrm{C}(\mathrm{H})(\mathrm{Cl}) \mathrm{H})(\mathrm{Cl}) \mathrm{H})(\mathrm{H}) \mathrm{H})(\mathrm{H}) \mathrm{F})(\mathrm{F}) \mathrm{H})(\mathrm{Cl}) \mathrm{H})(\mathrm{H}) \mathrm{H})(\mathrm{H}) \mathrm{H})(\mathrm{H}) \mathrm{H})(\mathrm{Br})(\mathrm{Br}) \mathrm{Br}$ $\mathrm{C}(\mathrm{C}(\mathrm{C}(\mathrm{C}(\mathrm{C}(\mathrm{C}(\mathrm{C}(\mathrm{C}(\mathrm{C}(\mathrm{C}(\mathrm{Cl})(\mathrm{Br}) \mathrm{H})(\mathrm{Br}) \mathrm{F})(\mathrm{Br}) \mathrm{H})(\mathrm{H}) \mathrm{Br})(\mathrm{Cl}) \mathrm{H})(\mathrm{H}) \mathrm{Cl})(\mathrm{H}) \mathrm{H})(\mathrm{H}) \mathrm{H})(\mathrm{H}) \mathrm{H})(\mathrm{H})(\mathrm{H}) \mathrm{H}$ $\mathrm{C}(\mathrm{C}(\mathrm{C}(\mathrm{C}(\mathrm{C}(\mathrm{C}(\mathrm{C}(\mathrm{C}(\mathrm{C}(\mathrm{C}(\mathrm{H})(\mathrm{Cl}) \mathrm{H})(\mathrm{Br}) \mathrm{H})(\mathrm{H}) \mathrm{H})(\mathrm{F}) \mathrm{H})(\mathrm{H}) \mathrm{H})(\mathrm{Cl}) \mathrm{Br})(\mathrm{H}) \mathrm{Cl})(\mathrm{H}) \mathrm{H})(\mathrm{Cl}) \mathrm{H})(\mathrm{H})(\mathrm{F}) \mathrm{H}$ $\mathrm{C}(\mathrm{C}(\mathrm{C}(\mathrm{C}(\mathrm{C}(\mathrm{C}(\mathrm{C}(\mathrm{C}(\mathrm{C}(\mathrm{C}(\mathrm{F})(\mathrm{H}) \mathrm{Br})(\mathrm{Cl}) \mathrm{H})(\mathrm{Br}) \mathrm{Cl})(\mathrm{H}) \mathrm{Cl})(\mathrm{Br}) \mathrm{H})(\mathrm{H}) \mathrm{H})(\mathrm{H}) \mathrm{H})(\mathrm{H}) \mathrm{H})(\mathrm{H}) \mathrm{H})(\mathrm{H})(\mathrm{Cl}) \mathrm{H}$ $\mathrm{C}(\mathrm{C}(\mathrm{C}(\mathrm{C}(\mathrm{C}(\mathrm{C}(\mathrm{C}(\mathrm{C}(\mathrm{C}(\mathrm{C}(\mathrm{H})(\mathrm{H}) \mathrm{H})(\mathrm{H}) \mathrm{Cl})(\mathrm{H}) \mathrm{H})(\mathrm{Br}) \mathrm{H})(\mathrm{Cl}) \mathrm{Br})(\mathrm{Br}) \mathrm{Cl})(\mathrm{H}) \mathrm{H})(\mathrm{Cl}) \mathrm{H})(\mathrm{Br}) \mathrm{H})(\mathrm{H})(\mathrm{H}) \mathrm{H}$ $\mathrm{C}(\mathrm{C}(\mathrm{C}(\mathrm{C}(\mathrm{C}(\mathrm{C}(\mathrm{C}(\mathrm{C}(\mathrm{C}(\mathrm{C}(\mathrm{Cl})(\mathrm{H}) \mathrm{F})(\mathrm{H}) \mathrm{H})(\mathrm{H}) \mathrm{Cl})(\mathrm{H}) \mathrm{H})(\mathrm{H}) \mathrm{H})(\mathrm{H}) \mathrm{Cl})(\mathrm{Cl}) \mathrm{H})(\mathrm{Br}) \mathrm{H})(\mathrm{H}) \mathrm{Br})(\mathrm{H})(\mathrm{Cl}) \mathrm{H}$ $\mathrm{C}(\mathrm{C}(\mathrm{C}(\mathrm{C}(\mathrm{C}(\mathrm{C}(\mathrm{C}(\mathrm{C}(\mathrm{C}(\mathrm{C}(\mathrm{Cl})(\mathrm{H}) \mathrm{H})(\mathrm{H}) \mathrm{Br})(\mathrm{H}) \mathrm{H})(\mathrm{Cl}) \mathrm{H})(\mathrm{Cl}) \mathrm{H})(\mathrm{H}) \mathrm{Cl})(\mathrm{H}) \mathrm{H})(\mathrm{H}) \mathrm{Br})(\mathrm{H}) \mathrm{H})(\mathrm{Cl})(\mathrm{H}) \mathrm{Br}$ $\mathrm{C}(\mathrm{C}(\mathrm{C}(\mathrm{C}(\mathrm{C}(\mathrm{C}(\mathrm{C}(\mathrm{C}(\mathrm{C}(\mathrm{C}(\mathrm{Cl})(\mathrm{H}) \mathrm{Cl})(\mathrm{H}) \mathrm{H})(\mathrm{H}) \mathrm{H})(\mathrm{Cl}) \mathrm{H})(\mathrm{H}) \mathrm{H})(\mathrm{H}) \mathrm{H})(\mathrm{H}) \mathrm{H})(\mathrm{Cl}) \mathrm{F})(\mathrm{F}) \mathrm{H})(\mathrm{Cl})(\mathrm{H}) \mathrm{Br}$ $\mathrm{C}(\mathrm{C}(\mathrm{C}(\mathrm{C}(\mathrm{C}(\mathrm{C}(\mathrm{C}(\mathrm{C}(\mathrm{C}(\mathrm{C}(\mathrm{Cl})(\mathrm{H}) \mathrm{H})(\mathrm{H}) \mathrm{Cl})(\mathrm{H}) \mathrm{H})(\mathrm{H}) \mathrm{H})(\mathrm{Br}) \mathrm{Br})(\mathrm{Cl}) \mathrm{Cl})(\mathrm{H}) \mathrm{H})(\mathrm{H}) \mathrm{Cl})(\mathrm{H}) \mathrm{Cl})(\mathrm{H})(\mathrm{H}) \mathrm{H}$ $\mathrm{C}(\mathrm{C}(\mathrm{C}(\mathrm{C}(\mathrm{C}(\mathrm{C}(\mathrm{C}(\mathrm{C}(\mathrm{C}(\mathrm{C}(\mathrm{Cl})(\mathrm{Cl}) \mathrm{Cl})(\mathrm{H}) \mathrm{H})(\mathrm{H}) \mathrm{H})(\mathrm{Cl}) \mathrm{H})(\mathrm{H}) \mathrm{H})(\mathrm{H}) \mathrm{Cl})(\mathrm{H}) \mathrm{F})(\mathrm{H}) \mathrm{Br})(\mathrm{H}) \mathrm{H})(\mathrm{Cl})(\mathrm{H}) \mathrm{H}$ $\mathrm{C}(\mathrm{C}(\mathrm{C}(\mathrm{C}(\mathrm{C}(\mathrm{C}(\mathrm{C}(\mathrm{C}(\mathrm{C}(\mathrm{C}(\mathrm{Cl})(\mathrm{H}) \mathrm{H})(\mathrm{Cl}) \mathrm{H})(\mathrm{H}) \mathrm{Cl})(\mathrm{H}) \mathrm{H})(\mathrm{Cl}) \mathrm{H})(\mathrm{H}) \mathrm{H})(\mathrm{Br}) \mathrm{H})(\mathrm{H}) \mathrm{H})(\mathrm{Cl}) \mathrm{H})(\mathrm{Cl})(\mathrm{Cl}) \mathrm{H}$ $\mathrm{C}(\mathrm{C}(\mathrm{C}(\mathrm{C}(\mathrm{C}(\mathrm{C}(\mathrm{C}(\mathrm{C}(\mathrm{C}(\mathrm{C}(\mathrm{H})(\mathrm{H}) \mathrm{H})(\mathrm{Cl}) \mathrm{H})(\mathrm{F}) \mathrm{H})(\mathrm{Cl}) \mathrm{H})(\mathrm{H}) \mathrm{H})(\mathrm{H}) \mathrm{H})(\mathrm{Cl}) \mathrm{Cl})(\mathrm{H}) \mathrm{Cl})(\mathrm{H}) \mathrm{Cl})(\mathrm{H})(\mathrm{H}) \mathrm{Cl}$ $\mathrm{C}(\mathrm{C}(\mathrm{C}(\mathrm{C}(\mathrm{C}(\mathrm{C}(\mathrm{C}(\mathrm{C}(\mathrm{C}(\mathrm{C}(\mathrm{Cl})(\mathrm{H}) \mathrm{H})(\mathrm{H}) \mathrm{H})(\mathrm{Cl}) \mathrm{H})(\mathrm{Cl}) \mathrm{H})(\mathrm{Cl}) \mathrm{Cl})(\mathrm{H}) \mathrm{H})(\mathrm{H}) \mathrm{Cl})(\mathrm{Cl}) \mathrm{H})(\mathrm{H}) \mathrm{H})(\mathrm{Cl})(\mathrm{H}) \mathrm{H}$ $\mathrm{C}(\mathrm{C}(\mathrm{C}(\mathrm{C}(\mathrm{C}(\mathrm{C}(\mathrm{C}(\mathrm{C}(\mathrm{C}(\mathrm{C}(\mathrm{H})(\mathrm{H}) \mathrm{Cl})(\mathrm{F}) \mathrm{Br})(\mathrm{Br}) \mathrm{H})(\mathrm{F}) \mathrm{F})(\mathrm{H}) \mathrm{H})(\mathrm{H}) \mathrm{F})(\mathrm{H}) \mathrm{H})(\mathrm{Br}) \mathrm{H})(\mathrm{H}) \mathrm{H})(\mathrm{H})(\mathrm{H}) \mathrm{H}$ $\mathrm{C}(\mathrm{C}(\mathrm{C}(\mathrm{C}(\mathrm{C}(\mathrm{C}(\mathrm{C}(\mathrm{C}(\mathrm{C}(\mathrm{C}(\mathrm{H})(\mathrm{Br}) \mathrm{F})(\mathrm{H}) \mathrm{H})(\mathrm{F}) \mathrm{H})(\mathrm{Br}) \mathrm{H})(\mathrm{Br}) \mathrm{Cl})(\mathrm{H}) \mathrm{F})(\mathrm{H}) \mathrm{H})(\mathrm{H}) \mathrm{Br})(\mathrm{H}) \mathrm{H})(\mathrm{H})(\mathrm{H}) \mathrm{H}$ $\mathrm{C}(\mathrm{C}(\mathrm{C}(\mathrm{C}(\mathrm{C}(\mathrm{C}(\mathrm{C}(\mathrm{C}(\mathrm{C}(\mathrm{C}(\mathrm{H})(\mathrm{Br}) \mathrm{H})(\mathrm{H}) \mathrm{Br})(\mathrm{H}) \mathrm{H})(\mathrm{Br}) \mathrm{H})(\mathrm{H}) \mathrm{H})(\mathrm{H}) \mathrm{H})(\mathrm{H}) \mathrm{Cl})(\mathrm{H}) \mathrm{Br})(\mathrm{H}) \mathrm{H})(\mathrm{Br})(\mathrm{F}) \mathrm{F}$ $\mathrm{C}(\mathrm{C}(\mathrm{C}(\mathrm{C}(\mathrm{C}(\mathrm{C}(\mathrm{C}(\mathrm{C}(\mathrm{C}(\mathrm{C}(\mathrm{H})(\mathrm{H}) \mathrm{H})(\mathrm{H}) \mathrm{H})(\mathrm{Cl}) \mathrm{H})(\mathrm{Br}) \mathrm{H})(\mathrm{Br}) \mathrm{H})(\mathrm{F}) \mathrm{Br})(\mathrm{H}) \mathrm{Br})(\mathrm{H}) \mathrm{H})(\mathrm{H}) \mathrm{H})(\mathrm{H})(\mathrm{Br}) \mathrm{Br}$ $\mathrm{C}(\mathrm{C}(\mathrm{C}(\mathrm{C}(\mathrm{C}(\mathrm{C}(\mathrm{C}(\mathrm{C}(\mathrm{C}(\mathrm{C}(\mathrm{F})(\mathrm{H}) \mathrm{H})(\mathrm{H}) \mathrm{H})(\mathrm{H}) \mathrm{H})(\mathrm{Br}) \mathrm{F})(\mathrm{H}) \mathrm{Br})(\mathrm{H}) \mathrm{H})(\mathrm{Br}) \mathrm{H})(\mathrm{H}) \mathrm{F})(\mathrm{H}) \mathrm{H})(\mathrm{Br})(\mathrm{H}) \mathrm{H}$ $\mathrm{C}(\mathrm{C}(\mathrm{C}(\mathrm{C}(\mathrm{C}(\mathrm{C}(\mathrm{C}(\mathrm{C}(\mathrm{C}(\mathrm{C}(\mathrm{H})(\mathrm{H}) \mathrm{Br})(\mathrm{H}) \mathrm{F})(\mathrm{H}) \mathrm{H})(\mathrm{H}) \mathrm{H})(\mathrm{H}) \mathrm{Br})(\mathrm{F}) \mathrm{Br})(\mathrm{H}) \mathrm{Br})(\mathrm{H}) \mathrm{H})(\mathrm{H}) \mathrm{H})(\mathrm{Br})(\mathrm{H}) \mathrm{H}$ $\mathrm{C}(\mathrm{C}(\mathrm{C}(\mathrm{C}(\mathrm{C}(\mathrm{C}(\mathrm{C}(\mathrm{C}(\mathrm{C}(\mathrm{C}(\mathrm{H})(\mathrm{Br}) \mathrm{H})(\mathrm{Br}) \mathrm{H})(\mathrm{H}) \mathrm{Br})(\mathrm{H}) \mathrm{H})(\mathrm{H}) \mathrm{F})(\mathrm{Br}) \mathrm{H})(\mathrm{H}) \mathrm{H})(\mathrm{Br}) \mathrm{H})(\mathrm{Br}) \mathrm{H})(\mathrm{H})(\mathrm{H}) \mathrm{H}$ $\mathrm{C}(\mathrm{C}(\mathrm{C}(\mathrm{C}(\mathrm{C}(\mathrm{C}(\mathrm{C}(\mathrm{C}(\mathrm{C}(\mathrm{C}(\mathrm{Br})(\mathrm{Br}) \mathrm{H})(\mathrm{H}) \mathrm{F})(\mathrm{Br}) \mathrm{H})(\mathrm{H}) \mathrm{Cl})(\mathrm{H}) \mathrm{H})(\mathrm{H}) \mathrm{H})(\mathrm{H}) \mathrm{H})(\mathrm{H}) \mathrm{H})(\mathrm{F}) \mathrm{H})(\mathrm{H})(\mathrm{Cl}) \mathrm{H}$ $\mathrm{C}(\mathrm{C}(\mathrm{C}(\mathrm{C}(\mathrm{C}(\mathrm{C}(\mathrm{C}(\mathrm{C}(\mathrm{C}(\mathrm{C}(\mathrm{H})(\mathrm{Br}) \mathrm{H})(\mathrm{H}) \mathrm{H})(\mathrm{H}) \mathrm{H})(\mathrm{H}) \mathrm{H})(\mathrm{H}) \mathrm{Cl})(\mathrm{Br}) \mathrm{H})(\mathrm{H}) \mathrm{H})(\mathrm{Cl}) \mathrm{H})(\mathrm{H}) \mathrm{Br})(\mathrm{F})(\mathrm{H}) \mathrm{Br}$ $\mathrm{C}(\mathrm{C}(\mathrm{C}(\mathrm{C}(\mathrm{C}(\mathrm{C}(\mathrm{C}(\mathrm{C}(\mathrm{C}(\mathrm{C}(\mathrm{H})(\mathrm{Cl}) \mathrm{H})(\mathrm{H}) \mathrm{H})(\mathrm{H}) \mathrm{H})(\mathrm{H}) \mathrm{H})(\mathrm{H}) \mathrm{Br})(\mathrm{H}) \mathrm{Br})(\mathrm{Br}) \mathrm{H})(\mathrm{H}) \mathrm{H})(\mathrm{Br}) \mathrm{Br})(\mathrm{H})(\mathrm{Cl}) \mathrm{H}$ $\mathrm{C}(\mathrm{C}(\mathrm{C}(\mathrm{C}(\mathrm{C}(\mathrm{C}(\mathrm{C}(\mathrm{C}(\mathrm{C}(\mathrm{C}(\mathrm{H})(\mathrm{H}) \mathrm{Cl})(\mathrm{Br}) \mathrm{Br})(\mathrm{Cl}) \mathrm{H})(\mathrm{Cl}) \mathrm{H})(\mathrm{H}) \mathrm{H})(\mathrm{H}) \mathrm{H})(\mathrm{H}) \mathrm{H})(\mathrm{H}) \mathrm{H})(\mathrm{H}) \mathrm{Br})(\mathrm{F})(\mathrm{H}) \mathrm{H}$ $\mathrm{C}(\mathrm{C}(\mathrm{C}(\mathrm{C}(\mathrm{C}(\mathrm{C}(\mathrm{C}(\mathrm{C}(\mathrm{C}(\mathrm{C}(\mathrm{H})(\mathrm{H}) \mathrm{Cl})(\mathrm{H}) \mathrm{H})(\mathrm{Br}) \mathrm{H})(\mathrm{Br}) \mathrm{H})(\mathrm{Br}) \mathrm{H})(\mathrm{Cl}) \mathrm{H})(\mathrm{Br}) \mathrm{H})(\mathrm{H}) \mathrm{H})(\mathrm{H}) \mathrm{Cl})(\mathrm{H})(\mathrm{H}) \mathrm{H}$ $\mathrm{C}(\mathrm{C}(\mathrm{C}(\mathrm{C}(\mathrm{C}(\mathrm{C}(\mathrm{C}(\mathrm{C}(\mathrm{C}(\mathrm{C}(\mathrm{H})(\mathrm{H}) \mathrm{H})(\mathrm{Cl}) \mathrm{Cl})(\mathrm{H}) \mathrm{H})(\mathrm{H}) \mathrm{Cl})(\mathrm{H}) \mathrm{H})(\mathrm{H}) \mathrm{F})(\mathrm{H}) \mathrm{Cl})(\mathrm{H}) \mathrm{Br})(\mathrm{H}) \mathrm{H})(\mathrm{Br})(\mathrm{H}) \mathrm{H}$ $\mathrm{C}(\mathrm{C}(\mathrm{C}(\mathrm{C}(\mathrm{C}(\mathrm{C}(\mathrm{C}(\mathrm{C}(\mathrm{C}(\mathrm{C}(\mathrm{Cl})(\mathrm{H}) \mathrm{Cl})(\mathrm{H}) \mathrm{H})(\mathrm{H}) \mathrm{Cl})(\mathrm{H}) \mathrm{Br})(\mathrm{H}) \mathrm{H})(\mathrm{H}) \mathrm{Br})(\mathrm{Br}) \mathrm{H})(\mathrm{H}) \mathrm{H})(\mathrm{H}) \mathrm{H})(\mathrm{Cl})(\mathrm{H}) \mathrm{H}$ $\mathrm{C}(\mathrm{C}(\mathrm{C}(\mathrm{C}(\mathrm{C}(\mathrm{C}(\mathrm{C}(\mathrm{C}(\mathrm{C}(\mathrm{C}(\mathrm{H})(\mathrm{H}) \mathrm{H})(\mathrm{H}) \mathrm{Cl})(\mathrm{H}) \mathrm{H})(\mathrm{Cl}) \mathrm{Cl})(\mathrm{Br}) \mathrm{H})(\mathrm{H}) \mathrm{H})(\mathrm{H}) \mathrm{H})(\mathrm{H}) \mathrm{H})(\mathrm{Br}) \mathrm{Cl})(\mathrm{Cl})(\mathrm{H}) \mathrm{H}$ $\mathrm{C}(\mathrm{C}(\mathrm{C}(\mathrm{C}(\mathrm{C}(\mathrm{C}(\mathrm{C}(\mathrm{C}(\mathrm{C}(\mathrm{C}(\mathrm{Cl})(\mathrm{H}) \mathrm{H})(\mathrm{Cl}) \mathrm{F})(\mathrm{H}) \mathrm{H})(\mathrm{Br}) \mathrm{H})(\mathrm{H}) \mathrm{Cl})(\mathrm{H}) \mathrm{Cl})(\mathrm{H}) \mathrm{H})(\mathrm{Cl}) \mathrm{H})(\mathrm{H}) \mathrm{H})(\mathrm{H})(\mathrm{H}) \mathrm{H}$ $\mathrm{C}(\mathrm{C}(\mathrm{C}(\mathrm{C}(\mathrm{C}(\mathrm{C}(\mathrm{C}(\mathrm{C}(\mathrm{C}(\mathrm{C}(\mathrm{Cl})(\mathrm{Cl}) \mathrm{H})(\mathrm{H}) \mathrm{H})(\mathrm{H}) \mathrm{Cl})(\mathrm{H}) \mathrm{H})(\mathrm{Cl}) \mathrm{Cl})(\mathrm{H}) \mathrm{H})(\mathrm{H}) \mathrm{H})(\mathrm{Br}) \mathrm{H})(\mathrm{H}) \mathrm{H})(\mathrm{H})(\mathrm{Cl}) \mathrm{H}$ $\mathrm{C}(\mathrm{C}(\mathrm{C}(\mathrm{C}(\mathrm{C}(\mathrm{C}(\mathrm{C}(\mathrm{C}(\mathrm{C}(\mathrm{C}(\mathrm{H})(\mathrm{H}) \mathrm{H})(\mathrm{H}) \mathrm{H})(\mathrm{H}) \mathrm{H})(\mathrm{H}) \mathrm{F})(\mathrm{Cl}) \mathrm{H})(\mathrm{Cl}) \mathrm{Cl})(\mathrm{Cl}) \mathrm{Cl})(\mathrm{H}) \mathrm{H})(\mathrm{H}) \mathrm{H})(\mathrm{H})(\mathrm{H}) \mathrm{Cl}$ $\mathrm{C}(\mathrm{C}(\mathrm{C}(\mathrm{C}(\mathrm{C}(\mathrm{C}(\mathrm{C}(\mathrm{C}(\mathrm{C}(\mathrm{C}(\mathrm{Cl})(\mathrm{H}) \mathrm{H})(\mathrm{H}) \mathrm{H})(\mathrm{H}) \mathrm{H})(\mathrm{H}) \mathrm{Cl})(\mathrm{H}) \mathrm{Cl})(\mathrm{H}) \mathrm{Cl})(\mathrm{H}) \mathrm{H})(\mathrm{H}) \mathrm{H})(\mathrm{Cl}) \mathrm{H})(\mathrm{H})(\mathrm{Cl}) \mathrm{C}$ $\mathrm{C}(\mathrm{C}(\mathrm{C}(\mathrm{C}(\mathrm{C}(\mathrm{C}(\mathrm{C}(\mathrm{C}(\mathrm{C}(\mathrm{C}(\mathrm{H})(\mathrm{H}) \mathrm{H})(\mathrm{F}) \mathrm{Cl})(\mathrm{H}) \mathrm{H})(\mathrm{Br}) \mathrm{H})(\mathrm{H}) \mathrm{H})(\mathrm{H}) \mathrm{H})(\mathrm{H}) \mathrm{H})(\mathrm{H}) \mathrm{Br})(\mathrm{F}) \mathrm{Br})(\mathrm{H})(\mathrm{Br}) \mathrm{H}$ $\mathrm{C}(\mathrm{C}(\mathrm{C}(\mathrm{C}(\mathrm{C}(\mathrm{C}(\mathrm{C}(\mathrm{C}(\mathrm{C}(\mathrm{C}(\mathrm{H})(\mathrm{H}) \mathrm{H})(\mathrm{H}) \mathrm{H})(\mathrm{H}) \mathrm{H})(\mathrm{Br}) \mathrm{F})(\mathrm{Br}) \mathrm{H})(\mathrm{Br}) \mathrm{H})(\mathrm{H}) \mathrm{H})(\mathrm{Br}) \mathrm{H})(\mathrm{Cl}) \mathrm{H})(\mathrm{H})(\mathrm{H}) \mathrm{Br}$ $\mathrm{C}(\mathrm{C}(\mathrm{C}(\mathrm{C}(\mathrm{C}(\mathrm{C}(\mathrm{C}(\mathrm{C}(\mathrm{C}(\mathrm{C}(\mathrm{H})(\mathrm{H}) \mathrm{Br})(\mathrm{H}) \mathrm{H})(\mathrm{Br}) \mathrm{H})(\mathrm{H}) \mathrm{H})(\mathrm{H}) \mathrm{Br})(\mathrm{H}) \mathrm{Br})(\mathrm{H}) \mathrm{H})(\mathrm{Br}) \mathrm{Cl})(\mathrm{H}) \mathrm{H})(\mathrm{H})(\mathrm{Br}) \mathrm{H}$ $\mathrm{C}(\mathrm{C}(\mathrm{C}(\mathrm{C}(\mathrm{C}(\mathrm{C}(\mathrm{C}(\mathrm{C}(\mathrm{C}(\mathrm{C}(\mathrm{H})(\mathrm{H}) \mathrm{Br})(\mathrm{Br}) \mathrm{H})(\mathrm{H}) \mathrm{H})(\mathrm{H}) \mathrm{H})(\mathrm{H}) \mathrm{F})(\mathrm{H}) \mathrm{H})(\mathrm{Br}) \mathrm{Br})(\mathrm{Br}) \mathrm{H})(\mathrm{H}) \mathrm{H})(\mathrm{H})(\mathrm{H}) \mathrm{H}$ $\mathrm{C}(\mathrm{C}(\mathrm{C}(\mathrm{C}(\mathrm{C}(\mathrm{C}(\mathrm{C}(\mathrm{C}(\mathrm{C}(\mathrm{C}(\mathrm{Br})(\mathrm{H}) \mathrm{Br})(\mathrm{Br}) \mathrm{H})(\mathrm{Br}) \mathrm{H})(\mathrm{H}) \mathrm{H})(\mathrm{H}) \mathrm{H})(\mathrm{H}) \mathrm{H})(\mathrm{Br}) \mathrm{H})(\mathrm{H}) \mathrm{H})(\mathrm{H}) \mathrm{H})(\mathrm{H})(\mathrm{H}) \mathrm{Br}$ $\mathrm{C}(\mathrm{C}(\mathrm{C}(\mathrm{C}(\mathrm{C}(\mathrm{C}(\mathrm{C}(\mathrm{C}(\mathrm{C}(\mathrm{C}(\mathrm{H})(\mathrm{H}) \mathrm{Cl})(\mathrm{H}) \mathrm{Cl})(\mathrm{Br}) \mathrm{H})(\mathrm{H}) \mathrm{Br})(\mathrm{H}) \mathrm{H})(\mathrm{H}) \mathrm{H})(\mathrm{H}) \mathrm{H})(\mathrm{Br}) \mathrm{H})(\mathrm{H}) \mathrm{F})(\mathrm{H})(\mathrm{H}) \mathrm{H}$ $\mathrm{C}(\mathrm{C}(\mathrm{C}(\mathrm{C}(\mathrm{C}(\mathrm{C}(\mathrm{C}(\mathrm{C}(\mathrm{C}(\mathrm{C}(\mathrm{H})(\mathrm{H}) \mathrm{Br})(\mathrm{H}) \mathrm{Cl})(\mathrm{H}) \mathrm{H})(\mathrm{H}) \mathrm{H})(\mathrm{H}) \mathrm{Br})(\mathrm{Br}) \mathrm{H})(\mathrm{H}) \mathrm{Br})(\mathrm{H}) \mathrm{H})(\mathrm{H}) \mathrm{H})(\mathrm{H})(\mathrm{H}) \mathrm{C}$ $\mathrm{C}(\mathrm{C}(\mathrm{C}(\mathrm{C}(\mathrm{C}(\mathrm{C}(\mathrm{C}(\mathrm{C}(\mathrm{C}(\mathrm{C}(\mathrm{H})(\mathrm{H}) \mathrm{H})(\mathrm{H}) \mathrm{H})(\mathrm{H}) \mathrm{H})(\mathrm{Cl}) \mathrm{H})(\mathrm{H}) \mathrm{H})(\mathrm{H}) \mathrm{H})(\mathrm{H}) \mathrm{Cl})(\mathrm{H}) \mathrm{Br})(\mathrm{H}) \mathrm{Cl})(\mathrm{Br})(\mathrm{Br}) \mathrm{H}$ $\mathrm{C}(\mathrm{C}(\mathrm{C}(\mathrm{C}(\mathrm{C}(\mathrm{C}(\mathrm{C}(\mathrm{C}(\mathrm{C}(\mathrm{C}(\mathrm{H})(\mathrm{H}) \mathrm{H})(\mathrm{H}) \mathrm{Br})(\mathrm{H}) \mathrm{H})(\mathrm{Cl}) \mathrm{H})(\mathrm{H}) \mathrm{H})(\mathrm{Cl}) \mathrm{Cl})(\mathrm{H}) \mathrm{H})(\mathrm{H}) \mathrm{H})(\mathrm{Cl}) \mathrm{H})(\mathrm{Br})(\mathrm{H}) \mathrm{H}$ $\mathrm{C}(\mathrm{C}(\mathrm{C}(\mathrm{C}(\mathrm{C}(\mathrm{C}(\mathrm{C}(\mathrm{C}(\mathrm{C}(\mathrm{C}(\mathrm{Cl})(\mathrm{H}) \mathrm{Cl})(\mathrm{H}) \mathrm{Br})(\mathrm{H}) \mathrm{Cl})(\mathrm{H}) \mathrm{H})(\mathrm{H}) \mathrm{H})(\mathrm{H}) \mathrm{H})(\mathrm{H}) \mathrm{H})(\mathrm{Cl}) \mathrm{H})(\mathrm{H}) \mathrm{Cl})(\mathrm{H})(\mathrm{H}) \mathrm{H}$ $\mathrm{C}(\mathrm{C}(\mathrm{C}(\mathrm{C}(\mathrm{C}(\mathrm{C}(\mathrm{C}(\mathrm{C}(\mathrm{C}(\mathrm{C}(\mathrm{H})(\mathrm{H}) \mathrm{H})(\mathrm{H}) \mathrm{H})(\mathrm{Cl}) \mathrm{H})(\mathrm{Cl}) \mathrm{Cl})(\mathrm{Cl}) \mathrm{H})(\mathrm{H}) \mathrm{H})(\mathrm{Cl}) \mathrm{H})(\mathrm{H}) \mathrm{H})(\mathrm{Cl}) \mathrm{H})(\mathrm{H})(\mathrm{H}) \mathrm{H}$
Formula

$\mathrm{C} 10 \mathrm{H} 12 \mathrm{ClBr} 4 \mathrm{~F} 5$ C10H12ClBr5F4 C10H12ClBr6F3 C10H13Br4F5

C10H13Br5F4

C10H13Br6F3

C10H13Br7F2

$\mathrm{C} 10 \mathrm{H} 13 \mathrm{Cl} 2 \mathrm{Br} 2 \mathrm{~F} 5$

$\mathrm{C} 10 \mathrm{H} 13 \mathrm{Cl} 2 \mathrm{Br} 3 \mathrm{~F} 4$

$\mathrm{C} 10 \mathrm{H} 13 \mathrm{Cl} 2 \mathrm{Br} 4 \mathrm{~F} 3$

$\mathrm{C} 10 \mathrm{H} 13 \mathrm{Cl} 2 \mathrm{Br} 5 \mathrm{~F} 2$

C10H13Cl2Br6F

$\mathrm{C} 10 \mathrm{H} 13 \mathrm{Cl} 3 \mathrm{Br} 2 \mathrm{~F} 4$

C10H13Cl3Br3F3

$\mathrm{C} 10 \mathrm{H} 13 \mathrm{Cl} 3 \mathrm{Br} 4 \mathrm{~F} 2$

C10H13Cl3Br5F

$\mathrm{C} 10 \mathrm{H} 13 \mathrm{Cl} 14 \mathrm{Br} 2 \mathrm{~F} 3$

C10H13Cl4Br3F2

$\mathrm{C} 10 \mathrm{H} 13 \mathrm{Cl} 4 \mathrm{Br} 4 \mathrm{~F}$

$\mathrm{C} 10 \mathrm{H} 13 \mathrm{Cl} 15 \mathrm{Br} 2 \mathrm{~F} 2$

C10H13Cl5Br3F

$\mathrm{C} 10 \mathrm{H} 13 \mathrm{Cl} 5 \mathrm{Br} 4$

C10H13Cl5BrF3

C10H13Cl6Br2F

C10H13Cl6Br3

C10H13Cl6BrF2

$\mathrm{C} 10 \mathrm{H} 13 \mathrm{Cl} 7 \mathrm{Br} 2$

$\mathrm{C} 10 \mathrm{H} 13 \mathrm{Cl} 17 \mathrm{BrF}$

C10H13Cl7F2

$\mathrm{C} 10 \mathrm{H} 13 \mathrm{Cl} 8 \mathrm{Br}$

$\mathrm{C} 10 \mathrm{H} 13 \mathrm{Cl} 8 \mathrm{~F}$

$\mathrm{C} 10 \mathrm{H} 13 \mathrm{Cl}$

$\mathrm{C} 10 \mathrm{H} 13 \mathrm{ClBr} 4 \mathrm{~F} 4$

$\mathrm{C} 10 \mathrm{H} 13 \mathrm{ClBr} 5 \mathrm{~F} 3$

$\mathrm{C} 10 \mathrm{H} 13 \mathrm{ClBr} 6 \mathrm{~F} 2$

$\mathrm{C} 10 \mathrm{H} 14 \mathrm{Br} 4 \mathrm{~F} 4$

$\mathrm{C} 10 \mathrm{H} 14 \mathrm{Br} 5 \mathrm{~F} 3$

C10H14Br6F2

$\mathrm{C} 10 \mathrm{H} 14 \mathrm{Br} 7 \mathrm{~F}$

$\mathrm{C} 10 \mathrm{H} 14 \mathrm{Cl} 2 \mathrm{Br} 3 \mathrm{~F}$

$\mathrm{C} 10 \mathrm{H} 14 \mathrm{Cl} 2 \mathrm{Br} 4 \mathrm{~F} 2$

$\mathrm{C} 10 \mathrm{H} 14 \mathrm{Cl} 2 \mathrm{Br} 5 \mathrm{~F}$

$\mathrm{C} 10 \mathrm{H} 14 \mathrm{Cl} 3 \mathrm{Br} 3 \mathrm{~F} 2$

$\mathrm{C} 10 \mathrm{H} 14 \mathrm{Cl} 3 \mathrm{Br} 4 \mathrm{~F}$

$\mathrm{C} 10 \mathrm{H} 14 \mathrm{Cl} 4 \mathrm{Br} 2 \mathrm{~F} 2$

C10H14Cl4Br3F

$\mathrm{C} 10 \mathrm{H} 14 \mathrm{Cl} 4 \mathrm{Br} 4$

$\mathrm{C} 10 \mathrm{H} 14 \mathrm{Cl} 5 \mathrm{Br} 2 \mathrm{~F}$

$\mathrm{C} 10 \mathrm{H} 14 \mathrm{Cl} \mathrm{Br} 3$

$\mathrm{C} 10 \mathrm{H} 14 \mathrm{Cl} 5 \mathrm{BrF} 2$

$\mathrm{C} 10 \mathrm{H} 14 \mathrm{Cl} 6 \mathrm{Br} 2$

$\mathrm{C} 10 \mathrm{H} 14 \mathrm{Cl} 6 \mathrm{BrF}$

$\mathrm{C} 10 \mathrm{H} 14 \mathrm{Cl} 17 \mathrm{Br}$

C10H14Cl7F

C10H14Cl8

$\mathrm{C} 10 \mathrm{H} 14 \mathrm{ClBr} 3 \mathrm{~F} 4$

$\mathrm{C} 10 \mathrm{H} 14 \mathrm{ClBr} 4 \mathrm{~F} 3$

$\mathrm{C} 10 \mathrm{H} 14 \mathrm{ClBr} 5 \mathrm{~F} 2$

$\mathrm{C} 10 \mathrm{H} 14 \mathrm{ClBr} 6 \mathrm{~F}$

$\mathrm{C} 10 \mathrm{H} 15 \mathrm{Br} 4 \mathrm{~F}$

$\mathrm{C} 10 \mathrm{H} 15 \mathrm{Br} 5 \mathrm{~F} 2$

C10H15B

$\mathrm{C} 10 \mathrm{H} 15 \mathrm{Cl} 2 \mathrm{Br} 3 \mathrm{~F} 2$

$\mathrm{C} 10 \mathrm{H} 15 \mathrm{Cl} 2 \mathrm{Br} 4 \mathrm{~F}$

$\mathrm{C} 10 \mathrm{H} 15 \mathrm{Cl} 2 \mathrm{Br} 5$

C10H15Cl3Br3F

$\mathrm{C} 10 \mathrm{H} 15 \mathrm{Cl} 3 \mathrm{Br} 4$

C10H15Cl4Br2F

$\mathrm{C} 10 \mathrm{H} 15 \mathrm{Cl} 4 \mathrm{Br} 3$

$\mathrm{C} 10 \mathrm{H} 15 \mathrm{Cl} 5 \mathrm{Br} 2$

$\mathrm{C} 10 \mathrm{H} 15 \mathrm{Cl} \mathrm{BrF}$

$\mathrm{C} 10 \mathrm{H} 15 \mathrm{Cl} 6 \mathrm{Br}$

$\mathrm{C} 10 \mathrm{H} 15 \mathrm{Cl} 6 \mathrm{~F}$

$\mathrm{C} 10 \mathrm{H} 15 \mathrm{Cl} 7$

C10H15ClBr4F2

$\mathrm{C} 10 \mathrm{H} 15 \mathrm{ClBr} 5 \mathrm{~F}$

$\mathrm{C} 10 \mathrm{H} 15 \mathrm{ClBr} 6$

$\mathrm{C} 10 \mathrm{H} 16 \mathrm{Br} 5 \mathrm{~F}$

C10H16Br6

$\mathrm{C} 10 \mathrm{H} 16 \mathrm{Cl} 2 \mathrm{Br} 3 \mathrm{~F}$

$\mathrm{C} 10 \mathrm{H} 16 \mathrm{Cl} 2 \mathrm{Br} 4$

$\mathrm{C} 10 \mathrm{H} 16 \mathrm{Cl} 3 \mathrm{Br} 3$

$\mathrm{C} 10 \mathrm{H} 16 \mathrm{Cl} 4 \mathrm{Br} 2$

$\mathrm{C} 10 \mathrm{H} 16 \mathrm{Cl} 15 \mathrm{Br}$

$\mathrm{C} 10 \mathrm{H} 16 \mathrm{Cl} 6$
gKoa lgKow lgKaw lgKow lgKoa lgKaw lgKow lgKoa lgKaw EPI_EPI_EPI_Exp__Exp_Exp__DFT_DFT_DFT Suite Suite Suite corr corr corr_corr_corr corr $\begin{array}{llllllllll}7.87 & 6.74 & -1.13 & 5.13 & 6.26 & -1.13 & 5.94 & 12.46 & -6.52\end{array}$ $\begin{array}{lllllllll}10.2 & 7.81 & -2.36 & 6.73 & 9.09 & -2.36 & 6.76 & 16.70 & -9.94\end{array}$ $\begin{array}{llllllllll}11.9 & 8.28 & -3.60 & 7.43 & 11.03 & -3.60 & 7.12 & 19.84 & -12.72\end{array}$ $\begin{array}{lllllllll}7.89 & 7.22 & -0.67 & 5.85 & 6.52 & -0.67 & 6.31 & 12.51 & -6.20\end{array}$ $\begin{array}{lll}9.54 & 7.63 & -1.91 \\ 10.5 & 7.36 & -3.15\end{array}$ $\begin{array}{llllllllll}10.5 & 7.36 & -3.15 & 6.06 & 9.21 & -3.15 & 6.41 & 17.31 & -10.90\end{array}$ $\begin{array}{llllllllll}12.1 & 7.76 & -4.38 & 6.66 & 11.04 & -4.38 & 6.72 & 20.32 & -13.60\end{array}$ $\begin{array}{lllllllll}8.31 & 7.37 & -0.94 & 6.07 & 7.01 & -0.94 & 6.42 & 13.28 & -6.85\end{array}$ $\begin{array}{lllllllll}9.36 & 7.18 & -2.18 & 5.79 & 7.97 & -2.18 & 6.28 & 15.20 & -8.92\end{array}$ $\begin{array}{lllllllll}11 & 7.59 & -3.41 & 6.40 & 9.82 & -3.41 & 6.59 & 18.23 & -11.63\end{array}$ $\begin{array}{llllllllll}12.6 & 7.99 & -4.65 & 7.00 & 11.65 & -4.65 & 6.90 & 21.23 & -14.33\end{array}$ $\begin{array}{llllllllll}7.82 & 7.36 & -0.46 & 6.06 & 6.51 & -0.46 & 6.41 & 12.37 & -5.95\end{array}$ $\begin{array}{lllllllll}8.78 & 7.09 & -1.69 & 5.66 & 7.35 & -1.69 & 6.21 & 14.14 & -7.94\end{array}$ $\begin{array}{llllllllll}11.2 & 8.24 & -2.93 & 7.37 & 10.30 & -2.93 & 7.09 & 18.53 & -11.44\end{array}$ $\begin{array}{llllllllll}12.1 & 7.9 & -4.17 & 6.87 & 11.03 & -4.17 & 6.83 & 20.18 & -13.35\end{array}$ $\begin{array}{llllllllll}8.21 & 7 & -1.21 & 5.52 & 6.73 & -1.21 & 6.14 & 13.09 & -6.95 \\ 10.6 & 8.15 & -2.44 & 7.24 & 9.68 & -2.44 & 7.02 & 17.47 & -10.45\end{array}$ $\begin{array}{lllllllll}10.6 & 8.15 & -2.44 & 7.24 & 9.68 & -2.44 & 7.02 & 17.47 & -10.45\end{array}$ $\begin{array}{lllllllll}12.2 & 8.55 & -3.68 & 7.84 & 11.52 & -3.68 & 7.33 & 20.48 & -13.15\end{array}$ $\begin{array}{llllllllll}10 & 8.06 & -1.96 & 7.10 & 9.06 & -1.96 & 6.95 & 16.42 & -9.46\end{array}$ $\begin{array}{lllllllll}11.7 & 8.46 & -3.20 & 7.70 & 10.90 & -3.20 & 7.26 & 19.42 & -12.16\end{array}$ $\begin{array}{llllllllll}12.5 & 8.05 & -4.43 & 7.09 & 11.52 & -4.43 & 6.94 & 20.94 & -14.00\end{array}$ $\begin{array}{lllllllll}8.37 & 7.65 & -0.72 & 6.49 & 7.21 & -0.72 & 6.64 & 13.39 & -6.75\end{array}$ $\begin{array}{llllllllll}11.1 & 8.37 & -2.71 & 7.57 & 10.28 & -2.71 & 7.19 & 18.37 & -11.18\end{array}$ $\begin{array}{llllllllll}11.9 & 7.96 & -3.95 & 6.96 & 10.90 & -3.95 & 6.88 & 19.89 & -13.01\end{array}$ $\begin{array}{llllllllll}9.44 & 7.97 & -1.47 & 6.97 & 8.44 & -1.47 & 6.88 & 15.36 & -8.48\end{array}$ $\begin{array}{llllllllll}11.4 & 7.94 & -3.46 & 6.93 & 10.39 & -3.46 & 6.86 & 18.96 & -12.10\end{array}$ $\begin{array}{lllllllll}9.76 & 7.54 & -2.22 & 6.33 & 8.55 & -2.22 & 6.55 & 15.95 & -9.40\end{array}$ $\begin{array}{lllllllll}8.8 & 7.81 & -0.99 & 6.73 & 7.72 & -0.99 & 6.76 & 14.18 & -7.42\end{array}$ $\begin{array}{llllllllll}11.5 & 8.52 & -2.98 & 7.79 & 10.77 & -2.98 & 7.31 & 19.13 & -11.83\end{array}$ $\begin{array}{llllllllll}9.93 & 8.19 & -1.74 & 7.30 & 9.04 & -1.74 & 7.05 & 16.25 & -9.20\end{array}$ $\begin{array}{llllllllll}10.9 & 8.43 & -2.49 & 7.66 & 10.15 & -2.49 & 7.24 & 18.08 & -10.84\end{array}$ $\begin{array}{lllllllll}8.97 & 7.54 & -1.43 & 6.33 & 7.75 & -1.43 & 6.55 & 14.48 & -7.93\end{array}$ $\begin{array}{llllllllll}9.86 & 7.2 & -2.66 & 5.82 & 8.48 & -2.66 & 6.29 & 16.13 & -9.84\end{array}$ $\begin{array}{lllllllll}11.5 & 7.6 & -3.90 & 6.42 & 10.32 & -3.90 & 6.60 & 19.14 & -12.54\end{array}$ $\begin{array}{lllllllll}7.66 & 6.69 & -0.97 & 5.06 & 6.03 & -0.97 & 5.90 & 12.09 & -6.19\end{array}$ $\begin{array}{llllllllll}8.56 & 6.35 & -2.21 & 4.55 & 6.76 & -2.21 & 5.64 & 13.73 & -8.10 \\ 11.7 & 8.24 & -3.45 & 7.37 & 10.82 & -3.45 & 7.09 & 19.48 & -12.39\end{array}$ $\begin{array}{lllllllll}11.7 & 8.24 & -3.45 & 7.37 & 10.82 & -3.45 & 7.09 & 19.48 & -12.39\end{array}$ $\begin{array}{llllllllll}12.5 & 7.82 & -4.68 & 6.75 & 11.43 & -4.68 & 6.77 & 20.98 & -14.21\end{array}$ $\begin{array}{rrrrrrrrr}12.5 & 7.82 & -4.68 & 6.75 & 11.43 & -4.68 & 6.77 & 20.98 & -14.21 \\ 8.15 & 6.91 & -1.24 & 5.39 & 6.63 & -1.24 & 6.07 & 12.98 & -6.91\end{array}$ $\begin{array}{lllllllll}10.4 & 7.91 & -2.48 & 6.88 & 9.36 & -2.48 & 6.84 & 17.09 & -10.25\end{array}$ $\begin{array}{llllllllll}11.4 & 7.72 & -3.71 & 6.60 & 10.31 & -3.71 & 6.69 & 19.02 & -12.32\end{array}$ $\begin{array}{lllllllll}9.22 & 7.23 & -1.99 & 5.87 & 7.86 & -1.99 & 6.31 & 14.95 & -8.64\end{array}$ $\begin{array}{lllllllll}10.8 & 7.56 & -3.23 & 6.36 & 9.59 & -3.23 & 6.57 & 17.83 & -11.26\end{array}$ $\begin{array}{llllllllll}8.65 & 7.14 & -1.51 & 5.73 & 7.24 & -1.51 & 6.25 & 13.89 & -7.65\end{array}$ $\begin{array}{lllllllll}10.3 & 7.54 & -2.74 & 6.33 & 9.07 & -2.74 & 6.55 & 16.90 & -10.35\end{array}$ $\begin{array}{lllllllll}12.5 & 8.54 & -3.98 & 7.82 & 11.80 & -3.98 & 7.32 & 21.01 & -13.69\end{array}$ $\begin{array}{llllllllll}8.97 & 6.71 & -2.26 & 5.09 & 7.35 & -2.26 & 5.92 & 14.49 & -8.57\end{array}$ $\begin{array}{lllllllllll}8.97 & 6.71 & -2.26 & 5.09 & 7.35 & -2.26 & 5.92 & 14.49 & -8.57\end{array}$ $\begin{array}{lllllllllll}10.6 & 7.11 & -3.49 & 5.69 & 9.18 & -3.49 & 6.22 & 17.49 & -11.27\end{array}$ $\begin{array}{llllllllll}8.07 & 7.05 & -1.02 & 5.60 & 6.62 & -1.02 & 6.18 & 12.84 & -6.66\end{array}$ $\begin{array}{llllllllll}11.4 & 8.43 & -3.01 & 7.66 & 10.67 & -3.01 & 7.24 & 19.03 & -11.79\end{array}$ $\begin{array}{lllllllll}9.13 & 7.36 & -1.77 & 6.06 & 7.83 & -1.77 & 6.41 & 14.79 & -8.37\end{array}$ $\begin{array}{llllllllll}9.45 & 6.93 & -2.52 & 5.42 & 7.94 & -2.52 & 6.08 & 15.38 & -9.29\end{array}$ $\begin{array}{lllllllll}8.49 & 7.2 & -1.29 & 5.82 & 7.11 & -1.29 & 6.29 & 13.60 & -7.31\end{array}$ $\begin{array}{llllllllll}9.62 & 7.58 & -2.04 & 6.39 & 8.43 & -2.04 & 6.58 & 15.68 & -9.10\end{array}$ $\begin{array}{llllllllll}7.76 & 7.27 & -0.49 & 5.93 & 6.41 & -0.49 & 6.35 & 12.26 & -5.92\end{array}$ $\begin{array}{lllllllll}8.65 & 6.93 & -1.72 & 5.42 & 7.14 & -1.72 & 6.08 & 13.91 & -7.82\end{array}$ $\begin{array}{lllllllll}10.4 & 7.4 & -2.96 & 6.12 & 9.08 & -2.96 & 6.45 & 17.05 & -10.60\end{array}$ $\begin{array}{lllllllll}11.9 & 7.73 & -4.20 & 6.61 & 10.81 & -4.20 & 6.70 & 19.92 & -13.22\end{array}$ $\begin{array}{lllllllll}8.09 & 6.82 & -1.27 & 5.25 & 6.53 & -1.27 & 6.00 & 12.88 & -6.88\end{array}$ $\begin{array}{llllllllll}9.73 & 7.22 & -2.51 & 5.85 & 8.36 & -2.51 & 6.31 & 15.88 & -9.57\end{array}$ $\begin{array}{lllllllll}10.6 & 6.81 & -3.75 & 5.24 & 8.98 & -3.75 & 5.99 & 17.40 & -11.41\end{array}$ $\begin{array}{llllllllll}7.84 & 6.3 & -1.54 & 4.48 & 6.02 & -1.54 & 5.60 & 12.41 & -6.8\end{array}$ $\begin{array}{lllllllll}9.49 & 6.71 & -2.77 & 5.09 & 7.86 & -2.77 & 5.92 & 15.44 & -9.52\end{array}$ $\begin{array}{lllllllll}11.9 & 7.85 & -4.01 & 6.79 & 10.80 & -4.01 & 6.79 & 19.80 & -13.0\end{array}$ $\begin{array}{llllllllll}9.65 & 7.36 & -2.29 & 6.06 & 8.35 & -2.29 & 6.41 & 15.74 & -9.32\end{array}$ $\begin{array}{lllllllll}10.5 & 6.95 & -3.53 & 5.45 & 8.97 & -3.53 & 6.10 & 17.26 & -11.16\end{array}$ $\begin{array}{lllllllll}9 & 7.2 & -1.80 & 5.82 & 7.63 & -1.80 & 6.29 & 14.55 & -8.26\end{array}$ $\begin{array}{lllllllll}9.97 & 6.93 & -3.04 & 5.42 & 8.46 & -3.04 & 6.08 & 16.33 & -10.25\end{array}$ $\begin{array}{llllllllll}10.8 & 8.25 & -2.56 & 7.39 & 9.94 & -2.56 & 7.10 & 17.86 & -10.77\end{array}$ $\begin{array}{llllllllll}8.43 & 7.11 & -1.32 & 5.69 & 7.01 & -1.32 & 6.22 & 13.50 & -7.28\end{array}$ $\begin{array}{lllllllll}9.56 & 7.49 & -2.07 & 6.25 & 8.32 & -2.07 & 6.51 & 15.57 & -9.06\end{array}$ $\begin{array}{lllllllll}8.59 & 7.76 & -0.83 & 6.66 & 7.49 & -0.83 & 6.72 & 13.80 & -7.08\end{array}$ $\begin{array}{llllllllll}8.25 & 6.66 & -1.59 & 5.01 & 6.60 & -1.59 & 5.88 & 13.16 & -7.28\end{array}$ $\begin{array}{lllllllll}9.82 & 7.8 & -2.02 & 6.72 & 8.74 & -2.02 & 6.75 & 16.06 & -9.30\end{array}$ $\begin{array}{lllllllll}10.7 & 7.46 & -3.26 & 6.21 & 9.47 & -3.26 & 6.49 & 17.71 & -11.21\end{array}$ $\begin{array}{lllllllll}12.4 & 7.94 & -4.50 & 6.93 & 11.42 & -4.50 & 6.86 & 20.86 & -14.00\end{array}$ $\begin{array}{lllllllll}10.1 & 7.28 & -2.81 & 5.94 & 8.75 & -2.81 & 6.35 & 16.54 & -10.19\end{array}$ $\begin{array}{lllllllll}11.1 & 7.02 & -4.04 & 5.55 & 9.60 & -4.04 & 6.15 & 18.34 & -12.18\end{array}$ $\begin{array}{llllllllll}8.2 & 6.36 & -1.84 & 4.57 & 6.40 & -1.84 & 5.65 & 13.07 & -7.42\end{array}$ $\begin{array}{llllllllll}9.92 & 6.84 & -3.07 & 5.28 & 8.36 & -3.07 & 6.02 & 16.23 & -10.21\end{array}$ $\begin{array}{llllllllll}9.27 & 6.68 & -2.59 & 5.04 & 7.63 & -2.59 & 5.89 & 15.04 & -9.14\end{array}$ $\begin{array}{lllllllll}9.43 & 7.33 & -2.10 & 6.01 & 8.12 & -2.10 & 6.39 & 15.34 & -8.95\end{array}$ $\begin{array}{llllllllll}8.12 & 6.5 & -1.62 & 4.78 & 6.39 & -1.62 & 5.75 & 12.92 & -7.17\end{array}$ $\begin{array}{lllllllll}8.21 & 7.08 & -1.13 & 5.64 & 6.78 & -1.13 & 6.20 & 13.10 & -6.90\end{array}$ 
$\mathrm{C}(\mathrm{C}(\mathrm{C}(\mathrm{C}(\mathrm{C}(\mathrm{C}(\mathrm{C}(\mathrm{C}(\mathrm{C}(\mathrm{C}(\mathrm{H})(\mathrm{H}) \mathrm{H})(\mathrm{H}) \mathrm{H})(\mathrm{H}) \mathrm{H})(\mathrm{Cl}) \mathrm{F})(\mathrm{H}) \mathrm{F})(\mathrm{H}) \mathrm{H})(\mathrm{H}) \mathrm{H})(\mathrm{Br}) \mathrm{H})(\mathrm{Br}) \mathrm{H})(\mathrm{Br})(\mathrm{H}) \mathrm{H}$ $\mathrm{C}(\mathrm{C}(\mathrm{C}(\mathrm{C}(\mathrm{C}(\mathrm{C}(\mathrm{C}(\mathrm{C}(\mathrm{C}(\mathrm{C}(\mathrm{H})(\mathrm{H}) \mathrm{Br})(\mathrm{H}) \mathrm{H})(\mathrm{Cl}) \mathrm{H})(\mathrm{H}) \mathrm{H})(\mathrm{H}) \mathrm{Br})(\mathrm{F}) \mathrm{H})(\mathrm{H}) \mathrm{H})(\mathrm{Br}) \mathrm{Br})(\mathrm{H}) \mathrm{H})(\mathrm{H})(\mathrm{H}) \mathrm{H}$ $\mathrm{C}(\mathrm{C}(\mathrm{C}(\mathrm{C}(\mathrm{C}(\mathrm{C}(\mathrm{C}(\mathrm{C}(\mathrm{C}(\mathrm{C}(\mathrm{H})(\mathrm{H}) \mathrm{H})(\mathrm{H}) \mathrm{H})(\mathrm{H}) \mathrm{Cl})(\mathrm{H}) \mathrm{H})(\mathrm{Br}) \mathrm{Br})(\mathrm{H}) \mathrm{H})(\mathrm{Br}) \mathrm{H})(\mathrm{H}) \mathrm{H})(\mathrm{H}) \mathrm{Br})(\mathrm{H})(\mathrm{Br}) \mathrm{H}$ $\mathrm{C}(\mathrm{C}(\mathrm{C}(\mathrm{C}(\mathrm{C}(\mathrm{C}(\mathrm{C}(\mathrm{C}(\mathrm{C}(\mathrm{C}(\mathrm{H})(\mathrm{H}) \mathrm{H})(\mathrm{H}) \mathrm{H})(\mathrm{H}) \mathrm{H})(\mathrm{H}) \mathrm{H})(\mathrm{Br}) \mathrm{H})(\mathrm{H}) \mathrm{F})(\mathrm{Br}) \mathrm{Br})(\mathrm{H}) \mathrm{H})(\mathrm{H}) \mathrm{Br})(\mathrm{H})(\mathrm{H}) \mathrm{H}$ $\mathrm{C}(\mathrm{C}(\mathrm{C}(\mathrm{C}(\mathrm{C}(\mathrm{C}(\mathrm{C}(\mathrm{C}(\mathrm{C}(\mathrm{C}(\mathrm{H})(\mathrm{H}) \mathrm{H})(\mathrm{H}) \mathrm{H})(\mathrm{H}) \mathrm{H})(\mathrm{H}) \mathrm{H})(\mathrm{H}) \mathrm{H})(\mathrm{Br}) \mathrm{H})(\mathrm{Br}) \mathrm{H})(\mathrm{Br}) \mathrm{H})(\mathrm{H}) \mathrm{Br})(\mathrm{H})(\mathrm{H}) \mathrm{Br}$ $\mathrm{C}(\mathrm{C}(\mathrm{C}(\mathrm{C}(\mathrm{C}(\mathrm{C}(\mathrm{C}(\mathrm{C}(\mathrm{C}(\mathrm{C}(\mathrm{H})(\mathrm{Br}) \mathrm{H})(\mathrm{H}) \mathrm{H})(\mathrm{H}) \mathrm{H})(\mathrm{H}) \mathrm{H})(\mathrm{Br}) \mathrm{H})(\mathrm{H}) \mathrm{Cl})(\mathrm{Cl}) \mathrm{H})(\mathrm{H}) \mathrm{H})(\mathrm{H}) \mathrm{H})(\mathrm{H})(\mathrm{Br}) \mathrm{H}$ $\mathrm{C}(\mathrm{C}(\mathrm{C}(\mathrm{C}(\mathrm{C}(\mathrm{C}(\mathrm{C}(\mathrm{C}(\mathrm{C}(\mathrm{C}(\mathrm{H})(\mathrm{H}) \mathrm{H})(\mathrm{H}) \mathrm{Br})(\mathrm{H}) \mathrm{H})(\mathrm{H}) \mathrm{H})(\mathrm{Cl}) \mathrm{Cl})(\mathrm{H}) \mathrm{H})(\mathrm{Cl}) \mathrm{H})(\mathrm{Br}) \mathrm{H})(\mathrm{H}) \mathrm{H})(\mathrm{H})(\mathrm{H}) \mathrm{H}$ $\mathrm{C}(\mathrm{C}(\mathrm{C}(\mathrm{C}(\mathrm{C}(\mathrm{C}(\mathrm{C}(\mathrm{C}(\mathrm{C}(\mathrm{C}(\mathrm{H})(\mathrm{H}) \mathrm{H})(\mathrm{H}) \mathrm{H})(\mathrm{H}) \mathrm{H})(\mathrm{H}) \mathrm{H})(\mathrm{H}) \mathrm{Cl})(\mathrm{Cl}) \mathrm{Cl})(\mathrm{H}) \mathrm{H})(\mathrm{H}) \mathrm{H})(\mathrm{H}) \mathrm{H})(\mathrm{Cl})(\mathrm{H}) \mathrm{Cl}$ $\mathrm{C}(\mathrm{C}(\mathrm{C}(\mathrm{C}(\mathrm{C}(\mathrm{C}(\mathrm{C}(\mathrm{C}(\mathrm{C}(\mathrm{C}(\mathrm{H})(\mathrm{H}) \mathrm{H})(\mathrm{H}) \mathrm{H})(\mathrm{H}) \mathrm{H})(\mathrm{H}) \mathrm{H})(\mathrm{H}) \mathrm{Cl})(\mathrm{F}) \mathrm{Br})(\mathrm{H}) \mathrm{H})(\mathrm{H}) \mathrm{H})(\mathrm{Br}) \mathrm{H})(\mathrm{H})(\mathrm{H}) \mathrm{Br}$ $\mathrm{C}(\mathrm{C}(\mathrm{C}(\mathrm{C}(\mathrm{C}(\mathrm{C}(\mathrm{C}(\mathrm{C}(\mathrm{C}(\mathrm{C}(\mathrm{Br})(\mathrm{H}) \mathrm{H})(\mathrm{Br}) \mathrm{H})(\mathrm{H}) \mathrm{Cl})(\mathrm{H}) \mathrm{H})(\mathrm{H}) \mathrm{H})(\mathrm{H}) \mathrm{H})(\mathrm{Br}) \mathrm{H})(\mathrm{H}) \mathrm{H})(\mathrm{H}) \mathrm{H})(\mathrm{H})(\mathrm{H}) \mathrm{B}$ $\mathrm{C}(\mathrm{C}(\mathrm{C}(\mathrm{C}(\mathrm{C}(\mathrm{C}(\mathrm{C}(\mathrm{C}(\mathrm{C}(\mathrm{C}(\mathrm{H})(\mathrm{H}) \mathrm{Br})(\mathrm{Br}) \mathrm{H})(\mathrm{Br}) \mathrm{H})(\mathrm{H}) \mathrm{H})(\mathrm{H}) \mathrm{H})(\mathrm{H}) \mathrm{H})(\mathrm{H}) \mathrm{H})(\mathrm{H}) \mathrm{H})(\mathrm{H}) \mathrm{H})(\mathrm{H})(\mathrm{Br}) \mathrm{H}$ $\mathrm{C}(\mathrm{C}(\mathrm{C}(\mathrm{C}(\mathrm{C}(\mathrm{C}(\mathrm{C}(\mathrm{C}(\mathrm{C}(\mathrm{C}(\mathrm{H})(\mathrm{H}) \mathrm{H})(\mathrm{H}) \mathrm{Br})(\mathrm{H}) \mathrm{H})(\mathrm{H}) \mathrm{H})(\mathrm{H}) \mathrm{Br})(\mathrm{H}) \mathrm{H})(\mathrm{H}) \mathrm{Cl})(\mathrm{H}) \mathrm{H})(\mathrm{H}) \mathrm{H})(\mathrm{Br})(\mathrm{H}) \mathrm{H}$ $\mathrm{C}(\mathrm{C}(\mathrm{C}(\mathrm{C}(\mathrm{C}(\mathrm{C}(\mathrm{C}(\mathrm{C}(\mathrm{C}(\mathrm{C}(\mathrm{Br})(\mathrm{Br}) \mathrm{Br})(\mathrm{F}) \mathrm{F})(\mathrm{F}) \mathrm{F})(\mathrm{H}) \mathrm{F})(\mathrm{H}) \mathrm{F})(\mathrm{F}) \mathrm{F})(\mathrm{F}) \mathrm{Br})(\mathrm{Br}) \mathrm{H})(\mathrm{F}) \mathrm{H})(\mathrm{F})(\mathrm{H}) \mathrm{H}$ $\mathrm{C}(\mathrm{C}(\mathrm{C}(\mathrm{C}(\mathrm{C}(\mathrm{C}(\mathrm{C}(\mathrm{C}(\mathrm{C}(\mathrm{C}(\mathrm{H})(\mathrm{Cl}) \mathrm{F})(\mathrm{Br}) \mathrm{Br})(\mathrm{F}) \mathrm{Cl})(\mathrm{H}) \mathrm{F})(\mathrm{H}) \mathrm{F})(\mathrm{Br}) \mathrm{F})(\mathrm{Br}) \mathrm{Br})(\mathrm{F}) \mathrm{H})(\mathrm{H}) \mathrm{F})(\mathrm{F})(\mathrm{H}) \mathrm{F}$ $\mathrm{C}(\mathrm{C}(\mathrm{C}(\mathrm{C}(\mathrm{C}(\mathrm{C}(\mathrm{C}(\mathrm{C}(\mathrm{C}(\mathrm{C}(\mathrm{F})(\mathrm{F}) \mathrm{F})(\mathrm{Br}) \mathrm{H})(\mathrm{H}) \mathrm{Cl})(\mathrm{Br}) \mathrm{F})(\mathrm{H}) \mathrm{F})(\mathrm{H}) \mathrm{Br})(\mathrm{F}) \mathrm{H})(\mathrm{F}) \mathrm{F})(\mathrm{Cl}) \mathrm{Cl})(\mathrm{F})(\mathrm{H}) \mathrm{F}$ $\mathrm{C}(\mathrm{C}(\mathrm{C}(\mathrm{C}(\mathrm{C}(\mathrm{C}(\mathrm{C}(\mathrm{C}(\mathrm{C}(\mathrm{C}(\mathrm{F})(\mathrm{F}) \mathrm{F})(\mathrm{Cl}) \mathrm{H})(\mathrm{F}) \mathrm{Cl})(\mathrm{H}) \mathrm{F})(\mathrm{Cl}) \mathrm{Cl})(\mathrm{H}) \mathrm{F})(\mathrm{H}) \mathrm{Cl})(\mathrm{F}) \mathrm{H})(\mathrm{Cl}) \mathrm{Cl})(\mathrm{Cl})(\mathrm{F}) \mathrm{H}$ $\mathrm{C}(\mathrm{C}(\mathrm{C}(\mathrm{C}(\mathrm{C}(\mathrm{C}(\mathrm{C}(\mathrm{C}(\mathrm{C}(\mathrm{C}(\mathrm{H})(\mathrm{Cl}) \mathrm{Cl})(\mathrm{F}) \mathrm{H})(\mathrm{H}) \mathrm{Cl})(\mathrm{F}) \mathrm{F})(\mathrm{H}) \mathrm{Cl})(\mathrm{Cl}) \mathrm{Cl})(\mathrm{Cl}) \mathrm{Cl})(\mathrm{Cl}) \mathrm{H})(\mathrm{H}) \mathrm{F})(\mathrm{Cl})(\mathrm{F}) \mathrm{H}$ $\mathrm{C}(\mathrm{C}(\mathrm{C}(\mathrm{C}(\mathrm{C}(\mathrm{C}(\mathrm{C}(\mathrm{C}(\mathrm{C}(\mathrm{C}(\mathrm{Br})(\mathrm{Br}) \mathrm{F})(\mathrm{H}) \mathrm{F})(\mathrm{H}) \mathrm{F})(\mathrm{Cl}) \mathrm{F})(\mathrm{Cl}) \mathrm{H})(\mathrm{H}) \mathrm{Br})(\mathrm{H}) \mathrm{H})(\mathrm{H}) \mathrm{F})(\mathrm{Br}) \mathrm{F})(\mathrm{F})(\mathrm{F}) \mathrm{F}$ $\mathrm{C}(\mathrm{C}(\mathrm{C}(\mathrm{C}(\mathrm{C}(\mathrm{C}(\mathrm{C}(\mathrm{C}(\mathrm{C}(\mathrm{C}(\mathrm{H})(\mathrm{F}) \mathrm{F})(\mathrm{H}) \mathrm{F})(\mathrm{F}) \mathrm{Br})(\mathrm{H}) \mathrm{Br})(\mathrm{H}) \mathrm{F})(\mathrm{F}) \mathrm{H})(\mathrm{Br}) \mathrm{Cl})(\mathrm{Cl}) \mathrm{F})(\mathrm{H}) \mathrm{F})(\mathrm{Cl})(\mathrm{H}) \mathrm{F}$ $\mathrm{C}(\mathrm{C}(\mathrm{C}(\mathrm{C}(\mathrm{C}(\mathrm{C}(\mathrm{C}(\mathrm{C}(\mathrm{C}(\mathrm{C}(\mathrm{F})(\mathrm{Br}) \mathrm{H})(\mathrm{H}) \mathrm{F})(\mathrm{F}) \mathrm{F})(\mathrm{F}) \mathrm{Br})(\mathrm{Cl}) \mathrm{H})(\mathrm{H}) \mathrm{F})(\mathrm{Cl}) \mathrm{H})(\mathrm{Br}) \mathrm{H})(\mathrm{Br}) \mathrm{Br})(\mathrm{Cl})(\mathrm{F}) \mathrm{H}$ $\mathrm{C}(\mathrm{C}(\mathrm{C}(\mathrm{C}(\mathrm{C}(\mathrm{C}(\mathrm{C}(\mathrm{C}(\mathrm{C}(\mathrm{C}(\mathrm{F})(\mathrm{F}) \mathrm{H})(\mathrm{H}) \mathrm{H})(\mathrm{F}) \mathrm{Br})(\mathrm{Br}) \mathrm{H})(\mathrm{F}) \mathrm{F})(\mathrm{H}) \mathrm{Cl})(\mathrm{Cl}) \mathrm{F})(\mathrm{Cl}) \mathrm{F})(\mathrm{H}) \mathrm{F})(\mathrm{Br})(\mathrm{Cl}) \mathrm{H}$ $\mathrm{C}(\mathrm{C}(\mathrm{C}(\mathrm{C}(\mathrm{C}(\mathrm{C}(\mathrm{C}(\mathrm{C}(\mathrm{C}(\mathrm{C}(\mathrm{H})(\mathrm{Br}) \mathrm{F})(\mathrm{F}) \mathrm{H})(\mathrm{H}) \mathrm{Cl})(\mathrm{F}) \mathrm{Cl})(\mathrm{Br}) \mathrm{H})(\mathrm{Cl}) \mathrm{F})(\mathrm{F}) \mathrm{H})(\mathrm{H}) \mathrm{Br})(\mathrm{F}) \mathrm{H})(\mathrm{Cl})(\mathrm{F}) \mathrm{Br}$ $\mathrm{C}(\mathrm{C}(\mathrm{C}(\mathrm{C}(\mathrm{C}(\mathrm{C}(\mathrm{C}(\mathrm{C}(\mathrm{C}(\mathrm{C}(\mathrm{Cl})(\mathrm{Br}) \mathrm{H})(\mathrm{F}) \mathrm{F})(\mathrm{H}) \mathrm{H})(\mathrm{Cl}) \mathrm{F})(\mathrm{Cl}) \mathrm{H})(\mathrm{H}) \mathrm{Cl})(\mathrm{H}) \mathrm{Cl})(\mathrm{F}) \mathrm{F})(\mathrm{F}) \mathrm{F})(\mathrm{Cl})(\mathrm{F}) \mathrm{H}$ $\mathrm{C}(\mathrm{C}(\mathrm{C}(\mathrm{C}(\mathrm{C}(\mathrm{C}(\mathrm{C}(\mathrm{C}(\mathrm{C}(\mathrm{C}(\mathrm{H})(\mathrm{Cl}) \mathrm{F})(\mathrm{Cl}) \mathrm{F})(\mathrm{H}) \mathrm{Cl})(\mathrm{Br}) \mathrm{H})(\mathrm{H}) \mathrm{F})(\mathrm{F}) \mathrm{Cl})(\mathrm{Cl}) \mathrm{F})(\mathrm{F}) \mathrm{Cl})(\mathrm{H}) \mathrm{Cl})(\mathrm{H})(\mathrm{F}) \mathrm{H}$ $\mathrm{C}(\mathrm{C}(\mathrm{C}(\mathrm{C}(\mathrm{C}(\mathrm{C}(\mathrm{C}(\mathrm{C}(\mathrm{C}(\mathrm{C}(\mathrm{F})(\mathrm{Cl}) \mathrm{H})(\mathrm{H}) \mathrm{F})(\mathrm{Cl}) \mathrm{Cl})(\mathrm{F}) \mathrm{F})(\mathrm{F}) \mathrm{Cl})(\mathrm{H}) \mathrm{F})(\mathrm{F}) \mathrm{H})(\mathrm{Cl}) \mathrm{H})(\mathrm{H}) \mathrm{Cl})(\mathrm{H})(\mathrm{Cl}) \mathrm{Cl}$ $\mathrm{C}(\mathrm{C}(\mathrm{C}(\mathrm{C}(\mathrm{C}(\mathrm{C}(\mathrm{C}(\mathrm{C}(\mathrm{C}(\mathrm{C}(\mathrm{Cl})(\mathrm{Cl}) \mathrm{Cl})(\mathrm{F}) \mathrm{Br})(\mathrm{Cl}) \mathrm{H})(\mathrm{Cl}) \mathrm{H})(\mathrm{F}) \mathrm{H})(\mathrm{Cl}) \mathrm{F})(\mathrm{H}) \mathrm{F})(\mathrm{H}) \mathrm{F})(\mathrm{H}) \mathrm{Cl})(\mathrm{H})(\mathrm{Cl}) \mathrm{Cl}$ $\mathrm{C}(\mathrm{C}(\mathrm{C}(\mathrm{C}(\mathrm{C}(\mathrm{C}(\mathrm{C}(\mathrm{C}(\mathrm{C}(\mathrm{C}(\mathrm{Br})(\mathrm{F}) \mathrm{H})(\mathrm{Br}) \mathrm{H})(\mathrm{H}) \mathrm{H})(\mathrm{H}) \mathrm{F})(\mathrm{F}) \mathrm{F})(\mathrm{F}) \mathrm{F})(\mathrm{H}) \mathrm{F})(\mathrm{F}) \mathrm{Cl})(\mathrm{H}) \mathrm{Br})(\mathrm{Br})(\mathrm{F}) \mathrm{F}$ $\mathrm{C}(\mathrm{C}(\mathrm{C}(\mathrm{C}(\mathrm{C}(\mathrm{C}(\mathrm{C}(\mathrm{C}(\mathrm{C}(\mathrm{C}(\mathrm{F})(\mathrm{H}) \mathrm{F})(\mathrm{H}) \mathrm{H})(\mathrm{Br}) \mathrm{F})(\mathrm{F}) \mathrm{Cl})(\mathrm{F}) \mathrm{F})(\mathrm{Br}) \mathrm{H})(\mathrm{F}) \mathrm{H})(\mathrm{H}) \mathrm{Br})(\mathrm{F}) \mathrm{H})(\mathrm{F})(\mathrm{Br}) \mathrm{Br}$ $\mathrm{C}(\mathrm{C}(\mathrm{C}(\mathrm{C}(\mathrm{C}(\mathrm{C}(\mathrm{C}(\mathrm{C}(\mathrm{C}(\mathrm{C}(\mathrm{F})(\mathrm{H}) \mathrm{H})(\mathrm{H}) \mathrm{H})(\mathrm{Br}) \mathrm{H})(\mathrm{F}) \mathrm{Br})(\mathrm{F}) \mathrm{H})(\mathrm{F}) \mathrm{F})(\mathrm{H}) \mathrm{F})(\mathrm{F}) \mathrm{F})(\mathrm{F}) \mathrm{H})(\mathrm{Br})(\mathrm{Br}) \mathrm{Br}$ $\mathrm{C}(\mathrm{C}(\mathrm{C}(\mathrm{C}(\mathrm{C}(\mathrm{C}(\mathrm{C}(\mathrm{C}(\mathrm{C}(\mathrm{C}(\mathrm{Br})(\mathrm{Br}) \mathrm{H})(\mathrm{H}) \mathrm{Br})(\mathrm{H}) \mathrm{F})(\mathrm{F}) \mathrm{F})(\mathrm{H}) \mathrm{H})(\mathrm{F}) \mathrm{F})(\mathrm{Br}) \mathrm{Br})(\mathrm{H}) \mathrm{F})(\mathrm{F}) \mathrm{Br})(\mathrm{F})(\mathrm{H}) \mathrm{H}$ $\mathrm{C}(\mathrm{C}(\mathrm{C}(\mathrm{C}(\mathrm{C}(\mathrm{C}(\mathrm{C}(\mathrm{C}(\mathrm{C}(\mathrm{C}(\mathrm{H})(\mathrm{H}) \mathrm{F})(\mathrm{H}) \mathrm{Cl})(\mathrm{H}) \mathrm{Cl})(\mathrm{Cl}) \mathrm{Cl})(\mathrm{H}) \mathrm{Cl})(\mathrm{Cl}) \mathrm{F})(\mathrm{F}) \mathrm{Cl})(\mathrm{F}) \mathrm{H})(\mathrm{H}) \mathrm{Cl})(\mathrm{Cl})(\mathrm{Cl}) \mathrm{H}$ $\mathrm{C}(\mathrm{C}(\mathrm{C}(\mathrm{C}(\mathrm{C}(\mathrm{C}(\mathrm{C}(\mathrm{C}(\mathrm{C}(\mathrm{C}(\mathrm{H})(\mathrm{F}) \mathrm{H})(\mathrm{H}) \mathrm{Br})(\mathrm{F}) \mathrm{F})(\mathrm{Br}) \mathrm{Cl})(\mathrm{F}) \mathrm{Cl})(\mathrm{H}) \mathrm{F})(\mathrm{H}) \mathrm{F})(\mathrm{F}) \mathrm{Br})(\mathrm{H}) \mathrm{Br})(\mathrm{H})(\mathrm{F}) \mathrm{H}$ $\mathrm{C}(\mathrm{C}(\mathrm{C}(\mathrm{C}(\mathrm{C}(\mathrm{C}(\mathrm{C}(\mathrm{C}(\mathrm{C}(\mathrm{C}(\mathrm{F})(\mathrm{F}) \mathrm{H})(\mathrm{Br}) \mathrm{Cl})(\mathrm{Cl}) \mathrm{H})(\mathrm{Br}) \mathrm{Br})(\mathrm{F}) \mathrm{Cl})(\mathrm{H}) \mathrm{H})(\mathrm{F}) \mathrm{F})(\mathrm{H}) \mathrm{H})(\mathrm{F}) \mathrm{H})(\mathrm{F})(\mathrm{H}) \mathrm{F}$ $\mathrm{C}(\mathrm{C}(\mathrm{C}(\mathrm{C}(\mathrm{C}(\mathrm{C}(\mathrm{C}(\mathrm{C}(\mathrm{C}(\mathrm{C}(\mathrm{H})(\mathrm{Cl}) \mathrm{F})(\mathrm{Cl}) \mathrm{F})(\mathrm{F}) \mathrm{Br})(\mathrm{H}) \mathrm{H})(\mathrm{H}) \mathrm{Cl})(\mathrm{H}) \mathrm{F})(\mathrm{H}) \mathrm{H})(\mathrm{F}) \mathrm{F})(\mathrm{Cl}) \mathrm{F})(\mathrm{H})(\mathrm{Br}) \mathrm{F}$ $\mathrm{C}(\mathrm{C}(\mathrm{C}(\mathrm{C}(\mathrm{C}(\mathrm{C}(\mathrm{C}(\mathrm{C}(\mathrm{C}(\mathrm{C}(\mathrm{F})(\mathrm{H}) \mathrm{H})(\mathrm{Cl}) \mathrm{Br})(\mathrm{F}) \mathrm{H})(\mathrm{Br}) \mathrm{H})(\mathrm{Br}) \mathrm{F})(\mathrm{F}) \mathrm{H})(\mathrm{Cl}) \mathrm{F})(\mathrm{H}) \mathrm{F})(\mathrm{Cl}) \mathrm{Cl})(\mathrm{H})(\mathrm{H}) \mathrm{F}$ $\mathrm{C}(\mathrm{C}(\mathrm{C}(\mathrm{C}(\mathrm{C}(\mathrm{C}(\mathrm{C}(\mathrm{C}(\mathrm{C}(\mathrm{C}(\mathrm{Cl})(\mathrm{H}) \mathrm{F})(\mathrm{F}) \mathrm{F})(\mathrm{F}) \mathrm{H})(\mathrm{H}) \mathrm{Cl})(\mathrm{H}) \mathrm{Cl})(\mathrm{Br}) \mathrm{H})(\mathrm{Cl}) \mathrm{F})(\mathrm{Br}) \mathrm{H})(\mathrm{Cl}) \mathrm{H})(\mathrm{F})(\mathrm{F}) \mathrm{H}$ $\mathrm{C}(\mathrm{C}(\mathrm{C}(\mathrm{C}(\mathrm{C}(\mathrm{C}(\mathrm{C}(\mathrm{C}(\mathrm{C}(\mathrm{C}(\mathrm{Br})(\mathrm{H}) \mathrm{F})(\mathrm{Br}) \mathrm{Br})(\mathrm{H}) \mathrm{Cl})(\mathrm{F}) \mathrm{H})(\mathrm{Cl}) \mathrm{H})(\mathrm{H}) \mathrm{H})(\mathrm{F}) \mathrm{Cl})(\mathrm{H}) \mathrm{F})(\mathrm{F}) \mathrm{Cl})(\mathrm{Br})(\mathrm{Cl}) \mathrm{H}$ $\mathrm{C}(\mathrm{C}(\mathrm{C}(\mathrm{C}(\mathrm{C}(\mathrm{C}(\mathrm{C}(\mathrm{C}(\mathrm{C}(\mathrm{C}(\mathrm{F})(\mathrm{H}) \mathrm{F})(\mathrm{F}) \mathrm{Cl})(\mathrm{F}) \mathrm{Br})(\mathrm{H}) \mathrm{H})(\mathrm{H}) \mathrm{Cl})(\mathrm{Cl}) \mathrm{H})(\mathrm{H}) \mathrm{H})(\mathrm{Cl}) \mathrm{F})(\mathrm{F}) \mathrm{H})(\mathrm{F})(\mathrm{Cl}) \mathrm{Cl}$ $\mathrm{C}(\mathrm{C}(\mathrm{C}(\mathrm{C}(\mathrm{C}(\mathrm{C}(\mathrm{C}(\mathrm{C}(\mathrm{C}(\mathrm{C}(\mathrm{Cl})(\mathrm{Cl}) \mathrm{H})(\mathrm{Cl}) \mathrm{F})(\mathrm{H}) \mathrm{Br})(\mathrm{F}) \mathrm{F})(\mathrm{Cl}) \mathrm{F})(\mathrm{H}) \mathrm{Cl})(\mathrm{H}) \mathrm{H})(\mathrm{H}) \mathrm{Cl})(\mathrm{F}) \mathrm{H})(\mathrm{Cl})(\mathrm{H}) \mathrm{F}$ $\mathrm{C}(\mathrm{C}(\mathrm{C}(\mathrm{C}(\mathrm{C}(\mathrm{C}(\mathrm{C}(\mathrm{C}(\mathrm{C}(\mathrm{C}(\mathrm{Cl})(\mathrm{F}) \mathrm{F})(\mathrm{H}) \mathrm{Cl})(\mathrm{Cl}) \mathrm{Cl})(\mathrm{H}) \mathrm{F})(\mathrm{H}) \mathrm{H})(\mathrm{Cl}) \mathrm{Cl})(\mathrm{H}) \mathrm{Cl})(\mathrm{Br}) \mathrm{H})(\mathrm{Cl}) \mathrm{H})(\mathrm{F})(\mathrm{Cl}) \mathrm{H}$ $\mathrm{C}(\mathrm{C}(\mathrm{C}(\mathrm{C}(\mathrm{C}(\mathrm{C}(\mathrm{C}(\mathrm{C}(\mathrm{C}(\mathrm{C}(\mathrm{F})(\mathrm{H}) \mathrm{F})(\mathrm{H}) \mathrm{H})(\mathrm{Cl}) \mathrm{H})(\mathrm{Cl}) \mathrm{Cl})(\mathrm{F}) \mathrm{H})(\mathrm{Cl}) \mathrm{H})(\mathrm{Cl}) \mathrm{Cl})(\mathrm{Cl}) \mathrm{F})(\mathrm{Cl}) \mathrm{H})(\mathrm{Cl})(\mathrm{H}) \mathrm{F}$ $\mathrm{C}(\mathrm{C}(\mathrm{C}(\mathrm{C}(\mathrm{C}(\mathrm{C}(\mathrm{C}(\mathrm{C}(\mathrm{C}(\mathrm{C}(\mathrm{F})(\mathrm{F}) \mathrm{F})(\mathrm{F}) \mathrm{H})(\mathrm{Br}) \mathrm{H})(\mathrm{H}) \mathrm{H})(\mathrm{F}) \mathrm{H})(\mathrm{H}) \mathrm{H})(\mathrm{F}) \mathrm{Cl})(\mathrm{Br}) \mathrm{F})(\mathrm{Br}) \mathrm{F})(\mathrm{Br})(\mathrm{H}) \mathrm{F}$ $\mathrm{C}(\mathrm{C}(\mathrm{C}(\mathrm{C}(\mathrm{C}(\mathrm{C}(\mathrm{C}(\mathrm{C}(\mathrm{C}(\mathrm{C}(\mathrm{F})(\mathrm{Br}) \mathrm{F})(\mathrm{H}) \mathrm{Br})(\mathrm{H}) \mathrm{F})(\mathrm{H}) \mathrm{H})(\mathrm{Br}) \mathrm{H})(\mathrm{F}) \mathrm{Br})(\mathrm{Br}) \mathrm{H})(\mathrm{H}) \mathrm{F})(\mathrm{F}) \mathrm{F})(\mathrm{F})(\mathrm{H}) \mathrm{Cl}$ $\mathrm{C}(\mathrm{C}(\mathrm{C}(\mathrm{C}(\mathrm{C}(\mathrm{C}(\mathrm{C}(\mathrm{C}(\mathrm{C}(\mathrm{C}(\mathrm{H})(\mathrm{H}) \mathrm{Br})(\mathrm{F}) \mathrm{H})(\mathrm{Br}) \mathrm{F})(\mathrm{F}) \mathrm{H})(\mathrm{H}) \mathrm{F})(\mathrm{F}) \mathrm{F})(\mathrm{Br}) \mathrm{Br})(\mathrm{Br}) \mathrm{H})(\mathrm{F}) \mathrm{H})(\mathrm{H})(\mathrm{Br}) \mathrm{H}$ $\mathrm{C}(\mathrm{C}(\mathrm{C}(\mathrm{C}(\mathrm{C}(\mathrm{C}(\mathrm{C}(\mathrm{C}(\mathrm{C}(\mathrm{C}(\mathrm{Cl})(\mathrm{H}) \mathrm{H})(\mathrm{Cl}) \mathrm{H})(\mathrm{F}) \mathrm{H})(\mathrm{Cl}) \mathrm{H})(\mathrm{H}) \mathrm{Cl})(\mathrm{H}) \mathrm{Cl})(\mathrm{Cl}) \mathrm{Cl})(\mathrm{Cl}) \mathrm{H})(\mathrm{Br}) \mathrm{Cl})(\mathrm{F})(\mathrm{H}) \mathrm{Cl}$ $\mathrm{C}(\mathrm{C}(\mathrm{C}(\mathrm{C}(\mathrm{C}(\mathrm{C}(\mathrm{C}(\mathrm{C}(\mathrm{C}(\mathrm{C}(\mathrm{Br})(\mathrm{H}) \mathrm{H})(\mathrm{Cl}) \mathrm{Br})(\mathrm{F}) \mathrm{H})(\mathrm{Cl}) \mathrm{F})(\mathrm{H}) \mathrm{H})(\mathrm{F}) \mathrm{F})(\mathrm{H}) \mathrm{Br})(\mathrm{H}) \mathrm{H})(\mathrm{Br}) \mathrm{H})(\mathrm{F})(\mathrm{F}) \mathrm{F}$ $\mathrm{C}(\mathrm{C}(\mathrm{C}(\mathrm{C}(\mathrm{C}(\mathrm{C}(\mathrm{C}(\mathrm{C}(\mathrm{C}(\mathrm{C}(\mathrm{H})(\mathrm{Br}) \mathrm{H})(\mathrm{F}) \mathrm{F})(\mathrm{F}) \mathrm{H})(\mathrm{F}) \mathrm{H})(\mathrm{Br}) \mathrm{H})(\mathrm{Cl}) \mathrm{H})(\mathrm{H}) \mathrm{Br})(\mathrm{Br}) \mathrm{H})(\mathrm{Br}) \mathrm{F})(\mathrm{H})(\mathrm{F}) \mathrm{Cl}$ $\mathrm{C}(\mathrm{C}(\mathrm{C}(\mathrm{C}(\mathrm{C}(\mathrm{C}(\mathrm{C}(\mathrm{C}(\mathrm{C}(\mathrm{C}(\mathrm{F})(\mathrm{H}) \mathrm{H})(\mathrm{H}) \mathrm{Cl})(\mathrm{Br}) \mathrm{F})(\mathrm{F}) \mathrm{H})(\mathrm{Br}) \mathrm{Br})(\mathrm{Br}) \mathrm{H})(\mathrm{H}) \mathrm{Br})(\mathrm{H}) \mathrm{H})(\mathrm{F}) \mathrm{H})(\mathrm{Br})(\mathrm{Cl}) \mathrm{F}$ $\mathrm{C}(\mathrm{C}(\mathrm{C}(\mathrm{C}(\mathrm{C}(\mathrm{C}(\mathrm{C}(\mathrm{C}(\mathrm{C}(\mathrm{C}(\mathrm{F})(\mathrm{Cl}) \mathrm{F})(\mathrm{F}) \mathrm{H})(\mathrm{F}) \mathrm{H})(\mathrm{Cl}) \mathrm{Cl})(\mathrm{F}) \mathrm{H})(\mathrm{Br}) \mathrm{H})(\mathrm{Br}) \mathrm{Br})(\mathrm{H}) \mathrm{H})(\mathrm{F}) \mathrm{F})(\mathrm{H})(\mathrm{H}) \mathrm{H}$ $\mathrm{C}(\mathrm{C}(\mathrm{C}(\mathrm{C}(\mathrm{C}(\mathrm{C}(\mathrm{C}(\mathrm{C}(\mathrm{C}(\mathrm{C}(\mathrm{F})(\mathrm{H}) \mathrm{Br})(\mathrm{Cl}) \mathrm{H})(\mathrm{Cl}) \mathrm{H})(\mathrm{Cl}) \mathrm{Br})(\mathrm{F}) \mathrm{H})(\mathrm{H}) \mathrm{H})(\mathrm{H}) \mathrm{Br})(\mathrm{H}) \mathrm{Br})(\mathrm{F}) \mathrm{F})(\mathrm{F})(\mathrm{H}) \mathrm{F}$ $\mathrm{C}(\mathrm{C}(\mathrm{C}(\mathrm{C}(\mathrm{C}(\mathrm{C}(\mathrm{C}(\mathrm{C}(\mathrm{C}(\mathrm{C}(\mathrm{F})(\mathrm{Br}) \mathrm{H})(\mathrm{H}) \mathrm{H})(\mathrm{Cl}) \mathrm{Cl})(\mathrm{H}) \mathrm{Br})(\mathrm{F}) \mathrm{Cl})(\mathrm{F}) \mathrm{F})(\mathrm{F}) \mathrm{H})(\mathrm{H}) \mathrm{H})(\mathrm{F}) \mathrm{H})(\mathrm{F})(\mathrm{H}) \mathrm{Cl}$ $\mathrm{C}(\mathrm{C}(\mathrm{C}(\mathrm{C}(\mathrm{C}(\mathrm{C}(\mathrm{C}(\mathrm{C}(\mathrm{C}(\mathrm{C}(\mathrm{F})(\mathrm{Cl}) \mathrm{F})(\mathrm{F}) \mathrm{H})(\mathrm{H}) \mathrm{Br})(\mathrm{H}) \mathrm{Br})(\mathrm{Cl}) \mathrm{F})(\mathrm{Br}) \mathrm{Cl})(\mathrm{H}) \mathrm{H})(\mathrm{H}) \mathrm{F})(\mathrm{F}) \mathrm{H})(\mathrm{H})(\mathrm{H}) \mathrm{Cl}$ $\mathrm{C}(\mathrm{C}(\mathrm{C}(\mathrm{C}(\mathrm{C}(\mathrm{C}(\mathrm{C}(\mathrm{C}(\mathrm{C}(\mathrm{C}(\mathrm{H})(\mathrm{Br}) \mathrm{Br})(\mathrm{H}) \mathrm{F})(\mathrm{H}) \mathrm{H})(\mathrm{H}) \mathrm{F})(\mathrm{F}) \mathrm{Cl})(\mathrm{Cl}) \mathrm{F})(\mathrm{Br}) \mathrm{F})(\mathrm{H}) \mathrm{H})(\mathrm{H}) \mathrm{Cl})(\mathrm{H})(\mathrm{Br}) \mathrm{Cl}$ $\mathrm{C}(\mathrm{C}(\mathrm{C}(\mathrm{C}(\mathrm{C}(\mathrm{C}(\mathrm{C}(\mathrm{C}(\mathrm{C}(\mathrm{C}(\mathrm{H})(\mathrm{F}) \mathrm{F})(\mathrm{H}) \mathrm{Br})(\mathrm{F}) \mathrm{H})(\mathrm{Br}) \mathrm{H})(\mathrm{Cl}) \mathrm{H})(\mathrm{Br}) \mathrm{Cl})(\mathrm{H}) \mathrm{F})(\mathrm{Cl}) \mathrm{H})(\mathrm{H}) \mathrm{H})(\mathrm{Cl})(\mathrm{Br}) \mathrm{B}$ $\mathrm{C}(\mathrm{C}(\mathrm{C}(\mathrm{C}(\mathrm{C}(\mathrm{C}(\mathrm{C}(\mathrm{C}(\mathrm{C}(\mathrm{C}(\mathrm{H})(\mathrm{H}) \mathrm{H})(\mathrm{F}) \mathrm{H})(\mathrm{F}) \mathrm{F})(\mathrm{F}) \mathrm{Cl})(\mathrm{Cl}) \mathrm{H})(\mathrm{H}) \mathrm{F})(\mathrm{H}) \mathrm{Cl})(\mathrm{Br}) \mathrm{H})(\mathrm{F}) \mathrm{Cl})(\mathrm{Cl})(\mathrm{H}) \mathrm{Br}$ $\mathrm{C}(\mathrm{C}(\mathrm{C}(\mathrm{C}(\mathrm{C}(\mathrm{C}(\mathrm{C}(\mathrm{C}(\mathrm{C}(\mathrm{C}(\mathrm{Br})(\mathrm{F}) \mathrm{H})(\mathrm{Cl}) \mathrm{H})(\mathrm{H}) \mathrm{H})(\mathrm{H}) \mathrm{F})(\mathrm{F}) \mathrm{Cl})(\mathrm{H}) \mathrm{Cl})(\mathrm{H}) \mathrm{F})(\mathrm{H}) \mathrm{F})(\mathrm{Cl}) \mathrm{Br})(\mathrm{Cl})(\mathrm{H}) \mathrm{Br}$ $\mathrm{C}(\mathrm{C}(\mathrm{C}(\mathrm{C}(\mathrm{C}(\mathrm{C}(\mathrm{C}(\mathrm{C}(\mathrm{C}(\mathrm{C}(\mathrm{F})(\mathrm{H}) \mathrm{Cl})(\mathrm{H}) \mathrm{F})(\mathrm{F}) \mathrm{Cl})(\mathrm{H}) \mathrm{H})(\mathrm{H}) \mathrm{H})(\mathrm{F}) \mathrm{F})(\mathrm{H}) \mathrm{Cl})(\mathrm{Cl}) \mathrm{Br})(\mathrm{H}) \mathrm{F})(\mathrm{Cl})(\mathrm{Cl}) \mathrm{H}$ $\mathrm{C}(\mathrm{C}(\mathrm{C}(\mathrm{C}(\mathrm{C}(\mathrm{C}(\mathrm{C}(\mathrm{C}(\mathrm{C}(\mathrm{C}(\mathrm{Br})(\mathrm{Cl}) \mathrm{F})(\mathrm{H}) \mathrm{Cl})(\mathrm{Cl}) \mathrm{Cl})(\mathrm{H}) \mathrm{H})(\mathrm{H}) \mathrm{Cl})(\mathrm{H}) \mathrm{F})(\mathrm{Cl}) \mathrm{F})(\mathrm{H}) \mathrm{H})(\mathrm{Cl}) \mathrm{H})(\mathrm{H})(\mathrm{Br}) \mathrm{F}$ $\mathrm{C}(\mathrm{C}(\mathrm{C}(\mathrm{C}(\mathrm{C}(\mathrm{C}(\mathrm{C}(\mathrm{C}(\mathrm{C}(\mathrm{C}(\mathrm{H})(\mathrm{Cl}) \mathrm{F})(\mathrm{Cl}) \mathrm{Cl})(\mathrm{H}) \mathrm{H})(\mathrm{Cl}) \mathrm{F})(\mathrm{H}) \mathrm{Cl})(\mathrm{H}) \mathrm{H})(\mathrm{H}) \mathrm{Br})(\mathrm{F}) \mathrm{H})(\mathrm{F}) \mathrm{F})(\mathrm{Cl})(\mathrm{H}) \mathrm{Cl}$ $\mathrm{C}(\mathrm{C}(\mathrm{C}(\mathrm{C}(\mathrm{C}(\mathrm{C}(\mathrm{C}(\mathrm{C}(\mathrm{C}(\mathrm{C}(\mathrm{H})(\mathrm{H}) \mathrm{H})(\mathrm{F}) \mathrm{Cl})(\mathrm{Cl}) \mathrm{H})(\mathrm{F}) \mathrm{Cl})(\mathrm{H}) \mathrm{H})(\mathrm{F}) \mathrm{F})(\mathrm{Cl}) \mathrm{Cl})(\mathrm{F}) \mathrm{H})(\mathrm{H}) \mathrm{Cl})(\mathrm{Cl})(\mathrm{F}) \mathrm{H}$ $\mathrm{C}(\mathrm{C}(\mathrm{C}(\mathrm{C}(\mathrm{C}(\mathrm{C}(\mathrm{C}(\mathrm{C}(\mathrm{C}(\mathrm{C}(\mathrm{Cl})(\mathrm{H}) \mathrm{H})(\mathrm{H}) \mathrm{F})(\mathrm{H}) \mathrm{Cl})(\mathrm{Cl}) \mathrm{Cl})(\mathrm{F}) \mathrm{F})(\mathrm{Cl}) \mathrm{Cl})(\mathrm{H}) \mathrm{H})(\mathrm{F}) \mathrm{H})(\mathrm{H}) \mathrm{F})(\mathrm{H})(\mathrm{Cl}) \mathrm{Cl}$ $\mathrm{C}(\mathrm{C}(\mathrm{C}(\mathrm{C}(\mathrm{C}(\mathrm{C}(\mathrm{C}(\mathrm{C}(\mathrm{C}(\mathrm{C}(\mathrm{Cl})(\mathrm{H}) \mathrm{H})(\mathrm{Cl}) \mathrm{Br})(\mathrm{Cl}) \mathrm{H})(\mathrm{H}) \mathrm{Cl})(\mathrm{H}) \mathrm{Cl})(\mathrm{Br}) \mathrm{H})(\mathrm{Cl}) \mathrm{H})(\mathrm{Cl}) \mathrm{F})(\mathrm{Cl}) \mathrm{H})(\mathrm{F})(\mathrm{Cl}) \mathrm{H}$ $\mathrm{C}(\mathrm{C}(\mathrm{C}(\mathrm{C}(\mathrm{C}(\mathrm{C}(\mathrm{C}(\mathrm{C}(\mathrm{C}(\mathrm{C}(\mathrm{H})(\mathrm{F}) \mathrm{F})(\mathrm{Br}) \mathrm{F})(\mathrm{F}) \mathrm{H})(\mathrm{H}) \mathrm{H})(\mathrm{F}) \mathrm{Br})(\mathrm{Br}) \mathrm{Cl})(\mathrm{H}) \mathrm{F})(\mathrm{H}) \mathrm{H})(\mathrm{F}) \mathrm{H})(\mathrm{Br})(\mathrm{F}) \mathrm{H}$ $\mathrm{C}(\mathrm{C}(\mathrm{C}(\mathrm{C}(\mathrm{C}(\mathrm{C}(\mathrm{C}(\mathrm{C}(\mathrm{C}(\mathrm{C}(\mathrm{H})(\mathrm{Br}) \mathrm{F})(\mathrm{H}) \mathrm{Br})(\mathrm{Cl}) \mathrm{F})(\mathrm{H}) \mathrm{Br})(\mathrm{F}) \mathrm{F})(\mathrm{Br}) \mathrm{H})(\mathrm{H}) \mathrm{H})(\mathrm{F}) \mathrm{Br})(\mathrm{H}) \mathrm{F})(\mathrm{F})(\mathrm{H}) \mathrm{H}$ $\mathrm{C}(\mathrm{C}(\mathrm{C}(\mathrm{C}(\mathrm{C}(\mathrm{C}(\mathrm{C}(\mathrm{C}(\mathrm{C}(\mathrm{C}(\mathrm{F})(\mathrm{Br}) \mathrm{Br})(\mathrm{H}) \mathrm{H})(\mathrm{H}) \mathrm{H})(\mathrm{H}) \mathrm{Br})(\mathrm{Br}) \mathrm{H})(\mathrm{Cl}) \mathrm{F})(\mathrm{F}) \mathrm{H})(\mathrm{Br}) \mathrm{F})(\mathrm{F}) \mathrm{H})(\mathrm{Br})(\mathrm{H}) \mathrm{F}$ $\mathrm{C}(\mathrm{C}(\mathrm{C}(\mathrm{C}(\mathrm{C}(\mathrm{C}(\mathrm{C}(\mathrm{C}(\mathrm{C}(\mathrm{C}(\mathrm{C}(\mathrm{F})(\mathrm{F}) \mathrm{H})(\mathrm{F}) \mathrm{F})(\mathrm{H}) \mathrm{Br})(\mathrm{Br}) \mathrm{H})(\mathrm{F}) \mathrm{Br})(\mathrm{H}) \mathrm{H})(\mathrm{F}) \mathrm{H})(\mathrm{H}) \mathrm{H})(\mathrm{F}) \mathrm{F})(\mathrm{H}) \mathrm{F})(\mathrm{H})(\mathrm{Br}) \mathrm{Br}$ $\mathrm{C}(\mathrm{C}(\mathrm{C}(\mathrm{C}(\mathrm{C}(\mathrm{C}(\mathrm{C}(\mathrm{C}(\mathrm{C}(\mathrm{C}(\mathrm{C}(\mathrm{H})(\mathrm{H}) \mathrm{F})(\mathrm{H}) \mathrm{F})(\mathrm{Br}) \mathrm{F})(\mathrm{H}) \mathrm{Br})(\mathrm{Br}) \mathrm{H})(\mathrm{H}) \mathrm{H})(\mathrm{Br}) \mathrm{F})(\mathrm{Br}) \mathrm{Cl})(\mathrm{Cl}) \mathrm{H})(\mathrm{F}) \mathrm{H})(\mathrm{H})(\mathrm{F}) \mathrm{F}$ $\mathrm{C}(\mathrm{C}(\mathrm{C}(\mathrm{C}(\mathrm{C}(\mathrm{C}(\mathrm{C}(\mathrm{C}(\mathrm{C}(\mathrm{C}(\mathrm{C}(\mathrm{Cl})(\mathrm{H}) \mathrm{H})(\mathrm{F}) \mathrm{H})(\mathrm{F}) \mathrm{H})(\mathrm{H}) \mathrm{F})(\mathrm{Br}) \mathrm{Br})(\mathrm{H}) \mathrm{F})(\mathrm{Br}) \mathrm{Cl})(\mathrm{H}) \mathrm{F})(\mathrm{H}) \mathrm{F})(\mathrm{Cl}) \mathrm{H})(\mathrm{H})(\mathrm{F}) \mathrm{F}$ $\mathrm{C}(\mathrm{C}(\mathrm{C}(\mathrm{C}(\mathrm{C}(\mathrm{C}(\mathrm{C}(\mathrm{C}(\mathrm{C}(\mathrm{C}(\mathrm{C}(\mathrm{H})(\mathrm{H}) \mathrm{Cl})(\mathrm{H}) \mathrm{Br})(\mathrm{H}) \mathrm{F})(\mathrm{F}) \mathrm{F})(\mathrm{H}) \mathrm{F})(\mathrm{Cl}) \mathrm{H})(\mathrm{F}) \mathrm{H})(\mathrm{H}) \mathrm{F})(\mathrm{Br}) \mathrm{Cl})(\mathrm{F}) \mathrm{H})(\mathrm{H})(\mathrm{Br}) \mathrm{Cl}$ $\mathrm{C}(\mathrm{C}(\mathrm{C}(\mathrm{C}(\mathrm{C}(\mathrm{C}(\mathrm{C}(\mathrm{C}(\mathrm{C}(\mathrm{C}(\mathrm{C}(\mathrm{Cl})(\mathrm{F}) \mathrm{H})(\mathrm{F}) \mathrm{Cl})(\mathrm{H}) \mathrm{F})(\mathrm{Br}) \mathrm{F})(\mathrm{H}) \mathrm{H})(\mathrm{Cl}) \mathrm{H})(\mathrm{F}) \mathrm{H})(\mathrm{Cl}) \mathrm{H})(\mathrm{Cl}) \mathrm{F})(\mathrm{H}) \mathrm{F})(\mathrm{H})(\mathrm{H}) \mathrm{Br}$ $\mathrm{C}(\mathrm{C}(\mathrm{C}(\mathrm{C}(\mathrm{C}(\mathrm{C}(\mathrm{C}(\mathrm{C}(\mathrm{C}(\mathrm{C}(\mathrm{C}(\mathrm{H})(\mathrm{F}) \mathrm{Cl})(\mathrm{F}) \mathrm{H})(\mathrm{F}) \mathrm{H})(\mathrm{Cl}) \mathrm{H})(\mathrm{Br}) \mathrm{H})(\mathrm{F}) \mathrm{Cl})(\mathrm{F}) \mathrm{Cl})(\mathrm{H}) \mathrm{H})(\mathrm{H}) \mathrm{Cl})(\mathrm{Br}) \mathrm{H})(\mathrm{Br})(\mathrm{H}) \mathrm{F}$ $\mathrm{C}(\mathrm{C}(\mathrm{C}(\mathrm{C}(\mathrm{C}(\mathrm{C}(\mathrm{C}(\mathrm{C}(\mathrm{C}(\mathrm{C}(\mathrm{C}(\mathrm{H})(\mathrm{Cl}) \mathrm{Cl})(\mathrm{Cl}) \mathrm{H})(\mathrm{H}) \mathrm{F})(\mathrm{F}) \mathrm{Cl})(\mathrm{Br}) \mathrm{F})(\mathrm{F}) \mathrm{H})(\mathrm{H}) \mathrm{H})(\mathrm{Br}) \mathrm{F})(\mathrm{H}) \mathrm{H})(\mathrm{Cl}) \mathrm{H})(\mathrm{Cl})(\mathrm{H}) \mathrm{F}$ $\mathrm{C}(\mathrm{C}(\mathrm{C}(\mathrm{C}(\mathrm{C}(\mathrm{C}(\mathrm{C}(\mathrm{C}(\mathrm{C}(\mathrm{C}(\mathrm{C}(\mathrm{F})(\mathrm{F}) \mathrm{Cl})(\mathrm{H}) \mathrm{F})(\mathrm{H}) \mathrm{H})(\mathrm{Cl}) \mathrm{H})(\mathrm{F}) \mathrm{H})(\mathrm{H}) \mathrm{Cl})(\mathrm{H}) \mathrm{H})(\mathrm{F}) \mathrm{F})(\mathrm{Cl}) \mathrm{H})(\mathrm{Cl}) \mathrm{Cl})(\mathrm{Br})(\mathrm{Cl}) \mathrm{H}$ $\mathrm{C}(\mathrm{C}(\mathrm{C}(\mathrm{C}(\mathrm{C}(\mathrm{C}(\mathrm{C}(\mathrm{C}(\mathrm{C}(\mathrm{C}(\mathrm{C}(\mathrm{F})(\mathrm{H}) \mathrm{Cl})(\mathrm{H}) \mathrm{Cl})(\mathrm{Cl}) \mathrm{H})(\mathrm{Cl}) \mathrm{H})(\mathrm{F}) \mathrm{F})(\mathrm{H}) \mathrm{Cl})(\mathrm{H}) \mathrm{Cl})(\mathrm{F}) \mathrm{H})(\mathrm{Cl}) \mathrm{Cl})(\mathrm{H}) \mathrm{Cl})(\mathrm{H})(\mathrm{F}) \mathrm{H}$ $\mathrm{C}(\mathrm{C}(\mathrm{C}(\mathrm{C}(\mathrm{C}(\mathrm{C}(\mathrm{C}(\mathrm{C}(\mathrm{C}(\mathrm{C}(\mathrm{C}(\mathrm{F})(\mathrm{Br}) \mathrm{Br})(\mathrm{H}) \mathrm{H})(\mathrm{Cl}) \mathrm{F})(\mathrm{F}) \mathrm{H})(\mathrm{H}) \mathrm{F})(\mathrm{F}) \mathrm{H})(\mathrm{Br}) \mathrm{F})(\mathrm{H}) \mathrm{F})(\mathrm{F}) \mathrm{Br})(\mathrm{F}) \mathrm{H})(\mathrm{H})(\mathrm{H}) \mathrm{H}$ $\mathrm{C}(\mathrm{C}(\mathrm{C}(\mathrm{C}(\mathrm{C}(\mathrm{C}(\mathrm{C}(\mathrm{C}(\mathrm{C}(\mathrm{C}(\mathrm{C}(\mathrm{Cl})(\mathrm{H}) \mathrm{H})(\mathrm{Br}) \mathrm{H})(\mathrm{H}) \mathrm{Br})(\mathrm{F}) \mathrm{H})(\mathrm{H}) \mathrm{F})(\mathrm{F}) \mathrm{F})(\mathrm{H}) \mathrm{H})(\mathrm{F}) \mathrm{H})(\mathrm{F}) \mathrm{Br})(\mathrm{H}) \mathrm{Br})(\mathrm{F})(\mathrm{F}) \mathrm{B}$ $\mathrm{C}(\mathrm{C}(\mathrm{C}(\mathrm{C}(\mathrm{C}(\mathrm{C}(\mathrm{C}(\mathrm{C}(\mathrm{C}(\mathrm{C}(\mathrm{C}(\mathrm{Br})(\mathrm{Br}) \mathrm{H})(\mathrm{H}) \mathrm{H})(\mathrm{H}) \mathrm{H})(\mathrm{F}) \mathrm{H})(\mathrm{F}) \mathrm{H})(\mathrm{H}) \mathrm{H})(\mathrm{Br}) \mathrm{H})(\mathrm{H}) \mathrm{F})(\mathrm{Br}) \mathrm{F})(\mathrm{F}) \mathrm{F})(\mathrm{F})(\mathrm{Br}) \mathrm{F}$ $\mathrm{C}(\mathrm{C}(\mathrm{C}(\mathrm{C}(\mathrm{C}(\mathrm{C}(\mathrm{C}(\mathrm{C}(\mathrm{C}(\mathrm{C}(\mathrm{C}(\mathrm{H})(\mathrm{Cl}) \mathrm{Cl})(\mathrm{H}) \mathrm{Cl})(\mathrm{H}) \mathrm{H})(\mathrm{H}) \mathrm{Cl})(\mathrm{Cl}) \mathrm{H})(\mathrm{F}) \mathrm{Cl})(\mathrm{H}) \mathrm{F})(\mathrm{Cl}) \mathrm{H})(\mathrm{Cl}) \mathrm{H})(\mathrm{Cl}) \mathrm{H})(\mathrm{F})(\mathrm{H}) \mathrm{Cl}$ $\mathrm{C}(\mathrm{C}(\mathrm{C}(\mathrm{C}(\mathrm{C}(\mathrm{C}(\mathrm{C}(\mathrm{C}(\mathrm{C}(\mathrm{C}(\mathrm{C}(\mathrm{Cl})(\mathrm{Cl}) \mathrm{H})(\mathrm{H}) \mathrm{Cl})(\mathrm{H}) \mathrm{Cl})(\mathrm{Cl}) \mathrm{H})(\mathrm{H}) \mathrm{Cl})(\mathrm{F}) \mathrm{H})(\mathrm{Cl}) \mathrm{H})(\mathrm{Cl}) \mathrm{H})(\mathrm{H}) \mathrm{H})(\mathrm{Cl}) \mathrm{Cl})(\mathrm{Cl})(\mathrm{F}) \mathrm{H}$ $\mathrm{C}(\mathrm{C}(\mathrm{C}(\mathrm{C}(\mathrm{C}(\mathrm{C}(\mathrm{C}(\mathrm{C}(\mathrm{C}(\mathrm{C}(\mathrm{C}(\mathrm{F})(\mathrm{H}) \mathrm{F})(\mathrm{H}) \mathrm{H})(\mathrm{Br}) \mathrm{H})(\mathrm{Cl}) \mathrm{H})(\mathrm{F}) \mathrm{H})(\mathrm{F}) \mathrm{Br})(\mathrm{F}) \mathrm{F})(\mathrm{Br}) \mathrm{H})(\mathrm{H}) \mathrm{F})(\mathrm{H}) \mathrm{Br})(\mathrm{Cl})(\mathrm{H}) \mathrm{H}$ $\mathrm{C}(\mathrm{C}(\mathrm{C}(\mathrm{C}(\mathrm{C}(\mathrm{C}(\mathrm{C}(\mathrm{C}(\mathrm{C}(\mathrm{C}(\mathrm{C}(\mathrm{H})(\mathrm{Cl}) \mathrm{Cl})(\mathrm{H}) \mathrm{F})(\mathrm{H}) \mathrm{H})(\mathrm{F}) \mathrm{H})(\mathrm{H}) \mathrm{F})(\mathrm{H}) \mathrm{H})(\mathrm{H}) \mathrm{F})(\mathrm{Br}) \mathrm{F})(\mathrm{Cl}) \mathrm{F})(\mathrm{F}) \mathrm{Br})(\mathrm{H})(\mathrm{Br}) \mathrm{H}$ $\mathrm{C}(\mathrm{C}(\mathrm{C}(\mathrm{C}(\mathrm{C}(\mathrm{C}(\mathrm{C}(\mathrm{C}(\mathrm{C}(\mathrm{C}(\mathrm{C}(\mathrm{F})(\mathrm{F}) \mathrm{Br})(\mathrm{Br}) \mathrm{Br})(\mathrm{H}) \mathrm{H})(\mathrm{H}) \mathrm{H})(\mathrm{H}) \mathrm{H})(\mathrm{F}) \mathrm{F})(\mathrm{Br}) \mathrm{H})(\mathrm{F}) \mathrm{H})(\mathrm{Cl}) \mathrm{H})(\mathrm{F}) \mathrm{H})(\mathrm{Cl})(\mathrm{Cl}) \mathrm{H}$ $\mathrm{C}(\mathrm{C}(\mathrm{C}(\mathrm{C}(\mathrm{C}(\mathrm{C}(\mathrm{C}(\mathrm{C}(\mathrm{C}(\mathrm{C}(\mathrm{C}(\mathrm{F})(\mathrm{H}) \mathrm{Cl})(\mathrm{H}) \mathrm{Br})(\mathrm{F}) \mathrm{H})(\mathrm{H}) \mathrm{H})(\mathrm{Cl}) \mathrm{H})(\mathrm{H}) \mathrm{Br})(\mathrm{H}) \mathrm{Br})(\mathrm{Br}) \mathrm{F})(\mathrm{Cl}) \mathrm{H})(\mathrm{H}) \mathrm{Br})(\mathrm{Br})(\mathrm{H}) \mathrm{F}$ $\mathrm{C}(\mathrm{C}(\mathrm{C}(\mathrm{C}(\mathrm{C}(\mathrm{C}(\mathrm{C}(\mathrm{C}(\mathrm{C}(\mathrm{C}(\mathrm{C}(\mathrm{Cl})(\mathrm{H}) \mathrm{Br})(\mathrm{H}) \mathrm{Cl})(\mathrm{Cl}) \mathrm{F})(\mathrm{H}) \mathrm{Br})(\mathrm{F}) \mathrm{H})(\mathrm{F}) \mathrm{Cl})(\mathrm{H}) \mathrm{H})(\mathrm{H}) \mathrm{F})(\mathrm{F}) \mathrm{H})(\mathrm{F}) \mathrm{H})(\mathrm{F})(\mathrm{H}) \mathrm{H}$ $\mathrm{C}(\mathrm{C}(\mathrm{C}(\mathrm{C}(\mathrm{C}(\mathrm{C}(\mathrm{C}(\mathrm{C}(\mathrm{C}(\mathrm{C}(\mathrm{C}(\mathrm{Br})(\mathrm{H}) \mathrm{H})(\mathrm{Cl}) \mathrm{H})(\mathrm{F}) \mathrm{H})(\mathrm{Br}) \mathrm{H})(\mathrm{Br}) \mathrm{F})(\mathrm{H}) \mathrm{Cl})(\mathrm{H}) \mathrm{F})(\mathrm{F}) \mathrm{H})(\mathrm{H}) \mathrm{F})(\mathrm{H}) \mathrm{H})(\mathrm{Cl})(\mathrm{Cl}) \mathrm{F}$
Formula

lgKoa lgKow lgKaw lgKow lgKoa lgKaw lgKow lgKoa lgKaw EPI_EPI_EPI_Exp__Exp__Exp__DFT_DFT_DFT Suite Suite Suite corr corr corr_corr_corr corr $\begin{array}{lccccccccc}\mathrm{C} 10 \mathrm{H} 16 \mathrm{ClBr} 3 \mathrm{~F} 2 & 7.88 & 6.79 & -1.09 & 5.21 & 6.29 & -1.09 & 5.98 & 12.48 & -6.50\end{array}$ $\begin{array}{llllllllll}\mathrm{C} 10 \mathrm{H} 16 \mathrm{ClBr} 4 \mathrm{~F} & 9.51 & 7.19 & -2.32 & 5.81 & 8.13 & -2.32 & 6.28 & 15.48 & -9.20\end{array}$ $\begin{array}{llllllllll}\mathrm{C} 10 \mathrm{H} 16 \mathrm{ClBr} 5 & 11.2 & 7.6 & -3.56 & 6.42 & 9.98 & -3.56 & 6.60 & 18.51 & -11.9\end{array}$ $\begin{array}{llllllllll}\mathrm{C} 10 \mathrm{H} 17 \mathrm{Br} 4 \mathrm{~F} & 8.81 & 6.94 & -1.87 & 5.43 & 7.30 & -1.87 & 6.09 & 14.19 & -8.10\end{array}$ $\mathrm{C} 10 \mathrm{H} 17 \mathrm{Br}$ $\mathrm{C} 10 \mathrm{H} 17 \mathrm{Cl} 2 \mathrm{Br} 3$ $\mathrm{C} 10 \mathrm{H} 17 \mathrm{Cl} 3 \mathrm{Br} 2$ $\mathrm{C} 10 \mathrm{H} 17 \mathrm{Cl} 5$ $\mathrm{C} 10 \mathrm{H} 17 \mathrm{ClBr} 3 \mathrm{~F}$ $\mathrm{C} 10 \mathrm{H} 17 \mathrm{ClBr} 4$ $\mathrm{C} 10 \mathrm{H} 18 \mathrm{Br} 4$ $\mathrm{C} 10 \mathrm{H} 18 \mathrm{ClBr} 3$

$\mathrm{C} 10 \mathrm{H} 6 \mathrm{Br} 5 \mathrm{~F} 11$

$\mathrm{C} 10 \mathrm{H} 6 \mathrm{Cl} 2 \mathrm{Br} 5 \mathrm{~F} 9$

C10H6Cl3Br3F 10 C10H6Cl8F8 $\mathrm{C} 10 \mathrm{H} 7 \mathrm{Cl10F} 5$

$\mathrm{C} 10 \mathrm{H} 7 \mathrm{Cl} 2 \mathrm{Br} 4 \mathrm{~F} 9$

$\mathrm{C} 10 \mathrm{H} 7 \mathrm{Cl} 3 \mathrm{Br} 3 \mathrm{~F} 9$

$\mathrm{C} 10 \mathrm{H} 7 \mathrm{Cl} 3 \mathrm{Br} 5 \mathrm{~F} 7$

$\mathrm{C} 10 \mathrm{H} 7 \mathrm{Cl} 4 \mathrm{Br} 3 \mathrm{~F} 8$

$\mathrm{C} 10 \mathrm{H} 7 \mathrm{Cl} 4 \mathrm{Br} 4 \mathrm{~F} 7$

$\mathrm{C} 10 \mathrm{H} 7 \mathrm{Cl} 6 \mathrm{BrF} 8$

$\mathrm{C} 10 \mathrm{H} 7 \mathrm{Cl} 7 \mathrm{BrF} 7$

$\mathrm{C} 10 \mathrm{H} 7 \mathrm{Cl} 8 \mathrm{FF} 7$

$\mathrm{C} 10 \mathrm{H} 7 \mathrm{Cl} 19 \mathrm{BrF} 5$

$\mathrm{C} 10 \mathrm{H} 7 \mathrm{ClBr} 4 \mathrm{~F} 10$

$\mathrm{C} 10 \mathrm{H} 7 \mathrm{ClBr} 5 \mathrm{~F} 9$

$\mathrm{C} 10 \mathrm{H} 8 \mathrm{Br} 5 \mathrm{~F} 9$

$\mathrm{C} 10 \mathrm{H} 8 \mathrm{Br} 6 \mathrm{~F} 8$

C10H8Cl10F4

$\mathrm{C} 10 \mathrm{H} 8 \mathrm{Cl} 2 \mathrm{Br} 4 \mathrm{~F} 8$

$\mathrm{C} 10 \mathrm{H} 8 \mathrm{Cl} 3 \mathrm{Br} 3 \mathrm{~F} 8$

$\mathrm{C} 10 \mathrm{H} 8 \mathrm{C} 14 \mathrm{Br} 2 \mathrm{~F} 8$

$\mathrm{C} 10 \mathrm{H} 8 \mathrm{Cl} 4 \mathrm{Br} 3 \mathrm{~F} 7$

$\mathrm{C} 10 \mathrm{H} 8 \mathrm{Cl} 15 \mathrm{Br} 2 \mathrm{~F} 7$

$\mathrm{C} 10 \mathrm{H} 8 \mathrm{Cl} 5 \mathrm{Br} 4 \mathrm{~F} 5$

$\mathrm{C} 10 \mathrm{H} 8 \mathrm{Cl} 6 \mathrm{BrF} 7$

C10H8Cl7BrF6

$\mathrm{C} 10 \mathrm{H} 8 \mathrm{Cl} 9 \mathrm{BrF} 4$

C10H8Cl9F5

$\mathrm{C} 10 \mathrm{H} 8 \mathrm{ClBr} 4 \mathrm{~F} 9$

C10H8ClBr5F8

C10H9Br6F7

$\mathrm{C} 10 \mathrm{H} 9 \mathrm{C} 110 \mathrm{BrF} 2$

C10H9Cl2Br4F7

C10H9Cl2Br5F6

C10H9Cl2Br6F5

C10H9Cl3Br3F7

C10H9Cl3Br4F6

C10H9Cl4Br2F7

C10H9Cl4Br3F6

$\mathrm{C} 10 \mathrm{H} 9 \mathrm{Cl} 4 \mathrm{Br} 4 \mathrm{~F} 5$

C10H9Cl4Br5F4

$\mathrm{C} 10 \mathrm{H} 9 \mathrm{Cl} 5 \mathrm{Br} 2 \mathrm{~F} 6$

$\mathrm{C} 10 \mathrm{H} 9 \mathrm{Cl} 5 \mathrm{Br} 3 \mathrm{~F} 5$

C10H9Cl6BrF6

C10H9Cl7Br2F4

C10H9Cl7BrF5

C10H9C17F6

C10H9Cl8F5

C10H9Cl9Br2F2

C10H9ClBr4F8

C10H9ClBr5F7

C10H9ClBr6F6

C11H10Br5F9

C11H10Cl2Br5F7

C11H10Cl3Br3F8

C11H10Cl4Br3F7

$\mathrm{C} 11 \mathrm{H} 10 \mathrm{Cl} 5 \mathrm{Br} 2 \mathrm{~F} 7$

C11H10Cl5Br3F6

C11H10Cl6Br2F6

C11H10Cl7BrF6

C11H10C19F5

C11H10ClBr4F9

$\mathrm{C} 11 \mathrm{H} 10 \mathrm{ClBr} 5 \mathrm{~F} 8$

C11H11Br5F8

C11H11Cl10F3

C11H11C111F2

C11H11Cl2Br4F7

C11H11Cl3Br3F7

C11H11Cl3Br4F6

C11H11Cl3Br6F4

$\mathrm{C} 11 \mathrm{H} 11 \mathrm{Cl} 4 \mathrm{Br} 2 \mathrm{~F} 7$

C11H11Cl4Br3F6

$\begin{array}{lllllllll}9.79 & 6.68 & -3.11 & 5.04 & 8.15 & -3.11 & 5.89 & 15.99 & -10.09\end{array}$

$\begin{array}{llllllllll}8.71 & 6.57 & -2.14 & 4.88 & 7.02 & -2.14 & 5.81 & 14.00 & -8.20\end{array}$

$\begin{array}{llllllllll}8.72 & 7.07 & -1.65 & 5.63 & 7.28 & -1.65 & 6.19 & 14.03 & -7.84\end{array}$

$\begin{array}{llllllllll}7.72 & 7.07 & -1.65 & 5.63 & 7.28 & -1.65 & 6.19 & 14.03 & -7.84 \\ 8.3 & 6.97 & -0.68 & 5.48 & 6.16 & -0.68 & 6.12 & 12.06 & -5.95\end{array}$

$\begin{array}{lllllllll}8.3 & 6.92 & -1.38 & 5.40 & 6.79 & -1.38 & 6.08 & 13.27 & -7.19\end{array}$

$\begin{array}{lllllllll}9.28 & 6.66 & -2.62 & 5.01 & 7.64 & -2.62 & 5.88 & 15.06 & -9.18\end{array}$

$\begin{array}{lllllllll}8.65 & 6.48 & -2.17 & 4.75 & 6.91 & -2.17 & 5.74 & 13.90 & -8.16\end{array}$

$\begin{array}{llllllllll}8 & 6.32 & -1.68 & 4.51 & 6.19 & -1.68 & 5.62 & 12.71 & -7.10\end{array}$

$\begin{array}{lllllllll}8 & 6.32 & -1.68 & 4.51 & 6.19 & -1.68 & 5.62 & 12.71 & -7.10\end{array}$

$\begin{array}{lllllllllll}8.81 & 8.99 & 0.18 & 8.49 & 8.31 & 0.18 & 7.67 & 14.19 & -6\end{array}$

$\begin{array}{lllllllllll}7.99 & 8.39 & 0.40 & 7.60 & 7.20 & 0.40 & 7.21 & 12.69 & -5.49\end{array}$

$\begin{array}{lllllllll}8.39 & 8.74 & 0.35 & 8.12 & 7.77 & 0.35 & 7.47 & 13.42 & -5.95\end{array}$

$\begin{array}{llllllllll}10.2 & 8.76 & -1.45 & 8.15 & 9.60 & -1.45 & 7.49 & 16.77 & -9.28\end{array}$

$\begin{array}{llllllllll}10.2 & 8.76 & -1.45 & 8.15 & 9.60 & -1.45 & 7.49 & 16.77 & -9.28\end{array}$

$\begin{array}{lllllllllll}8.68 & 7.78 & 0.10 & 6.69 & 6.59 & 0.10 & 6.74 & 12.12 & -5.38\end{array}$

$\begin{array}{llllllllll}11 & 8.58 & -2.38 & 7.88 & 10.26 & -2.38 & 7.35 & 18.14 & -10.79\end{array}$

$\begin{array}{llllllllll}9.48 & 8.83 & -0.65 & 8.25 & 8.91 & -0.65 & 7.54 & 15.43 & -7.88\end{array}$

$\begin{array}{llllllllll}10.4 & 8.49 & -1.89 & 7.75 & 9.64 & -1.89 & 7.28 & 17.08 & -9.80\end{array}$

$\begin{array}{llllllllll}8.33 & 8.65 & 0.32 & 7.99 & 7.67 & 0.32 & 7.41 & 13.32 & -5.91\end{array}$

$\begin{array}{lllllllll}9.4 & 8.97 & -0.43 & 8.46 & 8.90 & -0.43 & 7.65 & 15.29 & -7.63\end{array}$

$\begin{array}{llllllllll}8.09 & 8.14 & 0.05 & 7.22 & 7.17 & 0.05 & 7.01 & 12.87 & -5.86\end{array}$

$\begin{array}{lllllllll}10.8 & 8.85 & -1.94 & 8.28 & 10.22 & -1.94 & 7.56 & 17.83 & -10.27\end{array}$

$\begin{array}{llllllllll}7.92 & 8.29 & 0.37 & 7.45 & 7.08 & 0.37 & 7.13 & 12.57 & -5.44\end{array}$

$\begin{array}{lllllllllll}7.92 & 8.29 & 0.37 & 7.45 & 7.08 & 0.37 & 7.13 & 12.57 & -5.44\end{array}$

$\begin{array}{lllllllll}8.94 & 8.52 & -0.42 & 7.79 & 8.21 & -0.42 & 7.31 & 14.43 & -7.12\end{array}$

$\begin{array}{llllllllll}10.6 & 8.92 & -1.65 & 8.39 & 10.04 & -1.65 & 7.61 & 17.44 & -9.82\end{array}$

$\begin{array}{lllllllll}10.7 & 8.9 & -1.75 & 8.36 & 10.11 & -1.75 & 7.60 & 17.58 & -9.98\end{array}$

$\begin{array}{llllllllll}9.42 & 8.74 & -0.68 & 8.12 & 8.80 & -0.68 & 7.47 & 15.32 & -7.85\end{array}$

$\begin{array}{llllllllll}9.42 & 8.74 & -0.68 & 8.12 & 8.80 & -0.68 & 7.47 & 15.32 & -7.85 \\ 8.85 & 8.65 & -0.20 & 7.99 & 8.18 & -0.20 & 7.41 & 14.27 & -6.86\end{array}$

$\begin{array}{lllllllll}8.27 & 8.56 & 0.29 & 7.85 & 7.56 & 0.29 & 7.34 & 13.21 & -5.87\end{array}$

$\begin{array}{rrrrrrrrrr}9.91 & 8.96 & -0.95 & 8.45 & 9.40 & -0.95 & 7.64 & 16.22 & -8.57\end{array}$

$\begin{array}{lllllllll}7.86 & 7.39 & -0.47 & 6.10 & 6.57 & -0.47 & 6.44 & 12.44 & -6.00\end{array}$

$\begin{array}{rrrrrrrrr}11.9 & 8.94 & -2.94 & 8.42 & 11.36 & -2.94 & 7.63 & 19.84 & -12.21\end{array}$

$\begin{array}{lllllllllll}11.9 & 8.94 & -2.94 & 8.42 & 11.36 & -2.94 & 7.63 & 19.84 & -12.21\end{array}$ $\begin{array}{llllllllll}9.09 & 8.36 & -0.73 & 7.55 & 8.28 & -0.73 & 7.18 & 14.71 & -7.53\end{array}$ $\begin{array}{lllllllll}11.2 & 8.98 & -2.24 & 8.48 & 10.71 & -2.24 & 7.66 & 18.62 & -10.96\end{array}$ $\begin{array}{lllllllll}9.58 & 8.58 & -1.00 & 7.88 & 8.88 & -1.00 & 7.35 & 15.61 & -8.25\end{array}$ $\begin{array}{llllllllll}8.36 & 8.43 & 0.07 & 7.66 & 7.59 & 0.07 & 7.24 & 13.37 & -6.14\end{array}$ $\begin{array}{llllllllll}8.36 & 8.43 & 0.07 & 7.66 & 7.59 & 0.07 & 7.24 & 13.37 & -6.14\end{array}$ $\begin{array}{llllllllll}9.26 & 8.09 & -1.17 & 7.15 & 8.32 & -1.17 & 6.98 & 15.02 & -8.04\end{array}$ $\begin{array}{lllllllllll}10.3 & 8.31 & -1.95 & 7.48 & 9.43 & -1.95 & 7.14 & 16.86 & -9.72\end{array}$ $\begin{array}{lllllllll}12 & 8.69 & -3.28 & 8.04 & 11.33 & -3.28 & 7.44 & 20.01 & -12.57\end{array}$ $\begin{array}{llllllllll}9.85 & 8.87 & -0.98 & 8.31 & 9.30 & -0.98 & 7.57 & 16.11 & -8.54\end{array}$

$\begin{array}{llllllllll}10 & 7.79 & -2.22 & 6.70 & 8.92 & -2.22 & 6.75 & 16.40 & -9.65\end{array}$

$\begin{array}{lllllllll}2.4 & 8.94 & -3.46 & 8.42 & 11.87 & -3.46 & 7.63 & 20.78 & -13.15\end{array}$ $\begin{array}{llllllllll}9.21 & 8.71 & -0.50 & 8.07 & 8.57 & -0.50 & 7.45 & 14.93 & -7.47\end{array}$ $\begin{array}{llllllllll}9.44 & 7.71 & -1.73 & 6.58 & 8.32 & -1.73 & 6.68 & 15.36 & -8.68\end{array}$ $\begin{array}{lllllllll}7.96 & 7.95 & -0.01 & 6.94 & 6.95 & -0.01 & 6.87 & 12.64 & -5.77\end{array}$ $\begin{array}{llllllllll}9.61 & 8.36 & -1.25 & 7.55 & 8.80 & -1.25 & 7.18 & 15.66 & -8.48 \\ 11.2 & 8.76 & -2.49 & 8.15 & 10.64 & -2.49 & 7.49 & 18.67 & -11.18\end{array}$ $\begin{array}{lllllllll}11.2 & 8.76 & -2.49 & 8.15 & 10.64 & -2.49 & 7.49 & 18.67 & -11.18\end{array}$ $\begin{array}{llllllllll}12.1 & 8.42 & -3.72 & 7.64 & 11.36 & -3.72 & 7.23 & 20.32 & -13.09\end{array}$ $\begin{array}{llllllllll}8.95 & 8.19 & -0.76 & 7.30 & 8.06 & -0.76 & 7.05 & 14.46 & -7.41\end{array}$ $\begin{array}{llllllllll}9.93 & 7.93 & -2.00 & 6.91 & 8.91 & -2.00 & 6.85 & 16.25 & -9.40\end{array}$ $\begin{array}{llllllllll}8.46 & 8.18 & -0.28 & 7.28 & 7.56 & -0.28 & 7.04 & 13.55 & -6.50\end{array}$ $\begin{array}{lllllllll}11.2 & 8.89 & -2.27 & 8.34 & 10.61 & -2.27 & 7.59 & 18.51 & -10.92\end{array}$ $\begin{array}{llllllllll}9.52 & 8.49 & -1.03 & 7.75 & 8.78 & -1.03 & 7.28 & 15.50 & -8.22\end{array}$ $\begin{array}{llllllllll}8.54 & 8.75 & 0.21 & 8.13 & 7.93 & 0.21 & 7.48 & 13.71 & -6.22\end{array}$ $\begin{array}{llllllllll}8.95 & 8.4 & -0.55 & 7.61 & 8.16 & -0.55 & 7.21 & 14.44 & -7.23 \\ 12.6 & 8.78 & -3.77 & 8.18 & 11.95 & -3.77 & 7.51 & 21.07 & -13.56\end{array}$ $\begin{array}{lllllllll}12.6 & 8.78 & -3.77 & 8.18 & 11.95 & -3.77 & 7.51 & 21.07 & -13.56\end{array}$ $\begin{array}{lllllllll}8.05 & 7.82 & -0.23 & 6.75 & 6.98 & -0.23 & 6.77 & 12.80 & -6.03\end{array}$ $\begin{array}{llllllllll}9.69 & 8.22 & -1.47 & 7.34 & 8.81 & -1.47 & 7.08 & 15.81 & -8.73\end{array}$ $\begin{array}{lllllllll}11.3 & 8.62 & -2.70 & 7.94 & 10.64 & -2.70 & 7.38 & 18.82 & -11.43\end{array}$ $\begin{array}{llllllllll}8.57 & 8.27 & -0.30 & 7.42 & 7.71 & -0.30 & 7.11 & 13.75 & -6.63\end{array}$ $\begin{array}{llllllllll}8.57 & 8.27 & -0.30 & 7.42 & 7.71 & -0.30 & 7.11 & 13.75 & -6.63 \\ 10.7 & 8.89 & -1.80 & 8.34 & 10.14 & -1.80 & 7.59 & 17.64 & -10.05\end{array}$ $\begin{array}{lllllllll}7.74 & 7.66 & -0.07 & 6.51 & 6.58 & -0.07 & 6.65 & 12.22 & -5.58\end{array}$ $\begin{array}{lllllllll}8.8 & 7.97 & -0.83 & 6.97 & 7.80 & -0.83 & 6.88 & 14.17 & -7.29\end{array}$ $\begin{array}{llllllllll}8.97 & 8.63 & -0.34 & 7.96 & 8.30 & -0.34 & 7.39 & 14.50 & -7.10\end{array}$ $\begin{array}{llllllllll}9.87 & 8.29 & -1.58 & 7.45 & 9.03 & -1.58 & 7.13 & 16.14 & -9.01\end{array}$ $\begin{array}{lllllllll}10 & 8.94 & -1.09 & 8.42 & 9.51 & -1.09 & 7.63 & 16.44 & -8.82\end{array}$ $\begin{array}{lllllllll}9.46 & 8.85 & -0.61 & 8.28 & 8.89 & -0.61 & 7.56 & 15.39 & -7.83\end{array}$ $\begin{array}{llllllllll}9.21 & 8.33 & -0.88 & 7.51 & 8.38 & -0.88 & 7.16 & 14.92 & -7.76\end{array}$ $\begin{array}{llllllllll}8.65 & 8.84 & 0.19 & 8.27 & 8.08 & 0.19 & 7.55 & 13.90 & -6.35\end{array}$ $\begin{array}{llllllllll}9.63 & 8.58 & -1.05 & 7.88 & 8.93 & -1.05 & 7.35 & 15.69 & -8.34\end{array}$ $\begin{array}{lllllllll}8.99 & 8.4 & -0.59 & 7.61 & 8.20 & -0.59 & 7.21 & 14.53 & -7.32\end{array}$ $\begin{array}{lllllllll}9.97 & 8.04 & -1.93 & 7.07 & 9.00 & -1.93 & 6.94 & 16.32 & -9.38\end{array}$ $\begin{array}{lllllllll}11 & 8.35 & -2.68 & 7.54 & 10.21 & -2.68 & 7.18 & 18.27 & -11.09\end{array}$ $\begin{array}{lllllllll}8.74 & 7.88 & -0.86 & 6.84 & 7.70 & -0.86 & 6.81 & 14.07 & -7.25\end{array}$ $\begin{array}{llllllllll}8.91 & 8.53 & -0.38 & 7.81 & 8.18 & -0.38 & 7.31 & 14.37 & -7.06\end{array}$ $\begin{array}{llllllllll}10.6 & 8.94 & -1.61 & 8.42 & 10.03 & -1.61 & 7.63 & 17.39 & -9.77\end{array}$ $\begin{array}{llllllllll}12.3 & 8.26 & -4.09 & 7.40 & 11.49 & -4.09 & 7.11 & 20.69 & -13.58\end{array}$ $\begin{array}{llllllllll}7.59 & 7.7 & 0.11 & 6.57 & 6.46 & 0.11 & 6.68 & 11.95 & -5.28\end{array}$ $\begin{array}{lllllllll}9.24 & 8.11 & -1.13 & 7.18 & 8.31 & -1.13 & 6.99 & 14.98 & -7.99\end{array}$ 
Formula

$\mathrm{C}(\mathrm{C}(\mathrm{C}(\mathrm{C}(\mathrm{C}(\mathrm{C}(\mathrm{C}(\mathrm{C}(\mathrm{C}(\mathrm{C}(\mathrm{C}(\mathrm{F})(\mathrm{F}) \mathrm{Cl})(\mathrm{H}) \mathrm{Br})(\mathrm{F}) \mathrm{H})(\mathrm{Br}) \mathrm{H})(\mathrm{H}) \mathrm{F})(\mathrm{Cl}) \mathrm{H})(\mathrm{H}) \mathrm{H})(\mathrm{F}) \mathrm{H})(\mathrm{Cl}) \mathrm{Br})(\mathrm{Br}) \mathrm{H})(\mathrm{H})(\mathrm{H}) \mathrm{C}$ $\mathrm{C}(\mathrm{C}(\mathrm{C}(\mathrm{C}(\mathrm{C}(\mathrm{C}(\mathrm{C}(\mathrm{C}(\mathrm{C}(\mathrm{C}(\mathrm{C}(\mathrm{H})(\mathrm{Br}) \mathrm{H})(\mathrm{Cl}) \mathrm{H})(\mathrm{Cl}) \mathrm{Cl})(\mathrm{Br}) \mathrm{H})(\mathrm{F}) \mathrm{H})(\mathrm{F}) \mathrm{Cl})(\mathrm{Cl}) \mathrm{H})(\mathrm{F}) \mathrm{H})(\mathrm{F}) \mathrm{H})(\mathrm{H}) \mathrm{F})(\mathrm{H})(\mathrm{F}) \mathrm{H}$ $\mathrm{C}(\mathrm{C}(\mathrm{C}(\mathrm{C}(\mathrm{C}(\mathrm{C}(\mathrm{C}(\mathrm{C}(\mathrm{C}(\mathrm{C}(\mathrm{C}(\mathrm{H})(\mathrm{H}) \mathrm{H})(\mathrm{F}) \mathrm{H})(\mathrm{F}) \mathrm{Cl})(\mathrm{H}) \mathrm{Cl})(\mathrm{Cl}) \mathrm{Br})(\mathrm{Cl}) \mathrm{H})(\mathrm{H}) \mathrm{F})(\mathrm{Cl}) \mathrm{H})(\mathrm{Br}) \mathrm{H})(\mathrm{H}) \mathrm{F})(\mathrm{Br})(\mathrm{F}) \mathrm{H}$ $\mathrm{C}(\mathrm{C}(\mathrm{C}(\mathrm{C}(\mathrm{C}(\mathrm{C}(\mathrm{C}(\mathrm{C}(\mathrm{C}(\mathrm{C}(\mathrm{C}(\mathrm{F})(\mathrm{H}) \mathrm{Br})(\mathrm{Br}) \mathrm{H})(\mathrm{H}) \mathrm{H})(\mathrm{H}) \mathrm{Cl})(\mathrm{H}) \mathrm{F})(\mathrm{Cl}) \mathrm{H})(\mathrm{H}) \mathrm{H})(\mathrm{Cl}) \mathrm{F})(\mathrm{H}) \mathrm{Cl})(\mathrm{F}) \mathrm{Cl})(\mathrm{Br})(\mathrm{Br}) \mathrm{H}$ $\mathrm{C}(\mathrm{C}(\mathrm{C}(\mathrm{C}(\mathrm{C}(\mathrm{C}(\mathrm{C}(\mathrm{C}(\mathrm{C}(\mathrm{C}(\mathrm{C}(\mathrm{Cl})(\mathrm{H}) \mathrm{Cl})(\mathrm{H}) \mathrm{H})(\mathrm{Br}) \mathrm{H})(\mathrm{F}) \mathrm{H})(\mathrm{H}) \mathrm{Cl})(\mathrm{H}) \mathrm{H})(\mathrm{Cl}) \mathrm{Br})(\mathrm{F}) \mathrm{F})(\mathrm{Cl}) \mathrm{H})(\mathrm{F}) \mathrm{H})(\mathrm{F})(\mathrm{H}) \mathrm{Cl}$ $\mathrm{C}(\mathrm{C}(\mathrm{C}(\mathrm{C}(\mathrm{C}(\mathrm{C}(\mathrm{C}(\mathrm{C}(\mathrm{C}(\mathrm{C}(\mathrm{C}(\mathrm{H})(\mathrm{F}) \mathrm{H})(\mathrm{H}) \mathrm{Cl})(\mathrm{F}) \mathrm{F})(\mathrm{H}) \mathrm{H})(\mathrm{F}) \mathrm{Br})(\mathrm{Br}) \mathrm{H})(\mathrm{Br}) \mathrm{H})(\mathrm{Cl}) \mathrm{H})(\mathrm{H}) \mathrm{Cl})(\mathrm{Cl}) \mathrm{H})(\mathrm{Cl})(\mathrm{Cl}) \mathrm{H}$ $\mathrm{C}(\mathrm{C}(\mathrm{C}(\mathrm{C}(\mathrm{C}(\mathrm{C}(\mathrm{C}(\mathrm{C}(\mathrm{C}(\mathrm{C}(\mathrm{C}(\mathrm{H})(\mathrm{F}) \mathrm{H})(\mathrm{F}) \mathrm{H})(\mathrm{Cl}) \mathrm{H})(\mathrm{H}) \mathrm{Cl})(\mathrm{H}) \mathrm{Cl})(\mathrm{Cl}) \mathrm{F})(\mathrm{H}) \mathrm{F})(\mathrm{F}) \mathrm{Br})(\mathrm{F}) \mathrm{Cl})(\mathrm{H}) \mathrm{H})(\mathrm{Cl})(\mathrm{H}) \mathrm{H}$ $\mathrm{C}(\mathrm{C}(\mathrm{C}(\mathrm{C}(\mathrm{C}(\mathrm{C}(\mathrm{C}(\mathrm{C}(\mathrm{C}(\mathrm{C}(\mathrm{C}(\mathrm{H})(\mathrm{H}) \mathrm{Br})(\mathrm{Cl}) \mathrm{Cl})(\mathrm{F}) \mathrm{H})(\mathrm{F}) \mathrm{Cl})(\mathrm{H}) \mathrm{Cl})(\mathrm{H}) \mathrm{Cl})(\mathrm{F}) \mathrm{H})(\mathrm{F}) \mathrm{Cl})(\mathrm{H}) \mathrm{H})(\mathrm{H}) \mathrm{H})(\mathrm{H})(\mathrm{Cl}) \mathrm{F}$ $\mathrm{C}(\mathrm{C}(\mathrm{C}(\mathrm{C}(\mathrm{C}(\mathrm{C}(\mathrm{C}(\mathrm{C}(\mathrm{C}(\mathrm{C}(\mathrm{C}(\mathrm{H})(\mathrm{H}) \mathrm{F})(\mathrm{H}) \mathrm{H})(\mathrm{Cl}) \mathrm{Cl})(\mathrm{H}) \mathrm{H})(\mathrm{Cl}) \mathrm{F})(\mathrm{Cl}) \mathrm{H})(\mathrm{Cl}) \mathrm{F})(\mathrm{H}) \mathrm{F})(\mathrm{H}) \mathrm{F})(\mathrm{H}) \mathrm{F})(\mathrm{Cl})(\mathrm{H}) \mathrm{C}$ $\mathrm{C}(\mathrm{C}(\mathrm{C}(\mathrm{C}(\mathrm{C}(\mathrm{C}(\mathrm{C}(\mathrm{C}(\mathrm{C}(\mathrm{C}(\mathrm{C}(\mathrm{H})(\mathrm{H}) \mathrm{F})(\mathrm{H}) \mathrm{H})(\mathrm{Br}) \mathrm{H})(\mathrm{H}) \mathrm{F})(\mathrm{Cl}) \mathrm{F})(\mathrm{Cl}) \mathrm{Cl})(\mathrm{H}) \mathrm{Cl})(\mathrm{H}) \mathrm{Cl})(\mathrm{H}) \mathrm{Cl})(\mathrm{Cl}) \mathrm{H})(\mathrm{Cl})(\mathrm{H}) \mathrm{B}$ $\mathrm{C}(\mathrm{C}(\mathrm{C}(\mathrm{C}(\mathrm{C}(\mathrm{C}(\mathrm{C}(\mathrm{C}(\mathrm{C}(\mathrm{C}(\mathrm{C}(\mathrm{H})(\mathrm{F}) \mathrm{F})(\mathrm{H}) \mathrm{Cl})(\mathrm{H}) \mathrm{F})(\mathrm{Cl}) \mathrm{H})(\mathrm{Cl}) \mathrm{Br})(\mathrm{Cl}) \mathrm{H})(\mathrm{Cl}) \mathrm{H})(\mathrm{Cl}) \mathrm{Cl})(\mathrm{H}) \mathrm{F})(\mathrm{Cl}) \mathrm{H})(\mathrm{H})(\mathrm{H}) \mathrm{H}$ $\mathrm{C}(\mathrm{C}(\mathrm{C}(\mathrm{C}(\mathrm{C}(\mathrm{C}(\mathrm{C}(\mathrm{C}(\mathrm{C}(\mathrm{C}(\mathrm{C}(\mathrm{F})(\mathrm{H}) \mathrm{Cl})(\mathrm{Cl}) \mathrm{H})(\mathrm{Cl}) \mathrm{H})(\mathrm{Cl}) \mathrm{Cl})(\mathrm{H}) \mathrm{F})(\mathrm{F}) \mathrm{Cl})(\mathrm{H}) \mathrm{Cl})(\mathrm{H}) \mathrm{Cl})(\mathrm{H}) \mathrm{F})(\mathrm{H}) \mathrm{F})(\mathrm{H})(\mathrm{H}) \mathrm{H}$ $\mathrm{C}(\mathrm{C}(\mathrm{C}(\mathrm{C}(\mathrm{C}(\mathrm{C}(\mathrm{C}(\mathrm{C}(\mathrm{C}(\mathrm{C}(\mathrm{C}(\mathrm{H})(\mathrm{H}) \mathrm{Br})(\mathrm{H}) \mathrm{F})(\mathrm{F}) \mathrm{H})(\mathrm{H}) \mathrm{Br})(\mathrm{F}) \mathrm{H})(\mathrm{H}) \mathrm{Br})(\mathrm{F}) \mathrm{Br})(\mathrm{F}) \mathrm{F})(\mathrm{H}) \mathrm{F})(\mathrm{Cl}) \mathrm{H})(\mathrm{H})(\mathrm{H}) \mathrm{F}$ $\mathrm{C}(\mathrm{C}(\mathrm{C}(\mathrm{C}(\mathrm{C}(\mathrm{C}(\mathrm{C}(\mathrm{C}(\mathrm{C}(\mathrm{C}(\mathrm{C}(\mathrm{F})(\mathrm{H}) \mathrm{H})(\mathrm{H}) \mathrm{Br})(\mathrm{H}) \mathrm{Cl})(\mathrm{Br}) \mathrm{H})(\mathrm{Br}) \mathrm{F})(\mathrm{H}) \mathrm{Br})(\mathrm{F}) \mathrm{F})(\mathrm{Br}) \mathrm{F})(\mathrm{H}) \mathrm{H})(\mathrm{H}) \mathrm{F})(\mathrm{H})(\mathrm{F}) \mathrm{H}$ $\mathrm{C}(\mathrm{C}(\mathrm{C}(\mathrm{C}(\mathrm{C}(\mathrm{C}(\mathrm{C}(\mathrm{C}(\mathrm{C}(\mathrm{C}(\mathrm{C}(\mathrm{H})(\mathrm{Br}) \mathrm{F})(\mathrm{F}) \mathrm{H})(\mathrm{Cl}) \mathrm{F})(\mathrm{Br}) \mathrm{H})(\mathrm{Br}) \mathrm{H})(\mathrm{Br}) \mathrm{H})(\mathrm{H}) \mathrm{H})(\mathrm{H}) \mathrm{F})(\mathrm{Br}) \mathrm{H})(\mathrm{Br}) \mathrm{F})(\mathrm{H})(\mathrm{Br}) \mathrm{H}$ $\mathrm{C}(\mathrm{C}(\mathrm{C}(\mathrm{C}(\mathrm{C}(\mathrm{C}(\mathrm{C}(\mathrm{C}(\mathrm{C}(\mathrm{C}(\mathrm{C}(\mathrm{H})(\mathrm{H}) \mathrm{F})(\mathrm{H}) \mathrm{H})(\mathrm{F}) \mathrm{Br})(\mathrm{H}) \mathrm{H})(\mathrm{H}) \mathrm{Br})(\mathrm{F}) \mathrm{H})(\mathrm{H}) \mathrm{H})(\mathrm{F}) \mathrm{H})(\mathrm{F}) \mathrm{H})(\mathrm{Br}) \mathrm{F})(\mathrm{Br})(\mathrm{F}) \mathrm{Br}$ $\mathrm{C}(\mathrm{C}(\mathrm{C}(\mathrm{C}(\mathrm{C}(\mathrm{C}(\mathrm{C}(\mathrm{C}(\mathrm{C}(\mathrm{C}(\mathrm{C}(\mathrm{H})(\mathrm{H}) \mathrm{H})(\mathrm{Br}) \mathrm{Br})(\mathrm{Br}) \mathrm{F})(\mathrm{H}) \mathrm{Br})(\mathrm{F}) \mathrm{H})(\mathrm{H}) \mathrm{Br})(\mathrm{H}) \mathrm{Br})(\mathrm{H}) \mathrm{F})(\mathrm{H}) \mathrm{H})(\mathrm{H}) \mathrm{F})(\mathrm{H})(\mathrm{Br}) \mathrm{F}$ $\mathrm{C}(\mathrm{C}(\mathrm{C}(\mathrm{C}(\mathrm{C}(\mathrm{C}(\mathrm{C}(\mathrm{C}(\mathrm{C}(\mathrm{C}(\mathrm{C}(\mathrm{H})(\mathrm{Cl}) \mathrm{Cl})(\mathrm{H}) \mathrm{Cl})(\mathrm{Cl}) \mathrm{H})(\mathrm{H}) \mathrm{Cl})(\mathrm{H}) \mathrm{Cl})(\mathrm{H}) \mathrm{H})(\mathrm{Cl}) \mathrm{Cl})(\mathrm{Cl}) \mathrm{H})(\mathrm{F}) \mathrm{Cl})(\mathrm{H}) \mathrm{H})(\mathrm{H})(\mathrm{H}) \mathrm{F}$ $\mathrm{C}(\mathrm{C}(\mathrm{C}(\mathrm{C}(\mathrm{C}(\mathrm{C}(\mathrm{C}(\mathrm{C}(\mathrm{C}(\mathrm{C}(\mathrm{C}(\mathrm{Cl})(\mathrm{H}) \mathrm{Cl})(\mathrm{H}) \mathrm{H})(\mathrm{F}) \mathrm{Br})(\mathrm{H}) \mathrm{F})(\mathrm{H}) \mathrm{H})(\mathrm{H}) \mathrm{H})(\mathrm{F}) \mathrm{F})(\mathrm{F}) \mathrm{H})(\mathrm{F}) \mathrm{Br})(\mathrm{H}) \mathrm{Br})(\mathrm{F})(\mathrm{H}) \mathrm{H}$ $\mathrm{C}(\mathrm{C}(\mathrm{C}(\mathrm{C}(\mathrm{C}(\mathrm{C}(\mathrm{C}(\mathrm{C}(\mathrm{C}(\mathrm{C}(\mathrm{C}(\mathrm{Cl})(\mathrm{F}) \mathrm{F})(\mathrm{H}) \mathrm{Br})(\mathrm{H}) \mathrm{H})(\mathrm{F}) \mathrm{H})(\mathrm{H}) \mathrm{H})(\mathrm{Br}) \mathrm{F})(\mathrm{H}) \mathrm{F})(\mathrm{Br}) \mathrm{F})(\mathrm{H}) \mathrm{H})(\mathrm{Cl}) \mathrm{H})(\mathrm{H})(\mathrm{Br}) \mathrm{H}$ $\mathrm{C}(\mathrm{C}(\mathrm{C}(\mathrm{C}(\mathrm{C}(\mathrm{C}(\mathrm{C}(\mathrm{C}(\mathrm{C}(\mathrm{C}(\mathrm{C}(\mathrm{Cl})(\mathrm{H}) \mathrm{Br})(\mathrm{H}) \mathrm{H})(\mathrm{H}) \mathrm{Cl})(\mathrm{H}) \mathrm{H})(\mathrm{F}) \mathrm{Br})(\mathrm{F}) \mathrm{F})(\mathrm{H}) \mathrm{H})(\mathrm{Cl}) \mathrm{F})(\mathrm{H}) \mathrm{H})(\mathrm{F}) \mathrm{H})(\mathrm{Br})(\mathrm{H}) \mathrm{F}$ $\mathrm{C}(\mathrm{C}(\mathrm{C}(\mathrm{C}(\mathrm{C}(\mathrm{C}(\mathrm{C}(\mathrm{C}(\mathrm{C}(\mathrm{C}(\mathrm{C}(\mathrm{F})(\mathrm{H}) \mathrm{F})(\mathrm{H}) \mathrm{H})(\mathrm{H}) \mathrm{H})(\mathrm{Cl}) \mathrm{H})(\mathrm{H}) \mathrm{Br})(\mathrm{Cl}) \mathrm{Cl})(\mathrm{F}) \mathrm{H})(\mathrm{Cl}) \mathrm{H})(\mathrm{Br}) \mathrm{F})(\mathrm{H}) \mathrm{F})(\mathrm{H})(\mathrm{H}) \mathrm{F}$ $\mathrm{C}(\mathrm{C}(\mathrm{C}(\mathrm{C}(\mathrm{C}(\mathrm{C}(\mathrm{C}(\mathrm{C}(\mathrm{C}(\mathrm{C}(\mathrm{C}(\mathrm{H})(\mathrm{Br}) \mathrm{F})(\mathrm{H}) \mathrm{H})(\mathrm{Br}) \mathrm{H})(\mathrm{H}) \mathrm{H})(\mathrm{Cl}) \mathrm{Cl})(\mathrm{H}) \mathrm{Cl})(\mathrm{H}) \mathrm{Br})(\mathrm{F}) \mathrm{Cl})(\mathrm{F}) \mathrm{F})(\mathrm{H}) \mathrm{F})(\mathrm{H})(\mathrm{H}) \mathrm{H}$ $\mathrm{C}(\mathrm{C}(\mathrm{C}(\mathrm{C}(\mathrm{C}(\mathrm{C}(\mathrm{C}(\mathrm{C}(\mathrm{C}(\mathrm{C}(\mathrm{C}(\mathrm{Cl})(\mathrm{H}) \mathrm{F})(\mathrm{F}) \mathrm{H})(\mathrm{H}) \mathrm{H})(\mathrm{H}) \mathrm{Br})(\mathrm{H}) \mathrm{Cl})(\mathrm{Br}) \mathrm{H})(\mathrm{Cl}) \mathrm{H})(\mathrm{H}) \mathrm{H})(\mathrm{Cl}) \mathrm{Cl})(\mathrm{F}) \mathrm{F})(\mathrm{H})(\mathrm{F}) \mathrm{H}$ $\mathrm{C}(\mathrm{C}(\mathrm{C}(\mathrm{C}(\mathrm{C}(\mathrm{C}(\mathrm{C}(\mathrm{C}(\mathrm{C}(\mathrm{C}(\mathrm{C}(\mathrm{H})(\mathrm{H}) \mathrm{Cl})(\mathrm{Br}) \mathrm{Cl})(\mathrm{H}) \mathrm{F})(\mathrm{H}) \mathrm{Br})(\mathrm{H}) \mathrm{Cl})(\mathrm{H}) \mathrm{Cl})(\mathrm{F}) \mathrm{F})(\mathrm{H}) \mathrm{Br})(\mathrm{H}) \mathrm{H})(\mathrm{H}) \mathrm{H})(\mathrm{Cl})(\mathrm{H}) \mathrm{F}$ $\mathrm{C}(\mathrm{C}(\mathrm{C}(\mathrm{C}(\mathrm{C}(\mathrm{C}(\mathrm{C}(\mathrm{C}(\mathrm{C}(\mathrm{C}(\mathrm{C}(\mathrm{F})(\mathrm{Cl}) \mathrm{F})(\mathrm{H}) \mathrm{F})(\mathrm{Cl}) \mathrm{H})(\mathrm{H}) \mathrm{H})(\mathrm{Cl}) \mathrm{H})(\mathrm{Cl}) \mathrm{H})(\mathrm{H}) \mathrm{F})(\mathrm{Cl}) \mathrm{F})(\mathrm{F}) \mathrm{H})(\mathrm{H}) \mathrm{H})(\mathrm{Br})(\mathrm{H}) \mathrm{H}$ $\mathrm{C}(\mathrm{C}(\mathrm{C}(\mathrm{C}(\mathrm{C}(\mathrm{C}(\mathrm{C}(\mathrm{C}(\mathrm{C}(\mathrm{C}(\mathrm{C}(\mathrm{F})(\mathrm{H}) \mathrm{Cl})(\mathrm{H}) \mathrm{H})(\mathrm{H}) \mathrm{Cl})(\mathrm{H}) \mathrm{H})(\mathrm{Cl}) \mathrm{Br})(\mathrm{H}) \mathrm{F})(\mathrm{H}) \mathrm{H})(\mathrm{H}) \mathrm{Cl})(\mathrm{H}) \mathrm{F})(\mathrm{F}) \mathrm{Cl})(\mathrm{Br})(\mathrm{H}) \mathrm{Cl}$ $\mathrm{C}(\mathrm{C}(\mathrm{C}(\mathrm{C}(\mathrm{C}(\mathrm{C}(\mathrm{C}(\mathrm{C}(\mathrm{C}(\mathrm{C}(\mathrm{C}(\mathrm{H})(\mathrm{F}) \mathrm{Cl})(\mathrm{H}) \mathrm{Cl})(\mathrm{H}) \mathrm{Br})(\mathrm{H}) \mathrm{Br})(\mathrm{H}) \mathrm{H})(\mathrm{H}) \mathrm{H})(\mathrm{H}) \mathrm{H})(\mathrm{H}) \mathrm{Cl})(\mathrm{Cl}) \mathrm{F})(\mathrm{F}) \mathrm{Cl})(\mathrm{Br})(\mathrm{Cl}) \mathrm{H}$ $\mathrm{C}(\mathrm{C}(\mathrm{C}(\mathrm{C}(\mathrm{C}(\mathrm{C}(\mathrm{C}(\mathrm{C}(\mathrm{C}(\mathrm{C}(\mathrm{C}(\mathrm{H})(\mathrm{H}) \mathrm{F})(\mathrm{H}) \mathrm{Cl})(\mathrm{H}) \mathrm{Br})(\mathrm{Cl}) \mathrm{Cl})(\mathrm{H}) \mathrm{H})(\mathrm{H}) \mathrm{H})(\mathrm{H}) \mathrm{H})(\mathrm{H}) \mathrm{Cl})(\mathrm{F}) \mathrm{Cl})(\mathrm{H}) \mathrm{F})(\mathrm{F})(\mathrm{F}) \mathrm{Cl}$ $\mathrm{C}(\mathrm{C}(\mathrm{C}(\mathrm{C}(\mathrm{C}(\mathrm{C}(\mathrm{C}(\mathrm{C}(\mathrm{C}(\mathrm{C}(\mathrm{C}(\mathrm{H})(\mathrm{H}) \mathrm{Cl})(\mathrm{Cl}) \mathrm{Cl})(\mathrm{H}) \mathrm{Cl})(\mathrm{H}) \mathrm{H})(\mathrm{H}) \mathrm{F})(\mathrm{H}) \mathrm{Br})(\mathrm{F}) \mathrm{H})(\mathrm{F}) \mathrm{H})(\mathrm{F}) \mathrm{Cl})(\mathrm{H}) \mathrm{H})(\mathrm{Cl})(\mathrm{Cl}) \mathrm{H}$ $\mathrm{C}(\mathrm{C}(\mathrm{C}(\mathrm{C}(\mathrm{C}(\mathrm{C}(\mathrm{C}(\mathrm{C}(\mathrm{C}(\mathrm{C}(\mathrm{C}(\mathrm{F})(\mathrm{F}) \mathrm{H})(\mathrm{H}) \mathrm{Cl})(\mathrm{H}) \mathrm{H})(\mathrm{Cl}) \mathrm{H})(\mathrm{H}) \mathrm{H})(\mathrm{H}) \mathrm{H})(\mathrm{H}) \mathrm{H})(\mathrm{Cl}) \mathrm{Cl})(\mathrm{H}) \mathrm{Cl})(\mathrm{Cl}) \mathrm{F})(\mathrm{Cl})(\mathrm{F}) \mathrm{F}$ $\mathrm{C}(\mathrm{C}(\mathrm{C}(\mathrm{C}(\mathrm{C}(\mathrm{C}(\mathrm{C}(\mathrm{C}(\mathrm{C}(\mathrm{C}(\mathrm{C}(\mathrm{H})(\mathrm{Cl}) \mathrm{Cl})(\mathrm{Cl}) \mathrm{Cl})(\mathrm{Br}) \mathrm{F})(\mathrm{H}) \mathrm{Cl})(\mathrm{H}) \mathrm{H})(\mathrm{H}) \mathrm{F})(\mathrm{H}) \mathrm{H})(\mathrm{H}) \mathrm{H})(\mathrm{Cl}) \mathrm{H})(\mathrm{F}) \mathrm{H})(\mathrm{H})(\mathrm{Cl}) \mathrm{C}$ $\mathrm{C}(\mathrm{C}(\mathrm{C}(\mathrm{C}(\mathrm{C}(\mathrm{C}(\mathrm{C}(\mathrm{C}(\mathrm{C}(\mathrm{C}(\mathrm{C}(\mathrm{H})(\mathrm{Cl}) \mathrm{H})(\mathrm{F}) \mathrm{H})(\mathrm{H}) \mathrm{Cl})(\mathrm{H}) \mathrm{Cl})(\mathrm{Cl}) \mathrm{H})(\mathrm{H}) \mathrm{F})(\mathrm{Cl}) \mathrm{F})(\mathrm{H}) \mathrm{Cl})(\mathrm{Cl}) \mathrm{Cl})(\mathrm{H}) \mathrm{H})(\mathrm{F})(\mathrm{H}) \mathrm{H}$ $\mathrm{C}(\mathrm{C}(\mathrm{C}(\mathrm{C}(\mathrm{C}(\mathrm{C}(\mathrm{C}(\mathrm{C}(\mathrm{C}(\mathrm{C}(\mathrm{C}(\mathrm{F})(\mathrm{H}) \mathrm{H})(\mathrm{H}) \mathrm{F})(\mathrm{Br}) \mathrm{F})(\mathrm{H}) \mathrm{H})(\mathrm{H}) \mathrm{Cl})(\mathrm{F}) \mathrm{F})(\mathrm{Br}) \mathrm{H})(\mathrm{H}) \mathrm{H})(\mathrm{H}) \mathrm{H})(\mathrm{Br}) \mathrm{F})(\mathrm{F})(\mathrm{H}) \mathrm{Br}$ $\mathrm{C}(\mathrm{C}(\mathrm{C}(\mathrm{C}(\mathrm{C}(\mathrm{C}(\mathrm{C}(\mathrm{C}(\mathrm{C}(\mathrm{C}(\mathrm{C}(\mathrm{H})(\mathrm{H}) \mathrm{F})(\mathrm{Br}) \mathrm{H})(\mathrm{F}) \mathrm{Br})(\mathrm{Br}) \mathrm{H})(\mathrm{H}) \mathrm{Br})(\mathrm{Br}) \mathrm{H})(\mathrm{H}) \mathrm{H})(\mathrm{H}) \mathrm{H})(\mathrm{F}) \mathrm{F})(\mathrm{Cl}) \mathrm{F})(\mathrm{F})(\mathrm{H}) \mathrm{H}$ $\mathrm{C}(\mathrm{C}(\mathrm{C}(\mathrm{C}(\mathrm{C}(\mathrm{C}(\mathrm{C}(\mathrm{C}(\mathrm{C}(\mathrm{C}(\mathrm{C}(\mathrm{F})(\mathrm{F}) \mathrm{H})(\mathrm{Br}) \mathrm{H})(\mathrm{H}) \mathrm{F})(\mathrm{H}) \mathrm{Br})(\mathrm{H}) \mathrm{H})(\mathrm{H}) \mathrm{H})(\mathrm{H}) \mathrm{H})(\mathrm{H}) \mathrm{Br})(\mathrm{Cl}) \mathrm{Br})(\mathrm{F}) \mathrm{Br})(\mathrm{H})(\mathrm{Br}) \mathrm{F}$ $\mathrm{C}(\mathrm{C}(\mathrm{C}(\mathrm{C}(\mathrm{C}(\mathrm{C}(\mathrm{C}(\mathrm{C}(\mathrm{C}(\mathrm{C}(\mathrm{C}(\mathrm{H})(\mathrm{H}) \mathrm{H})(\mathrm{F}) \mathrm{H})(\mathrm{H}) \mathrm{H})(\mathrm{F}) \mathrm{Br})(\mathrm{Br}) \mathrm{H})(\mathrm{F}) \mathrm{H})(\mathrm{F}) \mathrm{H})(\mathrm{H}) \mathrm{Br})(\mathrm{F}) \mathrm{F})(\mathrm{H}) \mathrm{H})(\mathrm{H})(\mathrm{F}) \mathrm{Br}$ $\mathrm{C}(\mathrm{C}(\mathrm{C}(\mathrm{C}(\mathrm{C}(\mathrm{C}(\mathrm{C}(\mathrm{C}(\mathrm{C}(\mathrm{C}(\mathrm{C}(\mathrm{H})(\mathrm{F}) \mathrm{H})(\mathrm{Br}) \mathrm{F})(\mathrm{Br}) \mathrm{H})(\mathrm{H}) \mathrm{F})(\mathrm{H}) \mathrm{H})(\mathrm{F}) \mathrm{H})(\mathrm{Br}) \mathrm{H})(\mathrm{H}) \mathrm{Br})(\mathrm{H}) \mathrm{F})(\mathrm{H}) \mathrm{F})(\mathrm{Br})(\mathrm{H}) \mathrm{H}$ $\mathrm{C}(\mathrm{C}(\mathrm{C}(\mathrm{C}(\mathrm{C}(\mathrm{C}(\mathrm{C}(\mathrm{C}(\mathrm{C}(\mathrm{C}(\mathrm{C}(\mathrm{H})(\mathrm{H}) \mathrm{F})(\mathrm{Br}) \mathrm{F})(\mathrm{H}) \mathrm{Br})(\mathrm{H}) \mathrm{H})(\mathrm{Br}) \mathrm{F})(\mathrm{H}) \mathrm{H})(\mathrm{H}) \mathrm{F})(\mathrm{H}) \mathrm{Br})(\mathrm{Br}) \mathrm{H})(\mathrm{F}) \mathrm{Br})(\mathrm{H})(\mathrm{H}) \mathrm{H}$ $\mathrm{C}(\mathrm{C}(\mathrm{C}(\mathrm{C}(\mathrm{C}(\mathrm{C}(\mathrm{C}(\mathrm{C}(\mathrm{C}(\mathrm{C}(\mathrm{C}(\mathrm{Cl})(\mathrm{Cl}) \mathrm{H})(\mathrm{H}) \mathrm{Cl})(\mathrm{H}) \mathrm{Cl})(\mathrm{H}) \mathrm{H})(\mathrm{Cl}) \mathrm{Cl})(\mathrm{H}) \mathrm{Cl})(\mathrm{H}) \mathrm{H})(\mathrm{Cl}) \mathrm{H})(\mathrm{Cl}) \mathrm{H})(\mathrm{Cl}) \mathrm{H})(\mathrm{Br})(\mathrm{H}) \mathrm{H}$ $\mathrm{C}(\mathrm{C}(\mathrm{C}(\mathrm{C}(\mathrm{C}(\mathrm{C}(\mathrm{C}(\mathrm{C}(\mathrm{C}(\mathrm{C}(\mathrm{C}(\mathrm{Cl})(\mathrm{H}) \mathrm{H})(\mathrm{Cl}) \mathrm{H})(\mathrm{Cl}) \mathrm{Cl})(\mathrm{Cl}) \mathrm{H})(\mathrm{H}) \mathrm{Cl})(\mathrm{H}) \mathrm{Cl})(\mathrm{Cl}) \mathrm{H})(\mathrm{Cl}) \mathrm{H})(\mathrm{H}) \mathrm{H})(\mathrm{H}) \mathrm{H})(\mathrm{F})(\mathrm{H}) \mathrm{Cl}$ $\mathrm{C}(\mathrm{C}(\mathrm{C}(\mathrm{C}(\mathrm{C}(\mathrm{C}(\mathrm{C}(\mathrm{C}(\mathrm{C}(\mathrm{C}(\mathrm{C}(\mathrm{Cl})(\mathrm{Cl}) \mathrm{H})(\mathrm{Cl}) \mathrm{H})(\mathrm{Cl}) \mathrm{H})(\mathrm{H}) \mathrm{Cl})(\mathrm{Cl}) \mathrm{H})(\mathrm{Cl}) \mathrm{H})(\mathrm{H}) \mathrm{H})(\mathrm{Cl}) \mathrm{Cl})(\mathrm{H}) \mathrm{H})(\mathrm{H}) \mathrm{Cl})(\mathrm{Cl})(\mathrm{H}) \mathrm{H}$ $\mathrm{C}(\mathrm{C}(\mathrm{C}(\mathrm{C}(\mathrm{C}(\mathrm{C}(\mathrm{C}(\mathrm{C}(\mathrm{C}(\mathrm{C}(\mathrm{C}(\mathrm{H})(\mathrm{Br}) \mathrm{Cl})(\mathrm{F}) \mathrm{F})(\mathrm{H}) \mathrm{Cl})(\mathrm{H}) \mathrm{H})(\mathrm{F}) \mathrm{F})(\mathrm{H}) \mathrm{H})(\mathrm{H}) \mathrm{Br})(\mathrm{H}) \mathrm{H})(\mathrm{Br}) \mathrm{H})(\mathrm{H}) \mathrm{F})(\mathrm{H})(\mathrm{F}) \mathrm{H}$ $\mathrm{C}(\mathrm{C}(\mathrm{C}(\mathrm{C}(\mathrm{C}(\mathrm{C}(\mathrm{C}(\mathrm{C}(\mathrm{C}(\mathrm{C}(\mathrm{C}(\mathrm{Br})(\mathrm{H}) \mathrm{H})(\mathrm{F}) \mathrm{H})(\mathrm{H}) \mathrm{H})(\mathrm{F}) \mathrm{Br})(\mathrm{Cl}) \mathrm{H})(\mathrm{F}) \mathrm{F})(\mathrm{H}) \mathrm{Cl})(\mathrm{H}) \mathrm{H})(\mathrm{Br}) \mathrm{H})(\mathrm{H}) \mathrm{Br})(\mathrm{Br})(\mathrm{H}) \mathrm{H}$ $\mathrm{C}(\mathrm{C}(\mathrm{C}(\mathrm{C}(\mathrm{C}(\mathrm{C}(\mathrm{C}(\mathrm{C}(\mathrm{C}(\mathrm{C}(\mathrm{C}(\mathrm{H})(\mathrm{F}) \mathrm{H})(\mathrm{H}) \mathrm{H})(\mathrm{F}) \mathrm{F})(\mathrm{F}) \mathrm{F})(\mathrm{Br}) \mathrm{H})(\mathrm{Cl}) \mathrm{H})(\mathrm{Br}) \mathrm{H})(\mathrm{H}) \mathrm{Cl})(\mathrm{H}) \mathrm{H})(\mathrm{H}) \mathrm{Cl})(\mathrm{H})(\mathrm{Br}) \mathrm{H}$ $\mathrm{C}(\mathrm{C}(\mathrm{C}(\mathrm{C}(\mathrm{C}(\mathrm{C}(\mathrm{C}(\mathrm{C}(\mathrm{C}(\mathrm{C}(\mathrm{C}(\mathrm{Cl})(\mathrm{H}) \mathrm{F})(\mathrm{F}) \mathrm{Br})(\mathrm{F}) \mathrm{H})(\mathrm{H}) \mathrm{H})(\mathrm{H}) \mathrm{Br})(\mathrm{H}) \mathrm{Br})(\mathrm{H}) \mathrm{Cl})(\mathrm{H}) \mathrm{H})(\mathrm{H}) \mathrm{F})(\mathrm{H}) \mathrm{Br})(\mathrm{H})(\mathrm{Cl}) \mathrm{H}$ $\mathrm{C}(\mathrm{C}(\mathrm{C}(\mathrm{C}(\mathrm{C}(\mathrm{C}(\mathrm{C}(\mathrm{C}(\mathrm{C}(\mathrm{C}(\mathrm{C}(\mathrm{H})(\mathrm{F}) \mathrm{H})(\mathrm{H}) \mathrm{Br})(\mathrm{Cl}) \mathrm{H})(\mathrm{Cl}) \mathrm{Br})(\mathrm{H}) \mathrm{H})(\mathrm{Br}) \mathrm{H})(\mathrm{H}) \mathrm{H})(\mathrm{H}) \mathrm{F})(\mathrm{Cl}) \mathrm{Br})(\mathrm{H}) \mathrm{H})(\mathrm{H})(\mathrm{F}) \mathrm{B}$ $\mathrm{C}(\mathrm{C}(\mathrm{C}(\mathrm{C}(\mathrm{C}(\mathrm{C}(\mathrm{C}(\mathrm{C}(\mathrm{C}(\mathrm{C}(\mathrm{C}(\mathrm{H})(\mathrm{H}) \mathrm{Cl})(\mathrm{Br}) \mathrm{H})(\mathrm{Cl}) \mathrm{H})(\mathrm{F}) \mathrm{H})(\mathrm{H}) \mathrm{H})(\mathrm{F}) \mathrm{H})(\mathrm{H}) \mathrm{H})(\mathrm{F}) \mathrm{H})(\mathrm{H}) \mathrm{Cl})(\mathrm{H}) \mathrm{F})(\mathrm{Cl})(\mathrm{Br}) \mathrm{F}$ $\mathrm{C}(\mathrm{C}(\mathrm{C}(\mathrm{C}(\mathrm{C}(\mathrm{C}(\mathrm{C}(\mathrm{C}(\mathrm{C}(\mathrm{C}(\mathrm{C}(\mathrm{H})(\mathrm{Br}) \mathrm{F})(\mathrm{Cl}) \mathrm{H})(\mathrm{H}) \mathrm{Cl})(\mathrm{F}) \mathrm{H})(\mathrm{Br}) \mathrm{F})(\mathrm{H}) \mathrm{Cl})(\mathrm{H}) \mathrm{Cl})(\mathrm{H}) \mathrm{H})(\mathrm{H}) \mathrm{H})(\mathrm{F}) \mathrm{H})(\mathrm{Br})(\mathrm{H}) \mathrm{H}$ $\mathrm{C}(\mathrm{C}(\mathrm{C}(\mathrm{C}(\mathrm{C}(\mathrm{C}(\mathrm{C}(\mathrm{C}(\mathrm{C}(\mathrm{C}(\mathrm{C}(\mathrm{H})(\mathrm{Cl}) \mathrm{F})(\mathrm{H}) \mathrm{H})(\mathrm{Br}) \mathrm{Cl})(\mathrm{H}) \mathrm{Br})(\mathrm{H}) \mathrm{H})(\mathrm{F}) \mathrm{F})(\mathrm{H}) \mathrm{Br})(\mathrm{Cl}) \mathrm{H})(\mathrm{H}) \mathrm{H})(\mathrm{H}) \mathrm{Cl})(\mathrm{Br})(\mathrm{H}) \mathrm{H}$ $\mathrm{C}(\mathrm{C}(\mathrm{C}(\mathrm{C}(\mathrm{C}(\mathrm{C}(\mathrm{C}(\mathrm{C}(\mathrm{C}(\mathrm{C}(\mathrm{C}(\mathrm{H})(\mathrm{H}) \mathrm{F})(\mathrm{F}) \mathrm{H})(\mathrm{H}) \mathrm{Br})(\mathrm{Br}) \mathrm{H})(\mathrm{H}) \mathrm{H})(\mathrm{H}) \mathrm{H})(\mathrm{Br}) \mathrm{H})(\mathrm{H}) \mathrm{Br})(\mathrm{H}) \mathrm{Cl})(\mathrm{Br}) \mathrm{H})(\mathrm{Cl})(\mathrm{Cl}) \mathrm{Cl}$ $\mathrm{C}(\mathrm{C}(\mathrm{C}(\mathrm{C}(\mathrm{C}(\mathrm{C}(\mathrm{C}(\mathrm{C}(\mathrm{C}(\mathrm{C}(\mathrm{C}(\mathrm{Cl})(\mathrm{H}) \mathrm{F})(\mathrm{H}) \mathrm{H})(\mathrm{Cl}) \mathrm{Cl})(\mathrm{Br}) \mathrm{H})(\mathrm{F}) \mathrm{H})(\mathrm{H}) \mathrm{H})(\mathrm{H}) \mathrm{H})(\mathrm{H}) \mathrm{Cl})(\mathrm{F}) \mathrm{H})(\mathrm{H}) \mathrm{Cl})(\mathrm{Br})(\mathrm{F}) \mathrm{H}$ $\mathrm{C}(\mathrm{C}(\mathrm{C}(\mathrm{C}(\mathrm{C}(\mathrm{C}(\mathrm{C}(\mathrm{C}(\mathrm{C}(\mathrm{C}(\mathrm{C}(\mathrm{F})(\mathrm{F}) \mathrm{H})(\mathrm{Br}) \mathrm{Br})(\mathrm{H}) \mathrm{H})(\mathrm{H}) \mathrm{Cl})(\mathrm{Cl}) \mathrm{H})(\mathrm{H}) \mathrm{F})(\mathrm{Cl}) \mathrm{H})(\mathrm{H}) \mathrm{H})(\mathrm{H}) \mathrm{H})(\mathrm{H}) \mathrm{H})(\mathrm{Br})(\mathrm{Cl}) \mathrm{C}$ $\mathrm{C}(\mathrm{C}(\mathrm{C}(\mathrm{C}(\mathrm{C}(\mathrm{C}(\mathrm{C}(\mathrm{C}(\mathrm{C}(\mathrm{C}(\mathrm{C}(\mathrm{H})(\mathrm{F}) \mathrm{F})(\mathrm{H}) \mathrm{H})(\mathrm{Cl}) \mathrm{H})(\mathrm{H}) \mathrm{H})(\mathrm{F}) \mathrm{Cl})(\mathrm{H}) \mathrm{Cl})(\mathrm{H}) \mathrm{H})(\mathrm{H}) \mathrm{H})(\mathrm{F}) \mathrm{Cl})(\mathrm{F}) \mathrm{H})(\mathrm{Br})(\mathrm{H}) \mathrm{C}$ $\mathrm{C}(\mathrm{C}(\mathrm{C}(\mathrm{C}(\mathrm{C}(\mathrm{C}(\mathrm{C}(\mathrm{C}(\mathrm{C}(\mathrm{C}(\mathrm{C}(\mathrm{Cl})(\mathrm{H}) \mathrm{Cl})(\mathrm{H}) \mathrm{Br})(\mathrm{H}) \mathrm{Cl})(\mathrm{Cl}) \mathrm{H})(\mathrm{Cl}) \mathrm{H})(\mathrm{H}) \mathrm{Cl})(\mathrm{H}) \mathrm{H})(\mathrm{H}) \mathrm{H})(\mathrm{H}) \mathrm{Br})(\mathrm{Br}) \mathrm{H})(\mathrm{H})(\mathrm{F}) \mathrm{F}$ $\mathrm{C}(\mathrm{C}(\mathrm{C}(\mathrm{C}(\mathrm{C}(\mathrm{C}(\mathrm{C}(\mathrm{C}(\mathrm{C}(\mathrm{C}(\mathrm{C}(\mathrm{H})(\mathrm{H}) \mathrm{H})(\mathrm{Cl}) \mathrm{H})(\mathrm{H}) \mathrm{H})(\mathrm{F}) \mathrm{Br})(\mathrm{F}) \mathrm{H})(\mathrm{F}) \mathrm{H})(\mathrm{Cl}) \mathrm{H})(\mathrm{H}) \mathrm{Cl})(\mathrm{H}) \mathrm{Cl})(\mathrm{H}) \mathrm{Cl})(\mathrm{Cl})(\mathrm{F}) \mathrm{H}$ $\mathrm{C}(\mathrm{C}(\mathrm{C}(\mathrm{C}(\mathrm{C}(\mathrm{C}(\mathrm{C}(\mathrm{C}(\mathrm{C}(\mathrm{C}(\mathrm{C}(\mathrm{Cl})(\mathrm{F}) \mathrm{H})(\mathrm{Cl}) \mathrm{Cl})(\mathrm{H}) \mathrm{Br})(\mathrm{H}) \mathrm{F})(\mathrm{H}) \mathrm{H})(\mathrm{H}) \mathrm{Br})(\mathrm{Cl}) \mathrm{H})(\mathrm{H}) \mathrm{Cl})(\mathrm{H}) \mathrm{H})(\mathrm{Cl}) \mathrm{H})(\mathrm{H})(\mathrm{H}) \mathrm{Cl}$ $\mathrm{C}(\mathrm{C}(\mathrm{C}(\mathrm{C}(\mathrm{C}(\mathrm{C}(\mathrm{C}(\mathrm{C}(\mathrm{C}(\mathrm{C}(\mathrm{C}(\mathrm{H})(\mathrm{H}) \mathrm{H})(\mathrm{F}) \mathrm{H})(\mathrm{H}) \mathrm{H})(\mathrm{Cl}) \mathrm{H})(\mathrm{Cl}) \mathrm{H})(\mathrm{Cl}) \mathrm{Cl})(\mathrm{Cl}) \mathrm{H})(\mathrm{Br}) \mathrm{H})(\mathrm{F}) \mathrm{F})(\mathrm{Cl}) \mathrm{H})(\mathrm{H})(\mathrm{Cl}) \mathrm{H}$ $\mathrm{C}(\mathrm{C}(\mathrm{C}(\mathrm{C}(\mathrm{C}(\mathrm{C}(\mathrm{C}(\mathrm{C}(\mathrm{C}(\mathrm{C}(\mathrm{C}(\mathrm{H})(\mathrm{Cl}) \mathrm{Cl})(\mathrm{H}) \mathrm{H})(\mathrm{H}) \mathrm{Cl})(\mathrm{F}) \mathrm{Cl})(\mathrm{H}) \mathrm{H})(\mathrm{H}) \mathrm{Cl})(\mathrm{H}) \mathrm{F})(\mathrm{H}) \mathrm{Cl})(\mathrm{F}) \mathrm{H})(\mathrm{F}) \mathrm{H})(\mathrm{H})(\mathrm{H}) \mathrm{Cl}$ $\mathrm{C}(\mathrm{C}(\mathrm{C}(\mathrm{C}(\mathrm{C}(\mathrm{C}(\mathrm{C}(\mathrm{C}(\mathrm{C}(\mathrm{C}(\mathrm{C}(\mathrm{F})(\mathrm{H}) \mathrm{H})(\mathrm{H}) \mathrm{H})(\mathrm{F}) \mathrm{Cl})(\mathrm{Cl}) \mathrm{Cl})(\mathrm{Cl}) \mathrm{H})(\mathrm{H}) \mathrm{H})(\mathrm{H}) \mathrm{Cl})(\mathrm{Cl}) \mathrm{H})(\mathrm{H}) \mathrm{F})(\mathrm{Cl}) \mathrm{H})(\mathrm{H})(\mathrm{Cl}) \mathrm{H}$ $\mathrm{C}(\mathrm{C}(\mathrm{C}(\mathrm{C}(\mathrm{C}(\mathrm{C}(\mathrm{C}(\mathrm{C}(\mathrm{C}(\mathrm{C}(\mathrm{C}(\mathrm{Cl})(\mathrm{Cl}) \mathrm{H})(\mathrm{H}) \mathrm{H})(\mathrm{H}) \mathrm{Cl})(\mathrm{H}) \mathrm{Cl})(\mathrm{H}) \mathrm{Cl})(\mathrm{H}) \mathrm{Cl})(\mathrm{Cl}) \mathrm{H})(\mathrm{H}) \mathrm{H})(\mathrm{H}) \mathrm{Br})(\mathrm{H}) \mathrm{H})(\mathrm{Cl})(\mathrm{Cl}) \mathrm{F}$ $\mathrm{C}(\mathrm{C}(\mathrm{C}(\mathrm{C}(\mathrm{C}(\mathrm{C}(\mathrm{C}(\mathrm{C}(\mathrm{C}(\mathrm{C}(\mathrm{C}(\mathrm{F})(\mathrm{H}) \mathrm{H})(\mathrm{F}) \mathrm{H})(\mathrm{H}) \mathrm{H})(\mathrm{H}) \mathrm{H})(\mathrm{H}) \mathrm{F})(\mathrm{Br}) \mathrm{Br})(\mathrm{F}) \mathrm{H})(\mathrm{F}) \mathrm{H})(\mathrm{Br}) \mathrm{H})(\mathrm{Cl}) \mathrm{H})(\mathrm{Br})(\mathrm{F}) \mathrm{H}$ $\mathrm{C}(\mathrm{C}(\mathrm{C}(\mathrm{C}(\mathrm{C}(\mathrm{C}(\mathrm{C}(\mathrm{C}(\mathrm{C}(\mathrm{C}(\mathrm{C}(\mathrm{F})(\mathrm{H}) \mathrm{H})(\mathrm{H}) \mathrm{H})(\mathrm{Br}) \mathrm{H})(\mathrm{H}) \mathrm{H})(\mathrm{H}) \mathrm{Br})(\mathrm{F}) \mathrm{H})(\mathrm{H}) \mathrm{F})(\mathrm{Br}) \mathrm{F})(\mathrm{Cl}) \mathrm{H})(\mathrm{H}) \mathrm{H})(\mathrm{F})(\mathrm{Br}) \mathrm{Br}$ $\mathrm{C}(\mathrm{C}(\mathrm{C}(\mathrm{C}(\mathrm{C}(\mathrm{C}(\mathrm{C}(\mathrm{C}(\mathrm{C}(\mathrm{C}(\mathrm{C}(\mathrm{F})(\mathrm{H}) \mathrm{F})(\mathrm{F}) \mathrm{H})(\mathrm{H}) \mathrm{H})(\mathrm{Br}) \mathrm{H})(\mathrm{H}) \mathrm{H})(\mathrm{H}) \mathrm{F})(\mathrm{H}) \mathrm{Br})(\mathrm{H}) \mathrm{Br})(\mathrm{Br}) \mathrm{H})(\mathrm{Br}) \mathrm{Br})(\mathrm{H})(\mathrm{Cl}) \mathrm{H}$ $\mathrm{C}(\mathrm{C}(\mathrm{C}(\mathrm{C}(\mathrm{C}(\mathrm{C}(\mathrm{C}(\mathrm{C}(\mathrm{C}(\mathrm{C}(\mathrm{C}(\mathrm{F})(\mathrm{Br}) \mathrm{Br})(\mathrm{H}) \mathrm{H})(\mathrm{Br}) \mathrm{H})(\mathrm{F}) \mathrm{H})(\mathrm{F}) \mathrm{H})(\mathrm{H}) \mathrm{F})(\mathrm{H}) \mathrm{H})(\mathrm{H}) \mathrm{F})(\mathrm{H}) \mathrm{H})(\mathrm{F}) \mathrm{Br})(\mathrm{H})(\mathrm{H}) \mathrm{H}$ $\mathrm{C}(\mathrm{C}(\mathrm{C}(\mathrm{C}(\mathrm{C}(\mathrm{C}(\mathrm{C}(\mathrm{C}(\mathrm{C}(\mathrm{C}(\mathrm{C}(\mathrm{H})(\mathrm{F}) \mathrm{H})(\mathrm{H}) \mathrm{H})(\mathrm{H}) \mathrm{Br})(\mathrm{H}) \mathrm{H})(\mathrm{F}) \mathrm{H})(\mathrm{Br}) \mathrm{F})(\mathrm{F}) \mathrm{H})(\mathrm{H}) \mathrm{Br})(\mathrm{Br}) \mathrm{Br})(\mathrm{H}) \mathrm{H})(\mathrm{F})(\mathrm{H}) \mathrm{H}$ $\mathrm{C}(\mathrm{C}(\mathrm{C}(\mathrm{C}(\mathrm{C}(\mathrm{C}(\mathrm{C}(\mathrm{C}(\mathrm{C}(\mathrm{C}(\mathrm{C}(\mathrm{H})(\mathrm{H}) \mathrm{Br})(\mathrm{Br}) \mathrm{F})(\mathrm{H}) \mathrm{H})(\mathrm{H}) \mathrm{Br})(\mathrm{H}) \mathrm{Br})(\mathrm{H}) \mathrm{H})(\mathrm{F}) \mathrm{H})(\mathrm{H}) \mathrm{H})(\mathrm{H}) \mathrm{F})(\mathrm{H}) \mathrm{Br})(\mathrm{H})(\mathrm{Br}) \mathrm{F}$ $\mathrm{C}(\mathrm{C}(\mathrm{C}(\mathrm{C}(\mathrm{C}(\mathrm{C}(\mathrm{C}(\mathrm{C}(\mathrm{C}(\mathrm{C}(\mathrm{C}(\mathrm{H})(\mathrm{H}) \mathrm{H})(\mathrm{Br}) \mathrm{H})(\mathrm{H}) \mathrm{Br})(\mathrm{Br}) \mathrm{Br})(\mathrm{H}) \mathrm{H})(\mathrm{F}) \mathrm{H})(\mathrm{H}) \mathrm{Br})(\mathrm{H}) \mathrm{Br})(\mathrm{H}) \mathrm{F})(\mathrm{H}) \mathrm{Br})(\mathrm{F})(\mathrm{H}) \mathrm{H}$ $\mathrm{C}(\mathrm{C}(\mathrm{C}(\mathrm{C}(\mathrm{C}(\mathrm{C}(\mathrm{C}(\mathrm{C}(\mathrm{C}(\mathrm{C}(\mathrm{C}(\mathrm{H})(\mathrm{Cl}) \mathrm{H})(\mathrm{Cl}) \mathrm{H})(\mathrm{Cl}) \mathrm{H})(\mathrm{Cl}) \mathrm{Cl})(\mathrm{Cl}) \mathrm{H})(\mathrm{H}) \mathrm{H})(\mathrm{Cl}) \mathrm{H})(\mathrm{H}) \mathrm{Cl})(\mathrm{Cl}) \mathrm{H})(\mathrm{Cl}) \mathrm{H})(\mathrm{H})(\mathrm{H}) \mathrm{H}$ $\mathrm{C}(\mathrm{C}(\mathrm{C}(\mathrm{C}(\mathrm{C}(\mathrm{C}(\mathrm{C}(\mathrm{C}(\mathrm{C}(\mathrm{C}(\mathrm{C}(\mathrm{F})(\mathrm{H}) \mathrm{Br})(\mathrm{F}) \mathrm{Br})(\mathrm{F}) \mathrm{H})(\mathrm{H}) \mathrm{H})(\mathrm{H}) \mathrm{F})(\mathrm{H}) \mathrm{H})(\mathrm{H}) \mathrm{H})(\mathrm{Br}) \mathrm{F})(\mathrm{Cl}) \mathrm{H})(\mathrm{H}) \mathrm{H})(\mathrm{H})(\mathrm{Cl}) \mathrm{H}$ $\mathrm{C}(\mathrm{C}(\mathrm{C}(\mathrm{C}(\mathrm{C}(\mathrm{C}(\mathrm{C}(\mathrm{C}(\mathrm{C}(\mathrm{C}(\mathrm{C}(\mathrm{Br})(\mathrm{H}) \mathrm{H})(\mathrm{Cl}) \mathrm{Br})(\mathrm{H}) \mathrm{H})(\mathrm{H}) \mathrm{H})(\mathrm{H}) \mathrm{H})(\mathrm{H}) \mathrm{H})(\mathrm{H}) \mathrm{Br})(\mathrm{F}) \mathrm{H})(\mathrm{H}) \mathrm{F})(\mathrm{Br}) \mathrm{H})(\mathrm{Cl})(\mathrm{F}) \mathrm{F}$ $\mathrm{C}(\mathrm{C}(\mathrm{C}(\mathrm{C}(\mathrm{C}(\mathrm{C}(\mathrm{C}(\mathrm{C}(\mathrm{C}(\mathrm{C}(\mathrm{C}(\mathrm{F})(\mathrm{Br}) \mathrm{H})(\mathrm{H}) \mathrm{H})(\mathrm{H}) \mathrm{Br})(\mathrm{Cl}) \mathrm{H})(\mathrm{F}) \mathrm{H})(\mathrm{Cl}) \mathrm{Br})(\mathrm{H}) \mathrm{Br})(\mathrm{F}) \mathrm{H})(\mathrm{H}) \mathrm{H})(\mathrm{H}) \mathrm{H})(\mathrm{H})(\mathrm{H}) \mathrm{Br}$ $\mathrm{C}(\mathrm{C}(\mathrm{C}(\mathrm{C}(\mathrm{C}(\mathrm{C}(\mathrm{C}(\mathrm{C}(\mathrm{C}(\mathrm{C}(\mathrm{C}(\mathrm{H})(\mathrm{Br}) \mathrm{Cl})(\mathrm{H}) \mathrm{H})(\mathrm{F}) \mathrm{H})(\mathrm{H}) \mathrm{Br})(\mathrm{H}) \mathrm{Cl})(\mathrm{H}) \mathrm{H})(\mathrm{H}) \mathrm{Br})(\mathrm{H}) \mathrm{H})(\mathrm{H}) \mathrm{Br})(\mathrm{F}) \mathrm{H})(\mathrm{Br})(\mathrm{Br}) \mathrm{H}$ $\mathrm{C}(\mathrm{C}(\mathrm{C}(\mathrm{C}(\mathrm{C}(\mathrm{C}(\mathrm{C}(\mathrm{C}(\mathrm{C}(\mathrm{C}(\mathrm{C}(\mathrm{H})(\mathrm{H}) \mathrm{H})(\mathrm{H}) \mathrm{H})(\mathrm{F}) \mathrm{H})(\mathrm{Cl}) \mathrm{H})(\mathrm{H}) \mathrm{H})(\mathrm{H}) \mathrm{H})(\mathrm{Cl}) \mathrm{H})(\mathrm{F}) \mathrm{H})(\mathrm{Cl}) \mathrm{F})(\mathrm{Br}) \mathrm{F})(\mathrm{H})(\mathrm{F}) \mathrm{B}$ $\mathrm{C}(\mathrm{C}(\mathrm{C}(\mathrm{C}(\mathrm{C}(\mathrm{C}(\mathrm{C}(\mathrm{C}(\mathrm{C}(\mathrm{C}(\mathrm{C}(\mathrm{H})(\mathrm{F}) \mathrm{H})(\mathrm{H}) \mathrm{H})(\mathrm{H}) \mathrm{H})(\mathrm{Cl}) \mathrm{H})(\mathrm{Cl}) \mathrm{Br})(\mathrm{H}) \mathrm{F})(\mathrm{H}) \mathrm{Br})(\mathrm{H}) \mathrm{Br})(\mathrm{Cl}) \mathrm{F})(\mathrm{H}) \mathrm{H})(\mathrm{H})(\mathrm{H}) \mathrm{F}$ $\mathrm{C}(\mathrm{C}(\mathrm{C}(\mathrm{C}(\mathrm{C}(\mathrm{C}(\mathrm{C}(\mathrm{C}(\mathrm{C}(\mathrm{C}(\mathrm{C}(\mathrm{H})(\mathrm{Br}) \mathrm{H})(\mathrm{Cl}) \mathrm{H})(\mathrm{H}) \mathrm{F})(\mathrm{Br}) \mathrm{F})(\mathrm{H}) \mathrm{H})(\mathrm{H}) \mathrm{F})(\mathrm{Cl}) \mathrm{Cl})(\mathrm{Br}) \mathrm{H})(\mathrm{H}) \mathrm{H})(\mathrm{H}) \mathrm{H})(\mathrm{H})(\mathrm{H}) \mathrm{B}$ $\mathrm{C}(\mathrm{C}(\mathrm{C}(\mathrm{C}(\mathrm{C}(\mathrm{C}(\mathrm{C}(\mathrm{C}(\mathrm{C}(\mathrm{C}(\mathrm{C}(\mathrm{H})(\mathrm{F}) \mathrm{Cl})(\mathrm{H}) \mathrm{H})(\mathrm{Cl}) \mathrm{Br})(\mathrm{H}) \mathrm{H})(\mathrm{H}) \mathrm{Br})(\mathrm{H}) \mathrm{Cl})(\mathrm{H}) \mathrm{H})(\mathrm{H}) \mathrm{Cl})(\mathrm{H}) \mathrm{H})(\mathrm{F}) \mathrm{H})(\mathrm{F})(\mathrm{H}) \mathrm{Br}$ $\mathrm{C}(\mathrm{C}(\mathrm{C}(\mathrm{C}(\mathrm{C}(\mathrm{C}(\mathrm{C}(\mathrm{C}(\mathrm{C}(\mathrm{C}(\mathrm{C}(\mathrm{H})(\mathrm{H}) \mathrm{H})(\mathrm{H}) \mathrm{F})(\mathrm{Cl}) \mathrm{H})(\mathrm{H}) \mathrm{Br})(\mathrm{H}) \mathrm{F})(\mathrm{H}) \mathrm{Cl})(\mathrm{H}) \mathrm{Br})(\mathrm{Br}) \mathrm{Br})(\mathrm{H}) \mathrm{H})(\mathrm{Cl}) \mathrm{Cl})(\mathrm{H})(\mathrm{H}) \mathrm{H}$ $\mathrm{C}(\mathrm{C}(\mathrm{C}(\mathrm{C}(\mathrm{C}(\mathrm{C}(\mathrm{C}(\mathrm{C}(\mathrm{C}(\mathrm{C}(\mathrm{C}(\mathrm{H})(\mathrm{H}) \mathrm{H})(\mathrm{Cl}) \mathrm{F})(\mathrm{F}) \mathrm{H})(\mathrm{F}) \mathrm{H})(\mathrm{Cl}) \mathrm{Cl})(\mathrm{H}) \mathrm{Br})(\mathrm{H}) \mathrm{Cl})(\mathrm{H}) \mathrm{H})(\mathrm{H}) \mathrm{Br})(\mathrm{Cl}) \mathrm{H})(\mathrm{H})(\mathrm{H}) \mathrm{H}$ $\mathrm{C}(\mathrm{C}(\mathrm{C}(\mathrm{C}(\mathrm{C}(\mathrm{C}(\mathrm{C}(\mathrm{C}(\mathrm{C}(\mathrm{C}(\mathrm{C}(\mathrm{Cl})(\mathrm{H}) \mathrm{Br})(\mathrm{H}) \mathrm{H})(\mathrm{H}) \mathrm{H})(\mathrm{H}) \mathrm{Cl})(\mathrm{H}) \mathrm{Cl})(\mathrm{Br}) \mathrm{H})(\mathrm{H}) \mathrm{H})(\mathrm{F}) \mathrm{Cl})(\mathrm{F}) \mathrm{H})(\mathrm{H}) \mathrm{H})(\mathrm{Cl})(\mathrm{Br}) \mathrm{H}$ $\mathrm{C}(\mathrm{C}(\mathrm{C}(\mathrm{C}(\mathrm{C}(\mathrm{C}(\mathrm{C}(\mathrm{C}(\mathrm{C}(\mathrm{C}(\mathrm{C}(\mathrm{Br})(\mathrm{H}) \mathrm{Cl})(\mathrm{Cl}) \mathrm{H})(\mathrm{Cl}) \mathrm{H})(\mathrm{H}) \mathrm{H})(\mathrm{H}) \mathrm{H})(\mathrm{Cl}) \mathrm{H})(\mathrm{F}) \mathrm{H})(\mathrm{H}) \mathrm{Br})(\mathrm{Cl}) \mathrm{H})(\mathrm{Br}) \mathrm{Br})(\mathrm{H})(\mathrm{H}) \mathrm{H}$ $\mathrm{C}(\mathrm{C}(\mathrm{C}(\mathrm{C}(\mathrm{C}(\mathrm{C}(\mathrm{C}(\mathrm{C}(\mathrm{C}(\mathrm{C}(\mathrm{C}(\mathrm{H})(\mathrm{H}) \mathrm{Cl})(\mathrm{H}) \mathrm{Cl})(\mathrm{H}) \mathrm{H})(\mathrm{H}) \mathrm{H})(\mathrm{F}) \mathrm{Cl})(\mathrm{F}) \mathrm{H})(\mathrm{H}) \mathrm{H})(\mathrm{H}) \mathrm{H})(\mathrm{H}) \mathrm{Cl})(\mathrm{Cl}) \mathrm{Br})(\mathrm{H})(\mathrm{F}) \mathrm{F}$ $\mathrm{C}(\mathrm{C}(\mathrm{C}(\mathrm{C}(\mathrm{C}(\mathrm{C}(\mathrm{C}(\mathrm{C}(\mathrm{C}(\mathrm{C}(\mathrm{C}(\mathrm{H})(\mathrm{Br}) \mathrm{Cl})(\mathrm{H}) \mathrm{H})(\mathrm{H}) \mathrm{Cl})(\mathrm{Br}) \mathrm{Cl})(\mathrm{H}) \mathrm{H})(\mathrm{H}) \mathrm{Cl})(\mathrm{H}) \mathrm{Cl})(\mathrm{H}) \mathrm{Cl})(\mathrm{F}) \mathrm{H})(\mathrm{H}) \mathrm{H})(\mathrm{H})(\mathrm{F}) \mathrm{H}$ $\mathrm{C}(\mathrm{C}(\mathrm{C}(\mathrm{C}(\mathrm{C}(\mathrm{C}(\mathrm{C}(\mathrm{C}(\mathrm{C}(\mathrm{C}(\mathrm{C}(\mathrm{H})(\mathrm{Br}) \mathrm{Br})(\mathrm{H}) \mathrm{Br})(\mathrm{Cl}) \mathrm{H})(\mathrm{H}) \mathrm{H})(\mathrm{F}) \mathrm{Cl})(\mathrm{H}) \mathrm{Cl})(\mathrm{Cl}) \mathrm{H})(\mathrm{H}) \mathrm{Cl})(\mathrm{H}) \mathrm{Cl})(\mathrm{H}) \mathrm{H})(\mathrm{H})(\mathrm{H}) \mathrm{H}$ $\mathrm{C}(\mathrm{C}(\mathrm{C}(\mathrm{C}(\mathrm{C}(\mathrm{C}(\mathrm{C}(\mathrm{C}(\mathrm{C}(\mathrm{C}(\mathrm{C}(\mathrm{Br})(\mathrm{H}) \mathrm{Cl})(\mathrm{F}) \mathrm{H})(\mathrm{Cl}) \mathrm{F})(\mathrm{Cl}) \mathrm{H})(\mathrm{H}) \mathrm{H})(\mathrm{H}) \mathrm{H})(\mathrm{H}) \mathrm{H})(\mathrm{H}) \mathrm{H})(\mathrm{H}) \mathrm{Cl})(\mathrm{F}) \mathrm{H})(\mathrm{H})(\mathrm{Cl}) \mathrm{Cl}$
C11H11C14Br4F5 $\mathrm{C} 11 \mathrm{H} 11 \mathrm{Cl} \mathrm{B} \mathrm{B} 2 \mathrm{~F} 6$ $\mathrm{C} 11 \mathrm{H} 11 \mathrm{Cl} \mathrm{B} \mathrm{Br} 3 \mathrm{~F} 5$ $\mathrm{C} 11 \mathrm{H} 11 \mathrm{Cl} 5 \mathrm{Br} 4 \mathrm{~F} 4$ $\mathrm{C} 11 \mathrm{H} 11 \mathrm{C} 16 \mathrm{Br} 2 \mathrm{~F} 5$ C11H11Cl6Br3F4 $\mathrm{C} 11 \mathrm{H} 11 \mathrm{Cl}$ BrF6 $\mathrm{C} 11 \mathrm{H} 11 \mathrm{Cl} 1 \mathrm{BrF}$ C11H11Cl7F6

$\mathrm{C} 11 \mathrm{H} 11 \mathrm{Cl} 8 \mathrm{Br} 2 \mathrm{~F} 3$ $\mathrm{C} 11 \mathrm{H} 11 \mathrm{Cl} 8 \mathrm{BrF} 4$ C11H11Cl8F5

C11H11ClBr4F8 C11H11ClBr5F7 C11H11ClBr7F5 $\mathrm{C} 11 \mathrm{H} 12 \mathrm{Br} 5 \mathrm{~F} 7$

C11H12Br7F5

$\mathrm{C} 11 \mathrm{H} 12 \mathrm{Cl10F} 2$

$\mathrm{C} 11 \mathrm{H} 12 \mathrm{Cl} 2 \mathrm{Br} 3 \mathrm{~F} 7$

C11H12Cl2Br4F6

C11H12Cl3Br3F6

C11H12C14Br2F6

C11H12Cl4Br3F5

$\mathrm{C} 11 \mathrm{H} 12 \mathrm{Cl} \mathrm{BB} 2 \mathrm{~F} 5$

$\mathrm{C} 11 \mathrm{H} 12 \mathrm{Cl} 5 \mathrm{Br} 3 \mathrm{~F} 4$

C11H12Cl5BrF6

$\mathrm{C} 11 \mathrm{H} 12 \mathrm{Cl} 6 \mathrm{Br} 2 \mathrm{~F} 4$

$\mathrm{C} 11 \mathrm{H} 12 \mathrm{Cl} 6 \mathrm{Br} 3 \mathrm{~F} 3$

C11H12Cl6BrF5

C11H12C17BrF4

C11H12Cl7F5

C11H12Cl8BrF3

C11H12Cl8F4

C11H12ClBr4F7

C11H12ClBr5F6

C11H12ClBr6F5

11H13Br4F7

C11H13Br5F6

C11H13Br6F5

C11H13Cl10Br

C11H13Cl10F

C11H13Cl2Br3F6

C11H13Cl2Br5F4

C11H13Cl3Br3F5

$\mathrm{C} 11 \mathrm{H} 13 \mathrm{Cl} 3 \mathrm{Br} 4 \mathrm{~F} 4$

$\mathrm{C} 11 \mathrm{H} 13 \mathrm{Cl} 3 \mathrm{Br} 5 \mathrm{~F} 3$

C11H13Cl4Br2F5

C11H13Cl4Br3F4

$\mathrm{C} 11 \mathrm{H} 13 \mathrm{Cl} 4 \mathrm{Br} 4 \mathrm{~F} 3$

C11H13Cl4Br5F2

$\mathrm{C} 11 \mathrm{H} 13 \mathrm{Cl} 5 \mathrm{Br} 2 \mathrm{~F} 4$

$\mathrm{C} 11 \mathrm{H} 13 \mathrm{Cl} \mathrm{BBr} 3 \mathrm{~F} 3$

C11H13Cl5BrF5

C11H13Cl6Br3F2

$\mathrm{C} 11 \mathrm{H} 13 \mathrm{Cl} 6 \mathrm{BrF} 4$

C11H13Cl7Br2F2

C11H13Cl7BrF3

C11H13C17F4

C11H13Cl8F 3

$\mathrm{C} 11 \mathrm{H} 13 \mathrm{Cl} 9 \mathrm{BrF}$

C11H13ClBr4F6

C11H13ClBr5F5

$\mathrm{C} 11 \mathrm{H} 13 \mathrm{ClBr} 6 \mathrm{~F} 4$

C11H14Br4F6

C11H14Br5F

C11H14Br6F

$\mathrm{C} 11 \mathrm{H} 14 \mathrm{Br} 7 \mathrm{~F} 3$

C11H14Cl10

C11H14Cl2Br3F

$\mathrm{C} 11 \mathrm{H} 14 \mathrm{Cl} 2 \mathrm{Br} 4 \mathrm{~F} 4$

$\mathrm{C} 11 \mathrm{H} 14 \mathrm{Cl} 2 \mathrm{Br} 5 \mathrm{~F} 3$

$\mathrm{C} 11 \mathrm{H} 14 \mathrm{Cl} 2 \mathrm{Br} 6 \mathrm{~F} 2$

$\mathrm{C} 11 \mathrm{H} 14 \mathrm{Cl} 3 \mathrm{Br} 2 \mathrm{~F}$

$\mathrm{C} 11 \mathrm{H} 14 \mathrm{Cl} 3 \mathrm{Br} 3 \mathrm{~F} 4$

$\mathrm{C} 11 \mathrm{H} 14 \mathrm{Cl} 3 \mathrm{Br} 4 \mathrm{~F} 3$

C11H14Cl4Br3F3

$\mathrm{C} 11 \mathrm{H} 14 \mathrm{Cl} 1 \mathrm{Br} 4 \mathrm{~F} 2$

$\mathrm{C} 11 \mathrm{H} 14 \mathrm{Cl} 15 \mathrm{Br} 2 \mathrm{~F} 3$

$\mathrm{C} 11 \mathrm{H} 14 \mathrm{Cl} 15 \mathrm{Br} 3 \mathrm{~F} 2$

C11H14Cl5Br4F

$\mathrm{C} 11 \mathrm{H} 14 \mathrm{Cl} 15 \mathrm{BrF} 4$

$\mathrm{C} 11 \mathrm{H} 14 \mathrm{C} 16 \mathrm{Br} 2 \mathrm{~F} 2$

C11H14Cl6Br3F

C11H14Cl6BrF3
Koa lgKow lgKaw lgKow lgKoa lgKaw lgKow lgKoa lgKaw EPI EPI Exp Exp Exp DFT DFT DFT $1{ }_{-}$$\begin{array}{llllllllllll}10.9 & 8.51 & -2.36 & 7.78 & 10.14 & -2.36 & 7.30 & 17.99 & -10.69\end{array}$ $\begin{array}{llllllllll}8.66 & 8.02 & -0.64 & 7.04 & 7.69 & -0.64 & 6.92 & 13.92 & -7.00\end{array}$ $\begin{array}{llllllllll}10.2 & 8.35 & -1.88 & 7.54 & 9.42 & -1.88 & 7.18 & 16.80 & -9.63\end{array}$ $\begin{array}{llllllllll}11.9 & 8.82 & -3.11 & 8.24 & 11.35 & -3.11 & 7.54 & 19.93 & -12\end{array}$ $\begin{array}{llllll}8.90 & -1.39 & 7.16 & 15.87 & -8.7\end{array}$ $\begin{array}{lllllllll}1.4 & 8.73 & -2.63 & 8.10 & 10.73 & -2.63 & 7.47 & 18.88 & -11.4\end{array}$ $\begin{array}{llllllllll}8.83 & 8.67 & -0.16 & 8.01 & 8.17 & -0.16 & 7.42 & 14.22 & -6.80\end{array}$ $\begin{array}{llllllllll}9.89 & 8.98 & -0.91 & 8.48 & 9.38 & -0.91 & 7.66 & 16.17 & -8.51\end{array}$ $\begin{array}{llllllllll}8.25 & 8.58 & 0.33 & 7.88 & 7.55 & 0.33 & 7.35 & 13.17 & -5.82\end{array}$ $\begin{array}{llllllllll}11.9 & 8.96 & -2.90 & 8.45 & 11.34 & -2.90 & 7.64 & 19.79 & -12.15\end{array}$ $\begin{array}{llllllllll}10.1 & 8.48 & -1.66 & 7.73 & 9.39 & -1.66 & 7.28 & 16.64 & -9.36\end{array}$ $\begin{array}{llllllllll}8.5 & 8.08 & -0.42 & 7.13 & 7.56 & -0.42 & 6.97 & 13.63 & -6.66\end{array}$ $\begin{array}{llllllllll}7.68 & 7.57 & -0.11 & 6.37 & 6.48 & -0.11 & 6.58 & 12.11 & -5.54\end{array}$ $\begin{array}{lllllllll}10.1 & 8.71 & -1.34 & 8.07 & 9.42 & -1.34 & 7.45 & 16.48 & -9.03\end{array}$ $\begin{array}{llllllllll}12.6 & 8.78 & -3.82 & 8.18 & 12.00 & -3.82 & 7.51 & 21.16 & -13.65\end{array}$ $\begin{array}{llllllllll}9.42 & 8.53 & -0.89 & 7.81 & 8.70 & -0.89 & 7.31 & 15.32 & -8.0\end{array}$ $\begin{array}{llllllllll}11.9 & 8.52 & -3.37 & 7.79 & 11.16 & -3.37 & 7.31 & 19.85 & -12.54\end{array}$ $\begin{array}{llllllllll}11.1 & 8.91 & -2.22 & 8.37 & 10.60 & -2.22 & 7.61 & 18.46 & -10.86\end{array}$ $\begin{array}{lllllllll}8.27 & 8.35 & 0.08 & 7.54 & 7.46 & 0.08 & 7.18 & 13.21 & -6.03\end{array}$ $\begin{array}{lllllllll}9.92 & 8.76 & -1.16 & 8.15 & 9.31 & -1.16 & 7.49 & 16.23 & -8.74\end{array}$ $\begin{array}{llllllllll}9.34 & 8.67 & -0.67 & 8.01 & 8.69 & -0.67 & 7.42 & 15.17 & -7.75\end{array}$ $\begin{array}{llllllllll}8.03 & 7.84 & -0.19 & 6.78 & 6.96 & -0.19 & 6.78 & 12.76 & -5.97\end{array}$ $\begin{array}{lllllllll}10.3 & 8.91 & -1.42 & 8.37 & 9.80 & -1.42 & 7.61 & 17.00 & -9.39\end{array}$ $\begin{array}{lllllllll}9.09 & 8.15 & -0.94 & 7.24 & 8.18 & -0.94 & 7.02 & 14.71 & -7.69\end{array}$ $\begin{array}{llllllllll}10.7 & 8.55 & -2.18 & 7.84 & 10.01 & -2.18 & 7.33 & 17.72 & -10.39\end{array}$ $\begin{array}{lllllllll}7.45 & 7.75 & 0.30 & 6.64 & 6.34 & 0.30 & 6.71 & 11.70 & -4.99\end{array}$ $\begin{array}{llllllllll}10.2 & 8.46 & -1.69 & 7.70 & 9.39 & -1.69 & 7.26 & 16.66 & -9.40\end{array}$ $\begin{array}{lllllllll}11.8 & 8.87 & -2.93 & 8.31 & 11.24 & -2.93 & 7.57 & 19.69 & -12.11\end{array}$ $\begin{array}{lllllllll}9.25 & 8.8 & -0.45 & 8.21 & 8.66 & -0.45 & 7.52 & 15.01 & -7.49\end{array}$ $\begin{array}{lllllllll}9.58 & 8.37 & -1.21 & 7.57 & 8.77 & -1.21 & 7.19 & 15.60 & -8.4\end{array}$ $\begin{array}{lllllllll}8.68 & 8.71 & 0.03 & 8.07 & 8.04 & 0.03 & 7.45 & 13.96 & -6.50\end{array}$ \begin{tabular}{llllllllll}
10.6 & 8.69 & -1.96 & 8.04 & 10.00 & -1.96 & 7.44 & 17.57 & -10.14 \\
\hline & 8.28 & -0.72 & 7.43 & 8.15 & -0.72 & 7.2 & 14.55 & -7.43
\end{tabular}

$\begin{array}{lllllllll}9 & 8.28 & -0.72 & 7.43 & 8.15 & -0.72 & 7.12 & 14.55 & -7.43\end{array}$ $\begin{array}{lllllllll}8.85 & 8.44 & -0.41 & 7.67 & 8.08 & -0.41 & 7.24 & 14.26 & -7.02\end{array}$ $\begin{array}{lllllllll}10.5 & 8.85 & -1.64 & 8.28 & 9.93 & -1.64 & 7.56 & 17.29 & -9.73\end{array}$ $\begin{array}{rrrrrrrrr}11.4 & 8.51 & -2.88 & 7.78 & 10.66 & -2.88 & 7.30 & 18.94 & -11.64\end{array}$ $\begin{array}{llllllllll}7.4 & 7.45 & 0.05 & 6.19 & 6.15 & 0.05 & 6.48 & 11.61 & -5.13\end{array}$ $\begin{array}{lllllllll}8.37 & 7.18 & -1.19 & 5.79 & 6.98 & -1.19 & 6.28 & 13.39 & -7.11\end{array}$ $\begin{array}{lllllllll}11.4 & 8.99 & -2.43 & 8.49 & 10.92 & -2.43 & 7.67 & 18.98 & -11.32\end{array}$ $\begin{array}{llllllllll}12.5 & 8.71 & -3.76 & 8.07 & 11.83 & -3.76 & 7.45 & 20.92 & -13.47\end{array}$ $\begin{array}{lllllllll}10.8 & 8.3 & -2.52 & 7.46 & 9.99 & -2.52 & 7.14 & 17.89 & -10.76\end{array}$ $\begin{array}{lllllllll}11.9 & 8.62 & -3.27 & 7.94 & 11.21 & -3.27 & 7.38 & 19.86 & -12.48\end{array}$ $\begin{array}{lllllllll}7.97 & 7.75 & -0.22 & 6.64 & 6.86 & -0.22 & 6.71 & 12.65 & -5.93\end{array}$ $\begin{array}{llllllllll}11.2 & 8.55 & -2.69 & 7.84 & 10.53 & -2.69 & 7.33 & 18.67 & -11.34\end{array}$ $\begin{array}{llllllllll}9.03 & 8.06 & -0.97 & 7.10 & 8.08 & -0.97 & 6.95 & 14.60 & -7.65\end{array}$ $\begin{array}{llllllllll}9.93 & 7.72 & -2.21 & 6.60 & 8.81 & -2.21 & 6.69 & 16.25 & -9.56\end{array}$ $\begin{array}{lllllllll}12.3 & 8.86 & -3.45 & 8.30 & 11.74 & -3.45 & 7.57 & 20.62 & -13.05\end{array}$ $\begin{array}{lllllllll}7.72 & 7.23 & -0.49 & 5.87 & 6.35 & -0.49 & 6.31 & 12.19 & -5.87\end{array}$ $\begin{array}{llllllllll}9.35 & 7.63 & -1.72 & 6.46 & 8.19 & -1.72 & 6.62 & 15.20 & -8.5\end{array}$ $\begin{array}{llllllllll}11.7 & 8.78 & -2.96 & 8.18 & 11.14 & -2.96 & 7.51 & 19.58 & -12.07\end{array}$ $\begin{array}{llllllllll}12.6 & 8.44 & -4.20 & 7.67 & 11.87 & -4.20 & 7.24 & 21.23 & -13.98\end{array}$ $\begin{array}{llllllllll}8.78 & 7.54 & -1.24 & 6.33 & 7.57 & -1.24 & 6.55 & 14.14 & -7.59\end{array}$ $\begin{array}{lllllllll}11.2 & 8.69 & -2.48 & 8.04 & 10.52 & -2.48 & 7.44 & 18.52 & -11.09\end{array}$ $\begin{array}{llllllllll}7.88 & 7.88 & 0.00 & 6.84 & 6.84 & 0.00 & 6.81 & 12.49 & -5.68\end{array}$ $\begin{array}{llllllllll}10.7 & 7.52 & -3.23 & 6.30 & 9.53 & -3.23 & 6.54 & 17.75 & -11.22\end{array}$ $\begin{array}{llllllllll}8.13 & 7.38 & -0.75 & 6.09 & 6.84 & -0.75 & 6.43 & 12.95 & -6.52\end{array}$ $\begin{array}{lllllllll}10.9 & 8.17 & -2.74 & 7.27 & 10.01 & -2.74 & 7.04 & 18.06 & -11.02\end{array}$ $\begin{array}{lllllllll}9.94 & 8.43 & -1.50 & 7.66 & 9.16 & -1.50 & 7.24 & 16.26 & -9.03\end{array}$ $\begin{array}{lllllllll}7.63 & 7.36 & -0.27 & 6.06 & 6.33 & -0.27 & 6.41 & 12.02 & -5.61\end{array}$ $\begin{array}{llllllllll}9.44 & 8.42 & -1.02 & 7.64 & 8.66 & -1.02 & 7.23 & 15.35 & -8.12\end{array}$ $\begin{array}{llllllllll}11.4 & 8.39 & -3.01 & 7.60 & 10.61 & -3.01 & 7.21 & 18.95 & -11.74\end{array}$ $\begin{array}{llllllllll}7.8 & 7.09 & -0.70 & 5.66 & 6.36 & -0.70 & 6.21 & 12.33 & -6.12\end{array}$ $\begin{array}{lllllllll}10.2 & 8.24 & -1.94 & 7.37 & 9.31 & -1.94 & 7.09 & 16.71 & -9.62\end{array}$ $\begin{array}{llllllllll}11.1 & 7.9 & -3.18 & 6.87 & 10.04 & -3.18 & 6.83 & 18.36 & -11.53\end{array}$ $\begin{array}{llllllllll}7.83 & 7.58 & -0.25 & 6.39 & 6.64 & -0.25 & 6.58 & 12.40 & -5.82\end{array}$ $\begin{array}{llllllllll}9.55 & 8.06 & -1.49 & 7.10 & 8.59 & -1.49 & 6.95 & 15.55 & -8.60\end{array}$ $\begin{array}{lllllllll}10.4 & 7.72 & -2.73 & 6.60 & 9.32 & -2.73 & 6.69 & 17.20 & -10.51\end{array}$

$\begin{array}{lllllllll}12 & 8.05 & -3.96 & 7.09 & 11.05 & -3.96 & 6.94 & 20.08 & -13.14\end{array}$ $\begin{array}{llllllllll}11.2 & 8.36 & -2.82 & 7.55 & 10.37 & -2.82 & 7.18 & 18.55 & -11.37\end{array}$ $\begin{array}{llllllllll}8.4 & 7.88 & -0.52 & 6.84 & 7.35 & -0.52 & 6.81 & 13.44 & -6.63\end{array}$ $\begin{array}{llllllllll}10 & 8.28 & -1.76 & 7.43 & 9.19 & -1.76 & 7.12 & 16.45 & -9.33\end{array}$ $\begin{array}{lllllllll}10.9 & 7.94 & -2.99 & 6.93 & 9.92 & -2.99 & 6.86 & 18.09 & -11.23\end{array}$ $\begin{array}{lllllllll}11.8 & 7.61 & -4.23 & 6.43 & 10.66 & -4.23 & 6.61 & 19.76 & -13.15\end{array}$ $\begin{array}{lllllllll}7.75 & 7.72 & -0.03 & 6.60 & 6.63 & -0.03 & 6.69 & 12.25 & -5.56\end{array}$ $\begin{array}{lllllllll}9.46 & 8.19 & -1.27 & 7.30 & 8.57 & -1.27 & 7.05 & 15.39 & -8.34\end{array}$ $\begin{array}{llllllllll}11.1 & 8.59 & -2.51 & 7.90 & 10.40 & -2.51 & 7.36 & 18.40 & -11.04\end{array}$ $\begin{array}{llllllllll}9.78 & 7.76 & -2.02 & 6.66 & 8.68 & -2.02 & 6.72 & 15.98 & -9.26\end{array}$ $\begin{array}{llllllllll}12 & 8.76 & -3.26 & 8.15 & 11.41 & -3.26 & 7.49 & 20.09 & -12.60\end{array}$ $\begin{array}{llllllllll}9.81 & 8.27 & -1.54 & 7.42 & 8.96 & -1.54 & 7.11 & 16.03 & -8.91\end{array}$ $\begin{array}{llllllllll}10.9 & 8.08 & -2.77 & 7.13 & 9.91 & -2.77 & 6.97 & 17.95 & -10.98\end{array}$ $\begin{array}{llllllllll}12.4 & 8.41 & -4.01 & 7.63 & 11.64 & -4.01 & 7.22 & 20.83 & -13.6\end{array}$ $\begin{array}{lllllllll}8.31 & 8.01 & -0.30 & 7.03 & 7.33 & -0.30 & 6.91 & 13.28 & -6.36\end{array}$ $\begin{array}{llllllllll}10.3 & 7.99 & -2.29 & 7.00 & 9.29 & -2.29 & 6.90 & 16.89 & -9.99\end{array}$ $\begin{array}{lllllllll}11.8 & 8.32 & -3.53 & 7.49 & 11.02 & -3.53 & 7.15 & 19.77 & -12.62\end{array}$ $\begin{array}{lllllllll}8.64 & 7.59 & -1.05 & 6.40 & 7.46 & -1.05 & 6.59 & 13.89 & -7.30\end{array}$ 
$\mathrm{C}(\mathrm{C}(\mathrm{C}(\mathrm{C}(\mathrm{C}(\mathrm{C}(\mathrm{C}(\mathrm{C}(\mathrm{C}(\mathrm{C}(\mathrm{C}(\mathrm{H})(\mathrm{Br}) \mathrm{H})(\mathrm{Cl}) \mathrm{F})(\mathrm{H}) \mathrm{H})(\mathrm{Cl}) \mathrm{H})(\mathrm{H}) \mathrm{H})(\mathrm{H}) \mathrm{Cl})(\mathrm{H}) \mathrm{H})(\mathrm{H}) \mathrm{Cl})(\mathrm{Cl}) \mathrm{H})(\mathrm{Cl}) \mathrm{H})(\mathrm{Cl})(\mathrm{H}) \mathrm{Br}$ $\mathrm{C}(\mathrm{C}(\mathrm{C}(\mathrm{C}(\mathrm{C}(\mathrm{C}(\mathrm{C}(\mathrm{C}(\mathrm{C}(\mathrm{C}(\mathrm{C}(\mathrm{H})(\mathrm{H}) \mathrm{Cl})(\mathrm{H}) \mathrm{H})(\mathrm{Cl}) \mathrm{F})(\mathrm{H}) \mathrm{Br})(\mathrm{Cl}) \mathrm{H})(\mathrm{H}) \mathrm{H})(\mathrm{H}) \mathrm{H})(\mathrm{H}) \mathrm{Cl})(\mathrm{Cl}) \mathrm{Cl})(\mathrm{Cl}) \mathrm{H})(\mathrm{H})(\mathrm{F}) \mathrm{H}$ $\mathrm{C}(\mathrm{C}(\mathrm{C}(\mathrm{C}(\mathrm{C}(\mathrm{C}(\mathrm{C}(\mathrm{C}(\mathrm{C}(\mathrm{C}(\mathrm{C}(\mathrm{H})(\mathrm{Cl}) \mathrm{H})(\mathrm{F}) \mathrm{H})(\mathrm{H}) \mathrm{H})(\mathrm{H}) \mathrm{H})(\mathrm{Cl}) \mathrm{Cl})(\mathrm{H}) \mathrm{Cl})(\mathrm{H}) \mathrm{H})(\mathrm{H}) \mathrm{Cl})(\mathrm{H}) \mathrm{F})(\mathrm{Cl}) \mathrm{F})(\mathrm{H})(\mathrm{Cl}) \mathrm{H}$ $\mathrm{C}(\mathrm{C}(\mathrm{C}(\mathrm{C}(\mathrm{C}(\mathrm{C}(\mathrm{C}(\mathrm{C}(\mathrm{C}(\mathrm{C}(\mathrm{C}(\mathrm{H})(\mathrm{H}) \mathrm{Cl})(\mathrm{H}) \mathrm{Cl})(\mathrm{Cl}) \mathrm{H})(\mathrm{H}) \mathrm{H})(\mathrm{Cl}) \mathrm{H})(\mathrm{Cl}) \mathrm{H})(\mathrm{F}) \mathrm{Br})(\mathrm{H}) \mathrm{H})(\mathrm{Cl}) \mathrm{H})(\mathrm{H}) \mathrm{H})(\mathrm{Cl})(\mathrm{H}) \mathrm{Cl}$ $\mathrm{C}(\mathrm{C}(\mathrm{C}(\mathrm{C}(\mathrm{C}(\mathrm{C}(\mathrm{C}(\mathrm{C}(\mathrm{C}(\mathrm{C}(\mathrm{C}(\mathrm{Cl})(\mathrm{H}) \mathrm{Cl})(\mathrm{F}) \mathrm{H})(\mathrm{Cl}) \mathrm{H})(\mathrm{H}) \mathrm{Cl})(\mathrm{H}) \mathrm{H})(\mathrm{H}) \mathrm{Cl})(\mathrm{F}) \mathrm{H})(\mathrm{H}) \mathrm{H})(\mathrm{Cl}) \mathrm{H})(\mathrm{H}) \mathrm{Cl})(\mathrm{H})(\mathrm{H}) \mathrm{Cl}$ $\mathrm{C}(\mathrm{C}(\mathrm{C}(\mathrm{C}(\mathrm{C}(\mathrm{C}(\mathrm{C}(\mathrm{C}(\mathrm{C}(\mathrm{C}(\mathrm{C}(\mathrm{H})(\mathrm{Cl}) \mathrm{H})(\mathrm{H}) \mathrm{Cl})(\mathrm{H}) \mathrm{Cl})(\mathrm{H}) \mathrm{H})(\mathrm{H}) \mathrm{H})(\mathrm{H}) \mathrm{Cl})(\mathrm{H}) \mathrm{Br})(\mathrm{H}) \mathrm{Cl})(\mathrm{H}) \mathrm{Cl})(\mathrm{Cl}) \mathrm{Cl})(\mathrm{Cl})(\mathrm{H}) \mathrm{H}$ $\mathrm{C}(\mathrm{C}(\mathrm{C}(\mathrm{C}(\mathrm{C}(\mathrm{C}(\mathrm{C}(\mathrm{C}(\mathrm{C}(\mathrm{C}(\mathrm{C}(\mathrm{H})(\mathrm{H}) \mathrm{H})(\mathrm{Cl}) \mathrm{F})(\mathrm{H}) \mathrm{H})(\mathrm{H}) \mathrm{Cl})(\mathrm{Cl}) \mathrm{H})(\mathrm{Cl}) \mathrm{H})(\mathrm{H}) \mathrm{H})(\mathrm{Cl}) \mathrm{H})(\mathrm{Cl}) \mathrm{Cl})(\mathrm{H}) \mathrm{Cl})(\mathrm{H})(\mathrm{Cl}) \mathrm{H}$ $\mathrm{C}(\mathrm{C}(\mathrm{C}(\mathrm{C}(\mathrm{C}(\mathrm{C}(\mathrm{C}(\mathrm{C}(\mathrm{C}(\mathrm{C}(\mathrm{C}(\mathrm{Cl})(\mathrm{H}) \mathrm{H})(\mathrm{H}) \mathrm{F})(\mathrm{F}) \mathrm{F})(\mathrm{H}) \mathrm{Br})(\mathrm{H}) \mathrm{F})(\mathrm{H}) \mathrm{F})(\mathrm{H}) \mathrm{H})(\mathrm{H}) \mathrm{Br})(\mathrm{H}) \mathrm{H})(\mathrm{H}) \mathrm{Br})(\mathrm{H})(\mathrm{H}) \mathrm{B}$ $\mathrm{C}(\mathrm{C}(\mathrm{C}(\mathrm{C}(\mathrm{C}(\mathrm{C}(\mathrm{C}(\mathrm{C}(\mathrm{C}(\mathrm{C}(\mathrm{C}(\mathrm{H})(\mathrm{H}) \mathrm{H})(\mathrm{H}) \mathrm{Br})(\mathrm{F}) \mathrm{F})(\mathrm{Br}) \mathrm{H})(\mathrm{Br}) \mathrm{H})(\mathrm{H}) \mathrm{H})(\mathrm{Br}) \mathrm{Cl})(\mathrm{H}) \mathrm{F})(\mathrm{H}) \mathrm{H})(\mathrm{Br}) \mathrm{F})(\mathrm{H})(\mathrm{H}) \mathrm{H}$ $\mathrm{C}(\mathrm{C}(\mathrm{C}(\mathrm{C}(\mathrm{C}(\mathrm{C}(\mathrm{C}(\mathrm{C}(\mathrm{C}(\mathrm{C}(\mathrm{C}(\mathrm{F})(\mathrm{H}) \mathrm{Br})(\mathrm{Br}) \mathrm{H})(\mathrm{H}) \mathrm{Br})(\mathrm{H}) \mathrm{H})(\mathrm{Br}) \mathrm{H})(\mathrm{Br}) \mathrm{F})(\mathrm{H}) \mathrm{H})(\mathrm{H}) \mathrm{H})(\mathrm{Br}) \mathrm{H})(\mathrm{F}) \mathrm{H})(\mathrm{Cl})(\mathrm{H}) \mathrm{H}$ $\mathrm{C}(\mathrm{C}(\mathrm{C}(\mathrm{C}(\mathrm{C}(\mathrm{C}(\mathrm{C}(\mathrm{C}(\mathrm{C}(\mathrm{C}(\mathrm{C}(\mathrm{H})(\mathrm{H}) \mathrm{F})(\mathrm{H}) \mathrm{H})(\mathrm{H}) \mathrm{Br})(\mathrm{H}) \mathrm{H})(\mathrm{F}) \mathrm{Br})(\mathrm{H}) \mathrm{H})(\mathrm{Br}) \mathrm{F})(\mathrm{H}) \mathrm{Br})(\mathrm{H}) \mathrm{F})(\mathrm{Br}) \mathrm{H})(\mathrm{H})(\mathrm{H}) \mathrm{H}$ $\mathrm{C}(\mathrm{C}(\mathrm{C}(\mathrm{C}(\mathrm{C}(\mathrm{C}(\mathrm{C}(\mathrm{C}(\mathrm{C}(\mathrm{C}(\mathrm{C}(\mathrm{H})(\mathrm{H}) \mathrm{Br})(\mathrm{Br}) \mathrm{H})(\mathrm{H}) \mathrm{H})(\mathrm{H}) \mathrm{H})(\mathrm{F}) \mathrm{Br})(\mathrm{H}) \mathrm{Br})(\mathrm{H}) \mathrm{H})(\mathrm{H}) \mathrm{F})(\mathrm{H}) \mathrm{Br})(\mathrm{H}) \mathrm{F})(\mathrm{Br})(\mathrm{H}) \mathrm{H}$ $\mathrm{C}(\mathrm{C}(\mathrm{C}(\mathrm{C}(\mathrm{C}(\mathrm{C}(\mathrm{C}(\mathrm{C}(\mathrm{C}(\mathrm{C}(\mathrm{C}(\mathrm{H})(\mathrm{H}) \mathrm{H})(\mathrm{F}) \mathrm{H})(\mathrm{H}) \mathrm{F})(\mathrm{H}) \mathrm{Br})(\mathrm{H}) \mathrm{H})(\mathrm{H}) \mathrm{Br})(\mathrm{H}) \mathrm{Br})(\mathrm{H}) \mathrm{H})(\mathrm{Br}) \mathrm{H})(\mathrm{H}) \mathrm{H})(\mathrm{Br})(\mathrm{Br}) \mathrm{Br}$ $\mathrm{C}(\mathrm{C}(\mathrm{C}(\mathrm{C}(\mathrm{C}(\mathrm{C}(\mathrm{C}(\mathrm{C}(\mathrm{C}(\mathrm{C}(\mathrm{C}(\mathrm{Cl})(\mathrm{H}) \mathrm{H})(\mathrm{F}) \mathrm{Cl})(\mathrm{H}) \mathrm{H})(\mathrm{H}) \mathrm{H})(\mathrm{H}) \mathrm{Br})(\mathrm{F}) \mathrm{H})(\mathrm{H}) \mathrm{H})(\mathrm{H}) \mathrm{H})(\mathrm{H}) \mathrm{H})(\mathrm{H}) \mathrm{F})(\mathrm{F})(\mathrm{F}) \mathrm{Br}$ $\mathrm{C}(\mathrm{C}(\mathrm{C}(\mathrm{C}(\mathrm{C}(\mathrm{C}(\mathrm{C}(\mathrm{C}(\mathrm{C}(\mathrm{C}(\mathrm{C}(\mathrm{H})(\mathrm{F}) \mathrm{F})(\mathrm{F}) \mathrm{H})(\mathrm{Br}) \mathrm{H})(\mathrm{Cl}) \mathrm{Cl})(\mathrm{H}) \mathrm{H})(\mathrm{H}) \mathrm{Br})(\mathrm{H}) \mathrm{H})(\mathrm{H}) \mathrm{H})(\mathrm{H}) \mathrm{H})(\mathrm{H}) \mathrm{H})(\mathrm{F})(\mathrm{Br}) \mathrm{H}$ $\mathrm{C}(\mathrm{C}(\mathrm{C}(\mathrm{C}(\mathrm{C}(\mathrm{C}(\mathrm{C}(\mathrm{C}(\mathrm{C}(\mathrm{C}(\mathrm{C}(\mathrm{H})(\mathrm{H}) \mathrm{Br})(\mathrm{H}) \mathrm{F})(\mathrm{H}) \mathrm{Cl})(\mathrm{H}) \mathrm{F})(\mathrm{Br}) \mathrm{H})(\mathrm{H}) \mathrm{Cl})(\mathrm{H}) \mathrm{Br})(\mathrm{Br}) \mathrm{H})(\mathrm{H}) \mathrm{H})(\mathrm{F}) \mathrm{H})(\mathrm{H})(\mathrm{H}) \mathrm{H}$ $\mathrm{C}(\mathrm{C}(\mathrm{C}(\mathrm{C}(\mathrm{C}(\mathrm{C}(\mathrm{C}(\mathrm{C}(\mathrm{C}(\mathrm{C}(\mathrm{C}(\mathrm{F})(\mathrm{H}) \mathrm{H})(\mathrm{H}) \mathrm{Br})(\mathrm{H}) \mathrm{H})(\mathrm{Br}) \mathrm{Cl})(\mathrm{H}) \mathrm{H})(\mathrm{H}) \mathrm{Br})(\mathrm{Br}) \mathrm{H})(\mathrm{Br}) \mathrm{H})(\mathrm{H}) \mathrm{H})(\mathrm{H}) \mathrm{F})(\mathrm{H})(\mathrm{H}) \mathrm{Cl}$ $\mathrm{C}(\mathrm{C}(\mathrm{C}(\mathrm{C}(\mathrm{C}(\mathrm{C}(\mathrm{C}(\mathrm{C}(\mathrm{C}(\mathrm{C}(\mathrm{C}(\mathrm{Br})(\mathrm{H}) \mathrm{Br})(\mathrm{Br}) \mathrm{H})(\mathrm{Br}) \mathrm{H})(\mathrm{H}) \mathrm{F})(\mathrm{H}) \mathrm{H})(\mathrm{H}) \mathrm{H})(\mathrm{Cl}) \mathrm{H})(\mathrm{H}) \mathrm{H})(\mathrm{Cl}) \mathrm{H})(\mathrm{H}) \mathrm{H})(\mathrm{Br})(\mathrm{H}) \mathrm{Br}$ $\mathrm{C}(\mathrm{C}(\mathrm{C}(\mathrm{C}(\mathrm{C}(\mathrm{C}(\mathrm{C}(\mathrm{C}(\mathrm{C}(\mathrm{C}(\mathrm{C}(\mathrm{H})(\mathrm{H}) \mathrm{Br})(\mathrm{Cl}) \mathrm{H})(\mathrm{H}) \mathrm{F})(\mathrm{H}) \mathrm{H})(\mathrm{Br}) \mathrm{H})(\mathrm{F}) \mathrm{Cl})(\mathrm{H}) \mathrm{H})(\mathrm{Cl}) \mathrm{F})(\mathrm{H}) \mathrm{F})(\mathrm{H}) \mathrm{H})(\mathrm{H})(\mathrm{H}) \mathrm{H}$ $\mathrm{C}(\mathrm{C}(\mathrm{C}(\mathrm{C}(\mathrm{C}(\mathrm{C}(\mathrm{C}(\mathrm{C}(\mathrm{C}(\mathrm{C}(\mathrm{C}(\mathrm{H})(\mathrm{H}) \mathrm{H})(\mathrm{H}) \mathrm{H})(\mathrm{Cl}) \mathrm{H})(\mathrm{F}) \mathrm{Cl})(\mathrm{H}) \mathrm{H})(\mathrm{Br}) \mathrm{F})(\mathrm{H}) \mathrm{H})(\mathrm{Cl}) \mathrm{F})(\mathrm{H}) \mathrm{H})(\mathrm{H}) \mathrm{Br})(\mathrm{Br})(\mathrm{H}) \mathrm{H}$ $\mathrm{C}(\mathrm{C}(\mathrm{C}(\mathrm{C}(\mathrm{C}(\mathrm{C}(\mathrm{C}(\mathrm{C}(\mathrm{C}(\mathrm{C}(\mathrm{C}(\mathrm{H})(\mathrm{H}) \mathrm{H})(\mathrm{Br}) \mathrm{H})(\mathrm{H}) \mathrm{Cl})(\mathrm{H}) \mathrm{F})(\mathrm{H}) \mathrm{H})(\mathrm{F}) \mathrm{H})(\mathrm{Cl}) \mathrm{H})(\mathrm{H}) \mathrm{H})(\mathrm{Br}) \mathrm{Br})(\mathrm{Cl}) \mathrm{H})(\mathrm{Br})(\mathrm{H}) \mathrm{H}$ $\mathrm{C}(\mathrm{C}(\mathrm{C}(\mathrm{C}(\mathrm{C}(\mathrm{C}(\mathrm{C}(\mathrm{C}(\mathrm{C}(\mathrm{C}(\mathrm{C}(\mathrm{H})(\mathrm{H}) \mathrm{H})(\mathrm{H}) \mathrm{H})(\mathrm{Cl}) \mathrm{H})(\mathrm{H}) \mathrm{Br})(\mathrm{Br}) \mathrm{H})(\mathrm{Br}) \mathrm{H})(\mathrm{Br}) \mathrm{H})(\mathrm{H}) \mathrm{H})(\mathrm{Br}) \mathrm{Cl})(\mathrm{H}) \mathrm{H})(\mathrm{F})(\mathrm{H}) \mathrm{Cl}$ $\mathrm{C}(\mathrm{C}(\mathrm{C}(\mathrm{C}(\mathrm{C}(\mathrm{C}(\mathrm{C}(\mathrm{C}(\mathrm{C}(\mathrm{C}(\mathrm{C}(\mathrm{H})(\mathrm{Br}) \mathrm{Cl})(\mathrm{H}) \mathrm{H})(\mathrm{H}) \mathrm{Br})(\mathrm{H}) \mathrm{H})(\mathrm{Cl}) \mathrm{H})(\mathrm{H}) \mathrm{F})(\mathrm{H}) \mathrm{H})(\mathrm{Cl}) \mathrm{H})(\mathrm{Cl}) \mathrm{H})(\mathrm{F}) \mathrm{H})(\mathrm{F})(\mathrm{H}) \mathrm{H}$ $\mathrm{C}(\mathrm{C}(\mathrm{C}(\mathrm{C}(\mathrm{C}(\mathrm{C}(\mathrm{C}(\mathrm{C}(\mathrm{C}(\mathrm{C}(\mathrm{C}(\mathrm{F})(\mathrm{H}) \mathrm{H})(\mathrm{F}) \mathrm{H})(\mathrm{Cl}) \mathrm{H})(\mathrm{H}) \mathrm{Cl})(\mathrm{H}) \mathrm{H})(\mathrm{Br}) \mathrm{H})(\mathrm{Br}) \mathrm{Cl})(\mathrm{H}) \mathrm{H})(\mathrm{Cl}) \mathrm{Br})(\mathrm{H}) \mathrm{H})(\mathrm{H})(\mathrm{H}) \mathrm{H}$ $\mathrm{C}(\mathrm{C}(\mathrm{C}(\mathrm{C}(\mathrm{C}(\mathrm{C}(\mathrm{C}(\mathrm{C}(\mathrm{C}(\mathrm{C}(\mathrm{C}(\mathrm{H})(\mathrm{Cl}) \mathrm{Cl})(\mathrm{H}) \mathrm{Br})(\mathrm{H}) \mathrm{H})(\mathrm{H}) \mathrm{H})(\mathrm{H}) \mathrm{H})(\mathrm{H}) \mathrm{H})(\mathrm{H}) \mathrm{Cl})(\mathrm{H}) \mathrm{Cl})(\mathrm{H}) \mathrm{Br})(\mathrm{H}) \mathrm{Br})(\mathrm{H})(\mathrm{F}) \mathrm{Br}$ $\mathrm{C}(\mathrm{C}(\mathrm{C}(\mathrm{C}(\mathrm{C}(\mathrm{C}(\mathrm{C}(\mathrm{C}(\mathrm{C}(\mathrm{C}(\mathrm{C}(\mathrm{H})(\mathrm{H}) \mathrm{H})(\mathrm{H}) \mathrm{H})(\mathrm{H}) \mathrm{H})(\mathrm{H}) \mathrm{Br})(\mathrm{F}) \mathrm{Cl})(\mathrm{Cl}) \mathrm{H})(\mathrm{H}) \mathrm{H})(\mathrm{Cl}) \mathrm{Cl})(\mathrm{H}) \mathrm{Cl})(\mathrm{H}) \mathrm{H})(\mathrm{H})(\mathrm{Br}) \mathrm{F}$ $\mathrm{C}(\mathrm{C}(\mathrm{C}(\mathrm{C}(\mathrm{C}(\mathrm{C}(\mathrm{C}(\mathrm{C}(\mathrm{C}(\mathrm{C}(\mathrm{C}(\mathrm{H})(\mathrm{Br}) \mathrm{H})(\mathrm{Cl}) \mathrm{Br})(\mathrm{H}) \mathrm{H})(\mathrm{H}) \mathrm{F})(\mathrm{Cl}) \mathrm{Cl})(\mathrm{Cl}) \mathrm{H})(\mathrm{H}) \mathrm{H})(\mathrm{H}) \mathrm{Cl})(\mathrm{H}) \mathrm{Br})(\mathrm{H}) \mathrm{H})(\mathrm{H})(\mathrm{H}) \mathrm{H}$ $\mathrm{C}(\mathrm{C}(\mathrm{C}(\mathrm{C}(\mathrm{C}(\mathrm{C}(\mathrm{C}(\mathrm{C}(\mathrm{C}(\mathrm{C}(\mathrm{C}(\mathrm{H})(\mathrm{H}) \mathrm{Cl})(\mathrm{F}) \mathrm{H})(\mathrm{H}) \mathrm{Cl})(\mathrm{H}) \mathrm{H})(\mathrm{Cl}) \mathrm{H})(\mathrm{H}) \mathrm{H})(\mathrm{H}) \mathrm{Cl})(\mathrm{F}) \mathrm{Br})(\mathrm{H}) \mathrm{H})(\mathrm{F}) \mathrm{H})(\mathrm{Cl})(\mathrm{H}) \mathrm{H}$ $\mathrm{C}(\mathrm{C}(\mathrm{C}(\mathrm{C}(\mathrm{C}(\mathrm{C}(\mathrm{C}(\mathrm{C}(\mathrm{C}(\mathrm{C}(\mathrm{C}(\mathrm{Cl})(\mathrm{H}) \mathrm{H})(\mathrm{F}) \mathrm{Cl})(\mathrm{Br}) \mathrm{H})(\mathrm{Cl}) \mathrm{Cl})(\mathrm{H}) \mathrm{H})(\mathrm{H}) \mathrm{H})(\mathrm{H}) \mathrm{H})(\mathrm{Cl}) \mathrm{H})(\mathrm{H}) \mathrm{H})(\mathrm{H}) \mathrm{Cl})(\mathrm{Br})(\mathrm{H}) \mathrm{H}$ $\mathrm{C}(\mathrm{C}(\mathrm{C}(\mathrm{C}(\mathrm{C}(\mathrm{C}(\mathrm{C}(\mathrm{C}(\mathrm{C}(\mathrm{C}(\mathrm{C}(\mathrm{H})(\mathrm{Cl}) \mathrm{H})(\mathrm{H}) \mathrm{H})(\mathrm{Cl}) \mathrm{H})(\mathrm{H}) \mathrm{H})(\mathrm{Br}) \mathrm{H})(\mathrm{H}) \mathrm{Cl})(\mathrm{Br}) \mathrm{H})(\mathrm{Br}) \mathrm{Cl})(\mathrm{Cl}) \mathrm{H})(\mathrm{H}) \mathrm{H})(\mathrm{H})(\mathrm{H}) \mathrm{Cl}$ $\mathrm{C}(\mathrm{C}(\mathrm{C}(\mathrm{C}(\mathrm{C}(\mathrm{C}(\mathrm{C}(\mathrm{C}(\mathrm{C}(\mathrm{C}(\mathrm{C}(\mathrm{Cl})(\mathrm{H}) \mathrm{F})(\mathrm{H}) \mathrm{H})(\mathrm{H}) \mathrm{Br})(\mathrm{H}) \mathrm{H})(\mathrm{H}) \mathrm{Cl}(\mathrm{Cl}) \mathrm{Cl})(\mathrm{Cl}) \mathrm{H})(\mathrm{H}) \mathrm{H})(\mathrm{Cl}) \mathrm{H})(\mathrm{H}) \mathrm{H})(\mathrm{F})(\mathrm{H}) \mathrm{H}$ $\mathrm{C}(\mathrm{C}(\mathrm{C}(\mathrm{C}(\mathrm{C}(\mathrm{C}(\mathrm{C}(\mathrm{C}(\mathrm{C}(\mathrm{C}(\mathrm{C}(\mathrm{Cl})(\mathrm{Cl}) \mathrm{Cl})(\mathrm{H}) \mathrm{H})(\mathrm{H}) \mathrm{H})(\mathrm{H}) \mathrm{H})(\mathrm{H}) \mathrm{Cl})(\mathrm{H}) \mathrm{F})(\mathrm{F}) \mathrm{H})(\mathrm{H}) \mathrm{Cl})(\mathrm{Cl}) \mathrm{H})(\mathrm{H}) \mathrm{H})(\mathrm{H})(\mathrm{F}) \mathrm{H}$ $\mathrm{C}(\mathrm{C}(\mathrm{C}(\mathrm{C}(\mathrm{C}(\mathrm{C}(\mathrm{C}(\mathrm{C}(\mathrm{C}(\mathrm{C}(\mathrm{C}(\mathrm{Cl})(\mathrm{H}) \mathrm{H})(\mathrm{H}) \mathrm{H})(\mathrm{Br}) \mathrm{H})(\mathrm{H}) \mathrm{H})(\mathrm{H}) \mathrm{H})(\mathrm{H}) \mathrm{Cl})(\mathrm{H}) \mathrm{H})(\mathrm{Cl}) \mathrm{Cl})(\mathrm{Cl}) \mathrm{H})(\mathrm{H}) \mathrm{Cl})(\mathrm{Br})(\mathrm{Cl}) \mathrm{H}$ $\mathrm{C}(\mathrm{C}(\mathrm{C}(\mathrm{C}(\mathrm{C}(\mathrm{C}(\mathrm{C}(\mathrm{C}(\mathrm{C}(\mathrm{C}(\mathrm{C}(\mathrm{Cl})(\mathrm{F}) \mathrm{Cl})(\mathrm{Cl}) \mathrm{H})(\mathrm{H}) \mathrm{Cl})(\mathrm{H}) \mathrm{H})(\mathrm{H}) \mathrm{H})(\mathrm{H}) \mathrm{H})(\mathrm{H}) \mathrm{H})(\mathrm{H}) \mathrm{H})(\mathrm{Cl}) \mathrm{Cl})(\mathrm{H}) \mathrm{Cl})(\mathrm{H})(\mathrm{H}) \mathrm{Br}$ $\mathrm{C}(\mathrm{C}(\mathrm{C}(\mathrm{C}(\mathrm{C}(\mathrm{C}(\mathrm{C}(\mathrm{C}(\mathrm{C}(\mathrm{C}(\mathrm{C}(\mathrm{Cl})(\mathrm{H}) \mathrm{Cl})(\mathrm{Cl}) \mathrm{H})(\mathrm{Cl}) \mathrm{H})(\mathrm{H}) \mathrm{H})(\mathrm{H}) \mathrm{F})(\mathrm{H}) \mathrm{H})(\mathrm{H}) \mathrm{H})(\mathrm{H}) \mathrm{H})(\mathrm{H}) \mathrm{Cl})(\mathrm{Cl}) \mathrm{F})(\mathrm{Cl})(\mathrm{H}) \mathrm{H}$ $\mathrm{C}(\mathrm{C}(\mathrm{C}(\mathrm{C}(\mathrm{C}(\mathrm{C}(\mathrm{C}(\mathrm{C}(\mathrm{C}(\mathrm{C}(\mathrm{C}(\mathrm{H})(\mathrm{H}) \mathrm{Cl})(\mathrm{H}) \mathrm{Cl})(\mathrm{Cl}) \mathrm{H})(\mathrm{H}) \mathrm{H})(\mathrm{H}) \mathrm{H})(\mathrm{H}) \mathrm{Cl})(\mathrm{H}) \mathrm{H})(\mathrm{H}) \mathrm{Cl})(\mathrm{H}) \mathrm{Br})(\mathrm{Cl}) \mathrm{H})(\mathrm{H})(\mathrm{Cl}) \mathrm{Cl}$ $\mathrm{C}(\mathrm{C}(\mathrm{C}(\mathrm{C}(\mathrm{C}(\mathrm{C}(\mathrm{C}(\mathrm{C}(\mathrm{C}(\mathrm{C}(\mathrm{C}(\mathrm{H})(\mathrm{H}) \mathrm{Cl})(\mathrm{Cl}) \mathrm{H})(\mathrm{Cl}) \mathrm{H})(\mathrm{H}) \mathrm{H})(\mathrm{Cl}) \mathrm{Cl})(\mathrm{H}) \mathrm{H})(\mathrm{H}) \mathrm{H})(\mathrm{Cl}) \mathrm{H})(\mathrm{H}) \mathrm{H})(\mathrm{H}) \mathrm{F})(\mathrm{Cl})(\mathrm{Cl}) \mathrm{H}$ $\mathrm{C}(\mathrm{C}(\mathrm{C}(\mathrm{C}(\mathrm{C}(\mathrm{C}(\mathrm{C}(\mathrm{C}(\mathrm{C}(\mathrm{C}(\mathrm{C}(\mathrm{H})(\mathrm{Cl}) \mathrm{Cl})(\mathrm{Cl}) \mathrm{Cl})(\mathrm{H}) \mathrm{H})(\mathrm{Cl}) \mathrm{H})(\mathrm{H}) \mathrm{Cl})(\mathrm{H}) \mathrm{H})(\mathrm{H}) \mathrm{H})(\mathrm{Cl}) \mathrm{H})(\mathrm{H}) \mathrm{H})(\mathrm{Cl}) \mathrm{H})(\mathrm{H})(\mathrm{H}) \mathrm{Cl}$ $\mathrm{C}(\mathrm{C}(\mathrm{C}(\mathrm{C}(\mathrm{C}(\mathrm{C}(\mathrm{C}(\mathrm{C}(\mathrm{C}(\mathrm{C}(\mathrm{C}(\mathrm{H})(\mathrm{F}) \mathrm{Br})(\mathrm{F}) \mathrm{H})(\mathrm{Br}) \mathrm{Cl})(\mathrm{H}) \mathrm{H})(\mathrm{H}) \mathrm{H})(\mathrm{F}) \mathrm{Br})(\mathrm{H}) \mathrm{H})(\mathrm{H}) \mathrm{H})(\mathrm{H}) \mathrm{F})(\mathrm{H}) \mathrm{H})(\mathrm{Br})(\mathrm{H}) \mathrm{H}$ $\mathrm{C}(\mathrm{C}(\mathrm{C}(\mathrm{C}(\mathrm{C}(\mathrm{C}(\mathrm{C}(\mathrm{C}(\mathrm{C}(\mathrm{C}(\mathrm{C}(\mathrm{H})(\mathrm{Br}) \mathrm{F})(\mathrm{H}) \mathrm{F})(\mathrm{H}) \mathrm{H})(\mathrm{H}) \mathrm{H})(\mathrm{H}) \mathrm{H})(\mathrm{Br}) \mathrm{H})(\mathrm{Br}) \mathrm{H})(\mathrm{F}) \mathrm{H})(\mathrm{H}) \mathrm{H})(\mathrm{Br}) \mathrm{H})(\mathrm{Br})(\mathrm{Cl}) \mathrm{H}$ $\mathrm{C}(\mathrm{C}(\mathrm{C}(\mathrm{C}(\mathrm{C}(\mathrm{C}(\mathrm{C}(\mathrm{C}(\mathrm{C}(\mathrm{C}(\mathrm{C}(\mathrm{H})(\mathrm{H}) \mathrm{Br})(\mathrm{H}) \mathrm{Cl})(\mathrm{H}) \mathrm{Br})(\mathrm{H}) \mathrm{F})(\mathrm{H}) \mathrm{Br})(\mathrm{H}) \mathrm{H})(\mathrm{H}) \mathrm{H})(\mathrm{Br}) \mathrm{H})(\mathrm{H}) \mathrm{Br})(\mathrm{Br}) \mathrm{H})(\mathrm{H})(\mathrm{F}) \mathrm{H}$ $\mathrm{C}(\mathrm{C}(\mathrm{C}(\mathrm{C}(\mathrm{C}(\mathrm{C}(\mathrm{C}(\mathrm{C}(\mathrm{C}(\mathrm{C}(\mathrm{C}(\mathrm{H})(\mathrm{H}) \mathrm{H})(\mathrm{H}) \mathrm{H})(\mathrm{H}) \mathrm{H})(\mathrm{Br}) \mathrm{F})(\mathrm{F}) \mathrm{F})(\mathrm{H}) \mathrm{H})(\mathrm{H}) \mathrm{Br})(\mathrm{F}) \mathrm{H})(\mathrm{H}) \mathrm{H})(\mathrm{H}) \mathrm{Br})(\mathrm{H})(\mathrm{H}) \mathrm{Br}$ $\mathrm{C}(\mathrm{C}(\mathrm{C}(\mathrm{C}(\mathrm{C}(\mathrm{C}(\mathrm{C}(\mathrm{C}(\mathrm{C}(\mathrm{C}(\mathrm{C}(\mathrm{Br})(\mathrm{F}) \mathrm{H})(\mathrm{H}) \mathrm{Br})(\mathrm{H}) \mathrm{Br})(\mathrm{H}) \mathrm{Br})(\mathrm{H}) \mathrm{H})(\mathrm{H}) \mathrm{Br})(\mathrm{F}) \mathrm{H})(\mathrm{H}) \mathrm{H})(\mathrm{H}) \mathrm{H})(\mathrm{H}) \mathrm{H})(\mathrm{F})(\mathrm{H}) \mathrm{H}$ $\mathrm{C}(\mathrm{C}(\mathrm{C}(\mathrm{C}(\mathrm{C}(\mathrm{C}(\mathrm{C}(\mathrm{C}(\mathrm{C}(\mathrm{C}(\mathrm{C}(\mathrm{Br})(\mathrm{H}) \mathrm{H})(\mathrm{H}) \mathrm{H})(\mathrm{H}) \mathrm{H})(\mathrm{F}) \mathrm{Br})(\mathrm{Br}) \mathrm{Br})(\mathrm{H}) \mathrm{H})(\mathrm{H}) \mathrm{H})(\mathrm{H}) \mathrm{Br})(\mathrm{H}) \mathrm{F})(\mathrm{Br}) \mathrm{H})(\mathrm{H})(\mathrm{H}) \mathrm{H}$ $\mathrm{C}(\mathrm{C}(\mathrm{C}(\mathrm{C}(\mathrm{C}(\mathrm{C}(\mathrm{C}(\mathrm{C}(\mathrm{C}(\mathrm{C}(\mathrm{C}(\mathrm{H})(\mathrm{H}) \mathrm{F})(\mathrm{H}) \mathrm{H})(\mathrm{Cl}) \mathrm{Cl})(\mathrm{F}) \mathrm{H})(\mathrm{H}) \mathrm{H})(\mathrm{H}) \mathrm{H})(\mathrm{H}) \mathrm{Br})(\mathrm{H}) \mathrm{H})(\mathrm{F}) \mathrm{H})(\mathrm{H}) \mathrm{Br})(\mathrm{Br})(\mathrm{H}) \mathrm{H}$ $\mathrm{C}(\mathrm{C}(\mathrm{C}(\mathrm{C}(\mathrm{C}(\mathrm{C}(\mathrm{C}(\mathrm{C}(\mathrm{C}(\mathrm{C}(\mathrm{C}(\mathrm{H})(\mathrm{Br}) \mathrm{H})(\mathrm{H}) \mathrm{Br})(\mathrm{H}) \mathrm{F})(\mathrm{H}) \mathrm{Cl})(\mathrm{H}) \mathrm{H})(\mathrm{H}) \mathrm{F})(\mathrm{H}) \mathrm{H})(\mathrm{H}) \mathrm{H})(\mathrm{Br}) \mathrm{Cl})(\mathrm{H}) \mathrm{Br})(\mathrm{H})(\mathrm{H}) \mathrm{H}$ $\mathrm{C}(\mathrm{C}(\mathrm{C}(\mathrm{C}(\mathrm{C}(\mathrm{C}(\mathrm{C}(\mathrm{C}(\mathrm{C}(\mathrm{C}(\mathrm{C}(\mathrm{Br})(\mathrm{H}) \mathrm{H})(\mathrm{H}) \mathrm{H})(\mathrm{H}) \mathrm{Cl})(\mathrm{H}) \mathrm{Br})(\mathrm{H}) \mathrm{Br})(\mathrm{H}) \mathrm{H})(\mathrm{H}) \mathrm{H})(\mathrm{F}) \mathrm{Cl})(\mathrm{H}) \mathrm{Br})(\mathrm{H}) \mathrm{H})(\mathrm{H})(\mathrm{H}) \mathrm{B}$ $\mathrm{C}(\mathrm{C}(\mathrm{C}(\mathrm{C}(\mathrm{C}(\mathrm{C}(\mathrm{C}(\mathrm{C}(\mathrm{C}(\mathrm{C}(\mathrm{C}(\mathrm{H})(\mathrm{H}) \mathrm{H})(\mathrm{Cl}) \mathrm{H})(\mathrm{H}) \mathrm{H})(\mathrm{H}) \mathrm{H})(\mathrm{H}) \mathrm{Cl})(\mathrm{Cl}) \mathrm{H})(\mathrm{H}) \mathrm{H})(\mathrm{Br}) \mathrm{H})(\mathrm{F}) \mathrm{F})(\mathrm{Br}) \mathrm{Br})(\mathrm{H})(\mathrm{H}) \mathrm{H}$ $\mathrm{C}(\mathrm{C}(\mathrm{C}(\mathrm{C}(\mathrm{C}(\mathrm{C}(\mathrm{C}(\mathrm{C}(\mathrm{C}(\mathrm{C}(\mathrm{C}(\mathrm{H})(\mathrm{H}) \mathrm{Cl})(\mathrm{Br}) \mathrm{H})(\mathrm{Cl}) \mathrm{H})(\mathrm{H}) \mathrm{Cl})(\mathrm{Br}) \mathrm{H})(\mathrm{F}) \mathrm{H})(\mathrm{H}) \mathrm{H})(\mathrm{H}) \mathrm{H})(\mathrm{H}) \mathrm{Br})(\mathrm{H}) \mathrm{H})(\mathrm{H})(\mathrm{Br}) \mathrm{H}$ $\mathrm{C}(\mathrm{C}(\mathrm{C}(\mathrm{C}(\mathrm{C}(\mathrm{C}(\mathrm{C}(\mathrm{C}(\mathrm{C}(\mathrm{C}(\mathrm{C}(\mathrm{H})(\mathrm{Br}) \mathrm{H})(\mathrm{Br}) \mathrm{H})(\mathrm{H}) \mathrm{F})(\mathrm{Cl}) \mathrm{H})(\mathrm{F}) \mathrm{H})(\mathrm{H}) \mathrm{H})(\mathrm{H}) \mathrm{H})(\mathrm{Cl}) \mathrm{H})(\mathrm{H}) \mathrm{H})(\mathrm{Cl}) \mathrm{H})(\mathrm{Cl})(\mathrm{H}) \mathrm{H}$ $\mathrm{C}(\mathrm{C}(\mathrm{C}(\mathrm{C}(\mathrm{C}(\mathrm{C}(\mathrm{C}(\mathrm{C}(\mathrm{C}(\mathrm{C}(\mathrm{C}(\mathrm{Cl})(\mathrm{Br}) \mathrm{H})(\mathrm{H}) \mathrm{H})(\mathrm{H}) \mathrm{F})(\mathrm{H}) \mathrm{H})(\mathrm{H}) \mathrm{H})(\mathrm{H}) \mathrm{H})(\mathrm{Cl}) \mathrm{H})(\mathrm{Br}) \mathrm{H})(\mathrm{Cl}) \mathrm{Br})(\mathrm{H}) \mathrm{H})(\mathrm{H})(\mathrm{Cl}) \mathrm{H}$ $\mathrm{C}(\mathrm{C}(\mathrm{C}(\mathrm{C}(\mathrm{C}(\mathrm{C}(\mathrm{C}(\mathrm{C}(\mathrm{C}(\mathrm{C}(\mathrm{C}(\mathrm{H})(\mathrm{H}) \mathrm{H})(\mathrm{Br}) \mathrm{H})(\mathrm{H}) \mathrm{Br})(\mathrm{H}) \mathrm{H})(\mathrm{H}) \mathrm{H})(\mathrm{Cl}) \mathrm{H})(\mathrm{Br}) \mathrm{H})(\mathrm{H}) \mathrm{H})(\mathrm{Cl}) \mathrm{H})(\mathrm{H}) \mathrm{Cl})(\mathrm{H})(\mathrm{Br}) \mathrm{Cl}$ $\mathrm{C}(\mathrm{C}(\mathrm{C}(\mathrm{C}(\mathrm{C}(\mathrm{C}(\mathrm{C}(\mathrm{C}(\mathrm{C}(\mathrm{C}(\mathrm{C}(\mathrm{H})(\mathrm{Cl}) \mathrm{H})(\mathrm{H}) \mathrm{H})(\mathrm{H}) \mathrm{H})(\mathrm{H}) \mathrm{H})(\mathrm{H}) \mathrm{H})(\mathrm{Cl}) \mathrm{H})(\mathrm{F}) \mathrm{H})(\mathrm{Br}) \mathrm{Cl})(\mathrm{F}) \mathrm{Cl})(\mathrm{F}) \mathrm{H})(\mathrm{H})(\mathrm{H}) \mathrm{H}$ $\mathrm{C}(\mathrm{C}(\mathrm{C}(\mathrm{C}(\mathrm{C}(\mathrm{C}(\mathrm{C}(\mathrm{C}(\mathrm{C}(\mathrm{C}(\mathrm{C}(\mathrm{Cl})(\mathrm{H}) \mathrm{H})(\mathrm{Cl}) \mathrm{Br})(\mathrm{H}) \mathrm{Cl})(\mathrm{H}) \mathrm{Br})(\mathrm{H}) \mathrm{Cl})(\mathrm{H}) \mathrm{H})(\mathrm{H}) \mathrm{H})(\mathrm{H}) \mathrm{Cl})(\mathrm{H}) \mathrm{H})(\mathrm{F}) \mathrm{H})(\mathrm{H})(\mathrm{H}) \mathrm{H}$ $\mathrm{C}(\mathrm{C}(\mathrm{C}(\mathrm{C}(\mathrm{C}(\mathrm{C}(\mathrm{C}(\mathrm{C}(\mathrm{C}(\mathrm{C}(\mathrm{C}(\mathrm{H})(\mathrm{H}) \mathrm{Cl})(\mathrm{H}) \mathrm{Br})(\mathrm{H}) \mathrm{H})(\mathrm{Cl}) \mathrm{H})(\mathrm{Cl}) \mathrm{H})(\mathrm{H}) \mathrm{H})(\mathrm{H}) \mathrm{H})(\mathrm{Br}) \mathrm{H})(\mathrm{Br}) \mathrm{H})(\mathrm{Cl}) \mathrm{H})(\mathrm{Cl})(\mathrm{H}) \mathrm{H}$ $\mathrm{C}(\mathrm{C}(\mathrm{C}(\mathrm{C}(\mathrm{C}(\mathrm{C}(\mathrm{C}(\mathrm{C}(\mathrm{C}(\mathrm{C}(\mathrm{C}(\mathrm{F})(\mathrm{H}) \mathrm{Cl})(\mathrm{H}) \mathrm{H})(\mathrm{H}) \mathrm{H})(\mathrm{H}) \mathrm{H})(\mathrm{F}) \mathrm{Cl})(\mathrm{Cl}) \mathrm{H})(\mathrm{H}) \mathrm{H})(\mathrm{H}) \mathrm{Cl})(\mathrm{H}) \mathrm{H})(\mathrm{H}) \mathrm{Cl})(\mathrm{H})(\mathrm{Br}) \mathrm{H}$ $\mathrm{C}(\mathrm{C}(\mathrm{C}(\mathrm{C}(\mathrm{C}(\mathrm{C}(\mathrm{C}(\mathrm{C}(\mathrm{C}(\mathrm{C}(\mathrm{C}(\mathrm{H})(\mathrm{H}) \mathrm{H})(\mathrm{Cl}) \mathrm{H})(\mathrm{H}) \mathrm{H})(\mathrm{H}) \mathrm{H})(\mathrm{H}) \mathrm{Br})(\mathrm{H}) \mathrm{Cl})(\mathrm{Cl}) \mathrm{Cl})(\mathrm{H}) \mathrm{Cl})(\mathrm{H}) \mathrm{Br})(\mathrm{H}) \mathrm{H})(\mathrm{H})(\mathrm{Cl}) \mathrm{H}$ $\mathrm{C}(\mathrm{C}(\mathrm{C}(\mathrm{C}(\mathrm{C}(\mathrm{C}(\mathrm{C}(\mathrm{C}(\mathrm{C}(\mathrm{C}(\mathrm{C}(\mathrm{H})(\mathrm{H}) \mathrm{Cl})(\mathrm{H}) \mathrm{H})(\mathrm{H}) \mathrm{Br})(\mathrm{H}) \mathrm{H})(\mathrm{H}) \mathrm{Cl})(\mathrm{F}) \mathrm{H})(\mathrm{H}) \mathrm{H})(\mathrm{Cl}) \mathrm{Cl})(\mathrm{Cl}) \mathrm{H})(\mathrm{Cl}) \mathrm{H})(\mathrm{H})(\mathrm{H}) \mathrm{H}$ $\mathrm{C}(\mathrm{C}(\mathrm{C}(\mathrm{C}(\mathrm{C}(\mathrm{C}(\mathrm{C}(\mathrm{C}(\mathrm{C}(\mathrm{C}(\mathrm{C}(\mathrm{Cl})(\mathrm{Cl}) \mathrm{H})(\mathrm{H}) \mathrm{H})(\mathrm{H}) \mathrm{H})(\mathrm{H}) \mathrm{H})(\mathrm{H}) \mathrm{H})(\mathrm{H}) \mathrm{F})(\mathrm{H}) \mathrm{Cl})(\mathrm{H}) \mathrm{H})(\mathrm{Cl}) \mathrm{F})(\mathrm{H}) \mathrm{H})(\mathrm{H})(\mathrm{Cl}) \mathrm{Cl}$ $\mathrm{C}(\mathrm{C}(\mathrm{C}(\mathrm{C}(\mathrm{C}(\mathrm{C}(\mathrm{C}(\mathrm{C}(\mathrm{C}(\mathrm{C}(\mathrm{C}(\mathrm{Cl})(\mathrm{Br}) \mathrm{H})(\mathrm{H}) \mathrm{Cl})(\mathrm{Cl}) \mathrm{H})(\mathrm{H}) \mathrm{H})(\mathrm{Cl}) \mathrm{H})(\mathrm{H}) \mathrm{H})(\mathrm{H}) \mathrm{H})(\mathrm{H}) \mathrm{Cl})(\mathrm{Cl}) \mathrm{H})(\mathrm{H}) \mathrm{H})(\mathrm{H})(\mathrm{H}) \mathrm{Cl}$ $\mathrm{C}(\mathrm{C}(\mathrm{C}(\mathrm{C}(\mathrm{C}(\mathrm{C}(\mathrm{C}(\mathrm{C}(\mathrm{C}(\mathrm{C}(\mathrm{C}(\mathrm{Cl})(\mathrm{F}) \mathrm{H})(\mathrm{H}) \mathrm{Cl})(\mathrm{H}) \mathrm{H})(\mathrm{H}) \mathrm{H})(\mathrm{Cl}) \mathrm{H})(\mathrm{H}) \mathrm{H})(\mathrm{H}) \mathrm{Cl})(\mathrm{H}) \mathrm{H})(\mathrm{H}) \mathrm{Cl})(\mathrm{H}) \mathrm{H})(\mathrm{Cl})(\mathrm{H}) \mathrm{Cl}$ $\mathrm{C}(\mathrm{C}(\mathrm{C}(\mathrm{C}(\mathrm{C}(\mathrm{C}(\mathrm{C}(\mathrm{C}(\mathrm{C}(\mathrm{C}(\mathrm{C}(\mathrm{H})(\mathrm{H}) \mathrm{H})(\mathrm{H}) \mathrm{H})(\mathrm{H}) \mathrm{Cl})(\mathrm{Cl}) \mathrm{H})(\mathrm{Cl}) \mathrm{H})(\mathrm{H}) \mathrm{H})(\mathrm{Cl}) \mathrm{Cl})(\mathrm{H}) \mathrm{H})(\mathrm{H}) \mathrm{Cl})(\mathrm{H}) \mathrm{Cl})(\mathrm{H})(\mathrm{H}) \mathrm{Cl}$ $\mathrm{C}(\mathrm{C}(\mathrm{C}(\mathrm{C}(\mathrm{C}(\mathrm{C}(\mathrm{C}(\mathrm{C}(\mathrm{C}(\mathrm{C}(\mathrm{C}(\mathrm{H})(\mathrm{H}) \mathrm{H})(\mathrm{Br}) \mathrm{H})(\mathrm{H}) \mathrm{H})(\mathrm{F}) \mathrm{H})(\mathrm{H}) \mathrm{H})(\mathrm{H}) \mathrm{Br})(\mathrm{H}) \mathrm{F})(\mathrm{H}) \mathrm{H})(\mathrm{H}) \mathrm{Br})(\mathrm{H}) \mathrm{F})(\mathrm{Br})(\mathrm{H}) \mathrm{Cl}$ $\mathrm{C}(\mathrm{C}(\mathrm{C}(\mathrm{C}(\mathrm{C}(\mathrm{C}(\mathrm{C}(\mathrm{C}(\mathrm{C}(\mathrm{C}(\mathrm{C}(\mathrm{H})(\mathrm{H}) \mathrm{H})(\mathrm{H}) \mathrm{Br})(\mathrm{Cl}) \mathrm{F})(\mathrm{H}) \mathrm{Br})(\mathrm{H}) \mathrm{H})(\mathrm{H}) \mathrm{H})(\mathrm{H}) \mathrm{Br})(\mathrm{H}) \mathrm{H})(\mathrm{H}) \mathrm{H})(\mathrm{H}) \mathrm{Br})(\mathrm{F})(\mathrm{H}) \mathrm{B}$ $\mathrm{C}(\mathrm{C}(\mathrm{C}(\mathrm{C}(\mathrm{C}(\mathrm{C}(\mathrm{C}(\mathrm{C}(\mathrm{C}(\mathrm{C}(\mathrm{C}(\mathrm{H})(\mathrm{H}) \mathrm{H})(\mathrm{H}) \mathrm{H})(\mathrm{H}) \mathrm{H})(\mathrm{H}) \mathrm{H})(\mathrm{Br}) \mathrm{H})(\mathrm{H}) \mathrm{H})(\mathrm{Br}) \mathrm{H})(\mathrm{Br}) \mathrm{H})(\mathrm{Br}) \mathrm{H})(\mathrm{Br}) \mathrm{Cl})(\mathrm{Br})(\mathrm{F}) \mathrm{H}$ $\mathrm{C}(\mathrm{C}(\mathrm{C}(\mathrm{C}(\mathrm{C}(\mathrm{C}(\mathrm{C}(\mathrm{C}(\mathrm{C}(\mathrm{C}(\mathrm{C}(\mathrm{Br})(\mathrm{H}) \mathrm{Br})(\mathrm{Br}) \mathrm{F})(\mathrm{H}) \mathrm{H})(\mathrm{H}) \mathrm{H})(\mathrm{H}) \mathrm{H})(\mathrm{F}) \mathrm{H})(\mathrm{H}) \mathrm{H})(\mathrm{H}) \mathrm{F})(\mathrm{H}) \mathrm{H})(\mathrm{H}) \mathrm{H})(\mathrm{H})(\mathrm{Br}) \mathrm{H}$ $\mathrm{C}(\mathrm{C}(\mathrm{C}(\mathrm{C}(\mathrm{C}(\mathrm{C}(\mathrm{C}(\mathrm{C}(\mathrm{C}(\mathrm{C}(\mathrm{C}(\mathrm{H})(\mathrm{F}) \mathrm{Br})(\mathrm{H}) \mathrm{Br})(\mathrm{H}) \mathrm{H})(\mathrm{H}) \mathrm{H})(\mathrm{H}) \mathrm{Br})(\mathrm{H}) \mathrm{H})(\mathrm{Br}) \mathrm{F})(\mathrm{H}) \mathrm{H})(\mathrm{H}) \mathrm{H})(\mathrm{Br}) \mathrm{H})(\mathrm{H})(\mathrm{H}) \mathrm{H}$ $\mathrm{C}(\mathrm{C}(\mathrm{C}(\mathrm{C}(\mathrm{C}(\mathrm{C}(\mathrm{C}(\mathrm{C}(\mathrm{C}(\mathrm{C}(\mathrm{C}(\mathrm{H})(\mathrm{H}) \mathrm{H})(\mathrm{Br}) \mathrm{H})(\mathrm{H}) \mathrm{H})(\mathrm{Br}) \mathrm{H})(\mathrm{H}) \mathrm{H})(\mathrm{H}) \mathrm{H})(\mathrm{F}) \mathrm{Br})(\mathrm{H}) \mathrm{H})(\mathrm{H}) \mathrm{H})(\mathrm{H}) \mathrm{Br})(\mathrm{H})(\mathrm{Br}) \mathrm{B}$ $\mathrm{C}(\mathrm{C}(\mathrm{C}(\mathrm{C}(\mathrm{C}(\mathrm{C}(\mathrm{C}(\mathrm{C}(\mathrm{C}(\mathrm{C}(\mathrm{C}(\mathrm{H})(\mathrm{H}) \mathrm{H})(\mathrm{Br}) \mathrm{H})(\mathrm{Br}) \mathrm{H})(\mathrm{H}) \mathrm{H})(\mathrm{H}) \mathrm{Br})(\mathrm{Cl}) \mathrm{H})(\mathrm{H}) \mathrm{H})(\mathrm{H}) \mathrm{H})(\mathrm{H}) \mathrm{H})(\mathrm{Cl}) \mathrm{F})(\mathrm{H})(\mathrm{H}) \mathrm{F}$ $\mathrm{C}(\mathrm{C}(\mathrm{C}(\mathrm{C}(\mathrm{C}(\mathrm{C}(\mathrm{C}(\mathrm{C}(\mathrm{C}(\mathrm{C}(\mathrm{C}(\mathrm{H})(\mathrm{H}) \mathrm{Cl})(\mathrm{Br}) \mathrm{H})(\mathrm{Br}) \mathrm{H})(\mathrm{H}) \mathrm{H})(\mathrm{H}) \mathrm{H})(\mathrm{H}) \mathrm{H})(\mathrm{H}) \mathrm{Cl})(\mathrm{H}) \mathrm{Br})(\mathrm{H}) \mathrm{H})(\mathrm{F}) \mathrm{H})(\mathrm{H})(\mathrm{Br}) \mathrm{H}$ $\mathrm{C}(\mathrm{C}(\mathrm{C}(\mathrm{C}(\mathrm{C}(\mathrm{C}(\mathrm{C}(\mathrm{C}(\mathrm{C}(\mathrm{C}(\mathrm{C}(\mathrm{H})(\mathrm{H}) \mathrm{Br})(\mathrm{H}) \mathrm{H})(\mathrm{H}) \mathrm{Br})(\mathrm{Br}) \mathrm{Cl})(\mathrm{H}) \mathrm{H})(\mathrm{H}) \mathrm{H})(\mathrm{H}) \mathrm{H})(\mathrm{H}) \mathrm{Cl})(\mathrm{Br}) \mathrm{H})(\mathrm{H}) \mathrm{Br})(\mathrm{H})(\mathrm{H}) \mathrm{H}$ $\mathrm{C}(\mathrm{C}(\mathrm{C}(\mathrm{C}(\mathrm{C}(\mathrm{C}(\mathrm{C}(\mathrm{C}(\mathrm{C}(\mathrm{C}(\mathrm{C}(\mathrm{H})(\mathrm{Br}) \mathrm{H})(\mathrm{H}) \mathrm{H})(\mathrm{H}) \mathrm{H})(\mathrm{Br}) \mathrm{H})(\mathrm{H}) \mathrm{H})(\mathrm{Cl}) \mathrm{H})(\mathrm{H}) \mathrm{H})(\mathrm{H}) \mathrm{H})(\mathrm{H}) \mathrm{F})(\mathrm{H}) \mathrm{Cl})(\mathrm{H})(\mathrm{F}) \mathrm{Cl}$ $\mathrm{C}(\mathrm{C}(\mathrm{C}(\mathrm{C}(\mathrm{C}(\mathrm{C}(\mathrm{C}(\mathrm{C}(\mathrm{C}(\mathrm{C}(\mathrm{C}(\mathrm{H})(\mathrm{H}) \mathrm{H})(\mathrm{H}) \mathrm{H})(\mathrm{Cl}) \mathrm{Br})(\mathrm{H}) \mathrm{H})(\mathrm{H}) \mathrm{H})(\mathrm{H}) \mathrm{H})(\mathrm{H}) \mathrm{H})(\mathrm{Cl}) \mathrm{H})(\mathrm{F}) \mathrm{H})(\mathrm{Br}) \mathrm{Br})(\mathrm{H})(\mathrm{Cl}) \mathrm{H}$ $\mathrm{C}(\mathrm{C}(\mathrm{C}(\mathrm{C}(\mathrm{C}(\mathrm{C}(\mathrm{C}(\mathrm{C}(\mathrm{C}(\mathrm{C}(\mathrm{C}(\mathrm{Cl})(\mathrm{Br}) \mathrm{H})(\mathrm{H}) \mathrm{H})(\mathrm{Br}) \mathrm{H})(\mathrm{H}) \mathrm{Cl})(\mathrm{H}) \mathrm{Cl})(\mathrm{H}) \mathrm{H})(\mathrm{H}) \mathrm{H})(\mathrm{H}) \mathrm{Br})(\mathrm{H}) \mathrm{H})(\mathrm{H}) \mathrm{Br})(\mathrm{H})(\mathrm{H}) \mathrm{H}$ $\mathrm{C}(\mathrm{C}(\mathrm{C}(\mathrm{C}(\mathrm{C}(\mathrm{C}(\mathrm{C}(\mathrm{C}(\mathrm{C}(\mathrm{C}(\mathrm{C}(\mathrm{H})(\mathrm{H}) \mathrm{H})(\mathrm{H}) \mathrm{H})(\mathrm{H}) \mathrm{Br})(\mathrm{H}) \mathrm{F})(\mathrm{H}) \mathrm{Cl})(\mathrm{H}) \mathrm{H})(\mathrm{H}) \mathrm{H})(\mathrm{H}) \mathrm{H})(\mathrm{Cl}) \mathrm{F})(\mathrm{Cl}) \mathrm{F})(\mathrm{H})(\mathrm{H}) \mathrm{H}$ $\mathrm{C}(\mathrm{C}(\mathrm{C}(\mathrm{C}(\mathrm{C}(\mathrm{C}(\mathrm{C}(\mathrm{C}(\mathrm{C}(\mathrm{C}(\mathrm{C}(\mathrm{H})(\mathrm{H}) \mathrm{H})(\mathrm{H}) \mathrm{Cl})(\mathrm{F}) \mathrm{H})(\mathrm{H}) \mathrm{Br})(\mathrm{Cl}) \mathrm{Br})(\mathrm{H}) \mathrm{H})(\mathrm{Cl}) \mathrm{H})(\mathrm{H}) \mathrm{H})(\mathrm{H}) \mathrm{H})(\mathrm{Cl}) \mathrm{H})(\mathrm{H})(\mathrm{H}) \mathrm{H}$ $\mathrm{C}(\mathrm{C}(\mathrm{C}(\mathrm{C}(\mathrm{C}(\mathrm{C}(\mathrm{C}(\mathrm{C}(\mathrm{C}(\mathrm{C}(\mathrm{C}(\mathrm{Cl})(\mathrm{H}) \mathrm{Cl})(\mathrm{H}) \mathrm{Br})(\mathrm{H}) \mathrm{H})(\mathrm{H}) \mathrm{H})(\mathrm{Cl}) \mathrm{Cl})(\mathrm{H}) \mathrm{H})(\mathrm{H}) \mathrm{H})(\mathrm{H}) \mathrm{H})(\mathrm{Br}) \mathrm{H})(\mathrm{H}) \mathrm{H})(\mathrm{H})(\mathrm{H}) \mathrm{Br}$ $\mathrm{C}(\mathrm{C}(\mathrm{C}(\mathrm{C}(\mathrm{C}(\mathrm{C}(\mathrm{C}(\mathrm{C}(\mathrm{C}(\mathrm{C}(\mathrm{C}(\mathrm{H})(\mathrm{H}) \mathrm{Cl})(\mathrm{H}) \mathrm{Br})(\mathrm{Br}) \mathrm{Cl})(\mathrm{H}) \mathrm{H})(\mathrm{H}) \mathrm{H})(\mathrm{H}) \mathrm{Cl})(\mathrm{H}) \mathrm{H})(\mathrm{H}) \mathrm{Cl})(\mathrm{H}) \mathrm{H})(\mathrm{H}) \mathrm{H})(\mathrm{Cl})(\mathrm{H}) \mathrm{H}$ $\mathrm{C}(\mathrm{C}(\mathrm{C}(\mathrm{C}(\mathrm{C}(\mathrm{C}(\mathrm{C}(\mathrm{C}(\mathrm{C}(\mathrm{C}(\mathrm{C}(\mathrm{H})(\mathrm{H}) \mathrm{Cl})(\mathrm{Cl}) \mathrm{H})(\mathrm{H}) \mathrm{F})(\mathrm{H}) \mathrm{H})(\mathrm{Cl}) \mathrm{H})(\mathrm{Br}) \mathrm{H})(\mathrm{Cl}) \mathrm{H})(\mathrm{H}) \mathrm{H})(\mathrm{H}) \mathrm{H})(\mathrm{H}) \mathrm{H})(\mathrm{Cl})(\mathrm{H}) \mathrm{H}$ $\mathrm{C}(\mathrm{C}(\mathrm{C}(\mathrm{C}(\mathrm{C}(\mathrm{C}(\mathrm{C}(\mathrm{C}(\mathrm{C}(\mathrm{C}(\mathrm{C}(\mathrm{H})(\mathrm{H}) \mathrm{Cl})(\mathrm{H}) \mathrm{H})(\mathrm{H}) \mathrm{H})(\mathrm{H}) \mathrm{H})(\mathrm{Cl}) \mathrm{H})(\mathrm{Cl}) \mathrm{H})(\mathrm{H}) \mathrm{H})(\mathrm{H}) \mathrm{Cl})(\mathrm{H}) \mathrm{Cl})(\mathrm{Cl}) \mathrm{H})(\mathrm{H})(\mathrm{Br}) \mathrm{H}$ $\mathrm{C}(\mathrm{C}(\mathrm{C}(\mathrm{C}(\mathrm{C}(\mathrm{C}(\mathrm{C}(\mathrm{C}(\mathrm{C}(\mathrm{C}(\mathrm{C}(\mathrm{H})(\mathrm{H}) \mathrm{H})(\mathrm{H}) \mathrm{Cl})(\mathrm{Cl}) \mathrm{H})(\mathrm{Cl}) \mathrm{Cl})(\mathrm{H}) \mathrm{H})(\mathrm{H}) \mathrm{H})(\mathrm{F}) \mathrm{H})(\mathrm{Cl}) \mathrm{H})(\mathrm{H}) \mathrm{Cl})(\mathrm{H}) \mathrm{H})(\mathrm{H})(\mathrm{H}) \mathrm{H}$ $\mathrm{C}(\mathrm{C}(\mathrm{C}(\mathrm{C}(\mathrm{C}(\mathrm{C}(\mathrm{C}(\mathrm{C}(\mathrm{C}(\mathrm{C}(\mathrm{C}(\mathrm{Cl})(\mathrm{Cl}) \mathrm{H})(\mathrm{H}) \mathrm{H})(\mathrm{H}) \mathrm{H})(\mathrm{H}) \mathrm{H})(\mathrm{H}) \mathrm{Cl})(\mathrm{Cl}) \mathrm{H})(\mathrm{Cl}) \mathrm{Cl})(\mathrm{H}) \mathrm{H})(\mathrm{H}) \mathrm{H})(\mathrm{H}) \mathrm{H})(\mathrm{Cl})(\mathrm{H}) \mathrm{H}$ $\mathrm{C}(\mathrm{C}(\mathrm{C}(\mathrm{C}(\mathrm{C}(\mathrm{C}(\mathrm{C}(\mathrm{C}(\mathrm{C}(\mathrm{C}(\mathrm{C}(\mathrm{H})(\mathrm{H}) \mathrm{H})(\mathrm{H}) \mathrm{Cl})(\mathrm{Br}) \mathrm{H})(\mathrm{H}) \mathrm{H})(\mathrm{Br}) \mathrm{H})(\mathrm{H}) \mathrm{H})(\mathrm{F}) \mathrm{F})(\mathrm{H}) \mathrm{H})(\mathrm{H}) \mathrm{F})(\mathrm{H}) \mathrm{H})(\mathrm{H})(\mathrm{Br}) \mathrm{H}$ $\mathrm{C}(\mathrm{C}(\mathrm{C}(\mathrm{C}(\mathrm{C}(\mathrm{C}(\mathrm{C}(\mathrm{C}(\mathrm{C}(\mathrm{C}(\mathrm{C}(\mathrm{F})(\mathrm{Br}) \mathrm{H})(\mathrm{F}) \mathrm{Cl})(\mathrm{Br}) \mathrm{H})(\mathrm{H}) \mathrm{H})(\mathrm{Br}) \mathrm{H})(\mathrm{H}) \mathrm{H})(\mathrm{H}) \mathrm{H})(\mathrm{H}) \mathrm{H})(\mathrm{H}) \mathrm{H})(\mathrm{H}) \mathrm{Br})(\mathrm{H})(\mathrm{H}) \mathrm{H}$ $\mathrm{C}(\mathrm{C}(\mathrm{C}(\mathrm{C}(\mathrm{C}(\mathrm{C}(\mathrm{C}(\mathrm{C}(\mathrm{C}(\mathrm{C}(\mathrm{C}(\mathrm{Br})(\mathrm{H}) \mathrm{H})(\mathrm{H}) \mathrm{H})(\mathrm{H}) \mathrm{H})(\mathrm{H}) \mathrm{Br})(\mathrm{H}) \mathrm{Br})(\mathrm{H}) \mathrm{Br})(\mathrm{H}) \mathrm{H})(\mathrm{H}) \mathrm{H})(\mathrm{H}) \mathrm{Br})(\mathrm{H}) \mathrm{F})(\mathrm{H})(\mathrm{H}) \mathrm{Cl}$
$\mathrm{C} 11 \mathrm{H} 14 \mathrm{Cl} 1 \mathrm{Br} 2 \mathrm{~F}$ $\mathrm{C} 11 \mathrm{H} 14 \mathrm{Cl} 7 \mathrm{BrF} 2$ $\mathrm{C} 11 \mathrm{H} 14 \mathrm{Cl} 7 \mathrm{~F} 3$ $\mathrm{C} 11 \mathrm{H} 14 \mathrm{Cl} 8 \mathrm{BrF}$ $\mathrm{C} 11 \mathrm{H} 14 \mathrm{Cl} 18 \mathrm{~F} 2$ $\mathrm{C} 11 \mathrm{H} 14 \mathrm{Cl} 19 \mathrm{Br}$ $\mathrm{C} 11 \mathrm{H} 14 \mathrm{Cl} 9 \mathrm{~F}$

C11H14ClBr4F5 $\mathrm{C} 11 \mathrm{H} 14 \mathrm{ClBr} 5 \mathrm{~F} 4$ $\mathrm{C} 11 \mathrm{H} 14 \mathrm{ClBr} 6 \mathrm{~F} 3$ $\mathrm{C} 11 \mathrm{H} 15 \mathrm{Br} 5 \mathrm{~F} 4$ C11H15Br6F3

C11H15Br7F $\mathrm{C} 11 \mathrm{H} 15 \mathrm{Cl} 2 \mathrm{Br} 2 \mathrm{~F} 5$ $\mathrm{C} 11 \mathrm{H} 15 \mathrm{Cl} 2 \mathrm{Br} 3 \mathrm{~F} 4$ C11H15Cl2Br4F3 $\mathrm{C} 11 \mathrm{H} 15 \mathrm{Cl} 2 \mathrm{Br} 5 \mathrm{~F} 2$ $\mathrm{C} 11 \mathrm{H} 15 \mathrm{Cl} 2 \mathrm{Br} 6 \mathrm{~F}$ $\mathrm{C} 11 \mathrm{H} 15 \mathrm{Cl} 3 \mathrm{Br} 2 \mathrm{~F} 4$ $\mathrm{C} 11 \mathrm{H} 15 \mathrm{Cl} 3 \mathrm{Br} 3 \mathrm{~F} 3$ $\mathrm{C} 11 \mathrm{H} 15 \mathrm{Cl} 3 \mathrm{Br} 4 \mathrm{~F} 2$ C11H15Cl3Br5F $\mathrm{C} 11 \mathrm{H} 15 \mathrm{Cl} 4 \mathrm{Br} 2 \mathrm{~F} 3$ C11H15Cl4Br3F2 C11H15Cl4Br4F C11H15C15Br2F2 $\mathrm{C} 11 \mathrm{H} 15 \mathrm{Cl} 5 \mathrm{Br} 3 \mathrm{~F}$ $\mathrm{C} 11 \mathrm{H} 15 \mathrm{Cl} 5 \mathrm{BrF} 3$ $\mathrm{C} 11 \mathrm{H} 15 \mathrm{Cl} 6 \mathrm{Br} 2 \mathrm{~F}$ C11H15Cl6Br3 C11H15Cl6BrF2 C11H15Cl6F3

$\mathrm{C} 11 \mathrm{H} 15 \mathrm{Cl} \mathrm{Br} 2$

C11H15C17BrF C11H15Cl7F2 C11H15Cl8B $\mathrm{C} 11 \mathrm{H} 15 \mathrm{Cl} 8 \mathrm{~F}$ C11H15Cl9

C11H15ClBr4F4 $\mathrm{C} 11 \mathrm{H} 15 \mathrm{ClBr} 5 \mathrm{~F} 3$ $\mathrm{C} 11 \mathrm{H} 15 \mathrm{ClBr} 6 \mathrm{~F} 2$ $\mathrm{C} 11 \mathrm{H} 16 \mathrm{Br} 4 \mathrm{~F} 4$

C11H16Br5F

$\mathrm{C} 11 \mathrm{H} 16 \mathrm{Br} 6 \mathrm{~F} 2$

C11H16Cl2Br3F3

$\mathrm{C} 11 \mathrm{H} 16 \mathrm{Cl} 2 \mathrm{Br} 4 \mathrm{~F} 2$

C11H16Cl2Br5F

$\mathrm{C} 11 \mathrm{H} 16 \mathrm{Cl} 3 \mathrm{Br} 3 \mathrm{~F} 2$

$\mathrm{C} 11 \mathrm{H} 16 \mathrm{Cl} 3 \mathrm{Br} 4 \mathrm{~F}$

C11H16Cl4Br2F2

$\mathrm{C} 11 \mathrm{H} 16 \mathrm{Cl} 4 \mathrm{Br} 3 \mathrm{~F}$

$\mathrm{C} 11 \mathrm{H} 16 \mathrm{Cl} 4 \mathrm{Br}$

$\mathrm{C} 11 \mathrm{H} 16 \mathrm{Cl} 4 \mathrm{BrF} 3$

C11H16Cl5Br2F

$\mathrm{C} 11 \mathrm{H} 16 \mathrm{Cl} 5 \mathrm{Br} 3$

C11H16Cl5BrF2

$\mathrm{C} 11 \mathrm{H} 16 \mathrm{Cl} 6 \mathrm{Br} 2$

C11H16Cl6BrF

C11H16Cl6F2

$\mathrm{C} 11 \mathrm{H} 16 \mathrm{Cl} 7 \mathrm{Br}$

C11H16Cl7F

C11H16Cl8

C11H16ClBr4F3

$\mathrm{C} 11 \mathrm{H} 16 \mathrm{ClBr} 5 \mathrm{~F} 2$

C11H16ClBr6F

$\mathrm{C} 11 \mathrm{H} 17 \mathrm{Br} 4 \mathrm{~F} 3$

$11 \mathrm{H} 17 \mathrm{Br} 5 \mathrm{~F} 2$

$\mathrm{C} 11 \mathrm{H} 17 \mathrm{Br} 6 \mathrm{~F}$

$\mathrm{C} 11 \mathrm{H} 17 \mathrm{Cl} 2 \mathrm{Br} 3 \mathrm{~F} 2$

$\mathrm{C} 11 \mathrm{H} 17 \mathrm{Cl} 2 \mathrm{Br} 4 \mathrm{~F}$

$\mathrm{C} 11 \mathrm{H} 17 \mathrm{Cl} 3 \mathrm{Br} 2 \mathrm{~F} 2$

$\mathrm{C} 11 \mathrm{H} 17 \mathrm{Cl} 3 \mathrm{Br} 3 \mathrm{~F}$

$\mathrm{C} 11 \mathrm{H} 17 \mathrm{Cl} 3 \mathrm{Br} 4$

$\mathrm{C} 11 \mathrm{H} 17 \mathrm{Cl} 3 \mathrm{BrF} 3$

C11 $117 \mathrm{Cl} 4 \mathrm{Br} 2$

$\mathrm{C} 11 \mathrm{H} 17 \mathrm{Cl} 4 \mathrm{Br} 3$

$\mathrm{C} 11 \mathrm{H} 17 \mathrm{Cl} 5 \mathrm{Br} 2$

$\mathrm{C} 11 \mathrm{H} 17 \mathrm{Cl} 5 \mathrm{BrF}$

$\mathrm{C} 11 \mathrm{H} 17 \mathrm{Cl6B}$

$\mathrm{C} 11 \mathrm{H} 17 \mathrm{Cl} 6 \mathrm{~F}$

$\mathrm{C} 11 \mathrm{H} 17 \mathrm{Cl} 7$

$\mathrm{C} 11 \mathrm{H} 17 \mathrm{ClBr} 3 \mathrm{~F} 3$

$\mathrm{C} 11 \mathrm{H} 17 \mathrm{ClBr} 4 \mathrm{~F} 2$

$\mathrm{C} 11 \mathrm{H} 17 \mathrm{ClBr} 5 \mathrm{~F}$
EPI EPI EPI Exp Exp Exp DFT DFT DFT ${ }_{\text {Suite }}$ Suite $\quad$ Suite corr corr corr corr corr corr \begin{tabular}{cccccccccc} 
Suite Suite & \multicolumn{2}{c}{ Suite } & \multicolumn{1}{c}{ corr } & corr & corr & \multicolumn{1}{c}{ corr } & corr corr \\
11.3 & 8.3 & -3.04 & 7.46 & 10.50 & -3.04 & 7.14 & 18.84 & -11.7
\end{tabular} $\begin{array}{lllllllll}10.4 & 8.64 & -1.80 & 7.97 & 9.77 & -1.80 & 7.40 & 17.20 & -9.80\end{array}$ $\begin{array}{llllllllll}8.81 & 8.24 & -0.57 & 7.37 & 7.94 & -0.57 & 7.09 & 14.19 & -7.10 \\ 10.8 & 8.21 & -2.56 & 7.33 & 9.88 & -2.56 & 7.07 & 17.79 & -10.72\end{array}$ $\begin{array}{llllll}9.88 & -2.56 & 7.07 & 17.79 & -10.72\end{array}$ $\begin{array}{lllllllll}8.39 & 7.07 & -1.32 & 5.63 & 6.94 & -1.32 & 6.19 & 13.42 & -7.23\end{array}$ $\begin{array}{llllllllll}11.8 & 8.53 & -3.31 & 7.81 & 11.11 & -3.31 & 7.31 & 19.75 & -12.44\end{array}$ $\begin{array}{llllllllll}10.9 & 8.79 & -2.07 & 8.19 & 10.26 & -2.07 & 7.51 & 17.96 & -10.45\end{array}$ $\begin{array}{llllllllll}8.23 & 7.23 & -1.00 & 5.87 & 6.87 & -1.00 & 6.31 & 13.14 & -6.82\end{array}$ $\begin{array}{lllllllll}11.2 & 8.96 & -2.24 & 8.45 & 10.69 & -2.24 & 7.64 & 18.58 & -10.94\end{array}$ $\begin{array}{llllllllll}11.2 & 8.96 & -2.24 & 8.45 & 10.69 & -2.24 & 7.64 & 18.58 & -10.94 \\ 11.5 & 8.03 & -3.48 & 7.06 & 10.54 & -3.48 & 6.93 & 19.15 & -12.22\end{array}$ $\begin{array}{llllllllll}9.91 & 8.12 & -1.79 & 7.19 & 8.98 & -1.79 & 7.00 & 16.21 & -9.2\end{array}$ $\begin{array}{llllllllll}10.9 & 7.85 & -3.02 & 6.79 & 9.82 & -3.02 & 6.79 & 17.99 & -11.20\end{array}$ $\begin{array}{lllllllll}12.4 & 8.18 & -4.26 & 7.28 & 11.55 & -4.26 & 7.04 & 20.87 & -13.82\end{array}$ $\begin{array}{lllllllll}7.19 & 7.61 & 0.42 & 6.43 & 6.01 & 0.42 & 6.61 & 11.22 & -4.61\end{array}$ $\begin{array}{rrrrrrrrr}8.09 & 7.27 & -0.82 & 5.93 & 6.74 & -0.82 & 6.35 & 12.87 & -6.52\end{array}$ $\begin{array}{llllllllll}8.91 & 6.86 & -2.05 & 5.31 & 7.37 & -2.05 & 6.03 & 14.39 & -8.36\end{array}$ $\begin{array}{llllllllll}11.4 & 8.08 & -3.29 & 7.13 & 10.43 & -3.29 & 6.97 & 18.90 & -11.93\end{array}$ $\begin{array}{llllllllll}12.3 & 7.74 & -4.53 & 6.63 & 11.16 & -4.53 & 6.71 & 20.55 & -13.84\end{array}$ $\begin{array}{rrrrrrrrrr}12.3 & 7.74 & -4.53 & 6.63 & 11.16 & -4.53 & 6.71 & 20.55 & -13.84 \\ 8.18 & 7.85 & -0.33 & 6.79 & 7.12 & -0.33 & 6.79 & 13.04 & -6.25\end{array}$ $\begin{array}{llllllllll}10.6 & 8.99 & -1.57 & 8.49 & 10.06 & -1.57 & 7.67 & 17.41 & -9.74\end{array}$ $\begin{array}{lllllllll}10.7 & 7.91 & -2.81 & 6.88 & 9.69 & -2.81 & 6.84 & 17.70 & -10.86\end{array}$ $\begin{array}{llllllllll}12.4 & 8.32 & -4.04 & 7.49 & 11.54 & -4.04 & 7.15 & 20.72 & -13.57\end{array}$ $\begin{array}{lllllllll}7.83 & 6.75 & -1.08 & 5.15 & 6.23 & -1.08 & 5.95 & 12.40 & -6.46\end{array}$ $\begin{array}{rrrrrrrrr}10.9 & 8.56 & -2.32 & 7.85 & 10.17 & -2.32 & 7.34 & 18.00 & -10.66\end{array}$ $\begin{array}{llllllllll}11.1 & 7.56 & -3.56 & 6.36 & 9.92 & -3.56 & 6.57 & 18.44 & -11.87\end{array}$ $\begin{array}{lllllllll}10.3 & 8.48 & -1.84 & 7.73 & 9.57 & -1.84 & 7.28 & 16.96 & -9.69\end{array}$ $\begin{array}{lllllllll}12 & 8.88 & -3.07 & 8.33 & 11.40 & -3.07 & 7.58 & 19.97 & -12.38\end{array}$ $\begin{array}{llllllllll}8.01 & 7.41 & -0.60 & 6.13 & 6.73 & -0.60 & 6.45 & 12.72 & -6.27\end{array}$ $\begin{array}{lllllllll}11.4 & 8.86 & -2.59 & 8.30 & 10.89 & -2.59 & 7.57 & 19.04 & -11.47\end{array}$ $\begin{array}{llllllllll}12.3 & 8.52 & -3.83 & 7.79 & 11.62 & -3.83 & 7.31 & 20.69 & -13.38\end{array}$ $\begin{array}{lllllllll}9.07 & 7.72 & -1.35 & 6.60 & 7.95 & -1.35 & 6.69 & 14.68 & -7.98\end{array}$ $\begin{array}{llllllllll}7.43 & 7.32 & -0.11 & 6.00 & 6.11 & -0.11 & 6.38 & 11.67 & -5.28\end{array}$ $\begin{array}{lllllllll}11.8 & 8.43 & -3.34 & 7.66 & 11.00 & -3.34 & 7.24 & 19.63 & -12.39\end{array}$ $\begin{array}{llllllllll}10.9 & 8.77 & -2.10 & 8.16 & 10.27 & -2.10 & 7.50 & 17.99 & -10.49\end{array}$ $\begin{array}{rrrrrrrrr}10.9 & 8.77 & -2.10 & 8.16 & 10.27 & -2.10 & 7.50 & 17.99 & -10.49 \\ 8.5 & 7.63 & -0.86 & 6.46 & 7.33 & -0.86 & 6.62 & 13.62 & -7.00\end{array}$ $\begin{array}{llllllllll}10.5 & 7.6 & -2.85 & 6.42 & 9.27 & -2.85 & 6.60 & 17.22 & -10.62\end{array}$ $\begin{array}{llllllllll}9.56 & 7.94 & -1.62 & 6.93 & 8.54 & -1.62 & 6.86 & 15.57 & -8.71\end{array}$ $\begin{array}{lllllllll}10.6 & 8.26 & -2.37 & 7.40 & 9.77 & -2.37 & 7.11 & 17.53 & -10.43\end{array}$ $\begin{array}{rrrrrrrrr}10.6 & 8.26 & -2.37 & 7.40 & 9.77 & -2.37 & 7.11 & 17.53 & -10.43 \\ 9.4 & 8.1 & -1.30 & 7.16 & 8.47 & -1.30 & 6.98 & 15.28 & -8.30\end{array}$ $\begin{array}{rrrrrrrrr}9.4 & 8.1 & -1.30 & 7.16 & 8.47 & -1.30 & 6.98 & 15.28 & -8.30 \\ 9.56 & 7.02 & -2.54 & 5.55 & 8.09 & -2.54 & 6.15 & 15.57 & -9.42\end{array}$ $\begin{array}{lllllllll}11.2 & 7.43 & -3.78 & 6.16 & 9.94 & -3.78 & 6.47 & 18.60 & -12.13\end{array}$ $\begin{array}{llllllllll}8.7 & 7.85 & -0.85 & 6.79 & 7.64 & -0.85 & 6.79 & 13.99 & -7.20\end{array}$ $\begin{array}{llllllllll}8.93 & 6.84 & -2.09 & 5.28 & 7.37 & -2.09 & 6.02 & 14.41 & -8.40\end{array}$ $\begin{array}{lllllllll}12 & 8.65 & -3.32 & 7.99 & 11.31 & -3.32 & 7.41 & 20.01 & -12.60\end{array}$ $\begin{array}{llllllllll}8.52 & 7.4 & -1.12 & 6.12 & 7.24 & -1.12 & 6.45 & 13.66 & -7.21\end{array}$ $\begin{array}{llllllllll}10.1 & 7.73 & -2.36 & 6.61 & 8.97 & -2.36 & 6.70 & 16.54 & -9.84\end{array}$ $\begin{array}{lllllllll}11.8 & 8.21 & -3.59 & 7.33 & 10.92 & -3.59 & 7.07 & 19.69 & -12.62\end{array}$ $\begin{array}{llllllllll}10.2 & 8.31 & -1.87 & 7.48 & 9.35 & -1.87 & 7.14 & 16.71 & -9.56\end{array}$ $\begin{array}{llllllllll}10.5 & 7.38 & -3.11 & 6.09 & 9.19 & -3.11 & 6.43 & 17.27 & -10.84\end{array}$ $\begin{array}{llllllllll}8.27 & 6.89 & -1.38 & 5.36 & 6.74 & -1.38 & 6.05 & 13.21 & -7.16\end{array}$ $\begin{array}{llllllllll}10.7 & 8.03 & -2.62 & 7.06 & 9.68 & -2.62 & 6.93 & 17.58 & -10.65\end{array}$ $\begin{array}{lllllllll}11.5 & 7.62 & -3.86 & 6.45 & 10.30 & -3.86 & 6.61 & 19.09 & -12.48\end{array}$ $\begin{array}{lllllllll}8.04 & 7.89 & -0.15 & 6.85 & 7.00 & -0.15 & 6.82 & 12.77 & -5.95\end{array}$ $\begin{array}{lllllllll}10 & 7.87 & -2.14 & 6.82 & 8.96 & -2.14 & 6.81 & 16.39 & -9.59\end{array}$ $\begin{array}{lllllllll}11 & 7.6 & -3.37 & 6.42 & 9.79 & -3.37 & 6.60 & 18.17 & -11.57\end{array}$ $\begin{array}{llllllllll}8.44 & 7.54 & -0.90 & 6.33 & 7.23 & -0.90 & 6.55 & 13.51 & -6.96\end{array}$ $\begin{array}{lllllllll}11.1 & 8.18 & -2.89 & 7.28 & 10.17 & -2.89 & 7.04 & 18.34 & -11.30\end{array}$ $\begin{array}{llllllllll}9.43 & 7.78 & -1.65 & 6.69 & 8.34 & -1.65 & 6.74 & 15.33 & -8.60\end{array}$ $\begin{array}{lllllllll}7.86 & 7.45 & -0.41 & 6.19 & 6.61 & -0.41 & 6.48 & 12.45 & -5.97\end{array}$ $\begin{array}{llllllllll}9.82 & 7.42 & -2.40 & 6.15 & 8.55 & -2.40 & 6.46 & 16.05 & -9.59\end{array}$ $\begin{array}{llllllllll}8.18 & 7.02 & -1.16 & 5.55 & 6.72 & -1.16 & 6.15 & 13.04 & -6.89\end{array}$ $\begin{array}{rrrrrrrrr}9.92 & 8 & -1.92 & 7.01 & 8.93 & -1.92 & 6.91 & 16.23 & -9.32\end{array}$ $\begin{array}{lllllllll}8.28 & 6.68 & -1.60 & 5.04 & 6.65 & -1.60 & 5.89 & 13.22 & -7.33\end{array}$ $\begin{array}{llllllllll}10.7 & 7.82 & -2.84 & 6.75 & 9.58 & -2.84 & 6.77 & 17.59 & -10.82\end{array}$ $\begin{array}{lllllllll}12.3 & 8.23 & -4.07 & 7.36 & 11.43 & -4.07 & 7.08 & 20.62 & -13.53\end{array}$ $\begin{array}{llllllllll}8.46 & 7.31 & -1.15 & 5.99 & 7.13 & -1.15 & 6.38 & 13.55 & -7.17\end{array}$

$\begin{array}{lllllllll}10 & 7.64 & -2.38 & 6.48 & 8.86 & -2.38 & 6.63 & 16.43 & -9.80\end{array}$ $\begin{array}{lllllllll}11.7 & 8.04 & -3.62 & 7.07 & 10.70 & -3.62 & 6.94 & 19.43 & -12.50\end{array}$ $\begin{array}{llllllllll}8.88 & 7.46 & -1.41 & 6.21 & 7.62 & -1.41 & 6.49 & 14.32 & -7.82\end{array}$ $\begin{array}{llllllllll}9.85 & 7.2 & -2.65 & 5.82 & 8.47 & -2.65 & 6.29 & 16.11 & -9.82\end{array}$ $\begin{array}{lllllllll}12.2 & 8.27 & -3.89 & 7.42 & 11.31 & -3.89 & 7.11 & 20.35 & -13.23\end{array}$ $\begin{array}{lllllllll}7.64 & 6.71 & -0.93 & 5.09 & 6.02 & -0.93 & 5.92 & 12.04 & -6.13\end{array}$ $\begin{array}{lllllllll}10.7 & 8.52 & -2.17 & 7.79 & 9.96 & -2.17 & 7.31 & 17.64 & -10.34\end{array}$ $\begin{array}{lllllllll}10.8 & 7.44 & -3.40 & 6.18 & 9.58 & -3.40 & 6.48 & 17.93 & -11.45\end{array}$ $\begin{array}{llllllllll}7.33 & 7.64 & 0.31 & 6.48 & 6.17 & 0.31 & 6.63 & 11.48 & -4.85\end{array}$ $\begin{array}{llllllllll}9.29 & 7.61 & -1.68 & 6.43 & 8.11 & -1.68 & 6.61 & 15.08 & -8.47\end{array}$ $\begin{array}{lllllllll}11.1 & 8.16 & -2.92 & 7.25 & 10.17 & -2.92 & 7.03 & 18.36 & -11.33\end{array}$ $\begin{array}{lllllllll}10.5 & 8.07 & -2.43 & 7.12 & 9.55 & -2.43 & 6.96 & 17.31 & -10.35\end{array}$ $\begin{array}{llllllllll}8.13 & 6.93 & -1.20 & 5.42 & 6.61 & -1.20 & 6.08 & 12.94 & -6.85\end{array}$ $\begin{array}{llllllllll}9.19 & 7.24 & -1.95 & 5.88 & 7.83 & -1.95 & 6.32 & 14.89 & -8.57\end{array}$ $\begin{array}{llllllllll}8.14 & 7.43 & -0.71 & 6.16 & 6.88 & -0.71 & 6.47 & 12.97 & -6.50\end{array}$ $\begin{array}{lllllllll}9.35 & 7.89 & -1.46 & 6.85 & 8.31 & -1.46 & 6.82 & 15.19 & -8.37\end{array}$ $\begin{array}{lllllllll}7.81 & 7.15 & -0.66 & 5.75 & 6.41 & -0.66 & 6.25 & 12.36 & -6.11\end{array}$ $\begin{array}{llllllllll}9.45 & 7.55 & -1.90 & 6.34 & 8.24 & -1.90 & 6.56 & 15.37 & -8.81\end{array}$ $\begin{array}{lllllllll}10.4 & 7.29 & -3.14 & 5.96 & 9.09 & -3.14 & 6.36 & 17.17 & -10.81\end{array}$ 
Formula

$\mathrm{C}(\mathrm{C}(\mathrm{C}(\mathrm{C}(\mathrm{C}(\mathrm{C}(\mathrm{C}(\mathrm{C}(\mathrm{C}(\mathrm{C}(\mathrm{C}(\mathrm{Br})(\mathrm{H}) \mathrm{H})(\mathrm{H}) \mathrm{H})(\mathrm{Br}) \mathrm{H})(\mathrm{H}) \mathrm{H})(\mathrm{Br}) \mathrm{H})(\mathrm{Br}) \mathrm{H})(\mathrm{H}) \mathrm{Cl})(\mathrm{Br}) \mathrm{H})(\mathrm{Br}) \mathrm{H})(\mathrm{H}) \mathrm{H})(\mathrm{H})(\mathrm{H}) \mathrm{H}$ $\mathrm{C}(\mathrm{C}(\mathrm{C}(\mathrm{C}(\mathrm{C}(\mathrm{C}(\mathrm{C}(\mathrm{C}(\mathrm{C}(\mathrm{C}(\mathrm{C}(\mathrm{H})(\mathrm{Br}) \mathrm{H})(\mathrm{H}) \mathrm{Br})(\mathrm{H}) \mathrm{H})(\mathrm{H}) \mathrm{H})(\mathrm{Br}) \mathrm{F})(\mathrm{H}) \mathrm{H})(\mathrm{H}) \mathrm{H})(\mathrm{H}) \mathrm{H})(\mathrm{Br}) \mathrm{H})(\mathrm{F}) \mathrm{H})(\mathrm{H})(\mathrm{H}) \mathrm{H}$ $\mathrm{C}(\mathrm{C}(\mathrm{C}(\mathrm{C}(\mathrm{C}(\mathrm{C}(\mathrm{C}(\mathrm{C}(\mathrm{C}(\mathrm{C}(\mathrm{C}(\mathrm{Br})(\mathrm{H}) \mathrm{H})(\mathrm{H}) \mathrm{H})(\mathrm{H}) \mathrm{H})(\mathrm{H}) \mathrm{H})(\mathrm{Br}) \mathrm{H})(\mathrm{Br}) \mathrm{H})(\mathrm{H}) \mathrm{H})(\mathrm{F}) \mathrm{H})(\mathrm{H}) \mathrm{H})(\mathrm{H}) \mathrm{H})(\mathrm{Br})(\mathrm{H}) \mathrm{Br}$ $\mathrm{C}(\mathrm{C}(\mathrm{C}(\mathrm{C}(\mathrm{C}(\mathrm{C}(\mathrm{C}(\mathrm{C}(\mathrm{C}(\mathrm{C}(\mathrm{C}(\mathrm{H})(\mathrm{H}) \mathrm{H})(\mathrm{H}) \mathrm{H})(\mathrm{H}) \mathrm{H})(\mathrm{H}) \mathrm{H})(\mathrm{Br}) \mathrm{H})(\mathrm{H}) \mathrm{H})(\mathrm{H}) \mathrm{Br})(\mathrm{Br}) \mathrm{Br})(\mathrm{H}) \mathrm{Br})(\mathrm{H}) \mathrm{H})(\mathrm{H})(\mathrm{Br}) \mathrm{H}$ $\mathrm{C}(\mathrm{C}(\mathrm{C}(\mathrm{C}(\mathrm{C}(\mathrm{C}(\mathrm{C}(\mathrm{C}(\mathrm{C}(\mathrm{C}(\mathrm{C}(\mathrm{H})(\mathrm{H}) \mathrm{Br})(\mathrm{H}) \mathrm{H})(\mathrm{H}) \mathrm{H})(\mathrm{H}) \mathrm{Br})(\mathrm{H}) \mathrm{H})(\mathrm{Cl}) \mathrm{H})(\mathrm{F}) \mathrm{H})(\mathrm{H}) \mathrm{H})(\mathrm{H}) \mathrm{H})(\mathrm{H}) \mathrm{Br})(\mathrm{H})(\mathrm{Cl}) \mathrm{H}$ $\mathrm{C}(\mathrm{C}(\mathrm{C}(\mathrm{C}(\mathrm{C}(\mathrm{C}(\mathrm{C}(\mathrm{C}(\mathrm{C}(\mathrm{C}(\mathrm{C}(\mathrm{Cl})(\mathrm{H}) \mathrm{H})(\mathrm{H}) \mathrm{H})(\mathrm{H}) \mathrm{H})(\mathrm{Br}) \mathrm{Cl})(\mathrm{Br}) \mathrm{H})(\mathrm{H}) \mathrm{H})(\mathrm{H}) \mathrm{H})(\mathrm{H}) \mathrm{H})(\mathrm{H}) \mathrm{H})(\mathrm{H}) \mathrm{Br})(\mathrm{Br})(\mathrm{H}) \mathrm{H}$ $\mathrm{C}(\mathrm{C}(\mathrm{C}(\mathrm{C}(\mathrm{C}(\mathrm{C}(\mathrm{C}(\mathrm{C}(\mathrm{C}(\mathrm{C}(\mathrm{C}(\mathrm{H})(\mathrm{H}) \mathrm{H})(\mathrm{Br}) \mathrm{H})(\mathrm{Cl}) \mathrm{F})(\mathrm{H}) \mathrm{H})(\mathrm{Cl}) \mathrm{Cl})(\mathrm{H}) \mathrm{H})(\mathrm{H}) \mathrm{Br})(\mathrm{H}) \mathrm{H})(\mathrm{H}) \mathrm{H})(\mathrm{H}) \mathrm{H})(\mathrm{H})(\mathrm{H}) \mathrm{H}$ $\mathrm{C}(\mathrm{C}(\mathrm{C}(\mathrm{C}(\mathrm{C}(\mathrm{C}(\mathrm{C}(\mathrm{C}(\mathrm{C}(\mathrm{C}(\mathrm{C}(\mathrm{H})(\mathrm{H}) \mathrm{H})(\mathrm{H}) \mathrm{Cl})(\mathrm{H}) \mathrm{H})(\mathrm{Br}) \mathrm{H})(\mathrm{Cl}) \mathrm{H})(\mathrm{H}) \mathrm{H})(\mathrm{Br}) \mathrm{H})(\mathrm{Cl}) \mathrm{H})(\mathrm{H}) \mathrm{H})(\mathrm{H}) \mathrm{H})(\mathrm{H})(\mathrm{Br}) \mathrm{H}$ $\mathrm{C}(\mathrm{C}(\mathrm{C}(\mathrm{C}(\mathrm{C}(\mathrm{C}(\mathrm{C}(\mathrm{C}(\mathrm{C}(\mathrm{C}(\mathrm{C}(\mathrm{H})(\mathrm{H}) \mathrm{H})(\mathrm{Br}) \mathrm{H})(\mathrm{H}) \mathrm{H})(\mathrm{H}) \mathrm{Cl})(\mathrm{H}) \mathrm{H})(\mathrm{Cl}) \mathrm{H})(\mathrm{H}) \mathrm{Cl})(\mathrm{H}) \mathrm{H})(\mathrm{Br}) \mathrm{H})(\mathrm{H}) \mathrm{Cl})(\mathrm{H})(\mathrm{H}) \mathrm{H}$ $\mathrm{C}(\mathrm{C}(\mathrm{C}(\mathrm{C}(\mathrm{C}(\mathrm{C}(\mathrm{C}(\mathrm{C}(\mathrm{C}(\mathrm{C}(\mathrm{C}(\mathrm{H})(\mathrm{H}) \mathrm{H})(\mathrm{H}) \mathrm{H})(\mathrm{H}) \mathrm{H})(\mathrm{H}) \mathrm{Cl})(\mathrm{Br}) \mathrm{H})(\mathrm{H}) \mathrm{H})(\mathrm{Cl}) \mathrm{H})(\mathrm{H}) \mathrm{H})(\mathrm{H}) \mathrm{H})(\mathrm{Cl}) \mathrm{Cl})(\mathrm{F})(\mathrm{H}) \mathrm{H}$ $\mathrm{C}(\mathrm{C}(\mathrm{C}(\mathrm{C}(\mathrm{C}(\mathrm{C}(\mathrm{C}(\mathrm{C}(\mathrm{C}(\mathrm{C}(\mathrm{C}(\mathrm{Cl})(\mathrm{H}) \mathrm{H})(\mathrm{H}) \mathrm{H})(\mathrm{H}) \mathrm{Cl})(\mathrm{H}) \mathrm{Cl})(\mathrm{H}) \mathrm{H})(\mathrm{H}) \mathrm{H})(\mathrm{H}) \mathrm{H})(\mathrm{H}) \mathrm{H})(\mathrm{H}) \mathrm{H})(\mathrm{H}) \mathrm{Cl})(\mathrm{Br})(\mathrm{H}) \mathrm{Cl}$ $\mathrm{C}(\mathrm{C}(\mathrm{C}(\mathrm{C}(\mathrm{C}(\mathrm{C}(\mathrm{C}(\mathrm{C}(\mathrm{C}(\mathrm{C}(\mathrm{C}(\mathrm{H})(\mathrm{H}) \mathrm{Cl})(\mathrm{H}) \mathrm{H})(\mathrm{H}) \mathrm{H})(\mathrm{H}) \mathrm{H})(\mathrm{Cl}) \mathrm{H})(\mathrm{Cl}) \mathrm{H})(\mathrm{H}) \mathrm{H})(\mathrm{H}) \mathrm{H})(\mathrm{Cl}) \mathrm{H})(\mathrm{H}) \mathrm{H})(\mathrm{Cl})(\mathrm{Cl}) \mathrm{H}$ $\mathrm{C}(\mathrm{C}(\mathrm{C}(\mathrm{C}(\mathrm{C}(\mathrm{C}(\mathrm{C}(\mathrm{C}(\mathrm{C}(\mathrm{C}(\mathrm{C}(\mathrm{H})(\mathrm{H}) \mathrm{H})(\mathrm{Br}) \mathrm{H})(\mathrm{Br}) \mathrm{Cl})(\mathrm{Br}) \mathrm{H})(\mathrm{F}) \mathrm{F})(\mathrm{H}) \mathrm{H})(\mathrm{H}) \mathrm{H})(\mathrm{H}) \mathrm{H})(\mathrm{H}) \mathrm{H})(\mathrm{H}) \mathrm{H})(\mathrm{H})(\mathrm{H}) \mathrm{H}$ $\mathrm{C}(\mathrm{C}(\mathrm{C}(\mathrm{C}(\mathrm{C}(\mathrm{C}(\mathrm{C}(\mathrm{C}(\mathrm{C}(\mathrm{C}(\mathrm{C}(\mathrm{H})(\mathrm{H}) \mathrm{H})(\mathrm{H}) \mathrm{Br})(\mathrm{Br}) \mathrm{H})(\mathrm{H}) \mathrm{Br})(\mathrm{H}) \mathrm{Cl})(\mathrm{H}) \mathrm{Br})(\mathrm{H}) \mathrm{H})(\mathrm{H}) \mathrm{H})(\mathrm{H}) \mathrm{F})(\mathrm{H}) \mathrm{H})(\mathrm{H})(\mathrm{H}) \mathrm{H}$ $\mathrm{C}(\mathrm{C}(\mathrm{C}(\mathrm{C}(\mathrm{C}(\mathrm{C}(\mathrm{C}(\mathrm{C}(\mathrm{C}(\mathrm{C}(\mathrm{C}(\mathrm{H})(\mathrm{Br}) \mathrm{H})(\mathrm{H}) \mathrm{Br})(\mathrm{H}) \mathrm{H})(\mathrm{Cl}) \mathrm{H})(\mathrm{H}) \mathrm{H})(\mathrm{H}) \mathrm{H})(\mathrm{H}) \mathrm{Br})(\mathrm{H}) \mathrm{H})(\mathrm{Br}) \mathrm{H})(\mathrm{Br}) \mathrm{H})(\mathrm{H})(\mathrm{H}) \mathrm{H}$ $\mathrm{C}(\mathrm{C}(\mathrm{C}(\mathrm{C}(\mathrm{C}(\mathrm{C}(\mathrm{C}(\mathrm{C}(\mathrm{C}(\mathrm{C}(\mathrm{C}(\mathrm{H})(\mathrm{H}) \mathrm{Br})(\mathrm{H}) \mathrm{H})(\mathrm{H}) \mathrm{H})(\mathrm{H}) \mathrm{H})(\mathrm{H}) \mathrm{H})(\mathrm{H}) \mathrm{H})(\mathrm{Br}) \mathrm{H})(\mathrm{Br}) \mathrm{H})(\mathrm{H}) \mathrm{H})(\mathrm{Br}) \mathrm{F})(\mathrm{H})(\mathrm{H}) \mathrm{H}$ $\mathrm{C}(\mathrm{C}(\mathrm{C}(\mathrm{C}(\mathrm{C}(\mathrm{C}(\mathrm{C}(\mathrm{C}(\mathrm{C}(\mathrm{C}(\mathrm{C}(\mathrm{H})(\mathrm{H}) \mathrm{Br})(\mathrm{Br}) \mathrm{H})(\mathrm{H}) \mathrm{H})(\mathrm{H}) \mathrm{H})(\mathrm{Br}) \mathrm{H})(\mathrm{H}) \mathrm{Br})(\mathrm{H}) \mathrm{H})(\mathrm{H}) \mathrm{H})(\mathrm{Br}) \mathrm{H})(\mathrm{H}) \mathrm{H})(\mathrm{H})(\mathrm{H}) \mathrm{H}$ $\mathrm{C}(\mathrm{C}(\mathrm{C}(\mathrm{C}(\mathrm{C}(\mathrm{C}(\mathrm{C}(\mathrm{C}(\mathrm{C}(\mathrm{C}(\mathrm{C}(\mathrm{H})(\mathrm{H}) \mathrm{H})(\mathrm{H}) \mathrm{H})(\mathrm{H}) \mathrm{Br})(\mathrm{H}) \mathrm{H})(\mathrm{Cl}) \mathrm{H})(\mathrm{H}) \mathrm{H})(\mathrm{H}) \mathrm{H})(\mathrm{H}) \mathrm{H})(\mathrm{H}) \mathrm{H})(\mathrm{Br}) \mathrm{Br})(\mathrm{Cl})(\mathrm{H}) \mathrm{H}$ $\mathrm{C}(\mathrm{C}(\mathrm{C}(\mathrm{C}(\mathrm{C}(\mathrm{C}(\mathrm{C}(\mathrm{C}(\mathrm{C}(\mathrm{C}(\mathrm{C}(\mathrm{H})(\mathrm{H}) \mathrm{H})(\mathrm{H}) \mathrm{H})(\mathrm{H}) \mathrm{H})(\mathrm{H}) \mathrm{Br})(\mathrm{H}) \mathrm{H})(\mathrm{H}) \mathrm{Cl})(\mathrm{Br}) \mathrm{H})(\mathrm{H}) \mathrm{H})(\mathrm{H}) \mathrm{Cl})(\mathrm{H}) \mathrm{H})(\mathrm{H})(\mathrm{Cl}) \mathrm{H}$ $\mathrm{C}(\mathrm{C}(\mathrm{C}(\mathrm{C}(\mathrm{C}(\mathrm{C}(\mathrm{C}(\mathrm{C}(\mathrm{C}(\mathrm{C}(\mathrm{C}(\mathrm{H})(\mathrm{H}) \mathrm{Cl})(\mathrm{Cl}) \mathrm{H})(\mathrm{H}) \mathrm{H})(\mathrm{H}) \mathrm{Cl})(\mathrm{Br}) \mathrm{H})(\mathrm{H}) \mathrm{H})(\mathrm{H}) \mathrm{H})(\mathrm{Cl}) \mathrm{H})(\mathrm{H}) \mathrm{H})(\mathrm{H}) \mathrm{H})(\mathrm{H})(\mathrm{H}) \mathrm{H}$ $\mathrm{C}(\mathrm{C}(\mathrm{C}(\mathrm{C}(\mathrm{C}(\mathrm{C}(\mathrm{C}(\mathrm{C}(\mathrm{C}(\mathrm{C}(\mathrm{C}(\mathrm{H})(\mathrm{H}) \mathrm{F})(\mathrm{H}) \mathrm{Cl})(\mathrm{Br}) \mathrm{Br})(\mathrm{H}) \mathrm{H})(\mathrm{H}) \mathrm{H})(\mathrm{H}) \mathrm{H})(\mathrm{H}) \mathrm{H})(\mathrm{H}) \mathrm{Br})(\mathrm{H}) \mathrm{H})(\mathrm{H}) \mathrm{H})(\mathrm{H})(\mathrm{H}) \mathrm{H}$ $\mathrm{C}(\mathrm{C}(\mathrm{C}(\mathrm{C}(\mathrm{C}(\mathrm{C}(\mathrm{C}(\mathrm{C}(\mathrm{C}(\mathrm{C}(\mathrm{C}(\mathrm{Cl})(\mathrm{H}) \mathrm{H})(\mathrm{H}) \mathrm{H})(\mathrm{H}) \mathrm{Br})(\mathrm{H}) \mathrm{Br})(\mathrm{H}) \mathrm{H})(\mathrm{H}) \mathrm{H})(\mathrm{H}) \mathrm{Br})(\mathrm{H}) \mathrm{H})(\mathrm{H}) \mathrm{H})(\mathrm{H}) \mathrm{H})(\mathrm{H})(\mathrm{Br}) \mathrm{H}$ $\mathrm{C}(\mathrm{C}(\mathrm{C}(\mathrm{C}(\mathrm{C}(\mathrm{C}(\mathrm{C}(\mathrm{C}(\mathrm{C}(\mathrm{C}(\mathrm{C}(\mathrm{H})(\mathrm{H}) \mathrm{H})(\mathrm{H}) \mathrm{H})(\mathrm{Br}) \mathrm{H})(\mathrm{H}) \mathrm{H})(\mathrm{H}) \mathrm{H})(\mathrm{H}) \mathrm{H})(\mathrm{H}) \mathrm{H})(\mathrm{H}) \mathrm{H})(\mathrm{H}) \mathrm{H})(\mathrm{H}) \mathrm{Br})(\mathrm{Br})(\mathrm{H}) \mathrm{B}$ $\mathrm{C}(\mathrm{C}(\mathrm{C}(\mathrm{C}(\mathrm{C}(\mathrm{C}(\mathrm{C}(\mathrm{C}(\mathrm{C}(\mathrm{C}(\mathrm{C}(\mathrm{H})(\mathrm{H}) \mathrm{Cl})(\mathrm{H}) \mathrm{H})(\mathrm{Br}) \mathrm{Cl})(\mathrm{H}) \mathrm{H})(\mathrm{H}) \mathrm{H})(\mathrm{H}) \mathrm{H})(\mathrm{H}) \mathrm{H})(\mathrm{H}) \mathrm{Br})(\mathrm{H}) \mathrm{H})(\mathrm{H}) \mathrm{H})(\mathrm{H})(\mathrm{H}) \mathrm{H}$ $\mathrm{C}(\mathrm{C}(\mathrm{C}(\mathrm{C}(\mathrm{C}(\mathrm{C}(\mathrm{C}(\mathrm{C}(\mathrm{C}(\mathrm{C}(\mathrm{C}(\mathrm{H})(\mathrm{H}) \mathrm{Br})(\mathrm{Br}) \mathrm{H})(\mathrm{H}) \mathrm{Br})(\mathrm{H}) \mathrm{H})(\mathrm{H}) \mathrm{H})(\mathrm{H}) \mathrm{H})(\mathrm{H}) \mathrm{H})(\mathrm{H}) \mathrm{H})(\mathrm{H}) \mathrm{H})(\mathrm{H}) \mathrm{H})(\mathrm{Cl})(\mathrm{H}) \mathrm{H}$ $\mathrm{C}(\mathrm{C}(\mathrm{C}(\mathrm{C}(\mathrm{C}(\mathrm{C}(\mathrm{C}(\mathrm{C}(\mathrm{C}(\mathrm{C}(\mathrm{C}(\mathrm{H})(\mathrm{H}) \mathrm{H})(\mathrm{H}) \mathrm{H})(\mathrm{H}) \mathrm{H})(\mathrm{H}) \mathrm{Br})(\mathrm{H}) \mathrm{H})(\mathrm{H}) \mathrm{H})(\mathrm{H}) \mathrm{H})(\mathrm{H}) \mathrm{H})(\mathrm{Br}) \mathrm{H})(\mathrm{H}) \mathrm{H})(\mathrm{H})(\mathrm{Br}) \mathrm{H}$ $\mathrm{C}(\mathrm{C}(\mathrm{C}(\mathrm{C}(\mathrm{C}(\mathrm{C}(\mathrm{C}(\mathrm{C}(\mathrm{C}(\mathrm{C}(\mathrm{C}(\mathrm{Br})(\mathrm{F}) \mathrm{Br})(\mathrm{F}) \mathrm{H})(\mathrm{Br}) \mathrm{Br})(\mathrm{F}) \mathrm{H})(\mathrm{H}) \mathrm{F})(\mathrm{F}) \mathrm{F})(\mathrm{Br}) \mathrm{H})(\mathrm{F}) \mathrm{H})(\mathrm{H}) \mathrm{F})(\mathrm{H}) \mathrm{F})(\mathrm{F})(\mathrm{F}) \mathrm{H}$ $\mathrm{C}(\mathrm{C}(\mathrm{C}(\mathrm{C}(\mathrm{C}(\mathrm{C}(\mathrm{C}(\mathrm{C}(\mathrm{C}(\mathrm{C}(\mathrm{C}(\mathrm{F})(\mathrm{H}) \mathrm{Br})(\mathrm{F}) \mathrm{H})(\mathrm{F}) \mathrm{H})(\mathrm{Br}) \mathrm{F})(\mathrm{Br}) \mathrm{Br})(\mathrm{H}) \mathrm{Br})(\mathrm{F}) \mathrm{H})(\mathrm{F}) \mathrm{F})(\mathrm{Br}) \mathrm{H})(\mathrm{H}) \mathrm{Br})(\mathrm{F})(\mathrm{F}) \mathrm{H}$ $\mathrm{C}(\mathrm{C}(\mathrm{C}(\mathrm{C}(\mathrm{C}(\mathrm{C}(\mathrm{C}(\mathrm{C}(\mathrm{C}(\mathrm{C}(\mathrm{C}(\mathrm{F})(\mathrm{F}) \mathrm{H})(\mathrm{F}) \mathrm{H})(\mathrm{F}) \mathrm{Br})(\mathrm{F}) \mathrm{F})(\mathrm{Br}) \mathrm{F})(\mathrm{F}) \mathrm{H})(\mathrm{F}) \mathrm{Br})(\mathrm{H}) \mathrm{Cl})(\mathrm{H}) \mathrm{Br})(\mathrm{H}) \mathrm{H})(\mathrm{Cl})(\mathrm{F}) \mathrm{H}$ $\mathrm{C}(\mathrm{C}(\mathrm{C}(\mathrm{C}(\mathrm{C}(\mathrm{C}(\mathrm{C}(\mathrm{C}(\mathrm{C}(\mathrm{C}(\mathrm{C}(\mathrm{Cl})(\mathrm{H}) \mathrm{Br})(\mathrm{Cl}) \mathrm{Br})(\mathrm{H}) \mathrm{F})(\mathrm{Cl}) \mathrm{F})(\mathrm{Cl}) \mathrm{H})(\mathrm{F}) \mathrm{Br})(\mathrm{F}) \mathrm{H})(\mathrm{F}) \mathrm{H})(\mathrm{H}) \mathrm{Br})(\mathrm{F}) \mathrm{H})(\mathrm{F})(\mathrm{H}) \mathrm{F}$ $\mathrm{C}(\mathrm{C}(\mathrm{C}(\mathrm{C}(\mathrm{C}(\mathrm{C}(\mathrm{C}(\mathrm{C}(\mathrm{C}(\mathrm{C}(\mathrm{C}(\mathrm{Cl})(\mathrm{H}) \mathrm{F})(\mathrm{Br}) \mathrm{H})(\mathrm{F}) \mathrm{H})(\mathrm{Br}) \mathrm{H})(\mathrm{H}) \mathrm{F})(\mathrm{Cl}) \mathrm{Cl})(\mathrm{F}) \mathrm{Cl})(\mathrm{F}) \mathrm{F})(\mathrm{F}) \mathrm{H})(\mathrm{H}) \mathrm{F})(\mathrm{Cl})(\mathrm{Cl}) \mathrm{H}$ $\mathrm{C}(\mathrm{C}(\mathrm{C}(\mathrm{C}(\mathrm{C}(\mathrm{C}(\mathrm{C}(\mathrm{C}(\mathrm{C}(\mathrm{C}(\mathrm{C}(\mathrm{Br})(\mathrm{H}) \mathrm{F})(\mathrm{H}) \mathrm{Br})(\mathrm{H}) \mathrm{H})(\mathrm{H}) \mathrm{F})(\mathrm{F}) \mathrm{F})(\mathrm{Br}) \mathrm{Br})(\mathrm{F}) \mathrm{Br})(\mathrm{H}) \mathrm{F})(\mathrm{F}) \mathrm{H})(\mathrm{H}) \mathrm{F})(\mathrm{F})(\mathrm{H}) \mathrm{F}$ $\mathrm{C}(\mathrm{C}(\mathrm{C}(\mathrm{C}(\mathrm{C}(\mathrm{C}(\mathrm{C}(\mathrm{C}(\mathrm{C}(\mathrm{C}(\mathrm{C}(\mathrm{Cl})(\mathrm{F}) \mathrm{Br})(\mathrm{H}) \mathrm{F})(\mathrm{H}) \mathrm{H})(\mathrm{Cl}) \mathrm{H})(\mathrm{Br}) \mathrm{H})(\mathrm{F}) \mathrm{F})(\mathrm{F}) \mathrm{Br})(\mathrm{Cl}) \mathrm{H})(\mathrm{F}) \mathrm{H})(\mathrm{F}) \mathrm{H})(\mathrm{F})(\mathrm{H}) \mathrm{Br}$ $\mathrm{C}(\mathrm{C}(\mathrm{C}(\mathrm{C}(\mathrm{C}(\mathrm{C}(\mathrm{C}(\mathrm{C}(\mathrm{C}(\mathrm{C}(\mathrm{C}(\mathrm{F})(\mathrm{F}) \mathrm{H})(\mathrm{H}) \mathrm{Cl})(\mathrm{Cl}) \mathrm{H})(\mathrm{H}) \mathrm{Br})(\mathrm{F}) \mathrm{H})(\mathrm{Br}) \mathrm{Cl})(\mathrm{H}) \mathrm{Cl})(\mathrm{H}) \mathrm{Br})(\mathrm{Cl}) \mathrm{F})(\mathrm{H}) \mathrm{F})(\mathrm{Cl})(\mathrm{F}) \mathrm{H}$ $\mathrm{C}(\mathrm{C}(\mathrm{C}(\mathrm{C}(\mathrm{C}(\mathrm{C}(\mathrm{C}(\mathrm{C}(\mathrm{C}(\mathrm{C}(\mathrm{C}(\mathrm{F})(\mathrm{Br}) \mathrm{H})(\mathrm{Cl}) \mathrm{Cl})(\mathrm{Cl}) \mathrm{H})(\mathrm{H}) \mathrm{Cl})(\mathrm{H}) \mathrm{Cl})(\mathrm{H}) \mathrm{Br})(\mathrm{F}) \mathrm{H})(\mathrm{H}) \mathrm{Br})(\mathrm{F}) \mathrm{F})(\mathrm{H}) \mathrm{F})(\mathrm{Cl})(\mathrm{H}) \mathrm{B}$ $\mathrm{C}(\mathrm{C}(\mathrm{C}(\mathrm{C}(\mathrm{C}(\mathrm{C}(\mathrm{C}(\mathrm{C}(\mathrm{C}(\mathrm{C}(\mathrm{C}(\mathrm{F})(\mathrm{H}) \mathrm{F})(\mathrm{H}) \mathrm{H})(\mathrm{F}) \mathrm{Cl})(\mathrm{H}) \mathrm{Cl})(\mathrm{Cl}) \mathrm{Cl})(\mathrm{H}) \mathrm{Cl})(\mathrm{H}) \mathrm{Cl})(\mathrm{F}) \mathrm{Cl})(\mathrm{H}) \mathrm{F})(\mathrm{H}) \mathrm{F})(\mathrm{F})(\mathrm{H}) \mathrm{B}$ $\mathrm{C}(\mathrm{C}(\mathrm{C}(\mathrm{C}(\mathrm{C}(\mathrm{C}(\mathrm{C}(\mathrm{C}(\mathrm{C}(\mathrm{C}(\mathrm{C}(\mathrm{H})(\mathrm{H}) \mathrm{H})(\mathrm{Br}) \mathrm{F})(\mathrm{F}) \mathrm{H})(\mathrm{F}) \mathrm{Br})(\mathrm{F}) \mathrm{Br})(\mathrm{F}) \mathrm{H})(\mathrm{F}) \mathrm{H})(\mathrm{H}) \mathrm{Cl})(\mathrm{F}) \mathrm{F})(\mathrm{F}) \mathrm{H})(\mathrm{F})(\mathrm{Br}) \mathrm{H}$ $\mathrm{C}(\mathrm{C}(\mathrm{C}(\mathrm{C}(\mathrm{C}(\mathrm{C}(\mathrm{C}(\mathrm{C}(\mathrm{C}(\mathrm{C}(\mathrm{C}(\mathrm{C}(\mathrm{F})(\mathrm{F}) \mathrm{F})(\mathrm{Br}) \mathrm{H})(\mathrm{F}) \mathrm{Br})(\mathrm{Br}) \mathrm{H})(\mathrm{F}) \mathrm{H})(\mathrm{H}) \mathrm{F})(\mathrm{Cl}) \mathrm{H})(\mathrm{H}) \mathrm{F})(\mathrm{Br}) \mathrm{H})(\mathrm{Br}) \mathrm{H})(\mathrm{H}) \mathrm{Br})(\mathrm{H})(\mathrm{F}) \quad \mathrm{C} 12 \mathrm{H} 10 \mathrm{ClBr} 7 \mathrm{~F} 8$ $\mathrm{C}(\mathrm{C}(\mathrm{C}(\mathrm{C}(\mathrm{C}(\mathrm{C}(\mathrm{C}(\mathrm{C}(\mathrm{C}(\mathrm{C}(\mathrm{C}(\mathrm{C}(\mathrm{H})(\mathrm{F}) \mathrm{Cl})(\mathrm{H}) \mathrm{H})(\mathrm{F}) \mathrm{H})(\mathrm{H}) \mathrm{Cl})(\mathrm{F}) \mathrm{Cl})(\mathrm{H}) \mathrm{F})(\mathrm{Br}) \mathrm{F})(\mathrm{F}) \mathrm{F})(\mathrm{H}) \mathrm{H})(\mathrm{H}) \mathrm{F})(\mathrm{F}) \mathrm{H})(\mathrm{H})(\mathrm{Br}) \mathrm{Br} \quad \mathrm{C} 12 \mathrm{H} 11 \mathrm{Cl} 3 \mathrm{Br} 3 \mathrm{~F} 9$ $\mathrm{C}(\mathrm{C}(\mathrm{C}(\mathrm{C}(\mathrm{C}(\mathrm{C}(\mathrm{C}(\mathrm{C}(\mathrm{C}(\mathrm{C}(\mathrm{C}(\mathrm{C}(\mathrm{F})(\mathrm{H}) \mathrm{H})(\mathrm{Cl}) \mathrm{H})(\mathrm{Br}) \mathrm{H})(\mathrm{Cl}) \mathrm{H})(\mathrm{H}) \mathrm{F})(\mathrm{H}) \mathrm{Br})(\mathrm{F}) \mathrm{H})(\mathrm{Cl}) \mathrm{H})(\mathrm{Cl}) \mathrm{H})(\mathrm{F}) \mathrm{Br})(\mathrm{H}) \mathrm{F})(\mathrm{F})(\mathrm{F}) \mathrm{C}$ C12H11 $15 \mathrm{Br} 3 \mathrm{~F} 7$ $\mathrm{C}(\mathrm{C}(\mathrm{C}(\mathrm{C}(\mathrm{C}(\mathrm{C}(\mathrm{C}(\mathrm{C}(\mathrm{C}(\mathrm{C}(\mathrm{C}(\mathrm{C}(\mathrm{F})(\mathrm{Cl}) \mathrm{H})(\mathrm{Cl}) \mathrm{H})(\mathrm{Cl}) \mathrm{H})(\mathrm{F}) \mathrm{Cl})(\mathrm{H}) \mathrm{Cl})(\mathrm{H}) \mathrm{H})(\mathrm{F}) \mathrm{H})(\mathrm{Cl}) \mathrm{H})(\mathrm{H}) \mathrm{F})(\mathrm{Cl}) \mathrm{F})(\mathrm{H}) \mathrm{F})(\mathrm{Cl})(\mathrm{H}) \mathrm{C}$ C12 $\mathrm{H} 11 \mathrm{Cl}$ F 6 $\mathrm{C}(\mathrm{C}(\mathrm{C}(\mathrm{C}(\mathrm{C}(\mathrm{C}(\mathrm{C}(\mathrm{C}(\mathrm{C}(\mathrm{C}(\mathrm{C}(\mathrm{C}(\mathrm{Br})(\mathrm{H}) \mathrm{F})(\mathrm{Br}) \mathrm{F})(\mathrm{F}) \mathrm{H})(\mathrm{H}) \mathrm{H})(\mathrm{F}) \mathrm{Cl})(\mathrm{Br}) \mathrm{H})(\mathrm{H}) \mathrm{H})(\mathrm{H}) \mathrm{Br})(\mathrm{F}) \mathrm{H})(\mathrm{H}) \mathrm{F})(\mathrm{H}) \mathrm{H})(\mathrm{Cl})(\mathrm{F}) \mathrm{F} \quad \mathrm{C} 12 \mathrm{H} 12 \mathrm{Cl} 2 \mathrm{Br} 4 \mathrm{~F} 8$ $\mathrm{C}(\mathrm{C}(\mathrm{C}(\mathrm{C}(\mathrm{C}(\mathrm{C}(\mathrm{C}(\mathrm{C}(\mathrm{C}(\mathrm{C}(\mathrm{C}(\mathrm{C}(\mathrm{Cl})(\mathrm{Cl}) \mathrm{Cl})(\mathrm{Br}) \mathrm{H})(\mathrm{H}) \mathrm{H})(\mathrm{H}) \mathrm{F})(\mathrm{H}) \mathrm{F})(\mathrm{H}) \mathrm{F})(\mathrm{Br}) \mathrm{F})(\mathrm{H}) \mathrm{F})(\mathrm{F}) \mathrm{H})(\mathrm{F}) \mathrm{F})(\mathrm{H}) \mathrm{H})(\mathrm{Br})(\mathrm{H}) \mathrm{H} \quad \mathrm{C} 12 \mathrm{H} 12 \mathrm{Cl} 3 \mathrm{Br} 3 \mathrm{~F} 8$ $\mathrm{C}(\mathrm{C}(\mathrm{C}(\mathrm{C}(\mathrm{C}(\mathrm{C}(\mathrm{C}(\mathrm{C}(\mathrm{C}(\mathrm{C}(\mathrm{C}(\mathrm{C}(\mathrm{F})(\mathrm{Cl}) \mathrm{H})(\mathrm{F}) \mathrm{H})(\mathrm{H}) \mathrm{Br})(\mathrm{Br}) \mathrm{H})(\mathrm{Br}) \mathrm{H})(\mathrm{H}) \mathrm{Cl})(\mathrm{H}) \mathrm{F})(\mathrm{F}) \mathrm{Cl})(\mathrm{F}) \mathrm{H})(\mathrm{Br}) \mathrm{F})(\mathrm{Cl}) \mathrm{H})(\mathrm{H})(\mathrm{H}) \quad \mathrm{C} 12 \mathrm{H} 12 \mathrm{Cl} 4 \mathrm{Br} 4 \mathrm{~F} 6$ $\mathrm{C}(\mathrm{C}(\mathrm{C}(\mathrm{C}(\mathrm{C}(\mathrm{C}(\mathrm{C}(\mathrm{C}(\mathrm{C}(\mathrm{C}(\mathrm{C}(\mathrm{C}(\mathrm{Cl})(\mathrm{H}) \mathrm{Cl})(\mathrm{H}) \mathrm{H})(\mathrm{F}) \mathrm{F})(\mathrm{Cl}) \mathrm{Cl})(\mathrm{Cl}) \mathrm{H})(\mathrm{H}) \mathrm{Cl})(\mathrm{H}) \mathrm{Cl})(\mathrm{H}) \mathrm{H})(\mathrm{H}) \mathrm{F})(\mathrm{H}) \mathrm{F})(\mathrm{Br}) \mathrm{H})(\mathrm{Cl})(\mathrm{F}) \mathrm{C} 12 \mathrm{H} 12 \mathrm{Cl}$ B BrF5 $\mathrm{C}(\mathrm{C}(\mathrm{C}(\mathrm{C}(\mathrm{C}(\mathrm{C}(\mathrm{C}(\mathrm{C}(\mathrm{C}(\mathrm{C}(\mathrm{C}(\mathrm{C}(\mathrm{F})(\mathrm{H}) \mathrm{H})(\mathrm{F}) \mathrm{H})(\mathrm{Cl}) \mathrm{F})(\mathrm{Cl}) \mathrm{H})(\mathrm{H}) \mathrm{F})(\mathrm{H}) \mathrm{H})(\mathrm{Cl}) \mathrm{H})(\mathrm{H}) \mathrm{Cl})(\mathrm{Cl}) \mathrm{H})(\mathrm{Cl}) \mathrm{H})(\mathrm{Cl}) \mathrm{F})(\mathrm{Cl})(\mathrm{H}) \quad \mathrm{C} 12 \mathrm{H} 12 \mathrm{Cl} 1 \mathrm{~F} 5$ $\mathrm{C}(\mathrm{C}(\mathrm{C}(\mathrm{C}(\mathrm{C}(\mathrm{C}(\mathrm{C}(\mathrm{C}(\mathrm{C}(\mathrm{C}(\mathrm{C}(\mathrm{C}(\mathrm{H})(\mathrm{H}) \mathrm{H})(\mathrm{F}) \mathrm{H})(\mathrm{H}) \mathrm{H})(\mathrm{F}) \mathrm{F})(\mathrm{Cl}) \mathrm{Br})(\mathrm{H}) \mathrm{F})(\mathrm{F}) \mathrm{Br})(\mathrm{H}) \mathrm{Br})(\mathrm{F}) \mathrm{H})(\mathrm{F}) \mathrm{H})(\mathrm{F}) \mathrm{H})(\mathrm{H})(\mathrm{F}) \mathrm{Br} \quad \mathrm{C} 12 \mathrm{H} 12 \mathrm{ClBr} 4 \mathrm{~F} 9$ $\mathrm{C}(\mathrm{C}(\mathrm{C}(\mathrm{C}(\mathrm{C}(\mathrm{C}(\mathrm{C}(\mathrm{C}(\mathrm{C}(\mathrm{C}(\mathrm{C}(\mathrm{C}(\mathrm{H})(\mathrm{F}) \mathrm{H})(\mathrm{H}) \mathrm{H})(\mathrm{H}) \mathrm{F})(\mathrm{F}) \mathrm{H})(\mathrm{Br}) \mathrm{Br})(\mathrm{H}) \mathrm{H})(\mathrm{H}) \mathrm{F})(\mathrm{F}) \mathrm{H})(\mathrm{Br}) \mathrm{Br})(\mathrm{H}) \mathrm{Br})(\mathrm{H}) \mathrm{F})(\mathrm{F})(\mathrm{H}) \mathrm{F} \quad \mathrm{C} 12 \mathrm{H} 13 \mathrm{Br} 5 \mathrm{~F} 8$ $\mathrm{C}(\mathrm{C}(\mathrm{C}(\mathrm{C}(\mathrm{C}(\mathrm{C}(\mathrm{C}(\mathrm{C}(\mathrm{C}(\mathrm{C}(\mathrm{C}(\mathrm{C}(\mathrm{F})(\mathrm{H}) \mathrm{H})(\mathrm{Cl}) \mathrm{Br})(\mathrm{H}) \mathrm{H})(\mathrm{H}) \mathrm{H})(\mathrm{Cl}) \mathrm{H})(\mathrm{F}) \mathrm{F})(\mathrm{H}) \mathrm{F})(\mathrm{Br}) \mathrm{H})(\mathrm{F}) \mathrm{H})(\mathrm{Br}) \mathrm{H})(\mathrm{H}) \mathrm{F})(\mathrm{H})(\mathrm{Br}) \mathrm{F} \mathrm{C12H13Cl2Br} 4 \mathrm{~F}$ $\mathrm{C}(\mathrm{C}(\mathrm{C}(\mathrm{C}(\mathrm{C}(\mathrm{C}(\mathrm{C}(\mathrm{C}(\mathrm{C}(\mathrm{C}(\mathrm{C}(\mathrm{C}(\mathrm{F})(\mathrm{F}) \mathrm{H})(\mathrm{Br}) \mathrm{H})(\mathrm{H}) \mathrm{H})(\mathrm{Cl}) \mathrm{Cl})(\mathrm{H}) \mathrm{Br})(\mathrm{Br}) \mathrm{H})(\mathrm{H}) \mathrm{F})(\mathrm{F}) \mathrm{H})(\mathrm{H}) \mathrm{H})(\mathrm{H}) \mathrm{Cl})(\mathrm{F}) \mathrm{F})(\mathrm{F})(\mathrm{H}) \mathrm{H} \quad \mathrm{C}_{2} \mathrm{H}^{2} 3 \mathrm{Cl} 3 \mathrm{Br} 3 \mathrm{~F} 7$ $\mathrm{C}(\mathrm{C}(\mathrm{C}(\mathrm{C}(\mathrm{C}(\mathrm{C}(\mathrm{C}(\mathrm{C}(\mathrm{C}(\mathrm{C}(\mathrm{C}(\mathrm{C}(\mathrm{F})(\mathrm{H}) \mathrm{H})(\mathrm{H}) \mathrm{F})(\mathrm{H}) \mathrm{H})(\mathrm{Br}) \mathrm{H})(\mathrm{H}) \mathrm{F})(\mathrm{H}) \mathrm{F})(\mathrm{F}) \mathrm{H})(\mathrm{H}) \mathrm{Br})(\mathrm{Br}) \mathrm{Br})(\mathrm{H}) \mathrm{Cl})(\mathrm{Cl}) \mathrm{F})(\mathrm{H})(\mathrm{Cl}) \quad \mathrm{C} 12 \mathrm{H} 13 \mathrm{Cl} 3 \mathrm{Br} 4 \mathrm{~F} 6$ $\mathrm{C}(\mathrm{C}(\mathrm{C}(\mathrm{C}(\mathrm{C}(\mathrm{C}(\mathrm{C}(\mathrm{C}(\mathrm{C}(\mathrm{C}(\mathrm{C}(\mathrm{C}(\mathrm{F})(\mathrm{H}) \mathrm{H})(\mathrm{H}) \mathrm{F})(\mathrm{H}) \mathrm{Cl})(\mathrm{Cl}) \mathrm{Cl})(\mathrm{Br}) \mathrm{H})(\mathrm{H}) \mathrm{F})(\mathrm{H}) \mathrm{F})(\mathrm{Cl}) \mathrm{H})(\mathrm{H}) \mathrm{H})(\mathrm{F}) \mathrm{F})(\mathrm{H}) \mathrm{Br})(\mathrm{F})(\mathrm{H}) \mathrm{H} \quad \mathrm{C} 12 \mathrm{H} 13 \mathrm{Cl} 4 \mathrm{Br} 2 \mathrm{~F} 7$ $\mathrm{C}(\mathrm{C}(\mathrm{C}(\mathrm{C}(\mathrm{C}(\mathrm{C}(\mathrm{C}(\mathrm{C}(\mathrm{C}(\mathrm{C}(\mathrm{C}(\mathrm{C}(\mathrm{H})(\mathrm{Cl}) \mathrm{H})(\mathrm{H}) \mathrm{Cl})(\mathrm{H}) \mathrm{Cl})(\mathrm{F}) \mathrm{F})(\mathrm{H}) \mathrm{H})(\mathrm{Cl}) \mathrm{Br})(\mathrm{H}) \mathrm{H})(\mathrm{Br}) \mathrm{H})(\mathrm{H}) \mathrm{F})(\mathrm{F}) \mathrm{H})(\mathrm{H}) \mathrm{F})(\mathrm{F})(\mathrm{Br}) \quad \mathrm{C} 12 \mathrm{H} 13 \mathrm{Cl} 14 \mathrm{Br} 3 \mathrm{~F} 6$ $\mathrm{C}(\mathrm{C}(\mathrm{C}(\mathrm{C}(\mathrm{C}(\mathrm{C}(\mathrm{C}(\mathrm{C}(\mathrm{C}(\mathrm{C}(\mathrm{C}(\mathrm{C}(\mathrm{H})(\mathrm{H}) \mathrm{H})(\mathrm{F}) \mathrm{H})(\mathrm{F}) \mathrm{H})(\mathrm{F}) \mathrm{H})(\mathrm{H}) \mathrm{Br})(\mathrm{Cl}) \mathrm{H})(\mathrm{H}) \mathrm{Cl})(\mathrm{F}) \mathrm{H})(\mathrm{Br}) \mathrm{H})(\mathrm{H}) \mathrm{F})(\mathrm{H}) \mathrm{Cl})(\mathrm{Br})(\mathrm{Cl}) \mathrm{C}_{2} \mathrm{H}_{13} \mathrm{Cl} 5 \mathrm{Br} 3 \mathrm{~F}$ $\mathrm{C}(\mathrm{C}(\mathrm{C}(\mathrm{C}(\mathrm{C}(\mathrm{C}(\mathrm{C}(\mathrm{C}(\mathrm{C}(\mathrm{C}(\mathrm{C}(\mathrm{C}(\mathrm{F})(\mathrm{H}) \mathrm{Br})(\mathrm{H}) \mathrm{H})(\mathrm{H}) \mathrm{F})(\mathrm{Cl}) \mathrm{H})(\mathrm{Br}) \mathrm{Br})(\mathrm{H}) \mathrm{Cl})(\mathrm{Br}) \mathrm{H})(\mathrm{H}) \mathrm{F})(\mathrm{F}) \mathrm{H})(\mathrm{Cl}) \mathrm{H})(\mathrm{Cl}) \mathrm{H})(\mathrm{Cl}) \quad \mathrm{C} 12 \mathrm{H} 13 \mathrm{Cl} 5 \mathrm{Br} 4 \mathrm{~F} 4$ $\mathrm{C}(\mathrm{C}(\mathrm{C}(\mathrm{C}(\mathrm{C}(\mathrm{C}(\mathrm{C}(\mathrm{C}(\mathrm{C}(\mathrm{C}(\mathrm{C}(\mathrm{C}(\mathrm{H})(\mathrm{H}) \mathrm{Cl})(\mathrm{F}) \mathrm{Br})(\mathrm{Cl}) \mathrm{F})(\mathrm{F}) \mathrm{H})(\mathrm{H}) \mathrm{F})(\mathrm{H}) \mathrm{Cl})(\mathrm{H}) \mathrm{H})(\mathrm{Cl}) \mathrm{H})(\mathrm{H}) \mathrm{H})(\mathrm{H}) \mathrm{F})(\mathrm{H}) \mathrm{Cl})(\mathrm{F})(\mathrm{H}) \mathrm{Cl} \mathrm{C} 12 \mathrm{H} 13 \mathrm{Cl} 6 \mathrm{BrF} 6$ $\mathrm{C}(\mathrm{C}(\mathrm{C}(\mathrm{C}(\mathrm{C}(\mathrm{C}(\mathrm{C}(\mathrm{C}(\mathrm{C}(\mathrm{C}(\mathrm{C}(\mathrm{C}(\mathrm{H})(\mathrm{H}) \mathrm{H})(\mathrm{Cl}) \mathrm{H})(\mathrm{H}) \mathrm{F})(\mathrm{H}) \mathrm{Cl})(\mathrm{Cl}) \mathrm{Br})(\mathrm{Cl}) \mathrm{H})(\mathrm{H}) \mathrm{Cl})(\mathrm{Cl}) \mathrm{Cl})(\mathrm{H}) \mathrm{F})(\mathrm{H}) \mathrm{H})(\mathrm{Cl}) \mathrm{H})(\mathrm{F})(\mathrm{F}) \mathrm{C} 12 \mathrm{H} 13 \mathrm{Cl} 8 \mathrm{BrF} 4$ $\mathrm{C}(\mathrm{C}(\mathrm{C}(\mathrm{C}(\mathrm{C}(\mathrm{C}(\mathrm{C}(\mathrm{C}(\mathrm{C}(\mathrm{C}(\mathrm{C}(\mathrm{C}(\mathrm{H})(\mathrm{H}) \mathrm{F})(\mathrm{H}) \mathrm{Cl})(\mathrm{H}) \mathrm{H})(\mathrm{Cl}) \mathrm{H})(\mathrm{H}) \mathrm{H})(\mathrm{Cl}) \mathrm{H})(\mathrm{Cl}) \mathrm{F})(\mathrm{F}) \mathrm{H})(\mathrm{Cl}) \mathrm{H})(\mathrm{F}) \mathrm{H})(\mathrm{Cl}) \mathrm{F})(\mathrm{Cl})(\mathrm{H}) \mathrm{C}$ C12H13Cl8F5 $\mathrm{C}(\mathrm{C}(\mathrm{C}(\mathrm{C}(\mathrm{C}(\mathrm{C}(\mathrm{C}(\mathrm{C}(\mathrm{C}(\mathrm{C}(\mathrm{C}(\mathrm{C}(\mathrm{H})(\mathrm{Cl}) \mathrm{H})(\mathrm{H}) \mathrm{Cl})(\mathrm{H}) \mathrm{H})(\mathrm{H}) \mathrm{F})(\mathrm{H}) \mathrm{Cl})(\mathrm{F}) \mathrm{H})(\mathrm{Cl}) \mathrm{H})(\mathrm{Cl}) \mathrm{Cl})(\mathrm{F}) \mathrm{H})(\mathrm{H}) \mathrm{H})(\mathrm{Cl}) \mathrm{Cl})(\mathrm{Cl}) \quad \mathrm{C} 12 \mathrm{H} 13 \mathrm{Cl} 9 \mathrm{~F} 4$ $\mathrm{C}(\mathrm{C}(\mathrm{C}(\mathrm{C}(\mathrm{C}(\mathrm{C}(\mathrm{C}(\mathrm{C}(\mathrm{C}(\mathrm{C}(\mathrm{C}(\mathrm{C}(\mathrm{Br})(\mathrm{F}) \mathrm{H})(\mathrm{H}) \mathrm{H})(\mathrm{H}) \mathrm{F})(\mathrm{H}) \mathrm{F})(\mathrm{Br}) \mathrm{Br})(\mathrm{Cl}) \mathrm{H})(\mathrm{H}) \mathrm{F})(\mathrm{Br}) \mathrm{F})(\mathrm{H}) \mathrm{F})(\mathrm{H}) \mathrm{H})(\mathrm{H}) \mathrm{H})(\mathrm{H})(\mathrm{F}) \mathrm{F} \quad \mathrm{C} 12 \mathrm{H} 13 \mathrm{ClBr} 4 \mathrm{~F} 8$ $\mathrm{C}(\mathrm{C}(\mathrm{C}(\mathrm{C}(\mathrm{C}(\mathrm{C}(\mathrm{C}(\mathrm{C}(\mathrm{C}(\mathrm{C}(\mathrm{C}(\mathrm{C}(\mathrm{H})(\mathrm{H}) \mathrm{H})(\mathrm{F}) \mathrm{H})(\mathrm{H}) \mathrm{Br})(\mathrm{H}) \mathrm{H})(\mathrm{F}) \mathrm{F})(\mathrm{F}) \mathrm{F})(\mathrm{Br}) \mathrm{H})(\mathrm{F}) \mathrm{H})(\mathrm{Br}) \mathrm{H})(\mathrm{F}) \mathrm{H})(\mathrm{H}) \mathrm{H})(\mathrm{H})(\mathrm{Br}) \mathrm{F} \quad \mathrm{C} 12 \mathrm{H} 14 \mathrm{Br} 4 \mathrm{~F} 8$ $\mathrm{C}(\mathrm{C}(\mathrm{C}(\mathrm{C}(\mathrm{C}(\mathrm{C}(\mathrm{C}(\mathrm{C}(\mathrm{C}(\mathrm{C}(\mathrm{C}(\mathrm{C}(\mathrm{H})(\mathrm{F}) \mathrm{F})(\mathrm{H}) \mathrm{F})(\mathrm{H}) \mathrm{F})(\mathrm{H}) \mathrm{H})(\mathrm{Br}) \mathrm{H})(\mathrm{H}) \mathrm{Br})(\mathrm{Br}) \mathrm{H})(\mathrm{F}) \mathrm{H})(\mathrm{H}) \mathrm{H})(\mathrm{Br}) \mathrm{Br})(\mathrm{Br}) \mathrm{H})(\mathrm{H}) \quad \mathrm{C} 12 \mathrm{H} 14 \mathrm{Br} 7 \mathrm{~F} 5$ $\mathrm{C}(\mathrm{C}(\mathrm{C}(\mathrm{C}(\mathrm{C}(\mathrm{C}(\mathrm{C}(\mathrm{C}(\mathrm{C}(\mathrm{C}(\mathrm{C}(\mathrm{C}(\mathrm{H})(\mathrm{Br}) \mathrm{H})(\mathrm{Cl}) \mathrm{H})(\mathrm{H}) \mathrm{Cl})(\mathrm{H}) \mathrm{Cl})(\mathrm{Cl}) \mathrm{H})(\mathrm{H}) \mathrm{Cl})(\mathrm{H}) \mathrm{H})(\mathrm{H}) \mathrm{Cl})(\mathrm{Cl}) \mathrm{H})(\mathrm{H}) \mathrm{Cl})(\mathrm{Cl}) \mathrm{H})(\mathrm{F})(\mathrm{C} 12 \mathrm{H} 14 \mathrm{Cl} 10 \mathrm{BrF}$ $\mathrm{C}(\mathrm{C}(\mathrm{C}(\mathrm{C}(\mathrm{C}(\mathrm{C}(\mathrm{C}(\mathrm{C}(\mathrm{C}(\mathrm{C}(\mathrm{C}(\mathrm{C}(\mathrm{Cl})(\mathrm{Cl}) \mathrm{H})(\mathrm{Cl}) \mathrm{Cl})(\mathrm{H}) \mathrm{F})(\mathrm{Cl}) \mathrm{H})(\mathrm{H}) \mathrm{Cl})(\mathrm{H}) \mathrm{Cl})(\mathrm{H}) \mathrm{H})(\mathrm{F}) \mathrm{H})(\mathrm{Cl}) \mathrm{H})(\mathrm{Cl}) \mathrm{H})(\mathrm{Cl}) \mathrm{H})(\mathrm{H})(\mathrm{C} 12 \mathrm{H} 14 \mathrm{Cl} 10 \mathrm{~F} 2$ $\mathrm{C}(\mathrm{C}(\mathrm{C}(\mathrm{C}(\mathrm{C}(\mathrm{C}(\mathrm{C}(\mathrm{C}(\mathrm{C}(\mathrm{C}(\mathrm{C}(\mathrm{C}(\mathrm{H})(\mathrm{Br}) \mathrm{H})(\mathrm{F}) \mathrm{H})(\mathrm{F}) \mathrm{H})(\mathrm{H}) \mathrm{H})(\mathrm{F}) \mathrm{F})(\mathrm{H}) \mathrm{H})(\mathrm{F}) \mathrm{Cl})(\mathrm{F}) \mathrm{H})(\mathrm{H}) \mathrm{H})(\mathrm{Br}) \mathrm{H})(\mathrm{Br}) \mathrm{Cl})(\mathrm{F})(\mathrm{H}) \mathrm{H} \quad \mathrm{C} 12 \mathrm{H} 14 \mathrm{Cl} 2 \mathrm{Br} 3 \mathrm{~F} 7$ $\mathrm{C}(\mathrm{C}(\mathrm{C}(\mathrm{C}(\mathrm{C}(\mathrm{C}(\mathrm{C}(\mathrm{C}(\mathrm{C}(\mathrm{C}(\mathrm{C}(\mathrm{C}(\mathrm{Cl})(\mathrm{H}) \mathrm{F})(\mathrm{H}) \mathrm{H})(\mathrm{H}) \mathrm{H})(\mathrm{Br}) \mathrm{H})(\mathrm{Br}) \mathrm{F})(\mathrm{Cl}) \mathrm{H})(\mathrm{H}) \mathrm{F})(\mathrm{F}) \mathrm{H})(\mathrm{Br}) \mathrm{H})(\mathrm{F}) \mathrm{Br})(\mathrm{H}) \mathrm{H})(\mathrm{H})(\mathrm{H}) \quad \mathrm{C} 12 \mathrm{H} 14 \mathrm{Cl} 2 \mathrm{Br} 4 \mathrm{~F} 6$ $\mathrm{C}(\mathrm{C}(\mathrm{C}(\mathrm{C}(\mathrm{C}(\mathrm{C}(\mathrm{C}(\mathrm{C}(\mathrm{C}(\mathrm{C}(\mathrm{C}(\mathrm{C}(\mathrm{F})(\mathrm{Br}) \mathrm{H})(\mathrm{Br}) \mathrm{H})(\mathrm{F}) \mathrm{F})(\mathrm{H}) \mathrm{H})(\mathrm{H}) \mathrm{H})(\mathrm{H}) \mathrm{F})(\mathrm{Cl}) \mathrm{H})(\mathrm{H}) \mathrm{Cl})(\mathrm{H}) \mathrm{H})(\mathrm{Br}) \mathrm{H})(\mathrm{Br}) \mathrm{Br})(\mathrm{H})(\mathrm{F}) \mathrm{C} 12 \mathrm{H} 14 \mathrm{Cl} 2 \mathrm{Br} 5 \mathrm{~F} 5$ $\mathrm{C}(\mathrm{C}(\mathrm{C}(\mathrm{C}(\mathrm{C}(\mathrm{C}(\mathrm{C}(\mathrm{C}(\mathrm{C}(\mathrm{C}(\mathrm{C}(\mathrm{C}(\mathrm{H})(\mathrm{F}) \mathrm{H})(\mathrm{H}) \mathrm{Br})(\mathrm{Cl}) \mathrm{Br})(\mathrm{H}) \mathrm{F})(\mathrm{H}) \mathrm{H})(\mathrm{H}) \mathrm{F})(\mathrm{F}) \mathrm{H})(\mathrm{H}) \mathrm{Cl})(\mathrm{F}) \mathrm{H})(\mathrm{H}) \mathrm{H})(\mathrm{H}) \mathrm{Cl})(\mathrm{Br})(\mathrm{H}) \mathrm{F} \mathrm{C1}$ 2 $\mathrm{H} 14 \mathrm{Cl} 3 \mathrm{Br} 3 \mathrm{~F} 6$ $\mathrm{C}(\mathrm{C}(\mathrm{C}(\mathrm{C}(\mathrm{C}(\mathrm{C}(\mathrm{C}(\mathrm{C}(\mathrm{C}(\mathrm{C}(\mathrm{C}(\mathrm{C}(\mathrm{H})(\mathrm{H}) \mathrm{H})(\mathrm{H}) \mathrm{F})(\mathrm{H}) \mathrm{H})(\mathrm{F}) \mathrm{H})(\mathrm{Cl}) \mathrm{H})(\mathrm{Br}) \mathrm{F})(\mathrm{H}) \mathrm{Cl})(\mathrm{H}) \mathrm{H})(\mathrm{H}) \mathrm{F})(\mathrm{Br}) \mathrm{H})(\mathrm{F}) \mathrm{H})(\mathrm{Br})(\mathrm{Br}) \quad \mathrm{C} 12 \mathrm{H} 14 \mathrm{Cl} 3 \mathrm{Br} 4 \mathrm{~F} 5$ $\mathrm{C}(\mathrm{C}(\mathrm{C}(\mathrm{C}(\mathrm{C}(\mathrm{C}(\mathrm{C}(\mathrm{C}(\mathrm{C}(\mathrm{C}(\mathrm{C}(\mathrm{C}(\mathrm{H})(\mathrm{Br}) \mathrm{H})(\mathrm{Br}) \mathrm{F})(\mathrm{H}) \mathrm{H})(\mathrm{H}) \mathrm{F})(\mathrm{H}) \mathrm{H})(\mathrm{Cl}) \mathrm{H})(\mathrm{Cl}) \mathrm{H})(\mathrm{F}) \mathrm{F})(\mathrm{H}) \mathrm{Cl})(\mathrm{H}) \mathrm{F})(\mathrm{H}) \mathrm{H})(\mathrm{Cl})(\mathrm{H}) \mathrm{F}$ C12H14Cl4Br2F6 $\mathrm{C}(\mathrm{C}(\mathrm{C}(\mathrm{C}(\mathrm{C}(\mathrm{C}(\mathrm{C}(\mathrm{C}(\mathrm{C}(\mathrm{C}(\mathrm{C}(\mathrm{C}(\mathrm{F})(\mathrm{Br}) \mathrm{Cl})(\mathrm{Cl}) \mathrm{F})(\mathrm{H}) \mathrm{H})(\mathrm{F}) \mathrm{H})(\mathrm{H}) \mathrm{F})(\mathrm{Br}) \mathrm{H})(\mathrm{H}) \mathrm{H})(\mathrm{Cl}) \mathrm{H})(\mathrm{H}) \mathrm{Cl})(\mathrm{H}) \mathrm{H})(\mathrm{H}) \mathrm{Br})(\mathrm{H})(\mathrm{F}) \quad \mathrm{C} 12 \mathrm{H} 14 \mathrm{Cl}$ B Br3F5 $\mathrm{C}(\mathrm{C}(\mathrm{C}(\mathrm{C}(\mathrm{C}(\mathrm{C}(\mathrm{C}(\mathrm{C}(\mathrm{C}(\mathrm{C}(\mathrm{C}(\mathrm{C}(\mathrm{Br})(\mathrm{H}) \mathrm{H})(\mathrm{Cl}) \mathrm{H})(\mathrm{H}) \mathrm{F})(\mathrm{Br}) \mathrm{H})(\mathrm{Br}) \mathrm{H})(\mathrm{Cl}) \mathrm{H})(\mathrm{H}) \mathrm{H})(\mathrm{H}) \mathrm{H})(\mathrm{H}) \mathrm{F})(\mathrm{Cl}) \mathrm{H})(\mathrm{Br}) \mathrm{Br})(\mathrm{F})(\mathrm{C} \mathrm{C} 12 \mathrm{H} 14 \mathrm{Cl} 14 \mathrm{Br} 5 \mathrm{~F} 3$ $\mathrm{C}(\mathrm{C}(\mathrm{C}(\mathrm{C}(\mathrm{C}(\mathrm{C}(\mathrm{C}(\mathrm{C}(\mathrm{C}(\mathrm{C}(\mathrm{C}(\mathrm{C}(\mathrm{H})(\mathrm{F}) \mathrm{Cl})(\mathrm{H}) \mathrm{Cl})(\mathrm{H}) \mathrm{Cl})(\mathrm{F}) \mathrm{H})(\mathrm{F}) \mathrm{F})(\mathrm{F}) \mathrm{H})(\mathrm{H}) \mathrm{H})(\mathrm{H}) \mathrm{H})(\mathrm{Cl}) \mathrm{Br})(\mathrm{Br}) \mathrm{H})(\mathrm{H}) \mathrm{H})(\mathrm{Cl})(\mathrm{H}) \mathrm{C}_{2} \mathrm{H} 14 \mathrm{Cl} 5 \mathrm{Br} 2 \mathrm{~F} 5$ $\mathrm{C}(\mathrm{C}(\mathrm{C}(\mathrm{C}(\mathrm{C}(\mathrm{C}(\mathrm{C}(\mathrm{C}(\mathrm{C}(\mathrm{C}(\mathrm{C}(\mathrm{C}(\mathrm{Br})(\mathrm{H}) \mathrm{Br})(\mathrm{Cl}) \mathrm{F})(\mathrm{H}) \mathrm{Cl})(\mathrm{H}) \mathrm{F})(\mathrm{Br}) \mathrm{H})(\mathrm{H}) \mathrm{Cl})(\mathrm{H}) \mathrm{H})(\mathrm{H}) \mathrm{Cl})(\mathrm{H}) \mathrm{H})(\mathrm{Cl}) \mathrm{H})(\mathrm{F}) \mathrm{H})(\mathrm{H})\left(\mathrm{B} \mathrm{C}_{2} \mathrm{H}_{14} \mathrm{Cl} 5 \mathrm{Br} 4 \mathrm{~F}\right.$ $\mathrm{C}(\mathrm{C}(\mathrm{C}(\mathrm{C}(\mathrm{C}(\mathrm{C}(\mathrm{C}(\mathrm{C}(\mathrm{C}(\mathrm{C}(\mathrm{C}(\mathrm{C}(\mathrm{H})(\mathrm{F}) \mathrm{H})(\mathrm{H}) \mathrm{Cl})(\mathrm{H}) \mathrm{H})(\mathrm{H}) \mathrm{Cl})(\mathrm{H}) \mathrm{Cl})(\mathrm{H}) \mathrm{Cl})(\mathrm{H}) \mathrm{Br})(\mathrm{H}) \mathrm{Cl})(\mathrm{F}) \mathrm{H})(\mathrm{H}) \mathrm{Cl})(\mathrm{F}) \mathrm{H})(\mathrm{H}) \quad \mathrm{C} 12 \mathrm{H} 14 \mathrm{Cl} 6 \mathrm{Br} 2 \mathrm{~F} 4$ $\mathrm{C}(\mathrm{C}(\mathrm{C}(\mathrm{C}(\mathrm{C}(\mathrm{C}(\mathrm{C}(\mathrm{C}(\mathrm{C}(\mathrm{C}(\mathrm{C}(\mathrm{C}(\mathrm{H})(\mathrm{Br}) \mathrm{Cl})(\mathrm{Br}) \mathrm{Cl})(\mathrm{Cl}) \mathrm{H})(\mathrm{H}) \mathrm{Cl})(\mathrm{F}) \mathrm{H})(\mathrm{H}) \mathrm{H})(\mathrm{F}) \mathrm{H})(\mathrm{H}) \mathrm{H})(\mathrm{H}) \mathrm{Cl})(\mathrm{H}) \mathrm{Cl})(\mathrm{H}) \mathrm{Br})(\mathrm{H}) \quad \mathrm{C} 12 \mathrm{H} 14 \mathrm{Cl} 6 \mathrm{Br} 3 \mathrm{~F} 3$ $\mathrm{C}(\mathrm{C}(\mathrm{C}(\mathrm{C}(\mathrm{C}(\mathrm{C}(\mathrm{C}(\mathrm{C}(\mathrm{C}(\mathrm{C}(\mathrm{C}(\mathrm{C}(\mathrm{H})(\mathrm{F}) \mathrm{H})(\mathrm{H}) \mathrm{H})(\mathrm{H}) \mathrm{Cl})(\mathrm{H}) \mathrm{F})(\mathrm{Cl}) \mathrm{H})(\mathrm{H}) \mathrm{F})(\mathrm{Br}) \mathrm{H})(\mathrm{Cl}) \mathrm{Cl})(\mathrm{Cl}) \mathrm{H})(\mathrm{H}) \mathrm{H})(\mathrm{F}) \mathrm{H})(\mathrm{H})(\mathrm{F}) \mathrm{C} \mathrm{C} 12 \mathrm{H} 14 \mathrm{Cl} 6 \mathrm{BrF} 5$ $\mathrm{C}(\mathrm{C}(\mathrm{C}(\mathrm{C}(\mathrm{C}(\mathrm{C}(\mathrm{C}(\mathrm{C}(\mathrm{C}(\mathrm{C}(\mathrm{C}(\mathrm{C}(\mathrm{H})(\mathrm{H}) \mathrm{F})(\mathrm{H}) \mathrm{H})(\mathrm{Br}) \mathrm{Cl})(\mathrm{Cl}) \mathrm{H})(\mathrm{F}) \mathrm{H})(\mathrm{F}) \mathrm{H})(\mathrm{H}) \mathrm{Cl})(\mathrm{Cl}) \mathrm{H})(\mathrm{Cl}) \mathrm{H})(\mathrm{F}) \mathrm{H})(\mathrm{H}) \mathrm{Cl})(\mathrm{H})(\mathrm{Cl}) \mathrm{C} 12 \mathrm{H} 14 \mathrm{Cl} / \mathrm{BrF} 4$ $\mathrm{C}(\mathrm{C}(\mathrm{C}(\mathrm{C}(\mathrm{C}(\mathrm{C}(\mathrm{C}(\mathrm{C}(\mathrm{C}(\mathrm{C}(\mathrm{C}(\mathrm{C}(\mathrm{H})(\mathrm{H}) \mathrm{F})(\mathrm{H}) \mathrm{Cl})(\mathrm{Cl}) \mathrm{F})(\mathrm{H}) \mathrm{H})(\mathrm{H}) \mathrm{H})(\mathrm{H}) \mathrm{H})(\mathrm{H}) \mathrm{F})(\mathrm{F}) \mathrm{H})(\mathrm{H}) \mathrm{Cl})(\mathrm{F}) \mathrm{Cl})(\mathrm{Cl}) \mathrm{H})(\mathrm{H})(\mathrm{Cl}) \mathrm{C} \mathrm{C12H14 \textrm {Cl } 7 \mathrm { F } 5}$ $\mathrm{C}(\mathrm{C}(\mathrm{C}(\mathrm{C}(\mathrm{C}(\mathrm{C}(\mathrm{C}(\mathrm{C}(\mathrm{C}(\mathrm{C}(\mathrm{C}(\mathrm{C}(\mathrm{F})(\mathrm{F}) \mathrm{H})(\mathrm{H}) \mathrm{H})(\mathrm{H}) \mathrm{H})(\mathrm{H}) \mathrm{H})(\mathrm{Cl}) \mathrm{Cl})(\mathrm{Cl}) \mathrm{H})(\mathrm{H}) \mathrm{F})(\mathrm{Cl}) \mathrm{H})(\mathrm{H}) \mathrm{H})(\mathrm{F}) \mathrm{H})(\mathrm{H}) \mathrm{Cl})(\mathrm{Cl})(\mathrm{Cl}) \quad \mathrm{C} 12 \mathrm{H} 14 \mathrm{Cl} / \mathrm{F} 4$ $\mathrm{C}(\mathrm{C}(\mathrm{C}(\mathrm{C}(\mathrm{C}(\mathrm{C}(\mathrm{C}(\mathrm{C}(\mathrm{C}(\mathrm{C}(\mathrm{C}(\mathrm{C}(\mathrm{H})(\mathrm{F}) \mathrm{H})(\mathrm{H}) \mathrm{F})(\mathrm{Br}) \mathrm{H})(\mathrm{F}) \mathrm{Cl})(\mathrm{H}) \mathrm{Br})(\mathrm{F}) \mathrm{Br})(\mathrm{H}) \mathrm{F})(\mathrm{H}) \mathrm{F})(\mathrm{Br}) \mathrm{F})(\mathrm{H}) \mathrm{H})(\mathrm{H}) \mathrm{H})(\mathrm{H})(\mathrm{H}) \mathrm{H} \quad \mathrm{C} 12 \mathrm{H} 14 \mathrm{ClBr} 4 \mathrm{~F} 7$ $\mathrm{C}(\mathrm{C}(\mathrm{C}(\mathrm{C}(\mathrm{C}(\mathrm{C}(\mathrm{C}(\mathrm{C}(\mathrm{C}(\mathrm{C}(\mathrm{C}(\mathrm{C}(\mathrm{H})(\mathrm{H}) \mathrm{F})(\mathrm{H}) \mathrm{Br})(\mathrm{H}) \mathrm{F})(\mathrm{H}) \mathrm{Br})(\mathrm{Cl}) \mathrm{H})(\mathrm{H}) \mathrm{Br})(\mathrm{H}) \mathrm{H})(\mathrm{F}) \mathrm{H})(\mathrm{Br}) \mathrm{F})(\mathrm{H}) \mathrm{Br})(\mathrm{H}) \mathrm{H})(\mathrm{F})(\mathrm{F}) \quad \mathrm{C} 12 \mathrm{H} 14 \mathrm{ClBr} 5 \mathrm{~F} 6$ $\mathrm{C}(\mathrm{C}(\mathrm{C}(\mathrm{C}(\mathrm{C}(\mathrm{C}(\mathrm{C}(\mathrm{C}(\mathrm{C}(\mathrm{C}(\mathrm{C}(\mathrm{C}(\mathrm{H})(\mathrm{H}) \mathrm{H})(\mathrm{H}) \mathrm{F})(\mathrm{Br}) \mathrm{F})(\mathrm{F}) \mathrm{H})(\mathrm{H}) \mathrm{H})(\mathrm{Br}) \mathrm{H})(\mathrm{H}) \mathrm{H})(\mathrm{Br}) \mathrm{H})(\mathrm{H}) \mathrm{F})(\mathrm{Br}) \mathrm{F})(\mathrm{H}) \mathrm{H})(\mathrm{H})(\mathrm{F}) \mathrm{F} \quad \mathrm{C} 12 \mathrm{H} 15 \mathrm{Br} 4 \mathrm{~F} 7$ $\mathrm{C}(\mathrm{C}(\mathrm{C}(\mathrm{C}(\mathrm{C}(\mathrm{C}(\mathrm{C}(\mathrm{C}(\mathrm{C}(\mathrm{C}(\mathrm{C}(\mathrm{C}(\mathrm{F})(\mathrm{F}) \mathrm{H})(\mathrm{H}) \mathrm{H})(\mathrm{Br}) \mathrm{H})(\mathrm{H}) \mathrm{H})(\mathrm{Br}) \mathrm{F})(\mathrm{Br}) \mathrm{H})(\mathrm{Br}) \mathrm{H})(\mathrm{H}) \mathrm{F})(\mathrm{F}) \mathrm{H})(\mathrm{Br}) \mathrm{H})(\mathrm{H}) \mathrm{H})(\mathrm{H})(\mathrm{H}) \mathrm{F} \mathrm{C12H15Br5F}$
lgKoa lgKow lgKaw lgKow lgKoa lgKaw lgKow lgKoa lgKaw EPI_EPI EPI Exp_Exp_Exp_DFT DFT DFT Suite Suite Suite corr corr corr corr corr corr $\begin{array}{llllllllll}12 & 7.62 & -4.38 & 6.45 & 10.82 & -4.38 & 6.61 & 20.05 & -13.43\end{array}$ $\begin{array}{llllllllll}8.82 & 7.37 & -1.45 & 6.07 & 7.52 & -1.45 & 6.42 & 14.21 & -7.79\end{array}$ $\begin{array}{llllllllll}9.79 & 7.11 & -2.68 & 5.69 & 8.37 & -2.68 & 6.22 & 16.00 & -9.78\end{array}$ $\begin{array}{llllllllll}12.1 & 8.18 & -3.92 & 7.28 & 11.21 & -3.92 & 7.04 & 20.24 & -13.20\end{array}$ $\begin{array}{llllllllll}12.1 & 8.18 & -3.92 & 7.28 & 11.21 & -3.92 & 7.04 & 20.24 & -13.20 \\ 8.64 & 6.93 & -1.71 & 5.42 & 7.13 & -1.71 & 6.08 & 13.89 & -7.81\end{array}$ $\begin{array}{rrrrrrrrr}8.64 & 6.93 & -1.71 & 5.42 & 7.13 & -1.71 & 6.08 & 13.89 & -7.81 \\ 11 & 8.07 & -2.95 & 7.12 & 10.07 & -2.95 & 6.96 & 18.26 & -11.30\end{array}$ $\begin{array}{rrrrrrrrrr}11 & 8.07 & -2.95 & 7.12 & 10.07 & -2.95 & 6.96 & 18.26 & -11.30 \\ 9.4 & 8.17 & -1.23 & 7.27 & 8.50 & -1.23 & 7.04 & 15.27 & -8.24 \\ 9.64 & 7.17 & -2.47 & 5.78 & 8.24 & -2.47 & 6.27 & 15.71 & -9.44\end{array}$ $\begin{array}{llllllllll}9.64 & 7.17 & -2.47 & 5.78 & 8.24 & -2.47 & 6.27 & 15.71 & -9.44\end{array}$ $\begin{array}{llllllllll}9.699 & 7.01 & -1.98 & 5.54 & 7.52 & -1.98 & 6.15 & 14.53 & -8.38\end{array}$ $\begin{array}{llllllllll}8.16 & 7.42 & -0.74 & 6.15 & 6.89 & -0.74 & 6.46 & 13.01 & -6.55\end{array}$ $\begin{array}{llllllllll}8.56 & 7.06 & -1.49 & 5.61 & 7.11 & -1.49 & 6.18 & 13.73 & -7.54\end{array}$ $\begin{array}{llllllllll}7.98 & 6.97 & -1.01 & 5.48 & 6.49 & -1.01 & 6.12 & 12.67 & -6.56\end{array}$ $\begin{array}{lllllllll}8.91 & 7.95 & -0.96 & 6.94 & 7.90 & -0.96 & 6.87 & 14.38 & -7.52\end{array}$ $\begin{array}{llllllllll}9.07 & 6.87 & -2.20 & 5.33 & 7.53 & -2.20 & 6.04 & 14.67 & -8.63\end{array}$ $\begin{array}{lllllllll}9.07 & 6.87 & -2.20 & 5.33 & 7.53 & -2.20 & 6.04 & 14.67 & -8.63 \\ 10.8 & 7.35 & -3.44 & 6.04 & 9.48 & -3.44 & 6.41 & 17.83 & -11.42\end{array}$ $\begin{array}{lllllllll}9.25 & 7.5 & -1.75 & 6.27 & 8.01 & -1.75 & 6.52 & 15.00 & -8.47\end{array}$ $\begin{array}{llllllllll}10.2 & 7.17 & -2.98 & 5.78 & 8.76 & -2.98 & 6.27 & 16.66 & -10.39\end{array}$ $\begin{array}{lllllllll}9.74 & 7.73 & -2.01 & 6.61 & 8.62 & -2.01 & 6.70 & 15.91 & -9.21\end{array}$ $\begin{array}{rrrrrrrrr}8.43 & 6.9 & -1.53 & 5.37 & 6.90 & -1.53 & 6.06 & 13.49 & -7.43\end{array}$ $\begin{array}{lrllllllll}8.43 & 6.9 & -1.53 & 5.37 & 6.90 & -1.53 & 6.06 & 13.49 & -7.43 \\ 7.85 & 6.81 & -1.04 & 5.24 & 6.28 & -1.04 & 5.99 & 12.44 & -6.44\end{array}$ $\begin{array}{llllllllll}7.85 & 6.81 & -1.04 & 5.24 & 6.28 & -1.04 & 5.99 & 12.44 & -6.44 \\ 8.68 & 7.42 & -1.26 & 6.15 & 7.41 & -1.26 & 6.46 & 13.96 & -7.50\end{array}$ $\begin{array}{llllllllll}9.65 & 7.15 & -2.50 & 5.75 & 8.24 & -2.50 & 6.25 & 15.73 & -9.48\end{array}$ $\begin{array}{lllllllll}8.94 & 6.9 & -2.04 & 5.37 & 7.42 & -2.04 & 6.06 & 14.44 & -8.38\end{array}$ $\begin{array}{rrrrrrrrrr}8.94 & 6.9 & -2.04 & 5.37 & 7.42 & -2.04 & 6.06 & 14.44 & -8.38 \\ 8.54 & 7.46 & -1.07 & 6.21 & 7.28 & -1.07 & 6.49 & 13.69 & -7.20\end{array}$ $\begin{array}{llllllllll}8.44 & 6.88 & -1.56 & 5.34 & 6.90 & -1.56 & 6.05 & 13.51 & -7.47\end{array}$ $\begin{array}{llllllllll}7.74 & 6.63 & -1.11 & 4.97 & 6.08 & -1.11 & 5.85 & 12.22 & -6.37\end{array}$ $\begin{array}{lllllllll}7.7 & 8 & 0.30 & 7.01 & 6.71 & 0.30 & 6.91 & 12.15 & -5.24\end{array}$ $\begin{array}{rrrrrrrrr}11 & 8.81 & -2.17 & 8.22 & 10.39 & -2.17 & 7.53 & 18.18 & -10.65\end{array}$ $\begin{array}{rrrrrrrrr}8.93 & 8.97 & 0.04 & 8.46 & 8.43 & 0.04 & 7.65 & 14.42 & -6.77\end{array}$ $\begin{array}{lllllllll}10.3 & 8.85 & -1.47 & 8.28 & 9.75 & -1.47 & 7.56 & 16.96 & -9.40\end{array}$ $\begin{array}{lllllllll}9.17 & 8.67 & -0.50 & 8.01 & 8.51 & -0.50 & 7.42 & 14.85 & -7.43\end{array}$ $\begin{array}{llllllllll}8.13 & 8.13 & 0.00 & 7.21 & 7.20 & 0.00 & 7.01 & 12.94 & -5.93\end{array}$ $\begin{array}{lllllllll}9.68 & 8.67 & -1.01 & 8.01 & 9.03 & -1.01 & 7.42 & 15.80 & -8.38\end{array}$ $\begin{array}{llllllllll}10.5 & 8.47 & -2.03 & 7.72 & 9.75 & -2.03 & 7.27 & 17.30 & -10.04\end{array}$ $\begin{array}{rrrrrrrrrr}10.5 & 8.47 & -2.03 & 7.72 & 9.75 & -2.03 & 7.27 & 17.30 & -10.04 \\ 12.1 & 8.87 & -3.27 & 8.31 & 11.58 & -3.27 & 7.57 & 20.31 & -12.73\end{array}$ $\begin{array}{lllllllll}9.03 & 8.72 & -0.31 & 8.09 & 8.40 & -0.31 & 7.46 & 14.60 & -7.14\end{array}$ $\begin{array}{llllllllll}8.22 & 8.71 & 0.49 & 8.07 & 7.58 & 0.49 & 7.45 & 13.11 & -5.66\end{array}$ $\begin{array}{lllllllll}9.71 & 8.9 & -0.81 & 8.36 & 9.17 & -0.81 & 7.60 & 15.85 & -8.25\end{array}$ $\begin{array}{rrrrrrrrr}9.71 & 8.9 & -0.81 & 8.36 & 9.17 & -0.81 & 7.60 & 15.85 & -8.25 \\ 11.7 & 8.87 & -2.80 & 8.31 & 11.11 & -2.80 & 7.57 & 19.45 & -11.87\end{array}$ $\begin{array}{rrrrrrrrr}11.7 & 8.87 & -2.80 & 8.31 & 11.11 & -2.80 & 7.57 & 19.45 & -11.87 \\ 8.41 & 8.76 & 0.35 & 8.15 & 7.80 & 0.35 & 7.49 & 13.47 & -5.98\end{array}$ $\begin{array}{lllllllll}9.81 & 8.65 & -1.16 & 7.99 & 9.14 & -1.16 & 7.41 & 16.03 & -8.62\end{array}$ $\begin{array}{llllllllll}9.14 & 8.69 & -0.45 & 8.04 & 8.50 & -0.45 & 7.44 & 14.81 & -7.37\end{array}$ $\begin{array}{llllllllll}9.42 & 8.98 & -0.44 & 8.48 & 8.92 & -0.44 & 7.66 & 15.31 & -7.65\end{array}$ $\begin{array}{rrrrrrrrr}9.42 & 8.98 & -0.44 & 8.48 & 8.92 & -0.44 & 7.66 & 15.31 & -7.65 \\ 8.84 & 8.89 & 0.05 & 8.34 & 8.30 & 0.05 & 7.59 & 14.25 & -6.66\end{array}$ $\begin{array}{rrrrrrrrrr}8.84 & 8.89 & 0.05 & 8.34 & 8.30 & 0.05 & 7.59 & 14.25 & -6.66 \\ 10.7 & 8.79 & -1.94 & 8.19 & 10.14 & -1.94 & 7.51 & 17.72 & -10.21 \\ 10.1 & 8.91 & -1.24 & 8.37 & 9.61 & -1.24 & 7.61 & 16.65 & -9.04\end{array}$ $\begin{array}{llllllllll}10.1 & 8.91 & -1.24 & 8.37 & 9.61 & -1.24 & 7.61 & 16.65 & -9.04\end{array}$ $\begin{array}{rrrrrrrrr}9.57 & 8.82 & -0.75 & 8.24 & 8.99 & -0.75 & 7.54 & 15.60 & -8.06\end{array}$ $\begin{array}{rrrrrrrrr}8.29 & 8.6 & 0.31 & 7.91 & 7.60 & 0.31 & 7.37 & 13.23 & -5.86\end{array}$ $\begin{array}{rrrrrrrrr}8.62 & 8.15 & -0.47 & 7.24 & 7.71 & -0.47 & 7.02 & 13.84 & -6.82\end{array}$ $\begin{array}{llllllllll}9.11 & 8.37 & -0.74 & 7.57 & 8.30 & -0.74 & 7.19 & 14.74 & -7.55\end{array}$ $\begin{array}{llllllllll}8.53 & 8.28 & -0.25 & 7.43 & 7.68 & -0.25 & 7.12 & 13.69 & -6.56\end{array}$ $\begin{array}{lllllllll}10.2 & 8.69 & -1.49 & 8.04 & 9.53 & -1.49 & 7.44 & 16.71 & -9.27\end{array}$ $\begin{array}{lllllllll}7.97 & 8.2 & 0.23 & 7.31 & 7.08 & 0.23 & 7.06 & 12.64 & -5.58\end{array}$ $\begin{array}{lllllllll}9.6 & 8.6 & -1.00 & 7.91 & 8.91 & -1.00 & 7.37 & 15.65 & -8.29\end{array}$ $\begin{array}{llllllllll}9.86 & 8.1 & -1.76 & 7.16 & 8.92 & -1.76 & 6.98 & 16.12 & -9.13\end{array}$ $\begin{array}{lllllllll}11.6 & 8.57 & -2.99 & 7.87 & 10.86 & -2.99 & 7.34 & 19.25 & -11.91\end{array}$ $\begin{array}{lllllllll}8.45 & 8.42 & -0.03 & 7.64 & 7.67 & -0.03 & 7.23 & 13.54 & -6.31\end{array}$ $\begin{array}{lllllllll}10.5 & 8.97 & -1.54 & 8.46 & 10.00 & -1.54 & 7.65 & 17.31 & -9.66\end{array}$ $\begin{array}{lllllllll}8.94 & 8.64 & -0.30 & 7.97 & 8.27 & -0.30 & 7.40 & 14.43 & -7.03\end{array}$ $\begin{array}{llllllllll}10 & 8.96 & -1.05 & 8.45 & 9.50 & -1.05 & 7.64 & 16.40 & -8.76\end{array}$ $\begin{array}{lllllllll}8.04 & 8.06 & 0.02 & 7.10 & 7.09 & 0.02 & 6.95 & 12.79 & -5.84\end{array}$ $\begin{array}{lllllllll}7.34 & 7.81 & 0.47 & 6.73 & 6.26 & 0.47 & 6.76 & 11.50 & -4.74\end{array}$ $\begin{array}{lllllllll}11.6 & 8.35 & -3.24 & 7.54 & 10.78 & -3.24 & 7.18 & 19.31 & -12.13\end{array}$ $\begin{array}{lllllllll}11.7 & 8.32 & -3.34 & 7.49 & 10.83 & -3.34 & 7.15 & 19.43 & -12.28\end{array}$ $\begin{array}{llllllllll}10.7 & 8.59 & -2.10 & 7.90 & 10.00 & -2.10 & 7.36 & 17.65 & -10.29\end{array}$ $\begin{array}{llllllllll}8.64 & 8.84 & 0.20 & 8.27 & 8.07 & 0.20 & 7.55 & 13.88 & -6.33\end{array}$ $\begin{array}{lllllllll}9.54 & 8.51 & -1.03 & 7.78 & 8.81 & -1.03 & 7.30 & 15.54 & -8.25\end{array}$ $\begin{array}{rrrrrrrrrr}11.2 & 8.91 & -2.27 & 8.37 & 10.64 & -2.27 & 7.61 & 18.55 & -10.95\end{array}$ $\begin{array}{rrrrrrrrrr}11.2 & 8.91 & -2.27 & 8.37 & 10.64 & -2.27 & 7.61 & 18.55 & -10.95 \\ 8.23 & 7.68 & -0.55 & 6.54 & 7.09 & -0.55 & 6.66 & 13.13 & -6.47\end{array}$ $\begin{array}{lllllllll}10.5 & 8.75 & -1.79 & 8.13 & 9.92 & -1.79 & 7.48 & 17.37 & -9.88\end{array}$ $\begin{array}{lllllllll}8.39 & 8.33 & -0.06 & 7.51 & 7.57 & -0.06 & 7.16 & 13.43 & -6.27\end{array}$ $\begin{array}{llllllllll}10 & 8.73 & -1.30 & 8.10 & 9.41 & -1.30 & 7.47 & 16.44 & -8.97\end{array}$ $\begin{array}{lllllllll}12.6 & 8.8 & -3.78 & 8.21 & 11.98 & -3.78 & 7.52 & 21.11 & -13.59\end{array}$ $\begin{array}{lllllllll}9.46 & 8.64 & -0.82 & 7.97 & 8.79 & -0.82 & 7.40 & 15.38 & -7.99\end{array}$ $\begin{array}{lllllllll}12 & 8.71 & -3.29 & 8.07 & 11.37 & -3.29 & 7.45 & 20.06 & -12.6\end{array}$ $\begin{array}{lllllllll}9.04 & 7.47 & -1.57 & 6.22 & 7.79 & -1.57 & 6.50 & 14.61 & -8.12\end{array}$ $\begin{array}{lllllllll}11.4 & 8.62 & -2.81 & 7.94 & 10.75 & -2.81 & 7.38 & 19.00 & -11.62\end{array}$ $\begin{array}{lllllllll}8.14 & 7.81 & -0.33 & 6.73 & 7.06 & -0.33 & 6.76 & 12.97 & -6.21\end{array}$ $\begin{array}{lllllllll}9.2 & 8.12 & -1.08 & 7.19 & 8.28 & -1.08 & 7.00 & 14.92 & -7.92\end{array}$ $\begin{array}{lllllllll}8.31 & 8.46 & 0.15 & 7.70 & 7.55 & 0.15 & 7.26 & 13.27 & -6.0\end{array}$ $\begin{array}{llllllllll}9.38 & 8.78 & -0.60 & 8.18 & 8.78 & -0.60 & 7.51 & 15.24 & -7.73\end{array}$ $\begin{array}{lllllllll}9.15 & 8.86 & -0.28 & 8.30 & 8.58 & -0.28 & 7.57 & 14.81 & -7.24\end{array}$ $\begin{array}{llllllllll}9.15 & 8.86 & -0.28 & 8.30 & 8.58 & -0.28 & 7.57 & 14.81 & -7.24 \\ 9.38 & 7.86 & -1.52 & 6.81 & 8.33 & -1.52 & 6.80 & 15.24 & -8.44\end{array}$ $\begin{array}{rrrrrrrrrr}9.38 & 7.86 & -1.52 & 6.81 & 8.33 & -1.52 & 6.80 & 15.24 & -8.44 \\ 7.77 & 7.94 & 0.17 & 6.93 & 6.76 & 0.17 & 6.86 & 12.29 & -5.43\end{array}$ $\begin{array}{lllllllll}8.75 & 7.68 & -1.07 & 6.54 & 7.60 & -1.07 & 6.66 & 14.08 & -7.42\end{array}$ 
$\mathrm{C}(\mathrm{C}(\mathrm{C}(\mathrm{C}(\mathrm{C}(\mathrm{C}(\mathrm{C}(\mathrm{C}(\mathrm{C}(\mathrm{C}(\mathrm{C}(\mathrm{C}(\mathrm{H})(\mathrm{H}) \mathrm{H})(\mathrm{Br}) \mathrm{H})(\mathrm{H}) \mathrm{F})(\mathrm{H}) \mathrm{Br})(\mathrm{H}) \mathrm{F})(\mathrm{H}) \mathrm{H})(\mathrm{F}) \mathrm{F})(\mathrm{Br}) \mathrm{H})(\mathrm{H}) \mathrm{Br})(\mathrm{H}) \mathrm{Br})(\mathrm{H}) \mathrm{Br})(\mathrm{H})(\mathrm{F}) \quad \mathrm{C} 12 \mathrm{H} 15 \mathrm{Br} 6 \mathrm{~F} 5$ $\mathrm{C}(\mathrm{C}(\mathrm{C}(\mathrm{C}(\mathrm{C}(\mathrm{C}(\mathrm{C}(\mathrm{C}(\mathrm{C}(\mathrm{C}(\mathrm{C}(\mathrm{C}(\mathrm{Cl})(\mathrm{H}) \mathrm{Cl})(\mathrm{H}) \mathrm{H})(\mathrm{H}) \mathrm{H})(\mathrm{H}) \mathrm{H})(\mathrm{Cl}) \mathrm{F})(\mathrm{Cl}) \mathrm{H})(\mathrm{H}) \mathrm{Cl})(\mathrm{Cl}) \mathrm{H})(\mathrm{H}) \mathrm{H})(\mathrm{Cl}) \mathrm{H})(\mathrm{H}) \mathrm{Cl})(\mathrm{Cl})(\mathrm{C} \mathrm{C} 12 \mathrm{H} 15 \mathrm{Cl} 10 \mathrm{~F}$ $\mathrm{C}(\mathrm{C}(\mathrm{C}(\mathrm{C}(\mathrm{C}(\mathrm{C}(\mathrm{C}(\mathrm{C}(\mathrm{C}(\mathrm{C}(\mathrm{C}(\mathrm{C}(\mathrm{Cl})(\mathrm{H}) \mathrm{Br})(\mathrm{H}) \mathrm{F})(\mathrm{H}) \mathrm{H})(\mathrm{F}) \mathrm{F})(\mathrm{Br}) \mathrm{F})(\mathrm{F}) \mathrm{H})(\mathrm{H}) \mathrm{Br})(\mathrm{H}) \mathrm{H})(\mathrm{H}) \mathrm{Cl})(\mathrm{H}) \mathrm{H})(\mathrm{F}) \mathrm{H})(\mathrm{H})(\mathrm{H}) \mathrm{H} \quad \mathrm{C} 12 \mathrm{H} 15 \mathrm{Cl} 2 \mathrm{Br} 3 \mathrm{~F} 6$ $\mathrm{C}(\mathrm{C}(\mathrm{C}(\mathrm{C}(\mathrm{C}(\mathrm{C}(\mathrm{C}(\mathrm{C}(\mathrm{C}(\mathrm{C}(\mathrm{C}(\mathrm{C}(\mathrm{H})(\mathrm{H}) \mathrm{F})(\mathrm{H}) \mathrm{Br})(\mathrm{H}) \mathrm{H})(\mathrm{Cl}) \mathrm{H})(\mathrm{F}) \mathrm{H})(\mathrm{Cl}) \mathrm{F})(\mathrm{Br}) \mathrm{H})(\mathrm{F}) \mathrm{Br})(\mathrm{H}) \mathrm{H})(\mathrm{H}) \mathrm{Br})(\mathrm{H}) \mathrm{H})(\mathrm{H})(\mathrm{H}) \quad \mathrm{C}_{2} \mathrm{H}_{15} \mathrm{Cl} 2 \mathrm{Br} 4 \mathrm{~F} 5$ $\mathrm{C}(\mathrm{C}(\mathrm{C}(\mathrm{C}(\mathrm{C}(\mathrm{C}(\mathrm{C}(\mathrm{C}(\mathrm{C}(\mathrm{C}(\mathrm{C}(\mathrm{C}(\mathrm{F})(\mathrm{H}) \mathrm{Cl})(\mathrm{Br}) \mathrm{Br})(\mathrm{H}) \mathrm{Br})(\mathrm{Cl}) \mathrm{F})(\mathrm{H}) \mathrm{Br})(\mathrm{H}) \mathrm{H})(\mathrm{H}) \mathrm{H})(\mathrm{Br}) \mathrm{H})(\mathrm{H}) \mathrm{F})(\mathrm{H}) \mathrm{H})(\mathrm{F}) \mathrm{H})(\mathrm{H})(\mathrm{H}) \mathrm{C} 12 \mathrm{H} 15 \mathrm{Cl} 2 \mathrm{Br} 5 \mathrm{~F} 4$ $\mathrm{C}(\mathrm{C}(\mathrm{C}(\mathrm{C}(\mathrm{C}(\mathrm{C}(\mathrm{C}(\mathrm{C}(\mathrm{C}(\mathrm{C}(\mathrm{C}(\mathrm{C}(\mathrm{Cl})(\mathrm{H}) \mathrm{Br})(\mathrm{F}) \mathrm{H})(\mathrm{H}) \mathrm{H})(\mathrm{F}) \mathrm{H})(\mathrm{F}) \mathrm{H})(\mathrm{H}) \mathrm{H})(\mathrm{Br}) \mathrm{Br})(\mathrm{Cl}) \mathrm{Cl})(\mathrm{F}) \mathrm{H})(\mathrm{H}) \mathrm{H})(\mathrm{H}) \mathrm{H})(\mathrm{H})(\mathrm{Br}) \mathrm{C}_{2} \mathrm{H} 15 \mathrm{Cl} 3 \mathrm{Br} 4 \mathrm{~F} 4$ $\mathrm{C}(\mathrm{C}(\mathrm{C}(\mathrm{C}(\mathrm{C}(\mathrm{C}(\mathrm{C}(\mathrm{C}(\mathrm{C}(\mathrm{C}(\mathrm{C}(\mathrm{C}(\mathrm{H})(\mathrm{F}) \mathrm{H})(\mathrm{Br}) \mathrm{H})(\mathrm{H}) \mathrm{H})(\mathrm{H}) \mathrm{Cl})(\mathrm{H}) \mathrm{F})(\mathrm{H}) \mathrm{H})(\mathrm{H}) \mathrm{H})(\mathrm{Br}) \mathrm{Br})(\mathrm{Cl}) \mathrm{H})(\mathrm{Cl}) \mathrm{H})(\mathrm{Br}) \mathrm{H})(\mathrm{F})(\mathrm{B} \quad \mathrm{C} 12 \mathrm{H} 15 \mathrm{Cl} 3 \mathrm{Br} 5 \mathrm{~F} 3$ $\mathrm{C}(\mathrm{C}(\mathrm{C}(\mathrm{C}(\mathrm{C}(\mathrm{C}(\mathrm{C}(\mathrm{C}(\mathrm{C}(\mathrm{C}(\mathrm{C}(\mathrm{C}(\mathrm{H})(\mathrm{F}) \mathrm{Cl})(\mathrm{Br}) \mathrm{H})(\mathrm{F}) \mathrm{H})(\mathrm{H}) \mathrm{H})(\mathrm{Cl}) \mathrm{H})(\mathrm{H}) \mathrm{Cl})(\mathrm{H}) \mathrm{Cl})(\mathrm{Cl}) \mathrm{H})(\mathrm{H}) \mathrm{Br})(\mathrm{H}) \mathrm{H})(\mathrm{H}) \mathrm{F})(\mathrm{H})(\mathrm{F}) \quad \mathrm{C} 12 \mathrm{H} 15 \mathrm{Cl} 5 \mathrm{Br} 2 \mathrm{~F} 4$ $\mathrm{C}(\mathrm{C}(\mathrm{C}(\mathrm{C}(\mathrm{C}(\mathrm{C}(\mathrm{C}(\mathrm{C}(\mathrm{C}(\mathrm{C}(\mathrm{C}(\mathrm{C}(\mathrm{H})(\mathrm{Cl}) \mathrm{Cl})(\mathrm{H}) \mathrm{F})(\mathrm{F}) \mathrm{F})(\mathrm{H}) \mathrm{H})(\mathrm{F}) \mathrm{H})(\mathrm{H}) \mathrm{F})(\mathrm{H}) \mathrm{H})(\mathrm{H}) \mathrm{H})(\mathrm{Br}) \mathrm{H})(\mathrm{H}) \mathrm{H})(\mathrm{Cl}) \mathrm{Cl})(\mathrm{Cl})(\mathrm{H}) \mathrm{H} \mathrm{C1} 2 \mathrm{H} 15 \mathrm{Cl} 5 \mathrm{BrF} 5$ $\mathrm{C}(\mathrm{C}(\mathrm{C}(\mathrm{C}(\mathrm{C}(\mathrm{C}(\mathrm{C}(\mathrm{C}(\mathrm{C}(\mathrm{C}(\mathrm{C}(\mathrm{C}(\mathrm{H})(\mathrm{Br}) \mathrm{H})(\mathrm{Cl}) \mathrm{H})(\mathrm{H}) \mathrm{Cl})(\mathrm{Cl}) \mathrm{F})(\mathrm{H}) \mathrm{H})(\mathrm{H}) \mathrm{F})(\mathrm{H}) \mathrm{H})(\mathrm{H}) \mathrm{Cl})(\mathrm{H}) \mathrm{Cl})(\mathrm{H}) \mathrm{F})(\mathrm{H}) \mathrm{Cl})(\mathrm{H})(\mathrm{H}) \mathrm{C}_{2} \mathrm{H} 15 \mathrm{Cl} 6 \mathrm{Br} 2 \mathrm{~F} 3$ $\mathrm{C}(\mathrm{C}(\mathrm{C}(\mathrm{C}(\mathrm{C}(\mathrm{C}(\mathrm{C}(\mathrm{C}(\mathrm{C}(\mathrm{C}(\mathrm{C}(\mathrm{C}(\mathrm{Cl})(\mathrm{H}) \mathrm{Cl})(\mathrm{Cl}) \mathrm{H})(\mathrm{H}) \mathrm{F})(\mathrm{H}) \mathrm{Cl})(\mathrm{H}) \mathrm{H})(\mathrm{H}) \mathrm{F})(\mathrm{H}) \mathrm{Cl})(\mathrm{F}) \mathrm{H})(\mathrm{H}) \mathrm{H})(\mathrm{H}) \mathrm{H})(\mathrm{F}) \mathrm{H})(\mathrm{H})(\mathrm{Br}) \quad \mathrm{C} 12 \mathrm{H} 15 \mathrm{Cl} 6 \mathrm{BrF} 4$ $\mathrm{C}(\mathrm{C}(\mathrm{C}(\mathrm{C}(\mathrm{C}(\mathrm{C}(\mathrm{C}(\mathrm{C}(\mathrm{C}(\mathrm{C}(\mathrm{C}(\mathrm{C}(\mathrm{F})(\mathrm{Br}) \mathrm{H})(\mathrm{H}) \mathrm{H})(\mathrm{H}) \mathrm{H})(\mathrm{H}) \mathrm{Cl})(\mathrm{H}) \mathrm{Cl})(\mathrm{H}) \mathrm{H})(\mathrm{H}) \mathrm{Cl})(\mathrm{Br}) \mathrm{Cl})(\mathrm{Cl}) \mathrm{H})(\mathrm{H}) \mathrm{F})(\mathrm{H}) \mathrm{Cl})(\mathrm{H}) \quad \mathrm{C} 12 \mathrm{H} 15 \mathrm{Cl} 7 \mathrm{Br} 2 \mathrm{~F} 2$ $\mathrm{C}(\mathrm{C}(\mathrm{C}(\mathrm{C}(\mathrm{C}(\mathrm{C}(\mathrm{C}(\mathrm{C}(\mathrm{C}(\mathrm{C}(\mathrm{C}(\mathrm{C}(\mathrm{Br})(\mathrm{H}) \mathrm{H})(\mathrm{H}) \mathrm{H})(\mathrm{H}) \mathrm{Cl})(\mathrm{H}) \mathrm{Cl})(\mathrm{F}) \mathrm{Cl})(\mathrm{Cl}) \mathrm{H})(\mathrm{H}) \mathrm{Cl})(\mathrm{H}) \mathrm{Cl})(\mathrm{H}) \mathrm{Cl})(\mathrm{F}) \mathrm{H})(\mathrm{H}) \mathrm{H})(\mathrm{F})(\mathrm{H}) \mathrm{C}_{2} \mathrm{H} 15 \mathrm{Cl} 1 \mathrm{BrF} 3$ $\mathrm{C}(\mathrm{C}(\mathrm{C}(\mathrm{C}(\mathrm{C}(\mathrm{C}(\mathrm{C}(\mathrm{C}(\mathrm{C}(\mathrm{C}(\mathrm{C}(\mathrm{C}(\mathrm{Cl})(\mathrm{H}) \mathrm{H})(\mathrm{Cl}) \mathrm{H})(\mathrm{H}) \mathrm{Cl})(\mathrm{H}) \mathrm{Cl})(\mathrm{Cl}) \mathrm{Cl})(\mathrm{Cl}) \mathrm{F})(\mathrm{H}) \mathrm{F})(\mathrm{H}) \mathrm{H})(\mathrm{H}) \mathrm{H})(\mathrm{H}) \mathrm{H})(\mathrm{F}) \mathrm{H})(\mathrm{H})(\mathrm{F}) \quad \mathrm{C} 12 \mathrm{H} 15 \mathrm{Cl} 7 \mathrm{~F} 4$ $\mathrm{C}(\mathrm{C}(\mathrm{C}(\mathrm{C}(\mathrm{C}(\mathrm{C}(\mathrm{C}(\mathrm{C}(\mathrm{C}(\mathrm{C}(\mathrm{C}(\mathrm{C}(\mathrm{F})(\mathrm{Cl}) \mathrm{Cl})(\mathrm{H}) \mathrm{F})(\mathrm{H}) \mathrm{Cl})(\mathrm{H}) \mathrm{Cl})(\mathrm{H}) \mathrm{H})(\mathrm{Cl}) \mathrm{H})(\mathrm{F}) \mathrm{H})(\mathrm{H}) \mathrm{H})(\mathrm{H}) \mathrm{H})(\mathrm{Cl}) \mathrm{H})(\mathrm{H}) \mathrm{H})(\mathrm{H})(\mathrm{Cl}) \quad \mathrm{C}_{12} \mathrm{H} 15 \mathrm{Cl} 8 \mathrm{~F} 3$ $\mathrm{C}(\mathrm{C}(\mathrm{C}(\mathrm{C}(\mathrm{C}(\mathrm{C}(\mathrm{C}(\mathrm{C}(\mathrm{C}(\mathrm{C}(\mathrm{C}(\mathrm{C}(\mathrm{H})(\mathrm{H}) \mathrm{Cl})(\mathrm{H}) \mathrm{Cl})(\mathrm{H}) \mathrm{F})(\mathrm{Cl}) \mathrm{Cl})(\mathrm{H}) \mathrm{Cl})(\mathrm{H}) \mathrm{F})(\mathrm{H}) \mathrm{Cl})(\mathrm{H}) \mathrm{Cl})(\mathrm{H}) \mathrm{H})(\mathrm{H}) \mathrm{H})(\mathrm{H}) \mathrm{H})(\mathrm{Cl}) \quad \mathrm{C} 12 \mathrm{H} 15 \mathrm{Cl} 9 \mathrm{~F} 2$ $\mathrm{C}(\mathrm{C}(\mathrm{C}(\mathrm{C}(\mathrm{C}(\mathrm{C}(\mathrm{C}(\mathrm{C}(\mathrm{C}(\mathrm{C}(\mathrm{C}(\mathrm{C}(\mathrm{H})(\mathrm{H}) \mathrm{H})(\mathrm{Cl}) \mathrm{F})(\mathrm{H}) \mathrm{H})(\mathrm{Br}) \mathrm{Br})(\mathrm{H}) \mathrm{Br})(\mathrm{H}) \mathrm{H})(\mathrm{H}) \mathrm{H})(\mathrm{H}) \mathrm{F})(\mathrm{H}) \mathrm{F})(\mathrm{F}) \mathrm{H})(\mathrm{Br}) \mathrm{H})(\mathrm{F})(\mathrm{F}) \mathrm{H} \mathrm{C1} 2 \mathrm{H} 15 \mathrm{ClBr} 4 \mathrm{~F} 6$ $\mathrm{C}(\mathrm{C}(\mathrm{C}(\mathrm{C}(\mathrm{C}(\mathrm{C}(\mathrm{C}(\mathrm{C}(\mathrm{C}(\mathrm{C}(\mathrm{C}(\mathrm{C}(\mathrm{H})(\mathrm{F}) \mathrm{H})(\mathrm{Br}) \mathrm{H})(\mathrm{H}) \mathrm{H})(\mathrm{Br}) \mathrm{H})(\mathrm{H}) \mathrm{H})(\mathrm{Br}) \mathrm{Cl})(\mathrm{F}) \mathrm{Br})(\mathrm{H}) \mathrm{F})(\mathrm{F}) \mathrm{H})(\mathrm{H}) \mathrm{H})(\mathrm{H}) \mathrm{F})(\mathrm{H})(\mathrm{H}) \quad \mathrm{C} 12 \mathrm{H} 15 \mathrm{ClBr} 5 \mathrm{~F} 5$ $\mathrm{C}(\mathrm{C}(\mathrm{C}(\mathrm{C}(\mathrm{C}(\mathrm{C}(\mathrm{C}(\mathrm{C}(\mathrm{C}(\mathrm{C}(\mathrm{C}(\mathrm{C}(\mathrm{H})(\mathrm{H}) \mathrm{H})(\mathrm{F}) \mathrm{F})(\mathrm{Br}) \mathrm{H})(\mathrm{H}) \mathrm{H})(\mathrm{H}) \mathrm{Br})(\mathrm{H}) \mathrm{H})(\mathrm{H}) \mathrm{H})(\mathrm{F}) \mathrm{H})(\mathrm{H}) \mathrm{F})(\mathrm{H}) \mathrm{H})(\mathrm{Br}) \mathrm{Br})(\mathrm{Br})(\mathrm{F}) \quad \mathrm{C} 12 \mathrm{H} 16 \mathrm{Br} 5 \mathrm{~F} 5$ $\mathrm{C}(\mathrm{C}(\mathrm{C}(\mathrm{C}(\mathrm{C}(\mathrm{C}(\mathrm{C}(\mathrm{C}(\mathrm{C}(\mathrm{C}(\mathrm{C}(\mathrm{C}(\mathrm{H})(\mathrm{H}) \mathrm{Br})(\mathrm{H}) \mathrm{Br})(\mathrm{H}) \mathrm{Br})(\mathrm{Br}) \mathrm{H})(\mathrm{H}) \mathrm{H})(\mathrm{F}) \mathrm{H})(\mathrm{Br}) \mathrm{F})(\mathrm{H}) \mathrm{H})(\mathrm{H}) \mathrm{H})(\mathrm{F}) \mathrm{H})(\mathrm{H}) \mathrm{Br})(\mathrm{H})(\mathrm{F}) \mathrm{C} 12 \mathrm{H} 16 \mathrm{Br} 6 \mathrm{~F} 4$ $\mathrm{C}(\mathrm{C}(\mathrm{C}(\mathrm{C}(\mathrm{C}(\mathrm{C}(\mathrm{C}(\mathrm{C}(\mathrm{C}(\mathrm{C}(\mathrm{C}(\mathrm{C}(\mathrm{H})(\mathrm{Cl}) \mathrm{H})(\mathrm{H}) \mathrm{H})(\mathrm{H}) \mathrm{F})(\mathrm{H}) \mathrm{H})(\mathrm{H}) \mathrm{H})(\mathrm{H}) \mathrm{H})(\mathrm{H}) \mathrm{H})(\mathrm{Cl}) \mathrm{F})(\mathrm{F}) \mathrm{H})(\mathrm{F}) \mathrm{H})(\mathrm{Br}) \mathrm{F})(\mathrm{Br})(\mathrm{Br}) \mathrm{H} \mathrm{C12H} 16 \mathrm{Cl} 2 \mathrm{Br} 3 \mathrm{~F}$ $\mathrm{C}(\mathrm{C}(\mathrm{C}(\mathrm{C}(\mathrm{C}(\mathrm{C}(\mathrm{C}(\mathrm{C}(\mathrm{C}(\mathrm{C}(\mathrm{C}(\mathrm{C}(\mathrm{Br})(\mathrm{Cl}) \mathrm{H})(\mathrm{H}) \mathrm{H})(\mathrm{F}) \mathrm{H})(\mathrm{H}) \mathrm{H})(\mathrm{Br}) \mathrm{H})(\mathrm{H}) \mathrm{H})(\mathrm{Br}) \mathrm{Br})(\mathrm{Br}) \mathrm{H})(\mathrm{H}) \mathrm{H})(\mathrm{H}) \mathrm{F})(\mathrm{Cl}) \mathrm{H})(\mathrm{H}) \quad \mathrm{C} 12 \mathrm{H} 16 \mathrm{Cl} 2 \mathrm{Br} 5 \mathrm{~F} 3$ $\mathrm{C}(\mathrm{C}(\mathrm{C}(\mathrm{C}(\mathrm{C}(\mathrm{C}(\mathrm{C}(\mathrm{C}(\mathrm{C}(\mathrm{C}(\mathrm{C}(\mathrm{C}(\mathrm{H})(\mathrm{F}) \mathrm{H})(\mathrm{H}) \mathrm{F})(\mathrm{H}) \mathrm{H})(\mathrm{H}) \mathrm{Br})(\mathrm{H}) \mathrm{H})(\mathrm{Cl}) \mathrm{H})(\mathrm{H}) \mathrm{H})(\mathrm{F}) \mathrm{H})(\mathrm{Cl}) \mathrm{F})(\mathrm{H}) \mathrm{Br})(\mathrm{H}) \mathrm{H})(\mathrm{H})(\mathrm{Cl}) \mathrm{F} \mathrm{C12H16Cl3Br} 2 \mathrm{~F} 5$ $\mathrm{C}(\mathrm{C}(\mathrm{C}(\mathrm{C}(\mathrm{C}(\mathrm{C}(\mathrm{C}(\mathrm{C}(\mathrm{C}(\mathrm{C}(\mathrm{C}(\mathrm{C}(\mathrm{H})(\mathrm{F}) \mathrm{H})(\mathrm{H}) \mathrm{H})(\mathrm{H}) \mathrm{F})(\mathrm{H}) \mathrm{F})(\mathrm{H}) \mathrm{Cl})(\mathrm{H}) \mathrm{Br})(\mathrm{Cl}) \mathrm{H})(\mathrm{Cl}) \mathrm{H})(\mathrm{H}) \mathrm{Br})(\mathrm{H}) \mathrm{Br})(\mathrm{F}) \mathrm{H})(\mathrm{H})(\mathrm{H}) \quad \mathrm{C} 12 \mathrm{H} 16 \mathrm{Cl} 3 \mathrm{Br}_{3} \mathrm{~F} 4$ $\mathrm{C}(\mathrm{C}(\mathrm{C}(\mathrm{C}(\mathrm{C}(\mathrm{C}(\mathrm{C}(\mathrm{C}(\mathrm{C}(\mathrm{C}(\mathrm{C}(\mathrm{C}(\mathrm{H})(\mathrm{Cl}) \mathrm{Br})(\mathrm{H}) \mathrm{F})(\mathrm{H}) \mathrm{H})(\mathrm{H}) \mathrm{Br})(\mathrm{H}) \mathrm{H})(\mathrm{H}) \mathrm{Cl})(\mathrm{Br}) \mathrm{H})(\mathrm{H}) \mathrm{Br})(\mathrm{H}) \mathrm{F})(\mathrm{H}) \mathrm{H})(\mathrm{H}) \mathrm{Br})(\mathrm{H}) \quad \mathrm{C} 12 \mathrm{H} 16 \mathrm{Cl} 3 \mathrm{Br} 5 \mathrm{~F} 2$ $\mathrm{C}(\mathrm{C}(\mathrm{C}(\mathrm{C}(\mathrm{C}(\mathrm{C}(\mathrm{C}(\mathrm{C}(\mathrm{C}(\mathrm{C}(\mathrm{C}(\mathrm{C}(\mathrm{H})(\mathrm{F}) \mathrm{F})(\mathrm{H}) \mathrm{Br})(\mathrm{Cl}) \mathrm{Cl})(\mathrm{F}) \mathrm{H})(\mathrm{Cl}) \mathrm{H})(\mathrm{H}) \mathrm{H})(\mathrm{H}) \mathrm{H})(\mathrm{F}) \mathrm{H})(\mathrm{H}) \mathrm{H})(\mathrm{H}) \mathrm{H})(\mathrm{H}) \mathrm{H})(\mathrm{Br})(\mathrm{Cl}) \quad \mathrm{C} 12 \mathrm{H} 16 \mathrm{Cl} 4 \mathrm{Br} 2 \mathrm{~F} 4$ $\mathrm{C}(\mathrm{C}(\mathrm{C}(\mathrm{C}(\mathrm{C}(\mathrm{C}(\mathrm{C}(\mathrm{C}(\mathrm{C}(\mathrm{C}(\mathrm{C}(\mathrm{C}(\mathrm{F})(\mathrm{H}) \mathrm{Br})(\mathrm{H}) \mathrm{H})(\mathrm{H}) \mathrm{Cl})(\mathrm{H}) \mathrm{H})(\mathrm{H}) \mathrm{H})(\mathrm{H}) \mathrm{H})(\mathrm{F}) \mathrm{Cl})(\mathrm{H}) \mathrm{F})(\mathrm{H}) \mathrm{H})(\mathrm{Cl}) \mathrm{H})(\mathrm{Cl}) \mathrm{H})(\mathrm{Br})(\mathrm{H}) \quad \mathrm{C} 12 \mathrm{H} 16 \mathrm{Cl} 1 \mathrm{Br} 3 \mathrm{~F} 3$ $\mathrm{C}(\mathrm{C}(\mathrm{C}(\mathrm{C}(\mathrm{C}(\mathrm{C}(\mathrm{C}(\mathrm{C}(\mathrm{C}(\mathrm{C}(\mathrm{C}(\mathrm{C}(\mathrm{Br})(\mathrm{H}) \mathrm{F})(\mathrm{H}) \mathrm{H})(\mathrm{Cl}) \mathrm{F})(\mathrm{H}) \mathrm{Br})(\mathrm{H}) \mathrm{Br})(\mathrm{Cl}) \mathrm{H})(\mathrm{H}) \mathrm{Cl})(\mathrm{H}) \mathrm{H})(\mathrm{Cl}) \mathrm{H})(\mathrm{H}) \mathrm{H})(\mathrm{H}) \mathrm{H})(\mathrm{H}) \quad \mathrm{C} 12 \mathrm{H} 16 \mathrm{Cl} 5 \mathrm{Br} 3 \mathrm{~F} 2$ $\mathrm{C}(\mathrm{C}(\mathrm{C}(\mathrm{C}(\mathrm{C}(\mathrm{C}(\mathrm{C}(\mathrm{C}(\mathrm{C}(\mathrm{C}(\mathrm{C}(\mathrm{C}(\mathrm{H})(\mathrm{Cl}) \mathrm{F})(\mathrm{F}) \mathrm{H})(\mathrm{F}) \mathrm{Cl})(\mathrm{H}) \mathrm{H})(\mathrm{Cl}) \mathrm{H})(\mathrm{H}) \mathrm{F})(\mathrm{H}) \mathrm{Br})(\mathrm{Cl}) \mathrm{H})(\mathrm{H}) \mathrm{H})(\mathrm{H}) \mathrm{H})(\mathrm{H}) \mathrm{H})(\mathrm{Cl})(\mathrm{H}) \quad \mathrm{C} 12 \mathrm{H} 16 \mathrm{Cl} 5 \mathrm{BrF} 4$ $\mathrm{C}(\mathrm{C}(\mathrm{C}(\mathrm{C}(\mathrm{C}(\mathrm{C}(\mathrm{C}(\mathrm{C}(\mathrm{C}(\mathrm{C}(\mathrm{C}(\mathrm{C}(\mathrm{H})(\mathrm{H}) \mathrm{H})(\mathrm{H}) \mathrm{H})(\mathrm{H}) \mathrm{Cl})(\mathrm{Br}) \mathrm{H})(\mathrm{H}) \mathrm{H})(\mathrm{Br}) \mathrm{F})(\mathrm{Cl}) \mathrm{H})(\mathrm{H}) \mathrm{H})(\mathrm{Cl}) \mathrm{H})(\mathrm{Cl}) \mathrm{H})(\mathrm{H}) \mathrm{Cl})(\mathrm{Cl}) \quad \mathrm{C} 12 \mathrm{H} 16 \mathrm{Cl} 6 \mathrm{Br} 2 \mathrm{~F} 2$ $\mathrm{C}(\mathrm{C}(\mathrm{C}(\mathrm{C}(\mathrm{C}(\mathrm{C}(\mathrm{C}(\mathrm{C}(\mathrm{C}(\mathrm{C}(\mathrm{C}(\mathrm{C}(\mathrm{H})(\mathrm{Cl}) \mathrm{Br})(\mathrm{Cl}) \mathrm{H})(\mathrm{H}) \mathrm{Cl})(\mathrm{F}) \mathrm{Cl})(\mathrm{H}) \mathrm{H})(\mathrm{H}) \mathrm{F})(\mathrm{H}) \mathrm{H})(\mathrm{H}) \mathrm{H})(\mathrm{F}) \mathrm{H})(\mathrm{H}) \mathrm{H})(\mathrm{Cl}) \mathrm{Cl})(\mathrm{H})(\mathrm{H}) \mathrm{C}_{2} \mathrm{H}_{16 \mathrm{Cl}} \mathrm{BrF}^{2} 3$ $\mathrm{C}(\mathrm{C}(\mathrm{C}(\mathrm{C}(\mathrm{C}(\mathrm{C}(\mathrm{C}(\mathrm{C}(\mathrm{C}(\mathrm{C}(\mathrm{C}(\mathrm{C}(\mathrm{H})(\mathrm{Cl}) \mathrm{F})(\mathrm{H}) \mathrm{H})(\mathrm{F}) \mathrm{H})(\mathrm{Cl}) \mathrm{H})(\mathrm{H}) \mathrm{Cl})(\mathrm{F}) \mathrm{H})(\mathrm{Cl}) \mathrm{H})(\mathrm{Cl}) \mathrm{H})(\mathrm{Cl}) \mathrm{H})(\mathrm{H}) \mathrm{Cl})(\mathrm{H}) \mathrm{H})(\mathrm{H})(\mathrm{H}) \quad \mathrm{C} 12 \mathrm{H} 16 \mathrm{Cl} 7 \mathrm{~F} 3$ $\mathrm{C}(\mathrm{C}(\mathrm{C}(\mathrm{C}(\mathrm{C}(\mathrm{C}(\mathrm{C}(\mathrm{C}(\mathrm{C}(\mathrm{C}(\mathrm{C}(\mathrm{C}(\mathrm{H})(\mathrm{H}) \mathrm{Cl})(\mathrm{H}) \mathrm{Cl})(\mathrm{H}) \mathrm{H})(\mathrm{H}) \mathrm{H})(\mathrm{H}) \mathrm{Cl})(\mathrm{Cl}) \mathrm{H})(\mathrm{H}) \mathrm{Cl})(\mathrm{F}) \mathrm{F})(\mathrm{Cl}) \mathrm{H})(\mathrm{H}) \mathrm{H})(\mathrm{H}) \mathrm{Cl})(\mathrm{H})(\mathrm{H}) \mathrm{C} 12 \mathrm{H} 16 \mathrm{Cl} 8 \mathrm{~F} 2$ $\mathrm{C}(\mathrm{C}(\mathrm{C}(\mathrm{C}(\mathrm{C}(\mathrm{C}(\mathrm{C}(\mathrm{C}(\mathrm{C}(\mathrm{C}(\mathrm{C}(\mathrm{C}(\mathrm{H})(\mathrm{Br}) \mathrm{F})(\mathrm{F}) \mathrm{H})(\mathrm{H}) \mathrm{Br})(\mathrm{H}) \mathrm{Cl})(\mathrm{H}) \mathrm{H})(\mathrm{H}) \mathrm{H})(\mathrm{H}) \mathrm{H})(\mathrm{F}) \mathrm{H})(\mathrm{H}) \mathrm{H})(\mathrm{Br}) \mathrm{Br})(\mathrm{H}) \mathrm{H})(\mathrm{F})(\mathrm{Br}) \mathrm{C}_{2} \mathrm{H} 16 \mathrm{ClBr} 5 \mathrm{~F} 4$ $\mathrm{C}(\mathrm{C}(\mathrm{C}(\mathrm{C}(\mathrm{C}(\mathrm{C}(\mathrm{C}(\mathrm{C}(\mathrm{C}(\mathrm{C}(\mathrm{C}(\mathrm{C}(\mathrm{Br})(\mathrm{Br}) \mathrm{H})(\mathrm{Br}) \mathrm{H})(\mathrm{H}) \mathrm{F})(\mathrm{H}) \mathrm{H})(\mathrm{H}) \mathrm{H})(\mathrm{Br}) \mathrm{H})(\mathrm{H}) \mathrm{H})(\mathrm{Br}) \mathrm{H})(\mathrm{H}) \mathrm{Cl})(\mathrm{Br}) \mathrm{F})(\mathrm{H}) \mathrm{H})(\mathrm{H})\left(\mathrm{C} 12 \mathrm{H} 16 \mathrm{ClBr} 6 \mathrm{~F}^{3}\right.$ $\mathrm{C}(\mathrm{C}(\mathrm{C}(\mathrm{C}(\mathrm{C}(\mathrm{C}(\mathrm{C}(\mathrm{C}(\mathrm{C}(\mathrm{C}(\mathrm{C}(\mathrm{C}(\mathrm{F})(\mathrm{H}) \mathrm{H})(\mathrm{F}) \mathrm{H})(\mathrm{F}) \mathrm{F})(\mathrm{H}) \mathrm{Br})(\mathrm{H}) \mathrm{H})(\mathrm{H}) \mathrm{H})(\mathrm{H}) \mathrm{H})(\mathrm{H}) \mathrm{Br})(\mathrm{Br}) \mathrm{H})(\mathrm{H}) \mathrm{H})(\mathrm{F}) \mathrm{H})(\mathrm{H})(\mathrm{H}) \mathrm{Br}$ C12H17Br4F5 $\mathrm{C}(\mathrm{C}(\mathrm{C}(\mathrm{C}(\mathrm{C}(\mathrm{C}(\mathrm{C}(\mathrm{C}(\mathrm{C}(\mathrm{C}(\mathrm{C}(\mathrm{C}(\mathrm{F})(\mathrm{H}) \mathrm{F})(\mathrm{H}) \mathrm{H})(\mathrm{Br}) \mathrm{H})(\mathrm{H}) \mathrm{H})(\mathrm{H}) \mathrm{Br})(\mathrm{H}) \mathrm{Br})(\mathrm{H}) \mathrm{Br})(\mathrm{H}) \mathrm{H})(\mathrm{H}) \mathrm{H})(\mathrm{H}) \mathrm{Br})(\mathrm{H}) \mathrm{F})(\mathrm{F})(\mathrm{H}) \quad \mathrm{C} 12 \mathrm{H} 17 \mathrm{Br} 5 \mathrm{~F} 4$ $\mathrm{C}(\mathrm{C}(\mathrm{C}(\mathrm{C}(\mathrm{C}(\mathrm{C}(\mathrm{C}(\mathrm{C}(\mathrm{C}(\mathrm{C}(\mathrm{C}(\mathrm{C}(\mathrm{Br})(\mathrm{F}) \mathrm{H})(\mathrm{H}) \mathrm{H})(\mathrm{H}) \mathrm{Br})(\mathrm{H}) \mathrm{H})(\mathrm{H}) \mathrm{H})(\mathrm{F}) \mathrm{H})(\mathrm{H}) \mathrm{H})(\mathrm{H}) \mathrm{Br})(\mathrm{H}) \mathrm{H})(\mathrm{H}) \mathrm{H})(\mathrm{Br}) \mathrm{Br})(\mathrm{H}) \quad \mathrm{C} 12 \mathrm{H} 17 \mathrm{Br} 6 \mathrm{~F} 3$ $\mathrm{C}(\mathrm{C}(\mathrm{C}(\mathrm{C}(\mathrm{C}(\mathrm{C}(\mathrm{C}(\mathrm{C}(\mathrm{C}(\mathrm{C}(\mathrm{C}(\mathrm{C}(\mathrm{H})(\mathrm{H}) \mathrm{H})(\mathrm{Cl}) \mathrm{H})(\mathrm{H}) \mathrm{H})(\mathrm{H}) \mathrm{H})(\mathrm{H}) \mathrm{H})(\mathrm{H}) \mathrm{H})(\mathrm{Cl}) \mathrm{F})(\mathrm{H}) \mathrm{F})(\mathrm{Br}) \mathrm{H})(\mathrm{H}) \mathrm{H})(\mathrm{F}) \mathrm{Br})(\mathrm{Br})(\mathrm{F}) \quad \mathrm{C} 12 \mathrm{H} 17 \mathrm{Cl} 2 \mathrm{Br} 3 \mathrm{~F} 4$ $\mathrm{C}(\mathrm{C}(\mathrm{C}(\mathrm{C}(\mathrm{C}(\mathrm{C}(\mathrm{C}(\mathrm{C}(\mathrm{C}(\mathrm{C}(\mathrm{C}(\mathrm{C}(\mathrm{Cl})(\mathrm{F}) \mathrm{H})(\mathrm{H}) \mathrm{F})(\mathrm{H}) \mathrm{Br})(\mathrm{H}) \mathrm{H})(\mathrm{H}) \mathrm{Cl})(\mathrm{H}) \mathrm{Br})(\mathrm{H}) \mathrm{H})(\mathrm{H}) \mathrm{Br})(\mathrm{H}) \mathrm{H})(\mathrm{H}) \mathrm{H})(\mathrm{H}) \mathrm{F})(\mathrm{Br})(\mathrm{H}) \mathrm{C}_{2} \mathrm{H}_{17} \mathrm{Cl} 2 \mathrm{Br} 4 \mathrm{~F}$ $\mathrm{C}(\mathrm{C}(\mathrm{C}(\mathrm{C}(\mathrm{C}(\mathrm{C}(\mathrm{C}(\mathrm{C}(\mathrm{C}(\mathrm{C}(\mathrm{C}(\mathrm{C}(\mathrm{H})(\mathrm{Br}) \mathrm{Br})(\mathrm{H}) \mathrm{Br})(\mathrm{Cl}) \mathrm{H})(\mathrm{H}) \mathrm{Cl})(\mathrm{Br}) \mathrm{F})(\mathrm{H}) \mathrm{H})(\mathrm{H}) \mathrm{H})(\mathrm{H}) \mathrm{H})(\mathrm{Br}) \mathrm{H})(\mathrm{H}) \mathrm{H})(\mathrm{H}) \mathrm{F})(\mathrm{H}) \quad \mathrm{C} 12 \mathrm{H} 17 \mathrm{Cl} 2 \mathrm{Br} 5 \mathrm{~F} 2$ $\mathrm{C}(\mathrm{C}(\mathrm{C}(\mathrm{C}(\mathrm{C}(\mathrm{C}(\mathrm{C}(\mathrm{C}(\mathrm{C}(\mathrm{C}(\mathrm{C}(\mathrm{C}(\mathrm{H})(\mathrm{H}) \mathrm{H})(\mathrm{H}) \mathrm{F})(\mathrm{Cl}) \mathrm{F})(\mathrm{H}) \mathrm{Cl})(\mathrm{Br}) \mathrm{H})(\mathrm{Cl}) \mathrm{H})(\mathrm{H}) \mathrm{H})(\mathrm{F}) \mathrm{H})(\mathrm{H}) \mathrm{F})(\mathrm{H}) \mathrm{H})(\mathrm{H}) \mathrm{Br})(\mathrm{H})(\mathrm{H}) \quad \mathrm{C} 12 \mathrm{H} 17 \mathrm{Cl} 3 \mathrm{Br} 2 \mathrm{~F} 4$ $\mathrm{C}\left(\mathrm{C}(\mathrm{C}(\mathrm{C}(\mathrm{C}(\mathrm{C}(\mathrm{C}(\mathrm{C}(\mathrm{C}(\mathrm{C}(\mathrm{C}(\mathrm{C}(\mathrm{H})(\mathrm{H}) \mathrm{H})(\mathrm{H}) \mathrm{F})(\mathrm{Cl}) \mathrm{H})(\mathrm{H}) \mathrm{Cl}(\mathrm{Br}) \mathrm{H})(\mathrm{F}) \mathrm{H})(\mathrm{H}) \mathrm{Br})(\mathrm{Cl}) \mathrm{Br})(\mathrm{H}) \mathrm{H})(\mathrm{H}) \mathrm{H})(\mathrm{H}) \mathrm{H})(\mathrm{F})(\mathrm{H}) \mathrm{C}_{2} \mathrm{H}_{17} \mathrm{Cl}_{3} \mathrm{Br} 3 \mathrm{~F} 3\right.$ $\mathrm{C}(\mathrm{C}(\mathrm{C}(\mathrm{C}(\mathrm{C}(\mathrm{C}(\mathrm{C}(\mathrm{C}(\mathrm{C}(\mathrm{C}(\mathrm{C}(\mathrm{C}(\mathrm{H})(\mathrm{H}) \mathrm{F})(\mathrm{Cl}) \mathrm{F})(\mathrm{H}) \mathrm{H})(\mathrm{H}) \mathrm{H})(\mathrm{Cl}) \mathrm{F})(\mathrm{Br}) \mathrm{H})(\mathrm{H}) \mathrm{H})(\mathrm{Br}) \mathrm{H})(\mathrm{Cl}) \mathrm{H})(\mathrm{H}) \mathrm{H})(\mathrm{H}) \mathrm{H})(\mathrm{H})(\mathrm{Cl}) \quad \mathrm{C} 12 \mathrm{H} 17 \mathrm{Cl} 4 \mathrm{Br} 2 \mathrm{~F} 3$ $\mathrm{C}(\mathrm{C}(\mathrm{C}(\mathrm{C}(\mathrm{C}(\mathrm{C}(\mathrm{C}(\mathrm{C}(\mathrm{C}(\mathrm{C}(\mathrm{C}(\mathrm{C}(\mathrm{H})(\mathrm{H}) \mathrm{H})(\mathrm{H}) \mathrm{H})(\mathrm{H}) \mathrm{H})(\mathrm{Cl}) \mathrm{H})(\mathrm{H}) \mathrm{Cl})(\mathrm{H}) \mathrm{H})(\mathrm{H}) \mathrm{H})(\mathrm{F}) \mathrm{Cl})(\mathrm{H}) \mathrm{Br})(\mathrm{H}) \mathrm{Br})(\mathrm{H}) \mathrm{Br})(\mathrm{H}) \quad \mathrm{C} 12 \mathrm{H} 17 \mathrm{Cl} 4 \mathrm{Br} 3 \mathrm{~F} 2$ $\mathrm{C}(\mathrm{C}(\mathrm{C}(\mathrm{C}(\mathrm{C}(\mathrm{C}(\mathrm{C}(\mathrm{C}(\mathrm{C}(\mathrm{C}(\mathrm{C}(\mathrm{C}(\mathrm{H})(\mathrm{H}) \mathrm{H})(\mathrm{H}) \mathrm{H})(\mathrm{H}) \mathrm{H})(\mathrm{Cl}) \mathrm{F})(\mathrm{Cl}) \mathrm{H})(\mathrm{H}) \mathrm{Br})(\mathrm{H}) \mathrm{Br})(\mathrm{H}) \mathrm{H})(\mathrm{Cl}) \mathrm{H})(\mathrm{Br}) \mathrm{H})(\mathrm{H}) \mathrm{H})(\mathrm{H}) \quad \mathrm{C} 12 \mathrm{H} 17 \mathrm{Cl} 4 \mathrm{Br} 4 \mathrm{~F}$ $\mathrm{C}(\mathrm{C}(\mathrm{C}(\mathrm{C}(\mathrm{C}(\mathrm{C}(\mathrm{C}(\mathrm{C}(\mathrm{C}(\mathrm{C}(\mathrm{C}(\mathrm{C}(\mathrm{H})(\mathrm{H}) \mathrm{F})(\mathrm{H}) \mathrm{H})(\mathrm{H}) \mathrm{H})(\mathrm{Cl}) \mathrm{H})(\mathrm{H}) \mathrm{H})(\mathrm{F}) \mathrm{Cl})(\mathrm{H}) \mathrm{Br})(\mathrm{H}) \mathrm{H})(\mathrm{Cl}) \mathrm{H})(\mathrm{H}) \mathrm{Cl})(\mathrm{H}) \mathrm{H})(\mathrm{Cl}) \quad \mathrm{C} 12 \mathrm{H} 17 \mathrm{Cl} 5 \mathrm{Br} 2 \mathrm{~F} 2$ $\mathrm{C}(\mathrm{C}(\mathrm{C}(\mathrm{C}(\mathrm{C}(\mathrm{C}(\mathrm{C}(\mathrm{C}(\mathrm{C}(\mathrm{C}(\mathrm{C}(\mathrm{C}(\mathrm{H})(\mathrm{Br}) \mathrm{H})(\mathrm{H}) \mathrm{Br})(\mathrm{H}) \mathrm{Cl})(\mathrm{H}) \mathrm{Br})(\mathrm{H}) \mathrm{H})(\mathrm{H}) \mathrm{Cl})(\mathrm{H}) \mathrm{H})(\mathrm{H}) \mathrm{Cl})(\mathrm{Br}) \mathrm{H})(\mathrm{Cl}) \mathrm{H})(\mathrm{H}) \mathrm{H})(\mathrm{H})(\mathrm{C} 12 \mathrm{H} 17 \mathrm{Cl} 5 \mathrm{Br} 4$ $\mathrm{C}(\mathrm{C}(\mathrm{C}(\mathrm{C}(\mathrm{C}(\mathrm{C}(\mathrm{C}(\mathrm{C}(\mathrm{C}(\mathrm{C}(\mathrm{C}(\mathrm{C}(\mathrm{H})(\mathrm{H}) \mathrm{F})(\mathrm{F}) \mathrm{Cl})(\mathrm{H}) \mathrm{H})(\mathrm{Cl}) \mathrm{H})(\mathrm{Cl}) \mathrm{Br})(\mathrm{Cl}) \mathrm{H})(\mathrm{H}) \mathrm{H})(\mathrm{H}) \mathrm{H})(\mathrm{F}) \mathrm{H})(\mathrm{H}) \mathrm{H})(\mathrm{H}) \mathrm{H})(\mathrm{H})(\mathrm{H}) \quad \mathrm{C} 12 \mathrm{H} 17 \mathrm{Cl} 5 \mathrm{BrF} 3$ $\mathrm{C}(\mathrm{C}(\mathrm{C}(\mathrm{C}(\mathrm{C}(\mathrm{C}(\mathrm{C}(\mathrm{C}(\mathrm{C}(\mathrm{C}(\mathrm{C}(\mathrm{C}(\mathrm{H})(\mathrm{Cl}) \mathrm{Cl})(\mathrm{Br}) \mathrm{H})(\mathrm{H}) \mathrm{Cl})(\mathrm{H}) \mathrm{H})(\mathrm{Cl}) \mathrm{H})(\mathrm{H}) \mathrm{H})(\mathrm{Cl}) \mathrm{H})(\mathrm{H}) \mathrm{H})(\mathrm{F}) \mathrm{H})(\mathrm{H}) \mathrm{H})(\mathrm{H}) \mathrm{H})(\mathrm{H}) \quad \mathrm{C} 12 \mathrm{H} 17 \mathrm{Cl} 6 \mathrm{Br} 2 \mathrm{~F}$ $\mathrm{C}(\mathrm{C}(\mathrm{C}(\mathrm{C}(\mathrm{C}(\mathrm{C}(\mathrm{C}(\mathrm{C}(\mathrm{C}(\mathrm{C}(\mathrm{C}(\mathrm{C}(\mathrm{H})(\mathrm{H}) \mathrm{H})(\mathrm{H}) \mathrm{Cl})(\mathrm{F}) \mathrm{Cl})(\mathrm{H}) \mathrm{F})(\mathrm{H}) \mathrm{H})(\mathrm{H}) \mathrm{H})(\mathrm{Cl}) \mathrm{H})(\mathrm{Cl}) \mathrm{H})(\mathrm{H}) \mathrm{H})(\mathrm{H}) \mathrm{H})(\mathrm{Br}) \mathrm{Cl})(\mathrm{H})(\mathrm{H}) \quad \mathrm{C} 12 \mathrm{H} 17 \mathrm{Cl} 16 \mathrm{BrF} 2$ $\mathrm{C}(\mathrm{C}(\mathrm{C}(\mathrm{C}(\mathrm{C}(\mathrm{C}(\mathrm{C}(\mathrm{C}(\mathrm{C}(\mathrm{C}(\mathrm{C}(\mathrm{C}(\mathrm{Cl})(\mathrm{H}) \mathrm{H})(\mathrm{H}) \mathrm{Cl})(\mathrm{F}) \mathrm{Cl})(\mathrm{Cl}) \mathrm{H})(\mathrm{H}) \mathrm{H})(\mathrm{Cl}) \mathrm{H})(\mathrm{F}) \mathrm{H})(\mathrm{H}) \mathrm{H})(\mathrm{Cl}) \mathrm{H})(\mathrm{F}) \mathrm{H})(\mathrm{H}) \mathrm{H})(\mathrm{H})(\mathrm{H}) \quad \mathrm{C}_{2} \mathrm{H}_{17} \mathrm{Cl} 16 \mathrm{~F} 3$ $\mathrm{C}(\mathrm{C}(\mathrm{C}(\mathrm{C}(\mathrm{C}(\mathrm{C}(\mathrm{C}(\mathrm{C}(\mathrm{C}(\mathrm{C}(\mathrm{C}(\mathrm{C}(\mathrm{H})(\mathrm{H}) \mathrm{Cl})(\mathrm{H}) \mathrm{H})(\mathrm{Cl}) \mathrm{H})(\mathrm{Cl}) \mathrm{H})(\mathrm{H}) \mathrm{H})(\mathrm{H}) \mathrm{H})(\mathrm{Cl}) \mathrm{H})(\mathrm{Cl}) \mathrm{H})(\mathrm{H}) \mathrm{H})(\mathrm{Br}) \mathrm{H})(\mathrm{Cl}) \mathrm{H})(\mathrm{H})(\mathrm{C}$ C12 $\mathrm{H} 17 \mathrm{Cl} 7 \mathrm{Br} 2$ $\mathrm{C}(\mathrm{C}(\mathrm{C}(\mathrm{C}(\mathrm{C}(\mathrm{C}(\mathrm{C}(\mathrm{C}(\mathrm{C}(\mathrm{C}(\mathrm{C}(\mathrm{C}(\mathrm{H})(\mathrm{H}) \mathrm{H})(\mathrm{H}) \mathrm{Cl})(\mathrm{H}) \mathrm{H})(\mathrm{H}) \mathrm{H})(\mathrm{H}) \mathrm{H})(\mathrm{H}) \mathrm{Cl})(\mathrm{Cl}) \mathrm{H})(\mathrm{Cl}) \mathrm{H})(\mathrm{Cl}) \mathrm{H})(\mathrm{Br}) \mathrm{Cl}(\mathrm{H}) \mathrm{H})(\mathrm{Cl}) \quad \mathrm{C} 12 \mathrm{H} 17 \mathrm{Cl} 7 \mathrm{BrF}$ $\mathrm{C}(\mathrm{C}(\mathrm{C}(\mathrm{C}(\mathrm{C}(\mathrm{C}(\mathrm{C}(\mathrm{C}(\mathrm{C}(\mathrm{C}(\mathrm{C}(\mathrm{C}(\mathrm{Cl})(\mathrm{H}) \mathrm{H})(\mathrm{H}) \mathrm{H})(\mathrm{H}) \mathrm{F})(\mathrm{Cl}) \mathrm{Cl})(\mathrm{H}) \mathrm{H})(\mathrm{H}) \mathrm{H})(\mathrm{H}) \mathrm{H})(\mathrm{H}) \mathrm{Cl})(\mathrm{F}) \mathrm{H})(\mathrm{H}) \mathrm{H})(\mathrm{Cl}) \mathrm{H})(\mathrm{Cl})(\mathrm{Cl}) \mathrm{C} 12 \mathrm{H} 17 \mathrm{Cl} 7 \mathrm{~F} 2$ $\mathrm{C}(\mathrm{C}(\mathrm{C}(\mathrm{C}(\mathrm{C}(\mathrm{C}(\mathrm{C}(\mathrm{C}(\mathrm{C}(\mathrm{C}(\mathrm{C}(\mathrm{C}(\mathrm{H})(\mathrm{H}) \mathrm{H})(\mathrm{H}) \mathrm{H})(\mathrm{H}) \mathrm{H})(\mathrm{H}) \mathrm{Cl})(\mathrm{H}) \mathrm{Cl})(\mathrm{Cl}) \mathrm{Cl})(\mathrm{H}) \mathrm{H})(\mathrm{H}) \mathrm{H})(\mathrm{H}) \mathrm{Cl})(\mathrm{H}) \mathrm{Cl})(\mathrm{H}) \mathrm{Br})(\mathrm{H})(\mathrm{C} \mathrm{C12H}) \mathrm{H}$ Cl8Br $\mathrm{C}(\mathrm{C}(\mathrm{C}(\mathrm{C}(\mathrm{C}(\mathrm{C}(\mathrm{C}(\mathrm{C}(\mathrm{C}(\mathrm{C}(\mathrm{C}(\mathrm{C}(\mathrm{F})(\mathrm{F}) \mathrm{H})(\mathrm{H}) \mathrm{H})(\mathrm{H}) \mathrm{H})(\mathrm{H}) \mathrm{H})(\mathrm{H}) \mathrm{H})(\mathrm{Br}) \mathrm{H})(\mathrm{H}) \mathrm{F})(\mathrm{H}) \mathrm{F})(\mathrm{F}) \mathrm{Cl})(\mathrm{H}) \mathrm{Br})(\mathrm{H}) \mathrm{Br})(\mathrm{H})(\mathrm{H}) \mathrm{H} \mathrm{C}_{2} 2 \mathrm{H} 17 \mathrm{ClBr} 3 \mathrm{~F} 5$ $\mathrm{C}(\mathrm{C}(\mathrm{C}(\mathrm{C}(\mathrm{C}(\mathrm{C}(\mathrm{C}(\mathrm{C}(\mathrm{C}(\mathrm{C}(\mathrm{C}(\mathrm{C}(\mathrm{H})(\mathrm{H}) \mathrm{H})(\mathrm{H}) \mathrm{Br})(\mathrm{Cl}) \mathrm{H})(\mathrm{F}) \mathrm{F})(\mathrm{H}) \mathrm{F})(\mathrm{H}) \mathrm{H})(\mathrm{Br}) \mathrm{H})(\mathrm{H}) \mathrm{Br})(\mathrm{H}) \mathrm{Br})(\mathrm{H}) \mathrm{H})(\mathrm{H}) \mathrm{H})(\mathrm{H})(\mathrm{H}) \quad \mathrm{C} 12 \mathrm{H} 17 \mathrm{ClBr} 4 \mathrm{~F} 4$ $\mathrm{C}(\mathrm{C}(\mathrm{C}(\mathrm{C}(\mathrm{C}(\mathrm{C}(\mathrm{C}(\mathrm{C}(\mathrm{C}(\mathrm{C}(\mathrm{C}(\mathrm{C}(\mathrm{H})(\mathrm{F}) \mathrm{H})(\mathrm{H}) \mathrm{H})(\mathrm{H}) \mathrm{H})(\mathrm{Br}) \mathrm{Cl})(\mathrm{H}) \mathrm{F})(\mathrm{H}) \mathrm{Br})(\mathrm{H}) \mathrm{H})(\mathrm{H}) \mathrm{H})(\mathrm{H}) \mathrm{H})(\mathrm{Br}) \mathrm{Br})(\mathrm{H}) \mathrm{F})(\mathrm{H})(\mathrm{H}) \mathrm{C}_{2} \mathrm{H}_{17} \mathrm{ClBr}^{2} \mathrm{~F}^{3}$ $\mathrm{C}(\mathrm{C}(\mathrm{C}(\mathrm{C}(\mathrm{C}(\mathrm{C}(\mathrm{C}(\mathrm{C}(\mathrm{C}(\mathrm{C}(\mathrm{C}(\mathrm{C}(\mathrm{H})(\mathrm{Br}) \mathrm{H})(\mathrm{H}) \mathrm{H})(\mathrm{Br}) \mathrm{H})(\mathrm{H}) \mathrm{H})(\mathrm{H}) \mathrm{H})(\mathrm{Br}) \mathrm{Br})(\mathrm{H}) \mathrm{H})(\mathrm{H}) \mathrm{Br})(\mathrm{H}) \mathrm{H})(\mathrm{H}) \mathrm{F})(\mathrm{F}) \mathrm{H})(\mathrm{Cl}) \quad \mathrm{C} 12 \mathrm{H} 17 \mathrm{ClBr}^{2} \mathrm{~F} 2$ $\mathrm{C}(\mathrm{C}(\mathrm{C}(\mathrm{C}(\mathrm{C}(\mathrm{C}(\mathrm{C}(\mathrm{C}(\mathrm{C}(\mathrm{C}(\mathrm{C}(\mathrm{C}(\mathrm{H})(\mathrm{F}) \mathrm{H})(\mathrm{H}) \mathrm{H})(\mathrm{H}) \mathrm{H})(\mathrm{H}) \mathrm{H})(\mathrm{Br}) \mathrm{H})(\mathrm{F}) \mathrm{F})(\mathrm{H}) \mathrm{H})(\mathrm{H}) \mathrm{Br})(\mathrm{H}) \mathrm{Br})(\mathrm{H}) \mathrm{Br})(\mathrm{H}) \mathrm{H})(\mathrm{H})(\mathrm{H}) \quad \mathrm{C} 12 \mathrm{H} 18 \mathrm{Br} 4 \mathrm{~F} 4$ $\mathrm{C}(\mathrm{C}(\mathrm{C}(\mathrm{C}(\mathrm{C}(\mathrm{C}(\mathrm{C}(\mathrm{C}(\mathrm{C}(\mathrm{C}(\mathrm{C}(\mathrm{C}(\mathrm{H})(\mathrm{Br}) \mathrm{H})(\mathrm{Br}) \mathrm{H})(\mathrm{H}) \mathrm{H})(\mathrm{F}) \mathrm{H})(\mathrm{Br}) \mathrm{Br})(\mathrm{H}) \mathrm{H})(\mathrm{H}) \mathrm{Br})(\mathrm{H}) \mathrm{H})(\mathrm{H}) \mathrm{H})(\mathrm{H}) \mathrm{F})(\mathrm{F}) \mathrm{H})(\mathrm{H})(\mathrm{H}) \quad \mathrm{C} 12 \mathrm{H} 18 \mathrm{Br} 5 \mathrm{~F} 3$ $\mathrm{C}(\mathrm{C}(\mathrm{C}(\mathrm{C}(\mathrm{C}(\mathrm{C}(\mathrm{C}(\mathrm{C}(\mathrm{C}(\mathrm{C}(\mathrm{C}(\mathrm{C}(\mathrm{H})(\mathrm{F}) \mathrm{H})(\mathrm{H}) \mathrm{H})(\mathrm{H}) \mathrm{Br})(\mathrm{Br}) \mathrm{H})(\mathrm{H}) \mathrm{Br})(\mathrm{H}) \mathrm{Br})(\mathrm{H}) \mathrm{H})(\mathrm{H}) \mathrm{Br})(\mathrm{F}) \mathrm{H})(\mathrm{H}) \mathrm{H})(\mathrm{H}) \mathrm{Br})(\mathrm{H}) \quad \mathrm{C} 12 \mathrm{H} 18 \mathrm{Br} 6 \mathrm{~F} 2$ $\mathrm{C}(\mathrm{C}(\mathrm{C}(\mathrm{C}(\mathrm{C}(\mathrm{C}(\mathrm{C}(\mathrm{C}(\mathrm{C}(\mathrm{C}(\mathrm{C}(\mathrm{C}(\mathrm{Br})(\mathrm{H}) \mathrm{H})(\mathrm{H}) \mathrm{H})(\mathrm{Br}) \mathrm{H})(\mathrm{Cl}) \mathrm{H})(\mathrm{F}) \mathrm{Br})(\mathrm{H}) \mathrm{H})(\mathrm{H}) \mathrm{H})(\mathrm{F}) \mathrm{H})(\mathrm{H}) \mathrm{H})(\mathrm{H}) \mathrm{F})(\mathrm{H}) \mathrm{H})(\mathrm{Cl})(\mathrm{H}) \mathrm{C} 12 \mathrm{H} 18 \mathrm{Cl} 2 \mathrm{Br} 3 \mathrm{~F} 3$ $\mathrm{C}(\mathrm{C}(\mathrm{C}(\mathrm{C}(\mathrm{C}(\mathrm{C}(\mathrm{C}(\mathrm{C}(\mathrm{C}(\mathrm{C}(\mathrm{C}(\mathrm{C}(\mathrm{H})(\mathrm{H}) \mathrm{H})(\mathrm{H}) \mathrm{H})(\mathrm{Br}) \mathrm{F})(\mathrm{H}) \mathrm{Br})(\mathrm{Cl}) \mathrm{H})(\mathrm{H}) \mathrm{H})(\mathrm{Br}) \mathrm{H})(\mathrm{H}) \mathrm{H})(\mathrm{Br}) \mathrm{H})(\mathrm{H}) \mathrm{H})(\mathrm{F}) \mathrm{H})(\mathrm{H}) \quad \mathrm{C} 12 \mathrm{H} 18 \mathrm{Cl} 2 \mathrm{Br} 4 \mathrm{~F} 2$ $\mathrm{C}(\mathrm{C}(\mathrm{C}(\mathrm{C}(\mathrm{C}(\mathrm{C}(\mathrm{C}(\mathrm{C}(\mathrm{C}(\mathrm{C}(\mathrm{C}(\mathrm{C}(\mathrm{H})(\mathrm{Cl}) \mathrm{Br})(\mathrm{H}) \mathrm{F})(\mathrm{Br}) \mathrm{H})(\mathrm{H}) \mathrm{H})(\mathrm{H}) \mathrm{H})(\mathrm{H}) \mathrm{H})(\mathrm{H}) \mathrm{H})(\mathrm{H}) \mathrm{H})(\mathrm{Br}) \mathrm{H})(\mathrm{H}) \mathrm{H})(\mathrm{Br}) \mathrm{H})(\mathrm{H}) \quad \mathrm{C} 12 \mathrm{H} 18 \mathrm{Cl} 2 \mathrm{Br} 5 \mathrm{~F}$ $\mathrm{C}(\mathrm{C}(\mathrm{C}(\mathrm{C}(\mathrm{C}(\mathrm{C}(\mathrm{C}(\mathrm{C}(\mathrm{C}(\mathrm{C}(\mathrm{C}(\mathrm{C}(\mathrm{H})(\mathrm{H}) \mathrm{H})(\mathrm{H}) \mathrm{H})(\mathrm{H}) \mathrm{Cl})(\mathrm{H}) \mathrm{H})(\mathrm{F}) \mathrm{H})(\mathrm{H}) \mathrm{H})(\mathrm{H}) \mathrm{F})(\mathrm{H}) \mathrm{Br})(\mathrm{H}) \mathrm{Cl})(\mathrm{H}) \mathrm{Br})(\mathrm{F}) \mathrm{H})(\mathrm{H})(\mathrm{H}) \mathrm{C} \mathrm{Cl}_{2} \mathrm{H} 18 \mathrm{Cl} 3 \mathrm{Br} 2 \mathrm{~F} 3$ $\mathrm{C}(\mathrm{C}(\mathrm{C}(\mathrm{C}(\mathrm{C}(\mathrm{C}(\mathrm{C}(\mathrm{C}(\mathrm{C}(\mathrm{C}(\mathrm{C}(\mathrm{C}(\mathrm{Cl})(\mathrm{H}) \mathrm{H})(\mathrm{H}) \mathrm{H})(\mathrm{H}) \mathrm{H})(\mathrm{H}) \mathrm{H})(\mathrm{H}) \mathrm{Br})(\mathrm{Br}) \mathrm{H})(\mathrm{Cl}) \mathrm{Br})(\mathrm{H}) \mathrm{H})(\mathrm{H}) \mathrm{F})(\mathrm{H}) \mathrm{F})(\mathrm{H}) \mathrm{H})(\mathrm{Cl})(\mathrm{H}) \mathrm{C} 12 \mathrm{H} 18 \mathrm{Cl} 3 \mathrm{Br} 3 \mathrm{~F} 2$ $\mathrm{C}(\mathrm{C}(\mathrm{C}(\mathrm{C}(\mathrm{C}(\mathrm{C}(\mathrm{C}(\mathrm{C}(\mathrm{C}(\mathrm{C}(\mathrm{C}(\mathrm{C}(\mathrm{Br})(\mathrm{H}) \mathrm{H})(\mathrm{H}) \mathrm{H})(\mathrm{H}) \mathrm{H})(\mathrm{H}) \mathrm{H})(\mathrm{H}) \mathrm{Br})(\mathrm{Cl}) \mathrm{H})(\mathrm{Br}) \mathrm{Cl})(\mathrm{H}) \mathrm{H})(\mathrm{H}) \mathrm{F})(\mathrm{Br}) \mathrm{H})(\mathrm{Cl}) \mathrm{H})(\mathrm{H})(\mathrm{C} 12 \mathrm{H} 18 \mathrm{Cl} 3 \mathrm{Br} 4 \mathrm{~F}$ $\mathrm{C}(\mathrm{C}(\mathrm{C}(\mathrm{C}(\mathrm{C}(\mathrm{C}(\mathrm{C}(\mathrm{C}(\mathrm{C}(\mathrm{C}(\mathrm{C}(\mathrm{C}(\mathrm{H})(\mathrm{H}) \mathrm{H})(\mathrm{H}) \mathrm{H})(\mathrm{Cl}) \mathrm{H})(\mathrm{H}) \mathrm{H})(\mathrm{H}) \mathrm{Br})(\mathrm{H}) \mathrm{H})(\mathrm{H}) \mathrm{Br})(\mathrm{Br}) \mathrm{H})(\mathrm{Br}) \mathrm{H})(\mathrm{Cl}) \mathrm{H})(\mathrm{Cl}) \mathrm{H})(\mathrm{H})(\mathrm{C} 12 \mathrm{H} 18 \mathrm{Cl} 3 \mathrm{Br} 5$ $\mathrm{C}(\mathrm{C}(\mathrm{C}(\mathrm{C}(\mathrm{C}(\mathrm{C}(\mathrm{C}(\mathrm{C}(\mathrm{C}(\mathrm{C}(\mathrm{C}(\mathrm{C}(\mathrm{H})(\mathrm{Br}) \mathrm{H})(\mathrm{H}) \mathrm{H})(\mathrm{F}) \mathrm{H})(\mathrm{H}) \mathrm{H})(\mathrm{H}) \mathrm{H})(\mathrm{H}) \mathrm{H})(\mathrm{H}) \mathrm{H})(\mathrm{H}) \mathrm{Br})(\mathrm{Cl}) \mathrm{Cl})(\mathrm{Cl}) \mathrm{H})(\mathrm{F}) \mathrm{H})(\mathrm{H})(\mathrm{H}) \quad \mathrm{C} 12 \mathrm{H} 18 \mathrm{Cl} 4 \mathrm{Br} 2 \mathrm{~F} 2$ $\mathrm{C}(\mathrm{C}(\mathrm{C}(\mathrm{C}(\mathrm{C}(\mathrm{C}(\mathrm{C}(\mathrm{C}(\mathrm{C}(\mathrm{C}(\mathrm{C}(\mathrm{C}(\mathrm{Br})(\mathrm{H}) \mathrm{H})(\mathrm{H}) \mathrm{Br})(\mathrm{H}) \mathrm{H})(\mathrm{H}) \mathrm{H})(\mathrm{H}) \mathrm{Cl})(\mathrm{H}) \mathrm{H})(\mathrm{Br}) \mathrm{H})(\mathrm{Cl}) \mathrm{H})(\mathrm{Cl}) \mathrm{H})(\mathrm{H}) \mathrm{H})(\mathrm{H}) \mathrm{Cl})(\mathrm{H})\left(\mathrm{Cl}_{2} \mathrm{H} 18 \mathrm{Cl} 4 \mathrm{Br} 3 \mathrm{~F}\right.$ $\mathrm{C}(\mathrm{C}(\mathrm{C}(\mathrm{C}(\mathrm{C}(\mathrm{C}(\mathrm{C}(\mathrm{C}(\mathrm{C}(\mathrm{C}(\mathrm{C}(\mathrm{C}(\mathrm{H})(\mathrm{H}) \mathrm{Cl})(\mathrm{H}) \mathrm{H})(\mathrm{H}) \mathrm{H})(\mathrm{H}) \mathrm{F})(\mathrm{Br}) \mathrm{F})(\mathrm{H}) \mathrm{H})(\mathrm{H}) \mathrm{H})(\mathrm{Cl}) \mathrm{F})(\mathrm{H}) \mathrm{Cl})(\mathrm{H}) \mathrm{H})(\mathrm{H}) \mathrm{Cl})(\mathrm{H})(\mathrm{H}) \quad \mathrm{C} 12 \mathrm{H} 18 \mathrm{Cl} 4 \mathrm{BrF} 3$ $\mathrm{C}(\mathrm{C}(\mathrm{C}(\mathrm{C}(\mathrm{C}(\mathrm{C}(\mathrm{C}(\mathrm{C}(\mathrm{C}(\mathrm{C}(\mathrm{C}(\mathrm{C}(\mathrm{Cl})(\mathrm{Cl}) \mathrm{Cl})(\mathrm{H}) \mathrm{F})(\mathrm{H}) \mathrm{Br})(\mathrm{H}) \mathrm{H})(\mathrm{H}) \mathrm{H})(\mathrm{H}) \mathrm{H})(\mathrm{H}) \mathrm{H})(\mathrm{H}) \mathrm{Cl})(\mathrm{Br}) \mathrm{H})(\mathrm{H}) \mathrm{H})(\mathrm{H}) \mathrm{Cl})(\mathrm{H}) \quad \mathrm{C} 12 \mathrm{H} 18 \mathrm{Cl} / \mathrm{Br} 2 \mathrm{~F}$ $\mathrm{C}(\mathrm{C}(\mathrm{C}(\mathrm{C}(\mathrm{C}(\mathrm{C}(\mathrm{C}(\mathrm{C}(\mathrm{C}(\mathrm{C}(\mathrm{C}(\mathrm{C}(\mathrm{Cl})(\mathrm{Cl}) \mathrm{Br})(\mathrm{H}) \mathrm{H})(\mathrm{H}) \mathrm{H})(\mathrm{H}) \mathrm{H})(\mathrm{H}) \mathrm{Cl})(\mathrm{H}) \mathrm{F})(\mathrm{F}) \mathrm{H})(\mathrm{H}) \mathrm{H})(\mathrm{H}) \mathrm{H})(\mathrm{Cl}) \mathrm{H})(\mathrm{H}) \mathrm{H})(\mathrm{Cl})(\mathrm{H}) \mathrm{C}_{2} \mathrm{H} 18 \mathrm{Cl} 15 \mathrm{BrF} 2$ $\mathrm{C}(\mathrm{C}(\mathrm{C}(\mathrm{C}(\mathrm{C}(\mathrm{C}(\mathrm{C}(\mathrm{C}(\mathrm{C}(\mathrm{C}(\mathrm{C}(\mathrm{C}(\mathrm{H})(\mathrm{H}) \mathrm{H})(\mathrm{H}) \mathrm{H})(\mathrm{H}) \mathrm{H})(\mathrm{Cl}) \mathrm{H})(\mathrm{Cl}) \mathrm{H})(\mathrm{Cl}) \mathrm{Br})(\mathrm{H}) \mathrm{Cl})(\mathrm{H}) \mathrm{H})(\mathrm{H}) \mathrm{Cl})(\mathrm{H}) \mathrm{Br})(\mathrm{H}) \mathrm{Cl})(\mathrm{H})(\mathrm{C} 12 \mathrm{H} 18 \mathrm{Cl} 6 \mathrm{Br} 2$ $\mathrm{C}(\mathrm{C}(\mathrm{C}(\mathrm{C}(\mathrm{C}(\mathrm{C}(\mathrm{C}(\mathrm{C}(\mathrm{C}(\mathrm{C}(\mathrm{C}(\mathrm{C}(\mathrm{H})(\mathrm{H}) \mathrm{Cl})(\mathrm{Cl}) \mathrm{H})(\mathrm{Cl}) \mathrm{H})(\mathrm{Br}) \mathrm{H})(\mathrm{Cl}) \mathrm{H})(\mathrm{H}) \mathrm{H})(\mathrm{H}) \mathrm{H})(\mathrm{H}) \mathrm{H})(\mathrm{Cl}) \mathrm{H})(\mathrm{H}) \mathrm{H})(\mathrm{H}) \mathrm{F})(\mathrm{H}) \quad \mathrm{C} 12 \mathrm{H} 18 \mathrm{Cl} 6 \mathrm{BrF}$ $\mathrm{C}(\mathrm{C}(\mathrm{C}(\mathrm{C}(\mathrm{C}(\mathrm{C}(\mathrm{C}(\mathrm{C}(\mathrm{C}(\mathrm{C}(\mathrm{C}(\mathrm{C}(\mathrm{H})(\mathrm{H}) \mathrm{H})(\mathrm{H}) \mathrm{Cl})(\mathrm{H}) \mathrm{Cl})(\mathrm{H}) \mathrm{H})(\mathrm{H}) \mathrm{F})(\mathrm{H}) \mathrm{Cl})(\mathrm{H}) \mathrm{H})(\mathrm{Cl}) \mathrm{Cl})(\mathrm{H}) \mathrm{H})(\mathrm{H}) \mathrm{H})(\mathrm{F}) \mathrm{H})(\mathrm{Cl})(\mathrm{H}) \mathrm{C}_{2} \mathrm{H}_{18} \mathrm{Cl}_{6} \mathrm{~F} 2$ $\mathrm{C}(\mathrm{C}(\mathrm{C}(\mathrm{C}(\mathrm{C}(\mathrm{C}(\mathrm{C}(\mathrm{C}(\mathrm{C}(\mathrm{C}(\mathrm{C}(\mathrm{C}(\mathrm{H})(\mathrm{Cl}) \mathrm{H})(\mathrm{Cl}) \mathrm{H})(\mathrm{Cl}) \mathrm{Br})(\mathrm{H}) \mathrm{H})(\mathrm{Cl}) \mathrm{H})(\mathrm{H}) \mathrm{H})(\mathrm{H}) \mathrm{H})(\mathrm{H}) \mathrm{Cl})(\mathrm{H}) \mathrm{Cl})(\mathrm{H}) \mathrm{H})(\mathrm{H}) \mathrm{H})(\mathrm{H})(\mathrm{C} \mathrm{C} 12 \mathrm{H} 18 \mathrm{Cl} 1 \mathrm{~B}$ $\mathrm{C}(\mathrm{C}(\mathrm{C}(\mathrm{C}(\mathrm{C}(\mathrm{C}(\mathrm{C}(\mathrm{C}(\mathrm{C}(\mathrm{C}(\mathrm{C}(\mathrm{C}(\mathrm{H})(\mathrm{H}) \mathrm{H})(\mathrm{H}) \mathrm{Cl})(\mathrm{H}) \mathrm{Cl})(\mathrm{H}) \mathrm{Cl})(\mathrm{H}) \mathrm{H})(\mathrm{H}) \mathrm{H})(\mathrm{H}) \mathrm{H})(\mathrm{H}) \mathrm{H})(\mathrm{Cl}) \mathrm{Cl})(\mathrm{Cl}) \mathrm{Cl})(\mathrm{H}) \mathrm{F})(\mathrm{H}) \quad \mathrm{C} 12 \mathrm{H} 18 \mathrm{Cl} / \mathrm{F}$ $\mathrm{C}(\mathrm{C}(\mathrm{C}(\mathrm{C}(\mathrm{C}(\mathrm{C}(\mathrm{C}(\mathrm{C}(\mathrm{C}(\mathrm{C}(\mathrm{C}(\mathrm{C}(\mathrm{H})(\mathrm{H}) \mathrm{H})(\mathrm{F}) \mathrm{H})(\mathrm{H}) \mathrm{H})(\mathrm{Br}) \mathrm{Br})(\mathrm{H}) \mathrm{H})(\mathrm{H}) \mathrm{H})(\mathrm{H}) \mathrm{H})(\mathrm{Br}) \mathrm{H})(\mathrm{H}) \mathrm{H})(\mathrm{H}) \mathrm{F})(\mathrm{F}) \mathrm{H})(\mathrm{Cl})(\mathrm{H}) \mathrm{F}$ C12H18ClBr3F4 $\mathrm{C}(\mathrm{C}(\mathrm{C}(\mathrm{C}(\mathrm{C}(\mathrm{C}(\mathrm{C}(\mathrm{C}(\mathrm{C}(\mathrm{C}(\mathrm{C}(\mathrm{C}(\mathrm{H})(\mathrm{H}) \mathrm{Br})(\mathrm{Br}) \mathrm{H})(\mathrm{H}) \mathrm{Br})(\mathrm{H}) \mathrm{H})(\mathrm{H}) \mathrm{H})(\mathrm{H}) \mathrm{F})(\mathrm{H}) \mathrm{F})(\mathrm{H}) \mathrm{H})(\mathrm{H}) \mathrm{Cl})(\mathrm{Br}) \mathrm{F})(\mathrm{H}) \mathrm{H})(\mathrm{H})(\mathrm{H}) \quad \mathrm{C} 12 \mathrm{H} 18 \mathrm{ClBr} 4 \mathrm{~F} 3$ $\mathrm{C}(\mathrm{C}(\mathrm{C}(\mathrm{C}(\mathrm{C}(\mathrm{C}(\mathrm{C}(\mathrm{C}(\mathrm{C}(\mathrm{C}(\mathrm{C}(\mathrm{C}(\mathrm{H})(\mathrm{Br}) \mathrm{Br})(\mathrm{F}) \mathrm{H})(\mathrm{H}) \mathrm{H})(\mathrm{H}) \mathrm{Br})(\mathrm{H}) \mathrm{H})(\mathrm{F}) \mathrm{Cl})(\mathrm{H}) \mathrm{H})(\mathrm{H}) \mathrm{H})(\mathrm{H}) \mathrm{H})(\mathrm{H}) \mathrm{H})(\mathrm{Br}) \mathrm{H})(\mathrm{Br}) \quad \mathrm{C} 12 \mathrm{H} 18 \mathrm{ClBr} 5 \mathrm{~F} 2$ $\mathrm{C}(\mathrm{C}(\mathrm{C}(\mathrm{C}(\mathrm{C}(\mathrm{C}(\mathrm{C}(\mathrm{C}(\mathrm{C}(\mathrm{C}(\mathrm{C}(\mathrm{C}(\mathrm{F})(\mathrm{H}) \mathrm{H})(\mathrm{H}) \mathrm{H})(\mathrm{H}) \mathrm{H})(\mathrm{H}) \mathrm{Br})(\mathrm{H}) \mathrm{F})(\mathrm{H}) \mathrm{F})(\mathrm{H}) \mathrm{Br})(\mathrm{H}) \mathrm{H})(\mathrm{H}) \mathrm{H})(\mathrm{H}) \mathrm{H})(\mathrm{Br}) \mathrm{H})(\mathrm{Br})(\mathrm{H}) \quad \mathrm{C} 12 \mathrm{H} 19 \mathrm{Br} 4 \mathrm{~F} 3$ $\mathrm{C}(\mathrm{C}(\mathrm{C}(\mathrm{C}(\mathrm{C}(\mathrm{C}(\mathrm{C}(\mathrm{C}(\mathrm{C}(\mathrm{C}(\mathrm{C}(\mathrm{C}(\mathrm{H})(\mathrm{H}) \mathrm{F})(\mathrm{H}) \mathrm{Br})(\mathrm{F}) \mathrm{H})(\mathrm{H}) \mathrm{H})(\mathrm{H}) \mathrm{H})(\mathrm{H}) \mathrm{H})(\mathrm{H}) \mathrm{H})(\mathrm{H}) \mathrm{Br})(\mathrm{H}) \mathrm{Br})(\mathrm{H}) \mathrm{H})(\mathrm{H}) \mathrm{H})(\mathrm{Br})(\mathrm{H}) \quad \mathrm{C} 12 \mathrm{H} 19 \mathrm{Br} 5 \mathrm{~F} 2$
lgKoa lgKow lgKaw lgKow lgKoa lgKaw lgKow lgKoa lgKaw _EPI_EPI_EPI_Exp__Exp__Exp__DFT_DFT_DFT Suite Suite Suite corr corr corr corr corr corr $\begin{array}{lllllllllll}10.3 & 8 & -2.31 & 7.01 & 9.32 & -2.31 & 6.91 & 16.94 & -10.04\end{array}$ $\begin{array}{lllllllll}11.2 & 8.79 & -2.40 & 8.19 & 10.59 & -2.40 & 7.51 & 18.57 & -11.05\end{array}$ $\begin{array}{lllllllll}8.26 & 8.16 & -0.10 & 7.25 & 7.35 & -0.10 & 7.03 & 13.18 & -6.15\end{array}$ $\begin{array}{llllllllll}9.98 & 8.64 & -1.34 & 7.97 & 9.31 & -1.34 & 7.40 & 16.34 & -8.94\end{array}$ $\begin{array}{rrrrrrrrr}9.98 & 8.64 & -1.34 & 7.97 & 9.31 & -1.34 & 7.40 & 16.34 & -8.94 \\ 11.5 & 8.97 & -2.57 & 8.46 & 11.03 & -2.57 & 7.65 & 19.21 & -11.56\end{array}$ $\begin{array}{rrrrrrrrrr}11.5 & 8.97 & -2.57 & 8.46 & 11.03 & -2.57 & 7.65 & 19.21 & -11.56 \\ 11 & 8.95 & -2.09 & 8.43 & 10.52 & -2.09 & 7.64 & 18.28 & -10.65\end{array}$ $\begin{array}{lllllllll}11.9 & 8.62 & -3.32 & 7.94 & 11.26 & -3.32 & 7.38 & 19.95 & -12.57\end{array}$ $\begin{array}{llllllllll}8.4 & 7.29 & -1.11 & 5.96 & 7.07 & -1.11 & 6.36 & 13.45 & -7.09\end{array}$ $\begin{array}{rrrrrrrrr}8.25 & 8.37 & 0.12 & 7.57 & 7.45 & 0.12 & 7.19 & 13.16 & -5.97\end{array}$ $\begin{array}{rrrrrrrrr}8.25 & 8.37 & 0.12 & 7.57 & 7.45 & 0.12 & 7.19 & 13.16 & -5.97 \\ 10.2 & 8.35 & -1.87 & 7.54 & 9.40 & -1.87 & 7.18 & 16.78 & -9.60\end{array}$ $\begin{array}{llllllllll}7.83 & 7.2 & -0.63 & 5.82 & 6.45 & -0.63 & 6.29 & 12.40 & -6.10\end{array}$ $\begin{array}{lllllllll}11.3 & 8.66 & -2.62 & 8.00 & 10.62 & -2.62 & 7.41 & 18.73 & -11.32\end{array}$ $\begin{array}{llllllllll}9.64 & 8.26 & -1.38 & 7.40 & 8.78 & -1.38 & 7.11 & 15.72 & -8.61\end{array}$ $\begin{array}{lllllllll}8.75 & 8.6 & -0.15 & 7.91 & 8.06 & -0.15 & 7.37 & 14.08 & -6.7\end{array}$ $\begin{array}{llllllllll}9.07 & 8.17 & -0.90 & 7.27 & 8.17 & -0.90 & 7.04 & 14.67 & -7.63\end{array}$ $\begin{array}{llllllllll}10.1 & 8.48 & -1.65 & 7.73 & 9.38 & -1.65 & 7.28 & 16.62 & -9.34\end{array}$ $\begin{array}{llllllllll}8.83 & 8.25 & -0.58 & 7.39 & 7.97 & -0.58 & 7.10 & 14.24 & -7.14\end{array}$ $\begin{array}{lllllllll}10.5 & 8.73 & -1.82 & 8.10 & 9.92 & -1.82 & 7.47 & 17.39 & -9.92\end{array}$ $\begin{array}{lllllllll}9.85 & 8.48 & -1.37 & 7.73 & 9.10 & -1.37 & 7.28 & 16.10 & -8.83\end{array}$ $\begin{array}{llllllllll}10.8 & 8.21 & -2.60 & 7.33 & 9.93 & -2.60 & 7.07 & 17.88 & -10.81\end{array}$ $\begin{array}{llllllllll}8.77 & 8.37 & -0.40 & 7.57 & 7.96 & -0.40 & 7.19 & 14.11 & -6.92\end{array}$ $\begin{array}{lllllllll}11.3 & 8.43 & -2.87 & 7.66 & 10.53 & -2.87 & 7.24 & 18.77 & -11.53\end{array}$ $\begin{array}{lllllllll}7.45 & 7.54 & 0.09 & 6.33 & 6.24 & 0.09 & 6.55 & 11.70 & -5.14\end{array}$ $\begin{array}{lllllllll}8.28 & 7.13 & -1.15 & 5.72 & 6.86 & -1.15 & 6.24 & 13.22 & -6.98\end{array}$ $\begin{array}{llllllllll}11.6 & 8.01 & -3.62 & 7.03 & 10.65 & -3.62 & 6.91 & 19.38 & -12.46\end{array}$ $\begin{array}{llllllllll}8.51 & 7.85 & -0.66 & 6.79 & 7.45 & -0.66 & 6.79 & 13.65 & -6.86\end{array}$ $\begin{array}{lllllllll}10.2 & 8.26 & -1.90 & 7.40 & 9.30 & -1.90 & 7.11 & 16.67 & -9.57\end{array}$ $\begin{array}{lllllllll}11.2 & 8.57 & -2.65 & 7.87 & 10.52 & -2.65 & 7.34 & 18.62 & -11.28\end{array}$ $\begin{array}{rrrrrrrrr}11.2 & 8.57 & -2.65 & 7.87 & 10.52 & -2.65 & 7.34 & 18.62 & -11.28 \\ 7.94 & 7.76 & -0.18 & 6.66 & 6.83 & -0.18 & 6.72 & 12.59 & -5.87\end{array}$ $\begin{array}{lllllllll}10.6 & 8.41 & -2.17 & 7.63 & 9.79 & -2.17 & 7.22 & 17.44 & -10.22\end{array}$ $\begin{array}{lllllllll}9.67 & 8.74 & -0.93 & 8.12 & 9.05 & -0.93 & 7.47 & 15.77 & -8.30\end{array}$ $\begin{array}{llllllllll}7.61 & 7.17 & -0.44 & 5.78 & 6.22 & -0.44 & 6.27 & 12.00 & -5.73\end{array}$ $\begin{array}{llllllllll}9.5 & 8.3 & -1.20 & 7.46 & 8.66 & -1.20 & 7.14 & 15.45 & -8.32\end{array}$ $\begin{array}{rrrrrrrrr}9.5 & 8.3 & -1.20 & 7.46 & 8.66 & -1.20 & 7.14 & 15.45 & -8.32 \\ 10.2 & 8.12 & -2.12 & 7.19 & 9.31 & -2.12 & 7.00 & 16.82 & -9.82\end{array}$ $\begin{array}{llllllllll}11.9 & 8.52 & -3.36 & 7.79 & 11.15 & -3.36 & 7.31 & 19.83 & -12.52\end{array}$ $\begin{array}{lllllllll}7.97 & 7.54 & -0.43 & 6.33 & 6.76 & -0.43 & 6.55 & 12.65 & -6.10\end{array}$ $\begin{array}{lllllllll}8.86 & 7.2 & -1.66 & 5.82 & 7.49 & -1.66 & 6.29 & 14.30 & -8.00\end{array}$ $\begin{array}{lllllllll}11.2 & 8.34 & -2.90 & 7.52 & 10.42 & -2.90 & 7.17 & 18.66 & -11.49\end{array}$ $\begin{array}{rrrrrrrrr}9.12 & 8.43 & -0.69 & 7.66 & 8.35 & -0.69 & 7.24 & 14.77 & -7.54\end{array}$ $\begin{array}{lllllllll}9.12 & 8.43 & -0.69 & 7.66 & 8.35 & -0.69 & 7.24 & 14.77 & -7.54 \\ 9.35 & 7.42 & -1.93 & 6.15 & 8.08 & -1.93 & 6.46 & 15.19 & -8.73\end{array}$ $\begin{array}{lllllllll}11.7 & 8.49 & -3.17 & 7.75 & 10.91 & -3.17 & 7.28 & 19.43 & -12.14\end{array}$ $\begin{array}{llllllllll}7.74 & 7.53 & -0.21 & 6.31 & 6.52 & -0.21 & 6.55 & 12.23 & -5.68\end{array}$ $\begin{array}{rrrrrrrrr}9.45 & 8 & -1.45 & 7.01 & 8.46 & -1.45 & 6.91 & 15.36 & -8.46\end{array}$ $\begin{array}{llllllllll}9.69 & 8.73 & -0.96 & 8.10 & 9.06 & -0.96 & 7.47 & 15.81 & -8.34\end{array}$ $\begin{array}{lllllllll}10.5 & 8.32 & -2.20 & 7.49 & 9.69 & -2.20 & 7.15 & 17.33 & -10.18\end{array}$ $\begin{array}{lllllllll}12.2 & 8.72 & -3.44 & 8.09 & 11.52 & -3.44 & 7.46 & 20.34 & -12.88\end{array}$ $\begin{array}{llllllllll}10 & 8.3 & -1.71 & 7.46 & 9.18 & -1.71 & 7.14 & 16.41 & -9.27\end{array}$ $\begin{array}{lllllllll}12.5 & 8.36 & -4.19 & 7.55 & 11.74 & -4.19 & 7.18 & 21.06 & -13.88\end{array}$ $\begin{array}{llllllllll}9.12 & 8.64 & -0.48 & 7.97 & 8.45 & -0.48 & 7.40 & 14.76 & -7.36\end{array}$ $\begin{array}{lllllllll}10.3 & 7.87 & -2.46 & 6.82 & 9.29 & -2.46 & 6.81 & 17.00 & -10.19\end{array}$ $\begin{array}{lllllllll}10.1 & 8.88 & -1.23 & 8.33 & 9.56 & -1.23 & 7.58 & 16.58 & -9.00\end{array}$ $\begin{array}{llllllllll}7.72 & 7.73 & 0.01 & 6.61 & 6.60 & 0.01 & 6.70 & 12.20 & -5.50\end{array}$ $\begin{array}{lllll}11.4 & 8.19 & -3.22 & 7.30\end{array}$ $\begin{array}{llllllllll}11.4 & 8.19 & -3.22 & 7.30 & 10.51 & -3.22 & 7.05 & 18.96 & -11.91 \\ 10.4 & 8.45 & -1.98 & 7.69 & 9.67 & -1.98 & 7.25 & 17.17 & -9.92\end{array}$ $\begin{array}{llllllllll}10.4 & 8.45 & -1.98 & 7.69 & 9.67 & -1.98 & 7.25 & 17.17 & -9.92 \\ 8.86 & 8.12 & -0.74 & 7.19 & 7.94 & -0.74 & 7.00 & 14.29 & -7.29\end{array}$ $\begin{array}{rrrrrrrrr}11.5 & 8.76 & -2.73 & 8.15 & 10.88 & -2.73 & 7.49 & 19.12 & -11.63\end{array}$ $\begin{array}{llllllllll}7.32 & 7.38 & 0.06 & 6.09 & 6.03 & 0.06 & 6.43 & 11.46 & -5.03\end{array}$ $\begin{array}{rrrrrrrrr}8.96 & 7.78 & -1.18 & 6.69 & 7.87 & -1.18 & 6.74 & 14.47 & -7.73\end{array}$ $\begin{array}{rrrrrrrrr}8.96 & 7.78 & -1.18 & 6.69 & 7.87 & -1.18 & 6.74 & 14.47 & -7.73 \\ 11.4 & 8.99 & -2.42 & 8.49 & 10.91 & -2.42 & 7.67 & 18.96 & -11.30\end{array}$ $\begin{array}{llllllllll}11.4 & 8.99 & -2.42 & 8.49 & 10.91 & -2.42 & 7.67 & 18.96 & -11.30 \\ 12.3 & 8.66 & -3.65 & 8.00 & 11.65 & -3.65 & 7.41 & 20.63 & -13.22\end{array}$ $\begin{array}{lllllllll}8.4 & 7.67 & -0.73 & 6.52 & 7.25 & -0.73 & 6.65 & 13.44 & -6.78\end{array}$ $\begin{array}{llllllllll}9.96 & 8 & -1.96 & 7.01 & 8.98 & -1.96 & 6.91 & 16.32 & -9.41\end{array}$ $\begin{array}{llllllllll}10.9 & -7.66 & -3.20 & 6.51 & 9.71 & -3.20 & 6.65 & 17.96 & -9.41\end{array}$ $\begin{array}{llllllllll}10.9 & 7.66 & -3.20 & 6.51 & 9.71 & -3.20 & 6.65 & 17.96 & -11.32 \\ 8.88 & 7.89 & -0.99 & 6.85 & 7.84 & -0.99 & 6.82 & 14.33 & -7.51\end{array}$ $\begin{array}{rrrrrrrrrr}8.88 & 7.89 & -0.99 & 6.85 & 7.84 & -0.99 & 6.82 & 14.33 & -7.51 \\ 10.5 & 8.22 & -2.23 & 7.34 & 9.57 & -2.23 & 7.08 & 17.21 & -10.13 \\ 11.4 & 7.96 & -3.47 & 6.96 & 10.42 & -3.47 & 6.88 & 19.00 & -12.13\end{array}$ $\begin{array}{lllllllll}11.4 & 7.96 & -3.47 & 6.96 & 10.42 & -3.47 & 6.88 & 19.00 & -12.13\end{array}$ $\begin{array}{lllllllll}7.5 & 6.99 & -0.51 & 5.51 & 6.02 & -0.51 & 6.13 & 11.79 & -5.66\end{array}$ $\begin{array}{lllllllll}9.96 & 8.21 & -1.75 & 7.33 & 9.07 & -1.75 & 7.07 & 16.30 & -9.23\end{array}$ $\begin{array}{lllllllll}11.5 & 8.54 & -2.98 & 7.82 & 10.80 & -2.98 & 7.32 & 19.18 & -11.86\end{array}$ $\begin{array}{lllllllll}12.4 & 8.2 & -4.22 & 7.31 & 11.53 & -4.22 & 7.06 & 20.82 & -13.76\end{array}$ $\begin{array}{llllllllll}9.38 & 8.12 & -1.26 & 7.19 & 8.45 & -1.26 & 7.00 & 15.24 & -8.24\end{array}$ $\begin{array}{lllllllll}10.3 & 7.78 & -2.50 & 6.69 & 9.18 & -2.50 & 6.74 & 16.89 & -10.15\end{array}$ $\begin{array}{lllllllll}8.4 & 8.38 & -0.02 & 7.58 & 7.61 & -0.02 & 7.20 & 13.45 & -6.25\end{array}$ $\begin{array}{lllllllll}10.4 & 8.36 & -2.01 & 7.55 & 9.56 & -2.01 & 7.18 & 17.07 & -9.88\end{array}$ $\begin{array}{llllllllll}8.81 & 8.03 & -0.77 & 7.06 & 7.83 & -0.77 & 6.93 & 14.19 & -7.26\end{array}$ $\begin{array}{llllllllll}11.4 & 8.6 & -2.76 & 7.91 & 10.67 & -2.76 & 7.37 & 18.89 & -11.52\end{array}$ $\begin{array}{llllllllll}9.13 & 7.6 & -1.53 & 6.42 & 7.94 & -1.53 & 6.60 & 14.78 & -8.18\end{array}$ $\begin{array}{rrrrrrrrr}9.13 & 7.6 & -1.53 & 6.42 & 7.94 & -1.53 & 6.60 & 14.78 & -8.18 \\ 8.16 & 7.87 & -0.29 & 6.82 & 7.11 & -0.29 & 6.81 & 13.00 & -6.19\end{array}$ $\begin{array}{rrrrrrrrr}8.16 & 7.87 & -0.29 & 6.82 & 7.11 & -0.29 & 6.81 & 13.00 & -6.19 \\ 10.9 & 8.66 & -2.28 & 8.00 & 10.28 & -2.28 & 7.41 & 18.10 & -10.69\end{array}$ $\begin{array}{lllllllll}9.89 & 8.85 & -1.04 & 8.28 & 9.32 & -1.04 & 7.56 & 16.18 & -8.62\end{array}$ $\begin{array}{llllllllll}7.75 & 7.51 & -0.24 & 6.28 & 6.53 & -0.24 & 6.53 & 12.25 & -5.72\end{array}$ $\begin{array}{lllllllll}9.39 & 7.91 & -1.48 & 6.88 & 8.36 & -1.48 & 6.84 & 15.26 & -8.42\end{array}$ $\begin{array}{rrrrrrrrr}11.1 & 8.39 & -2.72 & 7.60 & 10.31 & -2.72 & 7.21 & 18.41 & -11.21\end{array}$ $\begin{array}{lllllllll}8.09 & 7.06 & -1.02 & 5.61 & 6.64 & -1.02 & 6.18 & 12.86 & -6.68\end{array}$ $\begin{array}{lllllllll}9.73 & 7.47 & -2.26 & 6.22 & 8.49 & -2.26 & 6.50 & 15.89 & -9.39\end{array}$ 
$\mathrm{C}(\mathrm{C}(\mathrm{C}(\mathrm{C}(\mathrm{C}(\mathrm{C}(\mathrm{C}(\mathrm{C}(\mathrm{C}(\mathrm{C}(\mathrm{C}(\mathrm{C}(\mathrm{H})(\mathrm{Cl}) \mathrm{H})(\mathrm{Cl}) \mathrm{H})(\mathrm{Br}) \mathrm{H})(\mathrm{F}) \mathrm{H})(\mathrm{F}) \mathrm{F})(\mathrm{H}) \mathrm{H})(\mathrm{H}) \mathrm{H})(\mathrm{H}) \mathrm{H})(\mathrm{H}) \mathrm{H})(\mathrm{Br}) \mathrm{H})(\mathrm{H}) \mathrm{H})(\mathrm{H})(\mathrm{H}) \quad \mathrm{C} 12 \mathrm{H} 19 \mathrm{Cl} 2 \mathrm{Br} 2 \mathrm{~F} 3$ $\mathrm{C}(\mathrm{C}(\mathrm{C}(\mathrm{C}(\mathrm{C}(\mathrm{C}(\mathrm{C}(\mathrm{C}(\mathrm{C}(\mathrm{C}(\mathrm{C}(\mathrm{C}(\mathrm{H})(\mathrm{H}) \mathrm{H})(\mathrm{Cl}) \mathrm{H})(\mathrm{H}) \mathrm{F})(\mathrm{H}) \mathrm{H})(\mathrm{H}) \mathrm{H})(\mathrm{Br}) \mathrm{Br})(\mathrm{H}) \mathrm{H})(\mathrm{H}) \mathrm{H})(\mathrm{Cl}) \mathrm{H})(\mathrm{H}) \mathrm{H})(\mathrm{F}) \mathrm{H})(\mathrm{Br})(\mathrm{H}) \quad \mathrm{C} 12 \mathrm{H} 19 \mathrm{Cl} 2 \mathrm{Br} 3 \mathrm{~F} 2$ $\mathrm{C}(\mathrm{C}(\mathrm{C}(\mathrm{C}(\mathrm{C}(\mathrm{C}(\mathrm{C}(\mathrm{C}(\mathrm{C}(\mathrm{C}(\mathrm{C}(\mathrm{C}(\mathrm{H})(\mathrm{H}) \mathrm{H})(\mathrm{Br}) \mathrm{H})(\mathrm{Cl}) \mathrm{H})(\mathrm{Br}) \mathrm{H})(\mathrm{H}) \mathrm{H})(\mathrm{H}) \mathrm{Br})(\mathrm{H}) \mathrm{H})(\mathrm{Cl}) \mathrm{Br})(\mathrm{H}) \mathrm{H})(\mathrm{F}) \mathrm{H})(\mathrm{H}) \mathrm{H})(\mathrm{H}) \quad \mathrm{C} 12 \mathrm{H} 19 \mathrm{Cl} 2 \mathrm{Br} 4 \mathrm{~F}$ $\mathrm{C}(\mathrm{C}(\mathrm{C}(\mathrm{C}(\mathrm{C}(\mathrm{C}(\mathrm{C}(\mathrm{C}(\mathrm{C}(\mathrm{C}(\mathrm{C}(\mathrm{C}(\mathrm{Cl})(\mathrm{H}) \mathrm{H})(\mathrm{Br}) \mathrm{H})(\mathrm{H}) \mathrm{Cl})(\mathrm{H}) \mathrm{H})(\mathrm{H}) \mathrm{Br})(\mathrm{H}) \mathrm{H})(\mathrm{H}) \mathrm{H})(\mathrm{Br}) \mathrm{H})(\mathrm{Br}) \mathrm{H})(\mathrm{H}) \mathrm{H})(\mathrm{H}) \mathrm{H})(\mathrm{H})(\mathrm{C} 12 \mathrm{H} 19 \mathrm{Cl} 2 \mathrm{Br} 5$ $\mathrm{C}(\mathrm{C}(\mathrm{C}(\mathrm{C}(\mathrm{C}(\mathrm{C}(\mathrm{C}(\mathrm{C}(\mathrm{C}(\mathrm{C}(\mathrm{C}(\mathrm{C}(\mathrm{H})(\mathrm{H}) \mathrm{H})(\mathrm{H}) \mathrm{H})(\mathrm{H}) \mathrm{H})(\mathrm{H}) \mathrm{F})(\mathrm{H}) \mathrm{Cl})(\mathrm{H}) \mathrm{H})(\mathrm{H}) \mathrm{Br})(\mathrm{H}) \mathrm{Cl})(\mathrm{H}) \mathrm{H})(\mathrm{H}) \mathrm{H})(\mathrm{H}) \mathrm{Br})(\mathrm{H})(\mathrm{Cl}) \mathrm{C} 12 \mathrm{H} 19 \mathrm{Cl} 3 \mathrm{Br} 2 \mathrm{~F} 2$ $\mathrm{C}(\mathrm{C}(\mathrm{C}(\mathrm{C}(\mathrm{C}(\mathrm{C}(\mathrm{C}(\mathrm{C}(\mathrm{C}(\mathrm{C}(\mathrm{C}(\mathrm{C}(\mathrm{Cl})(\mathrm{H}) \mathrm{Cl})(\mathrm{F}) \mathrm{H})(\mathrm{H}) \mathrm{H})(\mathrm{H}) \mathrm{H})(\mathrm{H}) \mathrm{H})(\mathrm{H}) \mathrm{H})(\mathrm{H}) \mathrm{H})(\mathrm{Br}) \mathrm{Br})(\mathrm{Br}) \mathrm{H})(\mathrm{H}) \mathrm{H})(\mathrm{H}) \mathrm{Cl})(\mathrm{H}) \quad \mathrm{C} 12 \mathrm{H} 19 \mathrm{Cl} 3 \mathrm{Br} 3 \mathrm{~F}$ $\mathrm{C}(\mathrm{C}(\mathrm{C}(\mathrm{C}(\mathrm{C}(\mathrm{C}(\mathrm{C}(\mathrm{C}(\mathrm{C}(\mathrm{C}(\mathrm{C}(\mathrm{C}(\mathrm{H})(\mathrm{H}) \mathrm{H})(\mathrm{H}) \mathrm{H})(\mathrm{H}) \mathrm{Cl})(\mathrm{H}) \mathrm{Cl})(\mathrm{Br}) \mathrm{Cl})(\mathrm{H}) \mathrm{H})(\mathrm{Br}) \mathrm{H})(\mathrm{Br}) \mathrm{H})(\mathrm{H}) \mathrm{H})(\mathrm{H}) \mathrm{H})(\mathrm{H}) \mathrm{H})(\mathrm{H})(\mathrm{B} \mathrm{C} 12 \mathrm{H} 19 \mathrm{Cl} 3 \mathrm{Br} 4$ $\mathrm{C}(\mathrm{C}(\mathrm{C}(\mathrm{C}(\mathrm{C}(\mathrm{C}(\mathrm{C}(\mathrm{C}(\mathrm{C}(\mathrm{C}(\mathrm{C}(\mathrm{C}(\mathrm{Cl})(\mathrm{Br}) \mathrm{H})(\mathrm{H}) \mathrm{Br})(\mathrm{H}) \mathrm{F})(\mathrm{Cl}) \mathrm{H})(\mathrm{H}) \mathrm{H})(\mathrm{H}) \mathrm{Cl})(\mathrm{H}) \mathrm{H})(\mathrm{H}) \mathrm{H})(\mathrm{H}) \mathrm{H})(\mathrm{H}) \mathrm{H})(\mathrm{H}) \mathrm{H})(\mathrm{H})(\mathrm{H}) \mathrm{C} 12 \mathrm{H} 19 \mathrm{Cl} 4 \mathrm{Br} 2 \mathrm{~F}$ $\mathrm{C}(\mathrm{C}(\mathrm{C}(\mathrm{C}(\mathrm{C}(\mathrm{C}(\mathrm{C}(\mathrm{C}(\mathrm{C}(\mathrm{C}(\mathrm{C}(\mathrm{C}(\mathrm{Cl})(\mathrm{H}) \mathrm{H})(\mathrm{H}) \mathrm{H})(\mathrm{H}) \mathrm{H})(\mathrm{Br}) \mathrm{H})(\mathrm{H}) \mathrm{H})(\mathrm{H}) \mathrm{H})(\mathrm{H}) \mathrm{H})(\mathrm{Br}) \mathrm{H})(\mathrm{Cl}) \mathrm{H})(\mathrm{Br}) \mathrm{H})(\mathrm{Cl}) \mathrm{Cl})(\mathrm{H})(\mathrm{C} 12 \mathrm{H} 19 \mathrm{Cl} 1 \mathrm{Br} 3$ $\mathrm{C}(\mathrm{C}(\mathrm{C}(\mathrm{C}(\mathrm{C}(\mathrm{C}(\mathrm{C}(\mathrm{C}(\mathrm{C}(\mathrm{C}(\mathrm{C}(\mathrm{C}(\mathrm{H})(\mathrm{Br}) \mathrm{H})(\mathrm{H}) \mathrm{H})(\mathrm{H}) \mathrm{H})(\mathrm{H}) \mathrm{H})(\mathrm{H}) \mathrm{Cl})(\mathrm{H}) \mathrm{H})(\mathrm{H}) \mathrm{H})(\mathrm{Cl}) \mathrm{Cl})(\mathrm{F}) \mathrm{H})(\mathrm{Cl}) \mathrm{H})(\mathrm{F}) \mathrm{H})(\mathrm{H})(\mathrm{H}) \quad \mathrm{C} 12 \mathrm{H} 19 \mathrm{Cl} 4 \mathrm{BrF} 2$ $\mathrm{C}(\mathrm{C}(\mathrm{C}(\mathrm{C}(\mathrm{C}(\mathrm{C}(\mathrm{C}(\mathrm{C}(\mathrm{C}(\mathrm{C}(\mathrm{C}(\mathrm{C}(\mathrm{Cl})(\mathrm{Cl}) \mathrm{H})(\mathrm{H}) \mathrm{H})(\mathrm{H}) \mathrm{H})(\mathrm{H}) \mathrm{H})(\mathrm{Cl}) \mathrm{Br})(\mathrm{Br}) \mathrm{H})(\mathrm{H}) \mathrm{H})(\mathrm{H}) \mathrm{H})(\mathrm{Cl}) \mathrm{H})(\mathrm{H}) \mathrm{H})(\mathrm{H}) \mathrm{Cl})(\mathrm{H})(\mathrm{C} 12 \mathrm{H} 19 \mathrm{Cl} 15 \mathrm{Br} 2$ $\mathrm{C}(\mathrm{C}(\mathrm{C}(\mathrm{C}(\mathrm{C}(\mathrm{C}(\mathrm{C}(\mathrm{C}(\mathrm{C}(\mathrm{C}(\mathrm{C}(\mathrm{C}(\mathrm{H})(\mathrm{H}) \mathrm{Cl})(\mathrm{H}) \mathrm{H})(\mathrm{H}) \mathrm{H})(\mathrm{H}) \mathrm{H})(\mathrm{H}) \mathrm{H})(\mathrm{H}) \mathrm{H})(\mathrm{H}) \mathrm{H})(\mathrm{H}) \mathrm{Br})(\mathrm{Cl}) \mathrm{H})(\mathrm{H}) \mathrm{Cl})(\mathrm{Cl}) \mathrm{Cl})(\mathrm{H}) \quad \mathrm{C} 12 \mathrm{H} 19 \mathrm{Cl} 15 \mathrm{BrF}$ $\mathrm{C}(\mathrm{C}(\mathrm{C}(\mathrm{C}(\mathrm{C}(\mathrm{C}(\mathrm{C}(\mathrm{C}(\mathrm{C}(\mathrm{C}(\mathrm{C}(\mathrm{C}(\mathrm{Cl})(\mathrm{H}) \mathrm{H})(\mathrm{H}) \mathrm{H})(\mathrm{H}) \mathrm{Cl})(\mathrm{H}) \mathrm{H})(\mathrm{H}) \mathrm{H})(\mathrm{Cl}) \mathrm{H})(\mathrm{H}) \mathrm{H})(\mathrm{H}) \mathrm{H})(\mathrm{F}) \mathrm{H})(\mathrm{H}) \mathrm{H})(\mathrm{Cl}) \mathrm{Cl})(\mathrm{H})(\mathrm{H}) \mathrm{Cl}_{2} \mathrm{H} 19 \mathrm{Cl}$ F 2 $\mathrm{C}(\mathrm{C}(\mathrm{C}(\mathrm{C}(\mathrm{C}(\mathrm{C}(\mathrm{C}(\mathrm{C}(\mathrm{C}(\mathrm{C}(\mathrm{C}(\mathrm{C}(\mathrm{Cl})(\mathrm{H}) \mathrm{H})(\mathrm{H}) \mathrm{H})(\mathrm{H}) \mathrm{H})(\mathrm{H}) \mathrm{H})(\mathrm{H}) \mathrm{Cl})(\mathrm{H}) \mathrm{H})(\mathrm{Cl}) \mathrm{H})(\mathrm{F}) \mathrm{Cl})(\mathrm{H}) \mathrm{H})(\mathrm{Cl}) \mathrm{Cl})(\mathrm{H}) \mathrm{H})(\mathrm{H})(\mathrm{H}) \mathrm{C1} 2 \mathrm{H} 19 \mathrm{Cl} 6 \mathrm{~F}$ $\mathrm{C}(\mathrm{C}(\mathrm{C}(\mathrm{C}(\mathrm{C}(\mathrm{C}(\mathrm{C}(\mathrm{C}(\mathrm{C}(\mathrm{C}(\mathrm{C}(\mathrm{C}(\mathrm{H})(\mathrm{Br}) \mathrm{H})(\mathrm{F}) \mathrm{H})(\mathrm{F}) \mathrm{H})(\mathrm{H}) \mathrm{H})(\mathrm{H}) \mathrm{H})(\mathrm{Br}) \mathrm{Cl})(\mathrm{H}) \mathrm{H})(\mathrm{H}) \mathrm{H})(\mathrm{H}) \mathrm{H})(\mathrm{Br}) \mathrm{F})(\mathrm{H}) \mathrm{H})(\mathrm{H})(\mathrm{H}) \quad \mathrm{C} 12 \mathrm{H} 19 \mathrm{ClBr} 3 \mathrm{~F} 3$ $\mathrm{C}(\mathrm{C}(\mathrm{C}(\mathrm{C}(\mathrm{C}(\mathrm{C}(\mathrm{C}(\mathrm{C}(\mathrm{C}(\mathrm{C}(\mathrm{C}(\mathrm{C}(\mathrm{H})(\mathrm{Cl}) \mathrm{Br})(\mathrm{H}) \mathrm{H})(\mathrm{H}) \mathrm{H})(\mathrm{H}) \mathrm{Br})(\mathrm{F}) \mathrm{H})(\mathrm{H}) \mathrm{Br})(\mathrm{H}) \mathrm{H})(\mathrm{H}) \mathrm{H})(\mathrm{H}) \mathrm{H})(\mathrm{Br}) \mathrm{H})(\mathrm{H}) \mathrm{F})(\mathrm{H})(\mathrm{H}) \mathrm{C}_{2} \mathrm{H} 19 \mathrm{ClBr} 4 \mathrm{~F} 2$ $\mathrm{C}(\mathrm{C}(\mathrm{C}(\mathrm{C}(\mathrm{C}(\mathrm{C}(\mathrm{C}(\mathrm{C}(\mathrm{C}(\mathrm{C}(\mathrm{C}(\mathrm{C}(\mathrm{H})(\mathrm{H}) \mathrm{H})(\mathrm{H}) \mathrm{H})(\mathrm{H}) \mathrm{H})(\mathrm{H}) \mathrm{H})(\mathrm{H}) \mathrm{H})(\mathrm{Br}) \mathrm{H})(\mathrm{H}) \mathrm{Br})(\mathrm{F}) \mathrm{H})(\mathrm{H}) \mathrm{Cl})(\mathrm{H}) \mathrm{H})(\mathrm{Br}) \mathrm{Br})(\mathrm{H}) \quad \mathrm{C} 12 \mathrm{H} 19 \mathrm{ClBr} 5 \mathrm{~F}$ $\mathrm{C}(\mathrm{C}(\mathrm{C}(\mathrm{C}(\mathrm{C}(\mathrm{C}(\mathrm{C}(\mathrm{C}(\mathrm{C}(\mathrm{C}(\mathrm{C}(\mathrm{C}(\mathrm{H})(\mathrm{H}) \mathrm{H})(\mathrm{Br}) \mathrm{H})(\mathrm{Br}) \mathrm{H})(\mathrm{Br}) \mathrm{H})(\mathrm{H}) \mathrm{H})(\mathrm{H}) \mathrm{H})(\mathrm{H}) \mathrm{Br})(\mathrm{H}) \mathrm{Br})(\mathrm{H}) \mathrm{H})(\mathrm{H}) \mathrm{Cl})(\mathrm{H}) \mathrm{H})(\mathrm{H})\left(\mathrm{C}_{2} \mathrm{H} 19 \mathrm{ClBr} 6\right.$ $\mathrm{C}(\mathrm{C}(\mathrm{C}(\mathrm{C}(\mathrm{C}(\mathrm{C}(\mathrm{C}(\mathrm{C}(\mathrm{C}(\mathrm{C}(\mathrm{C}(\mathrm{C}(\mathrm{H})(\mathrm{H}) \mathrm{H})(\mathrm{H}) \mathrm{F})(\mathrm{H}) \mathrm{F})(\mathrm{H}) \mathrm{H})(\mathrm{Br}) \mathrm{H})(\mathrm{H}) \mathrm{Br})(\mathrm{Br}) \mathrm{Br})(\mathrm{H}) \mathrm{H})(\mathrm{H}) \mathrm{H})(\mathrm{H}) \mathrm{H})(\mathrm{H}) \mathrm{H})(\mathrm{H})(\mathrm{H}) \mathrm{C}_{2} \mathrm{H} 20 \mathrm{Br} 4 \mathrm{~F} 2$ $\mathrm{C}(\mathrm{C}(\mathrm{C}(\mathrm{C}(\mathrm{C}(\mathrm{C}(\mathrm{C}(\mathrm{C}(\mathrm{C}(\mathrm{C}(\mathrm{C}(\mathrm{C}(\mathrm{H})(\mathrm{H}) \mathrm{Br})(\mathrm{H}) \mathrm{H})(\mathrm{H}) \mathrm{H})(\mathrm{H}) \mathrm{Br})(\mathrm{H}) \mathrm{H})(\mathrm{Br}) \mathrm{H})(\mathrm{H}) \mathrm{Br})(\mathrm{H}) \mathrm{H})(\mathrm{H}) \mathrm{H})(\mathrm{H}) \mathrm{H})(\mathrm{F}) \mathrm{H})(\mathrm{H}) \quad \mathrm{C} 12 \mathrm{H} 20 \mathrm{Br} 5 \mathrm{~F}$ $\mathrm{C}(\mathrm{C}(\mathrm{C}(\mathrm{C}(\mathrm{C}(\mathrm{C}(\mathrm{C}(\mathrm{C}(\mathrm{C}(\mathrm{C}(\mathrm{C}(\mathrm{C}(\mathrm{H})(\mathrm{H}) \mathrm{Br})(\mathrm{H}) \mathrm{H})(\mathrm{H}) \mathrm{H})(\mathrm{H}) \mathrm{H})(\mathrm{H}) \mathrm{H})(\mathrm{H}) \mathrm{Br})(\mathrm{H}) \mathrm{Br})(\mathrm{H}) \mathrm{H})(\mathrm{H}) \mathrm{H})(\mathrm{H}) \mathrm{H})(\mathrm{Br}) \mathrm{H})(\mathrm{Br}) \quad \mathrm{C} 12 \mathrm{H} 20 \mathrm{Br} 6$ $\mathrm{C}(\mathrm{C}(\mathrm{C}(\mathrm{C}(\mathrm{C}(\mathrm{C}(\mathrm{C}(\mathrm{C}(\mathrm{C}(\mathrm{C}(\mathrm{C}(\mathrm{C}(\mathrm{Br})(\mathrm{Cl}) \mathrm{H})(\mathrm{H}) \mathrm{H})(\mathrm{H}) \mathrm{H})(\mathrm{H}) \mathrm{F})(\mathrm{H}) \mathrm{H})(\mathrm{H}) \mathrm{H})(\mathrm{H}) \mathrm{H})(\mathrm{H}) \mathrm{H})(\mathrm{H}) \mathrm{H})(\mathrm{Br}) \mathrm{H})(\mathrm{H}) \mathrm{H})(\mathrm{H})(\mathrm{Cl}) \quad \mathrm{C} 12 \mathrm{H} 20 \mathrm{Cl} 2 \mathrm{Br} 3 \mathrm{~F}$ $\mathrm{C}(\mathrm{C}(\mathrm{C}(\mathrm{C}(\mathrm{C}(\mathrm{C}(\mathrm{C}(\mathrm{C}(\mathrm{C}(\mathrm{C}(\mathrm{C}(\mathrm{C}(\mathrm{H})(\mathrm{Cl}) \mathrm{H})(\mathrm{H}) \mathrm{H})(\mathrm{Br}) \mathrm{Cl})(\mathrm{H}) \mathrm{H})(\mathrm{H}) \mathrm{H})(\mathrm{H}) \mathrm{H})(\mathrm{Br}) \mathrm{H})(\mathrm{Br}) \mathrm{H})(\mathrm{H}) \mathrm{H})(\mathrm{H}) \mathrm{H})(\mathrm{Br}) \mathrm{H})(\mathrm{H})(\mathrm{C} 12 \mathrm{H} 20 \mathrm{Cl} 2 \mathrm{Br} 4$ $\mathrm{C}(\mathrm{C}(\mathrm{C}(\mathrm{C}(\mathrm{C}(\mathrm{C}(\mathrm{C}(\mathrm{C}(\mathrm{C}(\mathrm{C}(\mathrm{C}(\mathrm{C}(\mathrm{H})(\mathrm{H}) \mathrm{H})(\mathrm{Br}) \mathrm{H})(\mathrm{Cl}) \mathrm{Cl})(\mathrm{Cl}) \mathrm{H})(\mathrm{H}) \mathrm{H})(\mathrm{H}) \mathrm{H})(\mathrm{H}) \mathrm{H})(\mathrm{H}) \mathrm{H})(\mathrm{F}) \mathrm{H})(\mathrm{H}) \mathrm{H})(\mathrm{H}) \mathrm{H})(\mathrm{H})(\mathrm{H}) \quad \mathrm{C} 12 \mathrm{H} 20 \mathrm{Cl} 3 \mathrm{Br} 2 \mathrm{~F}$ $\mathrm{C}(\mathrm{C}(\mathrm{C}(\mathrm{C}(\mathrm{C}(\mathrm{C}(\mathrm{C}(\mathrm{C}(\mathrm{C}(\mathrm{C}(\mathrm{C}(\mathrm{C}(\mathrm{H})(\mathrm{H}) \mathrm{Cl})(\mathrm{H}) \mathrm{H})(\mathrm{H}) \mathrm{H})(\mathrm{Br}) \mathrm{Br})(\mathrm{H}) \mathrm{Br})(\mathrm{H}) \mathrm{H})(\mathrm{H}) \mathrm{H})(\mathrm{H}) \mathrm{Cl})(\mathrm{H}) \mathrm{H})(\mathrm{Cl}) \mathrm{H})(\mathrm{H}) \mathrm{H})(\mathrm{H}) \quad \mathrm{C} 12 \mathrm{H} 20 \mathrm{Cl} 3 \mathrm{Br} 3$ $\mathrm{C}(\mathrm{C}(\mathrm{C}(\mathrm{C}(\mathrm{C}(\mathrm{C}(\mathrm{C}(\mathrm{C}(\mathrm{C}(\mathrm{C}(\mathrm{C}(\mathrm{C}(\mathrm{H})(\mathrm{H}) \mathrm{H})(\mathrm{H}) \mathrm{Cl})(\mathrm{H}) \mathrm{H})(\mathrm{H}) \mathrm{H})(\mathrm{F}) \mathrm{H})(\mathrm{Cl}) \mathrm{H})(\mathrm{H}) \mathrm{H})(\mathrm{H}) \mathrm{H})(\mathrm{H}) \mathrm{Cl})(\mathrm{Br}) \mathrm{F})(\mathrm{H}) \mathrm{H})(\mathrm{H})(\mathrm{H}) \quad \mathrm{C} 12 \mathrm{H} 20 \mathrm{Cl} 3 \mathrm{BrF} 2$ $\mathrm{C}(\mathrm{C}(\mathrm{C}(\mathrm{C}(\mathrm{C}(\mathrm{C}(\mathrm{C}(\mathrm{C}(\mathrm{C}(\mathrm{C}(\mathrm{C}(\mathrm{C}(\mathrm{H})(\mathrm{H}) \mathrm{H})(\mathrm{H}) \mathrm{Cl})(\mathrm{Cl}) \mathrm{H})(\mathrm{H}) \mathrm{H})(\mathrm{H}) \mathrm{Cl})(\mathrm{H}) \mathrm{Br})(\mathrm{Cl}) \mathrm{H})(\mathrm{H}) \mathrm{H})(\mathrm{H}) \mathrm{H})(\mathrm{Br}) \mathrm{H})(\mathrm{H}) \mathrm{H})(\mathrm{H}) \quad \mathrm{C} 12 \mathrm{H} 20 \mathrm{Cl} 4 \mathrm{Br} 2$ $\mathrm{C}(\mathrm{C}(\mathrm{C}(\mathrm{C}(\mathrm{C}(\mathrm{C}(\mathrm{C}(\mathrm{C}(\mathrm{C}(\mathrm{C}(\mathrm{C}(\mathrm{C}(\mathrm{H})(\mathrm{Cl}) \mathrm{H})(\mathrm{H}) \mathrm{Cl})(\mathrm{H}) \mathrm{H})(\mathrm{H}) \mathrm{H})(\mathrm{F}) \mathrm{H})(\mathrm{Cl}) \mathrm{H})(\mathrm{Br}) \mathrm{H})(\mathrm{H}) \mathrm{H})(\mathrm{H}) \mathrm{H})(\mathrm{H}) \mathrm{H})(\mathrm{Cl}) \mathrm{H})(\mathrm{H})(\mathrm{H}) \mathrm{Cl}_{2} \mathrm{H} 20 \mathrm{Cl} 4 \mathrm{BrF}$ $\mathrm{C}(\mathrm{C}(\mathrm{C}(\mathrm{C}(\mathrm{C}(\mathrm{C}(\mathrm{C}(\mathrm{C}(\mathrm{C}(\mathrm{C}(\mathrm{C}(\mathrm{C}(\mathrm{H})(\mathrm{H}) \mathrm{H})(\mathrm{H}) \mathrm{H})(\mathrm{H}) \mathrm{H})(\mathrm{H}) \mathrm{H})(\mathrm{H}) \mathrm{Cl})(\mathrm{Cl}) \mathrm{H})(\mathrm{H}) \mathrm{H})(\mathrm{H}) \mathrm{Br})(\mathrm{H}) \mathrm{H})(\mathrm{H}) \mathrm{Cl})(\mathrm{H}) \mathrm{H})(\mathrm{Cl})(\mathrm{H}) \mathrm{C}_{2} 2 \mathrm{H} 20 \mathrm{Cl} 5 \mathrm{Br}$ $\mathrm{C}(\mathrm{C}(\mathrm{C}(\mathrm{C}(\mathrm{C}(\mathrm{C}(\mathrm{C}(\mathrm{C}(\mathrm{C}(\mathrm{C}(\mathrm{C}(\mathrm{C}(\mathrm{H})(\mathrm{H}) \mathrm{H})(\mathrm{H}) \mathrm{Cl})(\mathrm{Cl}) \mathrm{Cl})(\mathrm{H}) \mathrm{Cl})(\mathrm{H}) \mathrm{F})(\mathrm{H}) \mathrm{H})(\mathrm{H}) \mathrm{H})(\mathrm{H}) \mathrm{Cl})(\mathrm{H}) \mathrm{H})(\mathrm{H}) \mathrm{H})(\mathrm{H}) \mathrm{H})(\mathrm{H})(\mathrm{H}) \quad \mathrm{C} 12 \mathrm{H} 20 \mathrm{Cl} 5 \mathrm{~F}$ $\mathrm{C}(\mathrm{C}(\mathrm{C}(\mathrm{C}(\mathrm{C}(\mathrm{C}(\mathrm{C}(\mathrm{C}(\mathrm{C}(\mathrm{C}(\mathrm{C}(\mathrm{C}(\mathrm{H})(\mathrm{H}) \mathrm{H})(\mathrm{H}) \mathrm{Cl})(\mathrm{Cl}) \mathrm{Cl})(\mathrm{H}) \mathrm{H})(\mathrm{H}) \mathrm{H})(\mathrm{H}) \mathrm{H})(\mathrm{H}) \mathrm{H})(\mathrm{H}) \mathrm{H})(\mathrm{Cl}) \mathrm{Cl})(\mathrm{H}) \mathrm{H})(\mathrm{H}) \mathrm{H})(\mathrm{Cl}) \quad \mathrm{C} 12 \mathrm{H} 20 \mathrm{Cl} 6$ $\mathrm{C}(\mathrm{C}(\mathrm{C}(\mathrm{C}(\mathrm{C}(\mathrm{C}(\mathrm{C}(\mathrm{C}(\mathrm{C}(\mathrm{C}(\mathrm{C}(\mathrm{C}(\mathrm{Br})(\mathrm{H}) \mathrm{H})(\mathrm{H}) \mathrm{H})(\mathrm{H}) \mathrm{Cl})(\mathrm{H}) \mathrm{H})(\mathrm{Br}) \mathrm{H})(\mathrm{H}) \mathrm{H})(\mathrm{H}) \mathrm{H})(\mathrm{H}) \mathrm{H})(\mathrm{H}) \mathrm{Br})(\mathrm{F}) \mathrm{H})(\mathrm{H}) \mathrm{F})(\mathrm{H})(\mathrm{H}) \quad \mathrm{C} 12 \mathrm{H} 20 \mathrm{ClBr} 3 \mathrm{~F} 2$ $\mathrm{C}(\mathrm{C}(\mathrm{C}(\mathrm{C}(\mathrm{C}(\mathrm{C}(\mathrm{C}(\mathrm{C}(\mathrm{C}(\mathrm{C}(\mathrm{C}(\mathrm{C}(\mathrm{Br})(\mathrm{H}) \mathrm{H})(\mathrm{H}) \mathrm{Cl})(\mathrm{Br}) \mathrm{H})(\mathrm{H}) \mathrm{H})(\mathrm{H}) \mathrm{H})(\mathrm{H}) \mathrm{Br})(\mathrm{Br}) \mathrm{H})(\mathrm{H}) \mathrm{H})(\mathrm{H}) \mathrm{F})(\mathrm{H}) \mathrm{H})(\mathrm{H}) \mathrm{H})(\mathrm{H}) \quad \mathrm{C} 12 \mathrm{H} 20 \mathrm{ClBr} 4 \mathrm{~F}$ $\mathrm{C}(\mathrm{C}(\mathrm{C}(\mathrm{C}(\mathrm{C}(\mathrm{C}(\mathrm{C}(\mathrm{C}(\mathrm{C}(\mathrm{C}(\mathrm{C}(\mathrm{C}(\mathrm{Br})(\mathrm{Br}) \mathrm{H})(\mathrm{H}) \mathrm{H})(\mathrm{H}) \mathrm{H})(\mathrm{Br}) \mathrm{H})(\mathrm{H}) \mathrm{H})(\mathrm{H}) \mathrm{H})(\mathrm{H}) \mathrm{H})(\mathrm{H}) \mathrm{H})(\mathrm{H}) \mathrm{Cl})(\mathrm{H}) \mathrm{Br})(\mathrm{H}) \mathrm{H})(\mathrm{H})(\mathrm{B}$ C12 $2020 \mathrm{ClBr} 5$ $\mathrm{C}(\mathrm{C}(\mathrm{C}(\mathrm{C}(\mathrm{C}(\mathrm{C}(\mathrm{C}(\mathrm{C}(\mathrm{C}(\mathrm{C}(\mathrm{C}(\mathrm{C}(\mathrm{F})(\mathrm{H}) \mathrm{H})(\mathrm{H}) \mathrm{Br})(\mathrm{H}) \mathrm{H})(\mathrm{H}) \mathrm{H})(\mathrm{Br}) \mathrm{F})(\mathrm{H}) \mathrm{H})(\mathrm{H}) \mathrm{H})(\mathrm{Br}) \mathrm{H})(\mathrm{H}) \mathrm{H})(\mathrm{H}) \mathrm{H})(\mathrm{H}) \mathrm{H})(\mathrm{H})(\mathrm{H}) \quad \mathrm{C} 12 \mathrm{H} 21 \mathrm{Br} 3 \mathrm{~F} 2$ $\mathrm{C}(\mathrm{C}(\mathrm{C}(\mathrm{C}(\mathrm{C}(\mathrm{C}(\mathrm{C}(\mathrm{C}(\mathrm{C}(\mathrm{C}(\mathrm{C}(\mathrm{C}(\mathrm{H})(\mathrm{Br}) \mathrm{H})(\mathrm{H}) \mathrm{H})(\mathrm{H}) \mathrm{H})(\mathrm{H}) \mathrm{H})(\mathrm{Br}) \mathrm{Br})(\mathrm{H}) \mathrm{H})(\mathrm{Br}) \mathrm{H})(\mathrm{H}) \mathrm{H})(\mathrm{F}) \mathrm{H})(\mathrm{H}) \mathrm{H})(\mathrm{H}) \mathrm{H})(\mathrm{H})(\mathrm{H}) \mathrm{C}_{2} \mathrm{H} 21 \mathrm{Br} 4 \mathrm{~F}$ $\mathrm{C}(\mathrm{C}(\mathrm{C}(\mathrm{C}(\mathrm{C}(\mathrm{C}(\mathrm{C}(\mathrm{C}(\mathrm{C}(\mathrm{C}(\mathrm{C}(\mathrm{C}(\mathrm{H})(\mathrm{Br}) \mathrm{Br})(\mathrm{H}) \mathrm{H})(\mathrm{H}) \mathrm{H})(\mathrm{H}) \mathrm{H})(\mathrm{H}) \mathrm{H})(\mathrm{H}) \mathrm{Br})(\mathrm{Br}) \mathrm{H})(\mathrm{H}) \mathrm{H})(\mathrm{H}) \mathrm{Br})(\mathrm{H}) \mathrm{H})(\mathrm{H}) \mathrm{H})(\mathrm{H}) \quad \mathrm{C} 12 \mathrm{H} 21 \mathrm{Br} 5$ $\mathrm{C}(\mathrm{C}(\mathrm{C}(\mathrm{C}(\mathrm{C}(\mathrm{C}(\mathrm{C}(\mathrm{C}(\mathrm{C}(\mathrm{C}(\mathrm{C}(\mathrm{C}(\mathrm{H})(\mathrm{H}) \mathrm{Cl})(\mathrm{H}) \mathrm{H})(\mathrm{Br}) \mathrm{H})(\mathrm{H}) \mathrm{H})(\mathrm{H}) \mathrm{H})(\mathrm{Cl}) \mathrm{H})(\mathrm{H}) \mathrm{H})(\mathrm{H}) \mathrm{H})(\mathrm{H}) \mathrm{F})(\mathrm{H}) \mathrm{H})(\mathrm{Br}) \mathrm{H})(\mathrm{H})(\mathrm{H}) \quad \mathrm{C} 12 \mathrm{H} 21 \mathrm{Cl} 2 \mathrm{Br} 2$ $\mathrm{C}(\mathrm{C}(\mathrm{C}(\mathrm{C}(\mathrm{C}(\mathrm{C}(\mathrm{C}(\mathrm{C}(\mathrm{C}(\mathrm{C}(\mathrm{C}(\mathrm{C}(\mathrm{H})(\mathrm{Cl}) \mathrm{Br})(\mathrm{H}) \mathrm{H})(\mathrm{Cl}) \mathrm{H})(\mathrm{H}) \mathrm{Br})(\mathrm{H}) \mathrm{H})(\mathrm{H}) \mathrm{H})(\mathrm{H}) \mathrm{H})(\mathrm{H}) \mathrm{H})(\mathrm{Br}) \mathrm{H})(\mathrm{H}) \mathrm{H})(\mathrm{H}) \mathrm{H})(\mathrm{H}) \quad \mathrm{C} 12 \mathrm{H} 21 \mathrm{Cl} 2 \mathrm{Br} 3$ $\mathrm{C}(\mathrm{C}(\mathrm{C}(\mathrm{C}(\mathrm{C}(\mathrm{C}(\mathrm{C}(\mathrm{C}(\mathrm{C}(\mathrm{C}(\mathrm{C}(\mathrm{C}(\mathrm{H})(\mathrm{H}) \mathrm{H})(\mathrm{H}) \mathrm{H})(\mathrm{H}) \mathrm{H})(\mathrm{H}) \mathrm{Cl})(\mathrm{Br}) \mathrm{Br})(\mathrm{H}) \mathrm{H})(\mathrm{Cl}) \mathrm{H})(\mathrm{H}) \mathrm{H})(\mathrm{H}) \mathrm{H})(\mathrm{H}) \mathrm{H})(\mathrm{Cl}) \mathrm{H})(\mathrm{H}) \quad \mathrm{C} 12 \mathrm{H} 21 \mathrm{Cl} 3 \mathrm{Br} 2$ $\mathrm{C}(\mathrm{C}(\mathrm{C}(\mathrm{C}(\mathrm{C}(\mathrm{C}(\mathrm{C}(\mathrm{C}(\mathrm{C}(\mathrm{C}(\mathrm{C}(\mathrm{C}(\mathrm{Cl})(\mathrm{H}) \mathrm{H})(\mathrm{H}) \mathrm{H})(\mathrm{H}) \mathrm{Cl})(\mathrm{H}) \mathrm{H})(\mathrm{H}) \mathrm{H})(\mathrm{H}) \mathrm{H})(\mathrm{Br}) \mathrm{H})(\mathrm{H}) \mathrm{Cl})(\mathrm{H}) \mathrm{H})(\mathrm{H}) \mathrm{H})(\mathrm{H}) \mathrm{H})(\mathrm{H})(\mathrm{Cl}) \mathrm{C} 12 \mathrm{H} 21 \mathrm{Cl} 4 \mathrm{~B}$ $\mathrm{C}(\mathrm{C}(\mathrm{C}(\mathrm{C}(\mathrm{C}(\mathrm{C}(\mathrm{C}(\mathrm{C}(\mathrm{C}(\mathrm{C}(\mathrm{C}(\mathrm{C}(\mathrm{H})(\mathrm{H}) \mathrm{H})(\mathrm{H}) \mathrm{Cl})(\mathrm{Cl}) \mathrm{H})(\mathrm{H}) \mathrm{H})(\mathrm{H}) \mathrm{H})(\mathrm{Cl}) \mathrm{H})(\mathrm{H}) \mathrm{H})(\mathrm{Cl}) \mathrm{H})(\mathrm{H}) \mathrm{H})(\mathrm{H}) \mathrm{Cl})(\mathrm{H}) \mathrm{H})(\mathrm{H})(\mathrm{H}) \mathrm{C}_{2} 2 \mathrm{H} 21 \mathrm{Cl} 5$ $\mathrm{C}(\mathrm{C}(\mathrm{C}(\mathrm{C}(\mathrm{C}(\mathrm{C}(\mathrm{C}(\mathrm{C}(\mathrm{C}(\mathrm{C}(\mathrm{C}(\mathrm{C}(\mathrm{H})(\mathrm{H}) \mathrm{H})(\mathrm{H}) \mathrm{H})(\mathrm{H}) \mathrm{H})(\mathrm{H}) \mathrm{H})(\mathrm{H}) \mathrm{H})(\mathrm{H}) \mathrm{H})(\mathrm{Br}) \mathrm{H})(\mathrm{H}) \mathrm{Br})(\mathrm{H}) \mathrm{H})(\mathrm{F}) \mathrm{H})(\mathrm{Cl}) \mathrm{H})(\mathrm{H})(\mathrm{Br}) \mathrm{C}_{2} \mathrm{H}_{2} 1 \mathrm{ClBr} 3 \mathrm{~F}$ $\mathrm{C}(\mathrm{C}(\mathrm{C}(\mathrm{C}(\mathrm{C}(\mathrm{C}(\mathrm{C}(\mathrm{C}(\mathrm{C}(\mathrm{C}(\mathrm{C}(\mathrm{C}(\mathrm{H})(\mathrm{H}) \mathrm{H})(\mathrm{H}) \mathrm{H})(\mathrm{H}) \mathrm{Br})(\mathrm{H}) \mathrm{H})(\mathrm{H}) \mathrm{H})(\mathrm{H}) \mathrm{Br})(\mathrm{Cl}) \mathrm{H})(\mathrm{H}) \mathrm{H})(\mathrm{H}) \mathrm{H})(\mathrm{H}) \mathrm{H})(\mathrm{H}) \mathrm{H})(\mathrm{H})(\mathrm{Br}) \mathrm{C} 12 \mathrm{H} 21 \mathrm{ClBr} 4$ $\mathrm{C}(\mathrm{C}(\mathrm{C}(\mathrm{C}(\mathrm{C}(\mathrm{C}(\mathrm{C}(\mathrm{C}(\mathrm{C}(\mathrm{C}(\mathrm{C}(\mathrm{C}(\mathrm{H})(\mathrm{H}) \mathrm{H})(\mathrm{H}) \mathrm{Br})(\mathrm{H}) \mathrm{H})(\mathrm{H}) \mathrm{H})(\mathrm{H}) \mathrm{H})(\mathrm{H}) \mathrm{H})(\mathrm{H}) \mathrm{Br})(\mathrm{H}) \mathrm{H})(\mathrm{Br}) \mathrm{H})(\mathrm{H}) \mathrm{F})(\mathrm{H}) \mathrm{H})(\mathrm{H})(\mathrm{H}) \quad \mathrm{C} 12 \mathrm{H} 22 \mathrm{Br} 3 \mathrm{~F}$ $\mathrm{C}(\mathrm{C}(\mathrm{C}(\mathrm{C}(\mathrm{C}(\mathrm{C}(\mathrm{C}(\mathrm{C}(\mathrm{C}(\mathrm{C}(\mathrm{C}(\mathrm{C}(\mathrm{H})(\mathrm{H}) \mathrm{H})(\mathrm{H}) \mathrm{Br})(\mathrm{H}) \mathrm{H})(\mathrm{H}) \mathrm{H})(\mathrm{H}) \mathrm{H})(\mathrm{H}) \mathrm{H})(\mathrm{H}) \mathrm{H})(\mathrm{H}) \mathrm{H})(\mathrm{Br}) \mathrm{H})(\mathrm{H}) \mathrm{H})(\mathrm{Br}) \mathrm{H})(\mathrm{H}) \quad \mathrm{C} 12 \mathrm{H} 22 \mathrm{Br} 4$ $\mathrm{C}(\mathrm{C}(\mathrm{C}(\mathrm{C}(\mathrm{C}(\mathrm{C}(\mathrm{C}(\mathrm{C}(\mathrm{C}(\mathrm{C}(\mathrm{C}(\mathrm{C}(\mathrm{H})(\mathrm{H}) \mathrm{H})(\mathrm{H}) \mathrm{H})(\mathrm{H}) \mathrm{Cl})(\mathrm{H}) \mathrm{H})(\mathrm{Cl}) \mathrm{H})(\mathrm{H}) \mathrm{H})(\mathrm{H}) \mathrm{H})(\mathrm{H}) \mathrm{H})(\mathrm{H}) \mathrm{H})(\mathrm{H}) \mathrm{Br})(\mathrm{H}) \mathrm{H})(\mathrm{Br})(\mathrm{H}) \mathrm{Cl}_{2} \mathrm{H} 22 \mathrm{Cl} 2 \mathrm{Br} 2$ $\mathrm{C}(\mathrm{C}(\mathrm{C}(\mathrm{C}(\mathrm{C}(\mathrm{C}(\mathrm{C}(\mathrm{C}(\mathrm{C}(\mathrm{C}(\mathrm{C}(\mathrm{C}(\mathrm{H})(\mathrm{H}) \mathrm{H})(\mathrm{H}) \mathrm{H})(\mathrm{H}) \mathrm{H})(\mathrm{H}) \mathrm{H})(\mathrm{H}) \mathrm{H})(\mathrm{H}) \mathrm{H})(\mathrm{H}) \mathrm{H})(\mathrm{H}) \mathrm{H})(\mathrm{H}) \mathrm{H})(\mathrm{Br}) \mathrm{Cl})(\mathrm{Cl}) \mathrm{H})(\mathrm{Cl})(\mathrm{H}) \mathrm{C}_{2} 2 \mathrm{H} 22 \mathrm{Cl} 3 \mathrm{Br}$ $\mathrm{C}(\mathrm{C}(\mathrm{C}(\mathrm{C}(\mathrm{C}(\mathrm{C}(\mathrm{C}(\mathrm{C}(\mathrm{C}(\mathrm{C}(\mathrm{C}(\mathrm{C}(\mathrm{H})(\mathrm{H}) \mathrm{H})(\mathrm{H}) \mathrm{H})(\mathrm{H}) \mathrm{H})(\mathrm{H}) \mathrm{H})(\mathrm{Br}) \mathrm{H})(\mathrm{H}) \mathrm{H})(\mathrm{H}) \mathrm{Cl})(\mathrm{Br}) \mathrm{H})(\mathrm{Br}) \mathrm{H})(\mathrm{H}) \mathrm{H})(\mathrm{H}) \mathrm{H})(\mathrm{H})(\mathrm{H}) \mathrm{C} 12 \mathrm{H} 22 \mathrm{ClBr} 3$ $\mathrm{C}(\mathrm{C}(\mathrm{C}(\mathrm{C}(\mathrm{C}(\mathrm{C}(\mathrm{C}(\mathrm{C}(\mathrm{C}(\mathrm{C}(\mathrm{C}(\mathrm{C}(\mathrm{H})(\mathrm{H}) \mathrm{H})(\mathrm{H}) \mathrm{H})(\mathrm{H}) \mathrm{H})(\mathrm{H}) \mathrm{Br})(\mathrm{H}) \mathrm{H})(\mathrm{H}) \mathrm{Br})(\mathrm{H}) \mathrm{H})(\mathrm{H}) \mathrm{H})(\mathrm{H}) \mathrm{Br})(\mathrm{H}) \mathrm{H})(\mathrm{H}) \mathrm{H})(\mathrm{H})(\mathrm{H}) \mathrm{C}_{2} \mathrm{H} 23 \mathrm{Br} 3$ $\mathrm{C}(\mathrm{C}(\mathrm{C}(\mathrm{C}(\mathrm{C}(\mathrm{C}(\mathrm{C}(\mathrm{C}(\mathrm{C}(\mathrm{C}(\mathrm{C}(\mathrm{C}(\mathrm{H})(\mathrm{H}) \mathrm{H})(\mathrm{Br}) \mathrm{H})(\mathrm{H}) \mathrm{H})(\mathrm{Br}) \mathrm{H})(\mathrm{H}) \mathrm{H})(\mathrm{H}) \mathrm{H})(\mathrm{H}) \mathrm{H})(\mathrm{H}) \mathrm{H})(\mathrm{H}) \mathrm{H})(\mathrm{H}) \mathrm{H})(\mathrm{H}) \mathrm{H})(\mathrm{H})(\mathrm{H}) \quad \mathrm{C} 12 \mathrm{H} 23 \mathrm{ClBr} 2$ $\mathrm{C}(\mathrm{C}(\mathrm{C}(\mathrm{C}(\mathrm{C}(\mathrm{C}(\mathrm{C}(\mathrm{C}(\mathrm{C}(\mathrm{C}(\mathrm{C}(\mathrm{C}(\mathrm{C}(\mathrm{F})(\mathrm{H}) \mathrm{F})(\mathrm{Cl}) \mathrm{F})(\mathrm{H}) \mathrm{Cl})(\mathrm{Br}) \mathrm{H})(\mathrm{Cl}) \mathrm{H})(\mathrm{Cl}) \mathrm{H})(\mathrm{F}) \mathrm{H})(\mathrm{F}) \mathrm{F})(\mathrm{H}) \mathrm{H})(\mathrm{Cl}) \mathrm{H})(\mathrm{Cl}) \mathrm{H})(\mathrm{F}) \mathrm{H}){ }_{\mathrm{C} 13 \mathrm{H} 12 \mathrm{Cl} 6 \mathrm{Br} 2 \mathrm{~F} 8}$ (F)(H)Br

$\mathrm{C}(\mathrm{C}(\mathrm{C}(\mathrm{C}(\mathrm{C}(\mathrm{C}(\mathrm{C}(\mathrm{C}(\mathrm{C}(\mathrm{C}(\mathrm{C}(\mathrm{C}(\mathrm{C}(\mathrm{Br})(\mathrm{F}) \mathrm{H})(\mathrm{F}) \mathrm{H})(\mathrm{H}) \mathrm{F})(\mathrm{Br}) \mathrm{F})(\mathrm{Br}) \mathrm{H})(\mathrm{H}) \mathrm{F})(\mathrm{F}) \mathrm{H})(\mathrm{H}) \mathrm{F})(\mathrm{H}) \mathrm{F})(\mathrm{H}) \mathrm{Cl})(\mathrm{H}) \mathrm{H})(\mathrm{H}) \mathrm{Br})\left({ }_{\mathrm{C} 13 \mathrm{H} 12 \mathrm{ClBr} 5 \mathrm{~F} 10}\right.$ $\mathrm{F})(\mathrm{Br}) \mathrm{F}$

$\mathrm{C}(\mathrm{C}(\mathrm{C}(\mathrm{C}(\mathrm{C}(\mathrm{C}(\mathrm{C}(\mathrm{C}(\mathrm{C}(\mathrm{C}(\mathrm{C}(\mathrm{C}(\mathrm{C}(\mathrm{F})(\mathrm{H}) \mathrm{F})(\mathrm{F}) \mathrm{H})(\mathrm{F}) \mathrm{H})(\mathrm{Br}) \mathrm{Cl})(\mathrm{H}) \mathrm{H})(\mathrm{H}) \mathrm{H})(\mathrm{H}) \mathrm{F})(\mathrm{F}) \mathrm{F})(\mathrm{Br}) \mathrm{H})(\mathrm{H}) \mathrm{F})(\mathrm{Br}) \mathrm{H})(\mathrm{H}) \mathrm{F})(\quad \mathrm{C} 13 \mathrm{H} 13 \mathrm{Cl} 2 \mathrm{Br} 4 \mathrm{~F} 9$ $\mathrm{Cl})(\mathrm{H}) \mathrm{Br}$

$\mathrm{C}(\mathrm{C}(\mathrm{C}(\mathrm{C}(\mathrm{C}(\mathrm{C}(\mathrm{C}(\mathrm{C}(\mathrm{C}(\mathrm{C}(\mathrm{C}(\mathrm{C}(\mathrm{C}(\mathrm{H})(\mathrm{H}) \mathrm{H})(\mathrm{H}) \mathrm{F})(\mathrm{H}) \mathrm{Br})(\mathrm{H}) \mathrm{Cl})(\mathrm{F}) \mathrm{H})(\mathrm{H}) \mathrm{F})(\mathrm{F}) \mathrm{H})(\mathrm{Br}) \mathrm{F})(\mathrm{Br}) \mathrm{H})(\mathrm{Cl}) \mathrm{H})(\mathrm{H}) \mathrm{Br}) \quad \mathrm{C} 13 \mathrm{H} 13 \mathrm{Cl} 2 \mathrm{Br} 5 \mathrm{~F} 8$ $(\mathrm{Br}) \mathrm{F})(\mathrm{H})(\mathrm{F}) \mathrm{F}$

$\mathrm{C}(\mathrm{C}(\mathrm{C}(\mathrm{C}(\mathrm{C}(\mathrm{C}(\mathrm{C}(\mathrm{C}(\mathrm{C}(\mathrm{C}(\mathrm{C}(\mathrm{C}(\mathrm{C}(\mathrm{H})(\mathrm{F}) \mathrm{Cl})(\mathrm{F}) \mathrm{Br})(\mathrm{Br}) \mathrm{H})(\mathrm{Cl}) \mathrm{F})(\mathrm{H}) \mathrm{F})(\mathrm{H}) \mathrm{H})(\mathrm{F}) \mathrm{H})(\mathrm{F}) \mathrm{H})(\mathrm{Br}) \mathrm{H})(\mathrm{F}) \mathrm{H})(\mathrm{H}) \mathrm{H})(\mathrm{F}) \mathrm{H})\left({ }_{\mathrm{C} 13 \mathrm{H} 13 \mathrm{Cl} 3 \mathrm{Br} 3 \mathrm{~F} 9}\right.$ $\mathrm{Cl})(\mathrm{H}) \mathrm{F}$

$\mathrm{C} 13 \mathrm{H} 13 \mathrm{Cl} 3 \mathrm{Br} 3 \mathrm{~F}$

$\mathrm{C}(\mathrm{C}(\mathrm{C}(\mathrm{C}(\mathrm{C}(\mathrm{C}$

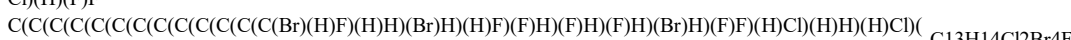
$\mathrm{F})(\mathrm{H}) \mathrm{Br}$

$\mathrm{C}(\mathrm{C}(\mathrm{C}(\mathrm{C}(\mathrm{C}(\mathrm{C}(\mathrm{C}(\mathrm{C}(\mathrm{C}(\mathrm{C}(\mathrm{C}(\mathrm{C}(\mathrm{C}(\mathrm{Br})(\mathrm{Cl}) \mathrm{H})(\mathrm{Br}) \mathrm{H})(\mathrm{H}) \mathrm{H})(\mathrm{H}) \mathrm{F})(\mathrm{H}) \mathrm{F})(\mathrm{H}) \mathrm{H})(\mathrm{F}) \mathrm{Cl})(\mathrm{H}) \mathrm{F})(\mathrm{H}) \mathrm{H})(\mathrm{H}) \mathrm{F})(\mathrm{F}) \mathrm{H})(\mathrm{Cl}) \mathrm{Br})$

$(\mathrm{F})(\mathrm{H}) \mathrm{Cl}$

$\mathrm{C}(\mathrm{C}(\mathrm{C}(\mathrm{C}(\mathrm{C}(\mathrm{C}(\mathrm{C}(\mathrm{C}(\mathrm{C}(\mathrm{C}(\mathrm{C}(\mathrm{C}(\mathrm{C}(\mathrm{H})(\mathrm{H}) \mathrm{H})(\mathrm{F}) \mathrm{F})(\mathrm{H}) \mathrm{H})(\mathrm{H}) \mathrm{Br})(\mathrm{H}) \mathrm{F})(\mathrm{H}) \mathrm{F})(\mathrm{F}) \mathrm{H})(\mathrm{H}) \mathrm{Br})(\mathrm{H}) \mathrm{Br})(\mathrm{F}) \mathrm{H})(\mathrm{F}) \mathrm{H})(\mathrm{F}) \mathrm{Cl})($

$\mathrm{Br})(\mathrm{F}) \mathrm{H}$

$\mathrm{C}(\mathrm{C}(\mathrm{C}(\mathrm{C}(\mathrm{C}(\mathrm{C}(\mathrm{C}(\mathrm{C}(\mathrm{C}(\mathrm{C}(\mathrm{C}(\mathrm{C}(\mathrm{C}(\mathrm{H})(\mathrm{H}) \mathrm{F})(\mathrm{H}) \mathrm{F})(\mathrm{Br}) \mathrm{H})(\mathrm{H}) \mathrm{Br})(\mathrm{H}) \mathrm{F})(\mathrm{H}) \mathrm{F})(\mathrm{Cl}) \mathrm{Br})(\mathrm{H}) \mathrm{Br})(\mathrm{H}) \mathrm{H})(\mathrm{H}) \mathrm{F})(\mathrm{H}) \mathrm{Br})$

$(\mathrm{H}) \mathrm{H})(\mathrm{Cl})(\mathrm{H}) \mathrm{Br}$

$\mathrm{C}(\mathrm{C}(\mathrm{C}(\mathrm{C}(\mathrm{C}(\mathrm{C}(\mathrm{C}(\mathrm{C}(\mathrm{C}(\mathrm{C}(\mathrm{C}(\mathrm{C}(\mathrm{C}(\mathrm{F})(\mathrm{Cl}) \mathrm{H})(\mathrm{H}) \mathrm{Br})(\mathrm{H}) \mathrm{Br})(\mathrm{Br}) \mathrm{H})(\mathrm{Cl}) \mathrm{H})(\mathrm{H}) \mathrm{H})(\mathrm{F}) \mathrm{F})(\mathrm{F}) \mathrm{H})(\mathrm{H}) \mathrm{H})(\mathrm{H}) \mathrm{H})(\mathrm{Cl}) \mathrm{H})$ $(\mathrm{F}) \mathrm{H})(\mathrm{F})(\mathrm{F}) \mathrm{H}$

$\mathrm{C}(\mathrm{C}(\mathrm{C}(\mathrm{C}(\mathrm{C}(\mathrm{C}(\mathrm{C}(\mathrm{C}(\mathrm{C}(\mathrm{C}(\mathrm{C}(\mathrm{C}(\mathrm{C}(\mathrm{F})(\mathrm{F}) \mathrm{Br})(\mathrm{Cl}) \mathrm{H})(\mathrm{Cl}) \mathrm{H})(\mathrm{H}) \mathrm{H})(\mathrm{H}) \mathrm{H})(\mathrm{H}) \mathrm{F})(\mathrm{H}) \mathrm{H})(\mathrm{H}) \mathrm{F})(\mathrm{H}) \mathrm{F})(\mathrm{Br}) \mathrm{F})(\mathrm{H}) \mathrm{H})(\mathrm{H}) \mathrm{F})\left({ }_{\mathrm{C}} 13 \mathrm{H} 15 \mathrm{Cl} 4 \mathrm{Br} 2 \mathrm{~F} 7\right.$ $\mathrm{Cl})(\mathrm{H}) \mathrm{Cl}$

$\mathrm{C}(\mathrm{C}(\mathrm{C}(\mathrm{C}(\mathrm{C}(\mathrm{C}(\mathrm{C}(\mathrm{C}(\mathrm{C}(\mathrm{C}(\mathrm{C}(\mathrm{C}(\mathrm{C}(\mathrm{H})(\mathrm{H}) \mathrm{Cl})(\mathrm{H}) \mathrm{Cl})(\mathrm{Cl}) \mathrm{F})(\mathrm{H}) \mathrm{Br})(\mathrm{F}) \mathrm{H})(\mathrm{F}) \mathrm{H})(\mathrm{Cl}) \mathrm{H})(\mathrm{H}) \mathrm{H})(\mathrm{Cl}) \mathrm{H})(\mathrm{H}) \mathrm{H})(\mathrm{Cl}) \mathrm{H})(\mathrm{H})$ $\mathrm{Br})(\mathrm{F})(\mathrm{F}) \mathrm{H}$

$\mathrm{C}(\mathrm{C}(\mathrm{C}(\mathrm{C}(\mathrm{C}(\mathrm{C}(\mathrm{C}(\mathrm{C}(\mathrm{C}(\mathrm{C}(\mathrm{C}(\mathrm{C}(\mathrm{C}(\mathrm{H})(\mathrm{H}) \mathrm{Cl})(\mathrm{H}) \mathrm{Cl})(\mathrm{H}) \mathrm{F})(\mathrm{H}) \mathrm{H})(\mathrm{H}) \mathrm{F})(\mathrm{Cl}) \mathrm{H})(\mathrm{Cl}) \mathrm{H})(\mathrm{Cl}) \mathrm{H})(\mathrm{Br}) \mathrm{H})(\mathrm{H}) \mathrm{H})(\mathrm{H}) \mathrm{F})$

$(\mathrm{F}) \mathrm{H})(\mathrm{Cl})(\mathrm{Cl}) \mathrm{Cl}$

$\mathrm{C}(\mathrm{C}(\mathrm{C}(\mathrm{C}(\mathrm{C}(\mathrm{C}(\mathrm{C}(\mathrm{C}(\mathrm{C}(\mathrm{C}(\mathrm{C}(\mathrm{C}(\mathrm{C}(\mathrm{H})(\mathrm{F}) \mathrm{H})(\mathrm{H}) \mathrm{Br})(\mathrm{H}) \mathrm{F})(\mathrm{Br}) \mathrm{H})(\mathrm{Br}) \mathrm{H})(\mathrm{Br}) \mathrm{F})(\mathrm{H}) \mathrm{H})(\mathrm{F}) \mathrm{H})(\mathrm{H}) \mathrm{H})(\mathrm{H}) \mathrm{F})(\mathrm{H}) \mathrm{H})(\mathrm{F}) \mathrm{F})\left({ }_{\mathrm{C}}{ }^{2} \mathrm{H}^{2} 6 \mathrm{Br} 5 \mathrm{~F} 7\right.$ $\mathrm{H})(\mathrm{H}) \mathrm{Br}$

$\mathrm{C}(\mathrm{C}(\mathrm{C}(\mathrm{C}(\mathrm{C}(\mathrm{C}(\mathrm{C}(\mathrm{C}(\mathrm{C}(\mathrm{C}(\mathrm{C}(\mathrm{C}(\mathrm{C}(\mathrm{F})(\mathrm{H}) \mathrm{H})(\mathrm{H}) \mathrm{Br})(\mathrm{H}) \mathrm{F})(\mathrm{H}) \mathrm{H})(\mathrm{H}) \mathrm{Cl})(\mathrm{H}) \mathrm{H})(\mathrm{F}) \mathrm{H})(\mathrm{H}) \mathrm{H})(\mathrm{F}) \mathrm{Br})(\mathrm{F}) \mathrm{F})(\mathrm{Br}) \mathrm{H})(\mathrm{H}) \mathrm{H})($ $\mathrm{Cl})(\mathrm{F}) \mathrm{H}$

$\mathrm{C}(\mathrm{C}(\mathrm{C}(\mathrm{C}(\mathrm{C}(\mathrm{C}(\mathrm{C}(\mathrm{C}(\mathrm{C}(\mathrm{C}(\mathrm{C}(\mathrm{C}(\mathrm{C}(\mathrm{H})(\mathrm{F}) \mathrm{H})(\mathrm{H}) \mathrm{H})(\mathrm{H}) \mathrm{H})(\mathrm{F}) \mathrm{Br})(\mathrm{H}) \mathrm{Br})(\mathrm{F}) \mathrm{H})(\mathrm{H}) \mathrm{F})(\mathrm{H}) \mathrm{F})(\mathrm{H}) \mathrm{Cl})(\mathrm{H}) \mathrm{F})(\mathrm{Cl}) \mathrm{H})(\mathrm{Br}) \mathrm{H})$ $(\mathrm{H})(\mathrm{Br}) \mathrm{H}$

$\mathrm{C} 13 \mathrm{H} 14 \mathrm{ClBr} 4 \mathrm{~F} 9$

$\mathrm{C} 13 \mathrm{H} 15 \mathrm{Cl} 2 \mathrm{Br} 6 \mathrm{~F} 5$

$\mathrm{C} 13 \mathrm{H} 15 \mathrm{Cl} \mathrm{Br} 3 \mathrm{~F} 7$

$13 \mathrm{H} 15 \mathrm{Cl} 4 \mathrm{Br} 2 \mathrm{~F}$

$\mathrm{C} 13 \mathrm{H} 15 \mathrm{Cl} 16 \mathrm{Br} 2 \mathrm{~F} 5$

$13 \mathrm{H} 15 \mathrm{Cl} 8 \mathrm{BrF} 4$

$13 \mathrm{H} 16 \mathrm{Cl} 2 \mathrm{Br} 3 \mathrm{~F} 7$

$\mathrm{C} 13 \mathrm{H} 16 \mathrm{Cl} 2 \mathrm{Br} 4 \mathrm{~F} 6$
EPI_EPI_EPI_Exp__Exp__Exp__DFT_DFT_DFT Suite Suite Suite corr corr corr_corr_corr corr

$\begin{array}{lllllllllll}7.6 & 7.55 & -0.05 & 6.34 & 6.40 & -0.05 & 6.56 & 11.98 & -5.42\end{array}$ $\begin{array}{lllllllll}9.24 & 7.95 & -1.29 & 6.94 & 8.23 & -1.29 & 6.87 & 14.99 & -8.12\end{array}$ $\begin{array}{lllllllll}10.8 & 8.28 & -2.53 & 7.43 & 9.96 & -2.53 & 7.12 & 17.87 & -10.75\end{array}$ $\begin{array}{lllllllll}11.9 & 8.09 & -3.77 & 7.15 & 10.92 & -3.77 & 6.98 & 19.79 & -12.82\end{array}$ $\begin{array}{llllrrrrr}7.93 & 7.12 & -0.81 & 5.70 & 6.51 & -0.81 & 6.23 & 12.57 & -6.34\end{array}$ $\begin{array}{llllllllll}7.93 & 7.12 & -0.81 & 5.70 & 6.51 & -0.81 & 6.23 & 12.57 & -6.34 \\ 10.3 & 8.27 & -2.04 & 7.42 & 9.46 & -2.04 & 7.11 & 16.96 & -9.84\end{array}$ $\begin{array}{lllllllll}12 & 8.67 & -3.28 & 8.01 & 11.30 & -3.28 & 7.42 & 19.97 & -12.54\end{array}$ $\begin{array}{llllllllll}9.07 & 7.51 & -1.56 & 6.28 & 7.84 & -1.56 & 6.53 & 14.67 & -8.14\end{array}$ $\begin{array}{llllllllll}11.4 & 8.58 & -2.80 & 7.88 & 10.68 & -2.80 & 7.35 & 18.91 & -11.56\end{array}$ $\begin{array}{rrrrrrrrrr}8.1 & 7.78 & -0.32 & 6.69 & 7.01 & -0.32 & 6.74 & 12.89 & -6.15\end{array}$ $\begin{array}{lllllllll}10.8 & 8.49 & -2.31 & 7.75 & 10.06 & -2.31 & 7.28 & 17.85 & -10.57\end{array}$ $\begin{array}{llllllllll}9.23 & 8.16 & -1.07 & 7.25 & 8.33 & -1.07 & 7.03 & 14.97 & -7.94\end{array}$

$\begin{array}{lllllllll}7.6 & 7.76 & 0.16 & 6.66 & 6.49 & 0.16 & 6.72 & 11.97 & -5.24\end{array}$ $\begin{array}{llllllllll}9.33 & 8.74 & -0.59 & 8.12 & 8.71 & -0.59 & 7.47 & 15.15 & -7.67\end{array}$ $\begin{array}{llllllllll}9.33 & 8.74 & -0.59 & 8.12 & 8.71 & -0.59 & 7.47 & 15.15 & -7.67 \\ 8.92 & 8.38 & -0.54 & 7.58 & 8.12 & -0.54 & 7.20 & 14.40 & -7.20\end{array}$ $\begin{array}{llllllllll}9.08 & 7.3 & -1.78 & 5.97 & 7.75 & -1.78 & 6.37 & 14.69 & -8.32\end{array}$ $\begin{array}{lllllllll}11.5 & 8.45 & -3.01 & 7.69 & 10.70 & -3.01 & 7.25 & 19.07 & -11.82\end{array}$ $\begin{array}{lllllllll}12.4 & 8.11 & -4.25 & 7.18 & 11.43 & -4.25 & 6.99 & 20.72 & -13.73\end{array}$ $\begin{array}{rrrrrrrrrr}12.4 & 8.11 & -4.25 & 7.18 & 11.43 & -4.25 & 6.99 & 20.72 & -13.73 \\ 9.11 & 7.79 & -1.32 & 6.70 & 8.03 & -1.32 & 6.75 & 14.75 & -8.01\end{array}$ $10.2 \quad \begin{array}{rrrrrrrrr}1.6 & -2.56 & 6.42 & 8.98 & -2.56 & 6.60 & 16.68 & -10.08\end{array}$ $\begin{array}{rrrrrrrrr}11.8 & 8 & -3.80 & 7.01 & 10.81 & -3.80 & 6.91 & 19.69 & -12.78\end{array}$ $\begin{array}{llllllllll}9.01 & 7.42 & -1.59 & 6.15 & 7.74 & -1.59 & 6.46 & 14.56 & -8.10\end{array}$ $\begin{array}{lllllllll}11.3 & 8.49 & -2.83 & 7.75 & 10.57 & -2.83 & 7.28 & 18.80 & -11.52\end{array}$ $\begin{array}{rrrrrrrrr}1.3 & 8.49 & -2.83 & 7.75 & 10.57 & -2.83 & 7.28 & 18.80 & -11.52 \\ 9.11 & 8 & -1.11 & 7.01 & 8.12 & -1.11 & 6.91 & 14.74 & -7.83\end{array}$ $\begin{array}{lrlllllll}9.11 & 8 & -1.11 & 7.01 & 8.12 & -1.11 & 6.91 & 14.74 & -7.83 \\ 10.7 & 8.4 & -2.34 & 7.61 & 9.96 & -2.34 & 7.21 & 17.75 & -10.53\end{array}$ $\begin{array}{lllllllll}7.39 & 7.52 & 0.13 & 6.30 & 6.17 & 0.13 & 6.54 & 11.59 & -5.05\end{array}$ $\begin{array}{llllllllll}9.36 & 7.5 & -1.86 & 6.27 & 8.13 & -1.86 & 6.52 & 15.20 & -8.68\end{array}$ $\begin{array}{lllllllll}7.79 & 7.17 & -0.62 & 5.78 & 6.40 & -0.62 & 6.27 & 12.32 & -6.05\end{array}$ $\begin{array}{lllllllll}7.79 & 7.17 & -0.62 & 5.78 & 6.40 & -0.62 & 6.27 & 12.32 & -6.05 \\ 8.85 & 7.48 & -1.37 & 6.24 & 7.61 & -1.37 & 6.51 & 14.27 & -7.76\end{array}$ $\begin{array}{llllllllll}8.85 & 7.48 & -1.37 & 6.24 & 7.61 & -1.37 & 6.51 & 14.27 & -7.76 \\ 7.88 & 7.74 & -0.14 & 6.63 & 6.76 & -0.14 & 6.71 & 12.48 & -5.77\end{array}$ $\begin{array}{lllllllll}9.76 & 8.87 & -0.89 & 8.31 & 9.20 & -0.89 & 7.57 & 15.93 & -8.36\end{array}$ $\begin{array}{llllllllll}7.87 & 7.03 & -0.84 & 5.57 & 6.41 & -0.84 & 6.16 & 12.47 & -6.30\end{array}$ $\begin{array}{lllllllll}9.52 & 7.44 & -2.07 & 6.18 & 8.25 & -2.07 & 6.48 & 15.49 & -9.01\end{array}$ $\begin{array}{rrrrrrrrr}9.52 & 7.44 & -2.07 & 6.18 & 8.25 & -2.07 & 6.48 & 15.49 & -9.01 \\ 11.2 & 7.91 & -3.31 & 6.88 & 10.19 & -3.31 & 6.84 & 18.63 & -11.79\end{array}$ $\begin{array}{llllllllll}7.97 & 7.59 & -0.38 & 6.40 & 6.79 & -0.38 & 6.59 & 12.66 & -6.07\end{array}$ $\begin{array}{rrrrrrrrr}9.62 & 8 & -1.62 & 7.01 & 8.64 & -1.62 & 6.91 & 15.69 & -8.78\end{array}$ $\begin{array}{llllllllll}10.5 & 7.66 & -2.86 & 6.51 & 9.37 & -2.86 & 6.65 & 17.34 & -10.69\end{array}$ $\begin{array}{lllllllll}7.73 & 7.08 & -0.65 & 5.64 & 6.29 & -0.65 & 6.20 & 12.22 & -6.02\end{array}$ $\begin{array}{lllllllll}7.73 & 7.08 & -0.65 & 5.64 & 6.29 & -0.65 & 6.20 & 12.22 & -6.02 \\ 9.37 & 7.48 & -1.89 & 6.24 & 8.13 & -1.89 & 6.51 & 15.22 & -8.72\end{array}$ $\begin{array}{llllllllll}9.46 & 8.06 & -1.40 & 7.10 & 8.51 & -1.40 & 6.95 & 15.40 & -8.44\end{array}$ $\begin{array}{lllllllll}8.29 & 7.37 & -0.92 & 6.07 & 6.99 & -0.92 & 6.42 & 13.24 & -6.82\end{array}$ $\begin{array}{llllllllll}7.57 & 7.14 & -0.43 & 5.73 & 6.16 & -0.43 & 6.25 & 11.92 & -5.68\end{array}$ $\begin{array}{lllllllll}8.31 & 7.17 & -1.14 & 5.78 & 6.91 & -1.14 & 6.27 & 13.27 & -7.00\end{array}$ $\begin{array}{llllllllll}9.95 & 7.57 & -2.38 & 6.37 & 8.75 & -2.38 & 6.58 & 16.28 & -9.71\end{array}$ $\begin{array}{llllllllll}7.59 & 6.91 & -0.68 & 5.39 & 6.07 & -0.68 & 6.07 & 11.96 & -5.89\end{array}$ $\begin{array}{llllllllll}9.31 & 7.39 & -1.92 & 6.10 & 8.03 & -1.92 & 6.44 & 15.12 & -8.68\end{array}$ $\begin{array}{lllllllll}8.16 & 7.21 & -0.95 & 5.84 & 6.79 & -0.95 & 6.30 & 13.00 & -6.70\end{array}$ $\begin{array}{lllllllll}8.33 & 7.86 & -0.47 & 6.81 & 7.27 & -0.47 & 6.80 & 13.31 & -6.51\end{array}$ $\begin{array}{llllllllll}8.67 & 7.23 & -1.44 & 5.87 & 7.30 & -1.44 & 6.31 & 13.93 & -7.62\end{array}$ $\begin{array}{llllllllll}8.02 & 7.04 & -0.98 & 5.58 & 6.57 & -0.98 & 6.17 & 12.75 & -6.58\end{array}$ $\begin{array}{llllllllll}7.53 & 7.03 & -0.50 & 5.57 & 6.06 & -0.50 & 6.16 & 11.84 & -5.68\end{array}$ $\begin{array}{llllllllll}9.16 & 8.91 & -0.25 & 8.37 & 8.62 & -0.25 & 7.61 & 14.84 & -7.24\end{array}$ $\begin{array}{lllllllll}8.76 & 8.56 & -0.20 & 7.85 & 8.05 & -0.20 & 7.34 & 14.11 & -6.77\end{array}$ $\begin{array}{lllllllll}8.62 & 8.6 & -0.02 & 7.91 & 7.93 & -0.02 & 7.37 & 13.84 & -6.47\end{array}$ $\begin{array}{lllllllll}10.2 & 8.93 & -1.25 & 8.40 & 9.65 & -1.25 & 7.62 & 16.72 & -9.10\end{array}$ $\begin{array}{lllllllll}8.04 & 8.51 & 0.47 & 7.78 & 7.31 & 0.47 & 7.30 & 12.78 & -5.48\end{array}$ $\begin{array}{lllllllll}9.35 & 8.53 & -0.82 & 7.81 & 8.62 & -0.82 & 7.31 & 15.18 & -7.87\end{array}$ $\begin{array}{lllllllll}8.3 & 7.99 & -0.31 & 7.00 & 7.31 & -0.31 & 6.90 & 13.26 & -6.37\end{array}$ $\begin{array}{lllllllll}9.54 & 8.96 & -0.58 & 8.45 & 9.03 & -0.58 & 7.64 & 15.54 & -7.89\end{array}$ $\begin{array}{lllllllll}7.91 & 8.35 & 0.44 & 7.54 & 7.10 & 0.44 & 7.18 & 12.55 & -5.37\end{array}$ $\begin{array}{lllllllll}12 & 8.93 & -3.09 & 8.40 & 11.49 & -3.09 & 7.62 & 20.09 & -12.47\end{array}$ $\begin{array}{lllllllll}8.17 & 8.04 & -0.13 & 7.07 & 7.20 & -0.13 & 6.94 & 13.02 & -6.08\end{array}$ $\begin{array}{lllllllll}8.33 & 8.69 & 0.36 & 8.04 & 7.69 & 0.36 & 7.44 & 13.32 & -5.88\end{array}$ $\begin{array}{lllllllll}9.72 & 8.57 & -1.15 & 7.87 & 9.01 & -1.15 & 7.34 & 15.86 & -8.51\end{array}$ $\begin{array}{lllllllll}10.2 & 8.8 & -1.41 & 8.21 & 9.62 & -1.41 & 7.52 & 16.77 & -9.25\end{array}$ $\begin{array}{lllllllll}9.42 & 8.77 & -0.65 & 8.16 & 8.81 & -0.65 & 7.50 & 15.31 & -7.81\end{array}$ $\begin{array}{lllllllll}8.28 & 8.6 & 0.32 & 7.91 & 7.59 & 0.32 & 7.37 & 13.21 & -5.85\end{array}$ $\begin{array}{lllllllll}9.17 & 8.26 & -0.91 & 7.40 & 8.31 & -0.91 & 7.11 & 14.86 & -7.75\end{array}$ 
SMILE Generated

$\mathrm{C}(\mathrm{C}(\mathrm{C}(\mathrm{C}(\mathrm{C}(\mathrm{C}(\mathrm{C}(\mathrm{C}(\mathrm{C}(\mathrm{C}(\mathrm{C}(\mathrm{C}(\mathrm{C}(\mathrm{F})(\mathrm{H}) \mathrm{F})(\mathrm{F}) \mathrm{H})(\mathrm{H}) \mathrm{H})(\mathrm{H}) \mathrm{Br})(\mathrm{Cl}) \mathrm{Br})(\mathrm{H}) \mathrm{H})(\mathrm{H}) \mathrm{Cl})(\mathrm{H}) \mathrm{H})(\mathrm{F}) \mathrm{H})(\mathrm{H}) \mathrm{F})(\mathrm{Cl}) \mathrm{F})(\mathrm{H}) \mathrm{H})$ $\mathrm{Br})(\mathrm{H}) \mathrm{H}$

$\mathrm{C}(\mathrm{C}(\mathrm{C}(\mathrm{C}(\mathrm{C}(\mathrm{C}(\mathrm{C}(\mathrm{C}(\mathrm{C}(\mathrm{C}(\mathrm{C}(\mathrm{C}(\mathrm{C}(\mathrm{H})(\mathrm{H}) \mathrm{Cl})(\mathrm{Cl}) \mathrm{F})(\mathrm{H}) \mathrm{Cl})(\mathrm{H}) \mathrm{F})(\mathrm{H}) \mathrm{H})(\mathrm{H}) \mathrm{H})(\mathrm{H}) \mathrm{H})(\mathrm{Br}) \mathrm{Br})(\mathrm{F}) \mathrm{H})(\mathrm{Cl}) \mathrm{H})(\mathrm{H}) \mathrm{H})$ $(\mathrm{H}) \mathrm{F})(\mathrm{F})(\mathrm{H}) \mathrm{F}$

$\mathrm{C}(\mathrm{C}(\mathrm{C}(\mathrm{C}(\mathrm{C}(\mathrm{C}(\mathrm{C}(\mathrm{C}(\mathrm{C}(\mathrm{C}(\mathrm{C}(\mathrm{C}(\mathrm{C}(\mathrm{Br})(\mathrm{F}) \mathrm{H})(\mathrm{H}) \mathrm{H})(\mathrm{H}) \mathrm{H})(\mathrm{Cl}) \mathrm{H})(\mathrm{H}) \mathrm{H})(\mathrm{Cl}) \mathrm{Br})(\mathrm{H}) \mathrm{F})(\mathrm{H}) \mathrm{H})(\mathrm{H}) \mathrm{Cl})(\mathrm{F}) \mathrm{H})(\mathrm{H}) \mathrm{F})(\mathrm{F}) \mathrm{H})$ $(\mathrm{H})(\mathrm{Cl}) \mathrm{Br}$

$\mathrm{C}(\mathrm{C}(\mathrm{C}(\mathrm{C}(\mathrm{C}(\mathrm{C}(\mathrm{C}(\mathrm{C}(\mathrm{C}(\mathrm{C}(\mathrm{C}(\mathrm{C}(\mathrm{C}(\mathrm{H})(\mathrm{H}) \mathrm{F})(\mathrm{H}) \mathrm{Cl})(\mathrm{H}) \mathrm{H})(\mathrm{H}) \mathrm{F})(\mathrm{H}) \mathrm{H})(\mathrm{Cl}) \mathrm{H})(\mathrm{H}) \mathrm{H})(\mathrm{H}) \mathrm{Cl})(\mathrm{H}) \mathrm{Br})(\mathrm{Br}) \mathrm{H})(\mathrm{F}) \mathrm{F})$

$(\mathrm{H}) \mathrm{Cl})(\mathrm{H})(\mathrm{Br}) \mathrm{Cl}$

$\mathrm{C}(\mathrm{C}(\mathrm{C}(\mathrm{C}(\mathrm{C}(\mathrm{C}(\mathrm{C}(\mathrm{C}(\mathrm{C}(\mathrm{C}(\mathrm{C}(\mathrm{C}(\mathrm{C}(\mathrm{Cl})(\mathrm{Cl}) \mathrm{H})(\mathrm{H}) \mathrm{H})(\mathrm{F}) \mathrm{H})(\mathrm{H}) \mathrm{F})(\mathrm{H}) \mathrm{Cl})(\mathrm{Cl}) \mathrm{H})(\mathrm{Cl}) \mathrm{Cl})(\mathrm{H}) \mathrm{H})(\mathrm{F}) \mathrm{H})(\mathrm{H}) \mathrm{H})(\mathrm{F}) \mathrm{H})$

$(\mathrm{Cl}) \mathrm{H})(\mathrm{H})(\mathrm{Cl}) \mathrm{H}$

$\mathrm{C}(\mathrm{C}(\mathrm{C}(\mathrm{C}(\mathrm{C}(\mathrm{C}(\mathrm{C}(\mathrm{C}(\mathrm{C}(\mathrm{C}(\mathrm{C}(\mathrm{C}(\mathrm{C}(\mathrm{F})(\mathrm{H}) \mathrm{F})(\mathrm{Cl}) \mathrm{H})(\mathrm{H}) \mathrm{F})(\mathrm{Cl}) \mathrm{Cl})(\mathrm{H}) \mathrm{Cl})(\mathrm{Cl}) \mathrm{H})(\mathrm{Cl}) \mathrm{H})(\mathrm{H}) \mathrm{Cl})(\mathrm{H}) \mathrm{H})(\mathrm{H}) \mathrm{Cl})(\mathrm{H}) \mathrm{Cl})(\mathrm{H})$ $\mathrm{H})(\mathrm{H})(\mathrm{H}) \mathrm{H}$

$\mathrm{C}(\mathrm{C}(\mathrm{C}(\mathrm{C}(\mathrm{C}(\mathrm{C}(\mathrm{C}(\mathrm{C}(\mathrm{C}(\mathrm{C}(\mathrm{C}(\mathrm{C}(\mathrm{C}(\mathrm{F})(\mathrm{H}) \mathrm{H})(\mathrm{H}) \mathrm{H})(\mathrm{H}) \mathrm{Cl})(\mathrm{H}) \mathrm{H})(\mathrm{Br}) \mathrm{H})(\mathrm{F}) \mathrm{H})(\mathrm{F}) \mathrm{H})(\mathrm{H}) \mathrm{H})(\mathrm{H}) \mathrm{F})(\mathrm{H}) \mathrm{Br})(\mathrm{Br}) \mathrm{H})$

$(\mathrm{H}) \mathrm{Br})(\mathrm{Br})(\mathrm{F}) \mathrm{Br}$

$\mathrm{C}(\mathrm{C}(\mathrm{C}(\mathrm{C}(\mathrm{C}(\mathrm{C}(\mathrm{C}(\mathrm{C}(\mathrm{C}(\mathrm{C}(\mathrm{C}(\mathrm{C}(\mathrm{C}(\mathrm{H})(\mathrm{H}) \mathrm{F})(\mathrm{H}) \mathrm{H})(\mathrm{H}) \mathrm{Br})(\mathrm{H}) \mathrm{Br})(\mathrm{F}) \mathrm{H})(\mathrm{H}) \mathrm{Br})(\mathrm{H}) \mathrm{H})(\mathrm{Br}) \mathrm{H})(\mathrm{H}) \mathrm{Br})(\mathrm{H}) \mathrm{F})(\mathrm{F}) \mathrm{H})(\mathrm{F}) \mathrm{F})$

$(\mathrm{H})(\mathrm{H}) \mathrm{H}$

$\mathrm{C}(\mathrm{C}(\mathrm{C}(\mathrm{C}(\mathrm{C}(\mathrm{C}(\mathrm{C}(\mathrm{C}(\mathrm{C}(\mathrm{C}(\mathrm{C}(\mathrm{C}(\mathrm{C}(\mathrm{H})(\mathrm{H}) \mathrm{H})(\mathrm{H}) \mathrm{F})(\mathrm{H}) \mathrm{Br})(\mathrm{H}) \mathrm{Br})(\mathrm{H}) \mathrm{F})(\mathrm{Br}) \mathrm{H})(\mathrm{Br}) \mathrm{H})(\mathrm{Br}) \mathrm{H})(\mathrm{F}) \mathrm{H})(\mathrm{H}) \mathrm{H})(\mathrm{H}) \mathrm{H})(\mathrm{F}) \mathrm{B}$

r) $(\mathrm{H})(\mathrm{H}) \mathrm{Br}$

$\mathrm{C}(\mathrm{C}(\mathrm{C}(\mathrm{C}(\mathrm{C}(\mathrm{C}(\mathrm{C}(\mathrm{C}(\mathrm{C}(\mathrm{C}(\mathrm{C}(\mathrm{C}(\mathrm{C}(\mathrm{Cl})(\mathrm{H}) \mathrm{Br})(\mathrm{H}) \mathrm{F})(\mathrm{F}) \mathrm{H})(\mathrm{H}) \mathrm{H})(\mathrm{H}) \mathrm{F})(\mathrm{Br}) \mathrm{H})(\mathrm{H}) \mathrm{H})(\mathrm{H}) \mathrm{H})(\mathrm{H}) \mathrm{H})(\mathrm{H}) \mathrm{F})(\mathrm{H}) \mathrm{H})(\mathrm{F}) \mathrm{F})($ $\mathrm{Br})(\mathrm{Cl}) \mathrm{H}$

$\mathrm{C}(\mathrm{C}(\mathrm{C}(\mathrm{C}(\mathrm{C}(\mathrm{C}(\mathrm{C}(\mathrm{C}(\mathrm{C}(\mathrm{C}(\mathrm{C}(\mathrm{C}(\mathrm{C}(\mathrm{Br})(\mathrm{F}) \mathrm{H})(\mathrm{Br}) \mathrm{H})(\mathrm{H}) \mathrm{H})(\mathrm{H}) \mathrm{H})(\mathrm{H}) \mathrm{H})(\mathrm{H}) \mathrm{F})(\mathrm{Br}) \mathrm{H})(\mathrm{Br}) \mathrm{H})(\mathrm{H}) \mathrm{Cl})(\mathrm{H}) \mathrm{H})(\mathrm{H}) \mathrm{H})$

(F)F)(F)(H)Cl

$\mathrm{C}(\mathrm{C}(\mathrm{C}(\mathrm{C}(\mathrm{C}(\mathrm{C}(\mathrm{C}(\mathrm{C}(\mathrm{C}(\mathrm{C}(\mathrm{C}(\mathrm{C}(\mathrm{C}(\mathrm{H})(\mathrm{H}) \mathrm{H})(\mathrm{Br}) \mathrm{H})(\mathrm{H}) \mathrm{Cl})(\mathrm{H}) \mathrm{H})(\mathrm{Cl}) \mathrm{Br})(\mathrm{F}) \mathrm{H})(\mathrm{F}) \mathrm{H})(\mathrm{H}) \mathrm{H})(\mathrm{Cl}) \mathrm{H})(\mathrm{Br}) \mathrm{F})(\mathrm{H}) \mathrm{H})(\mathrm{H})$ $\mathrm{H})(\mathrm{F})(\mathrm{H}) \mathrm{F}$

$\mathrm{C}(\mathrm{C}(\mathrm{C}(\mathrm{C}(\mathrm{C}(\mathrm{C}(\mathrm{C}(\mathrm{C}(\mathrm{C}(\mathrm{C}(\mathrm{C}(\mathrm{C}(\mathrm{C}(\mathrm{Cl})(\mathrm{H}) \mathrm{H})(\mathrm{F}) \mathrm{H})(\mathrm{H}) \mathrm{H})(\mathrm{H}) \mathrm{F})(\mathrm{Cl}) \mathrm{Br})(\mathrm{H}) \mathrm{Br})(\mathrm{H}) \mathrm{H})(\mathrm{F}) \mathrm{H})(\mathrm{Cl}) \mathrm{H})(\mathrm{H}) \mathrm{H})(\mathrm{H}) \mathrm{Cl})$

(F)H)(H)(H)F

$\mathrm{C}(\mathrm{C}(\mathrm{C}(\mathrm{C}(\mathrm{C}(\mathrm{C}(\mathrm{C}(\mathrm{C}(\mathrm{C}(\mathrm{C}(\mathrm{C}(\mathrm{C}(\mathrm{C}(\mathrm{H})(\mathrm{H}) \mathrm{H})(\mathrm{Br}) \mathrm{H})(\mathrm{H}) \mathrm{Cl})(\mathrm{H}) \mathrm{H})(\mathrm{Br}) \mathrm{H})(\mathrm{Cl}) \mathrm{H})(\mathrm{H}) \mathrm{H})(\mathrm{H}) \mathrm{F})(\mathrm{H}) \mathrm{Cl})(\mathrm{H}) \mathrm{H})(\mathrm{Cl}) \mathrm{F})(\mathrm{Br}$

$\mathrm{H})(\mathrm{F})(\mathrm{H}) \mathrm{Br}$

$\mathrm{C}(\mathrm{C}(\mathrm{C}(\mathrm{C}(\mathrm{C}(\mathrm{C}(\mathrm{C}(\mathrm{C}(\mathrm{C}(\mathrm{C}(\mathrm{C}(\mathrm{C}(\mathrm{C}(\mathrm{H})(\mathrm{F}) \mathrm{H})(\mathrm{H}) \mathrm{H})(\mathrm{Cl}) \mathrm{Cl})(\mathrm{F}) \mathrm{H})(\mathrm{Br}) \mathrm{H})(\mathrm{H}) \mathrm{H})(\mathrm{F}) \mathrm{Cl})(\mathrm{Cl}) \mathrm{H})(\mathrm{H}) \mathrm{Cl}(\mathrm{H}) \mathrm{H})(\mathrm{H}) \mathrm{H})$

$(\mathrm{H}) \mathrm{H})(\mathrm{H})(\mathrm{F}) \mathrm{F}$

$\mathrm{C}(\mathrm{C}(\mathrm{C}(\mathrm{C}(\mathrm{C}(\mathrm{C}(\mathrm{C}(\mathrm{C}(\mathrm{C}(\mathrm{C}(\mathrm{C}(\mathrm{C}(\mathrm{C}(\mathrm{H})(\mathrm{H}) \mathrm{Cl})(\mathrm{H}) \mathrm{H})(\mathrm{Cl}) \mathrm{H})(\mathrm{H}) \mathrm{H})(\mathrm{F}) \mathrm{H})(\mathrm{F}) \mathrm{H})(\mathrm{H}) \mathrm{Cl})(\mathrm{H}) \mathrm{Cl})(\mathrm{Cl}) \mathrm{F})(\mathrm{H}) \mathrm{H})(\mathrm{H}) \mathrm{F})(\mathrm{H}) \mathrm{Cl})$

$(\mathrm{H})(\mathrm{H}) \mathrm{Br}$

$\mathrm{C}(\mathrm{C}(\mathrm{C}(\mathrm{C}(\mathrm{C}(\mathrm{C}(\mathrm{C}(\mathrm{C}(\mathrm{C}(\mathrm{C}(\mathrm{C}(\mathrm{C}(\mathrm{C}(\mathrm{H})(\mathrm{Cl}) \mathrm{H})(\mathrm{H}) \mathrm{H})(\mathrm{Cl}) \mathrm{H})(\mathrm{Cl}) \mathrm{Br})(\mathrm{F}) \mathrm{H})(\mathrm{H}) \mathrm{H})(\mathrm{H}) \mathrm{Cl})(\mathrm{H}) \mathrm{H})(\mathrm{Cl}) \mathrm{H})(\mathrm{H}) \mathrm{H})(\mathrm{F}) \mathrm{H})(\mathrm{Cl})$

$\mathrm{H})(\mathrm{H})(\mathrm{F}) \mathrm{Cl}$

$\mathrm{C}(\mathrm{C}(\mathrm{C}(\mathrm{C}(\mathrm{C}(\mathrm{C}(\mathrm{C}(\mathrm{C}(\mathrm{C}(\mathrm{C}(\mathrm{C}(\mathrm{C}(\mathrm{C}(\mathrm{H})(\mathrm{H}) \mathrm{H})(\mathrm{H}) \mathrm{H})(\mathrm{H}) \mathrm{H})(\mathrm{Cl}) \mathrm{H})(\mathrm{H}) \mathrm{Cl})(\mathrm{H}) \mathrm{F})(\mathrm{Cl}) \mathrm{H})(\mathrm{F}) \mathrm{H})(\mathrm{Cl}) \mathrm{Cl})(\mathrm{H}) \mathrm{Cl})(\mathrm{Cl}) \mathrm{H})(\mathrm{H})$

$\mathrm{H})(\mathrm{Cl})(\mathrm{F}) \mathrm{H}$

$\mathrm{C}(\mathrm{C}(\mathrm{C}(\mathrm{C}(\mathrm{C}(\mathrm{C}(\mathrm{C}(\mathrm{C}(\mathrm{C}(\mathrm{C}(\mathrm{C}(\mathrm{C}(\mathrm{C}(\mathrm{H})(\mathrm{H}) \mathrm{Cl})(\mathrm{F}) \mathrm{H})(\mathrm{H}) \mathrm{Cl})(\mathrm{H}) \mathrm{Br})(\mathrm{Cl}) \mathrm{H})(\mathrm{Cl}) \mathrm{H})(\mathrm{Cl}) \mathrm{H})(\mathrm{H}) \mathrm{Cl})(\mathrm{Cl}) \mathrm{H})(\mathrm{H}) \mathrm{H})(\mathrm{Cl}) \mathrm{H})$

$(\mathrm{Cl}) \mathrm{H})(\mathrm{H})(\mathrm{H}) \mathrm{H}$

$\mathrm{C}(\mathrm{C}(\mathrm{C}(\mathrm{C}(\mathrm{C}(\mathrm{C}(\mathrm{C}(\mathrm{C}(\mathrm{C}(\mathrm{C}(\mathrm{C}(\mathrm{C}(\mathrm{C}(\mathrm{H})(\mathrm{H}) \mathrm{H})(\mathrm{Br}) \mathrm{H})(\mathrm{F}) \mathrm{F})(\mathrm{Br}) \mathrm{Br})(\mathrm{Br}) \mathrm{H})(\mathrm{H}) \mathrm{H})(\mathrm{F}) \mathrm{H})(\mathrm{H}) \mathrm{F})(\mathrm{H}) \mathrm{H})(\mathrm{Cl}) \mathrm{H})(\mathrm{H}) \mathrm{F})(\mathrm{H}) \mathrm{F})$ $(\mathrm{H})(\mathrm{H}) \mathrm{H}$

$\mathrm{C}(\mathrm{C}(\mathrm{C}(\mathrm{C}(\mathrm{C}(\mathrm{C}(\mathrm{C}(\mathrm{C}(\mathrm{C}(\mathrm{C}(\mathrm{C}(\mathrm{C}(\mathrm{C}(\mathrm{H})(\mathrm{F}) \mathrm{H})(\mathrm{H}) \mathrm{F})(\mathrm{F}) \mathrm{Br})(\mathrm{H}) \mathrm{H})(\mathrm{H}) \mathrm{H})(\mathrm{H}) \mathrm{H})(\mathrm{Br}) \mathrm{H})(\mathrm{H}) \mathrm{F})(\mathrm{H}) \mathrm{H})(\mathrm{H}) \mathrm{Br})(\mathrm{H}) \mathrm{Cl})(\mathrm{F}) \mathrm{H})$ $(\mathrm{Br})(\mathrm{Br}) \mathrm{H}$

$\mathrm{C}(\mathrm{C}(\mathrm{C}(\mathrm{C}(\mathrm{C}(\mathrm{C}(\mathrm{C}(\mathrm{C}(\mathrm{C}(\mathrm{C}(\mathrm{C}(\mathrm{C}(\mathrm{C}(\mathrm{H})(\mathrm{F}) \mathrm{F})(\mathrm{H}) \mathrm{Cl})(\mathrm{H}) \mathrm{H})(\mathrm{H}) \mathrm{H})(\mathrm{Br}) \mathrm{H})(\mathrm{H}) \mathrm{F})(\mathrm{Br}) \mathrm{Br})(\mathrm{Br}) \mathrm{H})(\mathrm{F}) \mathrm{H})(\mathrm{Br}) \mathrm{H})(\mathrm{H}) \mathrm{H})(\mathrm{Br})$ $\mathrm{H})(\mathrm{H})(\mathrm{H}) \mathrm{H}$

$\mathrm{C}(\mathrm{C}(\mathrm{C}(\mathrm{C}(\mathrm{C}(\mathrm{C}(\mathrm{C}(\mathrm{C}(\mathrm{C}(\mathrm{C}(\mathrm{C}(\mathrm{C}(\mathrm{C}(\mathrm{H})(\mathrm{H}) \mathrm{F})(\mathrm{F}) \mathrm{H})(\mathrm{H}) \mathrm{Br})(\mathrm{H}) \mathrm{Br})(\mathrm{H}) \mathrm{F})(\mathrm{H}) \mathrm{H})(\mathrm{H}) \mathrm{H})(\mathrm{H}) \mathrm{H})(\mathrm{H}) \mathrm{H})(\mathrm{H}) \mathrm{H})(\mathrm{H}) \mathrm{Br})(\mathrm{Br}) \mathrm{F})$

(F)(F)H

$\mathrm{C}(\mathrm{C}(\mathrm{C}(\mathrm{C}(\mathrm{C}(\mathrm{C}(\mathrm{C}(\mathrm{C}(\mathrm{C}(\mathrm{C}(\mathrm{C}(\mathrm{C}(\mathrm{C}(\mathrm{F})(\mathrm{H}) \mathrm{H})(\mathrm{H}) \mathrm{Br})(\mathrm{H}) \mathrm{H})(\mathrm{H}) \mathrm{H})(\mathrm{F}) \mathrm{H})(\mathrm{Br}) \mathrm{H})(\mathrm{H}) \mathrm{F})(\mathrm{H}) \mathrm{H})(\mathrm{F}) \mathrm{H})(\mathrm{F}) \mathrm{H})(\mathrm{H}) \mathrm{H})(\mathrm{Br}) \mathrm{B}$

$(\mathrm{H})(\mathrm{Br}) \mathrm{H}$

$\mathrm{C}(\mathrm{C}(\mathrm{C}(\mathrm{C}(\mathrm{C}(\mathrm{C}(\mathrm{C}(\mathrm{C}(\mathrm{C}(\mathrm{C}(\mathrm{C}(\mathrm{C}(\mathrm{C}(\mathrm{H})(\mathrm{H}) \mathrm{H})(\mathrm{Br}) \mathrm{H})(\mathrm{Br}) \mathrm{H})(\mathrm{H}) \mathrm{H})(\mathrm{H}) \mathrm{Br})(\mathrm{F}) \mathrm{H})(\mathrm{H}) \mathrm{Br})(\mathrm{H}) \mathrm{Br})(\mathrm{F}) \mathrm{H})(\mathrm{H}) \mathrm{F})(\mathrm{F}) \mathrm{Br})(\mathrm{H})$ $\mathrm{H})(\mathrm{H})(\mathrm{H}) \mathrm{H}$

$\mathrm{C}(\mathrm{C}(\mathrm{C}(\mathrm{C}(\mathrm{C}(\mathrm{C}(\mathrm{C}(\mathrm{C}(\mathrm{C}(\mathrm{C}(\mathrm{C}(\mathrm{C}(\mathrm{C}(\mathrm{H})(\mathrm{F}) \mathrm{H})(\mathrm{H}) \mathrm{Br})(\mathrm{Br}) \mathrm{H})(\mathrm{H}) \mathrm{Br})(\mathrm{H}) \mathrm{F})(\mathrm{H}) \mathrm{F})(\mathrm{F}) \mathrm{H})(\mathrm{H}) \mathrm{H})(\mathrm{Cl}) \mathrm{H})(\mathrm{H}) \mathrm{H})(\mathrm{H}) \mathrm{H})(\mathrm{F}) \mathrm{H})$ $(\mathrm{H})(\mathrm{Cl}) \mathrm{H}$

$\mathrm{C}(\mathrm{C}(\mathrm{C}(\mathrm{C}(\mathrm{C}(\mathrm{C}(\mathrm{C}(\mathrm{C}(\mathrm{C}(\mathrm{C}(\mathrm{C}(\mathrm{C}(\mathrm{C}(\mathrm{H})(\mathrm{H}) \mathrm{Br})(\mathrm{F}) \mathrm{Br})(\mathrm{Cl}) \mathrm{H})(\mathrm{H}) \mathrm{H})(\mathrm{H}) \mathrm{Cl})(\mathrm{H}) \mathrm{F})(\mathrm{H}) \mathrm{H})(\mathrm{Cl}) \mathrm{H})(\mathrm{H}) \mathrm{H})(\mathrm{H}) \mathrm{H})(\mathrm{H}) \mathrm{H})$

(F)H)(H)(F)F

$\mathrm{C}(\mathrm{C}(\mathrm{C}(\mathrm{C}(\mathrm{C}(\mathrm{C}(\mathrm{C}(\mathrm{C}(\mathrm{C}(\mathrm{C}(\mathrm{C}(\mathrm{C}(\mathrm{C}(\mathrm{H})(\mathrm{Br}) \mathrm{H})(\mathrm{Br}) \mathrm{H})(\mathrm{H}) \mathrm{H})(\mathrm{H}) \mathrm{H})(\mathrm{H}) \mathrm{H})(\mathrm{H}) \mathrm{F})(\mathrm{H}) \mathrm{H})(\mathrm{Cl}) \mathrm{H})(\mathrm{Cl}) \mathrm{H})(\mathrm{F}) \mathrm{H})(\mathrm{Cl}) \mathrm{H})(\mathrm{Cl})$

$\mathrm{Cl})(\mathrm{H})(\mathrm{F}) \mathrm{H}$

$\mathrm{C}(\mathrm{C}(\mathrm{C}(\mathrm{C}(\mathrm{C}(\mathrm{C}(\mathrm{C}(\mathrm{C}(\mathrm{C}(\mathrm{C}(\mathrm{C}(\mathrm{C}(\mathrm{C}(\mathrm{H})(\mathrm{H}) \mathrm{F})(\mathrm{H}) \mathrm{Cl})(\mathrm{H}) \mathrm{H})(\mathrm{Cl}) \mathrm{H})(\mathrm{F}) \mathrm{H})(\mathrm{F}) \mathrm{Br})(\mathrm{H}) \mathrm{Cl})(\mathrm{H}) \mathrm{H})(\mathrm{Cl}) \mathrm{H})(\mathrm{Cl}) \mathrm{H})(\mathrm{F}) \mathrm{H})$

$(\mathrm{H}) \mathrm{H})(\mathrm{H})(\mathrm{H}) \mathrm{H}$

$\mathrm{C}(\mathrm{C}(\mathrm{C}(\mathrm{C}(\mathrm{C}(\mathrm{C}(\mathrm{C}(\mathrm{C}(\mathrm{C}(\mathrm{C}(\mathrm{C}(\mathrm{C}(\mathrm{C}(\mathrm{F})(\mathrm{Cl}) \mathrm{H})(\mathrm{Br}) \mathrm{Cl})(\mathrm{H}) \mathrm{Cl})(\mathrm{H}) \mathrm{H})(\mathrm{H}) \mathrm{H})(\mathrm{H}) \mathrm{Cl})(\mathrm{H}) \mathrm{Cl})(\mathrm{Cl}) \mathrm{H})(\mathrm{H}) \mathrm{Br})(\mathrm{F}) \mathrm{H})(\mathrm{H}) \mathrm{H})(\mathrm{H})$ $\mathrm{H})(\mathrm{H})(\mathrm{H}) \mathrm{H}$

$\mathrm{C}(\mathrm{C}(\mathrm{C}(\mathrm{C}(\mathrm{C}(\mathrm{C}(\mathrm{C}(\mathrm{C}(\mathrm{C}(\mathrm{C}(\mathrm{C}(\mathrm{C}(\mathrm{C}(\mathrm{Cl})(\mathrm{H}) \mathrm{H})(\mathrm{H}) \mathrm{H})(\mathrm{H}) \mathrm{Br})(\mathrm{F}) \mathrm{H})(\mathrm{H}) \mathrm{H})(\mathrm{H}) \mathrm{F})(\mathrm{F}) \mathrm{H})(\mathrm{Cl}) \mathrm{H})(\mathrm{Cl}) \mathrm{Cl})(\mathrm{H}) \mathrm{H})(\mathrm{Cl}) \mathrm{H})$

$(\mathrm{H}) \mathrm{H})(\mathrm{H})(\mathrm{Cl}) \mathrm{H}$

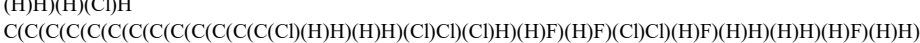

$(\mathrm{H})(\mathrm{H}) \mathrm{H}$

$\mathrm{C}(\mathrm{C}(\mathrm{C}(\mathrm{C}(\mathrm{C}(\mathrm{C}(\mathrm{C}(\mathrm{C}(\mathrm{C}(\mathrm{C}(\mathrm{C}(\mathrm{C}(\mathrm{C}(\mathrm{H})(\mathrm{H}) \mathrm{Cl})(\mathrm{Cl}) \mathrm{H})(\mathrm{Cl}) \mathrm{H})(\mathrm{H}) \mathrm{F})(\mathrm{H}) \mathrm{H})(\mathrm{H}) \mathrm{H})(\mathrm{Br}) \mathrm{H})(\mathrm{H}) \mathrm{Cl})(\mathrm{H}) \mathrm{H})(\mathrm{H}) \mathrm{Br})(\mathrm{Cl}) \mathrm{H})(\mathrm{Cl})$ $\mathrm{H})(\mathrm{H})(\mathrm{H}) \mathrm{Cl}$

$\mathrm{C}(\mathrm{C}(\mathrm{C}(\mathrm{C}(\mathrm{C}(\mathrm{C}(\mathrm{C}(\mathrm{C}(\mathrm{C}(\mathrm{C}(\mathrm{C}(\mathrm{C}(\mathrm{C}(\mathrm{H})(\mathrm{Cl}) \mathrm{H})(\mathrm{H}) \mathrm{H})(\mathrm{Cl}) \mathrm{H})(\mathrm{H}) \mathrm{Cl})(\mathrm{H}) \mathrm{H})(\mathrm{Cl}) \mathrm{Cl})(\mathrm{H}) \mathrm{H})(\mathrm{Cl}) \mathrm{H})(\mathrm{H}) \mathrm{F})(\mathrm{Cl}) \mathrm{H})(\mathrm{H}) \mathrm{H})(\mathrm{F})$

$\mathrm{H})(\mathrm{H})(\mathrm{H}) \mathrm{Cl}$

$\mathrm{C}(\mathrm{C}(\mathrm{C}(\mathrm{C}(\mathrm{C}(\mathrm{C}(\mathrm{C}(\mathrm{C}(\mathrm{C}(\mathrm{C}(\mathrm{C}(\mathrm{C}(\mathrm{C}(\mathrm{H})(\mathrm{F}) \mathrm{H})(\mathrm{H}) \mathrm{H})(\mathrm{F}) \mathrm{H})(\mathrm{H}) \mathrm{H})(\mathrm{F}) \mathrm{H})(\mathrm{Br}) \mathrm{H})(\mathrm{H}) \mathrm{H})(\mathrm{F}) \mathrm{H})(\mathrm{F}) \mathrm{H})(\mathrm{H}) \mathrm{Cl})(\mathrm{Br}) \mathrm{F})(\mathrm{H}) \mathrm{H})($

$\mathrm{H})(\mathrm{Br}) \mathrm{H}$

$\mathrm{C}(\mathrm{C}(\mathrm{C}(\mathrm{C}(\mathrm{C}(\mathrm{C}(\mathrm{C}(\mathrm{C}(\mathrm{C}(\mathrm{C}(\mathrm{C}(\mathrm{C}(\mathrm{C}(\mathrm{H})(\mathrm{F}) \mathrm{H})(\mathrm{H}) \mathrm{H})(\mathrm{H}) \mathrm{H})(\mathrm{H}) \mathrm{F})(\mathrm{H}) \mathrm{Br})(\mathrm{H}) \mathrm{H})(\mathrm{H}) \mathrm{Cl})(\mathrm{H}) \mathrm{H})(\mathrm{F}) \mathrm{H})(\mathrm{H}) \mathrm{Br})(\mathrm{H}) \mathrm{F})(\mathrm{Br}) \mathrm{H})$

$(\mathrm{Br})(\mathrm{H}) \mathrm{F}$

$\mathrm{C}(\mathrm{C}(\mathrm{C}(\mathrm{C}(\mathrm{C}(\mathrm{C}(\mathrm{C}(\mathrm{C}(\mathrm{C}(\mathrm{C}(\mathrm{C}(\mathrm{C}(\mathrm{C}(\mathrm{H})(\mathrm{H}) \mathrm{F})(\mathrm{H}) \mathrm{H})(\mathrm{H}) \mathrm{H})(\mathrm{F}) \mathrm{H})(\mathrm{H}) \mathrm{H})(\mathrm{H}) \mathrm{H})(\mathrm{H}) \mathrm{Br})(\mathrm{F}) \mathrm{Br})(\mathrm{H}) \mathrm{H})(\mathrm{H}) \mathrm{Br})(\mathrm{H}) \mathrm{Br})(\mathrm{F}) \mathrm{H})$

(H)(H)F

$\mathrm{C}(\mathrm{C}(\mathrm{C}(\mathrm{C}(\mathrm{C}(\mathrm{C}(\mathrm{C}(\mathrm{C}(\mathrm{C}(\mathrm{C}(\mathrm{C}(\mathrm{C}(\mathrm{C}(\mathrm{F})(\mathrm{H}) \mathrm{Br})(\mathrm{H}) \mathrm{H})(\mathrm{H}) \mathrm{H})(\mathrm{Br}) \mathrm{H})(\mathrm{Br}) \mathrm{H})(\mathrm{H}) \mathrm{H})(\mathrm{F}) \mathrm{F})(\mathrm{H}) \mathrm{H})(\mathrm{H}) \mathrm{F})(\mathrm{H}) \mathrm{Br})(\mathrm{H}) \mathrm{H})(\mathrm{H}) \mathrm{H})$

$(\mathrm{H})(\mathrm{Br}) \mathrm{H}$

$\mathrm{C}(\mathrm{C}(\mathrm{C}(\mathrm{C}(\mathrm{C}(\mathrm{C}(\mathrm{C}(\mathrm{C}(\mathrm{C}(\mathrm{C}(\mathrm{C}(\mathrm{C}(\mathrm{C}(\mathrm{Br})(\mathrm{Cl}) \mathrm{H})(\mathrm{H}) \mathrm{H})(\mathrm{H}) \mathrm{H})(\mathrm{H}) \mathrm{H})(\mathrm{H}) \mathrm{H})(\mathrm{H}) \mathrm{F})(\mathrm{H}) \mathrm{Br})(\mathrm{H}) \mathrm{F})(\mathrm{H}) \mathrm{H})(\mathrm{F}) \mathrm{H})(\mathrm{Br}) \mathrm{H})$

$(\mathrm{H}) \mathrm{H})(\mathrm{F})(\mathrm{H}) \mathrm{Cl}$

$\mathrm{C}(\mathrm{C}(\mathrm{C}(\mathrm{C}(\mathrm{C}(\mathrm{C}(\mathrm{C}(\mathrm{C}(\mathrm{C}(\mathrm{C}(\mathrm{C}(\mathrm{C}(\mathrm{C}(\mathrm{H})(\mathrm{H}) \mathrm{Br})(\mathrm{H}) \mathrm{H})(\mathrm{H}) \mathrm{F})(\mathrm{H}) \mathrm{H})(\mathrm{F}) \mathrm{H})(\mathrm{F}) \mathrm{H})(\mathrm{H}) \mathrm{Cl})(\mathrm{H}) \mathrm{H})(\mathrm{Br}) \mathrm{H})(\mathrm{H}) \mathrm{H})(\mathrm{Br}) \mathrm{Br})(\mathrm{Cl})$

$\mathrm{H})(\mathrm{H})(\mathrm{H}) \mathrm{H}$

$\mathrm{C}(\mathrm{C}(\mathrm{C}(\mathrm{C}(\mathrm{C}(\mathrm{C}(\mathrm{C}(\mathrm{C}(\mathrm{C}(\mathrm{C}(\mathrm{C}(\mathrm{C}(\mathrm{C}(\mathrm{Cl})(\mathrm{F}) \mathrm{H})(\mathrm{H}) \mathrm{H})(\mathrm{Cl}) \mathrm{H})(\mathrm{H}) \mathrm{H})(\mathrm{H}) \mathrm{H})(\mathrm{Br}) \mathrm{H})(\mathrm{Br}) \mathrm{H})(\mathrm{H}) \mathrm{H})(\mathrm{F}) \mathrm{Br})(\mathrm{H}) \mathrm{H})(\mathrm{H}) \mathrm{Br})(\mathrm{Br})$

$\mathrm{H})(\mathrm{H})(\mathrm{H}) \mathrm{H}$

$\mathrm{C}(\mathrm{C}(\mathrm{C}(\mathrm{C}(\mathrm{C}(\mathrm{C}(\mathrm{C}(\mathrm{C}(\mathrm{C}(\mathrm{C}(\mathrm{C}(\mathrm{C}(\mathrm{C}(\mathrm{Br})(\mathrm{H}) \mathrm{H})(\mathrm{H}) \mathrm{H})(\mathrm{H}) \mathrm{H})(\mathrm{H}) \mathrm{H})(\mathrm{H}) \mathrm{H})(\mathrm{Cl}) \mathrm{H})(\mathrm{H}) \mathrm{H})(\mathrm{F}) \mathrm{H})(\mathrm{Cl}) \mathrm{H})(\mathrm{F}) \mathrm{H})(\mathrm{Cl}) \mathrm{H})$ $(\mathrm{H}) \mathrm{Br})(\mathrm{H})(\mathrm{F}) \mathrm{F}$

\section{Formula}

$\mathrm{C} 13 \mathrm{H} 16 \mathrm{Cl} 3 \mathrm{Br} 3 \mathrm{~F} 6$

$\mathrm{C} 13 \mathrm{H} 16 \mathrm{Cl} 4 \mathrm{Br} 2 \mathrm{~F}$

$\mathrm{C} 13 \mathrm{H} 16 \mathrm{Cl} 4 \mathrm{Br} 3 \mathrm{~F} 5$

$\mathrm{C} 13 \mathrm{H} 16 \mathrm{Cl} 15 \mathrm{Br} 3 \mathrm{~F} 4$

$\mathrm{C} 13 \mathrm{H} 16 \mathrm{Cl} 18 \mathrm{~F} 4$

$\mathrm{C} 13 \mathrm{H} 16 \mathrm{Cl} 19 \mathrm{~F} 3$

C13H16ClBr6F5

$\mathrm{C} 13 \mathrm{H} 17 \mathrm{Br} 5 \mathrm{~F} 6$

C13H17Br7F4

$\mathrm{C} 13 \mathrm{H} 17 \mathrm{Cl} 2 \mathrm{Br} 3 \mathrm{~F} 6$

C13H17Cl2Br4F5

C13H17Cl3Br3F 5

C13H17Cl4Br2F5

$\mathrm{C} 13 \mathrm{H} 17 \mathrm{Cl} 4 \mathrm{Br} 4 \mathrm{~F} 3$

C13H17Cl5BrF5

$\mathrm{C} 13 \mathrm{H} 17 \mathrm{Cl} 6 \mathrm{BrF} 4$

13H17Cl7BrF3

C13H17Cl8F3

$\mathrm{C} 13 \mathrm{H} 17 \mathrm{Cl} 19 \mathrm{BrF}$

C13H17ClBr4F6

$\mathrm{C} 13 \mathrm{H} 17 \mathrm{ClBr} 5 \mathrm{~F} 5$

C13H17ClBr6F4

$\mathrm{C} 13 \mathrm{H} 18 \mathrm{Br} 4 \mathrm{~F} 6$

$\mathrm{C} 13 \mathrm{H} 18 \mathrm{Br} 5 \mathrm{~F}$

$\mathrm{C} 13 \mathrm{H} 18 \mathrm{Br} 6 \mathrm{~F} 4$

$\mathrm{C} 13 \mathrm{H} 18 \mathrm{Cl} 2 \mathrm{Br} 3 \mathrm{~F}$

$\mathrm{C} 13 \mathrm{H} 18 \mathrm{Cl} 3 \mathrm{Br} 2 \mathrm{~F}$

$\mathrm{C} 13 \mathrm{H} 18 \mathrm{C} 15 \mathrm{Br} 2 \mathrm{~F} 3$

$\mathrm{C} 13 \mathrm{H} 18 \mathrm{Cl} 5 \mathrm{BrF} 4$

$\mathrm{C} 13 \mathrm{H} 18 \mathrm{Cl} 6 \mathrm{Br} 2 \mathrm{~F} 2$

C13H18Cl6BrF3

$\mathrm{C} 13 \mathrm{H} 18 \mathrm{Cl} 6 \mathrm{~F} 4$

$\mathrm{C} 13 \mathrm{H} 18 \mathrm{Cl} 17 \mathrm{Br} 2 \mathrm{~F}$

$\mathrm{C} 13 \mathrm{H} 18 \mathrm{Cl} 18 \mathrm{~F} 2$

C13H18ClBr3F 6

$\mathrm{C} 13 \mathrm{H} 18 \mathrm{ClBr} 4 \mathrm{~F} 5$

$\mathrm{C} 13 \mathrm{H} 19 \mathrm{Br} 4 \mathrm{~F} 5$

$\mathrm{C} 13 \mathrm{H} 19 \mathrm{Br} 5 \mathrm{~F} 4$

$\mathrm{C} 13 \mathrm{H} 19 \mathrm{Cl} 2 \mathrm{Br} 3 \mathrm{~F} 4$

$\mathrm{C} 13 \mathrm{H} 19 \mathrm{Cl} 2 \mathrm{Br} 4 \mathrm{~F} 3$

$\mathrm{C} 13 \mathrm{H} 19 \mathrm{Cl} 2 \mathrm{Br} 5 \mathrm{~F} 2$

$\mathrm{C} 13 \mathrm{H} 19 \mathrm{Cl} 3 \mathrm{Br} 2 \mathrm{~F} 4$
lgKoa lgKow lgKaw lgKow lgKoa lgKaw lgKow lgKoa lgKaw _EPI_EPI_EPI_Exp__Exp__Exp__DFT_DFT_DFT Suite Suite Suite corr corr corr_corr _corr corr

$\begin{array}{lllllllll}9.34 & 8.91 & -0.43 & 8.37 & 8.80 & -0.43 & 7.61 & 15.16 & -7.56\end{array}$

$\begin{array}{lllllllll}8.76 & 8.82 & 0.06 & 8.24 & 8.18 & 0.06 & 7.54 & 14.11 & -6.57\end{array}$

$\begin{array}{lllllllll}9.66 & 8.48 & -1.18 & 7.73 & 8.91 & -1.18 & 7.28 & 15.76 & -8.48\end{array}$

$\begin{array}{lllllllll}10.7 & 8.79 & -1.93 & 8.19 & 10.12 & -1.93 & 7.51 & 17.71 & -10.19\end{array}$

$\begin{array}{lllllllll}9.01 & 8.53 & -0.47 & 7.81 & 8.28 & -0.47 & 7.31 & 14.55 & -7.24\end{array}$

$\begin{array}{lllllllll}10 & 8.77 & -1.23 & 8.16 & 9.39 & -1.23 & 7.50 & 16.38 & -8.88\end{array}$

$\begin{array}{lllllllll}11.4 & 8.75 & -2.63 & 8.13 & 10.77 & -2.63 & 7.48 & 18.92 & -11.44\end{array}$

$\begin{array}{lllllllll}9.03 & 8.09 & -0.94 & 7.15 & 8.09 & -0.94 & 6.98 & 14.61 & -7.63\end{array}$

$\begin{array}{lllllllll}12.3 & 8.9 & -3.42 & 8.36 & 11.78 & -3.42 & 7.60 & 20.64 & -13.04\end{array}$

$\begin{array}{lllllllll}7.96 & 7.99 & 0.03 & 7.00 & 6.97 & 0.03 & 6.90 & 12.64 & -5.74\end{array}$

$\begin{array}{lllllllll}9.6 & 8.39 & -1.21 & 7.60 & 8.81 & -1.21 & 7.21 & 15.65 & -8.44\end{array}$

$\begin{array}{lllllllll}9.7 & 8.97 & -0.73 & 8.46 & 9.19 & -0.73 & 7.65 & 15.82 & -8.17\end{array}$

$\begin{array}{lllllllll}8.45 & 8.21 & -0.24 & 7.33 & 7.57 & -0.24 & 7.07 & 13.53 & -6.46\end{array}$

$\begin{array}{lllllllll}11.7 & 8.94 & -2.71 & 8.42 & 11.13 & -2.71 & 7.63 & 19.42 & -11.79\end{array}$

$\begin{array}{lllllllll}8.62 & 8.86 & 0.24 & 8.30 & 8.05 & 0.24 & 7.57 & 13.84 & -6.27\end{array}$

$\begin{array}{lllllllll}8.95 & 8.44 & -0.51 & 7.67 & 8.18 & -0.51 & 7.24 & 14.45 & -7.20\end{array}$

$\begin{array}{lllllllll}10 & 8.75 & -1.26 & 8.13 & 9.39 & -1.26 & 7.48 & 16.40 & -8.91\end{array}$

$\begin{array}{lllllllll}9.36 & 8.59 & -0.77 & 7.90 & 8.67 & -0.77 & 7.36 & 15.21 & -7.85\end{array}$

$\begin{array}{lllllllll}11.3 & 8.56 & -2.76 & 7.85 & 10.61 & -2.76 & 7.34 & 18.81 & -11.47\end{array}$

$\begin{array}{lllllllll}9.13 & 8.67 & -0.46 & 8.01 & 8.47 & -0.46 & 7.42 & 14.78 & -7.36\end{array}$

$\begin{array}{lllllllll}10.2 & 8.48 & -1.70 & 7.73 & 9.43 & -1.70 & 7.28 & 16.70 & -9.43\end{array}$

$\begin{array}{lllllllll}11.7 & 8.81 & -2.93 & 8.22 & 11.16 & -2.93 & 7.53 & 19.59 & -12.06\end{array}$

$\begin{array}{lllllllll}7.91 & 7.9 & -0.01 & 6.87 & 6.87 & -0.01 & 6.83 & 12.54 & -5.71\end{array}$

$\begin{array}{lllllllll}9.54 & 8.3 & -1.24 & 7.46 & 8.71 & -1.24 & 7.14 & 15.54 & -8.40\end{array}$

$\begin{array}{lllllllll}11 & 8.56 & -2.48 & 7.85 & 10.33 & -2.48 & 7.34 & 18.29 & -10.96\end{array}$

$\begin{array}{lllllllll}7.65 & 7.38 & -0.27 & 6.09 & 6.36 & -0.27 & 6.43 & 12.07 & -5.64\end{array}$

$\begin{array}{lllllllll}7.82 & 8.03 & 0.21 & 7.06 & 6.85 & 0.21 & 6.93 & 12.37 & -5.44\end{array}$

$\begin{array}{lllllllll}9.95 & 8.66 & -1.29 & 8.00 & 9.29 & -1.29 & 7.41 & 16.29 & -8.88\end{array}$

$\begin{array}{lllllllll}8.23 & 8.18 & -0.05 & 7.28 & 7.34 & -0.05 & 7.04 & 13.14 & -6.09\end{array}$

$\begin{array}{lllllllll}10.9 & 8.9 & -2.04 & 8.36 & 10.40 & -2.04 & 7.60 & 18.11 & -10.51\end{array}$

$\begin{array}{lllllllll}9.38 & 8.57 & -0.81 & 7.87 & 8.67 & -0.81 & 7.34 & 15.23 & -7.89\end{array}$

$\begin{array}{lllllllll}8.4 & 8.83 & 0.43 & 8.25 & 7.82 & 0.43 & 7.54 & 13.44 & -5.89\end{array}$

$\begin{array}{lllllllll}11.3 & 8.54 & -2.80 & 7.82 & 10.62 & -2.80 & 7.32 & 18.83 & -11.51\end{array}$

$\begin{array}{lllllllll}9.86 & 8.79 & -1.07 & 8.19 & 9.27 & -1.07 & 7.51 & 16.13 & -8.61\end{array}$

$\begin{array}{lllllllll}7.33 & 7.81 & 0.48 & 6.73 & 6.25 & 0.48 & 6.76 & 11.48 & -4.72\end{array}$

$\begin{array}{lllllllll}8.23 & 7.47 & -0.76 & 6.22 & 6.98 & -0.76 & 6.50 & 13.12 & -6.63\end{array}$

$\begin{array}{lllllllll}8.34 & 8.03 & -0.31 & 7.06 & 7.37 & -0.31 & 6.93 & 13.33 & -6.40\end{array}$

$\begin{array}{lllllllll}9.97 & 8.43 & -1.54 & 7.66 & 9.20 & -1.54 & 7.24 & 16.33 & -9.09\end{array}$

$\begin{array}{lllllllll}8.08 & 7.51 & -0.57 & 6.28 & 6.85 & -0.57 & 6.53 & 12.86 & -6.33\end{array}$

$\begin{array}{lllllllll}10.4 & 8.58 & -1.81 & 7.88 & 9.69 & -1.81 & 7.35 & 17.10 & -9.74\end{array}$

$\begin{array}{lllllllll}12 & 8.99 & -3.05 & 8.49 & 11.54 & -3.05 & 7.67 & 20.12 & -12.45\end{array}$

$\begin{array}{lllllllll}7.51 & 7.42 & -0.09 & 6.15 & 6.23 & -0.09 & 6.46 & 11.80 & -5.34\end{array}$ 
SMILE Generated

$\mathrm{C}(\mathrm{C}(\mathrm{C}(\mathrm{C}(\mathrm{C}(\mathrm{C}(\mathrm{C}(\mathrm{C}(\mathrm{C}(\mathrm{C}(\mathrm{C}(\mathrm{C}(\mathrm{C}(\mathrm{H})(\mathrm{F}) \mathrm{Cl})(\mathrm{H}) \mathrm{F})(\mathrm{H}) \mathrm{Br})(\mathrm{H}) \mathrm{H})(\mathrm{H}) \mathrm{H})(\mathrm{H}) \mathrm{H})(\mathrm{H}) \mathrm{H})(\mathrm{H}) \mathrm{Cl})(\mathrm{Br}) \mathrm{H})(\mathrm{H}) \mathrm{H})(\mathrm{Br}) \mathrm{F})$ $(\mathrm{H}) \mathrm{H})(\mathrm{H})(\mathrm{H}) \mathrm{Cl}$

$\mathrm{C}(\mathrm{C}(\mathrm{C}(\mathrm{C}(\mathrm{C}(\mathrm{C}(\mathrm{C}(\mathrm{C}(\mathrm{C}(\mathrm{C}(\mathrm{C}(\mathrm{C}(\mathrm{C}(\mathrm{H})(\mathrm{F}) \mathrm{H})(\mathrm{H}) \mathrm{H})(\mathrm{H}) \mathrm{H})(\mathrm{H}) \mathrm{Br})(\mathrm{H}) \mathrm{H})(\mathrm{Cl}) \mathrm{H})(\mathrm{H}) \mathrm{H})(\mathrm{H}) \mathrm{Cl})(\mathrm{Br}) \mathrm{H})(\mathrm{Cl}) \mathrm{H})(\mathrm{H}) \mathrm{Br})$ $(\mathrm{Br}) \mathrm{H})(\mathrm{H})(\mathrm{H}) \mathrm{F}$

$\mathrm{C}(\mathrm{C}(\mathrm{C}(\mathrm{C}(\mathrm{C}(\mathrm{C}(\mathrm{C}(\mathrm{C}(\mathrm{C}(\mathrm{C}(\mathrm{C}(\mathrm{C}(\mathrm{C}(\mathrm{H})(\mathrm{H}) \mathrm{Br})(\mathrm{Br}) \mathrm{H})(\mathrm{H}) \mathrm{H})(\mathrm{H}) \mathrm{H})(\mathrm{H}) \mathrm{Br})(\mathrm{Br}) \mathrm{H})(\mathrm{H}) \mathrm{H})(\mathrm{F}) \mathrm{H})(\mathrm{H}) \mathrm{Cl})(\mathrm{Cl}) \mathrm{H})(\mathrm{H}) \mathrm{Cl}$ $(\mathrm{H}) \mathrm{H})(\mathrm{Br})(\mathrm{H}) \mathrm{H}$

$\mathrm{C}(\mathrm{C}(\mathrm{C}(\mathrm{C}(\mathrm{C}(\mathrm{C}(\mathrm{C}(\mathrm{C}(\mathrm{C}(\mathrm{C}(\mathrm{C}(\mathrm{C}(\mathrm{C}(\mathrm{F})(\mathrm{Cl}) \mathrm{Br})(\mathrm{Cl}) \mathrm{H})(\mathrm{H}) \mathrm{H})(\mathrm{Cl}) \mathrm{H})(\mathrm{F}) \mathrm{H})(\mathrm{H}) \mathrm{H})(\mathrm{H}) \mathrm{Cl})(\mathrm{H}) \mathrm{H})(\mathrm{H}) \mathrm{H})(\mathrm{H}) \mathrm{F})(\mathrm{H}) \mathrm{H})$

$(\mathrm{H}) \mathrm{H})(\mathrm{H})(\mathrm{Br}) \mathrm{H}$

$\mathrm{C}(\mathrm{C}(\mathrm{C}(\mathrm{C}(\mathrm{C}(\mathrm{C}(\mathrm{C}(\mathrm{C}(\mathrm{C}(\mathrm{C}(\mathrm{C}(\mathrm{C}(\mathrm{C}(\mathrm{H})(\mathrm{Br}) \mathrm{H})(\mathrm{H}) \mathrm{H})(\mathrm{F}) \mathrm{F})(\mathrm{Cl}) \mathrm{H})(\mathrm{H}) \mathrm{H})(\mathrm{F}) \mathrm{Cl})(\mathrm{Cl}) \mathrm{H})(\mathrm{H}) \mathrm{H})(\mathrm{H}) \mathrm{H})(\mathrm{H}) \mathrm{F})(\mathrm{H}) \mathrm{H})(\mathrm{Cl}) \mathrm{H})$

$(\mathrm{H})(\mathrm{H}) \mathrm{H}$

$\mathrm{C}(\mathrm{C}(\mathrm{C}(\mathrm{C}(\mathrm{C}(\mathrm{C}(\mathrm{C}(\mathrm{C}(\mathrm{C}(\mathrm{C}(\mathrm{C}(\mathrm{C}(\mathrm{C}(\mathrm{Cl})(\mathrm{H}) \mathrm{Cl})(\mathrm{H}) \mathrm{H})(\mathrm{Cl}) \mathrm{H})(\mathrm{H}) \mathrm{F})(\mathrm{H}) \mathrm{H})(\mathrm{H}) \mathrm{H})(\mathrm{Br}) \mathrm{H})(\mathrm{H}) \mathrm{Br})(\mathrm{H}) \mathrm{H})(\mathrm{H}) \mathrm{H})(\mathrm{H}) \mathrm{Cl})(\mathrm{H})$ $\mathrm{H})(\mathrm{H})(\mathrm{Cl}) \mathrm{F}$

$\mathrm{C}(\mathrm{C}(\mathrm{C}(\mathrm{C}(\mathrm{C}(\mathrm{C}(\mathrm{C}(\mathrm{C}(\mathrm{C}(\mathrm{C}(\mathrm{C}(\mathrm{C}(\mathrm{C}(\mathrm{H})(\mathrm{H}) \mathrm{H})(\mathrm{H}) \mathrm{H})(\mathrm{H}) \mathrm{F})(\mathrm{Br}) \mathrm{H})(\mathrm{Cl}) \mathrm{H})(\mathrm{H}) \mathrm{Cl})(\mathrm{H}) \mathrm{H})(\mathrm{H}) \mathrm{H})(\mathrm{Cl}) \mathrm{Cl})(\mathrm{F}) \mathrm{H})(\mathrm{H}) \mathrm{H})$ $(\mathrm{H}) \mathrm{F})(\mathrm{H})(\mathrm{Cl}) \mathrm{H}$

$\mathrm{C}(\mathrm{C}(\mathrm{C}(\mathrm{C}(\mathrm{C}(\mathrm{C}(\mathrm{C}(\mathrm{C}(\mathrm{C}(\mathrm{C}(\mathrm{C}(\mathrm{C}(\mathrm{C}(\mathrm{F})(\mathrm{H}) \mathrm{H})(\mathrm{Cl}) \mathrm{H})(\mathrm{H}) \mathrm{F})(\mathrm{H}) \mathrm{Cl})(\mathrm{H}) \mathrm{H})(\mathrm{H}) \mathrm{Cl})(\mathrm{H}) \mathrm{H})(\mathrm{H}) \mathrm{Cl})(\mathrm{Cl}) \mathrm{H})(\mathrm{H}) \mathrm{H})(\mathrm{H}) \mathrm{Cl})$

$(\mathrm{H}) \mathrm{H})(\mathrm{H})(\mathrm{Br}) \mathrm{H}$

$\mathrm{C}(\mathrm{C}(\mathrm{C}(\mathrm{C}(\mathrm{C}(\mathrm{C}(\mathrm{C}(\mathrm{C}(\mathrm{C}(\mathrm{C}(\mathrm{C}(\mathrm{C}(\mathrm{C}(\mathrm{H})(\mathrm{H}) \mathrm{H})(\mathrm{H}) \mathrm{H})(\mathrm{F}) \mathrm{Cl})(\mathrm{H}) \mathrm{Cl})(\mathrm{Cl}) \mathrm{H})(\mathrm{F}) \mathrm{H})(\mathrm{H}) \mathrm{H})(\mathrm{H}) \mathrm{H})(\mathrm{H}) \mathrm{H})(\mathrm{H}) \mathrm{F})(\mathrm{Cl}) \mathrm{H})(\mathrm{H}) \mathrm{H})$

$(\mathrm{Cl})(\mathrm{H}) \mathrm{Cl}$

$\mathrm{C}(\mathrm{C}(\mathrm{C}(\mathrm{C}(\mathrm{C}(\mathrm{C}(\mathrm{C}(\mathrm{C}(\mathrm{C}(\mathrm{C}(\mathrm{C}(\mathrm{C}(\mathrm{C}(\mathrm{Cl})(\mathrm{Cl}) \mathrm{H})(\mathrm{H}) \mathrm{H})(\mathrm{H}) \mathrm{Cl})(\mathrm{H}) \mathrm{H})(\mathrm{H}) \mathrm{Cl})(\mathrm{Br}) \mathrm{H})(\mathrm{H}) \mathrm{Cl})(\mathrm{H}) \mathrm{H})(\mathrm{H}) \mathrm{Cl})(\mathrm{H}) \mathrm{H})(\mathrm{H}) \mathrm{H})(\mathrm{H})$

$\mathrm{H})(\mathrm{Cl})(\mathrm{H}) \mathrm{Cl}$

$\mathrm{C}(\mathrm{C}(\mathrm{C}(\mathrm{C}(\mathrm{C}(\mathrm{C}(\mathrm{C}(\mathrm{C}(\mathrm{C}(\mathrm{C}(\mathrm{C}(\mathrm{C}(\mathrm{C}(\mathrm{Cl})(\mathrm{Cl}) \mathrm{H})(\mathrm{Cl}) \mathrm{H})(\mathrm{H}) \mathrm{H})(\mathrm{H}) \mathrm{H})(\mathrm{Cl}) \mathrm{H})(\mathrm{H}) \mathrm{H})(\mathrm{Cl}) \mathrm{H})(\mathrm{H}) \mathrm{H})(\mathrm{H}) \mathrm{F})(\mathrm{Cl}) \mathrm{H})(\mathrm{H}) \mathrm{Cl})(\mathrm{H})$

$\mathrm{Cl})(\mathrm{H})(\mathrm{H}) \mathrm{H}$

$\mathrm{C}(\mathrm{C}(\mathrm{C}(\mathrm{C}(\mathrm{C}(\mathrm{C}(\mathrm{C}(\mathrm{C}(\mathrm{C}(\mathrm{C}(\mathrm{C}(\mathrm{C}(\mathrm{C}(\mathrm{H})(\mathrm{Br}) \mathrm{F})(\mathrm{Br}) \mathrm{H})(\mathrm{H}) \mathrm{H})(\mathrm{H}) \mathrm{Cl})(\mathrm{H}) \mathrm{F})(\mathrm{H}) \mathrm{H})(\mathrm{H}) \mathrm{Br})(\mathrm{H}) \mathrm{H})(\mathrm{Br}) \mathrm{H})(\mathrm{H}) \mathrm{H})(\mathrm{H}) \mathrm{H})(\mathrm{H})$ $\mathrm{Br})(\mathrm{Br})(\mathrm{H}) \mathrm{H}$

$\mathrm{C}(\mathrm{C}(\mathrm{C}(\mathrm{C}(\mathrm{C}(\mathrm{C}(\mathrm{C}(\mathrm{C}(\mathrm{C}(\mathrm{C}(\mathrm{C}(\mathrm{C}(\mathrm{C}(\mathrm{H})(\mathrm{H}) \mathrm{Br})(\mathrm{H}) \mathrm{H})(\mathrm{H}) \mathrm{F})(\mathrm{H}) \mathrm{H})(\mathrm{H}) \mathrm{F})(\mathrm{H}) \mathrm{H})(\mathrm{Br}) \mathrm{H})(\mathrm{F}) \mathrm{Br})(\mathrm{H}) \mathrm{H})(\mathrm{H}) \mathrm{H})(\mathrm{H}) \mathrm{H})$

$(\mathrm{Br}) \mathrm{H})(\mathrm{H})(\mathrm{F}) \mathrm{H}$

$\mathrm{C}(\mathrm{C}(\mathrm{C}(\mathrm{C}(\mathrm{C}(\mathrm{C}(\mathrm{C}(\mathrm{C}(\mathrm{C}(\mathrm{C}(\mathrm{C}(\mathrm{C}(\mathrm{C}(\mathrm{F})(\mathrm{H}) \mathrm{H})(\mathrm{F}) \mathrm{H})(\mathrm{H}) \mathrm{Br})(\mathrm{H}) \mathrm{H})(\mathrm{H}) \mathrm{H})(\mathrm{H}) \mathrm{H})(\mathrm{H}) \mathrm{H})(\mathrm{Br}) \mathrm{H})(\mathrm{H}) \mathrm{H})(\mathrm{H}) \mathrm{H})(\mathrm{H}) \mathrm{Br})(\mathrm{Br}) \mathrm{B}$

r) $(\mathrm{H})(\mathrm{F}) \mathrm{H}$

$\mathrm{C}(\mathrm{C}(\mathrm{C}(\mathrm{C}(\mathrm{C}(\mathrm{C}(\mathrm{C}(\mathrm{C}(\mathrm{C}(\mathrm{C}(\mathrm{C}(\mathrm{C}(\mathrm{C}(\mathrm{Br})(\mathrm{Br}) \mathrm{Br})(\mathrm{H}) \mathrm{H})(\mathrm{H}) \mathrm{H})(\mathrm{F}) \mathrm{H})(\mathrm{H}) \mathrm{H})(\mathrm{Br}) \mathrm{H})(\mathrm{H}) \mathrm{H})(\mathrm{H}) \mathrm{H})(\mathrm{H}) \mathrm{H})(\mathrm{H}) \mathrm{F})(\mathrm{H}) \mathrm{H})(\mathrm{H})$ $\mathrm{H})(\mathrm{H})(\mathrm{Br}) \mathrm{Br}$

$\mathrm{C}(\mathrm{C}(\mathrm{C}(\mathrm{C}(\mathrm{C}(\mathrm{C}(\mathrm{C}(\mathrm{C}(\mathrm{C}(\mathrm{C}(\mathrm{C}(\mathrm{C}(\mathrm{C}(\mathrm{F})(\mathrm{H}) \mathrm{F})(\mathrm{H}) \mathrm{H})(\mathrm{H}) \mathrm{Br})(\mathrm{H}) \mathrm{F})(\mathrm{H}) \mathrm{H})(\mathrm{H}) \mathrm{Cl})(\mathrm{H}) \mathrm{H})(\mathrm{H}) \mathrm{H})(\mathrm{Cl}) \mathrm{H})(\mathrm{H}) \mathrm{H})(\mathrm{H}) \mathrm{H})(\mathrm{Br}) \mathrm{H})$ (H) $(\mathrm{H}) \mathrm{Br}$

$\mathrm{C}(\mathrm{C}(\mathrm{C}(\mathrm{C}(\mathrm{C}(\mathrm{C}(\mathrm{C}(\mathrm{C}(\mathrm{C}(\mathrm{C}(\mathrm{C}(\mathrm{C}(\mathrm{C}(\mathrm{H})(\mathrm{H}) \mathrm{Cl})(\mathrm{H}) \mathrm{H})(\mathrm{H}) \mathrm{H})(\mathrm{H}) \mathrm{Br})(\mathrm{H}) \mathrm{Br})(\mathrm{H}) \mathrm{Cl})(\mathrm{H}) \mathrm{H})(\mathrm{H}) \mathrm{F})(\mathrm{Br}) \mathrm{H})(\mathrm{F}) \mathrm{H})(\mathrm{H}) \mathrm{H})(\mathrm{H})$ $\mathrm{H})(\mathrm{Br})(\mathrm{H}) \mathrm{H}$

$\mathrm{C}(\mathrm{C}(\mathrm{C}(\mathrm{C}(\mathrm{C}(\mathrm{C}(\mathrm{C}(\mathrm{C}(\mathrm{C}(\mathrm{C}(\mathrm{C}(\mathrm{C}(\mathrm{C}(\mathrm{Br})(\mathrm{H}) \mathrm{Br})(\mathrm{H}) \mathrm{H})(\mathrm{H}) \mathrm{Br})(\mathrm{H}) \mathrm{Br})(\mathrm{H}) \mathrm{H})(\mathrm{H}) \mathrm{H})(\mathrm{H}) \mathrm{Cl})(\mathrm{H}) \mathrm{H})(\mathrm{H}) \mathrm{H})(\mathrm{F}) \mathrm{H})(\mathrm{H}) \mathrm{H})(\mathrm{H})$

$\mathrm{Br})(\mathrm{H})(\mathrm{Cl}) \mathrm{H}$

$\mathrm{C}(\mathrm{C}(\mathrm{C}(\mathrm{C}(\mathrm{C}(\mathrm{C}(\mathrm{C}(\mathrm{C}(\mathrm{C}(\mathrm{C}(\mathrm{C}(\mathrm{C}(\mathrm{C}(\mathrm{Br})(\mathrm{H}) \mathrm{H})(\mathrm{H}) \mathrm{H})(\mathrm{H}) \mathrm{H})(\mathrm{F}) \mathrm{F})(\mathrm{H}) \mathrm{H})(\mathrm{Cl}) \mathrm{H})(\mathrm{H}) \mathrm{F})(\mathrm{H}) \mathrm{H})(\mathrm{Cl}) \mathrm{H})(\mathrm{H}) \mathrm{Br})(\mathrm{H}) \mathrm{H})(\mathrm{H}) \mathrm{H})$

$(\mathrm{H})(\mathrm{Cl}) \mathrm{H}$

$\mathrm{C}(\mathrm{C}(\mathrm{C}(\mathrm{C}(\mathrm{C}(\mathrm{C}(\mathrm{C}(\mathrm{C}(\mathrm{C}(\mathrm{C}(\mathrm{C}(\mathrm{C}(\mathrm{C}(\mathrm{H})(\mathrm{H}) \mathrm{H})(\mathrm{H}) \mathrm{H})(\mathrm{H}) \mathrm{H})(\mathrm{F}) \mathrm{H})(\mathrm{Br}) \mathrm{H})(\mathrm{Br}) \mathrm{H})(\mathrm{F}) \mathrm{H})(\mathrm{H}) \mathrm{H})(\mathrm{H}) \mathrm{Br})(\mathrm{H}) \mathrm{Cl})(\mathrm{H}) \mathrm{Cl})(\mathrm{H})$ $\mathrm{H})(\mathrm{H})(\mathrm{H}) \mathrm{Cl}$

$\mathrm{C}(\mathrm{C}(\mathrm{C}(\mathrm{C}(\mathrm{C}(\mathrm{C}(\mathrm{C}(\mathrm{C}(\mathrm{C}(\mathrm{C}(\mathrm{C}(\mathrm{C}(\mathrm{C}(\mathrm{F})(\mathrm{Cl}) \mathrm{H})(\mathrm{Br}) \mathrm{H})(\mathrm{H}) \mathrm{H})(\mathrm{H}) \mathrm{H})(\mathrm{H}) \mathrm{H})(\mathrm{Br}) \mathrm{H})(\mathrm{H}) \mathrm{Br})(\mathrm{H}) \mathrm{H})(\mathrm{H}) \mathrm{Cl})(\mathrm{H}) \mathrm{Br})(\mathrm{H}) \mathrm{Cl})$

$(\mathrm{H}) \mathrm{H})(\mathrm{H})(\mathrm{H}) \mathrm{H}$

$\mathrm{C}(\mathrm{C}(\mathrm{C}(\mathrm{C}(\mathrm{C}(\mathrm{C}(\mathrm{C}(\mathrm{C}(\mathrm{C}(\mathrm{C}(\mathrm{C}(\mathrm{C}(\mathrm{C}(\mathrm{F})(\mathrm{H}) \mathrm{H})(\mathrm{H}) \mathrm{H})(\mathrm{H}) \mathrm{H})(\mathrm{H}) \mathrm{H})(\mathrm{Br}) \mathrm{H})(\mathrm{H}) \mathrm{H})(\mathrm{H}) \mathrm{H})(\mathrm{H}) \mathrm{H})(\mathrm{Cl}) \mathrm{H})(\mathrm{H}) \mathrm{Cl})(\mathrm{Cl}) \mathrm{H})$

$(\mathrm{F}) \mathrm{Cl})(\mathrm{Br})(\mathrm{H}) \mathrm{H}$

$\mathrm{C}(\mathrm{C}(\mathrm{C}(\mathrm{C}(\mathrm{C}(\mathrm{C}(\mathrm{C}(\mathrm{C}(\mathrm{C}(\mathrm{C}(\mathrm{C}(\mathrm{C}(\mathrm{C}(\mathrm{Br})(\mathrm{H}) \mathrm{H})(\mathrm{H}) \mathrm{H})(\mathrm{H}) \mathrm{H})(\mathrm{H}) \mathrm{H})(\mathrm{Cl}) \mathrm{H})(\mathrm{Cl}) \mathrm{H})(\mathrm{Cl}) \mathrm{H})(\mathrm{H}) \mathrm{H})(\mathrm{H}) \mathrm{Cl})(\mathrm{H}) \mathrm{H})(\mathrm{H}) \mathrm{H})(\mathrm{H})$

$\mathrm{F})(\mathrm{H})(\mathrm{Br}) \mathrm{Br}$

$\mathrm{C}(\mathrm{C}(\mathrm{C}(\mathrm{C}(\mathrm{C}(\mathrm{C}(\mathrm{C}(\mathrm{C}(\mathrm{C}(\mathrm{C}(\mathrm{C}(\mathrm{C}(\mathrm{C}(\mathrm{H})(\mathrm{H}) \mathrm{Cl})(\mathrm{H}) \mathrm{Br})(\mathrm{H}) \mathrm{H})(\mathrm{Br}) \mathrm{H})(\mathrm{H}) \mathrm{H})(\mathrm{H}) \mathrm{H})(\mathrm{H}) \mathrm{H})(\mathrm{H}) \mathrm{H})(\mathrm{H}) \mathrm{Br})(\mathrm{H}) \mathrm{H})(\mathrm{Cl}) \mathrm{H})(\mathrm{Cl})$ $\mathrm{H})(\mathrm{Cl})(\mathrm{H}) \mathrm{Br}$

$\mathrm{C}(\mathrm{C}(\mathrm{C}(\mathrm{C}(\mathrm{C}(\mathrm{C}(\mathrm{C}(\mathrm{C}(\mathrm{C}(\mathrm{C}(\mathrm{C}(\mathrm{C}(\mathrm{C}(\mathrm{H})(\mathrm{H}) \mathrm{H})(\mathrm{F}) \mathrm{Cl})(\mathrm{H}) \mathrm{H})(\mathrm{H}) \mathrm{H})(\mathrm{F}) \mathrm{Cl})(\mathrm{H}) \mathrm{H})(\mathrm{H}) \mathrm{Br})(\mathrm{H}) \mathrm{H})(\mathrm{H}) \mathrm{H})(\mathrm{H}) \mathrm{H})(\mathrm{F}) \mathrm{H})(\mathrm{H}) \mathrm{H})$ (H)(C)Cl

$\mathrm{C}(\mathrm{C}(\mathrm{C}(\mathrm{C}(\mathrm{C}(\mathrm{C}(\mathrm{C}(\mathrm{C}(\mathrm{C}(\mathrm{C}(\mathrm{C}(\mathrm{C}(\mathrm{C}(\mathrm{H})(\mathrm{H}) \mathrm{H})(\mathrm{H}) \mathrm{Cl})(\mathrm{Br}) \mathrm{H})(\mathrm{H}) \mathrm{Br})(\mathrm{H}) \mathrm{H})(\mathrm{H}) \mathrm{Cl})(\mathrm{H}) \mathrm{Cl})(\mathrm{H}) \mathrm{H})(\mathrm{H}) \mathrm{H})(\mathrm{H}) \mathrm{H})(\mathrm{Cl}) \mathrm{Cl})(\mathrm{H})$ $\mathrm{H})(\mathrm{H})(\mathrm{F}) \mathrm{H}$

$\mathrm{C}(\mathrm{C}(\mathrm{C}(\mathrm{C}(\mathrm{C}(\mathrm{C}(\mathrm{C}(\mathrm{C}(\mathrm{C}(\mathrm{C}(\mathrm{C}(\mathrm{C}(\mathrm{C}(\mathrm{Cl})(\mathrm{H}) \mathrm{Br})(\mathrm{Br}) \mathrm{H})(\mathrm{H}) \mathrm{H})(\mathrm{Cl}) \mathrm{H})(\mathrm{H}) \mathrm{H})(\mathrm{Br}) \mathrm{H})(\mathrm{H}) \mathrm{H})(\mathrm{H}) \mathrm{H})(\mathrm{Cl}) \mathrm{H})(\mathrm{H}) \mathrm{H})(\mathrm{H}) \mathrm{Cl})$

$(\mathrm{H}) \mathrm{H})(\mathrm{H})(\mathrm{H}) \mathrm{Cl}$

$\mathrm{C}(\mathrm{C}(\mathrm{C}(\mathrm{C}(\mathrm{C}(\mathrm{C}(\mathrm{C}(\mathrm{C}(\mathrm{C}(\mathrm{C}(\mathrm{C}(\mathrm{C}(\mathrm{C}(\mathrm{H})(\mathrm{Cl}) \mathrm{H})(\mathrm{H}) \mathrm{H})(\mathrm{H}) \mathrm{F})(\mathrm{H}) \mathrm{H})(\mathrm{F}) \mathrm{H})(\mathrm{H}) \mathrm{H})(\mathrm{H}) \mathrm{H})(\mathrm{H}) \mathrm{Cl})(\mathrm{Cl}) \mathrm{H})(\mathrm{H}) \mathrm{H})(\mathrm{H}) \mathrm{Br})$

$(\mathrm{H}) \mathrm{H})(\mathrm{H})(\mathrm{Cl}) \mathrm{Cl}$

$\mathrm{C}(\mathrm{C}(\mathrm{C}(\mathrm{C}(\mathrm{C}(\mathrm{C}(\mathrm{C}(\mathrm{C}(\mathrm{C}(\mathrm{C}(\mathrm{C}(\mathrm{C}(\mathrm{C}(\mathrm{H})(\mathrm{H}) \mathrm{Br})(\mathrm{H}) \mathrm{H})(\mathrm{Cl}) \mathrm{H})(\mathrm{H}) \mathrm{H})(\mathrm{H}) \mathrm{H})(\mathrm{H}) \mathrm{H})(\mathrm{Cl}) \mathrm{H})(\mathrm{H}) \mathrm{H})(\mathrm{Cl}) \mathrm{H})(\mathrm{Br}) \mathrm{H})(\mathrm{H}) \mathrm{H})(\mathrm{H})$

$\mathrm{Cl})(\mathrm{Cl})(\mathrm{H}) \mathrm{Cl}$

$\mathrm{C}(\mathrm{C}(\mathrm{C}(\mathrm{C}(\mathrm{C}(\mathrm{C}(\mathrm{C}(\mathrm{C}(\mathrm{C}(\mathrm{C}(\mathrm{C}(\mathrm{C}(\mathrm{C}(\mathrm{H})(\mathrm{H}) \mathrm{H})(\mathrm{Cl}) \mathrm{H})(\mathrm{Cl}) \mathrm{H})(\mathrm{H}) \mathrm{H})(\mathrm{Br}) \mathrm{Cl})(\mathrm{H}) \mathrm{H})(\mathrm{H}) \mathrm{H})(\mathrm{H}) \mathrm{H})(\mathrm{H}) \mathrm{H})(\mathrm{H}) \mathrm{H})(\mathrm{H}) \mathrm{Cl})(\mathrm{H})$ $\mathrm{Cl})(\mathrm{F})(\mathrm{H}) \mathrm{Cl}$

$\mathrm{C}(\mathrm{C}(\mathrm{C}(\mathrm{C}(\mathrm{C}(\mathrm{C}(\mathrm{C}(\mathrm{C}(\mathrm{C}(\mathrm{C}(\mathrm{C}(\mathrm{C}(\mathrm{C}(\mathrm{H})(\mathrm{H}) \mathrm{H})(\mathrm{H}) \mathrm{H})(\mathrm{H}) \mathrm{H})(\mathrm{H}) \mathrm{Cl})(\mathrm{H}) \mathrm{H})(\mathrm{F}) \mathrm{H})(\mathrm{Cl}) \mathrm{H})(\mathrm{H}) \mathrm{F})(\mathrm{Cl}) \mathrm{Cl})(\mathrm{H}) \mathrm{Cl})(\mathrm{H}) \mathrm{H})$

(H)H $(\mathrm{Cl})(\mathrm{H}) \mathrm{H}$

$\mathrm{C}(\mathrm{C}(\mathrm{C}(\mathrm{C}(\mathrm{C}(\mathrm{C}(\mathrm{C}(\mathrm{C}(\mathrm{C}(\mathrm{C}(\mathrm{C}(\mathrm{C}(\mathrm{C}(\mathrm{H})(\mathrm{H}) \mathrm{H})(\mathrm{Cl}) \mathrm{H})(\mathrm{H}) \mathrm{H})(\mathrm{H}) \mathrm{H})(\mathrm{H}) \mathrm{H})(\mathrm{Cl}) \mathrm{H})(\mathrm{H}) \mathrm{H})(\mathrm{H}) \mathrm{Cl})(\mathrm{Cl}) \mathrm{H})(\mathrm{Cl}) \mathrm{H})(\mathrm{H}) \mathrm{H})(\mathrm{Cl})$

$\mathrm{H})(\mathrm{Cl})(\mathrm{H}) \mathrm{Cl}$

$\mathrm{C}(\mathrm{C}(\mathrm{C}(\mathrm{C}(\mathrm{C}(\mathrm{C}(\mathrm{C}(\mathrm{C}(\mathrm{C}(\mathrm{C}(\mathrm{C}(\mathrm{C}(\mathrm{C}(\mathrm{H})(\mathrm{H}) \mathrm{Cl})(\mathrm{H}) \mathrm{F})(\mathrm{H}) \mathrm{H})(\mathrm{H}) \mathrm{H})(\mathrm{H}) \mathrm{H})(\mathrm{H}) \mathrm{H})(\mathrm{F}) \mathrm{Br})(\mathrm{H}) \mathrm{F})(\mathrm{F}) \mathrm{H})(\mathrm{H}) \mathrm{H})(\mathrm{H}) \mathrm{H})(\mathrm{Br}) \mathrm{H})($ $\mathrm{Br})(\mathrm{H}) \mathrm{H}$

$\mathrm{C}(\mathrm{C}(\mathrm{C}(\mathrm{C}(\mathrm{C}(\mathrm{C}(\mathrm{C}(\mathrm{C}(\mathrm{C}(\mathrm{C}(\mathrm{C}(\mathrm{C}(\mathrm{C}(\mathrm{Cl})(\mathrm{H}) \mathrm{Br})(\mathrm{H}) \mathrm{H})(\mathrm{H}) \mathrm{H})(\mathrm{H}) \mathrm{Br})(\mathrm{Br}) \mathrm{H})(\mathrm{H}) \mathrm{H})(\mathrm{H}) \mathrm{H})(\mathrm{H}) \mathrm{F})(\mathrm{H}) \mathrm{H})(\mathrm{F}) \mathrm{F})(\mathrm{H}) \mathrm{H})$

$(\mathrm{H}) \mathrm{H})(\mathrm{H})(\mathrm{Br}) \mathrm{H}$

$\mathrm{C}(\mathrm{C}(\mathrm{C}(\mathrm{C}(\mathrm{C}(\mathrm{C}(\mathrm{C}(\mathrm{C}(\mathrm{C}(\mathrm{C}(\mathrm{C}(\mathrm{C}(\mathrm{C}(\mathrm{H})(\mathrm{H}) \mathrm{H})(\mathrm{H}) \mathrm{Br})(\mathrm{Br}) \mathrm{H})(\mathrm{H}) \mathrm{H})(\mathrm{F}) \mathrm{H})(\mathrm{Cl}) \mathrm{H})(\mathrm{H}) \mathrm{Br})(\mathrm{H}) \mathrm{H})(\mathrm{Br}) \mathrm{H})(\mathrm{H}) \mathrm{Br})(\mathrm{H}) \mathrm{H})(\mathrm{H})$ $\mathrm{H})(\mathrm{H})(\mathrm{H}) \mathrm{F}$

$\mathrm{C}(\mathrm{C}(\mathrm{C}(\mathrm{C}(\mathrm{C}(\mathrm{C}(\mathrm{C}(\mathrm{C}(\mathrm{C}(\mathrm{C}(\mathrm{C}(\mathrm{C}(\mathrm{C}(\mathrm{F})(\mathrm{H}) \mathrm{H})(\mathrm{H}) \mathrm{Br})(\mathrm{H}) \mathrm{F})(\mathrm{H}) \mathrm{H})(\mathrm{H}) \mathrm{H})(\mathrm{H}) \mathrm{H})(\mathrm{H}) \mathrm{H})(\mathrm{F}) \mathrm{Br})(\mathrm{H}) \mathrm{H})(\mathrm{H}) \mathrm{H})(\mathrm{H}) \mathrm{H})(\mathrm{H}) \mathrm{H})($

$\mathrm{Br})(\mathrm{F}) \mathrm{H}$

$\mathrm{C}(\mathrm{C}(\mathrm{C}(\mathrm{C}(\mathrm{C}(\mathrm{C}(\mathrm{C}(\mathrm{C}(\mathrm{C}(\mathrm{C}(\mathrm{C}(\mathrm{C}(\mathrm{C}(\mathrm{H})(\mathrm{F}) \mathrm{H})(\mathrm{H}) \mathrm{H})(\mathrm{H}) \mathrm{H})(\mathrm{H}) \mathrm{H})(\mathrm{F}) \mathrm{H})(\mathrm{H}) \mathrm{H})(\mathrm{Br}) \mathrm{H})(\mathrm{H}) \mathrm{H})(\mathrm{H}) \mathrm{H})(\mathrm{H}) \mathrm{Br})(\mathrm{H}) \mathrm{H})$

$(\mathrm{Br}) \mathrm{H})(\mathrm{Br})(\mathrm{H}) \mathrm{F}$

$\mathrm{C}(\mathrm{C}(\mathrm{C}(\mathrm{C}(\mathrm{C}(\mathrm{C}(\mathrm{C}(\mathrm{C}(\mathrm{C}(\mathrm{C}(\mathrm{C}(\mathrm{C}(\mathrm{C}(\mathrm{H})(\mathrm{H}) \mathrm{H})(\mathrm{H}) \mathrm{H})(\mathrm{Br}) \mathrm{Br})(\mathrm{H}) \mathrm{H})(\mathrm{H}) \mathrm{H})(\mathrm{F}) \mathrm{H})(\mathrm{H}) \mathrm{H})(\mathrm{Br}) \mathrm{H})(\mathrm{H}) \mathrm{H})(\mathrm{Br}) \mathrm{H})(\mathrm{H}) \mathrm{H})(\mathrm{H})$ $\mathrm{Br})(\mathrm{H})(\mathrm{H}) \mathrm{F}$

$\mathrm{C}(\mathrm{C}(\mathrm{C}(\mathrm{C}(\mathrm{C}(\mathrm{C}(\mathrm{C}(\mathrm{C}(\mathrm{C}(\mathrm{C}(\mathrm{C}(\mathrm{C}(\mathrm{C}(\mathrm{H})(\mathrm{H}) \mathrm{H})(\mathrm{Br}) \mathrm{H})(\mathrm{H}) \mathrm{H})(\mathrm{H}) \mathrm{Br})(\mathrm{H}) \mathrm{H})(\mathrm{H}) \mathrm{H})(\mathrm{H}) \mathrm{Br})(\mathrm{H}) \mathrm{H})(\mathrm{H}) \mathrm{F})(\mathrm{H}) \mathrm{H})(\mathrm{H}) \mathrm{H})(\mathrm{Br})$ $\mathrm{H})(\mathrm{Br})(\mathrm{H}) \mathrm{Br}$

$\mathrm{C}(\mathrm{C}(\mathrm{C}(\mathrm{C}(\mathrm{C}(\mathrm{C}(\mathrm{C}(\mathrm{C}(\mathrm{C}(\mathrm{C}(\mathrm{C}(\mathrm{C}(\mathrm{C}(\mathrm{H})(\mathrm{H}) \mathrm{F})(\mathrm{Cl}) \mathrm{H})(\mathrm{H}) \mathrm{H})(\mathrm{Cl}) \mathrm{H})(\mathrm{H}) \mathrm{H})(\mathrm{Br}) \mathrm{H})(\mathrm{H}) \mathrm{H})(\mathrm{H}) \mathrm{Br})(\mathrm{Br}) \mathrm{H})(\mathrm{H}) \mathrm{H})(\mathrm{H}) \mathrm{H})(\mathrm{H})$

$\mathrm{F})(\mathrm{H})(\mathrm{H}) \mathrm{H}$

$\mathrm{C}(\mathrm{C}(\mathrm{C}(\mathrm{C}(\mathrm{C}(\mathrm{C}(\mathrm{C}(\mathrm{C}(\mathrm{C}(\mathrm{C}(\mathrm{C}(\mathrm{C}(\mathrm{C}(\mathrm{H})(\mathrm{H}) \mathrm{H})(\mathrm{H}) \mathrm{H})(\mathrm{H}) \mathrm{H})(\mathrm{H}) \mathrm{H})(\mathrm{Br}) \mathrm{H})(\mathrm{H}) \mathrm{Br})(\mathrm{H}) \mathrm{H})(\mathrm{H}) \mathrm{Cl})(\mathrm{H}) \mathrm{Br})(\mathrm{H}) \mathrm{Br})(\mathrm{H}) \mathrm{H})(\mathrm{H})$

$\mathrm{Cl})(\mathrm{F})(\mathrm{H}) \mathrm{H}$

$\mathrm{C}(\mathrm{C}(\mathrm{C}(\mathrm{C}(\mathrm{C}(\mathrm{C}(\mathrm{C}(\mathrm{C}(\mathrm{C}(\mathrm{C}(\mathrm{C}(\mathrm{C}(\mathrm{C}(\mathrm{Br})(\mathrm{H}) \mathrm{Br})(\mathrm{H}) \mathrm{H})(\mathrm{H}) \mathrm{Cl})(\mathrm{H}) \mathrm{H})(\mathrm{H}) \mathrm{H})(\mathrm{H}) \mathrm{H})(\mathrm{Cl}) \mathrm{H})(\mathrm{H}) \mathrm{Br})(\mathrm{H}) \mathrm{Br})(\mathrm{H}) \mathrm{H})(\mathrm{H}) \mathrm{Br})$ $(\mathrm{H}) \mathrm{H})(\mathrm{H})(\mathrm{H}) \mathrm{H}$

\section{Formula}

$\mathrm{C} 13 \mathrm{H} 19 \mathrm{Cl} 3 \mathrm{Br} 3 \mathrm{~F} 3$

$\mathrm{C} 13 \mathrm{H} 19 \mathrm{Cl} 3 \mathrm{Br} 4 \mathrm{~F} 2$

$\mathrm{C} 13 \mathrm{H} 19 \mathrm{Cl} 3 \mathrm{Br} 5 \mathrm{~F}$

$\mathrm{C} 13 \mathrm{H} 19 \mathrm{C} 14 \mathrm{Br} 2 \mathrm{~F} 3$

$\mathrm{C} 13 \mathrm{H} 19 \mathrm{Cl} 1 \mathrm{BrF} 4$

$\mathrm{C} 13 \mathrm{H} 19 \mathrm{Cl} 15 \mathrm{Br} 2 \mathrm{~F} 2$

C13H19Cl5BrF3

$\mathrm{C} 13 \mathrm{H} 19 \mathrm{Cl6BrF} 2$

$\mathrm{C} 13 \mathrm{H} 19 \mathrm{Cl} 16 \mathrm{~F} 3$

$\mathrm{C} 13 \mathrm{H} 19 \mathrm{Cl} 18 \mathrm{Br}$

$\mathrm{C} 13 \mathrm{H} 19 \mathrm{Cl} 8 \mathrm{~F}$

$\mathrm{C} 13 \mathrm{H} 19 \mathrm{ClBr} 6 \mathrm{~F} 2$

$\mathrm{C} 13 \mathrm{H} 20 \mathrm{Br} 4 \mathrm{~F} 4$

$\mathrm{C} 13 \mathrm{H} 20 \mathrm{Br} 5 \mathrm{~F} 3$

13H20Br6F2

$\mathrm{C} 13 \mathrm{H} 20 \mathrm{Cl} 2 \mathrm{Br} 3 \mathrm{~F} 3$

C13H20Cl2Br4F2

$\mathrm{C} 13 \mathrm{H} 20 \mathrm{Cl} 2 \mathrm{Br} 5 \mathrm{~F}$

$\mathrm{C} 13 \mathrm{H} 20 \mathrm{Cl} 3 \mathrm{Br} 2 \mathrm{~F} 3$

$\mathrm{C} 13 \mathrm{H} 20 \mathrm{Cl} 3 \mathrm{Br} 3 \mathrm{~F} 2$

$\mathrm{C} 13 \mathrm{H} 20 \mathrm{Cl} 3 \mathrm{Br} 4 \mathrm{~F}$

$\mathrm{C} 13 \mathrm{H} 20 \mathrm{C} 14 \mathrm{Br} 2 \mathrm{~F} 2$

$\mathrm{C} 13 \mathrm{H} 20 \mathrm{Cl} 4 \mathrm{Br} 3 \mathrm{~F}$

$\mathrm{C} 13 \mathrm{H} 20 \mathrm{Cl} 4 \mathrm{Br} 4$

$\mathrm{C} 13 \mathrm{H} 20 \mathrm{Cl} 4 \mathrm{BrF} 3$

$\mathrm{C} 13 \mathrm{H} 20 \mathrm{Cl} 5 \mathrm{Br} 2 \mathrm{~F}$

$\mathrm{C} 13 \mathrm{H} 20 \mathrm{C} 15 \mathrm{Br} 3$

$\mathrm{C} 13 \mathrm{H} 20 \mathrm{Cl} 5 \mathrm{BrF} 2$

$\mathrm{C} 13 \mathrm{H} 20 \mathrm{Cl} 6 \mathrm{Br} 2$

$\mathrm{C} 13 \mathrm{H} 20 \mathrm{Cl} 16 \mathrm{BrF}$

$\mathrm{C} 13 \mathrm{H} 20 \mathrm{Cl} 6 \mathrm{~F} 2$

$\mathrm{C} 13 \mathrm{H} 20 \mathrm{Cl}$

$\mathrm{C} 13 \mathrm{H} 20 \mathrm{ClBr} 3 \mathrm{~F} 4$

$\mathrm{C} 13 \mathrm{H} 20 \mathrm{ClBr} 4 \mathrm{~F} 3$

$\mathrm{C} 13 \mathrm{H} 20 \mathrm{ClBr} 5 \mathrm{~F} 2$

$\mathrm{C} 13 \mathrm{H} 21 \mathrm{Br} 3 \mathrm{~F} 4$

$\mathrm{C} 13 \mathrm{H} 21 \mathrm{Br} 4 \mathrm{~F} 3$

$\mathrm{C} 13 \mathrm{H} 21 \mathrm{Br} 5 \mathrm{~F} 2$

$\mathrm{C} 13 \mathrm{H} 21 \mathrm{Br} 6 \mathrm{~F}$

$\mathrm{C} 13 \mathrm{H} 21 \mathrm{Cl} 2 \mathrm{Br} 3 \mathrm{~F} 2$

$\mathrm{C} 13 \mathrm{H} 21 \mathrm{Cl} 2 \mathrm{Br} 4 \mathrm{~F}$

$\mathrm{C} 13 \mathrm{H} 21 \mathrm{Cl} 2 \mathrm{Br} 5$
lgKoa lgKow lgKaw lgKow lgKoa lgKaw lgKow lgKoa lgKaw _EPI_EPI_EPI_Exp__Exp__Exp__DFT_DFT_DFT Suite Suite Suite corr corr corr_corr_corr corr

$\begin{array}{lllllllll}9.89 & 8.57 & -1.32 & 7.87 & 9.19 & -1.32 & 7.34 & 16.19 & -8.84\end{array}$

$\begin{array}{lllllllll}10.8 & 8.23 & -2.56 & 7.36 & 9.92 & -2.56 & 7.08 & 17.83 & -10.75\end{array}$

$\begin{array}{lllllllll}12.4 & 8.63 & -3.80 & 7.96 & 11.75 & -3.80 & 7.39 & 20.84 & -13.45\end{array}$

$\begin{array}{lllllllll}9.32 & 8.48 & -0.84 & 7.73 & 8.57 & -0.84 & 7.28 & 15.13 & -7.85\end{array}$

$\begin{array}{lllllllll}8.34 & 8.74 & 0.40 & 8.12 & 7.72 & 0.40 & 7.47 & 13.33 & -5.86\end{array}$

$\begin{array}{lllllllll}9.64 & 8.05 & -1.59 & 7.09 & 8.68 & -1.59 & 6.94 & 15.72 & -8.78\end{array}$

$\begin{array}{lllllllll}8.66 & 8.31 & -0.35 & 7.48 & 7.83 & -0.35 & 7.14 & 13.92 & -6.78\end{array}$

$\begin{array}{lllllllll}9.07 & 7.96 & -1.11 & 6.96 & 8.06 & -1.11 & 6.88 & 14.66 & -7.79\end{array}$

$\begin{array}{lllllllll}8.09 & 8.22 & 0.13 & 7.34 & 7.21 & 0.13 & 7.08 & 12.87 & -5.79\end{array}$

$\begin{array}{lllllllll}11.2 & 8.59 & -2.61 & 7.90 & 10.50 & -2.61 & 7.36 & 18.58 & -11.22\end{array}$

$\begin{array}{lllllllll}9.48 & 8.11 & -1.37 & 7.18 & 8.55 & -1.37 & 6.99 & 15.43 & -8.44\end{array}$

$\begin{array}{lllllllll}11.9 & 8.41 & -3.53 & 7.63 & 11.16 & -3.53 & 7.22 & 19.95 & -12.73\end{array}$

$\begin{array}{lllllllll}8.76 & 8.16 & -0.60 & 7.25 & 7.86 & -0.60 & 7.03 & 14.11 & -7.08\end{array}$

$\begin{array}{lllllllll}10.4 & 8.56 & -1.84 & 7.85 & 9.69 & -1.84 & 7.34 & 17.12 & -9.78\end{array}$

$\begin{array}{lllllllll}12 & 8.97 & -3.08 & 8.46 & 11.54 & -3.08 & 7.65 & 20.14 & -12.49\end{array}$

$\begin{array}{lllllllll}8.52 & 7.65 & -0.87 & 6.49 & 7.36 & -0.87 & 6.64 & 13.66 & -7.03\end{array}$

$\begin{array}{lllllllll}10.2 & 8.05 & -2.11 & 7.09 & 9.20 & -2.11 & 6.94 & 16.67 & -9.73\end{array}$

$\begin{array}{lllllllll}11.8 & 8.45 & -3.34 & 7.69 & 11.03 & -3.34 & 7.25 & 19.68 & -12.42\end{array}$

$\begin{array}{lllllllll}8.68 & 8.3 & -0.38 & 7.46 & 7.85 & -0.38 & 7.14 & 13.96 & -6.83\end{array}$

$\begin{array}{lllllllll}9.51 & 7.89 & -1.62 & 6.85 & 8.47 & -1.62 & 6.82 & 15.49 & -8.66\end{array}$

$\begin{array}{lllllllll}11.1 & 8.29 & -2.86 & 7.45 & 10.31 & -2.86 & 7.13 & 18.49 & -11.36\end{array}$

$\begin{array}{lllllllll}9.75 & 8.61 & -1.14 & 7.93 & 9.06 & -1.14 & 7.38 & 15.92 & -8.54\end{array}$

$\begin{array}{lllllllll}10.6 & 8.27 & -2.38 & 7.42 & 9.79 & -2.38 & 7.11 & 17.57 & -10.45\end{array}$

$\begin{array}{lllllllll}12.3 & 8.67 & -3.61 & 8.01 & 11.63 & -3.61 & 7.42 & 20.57 & -13.15\end{array}$

$\begin{array}{lllllllll}8.77 & 8.87 & 0.10 & 8.31 & 8.21 & 0.10 & 7.57 & 14.12 & -6.55\end{array}$

$\begin{array}{lllllllll}10.7 & 8.85 & -1.89 & 8.28 & 10.17 & -1.89 & 7.56 & 17.74 & -10.18\end{array}$

$\begin{array}{lllllllll}11.7 & 8.59 & -3.13 & 7.90 & 11.02 & -3.13 & 7.36 & 19.53 & -12.17\end{array}$

$\begin{array}{lllllllll}8.43 & 7.78 & -0.65 & 6.69 & 7.34 & -0.65 & 6.74 & 13.50 & -6.76\end{array}$

$\begin{array}{lllllllll}11.1 & 8.5 & -2.64 & 7.76 & 10.40 & -2.64 & 7.29 & 18.48 & -11.19\end{array}$

$\begin{array}{lllllllll}10.2 & 8.76 & -1.40 & 8.15 & 9.55 & -1.40 & 7.49 & 16.68 & -9.19\end{array}$

$\begin{array}{lllllllll}8.53 & 8.36 & -0.17 & 7.55 & 7.72 & -0.17 & 7.18 & 13.67 & -6.49\end{array}$

$\begin{array}{lllllllll}9.91 & 8.24 & -1.67 & 7.37 & 9.04 & -1.67 & 7.09 & 16.22 & -9.13\end{array}$

$\begin{array}{lllllllll}8.19 & 8.07 & -0.12 & 7.12 & 7.24 & -0.12 & 6.96 & 13.06 & -6.09\end{array}$

$\begin{array}{lllllllll}9.84 & 8.48 & -1.36 & 7.73 & 9.09 & -1.36 & 7.28 & 16.08 & -8.80\end{array}$

$\begin{array}{lllllllll}10.7 & 8.06 & -2.59 & 7.10 & 9.70 & -2.59 & 6.95 & 17.58 & -10.63\end{array}$

$\begin{array}{lllllllll}7.56 & 7.89 & 0.33 & 6.85 & 6.52 & 0.33 & 6.82 & 11.89 & -5.07\end{array}$

$\begin{array}{lllllllll}8.45 & 7.55 & -0.90 & 6.34 & 7.24 & -0.90 & 6.56 & 13.54 & -6.98\end{array}$

$\begin{array}{lllllllll}10.8 & 8.62 & -2.14 & 7.94 & 10.08 & -2.14 & 7.38 & 17.77 & -10.39\end{array}$

$\begin{array}{lllllllll}11.7 & 8.29 & -3.38 & 7.45 & 10.82 & -3.38 & 7.13 & 19.44 & -12.31\end{array}$

$\begin{array}{lllllllll}8.87 & 7.7 & -1.17 & 6.57 & 7.74 & -1.17 & 6.68 & 14.30 & -7.63\end{array}$

$\begin{array}{lllllllll}10.5 & 8.11 & -2.41 & 7.18 & 9.58 & -2.41 & 6.99 & 17.33 & -10.34\end{array}$

$\begin{array}{llllllllll}12.2 & 8.51 & -3.64 & 7.78 & 11.42 & -3.64 & 7.30 & 20.34 & -13.04\end{array}$ 
SMILE Generated

$\mathrm{C}(\mathrm{C}(\mathrm{C}(\mathrm{C}(\mathrm{C}(\mathrm{C}(\mathrm{C}(\mathrm{C}(\mathrm{C}(\mathrm{C}(\mathrm{C}(\mathrm{C}(\mathrm{C}(\mathrm{H})(\mathrm{H}) \mathrm{H})(\mathrm{H}) \mathrm{H})(\mathrm{H}) \mathrm{H})(\mathrm{H}) \mathrm{Br})(\mathrm{H}) \mathrm{H})(\mathrm{H}) \mathrm{F})(\mathrm{Br}) \mathrm{H})(\mathrm{H}) \mathrm{Cl})(\mathrm{Cl}) \mathrm{F})(\mathrm{H}) \mathrm{H})(\mathrm{H}) \mathrm{H})$ $(\mathrm{H}) \mathrm{H})(\mathrm{H})(\mathrm{H}) \mathrm{Cl}$

$\mathrm{C}(\mathrm{C}(\mathrm{C}(\mathrm{C}(\mathrm{C}(\mathrm{C}(\mathrm{C}(\mathrm{C}(\mathrm{C}(\mathrm{C}(\mathrm{C}(\mathrm{C}(\mathrm{C}(\mathrm{H})(\mathrm{H}) \mathrm{H})(\mathrm{H}) \mathrm{Cl})(\mathrm{H}) \mathrm{H})(\mathrm{H}) \mathrm{H})(\mathrm{H}) \mathrm{H})(\mathrm{H}) \mathrm{F})(\mathrm{H}) \mathrm{H})(\mathrm{Br}) \mathrm{H})(\mathrm{H}) \mathrm{H})(\mathrm{H}) \mathrm{H})(\mathrm{H}) \mathrm{Cl})$ $(\mathrm{H}) \mathrm{H})(\mathrm{Br})(\mathrm{Cl}) \mathrm{Cl}$

$\mathrm{C}(\mathrm{C}(\mathrm{C}(\mathrm{C}(\mathrm{C}(\mathrm{C}(\mathrm{C}(\mathrm{C}(\mathrm{C}(\mathrm{C}(\mathrm{C}(\mathrm{C}(\mathrm{C}(\mathrm{H})(\mathrm{Cl}) \mathrm{H})(\mathrm{H}) \mathrm{F})(\mathrm{H}) \mathrm{Cl})(\mathrm{H}) \mathrm{H})(\mathrm{H}) \mathrm{H})(\mathrm{H}) \mathrm{H})(\mathrm{H}) \mathrm{H})(\mathrm{H}) \mathrm{Cl})(\mathrm{H}) \mathrm{H})(\mathrm{Br}) \mathrm{Cl})(\mathrm{H}) \mathrm{H})$ $(\mathrm{H}) \mathrm{F})(\mathrm{H})(\mathrm{H}) \mathrm{H}$

$\mathrm{C}(\mathrm{C}(\mathrm{C}(\mathrm{C}(\mathrm{C}(\mathrm{C}(\mathrm{C}(\mathrm{C}(\mathrm{C}(\mathrm{C}(\mathrm{C}(\mathrm{C}(\mathrm{C}(\mathrm{Cl})(\mathrm{H}) \mathrm{Cl})(\mathrm{H}) \mathrm{F})(\mathrm{H}) \mathrm{H})(\mathrm{H}) \mathrm{Cl})(\mathrm{H}) \mathrm{H})(\mathrm{H}) \mathrm{H})(\mathrm{H}) \mathrm{H})(\mathrm{H}) \mathrm{H})(\mathrm{H}) \mathrm{H})(\mathrm{Cl}) \mathrm{H})(\mathrm{H}) \mathrm{Br})(\mathrm{H})$ $\mathrm{H})(\mathrm{H})(\mathrm{Cl}) \mathrm{H}$

$\mathrm{C}(\mathrm{C}(\mathrm{C}(\mathrm{C}(\mathrm{C}(\mathrm{C}(\mathrm{C}(\mathrm{C}(\mathrm{C}(\mathrm{C}(\mathrm{C}(\mathrm{C}(\mathrm{C}(\mathrm{Br})(\mathrm{H}) \mathrm{H})(\mathrm{H}) \mathrm{Cl})(\mathrm{H}) \mathrm{H})(\mathrm{H}) \mathrm{H})(\mathrm{H}) \mathrm{Cl})(\mathrm{H}) \mathrm{H})(\mathrm{H}) \mathrm{H})(\mathrm{H}) \mathrm{H})(\mathrm{Cl}) \mathrm{H})(\mathrm{Cl}) \mathrm{H})(\mathrm{Cl}) \mathrm{Cl})(\mathrm{H})$ $\mathrm{H})(\mathrm{H})(\mathrm{H}) \mathrm{H}$

$\mathrm{C}(\mathrm{C}(\mathrm{C}(\mathrm{C}(\mathrm{C}(\mathrm{C}(\mathrm{C}(\mathrm{C}(\mathrm{C}(\mathrm{C}(\mathrm{C}(\mathrm{C}(\mathrm{C}(\mathrm{H})(\mathrm{Cl}) \mathrm{F})(\mathrm{H}) \mathrm{H})(\mathrm{H}) \mathrm{H})(\mathrm{Cl}) \mathrm{H})(\mathrm{H}) \mathrm{Cl})(\mathrm{H}) \mathrm{Cl})(\mathrm{H}) \mathrm{H})(\mathrm{H}) \mathrm{Cl})(\mathrm{Cl}) \mathrm{H})(\mathrm{H}) \mathrm{H})(\mathrm{H}) \mathrm{H})(\mathrm{H})$ $\mathrm{H})(\mathrm{H})(\mathrm{H}) \mathrm{H}$

$\mathrm{C}(\mathrm{C}(\mathrm{C}(\mathrm{C}(\mathrm{C}(\mathrm{C}(\mathrm{C}(\mathrm{C}(\mathrm{C}(\mathrm{C}(\mathrm{C}(\mathrm{C}(\mathrm{C}(\mathrm{Cl})(\mathrm{H}) \mathrm{Cl})(\mathrm{H}) \mathrm{H})(\mathrm{H}) \mathrm{H})(\mathrm{Cl}) \mathrm{H})(\mathrm{Cl}) \mathrm{H})(\mathrm{H}) \mathrm{H})(\mathrm{H}) \mathrm{H})(\mathrm{H}) \mathrm{Cl})(\mathrm{H}) \mathrm{Cl})(\mathrm{H}) \mathrm{H})(\mathrm{H}) \mathrm{H})(\mathrm{H})$ $\mathrm{H})(\mathrm{Cl})(\mathrm{H}) \mathrm{H}$

$\mathrm{C}(\mathrm{C}(\mathrm{C}(\mathrm{C}(\mathrm{C}(\mathrm{C}(\mathrm{C}(\mathrm{C}(\mathrm{C}(\mathrm{C}(\mathrm{C}(\mathrm{C}(\mathrm{C}(\mathrm{H})(\mathrm{H}) \mathrm{Br})(\mathrm{H}) \mathrm{H})(\mathrm{H}) \mathrm{H})(\mathrm{H}) \mathrm{F})(\mathrm{F}) \mathrm{H})(\mathrm{H}) \mathrm{Br})(\mathrm{H}) \mathrm{H})(\mathrm{Cl}) \mathrm{H})(\mathrm{H}) \mathrm{H})(\mathrm{H}) \mathrm{H})(\mathrm{H}) \mathrm{Br})$

$(\mathrm{H}) \mathrm{H})(\mathrm{H})(\mathrm{H}) \mathrm{F}$

$\mathrm{C}(\mathrm{C}(\mathrm{C}(\mathrm{C}(\mathrm{C}(\mathrm{C}(\mathrm{C}(\mathrm{C}(\mathrm{C}(\mathrm{C}(\mathrm{C}(\mathrm{C}(\mathrm{C}(\mathrm{H})(\mathrm{H}) \mathrm{H})(\mathrm{H}) \mathrm{H})(\mathrm{H}) \mathrm{Br})(\mathrm{H}) \mathrm{H})(\mathrm{F}) \mathrm{H})(\mathrm{H}) \mathrm{H})(\mathrm{H}) \mathrm{F})(\mathrm{Cl}) \mathrm{Br})(\mathrm{H}) \mathrm{H})(\mathrm{H}) \mathrm{Br})(\mathrm{H}) \mathrm{H})$

(H)H)(Br)(H)H

$\mathrm{C}(\mathrm{C}(\mathrm{C}(\mathrm{C}(\mathrm{C}(\mathrm{C}(\mathrm{C}(\mathrm{C}(\mathrm{C}(\mathrm{C}(\mathrm{C}(\mathrm{C}(\mathrm{C}(\mathrm{H})(\mathrm{H}) \mathrm{H})(\mathrm{H}) \mathrm{Br})(\mathrm{H}) \mathrm{H})(\mathrm{Br}) \mathrm{H})(\mathrm{H}) \mathrm{Cl})(\mathrm{H}) \mathrm{H})(\mathrm{H}) \mathrm{Br})(\mathrm{H}) \mathrm{H})(\mathrm{H}) \mathrm{H})(\mathrm{H}) \mathrm{H})(\mathrm{Br}) \mathrm{F})(\mathrm{H})$

$\mathrm{H})(\mathrm{H})(\mathrm{H}) \mathrm{Br}$

$\mathrm{C}(\mathrm{C}(\mathrm{C}(\mathrm{C}(\mathrm{C}(\mathrm{C}(\mathrm{C}(\mathrm{C}(\mathrm{C}(\mathrm{C}(\mathrm{C}(\mathrm{C}(\mathrm{C}(\mathrm{H})(\mathrm{H}) \mathrm{F})(\mathrm{H}) \mathrm{H})(\mathrm{H}) \mathrm{H})(\mathrm{H}) \mathrm{H})(\mathrm{H}) \mathrm{F})(\mathrm{H}) \mathrm{H})(\mathrm{H}) \mathrm{H})(\mathrm{H}) \mathrm{H})(\mathrm{Br}) \mathrm{Br})(\mathrm{H}) \mathrm{H})(\mathrm{H}) \mathrm{H})$

$(\mathrm{H}) \mathrm{Br})(\mathrm{H})(\mathrm{H}) \mathrm{F}$

$\mathrm{C}(\mathrm{C}(\mathrm{C}(\mathrm{C}(\mathrm{C}(\mathrm{C}(\mathrm{C}(\mathrm{C}(\mathrm{C}(\mathrm{C}(\mathrm{C}(\mathrm{C}(\mathrm{C}(\mathrm{H})(\mathrm{H}) \mathrm{H})(\mathrm{H}) \mathrm{H})(\mathrm{F}) \mathrm{H})(\mathrm{H}) \mathrm{Br})(\mathrm{H}) \mathrm{H})(\mathrm{H}) \mathrm{H})(\mathrm{H}) \mathrm{H})(\mathrm{H}) \mathrm{H})(\mathrm{H}) \mathrm{H})(\mathrm{H}) \mathrm{F})(\mathrm{H}) \mathrm{Br})(\mathrm{H}) \mathrm{H})$ $(\mathrm{H})(\mathrm{Br}) \mathrm{Br}$

$\mathrm{C}(\mathrm{C}(\mathrm{C}(\mathrm{C}(\mathrm{C}(\mathrm{C}(\mathrm{C}(\mathrm{C}(\mathrm{C}(\mathrm{C}(\mathrm{C}(\mathrm{C}(\mathrm{C}(\mathrm{H})(\mathrm{H}) \mathrm{F})(\mathrm{Br}) \mathrm{H})(\mathrm{H}) \mathrm{H})(\mathrm{Br}) \mathrm{Br})(\mathrm{H}) \mathrm{H})(\mathrm{Br}) \mathrm{H})(\mathrm{H}) \mathrm{H})(\mathrm{H}) \mathrm{H})(\mathrm{H}) \mathrm{H})(\mathrm{H}) \mathrm{Br})(\mathrm{H}) \mathrm{H})(\mathrm{H})$

$\mathrm{H})(\mathrm{H})(\mathrm{H}) \mathrm{H}$

$\mathrm{C}(\mathrm{C}(\mathrm{C}(\mathrm{C}(\mathrm{C}(\mathrm{C}(\mathrm{C}(\mathrm{C}(\mathrm{C}(\mathrm{C}(\mathrm{C}(\mathrm{C}(\mathrm{C}(\mathrm{F})(\mathrm{Br}) \mathrm{H})(\mathrm{Cl}) \mathrm{H})(\mathrm{H}) \mathrm{H})(\mathrm{H}) \mathrm{H})(\mathrm{H}) \mathrm{H})(\mathrm{H}) \mathrm{H})(\mathrm{Br}) \mathrm{H})(\mathrm{Cl}) \mathrm{H})(\mathrm{H}) \mathrm{H})(\mathrm{H}) \mathrm{H})(\mathrm{H}) \mathrm{H})$

$(\mathrm{H}) \mathrm{H})(\mathrm{F})(\mathrm{H}) \mathrm{H}$

$\mathrm{C}(\mathrm{C}(\mathrm{C}(\mathrm{C}(\mathrm{C}(\mathrm{C}(\mathrm{C}(\mathrm{C}(\mathrm{C}(\mathrm{C}(\mathrm{C}(\mathrm{C}(\mathrm{C}(\mathrm{H})(\mathrm{H}) \mathrm{H})(\mathrm{H}) \mathrm{H})(\mathrm{H}) \mathrm{Br})(\mathrm{H}) \mathrm{H})(\mathrm{H}) \mathrm{H})(\mathrm{H}) \mathrm{Cl})(\mathrm{H}) \mathrm{H})(\mathrm{H}) \mathrm{H})(\mathrm{Cl}) \mathrm{H})(\mathrm{H}) \mathrm{Br})(\mathrm{Br}) \mathrm{H})(\mathrm{H})$ $\mathrm{H})(\mathrm{H})(\mathrm{H}) \mathrm{B}$

$\mathrm{C}(\mathrm{C}(\mathrm{C}(\mathrm{C}(\mathrm{C}(\mathrm{C}(\mathrm{C}(\mathrm{C}(\mathrm{C}(\mathrm{C}(\mathrm{C}(\mathrm{C}(\mathrm{C}(\mathrm{H})(\mathrm{Br}) \mathrm{H})(\mathrm{H}) \mathrm{Br})(\mathrm{H}) \mathrm{H})(\mathrm{H}) \mathrm{H})(\mathrm{H}) \mathrm{F})(\mathrm{H}) \mathrm{Cl})(\mathrm{H}) \mathrm{H})(\mathrm{Cl}) \mathrm{H})(\mathrm{H}) \mathrm{H})(\mathrm{H}) \mathrm{H})(\mathrm{Cl}) \mathrm{H})(\mathrm{H})$ $\mathrm{H})(\mathrm{H})(\mathrm{H}) \mathrm{H}$

$\mathrm{C}(\mathrm{C}(\mathrm{C}(\mathrm{C}(\mathrm{C}(\mathrm{C}(\mathrm{C}(\mathrm{C}(\mathrm{C}(\mathrm{C}(\mathrm{C}(\mathrm{C}(\mathrm{C}(\mathrm{H})(\mathrm{H}) \mathrm{Cl})(\mathrm{H}) \mathrm{Br})(\mathrm{H}) \mathrm{H})(\mathrm{Br}) \mathrm{H})(\mathrm{H}) \mathrm{H})(\mathrm{H}) \mathrm{H})(\mathrm{H}) \mathrm{Cl})(\mathrm{H}) \mathrm{H})(\mathrm{H}) \mathrm{H})(\mathrm{H}) \mathrm{H})(\mathrm{H}) \mathrm{H})(\mathrm{Br})$ $\mathrm{H})(\mathrm{Cl})(\mathrm{H}) \mathrm{H}$

$\mathrm{C}(\mathrm{C}(\mathrm{C}(\mathrm{C}(\mathrm{C}(\mathrm{C}(\mathrm{C}(\mathrm{C}(\mathrm{C}(\mathrm{C}(\mathrm{C}(\mathrm{C}(\mathrm{C}(\mathrm{H})(\mathrm{H}) \mathrm{H})(\mathrm{Cl}) \mathrm{Cl})(\mathrm{H}) \mathrm{Br})(\mathrm{H}) \mathrm{H})(\mathrm{H}) \mathrm{H})(\mathrm{H}) \mathrm{H})(\mathrm{F}) \mathrm{H})(\mathrm{Cl}) \mathrm{H})(\mathrm{H}) \mathrm{H})(\mathrm{H}) \mathrm{H})(\mathrm{H}) \mathrm{H})$

$(\mathrm{H}) \mathrm{F})(\mathrm{H})(\mathrm{H}) \mathrm{H}$

$\mathrm{C}(\mathrm{C}(\mathrm{C}(\mathrm{C}(\mathrm{C}(\mathrm{C}(\mathrm{C}(\mathrm{C}(\mathrm{C}(\mathrm{C}(\mathrm{C}(\mathrm{C}(\mathrm{C}(\mathrm{H})(\mathrm{H}) \mathrm{H})(\mathrm{H}) \mathrm{H})(\mathrm{H}) \mathrm{Cl})(\mathrm{H}) \mathrm{H})(\mathrm{H}) \mathrm{H})(\mathrm{Cl}) \mathrm{H})(\mathrm{H}) \mathrm{Br})(\mathrm{H}) \mathrm{H})(\mathrm{H}) \mathrm{H})(\mathrm{Cl}) \mathrm{H})(\mathrm{Cl}) \mathrm{Br})(\mathrm{H})$ $\mathrm{H})(\mathrm{H})(\mathrm{H}) \mathrm{H}$

$\mathrm{C}(\mathrm{C}(\mathrm{C}(\mathrm{C}(\mathrm{C}(\mathrm{C}(\mathrm{C}(\mathrm{C}(\mathrm{C}(\mathrm{C}(\mathrm{C}(\mathrm{C}(\mathrm{C}(\mathrm{H})(\mathrm{H}) \mathrm{H})(\mathrm{H}) \mathrm{H})(\mathrm{H}) \mathrm{H})(\mathrm{Cl}) \mathrm{H})(\mathrm{F}) \mathrm{H})(\mathrm{H}) \mathrm{Cl})(\mathrm{H}) \mathrm{Cl})(\mathrm{H}) \mathrm{H})(\mathrm{H}) \mathrm{H})(\mathrm{H}) \mathrm{Br})(\mathrm{H}) \mathrm{H})$ $(\mathrm{H}) \mathrm{H})(\mathrm{H})(\mathrm{H}) \mathrm{Cl}$

$\mathrm{C}(\mathrm{C}(\mathrm{C}(\mathrm{C}(\mathrm{C}(\mathrm{C}(\mathrm{C}(\mathrm{C}(\mathrm{C}(\mathrm{C}(\mathrm{C}(\mathrm{C}(\mathrm{C}(\mathrm{H})(\mathrm{H}) \mathrm{H})(\mathrm{H}) \mathrm{H})(\mathrm{H}) \mathrm{H})(\mathrm{H}) \mathrm{Cl})(\mathrm{H}) \mathrm{Cl})(\mathrm{H}) \mathrm{Cl})(\mathrm{Br}) \mathrm{Cl})(\mathrm{H}) \mathrm{H})(\mathrm{H}) \mathrm{H})(\mathrm{H}) \mathrm{H})(\mathrm{H}) \mathrm{H})(\mathrm{H})$ $\mathrm{H})(\mathrm{H})(\mathrm{H}) \mathrm{Cl}$

$\mathrm{C}(\mathrm{C}(\mathrm{C}(\mathrm{C}(\mathrm{C}(\mathrm{C}(\mathrm{C}(\mathrm{C}(\mathrm{C}(\mathrm{C}(\mathrm{C}(\mathrm{C}(\mathrm{C}(\mathrm{Cl})(\mathrm{H}) \mathrm{H})(\mathrm{H}) \mathrm{H})(\mathrm{Cl}) \mathrm{H})(\mathrm{H}) \mathrm{H})(\mathrm{H}) \mathrm{H})(\mathrm{H}) \mathrm{H})(\mathrm{Cl}) \mathrm{H})(\mathrm{Cl}) \mathrm{Cl})(\mathrm{H}) \mathrm{H})(\mathrm{H}) \mathrm{H})(\mathrm{H}) \mathrm{F})$

$(\mathrm{H}) \mathrm{H})(\mathrm{H})(\mathrm{H}) \mathrm{H}$

$\mathrm{C}(\mathrm{C}(\mathrm{C}(\mathrm{C}(\mathrm{C}(\mathrm{C}(\mathrm{C}(\mathrm{C}(\mathrm{C}(\mathrm{C}(\mathrm{C}(\mathrm{C}(\mathrm{C}(\mathrm{Cl})(\mathrm{H}) \mathrm{H})(\mathrm{H}) \mathrm{H})(\mathrm{H}) \mathrm{Cl})(\mathrm{H}) \mathrm{H})(\mathrm{Cl}) \mathrm{H})(\mathrm{Cl}) \mathrm{H})(\mathrm{H}) \mathrm{H})(\mathrm{H}) \mathrm{H})(\mathrm{H}) \mathrm{H})(\mathrm{H}) \mathrm{H})(\mathrm{H}) \mathrm{H})$

$(\mathrm{H}) \mathrm{H})(\mathrm{H})(\mathrm{Cl}) \mathrm{Cl}$

$\mathrm{C}(\mathrm{C}(\mathrm{C}(\mathrm{C}(\mathrm{C}(\mathrm{C}(\mathrm{C}(\mathrm{C}(\mathrm{C}(\mathrm{C}(\mathrm{C}(\mathrm{C}(\mathrm{C}(\mathrm{H})(\mathrm{H}) \mathrm{H})(\mathrm{Br}) \mathrm{H})(\mathrm{H}) \mathrm{Cl})(\mathrm{H}) \mathrm{H})(\mathrm{H}) \mathrm{H})(\mathrm{H}) \mathrm{F})(\mathrm{F}) \mathrm{Br})(\mathrm{H}) \mathrm{H})(\mathrm{H}) \mathrm{H})(\mathrm{H}) \mathrm{H})(\mathrm{H}) \mathrm{H})(\mathrm{H}) \mathrm{H})$ $(\mathrm{Br})(\mathrm{H}) \mathrm{H}$

$\mathrm{C}(\mathrm{C}(\mathrm{C}(\mathrm{C}(\mathrm{C}(\mathrm{C}(\mathrm{C}(\mathrm{C}(\mathrm{C}(\mathrm{C}(\mathrm{C}(\mathrm{C}(\mathrm{C}(\mathrm{Br})(\mathrm{H}) \mathrm{Br})(\mathrm{H}) \mathrm{H})(\mathrm{F}) \mathrm{Br})(\mathrm{H}) \mathrm{H})(\mathrm{H}) \mathrm{H})(\mathrm{H}) \mathrm{Cl})(\mathrm{Br}) \mathrm{H})(\mathrm{H}) \mathrm{H})(\mathrm{H}) \mathrm{H})(\mathrm{H}) \mathrm{H})(\mathrm{H}) \mathrm{H})(\mathrm{H})$ $\mathrm{H})(\mathrm{H})(\mathrm{H}) \mathrm{H}$

$\mathrm{C}(\mathrm{C}(\mathrm{C}(\mathrm{C}(\mathrm{C}(\mathrm{C}(\mathrm{C}(\mathrm{C}(\mathrm{C}(\mathrm{C}(\mathrm{C}(\mathrm{C}(\mathrm{C}(\mathrm{H})(\mathrm{H}) \mathrm{Br})(\mathrm{H}) \mathrm{F})(\mathrm{H}) \mathrm{H})(\mathrm{H}) \mathrm{Br})(\mathrm{H}) \mathrm{H})(\mathrm{Br}) \mathrm{F})(\mathrm{H}) \mathrm{H})(\mathrm{H}) \mathrm{H})(\mathrm{H}) \mathrm{H})(\mathrm{H}) \mathrm{H})(\mathrm{H}) \mathrm{H})$

$(\mathrm{H}) \mathrm{H})(\mathrm{H})(\mathrm{H}) \mathrm{H}$

$\mathrm{C}(\mathrm{C}(\mathrm{C}(\mathrm{C}(\mathrm{C}(\mathrm{C}(\mathrm{C}(\mathrm{C}(\mathrm{C}(\mathrm{C}(\mathrm{C}(\mathrm{C}(\mathrm{C}(\mathrm{H})(\mathrm{H}) \mathrm{H})(\mathrm{H}) \mathrm{Br})(\mathrm{H}) \mathrm{H})(\mathrm{H}) \mathrm{H})(\mathrm{H}) \mathrm{F})(\mathrm{H}) \mathrm{H})(\mathrm{H}) \mathrm{H})(\mathrm{H}) \mathrm{Br})(\mathrm{H}) \mathrm{H})(\mathrm{H}) \mathrm{H})(\mathrm{Br}) \mathrm{H})$

$(\mathrm{H}) \mathrm{H})(\mathrm{H})(\mathrm{Br}) \mathrm{H}$

$\mathrm{C}(\mathrm{C}(\mathrm{C}(\mathrm{C}(\mathrm{C}(\mathrm{C}(\mathrm{C}(\mathrm{C}(\mathrm{C}(\mathrm{C}(\mathrm{C}(\mathrm{C}(\mathrm{C}(\mathrm{H})(\mathrm{Br}) \mathrm{H})(\mathrm{H}) \mathrm{H})(\mathrm{Br}) \mathrm{H})(\mathrm{H}) \mathrm{Br})(\mathrm{H}) \mathrm{H})(\mathrm{H}) \mathrm{H})(\mathrm{H}) \mathrm{H})(\mathrm{H}) \mathrm{H})(\mathrm{H}) \mathrm{H})(\mathrm{H}) \mathrm{H})(\mathrm{H}) \mathrm{H})(\mathrm{Br})$ $\mathrm{H})(\mathrm{H})(\mathrm{H}) \mathrm{Br}$

C(C(C(C(C(C(C(C(C(C(C(C(C(H)(H)H)(H)H)(H)H)(H)H)(H)H)(H)H)(Cl)H)(H)H)(H)Cl)(H)H)(H)H)

(F)Br)(H)(Br)H

$\mathrm{C}(\mathrm{C}(\mathrm{C}(\mathrm{C}(\mathrm{C}(\mathrm{C}(\mathrm{C}(\mathrm{C}(\mathrm{C}(\mathrm{C}(\mathrm{C}(\mathrm{C}(\mathrm{C}(\mathrm{H})(\mathrm{H}) \mathrm{H})(\mathrm{H}) \mathrm{H})(\mathrm{Br}) \mathrm{H})(\mathrm{H}) \mathrm{H})(\mathrm{H}) \mathrm{H})(\mathrm{H}) \mathrm{Br})(\mathrm{H}) \mathrm{H})(\mathrm{H}) \mathrm{H})(\mathrm{H}) \mathrm{H})(\mathrm{H}) \mathrm{H})(\mathrm{Cl}) \mathrm{H})(\mathrm{Cl})$ $\mathrm{H})(\mathrm{Br})(\mathrm{H}) \mathrm{H}$

$\mathrm{C}(\mathrm{C}(\mathrm{C}(\mathrm{C}(\mathrm{C}(\mathrm{C}(\mathrm{C}(\mathrm{C}(\mathrm{C}(\mathrm{C}(\mathrm{C}(\mathrm{C}(\mathrm{C}(\mathrm{H})(\mathrm{Br}) \mathrm{H})(\mathrm{H}) \mathrm{H})(\mathrm{H}) \mathrm{H})(\mathrm{H}) \mathrm{H})(\mathrm{H}) \mathrm{Br})(\mathrm{H}) \mathrm{H})(\mathrm{Cl}) \mathrm{Cl})(\mathrm{H}) \mathrm{H})(\mathrm{H}) \mathrm{H})(\mathrm{H}) \mathrm{H})(\mathrm{H}) \mathrm{H})(\mathrm{H})$ $\mathrm{H})(\mathrm{H})(\mathrm{Cl}) \mathrm{H}$

$\mathrm{C}(\mathrm{C}(\mathrm{C}(\mathrm{C}(\mathrm{C}(\mathrm{C}(\mathrm{C}(\mathrm{C}(\mathrm{C}(\mathrm{C}(\mathrm{C}(\mathrm{C}(\mathrm{C}(\mathrm{H})(\mathrm{H}) \mathrm{H})(\mathrm{H}) \mathrm{Cl})(\mathrm{Cl}) \mathrm{H})(\mathrm{H}) \mathrm{H})(\mathrm{H}) \mathrm{H})(\mathrm{H}) \mathrm{H})(\mathrm{H}) \mathrm{H})(\mathrm{H}) \mathrm{H})(\mathrm{H}) \mathrm{Br})(\mathrm{H}) \mathrm{F})(\mathrm{H}) \mathrm{H})$

$(\mathrm{H}) \mathrm{H})(\mathrm{Cl})(\mathrm{H}) \mathrm{H}$

$\mathrm{C}(\mathrm{C}(\mathrm{C}(\mathrm{C}(\mathrm{C}(\mathrm{C}(\mathrm{C}(\mathrm{C}(\mathrm{C}(\mathrm{C}(\mathrm{C}(\mathrm{C}(\mathrm{C}(\mathrm{Cl})(\mathrm{H}) \mathrm{H})(\mathrm{Cl}) \mathrm{H})(\mathrm{H}) \mathrm{Cl})(\mathrm{H}) \mathrm{H})(\mathrm{H}) \mathrm{H})(\mathrm{H}) \mathrm{Cl})(\mathrm{H}) \mathrm{H})(\mathrm{H}) \mathrm{H})(\mathrm{H}) \mathrm{Br})(\mathrm{H}) \mathrm{H})(\mathrm{H}) \mathrm{H})(\mathrm{H})$ $\mathrm{H})(\mathrm{H})(\mathrm{H}) \mathrm{H}$

$\mathrm{C}(\mathrm{C}(\mathrm{C}(\mathrm{C}(\mathrm{C}(\mathrm{C}(\mathrm{C}(\mathrm{C}(\mathrm{C}(\mathrm{C}(\mathrm{C}(\mathrm{C}(\mathrm{C}(\mathrm{H})(\mathrm{H}) \mathrm{Cl})(\mathrm{Cl}) \mathrm{H})(\mathrm{Cl}) \mathrm{H})(\mathrm{H}) \mathrm{H})(\mathrm{H}) \mathrm{Cl})(\mathrm{H}) \mathrm{H})(\mathrm{H}) \mathrm{H})(\mathrm{H}) \mathrm{H})(\mathrm{H}) \mathrm{H})(\mathrm{H}) \mathrm{H})(\mathrm{H}) \mathrm{H})(\mathrm{Cl})$ $\mathrm{H})(\mathrm{H})(\mathrm{H}) \mathrm{H}$

$\mathrm{C}(\mathrm{C}(\mathrm{C}(\mathrm{C}(\mathrm{C}(\mathrm{C}(\mathrm{C}(\mathrm{C}(\mathrm{C}(\mathrm{C}(\mathrm{C}(\mathrm{C}(\mathrm{C}(\mathrm{H})(\mathrm{H}) \mathrm{H})(\mathrm{H}) \mathrm{H})(\mathrm{H}) \mathrm{H})(\mathrm{H}) \mathrm{Br})(\mathrm{H}) \mathrm{Br})(\mathrm{H}) \mathrm{H})(\mathrm{Cl}) \mathrm{H})(\mathrm{H}) \mathrm{H})(\mathrm{H}) \mathrm{H})(\mathrm{H}) \mathrm{H})(\mathrm{H}) \mathrm{H})$ $(\mathrm{H}) \mathrm{F})(\mathrm{H})(\mathrm{H}) \mathrm{Br}$

$\mathrm{C}(\mathrm{C}(\mathrm{C}(\mathrm{C}(\mathrm{C}(\mathrm{C}(\mathrm{C}(\mathrm{C}(\mathrm{C}(\mathrm{C}(\mathrm{C}(\mathrm{C}(\mathrm{C}(\mathrm{H})(\mathrm{H}) \mathrm{Br})(\mathrm{H}) \mathrm{H})(\mathrm{H}) \mathrm{H})(\mathrm{H}) \mathrm{Cl})(\mathrm{H}) \mathrm{H})(\mathrm{H}) \mathrm{H})(\mathrm{H}) \mathrm{H})(\mathrm{H}) \mathrm{H})(\mathrm{H}) \mathrm{H})(\mathrm{H}) \mathrm{Br})(\mathrm{H}) \mathrm{H})$

$(\mathrm{H}) \mathrm{H})(\mathrm{Br})(\mathrm{H}) \mathrm{Br}$

$\mathrm{C}(\mathrm{C}(\mathrm{C}(\mathrm{C}(\mathrm{C}(\mathrm{C}(\mathrm{C}(\mathrm{C}(\mathrm{C}(\mathrm{C}(\mathrm{C}(\mathrm{C}(\mathrm{C}(\mathrm{H})(\mathrm{H}) \mathrm{Br})(\mathrm{H}) \mathrm{Br})(\mathrm{H}) \mathrm{H})(\mathrm{H}) \mathrm{H})(\mathrm{H}) \mathrm{H})(\mathrm{H}) \mathrm{H})(\mathrm{H}) \mathrm{H})(\mathrm{Br}) \mathrm{H})(\mathrm{H}) \mathrm{H})(\mathrm{H}) \mathrm{H})(\mathrm{H}) \mathrm{H})$

(H)F)(H)(H)H

$\mathrm{C}(\mathrm{C}(\mathrm{C}(\mathrm{C}(\mathrm{C}(\mathrm{C}(\mathrm{C}(\mathrm{C}(\mathrm{C}(\mathrm{C}(\mathrm{C}(\mathrm{C}(\mathrm{C}(\mathrm{H})(\mathrm{H}) \mathrm{H})(\mathrm{H}) \mathrm{H})(\mathrm{H}) \mathrm{Br})(\mathrm{H}) \mathrm{H})(\mathrm{H}) \mathrm{H})(\mathrm{H}) \mathrm{H})(\mathrm{H}) \mathrm{H})(\mathrm{H}) \mathrm{H})(\mathrm{Br}) \mathrm{H})(\mathrm{H}) \mathrm{H})(\mathrm{Br}) \mathrm{H})(\mathrm{H})$ $\mathrm{Br})(\mathrm{H})(\mathrm{H}) \mathrm{H}$

$\mathrm{C}(\mathrm{C}(\mathrm{C}(\mathrm{C}(\mathrm{C}(\mathrm{C}(\mathrm{C}(\mathrm{C}(\mathrm{C}(\mathrm{C}(\mathrm{C}(\mathrm{C}(\mathrm{C}(\mathrm{H})(\mathrm{H}) \mathrm{H})(\mathrm{H}) \mathrm{Cl})(\mathrm{H}) \mathrm{H})(\mathrm{H}) \mathrm{H})(\mathrm{H}) \mathrm{Br})(\mathrm{H}) \mathrm{H})(\mathrm{H}) \mathrm{H})(\mathrm{H}) \mathrm{H})(\mathrm{Br}) \mathrm{H})(\mathrm{H}) \mathrm{Cl})(\mathrm{H}) \mathrm{H})(\mathrm{H})$ $\mathrm{H})(\mathrm{H})(\mathrm{H}) \mathrm{H}$

$\mathrm{C}(\mathrm{C}(\mathrm{C}(\mathrm{C}(\mathrm{C}(\mathrm{C}(\mathrm{C}(\mathrm{C}(\mathrm{C}(\mathrm{C}(\mathrm{C}(\mathrm{C}(\mathrm{C}(\mathrm{H})(\mathrm{H}) \mathrm{H})(\mathrm{H}) \mathrm{H})(\mathrm{F}) \mathrm{Br})(\mathrm{H}) \mathrm{Cl})(\mathrm{H}) \mathrm{H})(\mathrm{H}) \mathrm{H})(\mathrm{H}) \mathrm{H})(\mathrm{H}) \mathrm{H})(\mathrm{Cl}) \mathrm{H})(\mathrm{H}) \mathrm{H})(\mathrm{H}) \mathrm{H})$

$(\mathrm{H}) \mathrm{H})(\mathrm{H})(\mathrm{H}) \mathrm{H}$

$\mathrm{C}(\mathrm{C}(\mathrm{C}(\mathrm{C}(\mathrm{C}(\mathrm{C}(\mathrm{C}(\mathrm{C}(\mathrm{C}(\mathrm{C}(\mathrm{C}(\mathrm{C}(\mathrm{C}(\mathrm{H})(\mathrm{H}) \mathrm{H})(\mathrm{H}) \mathrm{H})(\mathrm{H}) \mathrm{H})(\mathrm{Cl}) \mathrm{H})(\mathrm{Br}) \mathrm{H})(\mathrm{H}) \mathrm{Cl})(\mathrm{H}) \mathrm{Cl})(\mathrm{H}) \mathrm{H})(\mathrm{H}) \mathrm{H})(\mathrm{H}) \mathrm{H})(\mathrm{H}) \mathrm{H})(\mathrm{H})$

$\mathrm{H})(\mathrm{H})(\mathrm{H}) \mathrm{H}$

$\mathrm{C}(\mathrm{C}(\mathrm{C}(\mathrm{C}(\mathrm{C}(\mathrm{C}(\mathrm{C}(\mathrm{C}(\mathrm{C}(\mathrm{C}(\mathrm{C}(\mathrm{C}(\mathrm{C}(\mathrm{H})(\mathrm{H}) \mathrm{Cl})(\mathrm{H}) \mathrm{H})(\mathrm{H}) \mathrm{Cl})(\mathrm{H}) \mathrm{H})(\mathrm{H}) \mathrm{H})(\mathrm{H}) \mathrm{H})(\mathrm{H}) \mathrm{H})(\mathrm{H}) \mathrm{H})(\mathrm{Cl}) \mathrm{H})(\mathrm{Cl}) \mathrm{H})(\mathrm{H}) \mathrm{H})$ $(\mathrm{H}) \mathrm{H})(\mathrm{H})(\mathrm{H}) \mathrm{H}$

\section{Formula}

$\mathrm{C} 13 \mathrm{H} 21 \mathrm{Cl} 3 \mathrm{Br} 2 \mathrm{~F} 2$

$\mathrm{C} 13 \mathrm{H} 21 \mathrm{Cl} 4 \mathrm{Br} 2 \mathrm{~F}$

$\mathrm{C} 13 \mathrm{H} 21 \mathrm{Cl} 4 \mathrm{BrF} 2$

C13H21Cl5BrF

$\mathrm{C} 13 \mathrm{H} 21 \mathrm{Cl} 6 \mathrm{Br}$

$\mathrm{C} 13 \mathrm{H} 21 \mathrm{Cl} 6 \mathrm{~F}$

$\mathrm{C} 13 \mathrm{H} 21 \mathrm{Cl} 7$

$\mathrm{C} 13 \mathrm{H} 21 \mathrm{ClBr} 3 \mathrm{~F} 3$

$\mathrm{C} 13 \mathrm{H} 21 \mathrm{ClBr} 4 \mathrm{~F} 2$

$\mathrm{C} 13 \mathrm{H} 21 \mathrm{ClBr} 5 \mathrm{~F}$

$\mathrm{C} 13 \mathrm{H} 22 \mathrm{Br} 3 \mathrm{~F} 3$

$\mathrm{C} 13 \mathrm{H} 22 \mathrm{Br} 4 \mathrm{~F} 2$

$\mathrm{C} 13 \mathrm{H} 22 \mathrm{Br} 5 \mathrm{~F}$

$\mathrm{C} 13 \mathrm{H} 22 \mathrm{C} 2 \mathrm{Br} 2 \mathrm{~F} 2$

$\mathrm{C} 13 \mathrm{H} 22 \mathrm{Cl} 2 \mathrm{Br} 4$

$\mathrm{C} 13 \mathrm{H} 22 \mathrm{Cl} 3 \mathrm{Br} 2 \mathrm{~F}$

$\mathrm{C} 13 \mathrm{H} 22 \mathrm{Cl} 3 \mathrm{Br} 3$

$\mathrm{C} 13 \mathrm{H} 22 \mathrm{Cl} 3 \mathrm{BrF} 2$

$\mathrm{C} 13 \mathrm{H} 22 \mathrm{Cl} 4 \mathrm{Br} 2$

$\mathrm{C} 13 \mathrm{H} 22 \mathrm{Cl} 4 \mathrm{BrF}$

$\mathrm{C} 13 \mathrm{H} 22 \mathrm{Cl} 5 \mathrm{Br}$

$\mathrm{C} 13 \mathrm{H} 22 \mathrm{Cl} 5 \mathrm{~F}$

$\mathrm{C} 13 \mathrm{H} 22 \mathrm{Cl} 6$

$\mathrm{C} 13 \mathrm{H} 22 \mathrm{ClBr} 3 \mathrm{~F} 2$

$\mathrm{C} 13 \mathrm{H} 22 \mathrm{ClBr} 4 \mathrm{~F}$

$\mathrm{C} 13 \mathrm{H} 23 \mathrm{Br} 3 \mathrm{~F} 2$

$\mathrm{C} 13 \mathrm{H} 23 \mathrm{Br} 4 \mathrm{~F}$

$\mathrm{C} 13 \mathrm{H} 23 \mathrm{Br} 5$

$\mathrm{C} 13 \mathrm{H} 23 \mathrm{Cl} 2 \mathrm{Br} 2 \mathrm{~F}$

$\mathrm{C} 13 \mathrm{H} 23 \mathrm{Cl} 2 \mathrm{Br} 3$

$\mathrm{C} 13 \mathrm{H} 23 \mathrm{Cl} 3 \mathrm{Br} 2$

$\mathrm{C} 13 \mathrm{H} 23 \mathrm{Cl} 3 \mathrm{BrF}$

$\mathrm{C} 13 \mathrm{H} 23 \mathrm{Cl} 4 \mathrm{Br}$

$\mathrm{C} 13 \mathrm{H} 23 \mathrm{Cl} 5$

C13H23ClBr3F

$\mathrm{C} 13 \mathrm{H} 23 \mathrm{ClBr} 4$

$\mathrm{C} 13 \mathrm{H} 24 \mathrm{Br} 3 \mathrm{~F}$

$\mathrm{C} 13 \mathrm{H} 24 \mathrm{Br} 4$

$\mathrm{C} 13 \mathrm{H} 24 \mathrm{Cl} 2 \mathrm{Br} 2$

$\mathrm{C} 13 \mathrm{H} 24 \mathrm{Cl} 2 \mathrm{BrF}$

$\mathrm{C} 13 \mathrm{H} 24 \mathrm{Cl} 3 \mathrm{Br}$

$\mathrm{C} 13 \mathrm{H} 24 \mathrm{Cl} 4$
lgKoa lgKow lgKaw loKow lgKoa lgKaw lgKow lgKoa lgKaw _EPI_EPI_EPI_Exp__Exp__Exp__DFT_DFT_DFT Suite Suite Suite corr corr corr _corr _corr corr

$\begin{array}{lllllllll}9.04 & 8.36 & -0.68 & 7.55 & 8.24 & -0.68 & 7.18 & 14.62 & -7.44\end{array}$

$\begin{array}{lllllllll}10.1 & 8.67 & -1.44 & 8.01 & 9.45 & -1.44 & 7.42 & 16.57 & -9.15\end{array}$

$\begin{array}{lllllllll}8.47 & 8.27 & -0.20 & 7.42 & 7.62 & -0.20 & 7.11 & 13.57 & -6.45\end{array}$

$\begin{array}{lllllllll}8.86 & 7.91 & -0.95 & 6.88 & 7.83 & -0.95 & 6.84 & 14.29 & -7.45\end{array}$

$\begin{array}{lllllllll}10.6 & 8.89 & -1.70 & 8.34 & 10.05 & -1.70 & 7.59 & 17.47 & -9.88\end{array}$

$\begin{array}{lllllllll}8.22 & 7.75 & -0.46 & 6.64 & 7.11 & -0.46 & 6.71 & 13.10 & -6.39\end{array}$

$\begin{array}{lllllllll}9.36 & 8.14 & -1.22 & 7.22 & 8.44 & -1.22 & 7.01 & 15.20 & -8.18\end{array}$

$\begin{array}{lllllllll}7.88 & 7.46 & -0.42 & 6.21 & 6.63 & -0.42 & 6.49 & 12.48 & -5.99\end{array}$

$\begin{array}{lllllllll}10.2 & 8.53 & -1.65 & 7.81 & 9.46 & -1.65 & 7.31 & 16.72 & -9.41\end{array}$

$\begin{array}{lllllllll}11.8 & 8.94 & -2.89 & 8.42 & 11.31 & -2.89 & 7.63 & 19.75 & -12.12\end{array}$

$\begin{array}{lllllllll}7.98 & 8.02 & 0.04 & 7.04 & 7.01 & 0.04 & 6.92 & 12.68 & -5.76\end{array}$

$\begin{array}{lllllllll}8.81 & 7.61 & -1.20 & 6.43 & 7.63 & -1.20 & 6.61 & 14.20 & -7.59\end{array}$

$\begin{array}{lllllllll}11.2 & 8.76 & -2.44 & 8.15 & 10.59 & -2.44 & 7.49 & 18.58 & -11.09\end{array}$

$\begin{array}{lllllllll}7.74 & 7.51 & -0.23 & 6.28 & 6.51 & -0.23 & 6.53 & 12.23 & -5.70\end{array}$

$\begin{array}{lllllllll}10.9 & 8.24 & -2.70 & 7.37 & 10.08 & -2.70 & 7.09 & 18.12 & -11.03\end{array}$

$\begin{array}{lllllllll}8.73 & 7.75 & -0.98 & 6.64 & 7.62 & -0.98 & 6.71 & 14.05 & -7.34\end{array}$

$\begin{array}{lllllllll}10.4 & 8.22 & -2.22 & 7.34 & 9.56 & -2.22 & 7.08 & 17.19 & -10.11\end{array}$

$\begin{array}{lllllllll}7.76 & 8.01 & 0.25 & 7.03 & 6.77 & 0.25 & 6.91 & 12.26 & -5.34\end{array}$

$\begin{array}{lllllllll}10.5 & 8.73 & -1.73 & 8.10 & 9.84 & -1.73 & 7.47 & 17.23 & -9.77\end{array}$

$\begin{array}{lllllllll}8.16 & 7.66 & -0.50 & 6.51 & 7.00 & -0.50 & 6.65 & 13.00 & -6.35\end{array}$

$\begin{array}{lllllllll}9.96 & 8.71 & -1.25 & 8.07 & 9.32 & -1.25 & 7.45 & 16.31 & -8.85\end{array}$

$\begin{array}{lllllllll}8.32 & 8.31 & -0.01 & 7.48 & 7.49 & -0.01 & 7.14 & 13.30 & -6.15\end{array}$

$\begin{array}{lllllllll}8.72 & 7.96 & -0.76 & 6.96 & 7.72 & -0.76 & 6.88 & 14.04 & -7.16\end{array}$

$\begin{array}{lllllllll}8.98 & 8.26 & -0.72 & 7.40 & 8.12 & -0.72 & 7.11 & 14.50 & -7.39\end{array}$

$\begin{array}{lllllllll}10.6 & 8.67 & -1.95 & 8.01 & 9.97 & -1.95 & 7.42 & 17.52 & -10.10\end{array}$

$\begin{array}{lllllllll}8.34 & 8.08 & -0.26 & 7.13 & 7.40 & -0.26 & 6.97 & 13.33 & -6.37\end{array}$

$\begin{array}{lllllllll}9.25 & 7.75 & -1.50 & 6.64 & 8.14 & -1.50 & 6.71 & 15.00 & -8.29\end{array}$

$\begin{array}{lllllllll}11 & 8.22 & -2.74 & 7.34 & 10.08 & -2.74 & 7.08 & 18.14 & -11.06\end{array}$

$\begin{array}{lllllllll}8.84 & 8.31 & -0.53 & 7.48 & 8.01 & -0.53 & 7.14 & 14.25 & -7.10\end{array}$

$\begin{array}{lllllllll}9.74 & 7.97 & -1.77 & 6.97 & 8.74 & -1.77 & 6.88 & 15.90 & -9.01\end{array}$

$\begin{array}{lllllllll}9.97 & 8.69 & -1.28 & 8.04 & 9.33 & -1.28 & 7.44 & 16.33 & -8.89\end{array}$

$\begin{array}{lllllllll}7.52 & 7.48 & -0.04 & 6.24 & 6.28 & -0.04 & 6.51 & 11.83 & -5.33\end{array}$

$\begin{array}{lllllllll}8.59 & 7.79 & -0.80 & 6.70 & 7.50 & -0.80 & 6.75 & 13.78 & -7.04\end{array}$

$\begin{array}{lllllllll}8.01 & 7.7 & -0.31 & 6.57 & 6.88 & -0.31 & 6.68 & 12.72 & -6.05\end{array}$

$\begin{array}{lllllllll}8.67 & 7.66 & -1.01 & 6.51 & 7.52 & -1.01 & 6.65 & 13.95 & -7.30\end{array}$

$\begin{array}{lllllllll}10.4 & 8.13 & -2.25 & 7.21 & 9.46 & -2.25 & 7.01 & 17.08 & -10.08\end{array}$

$\begin{array}{lllllllll}8.04 & 7.48 & -0.56 & 6.24 & 6.80 & -0.56 & 6.51 & 12.78 & -6.28\end{array}$

$\begin{array}{lllllllll}9.61 & 7.81 & -1.80 & 6.73 & 8.53 & -1.80 & 6.76 & 15.66 & -8.90\end{array}$

$\begin{array}{lllllllll}8.46 & 7.63 & -0.83 & 6.46 & 7.29 & -0.83 & 6.62 & 13.55 & -6.93\end{array}$

$\begin{array}{lllllllll}7.55 & 7.96 & 0.41 & 6.96 & 6.55 & 0.41 & 6.88 & 11.88 & -5.01\end{array}$

$\begin{array}{lllllllll}7.88 & 7.54 & -0.34 & 6.33 & 6.67 & -0.34 & 6.55 & 12.49 & -5.94\end{array}$

$\begin{array}{lllllllll}7.38 & 7.52 & 0.14 & 6.30 & 6.16 & 0.14 & 6.54 & 11.56 & -5.03\end{array}$ 
SMILE Generated

$\mathrm{C}(\mathrm{C}(\mathrm{C}(\mathrm{C}(\mathrm{C}(\mathrm{C}(\mathrm{C}(\mathrm{C}(\mathrm{C}(\mathrm{C}(\mathrm{C}(\mathrm{C}(\mathrm{C}(\mathrm{H})(\mathrm{H}) \mathrm{H})(\mathrm{H}) \mathrm{H})(\mathrm{H}) \mathrm{H})(\mathrm{H}) \mathrm{H})(\mathrm{H}) \mathrm{H})(\mathrm{H}) \mathrm{Br})(\mathrm{H}) \mathrm{Cl})(\mathrm{H}) \mathrm{F})(\mathrm{H}) \mathrm{H})(\mathrm{H}) \mathrm{Br})(\mathrm{H}) \mathrm{H})$ $(\mathrm{H}) \mathrm{H})(\mathrm{H})(\mathrm{H}) \mathrm{H}$

$\mathrm{C}(\mathrm{C}(\mathrm{C}(\mathrm{C}(\mathrm{C}(\mathrm{C}(\mathrm{C}(\mathrm{C}(\mathrm{C}(\mathrm{C}(\mathrm{C}(\mathrm{C}(\mathrm{C}(\mathrm{H})(\mathrm{H}) \mathrm{H})(\mathrm{H}) \mathrm{Br})(\mathrm{H}) \mathrm{H})(\mathrm{Br}) \mathrm{H})(\mathrm{H}) \mathrm{H})(\mathrm{H}) \mathrm{H})(\mathrm{H}) \mathrm{H})(\mathrm{H}) \mathrm{Br})(\mathrm{H}) \mathrm{H})(\mathrm{H}) \mathrm{H})(\mathrm{H}) \mathrm{H})(\mathrm{Cl})$ $\mathrm{H})(\mathrm{H})(\mathrm{H}) \mathrm{H}$

$\mathrm{C}(\mathrm{C}(\mathrm{C}(\mathrm{C}(\mathrm{C}(\mathrm{C}(\mathrm{C}(\mathrm{C}(\mathrm{C}(\mathrm{C}(\mathrm{C}(\mathrm{C}(\mathrm{C}(\mathrm{H})(\mathrm{Br}) \mathrm{H})(\mathrm{H}) \mathrm{Br})(\mathrm{H}) \mathrm{H})(\mathrm{H}) \mathrm{H})(\mathrm{H}) \mathrm{H})(\mathrm{H}) \mathrm{H})(\mathrm{H}) \mathrm{H})(\mathrm{H}) \mathrm{H})(\mathrm{H}) \mathrm{Br})(\mathrm{H}) \mathrm{H})(\mathrm{H}) \mathrm{H})(\mathrm{H})$ $\mathrm{H})(\mathrm{H})(\mathrm{H}) \mathrm{H}$

$\mathrm{C}(\mathrm{C}(\mathrm{C}(\mathrm{C}(\mathrm{C}(\mathrm{C}(\mathrm{C}(\mathrm{C}(\mathrm{C}(\mathrm{C}(\mathrm{C}(\mathrm{C}(\mathrm{C}(\mathrm{H})(\mathrm{H}) \mathrm{H})(\mathrm{Br}) \mathrm{Cl})(\mathrm{H}) \mathrm{H})(\mathrm{H}) \mathrm{H})(\mathrm{H}) \mathrm{H})(\mathrm{H}) \mathrm{H})(\mathrm{H}) \mathrm{H})(\mathrm{H}) \mathrm{H})(\mathrm{H}) \mathrm{H})(\mathrm{H}) \mathrm{H})(\mathrm{H}) \mathrm{H})$

$(\mathrm{H}) \mathrm{H})(\mathrm{H})(\mathrm{H}) \mathrm{Cl}$

$\mathrm{C}(\mathrm{C}(\mathrm{C}(\mathrm{C}(\mathrm{C}(\mathrm{C}(\mathrm{C}(\mathrm{C}(\mathrm{C}(\mathrm{C}(\mathrm{C}(\mathrm{C}(\mathrm{C}(\mathrm{H})(\mathrm{H}) \mathrm{H})(\mathrm{H}) \mathrm{H})(\mathrm{H}) \mathrm{H})(\mathrm{H}) \mathrm{H})(\mathrm{H}) \mathrm{H})(\mathrm{H}) \mathrm{H})(\mathrm{H}) \mathrm{H})(\mathrm{H}) \mathrm{H})(\mathrm{H}) \mathrm{Br})(\mathrm{Br}) \mathrm{H})(\mathrm{H}) \mathrm{H})$

$(\mathrm{Cl}) \mathrm{H})(\mathrm{H})(\mathrm{H}) \mathrm{H}$

$\mathrm{C}(\mathrm{C}(\mathrm{C}(\mathrm{C}(\mathrm{C}(\mathrm{C}(\mathrm{C}(\mathrm{C}(\mathrm{C}(\mathrm{C}(\mathrm{C}(\mathrm{C}(\mathrm{C}(\mathrm{C}(\mathrm{F})(\mathrm{H}) \mathrm{Br})(\mathrm{F}) \mathrm{H})(\mathrm{H}) \mathrm{Br})(\mathrm{F}) \mathrm{H})(\mathrm{F}) \mathrm{H})(\mathrm{Cl}) \mathrm{F})(\mathrm{H}) \mathrm{F})(\mathrm{H}) \mathrm{F})(\mathrm{H}) \mathrm{F})(\mathrm{H}) \mathrm{F})(\mathrm{Cl}) \mathrm{H})(\mathrm{H}) \mathrm{H})$ $(\mathrm{Br}) \mathrm{H})(\mathrm{Br})(\mathrm{H}) \mathrm{H}$

$\mathrm{C}(\mathrm{C}(\mathrm{C}(\mathrm{C}(\mathrm{C}(\mathrm{C}(\mathrm{C}(\mathrm{C}(\mathrm{C}(\mathrm{C}(\mathrm{C}(\mathrm{C}(\mathrm{C}(\mathrm{C}(\mathrm{H})(\mathrm{H}) \mathrm{F})(\mathrm{H}) \mathrm{Br})(\mathrm{F}) \mathrm{H})(\mathrm{Br}) \mathrm{H})(\mathrm{F}) \mathrm{Br})(\mathrm{H}) \mathrm{Br})(\mathrm{H}) \mathrm{Cl})(\mathrm{F}) \mathrm{H})(\mathrm{F}) \mathrm{H})(\mathrm{H}) \mathrm{Br})(\mathrm{H}) \mathrm{H})$ $(\mathrm{H}) \mathrm{F})(\mathrm{H}) \mathrm{H})(\mathrm{H})(\mathrm{Br}) \mathrm{F}$

$\mathrm{C}(\mathrm{C}(\mathrm{C}(\mathrm{C}(\mathrm{C}(\mathrm{C}(\mathrm{C}(\mathrm{C}(\mathrm{C}(\mathrm{C}(\mathrm{C}(\mathrm{C}(\mathrm{C}(\mathrm{C}(\mathrm{F})(\mathrm{H}) \mathrm{F})(\mathrm{H}) \mathrm{H})(\mathrm{F}) \mathrm{H})(\mathrm{H}) \mathrm{H})(\mathrm{H}) \mathrm{F})(\mathrm{H}) \mathrm{H})(\mathrm{H}) \mathrm{F})(\mathrm{Br}) \mathrm{H})(\mathrm{Br}) \mathrm{F})(\mathrm{H}) \mathrm{H})(\mathrm{F}) \mathrm{H})$

$(\mathrm{Br}) \mathrm{H})(\mathrm{Br}) \mathrm{H})(\mathrm{Br})(\mathrm{Br}) \mathrm{H}$

$\mathrm{C}(\mathrm{C}(\mathrm{C}(\mathrm{C}(\mathrm{C}(\mathrm{C}(\mathrm{C}(\mathrm{C}(\mathrm{C}(\mathrm{C}(\mathrm{C}(\mathrm{C}(\mathrm{C}(\mathrm{C}(\mathrm{H})(\mathrm{Br}) \mathrm{H})(\mathrm{H}) \mathrm{F})(\mathrm{H}) \mathrm{Br})(\mathrm{H}) \mathrm{F})(\mathrm{H}) \mathrm{Br})(\mathrm{Cl}) \mathrm{F})(\mathrm{H}) \mathrm{F})(\mathrm{Cl}) \mathrm{H})(\mathrm{H}) \mathrm{F})(\mathrm{H}) \mathrm{Cl})(\mathrm{H}) \mathrm{H})$

$(\mathrm{H}) \mathrm{H})(\mathrm{H}) \mathrm{F})(\mathrm{H})(\mathrm{Br}) \mathrm{H}$

$\mathrm{C}(\mathrm{C}(\mathrm{C}(\mathrm{C}(\mathrm{C}(\mathrm{C}(\mathrm{C}(\mathrm{C}(\mathrm{C}(\mathrm{C}(\mathrm{C}(\mathrm{C}(\mathrm{C}(\mathrm{C}(\mathrm{H})(\mathrm{F}) \mathrm{Br})(\mathrm{H}) \mathrm{F})(\mathrm{H}) \mathrm{Cl})(\mathrm{H}) \mathrm{Cl})(\mathrm{Cl}) \mathrm{Cl})(\mathrm{F}) \mathrm{H})(\mathrm{F}) \mathrm{H})(\mathrm{H}) \mathrm{H})(\mathrm{H}) \mathrm{F})(\mathrm{H}) \mathrm{Cl})(\mathrm{H}) \mathrm{H})(\mathrm{H})$

$\mathrm{H})(\mathrm{H}) \mathrm{H})(\mathrm{Cl})(\mathrm{H}) \mathrm{Cl}$

$\mathrm{C}(\mathrm{C}(\mathrm{C}(\mathrm{C}(\mathrm{C}(\mathrm{C}(\mathrm{C}(\mathrm{C}(\mathrm{C}(\mathrm{C}(\mathrm{C}(\mathrm{C}(\mathrm{C}(\mathrm{C}(\mathrm{H})(\mathrm{Cl}) \mathrm{H})(\mathrm{H}) \mathrm{Cl})(\mathrm{H}) \mathrm{Cl})(\mathrm{Cl}) \mathrm{H})(\mathrm{F}) \mathrm{Cl})(\mathrm{F}) \mathrm{H})(\mathrm{H}) \mathrm{H})(\mathrm{F}) \mathrm{H})(\mathrm{H}) \mathrm{H})(\mathrm{H}) \mathrm{Cl})(\mathrm{Cl}) \mathrm{H})$

$(\mathrm{F}) \mathrm{H})(\mathrm{H}) \mathrm{H})(\mathrm{Cl})(\mathrm{F}) \mathrm{H}$

$\mathrm{C}(\mathrm{C}(\mathrm{C}(\mathrm{C}(\mathrm{C}(\mathrm{C}(\mathrm{C}(\mathrm{C}(\mathrm{C}(\mathrm{C}(\mathrm{C}(\mathrm{C}(\mathrm{C}(\mathrm{C}(\mathrm{F})(\mathrm{H}) \mathrm{H})(\mathrm{H}) \mathrm{Br})(\mathrm{Br}) \mathrm{H})(\mathrm{F}) \mathrm{H})(\mathrm{H}) \mathrm{H})(\mathrm{F}) \mathrm{H})(\mathrm{H}) \mathrm{Br})(\mathrm{H}) \mathrm{F})(\mathrm{H}) \mathrm{F})(\mathrm{H}) \mathrm{Br})(\mathrm{F}) \mathrm{H})(\mathrm{H})$ $\mathrm{F})(\mathrm{Br}) \mathrm{H})(\mathrm{H})(\mathrm{H}) \mathrm{H}$

$\mathrm{C}(\mathrm{C}(\mathrm{C}(\mathrm{C}(\mathrm{C}(\mathrm{C}(\mathrm{C}(\mathrm{C}(\mathrm{C}(\mathrm{C}(\mathrm{C}(\mathrm{C}(\mathrm{C}(\mathrm{C}(\mathrm{H})(\mathrm{H}) \mathrm{F})(\mathrm{H}) \mathrm{F})(\mathrm{H}) \mathrm{H})(\mathrm{H}) \mathrm{H})(\mathrm{Br}) \mathrm{H})(\mathrm{Br}) \mathrm{H})(\mathrm{Br}) \mathrm{H})(\mathrm{F}) \mathrm{H})(\mathrm{H}) \mathrm{F})(\mathrm{H}) \mathrm{H})(\mathrm{H}) \mathrm{Br})(\mathrm{F})$

$\mathrm{Br})(\mathrm{Br}) \mathrm{H})(\mathrm{H})(\mathrm{F}) \mathrm{H}$

$\mathrm{C}(\mathrm{C}(\mathrm{C}(\mathrm{C}(\mathrm{C}(\mathrm{C}(\mathrm{C}(\mathrm{C}(\mathrm{C}(\mathrm{C}(\mathrm{C}(\mathrm{C}(\mathrm{C}(\mathrm{C}(\mathrm{Cl})(\mathrm{H}) \mathrm{Cl})(\mathrm{H}) \mathrm{H})(\mathrm{H}) \mathrm{H})(\mathrm{F}) \mathrm{H})(\mathrm{H}) \mathrm{Cl})(\mathrm{H}) \mathrm{H})(\mathrm{H}) \mathrm{Cl})(\mathrm{Cl}) \mathrm{H})(\mathrm{H}) \mathrm{Cl})(\mathrm{H}) \mathrm{Cl})(\mathrm{H}) \mathrm{Cl})($

$\mathrm{H}) \mathrm{Cl})(\mathrm{H}) \mathrm{F})(\mathrm{H})(\mathrm{Cl}) \mathrm{H}$

$\mathrm{C}(\mathrm{C}(\mathrm{C}(\mathrm{C}(\mathrm{C}(\mathrm{C}(\mathrm{C}(\mathrm{C}(\mathrm{C}(\mathrm{C}(\mathrm{C}(\mathrm{C}(\mathrm{C}(\mathrm{C}(\mathrm{H})(\mathrm{H}) \mathrm{H})(\mathrm{H}) \mathrm{H})(\mathrm{F}) \mathrm{H})(\mathrm{Br}) \mathrm{H})(\mathrm{H}) \mathrm{H})(\mathrm{F}) \mathrm{H})(\mathrm{Cl}) \mathrm{F})(\mathrm{H}) \mathrm{Br})(\mathrm{H}) \mathrm{H})(\mathrm{Br}) \mathrm{H})(\mathrm{H}) \mathrm{F})(\mathrm{F})$ $\mathrm{H})(\mathrm{H}) \mathrm{Br})(\mathrm{Cl})(\mathrm{H}) \mathrm{F}$

$\mathrm{C}(\mathrm{C}(\mathrm{C}(\mathrm{C}(\mathrm{C}(\mathrm{C}(\mathrm{C}(\mathrm{C}(\mathrm{C}(\mathrm{C}(\mathrm{C}(\mathrm{C}(\mathrm{C}(\mathrm{C}(\mathrm{H})(\mathrm{H}) \mathrm{F})(\mathrm{Cl}) \mathrm{H})(\mathrm{H}) \mathrm{F})(\mathrm{Cl}) \mathrm{H})(\mathrm{H}) \mathrm{H})(\mathrm{Cl}) \mathrm{H})(\mathrm{H}) \mathrm{Br})(\mathrm{F}) \mathrm{Cl})(\mathrm{F}) \mathrm{H})(\mathrm{H}) \mathrm{H})(\mathrm{H}) \mathrm{H})(\mathrm{H})$ $\mathrm{Br})(\mathrm{H}) \mathrm{H})(\mathrm{Br})(\mathrm{F}) \mathrm{H}$

$\mathrm{C}(\mathrm{C}(\mathrm{C}(\mathrm{C}(\mathrm{C}(\mathrm{C}(\mathrm{C}(\mathrm{C}(\mathrm{C}(\mathrm{C}(\mathrm{C}(\mathrm{C}(\mathrm{C}(\mathrm{C}(\mathrm{H})(\mathrm{Br}) \mathrm{H})(\mathrm{F}) \mathrm{H})(\mathrm{F}) \mathrm{H})(\mathrm{H}) \mathrm{F})(\mathrm{H}) \mathrm{Cl})(\mathrm{Cl}) \mathrm{H})(\mathrm{H}) \mathrm{H})(\mathrm{H}) \mathrm{H})(\mathrm{H}) \mathrm{H})(\mathrm{Cl}) \mathrm{H})(\mathrm{H}) \mathrm{Br})$

$(\mathrm{Cl}) \mathrm{H})(\mathrm{H}) \mathrm{Br})(\mathrm{Br})(\mathrm{H}) \mathrm{Cl}$

$\mathrm{C}(\mathrm{C}(\mathrm{C}(\mathrm{C}(\mathrm{C}(\mathrm{C}(\mathrm{C}(\mathrm{C}(\mathrm{C}(\mathrm{C}(\mathrm{C}(\mathrm{C}(\mathrm{C}(\mathrm{C}(\mathrm{H})(\mathrm{Br}) \mathrm{H})(\mathrm{F}) \mathrm{F})(\mathrm{H}) \mathrm{H})(\mathrm{F}) \mathrm{H})(\mathrm{Br}) \mathrm{H})(\mathrm{F}) \mathrm{H})(\mathrm{H}) \mathrm{H})(\mathrm{F}) \mathrm{H})(\mathrm{H}) \mathrm{H})(\mathrm{H}) \mathrm{F})(\mathrm{H}) \mathrm{H})(\mathrm{F}) \mathrm{H}$

$(\mathrm{H}) \mathrm{Br})(\mathrm{H})(\mathrm{Br}) \mathrm{H}$

$\mathrm{C}(\mathrm{C}(\mathrm{C}(\mathrm{C}(\mathrm{C}(\mathrm{C}(\mathrm{C}(\mathrm{C}(\mathrm{C}(\mathrm{C}(\mathrm{C}(\mathrm{C}(\mathrm{C}(\mathrm{C}(\mathrm{H})(\mathrm{H}) \mathrm{H})(\mathrm{F}) \mathrm{H})(\mathrm{H}) \mathrm{F})(\mathrm{H}) \mathrm{Br})(\mathrm{H}) \mathrm{H})(\mathrm{F}) \mathrm{H})(\mathrm{Cl}) \mathrm{H})(\mathrm{H}) \mathrm{Br})(\mathrm{Br}) \mathrm{Cl})(\mathrm{F}) \mathrm{H})(\mathrm{H}) \mathrm{H})$

$(\mathrm{H}) \mathrm{H})(\mathrm{H}) \mathrm{F})(\mathrm{H})(\mathrm{H}) \mathrm{F}$

$\mathrm{C}(\mathrm{C}(\mathrm{C}(\mathrm{C}(\mathrm{C}(\mathrm{C}(\mathrm{C}(\mathrm{C}(\mathrm{C}(\mathrm{C}(\mathrm{C}(\mathrm{C}(\mathrm{C}(\mathrm{C}(\mathrm{F})(\mathrm{H}) \mathrm{H})(\mathrm{H}) \mathrm{Br})(\mathrm{H}) \mathrm{H})(\mathrm{F}) \mathrm{H})(\mathrm{Br}) \mathrm{H})(\mathrm{H}) \mathrm{H})(\mathrm{H}) \mathrm{H})(\mathrm{Br}) \mathrm{H})(\mathrm{Cl}) \mathrm{H})(\mathrm{H}) \mathrm{H})(\mathrm{Cl}) \mathrm{H})($ $\mathrm{H}) \mathrm{F})(\mathrm{Br}) \mathrm{H})(\mathrm{Br})(\mathrm{H}) \mathrm{Br}$

$\mathrm{C}(\mathrm{C}(\mathrm{C}(\mathrm{C}(\mathrm{C}(\mathrm{C}(\mathrm{C}(\mathrm{C}(\mathrm{C}(\mathrm{C}(\mathrm{C}(\mathrm{C}(\mathrm{C}(\mathrm{C}(\mathrm{H})(\mathrm{H}) \mathrm{H})(\mathrm{Cl}) \mathrm{H})(\mathrm{H}) \mathrm{Cl})(\mathrm{H}) \mathrm{F})(\mathrm{H}) \mathrm{Cl})(\mathrm{H}) \mathrm{Cl})(\mathrm{Br}) \mathrm{H})(\mathrm{Br}) \mathrm{H})(\mathrm{H}) \mathrm{Cl})(\mathrm{H}) \mathrm{H})(\mathrm{H}) \mathrm{H})($ $\mathrm{H}) \mathrm{H})(\mathrm{F}) \mathrm{H})(\mathrm{F})(\mathrm{F}) \mathrm{H}$

$\mathrm{C}(\mathrm{C}(\mathrm{C}(\mathrm{C}(\mathrm{C}(\mathrm{C}(\mathrm{C}(\mathrm{C}(\mathrm{C}(\mathrm{C}(\mathrm{C}(\mathrm{C}(\mathrm{C}(\mathrm{C}(\mathrm{H})(\mathrm{Cl}) \mathrm{H})(\mathrm{H}) \mathrm{H})(\mathrm{H}) \mathrm{F})(\mathrm{F}) \mathrm{H})(\mathrm{H}) \mathrm{H})(\mathrm{Br}) \mathrm{H})(\mathrm{H}) \mathrm{F})(\mathrm{H}) \mathrm{F})(\mathrm{Cl}) \mathrm{H})(\mathrm{Cl}) \mathrm{H})(\mathrm{F}) \mathrm{H})(\mathrm{Cl})$

$\mathrm{Cl})(\mathrm{H}) \mathrm{H})(\mathrm{H})(\mathrm{H}) \mathrm{H}$

$\mathrm{C}(\mathrm{C}(\mathrm{C}(\mathrm{C}(\mathrm{C}(\mathrm{C}(\mathrm{C}(\mathrm{C}(\mathrm{C}(\mathrm{C}(\mathrm{C}(\mathrm{C}(\mathrm{C}(\mathrm{C}(\mathrm{F})(\mathrm{Cl}) \mathrm{H})(\mathrm{H}) \mathrm{H})(\mathrm{H}) \mathrm{Cl})(\mathrm{Cl}) \mathrm{H})(\mathrm{H}) \mathrm{Cl})(\mathrm{H}) \mathrm{F})(\mathrm{H}) \mathrm{Cl})(\mathrm{H}) \mathrm{Cl})(\mathrm{H}) \mathrm{H})(\mathrm{H}) \mathrm{Cl})(\mathrm{H}) \mathrm{H})($

$\mathrm{H}) \mathrm{H})(\mathrm{F}) \mathrm{H})(\mathrm{H})(\mathrm{H}) \mathrm{F}$

$\mathrm{C}(\mathrm{C}(\mathrm{C}(\mathrm{C}(\mathrm{C}(\mathrm{C}(\mathrm{C}(\mathrm{C}(\mathrm{C}(\mathrm{C}(\mathrm{C}(\mathrm{C}(\mathrm{C}(\mathrm{C}(\mathrm{Br})(\mathrm{H}) \mathrm{H})(\mathrm{H}) \mathrm{F})(\mathrm{H}) \mathrm{H})(\mathrm{F}) \mathrm{H})(\mathrm{H}) \mathrm{H})(\mathrm{Br}) \mathrm{H})(\mathrm{H}) \mathrm{H})(\mathrm{H}) \mathrm{F})(\mathrm{H}) \mathrm{F})(\mathrm{H}) \mathrm{H})(\mathrm{Br}) \mathrm{H})(\mathrm{H})$ $\mathrm{H})(\mathrm{H}) \mathrm{F})(\mathrm{F})(\mathrm{H}) \mathrm{Br}$

$\mathrm{C}(\mathrm{C}(\mathrm{C}(\mathrm{C}(\mathrm{C}(\mathrm{C}(\mathrm{C}(\mathrm{C}(\mathrm{C}(\mathrm{C}(\mathrm{C}(\mathrm{C}(\mathrm{C}(\mathrm{C}(\mathrm{F})(\mathrm{H}) \mathrm{F})(\mathrm{H}) \mathrm{H})(\mathrm{Br}) \mathrm{H})(\mathrm{F}) \mathrm{H})(\mathrm{H}) \mathrm{H})(\mathrm{H}) \mathrm{H})(\mathrm{Br}) \mathrm{H})(\mathrm{H}) \mathrm{H})(\mathrm{Cl}) \mathrm{H})(\mathrm{F}) \mathrm{H})(\mathrm{F}) \mathrm{Br})(\mathrm{Cl})$ $\mathrm{H})(\mathrm{H}) \mathrm{H})(\mathrm{H})(\mathrm{H}) \mathrm{H}$

$\mathrm{C}(\mathrm{C}(\mathrm{C}(\mathrm{C}(\mathrm{C}(\mathrm{C}(\mathrm{C}(\mathrm{C}(\mathrm{C}(\mathrm{C}(\mathrm{C}(\mathrm{C}(\mathrm{C}(\mathrm{C}(\mathrm{H})(\mathrm{H}) \mathrm{Cl})(\mathrm{F}) \mathrm{H})(\mathrm{H}) \mathrm{Cl})(\mathrm{F}) \mathrm{H})(\mathrm{F}) \mathrm{H})(\mathrm{H}) \mathrm{H})(\mathrm{Br}) \mathrm{H})(\mathrm{Br}) \mathrm{H})(\mathrm{H}) \mathrm{H})(\mathrm{H}) \mathrm{H})(\mathrm{H}) \mathrm{H})(\mathrm{F}$ $\mathrm{F})(\mathrm{H}) \mathrm{H})(\mathrm{H})(\mathrm{H}) \mathrm{Cl}$

$\mathrm{C}(\mathrm{C}(\mathrm{C}(\mathrm{C}(\mathrm{C}(\mathrm{C}(\mathrm{C}(\mathrm{C}(\mathrm{C}(\mathrm{C}(\mathrm{C}(\mathrm{C}(\mathrm{C}(\mathrm{C}(\mathrm{H})(\mathrm{H}) \mathrm{H})(\mathrm{H}) \mathrm{Br})(\mathrm{H}) \mathrm{Br})(\mathrm{H}) \mathrm{H})(\mathrm{H}) \mathrm{F})(\mathrm{H}) \mathrm{H})(\mathrm{F}) \mathrm{F})(\mathrm{F}) \mathrm{H})(\mathrm{H}) \mathrm{Cl})(\mathrm{Br}) \mathrm{H})(\mathrm{Cl}) \mathrm{H})$

$(\mathrm{H}) \mathrm{H})(\mathrm{H}) \mathrm{Cl})(\mathrm{H})(\mathrm{H}) \mathrm{H}$

$\mathrm{C}(\mathrm{C}(\mathrm{C}(\mathrm{C}(\mathrm{C}(\mathrm{C}(\mathrm{C}(\mathrm{C}(\mathrm{C}(\mathrm{C}(\mathrm{C}(\mathrm{C}(\mathrm{C}(\mathrm{C}(\mathrm{H})(\mathrm{Br}) \mathrm{H})(\mathrm{Cl}) \mathrm{H})(\mathrm{H}) \mathrm{H})(\mathrm{H}) \mathrm{H})(\mathrm{H}) \mathrm{Br})(\mathrm{H}) \mathrm{Cl})(\mathrm{F}) \mathrm{H})(\mathrm{H}) \mathrm{H})(\mathrm{H}) \mathrm{H})(\mathrm{Cl}) \mathrm{F})(\mathrm{H}) \mathrm{F})$

$(\mathrm{H}) \mathrm{H})(\mathrm{H}) \mathrm{F})(\mathrm{Cl})(\mathrm{H}) \mathrm{H}$

$\mathrm{C}(\mathrm{C}(\mathrm{C}(\mathrm{C}(\mathrm{C}(\mathrm{C}(\mathrm{C}(\mathrm{C}(\mathrm{C}(\mathrm{C}(\mathrm{C}(\mathrm{C}(\mathrm{C}(\mathrm{C}(\mathrm{Br})(\mathrm{H}) \mathrm{H})(\mathrm{Br}) \mathrm{H})(\mathrm{Cl}) \mathrm{H})(\mathrm{H}) \mathrm{H})(\mathrm{F}) \mathrm{H})(\mathrm{H}) \mathrm{H})(\mathrm{H}) \mathrm{Cl})(\mathrm{F}) \mathrm{H})(\mathrm{F}) \mathrm{H})(\mathrm{H}) \mathrm{H})(\mathrm{H}) \mathrm{Cl})$

$(\mathrm{H}) \mathrm{H})(\mathrm{H}) \mathrm{Br})(\mathrm{H})(\mathrm{Cl}) \mathrm{H}$

$\mathrm{C}(\mathrm{C}(\mathrm{C}(\mathrm{C}(\mathrm{C}(\mathrm{C}(\mathrm{C}(\mathrm{C}(\mathrm{C}(\mathrm{C}(\mathrm{C}(\mathrm{C}(\mathrm{C}(\mathrm{C}(\mathrm{Cl})(\mathrm{H}) \mathrm{H})(\mathrm{H}) \mathrm{H})(\mathrm{Br}) \mathrm{H})(\mathrm{H}) \mathrm{Cl})(\mathrm{H}) \mathrm{Cl})(\mathrm{H}) \mathrm{H})(\mathrm{H}) \mathrm{F})(\mathrm{H}) \mathrm{F})(\mathrm{H}) \mathrm{H})(\mathrm{H}) \mathrm{H})(\mathrm{F}) \mathrm{H})(\mathrm{F})$ $\mathrm{H})(\mathrm{Cl}) \mathrm{H})(\mathrm{H})(\mathrm{Cl}) \mathrm{H}$

$\mathrm{C}(\mathrm{C}(\mathrm{C}(\mathrm{C}(\mathrm{C}(\mathrm{C}(\mathrm{C}(\mathrm{C}(\mathrm{C}(\mathrm{C}(\mathrm{C}(\mathrm{C}(\mathrm{C}(\mathrm{C}(\mathrm{H})(\mathrm{F}) \mathrm{Cl})(\mathrm{H}) \mathrm{H})(\mathrm{H}) \mathrm{H})(\mathrm{H}) \mathrm{Br})(\mathrm{H}) \mathrm{F})(\mathrm{H}) \mathrm{H})(\mathrm{Cl}) \mathrm{H})(\mathrm{Cl}) \mathrm{H})(\mathrm{Cl}) \mathrm{H})(\mathrm{H}) \mathrm{H})(\mathrm{H}) \mathrm{Cl})($ $\mathrm{H}) \mathrm{H})(\mathrm{H}) \mathrm{H})(\mathrm{H})(\mathrm{Cl}) \mathrm{F}$

$\mathrm{C}(\mathrm{C}(\mathrm{C}(\mathrm{C}(\mathrm{C}(\mathrm{C}(\mathrm{C}(\mathrm{C}(\mathrm{C}(\mathrm{C}(\mathrm{C}(\mathrm{C}(\mathrm{C}(\mathrm{C}(\mathrm{H})(\mathrm{Cl}) \mathrm{Cl})(\mathrm{H}) \mathrm{H})(\mathrm{H}) \mathrm{F})(\mathrm{Cl}) \mathrm{H})(\mathrm{H}) \mathrm{H})(\mathrm{H}) \mathrm{H})(\mathrm{H}) \mathrm{H})(\mathrm{H}) \mathrm{Cl})(\mathrm{H}) \mathrm{H})(\mathrm{H}) \mathrm{Br})(\mathrm{H}) \mathrm{Cl})($

$\mathrm{Cl}) \mathrm{H})(\mathrm{H}) \mathrm{Cl})(\mathrm{H})(\mathrm{H}) \mathrm{Cl}$

$\mathrm{C}(\mathrm{C}(\mathrm{C}(\mathrm{C}(\mathrm{C}(\mathrm{C}(\mathrm{C}(\mathrm{C}(\mathrm{C}(\mathrm{C}(\mathrm{C}(\mathrm{C}(\mathrm{C}(\mathrm{C}(\mathrm{Br})(\mathrm{Br}) \mathrm{H})(\mathrm{H}) \mathrm{H})(\mathrm{H}) \mathrm{Cl})(\mathrm{H}) \mathrm{F})(\mathrm{H}) \mathrm{H})(\mathrm{H}) \mathrm{H})(\mathrm{H}) \mathrm{H})(\mathrm{H}) \mathrm{H})(\mathrm{Br}) \mathrm{H})(\mathrm{Br}) \mathrm{H})(\mathrm{H}) \mathrm{F})($ $\mathrm{H}) \mathrm{F})(\mathrm{Br}) \mathrm{H})(\mathrm{F})(\mathrm{H}) \mathrm{H}$

$\mathrm{C}(\mathrm{C}(\mathrm{C}(\mathrm{C}(\mathrm{C}(\mathrm{C}(\mathrm{C}(\mathrm{C}(\mathrm{C}(\mathrm{C}(\mathrm{C}(\mathrm{C}(\mathrm{C}(\mathrm{C}(\mathrm{H})(\mathrm{H}) \mathrm{F})(\mathrm{Br}) \mathrm{H})(\mathrm{H}) \mathrm{Br})(\mathrm{H}) \mathrm{Br})(\mathrm{H}) \mathrm{H})(\mathrm{H}) \mathrm{H})(\mathrm{H}) \mathrm{H})(\mathrm{H}) \mathrm{H})(\mathrm{H}) \mathrm{F})(\mathrm{H}) \mathrm{H})(\mathrm{H}) \mathrm{Br})$

$(\mathrm{H}) \mathrm{H})(\mathrm{F}) \mathrm{F})(\mathrm{F})(\mathrm{H}) \mathrm{H}$

$\mathrm{C}(\mathrm{C}(\mathrm{C}(\mathrm{C}(\mathrm{C}(\mathrm{C}(\mathrm{C}(\mathrm{C}(\mathrm{C}(\mathrm{C}(\mathrm{C}(\mathrm{C}(\mathrm{C}(\mathrm{C}(\mathrm{F})(\mathrm{H}) \mathrm{H})(\mathrm{Br}) \mathrm{H})(\mathrm{H}) \mathrm{H})(\mathrm{Br}) \mathrm{Br})(\mathrm{F}) \mathrm{H})(\mathrm{F}) \mathrm{H})(\mathrm{H}) \mathrm{H})(\mathrm{H}) \mathrm{H})(\mathrm{H}) \mathrm{Br})(\mathrm{H}) \mathrm{H})(\mathrm{F}) \mathrm{H})(\mathrm{H})$ $\mathrm{H})(\mathrm{H}) \mathrm{H})(\mathrm{H})(\mathrm{H}) \mathrm{Br}$

$\mathrm{C}(\mathrm{C}(\mathrm{C}(\mathrm{C}(\mathrm{C}(\mathrm{C}(\mathrm{C}(\mathrm{C}(\mathrm{C}(\mathrm{C}(\mathrm{C}(\mathrm{C}(\mathrm{C}(\mathrm{C}(\mathrm{F})(\mathrm{H}) \mathrm{H})(\mathrm{H}) \mathrm{H})(\mathrm{Br}) \mathrm{H})(\mathrm{H}) \mathrm{Br})(\mathrm{H}) \mathrm{F})(\mathrm{F}) \mathrm{H})(\mathrm{Br}) \mathrm{H})(\mathrm{H}) \mathrm{H})(\mathrm{Br}) \mathrm{H})(\mathrm{Br}) \mathrm{H})(\mathrm{H}) \mathrm{H})($

$\mathrm{H}) \mathrm{H})(\mathrm{H}) \mathrm{H})(\mathrm{H})(\mathrm{H}) \mathrm{B}$

$\mathrm{C}(\mathrm{C}(\mathrm{C}(\mathrm{C}(\mathrm{C}(\mathrm{C}(\mathrm{C}(\mathrm{C}(\mathrm{C}(\mathrm{C}(\mathrm{C}(\mathrm{C}(\mathrm{C}(\mathrm{C}(\mathrm{Cl})(\mathrm{H}) \mathrm{Br})(\mathrm{H}) \mathrm{H})(\mathrm{H}) \mathrm{H})(\mathrm{Cl}) \mathrm{H})(\mathrm{H}) \mathrm{H})(\mathrm{H}) \mathrm{H})(\mathrm{F}) \mathrm{H})(\mathrm{H}) \mathrm{H})(\mathrm{H}) \mathrm{H})(\mathrm{H}) \mathrm{Br})(\mathrm{H}) \mathrm{H})(\mathrm{B}$ r)H)(H)H)(F)(F)F

$\mathrm{C}(\mathrm{C}(\mathrm{C}(\mathrm{C}(\mathrm{C}(\mathrm{C}(\mathrm{C}(\mathrm{C}(\mathrm{C}(\mathrm{C}(\mathrm{C}(\mathrm{C}(\mathrm{C}(\mathrm{C}(\mathrm{H})(\mathrm{H}) \mathrm{H})(\mathrm{H}) \mathrm{H})(\mathrm{H}) \mathrm{Br})(\mathrm{H}) \mathrm{F})(\mathrm{H}) \mathrm{Cl})(\mathrm{H}) \mathrm{H})(\mathrm{H}) \mathrm{H})(\mathrm{H}) \mathrm{H})(\mathrm{Br}) \mathrm{H})(\mathrm{H}) \mathrm{Br})(\mathrm{Br}) \mathrm{H})($ $\mathrm{H}) \mathrm{F})(\mathrm{F}) \mathrm{H})(\mathrm{H})(\mathrm{Cl}) \mathrm{H}$

$\mathrm{C}(\mathrm{C}(\mathrm{C}(\mathrm{C}(\mathrm{C}(\mathrm{C}(\mathrm{C}(\mathrm{C}(\mathrm{C}(\mathrm{C}(\mathrm{C}(\mathrm{C}(\mathrm{C}(\mathrm{C}(\mathrm{H})(\mathrm{H}) \mathrm{H})(\mathrm{Br}) \mathrm{F})(\mathrm{F}) \mathrm{H})(\mathrm{Cl}) \mathrm{H})(\mathrm{H}) \mathrm{H})(\mathrm{H}) \mathrm{H})(\mathrm{Br}) \mathrm{H})(\mathrm{Cl}) \mathrm{H})(\mathrm{H}) \mathrm{H})(\mathrm{Cl}) \mathrm{H})(\mathrm{H}) \mathrm{H})$ $(\mathrm{F}) \mathrm{H})(\mathrm{H}) \mathrm{H})(\mathrm{F})(\mathrm{H}) \mathrm{H}$

$\mathrm{C}(\mathrm{C}(\mathrm{C}(\mathrm{C}(\mathrm{C}(\mathrm{C}(\mathrm{C}(\mathrm{C}(\mathrm{C}(\mathrm{C}(\mathrm{C}(\mathrm{C}(\mathrm{C}(\mathrm{C}(\mathrm{Cl})(\mathrm{F}) \mathrm{H})(\mathrm{Br}) \mathrm{H})(\mathrm{H}) \mathrm{H})(\mathrm{H}) \mathrm{H})(\mathrm{Cl}) \mathrm{H})(\mathrm{H}) \mathrm{H})(\mathrm{H}) \mathrm{H})(\mathrm{H}) \mathrm{H})(\mathrm{H}) \mathrm{F})(\mathrm{Cl}) \mathrm{H})(\mathrm{H}) \mathrm{H})(\mathrm{H})$ $\mathrm{Cl})(\mathrm{F}) \mathrm{H})(\mathrm{Br})(\mathrm{H}) \mathrm{H}$

$\mathrm{C}(\mathrm{C}(\mathrm{C}(\mathrm{C}(\mathrm{C}(\mathrm{C}(\mathrm{C}(\mathrm{C}(\mathrm{C}(\mathrm{C}(\mathrm{C}(\mathrm{C}(\mathrm{C}(\mathrm{C}(\mathrm{H})(\mathrm{H}) \mathrm{H})(\mathrm{H}) \mathrm{Cl})(\mathrm{Br}) \mathrm{H})(\mathrm{H}) \mathrm{H})(\mathrm{Cl}) \mathrm{H})(\mathrm{H}) \mathrm{F})(\mathrm{H}) \mathrm{H})(\mathrm{H}) \mathrm{H})(\mathrm{H}) \mathrm{Cl})(\mathrm{Br}) \mathrm{H})(\mathrm{Cl}) \mathrm{H})($ $\mathrm{H}) \mathrm{Cl}(\mathrm{H}) \mathrm{H})(\mathrm{H})(\mathrm{F}) \mathrm{H}$

$\mathrm{C}(\mathrm{C}(\mathrm{C}(\mathrm{C}(\mathrm{C}(\mathrm{C}(\mathrm{C}(\mathrm{C}(\mathrm{C}(\mathrm{C}(\mathrm{C}(\mathrm{C}(\mathrm{C}(\mathrm{C}(\mathrm{H})(\mathrm{H}) \mathrm{Br})(\mathrm{H}) \mathrm{H})(\mathrm{H}) \mathrm{Br})(\mathrm{H}) \mathrm{H})(\mathrm{Cl}) \mathrm{H})(\mathrm{Cl}) \mathrm{H})(\mathrm{Br}) \mathrm{H})(\mathrm{H}) \mathrm{Cl})(\mathrm{Cl}) \mathrm{H})(\mathrm{H}) \mathrm{H})(\mathrm{H}) \mathrm{H})$ $(\mathrm{H}) \mathrm{H})(\mathrm{F}) \mathrm{H})(\mathrm{H})(\mathrm{H}) \mathrm{Cl}$
Formula

$\mathrm{C} 13 \mathrm{H} 24 \mathrm{ClBr} 2 \mathrm{~F}$

$\mathrm{C} 13 \mathrm{H} 24 \mathrm{ClBr} 3$

$\mathrm{C} 13 \mathrm{H} 25 \mathrm{Br} 3$

$\mathrm{C} 13 \mathrm{H} 25 \mathrm{Cl} 2 \mathrm{Br}$

$\mathrm{C} 13 \mathrm{H} 25 \mathrm{ClBr} 2$

$\mathrm{C} 14 \mathrm{H} 15 \mathrm{Cl} 2 \mathrm{Br} 4 \mathrm{~F} 9$

C14H16ClBr6F7

C14H17Br6F7

C14H17Cl3Br4F6

$\mathrm{C} 14 \mathrm{H} 17 \mathrm{Cl} 17 \mathrm{BrF} 5$

C14H17Cl8F5

$\mathrm{C} 14 \mathrm{H} 18 \mathrm{Br} 5 \mathrm{~F} 7$

C14H18Br6F6

C14H18Cl10F2

14H18Cl2Br4F6

14H18Cl4Br3F5

14H18Cl5Br4F3

C14H19Br4F7

C14H19C12Br3F6

14H19Cl2Br6F3

C14H19Cl5Br2F4

$14 \mathrm{H} 19 \mathrm{Cl} 15 \mathrm{BrF} 5$

C14H19Cl7F4

C14H20Br4F6

$14 \mathrm{H} 20 \mathrm{Cl} 2 \mathrm{Br} 3 \mathrm{~F} 5$

$\mathrm{C} 14 \mathrm{H} 20 \mathrm{Cl} 3 \mathrm{Br} 2 \mathrm{~F} 5$

$\mathrm{C} 14 \mathrm{H} 20 \mathrm{Cl} 3 \mathrm{Br} 3 \mathrm{~F} 4$

14H20Cl4Br2F4

14H20Cl4Br3F3

$\mathrm{C} 14 \mathrm{H} 20 \mathrm{C} 15 \mathrm{BrF} 4$

$\mathrm{C} 14 \mathrm{H} 20 \mathrm{Cl} 16 \mathrm{BrF} 3$

C14H20Cl8BrF

C14H20ClBr5F4

C14H21Br4F5

$\mathrm{C} 14 \mathrm{H} 21 \mathrm{Br} 5 \mathrm{~F} 4$

$\mathrm{C} 14 \mathrm{H} 21 \mathrm{Br} 6 \mathrm{~F} 3$

$\mathrm{C} 14 \mathrm{H} 21 \mathrm{Cl} 2 \mathrm{Br} 3 \mathrm{~F} 4$

$\mathrm{C} 14 \mathrm{H} 21 \mathrm{Cl} 2 \mathrm{Br} 4 \mathrm{~F} 3$

$\mathrm{C} 14 \mathrm{H} 21 \mathrm{Cl} 3 \mathrm{Br} 2 \mathrm{~F} 4$

$\mathrm{C} 14 \mathrm{H} 21 \mathrm{Cl} 4 \mathrm{Br} 2 \mathrm{~F} 3$

$\mathrm{C} 14 \mathrm{H} 21 \mathrm{Cl} 15 \mathrm{Br} 2 \mathrm{~F} 2$

$\mathrm{C} 14 \mathrm{H} 21 \mathrm{Cl} \mathrm{Br} 3 \mathrm{~F}$
gkKoa lgKow lgKaw loKow lgKoa lgKaw lgKow lgKoa lgKaw EPI_EPI_EPI_Exp__Exp__Exp__DFT_DFT_DFT Suite Suite Suite corr corr corr _corr_corr corr

$\begin{array}{lllllllll}7.39 & 7.31 & -0.08 & 5.99 & 6.06 & -0.08 & 6.38 & 11.58 & -5.21\end{array}$

$\begin{array}{lllllllll}9.03 & 7.72 & -1.31 & 6.60 & 7.91 & -1.31 & 6.69 & 14.61 & -7.9\end{array}$

$\begin{array}{lllllllll}8.47 & 7.61 & -0.86 & 6.43 & 7.29 & -0.86 & 6.61 & 13.57 & -6.96\end{array}$

$\begin{array}{lllllllll}8.06 & 8.17 & 0.11 & 7.27 & 7.16 & 0.11 & 7.04 & 12.82 & -5.78\end{array}$

$\begin{array}{lllllllll}7.83 & 7.45 & -0.38 & 6.19 & 6.57 & -0.38 & 6.48 & 12.39 & -5.90\end{array}$

$\begin{array}{lllllllll}8.24 & 8.35 & 0.11 & 7.54 & 7.43 & 0.11 & 7.18 & 13.15 & -5.98\end{array}$

$\begin{array}{lllllllll}10.9 & 8.98 & -1.91 & 8.48 & 10.39 & -1.91 & 7.66 & 18.02 & -10.36\end{array}$

$\begin{array}{lllllllll}10.3 & 8.79 & -1.46 & 8.19 & 9.65 & -1.46 & 7.51 & 16.84 & -9.33\end{array}$

$\begin{array}{lllllllll}10.2 & 8.93 & -1.24 & 8.40 & 9.65 & -1.24 & 7.62 & 16.70 & -9.08\end{array}$

$\begin{array}{lllllllll}9.51 & 8.97 & -0.54 & 8.46 & 9.00 & -0.54 & 7.65 & 15.48 & -7.83\end{array}$

$\begin{array}{lllllllll}8.93 & 8.88 & -0.05 & 8.33 & 8.38 & -0.05 & 7.58 & 14.42 & -6.84\end{array}$

$\begin{array}{lllllllll}8.23 & 7.71 & -0.52 & 6.58 & 7.10 & -0.52 & 6.68 & 13.13 & -6.45\end{array}$

$\begin{array}{lllllllll}10.7 & 8.93 & -1.76 & 8.40 & 10.16 & -1.76 & 7.62 & 17.65 & -10.03\end{array}$

$\begin{array}{lllllllll}10.8 & 8.9 & -1.86 & 8.36 & 10.21 & -1.86 & 7.60 & 17.77 & -10.17\end{array}$

$\begin{array}{lllllllll}9.47 & 8.68 & -0.79 & 8.03 & 8.82 & -0.79 & 7.43 & 15.41 & -7.98\end{array}$

$\begin{array}{lllllllll}10 & 8.97 & -1.06 & 8.46 & 9.52 & -1.06 & 7.65 & 16.43 & -8.78\end{array}$

$\begin{array}{lllllllll}12 & 8.95 & -3.04 & 8.43 & 11.48 & -3.04 & 7.64 & 20.04 & -12.41\end{array}$

$\begin{array}{lllllllll}7.83 & 8.25 & 0.42 & 7.39 & 6.97 & 0.42 & 7.10 & 12.40 & -5.30\end{array}$

$\begin{array}{lllllllll}8.26 & 8.41 & 0.15 & 7.63 & 7.48 & 0.15 & 7.22 & 13.19 & -5.97\end{array}$

$\begin{array}{lllllllll}12.5 & 8.95 & -3.56 & 8.43 & 11.99 & -3.56 & 7.64 & 21.00 & -13.36\end{array}$

$\begin{array}{lllllllll}9.07 & 8.2 & -0.87 & 7.31 & 8.18 & -0.87 & 7.06 & 14.67 & -7.61\end{array}$

$\begin{array}{lllllllll}8.17 & 8.54 & 0.37 & 7.82 & 7.45 & 0.37 & 7.32 & 13.02 & -5.70\end{array}$

$\begin{array}{lllllllll}8 & 8.1 & 0.10 & 7.16 & 7.06 & 0.10 & 6.98 & 12.70 & -5.72\end{array}$

$\begin{array}{lllllllll}7.53 & 7.65 & 0.12 & 6.49 & 6.37 & 0.12 & 6.64 & 11.85 & -5.21\end{array}$

$\begin{array}{lllllllll}8.69 & 8.54 & -0.15 & 7.82 & 7.97 & -0.15 & 7.32 & 13.98 & -6.65\end{array}$

$\begin{array}{lllllllll}8.18 & 8.52 & 0.34 & 7.79 & 7.46 & 0.34 & 7.31 & 13.05 & -5.74\end{array}$

$\begin{array}{lllllllll}9.68 & 8.78 & -0.90 & 8.18 & 9.08 & -0.90 & 7.51 & 15.80 & -8.29\end{array}$

$\begin{array}{lllllllll}9.26 & 8.84 & -0.42 & 8.27 & 8.68 & -0.42 & 7.55 & 15.02 & -7.46\end{array}$

$\begin{array}{lllllllll}10.2 & 8.5 & -1.65 & 7.76 & 9.41 & -1.65 & 7.29 & 16.66 & -9.37\end{array}$

$\begin{array}{lllllllll}7.94 & 8.01 & 0.07 & 7.03 & 6.96 & 0.07 & 6.91 & 12.60 & -5.69\end{array}$

$\begin{array}{lllllllll}9 & 8.32 & -0.68 & 7.49 & 8.18 & -0.68 & 7.15 & 14.55 & -7.40\end{array}$

$\begin{array}{lllllllll}11.1 & 8.94 & -2.19 & 8.42 & 10.61 & -2.19 & 7.63 & 18.45 & -10.82\end{array}$

$\begin{array}{lllllllll}10.2 & 8.36 & -1.87 & 7.55 & 9.42 & -1.87 & 7.18 & 16.81 & -9.62\end{array}$

$\begin{array}{lllllllll}8.7 & 8.52 & -0.18 & 7.79 & 7.97 & -0.18 & 7.31 & 14.00 & -6.69\end{array}$

$\begin{array}{lllllllll}10.3 & 8.92 & -1.42 & 8.39 & 9.81 & -1.42 & 7.61 & 17.00 & -9.39\end{array}$

$\begin{array}{lllllllll}11.2 & 8.59 & -2.66 & 7.90 & 10.55 & -2.66 & 7.36 & 18.67 & -11.31\end{array}$

$\begin{array}{lllllllll}9.19 & 8.74 & -0.45 & 8.12 & 8.57 & -0.45 & 7.47 & 14.89 & -7.42\end{array}$

$\begin{array}{lllllllll}10 & 8.33 & -1.69 & 7.51 & 9.19 & -1.69 & 7.16 & 16.41 & -9.25\end{array}$

$\begin{array}{lllllllll}8.54 & 8.58 & 0.04 & 7.88 & 7.84 & 0.04 & 7.35 & 13.71 & -6.36\end{array}$

$\begin{array}{lllllllll}8.95 & 8.23 & -0.71 & 7.36 & 8.07 & -0.71 & 7.08 & 14.44 & -7.36\end{array}$

$\begin{array}{lllllllll}9.94 & 8.47 & -1.47 & 7.72 & 9.18 & -1.47 & 7.27 & 16.27 & -9.00\end{array}$

$\begin{array}{lllllllll}11.6 & 8.94 & -2.70 & 8.42 & 11.12 & -2.70 & 7.63 & 19.40 & -11.77\end{array}$ 
SMILE Generated

$\mathrm{C}(\mathrm{C}(\mathrm{C}(\mathrm{C}(\mathrm{C}(\mathrm{C}(\mathrm{C}(\mathrm{C}(\mathrm{C}(\mathrm{C}(\mathrm{C}(\mathrm{C}(\mathrm{C}(\mathrm{C}(\mathrm{F})(\mathrm{H}) \mathrm{H})(\mathrm{F}) \mathrm{H})(\mathrm{H}) \mathrm{Cl})(\mathrm{H}) \mathrm{H})(\mathrm{H}) \mathrm{H})(\mathrm{Cl}) \mathrm{H})(\mathrm{H}) \mathrm{Cl})(\mathrm{H}) \mathrm{H})(\mathrm{H}) \mathrm{F})(\mathrm{H}) \mathrm{H})(\mathrm{Cl}) \mathrm{Cl})(\mathrm{H})$ $\mathrm{H})(\mathrm{H}) \mathrm{H})(\mathrm{H})(\mathrm{H}) \mathrm{Br}$

$\mathrm{C}(\mathrm{C}(\mathrm{C}(\mathrm{C}(\mathrm{C}(\mathrm{C}(\mathrm{C}(\mathrm{C}(\mathrm{C}(\mathrm{C}(\mathrm{C}(\mathrm{C}(\mathrm{C}(\mathrm{C}(\mathrm{H})(\mathrm{H}) \mathrm{Cl})(\mathrm{H}) \mathrm{H})(\mathrm{H}) \mathrm{H})(\mathrm{H}) \mathrm{H})(\mathrm{Cl}) \mathrm{H})(\mathrm{H}) \mathrm{H})(\mathrm{H}) \mathrm{H})(\mathrm{F}) \mathrm{F})(\mathrm{Cl}) \mathrm{H})(\mathrm{Cl}) \mathrm{H})(\mathrm{H}) \mathrm{H})$ $(\mathrm{Cl}) \mathrm{H})(\mathrm{H}) \mathrm{H})(\mathrm{Cl})(\mathrm{F}) \mathrm{H}$

$\mathrm{C}(\mathrm{C}(\mathrm{C}(\mathrm{C}(\mathrm{C}(\mathrm{C}(\mathrm{C}(\mathrm{C}(\mathrm{C}(\mathrm{C}(\mathrm{C}(\mathrm{C}(\mathrm{C}(\mathrm{C}(\mathrm{Cl})(\mathrm{H}) \mathrm{H})(\mathrm{H}) \mathrm{H})(\mathrm{Cl}) \mathrm{H})(\mathrm{H}) \mathrm{Cl})(\mathrm{H}) \mathrm{H})(\mathrm{H}) \mathrm{Cl})(\mathrm{Cl}) \mathrm{H})(\mathrm{Cl}) \mathrm{H})(\mathrm{H}) \mathrm{H})(\mathrm{H}) \mathrm{H})(\mathrm{H}) \mathrm{H})($ $\mathrm{H}) \mathrm{H})(\mathrm{F}) \mathrm{H})(\mathrm{H})(\mathrm{Cl}) \mathrm{F}$

$\mathrm{C}(\mathrm{C}(\mathrm{C}(\mathrm{C}(\mathrm{C}(\mathrm{C}(\mathrm{C}(\mathrm{C}(\mathrm{C}(\mathrm{C}(\mathrm{C}(\mathrm{C}(\mathrm{C}(\mathrm{C}(\mathrm{F})(\mathrm{H}) \mathrm{H})(\mathrm{Br}) \mathrm{H})(\mathrm{Br}) \mathrm{F})(\mathrm{H}) \mathrm{Cl})(\mathrm{Br}) \mathrm{H})(\mathrm{H}) \mathrm{F})(\mathrm{H}) \mathrm{H})(\mathrm{H}) \mathrm{H})(\mathrm{H}) \mathrm{H})(\mathrm{H}) \mathrm{H})(\mathrm{H}) \mathrm{H})$ $(\mathrm{H}) \mathrm{H})(\mathrm{H}) \mathrm{H})(\mathrm{F})(\mathrm{H}) \mathrm{F}$

$\mathrm{C}(\mathrm{C}(\mathrm{C}(\mathrm{C}(\mathrm{C}(\mathrm{C}(\mathrm{C}(\mathrm{C}(\mathrm{C}(\mathrm{C}(\mathrm{C}(\mathrm{C}(\mathrm{C}(\mathrm{C}(\mathrm{H})(\mathrm{F}) \mathrm{H})(\mathrm{H}) \mathrm{H})(\mathrm{H}) \mathrm{H})(\mathrm{H}) \mathrm{H})(\mathrm{H}) \mathrm{Br})(\mathrm{Br}) \mathrm{H})(\mathrm{H}) \mathrm{F})(\mathrm{H}) \mathrm{H})(\mathrm{H}) \mathrm{H})(\mathrm{Cl}) \mathrm{H})(\mathrm{H}) \mathrm{Br})$

(F) Br) $(\mathrm{H}) \mathrm{H})(\mathrm{H})(\mathrm{F}) \mathrm{H}$

$\mathrm{C}(\mathrm{C}(\mathrm{C}(\mathrm{C}(\mathrm{C}(\mathrm{C}(\mathrm{C}(\mathrm{C}(\mathrm{C}(\mathrm{C}(\mathrm{C}(\mathrm{C}(\mathrm{C}(\mathrm{C}(\mathrm{H})(\mathrm{H}) \mathrm{Br})(\mathrm{H}) \mathrm{H})(\mathrm{H}) \mathrm{H})(\mathrm{H}) \mathrm{H})(\mathrm{Br}) \mathrm{H})(\mathrm{F}) \mathrm{H})(\mathrm{H}) \mathrm{H})(\mathrm{F}) \mathrm{F})(\mathrm{H}) \mathrm{F})(\mathrm{Br}) \mathrm{H})(\mathrm{H}) \mathrm{H})(\mathrm{Br})$ $\mathrm{H})(\mathrm{H}) \mathrm{H})(\mathrm{H})(\mathrm{H}) \mathrm{H}$

$\mathrm{C}(\mathrm{C}(\mathrm{C}(\mathrm{C}(\mathrm{C}(\mathrm{C}(\mathrm{C}(\mathrm{C}(\mathrm{C}(\mathrm{C}(\mathrm{C}(\mathrm{C}(\mathrm{C}(\mathrm{C}(\mathrm{H})(\mathrm{H}) \mathrm{Br})(\mathrm{H}) \mathrm{H})(\mathrm{H}) \mathrm{F})(\mathrm{H}) \mathrm{H})(\mathrm{F}) \mathrm{H})(\mathrm{H}) \mathrm{H})(\mathrm{H}) \mathrm{Cl})(\mathrm{H}) \mathrm{Br})(\mathrm{H}) \mathrm{H})(\mathrm{H}) \mathrm{H})(\mathrm{H}) \mathrm{F})(\mathrm{H})$ $\mathrm{H})(\mathrm{F}) \mathrm{H})(\mathrm{Cl})(\mathrm{H}) \mathrm{H}$

$\mathrm{C}(\mathrm{C}(\mathrm{C}(\mathrm{C}(\mathrm{C}(\mathrm{C}(\mathrm{C}(\mathrm{C}(\mathrm{C}(\mathrm{C}(\mathrm{C}(\mathrm{C}(\mathrm{C}(\mathrm{C}(\mathrm{H})(\mathrm{Br}) \mathrm{H})(\mathrm{Cl}) \mathrm{H})(\mathrm{H}) \mathrm{H})(\mathrm{H}) \mathrm{H})(\mathrm{H}) \mathrm{H})(\mathrm{H}) \mathrm{F})(\mathrm{H}) \mathrm{H})(\mathrm{F}) \mathrm{H})(\mathrm{Br}) \mathrm{H})(\mathrm{H}) \mathrm{H})(\mathrm{H}) \mathrm{H})(\mathrm{H})$ $\mathrm{Cl})(\mathrm{Br}) \mathrm{H})(\mathrm{H})(\mathrm{F}) \mathrm{H}$

$\mathrm{C}(\mathrm{C}(\mathrm{C}(\mathrm{C}(\mathrm{C}(\mathrm{C}(\mathrm{C}(\mathrm{C}(\mathrm{C}(\mathrm{C}(\mathrm{C}(\mathrm{C}(\mathrm{C}(\mathrm{C}(\mathrm{Cl})(\mathrm{H}) \mathrm{H})(\mathrm{H}) \mathrm{H})(\mathrm{H}) \mathrm{H})(\mathrm{H}) \mathrm{H})(\mathrm{H}) \mathrm{H})(\mathrm{Br}) \mathrm{H})(\mathrm{H}) \mathrm{F})(\mathrm{H}) \mathrm{H})(\mathrm{H}) \mathrm{H})(\mathrm{F}) \mathrm{Cl})(\mathrm{F}) \mathrm{H})(\mathrm{H})$ $\mathrm{H})(\mathrm{Br}) \mathrm{H})(\mathrm{H})(\mathrm{H}) \mathrm{Cl}$

$\mathrm{C}(\mathrm{C}(\mathrm{C}(\mathrm{C}(\mathrm{C}(\mathrm{C}(\mathrm{C}(\mathrm{C}(\mathrm{C}(\mathrm{C}(\mathrm{C}(\mathrm{C}(\mathrm{C}(\mathrm{C}(\mathrm{F})(\mathrm{Br}) \mathrm{H})(\mathrm{H}) \mathrm{H})(\mathrm{H}) \mathrm{Cl})(\mathrm{H}) \mathrm{H})(\mathrm{Br}) \mathrm{H})(\mathrm{H}) \mathrm{H})(\mathrm{H}) \mathrm{Cl})(\mathrm{H}) \mathrm{H})(\mathrm{H}) \mathrm{H})(\mathrm{H}) \mathrm{F})(\mathrm{H}) \mathrm{Cl})$

$(\mathrm{H}) \mathrm{H})(\mathrm{Cl}) \mathrm{H})(\mathrm{H})(\mathrm{H}) \mathrm{H}$

$\mathrm{C}(\mathrm{C}(\mathrm{C}(\mathrm{C}(\mathrm{C}(\mathrm{C}(\mathrm{C}(\mathrm{C}(\mathrm{C}(\mathrm{C}(\mathrm{C}(\mathrm{C}(\mathrm{C}(\mathrm{C}(\mathrm{H})(\mathrm{H}) \mathrm{Cl})(\mathrm{Cl}) \mathrm{H})(\mathrm{H}) \mathrm{H})(\mathrm{H}) \mathrm{F})(\mathrm{H}) \mathrm{H})(\mathrm{H}) \mathrm{H})(\mathrm{Cl}) \mathrm{H})(\mathrm{H}) \mathrm{H})(\mathrm{H}) \mathrm{H})(\mathrm{H}) \mathrm{Br})(\mathrm{Cl}) \mathrm{H})(\mathrm{B}$ r) $\mathrm{H})(\mathrm{H}) \mathrm{H})(\mathrm{H})(\mathrm{Cl}) \mathrm{H}$

$\mathrm{C}(\mathrm{C}(\mathrm{C}(\mathrm{C}(\mathrm{C}(\mathrm{C}(\mathrm{C}(\mathrm{C}(\mathrm{C}(\mathrm{C}(\mathrm{C}(\mathrm{C}(\mathrm{C}(\mathrm{C}(\mathrm{H})(\mathrm{Cl}) \mathrm{Cl})(\mathrm{F}) \mathrm{H})(\mathrm{Cl}) \mathrm{H})(\mathrm{H}) \mathrm{H})(\mathrm{Cl}) \mathrm{H})(\mathrm{H}) \mathrm{H})(\mathrm{H}) \mathrm{H})(\mathrm{H}) \mathrm{H})(\mathrm{H}) \mathrm{H})(\mathrm{H}) \mathrm{Cl})(\mathrm{H}) \mathrm{H})$ $(\mathrm{F}) \mathrm{H})(\mathrm{H}) \mathrm{Br})(\mathrm{H})(\mathrm{H}) \mathrm{H}$

$\mathrm{C}(\mathrm{C}(\mathrm{C}(\mathrm{C}(\mathrm{C}(\mathrm{C}(\mathrm{C}(\mathrm{C}(\mathrm{C}(\mathrm{C}(\mathrm{C}(\mathrm{C}(\mathrm{C}(\mathrm{C}(\mathrm{Br})(\mathrm{H}) \mathrm{H})(\mathrm{H}) \mathrm{H})(\mathrm{H}) \mathrm{H})(\mathrm{H}) \mathrm{H})(\mathrm{H}) \mathrm{H})(\mathrm{H}) \mathrm{Cl})(\mathrm{Cl}) \mathrm{H})(\mathrm{H}) \mathrm{Cl})(\mathrm{H}) \mathrm{H})(\mathrm{Cl}) \mathrm{H})(\mathrm{Cl}) \mathrm{H})($

$\mathrm{H}) \mathrm{H})(\mathrm{H}) \mathrm{H})(\mathrm{H})(\mathrm{Br}) \mathrm{Cl}$

$\mathrm{C}(\mathrm{C}(\mathrm{C}(\mathrm{C}(\mathrm{C}(\mathrm{C}(\mathrm{C}(\mathrm{C}(\mathrm{C}(\mathrm{C}(\mathrm{C}(\mathrm{C}(\mathrm{C}(\mathrm{C}(\mathrm{H})(\mathrm{H}) \mathrm{H})(\mathrm{F}) \mathrm{Cl})(\mathrm{H}) \mathrm{H})(\mathrm{H}) \mathrm{H})(\mathrm{H}) \mathrm{H})(\mathrm{H}) \mathrm{F})(\mathrm{H}) \mathrm{H})(\mathrm{H}) \mathrm{H})(\mathrm{H}) \mathrm{Cl})(\mathrm{Cl}) \mathrm{H})(\mathrm{Cl}) \mathrm{H})(\mathrm{H})$

$\mathrm{Cl})(\mathrm{H}) \mathrm{H})(\mathrm{H})(\mathrm{Cl}) \mathrm{H}$

$\mathrm{C}(\mathrm{C}(\mathrm{C}(\mathrm{C}(\mathrm{C}(\mathrm{C}(\mathrm{C}(\mathrm{C}(\mathrm{C}(\mathrm{C}(\mathrm{C}(\mathrm{C}(\mathrm{C}(\mathrm{C}(\mathrm{H})(\mathrm{H}) \mathrm{F})(\mathrm{H}) \mathrm{H})(\mathrm{H}) \mathrm{H})(\mathrm{H}) \mathrm{H})(\mathrm{H}) \mathrm{H})(\mathrm{H}) \mathrm{H})(\mathrm{Br}) \mathrm{H})(\mathrm{H}) \mathrm{F})(\mathrm{H}) \mathrm{H})(\mathrm{F}) \mathrm{H})(\mathrm{H}) \mathrm{Cl})(\mathrm{F}) \mathrm{B}$ r) $(\mathrm{H}) \mathrm{Br})(\mathrm{H})(\mathrm{H}) \mathrm{H}$

$\mathrm{C}(\mathrm{C}(\mathrm{C}(\mathrm{C}(\mathrm{C}(\mathrm{C}(\mathrm{C}(\mathrm{C}(\mathrm{C}(\mathrm{C}(\mathrm{C}(\mathrm{C}(\mathrm{C}(\mathrm{C}(\mathrm{H})(\mathrm{H}) \mathrm{Br})(\mathrm{H}) \mathrm{H})(\mathrm{H}) \mathrm{H})(\mathrm{H}) \mathrm{Cl})(\mathrm{H}) \mathrm{H})(\mathrm{H}) \mathrm{H})(\mathrm{H}) \mathrm{H})(\mathrm{H}) \mathrm{H})(\mathrm{H}) \mathrm{F})(\mathrm{F}) \mathrm{Br})(\mathrm{H}) \mathrm{F})(\mathrm{H})$ $\mathrm{H})(\mathrm{H}) \mathrm{Br})(\mathrm{H})(\mathrm{Br}) \mathrm{H}$

$\mathrm{C}(\mathrm{C}(\mathrm{C}(\mathrm{C}(\mathrm{C}(\mathrm{C}(\mathrm{C}(\mathrm{C}(\mathrm{C}(\mathrm{C}(\mathrm{C}(\mathrm{C}(\mathrm{C}(\mathrm{C}(\mathrm{Br})(\mathrm{H}) \mathrm{H})(\mathrm{H}) \mathrm{Br})(\mathrm{H}) \mathrm{Cl})(\mathrm{H}) \mathrm{Br})(\mathrm{H}) \mathrm{H})(\mathrm{H}) \mathrm{H})(\mathrm{H}) \mathrm{H})(\mathrm{Br}) \mathrm{H})(\mathrm{H}) \mathrm{H})(\mathrm{H}) \mathrm{H})(\mathrm{H}) \mathrm{F})($ $\mathrm{H}) \mathrm{H})(\mathrm{H}) \mathrm{F})(\mathrm{Br})(\mathrm{H}) \mathrm{H}$

$\mathrm{C}(\mathrm{C}(\mathrm{C}(\mathrm{C}(\mathrm{C}(\mathrm{C}(\mathrm{C}(\mathrm{C}(\mathrm{C}(\mathrm{C}(\mathrm{C}(\mathrm{C}(\mathrm{C}(\mathrm{C}(\mathrm{H})(\mathrm{H}) \mathrm{Br})(\mathrm{H}) \mathrm{H})(\mathrm{H}) \mathrm{H})(\mathrm{H}) \mathrm{H})(\mathrm{H}) \mathrm{H})(\mathrm{H}) \mathrm{F})(\mathrm{Br}) \mathrm{H})(\mathrm{H}) \mathrm{H})(\mathrm{H}) \mathrm{H})(\mathrm{F}) \mathrm{H})(\mathrm{H}) \mathrm{Br})$

$(\mathrm{H}) \mathrm{H})(\mathrm{Br}) \mathrm{F})(\mathrm{H})(\mathrm{H}) \mathrm{H}$

$\mathrm{C}(\mathrm{C}(\mathrm{C}(\mathrm{C}(\mathrm{C}(\mathrm{C}(\mathrm{C}(\mathrm{C}(\mathrm{C}(\mathrm{C}(\mathrm{C}(\mathrm{C}(\mathrm{C}(\mathrm{C}(\mathrm{H})(\mathrm{H}) \mathrm{F})(\mathrm{Br}) \mathrm{H})(\mathrm{H}) \mathrm{H})(\mathrm{H}) \mathrm{H})(\mathrm{H}) \mathrm{Br})(\mathrm{H}) \mathrm{H})(\mathrm{H}) \mathrm{H})(\mathrm{H}) \mathrm{Br})(\mathrm{Br}) \mathrm{H})(\mathrm{H}) \mathrm{H})(\mathrm{Br}) \mathrm{H})($

$\mathrm{H}) \mathrm{H})(\mathrm{H}) \mathrm{H})(\mathrm{Br})(\mathrm{H}) \mathrm{H}$

$\mathrm{C}(\mathrm{C}(\mathrm{C}(\mathrm{C}(\mathrm{C}(\mathrm{C}(\mathrm{C}(\mathrm{C}(\mathrm{C}(\mathrm{C}(\mathrm{C}(\mathrm{C}(\mathrm{C}(\mathrm{C}(\mathrm{H})(\mathrm{H}) \mathrm{Br})(\mathrm{H}) \mathrm{H})(\mathrm{F}) \mathrm{F})(\mathrm{H}) \mathrm{H})(\mathrm{H}) \mathrm{H})(\mathrm{H}) \mathrm{H})(\mathrm{H}) \mathrm{H})(\mathrm{Cl}) \mathrm{H})(\mathrm{H}) \mathrm{Cl})(\mathrm{H}) \mathrm{H})(\mathrm{H}) \mathrm{H})(\mathrm{H})$ $\mathrm{H})(\mathrm{Br}) \mathrm{H})(\mathrm{H})(\mathrm{F}) \mathrm{H}$

$\mathrm{C}(\mathrm{C}(\mathrm{C}(\mathrm{C}(\mathrm{C}(\mathrm{C}(\mathrm{C}(\mathrm{C}(\mathrm{C}(\mathrm{C}(\mathrm{C}(\mathrm{C}(\mathrm{C}(\mathrm{C}(\mathrm{H})(\mathrm{Br}) \mathrm{H})(\mathrm{H}) \mathrm{H})(\mathrm{Cl}) \mathrm{H})(\mathrm{H}) \mathrm{H})(\mathrm{H}) \mathrm{Br})(\mathrm{Cl}) \mathrm{H})(\mathrm{H}) \mathrm{F})(\mathrm{H}) \mathrm{H})(\mathrm{H}) \mathrm{H})(\mathrm{H}) \mathrm{H})(\mathrm{H}) \mathrm{H})$

$(\mathrm{H}) \mathrm{H})(\mathrm{F}) \mathrm{H})(\mathrm{H})(\mathrm{Br}) \mathrm{H}$

$\mathrm{C}(\mathrm{C}(\mathrm{C}(\mathrm{C}(\mathrm{C}(\mathrm{C}(\mathrm{C}(\mathrm{C}(\mathrm{C}(\mathrm{C}(\mathrm{C}(\mathrm{C}(\mathrm{C}(\mathrm{C}(\mathrm{H})(\mathrm{H}) \mathrm{Br})(\mathrm{H}) \mathrm{H})(\mathrm{H}) \mathrm{H})(\mathrm{H}) \mathrm{H})(\mathrm{H}) \mathrm{H})(\mathrm{H}) \mathrm{H})(\mathrm{H}) \mathrm{Br})(\mathrm{H}) \mathrm{H})(\mathrm{Br}) \mathrm{H})(\mathrm{H}) \mathrm{Br})(\mathrm{H}) \mathrm{H})($

$\mathrm{H}) \mathrm{H})(\mathrm{H}) \mathrm{Cl})(\mathrm{F})(\mathrm{Cl}) \mathrm{H}$

$\mathrm{C}(\mathrm{C}(\mathrm{C}(\mathrm{C}(\mathrm{C}(\mathrm{C}(\mathrm{C}(\mathrm{C}(\mathrm{C}(\mathrm{C}(\mathrm{C}(\mathrm{C}(\mathrm{C}(\mathrm{C}(\mathrm{H})(\mathrm{H}) \mathrm{Cl})(\mathrm{H}) \mathrm{H})(\mathrm{H}) \mathrm{H})(\mathrm{H}) \mathrm{F})(\mathrm{Cl}) \mathrm{H})(\mathrm{H}) \mathrm{F})(\mathrm{H}) \mathrm{Br})(\mathrm{H}) \mathrm{H})(\mathrm{H}) \mathrm{Cl})(\mathrm{H}) \mathrm{H})(\mathrm{H}) \mathrm{H})(\mathrm{H})$

$\mathrm{H})(\mathrm{H}) \mathrm{H})(\mathrm{H})(\mathrm{H}) \mathrm{Br}$

$\mathrm{C}(\mathrm{C}(\mathrm{C}(\mathrm{C}(\mathrm{C}(\mathrm{C}(\mathrm{C}(\mathrm{C}(\mathrm{C}(\mathrm{C}(\mathrm{C}(\mathrm{C}(\mathrm{C}(\mathrm{C}(\mathrm{H})(\mathrm{H}) \mathrm{H})(\mathrm{H}) \mathrm{H})(\mathrm{Br}) \mathrm{H})(\mathrm{Cl}) \mathrm{H})(\mathrm{H}) \mathrm{H})(\mathrm{H}) \mathrm{Br})(\mathrm{Cl}) \mathrm{H})(\mathrm{Br}) \mathrm{H})(\mathrm{H}) \mathrm{H})(\mathrm{F}) \mathrm{H})(\mathrm{H}) \mathrm{H})($

$\mathrm{H}) \mathrm{H})(\mathrm{H}) \mathrm{Cl})(\mathrm{H})(\mathrm{H}) \mathrm{H}$

$\mathrm{C}(\mathrm{C}(\mathrm{C}(\mathrm{C}(\mathrm{C}(\mathrm{C}(\mathrm{C}(\mathrm{C}(\mathrm{C}(\mathrm{C}(\mathrm{C}(\mathrm{C}(\mathrm{C}(\mathrm{C}(\mathrm{Cl})(\mathrm{H}) \mathrm{Cl})(\mathrm{F}) \mathrm{H})(\mathrm{Cl}) \mathrm{H})(\mathrm{H}) \mathrm{H})(\mathrm{H}) \mathrm{H})(\mathrm{H}) \mathrm{H})(\mathrm{H}) \mathrm{Br})(\mathrm{H}) \mathrm{H})(\mathrm{H}) \mathrm{H})(\mathrm{H}) \mathrm{H})(\mathrm{H}) \mathrm{H})(\mathrm{C}$ 1)H)(H)Br)(H)(H)H

$\mathrm{C}(\mathrm{C}(\mathrm{C}(\mathrm{C}(\mathrm{C}(\mathrm{C}(\mathrm{C}(\mathrm{C}(\mathrm{C}(\mathrm{C}(\mathrm{C}(\mathrm{C}(\mathrm{C}(\mathrm{C}(\mathrm{Cl})(\mathrm{H}) \mathrm{H})(\mathrm{H}) \mathrm{H})(\mathrm{H}) \mathrm{Cl})(\mathrm{H}) \mathrm{H})(\mathrm{Br}) \mathrm{H})(\mathrm{Cl}) \mathrm{H})(\mathrm{H}) \mathrm{H})(\mathrm{H}) \mathrm{H})(\mathrm{Br}) \mathrm{H})(\mathrm{Cl}) \mathrm{H})(\mathrm{H}) \mathrm{H})$ $\mathrm{H}) \mathrm{H})(\mathrm{H}) \mathrm{H})(\mathrm{H})(\mathrm{Br}) \mathrm{H}$

$\mathrm{C}(\mathrm{C}(\mathrm{C}(\mathrm{C}(\mathrm{C}(\mathrm{C}(\mathrm{C}(\mathrm{C}(\mathrm{C}(\mathrm{C}(\mathrm{C}(\mathrm{C}(\mathrm{C}(\mathrm{C}(\mathrm{H})(\mathrm{H}) \mathrm{H})(\mathrm{Cl}) \mathrm{H})(\mathrm{H}) \mathrm{Cl})(\mathrm{Cl}) \mathrm{H})(\mathrm{H}) \mathrm{H})(\mathrm{H}) \mathrm{H})(\mathrm{H}) \mathrm{H})(\mathrm{H}) \mathrm{H})(\mathrm{H}) \mathrm{H})(\mathrm{H}) \mathrm{Cl})(\mathrm{H}) \mathrm{Br})($

$\mathrm{Cl}) \mathrm{H})(\mathrm{H}) \mathrm{H})(\mathrm{Br})(\mathrm{H}) \mathrm{H}$

$\mathrm{C}(\mathrm{C}(\mathrm{C}(\mathrm{C}(\mathrm{C}(\mathrm{C}(\mathrm{C}(\mathrm{C}(\mathrm{C}(\mathrm{C}(\mathrm{C}(\mathrm{C}(\mathrm{C}(\mathrm{C}(\mathrm{H})(\mathrm{H}) \mathrm{Br})(\mathrm{H}) \mathrm{H})(\mathrm{Cl}) \mathrm{H})(\mathrm{H}) \mathrm{H})(\mathrm{H}) \mathrm{H})(\mathrm{H}) \mathrm{H})(\mathrm{H}) \mathrm{F})(\mathrm{H}) \mathrm{H})(\mathrm{H}) \mathrm{H})(\mathrm{H}) \mathrm{Cl})(\mathrm{Cl}) \mathrm{H})$

$(\mathrm{H}) \mathrm{Cl})(\mathrm{H}) \mathrm{Cl}(\mathrm{H})(\mathrm{H}) \mathrm{H}$

$\mathrm{C}(\mathrm{C}(\mathrm{C}(\mathrm{C}(\mathrm{C}(\mathrm{C}(\mathrm{C}(\mathrm{C}(\mathrm{C}(\mathrm{C}(\mathrm{C}(\mathrm{C}(\mathrm{C}(\mathrm{C}(\mathrm{H})(\mathrm{H}) \mathrm{H})(\mathrm{H}) \mathrm{Cl})(\mathrm{H}) \mathrm{H})(\mathrm{H}) \mathrm{Cl})(\mathrm{H}) \mathrm{H})(\mathrm{Cl}) \mathrm{H})(\mathrm{H}) \mathrm{H})(\mathrm{Cl}) \mathrm{H})(\mathrm{H}) \mathrm{H})(\mathrm{F}) \mathrm{H})(\mathrm{H}) \mathrm{H})$

$(\mathrm{H}) \mathrm{H})(\mathrm{H}) \mathrm{H})(\mathrm{H})(\mathrm{F}) \mathrm{Cl}$

$\mathrm{C}(\mathrm{C}(\mathrm{C}(\mathrm{C}(\mathrm{C}(\mathrm{C}(\mathrm{C}(\mathrm{C}(\mathrm{C}(\mathrm{C}(\mathrm{C}(\mathrm{C}(\mathrm{C}(\mathrm{C}(\mathrm{H})(\mathrm{H}) \mathrm{Cl})(\mathrm{H}) \mathrm{Cl})(\mathrm{Cl}) \mathrm{H})(\mathrm{H}) \mathrm{Cl})(\mathrm{H}) \mathrm{H})(\mathrm{H}) \mathrm{H})(\mathrm{H}) \mathrm{H})(\mathrm{Cl}) \mathrm{H})(\mathrm{H}) \mathrm{H})(\mathrm{Cl}) \mathrm{H})(\mathrm{Cl}) \mathrm{H})($ $\mathrm{H}) \mathrm{H})(\mathrm{H}) \mathrm{H})(\mathrm{H})(\mathrm{H}) \mathrm{H}$

$\mathrm{C}(\mathrm{C}(\mathrm{C}(\mathrm{C}(\mathrm{C}(\mathrm{C}(\mathrm{C}(\mathrm{C}(\mathrm{C}(\mathrm{C}(\mathrm{C}(\mathrm{C}(\mathrm{C}(\mathrm{C}(\mathrm{H})(\mathrm{H}) \mathrm{H})(\mathrm{F}) \mathrm{H})(\mathrm{H}) \mathrm{F})(\mathrm{Br}) \mathrm{F})(\mathrm{H}) \mathrm{Br})(\mathrm{H}) \mathrm{H})(\mathrm{H}) \mathrm{H})(\mathrm{Br}) \mathrm{H})(\mathrm{H}) \mathrm{H})(\mathrm{H}) \mathrm{Cl})(\mathrm{H}) \mathrm{H})$

$(\mathrm{H}) \mathrm{H})(\mathrm{H}) \mathrm{H})(\mathrm{H})(\mathrm{H}) \mathrm{H}$

$\mathrm{C}(\mathrm{C}(\mathrm{C}(\mathrm{C}(\mathrm{C}(\mathrm{C}(\mathrm{C}(\mathrm{C}(\mathrm{C}(\mathrm{C}(\mathrm{C}(\mathrm{C}(\mathrm{C}(\mathrm{C}(\mathrm{H})(\mathrm{H}) \mathrm{H})(\mathrm{H}) \mathrm{H})(\mathrm{Br}) \mathrm{H})(\mathrm{H}) \mathrm{F})(\mathrm{H}) \mathrm{F})(\mathrm{H}) \mathrm{Br})(\mathrm{H}) \mathrm{Br})(\mathrm{H}) \mathrm{H})(\mathrm{H}) \mathrm{Cl})(\mathrm{H}) \mathrm{H})(\mathrm{H}) \mathrm{H})$

$(\mathrm{H}) \mathrm{H})(\mathrm{Br}) \mathrm{H})(\mathrm{H})(\mathrm{H}) \mathrm{H}$

$\mathrm{C}(\mathrm{C}(\mathrm{C}(\mathrm{C}(\mathrm{C}(\mathrm{C}(\mathrm{C}(\mathrm{C}(\mathrm{C}(\mathrm{C}(\mathrm{C}(\mathrm{C}(\mathrm{C}(\mathrm{C}(\mathrm{H})(\mathrm{H}) \mathrm{H})(\mathrm{H}) \mathrm{H})(\mathrm{H}) \mathrm{Br})(\mathrm{H}) \mathrm{H})(\mathrm{H}) \mathrm{H})(\mathrm{H}) \mathrm{Br})(\mathrm{H}) \mathrm{Br})(\mathrm{H}) \mathrm{H})(\mathrm{H}) \mathrm{F})(\mathrm{H}) \mathrm{H})(\mathrm{Cl}) \mathrm{H})($

$\mathrm{H}) \mathrm{H})(\mathrm{H}) \mathrm{H})(\mathrm{Br})(\mathrm{H}) \mathrm{Br}$

$\mathrm{C}(\mathrm{C}(\mathrm{C}(\mathrm{C}(\mathrm{C}(\mathrm{C}(\mathrm{C}(\mathrm{C}(\mathrm{C}(\mathrm{C}(\mathrm{C}(\mathrm{C}(\mathrm{C}(\mathrm{C}(\mathrm{H})(\mathrm{H}) \mathrm{H})(\mathrm{H}) \mathrm{F})(\mathrm{H}) \mathrm{Br})(\mathrm{H}) \mathrm{H})(\mathrm{H}) \mathrm{H})(\mathrm{H}) \mathrm{H})(\mathrm{H}) \mathrm{H})(\mathrm{F}) \mathrm{Br})(\mathrm{H}) \mathrm{H})(\mathrm{F}) \mathrm{H})(\mathrm{H}) \mathrm{H})(\mathrm{H})$

$\mathrm{Br})(\mathrm{H}) \mathrm{H})(\mathrm{H})(\mathrm{H}) \mathrm{H}$

$\mathrm{C}(\mathrm{C}(\mathrm{C}(\mathrm{C}(\mathrm{C}(\mathrm{C}(\mathrm{C}(\mathrm{C}(\mathrm{C}(\mathrm{C}(\mathrm{C}(\mathrm{C}(\mathrm{C}(\mathrm{C}(\mathrm{H})(\mathrm{H}) \mathrm{H})(\mathrm{Br}) \mathrm{H})(\mathrm{H}) \mathrm{H})(\mathrm{H}) \mathrm{H})(\mathrm{Br}) \mathrm{Br})(\mathrm{H}) \mathrm{H})(\mathrm{H}) \mathrm{F})(\mathrm{H}) \mathrm{H})(\mathrm{H}) \mathrm{H})(\mathrm{H}) \mathrm{H})(\mathrm{H}) \mathrm{H})$

$(\mathrm{H}) \mathrm{H})(\mathrm{Br}) \mathrm{H})(\mathrm{H})(\mathrm{F}) \mathrm{H}$

$\mathrm{C}(\mathrm{C}(\mathrm{C}(\mathrm{C}(\mathrm{C}(\mathrm{C}(\mathrm{C}(\mathrm{C}(\mathrm{C}(\mathrm{C}(\mathrm{C}(\mathrm{C}(\mathrm{C}(\mathrm{C}(\mathrm{H})(\mathrm{H}) \mathrm{H})(\mathrm{H}) \mathrm{H})(\mathrm{H}) \mathrm{H})(\mathrm{H}) \mathrm{H})(\mathrm{H}) \mathrm{Br})(\mathrm{Br}) \mathrm{H})(\mathrm{H}) \mathrm{Br})(\mathrm{H}) \mathrm{H})(\mathrm{H}) \mathrm{H})(\mathrm{H}) \mathrm{H})(\mathrm{H}) \mathrm{Br})($

$\mathrm{H}) \mathrm{H})(\mathrm{H}) \mathrm{Br})(\mathrm{F})(\mathrm{H}) \mathrm{H}$

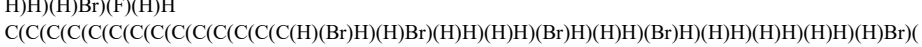

$\mathrm{H}) \mathrm{H})(\mathrm{H}) \mathrm{Br})(\mathrm{H})(\mathrm{H}) \mathrm{H}$

$\mathrm{C}(\mathrm{C}(\mathrm{C}(\mathrm{C}(\mathrm{C}(\mathrm{C}(\mathrm{C}(\mathrm{C}(\mathrm{C}(\mathrm{C}(\mathrm{C}(\mathrm{C}(\mathrm{C}(\mathrm{C}(\mathrm{H})(\mathrm{H}) \mathrm{H})(\mathrm{Cl}) \mathrm{H})(\mathrm{H}) \mathrm{H})(\mathrm{H}) \mathrm{H})(\mathrm{F}) \mathrm{H})(\mathrm{H}) \mathrm{H})(\mathrm{H}) \mathrm{H})(\mathrm{F}) \mathrm{H})(\mathrm{H}) \mathrm{H})(\mathrm{H}) \mathrm{H})(\mathrm{H}) \mathrm{H})(\mathrm{Br})$ $\mathrm{H})(\mathrm{H}) \mathrm{Cl})(\mathrm{Br})(\mathrm{H}) \mathrm{H}$

$\mathrm{C}(\mathrm{C}(\mathrm{C}(\mathrm{C}(\mathrm{C}(\mathrm{C}(\mathrm{C}(\mathrm{C}(\mathrm{C}(\mathrm{C}(\mathrm{C}(\mathrm{C}(\mathrm{C}(\mathrm{C}(\mathrm{Br})(\mathrm{H}) \mathrm{Br})(\mathrm{H}) \mathrm{H})(\mathrm{H}) \mathrm{H})(\mathrm{Cl}) \mathrm{H})(\mathrm{H}) \mathrm{Br})(\mathrm{Cl}) \mathrm{H})(\mathrm{H}) \mathrm{H})(\mathrm{H}) \mathrm{H})(\mathrm{H}) \mathrm{H})(\mathrm{H}) \mathrm{H})(\mathrm{H}) \mathrm{H})($ $\mathrm{H}) \mathrm{H})(\mathrm{F}) \mathrm{H})(\mathrm{H})(\mathrm{H}) \mathrm{H}$

$\mathrm{C}(\mathrm{C}(\mathrm{C}(\mathrm{C}(\mathrm{C}(\mathrm{C}(\mathrm{C}(\mathrm{C}(\mathrm{C}(\mathrm{C}(\mathrm{C}(\mathrm{C}(\mathrm{C}(\mathrm{C}(\mathrm{H})(\mathrm{H}) \mathrm{H})(\mathrm{Cl}) \mathrm{H})(\mathrm{H}) \mathrm{H})(\mathrm{H}) \mathrm{Cl})(\mathrm{H}) \mathrm{H})(\mathrm{H}) \mathrm{H})(\mathrm{Br}) \mathrm{H})(\mathrm{H}) \mathrm{H})(\mathrm{H}) \mathrm{H})(\mathrm{H}) \mathrm{H})(\mathrm{H}) \mathrm{H})(\mathrm{B}$ r) $\mathrm{H})(\mathrm{Br}) \mathrm{H})(\mathrm{H})(\mathrm{H}) \mathrm{Br}$

$\mathrm{C}(\mathrm{C}(\mathrm{C}(\mathrm{C}(\mathrm{C}(\mathrm{C}(\mathrm{C}(\mathrm{C}(\mathrm{C}(\mathrm{C}(\mathrm{C}(\mathrm{C}(\mathrm{C}(\mathrm{C}(\mathrm{H})(\mathrm{H}) \mathrm{H})(\mathrm{Br}) \mathrm{F})(\mathrm{H}) \mathrm{H})(\mathrm{Br}) \mathrm{H})(\mathrm{H}) \mathrm{H})(\mathrm{H}) \mathrm{H})(\mathrm{H}) \mathrm{H})(\mathrm{Cl}) \mathrm{H})(\mathrm{H}) \mathrm{Cl})(\mathrm{H}) \mathrm{H})(\mathrm{H}) \mathrm{H})$

$(\mathrm{H}) \mathrm{H})(\mathrm{H}) \mathrm{H})(\mathrm{Cl})(\mathrm{H}) \mathrm{H}$

$\mathrm{C}(\mathrm{C}(\mathrm{C}(\mathrm{C}(\mathrm{C}(\mathrm{C}(\mathrm{C}(\mathrm{C}(\mathrm{C}(\mathrm{C}(\mathrm{C}(\mathrm{C}(\mathrm{C}(\mathrm{C}(\mathrm{H})(\mathrm{H}) \mathrm{Br})(\mathrm{H}) \mathrm{Cl})(\mathrm{H}) \mathrm{Cl})(\mathrm{H}) \mathrm{H})(\mathrm{H}) \mathrm{H})(\mathrm{H}) \mathrm{H})(\mathrm{H}) \mathrm{H})(\mathrm{H}) \mathrm{H})(\mathrm{H}) \mathrm{H})(\mathrm{H}) \mathrm{Br})(\mathrm{H}) \mathrm{H})($ $\mathrm{H}) \mathrm{H})(\mathrm{Br}) \mathrm{H})(\mathrm{Cl})(\mathrm{H}) \mathrm{H}$
$\mathrm{C} 14 \mathrm{H} 21 \mathrm{Cl} \mathrm{BrF} 3$

C14H21Cl6F3

$\mathrm{C} 14 \mathrm{H} 21 \mathrm{Cl} 17 \mathrm{~F} 2$

$\mathrm{C} 14 \mathrm{H} 21 \mathrm{ClBr} 3 \mathrm{~F} 5$

$\mathrm{C} 14 \mathrm{H} 21 \mathrm{ClBr} 4 \mathrm{~F} 4$

$\mathrm{C} 14 \mathrm{H} 22 \mathrm{Br} 4 \mathrm{~F} 4$

$\mathrm{C} 14 \mathrm{H} 22 \mathrm{Cl} 2 \mathrm{Br} 2 \mathrm{~F} 4$

$\mathrm{C} 14 \mathrm{H} 22 \mathrm{Cl} 2 \mathrm{Br} 3 \mathrm{~F} 3$

$\mathrm{C} 14 \mathrm{H} 22 \mathrm{Cl} 3 \mathrm{Br} 2 \mathrm{~F} 3$

$14 \mathrm{H} 22 \mathrm{C} 14 \mathrm{Br} 2 \mathrm{~F} 2$

$\mathrm{C} 14 \mathrm{H} 22 \mathrm{Cl} 5 \mathrm{Br} 2 \mathrm{~F}$

$\mathrm{C} 14 \mathrm{H} 22 \mathrm{Cl} 5 \mathrm{BrF} 2$

$\mathrm{C} 14 \mathrm{H} 22 \mathrm{Cl} 6 \mathrm{Br} 2$

$\mathrm{C} 14 \mathrm{H} 22 \mathrm{Cl} 6 \mathrm{~F} 2$

$\mathrm{C} 14 \mathrm{H} 22 \mathrm{ClBr} 3 \mathrm{~F} 4$

$\mathrm{C} 14 \mathrm{H} 22 \mathrm{ClBr} 4 \mathrm{~F} 3$

14H22ClBr5F2

$\mathrm{C} 14 \mathrm{H} 23 \mathrm{Br} 4 \mathrm{~F} 3$

$\mathrm{C} 14 \mathrm{H} 23 \mathrm{Br} 6 \mathrm{~F}$

$\mathrm{C} 14 \mathrm{H} 23 \mathrm{Cl} 2 \mathrm{Br} 2 \mathrm{~F} 3$

$\mathrm{C} 14 \mathrm{H} 23 \mathrm{Cl} 2 \mathrm{Br} 3 \mathrm{~F} 2$

$\mathrm{C} 14 \mathrm{H} 23 \mathrm{Cl} 2 \mathrm{Br} 4 \mathrm{~F}$

$\mathrm{C} 14 \mathrm{H} 23 \mathrm{Cl} 3 \mathrm{Br} 2 \mathrm{~F} 2$

$\mathrm{C} 14 \mathrm{H} 23 \mathrm{Cl} 3 \mathrm{Br} 3 \mathrm{~F}$

C14H23Cl4Br2F

$\mathrm{C} 14 \mathrm{H} 23 \mathrm{Cl} 4 \mathrm{Br} 3$

$\mathrm{C} 14 \mathrm{H} 23 \mathrm{Cl} 5 \mathrm{Br} 2$

$\mathrm{C} 14 \mathrm{H} 23 \mathrm{Cl} 5 \mathrm{BrF}$

C14H23Cl5F2

$\mathrm{C} 14 \mathrm{H} 23 \mathrm{Cl} 7$

$\mathrm{C} 14 \mathrm{H} 23 \mathrm{ClBr} 3 \mathrm{~F} 3$

$\mathrm{C} 14 \mathrm{H} 23 \mathrm{ClBr} 4 \mathrm{~F} 2$

$\mathrm{C} 14 \mathrm{H} 23 \mathrm{ClBr} 5 \mathrm{~F}$

$\mathrm{C} 14 \mathrm{H} 24 \mathrm{Br} 3 \mathrm{~F} 3$

$\mathrm{C} 14 \mathrm{H} 24 \mathrm{Br} 4 \mathrm{~F} 2$

$\mathrm{C} 14 \mathrm{H} 24 \mathrm{Br} 5 \mathrm{~F}$

$\mathrm{C} 14 \mathrm{H} 24 \mathrm{Br} 6$

$\mathrm{C} 14 \mathrm{H} 24 \mathrm{Cl} 2 \mathrm{Br} 2 \mathrm{~F} 2$

$\mathrm{C} 14 \mathrm{H} 24 \mathrm{Cl} 2 \mathrm{Br} 3 \mathrm{~F}$

$\mathrm{C} 14 \mathrm{H} 24 \mathrm{Cl} 2 \mathrm{Br} 4$

$\mathrm{C} 14 \mathrm{H} 24 \mathrm{Cl} 3 \mathrm{Br} 2 \mathrm{~F}$

$\mathrm{C} 14 \mathrm{H} 24 \mathrm{Cl} 3 \mathrm{Br} 3$
lgKoa lgKow lgKaw lgKow lgKoa lgKaw lgKow lgKoa lgKaw EPI_EPI_EPI_Exp__Exp__Exp__DFT_DFT_DFT Suite Suite Suite corr corr corr_corr _corr corr $\begin{array}{lllllllll}9.11 & 8.88 & -0.23 & 8.33 & 8.56 & -0.23 & 7.58 & 14.75 & -7.16\end{array}$ $\begin{array}{lllllllll}8.53 & 8.79 & 0.26 & 8.19 & 7.94 & 0.26 & 7.51 & 13.69 & -6.1\end{array}$ $\begin{array}{lllllllll}8.86 & 8.36 & -0.50 & 7.55 & 8.05 & -0.50 & 7.18 & 14.28 & -7.10\end{array}$ $\begin{array}{lllllllll}8.13 & 8.43 & 0.30 & 7.66 & 7.35 & 0.30 & 7.24 & 12.94 & -5.70\end{array}$ $\begin{array}{lllllllll}9.76 & 8.83 & -0.93 & 8.25 & 9.19 & -0.93 & 7.54 & 15.95 & -8.40\end{array}$ $\begin{array}{lllllllll}9.06 & 8.58 & -0.48 & 7.88 & 8.36 & -0.48 & 7.35 & 14.66 & -7.30\end{array}$ $\begin{array}{lllllllll}7.24 & 7.73 & 0.49 & 6.61 & 6.12 & 0.49 & 6.70 & 11.31 & -4.6\end{array}$ $\begin{array}{lllllllll}8.89 & 8.14 & -0.75 & 7.22 & 7.97 & -0.75 & 7.01 & 14.34 & -7.32\end{array}$ $\begin{array}{lllllllll}9.05 & 8.79 & -0.26 & 8.19 & 8.46 & -0.26 & 7.51 & 14.64 & -7.13\end{array}$ $\begin{array}{lllllllll}9.3 & 8.29 & -1.01 & 7.45 & 8.46 & -1.01 & 7.13 & 15.10 & -7.97\end{array}$ $\begin{array}{lllllllll}10.4 & 8.67 & -1.77 & 8.01 & 9.78 & -1.77 & 7.42 & 17.18 & -9.76\end{array}$ $\begin{array}{lllllllll}8.73 & 8.2 & -0.53 & 7.31 & 7.84 & -0.53 & 7.06 & 14.05 & -6.99\end{array}$ $\begin{array}{lllllllll}11.5 & 8.99 & -2.52 & 8.49 & 11.01 & -2.52 & 7.67 & 19.15 & -11.48\end{array}$ $\begin{array}{lllllllll}8.89 & 8.85 & -0.04 & 8.28 & 8.33 & -0.04 & 7.56 & 14.35 & -6.79\end{array}$ $\begin{array}{lllllllll}8.48 & 8.49 & 0.01 & 7.75 & 7.74 & 0.01 & 7.28 & 13.60 & -6.31\end{array}$ $\begin{array}{lllllllll}10.2 & 8.97 & -1.23 & 8.46 & 9.70 & -1.23 & 7.65 & 16.75 & -9.10\end{array}$ $\begin{array}{lllllllll}11.1 & 8.63 & -2.47 & 7.96 & 10.42 & -2.47 & 7.39 & 18.40 & -11.01\end{array}$ $\begin{array}{lllllllll}9.49 & 8.71 & -0.78 & 8.07 & 8.85 & -0.78 & 7.45 & 15.44 & -7.99\end{array}$ $\begin{array}{lllllllll}12.1 & 8.85 & -3.25 & 8.28 & 11.54 & -3.25 & 7.56 & 20.24 & -12.68\end{array}$ $\begin{array}{lllllllll}8.42 & 8.61 & 0.19 & 7.93 & 7.73 & 0.19 & 7.38 & 13.48 & -6.10\end{array}$ $\begin{array}{lllllllll}9.32 & 8.27 & -1.05 & 7.42 & 8.46 & -1.05 & 7.11 & 15.13 & -8.01\end{array}$ $\begin{array}{lllllllll}11 & 8.67 & -2.28 & 8.01 & 10.30 & -2.28 & 7.42 & 18.13 & -10.71\end{array}$ $\begin{array}{lllllllll}8.74 & 8.18 & -0.56 & 7.28 & 7.84 & -0.56 & 7.04 & 14.07 & -7.02\end{array}$ $\begin{array}{lllllllll}10.2 & 8.44 & -1.80 & 7.67 & 9.47 & -1.80 & 7.24 & 16.82 & -9.57\end{array}$ $\begin{array}{lllllllll}9.73 & 8.42 & -1.31 & 7.64 & 8.95 & -1.31 & 7.23 & 15.89 & -8.66\end{array}$ $\begin{array}{lllllllll}11.5 & 8.9 & -2.55 & 8.36 & 10.91 & -2.55 & 7.60 & 19.05 & -11.45\end{array}$ $\begin{array}{lllllllll}10.8 & 8.73 & -2.06 & 8.10 & 10.17 & -2.06 & 7.47 & 17.84 & -10.37\end{array}$ $\begin{array}{lllllllll}9.16 & 8.33 & -0.83 & 7.51 & 8.33 & -0.83 & 7.16 & 14.83 & -7.67\end{array}$ $\begin{array}{lllllllll}7.52 & 7.93 & 0.41 & 6.91 & 6.50 & 0.41 & 6.85 & 11.83 & -4.97\end{array}$ $\begin{array}{lllllllll}9.64 & 8.55 & -1.09 & 7.84 & 8.93 & -1.09 & 7.33 & 15.73 & -8.40\end{array}$ $\begin{array}{lllllllll}8.85 & 8.55 & -0.30 & 7.84 & 8.13 & -0.30 & 7.33 & 14.26 & -6.93\end{array}$ $\begin{array}{lllllllll}9.74 & 8.21 & -1.53 & 7.33 & 8.86 & -1.53 & 7.07 & 15.91 & -8.84\end{array}$ $\begin{array}{lllllllll}11.5 & 8.69 & -2.77 & 8.04 & 10.81 & -2.77 & 7.44 & 19.06 & -11.62\end{array}$ $\begin{array}{lllllllll}8.21 & 8.37 & 0.16 & 7.57 & 7.41 & 0.16 & 7.19 & 13.10 & -5.90\end{array}$ $\begin{array}{lllllllll}9.93 & 8.85 & -1.08 & 8.28 & 9.36 & -1.08 & 7.56 & 16.25 & -8.69\end{array}$ $\begin{array}{lllllllll}10.8 & 8.51 & -2.31 & 7.78 & 10.09 & -2.31 & 7.30 & 17.89 & -10.60\end{array}$ $\begin{array}{lllllllll}12.5 & 8.91 & -3.55 & 8.37 & 11.93 & -3.55 & 7.61 & 20.90 & -13.30\end{array}$ $\begin{array}{lllllllll}8.04 & 7.93 & -0.11 & 6.91 & 7.02 & -0.11 & 6.85 & 12.78 & -5.92\end{array}$ $\begin{array}{lllllllll}9.67 & 8.33 & -1.34 & 7.51 & 8.85 & -1.34 & 7.16 & 15.78 & -8.62\end{array}$ $\begin{array}{lllllllll}11.3 & 8.73 & -2.58 & 8.10 & 10.69 & -2.58 & 7.47 & 18.79 & -11.32\end{array}$ $\begin{array}{lllllllll}9.84 & 8.98 & -0.86 & 8.48 & 9.34 & -0.86 & 7.66 & 16.09 & -8.43\end{array}$ $\begin{array}{lllllllll}10.8 & 8.72 & -2.10 & 8.09 & 10.19 & -2.10 & 7.46 & 17.88 & -10.42\end{array}$ 
SMILE Generated

$\mathrm{C}(\mathrm{C}(\mathrm{C}(\mathrm{C}(\mathrm{C}(\mathrm{C}(\mathrm{C}(\mathrm{C}(\mathrm{C}(\mathrm{C}(\mathrm{C}(\mathrm{C}(\mathrm{C}(\mathrm{C}(\mathrm{Br})(\mathrm{H}) \mathrm{H})(\mathrm{H}) \mathrm{H})(\mathrm{H}) \mathrm{H})(\mathrm{H}) \mathrm{H})(\mathrm{H}) \mathrm{Cl})(\mathrm{H}) \mathrm{H})(\mathrm{H}) \mathrm{H})(\mathrm{H}) \mathrm{H})(\mathrm{H}) \mathrm{Cl})(\mathrm{H}) \mathrm{H})(\mathrm{H}) \mathrm{H})(\mathrm{F})$ $\mathrm{F})(\mathrm{H}) \mathrm{H})(\mathrm{Cl})(\mathrm{H}) \mathrm{H}$

$\mathrm{C}(\mathrm{C}(\mathrm{C}(\mathrm{C}(\mathrm{C}(\mathrm{C}(\mathrm{C}(\mathrm{C}(\mathrm{C}(\mathrm{C}(\mathrm{C}(\mathrm{C}(\mathrm{C}(\mathrm{C}(\mathrm{H})(\mathrm{H}) \mathrm{Cl})(\mathrm{Cl}) \mathrm{H})(\mathrm{Br}) \mathrm{H})(\mathrm{H}) \mathrm{H})(\mathrm{Cl}) \mathrm{H})(\mathrm{H}) \mathrm{H})(\mathrm{H}) \mathrm{H})(\mathrm{H}) \mathrm{H})(\mathrm{H}) \mathrm{H})(\mathrm{H}) \mathrm{Cl})(\mathrm{H}) \mathrm{H})($ $\mathrm{H}) \mathrm{H})(\mathrm{H}) \mathrm{Br})(\mathrm{H})(\mathrm{H}) \mathrm{H}$

$\mathrm{C}(\mathrm{C}(\mathrm{C}(\mathrm{C}(\mathrm{C}(\mathrm{C}(\mathrm{C}(\mathrm{C}(\mathrm{C}(\mathrm{C}(\mathrm{C}(\mathrm{C}(\mathrm{C}(\mathrm{C}(\mathrm{H})(\mathrm{H}) \mathrm{H})(\mathrm{Br}) \mathrm{H})(\mathrm{H}) \mathrm{H})(\mathrm{H}) \mathrm{H})(\mathrm{H}) \mathrm{H})(\mathrm{H}) \mathrm{H})(\mathrm{H}) \mathrm{H})(\mathrm{F}) \mathrm{H})(\mathrm{Cl}) \mathrm{Cl})(\mathrm{H}) \mathrm{H})(\mathrm{H}) \mathrm{H})$ $(\mathrm{Cl}) \mathrm{H})(\mathrm{H}) \mathrm{H})(\mathrm{H})(\mathrm{H}) \mathrm{Cl}$

$\mathrm{C}(\mathrm{C}(\mathrm{C}(\mathrm{C}(\mathrm{C}(\mathrm{C}(\mathrm{C}(\mathrm{C}(\mathrm{C}(\mathrm{C}(\mathrm{C}(\mathrm{C}(\mathrm{C}(\mathrm{C}(\mathrm{Cl})(\mathrm{H}) \mathrm{H})(\mathrm{H}) \mathrm{H})(\mathrm{H}) \mathrm{H})(\mathrm{Cl}) \mathrm{H})(\mathrm{H}) \mathrm{Cl})(\mathrm{H}) \mathrm{H})(\mathrm{H}) \mathrm{H})(\mathrm{H}) \mathrm{Cl})(\mathrm{H}) \mathrm{H})(\mathrm{H}) \mathrm{H})(\mathrm{Br}) \mathrm{H})($ $\mathrm{H}) \mathrm{H})(\mathrm{H}) \mathrm{H})(\mathrm{H})(\mathrm{H}) \mathrm{Cl}$

$\mathrm{C}(\mathrm{C}(\mathrm{C}(\mathrm{C}(\mathrm{C}(\mathrm{C}(\mathrm{C}(\mathrm{C}(\mathrm{C}(\mathrm{C}(\mathrm{C}(\mathrm{C}(\mathrm{C}(\mathrm{C}(\mathrm{Cl})(\mathrm{Cl}) \mathrm{H})(\mathrm{H}) \mathrm{H})(\mathrm{H}) \mathrm{H})(\mathrm{F}) \mathrm{H})(\mathrm{H}) \mathrm{H})(\mathrm{H}) \mathrm{H})(\mathrm{H}) \mathrm{Cl})(\mathrm{H}) \mathrm{H})(\mathrm{H}) \mathrm{H})(\mathrm{H}) \mathrm{H})(\mathrm{H}) \mathrm{Cl}$

$(\mathrm{H}) \mathrm{H})(\mathrm{H}) \mathrm{H})(\mathrm{Cl})(\mathrm{H}) \mathrm{H}$

$\mathrm{C}(\mathrm{C}(\mathrm{C}(\mathrm{C}(\mathrm{C}(\mathrm{C}(\mathrm{C}(\mathrm{C}(\mathrm{C}(\mathrm{C}(\mathrm{C}(\mathrm{C}(\mathrm{C}(\mathrm{C}(\mathrm{H})(\mathrm{Cl}) \mathrm{H})(\mathrm{H}) \mathrm{H})(\mathrm{H}) \mathrm{Cl})(\mathrm{H}) \mathrm{Cl})(\mathrm{H}) \mathrm{H})(\mathrm{H}) \mathrm{H})(\mathrm{H}) \mathrm{H})(\mathrm{H}) \mathrm{H})(\mathrm{H}) \mathrm{H})(\mathrm{H}) \mathrm{Cl})(\mathrm{H}) \mathrm{Cl})($

$\mathrm{H}) \mathrm{H})(\mathrm{H}) \mathrm{H})(\mathrm{H})(\mathrm{Cl}) \mathrm{H}$

$\mathrm{C}(\mathrm{C}(\mathrm{C}(\mathrm{C}(\mathrm{C}(\mathrm{C}(\mathrm{C}(\mathrm{C}(\mathrm{C}(\mathrm{C}(\mathrm{C}(\mathrm{C}(\mathrm{C}(\mathrm{C}(\mathrm{F})(\mathrm{Br}) \mathrm{H})(\mathrm{H}) \mathrm{H})(\mathrm{H}) \mathrm{H})(\mathrm{H}) \mathrm{H})(\mathrm{H}) \mathrm{H})(\mathrm{H}) \mathrm{H})(\mathrm{H}) \mathrm{Br})(\mathrm{H}) \mathrm{H})(\mathrm{H}) \mathrm{H})(\mathrm{H}) \mathrm{H})(\mathrm{H}) \mathrm{H})(\mathrm{H})$ $\mathrm{H})(\mathrm{H}) \mathrm{H})(\mathrm{Br})(\mathrm{F}) \mathrm{Cl}$

$\mathrm{C}(\mathrm{C}(\mathrm{C}(\mathrm{C}(\mathrm{C}(\mathrm{C}(\mathrm{C}(\mathrm{C}(\mathrm{C}(\mathrm{C}(\mathrm{C}(\mathrm{C}(\mathrm{C}(\mathrm{C}(\mathrm{H})(\mathrm{F}) \mathrm{H})(\mathrm{H}) \mathrm{H})(\mathrm{H}) \mathrm{H})(\mathrm{H}) \mathrm{H})(\mathrm{H}) \mathrm{H})(\mathrm{H}) \mathrm{H})(\mathrm{H}) \mathrm{H})(\mathrm{H}) \mathrm{H})(\mathrm{Cl}) \mathrm{H})(\mathrm{Br}) \mathrm{H})(\mathrm{H}) \mathrm{H})(\mathrm{H})$ $\mathrm{H})(\mathrm{H}) \mathrm{Br})(\mathrm{H})(\mathrm{Br}) \mathrm{Br}$

$\mathrm{C}(\mathrm{C}(\mathrm{C}(\mathrm{C}(\mathrm{C}(\mathrm{C}(\mathrm{C}(\mathrm{C}(\mathrm{C}(\mathrm{C}(\mathrm{C}(\mathrm{C}(\mathrm{C}(\mathrm{C}(\mathrm{H})(\mathrm{H}) \mathrm{H})(\mathrm{Br}) \mathrm{H})(\mathrm{H}) \mathrm{H})(\mathrm{H}) \mathrm{Br})(\mathrm{H}) \mathrm{H})(\mathrm{H}) \mathrm{H})(\mathrm{H}) \mathrm{H})(\mathrm{H}) \mathrm{H})(\mathrm{H}) \mathrm{Br})(\mathrm{H}) \mathrm{H})(\mathrm{H}) \mathrm{Cl})($

$\mathrm{H}) \mathrm{H})(\mathrm{H}) \mathrm{H})(\mathrm{Br})(\mathrm{Br}) \mathrm{H}$

$\mathrm{C}(\mathrm{C}(\mathrm{C}(\mathrm{C}(\mathrm{C}(\mathrm{C}(\mathrm{C}(\mathrm{C}(\mathrm{C}(\mathrm{C}(\mathrm{C}(\mathrm{C}(\mathrm{C}(\mathrm{C}(\mathrm{H})(\mathrm{H}) \mathrm{F})(\mathrm{H}) \mathrm{H})(\mathrm{H}) \mathrm{H})(\mathrm{H}) \mathrm{H})(\mathrm{Br}) \mathrm{H})(\mathrm{H}) \mathrm{H})(\mathrm{H}) \mathrm{H})(\mathrm{H}) \mathrm{H})(\mathrm{H}) \mathrm{F})(\mathrm{H}) \mathrm{H})(\mathrm{H}) \mathrm{H})(\mathrm{H})$

$\mathrm{Br})(\mathrm{H}) \mathrm{H})(\mathrm{H})(\mathrm{Br}) \mathrm{H}$

$\mathrm{C}(\mathrm{C}(\mathrm{C}(\mathrm{C}(\mathrm{C}(\mathrm{C}(\mathrm{C}(\mathrm{C}(\mathrm{C}(\mathrm{C}(\mathrm{C}(\mathrm{C}(\mathrm{C}(\mathrm{C}(\mathrm{H})(\mathrm{H}) \mathrm{H})(\mathrm{H}) \mathrm{H})(\mathrm{Br}) \mathrm{H})(\mathrm{H}) \mathrm{H})(\mathrm{H}) \mathrm{H})(\mathrm{H}) \mathrm{H})(\mathrm{H}) \mathrm{H})(\mathrm{H}) \mathrm{Br})(\mathrm{F}) \mathrm{Br})(\mathrm{H}) \mathrm{H})(\mathrm{H}) \mathrm{H})$

$(\mathrm{H}) \mathrm{H})(\mathrm{H}) \mathrm{H})(\mathrm{H})(\mathrm{Br}) \mathrm{H}$

$\mathrm{C}(\mathrm{C}(\mathrm{C}(\mathrm{C}(\mathrm{C}(\mathrm{C}(\mathrm{C}(\mathrm{C}(\mathrm{C}(\mathrm{C}(\mathrm{C}(\mathrm{C}(\mathrm{C}(\mathrm{C}(\mathrm{H})(\mathrm{H}) \mathrm{H})(\mathrm{H}) \mathrm{H})(\mathrm{H}) \mathrm{H})(\mathrm{H}) \mathrm{H})(\mathrm{Br}) \mathrm{H})(\mathrm{Br}) \mathrm{H})(\mathrm{H}) \mathrm{H})(\mathrm{H}) \mathrm{H})(\mathrm{H}) \mathrm{Br})(\mathrm{H}) \mathrm{H})(\mathrm{H}) \mathrm{H})($ $\mathrm{H}) \mathrm{Br})(\mathrm{H}) \mathrm{H})(\mathrm{H})(\mathrm{H}) \mathrm{Br}$

$\mathrm{C}(\mathrm{C}(\mathrm{C}(\mathrm{C}(\mathrm{C}(\mathrm{C}(\mathrm{C}(\mathrm{C}(\mathrm{C}(\mathrm{C}(\mathrm{C}(\mathrm{C}(\mathrm{C}(\mathrm{C}(\mathrm{H})(\mathrm{H}) \mathrm{H})(\mathrm{H}) \mathrm{H})(\mathrm{H}) \mathrm{F})(\mathrm{H}) \mathrm{H})(\mathrm{H}) \mathrm{H})(\mathrm{H}) \mathrm{H})(\mathrm{Cl}) \mathrm{H})(\mathrm{H}) \mathrm{H})(\mathrm{H}) \mathrm{H})(\mathrm{H}) \mathrm{H})(\mathrm{H}) \mathrm{Br})(\mathrm{H})$ $\mathrm{H})(\mathrm{Cl}) \mathrm{H})(\mathrm{Br})(\mathrm{H}) \mathrm{H}$

$\mathrm{C}(\mathrm{C}(\mathrm{C}(\mathrm{C}(\mathrm{C}(\mathrm{C}(\mathrm{C}(\mathrm{C}(\mathrm{C}(\mathrm{C}(\mathrm{C}(\mathrm{C}(\mathrm{C}(\mathrm{C}(\mathrm{H})(\mathrm{H}) \mathrm{H})(\mathrm{H}) \mathrm{H})(\mathrm{H}) \mathrm{H})(\mathrm{H}) \mathrm{Cl})(\mathrm{H}) \mathrm{H})(\mathrm{H}) \mathrm{Cl})(\mathrm{H}) \mathrm{H})(\mathrm{F}) \mathrm{Br})(\mathrm{H}) \mathrm{H})(\mathrm{H}) \mathrm{H})(\mathrm{H}) \mathrm{H})(\mathrm{H})$

$\mathrm{H})(\mathrm{Cl}) \mathrm{H})(\mathrm{H})(\mathrm{H}) \mathrm{H}$

$\mathrm{C}(\mathrm{C}(\mathrm{C}(\mathrm{C}(\mathrm{C}(\mathrm{C}(\mathrm{C}(\mathrm{C}(\mathrm{C}(\mathrm{C}(\mathrm{C}(\mathrm{C}(\mathrm{C}(\mathrm{C}(\mathrm{H})(\mathrm{Cl}) \mathrm{H})(\mathrm{H}) \mathrm{H})(\mathrm{H}) \mathrm{H})(\mathrm{H}) \mathrm{H})(\mathrm{Cl}) \mathrm{H})(\mathrm{H}) \mathrm{Cl})(\mathrm{H}) \mathrm{H})(\mathrm{H}) \mathrm{H})(\mathrm{H}) \mathrm{Cl})(\mathrm{Cl}) \mathrm{H})(\mathrm{H}) \mathrm{H})($

$\mathrm{H}) \mathrm{H})(\mathrm{H}) \mathrm{H})(\mathrm{H})(\mathrm{H}) \mathrm{H}$

$\mathrm{C}(\mathrm{C}(\mathrm{C}(\mathrm{C}(\mathrm{C}(\mathrm{C}(\mathrm{C}(\mathrm{C}(\mathrm{C}(\mathrm{C}(\mathrm{C}(\mathrm{C}(\mathrm{C}(\mathrm{C}(\mathrm{H})(\mathrm{H}) \mathrm{H})(\mathrm{H}) \mathrm{H})(\mathrm{H}) \mathrm{F})(\mathrm{H}) \mathrm{Cl})(\mathrm{H}) \mathrm{H})(\mathrm{Br}) \mathrm{H})(\mathrm{H}) \mathrm{H})(\mathrm{H}) \mathrm{H})(\mathrm{H}) \mathrm{F})(\mathrm{H}) \mathrm{H})(\mathrm{H}) \mathrm{H})(\mathrm{H})$

$\mathrm{H})(\mathrm{Br}) \mathrm{H})(\mathrm{H})(\mathrm{H}) \mathrm{H}$

$\mathrm{C}(\mathrm{C}(\mathrm{C}(\mathrm{C}(\mathrm{C}(\mathrm{C}(\mathrm{C}(\mathrm{C}(\mathrm{C}(\mathrm{C}(\mathrm{C}(\mathrm{C}(\mathrm{C}(\mathrm{C}(\mathrm{H})(\mathrm{H}) \mathrm{H})(\mathrm{H}) \mathrm{H})(\mathrm{H}) \mathrm{H})(\mathrm{H}) \mathrm{H})(\mathrm{H}) \mathrm{H})(\mathrm{H}) \mathrm{H})(\mathrm{H}) \mathrm{H})(\mathrm{H}) \mathrm{H})(\mathrm{Br}) \mathrm{H})(\mathrm{Br}) \mathrm{H})(\mathrm{H}) \mathrm{Br})$

$(\mathrm{F}) \mathrm{Cl}(\mathrm{H}) \mathrm{H})(\mathrm{H})(\mathrm{H}) \mathrm{H}$

$\mathrm{C}(\mathrm{C}(\mathrm{C}(\mathrm{C}(\mathrm{C}(\mathrm{C}(\mathrm{C}(\mathrm{C}(\mathrm{C}(\mathrm{C}(\mathrm{C}(\mathrm{C}(\mathrm{C}(\mathrm{C}(\mathrm{H})(\mathrm{H}) \mathrm{H})(\mathrm{Br}) \mathrm{H})(\mathrm{H}) \mathrm{H})(\mathrm{H}) \mathrm{H})(\mathrm{Br}) \mathrm{H})(\mathrm{H}) \mathrm{H})(\mathrm{Br}) \mathrm{H})(\mathrm{H}) \mathrm{H})(\mathrm{H}) \mathrm{H})(\mathrm{Cl}) \mathrm{H})(\mathrm{H}) \mathrm{H})($

$\mathrm{Br}) \mathrm{H})(\mathrm{H}) \mathrm{H})(\mathrm{H})(\mathrm{H}) \mathrm{H}$

$\mathrm{C}(\mathrm{C}(\mathrm{C}(\mathrm{C}(\mathrm{C}(\mathrm{C}(\mathrm{C}(\mathrm{C}(\mathrm{C}(\mathrm{C}(\mathrm{C}(\mathrm{C}(\mathrm{C}(\mathrm{C}(\mathrm{H})(\mathrm{H}) \mathrm{Br})(\mathrm{H}) \mathrm{F})(\mathrm{H}) \mathrm{H})(\mathrm{H}) \mathrm{H})(\mathrm{H}) \mathrm{H})(\mathrm{H}) \mathrm{H})(\mathrm{H}) \mathrm{H})(\mathrm{H}) \mathrm{H})(\mathrm{H}) \mathrm{H})(\mathrm{H}) \mathrm{H})(\mathrm{H}) \mathrm{H})(\mathrm{H})$

$\mathrm{Br})(\mathrm{Br}) \mathrm{H})(\mathrm{H})(\mathrm{H}) \mathrm{H}$

$\mathrm{C}(\mathrm{C}(\mathrm{C}(\mathrm{C}(\mathrm{C}(\mathrm{C}(\mathrm{C}(\mathrm{C}(\mathrm{C}(\mathrm{C}(\mathrm{C}(\mathrm{C}(\mathrm{C}(\mathrm{C}(\mathrm{H})(\mathrm{Br}) \mathrm{H})(\mathrm{H}) \mathrm{H})(\mathrm{H}) \mathrm{H})(\mathrm{H}) \mathrm{H})(\mathrm{Br}) \mathrm{H})(\mathrm{H}) \mathrm{H})(\mathrm{H}) \mathrm{H})(\mathrm{H}) \mathrm{H})(\mathrm{H}) \mathrm{H})(\mathrm{Br}) \mathrm{H})(\mathrm{H}) \mathrm{H})($ $\mathrm{H}) \mathrm{H})(\mathrm{H}) \mathrm{H})(\mathrm{H})(\mathrm{H}) \mathrm{Br}$

$\mathrm{C}(\mathrm{C}(\mathrm{C}(\mathrm{C}(\mathrm{C}(\mathrm{C}(\mathrm{C}(\mathrm{C}(\mathrm{C}(\mathrm{C}(\mathrm{C}(\mathrm{C}(\mathrm{C}(\mathrm{C}(\mathrm{Cl})(\mathrm{H}) \mathrm{H})(\mathrm{H}) \mathrm{Br})(\mathrm{H}) \mathrm{H})(\mathrm{H}) \mathrm{H})(\mathrm{H}) \mathrm{H})(\mathrm{H}) \mathrm{H})(\mathrm{H}) \mathrm{Cl})(\mathrm{H}) \mathrm{Br})(\mathrm{H}) \mathrm{H})(\mathrm{H}) \mathrm{H})(\mathrm{H}) \mathrm{H})($ $\mathrm{H}) \mathrm{H})(\mathrm{H}) \mathrm{H})(\mathrm{H})(\mathrm{H}) \mathrm{H}$

$\mathrm{C}(\mathrm{C}(\mathrm{C}(\mathrm{C}(\mathrm{C}(\mathrm{C}(\mathrm{C}(\mathrm{C}(\mathrm{C}(\mathrm{C}(\mathrm{C}(\mathrm{C}(\mathrm{C}(\mathrm{C}(\mathrm{H})(\mathrm{H}) \mathrm{H})(\mathrm{H}) \mathrm{Br})(\mathrm{H}) \mathrm{H})(\mathrm{H}) \mathrm{H})(\mathrm{H}) \mathrm{Cl})(\mathrm{H}) \mathrm{H})(\mathrm{H}) \mathrm{Cl})(\mathrm{H}) \mathrm{H})(\mathrm{H}) \mathrm{H})(\mathrm{H}) \mathrm{H})(\mathrm{H}) \mathrm{H})$

$(\mathrm{Cl}) \mathrm{H})(\mathrm{H}) \mathrm{H})(\mathrm{H})(\mathrm{H}) \mathrm{H}$

$\mathrm{C}(\mathrm{C}(\mathrm{C}(\mathrm{C}(\mathrm{C}(\mathrm{C}(\mathrm{C}(\mathrm{C}(\mathrm{C}(\mathrm{C}(\mathrm{C}(\mathrm{C}(\mathrm{C}(\mathrm{C}(\mathrm{Cl})(\mathrm{H}) \mathrm{H})(\mathrm{H}) \mathrm{H})(\mathrm{Cl}) \mathrm{Cl})(\mathrm{H}) \mathrm{H})(\mathrm{H}) \mathrm{H})(\mathrm{H}) \mathrm{H})(\mathrm{H}) \mathrm{H})(\mathrm{H}) \mathrm{H})(\mathrm{H}) \mathrm{H})(\mathrm{H}) \mathrm{H})(\mathrm{Cl}) \mathrm{H})$

$(\mathrm{H}) \mathrm{H})(\mathrm{H}) \mathrm{H})(\mathrm{H})(\mathrm{H}) \mathrm{H}$

$\mathrm{C}(\mathrm{C}(\mathrm{C}(\mathrm{C}(\mathrm{C}(\mathrm{C}(\mathrm{C}(\mathrm{C}(\mathrm{C}(\mathrm{C}(\mathrm{C}(\mathrm{C}(\mathrm{C}(\mathrm{C}(\mathrm{H})(\mathrm{H}) \mathrm{F})(\mathrm{H}) \mathrm{H})(\mathrm{H}) \mathrm{Br})(\mathrm{H}) \mathrm{H})(\mathrm{H}) \mathrm{H})(\mathrm{H}) \mathrm{H})(\mathrm{H}) \mathrm{H})(\mathrm{H}) \mathrm{H})(\mathrm{Cl}) \mathrm{H})(\mathrm{H}) \mathrm{H})(\mathrm{H}) \mathrm{H})(\mathrm{H})$ $\mathrm{H})(\mathrm{H}) \mathrm{H})(\mathrm{H})(\mathrm{Br}) \mathrm{H}$

$\mathrm{C}(\mathrm{C}(\mathrm{C}(\mathrm{C}(\mathrm{C}(\mathrm{C}(\mathrm{C}(\mathrm{C}(\mathrm{C}(\mathrm{C}(\mathrm{C}(\mathrm{C}(\mathrm{C}(\mathrm{C}(\mathrm{H})(\mathrm{H}) \mathrm{H})(\mathrm{Cl}) \mathrm{H})(\mathrm{Br}) \mathrm{H})(\mathrm{H}) \mathrm{H})(\mathrm{H}) \mathrm{H})(\mathrm{H}) \mathrm{H})(\mathrm{H}) \mathrm{H})(\mathrm{Br}) \mathrm{H})(\mathrm{H}) \mathrm{H})(\mathrm{H}) \mathrm{H})(\mathrm{H}) \mathrm{H})$ $(\mathrm{H}) \mathrm{H})(\mathrm{H}) \mathrm{Br})(\mathrm{H})(\mathrm{H}) \mathrm{H}$

$\mathrm{C}(\mathrm{C}(\mathrm{C}(\mathrm{C}(\mathrm{C}(\mathrm{C}(\mathrm{C}(\mathrm{C}(\mathrm{C}(\mathrm{C}(\mathrm{C}(\mathrm{C}(\mathrm{C}(\mathrm{C}(\mathrm{H})(\mathrm{H}) \mathrm{H})(\mathrm{H}) \mathrm{H})(\mathrm{H}) \mathrm{H})(\mathrm{H}) \mathrm{H})(\mathrm{H}) \mathrm{Br})(\mathrm{H}) \mathrm{H})(\mathrm{H}) \mathrm{H})(\mathrm{H}) \mathrm{H})(\mathrm{H}) \mathrm{H})(\mathrm{H}) \mathrm{H})(\mathrm{Br}) \mathrm{H})$ $(\mathrm{H}) \mathrm{H})(\mathrm{H}) \mathrm{Br})(\mathrm{H})(\mathrm{H}) \mathrm{H}$

$\mathrm{C}(\mathrm{C}(\mathrm{C}(\mathrm{C}(\mathrm{C}(\mathrm{C}(\mathrm{C}(\mathrm{C}(\mathrm{C}(\mathrm{C}(\mathrm{C}(\mathrm{C}(\mathrm{C}(\mathrm{C}(\mathrm{H})(\mathrm{H}) \mathrm{H})(\mathrm{H}) \mathrm{H})(\mathrm{H}) \mathrm{H})(\mathrm{H}) \mathrm{H})(\mathrm{H}) \mathrm{Cl})(\mathrm{Cl}) \mathrm{H})(\mathrm{H}) \mathrm{H})(\mathrm{Br}) \mathrm{H})(\mathrm{H}) \mathrm{H})(\mathrm{H}) \mathrm{H})(\mathrm{H}) \mathrm{H})$

$(\mathrm{H}) \mathrm{H})(\mathrm{H}) \mathrm{H})(\mathrm{H})(\mathrm{H}) \mathrm{H}$

$\mathrm{C}(\mathrm{C}(\mathrm{C}(\mathrm{C}(\mathrm{C}(\mathrm{C}(\mathrm{C}(\mathrm{C}(\mathrm{C}(\mathrm{C}(\mathrm{C}(\mathrm{C}(\mathrm{C}(\mathrm{C}(\mathrm{H})(\mathrm{H}) \mathrm{H})(\mathrm{H}) \mathrm{H})(\mathrm{H}) \mathrm{H})(\mathrm{Br}) \mathrm{H})(\mathrm{H}) \mathrm{H})(\mathrm{H}) \mathrm{H})(\mathrm{H}) \mathrm{H})(\mathrm{H}) \mathrm{H})(\mathrm{H}) \mathrm{H})(\mathrm{Br}) \mathrm{H})(\mathrm{H}) \mathrm{H})$

$(\mathrm{H}) \mathrm{H})(\mathrm{H}) \mathrm{H})(\mathrm{H})(\mathrm{H}) \mathrm{Cl}$

$\mathrm{C}(\mathrm{C}(\mathrm{C}(\mathrm{C}(\mathrm{C}(\mathrm{C}(\mathrm{C}(\mathrm{C}(\mathrm{C}(\mathrm{C}(\mathrm{C}(\mathrm{C}(\mathrm{C}(\mathrm{C}(\mathrm{H})(\mathrm{H}) \mathrm{H})(\mathrm{H}) \mathrm{H})(\mathrm{H}) \mathrm{H})(\mathrm{H}) \mathrm{H})(\mathrm{H}) \mathrm{H})(\mathrm{H}) \mathrm{H})(\mathrm{H}) \mathrm{H})(\mathrm{Br}) \mathrm{H})(\mathrm{H}) \mathrm{H})(\mathrm{H}) \mathrm{H})(\mathrm{H}) \mathrm{H})(\mathrm{H})$

$\mathrm{Br})(\mathrm{H}) \mathrm{H})(\mathrm{H})(\mathrm{H}) \mathrm{H}$

$\mathrm{C}(\mathrm{C}(\mathrm{C}(\mathrm{C}(\mathrm{C}(\mathrm{C}(\mathrm{C}(\mathrm{C}(\mathrm{C}(\mathrm{C}(\mathrm{C}(\mathrm{C}(\mathrm{C}(\mathrm{C}(\mathrm{H})(\mathrm{Cl}) \mathrm{H})(\mathrm{H}) \mathrm{F})(\mathrm{H}) \mathrm{Br})(\mathrm{H}) \mathrm{H})(\mathrm{H}) \mathrm{Br})(\mathrm{H}) \mathrm{Cl})(\mathrm{Cl}) \mathrm{H})(\mathrm{F}) \mathrm{H})(\mathrm{F}) \mathrm{H})(\mathrm{H}) \mathrm{Br})(\mathrm{H}) \mathrm{F})(\mathrm{C}$ l) $\mathrm{H})(\mathrm{F}) \mathrm{H})(\mathrm{C}(\mathrm{Cl})(\mathrm{H}) \mathrm{F})(\mathrm{H}) \mathrm{F}$

$\mathrm{C}(\mathrm{C}(\mathrm{C}(\mathrm{C}(\mathrm{C}(\mathrm{C}(\mathrm{C}(\mathrm{C}(\mathrm{C}(\mathrm{C}(\mathrm{C}(\mathrm{C}(\mathrm{C}(\mathrm{C}(\mathrm{F})(\mathrm{H}) \mathrm{Br})(\mathrm{H}) \mathrm{F})(\mathrm{Br}) \mathrm{H})(\mathrm{H}) \mathrm{Cl})(\mathrm{Cl}) \mathrm{H})(\mathrm{H}) \mathrm{Br})(\mathrm{H}) \mathrm{H})(\mathrm{H}) \mathrm{F})(\mathrm{H}) \mathrm{Cl})(\mathrm{Cl}) \mathrm{H})(\mathrm{H}) \mathrm{H})($ $\mathrm{H}) \mathrm{H})(\mathrm{H}) \mathrm{F})(\mathrm{C}(\mathrm{Cl})(\mathrm{H}) \mathrm{F})(\mathrm{H}) \mathrm{F}$

$\mathrm{C}(\mathrm{C}(\mathrm{C}(\mathrm{C}(\mathrm{C}(\mathrm{C}(\mathrm{C}(\mathrm{C}(\mathrm{C}(\mathrm{C}(\mathrm{C}(\mathrm{C}(\mathrm{C}(\mathrm{C}(\mathrm{H})(\mathrm{Br}) \mathrm{H})(\mathrm{H}) \mathrm{F})(\mathrm{F}) \mathrm{H})(\mathrm{H}) \mathrm{Br})(\mathrm{H}) \mathrm{H})(\mathrm{F}) \mathrm{H})(\mathrm{H}) \mathrm{H})(\mathrm{F}) \mathrm{H})(\mathrm{H}) \mathrm{H})(\mathrm{F}) \mathrm{F})(\mathrm{H}) \mathrm{H})(\mathrm{F}) \mathrm{H})$

$(\mathrm{Br}) \mathrm{H})(\mathrm{C}(\mathrm{Br})(\mathrm{Br}) \mathrm{H})(\mathrm{F}) \mathrm{H}$

$\mathrm{C}(\mathrm{C}(\mathrm{C}(\mathrm{C}(\mathrm{C}(\mathrm{C}(\mathrm{C}(\mathrm{C}(\mathrm{C}(\mathrm{C}(\mathrm{C}(\mathrm{C}(\mathrm{C}(\mathrm{C}(\mathrm{Br})(\mathrm{H}) \mathrm{H})(\mathrm{H}) \mathrm{H})(\mathrm{H}) \mathrm{Cl})(\mathrm{H}) \mathrm{H})(\mathrm{Br}) \mathrm{F})(\mathrm{F}) \mathrm{H})(\mathrm{H}) \mathrm{H})(\mathrm{H}) \mathrm{Br})(\mathrm{H}) \mathrm{H})(\mathrm{H}) \mathrm{H})(\mathrm{F}) \mathrm{H})(\mathrm{F})$ $\mathrm{H})(\mathrm{F}) \mathrm{H})(\mathrm{C}(\mathrm{F})(\mathrm{F}) \mathrm{H})(\mathrm{Br}) \mathrm{H}$

C(C(C(C(C(C(C(C(C(C(C(C(C(C(H)(H)Br)(Br)H)(H)H)(H)F)(Br)H)(F)H)(Br)H)(Br)H)(H)H)(H)H)(H)F) $(\mathrm{F}) \mathrm{H})(\mathrm{H}) \mathrm{H})(\mathrm{C}(\mathrm{H})(\mathrm{Br}) \mathrm{H})(\mathrm{H}) \mathrm{H}$

$\mathrm{C}(\mathrm{C}(\mathrm{C}(\mathrm{C}(\mathrm{C}(\mathrm{C}(\mathrm{C}(\mathrm{C}(\mathrm{C}(\mathrm{C}(\mathrm{C}(\mathrm{C}(\mathrm{C}(\mathrm{C}(\mathrm{H})(\mathrm{F}) \mathrm{H})(\mathrm{Cl}) \mathrm{H})(\mathrm{H}) \mathrm{F})(\mathrm{H}) \mathrm{H})(\mathrm{Br}) \mathrm{H})(\mathrm{H}) \mathrm{Br})(\mathrm{H}) \mathrm{H})(\mathrm{F}) \mathrm{H})(\mathrm{H}) \mathrm{F})(\mathrm{H}) \mathrm{H})(\mathrm{H}) \mathrm{H})(\mathrm{F})$ $\mathrm{H})(\mathrm{H}) \mathrm{H})(\mathrm{C}(\mathrm{Br})(\mathrm{Cl}) \mathrm{H})(\mathrm{H}) \mathrm{H}$

$\mathrm{C}(\mathrm{C}(\mathrm{C}(\mathrm{C}(\mathrm{C}(\mathrm{C}(\mathrm{C}(\mathrm{C}(\mathrm{C}(\mathrm{C}(\mathrm{C}(\mathrm{C}(\mathrm{C}(\mathrm{C}(\mathrm{F})(\mathrm{H}) \mathrm{H})(\mathrm{Cl}) \mathrm{H})(\mathrm{F}) \mathrm{H})(\mathrm{H}) \mathrm{H})(\mathrm{H}) \mathrm{H})(\mathrm{H}) \mathrm{H})(\mathrm{F}) \mathrm{H})(\mathrm{Cl}) \mathrm{H})(\mathrm{H}) \mathrm{H})(\mathrm{H}) \mathrm{H})(\mathrm{Br}) \mathrm{H})(\mathrm{H})$

$\mathrm{Cl}(\mathrm{H}) \mathrm{H})(\mathrm{C}(\mathrm{F})(\mathrm{Cl}) \mathrm{H})(\mathrm{Cl}) \mathrm{H}$

$\mathrm{C}(\mathrm{C}(\mathrm{C}(\mathrm{C}(\mathrm{C}(\mathrm{C}(\mathrm{C}(\mathrm{C}(\mathrm{C}(\mathrm{C}(\mathrm{C}(\mathrm{C}(\mathrm{C}(\mathrm{C}(\mathrm{H})(\mathrm{H}) \mathrm{H})(\mathrm{H}) \mathrm{Cl})(\mathrm{Cl}) \mathrm{H})(\mathrm{H}) \mathrm{H})(\mathrm{H}) \mathrm{H})(\mathrm{H}) \mathrm{H})(\mathrm{F}) \mathrm{H})(\mathrm{H}) \mathrm{H})(\mathrm{H}) \mathrm{Cl})(\mathrm{Br}) \mathrm{H})(\mathrm{F}) \mathrm{H})(\mathrm{H})$ $\mathrm{H})(\mathrm{Cl}) \mathrm{H})(\mathrm{C}(\mathrm{H})(\mathrm{Cl}) \mathrm{F})(\mathrm{Cl}) \mathrm{H}$

$\mathrm{C}(\mathrm{C}(\mathrm{C}(\mathrm{C}(\mathrm{C}(\mathrm{C}(\mathrm{C}(\mathrm{C}(\mathrm{C}(\mathrm{C}(\mathrm{C}(\mathrm{C}(\mathrm{C}(\mathrm{C}(\mathrm{Br})(\mathrm{H}) \mathrm{H})(\mathrm{F}) \mathrm{H})(\mathrm{H}) \mathrm{H})(\mathrm{H}) \mathrm{H})(\mathrm{H}) \mathrm{H})(\mathrm{F}) \mathrm{H})(\mathrm{H}) \mathrm{Br})(\mathrm{Br}) \mathrm{H})(\mathrm{H}) \mathrm{Br})(\mathrm{H}) \mathrm{H})(\mathrm{H}) \mathrm{H})$ $(\mathrm{H}) \mathrm{H})(\mathrm{F}) \mathrm{H})(\mathrm{C}(\mathrm{F})(\mathrm{H}) \mathrm{H})(\mathrm{H}) \mathrm{F}$

$\mathrm{C}(\mathrm{C}(\mathrm{C}(\mathrm{C}(\mathrm{C}(\mathrm{C}(\mathrm{C}(\mathrm{C}(\mathrm{C}(\mathrm{C}(\mathrm{C}(\mathrm{C}(\mathrm{C}(\mathrm{C}(\mathrm{Br})(\mathrm{H}) \mathrm{H})(\mathrm{H}) \mathrm{Br})(\mathrm{F}) \mathrm{H})(\mathrm{H}) \mathrm{F})(\mathrm{H}) \mathrm{H})(\mathrm{H}) \mathrm{H})(\mathrm{Br}) \mathrm{H})(\mathrm{H}) \mathrm{H})(\mathrm{Br}) \mathrm{H})(\mathrm{H}) \mathrm{H})(\mathrm{F}) \mathrm{H})$ $(\mathrm{H}) \mathrm{H})(\mathrm{H}) \mathrm{H})(\mathrm{C}(\mathrm{H})(\mathrm{H}) \mathrm{F})(\mathrm{Br}) \mathrm{H}$

$\mathrm{C}(\mathrm{C}(\mathrm{C}(\mathrm{C}(\mathrm{C}(\mathrm{C}(\mathrm{C}(\mathrm{C}(\mathrm{C}(\mathrm{C}(\mathrm{C}(\mathrm{C}(\mathrm{C}(\mathrm{C}(\mathrm{H})(\mathrm{H}) \mathrm{F})(\mathrm{H}) \mathrm{H})(\mathrm{H}) \mathrm{H})(\mathrm{H}) \mathrm{H})(\mathrm{H}) \mathrm{H})(\mathrm{H}) \mathrm{Br})(\mathrm{H}) \mathrm{H})(\mathrm{H}) \mathrm{F})(\mathrm{H}) \mathrm{H})(\mathrm{Br}) \mathrm{H})(\mathrm{F}) \mathrm{H})(\mathrm{H})$ $\mathrm{H})(\mathrm{H}) \mathrm{Cl})(\mathrm{C}(\mathrm{F})(\mathrm{Br}) \mathrm{H})(\mathrm{Cl}) \mathrm{H}$

$\mathrm{C}(\mathrm{C}(\mathrm{C}(\mathrm{C}(\mathrm{C}(\mathrm{C}(\mathrm{C}(\mathrm{C}(\mathrm{C}(\mathrm{C}(\mathrm{C}(\mathrm{C}(\mathrm{C}(\mathrm{C}(\mathrm{H})(\mathrm{H}) \mathrm{H})(\mathrm{F}) \mathrm{H})(\mathrm{H}) \mathrm{H})(\mathrm{H}) \mathrm{F})(\mathrm{H}) \mathrm{H})(\mathrm{F}) \mathrm{H})(\mathrm{H}) \mathrm{Br})(\mathrm{H}) \mathrm{H})(\mathrm{H}) \mathrm{H})(\mathrm{Br}) \mathrm{H})(\mathrm{H}) \mathrm{Br})(\mathrm{F})$

$\mathrm{H})(\mathrm{H}) \mathrm{F})(\mathrm{C}(\mathrm{H})(\mathrm{H}) \mathrm{H})(\mathrm{H}) \mathrm{Cl}$

$\mathrm{C}(\mathrm{C}(\mathrm{C}(\mathrm{C}(\mathrm{C}(\mathrm{C}(\mathrm{C}(\mathrm{C}(\mathrm{C}(\mathrm{C}(\mathrm{C}(\mathrm{C}(\mathrm{C}(\mathrm{C}(\mathrm{H})(\mathrm{H}) \mathrm{Cl})(\mathrm{H}) \mathrm{H})(\mathrm{H}) \mathrm{H})(\mathrm{H}) \mathrm{Cl})(\mathrm{H}) \mathrm{H})(\mathrm{H}) \mathrm{H})(\mathrm{Br}) \mathrm{H})(\mathrm{H}) \mathrm{H})(\mathrm{H}) \mathrm{F})(\mathrm{H}) \mathrm{H})(\mathrm{H}) \mathrm{H})(\mathrm{F})$ $\mathrm{H})(\mathrm{H}) \mathrm{H})(\mathrm{C}(\mathrm{F})(\mathrm{Br}) \mathrm{H})(\mathrm{H}) \mathrm{B}$
$\mathrm{C} 14 \mathrm{H} 24 \mathrm{Cl} 3 \mathrm{BrF}$

$\mathrm{C} 14 \mathrm{H} 24 \mathrm{Cl} 14 \mathrm{Br}$

$\mathrm{C} 14 \mathrm{H} 24 \mathrm{Cl} 4 \mathrm{BrF}$

$\mathrm{C} 14 \mathrm{H} 24 \mathrm{Cl} 5 \mathrm{Br}$

$\mathrm{C} 14 \mathrm{H} 24 \mathrm{Cl} 5 \mathrm{~F}$

C14H24Cl6

C14H $24 \mathrm{ClBr} 3 \mathrm{~F} 2$

$\mathrm{C} 14 \mathrm{H} 24 \mathrm{ClBr} 4 \mathrm{~F}$

$\mathrm{C} 14 \mathrm{H} 24 \mathrm{ClBr} 5$

$\mathrm{C} 14 \mathrm{H} 25 \mathrm{Br} 3 \mathrm{~F} 2$

$\mathrm{C} 14 \mathrm{H} 25 \mathrm{Br} 4 \mathrm{~F}$

$14 \mathrm{H} 25 \mathrm{Br} 5$

$\mathrm{C} 14 \mathrm{H} 25 \mathrm{Cl} 2 \mathrm{Br} 2 \mathrm{~F}$

$\mathrm{C} 14 \mathrm{H} 25 \mathrm{Cl} 3 \mathrm{BrF}$

C14 $25 \mathrm{Cl} 5$

$\mathrm{C} 14 \mathrm{H} 25 \mathrm{ClBr} 2 \mathrm{~F} 2$

C14H25ClBr3F

$\mathrm{C} 14 \mathrm{H} 25 \mathrm{ClBr} 4$

$\mathrm{C} 14 \mathrm{H} 26 \mathrm{Br} 3 \mathrm{~F}$

C14H26Br4

$\mathrm{C} 14 \mathrm{H} 26 \mathrm{Cl} 2 \mathrm{Br} 2$

$\mathrm{C} 14 \mathrm{H} 26 \mathrm{Cl} 3 \mathrm{Br}$

$\mathrm{C} 14 \mathrm{H} 26 \mathrm{Cl} 4$

$\mathrm{C} 14 \mathrm{H} 26 \mathrm{ClBr} 2 \mathrm{~F}$

$14 \mathrm{H} 26 \mathrm{ClBr} 3$

$\mathrm{C} 14 \mathrm{H} 27 \mathrm{Br} 3$

$\mathrm{C} 14 \mathrm{H} 27 \mathrm{Cl} 2 \mathrm{Br}$

$\mathrm{C} 14 \mathrm{H} 27 \mathrm{ClBr} 2$

$\mathrm{C} 14 \mathrm{H} 28 \mathrm{Br} 2$

C15H17Cl5Br3F7

$\mathrm{C} 15 \mathrm{H} 18 \mathrm{Cl5Br} 3 \mathrm{~F} 6$

$\mathrm{C} 15 \mathrm{H} 19 \mathrm{Br} 5 \mathrm{~F} 8$

$15 \mathrm{H} 20 \mathrm{ClBr} 4 \mathrm{~F} 7$

C15H22Br6F4

$\mathrm{C} 15 \mathrm{H} 22 \mathrm{Cl} 2 \mathrm{Br} 3 \mathrm{~F} 5$

$\mathrm{C} 15 \mathrm{H} 22 \mathrm{Cl} 15 \mathrm{BrF} 4$

$\mathrm{C} 15 \mathrm{H} 22 \mathrm{Cl} 6 \mathrm{BrF} 3$

C15H23Br4F5

$\mathrm{C} 15 \mathrm{H} 23 \mathrm{Br} 5 \mathrm{~F} 4$

$\mathrm{C} 15 \mathrm{H} 23 \mathrm{Cl} 2 \mathrm{Br} 3 \mathrm{~F} 4$

$\mathrm{C} 15 \mathrm{H} 23 \mathrm{ClBr} 3 \mathrm{~F} 5$

C15H24C12Br3 3
lgKoa lgKow lgKaw loKow lgKoa lgKaw lgKow lgKoa lgKaw _EPI_EPI_EPI_Exp__Exp__Exp__DFT_DFT_DFT Suite Suite Suite corr corr corr_corr _corr corr

$\begin{array}{lllllllll}8.27 & 8.65 & 0.38 & 7.99 & 7.61 & 0.38 & 7.41 & 13.21 & -5.80\end{array}$

$\begin{array}{lllllllll}10.2 & 8.55 & -1.61 & 7.84 & 9.45 & -1.61 & 7.33 & 16.68 & -9.35\end{array}$

$\begin{array}{lllllllll}9.27 & 8.89 & -0.38 & 8.34 & 8.72 & -0.38 & 7.59 & 15.03 & -7.44\end{array}$

$\begin{array}{lllllllll}9.67 & 8.54 & -1.13 & 7.82 & 8.95 & -1.13 & 7.32 & 15.77 & -8.45\end{array}$

$\begin{array}{lllllllll}8.02 & 8.13 & 0.11 & 7.21 & 7.10 & 0.11 & 7.01 & 12.74 & -5.74\end{array}$

$\begin{array}{lllllllll}9.09 & 8.45 & -0.64 & 7.69 & 8.33 & -0.64 & 7.25 & 14.71 & -7.46\end{array}$

$\begin{array}{lllllllll}9.42 & 8.83 & -0.59 & 8.25 & 8.85 & -0.59 & 7.54 & 15.32 & -7.78\end{array}$

$\begin{array}{lllllllll}10.3 & 8.49 & -1.83 & 7.75 & 9.58 & -1.83 & 7.28 & 16.97 & -9.69\end{array}$

$\begin{array}{lllllllll}11.9 & 8.82 & -3.07 & 8.24 & 11.31 & -3.07 & 7.54 & 19.85 & -12.31\end{array}$

$\begin{array}{lllllllll}8.05 & 7.91 & -0.14 & 6.88 & 7.02 & -0.14 & 6.84 & 12.80 & -5.96\end{array}$

$\begin{array}{lllllllll}10.4 & 8.98 & -1.38 & 8.48 & 9.85 & -1.38 & 7.66 & 17.04 & -9.38\end{array}$

$\begin{array}{lllllllll}11.3 & 8.64 & -2.61 & 7.97 & 10.58 & -2.61 & 7.40 & 18.68 & -11.29\end{array}$

$\begin{array}{lllllllll}8.47 & 8.06 & -0.41 & 7.10 & 7.51 & -0.41 & 6.95 & 13.56 & -6.61\end{array}$

$\begin{array}{lllllllll}8.56 & 8.64 & 0.08 & 7.97 & 7.89 & 0.08 & 7.40 & 13.74 & -6.34\end{array}$

$\begin{array}{lllllllll}8.38 & 8.19 & -0.19 & 7.30 & 7.49 & -0.19 & 7.05 & 13.40 & -6.35\end{array}$

$\begin{array}{lllllllll}7.32 & 7.67 & 0.35 & 6.52 & 6.18 & 0.35 & 6.65 & 11.47 & -4.81\end{array}$

$\begin{array}{lllllllll}9.71 & 8.82 & -0.89 & 8.24 & 9.13 & -0.89 & 7.54 & 15.85 & -8.32\end{array}$

$\begin{array}{lllllllll}10.6 & 8.48 & -2.13 & 7.73 & 9.86 & -2.13 & 7.28 & 17.50 & -10.22\end{array}$

$\begin{array}{lllllllll}8.41 & 7.97 & -0.44 & 6.97 & 7.41 & -0.44 & 6.88 & 13.46 & -6.57\end{array}$

$\begin{array}{lllllllll}10.1 & 8.44 & -1.68 & 7.67 & 9.35 & -1.68 & 7.24 & 16.59 & -9.35\end{array}$

$\begin{array}{lllllllll}8.9 & 8.19 & -0.70 & 7.30 & 8.00 & -0.70 & 7.05 & 14.35 & -7.30\end{array}$

$\begin{array}{lllllllll}8.25 & 8.03 & -0.22 & 7.06 & 7.28 & -0.22 & 6.93 & 13.16 & -6.23\end{array}$

$\begin{array}{lllllllll}8.48 & 8.75 & 0.27 & 8.13 & 7.87 & 0.27 & 7.48 & 13.60 & -6.11\end{array}$

$\begin{array}{lllllllll}7.9 & 7.95 & 0.05 & 6.94 & 6.89 & 0.05 & 6.87 & 12.53 & -5.66\end{array}$

$\begin{array}{lllllllll}9.4 & 8.21 & -1.19 & 7.33 & 8.52 & -1.19 & 7.07 & 15.28 & -8.21\end{array}$

$\begin{array}{lllllllll}8.77 & 8.03 & -0.74 & 7.06 & 7.80 & -0.74 & 6.93 & 14.12 & -7.19\end{array}$

$\begin{array}{lllllllll}7.62 & 7.85 & 0.23 & 6.79 & 6.56 & 0.23 & 6.79 & 12.00 & -5.21\end{array}$

$\begin{array}{lllllllll}8.26 & 8.01 & -0.25 & 7.03 & 7.28 & -0.25 & 6.91 & 13.19 & -6.28\end{array}$

$\begin{array}{lllllllll}7.56 & 7.76 & 0.20 & 6.66 & 6.46 & 0.20 & 6.72 & 11.90 & -5.18\end{array}$

$\begin{array}{lllllllll}9.43 & 8.64 & -0.79 & 7.97 & 8.76 & -0.79 & 7.40 & 15.33 & -7.93\end{array}$

$\begin{array}{lllllllll}9.86 & 8.77 & -1.09 & 8.16 & 9.25 & -1.09 & 7.50 & 16.12 & -8.62\end{array}$

$\begin{array}{lllllllll}8.98 & 8.88 & -0.10 & 8.33 & 8.43 & -0.10 & 7.58 & 14.51 & -6.93\end{array}$

$\begin{array}{lllllllll}8.84 & 8.93 & 0.09 & 8.40 & 8.32 & 0.09 & 7.62 & 14.26 & -6.64\end{array}$

$\begin{array}{lllllllll}11.2 & 8.94 & -2.23 & 8.42 & 10.65 & -2.23 & 7.63 & 18.54 & -10.91\end{array}$

$\begin{array}{lllllllll}8.39 & 8.36 & -0.03 & 7.55 & 7.58 & -0.03 & 7.18 & 13.42 & -6.24\end{array}$

$\begin{array}{lllllllll}8.31 & 8.5 & 0.19 & 7.76 & 7.57 & 0.19 & 7.29 & 13.27 & -5.98\end{array}$

$\begin{array}{lllllllll}9.3 & 8.74 & -0.56 & 8.12 & 8.68 & -0.56 & 7.47 & 15.10 & -7.62\end{array}$

$\begin{array}{lllllllll}8.33 & 8.27 & -0.06 & 7.42 & 7.48 & -0.06 & 7.11 & 13.31 & -6.20\end{array}$

$\begin{array}{lllllllll}9.97 & 8.67 & -1.30 & 8.01 & 9.31 & -1.30 & 7.42 & 16.32 & -8.90\end{array}$

$\begin{array}{lllllllll}8.81 & 8.49 & -0.32 & 7.75 & 8.07 & -0.32 & 7.28 & 14.20 & -6.92\end{array}$

$\begin{array}{lllllllll}7.6 & 8.03 & 0.43 & 7.06 & 6.63 & 0.43 & 6.93 & 11.98 & -5.05\end{array}$

$\begin{array}{lllllllll}9.25 & 8.63 & -0.62 & 7.96 & 8.58 & -0.62 & 7.39 & 15.01 & -7.62\end{array}$ 
SMILE Generated

$\mathrm{C}(\mathrm{C}(\mathrm{C}(\mathrm{C}(\mathrm{C}(\mathrm{C}(\mathrm{C}(\mathrm{C}(\mathrm{C}(\mathrm{C}(\mathrm{C}(\mathrm{C}(\mathrm{C}(\mathrm{C}(\mathrm{Cl})(\mathrm{H}) \mathrm{Br})(\mathrm{H}) \mathrm{H})(\mathrm{F}) \mathrm{H})(\mathrm{Cl}) \mathrm{H})(\mathrm{F}) \mathrm{H})(\mathrm{F}) \mathrm{H})(\mathrm{Br}) \mathrm{H})(\mathrm{H}) \mathrm{Cl})(\mathrm{H}) \mathrm{H})(\mathrm{H}) \mathrm{H})(\mathrm{H}) \mathrm{H})$ $(\mathrm{H}) \mathrm{H})(\mathrm{H}) \mathrm{H})(\mathrm{C}(\mathrm{H})(\mathrm{H}) \mathrm{H})(\mathrm{H}) \mathrm{H}$

$\mathrm{C}(\mathrm{C}(\mathrm{C}(\mathrm{C}(\mathrm{C}(\mathrm{C}(\mathrm{C}(\mathrm{C}(\mathrm{C}(\mathrm{C}(\mathrm{C}(\mathrm{C}(\mathrm{C}(\mathrm{C}(\mathrm{H})(\mathrm{H}) \mathrm{H})(\mathrm{F}) \mathrm{H})(\mathrm{Cl}) \mathrm{H})(\mathrm{H}) \mathrm{H})(\mathrm{F}) \mathrm{H})(\mathrm{H}) \mathrm{Cl})(\mathrm{H}) \mathrm{H})(\mathrm{Br}) \mathrm{H})(\mathrm{H}) \mathrm{H})(\mathrm{H}) \mathrm{H})(\mathrm{H}) \mathrm{H})(\mathrm{H})$ F) $(\mathrm{Cl}) \mathrm{H})(\mathrm{C}(\mathrm{H})(\mathrm{Cl}) \mathrm{H})(\mathrm{H}) \mathrm{H}$

$\mathrm{C}(\mathrm{C}(\mathrm{C}(\mathrm{C}(\mathrm{C}(\mathrm{C}(\mathrm{C}(\mathrm{C}(\mathrm{C}(\mathrm{C}(\mathrm{C}(\mathrm{C}(\mathrm{C}(\mathrm{C}(\mathrm{H})(\mathrm{H}) \mathrm{Cl})(\mathrm{Cl}) \mathrm{H})(\mathrm{H}) \mathrm{H})(\mathrm{H}) \mathrm{H})(\mathrm{H}) \mathrm{Cl})(\mathrm{H}) \mathrm{H})(\mathrm{F}) \mathrm{H})(\mathrm{H}) \mathrm{H})(\mathrm{H}) \mathrm{H})(\mathrm{H}) \mathrm{Cl})(\mathrm{H}) \mathrm{H})$ $(\mathrm{Cl}) \mathrm{H})(\mathrm{H}) \mathrm{H})(\mathrm{C}(\mathrm{Cl})(\mathrm{H}) \mathrm{H})(\mathrm{H}) \mathrm{Cl}$

$\mathrm{C}(\mathrm{C}(\mathrm{C}(\mathrm{C}(\mathrm{C}(\mathrm{C}(\mathrm{C}(\mathrm{C}(\mathrm{C}(\mathrm{C}(\mathrm{C}(\mathrm{C}(\mathrm{C}(\mathrm{C}(\mathrm{H})(\mathrm{H}) \mathrm{H})(\mathrm{H}) \mathrm{F})(\mathrm{H}) \mathrm{H})(\mathrm{H}) \mathrm{H})(\mathrm{H}) \mathrm{H})(\mathrm{H}) \mathrm{H})(\mathrm{Cl}) \mathrm{H})(\mathrm{Br}) \mathrm{F})(\mathrm{H}) \mathrm{H})(\mathrm{H}) \mathrm{Br})(\mathrm{F}) \mathrm{H})(\mathrm{H})$ $\mathrm{H})(\mathrm{F}) \mathrm{H})(\mathrm{C}(\mathrm{Br})(\mathrm{H}) \mathrm{H})(\mathrm{H}) \mathrm{H}$

$\mathrm{C}(\mathrm{C}(\mathrm{C}(\mathrm{C}(\mathrm{C}(\mathrm{C}(\mathrm{C}(\mathrm{C}(\mathrm{C}(\mathrm{C}(\mathrm{C}(\mathrm{C}(\mathrm{C}(\mathrm{C}(\mathrm{H})(\mathrm{F}) \mathrm{H})(\mathrm{H}) \mathrm{H})(\mathrm{H}) \mathrm{H})(\mathrm{H}) \mathrm{H})(\mathrm{H}) \mathrm{H})(\mathrm{F}) \mathrm{H})(\mathrm{H}) \mathrm{F})(\mathrm{Br}) \mathrm{H})(\mathrm{H}) \mathrm{H})(\mathrm{Br}) \mathrm{H})(\mathrm{H}) \mathrm{Br})(\mathrm{H})$ $\mathrm{H})(\mathrm{H}) \mathrm{H})(\mathrm{C}(\mathrm{H})(\mathrm{H}) \mathrm{H})(\mathrm{Br}) \mathrm{H}$

$\mathrm{C}(\mathrm{C}(\mathrm{C}(\mathrm{C}(\mathrm{C}(\mathrm{C}(\mathrm{C}(\mathrm{C}(\mathrm{C}(\mathrm{C}(\mathrm{C}(\mathrm{C}(\mathrm{C}(\mathrm{C}(\mathrm{H})(\mathrm{H}) \mathrm{Br})(\mathrm{H}) \mathrm{H})(\mathrm{F}) \mathrm{H})(\mathrm{H}) \mathrm{H})(\mathrm{H}) \mathrm{Cl})(\mathrm{H}) \mathrm{H})(\mathrm{H}) \mathrm{Br})(\mathrm{H}) \mathrm{H})(\mathrm{H}) \mathrm{F})(\mathrm{H}) \mathrm{Cl})(\mathrm{H}) \mathrm{H})$ $(\mathrm{H}) \mathrm{H})(\mathrm{H}) \mathrm{H})(\mathrm{C}(\mathrm{H})(\mathrm{H}) \mathrm{F})(\mathrm{H}) \mathrm{H}$

$\mathrm{C}(\mathrm{C}(\mathrm{C}(\mathrm{C}(\mathrm{C}(\mathrm{C}(\mathrm{C}(\mathrm{C}(\mathrm{C}(\mathrm{C}(\mathrm{C}(\mathrm{C}(\mathrm{C}(\mathrm{C}(\mathrm{H})(\mathrm{Cl}) \mathrm{H})(\mathrm{F}) \mathrm{H})(\mathrm{H}) \mathrm{H})(\mathrm{H}) \mathrm{H})(\mathrm{H}) \mathrm{H})(\mathrm{H}) \mathrm{H})(\mathrm{H}) \mathrm{F})(\mathrm{H}) \mathrm{H})(\mathrm{H}) \mathrm{H})(\mathrm{H}) \mathrm{Cl})(\mathrm{H}) \mathrm{H})(\mathrm{H})$ $\mathrm{Cl}(\mathrm{H}) \mathrm{H})(\mathrm{C}(\mathrm{H})(\mathrm{Cl}) \mathrm{H})(\mathrm{Br}) \mathrm{H}$

$\mathrm{C}(\mathrm{C}(\mathrm{C}(\mathrm{C}(\mathrm{C}(\mathrm{C}(\mathrm{C}(\mathrm{C}(\mathrm{C}(\mathrm{C}(\mathrm{C}(\mathrm{C}(\mathrm{C}(\mathrm{C}(\mathrm{Cl})(\mathrm{H}) \mathrm{H})(\mathrm{H}) \mathrm{H})(\mathrm{H}) \mathrm{H})(\mathrm{H}) \mathrm{H})(\mathrm{Cl}) \mathrm{H})(\mathrm{H}) \mathrm{H})(\mathrm{H}) \mathrm{H})(\mathrm{H}) \mathrm{H})(\mathrm{H}) \mathrm{H})(\mathrm{Br}) \mathrm{H})(\mathrm{H}) \mathrm{Cl})$

$(\mathrm{H}) \mathrm{H})(\mathrm{H}) \mathrm{H})(\mathrm{C}(\mathrm{Cl})(\mathrm{F}) \mathrm{H})(\mathrm{Cl}) \mathrm{H}$

$\mathrm{C}(\mathrm{C}(\mathrm{C}(\mathrm{C}(\mathrm{C}(\mathrm{C}(\mathrm{C}(\mathrm{C}(\mathrm{C}(\mathrm{C}(\mathrm{C}(\mathrm{C}(\mathrm{C}(\mathrm{C}(\mathrm{Br})(\mathrm{H}) \mathrm{H})(\mathrm{F}) \mathrm{H})(\mathrm{H}) \mathrm{H})(\mathrm{H}) \mathrm{H})(\mathrm{H}) \mathrm{Cl})(\mathrm{F}) \mathrm{H})(\mathrm{Br}) \mathrm{H})(\mathrm{Br}) \mathrm{H})(\mathrm{H}) \mathrm{H})(\mathrm{H}) \mathrm{H})(\mathrm{H}) \mathrm{H})$

$(\mathrm{H}) \mathrm{H})(\mathrm{H}) \mathrm{H})(\mathrm{C}(\mathrm{F})(\mathrm{H}) \mathrm{H})(\mathrm{H}) \mathrm{H}$

$\mathrm{C}(\mathrm{C}(\mathrm{C}(\mathrm{C}(\mathrm{C}(\mathrm{C}(\mathrm{C}(\mathrm{C}(\mathrm{C}(\mathrm{C}(\mathrm{C}(\mathrm{C}(\mathrm{C}(\mathrm{C}(\mathrm{H})(\mathrm{H}) \mathrm{H})(\mathrm{H}) \mathrm{H})(\mathrm{H}) \mathrm{Br})(\mathrm{Br}) \mathrm{H})(\mathrm{F}) \mathrm{H})(\mathrm{F}) \mathrm{H})(\mathrm{H}) \mathrm{H})(\mathrm{H}) \mathrm{H})(\mathrm{H}) \mathrm{H})(\mathrm{H}) \mathrm{Cl})(\mathrm{H}) \mathrm{H})$

$(\mathrm{Br}) \mathrm{H})(\mathrm{H}) \mathrm{H})(\mathrm{C}(\mathrm{H})(\mathrm{H}) \mathrm{H})(\mathrm{Br}) \mathrm{H}$

$\mathrm{C}(\mathrm{C}(\mathrm{C}(\mathrm{C}(\mathrm{C}(\mathrm{C}(\mathrm{C}(\mathrm{C}(\mathrm{C}(\mathrm{C}(\mathrm{C}(\mathrm{C}(\mathrm{C}(\mathrm{C}(\mathrm{H})(\mathrm{H}) \mathrm{H})(\mathrm{H}) \mathrm{F})(\mathrm{H}) \mathrm{H})(\mathrm{H}) \mathrm{F})(\mathrm{H}) \mathrm{F})(\mathrm{H}) \mathrm{H})(\mathrm{Br}) \mathrm{H})(\mathrm{Br}) \mathrm{H})(\mathrm{H}) \mathrm{H})(\mathrm{H}) \mathrm{H})(\mathrm{H}) \mathrm{H})(\mathrm{H})$ $\mathrm{H})(\mathrm{H}) \mathrm{Br})(\mathrm{C}(\mathrm{H})(\mathrm{H}) \mathrm{H})(\mathrm{H}) \mathrm{H}$

$\mathrm{C}(\mathrm{C}(\mathrm{C}(\mathrm{C}(\mathrm{C}(\mathrm{C}(\mathrm{C}(\mathrm{C}(\mathrm{C}(\mathrm{C}(\mathrm{C}(\mathrm{C}(\mathrm{C}(\mathrm{C}(\mathrm{H})(\mathrm{H}) \mathrm{H})(\mathrm{H}) \mathrm{Br})(\mathrm{F}) \mathrm{H})(\mathrm{H}) \mathrm{Br})(\mathrm{H}) \mathrm{H})(\mathrm{F}) \mathrm{H})(\mathrm{H}) \mathrm{H})(\mathrm{H}) \mathrm{H})(\mathrm{H}) \mathrm{H})(\mathrm{H}) \mathrm{Br})(\mathrm{H}) \mathrm{H})$ $(\mathrm{H}) \mathrm{Br})(\mathrm{H}) \mathrm{H})(\mathrm{C}(\mathrm{H})(\mathrm{H}) \mathrm{H})(\mathrm{H}) \mathrm{H}$

$\mathrm{C}(\mathrm{C}(\mathrm{C}(\mathrm{C}(\mathrm{C}(\mathrm{C}(\mathrm{C}(\mathrm{C}(\mathrm{C}(\mathrm{C}(\mathrm{C}(\mathrm{C}(\mathrm{C}(\mathrm{C}(\mathrm{Cl})(\mathrm{H}) \mathrm{H})(\mathrm{H}) \mathrm{H})(\mathrm{H}) \mathrm{H})(\mathrm{H}) \mathrm{H})(\mathrm{Br}) \mathrm{H})(\mathrm{H}) \mathrm{H})(\mathrm{Cl}) \mathrm{H})(\mathrm{H}) \mathrm{F})(\mathrm{Br}) \mathrm{H})(\mathrm{H}) \mathrm{H})(\mathrm{H}) \mathrm{H})(\mathrm{B}$ r) $\mathrm{H})(\mathrm{H}) \mathrm{H})(\mathrm{C}(\mathrm{H})(\mathrm{H}) \mathrm{H})(\mathrm{H}) \mathrm{H}$

$\mathrm{C}(\mathrm{C}(\mathrm{C}(\mathrm{C}(\mathrm{C}(\mathrm{C}(\mathrm{C}(\mathrm{C}(\mathrm{C}(\mathrm{C}(\mathrm{C}(\mathrm{C}(\mathrm{C}(\mathrm{C}(\mathrm{H})(\mathrm{H}) \mathrm{H})(\mathrm{H}) \mathrm{Br})(\mathrm{H}) \mathrm{H})(\mathrm{H}) \mathrm{H})(\mathrm{H}) \mathrm{H})(\mathrm{H}) \mathrm{H})(\mathrm{Cl}) \mathrm{H})(\mathrm{H}) \mathrm{H})(\mathrm{H}) \mathrm{H})(\mathrm{H}) \mathrm{Br})(\mathrm{H}) \mathrm{Cl})($

$\mathrm{H}) \mathrm{F})(\mathrm{Cl}) \mathrm{H})(\mathrm{C}(\mathrm{H})(\mathrm{H}) \mathrm{H})(\mathrm{H}) \mathrm{H}$

$\mathrm{C}(\mathrm{C}(\mathrm{C}(\mathrm{C}(\mathrm{C}(\mathrm{C}(\mathrm{C}(\mathrm{C}(\mathrm{C}(\mathrm{C}(\mathrm{C}(\mathrm{C}(\mathrm{C}(\mathrm{C}(\mathrm{H})(\mathrm{H}) \mathrm{H})(\mathrm{H}) \mathrm{Cl})(\mathrm{Cl}) \mathrm{H})(\mathrm{H}) \mathrm{H})(\mathrm{H}) \mathrm{Br})(\mathrm{H}) \mathrm{H})(\mathrm{H}) \mathrm{H})(\mathrm{H}) \mathrm{H})(\mathrm{H}) \mathrm{H})(\mathrm{Br}) \mathrm{H})(\mathrm{H}) \mathrm{Cl})($ $\mathrm{H}) \mathrm{Cl})(\mathrm{H}) \mathrm{H})(\mathrm{C}(\mathrm{H})(\mathrm{H}) \mathrm{H})(\mathrm{H}) \mathrm{H}$

$\mathrm{C}(\mathrm{C}(\mathrm{C}(\mathrm{C}(\mathrm{C}(\mathrm{C}(\mathrm{C}(\mathrm{C}(\mathrm{C}(\mathrm{C}(\mathrm{C}(\mathrm{C}(\mathrm{C}(\mathrm{C}(\mathrm{H})(\mathrm{H}) \mathrm{F})(\mathrm{H}) \mathrm{H})(\mathrm{H}) \mathrm{H})(\mathrm{H}) \mathrm{Cl})(\mathrm{H}) \mathrm{Cl})(\mathrm{H}) \mathrm{H})(\mathrm{H}) \mathrm{H})(\mathrm{Cl}) \mathrm{H})(\mathrm{H}) \mathrm{H})(\mathrm{H}) \mathrm{Cl})(\mathrm{H}) \mathrm{H})$

$(\mathrm{H}) \mathrm{Br})(\mathrm{H}) \mathrm{H})(\mathrm{C}(\mathrm{H})(\mathrm{H}) \mathrm{H})(\mathrm{H}) \mathrm{H}$

$\mathrm{C}(\mathrm{C}(\mathrm{C}(\mathrm{C}(\mathrm{C}(\mathrm{C}(\mathrm{C}(\mathrm{C}(\mathrm{C}(\mathrm{C}(\mathrm{C}(\mathrm{C}(\mathrm{C}(\mathrm{C}(\mathrm{H})(\mathrm{Cl}) \mathrm{H})(\mathrm{H}) \mathrm{H})(\mathrm{Cl}) \mathrm{H})(\mathrm{H}) \mathrm{H})(\mathrm{Cl}) \mathrm{H})(\mathrm{H}) \mathrm{H})(\mathrm{H}) \mathrm{H})(\mathrm{Cl}) \mathrm{H})(\mathrm{H}) \mathrm{H})(\mathrm{H}) \mathrm{H})(\mathrm{H}) \mathrm{Cl})($ $\mathrm{H}) \mathrm{Br})(\mathrm{H}) \mathrm{H})(\mathrm{C}(\mathrm{H})(\mathrm{H}) \mathrm{H})(\mathrm{H}) \mathrm{H}$

$\mathrm{C}(\mathrm{C}(\mathrm{C}(\mathrm{C}(\mathrm{C}(\mathrm{C}(\mathrm{C}(\mathrm{C}(\mathrm{C}(\mathrm{C}(\mathrm{C}(\mathrm{C}(\mathrm{C}(\mathrm{C}(\mathrm{H})(\mathrm{H}) \mathrm{H})(\mathrm{H}) \mathrm{H})(\mathrm{H}) \mathrm{Cl})(\mathrm{H}) \mathrm{Cl})(\mathrm{F}) \mathrm{H})(\mathrm{H}) \mathrm{H})(\mathrm{H}) \mathrm{Cl})(\mathrm{Cl}) \mathrm{H})(\mathrm{H}) \mathrm{H})(\mathrm{H}) \mathrm{H})(\mathrm{H}) \mathrm{H})$

$(\mathrm{H}) \mathrm{H})(\mathrm{H}) \mathrm{H})(\mathrm{C}(\mathrm{H})(\mathrm{Cl}) \mathrm{H})(\mathrm{H}) \mathrm{H}$

$\mathrm{C}(\mathrm{C}(\mathrm{C}(\mathrm{C}(\mathrm{C}(\mathrm{C}(\mathrm{C}(\mathrm{C}(\mathrm{C}(\mathrm{C}(\mathrm{C}(\mathrm{C}(\mathrm{C}(\mathrm{C}(\mathrm{Cl})(\mathrm{H}) \mathrm{H})(\mathrm{H}) \mathrm{H})(\mathrm{H}) \mathrm{H})(\mathrm{H}) \mathrm{H})(\mathrm{Cl}) \mathrm{H})(\mathrm{H}) \mathrm{H})(\mathrm{H}) \mathrm{H})(\mathrm{H}) \mathrm{Cl})(\mathrm{H}) \mathrm{H})(\mathrm{H}) \mathrm{H})(\mathrm{H}) \mathrm{H})$

$(\mathrm{H}) \mathrm{Cl})(\mathrm{H}) \mathrm{Cl})(\mathrm{C}(\mathrm{H})(\mathrm{H}) \mathrm{H})(\mathrm{H}) \mathrm{Cl}$

$\mathrm{C}(\mathrm{C}(\mathrm{C}(\mathrm{C}(\mathrm{C}(\mathrm{C}(\mathrm{C}(\mathrm{C}(\mathrm{C}(\mathrm{C}(\mathrm{C}(\mathrm{C}(\mathrm{C}(\mathrm{C}(\mathrm{H})(\mathrm{H}) \mathrm{H})(\mathrm{H}) \mathrm{H})(\mathrm{Br}) \mathrm{H})(\mathrm{H}) \mathrm{H})(\mathrm{F}) \mathrm{H})(\mathrm{H}) \mathrm{H})(\mathrm{H}) \mathrm{H})(\mathrm{H}) \mathrm{H})(\mathrm{H}) \mathrm{H})(\mathrm{H}) \mathrm{H})(\mathrm{H}) \mathrm{H})(\mathrm{H})$ $\mathrm{Br})(\mathrm{Br}) \mathrm{H})(\mathrm{C}(\mathrm{F})(\mathrm{H}) \mathrm{H})(\mathrm{H}) \mathrm{Cl}$

$\mathrm{C}(\mathrm{C}(\mathrm{C}(\mathrm{C}(\mathrm{C}(\mathrm{C}(\mathrm{C}(\mathrm{C}(\mathrm{C}(\mathrm{C}(\mathrm{C}(\mathrm{C}(\mathrm{C}(\mathrm{C}(\mathrm{H})(\mathrm{F}) \mathrm{Br})(\mathrm{H}) \mathrm{H})(\mathrm{H}) \mathrm{H})(\mathrm{H}) \mathrm{H})(\mathrm{H}) \mathrm{H})(\mathrm{H}) \mathrm{H})(\mathrm{H}) \mathrm{H})(\mathrm{H}) \mathrm{H})(\mathrm{Br}) \mathrm{H})(\mathrm{H}) \mathrm{H})(\mathrm{H}) \mathrm{H})(\mathrm{H})$ $\mathrm{H})(\mathrm{Br}) \mathrm{H})(\mathrm{C}(\mathrm{H})(\mathrm{F}) \mathrm{H})(\mathrm{H}) \mathrm{H}$

$\mathrm{C}(\mathrm{C}(\mathrm{C}(\mathrm{C}(\mathrm{C}(\mathrm{C}(\mathrm{C}(\mathrm{C}(\mathrm{C}(\mathrm{C}(\mathrm{C}(\mathrm{C}(\mathrm{C}(\mathrm{C}(\mathrm{H})(\mathrm{H}) \mathrm{H})(\mathrm{H}) \mathrm{Br})(\mathrm{H}) \mathrm{Br})(\mathrm{H}) \mathrm{F})(\mathrm{H}) \mathrm{H})(\mathrm{H}) \mathrm{H})(\mathrm{Br}) \mathrm{H})(\mathrm{H}) \mathrm{H})(\mathrm{Br}) \mathrm{H})(\mathrm{H}) \mathrm{H})(\mathrm{H}) \mathrm{H})($ $\mathrm{H}) \mathrm{H})(\mathrm{H}) \mathrm{H})(\mathrm{C}(\mathrm{H})(\mathrm{H}) \mathrm{H})(\mathrm{H}) \mathrm{H}$

$\mathrm{C}(\mathrm{C}(\mathrm{C}(\mathrm{C}(\mathrm{C}(\mathrm{C}(\mathrm{C}(\mathrm{C}(\mathrm{C}(\mathrm{C}(\mathrm{C}(\mathrm{C}(\mathrm{C}(\mathrm{C}(\mathrm{Br})(\mathrm{H}) \mathrm{H})(\mathrm{H}) \mathrm{H})(\mathrm{H}) \mathrm{H})(\mathrm{F}) \mathrm{H})(\mathrm{H}) \mathrm{Cl})(\mathrm{H}) \mathrm{Cl})(\mathrm{H}) \mathrm{H})(\mathrm{H}) \mathrm{H})(\mathrm{H}) \mathrm{H})(\mathrm{H}) \mathrm{H})(\mathrm{H}) \mathrm{H})(\mathrm{H})$ $\mathrm{Br})(\mathrm{H}) \mathrm{H})(\mathrm{C}(\mathrm{H})(\mathrm{H}) \mathrm{H})(\mathrm{H}) \mathrm{H}$

$\mathrm{C}(\mathrm{C}(\mathrm{C}(\mathrm{C}(\mathrm{C}(\mathrm{C}(\mathrm{C}(\mathrm{C}(\mathrm{C}(\mathrm{C}(\mathrm{C}(\mathrm{C}(\mathrm{C}(\mathrm{C}(\mathrm{H})(\mathrm{Cl}) \mathrm{H})(\mathrm{H}) \mathrm{H})(\mathrm{H}) \mathrm{Cl})(\mathrm{H}) \mathrm{H})(\mathrm{H}) \mathrm{H})(\mathrm{Br}) \mathrm{H})(\mathrm{H}) \mathrm{H})(\mathrm{H}) \mathrm{Br})(\mathrm{H}) \mathrm{H})(\mathrm{H}) \mathrm{H})(\mathrm{H}) \mathrm{H})($ $\mathrm{H}) \mathrm{H})(\mathrm{H}) \mathrm{H})(\mathrm{C}(\mathrm{H})(\mathrm{H}) \mathrm{H})(\mathrm{Br}) \mathrm{H}$

$\mathrm{C}(\mathrm{C}(\mathrm{C}(\mathrm{C}(\mathrm{C}(\mathrm{C}(\mathrm{C}(\mathrm{C}(\mathrm{C}(\mathrm{C}(\mathrm{C}(\mathrm{C}(\mathrm{C}(\mathrm{C}(\mathrm{H})(\mathrm{H}) \mathrm{H})(\mathrm{H}) \mathrm{Cl})(\mathrm{Cl}) \mathrm{H})(\mathrm{H}) \mathrm{H})(\mathrm{H}) \mathrm{H})(\mathrm{Br}) \mathrm{H})(\mathrm{H}) \mathrm{H})(\mathrm{H}) \mathrm{Cl})(\mathrm{H}) \mathrm{H})(\mathrm{H}) \mathrm{H})(\mathrm{H}) \mathrm{Br})($ $\mathrm{H}) \mathrm{H})(\mathrm{H}) \mathrm{H})(\mathrm{C}(\mathrm{H})(\mathrm{H}) \mathrm{H})(\mathrm{H}) \mathrm{H}$

$\mathrm{C}(\mathrm{C}(\mathrm{C}(\mathrm{C}(\mathrm{C}(\mathrm{C}(\mathrm{C}(\mathrm{C}(\mathrm{C}(\mathrm{C}(\mathrm{C}(\mathrm{C}(\mathrm{C}(\mathrm{C}(\mathrm{H})(\mathrm{H}) \mathrm{Br})(\mathrm{H}) \mathrm{H})(\mathrm{Cl}) \mathrm{H})(\mathrm{H}) \mathrm{H})(\mathrm{H}) \mathrm{H})(\mathrm{H}) \mathrm{H})(\mathrm{H}) \mathrm{H})(\mathrm{H}) \mathrm{Cl})(\mathrm{H}) \mathrm{H})(\mathrm{F}) \mathrm{H})(\mathrm{H}) \mathrm{H})(\mathrm{H})$ $\mathrm{H})(\mathrm{H}) \mathrm{Cl})(\mathrm{C}(\mathrm{H})(\mathrm{H}) \mathrm{H})(\mathrm{H}) \mathrm{H}$

$\mathrm{C}(\mathrm{C}(\mathrm{C}(\mathrm{C}(\mathrm{C}(\mathrm{C}(\mathrm{C}(\mathrm{C}(\mathrm{C}(\mathrm{C}(\mathrm{C}(\mathrm{C}(\mathrm{C}(\mathrm{C}(\mathrm{H})(\mathrm{Cl}) \mathrm{H})(\mathrm{Cl}) \mathrm{H})(\mathrm{H}) \mathrm{H})(\mathrm{H}) \mathrm{H})(\mathrm{H}) \mathrm{H})(\mathrm{H}) \mathrm{H})(\mathrm{H}) \mathrm{H})(\mathrm{H}) \mathrm{H})(\mathrm{Cl}) \mathrm{H})(\mathrm{H}) \mathrm{H})(\mathrm{H}) \mathrm{H})$

$(\mathrm{H}) \mathrm{H})(\mathrm{H}) \mathrm{H})(\mathrm{C}(\mathrm{H})(\mathrm{Cl}) \mathrm{Cl})(\mathrm{H}) \mathrm{H}$

$\mathrm{C}(\mathrm{C}(\mathrm{C}(\mathrm{C}(\mathrm{C}(\mathrm{C}(\mathrm{C}(\mathrm{C}(\mathrm{C}(\mathrm{C}(\mathrm{C}(\mathrm{C}(\mathrm{C}(\mathrm{C}(\mathrm{H})(\mathrm{H}) \mathrm{Br})(\mathrm{H}) \mathrm{H})(\mathrm{F}) \mathrm{H})(\mathrm{H}) \mathrm{H})(\mathrm{H}) \mathrm{F})(\mathrm{H}) \mathrm{H})(\mathrm{Cl}) \mathrm{H})(\mathrm{H}) \mathrm{H})(\mathrm{H}) \mathrm{H})(\mathrm{H}) \mathrm{H})(\mathrm{H}) \mathrm{H})(\mathrm{H})$ $\mathrm{H})(\mathrm{H}) \mathrm{H})(\mathrm{C}(\mathrm{H})(\mathrm{Br}) \mathrm{H})(\mathrm{H}) \mathrm{H}$

$\mathrm{C}(\mathrm{C}(\mathrm{C}(\mathrm{C}(\mathrm{C}(\mathrm{C}(\mathrm{C}(\mathrm{C}(\mathrm{C}(\mathrm{C}(\mathrm{C}(\mathrm{C}(\mathrm{C}(\mathrm{C}(\mathrm{H})(\mathrm{H}) \mathrm{H})(\mathrm{H}) \mathrm{H})(\mathrm{H}) \mathrm{H})(\mathrm{H}) \mathrm{Cl})(\mathrm{H}) \mathrm{H})(\mathrm{H}) \mathrm{F})(\mathrm{H}) \mathrm{H})(\mathrm{Br}) \mathrm{H})(\mathrm{Br}) \mathrm{H})(\mathrm{H}) \mathrm{H})(\mathrm{H}) \mathrm{H})$ $(\mathrm{H}) \mathrm{Br})(\mathrm{H}) \mathrm{H})(\mathrm{C}(\mathrm{H})(\mathrm{H}) \mathrm{H})(\mathrm{H}) \mathrm{H}$

$\mathrm{C}(\mathrm{C}(\mathrm{C}(\mathrm{C}(\mathrm{C}(\mathrm{C}(\mathrm{C}(\mathrm{C}(\mathrm{C}(\mathrm{C}(\mathrm{C}(\mathrm{C}(\mathrm{C}(\mathrm{C}(\mathrm{H})(\mathrm{H}) \mathrm{H})(\mathrm{H}) \mathrm{H})(\mathrm{H}) \mathrm{H})(\mathrm{H}) \mathrm{H})(\mathrm{H}) \mathrm{H})(\mathrm{H}) \mathrm{H})(\mathrm{H}) \mathrm{H})(\mathrm{H}) \mathrm{H})(\mathrm{H}) \mathrm{H})(\mathrm{H}) \mathrm{F})(\mathrm{H}) \mathrm{H})(\mathrm{H}) \mathrm{B}$ r) $(\mathrm{H}) \mathrm{H})(\mathrm{C}(\mathrm{H})(\mathrm{Br}) \mathrm{Br})(\mathrm{H}) \mathrm{H}$

$\mathrm{C}(\mathrm{C}(\mathrm{C}(\mathrm{C}(\mathrm{C}(\mathrm{C}(\mathrm{C}(\mathrm{C}(\mathrm{C}(\mathrm{C}(\mathrm{C}(\mathrm{C}(\mathrm{C}(\mathrm{C}(\mathrm{Br})(\mathrm{H}) \mathrm{H})(\mathrm{H}) \mathrm{H})(\mathrm{H}) \mathrm{H})(\mathrm{H}) \mathrm{H})(\mathrm{Br}) \mathrm{H})(\mathrm{H}) \mathrm{H})(\mathrm{H}) \mathrm{H})(\mathrm{H}) \mathrm{Br})(\mathrm{H}) \mathrm{H})(\mathrm{H}) \mathrm{H})(\mathrm{H}) \mathrm{H})($

$\mathrm{H}) \mathrm{H})(\mathrm{H}) \mathrm{H})(\mathrm{C}(\mathrm{H})(\mathrm{H}) \mathrm{H})(\mathrm{H}) \mathrm{Br}$

$\mathrm{C}(\mathrm{C}(\mathrm{C}(\mathrm{C}(\mathrm{C}(\mathrm{C}(\mathrm{C}(\mathrm{C}(\mathrm{C}(\mathrm{C}(\mathrm{C}(\mathrm{C}(\mathrm{C}(\mathrm{C}(\mathrm{H})(\mathrm{H}) \mathrm{H})(\mathrm{Br}) \mathrm{H})(\mathrm{H}) \mathrm{H})(\mathrm{H}) \mathrm{H})(\mathrm{H}) \mathrm{H})(\mathrm{H}) \mathrm{H})(\mathrm{H}) \mathrm{H})(\mathrm{H}) \mathrm{H})(\mathrm{H}) \mathrm{Cl})(\mathrm{H}) \mathrm{H})(\mathrm{Br}) \mathrm{H})$

$(\mathrm{H}) \mathrm{H})(\mathrm{H}) \mathrm{H})(\mathrm{C}(\mathrm{H})(\mathrm{Cl}) \mathrm{H})(\mathrm{H}) \mathrm{H}$

$\mathrm{C}(\mathrm{C}(\mathrm{C}(\mathrm{C}(\mathrm{C}(\mathrm{C}(\mathrm{C}(\mathrm{C}(\mathrm{C}(\mathrm{C}(\mathrm{C}(\mathrm{C}(\mathrm{C}(\mathrm{C}(\mathrm{Cl})(\mathrm{H}) \mathrm{Cl})(\mathrm{H}) \mathrm{H})(\mathrm{H}) \mathrm{H})(\mathrm{H}) \mathrm{Cl})(\mathrm{H}) \mathrm{H})(\mathrm{H}) \mathrm{H})(\mathrm{H}) \mathrm{H})(\mathrm{H}) \mathrm{H})(\mathrm{H}) \mathrm{H})(\mathrm{H}) \mathrm{H})(\mathrm{H}) \mathrm{Br})$

$(\mathrm{H}) \mathrm{H})(\mathrm{H}) \mathrm{H})(\mathrm{C}(\mathrm{H})(\mathrm{H}) \mathrm{H})(\mathrm{H}) \mathrm{H}$

$\mathrm{C}(\mathrm{C}(\mathrm{C}(\mathrm{C}(\mathrm{C}(\mathrm{C}(\mathrm{C}(\mathrm{C}(\mathrm{C}(\mathrm{C}(\mathrm{C}(\mathrm{C}(\mathrm{C}(\mathrm{C}(\mathrm{H})(\mathrm{Cl}) \mathrm{Cl})(\mathrm{H}) \mathrm{H})(\mathrm{H}) \mathrm{H})(\mathrm{H}) \mathrm{H})(\mathrm{H}) \mathrm{H})(\mathrm{H}) \mathrm{H})(\mathrm{H}) \mathrm{H})(\mathrm{H}) \mathrm{H})(\mathrm{H}) \mathrm{H})(\mathrm{H}) \mathrm{H})(\mathrm{H}) \mathrm{Cl})$

$(\mathrm{H}) \mathrm{H})(\mathrm{H}) \mathrm{H})(\mathrm{C}(\mathrm{H})(\mathrm{H}) \mathrm{H})(\mathrm{Cl}) \mathrm{H}$

$\mathrm{C}(\mathrm{C}(\mathrm{C}(\mathrm{C}(\mathrm{C}(\mathrm{C}(\mathrm{C}(\mathrm{C}(\mathrm{C}(\mathrm{C}(\mathrm{C}(\mathrm{C}(\mathrm{C}(\mathrm{C}(\mathrm{Br})(\mathrm{Br}) \mathrm{H})(\mathrm{Br}) \mathrm{H})(\mathrm{H}) \mathrm{H})(\mathrm{H}) \mathrm{H})(\mathrm{H}) \mathrm{H})(\mathrm{H}) \mathrm{H})(\mathrm{H}) \mathrm{H})(\mathrm{H}) \mathrm{H})(\mathrm{H}) \mathrm{H})(\mathrm{H}) \mathrm{H})(\mathrm{H}) \mathrm{H})($

$\mathrm{H}) \mathrm{H})(\mathrm{H}) \mathrm{H})(\mathrm{C}(\mathrm{H})(\mathrm{H}) \mathrm{H})(\mathrm{Cl}) \mathrm{H}$

$\mathrm{C}(\mathrm{C}(\mathrm{C}(\mathrm{C}(\mathrm{C}(\mathrm{C}(\mathrm{C}(\mathrm{C}(\mathrm{C}(\mathrm{C}(\mathrm{C}(\mathrm{C}(\mathrm{C}(\mathrm{C}(\mathrm{H})(\mathrm{H}) \mathrm{H})(\mathrm{H}) \mathrm{Br})(\mathrm{H}) \mathrm{H})(\mathrm{Br}) \mathrm{H})(\mathrm{H}) \mathrm{H})(\mathrm{H}) \mathrm{H})(\mathrm{H}) \mathrm{Br})(\mathrm{H}) \mathrm{H})(\mathrm{H}) \mathrm{H})(\mathrm{H}) \mathrm{H})(\mathrm{H}) \mathrm{H})($

$\mathrm{H}) \mathrm{H})(\mathrm{H}) \mathrm{H})(\mathrm{C}(\mathrm{H})(\mathrm{H}) \mathrm{H})(\mathrm{H}) \mathrm{H}$

$\mathrm{C}(\mathrm{C}(\mathrm{C}(\mathrm{C}(\mathrm{C}(\mathrm{C}(\mathrm{C}(\mathrm{C}(\mathrm{C}(\mathrm{C}(\mathrm{C}(\mathrm{C}(\mathrm{C}(\mathrm{C}(\mathrm{H})(\mathrm{H}) \mathrm{H})(\mathrm{H}) \mathrm{H})(\mathrm{H}) \mathrm{H})(\mathrm{H}) \mathrm{H})(\mathrm{Br}) \mathrm{H})(\mathrm{H}) \mathrm{H})(\mathrm{H}) \mathrm{H})(\mathrm{H}) \mathrm{H})(\mathrm{H}) \mathrm{H})(\mathrm{H}) \mathrm{Cl})(\mathrm{Cl}) \mathrm{H})$

$(\mathrm{H}) \mathrm{H})(\mathrm{H}) \mathrm{H})(\mathrm{C}(\mathrm{H})(\mathrm{H}) \mathrm{H})(\mathrm{H}) \mathrm{H}$

$\mathrm{C}(\mathrm{C}(\mathrm{C}(\mathrm{C}(\mathrm{C}(\mathrm{C}(\mathrm{C}(\mathrm{C}(\mathrm{C}(\mathrm{C}(\mathrm{C}(\mathrm{C}(\mathrm{C}(\mathrm{C}(\mathrm{H})(\mathrm{Cl}) \mathrm{H})(\mathrm{H}) \mathrm{H})(\mathrm{H}) \mathrm{H})(\mathrm{H}) \mathrm{H})(\mathrm{H}) \mathrm{H})(\mathrm{H}) \mathrm{Br})(\mathrm{H}) \mathrm{H})(\mathrm{H}) \mathrm{H})(\mathrm{H}) \mathrm{H})(\mathrm{H}) \mathrm{H})(\mathrm{H}) \mathrm{H})(\mathrm{H})$ $\mathrm{H})(\mathrm{H}) \mathrm{H})(\mathrm{C}(\mathrm{H})(\mathrm{Br}) \mathrm{H})(\mathrm{H}) \mathrm{H}$

$\mathrm{C}(\mathrm{C}(\mathrm{C}(\mathrm{C}(\mathrm{C}(\mathrm{C}(\mathrm{C}(\mathrm{C}(\mathrm{C}(\mathrm{C}(\mathrm{C}(\mathrm{C}(\mathrm{C}(\mathrm{C}(\mathrm{H})(\mathrm{H}) \mathrm{H})(\mathrm{H}) \mathrm{H})(\mathrm{H}) \mathrm{H})(\mathrm{H}) \mathrm{H})(\mathrm{H}) \mathrm{Br})(\mathrm{H}) \mathrm{H})(\mathrm{H}) \mathrm{H})(\mathrm{H}) \mathrm{H})(\mathrm{H}) \mathrm{H})(\mathrm{H}) \mathrm{Br})(\mathrm{H}) \mathrm{H})$ $(\mathrm{H}) \mathrm{H})(\mathrm{H}) \mathrm{H})(\mathrm{C}(\mathrm{H})(\mathrm{H}) \mathrm{H})(\mathrm{H}) \mathrm{H}$

$\mathrm{C}(\mathrm{C}(\mathrm{C}(\mathrm{C}(\mathrm{C}(\mathrm{C}(\mathrm{C}(\mathrm{C}(\mathrm{C}(\mathrm{C}(\mathrm{C}(\mathrm{C}(\mathrm{C}(\mathrm{C}(\mathrm{C}(\mathrm{C}(\mathrm{H})(\mathrm{H}) \mathrm{H})(\mathrm{Br}) \mathrm{H})(\mathrm{F}) \mathrm{H})(\mathrm{H}) \mathrm{H})(\mathrm{F}) \mathrm{H})(\mathrm{Br}) \mathrm{H})(\mathrm{H}) \mathrm{Cl})(\mathrm{H}) \mathrm{F})(\mathrm{H}) \mathrm{F})(\mathrm{H}) \mathrm{Br})$

$(\mathrm{F}) \mathrm{H})(\mathrm{H}) \mathrm{F})(\mathrm{H}) \mathrm{Br})(\mathrm{H}) \mathrm{H})(\mathrm{Br}) \mathrm{H})(\mathrm{F})(\mathrm{F}) \mathrm{H}$

$\mathrm{C}(\mathrm{C}(\mathrm{C}(\mathrm{C}(\mathrm{C}(\mathrm{C}(\mathrm{C}(\mathrm{C}(\mathrm{C}(\mathrm{C}(\mathrm{C}(\mathrm{C}(\mathrm{C}(\mathrm{C}(\mathrm{C}(\mathrm{C}(\mathrm{Br})(\mathrm{H}) \mathrm{H})(\mathrm{Cl}) \mathrm{H})(\mathrm{H}) \mathrm{H})(\mathrm{H}) \mathrm{F})(\mathrm{Cl}) \mathrm{H})(\mathrm{H}) \mathrm{H})(\mathrm{H}) \mathrm{H})(\mathrm{F}) \mathrm{H})(\mathrm{F}) \mathrm{H})(\mathrm{F}) \mathrm{H})$

$(\mathrm{H}) \mathrm{Br})(\mathrm{H}) \mathrm{F})(\mathrm{Br}) \mathrm{H})(\mathrm{Br}) \mathrm{H})(\mathrm{H}) \mathrm{F})(\mathrm{H})(\mathrm{H}) \mathrm{H}$

$\mathrm{C}(\mathrm{C}(\mathrm{C}(\mathrm{C}(\mathrm{C}(\mathrm{C}(\mathrm{C}(\mathrm{C}(\mathrm{C}(\mathrm{C}(\mathrm{C}(\mathrm{C}(\mathrm{C}(\mathrm{C}(\mathrm{C}(\mathrm{C}(\mathrm{H})(\mathrm{H}) \mathrm{H})(\mathrm{H}) \mathrm{Br})(\mathrm{H}) \mathrm{H})(\mathrm{H}) \mathrm{H})(\mathrm{H}) \mathrm{H})(\mathrm{Cl}) \mathrm{H})(\mathrm{H}) \mathrm{Cl})(\mathrm{H}) \mathrm{Cl})(\mathrm{H}) \mathrm{F})(\mathrm{Cl}) \mathrm{H})(\mathrm{F})$ $\mathrm{H})(\mathrm{H}) \mathrm{F})(\mathrm{Br}) \mathrm{H})(\mathrm{H}) \mathrm{H})(\mathrm{H}) \mathrm{F})(\mathrm{H})(\mathrm{H})$
Formula

$\mathrm{C} 15 \mathrm{H} 24 \mathrm{Cl} 3 \mathrm{Br} 2 \mathrm{~F} 3$

$\mathrm{C} 15 \mathrm{H} 24 \mathrm{Cl} 4 \mathrm{BrF} 3$

C15H24C17F

$\mathrm{C} 15 \mathrm{H} 24 \mathrm{ClBr} 3 \mathrm{~F} 4$

$\mathrm{C} 15 \mathrm{H} 25 \mathrm{Br} 4 \mathrm{~F} 3$

$\mathrm{C} 15 \mathrm{H} 25 \mathrm{Cl} 2 \mathrm{Br} 2 \mathrm{~F} 3$

C15H25Cl4BrF2

$\mathrm{C} 15 \mathrm{H} 25 \mathrm{Cl} 15 \mathrm{BrF}$

$\mathrm{C} 15 \mathrm{H} 25 \mathrm{ClBr} 3 \mathrm{~F} 3$

$\mathrm{C} 15 \mathrm{H} 25 \mathrm{ClBr} 4 \mathrm{~F} 2$

$\mathrm{C} 15 \mathrm{H} 26 \mathrm{Br} 3 \mathrm{~F} 3$

$\mathrm{C} 15 \mathrm{H} 26 \mathrm{Br} 4 \mathrm{~F} 2$

$\mathrm{C} 15 \mathrm{H} 26 \mathrm{Cl} 2 \mathrm{Br} 3 \mathrm{~F}$

$\mathrm{C} 15 \mathrm{H} 26 \mathrm{Cl} 3 \mathrm{Br} 2 \mathrm{~F}$

C15H26Cl4Br2

$\mathrm{C} 15 \mathrm{H} 26 \mathrm{Cl} 4 \mathrm{BrF}$

$15 \mathrm{H} 26 \mathrm{Cl} 5 \mathrm{Br}$

C15H26Cl5F

$\mathrm{C} 15 \mathrm{H} 26 \mathrm{Cl} 6$

$\mathrm{C} 15 \mathrm{H} 26 \mathrm{ClBr} 3 \mathrm{~F} 2$

$\mathrm{C} 15 \mathrm{H} 27 \mathrm{Br} 3 \mathrm{~F} 2$

$\mathrm{C} 15 \mathrm{H} 27 \mathrm{Br} 4 \mathrm{~F}$

$\mathrm{C} 15 \mathrm{H} 27 \mathrm{Cl} 2 \mathrm{Br} 2 \mathrm{~F}$

$\mathrm{C} 15 \mathrm{H} 27 \mathrm{Cl} 2 \mathrm{Br} 3$

$\mathrm{C} 15 \mathrm{H} 27 \mathrm{Cl} 3 \mathrm{Br} 2$

$\mathrm{C} 15 \mathrm{H} 27 \mathrm{Cl} 3 \mathrm{BrF}$

$\mathrm{C} 15 \mathrm{H} 27 \mathrm{Cl} 5$

$\mathrm{C} 15 \mathrm{H} 27 \mathrm{ClBr} 2 \mathrm{~F} 2$

$\mathrm{C} 15 \mathrm{H} 27 \mathrm{ClBr} 3 \mathrm{~F}$

$\mathrm{C} 15 \mathrm{H} 28 \mathrm{Br} 3 \mathrm{~F}$

$\mathrm{C} 15 \mathrm{H} 28 \mathrm{Br} 4$

$\mathrm{C} 15 \mathrm{H} 28 \mathrm{Cl} 2 \mathrm{Br} 2$

$\mathrm{C} 15 \mathrm{H} 28 \mathrm{Cl} 3 \mathrm{Br}$

$\mathrm{C} 15 \mathrm{H} 28 \mathrm{Cl} 4$

$\mathrm{C} 15 \mathrm{H} 28 \mathrm{ClBr} 3$

$\mathrm{C} 15 \mathrm{H} 29 \mathrm{Br} 3$

$\mathrm{C} 15 \mathrm{H} 29 \mathrm{Cl} 2 \mathrm{Br}$

$\mathrm{C} 15 \mathrm{H} 29 \mathrm{ClBr} 2$

$\mathrm{C} 15 \mathrm{H} 30 \mathrm{Br} 2$

$\mathrm{C} 16 \mathrm{H} 20 \mathrm{ClBr} 5 \mathrm{~F} 8$

$\mathrm{C} 16 \mathrm{H} 22 \mathrm{Cl} 2 \mathrm{Br} 4 \mathrm{~F} 6$

$\mathrm{C} 16 \mathrm{H} 23 \mathrm{Cl} 4 \mathrm{Br} 2 \mathrm{~F} 5$
lgKoa lgKow lgKaw lgKow lgKoa lgKaw lgKow lgKoa lgKaw _EPI_EPI_EPI_Exp__Exp__Exp__DFT_DFT_DFT Suite Suite Suite corr corr corr_corr_corr corr

$\begin{array}{lllllllll}8.6 & 8.46 & -0.14 & 7.70 & 7.84 & -0.14 & 7.26 & 13.81 & -6.55\end{array}$

$\begin{array}{lllllllll}8.02 & 8.37 & 0.35 & 7.57 & 7.22 & 0.35 & 7.19 & 12.75 & -5.56\end{array}$

$\begin{array}{lllllllll}9.66 & 8.99 & -0.67 & 8.49 & 9.16 & -0.67 & 7.67 & 15.76 & -8.09\end{array}$

$\begin{array}{lllllllll}8.85 & 8.98 & 0.13 & 8.48 & 8.35 & 0.13 & 7.66 & 14.27 & -6.61\end{array}$

$\begin{array}{lllllllll}9.12 & 8.46 & -0.66 & 7.70 & 8.36 & -0.66 & 7.26 & 14.76 & -7.50\end{array}$

$\begin{array}{lllllllll}8.05 & 8.36 & 0.31 & 7.55 & 7.24 & 0.31 & 7.18 & 12.79 & -5.61\end{array}$

$\begin{array}{lllllllll}8.53 & 8.58 & 0.05 & 7.88 & 7.83 & 0.05 & 7.35 & 13.69 & -6.33\end{array}$

$\begin{array}{lllllllll}9.59 & 8.89 & -0.70 & 8.34 & 9.05 & -0.70 & 7.59 & 15.64 & -8.05\end{array}$

$\begin{array}{lllllllll}8.62 & 8.45 & -0.17 & 7.69 & 7.86 & -0.17 & 7.25 & 13.85 & -6.60\end{array}$

$\begin{array}{lllllllll}10.1 & 8.7 & -1.41 & 8.06 & 9.47 & -1.41 & 7.44 & 16.58 & -9.14\end{array}$

$\begin{array}{lllllllll}7.84 & 8.12 & 0.28 & 7.19 & 6.91 & 0.28 & 7.00 & 12.41 & -5.41\end{array}$

$\begin{array}{lllllllll}9.47 & 8.52 & -0.95 & 7.79 & 8.75 & -0.95 & 7.31 & 15.42 & -8.11\end{array}$

$\begin{array}{lllllllll}10 & 8.82 & -1.22 & 8.24 & 9.46 & -1.22 & 7.54 & 16.46 & -8.92\end{array}$

$\begin{array}{lllllllll}9.4 & 8.66 & -0.74 & 8.00 & 8.74 & -0.74 & 7.41 & 15.27 & -7.86\end{array}$

$\begin{array}{lllllllll}10.5 & 8.97 & -1.49 & 8.46 & 9.95 & -1.49 & 7.65 & 17.22 & -9.57\end{array}$

$\begin{array}{lllllllll}8.89 & 8.64 & -0.25 & 7.97 & 8.22 & -0.25 & 7.40 & 14.35 & -6.95\end{array}$

$\begin{array}{lllllllll}9.95 & 8.95 & -1.00 & 8.43 & 9.44 & -1.00 & 7.64 & 16.30 & -8.66\end{array}$

$\begin{array}{lllllllll}8.32 & 8.55 & 0.23 & 7.84 & 7.60 & 0.23 & 7.33 & 13.29 & -5.96\end{array}$

$\begin{array}{lllllllll}9.38 & 8.86 & -0.52 & 8.30 & 8.82 & -0.52 & 7.57 & 15.24 & -7.67\end{array}$

$\begin{array}{lllllllll}8.98 & 8.51 & -0.47 & 7.78 & 8.25 & -0.47 & 7.30 & 14.51 & -7.21\end{array}$

$\begin{array}{lllllllll}8.42 & 8.4 & -0.02 & 7.61 & 7.63 & -0.02 & 7.21 & 13.47 & -6.26\end{array}$

$\begin{array}{lllllllll}9.91 & 8.66 & -1.25 & 8.00 & 9.25 & -1.25 & 7.41 & 16.22 & -8.81\end{array}$

$\begin{array}{lllllllll}8.83 & 8.55 & -0.28 & 7.84 & 8.12 & -0.28 & 7.33 & 14.23 & -6.91\end{array}$

$\begin{array}{lllllllll}10.5 & 8.95 & -1.52 & 8.43 & 9.95 & -1.52 & 7.64 & 17.25 & -9.61\end{array}$

$\begin{array}{lllllllll}9.82 & 8.79 & -1.03 & 8.19 & 9.23 & -1.03 & 7.51 & 16.06 & -8.55\end{array}$

$\begin{array}{lllllllll}8.26 & 8.46 & 0.20 & 7.70 & 7.50 & 0.20 & 7.26 & 13.18 & -5.92\end{array}$

$\begin{array}{lllllllll}8.82 & 8.76 & -0.06 & 8.15 & 8.21 & -0.06 & 7.49 & 14.22 & -6.73\end{array}$

$\begin{array}{lllllllll}7.84 & 8.31 & 0.47 & 7.48 & 7.01 & 0.47 & 7.14 & 12.42 & -5.27\end{array}$

$\begin{array}{lllllllll}9.34 & 8.57 & -0.77 & 7.87 & 8.63 & -0.77 & 7.34 & 15.17 & -7.82\end{array}$

$\begin{array}{lllllllll}8.78 & 8.46 & -0.32 & 7.70 & 8.02 & -0.32 & 7.26 & 14.14 & -6.88\end{array}$

$\begin{array}{lllllllll}10.4 & 8.86 & -1.55 & 8.30 & 9.85 & -1.55 & 7.57 & 17.14 & -9.57\end{array}$

$\begin{array}{lllllllll}9.26 & 8.68 & -0.58 & 8.03 & 8.61 & -0.58 & 7.43 & 15.03 & -7.60\end{array}$

$\begin{array}{lllllllll}8.69 & 8.59 & -0.10 & 7.90 & 7.99 & -0.10 & 7.36 & 13.97 & -6.61\end{array}$

$\begin{array}{lllllllll}8.11 & 8.5 & 0.39 & 7.76 & 7.37 & 0.39 & 7.29 & 12.91 & -5.62\end{array}$

$\begin{array}{lllllllll}9.84 & 8.77 & -1.07 & 8.16 & 9.23 & -1.07 & 7.50 & 16.08 & -8.58\end{array}$

$\begin{array}{lllllllll}9.13 & 8.52 & -0.61 & 7.79 & 8.41 & -0.61 & 7.31 & 14.79 & -7.49\end{array}$

$\begin{array}{lllllllll}7.98 & 8.34 & 0.36 & 7.52 & 7.17 & 0.36 & 7.17 & 12.68 & -5.51\end{array}$

$\begin{array}{lllllllll}8.71 & 8.58 & -0.13 & 7.88 & 8.01 & -0.13 & 7.35 & 14.01 & -6.66\end{array}$

$\begin{array}{lllllllll}7.93 & 8.25 & 0.32 & 7.39 & 7.06 & 0.32 & 7.10 & 12.57 & -5.47\end{array}$

$\begin{array}{lllllllll}9.17 & 8.74 & -0.43 & 8.12 & 8.55 & -0.43 & 7.47 & 14.86 & -7.38\end{array}$

$\begin{array}{lllllllll}9.46 & 8.92 & -0.54 & 8.39 & 8.93 & -0.54 & 7.61 & 15.40 & -7.78\end{array}$

$\begin{array}{lllllllll}8.74 & 8.87 & 0.13 & 8.31 & 8.18 & 0.13 & 7.57 & 14.07 & -6.49\end{array}$ 
lgKoa lgKow lgKaw lgKow lgKoa lgKaw lgKow lgKoa lgKaw

$\mathrm{C}(\mathrm{C}(\mathrm{C}(\mathrm{C}(\mathrm{C}(\mathrm{C}(\mathrm{C}(\mathrm{C}(\mathrm{C}(\mathrm{C}(\mathrm{C}(\mathrm{C}(\mathrm{C}(\mathrm{C}(\mathrm{C}(\mathrm{C}(\mathrm{H})(\mathrm{F}) \mathrm{H})(\mathrm{H}) \mathrm{Br})(\mathrm{H}) \mathrm{H})(\mathrm{H}) \mathrm{F})(\mathrm{Br}) \mathrm{H})(\mathrm{H}) \mathrm{H})(\mathrm{H}) \mathrm{H})(\mathrm{H}) \mathrm{H})(\mathrm{Br}) \mathrm{H})(\mathrm{H}) \mathrm{H})(\mathrm{H})$

$\mathrm{H})(\mathrm{H}) \mathrm{H})(\mathrm{F}) \mathrm{H})(\mathrm{Br}) \mathrm{H})(\mathrm{H}) \mathrm{F})(\mathrm{H})(\mathrm{H}) \mathrm{H}$

$\mathrm{C} 16 \mathrm{H} 26 \mathrm{Br} 4 \mathrm{~F} 4$

_EPI_EPI_EPI_Exp___Exp__Exp__DFT_DFT_DFT

Suite Suite Suite corr corr corr_corr _corr corr

$\mathrm{C}(\mathrm{C}(\mathrm{C}(\mathrm{C}(\mathrm{C}(\mathrm{C}(\mathrm{C}(\mathrm{C}(\mathrm{C}(\mathrm{C}(\mathrm{C}(\mathrm{C}(\mathrm{C}(\mathrm{C}(\mathrm{C}(\mathrm{C}(\mathrm{Cl})(\mathrm{H}) \mathrm{H})(\mathrm{H}) \mathrm{H})(\mathrm{H}) \mathrm{H})(\mathrm{Cl}) \mathrm{H})(\mathrm{H}) \mathrm{H})(\mathrm{H}) \mathrm{H})(\mathrm{H}) \mathrm{Br})(\mathrm{H}) \mathrm{H})(\mathrm{H}) \mathrm{H})(\mathrm{Br}) \mathrm{H})(\mathrm{H})$

$\mathrm{H})(\mathrm{H}) \mathrm{H})(\mathrm{H}) \mathrm{F})(\mathrm{H}) \mathrm{F})(\mathrm{H}) \mathrm{H})(\mathrm{H})(\mathrm{H}) \mathrm{F}$

$\begin{array}{llllllllll}9.05 & 8.82 & -0.23 & 8.24 & 8.47 & -0.23 & 7.54 & 14.64 & -7.11\end{array}$

$\mathrm{C}\left(\mathrm{C}\left(\mathrm{C}\left(\mathrm{C}\left(\mathrm{C}\left(\mathrm{C}(\mathrm{C}(\mathrm{C}(\mathrm{C}(\mathrm{C}(\mathrm{C}(\mathrm{C}(\mathrm{C}(\mathrm{C}(\mathrm{C}(\mathrm{C}(\mathrm{H})(\mathrm{H}) \mathrm{H})(\mathrm{H}) \mathrm{H})(\mathrm{Br}) \mathrm{H})(\mathrm{Cl}) \mathrm{H})(\mathrm{F}) \mathrm{H})(\mathrm{H}) \mathrm{H})(\mathrm{Br}) \mathrm{H})(\mathrm{H}) \mathrm{H})(\mathrm{H}) \mathrm{H})(\mathrm{H}) \mathrm{H})(\mathrm{Br}){ }_{\mathrm{C} 16 \mathrm{H} 27 \mathrm{ClBr} 3 \mathrm{~F} 3}\right.\right.\right.\right.\right.$

$\mathrm{H})(\mathrm{H}) \mathrm{H})(\mathrm{H}) \mathrm{F})(\mathrm{H}) \mathrm{H})(\mathrm{H}) \mathrm{F})(\mathrm{H})(\mathrm{H}) \mathrm{H}$

CI6

$\begin{array}{lllllllll}8.41 & 8.85 & 0.44 & 8.28 & 7.85 & 0.44 & 7.56 & 13.46 & -5.91\end{array}$

$\begin{array}{lllllllll}8.84 & 8.79 & -0.05 & 8.19 & 8.24 & -0.05 & 7.51 & 14.25 & -6.73\end{array}$

$\mathrm{H})(\mathrm{H}) \mathrm{H})(\mathrm{H}) \mathrm{H})(\mathrm{H}) \mathrm{H})(\mathrm{H}) \mathrm{H})(\mathrm{H})(\mathrm{H}) \mathrm{H}$

$\mathrm{C} 16 \mathrm{H} 29 \mathrm{Br} 3 \mathrm{~F} 2$

$\begin{array}{lllllllll}8.63 & 8.74 & 0.11 & 8.12 & 8.01 & 0.11 & 7.47 & 13.87 & -6.40\end{array}$

$\mathrm{C}(\mathrm{C}(\mathrm{C}(\mathrm{C}(\mathrm{C}(\mathrm{C}(\mathrm{C}(\mathrm{C}(\mathrm{C}(\mathrm{C}(\mathrm{C}(\mathrm{C}(\mathrm{C}(\mathrm{C}(\mathrm{C}(\mathrm{C}(\mathrm{H})(\mathrm{H}) \mathrm{H})(\mathrm{H}) \mathrm{Br})(\mathrm{H}) \mathrm{H})(\mathrm{H}) \mathrm{H})(\mathrm{H}) \mathrm{H})(\mathrm{H}) \mathrm{H})(\mathrm{H}) \mathrm{H})(\mathrm{H}) \mathrm{H})(\mathrm{H}) \mathrm{F})(\mathrm{H}) \mathrm{H})$

$(\mathrm{H}) \mathrm{H})(\mathrm{H}) \mathrm{Br})(\mathrm{H}) \mathrm{Br})(\mathrm{H}) \mathrm{H})(\mathrm{H}) \mathrm{H})(\mathrm{H})(\mathrm{H}) \mathrm{H}$

C16H30Br3F

$\begin{array}{lllllllll}9.07 & 8.88 & -0.19 & 8.33 & 8.52 & -0.19 & 7.58 & 14.68 & -7.10\end{array}$

$\mathrm{C}(\mathrm{C}(\mathrm{C}(\mathrm{C}(\mathrm{C}(\mathrm{C}(\mathrm{C}(\mathrm{C}(\mathrm{C}(\mathrm{C}(\mathrm{C}(\mathrm{C}(\mathrm{C}(\mathrm{C}(\mathrm{C}(\mathrm{C}(\mathrm{H})(\mathrm{H}) \mathrm{H})(\mathrm{Br}) \mathrm{H})(\mathrm{H}) \mathrm{H})(\mathrm{H}) \mathrm{H})(\mathrm{H}) \mathrm{H})(\mathrm{Cl}) \mathrm{H})(\mathrm{H}) \mathrm{H})(\mathrm{H}) \mathrm{H})(\mathrm{H}) \mathrm{H})(\mathrm{H}) \mathrm{H})(\mathrm{H})$

$\mathrm{H})(\mathrm{Br}) \mathrm{H})(\mathrm{H}) \mathrm{H})(\mathrm{H}) \mathrm{H})(\mathrm{H}) \mathrm{H})(\mathrm{F})(\mathrm{H}) \mathrm{H}$

$\mathrm{C} 16 \mathrm{H} 30 \mathrm{ClBr} 2 \mathrm{~F}$

$\mathrm{C}(\mathrm{C}(\mathrm{C}) \mathrm{C}(\mathrm{C}(\mathrm{C}) \mathrm{C}(\mathrm{C}) \mathrm{C}(\mathrm{C}(\mathrm{C}) \mathrm{C}(\mathrm{C}(\mathrm{C}) \mathrm{C}$

$\mathrm{C} 16 \mathrm{H} 31 \mathrm{Cl} 2 \mathrm{Br}$

$\mathrm{H})(\mathrm{H}) \mathrm{H})(\mathrm{H}) \mathrm{H})(\mathrm{H}) \mathrm{H})(\mathrm{H}) \mathrm{H})(\mathrm{H})(\mathrm{H}) \mathrm{H}$

$\mathrm{C}(\mathrm{C}(\mathrm{C}(\mathrm{C}(\mathrm{C}(\mathrm{C}(\mathrm{C}(\mathrm{C}(\mathrm{C}(\mathrm{C}(\mathrm{C}(\mathrm{C}(\mathrm{C}(\mathrm{C}(\mathrm{C}(\mathrm{C}(\mathrm{H})(\mathrm{H}) \mathrm{H})(\mathrm{H}) \mathrm{H})(\mathrm{H}) \mathrm{H})(\mathrm{H}) \mathrm{H})(\mathrm{H}) \mathrm{H})(\mathrm{H}) \mathrm{H})(\mathrm{H}) \mathrm{H})(\mathrm{H}) \mathrm{H})(\mathrm{H}) \mathrm{H})(\mathrm{H}) \mathrm{H})$

$(\mathrm{H}) \mathrm{H})(\mathrm{H}) \mathrm{H})(\mathrm{Br}) \mathrm{H})(\mathrm{H}) \mathrm{H})(\mathrm{H}) \mathrm{H})(\mathrm{H})(\mathrm{Br}) \mathrm{Cl}$

$\mathrm{C} 16 \mathrm{H} 31 \mathrm{ClBr} 2$

$\mathrm{C}(\mathrm{C}(\mathrm{C}(\mathrm{C}(\mathrm{C}(\mathrm{C}(\mathrm{C}(\mathrm{C}(\mathrm{C}(\mathrm{C}(\mathrm{C}(\mathrm{C}(\mathrm{C}(\mathrm{C}(\mathrm{C}(\mathrm{C}(\mathrm{H})(\mathrm{H}) \mathrm{H})(\mathrm{H}) \mathrm{H})(\mathrm{H}) \mathrm{H})(\mathrm{H}) \mathrm{Br})(\mathrm{Br}) \mathrm{H})(\mathrm{H}) \mathrm{H})(\mathrm{H}) \mathrm{H})(\mathrm{H}) \mathrm{H})(\mathrm{H}) \mathrm{H})(\mathrm{H}) \mathrm{H})(\mathrm{H})$

$\mathrm{H})(\mathrm{H}) \mathrm{H})(\mathrm{H}) \mathrm{H})(\mathrm{H}) \mathrm{H})(\mathrm{H}) \mathrm{H})(\mathrm{H})(\mathrm{H}) \mathrm{H}$

$\mathrm{C} 16 \mathrm{H} 32 \mathrm{Br} 2$

$\begin{array}{lllllllll}8.57 & 8.86 & 0.29 & 8.30 & 8.00 & 0.29 & 7.57 & 13.75 & -6.18\end{array}$

$\begin{array}{lllllllll}8.35 & 8.83 & 0.48 & 8.25 & 7.77 & 0.48 & 7.54 & 13.35 & -5.8\end{array}$

$\begin{array}{lllllllll}9 & 8.99 & 0.00 & 8.49 & 8.50 & 0.00 & 7.67 & 14.54 & -6.87\end{array}$

$\begin{array}{lllllllll}8.29 & 8.74 & 0.45 & 8.12 & 7.67 & 0.45 & 7.47 & 13.24 & -5.77\end{array}$ 
the PXAs identified using partitioning space based on the EPISuite data corrected using DFT training results

SMILE Generated

$\mathrm{C}(\mathrm{C}(\mathrm{C}(\mathrm{C}(\mathrm{C}(\mathrm{C}(\mathrm{C}(\mathrm{C}(\mathrm{C}(\mathrm{C}(\mathrm{Br})(\mathrm{F}) \mathrm{Br})(\mathrm{Br}) \mathrm{H})(\mathrm{H}) \mathrm{H})(\mathrm{H}) \mathrm{F})(\mathrm{H}) \mathrm{F})(\mathrm{F}) \mathrm{Br})(\mathrm{H}) \mathrm{H})(\mathrm{F}) \mathrm{F})(\mathrm{H}) \mathrm{F})(\mathrm{H})(\mathrm{F}) \mathrm{H}$ $\mathrm{C}(\mathrm{C}(\mathrm{C}(\mathrm{C}(\mathrm{C}(\mathrm{C}(\mathrm{C}(\mathrm{C}(\mathrm{C}(\mathrm{C}(\mathrm{F})(\mathrm{H}) \mathrm{F})(\mathrm{H}) \mathrm{H})(\mathrm{Cl}) \mathrm{F})(\mathrm{H}) \mathrm{F})(\mathrm{H}) \mathrm{F})(\mathrm{Br}) \mathrm{Br})(\mathrm{H}) \mathrm{H})(\mathrm{H}) \mathrm{F})(\mathrm{H}) \mathrm{F})(\mathrm{Cl})(\mathrm{H}) \mathrm{F}$ $\mathrm{C}(\mathrm{C}(\mathrm{C}(\mathrm{C}(\mathrm{C}(\mathrm{C}(\mathrm{C}(\mathrm{C}(\mathrm{C}(\mathrm{C}(\mathrm{Cl})(\mathrm{F}) \mathrm{H})(\mathrm{H}) \mathrm{F})(\mathrm{F}) \mathrm{Br})(\mathrm{F}) \mathrm{H})(\mathrm{H}) \mathrm{H})(\mathrm{F}) \mathrm{F})(\mathrm{F}) \mathrm{H})(\mathrm{F}) \mathrm{F})(\mathrm{H}) \mathrm{H})(\mathrm{H})(\mathrm{H}) \mathrm{Cl}$ $\mathrm{C}(\mathrm{C}(\mathrm{C}(\mathrm{C}(\mathrm{C}(\mathrm{C}(\mathrm{C}(\mathrm{C}(\mathrm{C}(\mathrm{C}(\mathrm{F})(\mathrm{H}) \mathrm{H})(\mathrm{H}) \mathrm{Cl})(\mathrm{F}) \mathrm{H})(\mathrm{F}) \mathrm{Br})(\mathrm{F}) \mathrm{H})(\mathrm{H}) \mathrm{H})(\mathrm{H}) \mathrm{F})(\mathrm{H}) \mathrm{F})(\mathrm{Br}) \mathrm{Cl})(\mathrm{Cl})(\mathrm{H}) \mathrm{F}$ $\mathrm{C}(\mathrm{C}(\mathrm{C}(\mathrm{C}(\mathrm{C}(\mathrm{C}(\mathrm{C}(\mathrm{C}(\mathrm{C}(\mathrm{C}(\mathrm{F})(\mathrm{H}) \mathrm{H})(\mathrm{H}) \mathrm{F})(\mathrm{H}) \mathrm{Cl})(\mathrm{H}) \mathrm{F})(\mathrm{Cl}) \mathrm{Cl})(\mathrm{H}) \mathrm{H})(\mathrm{Br}) \mathrm{H})(\mathrm{F}) \mathrm{F})(\mathrm{H}) \mathrm{F})(\mathrm{H})(\mathrm{F}) \mathrm{F}$ $\mathrm{C}(\mathrm{C}(\mathrm{C}(\mathrm{C}(\mathrm{C}(\mathrm{C}(\mathrm{C}(\mathrm{C}(\mathrm{C}(\mathrm{C}(\mathrm{H})(\mathrm{F}) \mathrm{F})(\mathrm{Cl}) \mathrm{H})(\mathrm{H}) \mathrm{Cl})(\mathrm{F}) \mathrm{H})(\mathrm{H}) \mathrm{H})(\mathrm{Br}) \mathrm{H})(\mathrm{F}) \mathrm{Cl})(\mathrm{F}) \mathrm{H})(\mathrm{H}) \mathrm{F})(\mathrm{Cl})(\mathrm{H}) \mathrm{F}$ $\mathrm{C}(\mathrm{C}(\mathrm{C}(\mathrm{C}(\mathrm{C}(\mathrm{C}(\mathrm{C}(\mathrm{C}(\mathrm{C}(\mathrm{C}(\mathrm{H})(\mathrm{H}) \mathrm{F})(\mathrm{H}) \mathrm{F})(\mathrm{H}) \mathrm{F})(\mathrm{Cl}) \mathrm{H})(\mathrm{Cl}) \mathrm{F})(\mathrm{H}) \mathrm{F})(\mathrm{H}) \mathrm{F})(\mathrm{H}) \mathrm{F})(\mathrm{Cl}) \mathrm{F})(\mathrm{H})(\mathrm{H}) \mathrm{Cl}$ $\mathrm{C}(\mathrm{C}(\mathrm{C}(\mathrm{C}(\mathrm{C}(\mathrm{C}(\mathrm{C}(\mathrm{C}(\mathrm{C}(\mathrm{C}(\mathrm{H})(\mathrm{F}) \mathrm{Br})(\mathrm{H}) \mathrm{Cl})(\mathrm{F}) \mathrm{H})(\mathrm{Cl}) \mathrm{Cl})(\mathrm{H}) \mathrm{Cl})(\mathrm{H}) \mathrm{F})(\mathrm{H}) \mathrm{F})(\mathrm{F}) \mathrm{F})(\mathrm{H}) \mathrm{H})(\mathrm{H})(\mathrm{Cl}) \mathrm{H}$ $\mathrm{C}(\mathrm{C}(\mathrm{C}(\mathrm{C}(\mathrm{C}(\mathrm{C}(\mathrm{C}(\mathrm{C}(\mathrm{C}(\mathrm{C}(\mathrm{H})(\mathrm{F}) \mathrm{H})(\mathrm{Cl}) \mathrm{H})(\mathrm{H}) \mathrm{F})(\mathrm{H}) \mathrm{F})(\mathrm{F}) \mathrm{F})(\mathrm{Cl}) \mathrm{H})(\mathrm{F}) \mathrm{H})(\mathrm{Cl}) \mathrm{Cl})(\mathrm{H}) \mathrm{H})(\mathrm{F})(\mathrm{H}) \mathrm{Cl}$ $\mathrm{C}(\mathrm{C}(\mathrm{C}(\mathrm{C}(\mathrm{C}(\mathrm{C}(\mathrm{C}(\mathrm{C}(\mathrm{C}(\mathrm{C}(\mathrm{Cl})(\mathrm{H}) \mathrm{F})(\mathrm{H}) \mathrm{F})(\mathrm{F}) \mathrm{H})(\mathrm{H}) \mathrm{Cl})(\mathrm{Cl}) \mathrm{H})(\mathrm{Cl}) \mathrm{H})(\mathrm{Cl}) \mathrm{H})(\mathrm{Cl}) \mathrm{F})(\mathrm{F}) \mathrm{H})(\mathrm{H})(\mathrm{Cl}) \mathrm{H}$ $\mathrm{C}(\mathrm{C}(\mathrm{C}(\mathrm{C}(\mathrm{C}(\mathrm{C}(\mathrm{C}(\mathrm{C}(\mathrm{C}(\mathrm{C}(\mathrm{F})(\mathrm{F}) \mathrm{H})(\mathrm{F}) \mathrm{H})(\mathrm{F}) \mathrm{F})(\mathrm{H}) \mathrm{H})(\mathrm{Br}) \mathrm{F})(\mathrm{H}) \mathrm{H})(\mathrm{H}) \mathrm{Br})(\mathrm{F}) \mathrm{F})(\mathrm{F}) \mathrm{Cl})(\mathrm{H})(\mathrm{H}) \mathrm{H}$ $\mathrm{C}(\mathrm{C}(\mathrm{C}(\mathrm{C}(\mathrm{C}(\mathrm{C}(\mathrm{C}(\mathrm{C}(\mathrm{C}(\mathrm{C}(\mathrm{Br})(\mathrm{H}) \mathrm{H})(\mathrm{H}) \mathrm{Br})(\mathrm{F}) \mathrm{H})(\mathrm{F}) \mathrm{Cl})(\mathrm{Br}) \mathrm{H})(\mathrm{F}) \mathrm{F})(\mathrm{F}) \mathrm{H})(\mathrm{F}) \mathrm{H})(\mathrm{F}) \mathrm{F})(\mathrm{H})(\mathrm{H}) \mathrm{H}$ $\mathrm{C}(\mathrm{C}(\mathrm{C}(\mathrm{C}(\mathrm{C}(\mathrm{C}(\mathrm{C}(\mathrm{C}(\mathrm{C}(\mathrm{C}(\mathrm{F})(\mathrm{H}) \mathrm{F})(\mathrm{F}) \mathrm{H})(\mathrm{H}) \mathrm{H})(\mathrm{Br}) \mathrm{H})(\mathrm{H}) \mathrm{Br})(\mathrm{F}) \mathrm{H})(\mathrm{F}) \mathrm{F})(\mathrm{F}) \mathrm{H})(\mathrm{H}) \mathrm{H})(\mathrm{Br})(\mathrm{H}) \mathrm{F}$ $\mathrm{C}(\mathrm{C}(\mathrm{C}(\mathrm{C}(\mathrm{C}(\mathrm{C}(\mathrm{C}(\mathrm{C}(\mathrm{C}(\mathrm{C}(\mathrm{F})(\mathrm{H}) \mathrm{H})(\mathrm{F}) \mathrm{H})(\mathrm{Br}) \mathrm{H})(\mathrm{F}) \mathrm{Br})(\mathrm{Br}) \mathrm{F})(\mathrm{H}) \mathrm{H})(\mathrm{F}) \mathrm{H})(\mathrm{H}) \mathrm{F})(\mathrm{Br}) \mathrm{H})(\mathrm{H})(\mathrm{H}) \mathrm{F}$ $\mathrm{C}(\mathrm{C}(\mathrm{C}(\mathrm{C}(\mathrm{C}(\mathrm{C}(\mathrm{C}(\mathrm{C}(\mathrm{C}(\mathrm{C}(\mathrm{F})(\mathrm{Br}) \mathrm{H})(\mathrm{F}) \mathrm{Cl})(\mathrm{F}) \mathrm{F})(\mathrm{F}) \mathrm{H})(\mathrm{Cl}) \mathrm{H})(\mathrm{H}) \mathrm{H})(\mathrm{H}) \mathrm{H})(\mathrm{H}) \mathrm{Br})(\mathrm{F}) \mathrm{F})(\mathrm{H})(\mathrm{H}) \mathrm{H}$ $\mathrm{C}(\mathrm{C}(\mathrm{C}(\mathrm{C}(\mathrm{C}(\mathrm{C}(\mathrm{C}(\mathrm{C}(\mathrm{C}(\mathrm{C}(\mathrm{Br})(\mathrm{F}) \mathrm{H})(\mathrm{H}) \mathrm{H})(\mathrm{Cl}) \mathrm{F})(\mathrm{H}) \mathrm{H})(\mathrm{H}) \mathrm{F})(\mathrm{F}) \mathrm{F})(\mathrm{Cl}) \mathrm{F})(\mathrm{H}) \mathrm{H})(\mathrm{F}) \mathrm{H})(\mathrm{H})(\mathrm{F}) \mathrm{H}$ $\mathrm{C}(\mathrm{C}(\mathrm{C}(\mathrm{C}(\mathrm{C}(\mathrm{C}(\mathrm{C}(\mathrm{C}(\mathrm{C}(\mathrm{C}(\mathrm{F})(\mathrm{H}) \mathrm{F})(\mathrm{H}) \mathrm{F})(\mathrm{H}) \mathrm{Br})(\mathrm{H}) \mathrm{H})(\mathrm{F}) \mathrm{H})(\mathrm{Br}) \mathrm{F})(\mathrm{H}) \mathrm{Cl})(\mathrm{H}) \mathrm{F})(\mathrm{H}) \mathrm{H})(\mathrm{H})(\mathrm{Cl}) \mathrm{Cl}$ $\mathrm{C}(\mathrm{C}(\mathrm{C}(\mathrm{C}(\mathrm{C}(\mathrm{C}(\mathrm{C}(\mathrm{C}(\mathrm{C}(\mathrm{C}(\mathrm{H})(\mathrm{F}) \mathrm{Br})(\mathrm{H}) \mathrm{H})(\mathrm{H}) \mathrm{Cl})(\mathrm{H}) \mathrm{F})(\mathrm{H}) \mathrm{F})(\mathrm{H}) \mathrm{H})(\mathrm{F}) \mathrm{H})(\mathrm{Cl}) \mathrm{F})(\mathrm{Cl}) \mathrm{F})(\mathrm{H})(\mathrm{H}) \mathrm{F}$ $\mathrm{C}(\mathrm{C}(\mathrm{C}(\mathrm{C}(\mathrm{C}(\mathrm{C}(\mathrm{C}(\mathrm{C}(\mathrm{C}(\mathrm{C}(\mathrm{F})(\mathrm{F}) \mathrm{H})(\mathrm{F}) \mathrm{H})(\mathrm{Cl}) \mathrm{H})(\mathrm{F}) \mathrm{H})(\mathrm{H}) \mathrm{H})(\mathrm{Cl}) \mathrm{H})(\mathrm{Cl}) \mathrm{H})(\mathrm{Cl}) \mathrm{H})(\mathrm{Br}) \mathrm{H})(\mathrm{F})(\mathrm{F}) \mathrm{H}$ $\mathrm{C}(\mathrm{C}(\mathrm{C}(\mathrm{C}(\mathrm{C}(\mathrm{C}(\mathrm{C}(\mathrm{C}(\mathrm{C}(\mathrm{C}(\mathrm{Cl})(\mathrm{F}) \mathrm{H})(\mathrm{H}) \mathrm{H})(\mathrm{Cl}) \mathrm{Cl})(\mathrm{H}) \mathrm{Cl})(\mathrm{H}) \mathrm{H})(\mathrm{H}) \mathrm{Br})(\mathrm{H}) \mathrm{F})(\mathrm{Cl}) \mathrm{F})(\mathrm{H}) \mathrm{F})(\mathrm{H})(\mathrm{F}) \mathrm{H}$ $\mathrm{C}(\mathrm{C}(\mathrm{C}(\mathrm{C}(\mathrm{C}(\mathrm{C}(\mathrm{C}(\mathrm{C}(\mathrm{C}(\mathrm{C}(\mathrm{H})(\mathrm{F}) \mathrm{F})(\mathrm{H}) \mathrm{F})(\mathrm{Cl}) \mathrm{H})(\mathrm{H}) \mathrm{Cl})(\mathrm{H}) \mathrm{H})(\mathrm{Cl}) \mathrm{F})(\mathrm{Cl}) \mathrm{F})(\mathrm{Cl}) \mathrm{H})(\mathrm{H}) \mathrm{H})(\mathrm{F})(\mathrm{H}) \mathrm{H}$ $\mathrm{C}(\mathrm{C}(\mathrm{C}(\mathrm{C}(\mathrm{C}(\mathrm{C}(\mathrm{C}(\mathrm{C}(\mathrm{C}(\mathrm{C}(\mathrm{Cl})(\mathrm{Cl}) \mathrm{Cl})(\mathrm{F}) \mathrm{F})(\mathrm{F}) \mathrm{Cl})(\mathrm{Cl}) \mathrm{H})(\mathrm{F}) \mathrm{H})(\mathrm{H}) \mathrm{H})(\mathrm{H}) \mathrm{Cl})(\mathrm{F}) \mathrm{H})(\mathrm{H}) \mathrm{H})(\mathrm{H})(\mathrm{H}) \mathrm{H}$ $\mathrm{C}(\mathrm{C}(\mathrm{C}(\mathrm{C}(\mathrm{C}(\mathrm{C}(\mathrm{C}(\mathrm{C}(\mathrm{C}(\mathrm{C}(\mathrm{F})(\mathrm{F}) \mathrm{H})(\mathrm{H}) \mathrm{H})(\mathrm{F}) \mathrm{H})(\mathrm{Cl}) \mathrm{H})(\mathrm{H}) \mathrm{Cl})(\mathrm{Cl}) \mathrm{H})(\mathrm{Cl}) \mathrm{Cl})(\mathrm{H}) \mathrm{F})(\mathrm{Cl}) \mathrm{H})(\mathrm{Cl})(\mathrm{H}) \mathrm{H}$ $\mathrm{C}(\mathrm{C}(\mathrm{C}(\mathrm{C}(\mathrm{C}(\mathrm{C}(\mathrm{C}(\mathrm{C}(\mathrm{C}(\mathrm{C}(\mathrm{H})(\mathrm{Br}) \mathrm{F})(\mathrm{Cl}) \mathrm{H})(\mathrm{F}) \mathrm{H})(\mathrm{H}) \mathrm{H})(\mathrm{F}) \mathrm{H})(\mathrm{Br}) \mathrm{F})(\mathrm{H}) \mathrm{F})(\mathrm{F}) \mathrm{Br})(\mathrm{H}) \mathrm{H})(\mathrm{H})(\mathrm{H}) \mathrm{F}$ $\mathrm{C}(\mathrm{C}(\mathrm{C}(\mathrm{C}(\mathrm{C}(\mathrm{C}(\mathrm{C}(\mathrm{C}(\mathrm{C}(\mathrm{C}(\mathrm{Br})(\mathrm{H}) \mathrm{H})(\mathrm{F}) \mathrm{F})(\mathrm{Br}) \mathrm{H})(\mathrm{F}) \mathrm{H})(\mathrm{H}) \mathrm{H})(\mathrm{H}) \mathrm{H})(\mathrm{H}) \mathrm{H})(\mathrm{F}) \mathrm{F})(\mathrm{H}) \mathrm{F})(\mathrm{H})(\mathrm{F}) \mathrm{Br}$ $\mathrm{C}(\mathrm{C}(\mathrm{C}(\mathrm{C}(\mathrm{C}(\mathrm{C}(\mathrm{C}(\mathrm{C}(\mathrm{C}(\mathrm{C}(\mathrm{H})(\mathrm{H}) \mathrm{Cl})(\mathrm{H}) \mathrm{H})(\mathrm{F}) \mathrm{H})(\mathrm{H}) \mathrm{Cl})(\mathrm{F}) \mathrm{H})(\mathrm{Br}) \mathrm{F})(\mathrm{H}) \mathrm{F})(\mathrm{H}) \mathrm{F})(\mathrm{H}) \mathrm{Br})(\mathrm{F})(\mathrm{H}) \mathrm{H}$ $\mathrm{C}(\mathrm{C}(\mathrm{C}(\mathrm{C}(\mathrm{C}(\mathrm{C}(\mathrm{C}(\mathrm{C}(\mathrm{C}(\mathrm{C}(\mathrm{H})(\mathrm{H}) \mathrm{F})(\mathrm{H}) \mathrm{Cl})(\mathrm{H}) \mathrm{H})(\mathrm{Br}) \mathrm{Cl})(\mathrm{H}) \mathrm{Br})(\mathrm{H}) \mathrm{H})(\mathrm{Br}) \mathrm{H})(\mathrm{F}) \mathrm{H})(\mathrm{F}) \mathrm{H})(\mathrm{H})(\mathrm{F}) \mathrm{F}$ $\mathrm{C}(\mathrm{C}(\mathrm{C}(\mathrm{C}(\mathrm{C}(\mathrm{C}(\mathrm{C}(\mathrm{C}(\mathrm{C}(\mathrm{C}(\mathrm{H})(\mathrm{F}) \mathrm{H})(\mathrm{H}) \mathrm{H})(\mathrm{F}) \mathrm{H})(\mathrm{Br}) \mathrm{H})(\mathrm{F}) \mathrm{Cl})(\mathrm{H}) \mathrm{H})(\mathrm{F}) \mathrm{Cl})(\mathrm{F}) \mathrm{H})(\mathrm{H}) \mathrm{F})(\mathrm{H})(\mathrm{H}) \mathrm{Cl}$ $\mathrm{C}(\mathrm{C}(\mathrm{C}(\mathrm{C}(\mathrm{C}(\mathrm{C}(\mathrm{C}(\mathrm{C}(\mathrm{C}(\mathrm{C}(\mathrm{F})(\mathrm{Cl}) \mathrm{H})(\mathrm{H}) \mathrm{H})(\mathrm{H}) \mathrm{H})(\mathrm{H}) \mathrm{H})(\mathrm{H}) \mathrm{H})(\mathrm{F}) \mathrm{H})(\mathrm{F}) \mathrm{F})(\mathrm{F}) \mathrm{F})(\mathrm{H}) \mathrm{H})(\mathrm{F})(\mathrm{Cl}) \mathrm{Cl}$ $\mathrm{C}(\mathrm{C}(\mathrm{C}(\mathrm{C}(\mathrm{C}(\mathrm{C}(\mathrm{C}(\mathrm{C}(\mathrm{C}(\mathrm{C}(\mathrm{Cl})(\mathrm{Cl}) \mathrm{H})(\mathrm{Cl}) \mathrm{F})(\mathrm{Cl}) \mathrm{H})(\mathrm{H}) \mathrm{H})(\mathrm{H}) \mathrm{H})(\mathrm{H}) \mathrm{H})(\mathrm{F}) \mathrm{Br})(\mathrm{H}) \mathrm{F})(\mathrm{F}) \mathrm{H})(\mathrm{F})(\mathrm{H}) \mathrm{H}$ $\mathrm{C}(\mathrm{C}(\mathrm{C}(\mathrm{C}(\mathrm{C}(\mathrm{C}(\mathrm{C}(\mathrm{C}(\mathrm{C}(\mathrm{C}(\mathrm{H})(\mathrm{H}) \mathrm{Cl})(\mathrm{H}) \mathrm{F})(\mathrm{H}) \mathrm{H})(\mathrm{F}) \mathrm{F})(\mathrm{H}) \mathrm{F})(\mathrm{H}) \mathrm{Cl})(\mathrm{H}) \mathrm{H})(\mathrm{F}) \mathrm{Cl})(\mathrm{F}) \mathrm{H})(\mathrm{H})(\mathrm{H}) \mathrm{Cl}$ $\mathrm{C}(\mathrm{C}(\mathrm{C}(\mathrm{C}(\mathrm{C}(\mathrm{C}(\mathrm{C}(\mathrm{C}(\mathrm{C}(\mathrm{C}(\mathrm{F})(\mathrm{H}) \mathrm{H})(\mathrm{Cl}) \mathrm{Cl})(\mathrm{H}) \mathrm{F})(\mathrm{H}) \mathrm{Cl})(\mathrm{F}) \mathrm{F})(\mathrm{Cl}) \mathrm{H})(\mathrm{H}) \mathrm{H})(\mathrm{H}) \mathrm{H})(\mathrm{Cl}) \mathrm{H})(\mathrm{H})(\mathrm{F}) \mathrm{H}$ $\mathrm{C}(\mathrm{C}(\mathrm{C}(\mathrm{C}(\mathrm{C}(\mathrm{C}(\mathrm{C}(\mathrm{C}(\mathrm{C}(\mathrm{C}(\mathrm{H})(\mathrm{Cl}) \mathrm{H})(\mathrm{H}) \mathrm{Cl})(\mathrm{Cl}) \mathrm{H})(\mathrm{F}) \mathrm{H})(\mathrm{Cl}) \mathrm{H})(\mathrm{H}) \mathrm{H})(\mathrm{H}) \mathrm{H})(\mathrm{Cl}) \mathrm{F})(\mathrm{F}) \mathrm{F})(\mathrm{H})(\mathrm{H}) \mathrm{C}$ $\mathrm{C}(\mathrm{C}(\mathrm{C}(\mathrm{C}(\mathrm{C}(\mathrm{C}(\mathrm{C}(\mathrm{C}(\mathrm{C}(\mathrm{C}(\mathrm{Br})(\mathrm{F}) \mathrm{H})(\mathrm{H}) \mathrm{F})(\mathrm{H}) \mathrm{H})(\mathrm{F}) \mathrm{F})(\mathrm{H}) \mathrm{Cl})(\mathrm{H}) \mathrm{F})(\mathrm{H}) \mathrm{H})(\mathrm{Br}) \mathrm{H})(\mathrm{H}) \mathrm{F})(\mathrm{F})(\mathrm{H}) \mathrm{H}$ $\mathrm{C}(\mathrm{C}(\mathrm{C}(\mathrm{C}(\mathrm{C}(\mathrm{C}(\mathrm{C}(\mathrm{C}(\mathrm{C}(\mathrm{C}(\mathrm{Cl})(\mathrm{H}) \mathrm{F})(\mathrm{H}) \mathrm{F})(\mathrm{F}) \mathrm{Br})(\mathrm{Br}) \mathrm{H})(\mathrm{H}) \mathrm{H})(\mathrm{Br}) \mathrm{H})(\mathrm{H}) \mathrm{F})(\mathrm{H}) \mathrm{H})(\mathrm{H}) \mathrm{F})(\mathrm{F})(\mathrm{H}) \mathrm{H}$ $\mathrm{C}(\mathrm{C}(\mathrm{C}(\mathrm{C}(\mathrm{C}(\mathrm{C}(\mathrm{C}(\mathrm{C}(\mathrm{C}(\mathrm{C}(\mathrm{H})(\mathrm{F}) \mathrm{H})(\mathrm{F}) \mathrm{H})(\mathrm{F}) \mathrm{H})(\mathrm{H}) \mathrm{H})(\mathrm{Cl}) \mathrm{F})(\mathrm{H}) \mathrm{H})(\mathrm{Br}) \mathrm{F})(\mathrm{F}) \mathrm{F})(\mathrm{H}) \mathrm{F})(\mathrm{H})(\mathrm{H}) \mathrm{H}$ $\mathrm{C}(\mathrm{C}(\mathrm{C}(\mathrm{C}(\mathrm{C}(\mathrm{C}(\mathrm{C}(\mathrm{C}(\mathrm{C}(\mathrm{C}(\mathrm{H})(\mathrm{H}) \mathrm{F})(\mathrm{F}) \mathrm{Br})(\mathrm{F}) \mathrm{H})(\mathrm{H}) \mathrm{Br})(\mathrm{H}) \mathrm{F})(\mathrm{F}) \mathrm{F})(\mathrm{H}) \mathrm{H})(\mathrm{Br}) \mathrm{H})(\mathrm{H}) \mathrm{H})(\mathrm{H})(\mathrm{H}) \mathrm{H}$ $\mathrm{C}(\mathrm{C}(\mathrm{C}(\mathrm{C}(\mathrm{C}(\mathrm{C}(\mathrm{C}(\mathrm{C}(\mathrm{C}(\mathrm{C}(\mathrm{H})(\mathrm{H}) \mathrm{H})(\mathrm{H}) \mathrm{H})(\mathrm{F}) \mathrm{F})(\mathrm{H}) \mathrm{H})(\mathrm{H}) \mathrm{Cl})(\mathrm{Br}) \mathrm{F})(\mathrm{F}) \mathrm{Cl})(\mathrm{F}) \mathrm{H})(\mathrm{H}) \mathrm{Br})(\mathrm{H})(\mathrm{H}) \mathrm{H}$ $\mathrm{C}(\mathrm{C}(\mathrm{C}(\mathrm{C}(\mathrm{C}(\mathrm{C}(\mathrm{C}(\mathrm{C}(\mathrm{C}(\mathrm{C}(\mathrm{H})(\mathrm{H}) \mathrm{H})(\mathrm{Br}) \mathrm{H})(\mathrm{H}) \mathrm{H})(\mathrm{H}) \mathrm{F})(\mathrm{Cl}) \mathrm{H})(\mathrm{H}) \mathrm{F})(\mathrm{H}) \mathrm{H})(\mathrm{H}) \mathrm{F})(\mathrm{H}) \mathrm{Cl})(\mathrm{F})(\mathrm{F}) \mathrm{F}$ $\mathrm{C}(\mathrm{C}(\mathrm{C}(\mathrm{C}(\mathrm{C}(\mathrm{C}(\mathrm{C}(\mathrm{C}(\mathrm{C}(\mathrm{C}(\mathrm{Cl})(\mathrm{H}) \mathrm{H})(\mathrm{H}) \mathrm{H})(\mathrm{F}) \mathrm{Cl})(\mathrm{Br}) \mathrm{H})(\mathrm{H}) \mathrm{H})(\mathrm{F}) \mathrm{H})(\mathrm{H}) \mathrm{H})(\mathrm{F}) \mathrm{Cl})(\mathrm{H}) \mathrm{H})(\mathrm{F})(\mathrm{F}) \mathrm{H}$ $\mathrm{C}(\mathrm{C}(\mathrm{C}(\mathrm{C}(\mathrm{C}(\mathrm{C}(\mathrm{C}(\mathrm{C}(\mathrm{C}(\mathrm{C}(\mathrm{H})(\mathrm{F}) \mathrm{H})(\mathrm{H}) \mathrm{H})(\mathrm{H}) \mathrm{F})(\mathrm{H}) \mathrm{H})(\mathrm{F}) \mathrm{F})(\mathrm{H}) \mathrm{F})(\mathrm{H}) \mathrm{H})(\mathrm{Cl}) \mathrm{F})(\mathrm{Cl}) \mathrm{H})(\mathrm{H})(\mathrm{H}) \mathrm{Cl}$ $\mathrm{C}(\mathrm{C}(\mathrm{C}(\mathrm{C}(\mathrm{C}(\mathrm{C}(\mathrm{C}(\mathrm{C}(\mathrm{C}(\mathrm{C}(\mathrm{H})(\mathrm{Br}) \mathrm{H})(\mathrm{H}) \mathrm{H})(\mathrm{H}) \mathrm{F})(\mathrm{Cl}) \mathrm{Cl})(\mathrm{F}) \mathrm{H})(\mathrm{H}) \mathrm{F})(\mathrm{Cl}) \mathrm{H})(\mathrm{H}) \mathrm{H})(\mathrm{F}) \mathrm{H})(\mathrm{Cl})(\mathrm{H}) \mathrm{H}$ $\mathrm{C}(\mathrm{C}(\mathrm{C}(\mathrm{C}(\mathrm{C}(\mathrm{C}(\mathrm{C}(\mathrm{C}(\mathrm{C}(\mathrm{C}(\mathrm{H})(\mathrm{F}) \mathrm{H})(\mathrm{H}) \mathrm{Cl})(\mathrm{H}) \mathrm{H})(\mathrm{F}) \mathrm{Cl})(\mathrm{H}) \mathrm{H})(\mathrm{H}) \mathrm{F})(\mathrm{H}) \mathrm{F})(\mathrm{H}) \mathrm{F})(\mathrm{Cl}) \mathrm{Cl})(\mathrm{H})(\mathrm{H}) \mathrm{H}$ $\mathrm{C}(\mathrm{C}(\mathrm{C}(\mathrm{C}(\mathrm{C}(\mathrm{C}(\mathrm{C}(\mathrm{C}(\mathrm{C}(\mathrm{C}(\mathrm{Cl})(\mathrm{Cl}) \mathrm{Cl})(\mathrm{F}) \mathrm{H})(\mathrm{F}) \mathrm{H})(\mathrm{H}) \mathrm{F})(\mathrm{H}) \mathrm{H})(\mathrm{H}) \mathrm{H})(\mathrm{Cl}) \mathrm{H})(\mathrm{F}) \mathrm{H})(\mathrm{H}) \mathrm{H})(\mathrm{H})(\mathrm{Cl}) \mathrm{H}$ $\mathrm{C}(\mathrm{C}(\mathrm{C}(\mathrm{C}(\mathrm{C}(\mathrm{C}(\mathrm{C}(\mathrm{C}(\mathrm{C}(\mathrm{C}(\mathrm{F})(\mathrm{H}) \mathrm{Cl})(\mathrm{H}) \mathrm{Cl})(\mathrm{H}) \mathrm{Cl})(\mathrm{H}) \mathrm{H})(\mathrm{H}) \mathrm{H})(\mathrm{F}) \mathrm{H})(\mathrm{H}) \mathrm{H})(\mathrm{F}) \mathrm{Cl})(\mathrm{H}) \mathrm{Cl})(\mathrm{H})(\mathrm{Cl}) \mathrm{H}$ $\mathrm{C}(\mathrm{C}(\mathrm{C}(\mathrm{C}(\mathrm{C}(\mathrm{C}(\mathrm{C}(\mathrm{C}(\mathrm{C}(\mathrm{C}(\mathrm{H})(\mathrm{Cl}) \mathrm{H})(\mathrm{H}) \mathrm{Br})(\mathrm{H}) \mathrm{H})(\mathrm{H}) \mathrm{F})(\mathrm{F}) \mathrm{H})(\mathrm{H}) \mathrm{H})(\mathrm{F}) \mathrm{H})(\mathrm{H}) \mathrm{Br})(\mathrm{H}) \mathrm{Br})(\mathrm{F})(\mathrm{F}) \mathrm{H}$ $\mathrm{C}(\mathrm{C}(\mathrm{C}(\mathrm{C}(\mathrm{C}(\mathrm{C}(\mathrm{C}(\mathrm{C}(\mathrm{C}(\mathrm{C}(\mathrm{Br})(\mathrm{F}) \mathrm{F})(\mathrm{H}) \mathrm{H})(\mathrm{H}) \mathrm{H})(\mathrm{H}) \mathrm{H})(\mathrm{Br}) \mathrm{H})(\mathrm{H}) \mathrm{H})(\mathrm{F}) \mathrm{H})(\mathrm{H}) \mathrm{F})(\mathrm{F}) \mathrm{F})(\mathrm{H})(\mathrm{H}) \mathrm{H}$ $\mathrm{C}(\mathrm{C}(\mathrm{C}(\mathrm{C}(\mathrm{C}(\mathrm{C}(\mathrm{C}(\mathrm{C}(\mathrm{C}(\mathrm{C}(\mathrm{H})(\mathrm{F}) \mathrm{F})(\mathrm{H}) \mathrm{H})(\mathrm{Br}) \mathrm{Br})(\mathrm{H}) \mathrm{H})(\mathrm{H}) \mathrm{H})(\mathrm{H}) \mathrm{H})(\mathrm{F}) \mathrm{H})(\mathrm{H}) \mathrm{H})(\mathrm{F}) \mathrm{Br})(\mathrm{H})(\mathrm{H}) \mathrm{F}$ $\mathrm{C}(\mathrm{C}(\mathrm{C}(\mathrm{C}(\mathrm{C}(\mathrm{C}(\mathrm{C}(\mathrm{C}(\mathrm{C}(\mathrm{C}(\mathrm{F})(\mathrm{H}) \mathrm{H})(\mathrm{H}) \mathrm{H})(\mathrm{Cl}) \mathrm{H})(\mathrm{H}) \mathrm{H})(\mathrm{F}) \mathrm{Cl})(\mathrm{H}) \mathrm{F})(\mathrm{H}) \mathrm{H})(\mathrm{H}) \mathrm{Br})(\mathrm{F}) \mathrm{H})(\mathrm{H})(\mathrm{Br}) \mathrm{H}$ $\mathrm{C}(\mathrm{C}(\mathrm{C}(\mathrm{C}(\mathrm{C}(\mathrm{C}(\mathrm{C}(\mathrm{C}(\mathrm{C}(\mathrm{C}(\mathrm{F})(\mathrm{Cl}) \mathrm{H})(\mathrm{F}) \mathrm{F})(\mathrm{H}) \mathrm{H})(\mathrm{H}) \mathrm{H})(\mathrm{F}) \mathrm{H})(\mathrm{H}) \mathrm{H})(\mathrm{H}) \mathrm{H})(\mathrm{Cl}) \mathrm{F})(\mathrm{H}) \mathrm{Br})(\mathrm{H})(\mathrm{H}) \mathrm{H}$ $\mathrm{C}(\mathrm{C}(\mathrm{C}(\mathrm{C}(\mathrm{C}(\mathrm{C}(\mathrm{C}(\mathrm{C}(\mathrm{C}(\mathrm{C}(\mathrm{H})(\mathrm{H}) \mathrm{H})(\mathrm{H}) \mathrm{F})(\mathrm{H}) \mathrm{Br})(\mathrm{F}) \mathrm{F})(\mathrm{Cl}) \mathrm{H})(\mathrm{H}) \mathrm{H})(\mathrm{H}) \mathrm{H})(\mathrm{H}) \mathrm{Cl})(\mathrm{H}) \mathrm{Br})(\mathrm{Cl})(\mathrm{H}) \mathrm{H}$ $\mathrm{C}(\mathrm{C}(\mathrm{C}(\mathrm{C}(\mathrm{C}(\mathrm{C}(\mathrm{C}(\mathrm{C}(\mathrm{C}(\mathrm{C}(\mathrm{H})(\mathrm{H}) \mathrm{H})(\mathrm{H}) \mathrm{H})(\mathrm{H}) \mathrm{Cl})(\mathrm{F}) \mathrm{F})(\mathrm{H}) \mathrm{Br})(\mathrm{F}) \mathrm{H})(\mathrm{H}) \mathrm{Cl})(\mathrm{H}) \mathrm{H})(\mathrm{F}) \mathrm{H})(\mathrm{Cl})(\mathrm{H}) \mathrm{H}$ $\mathrm{C}(\mathrm{C}(\mathrm{C}(\mathrm{C}(\mathrm{C}(\mathrm{C}(\mathrm{C}(\mathrm{C}(\mathrm{C}(\mathrm{C}(\mathrm{H})(\mathrm{H}) \mathrm{H})(\mathrm{Cl}) \mathrm{H})(\mathrm{H}) \mathrm{H})(\mathrm{F}) \mathrm{F})(\mathrm{Cl}) \mathrm{H})(\mathrm{H}) \mathrm{Cl})(\mathrm{Cl}) \mathrm{H})(\mathrm{H}) \mathrm{H})(\mathrm{H}) \mathrm{H})(\mathrm{F})(\mathrm{Br}) \mathrm{H}$ $\mathrm{C}(\mathrm{C}(\mathrm{C}(\mathrm{C}(\mathrm{C}(\mathrm{C}(\mathrm{C}(\mathrm{C}(\mathrm{C}(\mathrm{C}(\mathrm{Cl})(\mathrm{F}) \mathrm{F})(\mathrm{F}) \mathrm{H})(\mathrm{H}) \mathrm{H})(\mathrm{H}) \mathrm{Cl})(\mathrm{Cl}) \mathrm{H})(\mathrm{H}) \mathrm{H})(\mathrm{Cl}) \mathrm{H})(\mathrm{H}) \mathrm{H})(\mathrm{H}) \mathrm{F})(\mathrm{H})(\mathrm{H}) \mathrm{H}$ $\mathrm{C}(\mathrm{C}(\mathrm{C}(\mathrm{C}(\mathrm{C}(\mathrm{C}(\mathrm{C}(\mathrm{C}(\mathrm{C}(\mathrm{C}(\mathrm{Cl})(\mathrm{H}) \mathrm{H})(\mathrm{F}) \mathrm{F})(\mathrm{H}) \mathrm{H})(\mathrm{Cl}) \mathrm{Cl})(\mathrm{H}) \mathrm{H})(\mathrm{H}) \mathrm{Cl})(\mathrm{H}) \mathrm{H})(\mathrm{Cl}) \mathrm{H})(\mathrm{F}) \mathrm{H})(\mathrm{H})(\mathrm{H}) \mathrm{H}$ $\mathrm{C}(\mathrm{C}(\mathrm{C}(\mathrm{C}(\mathrm{C}(\mathrm{C}(\mathrm{C}(\mathrm{C}(\mathrm{C}(\mathrm{C}(\mathrm{Cl})(\mathrm{H}) \mathrm{Cl})(\mathrm{F}) \mathrm{H})(\mathrm{H}) \mathrm{F})(\mathrm{H}) \mathrm{H})(\mathrm{Cl}) \mathrm{H})(\mathrm{Cl}) \mathrm{H})(\mathrm{H}) \mathrm{H})(\mathrm{H}) \mathrm{Cl})(\mathrm{H}) \mathrm{H})(\mathrm{Cl})(\mathrm{H}) \mathrm{H}$ $\mathrm{C}(\mathrm{C}(\mathrm{C}(\mathrm{C}(\mathrm{C}(\mathrm{C}(\mathrm{C}(\mathrm{C}(\mathrm{C}(\mathrm{C}(\mathrm{H})(\mathrm{F}) \mathrm{H})(\mathrm{H}) \mathrm{H})(\mathrm{Br}) \mathrm{H})(\mathrm{F}) \mathrm{H})(\mathrm{Br}) \mathrm{H})(\mathrm{H}) \mathrm{Cl})(\mathrm{H}) \mathrm{F})(\mathrm{F}) \mathrm{H})(\mathrm{H}) \mathrm{H})(\mathrm{F})(\mathrm{H}) \mathrm{H}$ $\mathrm{C}(\mathrm{C}(\mathrm{C}(\mathrm{C}(\mathrm{C}(\mathrm{C}(\mathrm{C}(\mathrm{C}(\mathrm{C}(\mathrm{C}(\mathrm{H})(\mathrm{H}) \mathrm{H})(\mathrm{H}) \mathrm{H})(\mathrm{H}) \mathrm{F})(\mathrm{Br}) \mathrm{F})(\mathrm{H}) \mathrm{H})(\mathrm{F}) \mathrm{F})(\mathrm{H}) \mathrm{H})(\mathrm{Cl}) \mathrm{H})(\mathrm{H}) \mathrm{H})(\mathrm{F})(\mathrm{H}) \mathrm{F}$ $\mathrm{C}(\mathrm{C}(\mathrm{C}(\mathrm{C}(\mathrm{C}(\mathrm{C}(\mathrm{C}(\mathrm{C}(\mathrm{C}(\mathrm{C}(\mathrm{F})(\mathrm{F}) \mathrm{F})(\mathrm{Br}) \mathrm{Br})(\mathrm{H}) \mathrm{H})(\mathrm{H}) \mathrm{H})(\mathrm{H}) \mathrm{H})(\mathrm{H}) \mathrm{H})(\mathrm{H}) \mathrm{H})(\mathrm{H}) \mathrm{Br})(\mathrm{H}) \mathrm{H})(\mathrm{H})(\mathrm{H}) \mathrm{F}$ $\mathrm{C}(\mathrm{C}(\mathrm{C}(\mathrm{C}(\mathrm{C}(\mathrm{C}(\mathrm{C}(\mathrm{C}(\mathrm{C}(\mathrm{C}(\mathrm{H})(\mathrm{Cl}) \mathrm{H})(\mathrm{F}) \mathrm{F})(\mathrm{F}) \mathrm{H})(\mathrm{H}) \mathrm{H})(\mathrm{H}) \mathrm{H})(\mathrm{H}) \mathrm{H})(\mathrm{H}) \mathrm{Cl})(\mathrm{H}) \mathrm{Br})(\mathrm{H}) \mathrm{Br})(\mathrm{H})(\mathrm{H}) \mathrm{H}$ $\mathrm{C}(\mathrm{C}(\mathrm{C}(\mathrm{C}(\mathrm{C}(\mathrm{C}(\mathrm{C}(\mathrm{C}(\mathrm{C}(\mathrm{C}(\mathrm{F})(\mathrm{Cl}) \mathrm{H})(\mathrm{H}) \mathrm{H})(\mathrm{H}) \mathrm{H})(\mathrm{Cl}) \mathrm{H})(\mathrm{H}) \mathrm{F})(\mathrm{H}) \mathrm{H})(\mathrm{F}) \mathrm{H})(\mathrm{H}) \mathrm{H})(\mathrm{H}) \mathrm{H})(\mathrm{H})(\mathrm{F}) \mathrm{Br}$ $\mathrm{C}(\mathrm{C}(\mathrm{C}(\mathrm{C}(\mathrm{C}(\mathrm{C}(\mathrm{C}(\mathrm{C}(\mathrm{C}(\mathrm{C}(\mathrm{H})(\mathrm{H}) \mathrm{Br})(\mathrm{H}) \mathrm{Cl})(\mathrm{H}) \mathrm{F})(\mathrm{H}) \mathrm{F})(\mathrm{H}) \mathrm{H})(\mathrm{H}) \mathrm{Cl})(\mathrm{Br}) \mathrm{H})(\mathrm{H}) \mathrm{H})(\mathrm{H}) \mathrm{Cl})(\mathrm{H})(\mathrm{H}) \mathrm{H}$ $\mathrm{C}(\mathrm{C}(\mathrm{C}(\mathrm{C}(\mathrm{C}(\mathrm{C}(\mathrm{C}(\mathrm{C}(\mathrm{C}(\mathrm{C}(\mathrm{H})(\mathrm{Cl}) \mathrm{Br})(\mathrm{F}) \mathrm{H})(\mathrm{H}) \mathrm{F})(\mathrm{H}) \mathrm{Cl})(\mathrm{H}) \mathrm{F})(\mathrm{H}) \mathrm{Cl})(\mathrm{H}) \mathrm{H})(\mathrm{H}) \mathrm{H})(\mathrm{H}) \mathrm{H})(\mathrm{H})(\mathrm{H}) \mathrm{H}$ $\mathrm{C}(\mathrm{C}(\mathrm{C}(\mathrm{C}(\mathrm{C}(\mathrm{C}(\mathrm{C}(\mathrm{C}(\mathrm{C}(\mathrm{C}(\mathrm{H})(\mathrm{F}) \mathrm{F})(\mathrm{H}) \mathrm{H})(\mathrm{H}) \mathrm{Cl})(\mathrm{Cl}) \mathrm{Cl})(\mathrm{H}) \mathrm{H})(\mathrm{H}) \mathrm{H})(\mathrm{H}) \mathrm{H})(\mathrm{H}) \mathrm{H})(\mathrm{H}) \mathrm{H})(\mathrm{F})(\mathrm{H}) \mathrm{F}$ $\mathrm{C}(\mathrm{C}(\mathrm{C}(\mathrm{C}(\mathrm{C}(\mathrm{C}(\mathrm{C}(\mathrm{C}(\mathrm{C}(\mathrm{C}(\mathrm{H})(\mathrm{F}) \mathrm{H})(\mathrm{Cl}) \mathrm{Cl})(\mathrm{H}) \mathrm{H})(\mathrm{H}) \mathrm{H})(\mathrm{H}) \mathrm{H})(\mathrm{H}) \mathrm{H})(\mathrm{H}) \mathrm{H})(\mathrm{F}) \mathrm{H})(\mathrm{Cl}) \mathrm{H})(\mathrm{H})(\mathrm{Br}) \mathrm{Cl}$ $\mathrm{C}(\mathrm{C}(\mathrm{C}(\mathrm{C}(\mathrm{C}(\mathrm{C}(\mathrm{C}(\mathrm{C}(\mathrm{C}(\mathrm{C}(\mathrm{Cl})(\mathrm{Cl}) \mathrm{H})(\mathrm{Cl}) \mathrm{F})(\mathrm{F}) \mathrm{H})(\mathrm{H}) \mathrm{H})(\mathrm{H}) \mathrm{H})(\mathrm{H}) \mathrm{H})(\mathrm{F}) \mathrm{H})(\mathrm{H}) \mathrm{H})(\mathrm{Cl}) \mathrm{H})(\mathrm{H})(\mathrm{H}) \mathrm{H}$ $\mathrm{C}(\mathrm{C}(\mathrm{C}(\mathrm{C}(\mathrm{C}(\mathrm{C}(\mathrm{C}(\mathrm{C}(\mathrm{C}(\mathrm{C}(\mathrm{H})(\mathrm{H}) \mathrm{Cl})(\mathrm{H}) \mathrm{H})(\mathrm{H}) \mathrm{H})(\mathrm{H}) \mathrm{Cl})(\mathrm{H}) \mathrm{H})(\mathrm{H}) \mathrm{H})(\mathrm{Cl}) \mathrm{H})(\mathrm{H}) \mathrm{H})(\mathrm{Cl}) \mathrm{F})(\mathrm{Cl})(\mathrm{H}) \mathrm{F}$ $\mathrm{C}(\mathrm{C}(\mathrm{C}(\mathrm{C}(\mathrm{C}(\mathrm{C}(\mathrm{C}(\mathrm{C}(\mathrm{C}(\mathrm{C}(\mathrm{H})(\mathrm{H}) \mathrm{H})(\mathrm{F}) \mathrm{H})(\mathrm{H}) \mathrm{H})(\mathrm{F}) \mathrm{H})(\mathrm{H}) \mathrm{F})(\mathrm{H}) \mathrm{Br})(\mathrm{F}) \mathrm{H})(\mathrm{H}) \mathrm{H})(\mathrm{H}) \mathrm{H})(\mathrm{Cl})(\mathrm{H}) \mathrm{Br}$ $\mathrm{C}(\mathrm{C}(\mathrm{C}(\mathrm{C}(\mathrm{C}(\mathrm{C}(\mathrm{C}(\mathrm{C}(\mathrm{C}(\mathrm{C}(\mathrm{F})(\mathrm{Br}) \mathrm{H})(\mathrm{F}) \mathrm{F})(\mathrm{H}) \mathrm{H})(\mathrm{H}) \mathrm{H})(\mathrm{Br}) \mathrm{H})(\mathrm{Cl}) \mathrm{H})(\mathrm{H}) \mathrm{H})(\mathrm{H}) \mathrm{H})(\mathrm{H}) \mathrm{H})(\mathrm{H})(\mathrm{Br}) \mathrm{H}$ $\mathrm{C}(\mathrm{C}(\mathrm{C}(\mathrm{C}(\mathrm{C}(\mathrm{C}(\mathrm{C}(\mathrm{C}(\mathrm{C}(\mathrm{C}(\mathrm{F})(\mathrm{H}) \mathrm{H})(\mathrm{H}) \mathrm{H})(\mathrm{H}) \mathrm{Br})(\mathrm{H}) \mathrm{H})(\mathrm{Br}) \mathrm{H})(\mathrm{H}) \mathrm{F})(\mathrm{H}) \mathrm{H})(\mathrm{F}) \mathrm{H})(\mathrm{F}) \mathrm{H})(\mathrm{H})(\mathrm{H}) \mathrm{H}$ $\mathrm{C}(\mathrm{C}(\mathrm{C}(\mathrm{C}(\mathrm{C}(\mathrm{C}(\mathrm{C}(\mathrm{C}(\mathrm{C}(\mathrm{C}(\mathrm{H})(\mathrm{Br}) \mathrm{H})(\mathrm{H}) \mathrm{H})(\mathrm{F}) \mathrm{H})(\mathrm{Br}) \mathrm{H})(\mathrm{Br}) \mathrm{H})(\mathrm{H}) \mathrm{H})(\mathrm{H}) \mathrm{H})(\mathrm{F}) \mathrm{H})(\mathrm{F}) \mathrm{H})(\mathrm{H})(\mathrm{H}) \mathrm{H}$ $\mathrm{C}(\mathrm{C}(\mathrm{C}(\mathrm{C}(\mathrm{C}(\mathrm{C}(\mathrm{C}(\mathrm{C}(\mathrm{C}(\mathrm{C}(\mathrm{H})(\mathrm{Cl}) \mathrm{Br})(\mathrm{Br}) \mathrm{Cl})(\mathrm{H}) \mathrm{H})(\mathrm{H}) \mathrm{H})(\mathrm{F}) \mathrm{H})(\mathrm{F}) \mathrm{H})(\mathrm{H}) \mathrm{H})(\mathrm{H}) \mathrm{H})(\mathrm{H}) \mathrm{H})(\mathrm{H})(\mathrm{H}) \mathrm{H}$ $\mathrm{C}(\mathrm{C}(\mathrm{C}(\mathrm{C}(\mathrm{C}(\mathrm{C}(\mathrm{C}(\mathrm{C}(\mathrm{C}(\mathrm{C}(\mathrm{H})(\mathrm{H}) \mathrm{H})(\mathrm{Br}) \mathrm{H})(\mathrm{F}) \mathrm{H})(\mathrm{H}) \mathrm{Cl})(\mathrm{F}) \mathrm{H})(\mathrm{H}) \mathrm{H})(\mathrm{H}) \mathrm{H})(\mathrm{H}) \mathrm{H})(\mathrm{F}) \mathrm{Cl})(\mathrm{H})(\mathrm{H}) \mathrm{H}$ $\mathrm{C}(\mathrm{C}(\mathrm{C}(\mathrm{C}(\mathrm{C}(\mathrm{C}(\mathrm{C}(\mathrm{C}(\mathrm{C}(\mathrm{C}(\mathrm{H})(\mathrm{Cl}) \mathrm{H})(\mathrm{H}) \mathrm{H})(\mathrm{H}) \mathrm{H})(\mathrm{F}) \mathrm{H})(\mathrm{H}) \mathrm{H})(\mathrm{H}) \mathrm{H})(\mathrm{Br}) \mathrm{H})(\mathrm{H}) \mathrm{Cl})(\mathrm{F}) \mathrm{H})(\mathrm{H})(\mathrm{Cl}) \mathrm{H}$ $\mathrm{C}(\mathrm{C}(\mathrm{C}(\mathrm{C}(\mathrm{C}(\mathrm{C}(\mathrm{C}(\mathrm{C}(\mathrm{C}(\mathrm{C}(\mathrm{H})(\mathrm{H}) \mathrm{H})(\mathrm{H}) \mathrm{H})(\mathrm{H}) \mathrm{H})(\mathrm{Cl}) \mathrm{Cl})(\mathrm{F}) \mathrm{F})(\mathrm{H}) \mathrm{H})(\mathrm{H}) \mathrm{H})(\mathrm{F}) \mathrm{H})(\mathrm{H}) \mathrm{H})(\mathrm{H})(\mathrm{Cl}) \mathrm{H}$ $\mathrm{C}(\mathrm{C}(\mathrm{C}(\mathrm{C}(\mathrm{C}(\mathrm{C}(\mathrm{C}(\mathrm{C}(\mathrm{C}(\mathrm{C}(\mathrm{F})(\mathrm{H}) \mathrm{Cl})(\mathrm{H}) \mathrm{H})(\mathrm{H}) \mathrm{Br})(\mathrm{H}) \mathrm{Cl})(\mathrm{H}) \mathrm{Cl})(\mathrm{H}) \mathrm{H})(\mathrm{Cl}) \mathrm{H})(\mathrm{H}) \mathrm{H})(\mathrm{H}) \mathrm{H})(\mathrm{H})(\mathrm{H}) \mathrm{H}$ $\mathrm{C}(\mathrm{C}(\mathrm{C}(\mathrm{C}(\mathrm{C}(\mathrm{C}(\mathrm{C}(\mathrm{C}(\mathrm{C}(\mathrm{C}(\mathrm{H})(\mathrm{Cl}) \mathrm{H})(\mathrm{F}) \mathrm{H})(\mathrm{H}) \mathrm{H})(\mathrm{H}) \mathrm{H})(\mathrm{H}) \mathrm{H})(\mathrm{H}) \mathrm{H})(\mathrm{Cl}) \mathrm{H})(\mathrm{H}) \mathrm{H})(\mathrm{Cl}) \mathrm{Cl})(\mathrm{H})(\mathrm{H}) \mathrm{F}$ $\mathrm{C}(\mathrm{C}(\mathrm{C}(\mathrm{C}(\mathrm{C}(\mathrm{C}(\mathrm{C}(\mathrm{C}(\mathrm{C}(\mathrm{C}(\mathrm{H})(\mathrm{H}) \mathrm{H})(\mathrm{Cl}) \mathrm{H})(\mathrm{H}) \mathrm{Cl})(\mathrm{H}) \mathrm{H})(\mathrm{H}) \mathrm{Cl})(\mathrm{F}) \mathrm{H})(\mathrm{H}) \mathrm{H})(\mathrm{H}) \mathrm{Cl})(\mathrm{H}) \mathrm{H})(\mathrm{H})(\mathrm{Cl}) \mathrm{H}$ $\mathrm{C}(\mathrm{C}(\mathrm{C}(\mathrm{C}(\mathrm{C}(\mathrm{C}(\mathrm{C}(\mathrm{C}(\mathrm{C}(\mathrm{C}(\mathrm{H})(\mathrm{F}) \mathrm{H})(\mathrm{Cl}) \mathrm{F})(\mathrm{H}) \mathrm{H})(\mathrm{H}) \mathrm{F})(\mathrm{H}) \mathrm{H})(\mathrm{H}) \mathrm{H})(\mathrm{Br}) \mathrm{H})(\mathrm{H}) \mathrm{H})(\mathrm{H}) \mathrm{H})(\mathrm{H})(\mathrm{Br}) \mathrm{H}$ $\mathrm{C}(\mathrm{C}(\mathrm{C}(\mathrm{C}(\mathrm{C}(\mathrm{C}(\mathrm{C}(\mathrm{C}(\mathrm{C}(\mathrm{C}(\mathrm{H})(\mathrm{H}) \mathrm{H})(\mathrm{Br}) \mathrm{H})(\mathrm{H}) \mathrm{H})(\mathrm{F}) \mathrm{H})(\mathrm{H}) \mathrm{H})(\mathrm{F}) \mathrm{H})(\mathrm{F}) \mathrm{Br})(\mathrm{H}) \mathrm{H})(\mathrm{H}) \mathrm{H})(\mathrm{H})(\mathrm{H}) \mathrm{H}$ $\mathrm{C}(\mathrm{C}(\mathrm{C}(\mathrm{C}(\mathrm{C}(\mathrm{C}(\mathrm{C}(\mathrm{C}(\mathrm{C}(\mathrm{C}(\mathrm{H})(\mathrm{Br}) \mathrm{H})(\mathrm{H}) \mathrm{H})(\mathrm{Br}) \mathrm{H})(\mathrm{H}) \mathrm{H})(\mathrm{H}) \mathrm{Br})(\mathrm{H}) \mathrm{H})(\mathrm{H}) \mathrm{F})(\mathrm{H}) \mathrm{H})(\mathrm{H}) \mathrm{H})(\mathrm{F})(\mathrm{H}) \mathrm{H}$ $\mathrm{C}(\mathrm{C}(\mathrm{C}(\mathrm{C}(\mathrm{C}(\mathrm{C}(\mathrm{C}(\mathrm{C}(\mathrm{C}(\mathrm{C}(\mathrm{H})(\mathrm{H}) \mathrm{H})(\mathrm{H}) \mathrm{Br})(\mathrm{H}) \mathrm{Br})(\mathrm{H}) \mathrm{H})(\mathrm{Cl}) \mathrm{H})(\mathrm{H}) \mathrm{H})(\mathrm{H}) \mathrm{H})(\mathrm{H}) \mathrm{H})(\mathrm{F}) \mathrm{H})(\mathrm{H})(\mathrm{H}) \mathrm{Cl}$ $\mathrm{C}(\mathrm{C}(\mathrm{C}(\mathrm{C}(\mathrm{C}(\mathrm{C}(\mathrm{C}(\mathrm{C}(\mathrm{C}(\mathrm{C}(\mathrm{H})(\mathrm{H}) \mathrm{H})(\mathrm{H}) \mathrm{H})(\mathrm{H}) \mathrm{Cl})(\mathrm{H}) \mathrm{Br})(\mathrm{H}) \mathrm{H})(\mathrm{H}) \mathrm{F})(\mathrm{H}) \mathrm{H})(\mathrm{H}) \mathrm{H})(\mathrm{H}) \mathrm{Cl})(\mathrm{H})(\mathrm{H}) \mathrm{F}$ $\mathrm{C}(\mathrm{C}(\mathrm{C}(\mathrm{C}(\mathrm{C}(\mathrm{C}(\mathrm{C}(\mathrm{C}(\mathrm{C}(\mathrm{C}(\mathrm{H})(\mathrm{H}) \mathrm{H})(\mathrm{H}) \mathrm{H})(\mathrm{H}) \mathrm{H})(\mathrm{H}) \mathrm{H})(\mathrm{H}) \mathrm{F})(\mathrm{H}) \mathrm{Br})(\mathrm{H}) \mathrm{Cl})(\mathrm{Cl}) \mathrm{Cl})(\mathrm{H}) \mathrm{H})(\mathrm{H})(\mathrm{H}) \mathrm{H}$
Formula

lgKoa lgKow lgKaw

$\mathrm{C} 10 \mathrm{H} 10 \mathrm{Br} 4 \mathrm{~F} 8$

$\mathrm{C} 10 \mathrm{H} 10 \mathrm{Cl} 2 \mathrm{Br} 2 \mathrm{~F} 8$

$\begin{array}{rrr}\text { EPISuit } & \text { EPI } & \text { EPI } \\ \text { Suite } & \text { Suite }\end{array}$

gKow lgKoa lgKa lgKow lgKoa lgKaw

$\mathrm{C} 10 \mathrm{H} 10 \mathrm{Cl} 2 \mathrm{Br} 2$ $\begin{array}{rr}7.417 & 7.64 \\ 5.526 & 6.72\end{array}$

\begin{tabular}{lrr}
$\mathrm{ClOH} 10 \mathrm{ClB} \mathrm{BF} 9$ & 5.526 & 6.72 \\
\hline
\end{tabular}

$\begin{array}{lrr}\mathrm{C} 10 \mathrm{H} 10 \mathrm{Cl} 13 \mathrm{Br} 2 \mathrm{~F} 7 & 6.589 & 7.03\end{array}$

$\mathrm{C} 10 \mathrm{H} 10 \mathrm{Cl} 3 \mathrm{BrF} 8$

$\mathrm{C} 10 \mathrm{H} 10 \mathrm{Cl} 4 \mathrm{BrF} 7$

C10H10C14F8

C10H10Cl5BrF6

C10H10Cl5F 7

C10H10C17F5

$\mathrm{C} 10 \mathrm{H} 10 \mathrm{ClBr} 2 \mathrm{~F} 9$

C10H10ClBr3F8

C10H11Br3F8

C10H11Br4F7

$\mathrm{C} 10 \mathrm{H} 11 \mathrm{Cl} 2 \mathrm{Br} 2 \mathrm{~F} 7$

C10H11Cl2BrF8

$\mathrm{C} 10 \mathrm{H} 11 \mathrm{Cl} 3 \mathrm{Br} 2 \mathrm{~F} 6$

$\mathrm{C} 10 \mathrm{H} 11 \mathrm{Cl} 3 \mathrm{BrF} 7$

C10H11Cl4BrF6

C10H11Cl5BrF5

C10H11C15F6

$\mathrm{C} 10 \mathrm{H} 11 \mathrm{Cl} 6 \mathrm{~F} 5$

C10H11Cl7F4

$\mathrm{C} 10 \mathrm{H} 11 \mathrm{ClBr} 3 \mathrm{~F} 7$

C10H12Br3F7

$\mathrm{C} 10 \mathrm{H} 12 \mathrm{Cl} 2 \mathrm{Br} 2 \mathrm{~F} 6$

$\mathrm{C} 10 \mathrm{H} 12 \mathrm{Cl} 2 \mathrm{Br} 3 \mathrm{~F} 5$

C10H12Cl3BrF6

C10H12Cl3F 7

C10H12Cl4BrF5

C10H12Cl4F6

$\mathrm{C} 10 \mathrm{H} 12 \mathrm{Cl} 5 \mathrm{~F} 5$

C10H12Cl6F4

$\mathrm{C} 10 \mathrm{H} 12 \mathrm{ClBr} 2 \mathrm{~F} 7$

$\mathrm{C} 10 \mathrm{H} 12 \mathrm{ClBr} 3 \mathrm{~F} 6$

C10H12ClBrF8

C10H13Br3F6

C10H13Cl2Br2F5

C10H13Cl2BrF6

C10H13Cl3BrF5

C10H13Cl3F6

C10H13Cl4BrF4

C10H13C14F5

$\mathrm{C} 10 \mathrm{H} 13 \mathrm{Cl} 5 \mathrm{~F} 4$

$\mathrm{C} 10 \mathrm{H} 13 \mathrm{Cl} 16 \mathrm{~F} 3$

$\mathrm{C} 10 \mathrm{H} 13 \mathrm{ClBr} 3 \mathrm{~F} 5$

C10H14Br2F6

C10H14Br3F5

$\mathrm{C} 10 \mathrm{H} 14 \mathrm{Cl} 2 \mathrm{Br} 2 \mathrm{~F} 4$

$\mathrm{C} 10 \mathrm{H} 14 \mathrm{Cl} 2 \mathrm{BrF} 5$

$\mathrm{C} 10 \mathrm{H} 14 \mathrm{Cl} 3 \mathrm{Br} 2 \mathrm{~F} 3$

$\mathrm{C} 10 \mathrm{H} 14 \mathrm{Cl} B \mathrm{BrF} 4$

$\mathrm{C} 10 \mathrm{H} 14 \mathrm{Cl} 4 \mathrm{BrF} 3$

$\mathrm{C} 10 \mathrm{H} 14 \mathrm{Cl} 4 \mathrm{~F} 4$

$\mathrm{C} 10 \mathrm{H} 14 \mathrm{Cl} 15 \mathrm{~F} 3$

$\mathrm{C} 10 \mathrm{H} 14 \mathrm{Cl} 6 \mathrm{~F} 2$

C10H14ClBr2F5

C10H14ClBrF6

$\mathrm{C} 10 \mathrm{H} 15 \mathrm{Br} 3 \mathrm{~F} 4$

$\mathrm{C} 10 \mathrm{H} 15 \mathrm{Cl} 2 \mathrm{Br} 2 \mathrm{~F} 3$

$\mathrm{C} 10 \mathrm{H} 15 \mathrm{Cl} 2 \mathrm{BrF} 4$

C10H15Cl3Br2F2

$\mathrm{C} 10 \mathrm{H} 15 \mathrm{Cl}_{3} \mathrm{BrF} 3$

$\mathrm{C} 10 \mathrm{H} 15 \mathrm{Cl} 3 \mathrm{~F} 4$

$\mathrm{C} 10 \mathrm{H} 15 \mathrm{Cl} 4 \mathrm{BrF} 2$

C10H15Cl4F3

C10H15Cl5F2

$\mathrm{C} 10 \mathrm{H} 15 \mathrm{ClBr} 2 \mathrm{~F} 4$

$\mathrm{C} 10 \mathrm{H} 15 \mathrm{ClBr} 3 \mathrm{~F} 3$

$\mathrm{C} 10 \mathrm{H} 16 \mathrm{Br} 2 \mathrm{~F} 4$

$\mathrm{C} 10 \mathrm{H} 16 \mathrm{Br} 3 \mathrm{~F} 3$

$\mathrm{C} 10 \mathrm{H} 16 \mathrm{Cl} 2 \mathrm{Br} 2 \mathrm{~F} 2$

$\mathrm{C} 10 \mathrm{H} 16 \mathrm{Cl} 2 \mathrm{BrF} 3$

$\mathrm{C} 10 \mathrm{H} 16 \mathrm{Cl} 3 \mathrm{BrF} 2$

C10H16Cl3F3

C10H16Cl4BrF

C10H16Cl4F2

C10H16Cl5F

$\mathrm{C} 10 \mathrm{H} 16 \mathrm{ClBr} 2 \mathrm{~F}$

C10H17Br2F3

C10H17Br3F2

$\mathrm{C} 10 \mathrm{H} 17 \mathrm{Cl} 2 \mathrm{Br} 2 \mathrm{~F}$

$\mathrm{C} 10 \mathrm{H} 17 \mathrm{Cl} 2 \mathrm{BrF} 2$

$\mathrm{C} 10 \mathrm{H} 17 \mathrm{Cl} 3 \mathrm{BrF}$

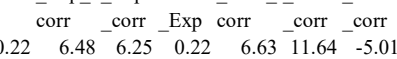
$\begin{array}{llllllll}1.19 & 5.10 & 3.91 & 1.19 & 5.92 & 8.16 & -2.24\end{array}$ $\begin{array}{llllllll}1.43 & 5.61 & 3.18 & 2.43 & 6.18 & 6.52 & -0.33\end{array}$ $\begin{array}{llllllll}0.44 & 5.57 & 5.13 & 0.44 & 6.16 & 10.12 & -3.95\end{array}$ $\begin{array}{llllllll}1.68 & 4.97 & 3.29 & 1.68 & 5.85 & 7.11 & -1.25\end{array}$ $\begin{array}{llllllll}2.16 & 4.84 & 2.67 & 2.16 & 5.78 & 6.05 & -0.27 \\ 0.17 & 5.91 & 5.74 & 0.17 & 6.34 & 11.03 & -4.69\end{array}$ $\begin{array}{llllllll}0.17 & 5.91 & 5.74 & 0.17 & 6.34 & 11.03 & -4.69\end{array}$ $\begin{array}{llllllll}1.41 & 5.30 & 3.89 & 1.41 & 6.02 & 8.00 & -1.98\end{array}$ $\begin{array}{llllllll}-0.09 & 5.13 & 5.23 & -0.09 & 5.94 & 10.56 & -4.62\end{array}$ $\begin{array}{llllllll}1.95 & 6.73 & 4.79 & 1.95 & 6.76 & 8.78 & -2.02\end{array}$ $\begin{array}{llllllll}1.95 & 6.73 & 4.79 & 1.95 & 6.76 & 8.78 & -2.02 \\ 0.71 & 6.24 & 5.53 & 0.71 & 6.51 & 10.45 & -3.95\end{array}$ $\begin{array}{llllllll}0.71 & 6.24 & 5.53 & 0.71 & 6.51 & 10.45 & -3.95\end{array}$ $\begin{array}{lllllll}1.16 & 3.87 & 2.71 & 1.16 & 5.29 & 6\end{array}$ $\begin{array}{llllllll}-0.08 & 5.57 & 5.64 & -0.08 & 6.16 & 11.07 & -4.9\end{array}$ $\begin{array}{llllllll}2.13 & 5.81 & 3.67 & 2.13 & 6.28 & 7.31 & -1.02\end{array}$ $\begin{array}{lllllllll}0.14 & 4.66 & 4.51 & 0.14 & 5.69 & 9.54 & -3.85\end{array}$ $\begin{array}{llllllll}1.38 & 5.16 & 3.78 & 1.38 & 5.95 & 7.90 & -1.94\end{array}$ $\begin{array}{lllllll}0.63 & 3.42 & 2.79 & 0.63 & 5.05 & 7.13 & -2.07\end{array}$ $\begin{array}{rrrrrrrr}-0.12 & 6.10 & 6.23 & -0.12 & 6.44 & 11.82 & -5.38\end{array}$ $\begin{array}{llllllll}1.11 & 5.51 & 4.39 & 1.11 & 6.13 & 8.81 & -2.68\end{array}$ $\begin{array}{llllllll}1.11 & 5.51 & 4.39 & 1.11 & 6.13 & 8.81 & -2.68\end{array}$ $\begin{array}{llllllllll}0.36 & 6.97 & 6.61 & 0.36 & 6.88 & 11.99 & -5.11\end{array}$ $\begin{array}{rrrrrrrr}-0.39 & 5.33 & 5.72 & -0.39 & 6.04 & 11.35 & -5.31 \\ 0.41 & 5.43 & 5.02 & 0.41 & 6.09 & 10.01 & -3.92\end{array}$ $\begin{array}{llllllll}0.86 & 5.16 & 4.30 & 0.86 & 5.95 & 8.85 & -2.89\end{array}$ $\begin{array}{llllllll}0.60 & 4.39 & 3.79 & 0.60 & 5.55 & 8.38 & -2.83\end{array}$ $\begin{array}{llllllll}0.60 & 4.39 & 3.79 & 0.60 & 5.55 & 8.38 & -3.6\end{array}$ $\begin{array}{llllllll}1.08 & 5.37 & 4.29 & 1.08 & 6.06 & 8.70 & -2.64\end{array}$ $\begin{array}{llllllll}1.08 & 5.37 & 4.29 & 1.08 & 6.06 & 8.70 & -2.64 \\ 2.32 & 5.87 & 3.55 & 2.32 & 6.31 & 7.04 & -0.72 \\ 0.33 & 5.84 & 5.51 & 0.33 & 6.30 & 10.65 & -4.35\end{array}$ $\begin{array}{llllllll}0.33 & 5.84 & 5.51 & 0.33 & 6.30 & 10.65 & -4.35\end{array}$ $\begin{array}{llllllll}1.57 & 5.24 & 3.67 & 1.57 & 5.99 & 7.65 & -1.65\end{array}$ $\begin{array}{llllllll}0.81 & 5.70 & 4.89 & 0.81 & 6.23 & 9.60 & -3.37\end{array}$ $\begin{array}{rrrrrrrr}0.06 & 6.16 & 6.10 & 0.06 & 6.47 & 11.55 & -5.08\end{array}$ $\begin{array}{llllllll}1.35 & 3.93 & 2.58 & 1.35 & 5.32 & 6.43 & -1.11\end{array}$ $\begin{array}{llllllll}0.11 & 4.52 & 4.41 & 0.11 & 5.62 & 9.44 & -3.81\end{array}$ $\begin{array}{llllllll}2.58 & 5.43 & 2.85 & 2.58 & 6.09 & 6.01 & 0.08\end{array}$ $\begin{array}{lllllll}0.56 & 5.25 & 4.69 & 0.56 & 6.00 & 9.51 & -3.51\end{array}$ $\begin{array}{rrrrrrr}0.30 & 6.58 & 6.28 & 0.30 & 6.68 & 11.63 & -4.95\end{array}$ $\begin{array}{rrrrrrrr}0.30 & 6.58 & 6.28 & 0.30 & 6.68 & 11.63 & -4.95 \\ 1.53 & 3.88 & 2.35 & 1.53 & 5.29 & 6.03 & -0.74 \\ 0.78 & 5.57 & 4.79 & 0.78 & 6.16 & 9.49 & -3.33\end{array}$ $\begin{array}{llllllll}0.78 & 5.57 & 4.79 & 0.78 & 6.16 & 9.49 & -3.33\end{array}$ $\begin{array}{llllllll}2.02 & 4.97 & 2.95 & 2.02 & 5.85 & 6.48 & -0.63 \\ 0.03 & 4.93 & 4.90 & 0.03 & 5.83 & 10.08 & -4.25\end{array}$ $\begin{array}{lllllll}0.03 & 4.93 & 4.90 & 0.03 & 5.83 & 10.08 & -4.25\end{array}$ $\begin{array}{llllllll}1.27 & 5.33 & 4.06 & 1.27 & 6.04 & 8.30 & -2.26\end{array}$ $\begin{array}{llllllll}1.27 & 5.33 & 4.06 & 1.27 & 6.04 & 8.30 & -2.26 \\ 0.52 & 4.79 & 4.28 & 0.52 & 5.76 & 9.02 & -3.26\end{array}$ $\begin{array}{rrrrrrrr}0.52 & 4.79 & 4.28 & 0.52 & 5.76 & 9.02 & -3.26 \\ -0.24 & 5.25 & 5.49 & -0.24 & 6.00 & 10.97 & -4.97\end{array}$ $\begin{array}{llllllll}-0.24 & 5.25 & 5.49 & 0.24 & 6.00 & 10.97 & -4.97 \\ -0.19 & 3.63 & 3.81 & -0.19 & 5.16 & 8.88 & -3.72\end{array}$ $\begin{array}{llllllll}1.50 & 4.85 & 3.35 & 1.50 & 5.79 & 7.29 & -1.49\end{array}$ $\begin{array}{rrrrrrrr}1.50 & 4.85 & 3.35 & 1.50 & 5.79 & 7.29 & -1.49 \\ 0.26 & 5.57 & 5.30 & 0.26 & 6.16 & 10.44 & -4.28 \\ 0.00 & 4.79 & 4.79 & 0.00 & 5.76 & 9.97 & -4.21\end{array}$ $\begin{array}{rrrrrrrr}0.26 & 5.57 & 5.30 & 0.26 & 6.16 & 10.44 & -4.28 \\ 0.00 & 4.79 & 4.79 & 0.00 & 5.76 & 9.97 & -4.21 \\ 1.23 & 5.18 & 3.94 & 1.23 & 5.96 & 8.18 & -2.22\end{array}$ $\begin{array}{llllllll}0.00 & 4.79 & 4.79 & 0.00 & 5.76 & 9.97 & -4.2 \\ 1.23 & 5.18 & 3.94 & 1.23 & 5.96 & 8.18 & -2.22\end{array}$ $\begin{array}{lllllll}-0.75 & 5.15 & 5.90 & -0.75 & 5.95 & 11.80 & -5.85\end{array}$ $\begin{array}{llllllll}0.48 & 4.55 & 4.07 & 0.48 & 5.64 & 8.79 & -3.15\end{array}$ $\begin{array}{rrrrrrr}0.48 & 4.55 & 4.07 & 0.48 & 5.64 & 8.79 & -3.15 \\ -0.27 & 5.01 & 5.28 & -0.27 & 5.88 & 10.74 & -4.86\end{array}$ $\begin{array}{rrrrrrr}-0.27 & 5.01 & 5.28 & -0.27 & 5.88 & 10.74 & -4.86 \\ 0.97 & 4.42 & 3.45 & 0.97 & 5.57 & 7.73 & -2.16 \\ 0.22 & 5.99 & 5.77 & 0.22 & 6.38 & 11.04 & -4.67\end{array}$ $\begin{array}{llllllll}0.22 & 5.99 & 5.77 & 0.22 & 6.38 & 11.04 & -4.67\end{array}$ $\begin{array}{lllllll}0.22 & 5.93 & 5.77 & 0.22 & 6.38 & 11.04 & -4.67\end{array}$ $\begin{array}{lllllll}0.75 & 3.22 & 2.47 & 0.75 & 4.95 & 6.66 & -1.71\end{array}$ $\begin{array}{lllllll}0.75 & 3.22 & 2.47 & 0.75 & 4.95 & 6.66 & -1.71 \\ 1.99 & 4.72 & 2.73 & 1.99 & 5.72 & 6.23 & -0.50\end{array}$ $\begin{array}{rrrrrrrr}1.99 & 4.72 & 2.73 & 1.99 & 5.72 & 6.23 & -0.50 \\ -0.03 & 5.76 & 5.80 & -0.03 & 6.26 & 11.23 & -4.97\end{array}$ $\begin{array}{rrrrrrr}-0.03 & 5.76 & 5.80 & -0.03 & 6.26 & 11.23 & -4.97 \\ -0.30 & 4.88 & 5.18 & -0.30 & 5.81 & 10.64 & -4.83 \\ 0.94 & 3.28 & 2.35 & 0.94 & 4.99 & 6.40 & -1.41\end{array}$ $\begin{array}{llllllll}0.94 & 3.28 & 2.35 & 0.94 & 4.99 & 6.40 & -1.41\end{array}$ $\begin{array}{rrrrrrrr}-1.05 & 4.24 & 5.29 & -1.05 & 5.48 & 11.22 & -5.75\end{array}$ $\begin{array}{rrrrrrr}-1.05 & 4.24 & 5.29 & -1.05 & 5.48 & 11.22 & -5.75 \\ 0.18 & 3.64 & 3.46 & 0.18 & 5.17 & 8.22 & -3.05 \\ 1.42 & 4.25 & 2.83 & 1.42 & 5.49 & 6.70 & -1.21\end{array}$ $\begin{array}{llllllll}1.42 & 4.25 & 2.83 & 1.42 & 5.49 & 6.70 & -1.2\end{array}$ $\begin{array}{llllllll}-0.57 & 5.33 & 5.90 & -0.57 & 6.04 & 11.67 & -5.64\end{array}$ $\begin{array}{llllllll}0.67 & 4.61 & 3.94 & 0.67 & 5.67 & 8.52 & -2.85\end{array}$ $\begin{array}{rrrrrrrr}-0.08 & 5.19 & 5.28 & -0.08 & 5.97 & 10.62 & -4.65\end{array}$ $\begin{array}{rrrrrrrr}0.45 & 3.31 & 2.86 & 0.45 & 5.00 & 7.32 & -2.32\end{array}$ $\begin{array}{llllllll}0.90 & 3.03 & 2.13 & 0.90 & 4.86 & 6.14 & -1.29\end{array}$ $\begin{array}{lllllll}-0.33 & 3.64 & 3.97 & -0.33 & 5.17 & 9.17 & -4.00\end{array}$ $\begin{array}{lllllll}-0.60 & 5.07 & 5.67 & -0.60 & 5.91 & 11.42 & -5.5\end{array}$ $\begin{array}{lllllll}0.64 & 4.37 & 3.74 & 0.64 & 5.55 & 8.29 & -2.74\end{array}$ $\begin{array}{lllllll}-0.11 & 3.96 & 4.07 & -0.11 & 5.33 & 9.15 & -3.82\end{array}$ $\begin{array}{llllllll}1.12 & 5.45 & 4.32 & 1.12 & 6.10 & 8.72 & -2.62\end{array}$ $\begin{array}{lllllll}-0.87 & 4.31 & 5.18 & -0.87 & 5.52 & 10.97 & -5.46\end{array}$ $\begin{array}{llllllll}0.37 & 4.93 & 4.55 & 0.37 & 5.83 & 9.45 & -3.62\end{array}$ $\begin{array}{lllllll}-0.38 & 4.18 & 4.56 & -0.38 & 5.45 & 9.92 & -4.47\end{array}$ $\begin{array}{lllllll}0.15 & 4.72 & 4.56 & 0.15 & 5.72 & 9.60 & -3.87\end{array}$ $\begin{array}{llllllll}0.61 & 4.22 & 3.62 & 0.61 & 5.47 & 8.16 & -2.69\end{array}$ $\begin{array}{lllllll}-0.63 & 3.94 & 4.57 & -0.63 & 5.32 & 10.08 & -4.76\end{array}$ $\begin{array}{lllllll}-0.90 & 4.16 & 5.06 & -0.90 & 5.44 & 10.85 & -5.41\end{array}$ $\begin{array}{lllllll}0.34 & 3.57 & 3.23 & 0.34 & 5.13 & 7.84 & -2.71\end{array}$ $\begin{array}{llllllll}-0.41 & 5.03 & 5.44 & -0.41 & 5.88 & 11.02 & -5.14\end{array}$ $\begin{array}{llllllll}0.93 & 4.33 & 3.40 & 0.93 & 5.52 & 7.70 & -2.17\end{array}$ $\begin{array}{llllllll}0.89 & 6.30 & 5.40 & 0.89 & 6.54 & 10.18 & -3.64\end{array}$ $\begin{array}{lllllll}-0.79 & 5.12 & 5.90 & -0.79 & 5.93 & 11.82 & -5.89\end{array}$ 
$\mathrm{C}(\mathrm{C}(\mathrm{C}(\mathrm{C}(\mathrm{C}(\mathrm{C}(\mathrm{C}(\mathrm{C}(\mathrm{C}(\mathrm{C}(\mathrm{F})(\mathrm{H}) \mathrm{H})(\mathrm{H}) \mathrm{Cl})(\mathrm{F}) \mathrm{H})(\mathrm{H}) \mathrm{H})(\mathrm{Cl}) \mathrm{Cl})(\mathrm{H}) \mathrm{H})(\mathrm{H}) \mathrm{H})(\mathrm{H}) \mathrm{H})(\mathrm{H}) \mathrm{H})(\mathrm{H})(\mathrm{H}) \mathrm{H}$ $\mathrm{C}(\mathrm{C}(\mathrm{C}(\mathrm{C}(\mathrm{C}(\mathrm{C}(\mathrm{C}(\mathrm{C}(\mathrm{C}(\mathrm{C}(\mathrm{H})(\mathrm{Br}) \mathrm{H})(\mathrm{Cl}) \mathrm{H})(\mathrm{H}) \mathrm{Cl})(\mathrm{H}) \mathrm{H})(\mathrm{H}) \mathrm{H})(\mathrm{Cl}) \mathrm{H})(\mathrm{Cl}) \mathrm{H})(\mathrm{H}) \mathrm{H})(\mathrm{H}) \mathrm{H})(\mathrm{H})(\mathrm{H}) \mathrm{H}$ $\mathrm{C}(\mathrm{C}(\mathrm{C}(\mathrm{C}(\mathrm{C}(\mathrm{C}(\mathrm{C}(\mathrm{C}(\mathrm{C}(\mathrm{C}(\mathrm{H})(\mathrm{H}) \mathrm{H})(\mathrm{Cl}) \mathrm{H})(\mathrm{Cl}) \mathrm{H})(\mathrm{H}) \mathrm{H})(\mathrm{H}) \mathrm{H})(\mathrm{Cl}) \mathrm{H})(\mathrm{H}) \mathrm{H})(\mathrm{H}) \mathrm{H})(\mathrm{H}) \mathrm{Cl})(\mathrm{H})(\mathrm{H}) \mathrm{F}$ $\mathrm{C}(\mathrm{C}(\mathrm{C}(\mathrm{C}(\mathrm{C}(\mathrm{C}(\mathrm{C}(\mathrm{C}(\mathrm{C}(\mathrm{C}(\mathrm{H})(\mathrm{H}) \mathrm{H})(\mathrm{H}) \mathrm{Br})(\mathrm{H}) \mathrm{H})(\mathrm{Br}) \mathrm{F})(\mathrm{H}) \mathrm{H})(\mathrm{H}) \mathrm{H})(\mathrm{H}) \mathrm{H})(\mathrm{Cl}) \mathrm{H})(\mathrm{H}) \mathrm{H})(\mathrm{H})(\mathrm{F}) \mathrm{H}$ $\mathrm{C}(\mathrm{C}(\mathrm{C}(\mathrm{C}(\mathrm{C}(\mathrm{C}(\mathrm{C}(\mathrm{C}(\mathrm{C}(\mathrm{C}(\mathrm{H})(\mathrm{H}) \mathrm{H})(\mathrm{H}) \mathrm{H})(\mathrm{H}) \mathrm{H})(\mathrm{H}) \mathrm{F})(\mathrm{H}) \mathrm{F})(\mathrm{Br}) \mathrm{H})(\mathrm{H}) \mathrm{H})(\mathrm{H}) \mathrm{H})(\mathrm{H}) \mathrm{H})(\mathrm{H})(\mathrm{Br}) \mathrm{H}$ $\mathrm{C}(\mathrm{C}(\mathrm{C}(\mathrm{C}(\mathrm{C}(\mathrm{C}(\mathrm{C}(\mathrm{C}(\mathrm{C}(\mathrm{C}(\mathrm{H})(\mathrm{H}) \mathrm{H})(\mathrm{H}) \mathrm{H})(\mathrm{H}) \mathrm{H})(\mathrm{H}) \mathrm{H})(\mathrm{H}) \mathrm{H})(\mathrm{Br}) \mathrm{H})(\mathrm{F}) \mathrm{H})(\mathrm{H}) \mathrm{Br})(\mathrm{H}) \mathrm{H})(\mathrm{H})(\mathrm{Br}) \mathrm{H}$ $\mathrm{C}(\mathrm{C}(\mathrm{C}(\mathrm{C}(\mathrm{C}(\mathrm{C}(\mathrm{C}(\mathrm{C}(\mathrm{C}(\mathrm{C}(\mathrm{H})(\mathrm{H}) \mathrm{H})(\mathrm{H}) \mathrm{H})(\mathrm{Cl}) \mathrm{H})(\mathrm{H}) \mathrm{Br})(\mathrm{H}) \mathrm{H})(\mathrm{H}) \mathrm{H})(\mathrm{H}) \mathrm{Br})(\mathrm{H}) \mathrm{Cl})(\mathrm{H}) \mathrm{H})(\mathrm{H})(\mathrm{H}) \mathrm{H}$ $\mathrm{C}(\mathrm{C}(\mathrm{C}(\mathrm{C}(\mathrm{C}(\mathrm{C}(\mathrm{C}(\mathrm{C}(\mathrm{C}(\mathrm{C}(\mathrm{H})(\mathrm{H}) \mathrm{H})(\mathrm{H}) \mathrm{H})(\mathrm{Cl}) \mathrm{Cl})(\mathrm{H}) \mathrm{Br})(\mathrm{H}) \mathrm{H})(\mathrm{F}) \mathrm{H})(\mathrm{H}) \mathrm{H})(\mathrm{H}) \mathrm{H})(\mathrm{H}) \mathrm{H})(\mathrm{H})(\mathrm{H}) \mathrm{H}$ $\mathrm{C}(\mathrm{C}(\mathrm{C}(\mathrm{C}(\mathrm{C}(\mathrm{C}(\mathrm{C}(\mathrm{C}(\mathrm{C}(\mathrm{C}(\mathrm{H})(\mathrm{H}) \mathrm{H})(\mathrm{Cl}) \mathrm{H})(\mathrm{H}) \mathrm{H})(\mathrm{H}) \mathrm{Br})(\mathrm{H}) \mathrm{Cl})(\mathrm{H}) \mathrm{H})(\mathrm{H}) \mathrm{H})(\mathrm{H}) \mathrm{H})(\mathrm{Cl}) \mathrm{H})(\mathrm{H})(\mathrm{H}) \mathrm{H}$ $\mathrm{C}(\mathrm{C}(\mathrm{C}(\mathrm{C}(\mathrm{C}(\mathrm{C}(\mathrm{C}(\mathrm{C}(\mathrm{C}(\mathrm{C}(\mathrm{H})(\mathrm{H}) \mathrm{F})(\mathrm{H}) \mathrm{H})(\mathrm{H}) \mathrm{Cl})(\mathrm{H}) \mathrm{H})(\mathrm{H}) \mathrm{Cl})(\mathrm{H}) \mathrm{H})(\mathrm{H}) \mathrm{Cl})(\mathrm{H}) \mathrm{H})(\mathrm{H}) \mathrm{H})(\mathrm{H})(\mathrm{H}) \mathrm{H}$ $\mathrm{C}(\mathrm{C}(\mathrm{C}(\mathrm{C}(\mathrm{C}(\mathrm{C}(\mathrm{C}(\mathrm{C}(\mathrm{C}(\mathrm{C}(\mathrm{Cl})(\mathrm{H}) \mathrm{H})(\mathrm{H}) \mathrm{Cl})(\mathrm{H}) \mathrm{H})(\mathrm{Cl}) \mathrm{H})(\mathrm{H}) \mathrm{H})(\mathrm{H}) \mathrm{H})(\mathrm{H}) \mathrm{H})(\mathrm{H}) \mathrm{H})(\mathrm{H}) \mathrm{H})(\mathrm{H})(\mathrm{H}) \mathrm{Cl}$ $\mathrm{C}(\mathrm{C}(\mathrm{C}(\mathrm{C}(\mathrm{C}(\mathrm{C}(\mathrm{C}(\mathrm{C}(\mathrm{C}(\mathrm{C}(\mathrm{H})(\mathrm{Cl}) \mathrm{H})(\mathrm{H}) \mathrm{H})(\mathrm{H}) \mathrm{H})(\mathrm{H}) \mathrm{Br})(\mathrm{F}) \mathrm{H})(\mathrm{Br}) \mathrm{H})(\mathrm{H}) \mathrm{H})(\mathrm{H}) \mathrm{H})(\mathrm{H}) \mathrm{H})(\mathrm{H})(\mathrm{H}) \mathrm{H}$ $\mathrm{C}(\mathrm{C}(\mathrm{C}(\mathrm{C}(\mathrm{C}(\mathrm{C}(\mathrm{C}(\mathrm{C}(\mathrm{C}(\mathrm{C}(\mathrm{F})(\mathrm{H}) \mathrm{H})(\mathrm{H}) \mathrm{H})(\mathrm{H}) \mathrm{H})(\mathrm{H}) \mathrm{H})(\mathrm{H}) \mathrm{H})(\mathrm{H}) \mathrm{H})(\mathrm{F}) \mathrm{H})(\mathrm{H}) \mathrm{H})(\mathrm{H}) \mathrm{H})(\mathrm{Br})(\mathrm{H}) \mathrm{Cl}$ $\mathrm{C}(\mathrm{C}(\mathrm{C}(\mathrm{C}(\mathrm{C}(\mathrm{C}(\mathrm{C}(\mathrm{C}(\mathrm{C}(\mathrm{C}(\mathrm{H})(\mathrm{H}) \mathrm{H})(\mathrm{H}) \mathrm{H})(\mathrm{H}) \mathrm{Br})(\mathrm{H}) \mathrm{H})(\mathrm{H}) \mathrm{H})(\mathrm{H}) \mathrm{F})(\mathrm{H}) \mathrm{H})(\mathrm{H}) \mathrm{H})(\mathrm{H}) \mathrm{H})(\mathrm{Br})(\mathrm{H}) \mathrm{H}$ $\mathrm{C}(\mathrm{C}(\mathrm{C}(\mathrm{C}(\mathrm{C}(\mathrm{C}(\mathrm{C}(\mathrm{C}(\mathrm{C}(\mathrm{C}(\mathrm{H})(\mathrm{H}) \mathrm{Br})(\mathrm{H}) \mathrm{H})(\mathrm{H}) \mathrm{H})(\mathrm{H}) \mathrm{Br})(\mathrm{Br}) \mathrm{H})(\mathrm{H}) \mathrm{H})(\mathrm{H}) \mathrm{H})(\mathrm{H}) \mathrm{H})(\mathrm{H}) \mathrm{H})(\mathrm{H})(\mathrm{H}) \mathrm{H}$ $\mathrm{C}(\mathrm{C}(\mathrm{C}(\mathrm{C}(\mathrm{C}(\mathrm{C}(\mathrm{C}(\mathrm{C}(\mathrm{C}(\mathrm{C}(\mathrm{H})(\mathrm{H}) \mathrm{H})(\mathrm{H}) \mathrm{H})(\mathrm{H}) \mathrm{H})(\mathrm{H}) \mathrm{H})(\mathrm{F}) \mathrm{Br})(\mathrm{H}) \mathrm{H})(\mathrm{H}) \mathrm{H})(\mathrm{H}) \mathrm{H})(\mathrm{H}) \mathrm{H})(\mathrm{H})(\mathrm{H}) \mathrm{F}$ $\mathrm{C}(\mathrm{C}(\mathrm{C}(\mathrm{C}(\mathrm{C}(\mathrm{C}(\mathrm{C}(\mathrm{C}(\mathrm{C}(\mathrm{C}(\mathrm{H})(\mathrm{H}) \mathrm{H})(\mathrm{H}) \mathrm{H})(\mathrm{H}) \mathrm{H})(\mathrm{H}) \mathrm{Cl})(\mathrm{Br}) \mathrm{Cl})(\mathrm{H}) \mathrm{H})(\mathrm{H}) \mathrm{H})(\mathrm{H}) \mathrm{H})(\mathrm{H}) \mathrm{H})(\mathrm{H})(\mathrm{H}) \mathrm{H}$ $\mathrm{C}(\mathrm{C}(\mathrm{C}(\mathrm{C}(\mathrm{C}(\mathrm{C}(\mathrm{C}(\mathrm{C}(\mathrm{C}(\mathrm{C}(\mathrm{H})(\mathrm{H}) \mathrm{H})(\mathrm{H}) \mathrm{H})(\mathrm{H}) \mathrm{H})(\mathrm{H}) \mathrm{H})(\mathrm{H}) \mathrm{H})(\mathrm{H}) \mathrm{H})(\mathrm{H}) \mathrm{Cl})(\mathrm{H}) \mathrm{F})(\mathrm{H}) \mathrm{Cl})(\mathrm{H})(\mathrm{H}) \mathrm{H}$ $\mathrm{C}(\mathrm{C}(\mathrm{C}(\mathrm{C}(\mathrm{C}(\mathrm{C}(\mathrm{C}(\mathrm{C}(\mathrm{C}(\mathrm{C}(\mathrm{H})(\mathrm{H}) \mathrm{H})(\mathrm{H}) \mathrm{Cl})(\mathrm{H}) \mathrm{H})(\mathrm{H}) \mathrm{H})(\mathrm{H}) \mathrm{H})(\mathrm{H}) \mathrm{H})(\mathrm{H}) \mathrm{H})(\mathrm{H}) \mathrm{Cl})(\mathrm{H}) \mathrm{H})(\mathrm{Cl})(\mathrm{H}) \mathrm{H}$ $\mathrm{C}(\mathrm{C}(\mathrm{C}(\mathrm{C}(\mathrm{C}(\mathrm{C}(\mathrm{C}(\mathrm{C}(\mathrm{C}(\mathrm{C}(\mathrm{H})(\mathrm{H}) \mathrm{H})(\mathrm{H}) \mathrm{H})(\mathrm{H}) \mathrm{H})(\mathrm{H}) \mathrm{H})(\mathrm{H}) \mathrm{Br})(\mathrm{H}) \mathrm{H})(\mathrm{H}) \mathrm{Br})(\mathrm{H}) \mathrm{H})(\mathrm{H}) \mathrm{H})(\mathrm{Cl})(\mathrm{H}) \mathrm{H}$ $\mathrm{C}(\mathrm{C}(\mathrm{C}(\mathrm{C}(\mathrm{C}(\mathrm{C}(\mathrm{C}(\mathrm{C}(\mathrm{C}(\mathrm{C}(\mathrm{H})(\mathrm{H}) \mathrm{H})(\mathrm{Cl}) \mathrm{H})(\mathrm{H}) \mathrm{H})(\mathrm{H}) \mathrm{H})(\mathrm{H}) \mathrm{F})(\mathrm{H}) \mathrm{H})(\mathrm{Br}) \mathrm{H})(\mathrm{H}) \mathrm{H})(\mathrm{H}) \mathrm{H})(\mathrm{H})(\mathrm{H}) \mathrm{H}$ $\mathrm{C}(\mathrm{C}(\mathrm{C}(\mathrm{C}(\mathrm{C}(\mathrm{C}(\mathrm{C}(\mathrm{C}(\mathrm{C}(\mathrm{C}(\mathrm{H})(\mathrm{H}) \mathrm{H})(\mathrm{H}) \mathrm{Br})(\mathrm{H}) \mathrm{H})(\mathrm{H}) \mathrm{H})(\mathrm{H}) \mathrm{H})(\mathrm{H}) \mathrm{H})(\mathrm{H}) \mathrm{H})(\mathrm{H}) \mathrm{H})(\mathrm{H}) \mathrm{Br})(\mathrm{H})(\mathrm{H}) \mathrm{H}$ $\mathrm{C}(\mathrm{C}(\mathrm{C}(\mathrm{C}(\mathrm{C}(\mathrm{C}(\mathrm{C}(\mathrm{C}(\mathrm{C}(\mathrm{C}(\mathrm{H})(\mathrm{H}) \mathrm{H})(\mathrm{H}) \mathrm{H})(\mathrm{H}) \mathrm{Br})(\mathrm{H}) \mathrm{H})(\mathrm{F}) \mathrm{H})(\mathrm{H}) \mathrm{H})(\mathrm{H}) \mathrm{H})(\mathrm{H}) \mathrm{H})(\mathrm{H}) \mathrm{H})(\mathrm{H})(\mathrm{H}) \mathrm{H}$ $\mathrm{C}(\mathrm{C}(\mathrm{C}(\mathrm{C}(\mathrm{C}(\mathrm{C}(\mathrm{C}(\mathrm{C}(\mathrm{C}(\mathrm{C}(\mathrm{H})(\mathrm{H}) \mathrm{H})(\mathrm{H}) \mathrm{Cl})(\mathrm{H}) \mathrm{H})(\mathrm{H}) \mathrm{H})(\mathrm{H}) \mathrm{H})(\mathrm{H}) \mathrm{H})(\mathrm{H}) \mathrm{H})(\mathrm{H}) \mathrm{H})(\mathrm{H}) \mathrm{H})(\mathrm{H})(\mathrm{Cl}) \mathrm{H}$ $\mathrm{C}(\mathrm{C}(\mathrm{C}(\mathrm{C}(\mathrm{C}(\mathrm{C}(\mathrm{C}(\mathrm{C}(\mathrm{C}(\mathrm{C}(\mathrm{Cl})(\mathrm{H}) \mathrm{H})(\mathrm{H}) \mathrm{H})(\mathrm{H}) \mathrm{H})(\mathrm{H}) \mathrm{H})(\mathrm{H}) \mathrm{H})(\mathrm{H}) \mathrm{H})(\mathrm{H}) \mathrm{H})(\mathrm{H}) \mathrm{Br})(\mathrm{H}) \mathrm{H})(\mathrm{H})(\mathrm{H}) \mathrm{H}$ $\mathrm{C}(\mathrm{C}(\mathrm{C}(\mathrm{C}(\mathrm{C}(\mathrm{C}(\mathrm{C}(\mathrm{C}(\mathrm{C}(\mathrm{C}(\mathrm{H})(\mathrm{H}) \mathrm{H})(\mathrm{H}) \mathrm{H})(\mathrm{H}) \mathrm{H})(\mathrm{H}) \mathrm{H})(\mathrm{H}) \mathrm{H})(\mathrm{H}) \mathrm{H})(\mathrm{H}) \mathrm{H})(\mathrm{H}) \mathrm{Br})(\mathrm{H}) \mathrm{H})(\mathrm{H})(\mathrm{H}) \mathrm{H}$ $\mathrm{C}(\mathrm{C}(\mathrm{C}(\mathrm{C}(\mathrm{C}(\mathrm{C}(\mathrm{C}(\mathrm{C}(\mathrm{C}(\mathrm{C}(\mathrm{H})(\mathrm{H}) \mathrm{H})(\mathrm{H}) \mathrm{H})(\mathrm{H}) \mathrm{H})(\mathrm{H}) \mathrm{H})(\mathrm{H}) \mathrm{H})(\mathrm{H}) \mathrm{H})(\mathrm{H}) \mathrm{H})(\mathrm{H}) \mathrm{H})(\mathrm{H}) \mathrm{Cl})(\mathrm{H})(\mathrm{H}) \mathrm{H}$ $\mathrm{C}(\mathrm{C}(\mathrm{C}(\mathrm{C}(\mathrm{C}(\mathrm{C}(\mathrm{C}(\mathrm{C}(\mathrm{C}(\mathrm{C}(\mathrm{F})(\mathrm{F}) \mathrm{F})(\mathrm{F}) \mathrm{F})(\mathrm{Br}) \mathrm{F})(\mathrm{F}) \mathrm{Br})(\mathrm{Br}) \mathrm{F})(\mathrm{F}) \mathrm{H})(\mathrm{F}) \mathrm{F})(\mathrm{F}) \mathrm{F})(\mathrm{F}) \mathrm{F})(\mathrm{F})(\mathrm{H}) \mathrm{F}$ $\mathrm{C}(\mathrm{C}(\mathrm{C}(\mathrm{C}(\mathrm{C}(\mathrm{C}(\mathrm{C}(\mathrm{C}(\mathrm{C}(\mathrm{C}(\mathrm{Br})(\mathrm{Cl}) \mathrm{F})(\mathrm{F}) \mathrm{F})(\mathrm{F}) \mathrm{F})(\mathrm{Cl}) \mathrm{F})(\mathrm{F}) \mathrm{H})(\mathrm{F}) \mathrm{F})(\mathrm{H}) \mathrm{F})(\mathrm{F}) \mathrm{F})(\mathrm{F}) \mathrm{F})(\mathrm{F})(\mathrm{F}) \mathrm{B}$ $\mathrm{C}(\mathrm{C}(\mathrm{C}(\mathrm{C}(\mathrm{C}(\mathrm{C}(\mathrm{C}(\mathrm{C}(\mathrm{C}(\mathrm{C}(\mathrm{F})(\mathrm{F}) \mathrm{F})(\mathrm{F}) \mathrm{F})(\mathrm{F}) \mathrm{H})(\mathrm{F}) \mathrm{Br})(\mathrm{F}) \mathrm{H})(\mathrm{Br}) \mathrm{F})(\mathrm{F}) \mathrm{H})(\mathrm{F}) \mathrm{F})(\mathrm{Br}) \mathrm{F})(\mathrm{F})(\mathrm{F}) \mathrm{F}$ $\mathrm{C}(\mathrm{C}(\mathrm{C}(\mathrm{C}(\mathrm{C}(\mathrm{C}(\mathrm{C}(\mathrm{C}(\mathrm{C}(\mathrm{C}(\mathrm{H})(\mathrm{F}) \mathrm{F})(\mathrm{F}) \mathrm{F})(\mathrm{F}) \mathrm{F})(\mathrm{Br}) \mathrm{F})(\mathrm{H}) \mathrm{F})(\mathrm{F}) \mathrm{F})(\mathrm{Br}) \mathrm{F})(\mathrm{Br}) \mathrm{F})(\mathrm{H}) \mathrm{F})(\mathrm{Br})(\mathrm{F}) \mathrm{F}$ $\mathrm{C}(\mathrm{C}(\mathrm{C}(\mathrm{C}(\mathrm{C}(\mathrm{C}(\mathrm{C}(\mathrm{C}(\mathrm{C}(\mathrm{C}(\mathrm{F})(\mathrm{H}) \mathrm{Br})(\mathrm{H}) \mathrm{F})(\mathrm{F}) \mathrm{F})(\mathrm{F}) \mathrm{F})(\mathrm{F}) \mathrm{Br})(\mathrm{Cl}) \mathrm{F})(\mathrm{F}) \mathrm{Cl})(\mathrm{F}) \mathrm{H})(\mathrm{F}) \mathrm{F})(\mathrm{F})(\mathrm{F}) \mathrm{F}$ $\mathrm{C}(\mathrm{C}(\mathrm{C}(\mathrm{C}(\mathrm{C}(\mathrm{C}(\mathrm{C}(\mathrm{C}(\mathrm{C}(\mathrm{C}(\mathrm{Cl})(\mathrm{Cl}) \mathrm{F})(\mathrm{H}) \mathrm{F})(\mathrm{F}) \mathrm{H})(\mathrm{F}) \mathrm{H})(\mathrm{Br}) \mathrm{F})(\mathrm{F}) \mathrm{F})(\mathrm{Br}) \mathrm{F})(\mathrm{Cl}) \mathrm{F})(\mathrm{F}) \mathrm{F})(\mathrm{F})(\mathrm{F}) \mathrm{F}$ $\mathrm{C}(\mathrm{C}(\mathrm{C}(\mathrm{C}(\mathrm{C}(\mathrm{C}(\mathrm{C}(\mathrm{C}(\mathrm{C}(\mathrm{C}(\mathrm{Cl})(\mathrm{F}) \mathrm{F})(\mathrm{F}) \mathrm{F})(\mathrm{F}) \mathrm{F})(\mathrm{Br}) \mathrm{F})(\mathrm{Cl}) \mathrm{F})(\mathrm{F}) \mathrm{F})(\mathrm{H}) \mathrm{F})(\mathrm{H}) \mathrm{Cl})(\mathrm{F}) \mathrm{F})(\mathrm{F})(\mathrm{H}) \mathrm{Cl}$ $\mathrm{C}(\mathrm{C}(\mathrm{C}(\mathrm{C}(\mathrm{C}(\mathrm{C}(\mathrm{C}(\mathrm{C}(\mathrm{C}(\mathrm{C}(\mathrm{Cl})(\mathrm{F}) \mathrm{F})(\mathrm{Cl}) \mathrm{H})(\mathrm{F}) \mathrm{F})(\mathrm{F}) \mathrm{F})(\mathrm{F}) \mathrm{F})(\mathrm{F}) \mathrm{F})(\mathrm{F}) \mathrm{F})(\mathrm{F}) \mathrm{Cl})(\mathrm{H}) \mathrm{Cl})(\mathrm{Cl})(\mathrm{F}) \mathrm{H}$ $\mathrm{C}(\mathrm{C}(\mathrm{C}(\mathrm{C}(\mathrm{C}(\mathrm{C}(\mathrm{C}(\mathrm{C}(\mathrm{C}(\mathrm{C}(\mathrm{F})(\mathrm{H}) \mathrm{F})(\mathrm{F}) \mathrm{F})(\mathrm{F}) \mathrm{F})(\mathrm{Cl}) \mathrm{F})(\mathrm{Cl}) \mathrm{F})(\mathrm{F}) \mathrm{Cl})(\mathrm{Cl}) \mathrm{F})(\mathrm{F}) \mathrm{H})(\mathrm{H}) \mathrm{F})(\mathrm{Cl})(\mathrm{Cl}) \mathrm{F}$ $\mathrm{C}(\mathrm{C}(\mathrm{C}(\mathrm{C}(\mathrm{C}(\mathrm{C}(\mathrm{C}(\mathrm{C}(\mathrm{C}(\mathrm{C}(\mathrm{F})(\mathrm{F}) \mathrm{F})(\mathrm{H}) \mathrm{F})(\mathrm{H}) \mathrm{Cl})(\mathrm{H}) \mathrm{F})(\mathrm{F}) \mathrm{F})(\mathrm{F}) \mathrm{F})(\mathrm{Br}) \mathrm{F})(\mathrm{Br}) \mathrm{F})(\mathrm{F}) \mathrm{F})(\mathrm{F})(\mathrm{F}) \mathrm{F}$ $\mathrm{C}(\mathrm{C}(\mathrm{C}(\mathrm{C}(\mathrm{C}(\mathrm{C}(\mathrm{C}(\mathrm{C}(\mathrm{C}(\mathrm{C}(\mathrm{F})(\mathrm{F}) \mathrm{F})(\mathrm{Br}) \mathrm{F})(\mathrm{Br}) \mathrm{F})(\mathrm{F}) \mathrm{F})(\mathrm{F}) \mathrm{F})(\mathrm{H}) \mathrm{F})(\mathrm{F}) \mathrm{H})(\mathrm{F}) \mathrm{F})(\mathrm{Cl}) \mathrm{F})(\mathrm{H})(\mathrm{Br}) \mathrm{F}$ $\mathrm{C}(\mathrm{C}(\mathrm{C}(\mathrm{C}(\mathrm{C}(\mathrm{C}(\mathrm{C}(\mathrm{C}(\mathrm{C}(\mathrm{C}(\mathrm{F})(\mathrm{F}) \mathrm{F})(\mathrm{F}) \mathrm{F})(\mathrm{F}) \mathrm{H})(\mathrm{H}) \mathrm{F})(\mathrm{Br}) \mathrm{F})(\mathrm{F}) \mathrm{Br})(\mathrm{F}) \mathrm{F})(\mathrm{H}) \mathrm{H})(\mathrm{F}) \mathrm{F})(\mathrm{Br})(\mathrm{F}) \mathrm{F}$ $\mathrm{C}(\mathrm{C}(\mathrm{C}(\mathrm{C}(\mathrm{C}(\mathrm{C}(\mathrm{C}(\mathrm{C}(\mathrm{C}(\mathrm{C}(\mathrm{Br})(\mathrm{H}) \mathrm{F})(\mathrm{Br}) \mathrm{F})(\mathrm{F}) \mathrm{H})(\mathrm{H}) \mathrm{Br})(\mathrm{H}) \mathrm{F})(\mathrm{F}) \mathrm{F})(\mathrm{F}) \mathrm{F})(\mathrm{F}) \mathrm{Br})(\mathrm{F}) \mathrm{F})(\mathrm{F})(\mathrm{F}) \mathrm{F}$ $\mathrm{C}(\mathrm{C}(\mathrm{C}(\mathrm{C}(\mathrm{C}(\mathrm{C}(\mathrm{C}(\mathrm{C}(\mathrm{C}(\mathrm{C}(\mathrm{H})(\mathrm{F}) \mathrm{F})(\mathrm{H}) \mathrm{F})(\mathrm{F}) \mathrm{F})(\mathrm{F}) \mathrm{F})(\mathrm{F}) \mathrm{H})(\mathrm{F}) \mathrm{H})(\mathrm{Cl}) \mathrm{F})(\mathrm{Br}) \mathrm{F})(\mathrm{F}) \mathrm{F})(\mathrm{Cl})(\mathrm{F}) \mathrm{Br}$ $\mathrm{C}(\mathrm{C}(\mathrm{C}(\mathrm{C}(\mathrm{C}(\mathrm{C}(\mathrm{C}(\mathrm{C}(\mathrm{C}(\mathrm{C}(\mathrm{F})(\mathrm{F}) \mathrm{F})(\mathrm{F}) \mathrm{Br})(\mathrm{Cl}) \mathrm{H})(\mathrm{F}) \mathrm{F})(\mathrm{F}) \mathrm{F})(\mathrm{Cl}) \mathrm{Br})(\mathrm{H}) \mathrm{F})(\mathrm{H}) \mathrm{F})(\mathrm{F}) \mathrm{Br})(\mathrm{F})(\mathrm{H}) \mathrm{F}$ $\mathrm{C}(\mathrm{C}(\mathrm{C}(\mathrm{C}(\mathrm{C}(\mathrm{C}(\mathrm{C}(\mathrm{C}(\mathrm{C}(\mathrm{C}(\mathrm{H})(\mathrm{Cl}) \mathrm{F})(\mathrm{F}) \mathrm{F})(\mathrm{H}) \mathrm{F})(\mathrm{Cl}) \mathrm{F})(\mathrm{F}) \mathrm{Cl})(\mathrm{F}) \mathrm{Br})(\mathrm{H}) \mathrm{F})(\mathrm{F}) \mathrm{F})(\mathrm{F}) \mathrm{F})(\mathrm{F})(\mathrm{H}) \mathrm{B}$ $\mathrm{C}(\mathrm{C}(\mathrm{C}(\mathrm{C}(\mathrm{C}(\mathrm{C}(\mathrm{C}(\mathrm{C}(\mathrm{C}(\mathrm{C}(\mathrm{F})(\mathrm{H}) \mathrm{F})(\mathrm{F}) \mathrm{F})(\mathrm{F}) \mathrm{Br})(\mathrm{H}) \mathrm{F})(\mathrm{F}) \mathrm{F})(\mathrm{F}) \mathrm{F})(\mathrm{Cl}) \mathrm{H})(\mathrm{Cl}) \mathrm{F})(\mathrm{Cl}) \mathrm{H})(\mathrm{F})(\mathrm{F}) \mathrm{F}$ $\mathrm{C}(\mathrm{C}(\mathrm{C}(\mathrm{C}(\mathrm{C}(\mathrm{C}(\mathrm{C}(\mathrm{C}(\mathrm{C}(\mathrm{C}(\mathrm{H})(\mathrm{F}) \mathrm{F})(\mathrm{F}) \mathrm{Cl})(\mathrm{Cl}) \mathrm{F})(\mathrm{H}) \mathrm{H})(\mathrm{F}) \mathrm{H})(\mathrm{F}) \mathrm{F})(\mathrm{Cl}) \mathrm{F})(\mathrm{F}) \mathrm{F})(\mathrm{Br}) \mathrm{Cl})(\mathrm{F})(\mathrm{F}) \mathrm{F}$ $\mathrm{C}(\mathrm{C}(\mathrm{C}(\mathrm{C}(\mathrm{C}(\mathrm{C}(\mathrm{C}(\mathrm{C}(\mathrm{C}(\mathrm{C}(\mathrm{Cl})(\mathrm{H}) \mathrm{F})(\mathrm{Cl}) \mathrm{F})(\mathrm{H}) \mathrm{F})(\mathrm{F}) \mathrm{Cl})(\mathrm{H}) \mathrm{F})(\mathrm{Cl}) \mathrm{F})(\mathrm{F}) \mathrm{F})(\mathrm{H}) \mathrm{F})(\mathrm{Cl}) \mathrm{F})(\mathrm{Br})(\mathrm{F}) \mathrm{F}$ $\mathrm{C}(\mathrm{C}(\mathrm{C}(\mathrm{C}(\mathrm{C}(\mathrm{C}(\mathrm{C}(\mathrm{C}(\mathrm{C}(\mathrm{C}(\mathrm{F})(\mathrm{F}) \mathrm{F})(\mathrm{F}) \mathrm{F})(\mathrm{F}) \mathrm{F})(\mathrm{H}) \mathrm{Cl})(\mathrm{F}) \mathrm{H})(\mathrm{H}) \mathrm{F})(\mathrm{F}) \mathrm{Cl})(\mathrm{Cl}) \mathrm{Cl})(\mathrm{Cl}) \mathrm{F})(\mathrm{H})(\mathrm{F}) \mathrm{F}$ $\mathrm{C}(\mathrm{C}(\mathrm{C}(\mathrm{C}(\mathrm{C}(\mathrm{C}(\mathrm{C}(\mathrm{C}(\mathrm{C}(\mathrm{C}(\mathrm{H})(\mathrm{Cl}) \mathrm{F})(\mathrm{F}) \mathrm{H})(\mathrm{Cl}) \mathrm{F})(\mathrm{F}) \mathrm{Cl})(\mathrm{F}) \mathrm{F})(\mathrm{H}) \mathrm{F})(\mathrm{Cl}) \mathrm{F})(\mathrm{F}) \mathrm{F})(\mathrm{Cl}) \mathrm{F})(\mathrm{F})(\mathrm{H}) \mathrm{Cl}$ $\mathrm{C}(\mathrm{C}(\mathrm{C}(\mathrm{C}(\mathrm{C}(\mathrm{C}(\mathrm{C}(\mathrm{C}(\mathrm{C}(\mathrm{C}(\mathrm{F})(\mathrm{H}) \mathrm{H})(\mathrm{F}) \mathrm{Cl})(\mathrm{F}) \mathrm{F})(\mathrm{H}) \mathrm{F})(\mathrm{F}) \mathrm{F})(\mathrm{F}) \mathrm{F})(\mathrm{H}) \mathrm{F})(\mathrm{F}) \mathrm{F})(\mathrm{F}) \mathrm{F})(\mathrm{F})(\mathrm{Br}) \mathrm{Br}$ $\mathrm{C}(\mathrm{C}(\mathrm{C}(\mathrm{C}(\mathrm{C}(\mathrm{C}(\mathrm{C}(\mathrm{C}(\mathrm{C}(\mathrm{C}(\mathrm{F})(\mathrm{F}) \mathrm{F})(\mathrm{F}) \mathrm{Cl})(\mathrm{F}) \mathrm{F})(\mathrm{Br}) \mathrm{F})(\mathrm{F}) \mathrm{H})(\mathrm{H}) \mathrm{F})(\mathrm{F}) \mathrm{F})(\mathrm{Br}) \mathrm{F})(\mathrm{F}) \mathrm{H})(\mathrm{H})(\mathrm{Br}) \mathrm{F}$ $\mathrm{C}(\mathrm{C}(\mathrm{C}(\mathrm{C}(\mathrm{C}(\mathrm{C}(\mathrm{C}(\mathrm{C}(\mathrm{C}(\mathrm{C}(\mathrm{F})(\mathrm{F}) \mathrm{F})(\mathrm{H}) \mathrm{F})(\mathrm{F}) \mathrm{Br})(\mathrm{F}) \mathrm{Br})(\mathrm{F}) \mathrm{F})(\mathrm{F}) \mathrm{F})(\mathrm{F}) \mathrm{H})(\mathrm{F}) \mathrm{H})(\mathrm{Br}) \mathrm{H})(\mathrm{F})(\mathrm{F}) \mathrm{H}$ $\mathrm{C}(\mathrm{C}(\mathrm{C}(\mathrm{C}(\mathrm{C}(\mathrm{C}(\mathrm{C}(\mathrm{C}(\mathrm{C}(\mathrm{C}(\mathrm{F})(\mathrm{Br}) \mathrm{F})(\mathrm{F}) \mathrm{F})(\mathrm{F}) \mathrm{F})(\mathrm{H}) \mathrm{Br})(\mathrm{Br}) \mathrm{H})(\mathrm{H}) \mathrm{F})(\mathrm{Br}) \mathrm{H})(\mathrm{F}) \mathrm{H})(\mathrm{F}) \mathrm{F})(\mathrm{F})(\mathrm{F}) \mathrm{F}$ $\mathrm{C}(\mathrm{C}(\mathrm{C}(\mathrm{C}(\mathrm{C}(\mathrm{C}(\mathrm{C}(\mathrm{C}(\mathrm{C}(\mathrm{C}(\mathrm{H})(\mathrm{F}) \mathrm{F})(\mathrm{F}) \mathrm{F})(\mathrm{H}) \mathrm{F})(\mathrm{F}) \mathrm{Cl})(\mathrm{F}) \mathrm{F})(\mathrm{F}) \mathrm{F})(\mathrm{Cl}) \mathrm{F})(\mathrm{Br}) \mathrm{F})(\mathrm{Br}) \mathrm{H})(\mathrm{H})(\mathrm{F}) \mathrm{H}$ $\mathrm{C}(\mathrm{C}(\mathrm{C}(\mathrm{C}(\mathrm{C}(\mathrm{C}(\mathrm{C}(\mathrm{C}(\mathrm{C}(\mathrm{C}(\mathrm{F})(\mathrm{F}) \mathrm{H})(\mathrm{F}) \mathrm{F})(\mathrm{F}) \mathrm{Cl})(\mathrm{F}) \mathrm{F})(\mathrm{F}) \mathrm{F})(\mathrm{H}) \mathrm{Cl})(\mathrm{Br}) \mathrm{Br})(\mathrm{H}) \mathrm{H})(\mathrm{H}) \mathrm{Cl})(\mathrm{F})(\mathrm{F}) \mathrm{F}$ $\mathrm{C}(\mathrm{C}(\mathrm{C}(\mathrm{C}(\mathrm{C}(\mathrm{C}(\mathrm{C}(\mathrm{C}(\mathrm{C}(\mathrm{C}(\mathrm{F})(\mathrm{H}) \mathrm{F})(\mathrm{Cl}) \mathrm{F})(\mathrm{H}) \mathrm{F})(\mathrm{Br}) \mathrm{F})(\mathrm{F}) \mathrm{H})(\mathrm{H}) \mathrm{F})(\mathrm{Cl}) \mathrm{H})(\mathrm{Cl}) \mathrm{F})(\mathrm{F}) \mathrm{F})(\mathrm{F})(\mathrm{F}) \mathrm{F}$ $\mathrm{C}(\mathrm{C}(\mathrm{C}(\mathrm{C}(\mathrm{C}(\mathrm{C}(\mathrm{C}(\mathrm{C}(\mathrm{C}(\mathrm{C}(\mathrm{Cl})(\mathrm{F}) \mathrm{Cl})(\mathrm{F}) \mathrm{H})(\mathrm{F}) \mathrm{F})(\mathrm{H}) \mathrm{F})(\mathrm{F}) \mathrm{F})(\mathrm{H}) \mathrm{Cl})(\mathrm{Cl}) \mathrm{F})(\mathrm{F}) \mathrm{F})(\mathrm{H}) \mathrm{Br})(\mathrm{H})(\mathrm{F}) \mathrm{F}$ $\mathrm{C}(\mathrm{C}(\mathrm{C}(\mathrm{C}(\mathrm{C}(\mathrm{C}(\mathrm{C}(\mathrm{C}(\mathrm{C}(\mathrm{C}(\mathrm{Cl})(\mathrm{F}) \mathrm{F})(\mathrm{Cl}) \mathrm{Cl})(\mathrm{F}) \mathrm{H})(\mathrm{F}) \mathrm{F})(\mathrm{F}) \mathrm{H})(\mathrm{F}) \mathrm{F})(\mathrm{H}) \mathrm{F})(\mathrm{F}) \mathrm{F})(\mathrm{F}) \mathrm{F})(\mathrm{Cl})(\mathrm{H}) \mathrm{H}$ $\mathrm{C}(\mathrm{C}(\mathrm{C}(\mathrm{C}(\mathrm{C}(\mathrm{C}(\mathrm{C}(\mathrm{C}(\mathrm{C}(\mathrm{C}(\mathrm{Cl})(\mathrm{Cl}) \mathrm{H})(\mathrm{F}) \mathrm{F})(\mathrm{Cl}) \mathrm{F})(\mathrm{H}) \mathrm{F})(\mathrm{F}) \mathrm{F})(\mathrm{Br}) \mathrm{F})(\mathrm{Cl}) \mathrm{H})(\mathrm{Cl}) \mathrm{H})(\mathrm{F}) \mathrm{H})(\mathrm{F})(\mathrm{F}) \mathrm{F}$ $\mathrm{C}(\mathrm{C}(\mathrm{C}(\mathrm{C}(\mathrm{C}(\mathrm{C}(\mathrm{C}(\mathrm{C}(\mathrm{C}(\mathrm{C}(\mathrm{Cl})(\mathrm{F}) \mathrm{F})(\mathrm{H}) \mathrm{F})(\mathrm{F}) \mathrm{F})(\mathrm{F}) \mathrm{F})(\mathrm{Cl}) \mathrm{H})(\mathrm{F}) \mathrm{H})(\mathrm{F}) \mathrm{Cl})(\mathrm{H}) \mathrm{F})(\mathrm{Cl}) \mathrm{F})(\mathrm{F})(\mathrm{Cl}) \mathrm{H}$ $\mathrm{C}(\mathrm{C}(\mathrm{C}(\mathrm{C}(\mathrm{C}(\mathrm{C}(\mathrm{C}(\mathrm{C}(\mathrm{C}(\mathrm{C}(\mathrm{Cl})(\mathrm{F}) \mathrm{F})(\mathrm{Cl}) \mathrm{F})(\mathrm{H}) \mathrm{F})(\mathrm{F}) \mathrm{H})(\mathrm{F}) \mathrm{F})(\mathrm{Cl}) \mathrm{F})(\mathrm{H}) \mathrm{Cl})(\mathrm{H}) \mathrm{F})(\mathrm{F}) \mathrm{F})(\mathrm{H})(\mathrm{Cl}) \mathrm{C}$ $\mathrm{C}(\mathrm{C}(\mathrm{C}(\mathrm{C}(\mathrm{C}(\mathrm{C}(\mathrm{C}(\mathrm{C}(\mathrm{C}(\mathrm{C}(\mathrm{F})(\mathrm{H}) \mathrm{Br})(\mathrm{F}) \mathrm{F})(\mathrm{H}) \mathrm{F})(\mathrm{F}) \mathrm{F})(\mathrm{H}) \mathrm{H})(\mathrm{F}) \mathrm{F})(\mathrm{Cl}) \mathrm{F})(\mathrm{F}) \mathrm{F})(\mathrm{F}) \mathrm{F})(\mathrm{Br})(\mathrm{H}) \mathrm{F}$ $\mathrm{C}(\mathrm{C}(\mathrm{C}(\mathrm{C}(\mathrm{C}(\mathrm{C}(\mathrm{C}(\mathrm{C}(\mathrm{C}(\mathrm{C}(\mathrm{H})(\mathrm{F}) \mathrm{Br})(\mathrm{F}) \mathrm{H})(\mathrm{F}) \mathrm{H})(\mathrm{F}) \mathrm{H})(\mathrm{F}) \mathrm{F})(\mathrm{F}) \mathrm{F})(\mathrm{F}) \mathrm{F})(\mathrm{Br}) \mathrm{H})(\mathrm{F}) \mathrm{F})(\mathrm{H})(\mathrm{Br}) \mathrm{F}$ $\mathrm{C}(\mathrm{C}(\mathrm{C}(\mathrm{C}(\mathrm{C}(\mathrm{C}(\mathrm{C}(\mathrm{C}(\mathrm{C}(\mathrm{C}(\mathrm{Br})(\mathrm{F}) \mathrm{F})(\mathrm{H}) \mathrm{Br})(\mathrm{H}) \mathrm{H})(\mathrm{F}) \mathrm{F})(\mathrm{F}) \mathrm{F})(\mathrm{Br}) \mathrm{F})(\mathrm{H}) \mathrm{Br})(\mathrm{F}) \mathrm{F})(\mathrm{H}) \mathrm{F})(\mathrm{H})(\mathrm{F}) \mathrm{F}$ $\mathrm{C}(\mathrm{C}(\mathrm{C}(\mathrm{C}(\mathrm{C}(\mathrm{C}(\mathrm{C}(\mathrm{C}(\mathrm{C}(\mathrm{C}(\mathrm{F})(\mathrm{H}) \mathrm{F})(\mathrm{F}) \mathrm{F})(\mathrm{H}) \mathrm{F})(\mathrm{F}) \mathrm{H})(\mathrm{Cl}) \mathrm{Br})(\mathrm{F}) \mathrm{F})(\mathrm{H}) \mathrm{Cl})(\mathrm{H}) \mathrm{F})(\mathrm{F}) \mathrm{H})(\mathrm{Br})(\mathrm{F}) \mathrm{F}$ $\mathrm{C}(\mathrm{C}(\mathrm{C}(\mathrm{C}(\mathrm{C}(\mathrm{C}(\mathrm{C}(\mathrm{C}(\mathrm{C}(\mathrm{C}(\mathrm{F})(\mathrm{H}) \mathrm{H})(\mathrm{F}) \mathrm{Cl})(\mathrm{Br}) \mathrm{F})(\mathrm{F}) \mathrm{Cl})(\mathrm{F}) \mathrm{H})(\mathrm{F}) \mathrm{Br})(\mathrm{Cl}) \mathrm{H})(\mathrm{F}) \mathrm{H})(\mathrm{F}) \mathrm{F})(\mathrm{F})(\mathrm{F}) \mathrm{H}$ $\mathrm{C}(\mathrm{C}(\mathrm{C}(\mathrm{C}(\mathrm{C}(\mathrm{C}(\mathrm{C}(\mathrm{C}(\mathrm{C}(\mathrm{C}(\mathrm{H})(\mathrm{F}) \mathrm{H})(\mathrm{Cl}) \mathrm{H})(\mathrm{F}) \mathrm{F})(\mathrm{F}) \mathrm{H})(\mathrm{F}) \mathrm{F})(\mathrm{F}) \mathrm{Cl})(\mathrm{F}) \mathrm{F})(\mathrm{Br}) \mathrm{H})(\mathrm{H}) \mathrm{Cl})(\mathrm{F})(\mathrm{F}) \mathrm{F}$ $\mathrm{C}(\mathrm{C}(\mathrm{C}(\mathrm{C}(\mathrm{C}(\mathrm{C}(\mathrm{C}(\mathrm{C}(\mathrm{C}(\mathrm{C}(\mathrm{H})(\mathrm{Cl}) \mathrm{F})(\mathrm{F}) \mathrm{Cl})(\mathrm{F}) \mathrm{F})(\mathrm{H}) \mathrm{F})(\mathrm{Br}) \mathrm{Br})(\mathrm{H}) \mathrm{Cl})(\mathrm{F}) \mathrm{F})(\mathrm{H}) \mathrm{Cl})(\mathrm{F}) \mathrm{H})(\mathrm{F})(\mathrm{F}) \mathrm{H}$ $\mathrm{C}(\mathrm{C}(\mathrm{C}(\mathrm{C}(\mathrm{C}(\mathrm{C}(\mathrm{C}(\mathrm{C}(\mathrm{C}(\mathrm{C}(\mathrm{Br})(\mathrm{F}) \mathrm{H})(\mathrm{F}) \mathrm{H})(\mathrm{F}) \mathrm{H})(\mathrm{F}) \mathrm{F})(\mathrm{Cl}) \mathrm{F})(\mathrm{Cl}) \mathrm{Cl})(\mathrm{F}) \mathrm{F})(\mathrm{F}) \mathrm{H})(\mathrm{Cl}) \mathrm{F})(\mathrm{H})(\mathrm{H}) \mathrm{F}$ $\mathrm{C}(\mathrm{C}(\mathrm{C}(\mathrm{C}(\mathrm{C}(\mathrm{C}(\mathrm{C}(\mathrm{C}(\mathrm{C}(\mathrm{C}(\mathrm{Cl})(\mathrm{Cl}) \mathrm{F})(\mathrm{Cl}) \mathrm{Cl})(\mathrm{F}) \mathrm{Br})(\mathrm{H}) \mathrm{F})(\mathrm{F}) \mathrm{Cl})(\mathrm{F}) \mathrm{F})(\mathrm{F}) \mathrm{H})(\mathrm{H}) \mathrm{F})(\mathrm{H}) \mathrm{F})(\mathrm{H})(\mathrm{H})$ $\mathrm{C}(\mathrm{C}(\mathrm{C}(\mathrm{C}(\mathrm{C}(\mathrm{C}(\mathrm{C}(\mathrm{C}(\mathrm{C}(\mathrm{C}(\mathrm{H})(\mathrm{F}) \mathrm{H})(\mathrm{H}) \mathrm{H})(\mathrm{F}) \mathrm{Cl})(\mathrm{Cl}) \mathrm{H})(\mathrm{F}) \mathrm{Cl})(\mathrm{F}) \mathrm{Cl})(\mathrm{F}) \mathrm{F})(\mathrm{Cl}) \mathrm{F})(\mathrm{F}) \mathrm{H})(\mathrm{F})(\mathrm{F}) \mathrm{F}$ $\mathrm{C}(\mathrm{C}(\mathrm{C}(\mathrm{C}(\mathrm{C}(\mathrm{C}(\mathrm{C}(\mathrm{C}(\mathrm{C}(\mathrm{C}(\mathrm{Br})(\mathrm{H}) \mathrm{F})(\mathrm{F}) \mathrm{F})(\mathrm{H}) \mathrm{F})(\mathrm{Br}) \mathrm{F})(\mathrm{F}) \mathrm{Cl})(\mathrm{F}) \mathrm{F})(\mathrm{F}) \mathrm{F})(\mathrm{H}) \mathrm{F})(\mathrm{F}) \mathrm{F})(\mathrm{H})(\mathrm{H}) \mathrm{H}$ $\mathrm{C}(\mathrm{C}(\mathrm{C}(\mathrm{C}(\mathrm{C}(\mathrm{C}(\mathrm{C}(\mathrm{C}(\mathrm{C}(\mathrm{C}(\mathrm{F})(\mathrm{H}) \mathrm{H})(\mathrm{H}) \mathrm{F})(\mathrm{F}) \mathrm{Br})(\mathrm{H}) \mathrm{F})(\mathrm{F}) \mathrm{Br})(\mathrm{H}) \mathrm{F})(\mathrm{Br}) \mathrm{F})(\mathrm{H}) \mathrm{Cl})(\mathrm{F}) \mathrm{F})(\mathrm{F})(\mathrm{F}) \mathrm{F}$ $\mathrm{C}(\mathrm{C}(\mathrm{C}(\mathrm{C}(\mathrm{C}(\mathrm{C}(\mathrm{C}(\mathrm{C}(\mathrm{C}(\mathrm{C}(\mathrm{Br})(\mathrm{F}) \mathrm{Br})(\mathrm{F}) \mathrm{F})(\mathrm{H}) \mathrm{F})(\mathrm{F}) \mathrm{H})(\mathrm{F}) \mathrm{H})(\mathrm{F}) \mathrm{Br})(\mathrm{H}) \mathrm{H})(\mathrm{F}) \mathrm{H})(\mathrm{F}) \mathrm{F})(\mathrm{F})(\mathrm{H}) \mathrm{F}$ C(C(C(C(C(C(C(C(C(C(H)(F)F)(F)F)(F)Br)(F)Br)(Br)H)(F)H)(H)H)(H)F)(F)F)(H)(F)B $\mathrm{C}(\mathrm{C}(\mathrm{C}(\mathrm{C}(\mathrm{C}(\mathrm{C}(\mathrm{C}(\mathrm{C}(\mathrm{C}(\mathrm{C}(\mathrm{Cl})(\mathrm{F}) \mathrm{F})(\mathrm{F}) \mathrm{F})(\mathrm{H}) \mathrm{H})(\mathrm{H}) \mathrm{Cl})(\mathrm{F}) \mathrm{F})(\mathrm{F}) \mathrm{H})(\mathrm{H}) \mathrm{H})(\mathrm{H}) \mathrm{F})(\mathrm{Br}) \mathrm{F})(\mathrm{F})(\mathrm{Br}) \mathrm{F}$ $\mathrm{C}(\mathrm{C}(\mathrm{C}(\mathrm{C}(\mathrm{C}(\mathrm{C}(\mathrm{C}(\mathrm{C}(\mathrm{C}(\mathrm{C}(\mathrm{H})(\mathrm{F}) \mathrm{H})(\mathrm{F}) \mathrm{H})(\mathrm{F}) \mathrm{F})(\mathrm{F}) \mathrm{F})(\mathrm{F}) \mathrm{Cl})(\mathrm{H}) \mathrm{H})(\mathrm{F}) \mathrm{H})(\mathrm{Br}) \mathrm{F})(\mathrm{F}) \mathrm{H})(\mathrm{F})(\mathrm{F}) \mathrm{Cl}$ $\mathrm{C}(\mathrm{C}(\mathrm{C}(\mathrm{C}(\mathrm{C}(\mathrm{C}(\mathrm{C}(\mathrm{C}(\mathrm{C}(\mathrm{C}(\mathrm{F})(\mathrm{Cl}) \mathrm{Cl})(\mathrm{H}) \mathrm{H})(\mathrm{H}) \mathrm{F})(\mathrm{F}) \mathrm{F})(\mathrm{F}) \mathrm{F})(\mathrm{H}) \mathrm{Br})(\mathrm{Br}) \mathrm{F})(\mathrm{H}) \mathrm{Cl})(\mathrm{H}) \mathrm{F})(\mathrm{F})(\mathrm{F}) \mathrm{H}$ $\mathrm{C}(\mathrm{C}(\mathrm{C}(\mathrm{C}(\mathrm{C}(\mathrm{C}(\mathrm{C}(\mathrm{C}(\mathrm{C}(\mathrm{C}(\mathrm{F})(\mathrm{F}) \mathrm{Cl})(\mathrm{F}) \mathrm{Cl})(\mathrm{H}) \mathrm{F})(\mathrm{F}) \mathrm{F})(\mathrm{H}) \mathrm{H})(\mathrm{Cl}) \mathrm{H})(\mathrm{F}) \mathrm{H})(\mathrm{F}) \mathrm{Br})(\mathrm{F}) \mathrm{F})(\mathrm{H})(\mathrm{H}) \mathrm{F}$ $\mathrm{C}(\mathrm{C}(\mathrm{C}(\mathrm{C}(\mathrm{C}(\mathrm{C}(\mathrm{C}(\mathrm{C}(\mathrm{C}(\mathrm{C}(\mathrm{F})(\mathrm{F}) \mathrm{F})(\mathrm{F}) \mathrm{Cl})(\mathrm{H}) \mathrm{H})(\mathrm{H}) \mathrm{Br})(\mathrm{Cl}) \mathrm{F})(\mathrm{F}) \mathrm{H})(\mathrm{H}) \mathrm{Cl})(\mathrm{H}) \mathrm{F})(\mathrm{F}) \mathrm{H})(\mathrm{F})(\mathrm{F}) \mathrm{C}$ $\mathrm{C}(\mathrm{C}(\mathrm{C}(\mathrm{C}(\mathrm{C}(\mathrm{C}(\mathrm{C}(\mathrm{C}(\mathrm{C}(\mathrm{C}(\mathrm{F})(\mathrm{F}) \mathrm{F})(\mathrm{H}) \mathrm{F})(\mathrm{F}) \mathrm{H})(\mathrm{F}) \mathrm{H})(\mathrm{H}) \mathrm{F})(\mathrm{H}) \mathrm{H})(\mathrm{Cl}) \mathrm{Cl})(\mathrm{H}) \mathrm{F})(\mathrm{F}) \mathrm{Cl})(\mathrm{F})(\mathrm{F}) \mathrm{Cl}$ $\mathrm{C}(\mathrm{C}(\mathrm{C}(\mathrm{C}(\mathrm{C}(\mathrm{C}(\mathrm{C}(\mathrm{C}(\mathrm{C}(\mathrm{C}(\mathrm{H})(\mathrm{Cl}) \mathrm{H})(\mathrm{Cl}) \mathrm{F})(\mathrm{H}) \mathrm{F})(\mathrm{F}) \mathrm{H})(\mathrm{Cl}) \mathrm{H})(\mathrm{H}) \mathrm{F})(\mathrm{Br}) \mathrm{H})(\mathrm{F}) \mathrm{Cl})(\mathrm{F}) \mathrm{F})(\mathrm{F})(\mathrm{Cl}) \mathrm{F}$ $\mathrm{C}(\mathrm{C}(\mathrm{C}(\mathrm{C}(\mathrm{C}(\mathrm{C}(\mathrm{C}(\mathrm{C}(\mathrm{C}(\mathrm{C}(\mathrm{H})(\mathrm{F}) \mathrm{F})(\mathrm{F}) \mathrm{H})(\mathrm{F}) \mathrm{H})(\mathrm{F}) \mathrm{Cl})(\mathrm{Cl}) \mathrm{Cl})(\mathrm{F}) \mathrm{H})(\mathrm{F}) \mathrm{Cl})(\mathrm{F}) \mathrm{F})(\mathrm{H}) \mathrm{H})(\mathrm{H})(\mathrm{F}) \mathrm{Cl}$ $\mathrm{C}(\mathrm{C}(\mathrm{C}(\mathrm{C}(\mathrm{C}(\mathrm{C}(\mathrm{C}(\mathrm{C}(\mathrm{C}(\mathrm{C}(\mathrm{H})(\mathrm{F}) \mathrm{H})(\mathrm{Cl}) \mathrm{F})(\mathrm{F}) \mathrm{Cl})(\mathrm{H}) \mathrm{Cl})(\mathrm{H}) \mathrm{Cl})(\mathrm{F}) \mathrm{H})(\mathrm{H}) \mathrm{F})(\mathrm{F}) \mathrm{Cl})(\mathrm{Cl}) \mathrm{H})(\mathrm{F})(\mathrm{F}) \mathrm{F}$ $\mathrm{C}(\mathrm{C}(\mathrm{C}(\mathrm{C}(\mathrm{C}(\mathrm{C}(\mathrm{C}(\mathrm{C}(\mathrm{C}(\mathrm{C}(\mathrm{F})(\mathrm{F}) \mathrm{F})(\mathrm{F}) \mathrm{Cl})(\mathrm{F}) \mathrm{Cl})(\mathrm{H}) \mathrm{Cl})(\mathrm{Cl}) \mathrm{H})(\mathrm{F}) \mathrm{H})(\mathrm{H}) \mathrm{Cl})(\mathrm{Cl}) \mathrm{H})(\mathrm{F}) \mathrm{H})(\mathrm{Cl})(\mathrm{F}) \mathrm{H}$ $\mathrm{C}(\mathrm{C}(\mathrm{C}(\mathrm{C}(\mathrm{C}(\mathrm{C}(\mathrm{C}(\mathrm{C}(\mathrm{C}(\mathrm{C}(\mathrm{F})(\mathrm{Br}) \mathrm{H})(\mathrm{Br}) \mathrm{F})(\mathrm{F}) \mathrm{Br})(\mathrm{F}) \mathrm{H})(\mathrm{F}) \mathrm{F})(\mathrm{H}) \mathrm{H})(\mathrm{H}) \mathrm{F})(\mathrm{H}) \mathrm{Cl})(\mathrm{F}) \mathrm{F})(\mathrm{H})(\mathrm{F}) \mathrm{F}$

Formula

$\mathrm{C} 10 \mathrm{H} 17 \mathrm{Cl} 3 \mathrm{~F} 2$ $\mathrm{C} 10 \mathrm{H} 17 \mathrm{Cl} 14 \mathrm{Br}$ C10H17Cl4F $\mathrm{C} 10 \mathrm{H} 17 \mathrm{ClBr} 2 \mathrm{~F} 2$ $\mathrm{C} 10 \mathrm{H} 18 \mathrm{Br} 2 \mathrm{~F} 2$ C10H18Br3F C10H18Cl2Br2 C10H18Cl2BrF $\mathrm{C} 10 \mathrm{H} 18 \mathrm{Cl} 3 \mathrm{Br}$ $\mathrm{C} 10 \mathrm{H} 18 \mathrm{Cl} 3 \mathrm{~F}$ $\mathrm{C} 10 \mathrm{H} 18 \mathrm{Cl}$ $\mathrm{C} 10 \mathrm{H} 18 \mathrm{ClBr} 2 \mathrm{~F}$ $\mathrm{C} 10 \mathrm{H} 18 \mathrm{ClBrF} 2$ C10H19Br2F $\mathrm{C} 10 \mathrm{H} 19 \mathrm{Br} 3$ $\mathrm{C} 10 \mathrm{H} 19 \mathrm{BrF} 2$ $\mathrm{C} 10 \mathrm{H} 19 \mathrm{Cl} 2 \mathrm{Br}$ $\mathrm{C} 10 \mathrm{H} 19 \mathrm{Cl} 2 \mathrm{~F}$ $\mathrm{C} 10 \mathrm{H} 19 \mathrm{Cl} 3$

$\mathrm{C} 10 \mathrm{H} 19 \mathrm{ClBr} 2$ C10H19ClBrF $\mathrm{C} 10 \mathrm{H} 20 \mathrm{Br} 2$

$\mathrm{C} 10 \mathrm{H} 20 \mathrm{BrF}$

$\mathrm{C} 10 \mathrm{H} 20 \mathrm{Cl} 2$

$\mathrm{C} 10 \mathrm{H} 20 \mathrm{ClBr}$

$\mathrm{C} 10 \mathrm{H} 21 \mathrm{~B}$

$\mathrm{C} 10 \mathrm{H} 21 \mathrm{Cl}$

C10H2Br3F17

$\mathrm{C} 10 \mathrm{H} 2 \mathrm{Cl} 2 \mathrm{Br} 2 \mathrm{~F} 16$

C10H3Br3F 16

$\mathrm{C} 10 \mathrm{H} 3 \mathrm{Br} 4 \mathrm{~F} 15$

$\mathrm{C} 10 \mathrm{H} 3 \mathrm{Cl} 2 \mathrm{Br} 2 \mathrm{~F} 15$

$\mathrm{C} 10 \mathrm{H} 3 \mathrm{Cl} 3 \mathrm{Br} 2 \mathrm{~F} 14$

$\mathrm{C} 10 \mathrm{H} 3 \mathrm{Cl} 4 \mathrm{BrF} 14$

C10H3Cl5F14

$\mathrm{C} 10 \mathrm{H} 3 \mathrm{Cl} 6 \mathrm{~F} 13$

$\mathrm{C} 10 \mathrm{H} 3 \mathrm{ClBr} 2 \mathrm{~F} 16$

$\mathrm{C} 10 \mathrm{H} 3 \mathrm{ClBr} 3 \mathrm{~F} 15$

$\mathrm{C} 10 \mathrm{H} 4 \mathrm{Br} 3 \mathrm{~F} 15$

C10H4Br4F14

$\mathrm{C} 10 \mathrm{H} 4 \mathrm{Cl} 2 \mathrm{Br} 2 \mathrm{~F} 14$

$\mathrm{C} 10 \mathrm{H} 4 \mathrm{Cl} 2 \mathrm{Br} 3 \mathrm{~F} 13$

$\mathrm{C} 10 \mathrm{H} 4 \mathrm{Cl} 3 \mathrm{Br} 2 \mathrm{~F} 13$

$\mathrm{C} 10 \mathrm{H} 4 \mathrm{Cl} 3 \mathrm{BrF} 14$

$\mathrm{C} 10 \mathrm{H} 4 \mathrm{Cl} 4 \mathrm{BrF} 13$

$\mathrm{C} 10 \mathrm{H} 4 \mathrm{Cl} 5 \mathrm{BrF} 12$

$\mathrm{C} 10 \mathrm{H} 4 \mathrm{Cl} 5 \mathrm{~F} 13$

$\mathrm{C} 10 \mathrm{H} 4 \mathrm{Cl} 6 \mathrm{~F} 12$

$\mathrm{C} 10 \mathrm{H} 4 \mathrm{ClBr} 2 \mathrm{~F} 15$

$\mathrm{C} 10 \mathrm{H} 4 \mathrm{ClBr} 3 \mathrm{~F} 1$

$\mathrm{C} 10 \mathrm{H} 5 \mathrm{Br} 3 \mathrm{~F} 14$

$\mathrm{C} 10 \mathrm{H} 5 \mathrm{Br} 4 \mathrm{~F} 13$

$\mathrm{C} 10 \mathrm{H} 5 \mathrm{Cl} 2 \mathrm{Br} 2 \mathrm{~F} 13$

$\mathrm{C} 10 \mathrm{H} 5 \mathrm{Cl} 3 \mathrm{Br} 2 \mathrm{~F} 12$

$\mathrm{C} 10 \mathrm{H} 5 \mathrm{Cl} 3 \mathrm{BrF} 13$

C10H5Cl4BrF12

$\mathrm{C} 10 \mathrm{H} 5 \mathrm{Cl} 4 \mathrm{~F} 13$

C10H5Cl5BrF11

C10H5Cl5F12

$\mathrm{C} 10 \mathrm{H} 5 \mathrm{Cl} 6 \mathrm{~F} 1$

$\mathrm{C} 10 \mathrm{H} 5 \mathrm{ClBr} 2 \mathrm{~F} 14$

C10H6Br3F13

$\mathrm{C} 10 \mathrm{H} 6 \mathrm{Br} 4 \mathrm{~F} 12$

C10H6Cl2Br2F12

$\mathrm{C} 10 \mathrm{H} 6 \mathrm{Cl} 3 \mathrm{Br} 2 \mathrm{~F} 11$

$\mathrm{C} 10 \mathrm{H} 6 \mathrm{Cl} 3 \mathrm{BrF} 12$

C10H6Cl4Br2F 10

C10H6Cl4BrF11

C10H6Cl5BrF10

C10H6Cl5F1

$\mathrm{C} 10 \mathrm{H} 6 \mathrm{ClBr} 2 \mathrm{~F} 13$

$\mathrm{C} 10 \mathrm{H} 6 \mathrm{ClBr} 3 \mathrm{~F} 12$

C10H7Br3F12

C10H7Br4F1

$\mathrm{C} 10 \mathrm{H} 7 \mathrm{Cl} 2 \mathrm{Br} 2 \mathrm{~F} 11$

$\mathrm{C} 10 \mathrm{H} 7 \mathrm{Cl} 2 \mathrm{BrF} 12$

$\mathrm{C} 10 \mathrm{H} 7 \mathrm{Cl} 3 \mathrm{Br} 2 \mathrm{~F} 10$

C10H7Cl3BrF11

$\mathrm{C} 10 \mathrm{H} 7 \mathrm{Cl} 4 \mathrm{BrF} 10$

C10H7Cl4F11

C10H7Cl5BrF9

$\mathrm{C} 10 \mathrm{H} 7 \mathrm{Cl} 5 \mathrm{~F} 10$

$\mathrm{C} 10 \mathrm{H} 7 \mathrm{Cl} 6 \mathrm{~F} 9$

$\mathrm{C} 10 \mathrm{H} 7 \mathrm{Cl} 7 \mathrm{~F} 8$

$\mathrm{C} 10 \mathrm{H} 7 \mathrm{ClBr} 3 \mathrm{~F} 11$
lgKoa lgKow lgKaw lgKow lgKoa lgKa lgKow lgKoa lgKaw EPISuit EPI EPI Exp Exp w DFT DFT DFT ${ }_{\text {Suite }}$ Suite ${ }_{-}$Exp $\begin{array}{llllllllll}5.516 & 6.34 & 0.82 & 4.54 & 3.71 & 0.82 & 5.63 & 8.15 & -2.51\end{array}$ $\begin{array}{llllllllll}7.486 & 6.32 & -1.17 & 4.51 & 5.67 & -1.17 & 5.62 & 11.76 & -6.15\end{array}$ $\begin{array}{llllllllll}5.848 & 5.92 & 0.07 & 3.91 & 3.84 & 0.07 & 5.31 & 8.75 & -3.45\end{array}$ $\begin{array}{lllllllll}-0.15 & 4.81 & 4.95 & -0.15 & 5.77 & 10.26 & -4.49\end{array}$ $5.293 \quad 5.6$ $\begin{array}{llllllllll}5.293 & 5.6 & 0.31 & 3.43 & 3.13 & 0.31 & 5.06 & 7.74 & -2.67\end{array}$ $\begin{array}{lllllllll}6.931 & 6 & -0.93 & 4.03 & 4.96 & -0.93 & 5.37 & 10.74 & -5.37\end{array}$ $\begin{array}{lllllllll}7.348 & 6.15 & -1.20 & 4.25 & 5.45 & -1.20 & 5.49 & 11.51 & -6.03\end{array}$ $\begin{array}{lllllllll}6.45 & 6.49 & 0.04 & 4.76 & 4.72 & 0.04 & 5.75 & 9.86 & -4.11\end{array}$ $\begin{array}{lllllllll}6.772 & 6.06 & 0.04 & 4.76 & 4.72 & 0.04 & 5.75 & 9.86 & -4.11\end{array}$ $\begin{array}{ll}6.772 & 6.06 \\ 5.205 & 5.73\end{array}$ $\begin{array}{llllllllll}5.205 & 5.73 & 0.53 & 3.63 & 3.10 & 0.53 & 5.16 & 7.57 & -2.41\end{array}$ $\begin{array}{llllllllll}6.347 & 6.12 & -0.23 & 4.21 & 4.44 & -0.23 & 5.46 & 9.67 & -4.21\end{array}$ $\begin{array}{lllllllll}6.355 & 5.91 & -0.45 & 3.90 & 4.34 & -0.45 & 5.30 & 9.69 & -4.39\end{array}$ $\begin{array}{lllllllll}4.787 & 5.58 & 0.79 & 3.40 & 2.61 & 0.79 & 5.05 & 6.81 & -1.76\end{array}$

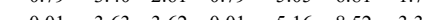
$\begin{array}{llllllllll}5.722 & 5.73 & 0.01 & 3.63 & 3.62 & 0.01 & 5.16 & 8.52 & -3.36 \\ 7.37 & 6.14 & -1.23 & 4.24 & 5.47 & -1.23 & 5.48 & 11.55 & -6.07\end{array}$ $\begin{array}{llllllllll}7.37 & 6.14 & -1.23 & 4.24 & 5.47 & -1.23 & 5.48 & 11.55 & -6.07\end{array}$ $\begin{array}{lllllllll}4.825 & 6.07 & 1.24 & 4.13 & 2.89 & 1.24 & 5.42 & 6.88 & -1.45\end{array}$ $\begin{array}{lllllllll}6.878 & 6.62 & -0.26 & 4.96 & 5.21 & -0.26 & 5.85 & 10.65 & -4.80\end{array}$ $\begin{array}{llllllllll}4.501 & 5.48 & 0.98 & 3.25 & 2.27 & 0.98 & 4.97 & 6.28 & -1.31\end{array}$ $\begin{array}{llllllll}-0.28 & 3.25 & 2.27 & 0.98 & 4.97 & 6.28 & -1.31\end{array}$ $\begin{array}{lll}5.644 & 5.87\end{array}$ $\begin{array}{lllllllll}6.794 & 6.05 & -0.74 & 4.10 & 4.85 & -0.74 & 5.41 & 10.49 & -5.08\end{array}$ $\begin{array}{lllllllll}5.077 & 5.57 & 0.49 & 3.39 & 2.89 & 0.49 & 5.04 & 7.34 & -2.30\end{array}$ $\begin{array}{lllllllll}6.082 & 5.79 & -0.29 & 3.72 & 4.01 & -0.29 & 5.21 & 9.18 & -3.98\end{array}$ $\begin{array}{llllllllll}6.444 & 5.39 & 0.95 & 3.12 & 2.17 & 0.95 & 4.90 & 6.18 & -1.27\end{array}$ $\begin{array}{llllllllll}5.01 & 5.39 & 0.95 & 3.12 & 2.17 & 0.95 & 4.90 & 6.18 & -1.27\end{array}$ $\begin{array}{lllllllllll}5.01 & 5.69 & 0.68 & 3.57 & 2.89 & 0.68 & 5.13 & 7.22 & -2.08\end{array}$ $\begin{array}{llllllllll}5.585 & 5.78 & 0.19 & 3.70 & 3.51 & 0.19 & 5.20 & 8.27 & -3.07\end{array}$ $\begin{array}{lllllllll}4.871 & 5.52 & 0.65 & 3.31 & 2.66 & 0.65 & 5.00 & 6.96 & -1.96\end{array}$ $\begin{array}{lllllllll}4.797 & 5.43 & 0.63 & 3.18 & 2.55 & 0.63 & 4.93 & 6.82 & -1.89\end{array}$ $\begin{array}{llllllll}3.63 & 3.18 & 2.55 & 0.63 & 4.93 & 6.82 & -1.89\end{array}$ $\begin{array}{lllllllll}6.217 & 9.8 & 3.58 & 9.70 & 6.12 & 3.58 & 8.29 & 9.43 & -1.14\end{array}$ $\begin{array}{llllllllll}5.719 & 9.27 & 3.55 & 8.91 & 5.36 & 3.55 & 7.88 & 8.52 & -0.64\end{array}$ $\begin{array}{lllllllll}7.056 & 9.37 & 2.31 & 9.06 & 6.75 & 2.31 & 7.96 & 10.97 & -3.01\end{array}$ $\begin{array}{llllllllll}6.205 & 9.49 & 3.28 & 9.24 & 5.95 & 3.28 & 8.05 & 9.41 & -1.36\end{array}$ $\begin{array}{lllllll}2.53 & 9.72 & 7.18 & 2.53 & 8.30 & 11.38 & -3.08\end{array}$ $7.277-9.81$ $\begin{array}{llllllllll}6.402 & 9.42 & 3.02 & 9.13 & 6.12 & 3.02 & 8.00 & 9.77 & -1.78\end{array}$ $\begin{array}{lllllllll}5.237 & 8.74 & 3.50 & 8.12 & 4.62 & 3.50 & 7.47 & 7.63 & -0.16\end{array}$ $\begin{array}{lllllllll}6.889 & 9.64 & 2.75 & 9.46 & 6.71 & 2.75 & 8.17 & 10.67 & -2.50\end{array}$ $\begin{array}{llllllllll}5.144 & 9.18 & 4.04 & 8.78 & 4.74 & 4.04 & 7.81 & 7.46 & 0.35\end{array}$ $\begin{array}{llllllll}4.80 & 9.37 & 6.57 & 2.80 & 8.12 & 10.47 & -2.35\end{array}$ $\begin{array}{llllllllll}6.148 & 9.4 & 3.25 & 9.10 & 5.85 & 3.25 & 7.98 & 9.31 & -1.32\end{array}$ $\begin{array}{lllllllll}7.045 & 9.06 & 2.01 & 8.60 & 6.58 & 2.01 & 7.72 & 10.95 & -3.23\end{array}$ $\begin{array}{lllllllll}5.894 & 8.88 & 2.99 & 8.33 & 5.34 & 2.99 & 7.58 & 8.84 & -1.26\end{array}$ $\begin{array}{lllllllll}7.542 & 9.29 & 1.75 & 8.94 & 7.19 & 1.75 & 7.90 & 11.87 & -3.97\end{array}$ $\begin{array}{llllllllll}2.23 & 8.81 & 6.57 & 2.23 & 7.90 & 7.87 & -3.97 & -2.98\end{array}$ $\begin{array}{lllllllllll}5.329 & 8.8 & 3.47 & 8.21 & 4.74 & 3.47 & 7.52 & 7.80 & -0.28\end{array}$ $\begin{array}{llllllllll}7.131 & 9.85 & 2.72 & 9.78 & 7.06 & 2.72 & 8.33 & 11.11 & -2.78\end{array}$ $\begin{array}{lllllllll}7.452 & 9.42 & 1.97 & 9.13 & 7.17 & 1.97 & 8.00 & 11.70 & -3.70\end{array}$ $\begin{array}{lllllllll}5.515 & 8.72 & 3.20 & 8.09 & 4.88 & 3.20 & 7.46 & 8.14 & -0.68\end{array}$ $\begin{array}{lllllllll}6.878 & 9.33 & 2.45 & 9.00 & 6.55 & 2.45 & 7.93 & 10.65 & -2.72\end{array}$ $\begin{array}{lllllllll}5.571 & 9.31 & 3.74 & 8.97 & 5.23 & 3.74 & 7.91 & 8.25 & -0.33\end{array}$ $\begin{array}{lllllllll}6.47 & 8.97 & 2.50 & 8.46 & 5.96 & 2.50 & 7.65 & 9.90 & -2.25\end{array}$ $\begin{array}{lllllllll}5.096 & 8.05 & 2.95 & 7.09 & 4.14 & 2.95 & 6.94 & 7.37 & -0.43\end{array}$ $\begin{array}{lllllllll}6.445 & 8.16 & 1.72 & 7.25 & 5.54 & 1.72 & 7.03 & 9.85 & -2.82\end{array}$ $\begin{array}{llllllll}1.69 & 8.25 & 5.54 & 1.72 & 7.03 & 9.85 \\ 0.65 & 2.69 & 7.69 & 9.65\end{array}$ $\begin{array}{llllllllll}6.333 & 9.02 & 2.69 & 8.54 & 5.85 & 2.69 & 7.69 & 9.65 & -1.96 \\ 5.394 & 9.33 & 1.94 & 9.00 & 7.06 & 1.94 & 7.93 & 11.59 & -3.67\end{array}$ $\begin{array}{lllllllll}5.017 & 8.19 & 3.17 & 7.30 & 4.13 & 3.17 & 7.05 & 7.23 & -0.18\end{array}$ $\begin{array}{lllllllll}6.08 & 8.5 & 2.42 & 7.76 & 5.34 & 2.42 & 7.29 & 9.18 & -1.89\end{array}$ $\begin{array}{llllllllll}5.183 & 8.84 & 3.66 & 8.27 & 4.61 & 3.66 & 7.55 & 7.53 & 0.02\end{array}$ $\begin{array}{lllllllll}7.142 & 8.81 & 1.67 & 8.22 & 6.56 & 1.67 & 7.53 & 11.13 & -3.60\end{array}$ $\begin{array}{lllllllll}5.504 & 8.41 & 2.91 & 7.63 & 4.72 & 2.91 & 7.22 & 8.12 & -0.90\end{array}$ $\begin{array}{llllllllll}6.567 & 8.72 & 2.15 & 8.09 & 5.94 & 2.15 & 7.46 & 10.08 & -2.62\end{array}$ $\begin{array}{llllllllll}5.261 & 8.7 & 3.44 & 8.06 & 4.62 & 3.44 & 7.44 & 7.68 & -0.23\end{array}$ $\begin{array}{lllllllll}4.493 & 7.15 & 2.66 & 5.75 & 3.09 & 2.66 & 6.25 & 6.27 & -0.01\end{array}$ $\begin{array}{llllllllll}7.172 & 8.59 & 1.42 & 7.90 & 6.48 & 1.42 & 7.36 & 11.19 & -3.83\end{array}$ $\begin{array}{lllllllll}5.282 & 7.67 & 2.39 & 6.52 & 4.13 & 2.39 & 6.65 & 7.72 & -1.06\end{array}$ $\begin{array}{llllllllll}7.083 & 8.72 & 1.64 & 8.09 & 6.45 & 1.64 & 7.46 & 11.02 & -3.56\end{array}$ $\begin{array}{llllllllll}5.446 & 8.32 & 2.87 & 7.49 & 4.62 & 2.87 & 7.15 & 8.02 & -0.86\end{array}$ $\begin{array}{llllllllll}7.417 & 8.3 & 0.88 & 7.46 & 6.58 & 0.88 & 7.14 & 11.64 & -4.50\end{array}$ $6.508-8.63$ $\begin{array}{ll}7.508 & 8.63 \\ 7.58 & 8.95\end{array}$ $\begin{array}{llllllllll}7.58 & 8.95 & 1.37 & 8.43 & 7.06 & 1.37 & 7.64 & 11.94 & -4.30\end{array}$ $\begin{array}{lllllllll}6.673 & 9.28 & 2.61 & 8.93 & 6.32 & 2.61 & 7.89 & 10.27 & -2.38\end{array}$ $\begin{array}{lllllllll}5.62 & 8.76 & 3.14 & 8.15 & 5.01 & 3.14 & 7.49 & 8.34 & -0.85\end{array}$ $\begin{array}{lllllllll}6.596 & 8.5 & 1.90 & 7.76 & 5.86 & 1.90 & 7.29 & 10.13 & -2.84\end{array}$ $\begin{array}{lllllllll}5.224 & 7.58 & 2.36 & 6.39 & 4.03 & 2.36 & 6.58 & 7.61 & -1.03\end{array}$ $\begin{array}{lllllllll}6.861 & 7.98 & 1.12 & 6.99 & 5.87 & 1.12 & 6.89 & 10.62 & -3.72\end{array}$ $\begin{array}{lllllllll}6.45 & 8.54 & 2.09 & 7.82 & 5.73 & 2.09 & 7.32 & 9.86 & -2.54\end{array}$ $\begin{array}{lllllllll}4.813 & 8.14 & 3.33 & 7.22 & 3.90 & 3.33 & 7.01 & 6.85 & 0.16\end{array}$ $\begin{array}{rrrrrrrrrr}6.783 & 8.12 & 1.34 & 7.19 & 5.86 & 1.34 & 7.00 & 10.47 & -3.47 \\ 5.875 & 8.45 & 2.57 & 7.69 & 5.11 & 2.57 & 7.25 & 8.80 & -1.55\end{array}$ $\begin{array}{llllllllll}5.875 & 8.45 & 2.57 & 7.69 & 5.11 & 2.57 & 7.25 & 8.80 & -1.55 \\ 6.206 & 8.03 & 1.82 & 7.06 & 5.24 & 1.82 & 6.93 & 9.41 & -2.48 \\ 4.56 & 7.62 & 3.06 & 6.45 & 3.39 & 3.06 & 6.61 & 6.39 & 0.23\end{array}$ $\begin{array}{lllllllll}4.56 & 7.62 & 3.06 & 6.45 & 3.39 & 3.06 & 6.61 & 6.39 & 0.23\end{array}$ $\begin{array}{llllllllll}7.269 & 8.34 & 1.07 & 7.52 & 6.45 & 1.07 & 7.17 & 11.37 & -4.20\end{array}$ $\begin{array}{lllllllll}5.632 & 7.94 & 2.31 & 6.93 & 4.62 & 2.31 & 6.86 & 8.36 & -1.50\end{array}$ $\begin{array}{llllllllll}6.694 & 8.25 & 1.56 & 7.39 & 5.83 & 1.56 & 7.10 & 10.31 & -3.21\end{array}$ $\begin{array}{llllllllll}7.015 & 7.82 & 0.80 & 6.75 & 5.94 & 0.80 & 6.77 & 10.90 & -4.13\end{array}$ $\begin{array}{lllllllll}6.286 & 7.89 & 1.60 & 6.85 & 5.25 & 1.60 & 6.82 & 9.56 & -2.74\end{array}$ 
$\mathrm{C}(\mathrm{C}(\mathrm{C}(\mathrm{C}(\mathrm{C}(\mathrm{C}(\mathrm{C}(\mathrm{C}(\mathrm{C}(\mathrm{C}(\mathrm{F})(\mathrm{H}) \mathrm{F})(\mathrm{H}) \mathrm{F})(\mathrm{F}) \mathrm{F})(\mathrm{F}) \mathrm{F})(\mathrm{H}) \mathrm{F})(\mathrm{Br}) \mathrm{F})(\mathrm{Br}) \mathrm{F})(\mathrm{F}) \mathrm{F})(\mathrm{H}) \mathrm{H})(\mathrm{H})(\mathrm{H}) \mathrm{H}$ $\mathrm{C}(\mathrm{C}(\mathrm{C}(\mathrm{C}(\mathrm{C}(\mathrm{C}(\mathrm{C}(\mathrm{C}(\mathrm{C}(\mathrm{C}(\mathrm{H})(\mathrm{H}) \mathrm{H})(\mathrm{H}) \mathrm{H})(\mathrm{H}) \mathrm{Br})(\mathrm{F}) \mathrm{F})(\mathrm{F}) \mathrm{F})(\mathrm{F}) \mathrm{F})(\mathrm{F}) \mathrm{F})(\mathrm{F}) \mathrm{F})(\mathrm{H}) \mathrm{Br})(\mathrm{F})(\mathrm{Br}) \mathrm{H}$ $\mathrm{C}(\mathrm{C}(\mathrm{C}(\mathrm{C}(\mathrm{C}(\mathrm{C}(\mathrm{C}(\mathrm{C}(\mathrm{C}(\mathrm{C}(\mathrm{Br})(\mathrm{H}) \mathrm{F})(\mathrm{Br}) \mathrm{H})(\mathrm{H}) \mathrm{H})(\mathrm{H}) \mathrm{F})(\mathrm{H}) \mathrm{Br})(\mathrm{F}) \mathrm{F})(\mathrm{F}) \mathrm{F})(\mathrm{F}) \mathrm{F})(\mathrm{H}) \mathrm{F})(\mathrm{F})(\mathrm{Br}) \mathrm{H}$ $\mathrm{C}(\mathrm{C}(\mathrm{C}(\mathrm{C}(\mathrm{C}(\mathrm{C}(\mathrm{C}(\mathrm{C}(\mathrm{C}(\mathrm{C}(\mathrm{H})(\mathrm{F}) \mathrm{F})(\mathrm{F}) \mathrm{F})(\mathrm{F}) \mathrm{Cl})(\mathrm{Br}) \mathrm{Br})(\mathrm{Cl}) \mathrm{H})(\mathrm{F}) \mathrm{F})(\mathrm{F}) \mathrm{F})(\mathrm{H}) \mathrm{H})(\mathrm{H}) \mathrm{H})(\mathrm{H})(\mathrm{F}) \mathrm{H}$ $\mathrm{C}(\mathrm{C}(\mathrm{C}(\mathrm{C}(\mathrm{C}(\mathrm{C}(\mathrm{C}(\mathrm{C}(\mathrm{C}(\mathrm{C}(\mathrm{Br})(\mathrm{H}) \mathrm{F})(\mathrm{F}) \mathrm{F})(\mathrm{H}) \mathrm{H})(\mathrm{Br}) \mathrm{Cl})(\mathrm{F}) \mathrm{H})(\mathrm{F}) \mathrm{F})(\mathrm{H}) \mathrm{F})(\mathrm{H}) \mathrm{F})(\mathrm{H}) \mathrm{Cl})(\mathrm{Cl})(\mathrm{H}) \mathrm{F}$ $\mathrm{C}(\mathrm{C}(\mathrm{C}(\mathrm{C}(\mathrm{C}(\mathrm{C}(\mathrm{C}(\mathrm{C}(\mathrm{C}(\mathrm{C}(\mathrm{F})(\mathrm{H}) \mathrm{H})(\mathrm{F}) \mathrm{H})(\mathrm{F}) \mathrm{F})(\mathrm{F}) \mathrm{H})(\mathrm{Cl}) \mathrm{F})(\mathrm{Cl}) \mathrm{Cl})(\mathrm{F}) \mathrm{H})(\mathrm{Br}) \mathrm{H})(\mathrm{H}) \mathrm{F})(\mathrm{F})(\mathrm{H}) \mathrm{F}$ $\mathrm{C}(\mathrm{C}(\mathrm{C}(\mathrm{C}(\mathrm{C}(\mathrm{C}(\mathrm{C}(\mathrm{C}(\mathrm{C}(\mathrm{C}(\mathrm{F})(\mathrm{H}) \mathrm{Cl})(\mathrm{H}) \mathrm{Cl})(\mathrm{Cl}) \mathrm{H})(\mathrm{Cl}) \mathrm{F})(\mathrm{H}) \mathrm{F})(\mathrm{F}) \mathrm{F})(\mathrm{H}) \mathrm{H})(\mathrm{H}) \mathrm{Br})(\mathrm{H}) \mathrm{F})(\mathrm{F})(\mathrm{F}) \mathrm{F}$ $\mathrm{C}(\mathrm{C}(\mathrm{C}(\mathrm{C}(\mathrm{C}(\mathrm{C}(\mathrm{C}(\mathrm{C}(\mathrm{C}(\mathrm{C}(\mathrm{F})(\mathrm{F}) \mathrm{Cl})(\mathrm{H}) \mathrm{H})(\mathrm{F}) \mathrm{H})(\mathrm{Cl}) \mathrm{F})(\mathrm{H}) \mathrm{F})(\mathrm{F}) \mathrm{Cl})(\mathrm{H}) \mathrm{Cl})(\mathrm{Cl}) \mathrm{F})(\mathrm{H}) \mathrm{H})(\mathrm{F})(\mathrm{H}) \mathrm{F}$ $\mathrm{C}(\mathrm{C}(\mathrm{C}(\mathrm{C}(\mathrm{C}(\mathrm{C}(\mathrm{C}(\mathrm{C}(\mathrm{C}(\mathrm{C}(\mathrm{H})(\mathrm{Cl}) \mathrm{H})(\mathrm{Cl}) \mathrm{F})(\mathrm{H}) \mathrm{H})(\mathrm{F}) \mathrm{Cl})(\mathrm{H}) \mathrm{F})(\mathrm{Cl}) \mathrm{H})(\mathrm{F}) \mathrm{F})(\mathrm{F}) \mathrm{Cl})(\mathrm{H}) \mathrm{Cl})(\mathrm{F})(\mathrm{H}) \mathrm{F}$ $\mathrm{C}(\mathrm{C}(\mathrm{C}(\mathrm{C}(\mathrm{C}(\mathrm{C}(\mathrm{C}(\mathrm{C}(\mathrm{C}(\mathrm{C}(\mathrm{H})(\mathrm{F}) \mathrm{F})(\mathrm{H}) \mathrm{F})(\mathrm{H}) \mathrm{H})(\mathrm{F}) \mathrm{F})(\mathrm{F}) \mathrm{F})(\mathrm{H}) \mathrm{H})(\mathrm{F}) \mathrm{F})(\mathrm{Br}) \mathrm{Cl})(\mathrm{H}) \mathrm{F})(\mathrm{H})(\mathrm{F}) \mathrm{Br}$ $\mathrm{C}(\mathrm{C}(\mathrm{C}(\mathrm{C}(\mathrm{C}(\mathrm{C}(\mathrm{C}(\mathrm{C}(\mathrm{C}(\mathrm{C}(\mathrm{F})(\mathrm{Br}) \mathrm{F})(\mathrm{F}) \mathrm{H})(\mathrm{H}) \mathrm{H})(\mathrm{H}) \mathrm{F})(\mathrm{H}) \mathrm{F})(\mathrm{Br}) \mathrm{Br})(\mathrm{F}) \mathrm{F})(\mathrm{H}) \mathrm{Cl})(\mathrm{F}) \mathrm{F})(\mathrm{F})(\mathrm{H}) \mathrm{H}$ $\mathrm{C}(\mathrm{C}(\mathrm{C}(\mathrm{C}(\mathrm{C}(\mathrm{C}(\mathrm{C}(\mathrm{C}(\mathrm{C}(\mathrm{C}(\mathrm{Br})(\mathrm{H}) \mathrm{H})(\mathrm{Br}) \mathrm{F})(\mathrm{F}) \mathrm{H})(\mathrm{H}) \mathrm{F})(\mathrm{H}) \mathrm{H})(\mathrm{H}) \mathrm{Br})(\mathrm{F}) \mathrm{F})(\mathrm{F}) \mathrm{F})(\mathrm{H}) \mathrm{H})(\mathrm{F})(\mathrm{F}) \mathrm{F}$ $\mathrm{C}(\mathrm{C}(\mathrm{C}(\mathrm{C}(\mathrm{C}(\mathrm{C}(\mathrm{C}(\mathrm{C}(\mathrm{C}(\mathrm{C}(\mathrm{H})(\mathrm{F}) \mathrm{F})(\mathrm{F}) \mathrm{H})(\mathrm{F}) \mathrm{H})(\mathrm{H}) \mathrm{F})(\mathrm{H}) \mathrm{F})(\mathrm{H}) \mathrm{Br})(\mathrm{H}) \mathrm{Br})(\mathrm{Br}) \mathrm{H})(\mathrm{H}) \mathrm{F})(\mathrm{Br})(\mathrm{Br}) \mathrm{F}$ $\mathrm{C}(\mathrm{C}(\mathrm{C}(\mathrm{C}(\mathrm{C}(\mathrm{C}(\mathrm{C}(\mathrm{C}(\mathrm{C}(\mathrm{C}(\mathrm{F})(\mathrm{H}) \mathrm{H})(\mathrm{F}) \mathrm{H})(\mathrm{H}) \mathrm{H})(\mathrm{Cl}) \mathrm{F})(\mathrm{H}) \mathrm{H})(\mathrm{F}) \mathrm{F})(\mathrm{Br}) \mathrm{Br})(\mathrm{F}) \mathrm{Cl})(\mathrm{F}) \mathrm{F})(\mathrm{H})(\mathrm{F}) \mathrm{H}$ $\mathrm{C}(\mathrm{C}(\mathrm{C}(\mathrm{C}(\mathrm{C}(\mathrm{C}(\mathrm{C}(\mathrm{C}(\mathrm{C}(\mathrm{C}(\mathrm{Cl})(\mathrm{Cl}) \mathrm{Br})(\mathrm{F}) \mathrm{H})(\mathrm{H}) \mathrm{F})(\mathrm{H}) \mathrm{Br})(\mathrm{F}) \mathrm{H})(\mathrm{H}) \mathrm{F})(\mathrm{F}) \mathrm{F})(\mathrm{H}) \mathrm{Br})(\mathrm{H}) \mathrm{F})(\mathrm{F})(\mathrm{H}) \mathrm{H}$ $\mathrm{C}(\mathrm{C}(\mathrm{C}(\mathrm{C}(\mathrm{C}(\mathrm{C}(\mathrm{C}(\mathrm{C}(\mathrm{C}(\mathrm{C}(\mathrm{F})(\mathrm{F}) \mathrm{F})(\mathrm{H}) \mathrm{F})(\mathrm{H}) \mathrm{H})(\mathrm{Cl}) \mathrm{Cl})(\mathrm{Cl}) \mathrm{H})(\mathrm{H}) \mathrm{H})(\mathrm{F}) \mathrm{H})(\mathrm{Br}) \mathrm{F})(\mathrm{F}) \mathrm{H})(\mathrm{Br})(\mathrm{F}) \mathrm{H}$ $\mathrm{C}(\mathrm{C}(\mathrm{C}(\mathrm{C}(\mathrm{C}(\mathrm{C}(\mathrm{C}(\mathrm{C}(\mathrm{C}(\mathrm{C}(\mathrm{F})(\mathrm{F}) \mathrm{F})(\mathrm{H}) \mathrm{Cl})(\mathrm{H}) \mathrm{F})(\mathrm{Cl}) \mathrm{H})(\mathrm{H}) \mathrm{Cl})(\mathrm{F}) \mathrm{F})(\mathrm{F}) \mathrm{H})(\mathrm{H}) \mathrm{H})(\mathrm{Br}) \mathrm{F})(\mathrm{H})(\mathrm{F}) \mathrm{H}$ $\mathrm{C}(\mathrm{C}(\mathrm{C}(\mathrm{C}(\mathrm{C}(\mathrm{C}(\mathrm{C}(\mathrm{C}(\mathrm{C}(\mathrm{C}(\mathrm{H})(\mathrm{Br}) \mathrm{H})(\mathrm{F}) \mathrm{F})(\mathrm{F}) \mathrm{H})(\mathrm{F}) \mathrm{F})(\mathrm{Cl}) \mathrm{F})(\mathrm{H}) \mathrm{F})(\mathrm{H}) \mathrm{Cl})(\mathrm{H}) \mathrm{H})(\mathrm{H}) \mathrm{Cl})(\mathrm{Cl})(\mathrm{F}) \mathrm{H}$ $\mathrm{C}(\mathrm{C}(\mathrm{C}(\mathrm{C}(\mathrm{C}(\mathrm{C}(\mathrm{C}(\mathrm{C}(\mathrm{C}(\mathrm{C}(\mathrm{F})(\mathrm{F}) \mathrm{H})(\mathrm{F}) \mathrm{H})(\mathrm{Cl}) \mathrm{H})(\mathrm{H}) \mathrm{H})(\mathrm{H}) \mathrm{H})(\mathrm{F}) \mathrm{Cl})(\mathrm{Cl}) \mathrm{H})(\mathrm{H}) \mathrm{F})(\mathrm{F}) \mathrm{F})(\mathrm{F})(\mathrm{F}) \mathrm{Cl}$ $\mathrm{C}(\mathrm{C}(\mathrm{C}(\mathrm{C}(\mathrm{C}(\mathrm{C}(\mathrm{C}(\mathrm{C}(\mathrm{C}(\mathrm{C}(\mathrm{H})(\mathrm{F}) \mathrm{F})(\mathrm{H}) \mathrm{Cl})(\mathrm{H}) \mathrm{F})(\mathrm{H}) \mathrm{Cl})(\mathrm{Cl}) \mathrm{H})(\mathrm{H}) \mathrm{F})(\mathrm{H}) \mathrm{H})(\mathrm{F}) \mathrm{Cl})(\mathrm{Cl}) \mathrm{F})(\mathrm{Br})(\mathrm{H}) \mathrm{F}$ $\mathrm{C}(\mathrm{C}(\mathrm{C}(\mathrm{C}(\mathrm{C}(\mathrm{C}(\mathrm{C}(\mathrm{C}(\mathrm{C}(\mathrm{C}(\mathrm{H})(\mathrm{F}) \mathrm{H})(\mathrm{F}) \mathrm{F})(\mathrm{H}) \mathrm{H})(\mathrm{F}) \mathrm{Cl})(\mathrm{H}) \mathrm{Cl})(\mathrm{F}) \mathrm{H})(\mathrm{H}) \mathrm{H})(\mathrm{F}) \mathrm{Cl})(\mathrm{H}) \mathrm{Cl})(\mathrm{F})(\mathrm{F}) \mathrm{Cl}$ $\mathrm{C}(\mathrm{C}(\mathrm{C}(\mathrm{C}(\mathrm{C}(\mathrm{C}(\mathrm{C}(\mathrm{C}(\mathrm{C}(\mathrm{C}(\mathrm{Br})(\mathrm{Br}) \mathrm{F})(\mathrm{F}) \mathrm{H})(\mathrm{F}) \mathrm{F})(\mathrm{F}) \mathrm{H})(\mathrm{F}) \mathrm{F})(\mathrm{H}) \mathrm{Br})(\mathrm{H}) \mathrm{F})(\mathrm{H}) \mathrm{H})(\mathrm{H}) \mathrm{H})(\mathrm{H})(\mathrm{Cl}) \mathrm{F}$ $\mathrm{C}(\mathrm{C}(\mathrm{C}(\mathrm{C}(\mathrm{C}(\mathrm{C}(\mathrm{C}(\mathrm{C}(\mathrm{C}(\mathrm{C}(\mathrm{F})(\mathrm{F}) \mathrm{F})(\mathrm{F}) \mathrm{H})(\mathrm{F}) \mathrm{F})(\mathrm{F}) \mathrm{F})(\mathrm{F}) \mathrm{F})(\mathrm{F}) \mathrm{F})(\mathrm{F}) \mathrm{F})(\mathrm{F}) \mathrm{Cl})(\mathrm{Cl}) \mathrm{F})(\mathrm{F})(\mathrm{Cl}) \mathrm{Br}$ $\mathrm{C}(\mathrm{C}(\mathrm{C}(\mathrm{C}(\mathrm{C}(\mathrm{C}(\mathrm{C}(\mathrm{C}(\mathrm{C}(\mathrm{C}(\mathrm{F})(\mathrm{H}) \mathrm{F})(\mathrm{F}) \mathrm{Br})(\mathrm{F}) \mathrm{F})(\mathrm{Br}) \mathrm{F})(\mathrm{Br}) \mathrm{Cl})(\mathrm{F}) \mathrm{F})(\mathrm{F}) \mathrm{F})(\mathrm{F}) \mathrm{F})(\mathrm{F}) \mathrm{F})(\mathrm{F})(\mathrm{F}) \mathrm{F}$ $\mathrm{C}(\mathrm{C}(\mathrm{C}(\mathrm{C}(\mathrm{C}(\mathrm{C}(\mathrm{C}(\mathrm{C}(\mathrm{C}(\mathrm{C}(\mathrm{C}(\mathrm{F})(\mathrm{F}) \mathrm{F})(\mathrm{H}) \mathrm{H})(\mathrm{F}) \mathrm{Br})(\mathrm{F}) \mathrm{F})(\mathrm{F}) \mathrm{H})(\mathrm{Br}) \mathrm{F})(\mathrm{H}) \mathrm{Br})(\mathrm{H}) \mathrm{H})(\mathrm{H}) \mathrm{H})(\mathrm{H}) \mathrm{F})(\mathrm{F})(\mathrm{F}) \mathrm{H}$ $\mathrm{C}(\mathrm{C}(\mathrm{C}(\mathrm{C}(\mathrm{C}(\mathrm{C}(\mathrm{C}(\mathrm{C}(\mathrm{C}(\mathrm{C}(\mathrm{C}(\mathrm{F})(\mathrm{H}) \mathrm{F})(\mathrm{Br}) \mathrm{F})(\mathrm{Br}) \mathrm{H})(\mathrm{F}) \mathrm{H})(\mathrm{H}) \mathrm{F})(\mathrm{Br}) \mathrm{F})(\mathrm{F}) \mathrm{H})(\mathrm{H}) \mathrm{Br})(\mathrm{F}) \mathrm{F})(\mathrm{F}) \mathrm{H})(\mathrm{H})(\mathrm{H}) \mathrm{H}$ $\mathrm{C}(\mathrm{C}(\mathrm{C}(\mathrm{C}(\mathrm{C}(\mathrm{C}(\mathrm{C}(\mathrm{C}(\mathrm{C}(\mathrm{C}(\mathrm{C}(\mathrm{F})(\mathrm{Cl}) \mathrm{F})(\mathrm{F}) \mathrm{H})(\mathrm{H}) \mathrm{F})(\mathrm{H}) \mathrm{Cl})(\mathrm{H}) \mathrm{H})(\mathrm{F}) \mathrm{F})(\mathrm{F}) \mathrm{H})(\mathrm{Br}) \mathrm{F})(\mathrm{F}) \mathrm{H})(\mathrm{H}) \mathrm{Br})(\mathrm{H})(\mathrm{H}) \mathrm{F}$

$\mathrm{C}(\mathrm{C}(\mathrm{C}(\mathrm{C}(\mathrm{C}(\mathrm{C}(\mathrm{C}(\mathrm{C}(\mathrm{C}(\mathrm{C}(\mathrm{C}(\mathrm{H})(\mathrm{Br}) \mathrm{H})(\mathrm{H}) \mathrm{F})(\mathrm{F}) \mathrm{F})(\mathrm{Br}) \mathrm{H})(\mathrm{Br}) \mathrm{F})(\mathrm{F}) \mathrm{H})(\mathrm{H}) \mathrm{Cl})(\mathrm{H}) \mathrm{F})(\mathrm{H}) \mathrm{F})(\mathrm{F}) \mathrm{F})(\mathrm{Cl})(\mathrm{H}) \mathrm{H}$ $\mathrm{C}(\mathrm{C}(\mathrm{C}(\mathrm{C}(\mathrm{C}(\mathrm{C}(\mathrm{C}(\mathrm{C}(\mathrm{C}(\mathrm{C}(\mathrm{C}(\mathrm{F})(\mathrm{F}) \mathrm{Cl})(\mathrm{H}) \mathrm{F})(\mathrm{F}) \mathrm{F})(\mathrm{F}) \mathrm{H})(\mathrm{F}) \mathrm{F})(\mathrm{H}) \mathrm{H})(\mathrm{F}) \mathrm{Br})(\mathrm{H}) \mathrm{H})(\mathrm{H}) \mathrm{F})(\mathrm{H}) \mathrm{F})(\mathrm{H})(\mathrm{H}) \mathrm{Cl}$ $\mathrm{C}(\mathrm{C}(\mathrm{C}(\mathrm{C}(\mathrm{C}(\mathrm{C}(\mathrm{C}(\mathrm{C}(\mathrm{C}(\mathrm{C}(\mathrm{C}(\mathrm{H})(\mathrm{F}) \mathrm{H})(\mathrm{F}) \mathrm{F})(\mathrm{H}) \mathrm{F})(\mathrm{H}) \mathrm{Br})(\mathrm{F}) \mathrm{Cl})(\mathrm{H}) \mathrm{H})(\mathrm{H}) \mathrm{F})(\mathrm{H}) \mathrm{Cl})(\mathrm{F}) \mathrm{H})(\mathrm{H}) \mathrm{Cl})(\mathrm{F})(\mathrm{Br}) \mathrm{F}$ $\mathrm{C}(\mathrm{C}(\mathrm{C}(\mathrm{C}(\mathrm{C}(\mathrm{C}(\mathrm{C}(\mathrm{C}(\mathrm{C}(\mathrm{C}(\mathrm{C}(\mathrm{F})(\mathrm{H}) \mathrm{Cl})(\mathrm{Cl}) \mathrm{Cl})(\mathrm{H}) \mathrm{F})(\mathrm{H}) \mathrm{H})(\mathrm{H}) \mathrm{H})(\mathrm{F}) \mathrm{H})(\mathrm{H}) \mathrm{H})(\mathrm{F}) \mathrm{H})(\mathrm{F}) \mathrm{F})(\mathrm{Br}) \mathrm{F})(\mathrm{F})(\mathrm{F}) \mathrm{F}$ $\mathrm{C}(\mathrm{C}(\mathrm{C}(\mathrm{C}(\mathrm{C}(\mathrm{C}(\mathrm{C}(\mathrm{C}(\mathrm{C}(\mathrm{C}(\mathrm{C}(\mathrm{F})(\mathrm{H}) \mathrm{F})(\mathrm{H}) \mathrm{Cl})(\mathrm{Cl}) \mathrm{H})(\mathrm{H}) \mathrm{F})(\mathrm{H}) \mathrm{Cl})(\mathrm{H}) \mathrm{F})(\mathrm{H}) \mathrm{H})(\mathrm{Cl}) \mathrm{H})(\mathrm{H}) \mathrm{F})(\mathrm{F}) \mathrm{F})(\mathrm{F})(\mathrm{F}) \mathrm{Br}$ $\mathrm{C}(\mathrm{C}(\mathrm{C}(\mathrm{C}(\mathrm{C}(\mathrm{C}(\mathrm{C}(\mathrm{C}(\mathrm{C}(\mathrm{C}(\mathrm{C}(\mathrm{Cl})(\mathrm{F}) \mathrm{F})(\mathrm{F}) \mathrm{H})(\mathrm{Cl}) \mathrm{F})(\mathrm{F}) \mathrm{H})(\mathrm{Cl}) \mathrm{F})(\mathrm{F}) \mathrm{H})(\mathrm{H}) \mathrm{H})(\mathrm{H}) \mathrm{H})(\mathrm{Cl}) \mathrm{F})(\mathrm{F}) \mathrm{H})(\mathrm{H})(\mathrm{F}) \mathrm{H}$ $\mathrm{C}(\mathrm{C}(\mathrm{C}(\mathrm{C}(\mathrm{C}(\mathrm{C}(\mathrm{C}(\mathrm{C}(\mathrm{C}(\mathrm{C}(\mathrm{C}(\mathrm{Cl})(\mathrm{H}) \mathrm{H})(\mathrm{F}) \mathrm{H})(\mathrm{H}) \mathrm{Cl})(\mathrm{H}) \mathrm{F})(\mathrm{H}) \mathrm{Cl})(\mathrm{H}) \mathrm{F})(\mathrm{Cl}) \mathrm{H})(\mathrm{F}) \mathrm{F})(\mathrm{F}) \mathrm{Br})(\mathrm{F}) \mathrm{Cl})(\mathrm{H})(\mathrm{H}) \mathrm{F}$ $\mathrm{C}(\mathrm{C}(\mathrm{C}(\mathrm{C}(\mathrm{C}(\mathrm{C}(\mathrm{C}(\mathrm{C}(\mathrm{C}(\mathrm{C}(\mathrm{C}(\mathrm{H})(\mathrm{F}) \mathrm{F})(\mathrm{F}) \mathrm{Cl})(\mathrm{F}) \mathrm{F})(\mathrm{H}) \mathrm{Cl})(\mathrm{Cl}) \mathrm{F})(\mathrm{H}) \mathrm{H})(\mathrm{F}) \mathrm{Cl})(\mathrm{H}) \mathrm{H})(\mathrm{H}) \mathrm{Cl})(\mathrm{F}) \mathrm{H})(\mathrm{F})(\mathrm{H}) \mathrm{H}$ $\mathrm{C}(\mathrm{C}(\mathrm{C}(\mathrm{C}(\mathrm{C}(\mathrm{C}(\mathrm{C}(\mathrm{C}(\mathrm{C}(\mathrm{C}(\mathrm{C}(\mathrm{F})(\mathrm{F}) \mathrm{Cl})(\mathrm{F}) \mathrm{H})(\mathrm{H}) \mathrm{H})(\mathrm{H}) \mathrm{Cl})(\mathrm{H}) \mathrm{Cl})(\mathrm{Cl}) \mathrm{F})(\mathrm{F}) \mathrm{H})(\mathrm{H}) \mathrm{Cl})(\mathrm{H}) \mathrm{F})(\mathrm{F}) \mathrm{H})(\mathrm{F})(\mathrm{H}) \mathrm{Cl}$ $\mathrm{C}(\mathrm{C}(\mathrm{C}(\mathrm{C}(\mathrm{C}(\mathrm{C}(\mathrm{C}(\mathrm{C}(\mathrm{C}(\mathrm{C}(\mathrm{C}(\mathrm{H})(\mathrm{F}) \mathrm{H})(\mathrm{H}) \mathrm{H})(\mathrm{Br}) \mathrm{H})(\mathrm{F}) \mathrm{H})(\mathrm{Br}) \mathrm{F})(\mathrm{F}) \mathrm{Cl})(\mathrm{F}) \mathrm{F})(\mathrm{F}) \mathrm{F})(\mathrm{F}) \mathrm{F})(\mathrm{H}) \mathrm{H})(\mathrm{H})(\mathrm{F}) \mathrm{H}$ $\mathrm{C}(\mathrm{C}(\mathrm{C}(\mathrm{C}(\mathrm{C}(\mathrm{C}(\mathrm{C}(\mathrm{C}(\mathrm{C}(\mathrm{C}(\mathrm{C}(\mathrm{Cl})(\mathrm{H}) \mathrm{H})(\mathrm{F}) \mathrm{F})(\mathrm{H}) \mathrm{F})(\mathrm{F}) \mathrm{F})(\mathrm{F}) \mathrm{F})(\mathrm{H}) \mathrm{F})(\mathrm{H}) \mathrm{Br})(\mathrm{H}) \mathrm{F})(\mathrm{H}) \mathrm{H})(\mathrm{H}) \mathrm{Br})(\mathrm{Br})(\mathrm{H}) \mathrm{F}$ $\mathrm{C}(\mathrm{C}(\mathrm{C}(\mathrm{C}(\mathrm{C}(\mathrm{C}(\mathrm{C}(\mathrm{C}(\mathrm{C}(\mathrm{C}(\mathrm{C}(\mathrm{F})(\mathrm{F}) \mathrm{F})(\mathrm{Br}) \mathrm{F})(\mathrm{H}) \mathrm{F})(\mathrm{H}) \mathrm{H})(\mathrm{F}) \mathrm{Br})(\mathrm{F}) \mathrm{F})(\mathrm{H}) \mathrm{F})(\mathrm{H}) \mathrm{H})(\mathrm{H}) \mathrm{H})(\mathrm{H}) \mathrm{H})(\mathrm{F})(\mathrm{F}) \mathrm{H}$ $\mathrm{C}(\mathrm{C}(\mathrm{C}(\mathrm{C}(\mathrm{C}(\mathrm{C}(\mathrm{C}(\mathrm{C}(\mathrm{C}(\mathrm{C}(\mathrm{C}(\mathrm{F})(\mathrm{F}) \mathrm{H})(\mathrm{Br}) \mathrm{H})(\mathrm{F}) \mathrm{H})(\mathrm{H}) \mathrm{F})(\mathrm{H}) \mathrm{H})(\mathrm{F}) \mathrm{H})(\mathrm{Br}) \mathrm{B})(\mathrm{F}) \mathrm{H})(\mathrm{F}) \mathrm{H})(\mathrm{F}) \mathrm{Br})(\mathrm{H})(\mathrm{H}) \mathrm{F}$ $\mathrm{C}(\mathrm{C}(\mathrm{C}(\mathrm{C}(\mathrm{C}(\mathrm{C}(\mathrm{C}(\mathrm{C}(\mathrm{C}(\mathrm{C}(\mathrm{C}(\mathrm{H})(\mathrm{F}) \mathrm{F})(\mathrm{H}) \mathrm{H})(\mathrm{H}) \mathrm{Br})(\mathrm{F}) \mathrm{H})(\mathrm{H}) \mathrm{H})(\mathrm{Br}) \mathrm{H})(\mathrm{Br}) \mathrm{F})(\mathrm{H}) \mathrm{H})(\mathrm{F}) \mathrm{H})(\mathrm{F}) \mathrm{F})(\mathrm{F})(\mathrm{Br}) \mathrm{F}$ $\mathrm{C}(\mathrm{C}(\mathrm{C}(\mathrm{C}(\mathrm{C}(\mathrm{C}(\mathrm{C}(\mathrm{C}(\mathrm{C}(\mathrm{C}(\mathrm{C}(\mathrm{F})(\mathrm{F}) \mathrm{H})(\mathrm{F}) \mathrm{H})(\mathrm{F}) \mathrm{F})(\mathrm{H}) \mathrm{H})(\mathrm{F}) \mathrm{H})(\mathrm{H}) \mathrm{Cl})(\mathrm{F}) \mathrm{F})(\mathrm{H}) \mathrm{H})(\mathrm{H}) \mathrm{Br})(\mathrm{Br}) \mathrm{H})(\mathrm{H})(\mathrm{Cl}) \mathrm{F}$ $\mathrm{C}(\mathrm{C}(\mathrm{C}(\mathrm{C}(\mathrm{C}(\mathrm{C}(\mathrm{C}(\mathrm{C}(\mathrm{C}(\mathrm{C}(\mathrm{C}(\mathrm{Br})(\mathrm{H}) \mathrm{F})(\mathrm{F}) \mathrm{H})(\mathrm{Cl}) \mathrm{Cl})(\mathrm{H}) \mathrm{F})(\mathrm{H}) \mathrm{H})(\mathrm{H}) \mathrm{F})(\mathrm{Br}) \mathrm{H})(\mathrm{F}) \mathrm{F})(\mathrm{H}) \mathrm{H})(\mathrm{Br}) \mathrm{H})(\mathrm{F})(\mathrm{F}) \mathrm{H}$ $\mathrm{C}(\mathrm{C}(\mathrm{C}(\mathrm{C}(\mathrm{C}(\mathrm{C}(\mathrm{C}(\mathrm{C}(\mathrm{C}(\mathrm{C}(\mathrm{C}(\mathrm{Cl})(\mathrm{H}) \mathrm{H})(\mathrm{F}) \mathrm{F})(\mathrm{H}) \mathrm{Br})(\mathrm{H}) \mathrm{F})(\mathrm{H}) \mathrm{Br})(\mathrm{F}) \mathrm{F})(\mathrm{H}) \mathrm{H})(\mathrm{H}) \mathrm{H})(\mathrm{Cl}) \mathrm{H})(\mathrm{F}) \mathrm{H})(\mathrm{F})(\mathrm{Cl}) \mathrm{F}$ $\mathrm{C}(\mathrm{C}(\mathrm{C}(\mathrm{C}(\mathrm{C}(\mathrm{C}(\mathrm{C}(\mathrm{C}(\mathrm{C}(\mathrm{C}(\mathrm{C}(\mathrm{F})(\mathrm{Cl}) \mathrm{H})(\mathrm{H}) \mathrm{H})(\mathrm{F}) \mathrm{F})(\mathrm{H}) \mathrm{H})(\mathrm{F}) \mathrm{F})(\mathrm{F}) \mathrm{H})(\mathrm{Br}) \mathrm{Cl})(\mathrm{H}) \mathrm{H})(\mathrm{F}) \mathrm{F})(\mathrm{H}) \mathrm{Cl})(\mathrm{H})(\mathrm{H}) \mathrm{F}$ $\mathrm{C}(\mathrm{C}(\mathrm{C}(\mathrm{C}(\mathrm{C}(\mathrm{C}(\mathrm{C}(\mathrm{C}(\mathrm{C}(\mathrm{C}(\mathrm{C}(\mathrm{Cl})(\mathrm{H}) \mathrm{Br})(\mathrm{H}) \mathrm{Cl})(\mathrm{Cl}) \mathrm{F})(\mathrm{H}) \mathrm{Br})(\mathrm{F}) \mathrm{H})(\mathrm{F}) \mathrm{Cl})(\mathrm{H}) \mathrm{H})(\mathrm{H}) \mathrm{F})(\mathrm{F}) \mathrm{H})(\mathrm{F}) \mathrm{H})(\mathrm{F})(\mathrm{H}) \mathrm{H}$ $\mathrm{C}(\mathrm{C}(\mathrm{C}(\mathrm{C}(\mathrm{C}(\mathrm{C}(\mathrm{C}(\mathrm{C}(\mathrm{C}(\mathrm{C}(\mathrm{C}(\mathrm{H})(\mathrm{Cl}) \mathrm{H})(\mathrm{F}) \mathrm{Cl})(\mathrm{F}) \mathrm{H})(\mathrm{F}) \mathrm{F})(\mathrm{H}) \mathrm{Cl})(\mathrm{Cl}) \mathrm{H})(\mathrm{H}) \mathrm{F})(\mathrm{Cl}) \mathrm{F})(\mathrm{H}) \mathrm{H})(\mathrm{H}) \mathrm{H})(\mathrm{F})(\mathrm{F}) \mathrm{H}$ $\mathrm{C}(\mathrm{C}(\mathrm{C}(\mathrm{C}(\mathrm{C}(\mathrm{C}(\mathrm{C}(\mathrm{C}(\mathrm{C}(\mathrm{C}(\mathrm{C}(\mathrm{H})(\mathrm{F}) \mathrm{H})(\mathrm{H}) \mathrm{H})(\mathrm{Cl}) \mathrm{Cl})(\mathrm{H}) \mathrm{F})(\mathrm{F}) \mathrm{Cl})(\mathrm{H}) \mathrm{Cl})(\mathrm{F}) \mathrm{Cl})(\mathrm{H}) \mathrm{H})(\mathrm{H}) \mathrm{F})(\mathrm{F}) \mathrm{H})(\mathrm{F})(\mathrm{Cl}) \mathrm{H}$ $\mathrm{C}(\mathrm{C}(\mathrm{C}(\mathrm{C}(\mathrm{C}(\mathrm{C}(\mathrm{C}(\mathrm{C}(\mathrm{C}(\mathrm{C}(\mathrm{C}(\mathrm{Br})(\mathrm{F}) \mathrm{F})(\mathrm{H}) \mathrm{H})(\mathrm{H}) \mathrm{F})(\mathrm{H}) \mathrm{H})(\mathrm{F}) \mathrm{F})(\mathrm{H}) \mathrm{F})(\mathrm{Br}) \mathrm{H})(\mathrm{F}) \mathrm{H})(\mathrm{H}) \mathrm{Cl})(\mathrm{F}) \mathrm{H})(\mathrm{F})(\mathrm{F}) \mathrm{H}$ $\mathrm{C}(\mathrm{C}(\mathrm{C}(\mathrm{C}(\mathrm{C}(\mathrm{C}(\mathrm{C}(\mathrm{C}(\mathrm{C}(\mathrm{C}(\mathrm{C}(\mathrm{H})(\mathrm{H}) \mathrm{H})(\mathrm{H}) \mathrm{F})(\mathrm{H}) \mathrm{F})(\mathrm{Br}) \mathrm{H})(\mathrm{F}) \mathrm{F})(\mathrm{H}) \mathrm{Cl})(\mathrm{F}) \mathrm{Br})(\mathrm{F}) \mathrm{H})(\mathrm{F}) \mathrm{H})(\mathrm{Br}) \mathrm{F})(\mathrm{H})(\mathrm{H}) \mathrm{F}$ $\mathrm{C}(\mathrm{C}(\mathrm{C}(\mathrm{C}(\mathrm{C}(\mathrm{C}(\mathrm{C}(\mathrm{C}(\mathrm{C}(\mathrm{C}(\mathrm{C}(\mathrm{H})(\mathrm{H}) \mathrm{F})(\mathrm{H}) \mathrm{H})(\mathrm{H}) \mathrm{F})(\mathrm{Br}) \mathrm{Br})(\mathrm{H}) \mathrm{F})(\mathrm{H}) \mathrm{H})(\mathrm{F}) \mathrm{F})(\mathrm{F}) \mathrm{F})(\mathrm{H}) \mathrm{H})(\mathrm{F}) \mathrm{F})(\mathrm{Br})(\mathrm{H}) \mathrm{H}$ $\mathrm{C}(\mathrm{C}(\mathrm{C}(\mathrm{C}(\mathrm{C}(\mathrm{C}(\mathrm{C}(\mathrm{C}(\mathrm{C}(\mathrm{C}(\mathrm{C}(\mathrm{F})(\mathrm{F}) \mathrm{H})(\mathrm{H}) \mathrm{H})(\mathrm{F}) \mathrm{Br})(\mathrm{F}) \mathrm{H})(\mathrm{F}) \mathrm{H})(\mathrm{F}) \mathrm{H})(\mathrm{H}) \mathrm{H})(\mathrm{Br}) \mathrm{F})(\mathrm{Br}) \mathrm{H})(\mathrm{F}) \mathrm{H})(\mathrm{H})(\mathrm{Br}) \mathrm{H}$ $\mathrm{C}(\mathrm{C}(\mathrm{C}(\mathrm{C}(\mathrm{C}(\mathrm{C}(\mathrm{C}(\mathrm{C}(\mathrm{C}(\mathrm{C}(\mathrm{C}(\mathrm{F})(\mathrm{H}) \mathrm{F})(\mathrm{H}) \mathrm{H})(\mathrm{F}) \mathrm{F})(\mathrm{H}) \mathrm{H})(\mathrm{F}) \mathrm{F})(\mathrm{H}) \mathrm{H})(\mathrm{H}) \mathrm{F})(\mathrm{Cl}) \mathrm{F})(\mathrm{Cl}) \mathrm{H})(\mathrm{H}) \mathrm{H})(\mathrm{H})(\mathrm{Br}) \mathrm{Br}$ $\mathrm{C}(\mathrm{C}(\mathrm{C}(\mathrm{C}(\mathrm{C}(\mathrm{C}(\mathrm{C}(\mathrm{C}(\mathrm{C}(\mathrm{C}(\mathrm{C}(\mathrm{H})(\mathrm{F}) \mathrm{F})(\mathrm{F}) \mathrm{F})(\mathrm{H}) \mathrm{H})(\mathrm{H}) \mathrm{H})(\mathrm{H}) \mathrm{Cl})(\mathrm{H}) \mathrm{Br})(\mathrm{H}) \mathrm{Cl})(\mathrm{F}) \mathrm{H})(\mathrm{H}) \mathrm{F})(\mathrm{H}) \mathrm{F})(\mathrm{F})(\mathrm{H}) \mathrm{Cl}$ $\mathrm{C}(\mathrm{C}(\mathrm{C}(\mathrm{C}(\mathrm{C}(\mathrm{C}(\mathrm{C}(\mathrm{C}(\mathrm{C}(\mathrm{C}(\mathrm{C}(\mathrm{H})(\mathrm{F}) \mathrm{Br})(\mathrm{F}) \mathrm{H})(\mathrm{F}) \mathrm{Cl})(\mathrm{H}) \mathrm{F})(\mathrm{Cl}) \mathrm{H})(\mathrm{Cl}) \mathrm{F})(\mathrm{H}) \mathrm{H})(\mathrm{H}) \mathrm{H})(\mathrm{F}) \mathrm{F})(\mathrm{H}) \mathrm{H})(\mathrm{Cl})(\mathrm{H}) \mathrm{H}$ $\mathrm{C}(\mathrm{C}(\mathrm{C}(\mathrm{C}(\mathrm{C}(\mathrm{C}(\mathrm{C}(\mathrm{C}(\mathrm{C}(\mathrm{C}(\mathrm{C}(\mathrm{H})(\mathrm{H}) \mathrm{F})(\mathrm{F}) \mathrm{Cl})(\mathrm{H}) \mathrm{H})(\mathrm{F}) \mathrm{H})(\mathrm{Cl}) \mathrm{H})(\mathrm{F}) \mathrm{H})(\mathrm{Cl}) \mathrm{Cl})(\mathrm{H}) \mathrm{F})(\mathrm{H}) \mathrm{F})(\mathrm{F}) \mathrm{F})(\mathrm{H})(\mathrm{H}) \mathrm{H}$ $\mathrm{C}(\mathrm{C}(\mathrm{C}(\mathrm{C}(\mathrm{C}(\mathrm{C}(\mathrm{C}(\mathrm{C}(\mathrm{C}(\mathrm{C}(\mathrm{C}(\mathrm{F})(\mathrm{Cl}) \mathrm{F})(\mathrm{H}) \mathrm{F})(\mathrm{Cl}) \mathrm{H})(\mathrm{H}) \mathrm{H})(\mathrm{Cl}) \mathrm{H})(\mathrm{Cl}) \mathrm{H})(\mathrm{H}) \mathrm{F})(\mathrm{Cl}) \mathrm{F})(\mathrm{F}) \mathrm{H})(\mathrm{H}) \mathrm{H})(\mathrm{Br})(\mathrm{H}) \mathrm{H}$ $\mathrm{C}(\mathrm{C}(\mathrm{C}(\mathrm{C}(\mathrm{C}(\mathrm{C}(\mathrm{C}(\mathrm{C}(\mathrm{C}(\mathrm{C}(\mathrm{C}(\mathrm{H})(\mathrm{H}) \mathrm{H})(\mathrm{H}) \mathrm{H})(\mathrm{F}) \mathrm{H})(\mathrm{F}) \mathrm{Cl})(\mathrm{H}) \mathrm{H})(\mathrm{H}) \mathrm{H})(\mathrm{F}) \mathrm{Cl})(\mathrm{F}) \mathrm{H})(\mathrm{F}) \mathrm{F})(\mathrm{F}) \mathrm{Cl})(\mathrm{Cl})(\mathrm{H}) \mathrm{Cl}$ $\mathrm{C}(\mathrm{C}(\mathrm{C}(\mathrm{C}(\mathrm{C}(\mathrm{C}(\mathrm{C}(\mathrm{C}(\mathrm{C}(\mathrm{C}(\mathrm{C}(\mathrm{Br})(\mathrm{H}) \mathrm{F})(\mathrm{H}) \mathrm{F})(\mathrm{Cl}) \mathrm{H})(\mathrm{F}) \mathrm{F})(\mathrm{H}) \mathrm{H})(\mathrm{H}) \mathrm{Br})(\mathrm{F}) \mathrm{H})(\mathrm{F}) \mathrm{H})(\mathrm{F}) \mathrm{F})(\mathrm{H}) \mathrm{H})(\mathrm{H})(\mathrm{H}) \mathrm{F}$ $\mathrm{C}(\mathrm{C}(\mathrm{C}(\mathrm{C}(\mathrm{C}(\mathrm{C}(\mathrm{C}(\mathrm{C}(\mathrm{C}(\mathrm{C}(\mathrm{C}(\mathrm{H})(\mathrm{Br}) \mathrm{F})(\mathrm{H}) \mathrm{F})(\mathrm{H}) \mathrm{Cl})(\mathrm{F}) \mathrm{H})(\mathrm{F}) \mathrm{H})(\mathrm{H}) \mathrm{Br})(\mathrm{H}) \mathrm{H})(\mathrm{F}) \mathrm{H})(\mathrm{H}) \mathrm{H})(\mathrm{F}) \mathrm{Br})(\mathrm{H})(\mathrm{F}) \mathrm{F}$ $\mathrm{C}(\mathrm{C}(\mathrm{C}(\mathrm{C}(\mathrm{C}(\mathrm{C}(\mathrm{C}(\mathrm{C}(\mathrm{C}(\mathrm{C}(\mathrm{C}(\mathrm{H})(\mathrm{H}) \mathrm{H})(\mathrm{F}) \mathrm{F})(\mathrm{H}) \mathrm{Br})(\mathrm{H}) \mathrm{F})(\mathrm{F}) \mathrm{F})(\mathrm{H}) \mathrm{Br})(\mathrm{H}) \mathrm{Br})(\mathrm{H}) \mathrm{F})(\mathrm{H}) \mathrm{H})(\mathrm{H}) \mathrm{F})(\mathrm{F})(\mathrm{H}) \mathrm{H}$ $\mathrm{C}(\mathrm{C}(\mathrm{C}(\mathrm{C}(\mathrm{C}(\mathrm{C}(\mathrm{C}(\mathrm{C}(\mathrm{C}(\mathrm{C}(\mathrm{C}(\mathrm{H})(\mathrm{H}) \mathrm{H})(\mathrm{F}) \mathrm{H})(\mathrm{H}) \mathrm{H})(\mathrm{F}) \mathrm{Br})(\mathrm{Br}) \mathrm{H})(\mathrm{F}) \mathrm{H})(\mathrm{F}) \mathrm{H})(\mathrm{H}) \mathrm{Br})(\mathrm{F}) \mathrm{F})(\mathrm{H}) \mathrm{H})(\mathrm{H})(\mathrm{F}) \mathrm{Br}$ $\mathrm{C}(\mathrm{C}(\mathrm{C}(\mathrm{C}(\mathrm{C}(\mathrm{C}(\mathrm{C}(\mathrm{C}(\mathrm{C}(\mathrm{C}(\mathrm{C}(\mathrm{F})(\mathrm{H}) \mathrm{Cl})(\mathrm{H}) \mathrm{H})(\mathrm{H}) \mathrm{F})(\mathrm{H}) \mathrm{H})(\mathrm{F}) \mathrm{H})(\mathrm{Cl}) \mathrm{H})(\mathrm{H}) \mathrm{H})(\mathrm{F}) \mathrm{Br})(\mathrm{Br}) \mathrm{F})(\mathrm{F}) \mathrm{F})(\mathrm{H})(\mathrm{H}) \mathrm{H}$ $\mathrm{C}(\mathrm{C}(\mathrm{C}(\mathrm{C}(\mathrm{C}(\mathrm{C}(\mathrm{C}(\mathrm{C}(\mathrm{C}(\mathrm{C}(\mathrm{C}(\mathrm{H})(\mathrm{H}) \mathrm{Br})(\mathrm{H}) \mathrm{F})(\mathrm{H}) \mathrm{F})(\mathrm{F}) \mathrm{H})(\mathrm{H}) \mathrm{H})(\mathrm{H}) \mathrm{Cl})(\mathrm{H}) \mathrm{H})(\mathrm{H}) \mathrm{F})(\mathrm{F}) \mathrm{Cl})(\mathrm{Cl}) \mathrm{H})(\mathrm{Br})(\mathrm{H}) \mathrm{F}$ $\mathrm{C}(\mathrm{C}(\mathrm{C}(\mathrm{C}(\mathrm{C}(\mathrm{C}(\mathrm{C}(\mathrm{C}(\mathrm{C}(\mathrm{C}(\mathrm{C}(\mathrm{Cl})(\mathrm{H}) \mathrm{H})(\mathrm{H}) \mathrm{H})(\mathrm{Cl}) \mathrm{H})(\mathrm{H}) \mathrm{H})(\mathrm{F}) \mathrm{F})(\mathrm{H}) \mathrm{F})(\mathrm{H}) \mathrm{F})(\mathrm{F}) \mathrm{Cl})(\mathrm{F}) \mathrm{H})(\mathrm{H}) \mathrm{H})(\mathrm{Br})(\mathrm{F}) \mathrm{H}$ $\mathrm{C}(\mathrm{C}(\mathrm{C}(\mathrm{C}(\mathrm{C}(\mathrm{C}(\mathrm{C}(\mathrm{C}(\mathrm{C}(\mathrm{C}(\mathrm{C}(\mathrm{Cl})(\mathrm{H}) \mathrm{Br})(\mathrm{F}) \mathrm{H})(\mathrm{F}) \mathrm{H})(\mathrm{H}) \mathrm{F})(\mathrm{H}) \mathrm{H})(\mathrm{Cl}) \mathrm{H})(\mathrm{H}) \mathrm{H})(\mathrm{F}) \mathrm{F})(\mathrm{Cl}) \mathrm{F})(\mathrm{H}) \mathrm{Cl})(\mathrm{H})(\mathrm{H}) \mathrm{H}$ $\mathrm{C}(\mathrm{C}(\mathrm{C}(\mathrm{C}(\mathrm{C}(\mathrm{C}(\mathrm{C}(\mathrm{C}(\mathrm{C}(\mathrm{C}(\mathrm{C}(\mathrm{F})(\mathrm{H}) \mathrm{H})(\mathrm{H}) \mathrm{H})(\mathrm{H}) \mathrm{H})(\mathrm{H}) \mathrm{F})(\mathrm{F}) \mathrm{F})(\mathrm{Cl}) \mathrm{H})(\mathrm{Cl}) \mathrm{F})(\mathrm{H}) \mathrm{F})(\mathrm{Cl}) \mathrm{H})(\mathrm{H}) \mathrm{Cl})(\mathrm{Cl})(\mathrm{H}) \mathrm{H}$ $\mathrm{C}(\mathrm{C}(\mathrm{C}(\mathrm{C}(\mathrm{C}(\mathrm{C}(\mathrm{C}(\mathrm{C}(\mathrm{C}(\mathrm{C}(\mathrm{C}(\mathrm{H})(\mathrm{F}) \mathrm{H})(\mathrm{F}) \mathrm{H})(\mathrm{H}) \mathrm{Br})(\mathrm{F}) \mathrm{H})(\mathrm{F}) \mathrm{Br})(\mathrm{F}) \mathrm{F})(\mathrm{H}) \mathrm{H})(\mathrm{H}) \mathrm{H})(\mathrm{H}) \mathrm{H})(\mathrm{H}) \mathrm{H})(\mathrm{H})(\mathrm{Br}) \mathrm{F}$ $\mathrm{C}(\mathrm{C}(\mathrm{C}(\mathrm{C}(\mathrm{C}(\mathrm{C}(\mathrm{C}(\mathrm{C}(\mathrm{C}(\mathrm{C}(\mathrm{C}(\mathrm{H})(\mathrm{H}) \mathrm{Br})(\mathrm{F}) \mathrm{H})(\mathrm{F}) \mathrm{H})(\mathrm{Cl}) \mathrm{H})(\mathrm{Br}) \mathrm{F})(\mathrm{H}) \mathrm{H})(\mathrm{H}) \mathrm{H})(\mathrm{F}) \mathrm{H})(\mathrm{H}) \mathrm{H})(\mathrm{Cl}) \mathrm{F})(\mathrm{H})(\mathrm{H}) \mathrm{F}$ $\mathrm{C}(\mathrm{C}(\mathrm{C}(\mathrm{C}(\mathrm{C}(\mathrm{C}(\mathrm{C}(\mathrm{C}(\mathrm{C}(\mathrm{C}(\mathrm{C}(\mathrm{H})(\mathrm{H}) \mathrm{F})(\mathrm{H}) \mathrm{F})(\mathrm{H}) \mathrm{Cl})(\mathrm{H}) \mathrm{H})(\mathrm{Cl}) \mathrm{H})(\mathrm{F}) \mathrm{H})(\mathrm{H}) \mathrm{Br})(\mathrm{H}) \mathrm{H})(\mathrm{H}) \mathrm{Cl})(\mathrm{F}) \mathrm{F})(\mathrm{H})(\mathrm{F}) \mathrm{H}$ $\mathrm{C}(\mathrm{C}(\mathrm{C}(\mathrm{C}(\mathrm{C}(\mathrm{C}(\mathrm{C}(\mathrm{C}(\mathrm{C}(\mathrm{C}(\mathrm{C}(\mathrm{Cl})(\mathrm{F}) \mathrm{H})(\mathrm{H}) \mathrm{F})(\mathrm{H}) \mathrm{H})(\mathrm{H}) \mathrm{F})(\mathrm{Br}) \mathrm{H})(\mathrm{H}) \mathrm{H})(\mathrm{H}) \mathrm{Cl})(\mathrm{H}) \mathrm{Br})(\mathrm{Cl}) \mathrm{H})(\mathrm{H}) \mathrm{H})(\mathrm{H})(\mathrm{Cl}) \mathrm{F}$ $\mathrm{C}(\mathrm{C}(\mathrm{C}(\mathrm{C}(\mathrm{C}(\mathrm{C}(\mathrm{C}(\mathrm{C}(\mathrm{C}(\mathrm{C}(\mathrm{C}(\mathrm{F})(\mathrm{Cl}) \mathrm{H})(\mathrm{H}) \mathrm{H})(\mathrm{H}) \mathrm{Cl})(\mathrm{H}) \mathrm{H})(\mathrm{Cl}) \mathrm{H})(\mathrm{Cl}) \mathrm{H})(\mathrm{H}) \mathrm{F})(\mathrm{F}) \mathrm{F})(\mathrm{H}) \mathrm{H})(\mathrm{H}) \mathrm{H})(\mathrm{H})(\mathrm{F}) \mathrm{B}$ $\mathrm{C}(\mathrm{C}(\mathrm{C}(\mathrm{C}(\mathrm{C}(\mathrm{C}(\mathrm{C}(\mathrm{C}(\mathrm{C}(\mathrm{C}(\mathrm{C}(\mathrm{H})(\mathrm{H}) \mathrm{F})(\mathrm{F}) \mathrm{H})(\mathrm{Cl}) \mathrm{Cl})(\mathrm{F}) \mathrm{H})(\mathrm{H}) \mathrm{F})(\mathrm{H}) \mathrm{H})(\mathrm{F}) \mathrm{Cl})(\mathrm{H}) \mathrm{H})(\mathrm{Cl}) \mathrm{H})(\mathrm{H}) \mathrm{F})(\mathrm{H})(\mathrm{H}) \mathrm{H}$ $\mathrm{C}(\mathrm{C}(\mathrm{C}(\mathrm{C}(\mathrm{C}(\mathrm{C}(\mathrm{C}(\mathrm{C}(\mathrm{C}(\mathrm{C}(\mathrm{C}(\mathrm{H})(\mathrm{Cl}) \mathrm{H})(\mathrm{H}) \mathrm{F})(\mathrm{F}) \mathrm{Cl})(\mathrm{H}) \mathrm{Cl})(\mathrm{H}) \mathrm{H})(\mathrm{H}) \mathrm{H})(\mathrm{H}) \mathrm{Cl})(\mathrm{F}) \mathrm{Cl})(\mathrm{F}) \mathrm{H})(\mathrm{F}) \mathrm{H})(\mathrm{H})(\mathrm{H}) \mathrm{H}$ $\mathrm{C}(\mathrm{C}(\mathrm{C}(\mathrm{C}(\mathrm{C}(\mathrm{C}(\mathrm{C}(\mathrm{C}(\mathrm{C}(\mathrm{C}(\mathrm{C}(\mathrm{Cl})(\mathrm{H}) \mathrm{H})(\mathrm{Cl}) \mathrm{H})(\mathrm{H}) \mathrm{Cl})(\mathrm{Cl}) \mathrm{H})(\mathrm{Cl}) \mathrm{Cl})(\mathrm{H}) \mathrm{H})(\mathrm{H}) \mathrm{H})(\mathrm{H}) \mathrm{F})(\mathrm{H}) \mathrm{F})(\mathrm{F}) \mathrm{H})(\mathrm{H})(\mathrm{H})$ $\mathrm{C}(\mathrm{C}(\mathrm{C}(\mathrm{C}(\mathrm{C}(\mathrm{C}(\mathrm{C}(\mathrm{C}(\mathrm{C}(\mathrm{C}(\mathrm{C}(\mathrm{H})(\mathrm{F}) \mathrm{H})(\mathrm{H}) \mathrm{H})(\mathrm{H}) \mathrm{H})(\mathrm{H}) \mathrm{F})(\mathrm{Br}) \mathrm{H})(\mathrm{H}) \mathrm{H})(\mathrm{F}) \mathrm{F})(\mathrm{F}) \mathrm{H})(\mathrm{F}) \mathrm{F})(\mathrm{H}) \mathrm{Cl})(\mathrm{Br})(\mathrm{H}) \mathrm{H}$ $\mathrm{C}(\mathrm{C}(\mathrm{C}(\mathrm{C}(\mathrm{C}(\mathrm{C}(\mathrm{C}(\mathrm{C}(\mathrm{C}(\mathrm{C}(\mathrm{C}(\mathrm{F})(\mathrm{H}) \mathrm{Br})(\mathrm{Br}) \mathrm{H})(\mathrm{H}) \mathrm{F})(\mathrm{H}) \mathrm{H})(\mathrm{Br}) \mathrm{H})(\mathrm{Cl}) \mathrm{H})(\mathrm{H}) \mathrm{H})(\mathrm{F}) \mathrm{H})(\mathrm{F}) \mathrm{F})(\mathrm{H}) \mathrm{H})(\mathrm{H})(\mathrm{F}) \mathrm{H}$ $\mathrm{C}(\mathrm{C}(\mathrm{C}(\mathrm{C}(\mathrm{C}(\mathrm{C}(\mathrm{C}(\mathrm{C}(\mathrm{C}(\mathrm{C}(\mathrm{C}(\mathrm{H})(\mathrm{H}) \mathrm{H})(\mathrm{H}) \mathrm{H})(\mathrm{F}) \mathrm{F})(\mathrm{H}) \mathrm{Br})(\mathrm{H}) \mathrm{F})(\mathrm{Br}) \mathrm{H})(\mathrm{F}) \mathrm{F})(\mathrm{F}) \mathrm{H})(\mathrm{H}) \mathrm{H})(\mathrm{H}) \mathrm{Br})(\mathrm{H})(\mathrm{H}) \mathrm{H}$ $\mathrm{C}(\mathrm{C}(\mathrm{C}(\mathrm{C}(\mathrm{C}(\mathrm{C}(\mathrm{C}(\mathrm{C}(\mathrm{C}(\mathrm{C}(\mathrm{C}(\mathrm{Br})(\mathrm{H}) \mathrm{H})(\mathrm{H}) \mathrm{H})(\mathrm{H}) \mathrm{Br})(\mathrm{H}) \mathrm{F})(\mathrm{H}) \mathrm{H})(\mathrm{F}) \mathrm{H})(\mathrm{H}) \mathrm{H})(\mathrm{H}) \mathrm{F})(\mathrm{Br}) \mathrm{H})(\mathrm{H}) \mathrm{F})(\mathrm{H})(\mathrm{F}) \mathrm{B}$ $\mathrm{C}(\mathrm{C}(\mathrm{C}(\mathrm{C}(\mathrm{C}(\mathrm{C}(\mathrm{C}(\mathrm{C}(\mathrm{C}(\mathrm{C}(\mathrm{C}(\mathrm{Cl})(\mathrm{H}) \mathrm{H})(\mathrm{F}) \mathrm{Cl})(\mathrm{H}) \mathrm{H})(\mathrm{H}) \mathrm{H})(\mathrm{H}) \mathrm{Br})(\mathrm{F}) \mathrm{H})(\mathrm{H}) \mathrm{H})(\mathrm{H}) \mathrm{H})(\mathrm{H}) \mathrm{H})(\mathrm{H}) \mathrm{F})(\mathrm{F})(\mathrm{F}) \mathrm{B}$ $\mathrm{C}(\mathrm{C}(\mathrm{C}(\mathrm{C}(\mathrm{C}(\mathrm{C}(\mathrm{C}(\mathrm{C}(\mathrm{C}(\mathrm{C}(\mathrm{C}(\mathrm{H})(\mathrm{H}) \mathrm{H})(\mathrm{F}) \mathrm{Cl})(\mathrm{H}) \mathrm{F})(\mathrm{Cl}) \mathrm{H})(\mathrm{Br}) \mathrm{H})(\mathrm{F}) \mathrm{H})(\mathrm{H}) \mathrm{F})(\mathrm{H}) \mathrm{F})(\mathrm{H}) \mathrm{F})(\mathrm{H}) \mathrm{H})(\mathrm{H})(\mathrm{H}) \mathrm{H}$ $\mathrm{C}(\mathrm{C}(\mathrm{C}(\mathrm{C}(\mathrm{C}(\mathrm{C}(\mathrm{C}(\mathrm{C}(\mathrm{C}(\mathrm{C}(\mathrm{C}(\mathrm{H})(\mathrm{H}) \mathrm{H})(\mathrm{Cl}) \mathrm{Br})(\mathrm{F}) \mathrm{H})(\mathrm{H}) \mathrm{H})(\mathrm{H}) \mathrm{H})(\mathrm{H}) \mathrm{H})(\mathrm{F}) \mathrm{Cl})(\mathrm{Cl}) \mathrm{H})(\mathrm{F}) \mathrm{H})(\mathrm{H}) \mathrm{F})(\mathrm{H})(\mathrm{H}) \mathrm{F}$ $\mathrm{C}(\mathrm{C}(\mathrm{C}(\mathrm{C}(\mathrm{C}(\mathrm{C}(\mathrm{C}(\mathrm{C}(\mathrm{C}(\mathrm{C}(\mathrm{C}(\mathrm{H})(\mathrm{H}) \mathrm{H})(\mathrm{Cl}) \mathrm{F})(\mathrm{H}) \mathrm{H})(\mathrm{H}) \mathrm{H})(\mathrm{H}) \mathrm{F})(\mathrm{H}) \mathrm{F})(\mathrm{H}) \mathrm{H})(\mathrm{Cl}) \mathrm{F})(\mathrm{H}) \mathrm{F})(\mathrm{H}) \mathrm{F})(\mathrm{H})(\mathrm{Cl}) \mathrm{H}$ $\mathrm{C}(\mathrm{C}(\mathrm{C}(\mathrm{C}(\mathrm{C}(\mathrm{C}(\mathrm{C}(\mathrm{C}(\mathrm{C}(\mathrm{C}(\mathrm{C}(\mathrm{H})(\mathrm{H}) \mathrm{F})(\mathrm{F}) \mathrm{H})(\mathrm{H}) \mathrm{H})(\mathrm{F}) \mathrm{H})(\mathrm{H}) \mathrm{Br})(\mathrm{H}) \mathrm{H})(\mathrm{H}) \mathrm{Cl})(\mathrm{Cl}) \mathrm{H})(\mathrm{H}) \mathrm{H})(\mathrm{Cl}) \mathrm{H})(\mathrm{Cl})(\mathrm{H})$

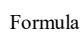

$\mathrm{C} 10 \mathrm{H} 8 \mathrm{Br} 2 \mathrm{~F} 12$

$\mathrm{C} 10 \mathrm{H} 8 \mathrm{Br} 3 \mathrm{~F} 11$

C10H8Br4F10

C10H8Cl2Br2F10

$\mathrm{C} 10 \mathrm{H} 8 \mathrm{Cl} 3 \mathrm{Br} 2 \mathrm{~F} 9$

$\mathrm{C} 10 \mathrm{H} 8 \mathrm{Cl} 3 \mathrm{BrF} 10$

C10H8Cl4BrF9

C10H8Cl5F9

C10H8Cl6F8

C10H8ClBr2F 11

C10H8ClBr3F10

C10H9Br3F10

C10H9Br5F8

$\mathrm{C} 10 \mathrm{H} 9 \mathrm{Cl} 2 \mathrm{Br} 2 \mathrm{~F} 9$

$\mathrm{C} 10 \mathrm{H} 9 \mathrm{Cl} 2 \mathrm{Br} 3 \mathrm{~F} 8$

C10H9Cl3Br2F

$\mathrm{C} 10 \mathrm{H} 9 \mathrm{Cl} 3 \mathrm{BrF} 9$

C10H9Cl4BrF8

$\mathrm{C} 10 \mathrm{H} 9 \mathrm{Cl} 4 \mathrm{F9}$

C10H9Cl5BrF7

C10H9Cl5F 8

$\mathrm{C} 10 \mathrm{H} 9 \mathrm{ClBr} 3 \mathrm{~F} 9$

C10HCl3BrF17

C10HClBr3F 17

C11H10Br3F11

$\mathrm{C} 11 \mathrm{H} 10 \mathrm{Br} 4 \mathrm{~F} 10$

$\mathrm{C} 11 \mathrm{H} 10 \mathrm{Cl} 2 \mathrm{Br} 2 \mathrm{~F} 1$

C11H10Cl2Br3F9

C11H10Cl2BrF11

C11H10Cl3Br2F9

$\mathrm{C} 11 \mathrm{H} 10 \mathrm{Cl} 3 \mathrm{BrF} 10$

C11H10Cl4BrF9

C11H10Cl4F10

C11H10Cl5BrF8

C11H10Cl5F9

C11H10Cl6F8

$\mathrm{C} 11 \mathrm{H} 10 \mathrm{ClBr} 2 \mathrm{~F} 11$

C11H10ClBr3F10

C11H11Br2F11

C11H11Br3F10

C11H11Br4F9

C11H11Cl2Br2F9

C11H11Cl2Br3F8

C11H11Cl3Br2F8

C11H11Cl3BrF9

C11H11Cl4Br2F7

C11H11Cl5F8

C11H11Cl6F7

C11H11ClBr2F10

$\mathrm{C} 11 \mathrm{H} 11 \mathrm{ClBr} 3 \mathrm{~F} 9$

C11H12Br3F9

C11H12Br4F8

$\mathrm{C} 11 \mathrm{H} 12 \mathrm{Cl} 2 \mathrm{Br} 2 \mathrm{~F} 8$

C11H12Cl3BrF8

$\mathrm{C} 11 \mathrm{H} 12 \mathrm{Cl} 4 \mathrm{BrF}$

$\mathrm{C} 11 \mathrm{H} 12 \mathrm{Cl} 4 \mathrm{~F} 8$

C11H12Cl5BrF6

C11H12Cl5F 7

C11H12ClBr2F9

$\mathrm{C} 11 \mathrm{H} 12 \mathrm{ClBr} 3 \mathrm{~F} 8$

C11H13Br3F8

C11H13Br4F7

C11H13Cl2Br2F7

C11H13Cl3Br2F6

C11H13Cl3BrF7

C11H13Cl4BrF6

C11H13Cl5F6

$\mathrm{C} 11 \mathrm{H} 14 \mathrm{Br} 3 \mathrm{~F} 7$

$\mathrm{C} 11 \mathrm{H} 14 \mathrm{Cl} 2 \mathrm{Br} 2 \mathrm{~F} 6$

$\mathrm{C} 11 \mathrm{H} 14 \mathrm{Cl} 3 \mathrm{BrF} 6$

$\mathrm{C} 11 \mathrm{H} 14 \mathrm{Cl} 14 \mathrm{Br} 2 \mathrm{~F} 4$

C11H14Cl4BrF5

$\mathrm{C} 11 \mathrm{H} 14 \mathrm{Cl} 14 \mathrm{~F} 6$

C11H14Cl5F

$\mathrm{C} 11 \mathrm{H} 14 \mathrm{Cl} 6 \mathrm{~F} 4$

$\mathrm{C} 11 \mathrm{H} 14 \mathrm{ClBr} 2 \mathrm{~F} 7$

$\mathrm{C} 11 \mathrm{H} 14 \mathrm{ClBr} 3 \mathrm{~F} 6$

C11H15Br3F6

$\mathrm{C} 11 \mathrm{H} 15 \mathrm{Br} 4 \mathrm{~F} 5$

$\mathrm{C} 11 \mathrm{H} 15 \mathrm{Cl} 2 \mathrm{Br} 2 \mathrm{~F} 5$

$\mathrm{C} 11 \mathrm{H} 15 \mathrm{Cl} 2 \mathrm{BrF} 6$

$\mathrm{C} 11 \mathrm{H} 15 \mathrm{Cl} 3 \mathrm{BrF} 5$

C11H15Cl3F6

$\mathrm{C} 11 \mathrm{H} 15 \mathrm{C} 14 \mathrm{BrF} 4$
gKoa lgKow lgKaw lgKow lgKoa lgKa lgKow lgKoa lgKaw EPISuit EPI EPI Exp Exp w DFT DFT DFT Suite Suite - $\bar{C}_{-}$corr Exp corr \begin{tabular}{lllllllllll}
\multicolumn{2}{c}{ 4.685 } & 7.98 & 3.29 & 6.99 & 3.69 & 3.29 & 6.89 & 6.62 & 0.27
\end{tabular} $\begin{array}{lllllllll}5.433 & 7.49 & 2.06 & 6.25 & 4.20 & 2.06 & 6.51 & 7.99 & -1.48\end{array}$ $\begin{array}{lllllll}0.82 & 5.64 & 4.82 & 0.82 & 6.20 & 9.51 & -3.31\end{array}$ $6.889-8.68$ $\begin{array}{lllllllll}6.472 & 7.51 & 1.04 & 6.28 & 5.25 & 1.04 & 6.53 & 9.90 & -3.37\end{array}$ $\begin{array}{llllllllll}4.824 & 7.1 & 2.28 & 5.67 & 3.40 & 2.28 & 6.21 & 6.87 & -0.66\end{array}$ $\begin{array}{llllllllll}5.896 & 7.42 & 1.52 & 6.15 & 4.63 & 1.52 & 6.46 & 8.84 & -2.38\end{array}$ $\begin{array}{llllllllll}6.061 & 8.07 & 2.01 & 7.12 & 5.11 & 2.01 & 6.96 & 9.15 & -2.19\end{array}$ $\begin{array}{llllllllll}5.078 & 7.62 & 2.54 & 6.45 & 3.91 & 2.54 & 6.61 & 7.34 & -0.73\end{array}$ $\begin{array}{llllllllll}6.715 & 8.02 & 1.31 & 7.04 & 5.74 & 1.31 & 6.92 & 10.35 & -3.43\end{array}$ $\begin{array}{llllllllll}6.082 & 7.84 & 1.76 & 6.78 & 5.02 & 1.76 & 6.78 & 9.18 & -2.40\end{array}$ $\begin{array}{lllllllll}7.145 & 6.43 & -0.72 & 4.67 & 5.39 & -0.72 & 5.70 & 11.14 & -5.44\end{array}$ $\begin{array}{llllllll}-1.49 & 8.22 & 6.73 & 1.49 & 7.53 & 11.46 & -3.93\end{array}$ $\begin{array}{llllllllll}6.735 & 6.99 & 0.25 & 5.51 & 5.25 & 0.25 & 6.13 & 10.38 & -4.25\end{array}$ $\begin{array}{llllllllll}6.901 & 7.64 & 0.74 & 6.48 & 5.74 & 0.74 & 6.63 & 10.69 & -4.06\end{array}$ $\begin{array}{llllllllll}5.263 & 7.24 & 1.98 & 5.88 & 3.90 & 1.98 & 6.32 & 7.68 & -1.36\end{array}$ $\begin{array}{lllllllll}1.23 & 6.34 & 5.12 & 1.23 & 6.56 & 9.63 & -3.07\end{array}$ $\begin{array}{lllllllll}-1.23 & 6.34 & 5.12 & 1.23 & 6.56 & 9.63 & -3.07\end{array}$ $\begin{array}{llllllllll}6.646 & 7.12 & 0.47 & 5.70 & 5.23 & 0.47 & 6.23 & 10.22 & -3.99\end{array}$ $\begin{array}{lllllllll}6.488 & 8.2 & 1.71 & 7.31 & 5.60 & 1.71 & 7.06 & 9.93 & -2.87\end{array}$ $\begin{array}{llllllllll}6.414 & 7.42 & 1.01 & 6.15 & 5.14 & 1.01 & 6.46 & 9.79 & -3.33\end{array}$ $\begin{array}{llllllll}4.37 & 9.60 & 5.23 & 4.37 & 8.24 & 7.86 & 0.37\end{array}$

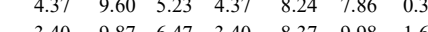
$\begin{array}{llllll}6.513 & 9.91 & 3.40 & 9.87 & 6.47 & 3\end{array}$ $\begin{array}{llllllllll}6.019 & 8.2 & 2.18 & 7.31 & 5.13 & 2.18 & 7.06 & 9.07 & -2.01\end{array}$ $\begin{array}{llllllllll}6.846 & 7.79 & 0.94 & 6.70 & 5.76 & 0.94 & 6.75 & 10.59 & -3.84\end{array}$ $\begin{array}{llllllllll}5.775 & 7.69 & 1.91 & 6.55 & 4.64 & 1.91 & 6.67 & 8.62 & -1.95\end{array}$ $\begin{array}{llllllllll}7.414 & 8.09 & 0.68 & 7.15 & 6.47 & 0.68 & 6.98 & 11.63 & -4.66\end{array}$ $\begin{array}{lllllllll}4.869 & 8.02 & 3.15 & 7.04 & 3.89 & 3.15 & 6.92 & 6.96 & -0.03\end{array}$ $\begin{array}{lllllllll}6.838 & 8 & 1.16 & 7.01 & 5.85 & 1.16 & 6.91 & 10.57 & -3.67\end{array}$ $\begin{array}{lllllllll}5.941 & 8.34 & 2.40 & 7.52 & 5.12 & 2.40 & 7.17 & 8.93 & -1.76\end{array}$ $\begin{array}{llllllll}1.65 & 5.78 & 4.13 & 1.65 & 6.27 & 8.15 & -1.89\end{array}$ $\begin{array}{lllllllll}1.65 & 5.78 & 4.13 & 1.65 & 6.27 & 8.15 & -1.89\end{array}$ $\begin{array}{lllllllllll}5.521 & 7.17 & 1.65 & 5.78 & 4.13 & 1.65 & 6.27 & 8.15 & -1.89 \\ 7.367 & 8.25 & 2.88 & 7.39 & 4.50 & 2.88 & 7.10 & 7.87 & -0.77\end{array}$ $\begin{array}{llllllllll}7.325 & 8.22 & 0.89 & 7.34 & 6.45 & 0.89 & 7.08 & 11.47 & -4.39\end{array}$ $\begin{array}{lllllllll}6.427 & 8.56 & 2.13 & 7.85 & 5.72 & 2.13 & 7.34 & 9.82 & -2.48\end{array}$ $\begin{array}{llllllllll}6.01 & 7.39 & 1.38 & 6.10 & 4.72 & 1.38 & 6.44 & 9.05 & -2.61\end{array}$ $\begin{array}{lllllllll}5.895 & 8.56 & 2.66 & 7.85 & 5.19 & 2.66 & 7.34 & 8.84 & -1.50\end{array}$ $\begin{array}{lllllllll}6.342 & 7.77 & 1.43 & 6.67 & 5.24 & 1.43 & 6.73 & 9.66 & -2.93\end{array}$ $\begin{array}{llllllllll}4.811 & 7.93 & 3.12 & 6.91 & 3.79 & 3.12 & 6.85 & 6.85 & 0.00\end{array}$ $\begin{array}{lllllllll}4.969 & 6.85 & 1.88 & 5.30 & 3.42 & 1.88 & 6.02 & 7.14 & -1.12\end{array}$ $\begin{array}{lllllllll}7.355 & 8 & 0.64 & 7.01 & 6.37 & 0.64 & 6.91 & 11.52 & -4.62\end{array}$ $7.102-7.48$ $\begin{array}{llllllll}-0.38 & 6.24 & 5.86 & 0.38 & 6.51 & 11.06 & -4.5\end{array}$ $\begin{array}{llllllllll}7.268 & 8.13 & 0.86 & 7.21 & 6.35 & 0.86 & 7.01 & 11.36 & -4.36\end{array}$ $\begin{array}{lllllllll}6.37 & 8.47 & 2.10 & 7.72 & 5.62 & 2.10 & 7.27 & 9.71 & -2.45\end{array}$ $\begin{array}{llllllll}0.11 & 6.57 & 6.46 & 0.11 & 6.68 & 11.95 & -5.28\end{array}$ $\begin{array}{llllllllll}6.116 & 7.95 & 1.83 & 6.94 & 5.11 & 1.83 & 6.87 & 9.25 & -2.38\end{array}$ $\begin{array}{llllllllll}7.189 & 8.27 & 1.08 & 7.42 & 6.34 & 1.08 & 7.11 & 11.22 & -4.10\end{array}$ $\begin{array}{llllllllll}4.393 & 6.76 & 2.37 & 5.16 & 2.80 & 2.37 & 5.95 & 6.08 & -0.13\end{array}$ $\begin{array}{lllllllll}6.7 & 7.83 & 1.13 & 6.76 & 5.63 & 1.13 & 6.78 & 10.32 & -3.54\end{array}$ $\begin{array}{lllllllll}6.887 & 8.47 & 1.58 & 7.72 & 6.13 & 1.58 & 7.27 & 10.66 & -3.40\end{array}$ $\begin{array}{llllllllll}7.044 & 7.39 & 0.35 & 6.10 & 5.76 & 0.35 & 6.44 & 10.95 & -4.51\end{array}$ $\begin{array}{lllllllll}6.633 & 7.95 & 1.32 & 6.94 & 5.62 & 1.32 & 6.87 & 10.20 & -3.33\end{array}$ $\begin{array}{lllllllll}4.578 & 6.38 & 1.80 & 4.60 & 2.80 & 1.80 & 5.66 & 6.42 & -0.76\end{array}$ $\begin{array}{llllllllll}7.121 & 8.17 & 1.05 & 7.27 & 6.22 & 1.05 & 7.04 & 11.09 & -4.06\end{array}$ $\begin{array}{lllllll}2.29 & 6.57 & 4.28 & 2.29 & 6.68 & 7.96 & -1.28\end{array}$ $7.453-7.75$ $\begin{array}{llllllll}1.53 & 8.13 & 6.60 & 1.53 & 7.48 & 11.27 & -3.78\end{array}$ $\begin{array}{lllllllll}4.832 & 6.9 & 2.07 & 5.37 & 3.31 & 2.07 & 6.06 & 6.89 & -0.83\end{array}$ $\begin{array}{lllllllll}5.728 & 6.56 & 0.83 & 4.87 & 4.03 & 0.83 & 5.80 & 8.53 & -2.73\end{array}$ $\begin{array}{lllllll}1.28 & 5.60 & 4.31 & 1.28 & 6.18 & 8.60 & -2.43\end{array}$ $\begin{array}{llllllllll}7.402 & 7.45 & 0.05 & 6.19 & 6.15 & 0.05 & 6.48 & 11.61 & -5.13\end{array}$ $\begin{array}{llllllllll}7.402 & 7.45 & 0.05 & 6.19 & 6.15 & 0.05 & 6.48 & 11.61 & -5.13 \\ 6.992 & 8.01 & 1.02 & 7.03 & 6.01 & 1.02 & 6.91 & 10.86 & -3.94\end{array}$ $\begin{array}{llllllllll}6.992 & 8.01 & 1.02 & 7.03 & 6.01 & 1.02 & 6.91 & 10.86 & -3.94 \\ 6.654 & 6.92 & 0.27 & 5.40 & 5.14 & 0.27 & 6.08 & 10.24 & -4.16\end{array}$ $\begin{array}{lllllllll}5.747 & 7.25 & 1.50 & 5.90 & 4.39 & 1.50 & 6.33 & 8.57 & -2.24\end{array}$ $\begin{array}{llllllllll}6.739 & 7.49 & 0.75 & 6.25 & 5.50 & 0.75 & 6.51 & 10.39 & -3.88\end{array}$ $\begin{array}{llllllllll}6.244 & 7.48 & 1.24 & 6.24 & 5.00 & 1.24 & 6.51 & 9.48 & -2.98\end{array}$ $\begin{array}{lllllllll}6.264 & 7.25 & 0.99 & 5.90 & 4.91 & 0.99 & 6.33 & 9.52 & -3.19\end{array}$ $\begin{array}{lllllllll}6.761 & 7.48 & 0.72 & 6.24 & 5.52 & 0.72 & 6.51 & 10.43 & -3.93\end{array}$ $\begin{array}{llllllllll}5.446 & 6.65 & 1.20 & 5.00 & 3.80 & 1.20 & 5.87 & 8.02 & -2.15\end{array}$ $\begin{array}{llllllllll}7.405 & 6.62 & -0.79 & 4.96 & 5.74 & -0.79 & 5.85 & 11.61 & -5.77\end{array}$ $\begin{array}{lllllllll}6.508 & 6.96 & 0.45 & 5.46 & 5.01 & 0.45 & 6.11 & 9.97 & -3.86\end{array}$ $\begin{array}{lllllllll}5.529 & 7.22 & 1.69 & 5.85 & 4.16 & 1.69 & 6.31 & 8.17 & -1.86\end{array}$ $\begin{array}{llllllllll}6.602 & 7.54 & 0.94 & 6.33 & 5.39 & 0.94 & 6.55 & 10.14 & -3.59\end{array}$ $\begin{array}{llllllllll}6.994 & 7.18 & 0.19 & 5.79 & 5.61 & 0.19 & 6.28 & 10.86 & -4.58\end{array}$ $\begin{array}{lllllllll}5.689 & 7.16 & 1.47 & 5.76 & 4.29 & 1.47 & 6.26 & 8.46 & -2.20\end{array}$ $\begin{array}{lllllllll}6.586 & 6.82 & 0.23 & 5.25 & 5.02 & 0.23 & 6.00 & 10.11 & -4.11\end{array}$ $\begin{array}{lllllllll}6.553 & 7.24 & 0.69 & 5.88 & 5.19 & 0.69 & 6.32 & 10.05 & -3.73\end{array}$ $\begin{array}{lllllllll}6.86 & 6.31 & -0.55 & 4.49 & 5.04 & -0.55 & 5.61 & 10.61 & -5.01\end{array}$ $\begin{array}{lllllllll}7.19 & 7.61 & 0.42 & 6.43 & 6.01 & 0.42 & 6.61 & 11.22 & -4.61\end{array}$ $\begin{array}{lllllllll}4.663 & 6.32 & 1.66 & 4.51 & 2.85 & 1.66 & 5.62 & 6.58 & -0.96\end{array}$ $\begin{array}{lllllllll}6.544 & 7.45 & 0.91 & 6.19 & 5.29 & 0.91 & 6.48 & 10.03 & -3.5\end{array}$ $\begin{array}{llllllllll}4.898 & 7.04 & 2.14 & 5.58 & 3.44 & 2.14 & 6.17 & 7.01 & -0.84\end{array}$ $\begin{array}{lllllllll}6.197 & 6.35 & 0.15 & 4.55 & 4.40 & 0.15 & 5.64 & 9.40 & -3.76\end{array}$ 
Formula

$\mathrm{C}(\mathrm{C}(\mathrm{C}(\mathrm{C}(\mathrm{C}(\mathrm{C}(\mathrm{C}(\mathrm{C}(\mathrm{C}(\mathrm{C}(\mathrm{C}(\mathrm{H})(\mathrm{H}) \mathrm{Cl})(\mathrm{H}) \mathrm{Cl})(\mathrm{H}) \mathrm{F})(\mathrm{H}) \mathrm{H})(\mathrm{F}) \mathrm{H})(\mathrm{F}) \mathrm{H})(\mathrm{Cl}) \mathrm{H})(\mathrm{H}) \mathrm{F})(\mathrm{H}) \mathrm{H})(\mathrm{H}) \mathrm{H})(\mathrm{H})(\mathrm{F}) \mathrm{Cl}$ $\mathrm{C}(\mathrm{C}(\mathrm{C}(\mathrm{C}(\mathrm{C}(\mathrm{C}(\mathrm{C}(\mathrm{C}(\mathrm{C}(\mathrm{C}(\mathrm{C}(\mathrm{Cl})(\mathrm{Cl}) \mathrm{Cl})(\mathrm{H}) \mathrm{H})(\mathrm{H}) \mathrm{H})(\mathrm{H}) \mathrm{H})(\mathrm{H}) \mathrm{Cl})(\mathrm{H}) \mathrm{F})(\mathrm{F}) \mathrm{H})(\mathrm{H}) \mathrm{Cl})(\mathrm{Cl}) \mathrm{H})(\mathrm{H}) \mathrm{H})(\mathrm{H})(\mathrm{F}) \mathrm{H}$ $\mathrm{C}(\mathrm{C}(\mathrm{C}(\mathrm{C}(\mathrm{C}(\mathrm{C}(\mathrm{C}(\mathrm{C}(\mathrm{C}(\mathrm{C}(\mathrm{C}(\mathrm{H})(\mathrm{H}) \mathrm{F})(\mathrm{H}) \mathrm{H})(\mathrm{H}) \mathrm{F})(\mathrm{H}) \mathrm{Br})(\mathrm{H}) \mathrm{Br})(\mathrm{H}) \mathrm{F})(\mathrm{Cl}) \mathrm{H})(\mathrm{H}) \mathrm{H})(\mathrm{F}) \mathrm{H})(\mathrm{H}) \mathrm{F})(\mathrm{H})(\mathrm{F}) \mathrm{H}$ $\mathrm{C}(\mathrm{C}(\mathrm{C}(\mathrm{C}(\mathrm{C}(\mathrm{C}(\mathrm{C}(\mathrm{C}(\mathrm{C}(\mathrm{C}(\mathrm{C}(\mathrm{H})(\mathrm{H}) \mathrm{Cl})(\mathrm{Br}) \mathrm{H})(\mathrm{H}) \mathrm{F})(\mathrm{Br}) \mathrm{H})(\mathrm{H}) \mathrm{H})(\mathrm{H}) \mathrm{H})(\mathrm{H}) \mathrm{F})(\mathrm{Br}) \mathrm{F})(\mathrm{F}) \mathrm{H})(\mathrm{H}) \mathrm{H})(\mathrm{F})(\mathrm{H}) \mathrm{H}$ $\mathrm{C}(\mathrm{C}(\mathrm{C}(\mathrm{C}(\mathrm{C}(\mathrm{C}(\mathrm{C}(\mathrm{C}(\mathrm{C}(\mathrm{C}(\mathrm{C}(\mathrm{H})(\mathrm{H}) \mathrm{H})(\mathrm{H}) \mathrm{H})(\mathrm{H}) \mathrm{F})(\mathrm{H}) \mathrm{Br})(\mathrm{F}) \mathrm{F})(\mathrm{Br}) \mathrm{H})(\mathrm{F}) \mathrm{H})(\mathrm{Br}) \mathrm{H})(\mathrm{H}) \mathrm{H})(\mathrm{H}) \mathrm{H})(\mathrm{H})(\mathrm{H}) \mathrm{F}$ $\mathrm{C}(\mathrm{C}(\mathrm{C}(\mathrm{C}(\mathrm{C}(\mathrm{C}(\mathrm{C}(\mathrm{C}(\mathrm{C}(\mathrm{C}(\mathrm{C}(\mathrm{H})(\mathrm{H}) \mathrm{H})(\mathrm{F}) \mathrm{H})(\mathrm{H}) \mathrm{Cl})(\mathrm{H}) \mathrm{F})(\mathrm{Br}) \mathrm{H})(\mathrm{H}) \mathrm{H})(\mathrm{F}) \mathrm{H})(\mathrm{H}) \mathrm{Br})(\mathrm{H}) \mathrm{H})(\mathrm{Cl}) \mathrm{H})(\mathrm{H})(\mathrm{F})$ $\mathrm{C}(\mathrm{C}(\mathrm{C}(\mathrm{C}(\mathrm{C}(\mathrm{C}(\mathrm{C}(\mathrm{C}(\mathrm{C}(\mathrm{C}(\mathrm{C}(\mathrm{H})(\mathrm{H}) \mathrm{F})(\mathrm{H}) \mathrm{Cl})(\mathrm{H}) \mathrm{F})(\mathrm{Cl}) \mathrm{H})(\mathrm{H}) \mathrm{H})(\mathrm{H}) \mathrm{H})(\mathrm{H}) \mathrm{H})(\mathrm{H}) \mathrm{H})(\mathrm{F}) \mathrm{F})(\mathrm{H}) \mathrm{H})(\mathrm{H})(\mathrm{Br}) \mathrm{F}$ $\mathrm{C}(\mathrm{C}(\mathrm{C}(\mathrm{C}(\mathrm{C}(\mathrm{C}(\mathrm{C}(\mathrm{C}(\mathrm{C}(\mathrm{C}(\mathrm{C}(\mathrm{Cl})(\mathrm{Cl}) \mathrm{H})(\mathrm{H}) \mathrm{H})(\mathrm{H}) \mathrm{H})(\mathrm{H}) \mathrm{H})(\mathrm{H}) \mathrm{Br})(\mathrm{H}) \mathrm{H})(\mathrm{H}) \mathrm{H})(\mathrm{H}) \mathrm{F})(\mathrm{F}) \mathrm{H})(\mathrm{Cl}) \mathrm{H})(\mathrm{F})(\mathrm{H}) \mathrm{B}$ $\mathrm{C}(\mathrm{C}(\mathrm{C}(\mathrm{C}(\mathrm{C}(\mathrm{C}(\mathrm{C}(\mathrm{C}(\mathrm{C}(\mathrm{C}(\mathrm{C}(\mathrm{H})(\mathrm{H}) \mathrm{F})(\mathrm{H}) \mathrm{Cl})(\mathrm{F}) \mathrm{H})(\mathrm{H}) \mathrm{Cl})(\mathrm{H}) \mathrm{H})(\mathrm{Cl}) \mathrm{Br})(\mathrm{H}) \mathrm{H})(\mathrm{H}) \mathrm{H})(\mathrm{H}) \mathrm{H})(\mathrm{F}) \mathrm{H})(\mathrm{H})(\mathrm{F}) \mathrm{H}$ $\mathrm{C}(\mathrm{C}(\mathrm{C}(\mathrm{C}(\mathrm{C}(\mathrm{C}(\mathrm{C}(\mathrm{C}(\mathrm{C}(\mathrm{C}(\mathrm{C}(\mathrm{F})(\mathrm{H}) \mathrm{H})(\mathrm{F}) \mathrm{H})(\mathrm{H}) \mathrm{Cl})(\mathrm{F}) \mathrm{H})(\mathrm{H}) \mathrm{F})(\mathrm{H}) \mathrm{H})(\mathrm{H}) \mathrm{H})(\mathrm{F}) \mathrm{H})(\mathrm{Cl}) \mathrm{Cl})(\mathrm{H}) \mathrm{H})(\mathrm{H})(\mathrm{H}) \mathrm{H}$ $\mathrm{C}(\mathrm{C}(\mathrm{C}(\mathrm{C}(\mathrm{C}(\mathrm{C}(\mathrm{C}(\mathrm{C}(\mathrm{C}(\mathrm{C}(\mathrm{C}(\mathrm{Cl})(\mathrm{Cl}) \mathrm{H})(\mathrm{H}) \mathrm{H})(\mathrm{H}) \mathrm{H})(\mathrm{H}) \mathrm{H})(\mathrm{H}) \mathrm{H})(\mathrm{H}) \mathrm{H})(\mathrm{F}) \mathrm{Cl})(\mathrm{H}) \mathrm{Cl})(\mathrm{H}) \mathrm{F})(\mathrm{F}) \mathrm{F})(\mathrm{H})(\mathrm{H}) \mathrm{H}$ $\mathrm{C}(\mathrm{C}(\mathrm{C}(\mathrm{C}(\mathrm{C}(\mathrm{C}(\mathrm{C}(\mathrm{C}(\mathrm{C}(\mathrm{C}(\mathrm{C}(\mathrm{H})(\mathrm{Cl}) \mathrm{Cl})(\mathrm{Cl}) \mathrm{H})(\mathrm{H}) \mathrm{H})(\mathrm{H}) \mathrm{F})(\mathrm{H}) \mathrm{H})(\mathrm{H}) \mathrm{Cl})(\mathrm{H}) \mathrm{H})(\mathrm{H}) \mathrm{H})(\mathrm{Cl}) \mathrm{F})(\mathrm{H}) \mathrm{H})(\mathrm{H})(\mathrm{H})$ $\mathrm{C}(\mathrm{C}(\mathrm{C}(\mathrm{C}(\mathrm{C}(\mathrm{C}(\mathrm{C}(\mathrm{C}(\mathrm{C}(\mathrm{C}(\mathrm{C}(\mathrm{H})(\mathrm{H}) \mathrm{F})(\mathrm{H}) \mathrm{H})(\mathrm{F}) \mathrm{F})(\mathrm{Br}) \mathrm{H})(\mathrm{H}) \mathrm{H})(\mathrm{H}) \mathrm{H})(\mathrm{H}) \mathrm{H})(\mathrm{Br}) \mathrm{F})(\mathrm{H}) \mathrm{Cl})(\mathrm{H}) \mathrm{H})(\mathrm{F})(\mathrm{H}) \mathrm{H}$ $\mathrm{C}(\mathrm{C}(\mathrm{C}(\mathrm{C}(\mathrm{C}(\mathrm{C}(\mathrm{C}(\mathrm{C}(\mathrm{C}(\mathrm{C}(\mathrm{C}(\mathrm{H})(\mathrm{H}) \mathrm{H})(\mathrm{H}) \mathrm{Br})(\mathrm{H}) \mathrm{H})(\mathrm{Br}) \mathrm{H})(\mathrm{H}) \mathrm{F})(\mathrm{Cl}) \mathrm{F})(\mathrm{H}) \mathrm{H})(\mathrm{H}) \mathrm{F})(\mathrm{H}) \mathrm{H})(\mathrm{H}) \mathrm{H})(\mathrm{Br})(\mathrm{F}) \mathrm{H}$ $\mathrm{C}(\mathrm{C}(\mathrm{C}(\mathrm{C}(\mathrm{C}(\mathrm{C}(\mathrm{C}(\mathrm{C}(\mathrm{C}(\mathrm{C}(\mathrm{C}(\mathrm{F})(\mathrm{F}) \mathrm{F})(\mathrm{H}) \mathrm{F})(\mathrm{H}) \mathrm{H})(\mathrm{H}) \mathrm{H})(\mathrm{H}) \mathrm{H})(\mathrm{Cl}) \mathrm{H})(\mathrm{F}) \mathrm{Br})(\mathrm{H}) \mathrm{H})(\mathrm{H}) \mathrm{H})(\mathrm{H}) \mathrm{H})(\mathrm{H})(\mathrm{F}) \mathrm{H}$ $\mathrm{C}(\mathrm{C}(\mathrm{C}(\mathrm{C}(\mathrm{C}(\mathrm{C}(\mathrm{C}(\mathrm{C}(\mathrm{C}(\mathrm{C}(\mathrm{C}(\mathrm{F})(\mathrm{H}) \mathrm{H})(\mathrm{F}) \mathrm{H})(\mathrm{H}) \mathrm{H})(\mathrm{F}) \mathrm{F})(\mathrm{H}) \mathrm{H})(\mathrm{H}) \mathrm{Br})(\mathrm{H}) \mathrm{H})(\mathrm{H}) \mathrm{H})(\mathrm{H}) \mathrm{Br})(\mathrm{H}) \mathrm{H})(\mathrm{H})(\mathrm{F}) \mathrm{H}$ $\mathrm{C}(\mathrm{C}(\mathrm{C}(\mathrm{C}(\mathrm{C}(\mathrm{C}(\mathrm{C}(\mathrm{C}(\mathrm{C}(\mathrm{C}(\mathrm{C}(\mathrm{H})(\mathrm{H}) \mathrm{H})(\mathrm{H}) \mathrm{Br})(\mathrm{H}) \mathrm{H})(\mathrm{H}) \mathrm{Br})(\mathrm{F}) \mathrm{H})(\mathrm{H}) \mathrm{H})(\mathrm{H}) \mathrm{F})(\mathrm{F}) \mathrm{H})(\mathrm{H}) \mathrm{Br})(\mathrm{H}) \mathrm{F})(\mathrm{H})(\mathrm{H}) \mathrm{H}$ $\mathrm{C}(\mathrm{C}(\mathrm{C}(\mathrm{C}(\mathrm{C}(\mathrm{C}(\mathrm{C}(\mathrm{C}(\mathrm{C}(\mathrm{C}(\mathrm{C}(\mathrm{H})(\mathrm{H}) \mathrm{H})(\mathrm{H}) \mathrm{Br})(\mathrm{H}) \mathrm{H})(\mathrm{H}) \mathrm{H})(\mathrm{H}) \mathrm{H})(\mathrm{H}) \mathrm{H})(\mathrm{F}) \mathrm{F})(\mathrm{H}) \mathrm{Cl})(\mathrm{H}) \mathrm{Cl})(\mathrm{F}) \mathrm{H})(\mathrm{H})(\mathrm{H}) \mathrm{B}$ $\mathrm{C}(\mathrm{C}(\mathrm{C}(\mathrm{C}(\mathrm{C}(\mathrm{C}(\mathrm{C}(\mathrm{C}(\mathrm{C}(\mathrm{C}(\mathrm{C}(\mathrm{H})(\mathrm{H}) \mathrm{H})(\mathrm{H}) \mathrm{H})(\mathrm{H}) \mathrm{H})(\mathrm{H}) \mathrm{H})(\mathrm{H}) \mathrm{Cl})(\mathrm{F}) \mathrm{Cl})(\mathrm{H}) \mathrm{H})(\mathrm{Br}) \mathrm{H})(\mathrm{H}) \mathrm{H})(\mathrm{F}) \mathrm{H})(\mathrm{H})(\mathrm{F}) \mathrm{F}$ $\mathrm{C}(\mathrm{C}(\mathrm{C}(\mathrm{C}(\mathrm{C}(\mathrm{C}(\mathrm{C}(\mathrm{C}(\mathrm{C}(\mathrm{C}(\mathrm{C}(\mathrm{H})(\mathrm{H}) \mathrm{H})(\mathrm{H}) \mathrm{H})(\mathrm{H}) \mathrm{Br})(\mathrm{H}) \mathrm{F})(\mathrm{H}) \mathrm{Cl})(\mathrm{H}) \mathrm{H})(\mathrm{H}) \mathrm{H})(\mathrm{H}) \mathrm{H})(\mathrm{Cl}) \mathrm{F})(\mathrm{Cl}) \mathrm{F})(\mathrm{H})(\mathrm{H}) \mathrm{H}$ $\mathrm{C}(\mathrm{C}(\mathrm{C}(\mathrm{C}(\mathrm{C}(\mathrm{C}(\mathrm{C}(\mathrm{C}(\mathrm{C}(\mathrm{C}(\mathrm{C}(\mathrm{H})(\mathrm{F}) \mathrm{F})(\mathrm{H}) \mathrm{Cl})(\mathrm{H}) \mathrm{H})(\mathrm{H}) \mathrm{H})(\mathrm{H}) \mathrm{Cl})(\mathrm{H}) \mathrm{H})(\mathrm{H}) \mathrm{H})(\mathrm{H}) \mathrm{H})(\mathrm{H}) \mathrm{H})(\mathrm{H}) \mathrm{Cl})(\mathrm{F})(\mathrm{F}) \mathrm{H}$ $\mathrm{C}(\mathrm{C}(\mathrm{C}(\mathrm{C}(\mathrm{C}(\mathrm{C}(\mathrm{C}(\mathrm{C}(\mathrm{C}(\mathrm{C}(\mathrm{C}(\mathrm{H})(\mathrm{H}) \mathrm{F})(\mathrm{H}) \mathrm{H})(\mathrm{H}) \mathrm{H})(\mathrm{Br}) \mathrm{H})(\mathrm{H}) \mathrm{H})(\mathrm{H}) \mathrm{H})(\mathrm{Cl}) \mathrm{H})(\mathrm{H}) \mathrm{Cl})(\mathrm{Cl}) \mathrm{H})(\mathrm{H}) \mathrm{Cl})(\mathrm{F})(\mathrm{H}) \mathrm{H}$ $\mathrm{C}(\mathrm{C}(\mathrm{C}(\mathrm{C}(\mathrm{C}(\mathrm{C}(\mathrm{C}(\mathrm{C}(\mathrm{C}(\mathrm{C}(\mathrm{C}(\mathrm{H})(\mathrm{Cl}) \mathrm{H})(\mathrm{H}) \mathrm{F})(\mathrm{Cl}) \mathrm{H})(\mathrm{H}) \mathrm{H})(\mathrm{H}) \mathrm{Cl})(\mathrm{H}) \mathrm{H})(\mathrm{H}) \mathrm{F})(\mathrm{F}) \mathrm{H})(\mathrm{H}) \mathrm{H})(\mathrm{H}) \mathrm{H})(\mathrm{H})(\mathrm{Cl}) \mathrm{H}$ $\mathrm{C}(\mathrm{C}(\mathrm{C}(\mathrm{C}(\mathrm{C}(\mathrm{C}(\mathrm{C}(\mathrm{C}(\mathrm{C}(\mathrm{C}(\mathrm{C}(\mathrm{H})(\mathrm{H}) \mathrm{Cl})(\mathrm{H}) \mathrm{Cl})(\mathrm{H}) \mathrm{H})(\mathrm{H}) \mathrm{H})(\mathrm{H}) \mathrm{H})(\mathrm{H}) \mathrm{H})(\mathrm{H}) \mathrm{H})(\mathrm{H}) \mathrm{Cl})(\mathrm{F}) \mathrm{H})(\mathrm{F}) \mathrm{H})(\mathrm{Cl})(\mathrm{H}) \mathrm{Cl}$ $\mathrm{C}(\mathrm{C}(\mathrm{C}(\mathrm{C}(\mathrm{C}(\mathrm{C}(\mathrm{C}(\mathrm{C}(\mathrm{C}(\mathrm{C}(\mathrm{C}(\mathrm{H})(\mathrm{Br}) \mathrm{Cl})(\mathrm{Br}) \mathrm{H})(\mathrm{F}) \mathrm{H})(\mathrm{H}) \mathrm{H})(\mathrm{H}) \mathrm{F})(\mathrm{H}) \mathrm{H})(\mathrm{H}) \mathrm{H})(\mathrm{H}) \mathrm{H})(\mathrm{F}) \mathrm{F})(\mathrm{H}) \mathrm{H})(\mathrm{H})(\mathrm{H}) \mathrm{H}$ $\mathrm{C}(\mathrm{C}(\mathrm{C}(\mathrm{C}(\mathrm{C}(\mathrm{C}(\mathrm{C}(\mathrm{C}(\mathrm{C}(\mathrm{C}(\mathrm{C}(\mathrm{H})(\mathrm{H}) \mathrm{H})(\mathrm{F}) \mathrm{F})(\mathrm{H}) \mathrm{H})(\mathrm{H}) \mathrm{Cl})(\mathrm{H}) \mathrm{F})(\mathrm{Br}) \mathrm{F})(\mathrm{H}) \mathrm{H})(\mathrm{H}) \mathrm{H})(\mathrm{H}) \mathrm{H})(\mathrm{H}) \mathrm{F})(\mathrm{H})(\mathrm{H}) \mathrm{H}$ $\mathrm{C}(\mathrm{C}(\mathrm{C}(\mathrm{C}(\mathrm{C}(\mathrm{C}(\mathrm{C}(\mathrm{C}(\mathrm{C}(\mathrm{C}(\mathrm{C}(\mathrm{H})(\mathrm{H}) \mathrm{Br})(\mathrm{H}) \mathrm{H})(\mathrm{H}) \mathrm{F})(\mathrm{H}) \mathrm{H})(\mathrm{H}) \mathrm{H})(\mathrm{H}) \mathrm{H})(\mathrm{F}) \mathrm{H})(\mathrm{H}) \mathrm{H})(\mathrm{F}) \mathrm{Br})(\mathrm{F}) \mathrm{H})(\mathrm{H})(\mathrm{H}) \mathrm{H}$ $\mathrm{C}(\mathrm{C}(\mathrm{C}(\mathrm{C}(\mathrm{C}(\mathrm{C}(\mathrm{C}(\mathrm{C}(\mathrm{C}(\mathrm{C}(\mathrm{C}(\mathrm{F})(\mathrm{H}) \mathrm{H})(\mathrm{H}) \mathrm{H})(\mathrm{H}) \mathrm{H})(\mathrm{H}) \mathrm{H})(\mathrm{H}) \mathrm{H})(\mathrm{Br}) \mathrm{H})(\mathrm{H}) \mathrm{H})(\mathrm{H}) \mathrm{F})(\mathrm{H}) \mathrm{H})(\mathrm{H}) \mathrm{F})(\mathrm{Br})(\mathrm{H}) \mathrm{Br}$ $\mathrm{C}(\mathrm{C}(\mathrm{C}(\mathrm{C}(\mathrm{C}(\mathrm{C}(\mathrm{C}(\mathrm{C}(\mathrm{C}(\mathrm{C}(\mathrm{C}(\mathrm{H})(\mathrm{H}) \mathrm{H})(\mathrm{H}) \mathrm{H})(\mathrm{H}) \mathrm{H})(\mathrm{H}) \mathrm{H})(\mathrm{Br}) \mathrm{H})(\mathrm{F}) \mathrm{H})(\mathrm{Cl}) \mathrm{H})(\mathrm{H}) \mathrm{H})(\mathrm{H}) \mathrm{H})(\mathrm{H}) \mathrm{F})(\mathrm{Br})(\mathrm{H}) \mathrm{Cl}$ $\mathrm{C}(\mathrm{C}(\mathrm{C}(\mathrm{C}(\mathrm{C}(\mathrm{C}(\mathrm{C}(\mathrm{C}(\mathrm{C}(\mathrm{C}(\mathrm{C}(\mathrm{H})(\mathrm{H}) \mathrm{F})(\mathrm{H}) \mathrm{H})(\mathrm{H}) \mathrm{Cl})(\mathrm{H}) \mathrm{H})(\mathrm{H}) \mathrm{H})(\mathrm{H}) \mathrm{H})(\mathrm{Br}) \mathrm{H})(\mathrm{H}) \mathrm{H})(\mathrm{H}) \mathrm{F})(\mathrm{H}) \mathrm{H})(\mathrm{Cl})(\mathrm{H}) \mathrm{F}$ $\mathrm{C}(\mathrm{C}(\mathrm{C}(\mathrm{C}(\mathrm{C}(\mathrm{C}(\mathrm{C}(\mathrm{C}(\mathrm{C}(\mathrm{C}(\mathrm{C}(\mathrm{H})(\mathrm{H}) \mathrm{H})(\mathrm{H}) \mathrm{H})(\mathrm{Cl}) \mathrm{F})(\mathrm{H}) \mathrm{H})(\mathrm{F}) \mathrm{H})(\mathrm{H}) \mathrm{H})(\mathrm{F}) \mathrm{Cl})(\mathrm{H}) \mathrm{H})(\mathrm{H}) \mathrm{H})(\mathrm{H}) \mathrm{H})(\mathrm{F})(\mathrm{H}) \mathrm{H}$

$\mathrm{C}(\mathrm{C}(\mathrm{C}(\mathrm{C}(\mathrm{C}(\mathrm{C}(\mathrm{C}(\mathrm{C}(\mathrm{C}(\mathrm{C}(\mathrm{C}(\mathrm{H})(\mathrm{H}) \mathrm{Cl})(\mathrm{F}) \mathrm{H})(\mathrm{H}) \mathrm{H})(\mathrm{H}) \mathrm{Cl})(\mathrm{H}) \mathrm{F})(\mathrm{Br}) \mathrm{H})(\mathrm{H}) \mathrm{H})(\mathrm{H}) \mathrm{H})(\mathrm{H}) \mathrm{H})(\mathrm{H}) \mathrm{H})(\mathrm{H})(\mathrm{H}) \mathrm{Cl}$ $\mathrm{C}(\mathrm{C}(\mathrm{C}(\mathrm{C}(\mathrm{C}(\mathrm{C}(\mathrm{C}(\mathrm{C}(\mathrm{C}(\mathrm{C}(\mathrm{C}(\mathrm{F})(\mathrm{H}) \mathrm{H})(\mathrm{H}) \mathrm{H})(\mathrm{H}) \mathrm{Cl})(\mathrm{H}) \mathrm{Cl})(\mathrm{H}) \mathrm{H})(\mathrm{H}) \mathrm{H})(\mathrm{F}) \mathrm{H})(\mathrm{H}) \mathrm{F})(\mathrm{H}) \mathrm{H})(\mathrm{H}) \mathrm{H})(\mathrm{H})(\mathrm{H}) \mathrm{Cl}$ $\mathrm{C}(\mathrm{C}(\mathrm{C}(\mathrm{C}(\mathrm{C}(\mathrm{C}(\mathrm{C}(\mathrm{C}(\mathrm{C}(\mathrm{C}(\mathrm{C}(\mathrm{F})(\mathrm{H}) \mathrm{H})(\mathrm{H}) \mathrm{H})(\mathrm{H}) \mathrm{H})(\mathrm{H}) \mathrm{H})(\mathrm{H}) \mathrm{Cl})(\mathrm{H}) \mathrm{Cl})(\mathrm{H}) \mathrm{Cl})(\mathrm{H}) \mathrm{H})(\mathrm{H}) \mathrm{H})(\mathrm{H}) \mathrm{F})(\mathrm{Cl})(\mathrm{H}) \mathrm{H}$ $\mathrm{C}(\mathrm{C}(\mathrm{C}(\mathrm{C}(\mathrm{C}(\mathrm{C}(\mathrm{C}(\mathrm{C}(\mathrm{C}(\mathrm{C}(\mathrm{C}(\mathrm{H})(\mathrm{H}) \mathrm{H})(\mathrm{H}) \mathrm{H})(\mathrm{H}) \mathrm{H})(\mathrm{H}) \mathrm{H})(\mathrm{F}) \mathrm{H})(\mathrm{H}) \mathrm{Cl})(\mathrm{H}) \mathrm{Cl})(\mathrm{H}) \mathrm{Cl})(\mathrm{H}) \mathrm{Cl})(\mathrm{Cl}) \mathrm{H})(\mathrm{H})(\mathrm{H}) \mathrm{H}$ $\mathrm{C}(\mathrm{C}(\mathrm{C}(\mathrm{C}(\mathrm{C}(\mathrm{C}(\mathrm{C}(\mathrm{C}(\mathrm{C}(\mathrm{C}(\mathrm{C}(\mathrm{Cl})(\mathrm{H}) \mathrm{H})(\mathrm{H}) \mathrm{H})(\mathrm{H}) \mathrm{H})(\mathrm{H}) \mathrm{H})(\mathrm{H}) \mathrm{Br})(\mathrm{F}) \mathrm{H})(\mathrm{H}) \mathrm{H})(\mathrm{H}) \mathrm{Br})(\mathrm{H}) \mathrm{H})(\mathrm{F}) \mathrm{H})(\mathrm{F})(\mathrm{H}) \mathrm{H}$ $\mathrm{C}(\mathrm{C}(\mathrm{C}(\mathrm{C}(\mathrm{C}(\mathrm{C}(\mathrm{C}(\mathrm{C}(\mathrm{C}(\mathrm{C}(\mathrm{C}(\mathrm{H})(\mathrm{H}) \mathrm{F})(\mathrm{H}) \mathrm{H})(\mathrm{H}) \mathrm{H})(\mathrm{H}) \mathrm{Br})(\mathrm{H}) \mathrm{H})(\mathrm{H}) \mathrm{H})(\mathrm{H}) \mathrm{H})(\mathrm{F}) \mathrm{Br})(\mathrm{H}) \mathrm{F})(\mathrm{H}) \mathrm{H})(\mathrm{H})(\mathrm{H}) \mathrm{H}$ $\mathrm{C}(\mathrm{C}(\mathrm{C}(\mathrm{C}(\mathrm{C}(\mathrm{C}(\mathrm{C}(\mathrm{C}(\mathrm{C}(\mathrm{C}(\mathrm{C}(\mathrm{H})(\mathrm{Br}) \mathrm{H})(\mathrm{H}) \mathrm{H})(\mathrm{F}) \mathrm{H})(\mathrm{H}) \mathrm{Br})(\mathrm{F}) \mathrm{H})(\mathrm{H}) \mathrm{H})(\mathrm{H}) \mathrm{H})(\mathrm{H}) \mathrm{Br})(\mathrm{H}) \mathrm{H})(\mathrm{H}) \mathrm{H})(\mathrm{H})(\mathrm{H}) \mathrm{H}$ $\mathrm{C}(\mathrm{C}(\mathrm{C}(\mathrm{C}(\mathrm{C}(\mathrm{C}(\mathrm{C}(\mathrm{C}(\mathrm{C}(\mathrm{C}(\mathrm{C}(\mathrm{H})(\mathrm{H}) \mathrm{H})(\mathrm{H}) \mathrm{H})(\mathrm{H}) \mathrm{H})(\mathrm{Br}) \mathrm{H})(\mathrm{H}) \mathrm{F})(\mathrm{Br}) \mathrm{H})(\mathrm{H}) \mathrm{H})(\mathrm{H}) \mathrm{H})(\mathrm{Cl}) \mathrm{H})(\mathrm{H}) \mathrm{H})(\mathrm{H})(\mathrm{H}) \mathrm{Cl}$ $\mathrm{C}(\mathrm{C}(\mathrm{C}(\mathrm{C}(\mathrm{C}(\mathrm{C}(\mathrm{C}(\mathrm{C}(\mathrm{C}(\mathrm{C}(\mathrm{C}(\mathrm{H})(\mathrm{H}) \mathrm{F})(\mathrm{H}) \mathrm{H})(\mathrm{H}) \mathrm{H})(\mathrm{H}) \mathrm{H})(\mathrm{H}) \mathrm{H})(\mathrm{Br}) \mathrm{H})(\mathrm{H}) \mathrm{Cl})(\mathrm{H}) \mathrm{H})(\mathrm{H}) \mathrm{H})(\mathrm{H}) \mathrm{H})(\mathrm{Cl})(\mathrm{H}) \mathrm{F}$ $\mathrm{C}(\mathrm{C}(\mathrm{C}(\mathrm{C}(\mathrm{C}(\mathrm{C}(\mathrm{C}(\mathrm{C}(\mathrm{C}(\mathrm{C}(\mathrm{C}(\mathrm{H})(\mathrm{H}) \mathrm{Cl})(\mathrm{H}) \mathrm{H})(\mathrm{Br}) \mathrm{H})(\mathrm{F}) \mathrm{H})(\mathrm{H}) \mathrm{H})(\mathrm{H}) \mathrm{H})(\mathrm{Cl}) \mathrm{H})(\mathrm{H}) \mathrm{H})(\mathrm{H}) \mathrm{H})(\mathrm{H}) \mathrm{H})(\mathrm{Cl})(\mathrm{H}) \mathrm{H}$ $\mathrm{C}(\mathrm{C}(\mathrm{C}(\mathrm{C}(\mathrm{C}(\mathrm{C}(\mathrm{C}(\mathrm{C}(\mathrm{C}(\mathrm{C}(\mathrm{C}(\mathrm{H})(\mathrm{Cl}) \mathrm{H})(\mathrm{H}) \mathrm{F})(\mathrm{H}) \mathrm{H})(\mathrm{H}) \mathrm{H})(\mathrm{H}) \mathrm{H})(\mathrm{H}) \mathrm{H})(\mathrm{H}) \mathrm{F})(\mathrm{H}) \mathrm{Cl})(\mathrm{H}) \mathrm{H})(\mathrm{Cl}) \mathrm{H})(\mathrm{H})(\mathrm{H}) \mathrm{H}$ $\mathrm{C}(\mathrm{C}(\mathrm{C}(\mathrm{C}(\mathrm{C}(\mathrm{C}(\mathrm{C}(\mathrm{C}(\mathrm{C}(\mathrm{C}(\mathrm{C}(\mathrm{H})(\mathrm{H}) \mathrm{H})(\mathrm{Cl}) \mathrm{Cl})(\mathrm{H}) \mathrm{H})(\mathrm{H}) \mathrm{H})(\mathrm{Cl}) \mathrm{H})(\mathrm{H}) \mathrm{H})(\mathrm{H}) \mathrm{H})(\mathrm{H}) \mathrm{H})(\mathrm{H}) \mathrm{Cl})(\mathrm{H}) \mathrm{H})(\mathrm{F})(\mathrm{H}) \mathrm{H}$ $\mathrm{C}(\mathrm{C}(\mathrm{C}(\mathrm{C}(\mathrm{C}(\mathrm{C}(\mathrm{C}(\mathrm{C}(\mathrm{C}(\mathrm{C}(\mathrm{C}(\mathrm{H})(\mathrm{H}) \mathrm{Cl})(\mathrm{H}) \mathrm{H})(\mathrm{H}) \mathrm{H})(\mathrm{H}) \mathrm{H})(\mathrm{H}) \mathrm{H})(\mathrm{H}) \mathrm{H})(\mathrm{H}) \mathrm{Cl})(\mathrm{H}) \mathrm{H})(\mathrm{H}) \mathrm{Cl})(\mathrm{H}) \mathrm{H})(\mathrm{H})(\mathrm{Cl}) \mathrm{Cl}$ $\mathrm{C}(\mathrm{C}(\mathrm{C}(\mathrm{C}(\mathrm{C}(\mathrm{C}(\mathrm{C}(\mathrm{C}(\mathrm{C}(\mathrm{C}(\mathrm{C}(\mathrm{H})(\mathrm{H}) \mathrm{H})(\mathrm{H}) \mathrm{H})(\mathrm{H}) \mathrm{H})(\mathrm{H}) \mathrm{H})(\mathrm{F}) \mathrm{H})(\mathrm{H}) \mathrm{H})(\mathrm{H}) \mathrm{H})(\mathrm{H}) \mathrm{H})(\mathrm{Cl}) \mathrm{F})(\mathrm{H}) \mathrm{Br})(\mathrm{H})(\mathrm{H}) \mathrm{Br}$ $\mathrm{C}(\mathrm{C}(\mathrm{C}(\mathrm{C}(\mathrm{C}(\mathrm{C}(\mathrm{C}(\mathrm{C}(\mathrm{C}(\mathrm{C}(\mathrm{C}(\mathrm{H})(\mathrm{H}) \mathrm{F})(\mathrm{F}) \mathrm{H})(\mathrm{H}) \mathrm{H})(\mathrm{H}) \mathrm{Br})(\mathrm{H}) \mathrm{H})(\mathrm{H}) \mathrm{H})(\mathrm{H}) \mathrm{Cl})(\mathrm{H}) \mathrm{H})(\mathrm{H}) \mathrm{F})(\mathrm{H}) \mathrm{H})(\mathrm{H})(\mathrm{H}) \mathrm{H}$ $\mathrm{C}(\mathrm{C}(\mathrm{C}(\mathrm{C}(\mathrm{C}(\mathrm{C}(\mathrm{C}(\mathrm{C}(\mathrm{C}(\mathrm{C}(\mathrm{C}(\mathrm{H})(\mathrm{H}) \mathrm{H})(\mathrm{H}) \mathrm{H})(\mathrm{H}) \mathrm{H})(\mathrm{H}) \mathrm{Br})(\mathrm{H}) \mathrm{F})(\mathrm{H}) \mathrm{H})(\mathrm{H}) \mathrm{H})(\mathrm{H}) \mathrm{F})(\mathrm{Br}) \mathrm{H})(\mathrm{H}) \mathrm{H})(\mathrm{H})(\mathrm{H}) \mathrm{H}$ $\mathrm{C}(\mathrm{C}(\mathrm{C}(\mathrm{C}(\mathrm{C}(\mathrm{C}(\mathrm{C}(\mathrm{C}(\mathrm{C}(\mathrm{C}(\mathrm{C}(\mathrm{F})(\mathrm{H}) \mathrm{H})(\mathrm{H}) \mathrm{H})(\mathrm{H}) \mathrm{H})(\mathrm{H}) \mathrm{H})(\mathrm{H}) \mathrm{H})(\mathrm{Br}) \mathrm{H})(\mathrm{H}) \mathrm{H})(\mathrm{H}) \mathrm{H})(\mathrm{Br}) \mathrm{H})(\mathrm{H}) \mathrm{H})(\mathrm{H})(\mathrm{H}) \mathrm{Br}$ $\mathrm{C}(\mathrm{C}(\mathrm{C}(\mathrm{C}(\mathrm{C}(\mathrm{C}(\mathrm{C}(\mathrm{C}(\mathrm{C}(\mathrm{C}(\mathrm{C}(\mathrm{H})(\mathrm{H}) \mathrm{H})(\mathrm{H}) \mathrm{H})(\mathrm{F}) \mathrm{H})(\mathrm{H}) \mathrm{H})(\mathrm{H}) \mathrm{H})(\mathrm{H}) \mathrm{Cl})(\mathrm{H}) \mathrm{Cl})(\mathrm{H}) \mathrm{H})(\mathrm{H}) \mathrm{H})(\mathrm{H}) \mathrm{Br})(\mathrm{H})(\mathrm{H}) \mathrm{H}$ $\mathrm{C}(\mathrm{C}(\mathrm{C}(\mathrm{C}(\mathrm{C}(\mathrm{C}(\mathrm{C}(\mathrm{C}(\mathrm{C}(\mathrm{C}(\mathrm{C}(\mathrm{H})(\mathrm{H}) \mathrm{H})(\mathrm{H}) \mathrm{F})(\mathrm{H}) \mathrm{H})(\mathrm{H}) \mathrm{Cl})(\mathrm{H}) \mathrm{H})(\mathrm{H}) \mathrm{H})(\mathrm{H}) \mathrm{H})(\mathrm{H}) \mathrm{H})(\mathrm{H}) \mathrm{Cl})(\mathrm{H}) \mathrm{H})(\mathrm{H})(\mathrm{F}) \mathrm{H}$ $\mathrm{C}(\mathrm{C}(\mathrm{C}(\mathrm{C}(\mathrm{C}(\mathrm{C}(\mathrm{C}(\mathrm{C}(\mathrm{C}(\mathrm{C}(\mathrm{C}(\mathrm{H})(\mathrm{Cl}) \mathrm{H})(\mathrm{H}) \mathrm{H})(\mathrm{H}) \mathrm{H})(\mathrm{H}) \mathrm{H})(\mathrm{Cl}) \mathrm{H})(\mathrm{H}) \mathrm{Br})(\mathrm{H}) \mathrm{H})(\mathrm{H}) \mathrm{H})(\mathrm{H}) \mathrm{H})(\mathrm{H}) \mathrm{H})(\mathrm{H})(\mathrm{Cl}) \mathrm{H}$ $\mathrm{C}(\mathrm{C}(\mathrm{C}(\mathrm{C}(\mathrm{C}(\mathrm{C}(\mathrm{C}(\mathrm{C}(\mathrm{C}(\mathrm{C}(\mathrm{C}(\mathrm{H})(\mathrm{H}) \mathrm{H})(\mathrm{H}) \mathrm{H})(\mathrm{H}) \mathrm{H})(\mathrm{H}) \mathrm{H})(\mathrm{H}) \mathrm{H})(\mathrm{H}) \mathrm{Cl})(\mathrm{H}) \mathrm{H})(\mathrm{Cl}) \mathrm{H})(\mathrm{H}) \mathrm{H})(\mathrm{Cl}) \mathrm{F})(\mathrm{H})(\mathrm{H}) \mathrm{H}$ $\mathrm{C}(\mathrm{C}(\mathrm{C}(\mathrm{C}(\mathrm{C}(\mathrm{C}(\mathrm{C}(\mathrm{C}(\mathrm{C}(\mathrm{C}(\mathrm{C}(\mathrm{H})(\mathrm{H}) \mathrm{H})(\mathrm{H}) \mathrm{H})(\mathrm{H}) \mathrm{H})(\mathrm{H}) \mathrm{H})(\mathrm{H}) \mathrm{Cl})(\mathrm{H}) \mathrm{H})(\mathrm{Cl}) \mathrm{H})(\mathrm{H}) \mathrm{Cl})(\mathrm{H}) \mathrm{H})(\mathrm{H}) \mathrm{H})(\mathrm{H})(\mathrm{Cl}) \mathrm{H}$ $\mathrm{C}(\mathrm{C}(\mathrm{C}(\mathrm{C}(\mathrm{C}(\mathrm{C}(\mathrm{C}(\mathrm{C}(\mathrm{C}(\mathrm{C}(\mathrm{C}(\mathrm{Br})(\mathrm{H}) \mathrm{H})(\mathrm{H}) \mathrm{H})(\mathrm{H}) \mathrm{H})(\mathrm{H}) \mathrm{Br})(\mathrm{H}) \mathrm{H})(\mathrm{H}) \mathrm{H})(\mathrm{H}) \mathrm{H})(\mathrm{H}) \mathrm{H})(\mathrm{H}) \mathrm{Cl})(\mathrm{H}) \mathrm{F})(\mathrm{H})(\mathrm{H}) \mathrm{H}$ $\mathrm{C}(\mathrm{C}(\mathrm{C}(\mathrm{C}(\mathrm{C}(\mathrm{C}(\mathrm{C}(\mathrm{C}(\mathrm{C}(\mathrm{C}(\mathrm{C}(\mathrm{H})(\mathrm{F}) \mathrm{H})(\mathrm{H}) \mathrm{Cl})(\mathrm{H}) \mathrm{Br})(\mathrm{H}) \mathrm{H})(\mathrm{H}) \mathrm{H})(\mathrm{H}) \mathrm{H})(\mathrm{H}) \mathrm{H})(\mathrm{H}) \mathrm{H})(\mathrm{H}) \mathrm{F})(\mathrm{H}) \mathrm{H})(\mathrm{H})(\mathrm{H}) \mathrm{H}$ $\mathrm{C}(\mathrm{C}(\mathrm{C}(\mathrm{C}(\mathrm{C}(\mathrm{C}(\mathrm{C}(\mathrm{C}(\mathrm{C}(\mathrm{C}(\mathrm{C}(\mathrm{Br})(\mathrm{H}) \mathrm{Br})(\mathrm{H}) \mathrm{H})(\mathrm{H}) \mathrm{H})(\mathrm{H}) \mathrm{H})(\mathrm{H}) \mathrm{H})(\mathrm{H}) \mathrm{H})(\mathrm{H}) \mathrm{H})(\mathrm{H}) \mathrm{H})(\mathrm{H}) \mathrm{H})(\mathrm{H}) \mathrm{H})(\mathrm{H})(\mathrm{F}) \mathrm{H}$ $\mathrm{C}(\mathrm{C}(\mathrm{C}(\mathrm{C}(\mathrm{C}(\mathrm{C}(\mathrm{C}(\mathrm{C}(\mathrm{C}(\mathrm{C}(\mathrm{C}(\mathrm{H})(\mathrm{Br}) \mathrm{H})(\mathrm{H}) \mathrm{H})(\mathrm{H}) \mathrm{H})(\mathrm{F}) \mathrm{H})(\mathrm{H}) \mathrm{H})(\mathrm{H}) \mathrm{H})(\mathrm{H}) \mathrm{H})(\mathrm{H}) \mathrm{H})(\mathrm{H}) \mathrm{F})(\mathrm{H}) \mathrm{H})(\mathrm{H})(\mathrm{H}) \mathrm{H}$ $\mathrm{C}(\mathrm{C}(\mathrm{C}(\mathrm{C}(\mathrm{C}(\mathrm{C}(\mathrm{C}(\mathrm{C}(\mathrm{C}(\mathrm{C}(\mathrm{C}(\mathrm{H})(\mathrm{H}) \mathrm{H})(\mathrm{H}) \mathrm{H})(\mathrm{Cl}) \mathrm{H})(\mathrm{H}) \mathrm{H})(\mathrm{H}) \mathrm{H})(\mathrm{H}) \mathrm{H})(\mathrm{H}) \mathrm{H})(\mathrm{H}) \mathrm{H})(\mathrm{Br}) \mathrm{H})(\mathrm{H}) \mathrm{H})(\mathrm{Cl})(\mathrm{H}) \mathrm{H}$ $\mathrm{C}(\mathrm{C}(\mathrm{C}(\mathrm{C}(\mathrm{C}(\mathrm{C}(\mathrm{C}(\mathrm{C}(\mathrm{C}(\mathrm{C}(\mathrm{C}(\mathrm{H})(\mathrm{H}) \mathrm{H})(\mathrm{H}) \mathrm{H})(\mathrm{Cl}) \mathrm{H})(\mathrm{H}) \mathrm{H})(\mathrm{H}) \mathrm{H})(\mathrm{H}) \mathrm{H})(\mathrm{H}) \mathrm{H})(\mathrm{H}) \mathrm{H})(\mathrm{H}) \mathrm{H})(\mathrm{H}) \mathrm{H})(\mathrm{H})(\mathrm{Cl}) \mathrm{F}$ $\mathrm{C}(\mathrm{C}(\mathrm{C}(\mathrm{C}(\mathrm{C}(\mathrm{C}(\mathrm{C}(\mathrm{C}(\mathrm{C}(\mathrm{C}(\mathrm{C}(\mathrm{H})(\mathrm{H}) \mathrm{H})(\mathrm{H}) \mathrm{H})(\mathrm{H}) \mathrm{H})(\mathrm{H}) \mathrm{H})(\mathrm{Cl}) \mathrm{H})(\mathrm{Cl}) \mathrm{H})(\mathrm{H}) \mathrm{H})(\mathrm{H}) \mathrm{Cl})(\mathrm{H}) \mathrm{H})(\mathrm{H}) \mathrm{H})(\mathrm{H})(\mathrm{H}) \mathrm{H}$ $\mathrm{C}(\mathrm{C}(\mathrm{C}(\mathrm{C}(\mathrm{C}(\mathrm{C}(\mathrm{C}(\mathrm{C}(\mathrm{C}(\mathrm{C}(\mathrm{C}(\mathrm{Br})(\mathrm{H}) \mathrm{H})(\mathrm{H}) \mathrm{H})(\mathrm{H}) \mathrm{H})(\mathrm{Br}) \mathrm{H})(\mathrm{H}) \mathrm{H})(\mathrm{H}) \mathrm{H})(\mathrm{H}) \mathrm{H})(\mathrm{H}) \mathrm{H})(\mathrm{H}) \mathrm{H})(\mathrm{H}) \mathrm{H})(\mathrm{H})(\mathrm{Cl}) \mathrm{H}$ $\mathrm{C}(\mathrm{C}(\mathrm{C}(\mathrm{C}(\mathrm{C}(\mathrm{C}(\mathrm{C}(\mathrm{C}(\mathrm{C}(\mathrm{C}(\mathrm{C}(\mathrm{H})(\mathrm{Cl}) \mathrm{H})(\mathrm{H}) \mathrm{H})(\mathrm{H}) \mathrm{H})(\mathrm{H}) \mathrm{H})(\mathrm{H}) \mathrm{F})(\mathrm{H}) \mathrm{H})(\mathrm{H}) \mathrm{H})(\mathrm{H}) \mathrm{H})(\mathrm{Br}) \mathrm{H})(\mathrm{H}) \mathrm{H})(\mathrm{H})(\mathrm{H}) \mathrm{H}$ $\mathrm{C}(\mathrm{C}(\mathrm{C}(\mathrm{C}(\mathrm{C}(\mathrm{C}(\mathrm{C}(\mathrm{C}(\mathrm{C}(\mathrm{C}(\mathrm{C}(\mathrm{H})(\mathrm{H}) \mathrm{H})(\mathrm{H}) \mathrm{H})(\mathrm{H}) \mathrm{Br})(\mathrm{H}) \mathrm{H})(\mathrm{Br}) \mathrm{H})(\mathrm{H}) \mathrm{H})(\mathrm{H}) \mathrm{H})(\mathrm{H}) \mathrm{H})(\mathrm{H}) \mathrm{H})(\mathrm{H}) \mathrm{H})(\mathrm{H})(\mathrm{H}) \mathrm{H}$ $\mathrm{C}(\mathrm{C}(\mathrm{C}(\mathrm{C}(\mathrm{C}(\mathrm{C}(\mathrm{C}(\mathrm{C}(\mathrm{C}(\mathrm{C}(\mathrm{C}(\mathrm{H})(\mathrm{H}) \mathrm{H})(\mathrm{H}) \mathrm{H})(\mathrm{H}) \mathrm{H})(\mathrm{Br}) \mathrm{H})(\mathrm{H}) \mathrm{H})(\mathrm{H}) \mathrm{H})(\mathrm{H}) \mathrm{H})(\mathrm{H}) \mathrm{H})(\mathrm{H}) \mathrm{H})(\mathrm{F}) \mathrm{H})(\mathrm{H})(\mathrm{H}) \mathrm{H}$ $\mathrm{C}(\mathrm{C}(\mathrm{C}(\mathrm{C}(\mathrm{C}(\mathrm{C}(\mathrm{C}(\mathrm{C}(\mathrm{C}(\mathrm{C}(\mathrm{C}(\mathrm{H})(\mathrm{H}) \mathrm{H})(\mathrm{Cl}) \mathrm{H})(\mathrm{H}) \mathrm{H})(\mathrm{Cl}) \mathrm{H})(\mathrm{H}) \mathrm{H})(\mathrm{H}) \mathrm{H})(\mathrm{H}) \mathrm{H})(\mathrm{H}) \mathrm{H})(\mathrm{H}) \mathrm{H})(\mathrm{H}) \mathrm{H})(\mathrm{H})(\mathrm{H})$ $\mathrm{C}(\mathrm{C}(\mathrm{C}(\mathrm{C}(\mathrm{C}(\mathrm{C}(\mathrm{C}(\mathrm{C}(\mathrm{C}(\mathrm{C}(\mathrm{C}(\mathrm{H})(\mathrm{H}) \mathrm{H})(\mathrm{H}) \mathrm{H})(\mathrm{H}) \mathrm{H})(\mathrm{H}) \mathrm{H})(\mathrm{H}) \mathrm{H})(\mathrm{H}) \mathrm{H})(\mathrm{H}) \mathrm{Cl})(\mathrm{Br}) \mathrm{H})(\mathrm{H}) \mathrm{H})(\mathrm{H}) \mathrm{H})(\mathrm{H})(\mathrm{H}) \mathrm{H}$ $\mathrm{C}(\mathrm{C}(\mathrm{C}(\mathrm{C}(\mathrm{C}(\mathrm{C}(\mathrm{C}(\mathrm{C}(\mathrm{C}(\mathrm{C}(\mathrm{C}(\mathrm{F})(\mathrm{H}) \mathrm{H})(\mathrm{H}) \mathrm{H})(\mathrm{H}) \mathrm{H})(\mathrm{H}) \mathrm{H})(\mathrm{H}) \mathrm{H})(\mathrm{H}) \mathrm{H})(\mathrm{H}) \mathrm{H})(\mathrm{H}) \mathrm{H})(\mathrm{H}) \mathrm{H})(\mathrm{H}) \mathrm{H})(\mathrm{Cl})(\mathrm{H}) \mathrm{H}$ $\mathrm{C}(\mathrm{C}(\mathrm{C}(\mathrm{C}(\mathrm{C}(\mathrm{C}(\mathrm{C}(\mathrm{C}(\mathrm{C}(\mathrm{C}(\mathrm{C}(\mathrm{H})(\mathrm{H}) \mathrm{H})(\mathrm{H}) \mathrm{H})(\mathrm{H}) \mathrm{H})(\mathrm{H}) \mathrm{H})(\mathrm{H}) \mathrm{H})(\mathrm{H}) \mathrm{H})(\mathrm{H}) \mathrm{H})(\mathrm{Br}) \mathrm{H})(\mathrm{H}) \mathrm{H})(\mathrm{H}) \mathrm{H})(\mathrm{H})(\mathrm{H}) \mathrm{H}$ $\mathrm{C}(\mathrm{C}(\mathrm{C}(\mathrm{C}(\mathrm{C}(\mathrm{C}(\mathrm{C}(\mathrm{C}(\mathrm{C}(\mathrm{C}(\mathrm{C}(\mathrm{H})(\mathrm{H}) \mathrm{H})(\mathrm{H}) \mathrm{H})(\mathrm{H}) \mathrm{H})(\mathrm{H}) \mathrm{H})(\mathrm{H}) \mathrm{H})(\mathrm{H}) \mathrm{H})(\mathrm{H}) \mathrm{Cl})(\mathrm{H}) \mathrm{H})(\mathrm{H}) \mathrm{H})(\mathrm{H}) \mathrm{H})(\mathrm{H})(\mathrm{H}) \mathrm{H}$ $\mathrm{C}(\mathrm{C}(\mathrm{C}(\mathrm{C}(\mathrm{C}(\mathrm{C}(\mathrm{C}(\mathrm{C}(\mathrm{C}(\mathrm{C}(\mathrm{C}(\mathrm{H})(\mathrm{H}) \mathrm{H})(\mathrm{H}) \mathrm{H})(\mathrm{H}) \mathrm{H})(\mathrm{H}) \mathrm{H})(\mathrm{H}) \mathrm{H})(\mathrm{H}) \mathrm{H})(\mathrm{H}) \mathrm{H})(\mathrm{H}) \mathrm{H})(\mathrm{H}) \mathrm{H})(\mathrm{H}) \mathrm{H})(\mathrm{F})(\mathrm{H}) \mathrm{H}$ $\mathrm{C}(\mathrm{C}(\mathrm{C}(\mathrm{C}(\mathrm{C}(\mathrm{C}(\mathrm{C}(\mathrm{C}(\mathrm{C}(\mathrm{C}(\mathrm{C}(\mathrm{F})(\mathrm{H}) \mathrm{F})(\mathrm{F}) \mathrm{F})(\mathrm{Br}) \mathrm{F})(\mathrm{Br}) \mathrm{H})(\mathrm{H}) \mathrm{F})(\mathrm{F}) \mathrm{F})(\mathrm{F}) \mathrm{Br})(\mathrm{F}) \mathrm{F})(\mathrm{F}) \mathrm{F})(\mathrm{F}) \mathrm{F})(\mathrm{Br})(\mathrm{F}) \mathrm{F}$ $\mathrm{C}(\mathrm{C}(\mathrm{C}(\mathrm{C}(\mathrm{C}(\mathrm{C}(\mathrm{C}(\mathrm{C}(\mathrm{C}(\mathrm{C}(\mathrm{C}(\mathrm{F})(\mathrm{F}) \mathrm{F})(\mathrm{F}) \mathrm{F})(\mathrm{F}) \mathrm{F})(\mathrm{H}) \mathrm{F})(\mathrm{F}) \mathrm{F})(\mathrm{F}) \mathrm{F})(\mathrm{Cl}) \mathrm{Cl})(\mathrm{F}) \mathrm{F})(\mathrm{F}) \mathrm{H})(\mathrm{F}) \mathrm{Br})(\mathrm{F})(\mathrm{Cl}) \mathrm{H}$ $\mathrm{C}(\mathrm{C}(\mathrm{C}(\mathrm{C}(\mathrm{C}(\mathrm{C}(\mathrm{C}(\mathrm{C}(\mathrm{C}(\mathrm{C}(\mathrm{C}(\mathrm{F})(\mathrm{F}) \mathrm{F})(\mathrm{F}) \mathrm{F})(\mathrm{H}) \mathrm{F})(\mathrm{F}) \mathrm{F})(\mathrm{F}) \mathrm{H})(\mathrm{H}) \mathrm{F})(\mathrm{F}) \mathrm{H})(\mathrm{Br}) \mathrm{F})(\mathrm{F}) \mathrm{F})(\mathrm{F}) \mathrm{Br})(\mathrm{Br})(\mathrm{F}) \mathrm{F}$ $\mathrm{C}(\mathrm{C}(\mathrm{C}(\mathrm{C}(\mathrm{C}(\mathrm{C}(\mathrm{C}(\mathrm{C}(\mathrm{C}(\mathrm{C}(\mathrm{C}(\mathrm{H})(\mathrm{F}) \mathrm{Cl})(\mathrm{F}) \mathrm{Cl})(\mathrm{H}) \mathrm{Br})(\mathrm{H}) \mathrm{Br})(\mathrm{F}) \mathrm{F})(\mathrm{F}) \mathrm{F})(\mathrm{F}) \mathrm{F})(\mathrm{F}) \mathrm{F})(\mathrm{F}) \mathrm{F})(\mathrm{H}) \mathrm{F})(\mathrm{F})(\mathrm{F}) \mathrm{F}$ $\mathrm{C}(\mathrm{C}(\mathrm{C}(\mathrm{C}(\mathrm{C}(\mathrm{C}(\mathrm{C}(\mathrm{C}(\mathrm{C}(\mathrm{C}(\mathrm{C}(\mathrm{H})(\mathrm{H}) \mathrm{Cl})(\mathrm{H}) \mathrm{F})(\mathrm{F}) \mathrm{H})(\mathrm{Br}) \mathrm{F})(\mathrm{F}) \mathrm{F})(\mathrm{Cl}) \mathrm{F})(\mathrm{F}) \mathrm{F})(\mathrm{F}) \mathrm{F})(\mathrm{F}) \mathrm{F})(\mathrm{F}) \mathrm{F})(\mathrm{Cl})(\mathrm{F}) \mathrm{F}$ $\mathrm{C}(\mathrm{C}(\mathrm{C}(\mathrm{C}(\mathrm{C}(\mathrm{C}(\mathrm{C}(\mathrm{C}(\mathrm{C}(\mathrm{C}(\mathrm{C}(\mathrm{F})(\mathrm{F}) \mathrm{F})(\mathrm{H}) \mathrm{F})(\mathrm{H}) \mathrm{Cl})(\mathrm{F}) \mathrm{F})(\mathrm{F}) \mathrm{F})(\mathrm{H}) \mathrm{F})(\mathrm{Cl}) \mathrm{Br})(\mathrm{H}) \mathrm{F})(\mathrm{F}) \mathrm{Cl})(\mathrm{F}) \mathrm{Cl})(\mathrm{F})(\mathrm{F}) \mathrm{F}$ $\mathrm{C}(\mathrm{C}(\mathrm{C}(\mathrm{C}(\mathrm{C}(\mathrm{C}(\mathrm{C}(\mathrm{C}(\mathrm{C}(\mathrm{C}(\mathrm{C}(\mathrm{Cl})(\mathrm{F}) \mathrm{Cl})(\mathrm{H}) \mathrm{F})(\mathrm{F}) \mathrm{H})(\mathrm{F}) \mathrm{H})(\mathrm{F}) \mathrm{Cl})(\mathrm{H}) \mathrm{F})(\mathrm{F}) \mathrm{Cl})(\mathrm{F}) \mathrm{F})(\mathrm{F}) \mathrm{F})(\mathrm{F}) \mathrm{Cl})(\mathrm{F})(\mathrm{F}) \mathrm{F}$ $\mathrm{C}(\mathrm{C}(\mathrm{C}(\mathrm{C}(\mathrm{C}(\mathrm{C}(\mathrm{C}(\mathrm{C}(\mathrm{C}(\mathrm{C}(\mathrm{C}(\mathrm{Br})(\mathrm{F}) \mathrm{H})(\mathrm{F}) \mathrm{F})(\mathrm{F}) \mathrm{Br})(\mathrm{F}) \mathrm{H})(\mathrm{F}) \mathrm{F})(\mathrm{F}) \mathrm{H})(\mathrm{F}) \mathrm{H})(\mathrm{F}) \mathrm{F})(\mathrm{F}) \mathrm{F})(\mathrm{H}) \mathrm{Br})(\mathrm{F})(\mathrm{F}) \mathrm{F}$ $\mathrm{C}(\mathrm{C}(\mathrm{C}(\mathrm{C}(\mathrm{C}(\mathrm{C}(\mathrm{C}(\mathrm{C}(\mathrm{C}(\mathrm{C}(\mathrm{C}(\mathrm{F})(\mathrm{F}) \mathrm{F})(\mathrm{F}) \mathrm{F})(\mathrm{F}) \mathrm{H})(\mathrm{F}) \mathrm{H})(\mathrm{H}) \mathrm{F})(\mathrm{H}) \mathrm{F})(\mathrm{F}) \mathrm{Br})(\mathrm{F}) \mathrm{H})(\mathrm{Br}) \mathrm{F})(\mathrm{Br}) \mathrm{F})(\mathrm{F})(\mathrm{Br}) \mathrm{F}$ $\mathrm{C}(\mathrm{C}(\mathrm{C}(\mathrm{C}(\mathrm{C}(\mathrm{C}(\mathrm{C}(\mathrm{C}(\mathrm{C}(\mathrm{C}(\mathrm{C}(\mathrm{Br})(\mathrm{H}) \mathrm{H})(\mathrm{H}) \mathrm{Cl})(\mathrm{F}) \mathrm{F})(\mathrm{F}) \mathrm{F})(\mathrm{Cl}) \mathrm{F})(\mathrm{F}) \mathrm{F})(\mathrm{F}) \mathrm{F})(\mathrm{F}) \mathrm{F})(\mathrm{F}) \mathrm{H})(\mathrm{F}) \mathrm{F})(\mathrm{F})(\mathrm{Br}) \mathrm{H}$ $\mathrm{C}(\mathrm{C}(\mathrm{C}(\mathrm{C}(\mathrm{C}(\mathrm{C}(\mathrm{C}(\mathrm{C}(\mathrm{C}(\mathrm{C}(\mathrm{C}(\mathrm{F})(\mathrm{F}) \mathrm{F})(\mathrm{F}) \mathrm{F})(\mathrm{H}) \mathrm{H})(\mathrm{F}) \mathrm{F})(\mathrm{F}) \mathrm{F})(\mathrm{Br}) \mathrm{H})(\mathrm{F}) \mathrm{F})(\mathrm{H}) \mathrm{Cl})(\mathrm{F}) \mathrm{F})(\mathrm{F}) \mathrm{Cl})(\mathrm{Cl})(\mathrm{H}) \mathrm{F}$ $\mathrm{C}(\mathrm{C}(\mathrm{C}(\mathrm{C}(\mathrm{C}(\mathrm{C}(\mathrm{C}(\mathrm{C}(\mathrm{C}(\mathrm{C}(\mathrm{C}(\mathrm{Cl})(\mathrm{F}) \mathrm{F})(\mathrm{F}) \mathrm{H})(\mathrm{Cl}) \mathrm{F})(\mathrm{F}) \mathrm{F})(\mathrm{F}) \mathrm{H})(\mathrm{F}) \mathrm{F})(\mathrm{F}) \mathrm{F})(\mathrm{H}) \mathrm{Br})(\mathrm{F}) \mathrm{Cl})(\mathrm{F}) \mathrm{H})(\mathrm{Cl})(\mathrm{F}) \mathrm{H}$ $\mathrm{C}(\mathrm{C}(\mathrm{C}(\mathrm{C}(\mathrm{C}(\mathrm{C}(\mathrm{C}(\mathrm{C}(\mathrm{C}(\mathrm{C}(\mathrm{C}(\mathrm{F})(\mathrm{F}) \mathrm{F})(\mathrm{Cl}) \mathrm{F})(\mathrm{F}) \mathrm{F})(\mathrm{Cl}) \mathrm{H})(\mathrm{F}) \mathrm{F})(\mathrm{Cl}) \mathrm{Cl})(\mathrm{F}) \mathrm{F})(\mathrm{H}) \mathrm{F})(\mathrm{F}) \mathrm{F})(\mathrm{H}) \mathrm{F})(\mathrm{F})(\mathrm{H}) \mathrm{H}$ $\mathrm{C}(\mathrm{C}(\mathrm{C}(\mathrm{C}(\mathrm{C}(\mathrm{C}(\mathrm{C}(\mathrm{C}(\mathrm{C}(\mathrm{C}(\mathrm{C}(\mathrm{F})(\mathrm{H}) \mathrm{Cl})(\mathrm{F}) \mathrm{F})(\mathrm{H}) \mathrm{F})(\mathrm{F}) \mathrm{F})(\mathrm{Cl}) \mathrm{F})(\mathrm{F}) \mathrm{F})(\mathrm{Cl}) \mathrm{H})(\mathrm{F}) \mathrm{F})(\mathrm{F}) \mathrm{F})(\mathrm{H}) \mathrm{Cl})(\mathrm{Cl})(\mathrm{H}) \mathrm{F}$ $\mathrm{C}(\mathrm{C}(\mathrm{C}(\mathrm{C}(\mathrm{C}(\mathrm{C}(\mathrm{C}(\mathrm{C}(\mathrm{C}(\mathrm{C}(\mathrm{C}(\mathrm{F})(\mathrm{F}) \mathrm{F})(\mathrm{F}) \mathrm{F})(\mathrm{F}) \mathrm{Br})(\mathrm{F}) \mathrm{F})(\mathrm{H}) \mathrm{F})(\mathrm{Br}) \mathrm{F})(\mathrm{H}) \mathrm{F})(\mathrm{Cl}) \mathrm{F})(\mathrm{Br}) \mathrm{H})(\mathrm{H}) \mathrm{F})(\mathrm{H})(\mathrm{F}) \mathrm{F}$
lgKoa lgKow lgKaw lgKow lgKoa lgKa lgKow lgKoa lgKaw EPISuit EPI EPI Exp Exp w DFT DFT DFT e Suite Suite corr__corr_Exp corr__corr_corr $\begin{array}{rrrrrrrrr}4.56 & 5.95 & 1.39 & 3.96 & 2.56 & 1.39 & 5.33 & 6.39 & -1.06 \\ 7.434 & 7.32 & -0.11 & 6.00 & 6.11 & -0.11 & 6.38 & 11.67 & -5.28\end{array}$ $\begin{array}{llllllllll}7.434 & 7.32 & -0.11 & 6.00 & 6.11 & -0.11 & 6.38 & 11.67 & -5.28\end{array}$ $\begin{array}{llllllllll}4.639 & 5.81 & 1.17 & 3.75 & 2.57 & 1.17 & 5.22 & 6.53 & -1.31\end{array}$ $\begin{array}{lllllllll}7.026 & 6.96 & -0.07 & 5.46 & 5.53 & -0.07 & 6.11 & 10.92 & -4.81\end{array}$ $\begin{array}{lllllllll}6.312 & 6.7 & 0.39 & 5.07 & 4.69 & 0.39 & 5.91 & 9.61 & -3.70\end{array}$ $\begin{array}{lllllllll}6.069 & 6.19 & 0.12 & 4.31 & 4.19 & 0.12 & 5.52 & 9.16 & -3.65\end{array}$ $\begin{array}{llllllllll}5.242 & 6.6 & 1.36 & 4.93 & 3.57 & 1.36 & 5.83 & 7.64 & -1.81\end{array}$ $\begin{array}{llllllllll}7.2 & 6.57 & -0.63 & 4.88 & 5.51 & -0.63 & 5.81 & 11.24 & -5.43\end{array}$ $6.304-6.91$ $6.304 \quad 6.91$ $\begin{array}{llllllllll}4.595 & 6.44 & 1.84 & 4.69 & 2.84 & 1.84 & 5.71 & 6.45 & -0.75\end{array}$ $\begin{array}{lllllllll}6.398 & 7.49 & 1.09 & 6.25 & 5.16 & 1.09 & 6.51 & 9.77 & -3.25\end{array}$ $\begin{array}{llllllllll}6.8 & 7.14 & 0.34 & 5.73 & 5.39 & 0.34 & 6.25 & 10.50 & -4.26\end{array}$ $\begin{array}{llllllllll}6.556 & 7.43 & 0.87 & 6.16 & 5.29 & 0.87 & 6.47 & 10.06 & -3.59\end{array}$ $\begin{array}{lllllllll}- & 0.87 & 6.16 & 5.29 & 0.87 & 6.47 & 10.06 & -3.59\end{array}$ $\begin{array}{ll}7.383 & 7.02 \\ 4.92 & 7.03\end{array}$ $\begin{array}{llllllllll}4.92 & 7.03 & 2.11 & 5.57 & 3.46 & 2.11 & 6.16 & 7.05 & -0.89\end{array}$ $\begin{array}{lllllllll}5.184 & 6.51 & 1.33 & 4.79 & 3.47 & 1.33 & 5.76 & 7.54 & -1.77\end{array}$ $\begin{array}{lllllllll}5.931 & 6.02 & 0.09 & 4.06 & 3.97 & 0.09 & 5.39 & 8.91 & -3.52\end{array}$ $\begin{array}{lllllllll}0.09 & 4.06 & 3.97 & 0.09 & 5.39 & 8.91 & -3.52\end{array}$ $\begin{array}{lllllllll}5.6 & 6.66 & 1.06 & 5.01 & 3.95 & 1.06 & 5.88 & 8.30 & -2.42\end{array}$ $\begin{array}{rrrrrrrrrr}7.332 & 7.64 & 0.31 & 6.48 & 6.17 & 0.31 & 6.63 & 11.48 & -4.85\end{array}$ $\begin{array}{lllllllll}4.355 & 5.9 & 1.54 & 3.88 & 2.34 & 1.54 & 5.29 & 6.01 & -0.72\end{array}$ $\begin{array}{lllllllll}7.064 & 6.62 & -0.44 & 4.96 & 5.40 & -0.44 & 5.85 & 10.99 & -5.14\end{array}$ $\begin{array}{lllllllll}5.417 & 6.21 & 0.79 & 4.34 & 3.55 & 0.79 & 5.53 & 7.96 & -2.43\end{array}$ $\begin{array}{llllllllll}6.489 & 6.53 & 0.04 & 4.82 & 4.78 & 0.04 & 5.78 & 9.93 & -4.16\end{array}$ $\begin{array}{lllllllll}6.176 & 6.75 & 0.57 & 5.15 & 4.57 & 0.57 & 5.95 & 9.36 & -3.41\end{array}$ $\begin{array}{llllllllll}5.2 & 7.01 & 1.81 & 5.54 & 3.73 & 1.81 & 6.15 & 7.56 & -1.42\end{array}$ $\begin{array}{lllllllll}5.542 & 6.57 & 1.03 & 4.88 & 3.85 & 1.03 & 5.81 & 8.19 & -2.39\end{array}$ $\begin{array}{lllllllll}6.509 & 6.3 & -0.21 & 4.48 & 4.69 & -0.21 & 5.60 & 9.97 & -4.37\end{array}$ $\begin{array}{rrrrrrrrr}6.509 & 6.3 & -0.21 & 4.48 & 4.69 & -0.21 & 5.60 & 9.97 & -4.37 \\ 6.926 & 6.45 & -0.48 & 4.70 & 5.18 & -0.48 & 5.72 & 10.74 & -5.02\end{array}$ $\begin{array}{rrrrrrrrr}6.926 & 6.45 & -0.48 & 4.70 & 5.18 & -0.48 & 5.72 & 10.74 & -5.02 \\ 5.359 & 6.12 & 0.76 & 4.21 & 3.45 & 0.76 & 5.46 & 7.86 & -2.39\end{array}$ $\begin{array}{lllllllll}5.133 & 7.13 & 2.00 & 5.72 & 3.72 & 2.00 & 6.24 & 7.44 & -1.20\end{array}$ $\begin{array}{lllllllll}6.431 & 6.44 & 0.01 & 4.69 & 4.68 & 0.01 & 5.71 & 9.83 & -4.12\end{array}$ $\begin{array}{lllllllll}4.784 & 6.03 & 1.25 & 4.07 & 2.83 & 1.25 & 5.39 & 6.80 & -1.41\end{array}$ $\begin{array}{lllllllll}5.856 & 6.35 & 0.49 & 4.55 & 4.06 & 0.49 & 5.64 & 8.77 & -3.13\end{array}$ $\begin{array}{rrrrrrrrrr}5.856 & 6.35 & 0.49 & 4.55 & 4.06 & 0.49 & 5.64 & 8.77 & -3.13 \\ 6.768 & 6.51 & -0.26 & 4.79 & 5.05 & -0.26 & 5.76 & 10.44 & -4.68\end{array}$ $\begin{array}{lllllllll}5.935 & 6.21 & 0.28 & 4.34 & 4.07 & 0.28 & 5.53 & 8.91 & -3.38\end{array}$ $\begin{array}{lllllllll}5.971 & 6.7 & 0.73 & 5.07 & 4.35 & 0.73 & 5.91 & 8.98 & -3.07\end{array}$ $\begin{array}{lllllllll}6.868 & 6.36 & -0.51 & 4.57 & 5.08 & -0.51 & 5.65 & 10.63 & -4.98\end{array}$ $\begin{array}{llllllllll}7.365 & 6.59 & -0.77 & 4.91 & 5.69 & -0.77 & 5.82 & 11.54 & -5.72\end{array}$ $\begin{array}{lllllllll}5.798 & 6.26 & 0.46 & 4.42 & 3.96 & 0.46 & 5.57 & 8.66 & -3.09\end{array}$ $\begin{array}{lllllllll}6.862 & 6.57 & -0.29 & 4.88 & 5.17 & -0.29 & 5.81 & 10.62 & -4.81\end{array}$ $\begin{array}{llllllllll}5.142 & 6.09 & 0.95 & 4.16 & 3.22 & 0.95 & 5.44 & 7.46 & -2.02\end{array}$ $\begin{array}{lllllllll}6.954 & 7.15 & 0.20 & 5.75 & 5.55 & 0.20 & 6.25 & 10.79 & -4.53\end{array}$ $\begin{array}{rrrrrrrrr}6.954 & 7.15 & 0.20 & 5.75 & 5.55 & 0.20 & 6.25 & 10.79 & -4.53 \\ 7.347 & 6.79 & -0.56 & 5.21 & 5.77 & -0.56 & 5.98 & 11.51 & -5.53\end{array}$ $\begin{array}{llllllllll}7.347 & 6.79 & -0.56 & 5.21 & 5.77 & -0.56 & 5.98 & 11.51 & -5.53 \\ 7.033 & 7.01 & -0.02 & 5.54 & 5.56 & -0.02 & 6.15 & 10.93 & -4.79\end{array}$ $\begin{array}{rrrrrrrr}-1.21 & 3.84 & 2.62 & 1.21 & 5.27 & 6.57 & -1.30 \\ 0.43 & 4.06 & 3.63 & 0.43 & 5.39 & 8.28 & -2.90\end{array}$ $\begin{array}{llllllllll}5.59 & 6.02 & 0.43 & 4.06 & 3.63 & 0.43 & 5.39 & 8.28 & -2.90\end{array}$ $\begin{array}{rrrrrrrrr}7.378 & 6.57 & -0.81 & 4.88 & 5.69 & -0.81 & 5.81 & 11.57 & -5.76\end{array}$ $\begin{array}{rrrrrrrrr}7.378 & 6.57 & -0.81 & 4.88 & 5.69 & -0.81 & 5.81 & 11.57 & -5.76 \\ 6.077 & 6.24 & 0.16 & 4.39 & 4.23 & 0.16 & 5.55 & 9.18 & -3.62\end{array}$ $\begin{array}{rrrrrrrrr}6.077 & 6.24 & 0.16 & 4.39 & 4.23 & 0.16 & 5.55 & 9.18 & -3.62 \\ 4.51 & 5.91 & 1.40 & 3.90 & 2.50 & 1.40 & 5.30 & 6.30 & -1.00\end{array}$ $\begin{array}{rrrrrrrrrr}7.588 & 6.7 & -0.59 & 5.07 & 5.66 & -0.59 & 5.91 & 11.40 & -5.49\end{array}$ $\begin{array}{lllllllll}6.241 & 6.89 & 0.65 & 5.36 & 4.71 & 0.65 & 6.05 & 9.48 & -3.42\end{array}$ $\begin{array}{rrrrrrrrrr}6.643 & 6.54 & -0.10 & 4.84 & 4.94 & -0.10 & 5.78 & 10.22 & -4.43\end{array}$ $\begin{array}{rrrrrrrrrr}6.643 & 6.54 & -0.10 & 4.84 & 4.94 & -0.10 & 5.78 & 10.22 & -4.43 \\ 6.72 & 6.4 & -0.32 & 4.63 & 4.95 & -0.32 & 5.68 & 10.36 & -4.68\end{array}$ $\begin{array}{rrrrrrrrr}6.72 & 6.4 & -0.32 & 4.63 & 4.95 & -0.32 & 5.68 & 10.36 & -4.68 \\ 5.085 & 6 & 0.91 & 4.03 & 3.12 & 0.91 & 5.37 & 7.35 & -1.98\end{array}$ $\begin{array}{lllllllll}6.169 & 6.3 & 0.13 & 4.48 & 4.35 & 0.13 & 5.60 & 9.34 & -3.74\end{array}$ $\begin{array}{lllllllll}4.452 & 5.82 & 1.37 & 3.76 & 2.39 & 1.37 & 5.23 & 6.19 & -0.96\end{array}$ $6.586-6.45$ $\begin{array}{rr}6.586 & 6.45 \\ 4.948 & 6.05\end{array}$ $\begin{array}{lllllllll}4.948 & 6.05 & 1.10 & 4.10 & 3.00 & 1.10 & 5.41 & 7.10 & -1.69\end{array}$ $\begin{array}{lllllllll}5.93 & 6.28 & 0.35 & 4.45 & 4.10 & 0.35 & 5.58 & 8.91 & -3.32\end{array}$ $\begin{array}{lllllllll}7.231 & 6.61 & -0.62 & 4.94 & 5.56 & -0.62 & 5.84 & 11.30 & -5.46\end{array}$ $\begin{array}{lllllllll}5.514 & 6.13 & 0.62 & 4.22 & 3.61 & 0.62 & 5.47 & 8.14 & -2.67\end{array}$ $\begin{array}{rrrrrrrrr}5.448 & 6.28 & -0.17 & 4.45 & 4.62 & -0.17 & 5.58 & 9.86 & -4.27\end{array}$ $\begin{array}{rrrrrrrrr}6.448 & 6.28 & -0.17 & 4.45 & 4.62 & -0.17 & 5.58 & 9.86 & -4.27 \\ 4.811 & 5.88 & 1.07 & 3.85 & 2.78 & 1.07 & 5.28 & 6.85 & -1.57\end{array}$ $\begin{array}{lllllllll}5.298 & 6.1 & 0.80 & 4.18 & 3.38 & 0.80 & 5.45 & 7.74 & -2.30\end{array}$ $\begin{array}{lllllllll}5.873 & 6.19 & 0.32 & 4.31 & 4.00 & 0.32 & 5.52 & 8.80 & -3.29\end{array}$ $\begin{array}{lllllllll}4.385 & 5.94 & 1.55 & 3.94 & 2.39 & 1.55 & 5.32 & 6.07 & -0.74\end{array}$ $\begin{array}{llllllllll}0.5 .37 & 4.04 & 3.27 & 0.77 & 5.38 & 7.64 & -2.26\end{array}$ $\begin{array}{lllllllllll}5.24 & 6.01 & 0.77 & 4.04 & 3.27 & 0.77 & 5.38 & 7.64 & -2.26\end{array}$ $\begin{array}{llllllllll}5.165 & 5.92 & 0.75 & 3.91 & 3.16 & 0.75 & 5.31 & 7.50 & -2.19\end{array}$ $\begin{array}{lllllllll}4.621 & 5.68 & 1.06 & 3.55 & 2.49 & 1.06 & 5.12 & 6.50 & -1.38\end{array}$ $\begin{array}{llllllllll}7.005 & 10.04 & 3.03 & 10.06 & 7.03 & 3.03 & 8.47 & 10.88 & -2.41\end{array}$ $\begin{array}{lllllllll}5.58 & 10.07 & 4.49 & 10.10 & 5.61 & 4.49 & 8.50 & 8.26 & 0.23\end{array}$ $\begin{array}{llllllllll}5.657 & 9.63 & 3.97 & 9.45 & 5.47 & 3.97 & 8.16 & 8.40 & -0.25\end{array}$ $\begin{array}{llllllllll}5.657 & 9.63 & 3.97 & 9.45 & 5.47 & 3.97 & 8.16 & 8.40 & -0.25 \\ 5.255 & 8.96 & 3.70 & 8.45 & 4.74 & 3.70 & 7.64 & 7.67 & -0.02\end{array}$ $\begin{array}{llllllllll}5.419 & 9.61 & 4.19 & 9.42 & 5.23 & 4.19 & 8.14 & 7.97 & 0.18\end{array}$ $\begin{array}{llllllllll}6.63 & 10.07 & 3.44 & 10.10 & 6.67 & 3.44 & 8.50 & 10.19 & -1.69\end{array}$ $\begin{array}{llllllllll}6.065 & 9.99 & 3.93 & 9.99 & 6.06 & 3.93 & 8.44 & 9.15 & -0.72\end{array}$ $\begin{array}{lllllllll}6.065 & 9.99 & 3.93 & 9.99 & 6.06 & 3.93 & 8.44 & 9.15 & -0.72 \\ 5.344 & 9.02 & 3.68 & 8.54 & 4.86 & 3.68 & 7.69 & 7.83 & -0.14\end{array}$ $\begin{array}{rrrrrrrrr}5.344 & 9.02 & 3.68 & 8.54 & 4.86 & 3.68 & 7.69 & 7.83 & -0.14 \\ 6.983 & 9.42 & 2.44 & 9.13 & 6.70 & 2.44 & 8.00 & 10.84 & -2.84\end{array}$ $\begin{array}{lllllllll}6.283 & 9.69 & 3.41 & 9.54 & 6.13 & 3.41 & 8.20 & 9.55 & -1.35\end{array}$ $\begin{array}{llllllllll}5.997 & 9.89 & 3.89 & 9.84 & 5.94 & 3.89 & 8.36 & 9.03 & -0.67\end{array}$ $\begin{array}{llllllll}3.14 & 9.21 & 6.07 & 3.14 & 8.04 & 9.64 & -1.60\end{array}$ $\begin{array}{llllllll}3.14 & 9.21 & 6.07 & 3.14 & 8.04 & 9.64 & -1.60 \\ -4.38 & 9.70 & 5.32 & 4.38 & 8.29 & 7.97 & 0.32\end{array}$ $\begin{array}{lllllllllll}5.422 & 9.8 & 4.38 & 9.70 & 5.32 & 4.38 & 8.29 & 7.97 & 0.32\end{array}$ $\begin{array}{lllllllll}5.756 & 9.38 & 3.62 & 9.07 & 5.45 & 3.62 & 7.97 & 8.59 & -0.62 \\ 6.407 & 9.33 & 2.92 & 9.00 & 6.08 & 2.92 & 7.93 & 9.78 & -1.85\end{array}$ 
$\mathrm{C}(\mathrm{C}(\mathrm{C}(\mathrm{C}(\mathrm{C}(\mathrm{C}(\mathrm{C}(\mathrm{C}(\mathrm{C}(\mathrm{C}(\mathrm{C}(\mathrm{H})(\mathrm{F}) \mathrm{H})(\mathrm{F}) \mathrm{F})(\mathrm{F}) \mathrm{F})(\mathrm{F}) \mathrm{F})(\mathrm{H}) \mathrm{F})(\mathrm{H}) \mathrm{F})(\mathrm{H}) \mathrm{Br})(\mathrm{F}) \mathrm{F})(\mathrm{F}) \mathrm{Br})(\mathrm{F}) \mathrm{H})(\mathrm{F})(\mathrm{Br}) \mathrm{F}$ $\mathrm{C}(\mathrm{C}(\mathrm{C}(\mathrm{C}(\mathrm{C}(\mathrm{C}(\mathrm{C}(\mathrm{C}(\mathrm{C}(\mathrm{C}(\mathrm{C}(\mathrm{F})(\mathrm{H}) \mathrm{H})(\mathrm{F}) \mathrm{H})(\mathrm{H}) \mathrm{F})(\mathrm{F}) \mathrm{F})(\mathrm{F}) \mathrm{F})(\mathrm{Br}) \mathrm{Br})(\mathrm{H}) \mathrm{F})(\mathrm{F}) \mathrm{Br})(\mathrm{F}) \mathrm{F})(\mathrm{Br}) \mathrm{H})(\mathrm{F})(\mathrm{F}) \mathrm{F}$ $\mathrm{C}(\mathrm{C}(\mathrm{C}(\mathrm{C}(\mathrm{C}(\mathrm{C}(\mathrm{C}(\mathrm{C}(\mathrm{C}(\mathrm{C}(\mathrm{C}(\mathrm{H})(\mathrm{F}) \mathrm{H})(\mathrm{Cl}) \mathrm{H})(\mathrm{F}) \mathrm{Br})(\mathrm{F}) \mathrm{F})(\mathrm{F}) \mathrm{F})(\mathrm{H}) \mathrm{F})(\mathrm{H}) \mathrm{F})(\mathrm{H}) \mathrm{Br})(\mathrm{F}) \mathrm{F})(\mathrm{F}) \mathrm{F})(\mathrm{F})(\mathrm{F}) \mathrm{Cl}$ $\mathrm{C}(\mathrm{C}(\mathrm{C}(\mathrm{C}(\mathrm{C}(\mathrm{C}(\mathrm{C}(\mathrm{C}(\mathrm{C}(\mathrm{C}(\mathrm{C}(\mathrm{F})(\mathrm{F}) \mathrm{Br})(\mathrm{F}) \mathrm{F})(\mathrm{Cl}) \mathrm{H})(\mathrm{H}) \mathrm{F})(\mathrm{F}) \mathrm{F})(\mathrm{F}) \mathrm{Cl})(\mathrm{F}) \mathrm{Cl})(\mathrm{H}) \mathrm{H})(\mathrm{F}) \mathrm{H})(\mathrm{F}) \mathrm{H})(\mathrm{F})(\mathrm{Br}) \mathrm{F}$ $\mathrm{C}(\mathrm{C}(\mathrm{C}(\mathrm{C}(\mathrm{C}(\mathrm{C}(\mathrm{C}(\mathrm{C}(\mathrm{C}(\mathrm{C}(\mathrm{C}(\mathrm{F})(\mathrm{F}) \mathrm{F})(\mathrm{F}) \mathrm{Cl})(\mathrm{H}) \mathrm{F})(\mathrm{F}) \mathrm{Cl})(\mathrm{F}) \mathrm{H})(\mathrm{F}) \mathrm{F})(\mathrm{H}) \mathrm{F})(\mathrm{Cl}) \mathrm{F})(\mathrm{F}) \mathrm{Br})(\mathrm{H}) \mathrm{H})(\mathrm{F})(\mathrm{F}) \mathrm{H}$ $\mathrm{C}(\mathrm{C}(\mathrm{C}(\mathrm{C}(\mathrm{C}(\mathrm{C}(\mathrm{C}(\mathrm{C}(\mathrm{C}(\mathrm{C}(\mathrm{C}(\mathrm{F})(\mathrm{Cl}) \mathrm{F})(\mathrm{F}) \mathrm{Cl})(\mathrm{F}) \mathrm{F})(\mathrm{F}) \mathrm{H})(\mathrm{F}) \mathrm{F})(\mathrm{F}) \mathrm{F})(\mathrm{H}) \mathrm{Cl})(\mathrm{F}) \mathrm{Cl})(\mathrm{F}) \mathrm{H})(\mathrm{H}) \mathrm{H})(\mathrm{F})(\mathrm{H}) \mathrm{F}$ $\mathrm{C}(\mathrm{C}(\mathrm{C}(\mathrm{C}(\mathrm{C}(\mathrm{C}(\mathrm{C}(\mathrm{C}(\mathrm{C}(\mathrm{C}(\mathrm{C}(\mathrm{Cl})(\mathrm{F}) \mathrm{H})(\mathrm{F}) \mathrm{F})(\mathrm{F}) \mathrm{F})(\mathrm{H}) \mathrm{Cl})(\mathrm{F}) \mathrm{H})(\mathrm{F}) \mathrm{F})(\mathrm{Cl}) \mathrm{F})(\mathrm{H}) \mathrm{H})(\mathrm{Cl}) \mathrm{F})(\mathrm{Cl}) \mathrm{F})(\mathrm{F})(\mathrm{H}) \mathrm{F}$ $\mathrm{C}(\mathrm{C}(\mathrm{C}(\mathrm{C}(\mathrm{C}(\mathrm{C}(\mathrm{C}(\mathrm{C}(\mathrm{C}(\mathrm{C}(\mathrm{C}(\mathrm{H})(\mathrm{F}) \mathrm{H})(\mathrm{Cl}) \mathrm{F})(\mathrm{Cl}) \mathrm{Cl})(\mathrm{F}) \mathrm{F})(\mathrm{H}) \mathrm{F})(\mathrm{F}) \mathrm{F})(\mathrm{F}) \mathrm{F})(\mathrm{Cl}) \mathrm{H})(\mathrm{H}) \mathrm{F})(\mathrm{F}) \mathrm{Cl})(\mathrm{H})(\mathrm{F}) \mathrm{Cl}$ $\mathrm{C}(\mathrm{C}(\mathrm{C}(\mathrm{C}(\mathrm{C}(\mathrm{C}(\mathrm{C}(\mathrm{C}(\mathrm{C}(\mathrm{C}(\mathrm{C}(\mathrm{F})(\mathrm{F}) \mathrm{F})(\mathrm{Cl}) \mathrm{F})(\mathrm{H}) \mathrm{Br})(\mathrm{F}) \mathrm{F})(\mathrm{F}) \mathrm{H})(\mathrm{H}) \mathrm{F})(\mathrm{F}) \mathrm{H})(\mathrm{H}) \mathrm{F})(\mathrm{F}) \mathrm{F})(\mathrm{F}) \mathrm{Br})(\mathrm{Br})(\mathrm{F}) \mathrm{H}$ $\mathrm{C}(\mathrm{C}(\mathrm{C}(\mathrm{C}(\mathrm{C}(\mathrm{C}(\mathrm{C}(\mathrm{C}(\mathrm{C}(\mathrm{C}(\mathrm{C}(\mathrm{H})(\mathrm{Br}) \mathrm{F})(\mathrm{H}) \mathrm{H})(\mathrm{F}) \mathrm{F})(\mathrm{H}) \mathrm{F})(\mathrm{Br}) \mathrm{F})(\mathrm{F}) \mathrm{F})(\mathrm{F}) \mathrm{H})(\mathrm{F}) \mathrm{F})(\mathrm{Br}) \mathrm{F})(\mathrm{H}) \mathrm{F})(\mathrm{F})(\mathrm{F}) \mathrm{H}$ $\mathrm{C}(\mathrm{C}(\mathrm{C}(\mathrm{C}(\mathrm{C}(\mathrm{C}(\mathrm{C}(\mathrm{C}(\mathrm{C}(\mathrm{C}(\mathrm{C}(\mathrm{H})(\mathrm{Br}) \mathrm{F})(\mathrm{F}) \mathrm{Br})(\mathrm{F}) \mathrm{F})(\mathrm{F}) \mathrm{H})(\mathrm{F}) \mathrm{F})(\mathrm{F}) \mathrm{H})(\mathrm{Br}) \mathrm{F})(\mathrm{H}) \mathrm{F})(\mathrm{F}) \mathrm{H})(\mathrm{H}) \mathrm{F})(\mathrm{F})(\mathrm{Br}) \mathrm{H}$ $\mathrm{C}(\mathrm{C}(\mathrm{C}(\mathrm{C}(\mathrm{C}(\mathrm{C}(\mathrm{C}(\mathrm{C}(\mathrm{C}(\mathrm{C}(\mathrm{C}(\mathrm{H})(\mathrm{F}) \mathrm{H})(\mathrm{H}) \mathrm{Br})(\mathrm{F}) \mathrm{H})(\mathrm{Cl}) \mathrm{F})(\mathrm{Br}) \mathrm{F})(\mathrm{F}) \mathrm{F})(\mathrm{F}) \mathrm{H})(\mathrm{H}) \mathrm{Cl})(\mathrm{F}) \mathrm{F})(\mathrm{H}) \mathrm{F})(\mathrm{F})(\mathrm{F}) \mathrm{F}$ $\mathrm{C}(\mathrm{C}(\mathrm{C}(\mathrm{C}(\mathrm{C}(\mathrm{C}(\mathrm{C}(\mathrm{C}(\mathrm{C}(\mathrm{C}(\mathrm{C}(\mathrm{Cl})(\mathrm{F}) \mathrm{F})(\mathrm{H}) \mathrm{H})(\mathrm{F}) \mathrm{F})(\mathrm{Br}) \mathrm{F})(\mathrm{Br}) \mathrm{H})(\mathrm{F}) \mathrm{H})(\mathrm{F}) \mathrm{F})(\mathrm{Br}) \mathrm{H})(\mathrm{F}) \mathrm{F})(\mathrm{F}) \mathrm{H})(\mathrm{Cl})(\mathrm{F}) \mathrm{H}$ $\mathrm{C}(\mathrm{C}(\mathrm{C}(\mathrm{C}(\mathrm{C}(\mathrm{C}(\mathrm{C}(\mathrm{C}(\mathrm{C}(\mathrm{C}(\mathrm{C}(\mathrm{H})(\mathrm{Cl}) \mathrm{H})(\mathrm{F}) \mathrm{F})(\mathrm{F}) \mathrm{F})(\mathrm{Cl}) \mathrm{F})(\mathrm{Br}) \mathrm{H})(\mathrm{F}) \mathrm{F})(\mathrm{H}) \mathrm{F})(\mathrm{H}) \mathrm{F})(\mathrm{F}) \mathrm{H})(\mathrm{H}) \mathrm{Br})(\mathrm{F})(\mathrm{Cl}) \mathrm{F}$ $\mathrm{C}(\mathrm{C}(\mathrm{C}(\mathrm{C}(\mathrm{C}(\mathrm{C}(\mathrm{C}(\mathrm{C}(\mathrm{C}(\mathrm{C}(\mathrm{C}(\mathrm{F})(\mathrm{Cl}) \mathrm{H})(\mathrm{Cl}) \mathrm{Cl})(\mathrm{F}) \mathrm{F})(\mathrm{F}) \mathrm{F})(\mathrm{H}) \mathrm{F})(\mathrm{F}) \mathrm{H})(\mathrm{F}) \mathrm{F})(\mathrm{Br}) \mathrm{F})(\mathrm{H}) \mathrm{F})(\mathrm{H}) \mathrm{F})(\mathrm{F})(\mathrm{H}) \mathrm{H}$ $\mathrm{C}(\mathrm{C}(\mathrm{C}(\mathrm{C}(\mathrm{C}(\mathrm{C}(\mathrm{C}(\mathrm{C}(\mathrm{C}(\mathrm{C}(\mathrm{C}(\mathrm{Cl})(\mathrm{F}) \mathrm{Br})(\mathrm{H}) \mathrm{F})(\mathrm{Cl}) \mathrm{H})(\mathrm{F}) \mathrm{H})(\mathrm{Cl}) \mathrm{F})(\mathrm{H}) \mathrm{H})(\mathrm{H}) \mathrm{H})(\mathrm{F}) \mathrm{F})(\mathrm{F}) \mathrm{F})(\mathrm{F}) \mathrm{F})(\mathrm{Cl})(\mathrm{F}) \mathrm{F}$ $\mathrm{C}(\mathrm{C}(\mathrm{C}(\mathrm{C}(\mathrm{C}(\mathrm{C}(\mathrm{C}(\mathrm{C}(\mathrm{C}(\mathrm{C}(\mathrm{C}(\mathrm{F})(\mathrm{Cl}) \mathrm{F})(\mathrm{F}) \mathrm{Cl})(\mathrm{F}) \mathrm{F})(\mathrm{F}) \mathrm{F})(\mathrm{H}) \mathrm{H})(\mathrm{F}) \mathrm{H})(\mathrm{F}) \mathrm{H})(\mathrm{Cl}) \mathrm{Cl})(\mathrm{F}) \mathrm{F})(\mathrm{H}) \mathrm{F})(\mathrm{H})(\mathrm{F}) \mathrm{H}$ $\mathrm{C}(\mathrm{C}(\mathrm{C}(\mathrm{C}(\mathrm{C}(\mathrm{C}(\mathrm{C}(\mathrm{C}(\mathrm{C}(\mathrm{C}(\mathrm{C}(\mathrm{F})(\mathrm{H}) \mathrm{H})(\mathrm{H}) \mathrm{F})(\mathrm{F}) \mathrm{F})(\mathrm{F}) \mathrm{H})(\mathrm{F}) \mathrm{H})(\mathrm{F}) \mathrm{F})(\mathrm{F}) \mathrm{Cl})(\mathrm{F}) \mathrm{Cl})(\mathrm{H}) \mathrm{Cl})(\mathrm{F}) \mathrm{F})(\mathrm{Cl})(\mathrm{Cl}) \mathrm{H}$ $\mathrm{C}(\mathrm{C}(\mathrm{C}(\mathrm{C}(\mathrm{C}(\mathrm{C}(\mathrm{C}(\mathrm{C}(\mathrm{C}(\mathrm{C}(\mathrm{C}(\mathrm{H})(\mathrm{F}) \mathrm{Cl})(\mathrm{Cl}) \mathrm{H})(\mathrm{F}) \mathrm{Cl})(\mathrm{H}) \mathrm{F})(\mathrm{F}) \mathrm{Cl})(\mathrm{F}) \mathrm{F})(\mathrm{F}) \mathrm{H})(\mathrm{F}) \mathrm{Cl})(\mathrm{Cl}) \mathrm{F})(\mathrm{H}) \mathrm{F})(\mathrm{H})(\mathrm{F}) \mathrm{H}$ $\mathrm{C}(\mathrm{C}(\mathrm{C}(\mathrm{C}(\mathrm{C}(\mathrm{C}(\mathrm{C}(\mathrm{C}(\mathrm{C}(\mathrm{C}(\mathrm{C}(\mathrm{F})(\mathrm{F}) \mathrm{F})(\mathrm{F}) \mathrm{H})(\mathrm{Br}) \mathrm{H})(\mathrm{F}) \mathrm{Br})(\mathrm{Cl}) \mathrm{H})(\mathrm{F}) \mathrm{F})(\mathrm{H}) \mathrm{H})(\mathrm{F}) \mathrm{F})(\mathrm{H}) \mathrm{H})(\mathrm{F}) \mathrm{F})(\mathrm{F})(\mathrm{F}) \mathrm{F}$ $\mathrm{C}(\mathrm{C}(\mathrm{C}(\mathrm{C}(\mathrm{C}(\mathrm{C}(\mathrm{C}(\mathrm{C}(\mathrm{C}(\mathrm{C}(\mathrm{C}(\mathrm{F})(\mathrm{H}) \mathrm{F})(\mathrm{H}) \mathrm{F})(\mathrm{F}) \mathrm{Br})(\mathrm{Cl}) \mathrm{F})(\mathrm{Br}) \mathrm{H})(\mathrm{F}) \mathrm{H})(\mathrm{F}) \mathrm{Br})(\mathrm{H}) \mathrm{F})(\mathrm{F}) \mathrm{F})(\mathrm{F}) \mathrm{H})(\mathrm{F})(\mathrm{H}) \mathrm{F}$ $\mathrm{C}(\mathrm{C}(\mathrm{C}(\mathrm{C}(\mathrm{C}(\mathrm{C}(\mathrm{C}(\mathrm{C}(\mathrm{C}(\mathrm{C}(\mathrm{C}(\mathrm{Cl})(\mathrm{Br}) \mathrm{H})(\mathrm{Br}) \mathrm{F})(\mathrm{F}) \mathrm{H})(\mathrm{H}) \mathrm{F})(\mathrm{H}) \mathrm{Br})(\mathrm{F}) \mathrm{F})(\mathrm{F}) \mathrm{F})(\mathrm{F}) \mathrm{H})(\mathrm{F}) \mathrm{F})(\mathrm{F}) \mathrm{H})(\mathrm{Br})(\mathrm{F}) \mathrm{H}$ $\mathrm{C}(\mathrm{C}(\mathrm{C}(\mathrm{C}(\mathrm{C}(\mathrm{C}(\mathrm{C}(\mathrm{C}(\mathrm{C}(\mathrm{C}(\mathrm{C}(\mathrm{H})(\mathrm{Br}) \mathrm{F})(\mathrm{H}) \mathrm{F})(\mathrm{H}) \mathrm{F})(\mathrm{H}) \mathrm{H})(\mathrm{H}) \mathrm{F})(\mathrm{F}) \mathrm{F})(\mathrm{H}) \mathrm{F})(\mathrm{F}) \mathrm{F})(\mathrm{F}) \mathrm{F})(\mathrm{H}) \mathrm{Br})(\mathrm{F})(\mathrm{Br}) \mathrm{F}$ $\mathrm{C}(\mathrm{C}(\mathrm{C}(\mathrm{C}(\mathrm{C}(\mathrm{C}(\mathrm{C}(\mathrm{C}(\mathrm{C}(\mathrm{C}(\mathrm{C}(\mathrm{Br})(\mathrm{F}) \mathrm{F})(\mathrm{F}) \mathrm{Br})(\mathrm{F}) \mathrm{F})(\mathrm{Br}) \mathrm{Br})(\mathrm{H}) \mathrm{H})(\mathrm{H}) \mathrm{F})(\mathrm{F}) \mathrm{H})(\mathrm{F}) \mathrm{F})(\mathrm{H}) \mathrm{F})(\mathrm{F}) \mathrm{H})(\mathrm{H})(\mathrm{F}) \mathrm{H}$ $\mathrm{C}(\mathrm{C}(\mathrm{C}(\mathrm{C}(\mathrm{C}(\mathrm{C}(\mathrm{C}(\mathrm{C}(\mathrm{C}(\mathrm{C}(\mathrm{C}(\mathrm{H})(\mathrm{Br}) \mathrm{H})(\mathrm{H}) \mathrm{F})(\mathrm{H}) \mathrm{F})(\mathrm{F}) \mathrm{F})(\mathrm{H}) \mathrm{F})(\mathrm{F}) \mathrm{Br})(\mathrm{F}) \mathrm{F})(\mathrm{Cl}) \mathrm{H})(\mathrm{H}) \mathrm{Cl})(\mathrm{H}) \mathrm{F})(\mathrm{F})(\mathrm{F}) \mathrm{F}$ $\mathrm{C}(\mathrm{C}(\mathrm{C}(\mathrm{C}(\mathrm{C}(\mathrm{C}(\mathrm{C}(\mathrm{C}(\mathrm{C}(\mathrm{C}(\mathrm{C}(\mathrm{F})(\mathrm{Br}) \mathrm{Cl})(\mathrm{H}) \mathrm{F})(\mathrm{F}) \mathrm{H})(\mathrm{H}) \mathrm{H})(\mathrm{F}) \mathrm{H})(\mathrm{H}) \mathrm{F})(\mathrm{Cl}) \mathrm{F})(\mathrm{F}) \mathrm{H})(\mathrm{F}) \mathrm{Cl})(\mathrm{F}) \mathrm{F})(\mathrm{H})(\mathrm{F}) \mathrm{F}$ $\mathrm{C}(\mathrm{C}(\mathrm{C}(\mathrm{C}(\mathrm{C}(\mathrm{C}(\mathrm{C}(\mathrm{C}(\mathrm{C}(\mathrm{C}(\mathrm{C}(\mathrm{H})(\mathrm{Cl}) \mathrm{F})(\mathrm{Cl}) \mathrm{H})(\mathrm{H}) \mathrm{Br})(\mathrm{H}) \mathrm{F})(\mathrm{H}) \mathrm{F})(\mathrm{Cl}) \mathrm{F})(\mathrm{F}) \mathrm{F})(\mathrm{H}) \mathrm{Cl})(\mathrm{H}) \mathrm{F})(\mathrm{F}) \mathrm{H})(\mathrm{F})(\mathrm{F}) \mathrm{F}$ $\mathrm{C}(\mathrm{C}(\mathrm{C}(\mathrm{C}(\mathrm{C}(\mathrm{C}(\mathrm{C}(\mathrm{C}(\mathrm{C}(\mathrm{C}(\mathrm{C}(\mathrm{Cl})(\mathrm{F}) \mathrm{F})(\mathrm{F}) \mathrm{H})(\mathrm{H}) \mathrm{H})(\mathrm{Cl}) \mathrm{F})(\mathrm{F}) \mathrm{H})(\mathrm{Cl}) \mathrm{F})(\mathrm{F}) \mathrm{F})(\mathrm{Cl}) \mathrm{F})(\mathrm{H}) \mathrm{F})(\mathrm{F}) \mathrm{H})(\mathrm{H})(\mathrm{H}) \mathrm{F}$ $\mathrm{C}(\mathrm{C}(\mathrm{C}(\mathrm{C}(\mathrm{C}(\mathrm{C}(\mathrm{C}(\mathrm{C}(\mathrm{C}(\mathrm{C}(\mathrm{C}(\mathrm{Cl})(\mathrm{F}) \mathrm{F})(\mathrm{H}) \mathrm{F})(\mathrm{H}) \mathrm{F})(\mathrm{Cl}) \mathrm{Br})(\mathrm{F}) \mathrm{H})(\mathrm{Cl}) \mathrm{H})(\mathrm{F}) \mathrm{H})(\mathrm{H}) \mathrm{Cl})(\mathrm{F}) \mathrm{H})(\mathrm{F}) \mathrm{F})(\mathrm{Cl})(\mathrm{H}) \mathrm{F}$ $\mathrm{C}(\mathrm{C}(\mathrm{C}(\mathrm{C}(\mathrm{C}(\mathrm{C}(\mathrm{C}(\mathrm{C}(\mathrm{C}(\mathrm{C}(\mathrm{C}(\mathrm{F})(\mathrm{Cl}) \mathrm{H})(\mathrm{F}) \mathrm{F})(\mathrm{F}) \mathrm{H})(\mathrm{H}) \mathrm{Cl})(\mathrm{Cl}) \mathrm{F})(\mathrm{Cl}) \mathrm{F})(\mathrm{H}) \mathrm{Cl})(\mathrm{F}) \mathrm{H})(\mathrm{F}) \mathrm{H})(\mathrm{F}) \mathrm{F})(\mathrm{H})(\mathrm{H}) \mathrm{F}$ $\mathrm{C}(\mathrm{C}(\mathrm{C}(\mathrm{C}(\mathrm{C}(\mathrm{C}(\mathrm{C}(\mathrm{C}(\mathrm{C}(\mathrm{C}(\mathrm{C}(\mathrm{F})(\mathrm{F}) \mathrm{F})(\mathrm{F}) \mathrm{H})(\mathrm{F}) \mathrm{H})(\mathrm{Cl}) \mathrm{Cl})(\mathrm{Cl}) \mathrm{H})(\mathrm{F}) \mathrm{H})(\mathrm{F}) \mathrm{F})(\mathrm{F}) \mathrm{H})(\mathrm{Cl}) \mathrm{H})(\mathrm{H}) \mathrm{H})(\mathrm{Cl})(\mathrm{Cl}) \mathrm{F}$ $\mathrm{C}(\mathrm{C}(\mathrm{C}(\mathrm{C}(\mathrm{C}(\mathrm{C}(\mathrm{C}(\mathrm{C}(\mathrm{C}(\mathrm{C}(\mathrm{C}(\mathrm{H})(\mathrm{F}) \mathrm{Cl})(\mathrm{H}) \mathrm{F})(\mathrm{F}) \mathrm{Cl})(\mathrm{H}) \mathrm{F})(\mathrm{F}) \mathrm{H})(\mathrm{H}) \mathrm{F})(\mathrm{Cl}) \mathrm{F})(\mathrm{H}) \mathrm{Cl})(\mathrm{F}) \mathrm{Cl})(\mathrm{H}) \mathrm{F})(\mathrm{H})(\mathrm{Cl}) \mathrm{Cl}$ $\mathrm{C}(\mathrm{C}(\mathrm{C}(\mathrm{C}(\mathrm{C}(\mathrm{C}(\mathrm{C}(\mathrm{C}(\mathrm{C}(\mathrm{C}(\mathrm{C}(\mathrm{H})(\mathrm{H}) \mathrm{H})(\mathrm{F}) \mathrm{F})(\mathrm{H}) \mathrm{F})(\mathrm{F}) \mathrm{F})(\mathrm{F}) \mathrm{H})(\mathrm{Br}) \mathrm{H})(\mathrm{F}) \mathrm{F})(\mathrm{Cl}) \mathrm{H})(\mathrm{H}) \mathrm{Br})(\mathrm{F}) \mathrm{F})(\mathrm{F})(\mathrm{F}) \mathrm{F}$ $\mathrm{C}(\mathrm{C}(\mathrm{C}(\mathrm{C}(\mathrm{C}(\mathrm{C}(\mathrm{C}(\mathrm{C}(\mathrm{C}(\mathrm{C}(\mathrm{C}(\mathrm{F})(\mathrm{F}) \mathrm{H})(\mathrm{H}) \mathrm{H})(\mathrm{F}) \mathrm{H})(\mathrm{F}) \mathrm{H})(\mathrm{F}) \mathrm{Br})(\mathrm{Br}) \mathrm{F})(\mathrm{F}) \mathrm{F})(\mathrm{F}) \mathrm{Cl})(\mathrm{H}) \mathrm{Br})(\mathrm{H}) \mathrm{F})(\mathrm{F})(\mathrm{F}) \mathrm{H}$ $\mathrm{C}(\mathrm{C}(\mathrm{C}(\mathrm{C}(\mathrm{C}(\mathrm{C}(\mathrm{C}(\mathrm{C}(\mathrm{C}(\mathrm{C}(\mathrm{C}(\mathrm{H})(\mathrm{F}) \mathrm{F})(\mathrm{Br}) \mathrm{H})(\mathrm{F}) \mathrm{F})(\mathrm{F}) \mathrm{F})(\mathrm{F}) \mathrm{H})(\mathrm{F}) \mathrm{F})(\mathrm{H}) \mathrm{H})(\mathrm{F}) \mathrm{H})(\mathrm{Br}) \mathrm{H})(\mathrm{F}) \mathrm{H})(\mathrm{Br})(\mathrm{F}) \mathrm{H}$ $\mathrm{C}(\mathrm{C}(\mathrm{C}(\mathrm{C}(\mathrm{C}(\mathrm{C}(\mathrm{C}(\mathrm{C}(\mathrm{C}(\mathrm{C}(\mathrm{C}(\mathrm{Br})(\mathrm{F}) \mathrm{F})(\mathrm{F}) \mathrm{H})(\mathrm{F}) \mathrm{H})(\mathrm{F}) \mathrm{H})(\mathrm{F}) \mathrm{Br})(\mathrm{F}) \mathrm{H})(\mathrm{Br}) \mathrm{H})(\mathrm{Br}) \mathrm{H})(\mathrm{H}) \mathrm{H})(\mathrm{F}) \mathrm{F})(\mathrm{H})(\mathrm{F}) \mathrm{F}$ $\mathrm{C}(\mathrm{C}(\mathrm{C}(\mathrm{C}(\mathrm{C}(\mathrm{C}(\mathrm{C}(\mathrm{C}(\mathrm{C}(\mathrm{C}(\mathrm{C}(\mathrm{F})(\mathrm{H}) \mathrm{F})(\mathrm{F}) \mathrm{Cl})(\mathrm{F}) \mathrm{F})(\mathrm{F}) \mathrm{Br})(\mathrm{H}) \mathrm{H})(\mathrm{H}) \mathrm{H})(\mathrm{H}) \mathrm{H})(\mathrm{F}) \mathrm{F})(\mathrm{Cl}) \mathrm{F})(\mathrm{F}) \mathrm{Br})(\mathrm{H})(\mathrm{F}) \mathrm{H}$ $\mathrm{C}(\mathrm{C}(\mathrm{C}(\mathrm{C}(\mathrm{C}(\mathrm{C}(\mathrm{C}(\mathrm{C}(\mathrm{C}(\mathrm{C}(\mathrm{C}(\mathrm{Cl})(\mathrm{Cl}) \mathrm{H})(\mathrm{H}) \mathrm{F})(\mathrm{F}) \mathrm{Br})(\mathrm{H}) \mathrm{H})(\mathrm{H}) \mathrm{Cl})(\mathrm{F}) \mathrm{Br})(\mathrm{F}) \mathrm{H})(\mathrm{F}) \mathrm{F})(\mathrm{F}) \mathrm{F})(\mathrm{H}) \mathrm{F})(\mathrm{H})(\mathrm{H}) \mathrm{F}$ $\mathrm{C}(\mathrm{C}(\mathrm{C}(\mathrm{C}(\mathrm{C}(\mathrm{C}(\mathrm{C}(\mathrm{C}(\mathrm{C}(\mathrm{C}(\mathrm{C}(\mathrm{H})(\mathrm{F}) \mathrm{H})(\mathrm{F}) \mathrm{Br})(\mathrm{F}) \mathrm{H})(\mathrm{F}) \mathrm{F})(\mathrm{H}) \mathrm{H})(\mathrm{F}) \mathrm{H})(\mathrm{Cl}) \mathrm{F})(\mathrm{F}) \mathrm{Cl})(\mathrm{H}) \mathrm{H})(\mathrm{F}) \mathrm{F})(\mathrm{Cl})(\mathrm{H}) \mathrm{F}$ $\mathrm{C}(\mathrm{C}(\mathrm{C}(\mathrm{C}(\mathrm{C}(\mathrm{C}(\mathrm{C}(\mathrm{C}(\mathrm{C}(\mathrm{C}(\mathrm{C}(\mathrm{H})(\mathrm{H}) \mathrm{H})(\mathrm{F}) \mathrm{F})(\mathrm{F}) \mathrm{F})(\mathrm{F}) \mathrm{F})(\mathrm{F}) \mathrm{F})(\mathrm{Cl}) \mathrm{H})(\mathrm{H}) \mathrm{F})(\mathrm{Br}) \mathrm{Cl})(\mathrm{Cl}) \mathrm{H})(\mathrm{H}) \mathrm{H})(\mathrm{F})(\mathrm{Cl}) \mathrm{H}$ $\mathrm{C}(\mathrm{C}(\mathrm{C}(\mathrm{C}(\mathrm{C}(\mathrm{C}(\mathrm{C}(\mathrm{C}(\mathrm{C}(\mathrm{C}(\mathrm{C}(\mathrm{F})(\mathrm{F}) \mathrm{H})(\mathrm{F}) \mathrm{H})(\mathrm{F}) \mathrm{H})(\mathrm{F}) \mathrm{Cl})(\mathrm{F}) \mathrm{Cl})(\mathrm{H}) \mathrm{F})(\mathrm{Cl}) \mathrm{F})(\mathrm{F}) \mathrm{F})(\mathrm{F}) \mathrm{H})(\mathrm{H}) \mathrm{Cl})(\mathrm{H})(\mathrm{H}) \mathrm{H}$ $\mathrm{C}(\mathrm{C}(\mathrm{C}(\mathrm{C}(\mathrm{C}(\mathrm{C}(\mathrm{C}(\mathrm{C}(\mathrm{C}(\mathrm{C}(\mathrm{C}(\mathrm{H})(\mathrm{H}) \mathrm{Cl})(\mathrm{H}) \mathrm{F})(\mathrm{Cl}) \mathrm{F})(\mathrm{F}) \mathrm{H})(\mathrm{F}) \mathrm{H})(\mathrm{Br}) \mathrm{F})(\mathrm{H}) \mathrm{F})(\mathrm{Cl}) \mathrm{Cl})(\mathrm{H}) \mathrm{F})(\mathrm{F}) \mathrm{H})(\mathrm{H})(\mathrm{Cl}) \mathrm{F}$ $\mathrm{C}(\mathrm{C}(\mathrm{C}(\mathrm{C}(\mathrm{C}(\mathrm{C}(\mathrm{C}(\mathrm{C}(\mathrm{C}(\mathrm{C}(\mathrm{C}(\mathrm{F})(\mathrm{H}) \mathrm{F})(\mathrm{Cl}) \mathrm{F})(\mathrm{H}) \mathrm{H})(\mathrm{Cl}) \mathrm{H})(\mathrm{F}) \mathrm{F})(\mathrm{H}) \mathrm{F})(\mathrm{F}) \mathrm{H})(\mathrm{H}) \mathrm{Cl})(\mathrm{Cl}) \mathrm{F})(\mathrm{H}) \mathrm{H})(\mathrm{F})(\mathrm{Cl}) \mathrm{F}$ $\mathrm{C}(\mathrm{C}(\mathrm{C}(\mathrm{C}(\mathrm{C}(\mathrm{C}(\mathrm{C}(\mathrm{C}(\mathrm{C}(\mathrm{C}(\mathrm{C}(\mathrm{H})(\mathrm{H}) \mathrm{F})(\mathrm{Cl}) \mathrm{H})(\mathrm{H}) \mathrm{F})(\mathrm{Cl}) \mathrm{F})(\mathrm{H}) \mathrm{H})(\mathrm{H}) \mathrm{Cl})(\mathrm{H}) \mathrm{Cl})(\mathrm{F}) \mathrm{F})(\mathrm{H}) \mathrm{F})(\mathrm{Cl}) \mathrm{F})(\mathrm{F})(\mathrm{Cl}) \mathrm{F}$ $\mathrm{C}(\mathrm{C}(\mathrm{C}(\mathrm{C}(\mathrm{C}(\mathrm{C}(\mathrm{C}(\mathrm{C}(\mathrm{C}(\mathrm{C}(\mathrm{C}(\mathrm{H})(\mathrm{F}) \mathrm{H})(\mathrm{H}) \mathrm{Cl})(\mathrm{H}) \mathrm{Cl})(\mathrm{H}) \mathrm{F})(\mathrm{Cl}) \mathrm{F})(\mathrm{F}) \mathrm{H})(\mathrm{Cl}) \mathrm{Cl})(\mathrm{F}) \mathrm{H})(\mathrm{H}) \mathrm{Cl})(\mathrm{F}) \mathrm{H})(\mathrm{Cl})(\mathrm{F}) \mathrm{F}$ $\mathrm{C}(\mathrm{C}(\mathrm{C}(\mathrm{C}(\mathrm{C}(\mathrm{C}(\mathrm{C}(\mathrm{C}(\mathrm{C}(\mathrm{C}(\mathrm{C}(\mathrm{H})(\mathrm{F}) \mathrm{F})(\mathrm{F}) \mathrm{H})(\mathrm{F}) \mathrm{F})(\mathrm{Cl}) \mathrm{H})(\mathrm{Br}) \mathrm{Br})(\mathrm{F}) \mathrm{H})(\mathrm{H}) \mathrm{H})(\mathrm{F}) \mathrm{F})(\mathrm{F}) \mathrm{F})(\mathrm{H}) \mathrm{F})(\mathrm{F})(\mathrm{H}) \mathrm{H}$ $\mathrm{C}(\mathrm{C}(\mathrm{C}(\mathrm{C}(\mathrm{C}(\mathrm{C}(\mathrm{C}(\mathrm{C}(\mathrm{C}(\mathrm{C}(\mathrm{C}(\mathrm{H})(\mathrm{F}) \mathrm{Br})(\mathrm{H}) \mathrm{Br})(\mathrm{H}) \mathrm{H})(\mathrm{F}) \mathrm{F})(\mathrm{F}) \mathrm{Br})(\mathrm{F}) \mathrm{H})(\mathrm{H}) \mathrm{Cl})(\mathrm{H}) \mathrm{H})(\mathrm{F}) \mathrm{F})(\mathrm{F}) \mathrm{F})(\mathrm{F})(\mathrm{H}) \mathrm{F}$ $\mathrm{C}(\mathrm{C}(\mathrm{C}(\mathrm{C}(\mathrm{C}(\mathrm{C}(\mathrm{C}(\mathrm{C}(\mathrm{C}(\mathrm{C}(\mathrm{C}(\mathrm{C}(\mathrm{F})(\mathrm{H}) \mathrm{H})(\mathrm{F}) \mathrm{H})(\mathrm{Br}) \mathrm{H})(\mathrm{F}) \mathrm{H})(\mathrm{Br}) \mathrm{H})(\mathrm{F}) \mathrm{F})(\mathrm{F}) \mathrm{F})(\mathrm{H}) \mathrm{H})(\mathrm{F}) \mathrm{F})(\mathrm{H}) \mathrm{F})(\mathrm{F}) \mathrm{F})(\mathrm{Br})(\mathrm{F}) \quad \mathrm{C} 12 \mathrm{H} 10 \mathrm{Br} 3 \mathrm{~F} 13$ $\mathrm{C}(\mathrm{C}(\mathrm{C}(\mathrm{C}(\mathrm{C}(\mathrm{C}(\mathrm{C}(\mathrm{C}(\mathrm{C}(\mathrm{C}(\mathrm{C}(\mathrm{C}(\mathrm{H})(\mathrm{F}) \mathrm{Br})(\mathrm{F}) \mathrm{F})(\mathrm{F}) \mathrm{H})(\mathrm{F}) \mathrm{H})(\mathrm{Br}) \mathrm{H})(\mathrm{H}) \mathrm{Br})(\mathrm{F}) \mathrm{F})(\mathrm{H}) \mathrm{F})(\mathrm{H}) \mathrm{H})(\mathrm{F}) \mathrm{F})(\mathrm{F}) \mathrm{Br})(\mathrm{H})(\mathrm{F}) \mathrm{C} 12 \mathrm{H} 10 \mathrm{Br} 4 \mathrm{~F} 12$ $\mathrm{C}(\mathrm{C}(\mathrm{C}(\mathrm{C}(\mathrm{C}(\mathrm{C}(\mathrm{C}(\mathrm{C}(\mathrm{C}(\mathrm{C}(\mathrm{C}(\mathrm{C}(\mathrm{Cl})(\mathrm{H}) \mathrm{F})(\mathrm{F}) \mathrm{Br})(\mathrm{H}) \mathrm{H})(\mathrm{F}) \mathrm{F})(\mathrm{H}) \mathrm{F})(\mathrm{H}) \mathrm{H})(\mathrm{H}) \mathrm{H})(\mathrm{H}) \mathrm{F})(\mathrm{Br}) \mathrm{F})(\mathrm{F}) \mathrm{H})(\mathrm{F}) \mathrm{F})(\mathrm{F})(\mathrm{Cl}) \mathrm{C} 12 \mathrm{H} 10 \mathrm{Cl} 2 \mathrm{Br} 2 \mathrm{~F} 1$ $\mathrm{C}(\mathrm{C}(\mathrm{C}(\mathrm{C}(\mathrm{C}(\mathrm{C}(\mathrm{C}(\mathrm{C}(\mathrm{C}(\mathrm{C}(\mathrm{C}(\mathrm{C}(\mathrm{F})(\mathrm{F}) \mathrm{F})(\mathrm{H}) \mathrm{H})(\mathrm{H}) \mathrm{F})(\mathrm{H}) \mathrm{F})(\mathrm{F}) \mathrm{F})(\mathrm{Cl}) \mathrm{F})(\mathrm{F}) \mathrm{H})(\mathrm{H}) \mathrm{Br})(\mathrm{H}) \mathrm{Br})(\mathrm{H}) \mathrm{Br})(\mathrm{H}) \mathrm{F})(\mathrm{H})$ $(\mathrm{Cl}) \mathrm{F}$ $\mathrm{C}(\mathrm{C}(\mathrm{C}(\mathrm{C}(\mathrm{C}(\mathrm{C}(\mathrm{C}(\mathrm{C}(\mathrm{C}(\mathrm{C}(\mathrm{C}(\mathrm{C}(\mathrm{Cl})(\mathrm{F}) \mathrm{H})(\mathrm{Cl}) \mathrm{F})(\mathrm{F}) \mathrm{H})(\mathrm{Cl}) \mathrm{F})(\mathrm{Br}) \mathrm{H})(\mathrm{H}) \mathrm{H})(\mathrm{F}) \mathrm{H})(\mathrm{H}) \mathrm{F})(\mathrm{F}) \mathrm{Br})(\mathrm{H}) \mathrm{H})(\mathrm{F}) \mathrm{F})(\mathrm{F})(\mathrm{F}) \mathrm{C} 12 \mathrm{H} 10 \mathrm{Cl} 3 \mathrm{Br} 2 \mathrm{~F} 1$

$\mathrm{C}(\mathrm{C}(\mathrm{C}(\mathrm{C}(\mathrm{C}(\mathrm{C}(\mathrm{C}(\mathrm{C}(\mathrm{C}(\mathrm{C}(\mathrm{C}(\mathrm{C}(\mathrm{F})(\mathrm{H}) \mathrm{F})(\mathrm{Cl}) \mathrm{F})(\mathrm{Cl}) \mathrm{F})(\mathrm{H}) \mathrm{F})(\mathrm{H}) \mathrm{H})(\mathrm{H}) \mathrm{F})(\mathrm{F}) \mathrm{F})(\mathrm{H}) \mathrm{F})(\mathrm{H}) \mathrm{Cl})(\mathrm{H}) \mathrm{F})(\mathrm{Br}) \mathrm{H})(\mathrm{F})(\mathrm{F}) \quad \mathrm{C} 12 \mathrm{H} 10 \mathrm{Cl} 3 \mathrm{BrF} 12$ $\mathrm{C}(\mathrm{C}(\mathrm{C}(\mathrm{C}(\mathrm{C}(\mathrm{C}(\mathrm{C}(\mathrm{C}(\mathrm{C}(\mathrm{C}(\mathrm{C}(\mathrm{C}(\mathrm{H})(\mathrm{Br}) \mathrm{F})(\mathrm{Cl}) \mathrm{H})(\mathrm{F}) \mathrm{Cl})(\mathrm{F}) \mathrm{H})(\mathrm{Cl}) \mathrm{H})(\mathrm{H}) \mathrm{F})(\mathrm{F}) \mathrm{H})(\mathrm{H}) \mathrm{F})(\mathrm{F}) \mathrm{F})(\mathrm{F}) \mathrm{H})(\mathrm{H}) \mathrm{F})(\mathrm{Cl}) \quad \mathrm{C} 12 \mathrm{H} 10 \mathrm{Cl} 4 \mathrm{BrF} 11$ $\mathrm{C}(\mathrm{C}(\mathrm{C}(\mathrm{C}(\mathrm{C}(\mathrm{C}(\mathrm{C}(\mathrm{C}(\mathrm{C}(\mathrm{C}(\mathrm{C}(\mathrm{C}(\mathrm{F})(\mathrm{F}) \mathrm{H})(\mathrm{F}) \mathrm{F})(\mathrm{F}) \mathrm{H})(\mathrm{Cl}) \mathrm{F})(\mathrm{H}) \mathrm{Cl})(\mathrm{H}) \mathrm{Br})(\mathrm{Cl}) \mathrm{H})(\mathrm{H}) \mathrm{F})(\mathrm{H}) \mathrm{H})(\mathrm{F}) \mathrm{F})(\mathrm{F}) \mathrm{H})(\mathrm{Cl}) \quad \mathrm{C} 12 \mathrm{H} 10 \mathrm{Cl} 5 \mathrm{BrF} 10$ $\mathrm{C}(\mathrm{C}(\mathrm{C}(\mathrm{C}(\mathrm{C}(\mathrm{C}(\mathrm{C}(\mathrm{C}(\mathrm{C}(\mathrm{C}(\mathrm{C}(\mathrm{C}(\mathrm{F})(\mathrm{H}) \mathrm{F})(\mathrm{H}) \mathrm{H})(\mathrm{F}) \mathrm{H})(\mathrm{Cl}) \mathrm{Cl})(\mathrm{Cl}) \mathrm{H})(\mathrm{H}) \mathrm{H})(\mathrm{H}) \mathrm{Cl})(\mathrm{H}) \mathrm{F})(\mathrm{F}) \mathrm{F})(\mathrm{F}) \mathrm{F})(\mathrm{Cl}) \mathrm{F})(\mathrm{F})(\mathrm{F}) \mathrm{C} 12 \mathrm{H} 10 \mathrm{Cl}$ F 11 $\mathrm{C}(\mathrm{C}(\mathrm{C}(\mathrm{C}(\mathrm{C}(\mathrm{C}(\mathrm{C}(\mathrm{C}(\mathrm{C}(\mathrm{C}(\mathrm{C}(\mathrm{C}(\mathrm{H})(\mathrm{F}) \mathrm{F})(\mathrm{F}) \mathrm{Cl})(\mathrm{H}) \mathrm{F})(\mathrm{H}) \mathrm{F})(\mathrm{H}) \mathrm{F})(\mathrm{H}) \mathrm{Cl})(\mathrm{F}) \mathrm{H})(\mathrm{H}) \mathrm{H})(\mathrm{F}) \mathrm{H})(\mathrm{Cl}) \mathrm{F})(\mathrm{Cl}) \mathrm{F})(\mathrm{Cl})(\mathrm{H}) \mathrm{C} 12 \mathrm{H} 10 \mathrm{Cl}$ F 10 $\mathrm{C}(\mathrm{C}(\mathrm{C}(\mathrm{C}(\mathrm{C}(\mathrm{C}(\mathrm{C}(\mathrm{C}(\mathrm{C}(\mathrm{C}(\mathrm{C}(\mathrm{C}(\mathrm{F})(\mathrm{F}) \mathrm{Br})(\mathrm{F}) \mathrm{F})(\mathrm{H}) \mathrm{H})(\mathrm{H}) \mathrm{H})(\mathrm{H}) \mathrm{H})(\mathrm{F}) \mathrm{H})(\mathrm{F}) \mathrm{F})(\mathrm{H}) \mathrm{H})(\mathrm{F}) \mathrm{F})(\mathrm{Cl}) \mathrm{F})(\mathrm{F}) \mathrm{F})(\mathrm{H})(\mathrm{F}) \mathrm{Br} \mathrm{C} 12 \mathrm{H} 10 \mathrm{ClBr} 2 \mathrm{~F} 13$ $\mathrm{C}(\mathrm{C}(\mathrm{C}(\mathrm{C}(\mathrm{C}(\mathrm{C}(\mathrm{C}(\mathrm{C}(\mathrm{C}(\mathrm{C}(\mathrm{C}(\mathrm{C}(\mathrm{H})(\mathrm{H}) \mathrm{F})(\mathrm{H}) \mathrm{F})(\mathrm{F}) \mathrm{H})(\mathrm{H}) \mathrm{F})(\mathrm{F}) \mathrm{Br})(\mathrm{H}) \mathrm{Cl})(\mathrm{F}) \mathrm{F})(\mathrm{Br}) \mathrm{H})(\mathrm{F}) \mathrm{F})(\mathrm{H}) \mathrm{F})(\mathrm{F}) \mathrm{Br})(\mathrm{H})(\mathrm{F}) \quad \mathrm{C} 12 \mathrm{H} 10 \mathrm{ClBr} 3 \mathrm{~F} 12$ $\mathrm{C}(\mathrm{C}(\mathrm{C}(\mathrm{C}(\mathrm{C}(\mathrm{C}(\mathrm{C}(\mathrm{C}(\mathrm{C}(\mathrm{C}(\mathrm{C}(\mathrm{C}(\mathrm{F})(\mathrm{F}) \mathrm{Br})(\mathrm{F}) \mathrm{F})(\mathrm{Br}) \mathrm{F})(\mathrm{F}) \mathrm{F})(\mathrm{H}) \mathrm{H})(\mathrm{F}) \mathrm{H})(\mathrm{H}) \mathrm{F})(\mathrm{Br}) \mathrm{H})(\mathrm{H}) \mathrm{H})(\mathrm{F}) \mathrm{H})(\mathrm{H}) \mathrm{H})(\mathrm{F})(\mathrm{F}) \quad \mathrm{C} 12 \mathrm{H} 11 \mathrm{Br} 3 \mathrm{~F} 12$ $\mathrm{C}(\mathrm{C}(\mathrm{C}(\mathrm{C}(\mathrm{C}(\mathrm{C}(\mathrm{C}(\mathrm{C}(\mathrm{C}(\mathrm{C}(\mathrm{C}(\mathrm{C}(\mathrm{F})(\mathrm{H}) \mathrm{F})(\mathrm{H}) \mathrm{F})(\mathrm{H}) \mathrm{F})(\mathrm{H}) \mathrm{H})(\mathrm{F}) \mathrm{Br})(\mathrm{F}) \mathrm{F})(\mathrm{H}) \mathrm{F})(\mathrm{H}) \mathrm{Br})(\mathrm{Br}) \mathrm{F})(\mathrm{H}) \mathrm{F})(\mathrm{F}) \mathrm{Br})(\mathrm{H})(\mathrm{H}) \mathrm{C} 12 \mathrm{H} 11 \mathrm{Br} 4 \mathrm{~F} 11$ $\mathrm{C}(\mathrm{C}(\mathrm{C}(\mathrm{C}(\mathrm{C}(\mathrm{C}(\mathrm{C}(\mathrm{C}(\mathrm{C}(\mathrm{C}(\mathrm{C}(\mathrm{C}(\mathrm{F})(\mathrm{F}) \mathrm{H})(\mathrm{H}) \mathrm{F})(\mathrm{H}) \mathrm{F})(\mathrm{H}) \mathrm{F})(\mathrm{Br}) \mathrm{F})(\mathrm{F}) \mathrm{F})(\mathrm{F}) \mathrm{H})(\mathrm{H}) \mathrm{Cl})(\mathrm{H}) \mathrm{H})(\mathrm{H}) \mathrm{F})(\mathrm{Cl}) \mathrm{H})(\mathrm{F})(\mathrm{H}) \quad \mathrm{C} 12 \mathrm{H} 1 \mathrm{Cl}^{\mathrm{B}} \mathrm{Br} 2 \mathrm{~F} 1$

$\mathrm{C}(\mathrm{C}(\mathrm{C}(\mathrm{C}(\mathrm{C}(\mathrm{C}(\mathrm{C}(\mathrm{C}(\mathrm{C}(\mathrm{C}(\mathrm{C}(\mathrm{C}(\mathrm{H})(\mathrm{Br}) \mathrm{F})(\mathrm{H}) \mathrm{H})(\mathrm{F}) \mathrm{F})(\mathrm{H}) \mathrm{Br})(\mathrm{H}) \mathrm{F})(\mathrm{F}) \mathrm{H})(\mathrm{Cl}) \mathrm{H})(\mathrm{Br}) \mathrm{F})(\mathrm{F}) \mathrm{H})(\mathrm{F}) \mathrm{F})(\mathrm{H}) \mathrm{F})(\mathrm{H}) \quad \mathrm{C} 12 \mathrm{H} 11 \mathrm{Cl} 2 \mathrm{Br} 3 \mathrm{~F} 1$ (H)Cl

$\mathrm{C}(\mathrm{C}(\mathrm{C}(\mathrm{C}(\mathrm{C}(\mathrm{C}(\mathrm{C}(\mathrm{C}(\mathrm{C}(\mathrm{C}(\mathrm{C}(\mathrm{C}(\mathrm{H})(\mathrm{F}) \mathrm{F})(\mathrm{F}) \mathrm{H})(\mathrm{F}) \mathrm{F})(\mathrm{H}) \mathrm{F})(\mathrm{H}) \mathrm{H})(\mathrm{H}) \mathrm{H})(\mathrm{H}) \mathrm{H})(\mathrm{F}) \mathrm{H})(\mathrm{H}) \mathrm{Cl})(\mathrm{Br}) \mathrm{F})(\mathrm{F}) \mathrm{F})(\mathrm{Cl})(\mathrm{F}) \quad \mathrm{C} 12 \mathrm{H} 11 \mathrm{Cl} 2 \mathrm{BrF} 12$ $\mathrm{C}(\mathrm{C}(\mathrm{C}(\mathrm{C}(\mathrm{C}(\mathrm{C}(\mathrm{C}(\mathrm{C}(\mathrm{C}(\mathrm{C}(\mathrm{C}(\mathrm{C}(\mathrm{H})(\mathrm{H}) \mathrm{F})(\mathrm{H}) \mathrm{H})(\mathrm{F}) \mathrm{F})(\mathrm{F}) \mathrm{F})(\mathrm{H}) \mathrm{H})(\mathrm{Br}) \mathrm{F})(\mathrm{Cl}) \mathrm{Cl})(\mathrm{H}) \mathrm{F})(\mathrm{F}) \mathrm{H})(\mathrm{F}) \mathrm{H})(\mathrm{Cl}) \mathrm{H})(\mathrm{F})(\mathrm{F}) \mathrm{C}_{2} \mathrm{H} 11 \mathrm{Cl} 3 \mathrm{BrF} 11$ $\mathrm{C}(\mathrm{C}(\mathrm{C}(\mathrm{C}(\mathrm{C}(\mathrm{C}(\mathrm{C}(\mathrm{C}(\mathrm{C}(\mathrm{C}(\mathrm{C}(\mathrm{C}(\mathrm{F})(\mathrm{F}) \mathrm{H})(\mathrm{F}) \mathrm{F})(\mathrm{H}) \mathrm{F})(\mathrm{H}) \mathrm{H})(\mathrm{F}) \mathrm{Cl})(\mathrm{H}) \mathrm{F})(\mathrm{H}) \mathrm{Cl})(\mathrm{H}) \mathrm{F})(\mathrm{H}) \mathrm{H})(\mathrm{Br}) \mathrm{F})(\mathrm{H}) \mathrm{H})(\mathrm{Cl})(\mathrm{F}) \mathrm{C} 12 \mathrm{H} 11 \mathrm{Cl} 4 \mathrm{BrF} 10$ $\mathrm{C}(\mathrm{C}(\mathrm{C}(\mathrm{C}(\mathrm{C}(\mathrm{C}(\mathrm{C}(\mathrm{C}(\mathrm{C}(\mathrm{C}(\mathrm{C}(\mathrm{C}(\mathrm{H})(\mathrm{F}) \mathrm{F})(\mathrm{H}) \mathrm{H})(\mathrm{H}) \mathrm{H})(\mathrm{F}) \mathrm{Cl})(\mathrm{Cl}) \mathrm{F})(\mathrm{F}) \mathrm{H})(\mathrm{H}) \mathrm{F})(\mathrm{H}) \mathrm{H})(\mathrm{H}) \mathrm{F})(\mathrm{F}) \mathrm{F})(\mathrm{F}) \mathrm{Cl})(\mathrm{Cl})(\mathrm{H}) \quad \mathrm{C} 12 \mathrm{H} 11 \mathrm{Cl} 4 \mathrm{~F} 11$ $\mathrm{C}(\mathrm{C}(\mathrm{C}(\mathrm{C}(\mathrm{C}(\mathrm{C}(\mathrm{C}(\mathrm{C}(\mathrm{C}(\mathrm{C}(\mathrm{C}(\mathrm{C}(\mathrm{H})(\mathrm{Cl}) \mathrm{F})(\mathrm{F}) \mathrm{H})(\mathrm{H}) \mathrm{F})(\mathrm{F}) \mathrm{H})(\mathrm{Cl}) \mathrm{H})(\mathrm{H}) \mathrm{F})(\mathrm{F}) \mathrm{F})(\mathrm{Br}) \mathrm{H})(\mathrm{H}) \mathrm{F})(\mathrm{Cl}) \mathrm{Cl})(\mathrm{H}) \mathrm{F})(\mathrm{H}) \quad \mathrm{C} 12 \mathrm{H} 11 \mathrm{Cl} 5 \mathrm{BrF}$ $\mathrm{C}(\mathrm{C}(\mathrm{C}(\mathrm{C}(\mathrm{C}(\mathrm{C}(\mathrm{C}(\mathrm{C}(\mathrm{C}(\mathrm{C}(\mathrm{C}(\mathrm{C}(\mathrm{Cl})(\mathrm{Cl}) \mathrm{H})(\mathrm{F}) \mathrm{Cl})(\mathrm{H}) \mathrm{F})(\mathrm{F}) \mathrm{H})(\mathrm{Cl}) \mathrm{H})(\mathrm{H}) \mathrm{Cl})(\mathrm{F}) \mathrm{F})(\mathrm{F}) \mathrm{H})(\mathrm{H}) \mathrm{F})(\mathrm{F}) \mathrm{H})(\mathrm{H}) \mathrm{F})(\mathrm{H})(\mathrm{F}) \mathrm{C} 12 \mathrm{H} 11 \mathrm{Cl} 5 \mathrm{~F} 10$ $\mathrm{C}(\mathrm{C}(\mathrm{C}(\mathrm{C}(\mathrm{C}(\mathrm{C}(\mathrm{C}(\mathrm{C}(\mathrm{C}(\mathrm{C}(\mathrm{C}(\mathrm{C}(\mathrm{F})(\mathrm{Cl}) \mathrm{Cl})(\mathrm{F}) \mathrm{F})(\mathrm{F}) \mathrm{H})(\mathrm{H}) \mathrm{Cl})(\mathrm{Cl}) \mathrm{Cl})(\mathrm{H}) \mathrm{F})(\mathrm{H}) \mathrm{H})(\mathrm{F}) \mathrm{Cl})(\mathrm{H}) \mathrm{H})(\mathrm{H}) \mathrm{F})(\mathrm{H}) \mathrm{H})(\mathrm{F}) \quad \mathrm{C} 12 \mathrm{H} 11 \mathrm{Cl} 6 \mathrm{~F} 9$ $\mathrm{C}(\mathrm{C}(\mathrm{C}(\mathrm{C}(\mathrm{C}(\mathrm{C}(\mathrm{C}(\mathrm{C}(\mathrm{C}(\mathrm{C}(\mathrm{C}(\mathrm{C}(\mathrm{H})(\mathrm{Br}) \mathrm{F})(\mathrm{H}) \mathrm{F})(\mathrm{H}) \mathrm{F})(\mathrm{F}) \mathrm{F})(\mathrm{F}) \mathrm{H})(\mathrm{F}) \mathrm{F})(\mathrm{F}) \mathrm{H})(\mathrm{F}) \mathrm{Br})(\mathrm{Cl}) \mathrm{H})(\mathrm{H}) \mathrm{H})(\mathrm{F}) \mathrm{F})(\mathrm{H})(\mathrm{H}) \quad \mathrm{C} 12 \mathrm{H} 11 \mathrm{ClBr} 2 \mathrm{~F} 12$ $\mathrm{C}(\mathrm{C}(\mathrm{C}(\mathrm{C}(\mathrm{C}(\mathrm{C}(\mathrm{C}(\mathrm{C}(\mathrm{C}(\mathrm{C}(\mathrm{C}(\mathrm{C}(\mathrm{H})(\mathrm{F}) \mathrm{H})(\mathrm{H}) \mathrm{F})(\mathrm{H}) \mathrm{H})(\mathrm{H}) \mathrm{F})(\mathrm{H}) \mathrm{F})(\mathrm{F}) \mathrm{H})(\mathrm{F}) \mathrm{H})(\mathrm{F}) \mathrm{H})(\mathrm{F}) \mathrm{F})(\mathrm{H}) \mathrm{Br})(\mathrm{Br}) \mathrm{H})(\mathrm{F})(\mathrm{Br}) \mathrm{C} 12 \mathrm{H} 12 \mathrm{Br} 3 \mathrm{~F} 11$ $\mathrm{C}(\mathrm{C}(\mathrm{C}(\mathrm{C}(\mathrm{C}(\mathrm{C}(\mathrm{C}(\mathrm{C}(\mathrm{C}(\mathrm{C}(\mathrm{C}(\mathrm{C}(\mathrm{H})(\mathrm{H}) \mathrm{H})(\mathrm{F}) \mathrm{Br})(\mathrm{H}) \mathrm{F})(\mathrm{F}) \mathrm{Cl})(\mathrm{F}) \mathrm{F})(\mathrm{H}) \mathrm{F})(\mathrm{H}) \mathrm{H})(\mathrm{H}) \mathrm{H})(\mathrm{Cl}) \mathrm{F})(\mathrm{H}) \mathrm{H})(\mathrm{F}) \mathrm{Br})(\mathrm{F}) \quad \mathrm{C} 12 \mathrm{H} 12 \mathrm{Cl} 2 \mathrm{Br} 2 \mathrm{~F} 1$ (H)F

$\mathrm{C}(\mathrm{C}(\mathrm{C}(\mathrm{C}(\mathrm{C}(\mathrm{C}(\mathrm{C}(\mathrm{C}(\mathrm{C}(\mathrm{C}(\mathrm{C}(\mathrm{C}(\mathrm{H})(\mathrm{Br}) \mathrm{H})(\mathrm{H}) \mathrm{F})(\mathrm{F}) \mathrm{Br})(\mathrm{F}) \mathrm{H})(\mathrm{Br}) \mathrm{H})(\mathrm{H}) \mathrm{Cl})(\mathrm{H}) \mathrm{F})(\mathrm{H}) \mathrm{H})(\mathrm{H}) \mathrm{F})(\mathrm{H}) \mathrm{F})(\mathrm{F}) \mathrm{Cl})(\mathrm{F})(\mathrm{C} 12 \mathrm{H} 12 \mathrm{Cl} 2 \mathrm{Br} 3 \mathrm{~F} 9$ $\mathrm{C}(\mathrm{C}(\mathrm{C}(\mathrm{C}(\mathrm{C}(\mathrm{C}(\mathrm{C}(\mathrm{C}(\mathrm{C}(\mathrm{C}(\mathrm{C}(\mathrm{C}(\mathrm{H})(\mathrm{H}) \mathrm{H})(\mathrm{F}) \mathrm{F})(\mathrm{H}) \mathrm{H})(\mathrm{F}) \mathrm{F})(\mathrm{F}) \mathrm{F})(\mathrm{F}) \mathrm{F})(\mathrm{H}) \mathrm{Br})(\mathrm{Cl}) \mathrm{F})(\mathrm{H}) \mathrm{H})(\mathrm{H}) \mathrm{F})(\mathrm{F}) \mathrm{H})(\mathrm{H})(\mathrm{H}) \mathrm{C}$ C12H12Cl2BrF1 1 $\mathrm{C}(\mathrm{C}(\mathrm{C}(\mathrm{C}(\mathrm{C}(\mathrm{C}(\mathrm{C}(\mathrm{C}(\mathrm{C}(\mathrm{C}(\mathrm{C}(\mathrm{C}(\mathrm{F})(\mathrm{Cl}) \mathrm{H})(\mathrm{H}) \mathrm{Br})(\mathrm{H}) \mathrm{H})(\mathrm{H}) \mathrm{F})(\mathrm{Cl}) \mathrm{Cl})(\mathrm{F}) \mathrm{H})(\mathrm{F}) \mathrm{H})(\mathrm{F}) \mathrm{F})(\mathrm{H}) \mathrm{F})(\mathrm{F}) \mathrm{F})(\mathrm{H}) \mathrm{H})(\mathrm{H})(\mathrm{F}) \mathrm{C} 12 \mathrm{H} 12 \mathrm{Cl} 3 \mathrm{BrF} 10$ $\mathrm{C}(\mathrm{C}(\mathrm{C}(\mathrm{C}(\mathrm{C}(\mathrm{C}(\mathrm{C}(\mathrm{C}(\mathrm{C}(\mathrm{C}(\mathrm{C}(\mathrm{C}(\mathrm{H})(\mathrm{F}) \mathrm{H})(\mathrm{H}) \mathrm{H})(\mathrm{Cl}) \mathrm{H})(\mathrm{H}) \mathrm{Cl})(\mathrm{Br}) \mathrm{F})(\mathrm{Cl}) \mathrm{F})(\mathrm{F}) \mathrm{F})(\mathrm{H}) \mathrm{H})(\mathrm{F}) \mathrm{H})(\mathrm{H}) \mathrm{Cl})(\mathrm{F}) \mathrm{F})(\mathrm{H})(\mathrm{C} 12 \mathrm{H} 12 \mathrm{Cl} 4 \mathrm{BrF}$ $\mathrm{C}(\mathrm{C}(\mathrm{C}(\mathrm{C}(\mathrm{C}(\mathrm{C}(\mathrm{C}(\mathrm{C}(\mathrm{C}(\mathrm{C}(\mathrm{C}(\mathrm{C}(\mathrm{F})(\mathrm{F}) \mathrm{Cl})(\mathrm{Cl}) \mathrm{H})(\mathrm{H}) \mathrm{F})(\mathrm{F}) \mathrm{F})(\mathrm{H}) \mathrm{H})(\mathrm{H}) \mathrm{H})(\mathrm{F}) \mathrm{F})(\mathrm{H}) \mathrm{F})(\mathrm{H}) \mathrm{H})(\mathrm{F}) \mathrm{Cl})(\mathrm{H}) \mathrm{Cl})(\mathrm{F})(\mathrm{H}) \mathrm{C} 12 \mathrm{H} 12 \mathrm{Cl} 4 \mathrm{~F} 10$ $\mathrm{C}(\mathrm{C}(\mathrm{C}(\mathrm{C}(\mathrm{C}(\mathrm{C}(\mathrm{C}(\mathrm{C}(\mathrm{C}(\mathrm{C}(\mathrm{C}(\mathrm{C}(\mathrm{H})(\mathrm{F}) \mathrm{F})(\mathrm{H}) \mathrm{F})(\mathrm{F}) \mathrm{H})(\mathrm{F}) \mathrm{Cl})(\mathrm{H}) \mathrm{H})(\mathrm{F}) \mathrm{Cl})(\mathrm{Cl}) \mathrm{Cl})(\mathrm{F}) \mathrm{F})(\mathrm{H}) \mathrm{H})(\mathrm{H}) \mathrm{H})(\mathrm{F}) \mathrm{H})(\mathrm{Cl}) \quad \mathrm{C} 12 \mathrm{H} 12 \mathrm{Cl} 5 \mathrm{~F} 9$

lgKoa lgKow lgKaw lgKow lgKoa lgKa lgKow lgKoa lgKaw EPISuit EPI EPI Exp Exp w DFT DFT DFT e Suite Suite corr_corr _Exp corr_corr_corr $\begin{array}{lllllllll}5.484 & 8.86 & 3.38 & 8.30 & 4.92 & 3.38 & 7.57 & 8.09 & -0.52 \\ 7.412 & 9.55 & 2.14 & 9.33 & 7.19 & 2.14 & 8.10 & 11.63 & -3.53\end{array}$ $\begin{array}{llllll}2.14 & 9.33 & 7.19 & 2.14 & 8.10 & 1\end{array}$ $\begin{array}{llllllll}3.11 & 8.63 & 5.52 & 3.11 & 7.74 & 8.98 & -1\end{array}$ $7.333 \quad 9.69$ $\begin{array}{llllllllll}5.696 & 9.29 & 3.59 & 8.94 & 5.35 & 3.59 & 7.90 & 8.48 & -0.58\end{array}$ $\begin{array}{llllllllll}5.12 & 9.2 & 4.08 & 8.81 & 4.73 & 4.08 & 7.83 & 7.42 & 0.41\end{array}$ $\begin{array}{llllllllll}6.182 & 9.51 & 3.33 & 9.27 & 5.94 & 3.33 & 8.07 & 9.37 & -1.30\end{array}$ $\begin{array}{lllllllllll}7.245 & 9.82 & 2.58 & 9.73 & 7.16 & 2.58 & 8.30 & 11.32 & -3.02\end{array}$ $\begin{array}{lllllllll}2.62 & 8.09 & 5.47 & 2.62 & 7.46 & 9.21 & -1.75 & 0\end{array}$ $\begin{array}{llllllllll}5.463 & 8.54 & 3.08 & 7.82 & 4.74 & 3.08 & 7.32 & 8.05 & -0.73\end{array}$ $\begin{array}{llllllllll}6.371 & 8.21 & 1.84 & 7.33 & 5.49 & 1.84 & 7.07 & 9.72 & -2.65\end{array}$ $\begin{array}{llllllllll}5.96 & 8.77 & 2.81 & 8.16 & 5.35 & 2.81 & 7.50 & 8.96 & -1.46\end{array}$ $\begin{array}{lllllllll}7.597 & 9.17 & 1.57 & 8.76 & 7.19 & 1.57 & 7.81 & 11.97 & -4.16\end{array}$ $\begin{array}{lllllllll}2.06 & 8.63 & 6.57 & 2.06 & 7.74 & 10.91 & -3.17\end{array}$ $\begin{array}{llllllll}7.021 & 9.08 & 2.06 & 8.63 & 6.57 & 2.06 & 7.74 & 11 \\ 5.385 & 8.68 & 3.30 & 8.03 & 4.73 & 3.30 & 7.43 & \end{array}$ $\begin{array}{llllllllll}5.385 & 8.68 & 3.30 & 8.03 & 4.73 & 3.30 & 7.43 & 7.90 & -0.48\end{array}$ $\begin{array}{llllllllll}6.596 & 9.14 & 2.54 & 8.72 & 6.17 & 2.54 & 7.78 & 10.13 & -2.35\end{array}$ $\begin{array}{llllllllll}5.548 & 9.33 & 3.78 & 9.00 & 5.22 & 3.78 & 7.93 & 8.20 & -0.28\end{array}$ $\begin{array}{llllllllll}5.872 & 8.9 & 3.03 & 8.36 & 5.33 & 3.03 & 7.60 & 8.80 & -1.20\end{array}$ $\begin{array}{lllllllll}-1.03 & 8.36 & 5.33 & 3.03 & 7.60 & 8.80 & -1.20\end{array}$ $\begin{array}{llllllllll}5.638 & 9.2 & 3.56 & 8.81 & 5.24 & 3.56 & 7.83 & 8.37 & -0.54\end{array}$ $\begin{array}{llllllllll}5.795 & 8.12 & 2.32 & 7.19 & 4.87 & 2.32 & 7.00 & 8.66 & -1.66\end{array}$ $\begin{array}{llllllllll}7.433 & 8.52 & 1.09 & 7.79 & 6.70 & 1.09 & 7.31 & 11.67 & -4.36\end{array}$ $\begin{array}{llllllll}1.09 & 7.79 & 6.70 & 1.09 & 7.31 & 11.67 & -4.36\end{array}$ $\begin{array}{lllllllll}-1.54 & 8.63 & 7.09 & 1.54 & 7.74 & 11.86 & -4.12\end{array}$ $\begin{array}{llllllllllll}7.539 & 9.08 & 1.54 & 8.63 & 7.09 & 1.54 & 7.74 & 11.86 & -4.12\end{array}$ $\begin{array}{llllllllll}5.649 & 8.16 & 2.51 & 7.25 & 4.74 & 2.51 & 7.03 & 8.39 & -1.36\end{array}$ $\begin{array}{lllllllll}5.073 & 8.07 & 3.00 & 7.12 & 4.12 & 3.00 & 6.96 & 7.33 & -0.37\end{array}$ $\begin{array}{llllllllll}5.395 & 7.64 & 2.24 & 6.48 & 4.23 & 2.24 & 6.63 & 7.92 & -1.29\end{array}$ $\begin{array}{llllllll}-3.48 & 8.09 & 4.61 & 3.48 & 7.46 & 7.63 & -0.17\end{array}$ $6.467-7.96$ $\begin{array}{llllllllll}5.561 & 8.29 & 2.73 & 7.45 & 4.72 & 2.73 & 7.13 & 8.23 & -1.10\end{array}$ $\begin{array}{lllllllll}6.631 & 8.61 & 1.98 & 7.93 & 5.95 & 1.98 & 7.38 & 10.19 & -2.82\end{array}$ $\begin{array}{llllllllll}6.954 & 8.18 & 1.23 & 7.28 & 6.06 & 1.23 & 7.04 & 10.79 & -3.74\end{array}$ $\begin{array}{lllllllll}3.26 & 7.78 & 4.51 & 3.26 & 7.30 & 7.65 & -0.35\end{array}$ $\begin{array}{lllllllll}6.223 & 8.25 & 2.03 & 7.39 & 5.36 & 2.03 & 7.10 & 9.44 & -2.35\end{array}$ $\begin{array}{lllllllll}6.223 & 8.25 & 2.03 & 7.39 & 5.36 & 2.03 & 7.10 & 9.44 & -2.35 \\ 4.851 & 7.33 & 2.48 & 6.01 & 3.54 & 2.48 & 6.39 & 6.92 & -0.53\end{array}$ $\begin{array}{lllllllll}6.488 & 7.73 & 1.24 & 6.61 & 5.37 & 1.24 & 6.70 & 9.93 & -3.23\end{array}$ $\begin{array}{llllllllll}7.557 & 9.77 & 2.21 & 9.66 & 7.44 & 2.21 & 8.27 & 11.89 & -3.63\end{array}$ $\begin{array}{llllllll}1.46 & 7.93 & 6.47 & 1.46 & 7.38 & 11.15 & -3.77\end{array}$ $\begin{array}{rrrrrrrrr}6.242 & 8.94 & 2.70 & 8.42 & 5.72 & 2.70 & 7.63 & 9.48 & -1.85\end{array}$ $\begin{array}{rrrrrrrrr}6.242 & 8.94 & 2.70 & 8.42 & 5.72 & 2.70 & 7.63 & 9.48 & -1.85 \\ 6.644 & 8.59 & 1.95 & 7.90 & 5.95 & 1.95 & 7.36 & 10.22 & -2.86\end{array}$ $\begin{array}{lllllllll}4.857 & 8.04 & 3.18 & 7.07 & 3.89 & 3.18 & 6.94 & 6.93 & 0.00\end{array}$ $\begin{array}{llllllllll}6.896 & 8.09 & 1.19 & 7.15 & 5.96 & 1.19 & 6.98 & 10.68 & -3.70\end{array}$ $\begin{array}{lllllllll}5.999 & 8.43 & 2.43 & 7.66 & 5.23 & 2.43 & 7.24 & 9.03 & -1.80\end{array}$ $\begin{array}{rrrrrrrrr}7.06 & 8.74 & 1.68 & 8.12 & 6.44 & 1.68 & 7.47 & 10.98 & -3.51\end{array}$ $\begin{array}{rrrrrrrrr}7.06 & 8.74 & 1.68 & 8.12 & 6.44 & 1.68 & 7.47 & 10.98 & -3.51 \\ 7.382 & 8.31 & 0.93 & 7.48 & 6.55 & 0.93 & 7.14 & 11.57 & -4.43 \\ 5.016 & 7.98 & 2.96 & 6.99 & 4.02 & 2.96 & 6.89 & 7.23 & -0.34\end{array}$ $\begin{array}{lllllllll}5.016 & 7.98 & 2.96 & 6.99 & 4.02 & 2.96 & 6.89 & 7.23 & -0.34\end{array}$ $\begin{array}{lllllllll}6.361 & 8.09 & 1.73 & 7.15 & 5.42 & 1.73 & 6.98 & 9.70 & -2.72\end{array}$ $\begin{array}{lllllllll}5.528 & 8.43 & 2.90 & 7.66 & 4.76 & 2.90 & 7.24 & 8.17 & -0.93\end{array}$ $\begin{array}{rrrrrrrrr}5.528 & 8.43 & 2.90 & 7.66 & 4.76 & 2.90 & 7.24 & 8.17 & -0.93 \\ 7.165 & 8.83 & 1.66 & 8.25 & 6.59 & 1.66 & 7.54 & 11.17 & -3.63\end{array}$ $\begin{array}{llllllllll}7.165 & 8.83 & 1.66 & 8.25 & 6.59 & 1.66 & 7.54 & 11.17 & -3.63 \\ 6.757 & 9.39 & 2.63 & 9.09 & 6.46 & 2.63 & 7.97 & 10.42 & -2.45\end{array}$ $\begin{array}{lllllll}1.40 & 7.48 & 6.08 & 1.40 & 7.14 & 10.71 & -3.57\end{array}$ $6.913 \quad 8.31$ $\begin{array}{lllllll}1.88 & 8.45 & 6.56 & 1.88 & 7.64 & 11.01 & -3.37\end{array}$ $7.077 \quad 8.96$ $4.701 \quad 7.82$ $5.023 \quad 7.39$ 8.45 8.79 $6.258 \quad 8.36$ $6.434 \quad 9.82$ 


\begin{tabular}{|c|c|c|c|c|c|c|c|c|c|c|}
\hline \multirow[t]{2}{*}{ SMILE Generated } & Formula & $\begin{array}{l}\text { lgKoa } \\
\text { EPISuit }\end{array}$ & $\begin{array}{l}\text { lgKow } \\
\text { EPI } \\
\text { Suite }\end{array}$ & $\begin{array}{l}\text { lgKaw } \\
\text { EPI } \\
\text { Suite }\end{array}$ & $\begin{array}{l}\text { lgKow } \\
\text { Exp_ } \\
\text { corr }\end{array}$ & $\begin{array}{l}\text { lgKoa } \\
\text { Exp } \\
\text { corr }\end{array}$ & $\begin{array}{l}\operatorname{lgKa} \\
\text { w } \\
\text { Exp }\end{array}$ & $\begin{array}{l}\text { lgKow } \\
\text { DFT_ } \\
\text { corr }\end{array}$ & $\begin{array}{r}\text { lgKoa } \\
\text { DFT } \\
\text { corr }\end{array}$ & $\begin{array}{l}\text { gKaw } \\
\text { DFT } \\
\text { corr }\end{array}$ \\
\hline & & & & & & corr & Exp & corr & & \\
\hline $\mathrm{C}(\mathrm{C}(\mathrm{C}(\mathrm{C}(\mathrm{C}(\mathrm{C}(\mathrm{C}(\mathrm{C}(\mathrm{C}(\mathrm{C}(\mathrm{C}(\mathrm{C}(\mathrm{F})(\mathrm{H}) \mathrm{H})(\mathrm{H}) \mathrm{F})(\mathrm{H}) \mathrm{Br})(\mathrm{H}) \mathrm{F})(\mathrm{F}) \mathrm{F})(\mathrm{Br}) \mathrm{F})(\mathrm{H}) \mathrm{F})(\mathrm{H}) \mathrm{Cl})(\mathrm{H}) \mathrm{H})(\mathrm{H}) \mathrm{F})(\mathrm{F}) \mathrm{F})(\mathrm{F})(\mathrm{H})$ & $\mathrm{C} 12 \mathrm{H} 12 \mathrm{ClBr} 2 \mathrm{~F} 11$ & 5.072 & 7.86 & 2.79 & 6.81 & 4.02 & 2.79 & $\begin{array}{l}6.80 \\
6.35\end{array}$ & 7.33 & \\
\hline $\begin{array}{c}C(C(C(C(C(C(C(C(C(C(C(C(H)(H) H)(F) F)(F) H)(F) B r)(F) H)(H) B r)(F) H)(H) H)(H) F)(H) F)(F) H)(H) \\
\text { (H) }\end{array}$ & $\mathrm{C} 12 \mathrm{H} 13 \mathrm{Br} 3 \mathrm{~F} 10$ & $\begin{array}{l}5.266 \\
6.983\end{array}$ & 7.27 & $\begin{array}{l}2.00 \\
0.77\end{array}$ & $\begin{array}{l}5.93 \\
6.64\end{array}$ & $\begin{array}{l}3.92 \\
5.88\end{array}$ & $\begin{array}{l}2.00 \\
0.77\end{array}$ & $\begin{array}{l}6.35 \\
6.71\end{array}$ & $\begin{array}{r}7.69 \\
10.84\end{array}$ & \\
\hline $\begin{array}{l}(\mathrm{C}(\mathrm{C}(\mathrm{C}(\mathrm{C}(\mathrm{C}(\mathrm{C}(\mathrm{C}(\mathrm{C}(\mathrm{C}(\mathrm{C}(\mathrm{C}(\mathrm{H})(\mathrm{Br}) \mathrm{H})(\mathrm{H}) \mathrm{H})(\mathrm{H}) \mathrm{F})(\mathrm{H}) \mathrm{F})(\mathrm{F}) \mathrm{F})(\mathrm{Br}) \mathrm{Br})(\mathrm{H}) \mathrm{Br})(\mathrm{H}) \mathrm{H})(\mathrm{F}) \mathrm{H})(\mathrm{H}) \mathrm{F})(\mathrm{H}) \mathrm{F})(\mathrm{F})( \\
\mathrm{C}(\mathrm{C}(\mathrm{C}(\mathrm{C}(\mathrm{C}(\mathrm{C}(\mathrm{C}(\mathrm{C}(\mathrm{C}(\mathrm{C}(\mathrm{C}(\mathrm{F})(\mathrm{F}) \mathrm{H})(\mathrm{H}) \mathrm{F})(\mathrm{H}) \mathrm{F})(\mathrm{Br}) \mathrm{H})(\mathrm{H}) \mathrm{H})(\mathrm{F}) \mathrm{H})(\mathrm{F}) \mathrm{H})(\mathrm{H}) \mathrm{H})(\mathrm{F}) \mathrm{Cl})(\mathrm{H}) \mathrm{H})(\mathrm{F}) \mathrm{H})(\mathrm{F})(\mathrm{Br})\end{array}$ & $\begin{array}{l}\mathrm{C} 12 \mathrm{H} 13 \mathrm{Br} 4 \mathrm{~F} 9 \\
\mathrm{C} 12 \mathrm{H} 13 \mathrm{Cl} 2 \mathrm{Br} 2 \mathrm{~F} 9\end{array}$ & $\begin{array}{l}6.983 \\
5.831\end{array}$ & $\begin{array}{l}7.75 \\
7.57\end{array}$ & $\begin{array}{l}0.77 \\
1.74\end{array}$ & $\begin{array}{l}6.64 \\
6.37\end{array}$ & 5.88 & $\begin{array}{l}0.77 \\
1.74\end{array}$ & $\begin{array}{l}0.71 \\
6.58\end{array}$ & $\begin{array}{r}10.84 \\
3.72\end{array}$ & \\
\hline$(\mathrm{C}(\mathrm{C}(\mathrm{C}(\mathrm{C}(\mathrm{C}(\mathrm{C}(\mathrm{C}(\mathrm{C}(\mathrm{C}(\mathrm{C}(\mathrm{C}(\mathrm{H})(\mathrm{H}) \mathrm{H})(\mathrm{Br}) \mathrm{F})(\mathrm{F}) \mathrm{H})(\mathrm{Cl}) \mathrm{Cl})(\mathrm{H}) \mathrm{F})(\mathrm{H}) \mathrm{H})(\mathrm{F}) \mathrm{F})(\mathrm{F}) \mathrm{F})(\mathrm{H}) \mathrm{F})(\mathrm{F}) \mathrm{F})(\mathrm{H}) \mathrm{H})(\mathrm{H})(\mathrm{H})$ & $\mathrm{C} 12 \mathrm{H} 13 \mathrm{Cl} 2 \mathrm{BrF} 10$ & 6.265 & 9.24 & 2.98 & 8.87 & 5.89 & 2.98 & 7.86 & 9.52 & -1.6 \\
\hline $\mathrm{C}(\mathrm{C}(\mathrm{C}(\mathrm{C}(\mathrm{C}(\mathrm{C}(\mathrm{C}(\mathrm{C}(\mathrm{C}(\mathrm{C}(\mathrm{C}(\mathrm{C}(\mathrm{H})(\mathrm{H}) \mathrm{F})(\mathrm{F}) \mathrm{F})(\mathrm{F}) \mathrm{Cl})(\mathrm{F}) \mathrm{H})(\mathrm{H}) \mathrm{H})(\mathrm{Cl}) \mathrm{H})(\mathrm{F}) \mathrm{H})(\mathrm{H}) \mathrm{Br})(\mathrm{H}) \mathrm{H})(\mathrm{F}) \mathrm{F})(\mathrm{Cl}) \mathrm{H})(\mathrm{H})$ & $\mathrm{C} 12 \mathrm{H} 13 \mathrm{Cl} 3 \mathrm{BrF} 9$ & 5.997 & 8.22 & 2.22 & 7.34 & 5.12 & 2.22 & 7.08 & 9.03 & -1.9 \\
\hline$(\mathrm{C}(\mathrm{C}(\mathrm{C}(\mathrm{C}(\mathrm{C}(\mathrm{C}(\mathrm{C}(\mathrm{C}(\mathrm{C}(\mathrm{C}(\mathrm{C}(\mathrm{Cl})(\mathrm{H}) \mathrm{F})(\mathrm{F}) \mathrm{H})(\mathrm{F}) \mathrm{F})(\mathrm{H}) \mathrm{H})(\mathrm{H}) \mathrm{F})(\mathrm{Cl}) \mathrm{F})(\mathrm{F}) \mathrm{H})(\mathrm{H}) \mathrm{H})(\mathrm{H}) \mathrm{Cl})(\mathrm{F}) \mathrm{H})(\mathrm{H}) \mathrm{H})(\mathrm{Cl})$ & $\mathrm{C} 12 \mathrm{H} 13 \mathrm{Cl} 4 \mathrm{~F} 9$ & 4.682 & 7.39 & 2.71 & 6.10 & 3.40 & 2.71 & 6.44 & 6.61 & -0.1 \\
\hline$(\mathrm{C}(\mathrm{C}(\mathrm{C}(\mathrm{C}(\mathrm{C}(\mathrm{C}(\mathrm{C}(\mathrm{C}(\mathrm{C}(\mathrm{C}(\mathrm{C}(\mathrm{H})(\mathrm{Cl}) \mathrm{F})(\mathrm{H}) \mathrm{F})(\mathrm{H}) \mathrm{H})(\mathrm{Br}) \mathrm{F})(\mathrm{F}) \mathrm{H})(\mathrm{H}) \mathrm{H})(\mathrm{F}) \mathrm{H})(\mathrm{Cl}) \mathrm{F})(\mathrm{H}) \mathrm{H})(\mathrm{F}) \mathrm{H})(\mathrm{Cl}) \mathrm{H})(\mathrm{H})(\mathrm{C}$ & $\mathrm{C} 12 \mathrm{H} 13 \mathrm{Cl} \mathrm{BrF} 7$ & 7.391 & 8.11 & 0.72 & 7.18 & 6.46 & 0.72 & 6.99 & 11.59 & -4.6 \\
\hline & & 7.224 & 9.18 & 1.96 & 8.78 & 6.82 & 1.96 & 7.81 & 11.28 & \\
\hline & $3 \mathrm{r} 2 \mathrm{~F} 10$ & 4.77 & 7.26 & 2.49 & 5.91 & 3.42 & 2.49 & 6.34 & 6.77 & \\
\hline$(\mathrm{H}) \mathrm{H})(\mathrm{F}) \mathrm{H})(\mathrm{H}) \mathrm{F})(\mathrm{F}) \mathrm{F})(\mathrm{F}) \mathrm{H})(\mathrm{Br}) \mathrm{F})(\mathrm{F}) \mathrm{F})(\mathrm{F}) \mathrm{H})(\mathrm{H}) \mathrm{H})(\mathrm{H})$ & $\mathrm{C} 12 \mathrm{H} 14 \mathrm{Br}$ & 6.435 & 8.14 & 1.70 & 7.22 & 5.52 & 1.70 & 7.01 & 9.83 & 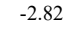 \\
\hline $\mathrm{C}(\mathrm{C}(\mathrm{C}(\mathrm{C}(\mathrm{C}(\mathrm{C}(\mathrm{C}(\mathrm{C}(\mathrm{C}(\mathrm{C}(\mathrm{C}(\mathrm{H})(\mathrm{H}) \mathrm{H})(\mathrm{F}) \mathrm{H})(\mathrm{H}) \mathrm{Br})(\mathrm{H}) \mathrm{H})(\mathrm{F}) \mathrm{F})(\mathrm{F}) \mathrm{F})(\mathrm{Br}) \mathrm{H})(\mathrm{F}) \mathrm{H})(\mathrm{Br}) \mathrm{H})(\mathrm{F}) \mathrm{H})(\mathrm{H}) \mathrm{H})(\mathrm{H})($ & $\mathrm{C} 12 \mathrm{H} 14 \mathrm{Br} 4 \mathrm{~F} 8$ & 7.341 & 7.81 & 0.47 & 6.73 & 6.26 & 0.47 & 6.76 & 11.50 & -4.7 \\
\hline$(\mathrm{C}(\mathrm{C}(\mathrm{C}(\mathrm{C}(\mathrm{C}(\mathrm{C}(\mathrm{C}(\mathrm{C}(\mathrm{C}(\mathrm{C}(\mathrm{C}(\mathrm{F})(\mathrm{H}) \mathrm{F})(\mathrm{H}) \mathrm{H})(\mathrm{Br}) \mathrm{H})(\mathrm{H}) \mathrm{H})(\mathrm{H}) \mathrm{F})(\mathrm{H}) \mathrm{F})(\mathrm{F}) \mathrm{F})(\mathrm{H}) \mathrm{H})(\mathrm{Br}) \mathrm{F})(\mathrm{F}) \mathrm{Cl})(\mathrm{H}) \mathrm{H})(\mathrm{H})$ & $\mathrm{C} 12 \mathrm{H} 14 \mathrm{Cl} 2 \mathrm{Br} 2 \mathrm{~F} 8$ & 7 & 8.44 & 1.44 & 7.67 & 6.23 & 1.44 & 7.24 & 10.87 & -3.6 \\
\hline $\mathrm{C}(\mathrm{C}(\mathrm{C}(\mathrm{C}(\mathrm{C}(\mathrm{C}(\mathrm{C}(\mathrm{C}(\mathrm{C}(\mathrm{C}(\mathrm{C}(\mathrm{C}(\mathrm{Cl})(\mathrm{H}) \mathrm{H})(\mathrm{F}) \mathrm{H})(\mathrm{H}) \mathrm{H})(\mathrm{H}) \mathrm{H})(\mathrm{F}) \mathrm{H})(\mathrm{F}) \mathrm{F})(\mathrm{H}) \mathrm{H})(\mathrm{F}) \mathrm{F})(\mathrm{H}) \mathrm{F})(\mathrm{F}) \mathrm{F})(\mathrm{H}) \mathrm{H})(\mathrm{H})(\mathrm{Br})$ & $\mathrm{C} 12 \mathrm{H} 14 \mathrm{Cl} 2 \mathrm{BrF} 9$ & 5.364 & 8.04 & 2.68 & 7.07 & 4.40 & 2.68 & 6.94 & 7.87 & -0.5 \\
\hline $\mathrm{C}(\mathrm{C}(\mathrm{C}(\mathrm{C}(\mathrm{C}(\mathrm{C}(\mathrm{C}(\mathrm{C}(\mathrm{C}(\mathrm{C}(\mathrm{C}(\mathrm{C}(\mathrm{F})(\mathrm{F}) \mathrm{H})(\mathrm{H}) \mathrm{H})(\mathrm{H}) \mathrm{H})(\mathrm{F}) \mathrm{Cl})(\mathrm{F}) \mathrm{H})(\mathrm{H}) \mathrm{Cl})(\mathrm{Br}) \mathrm{H})(\mathrm{H}) \mathrm{H})(\mathrm{H}) \mathrm{F})(\mathrm{Br}) \mathrm{F})(\mathrm{H}) \mathrm{H})(\mathrm{Cl})($ & $\mathrm{C} 12 \mathrm{H} 14 \mathrm{Cl} 3 \mathrm{Br} 2 \mathrm{~F} 7$ & 7.323 & 8.01 & 0.69 & 7.03 & 6.34 & 0.69 & 6.91 & 11.46 & -4. \\
\hline$(\mathrm{C}(\mathrm{C}(\mathrm{C}(\mathrm{C}(\mathrm{C}(\mathrm{C}(\mathrm{C}(\mathrm{C}(\mathrm{C}(\mathrm{C}(\mathrm{C}(\mathrm{F})(\mathrm{H}) \mathrm{H})(\mathrm{Cl}) \mathrm{F})(\mathrm{H}) \mathrm{H})(\mathrm{F}) \mathrm{H})(\mathrm{H}) \mathrm{H})(\mathrm{F}) \mathrm{F})(\mathrm{H}) \mathrm{F})(\mathrm{H}) \mathrm{H})(\mathrm{F}) \mathrm{Cl})(\mathrm{F}) \mathrm{Cl})(\mathrm{Br}) \mathrm{H})(\mathrm{H})$ & $\mathrm{C} 12 \mathrm{H} 1$ & 7.095 & 9.02 & 1.93 & 8.54 & 6.61 & 1.93 & 7.69 & 11.05 & 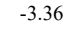 \\
\hline$(\mathrm{C}(\mathrm{C}) \mathrm{C}(\mathrm{C}) \mathrm{C}(\mathrm{C}) \mathrm{C}(\mathrm{C}) \mathrm{C}(\mathrm{C}$ & $\mathrm{C} 12 \mathrm{H} 1$ & 7.497 & 8.67 & 1.17 & 8.01 & 6.84 & 1.17 & 7.42 & 211.78 & -4.3 \\
\hline$(\mathrm{C}(\mathrm{C}) \mathrm{C}(\mathrm{C}) \mathrm{C}(\mathrm{C}) \mathrm{C}(\mathrm{C}) \mathrm{C}(\mathrm{C}$ & $\mathrm{C} 12 \mathrm{H} 1$ & 5.85 & 8 & .41 & 7.40 & 4.99 & 2.41 & 7.11 & 8.76 & -1.6 \\
\hline & BrF6 & 7 & & & 6.15 & 5.73 & & 6.46 & 510.87 & \\
\hline & & 6.183 & 7.84 & 1.66 & 6.78 & 5.12 & 1.66 & 6.78 & $\begin{array}{l}3 \quad 9.37 \\
\end{array}$ & \\
\hline & & 7.244 & .15 & 0.91 & 7.24 & 6.33 & 0.91 & 7.02 & 211.32 & \\
\hline$(\mathrm{C}) \mathrm{C}(\mathrm{C}) \mathrm{C}(\mathrm{C}) \mathrm{C}(\mathrm{C})$ & $\mathrm{C} 12 \mathrm{H}$ & 5.939 & & 2.19 & 7.21 & 5.02 & 2.19 & 7.01 & 8.92 & -1. \\
\hline (C) $\mathrm{C}(\mathrm{C}) \mathrm{C}(\mathrm{C}) \mathrm{C}(\mathrm{C}$ & & 7.576 & 8.53 & 0.95 & 7.81 & 6.85 & 0.95 & 7.31 & 11.93 & -4. \\
\hline$(\mathrm{C}) \mathrm{C}(\mathrm{C}) \mathrm{C}(\mathrm{C}) \mathrm{C}(\mathrm{C}) \mathrm{C}(\mathrm{C}) \mathrm{C}$ & & & 7.21 & 2.64 & 5.84 & 3.19 & 2.64 & 6.30 & 6.40 & -0 . \\
\hline$(\mathrm{C}(\mathrm{C}) \mathrm{C}(\mathrm{C}) \mathrm{C}(\mathrm{C}) \mathrm{C}(\mathrm{)}$ & $\mathrm{C} 12 \mathrm{H} 1$ & & & 1.41 & 6.43 & 5.03 & 1.41 & 6.61 & 9.41 & \\
\hline H) & & & & & & 4.52 & 1.14 & 6.21 & 8.94 & -2 \\
\hline H) & & .052 & & & 6.16 & 3.79 & 2.38 & 6.47 & 7.29 & -0.8 \\
\hline & & 7.021 & & & 6.13 & 5.75 & 0.39 & 6.45 & 510.91 & \\
\hline$(F)($ & $\mathrm{C} 12 \mathrm{H}$ & 6.866 & & 1.62 & 7.75 & 6.12 & 1.62 & 7.28 & 10.62 & -3 . \\
\hline & & & & & 7.13 & 4.27 & & 6.97 & 7.60 & \\
\hline $\mathrm{C}(\mathrm{C}(\mathrm{C}) \mathrm{C}(\mathrm{C}) \mathrm{C}(\mathrm{C}) \mathrm{C}(\mathrm{C}) \mathrm{C}(\mathrm{C}$ & $\mathrm{C} 12 \mathrm{H} 1$ & 5.706 & 6.58 & 0.87 & 4.90 & 4.02 & 0.87 & 5.82 & 8.49 & \\
\hline $\mathrm{C}(\mathrm{C}(\mathrm{C}) \mathrm{C}(\mathrm{C}) \mathrm{C}(\mathrm{C}) \mathrm{C}(\mathrm{C}$ & $\mathrm{C} 12 \mathrm{H}$ & 4.799 & & 2.11 & 5.39 & 3.28 & 2.11 & 6.07 & 6.83 & \\
\hline$(\mathrm{C}(\mathrm{C}(\mathrm{C}$ & & 6.611 & 7.97 & 1.36 & 6.97 & 5.61 & 1.36 & 88 & 30.16 & \\
\hline ( $\mathrm{C}(\mathrm{C}) \mathrm{C}(\mathrm{C}) \mathrm{C}(\mathrm{C}) \mathrm{C}(\mathrm{C}) \mathrm{C}(\mathrm{C}$ & & & & 61 & 7.21 & 6.60 & 0.61 & 7.01 & 11.83 & \\
\hline$\left.\left.(\mathrm{C}(\mathrm{C}))^{2}\right) \cdot\right)$ & & 67 & & 89 & 7.40 & 5.51 & 1.89 & 7.11 & 9.71 & -2 \\
\hline$(\mathrm{C}(\mathrm{C}$ & & 523 & & 66 & 5.79 & 5.13 & 0.66 & 6.28 & 9.99 & -3 . \\
\hline$(\mathrm{C}(\mathrm{C}$ & $\mathrm{C} 12 \mathrm{Hl}$ & 924 & 27 & 2.35 & 5.93 & 3.58 & 2.35 & 6.35 & 7.06 & -0 . \\
\hline$H)($ & & 892 & 7 & 1.11 & 5.52 & 4.41 & 1.11 & 6.14 & 8.84 & \\
\hline & & & & & 5.01 & 5.14 & -0.13 & 5.88 & 30.48 & \\
\hline$(\mathrm{C}(\mathrm{C}(\mathrm{C}$ & & & & & & 6.13 & & & 31.11 & -4. \\
\hline (C) $\mathrm{C}(\mathrm{C}) \mathrm{C}(\mathrm{C}) \mathrm{C}(\mathrm{C}$ & BrF7 & 4.602 & & & & 2.97 & 2.08 & 5.89 & 6.47 & \\
\hline (C(C) & & 7.45 & & 0.09 & 33 & 6.24 & 0.09 & 55 & 511.70 & \\
\hline( & & & & & & & 1.33 & & .90 & \\
\hline I) & & & & & & & & & 6.90 & -0 . \\
\hline$(\mathrm{C}$ & & 237 & & & 5.60 & 3.78 & 1.81 & 6.18 & 7.63 & -1. \\
\hline H)( & $\mathrm{C} 12 \mathrm{H} 16 \mathrm{Cl} 5 \mathrm{~F} 5$ & 6.3 & 7.36 & 1.06 & 6.06 & 5.00 & 1.06 & 6.41 & 9.59 & -5. \\
\hline $\begin{array}{l}\mathrm{C}(\mathrm{C}(\mathrm{C}(\mathrm{C}(\mathrm{C}(\mathrm{C}(\mathrm{C}(\mathrm{C}(\mathrm{C}(\mathrm{C}(\mathrm{C}(\mathrm{C}(\mathrm{H})(\mathrm{Cl}) \mathrm{F})(\mathrm{H}) \mathrm{H})(\mathrm{F}) \mathrm{H})(\mathrm{Cl}) \mathrm{H})(\mathrm{H}) \mathrm{Cl})(\mathrm{F}) \mathrm{H})(\mathrm{Cl}) \mathrm{H})(\mathrm{Cl} \\
(\mathrm{H})(\mathrm{H}) \mathrm{H}\end{array}$ & $\mathrm{C} 12 \mathrm{H} 16 \mathrm{Cl} 7 \mathrm{~F} 3$ & & & & & 6. & -0 & & 72 & \\
\hline $\mathrm{C}(\mathrm{C}(\mathrm{C}) \mathrm{C}(\mathrm{C}) \mathrm{C}(\mathrm{C}) \mathrm{C}$ & $\mathrm{C} 12 \mathrm{H} 16 \mathrm{ClBr} 2 \mathrm{~F} 7$ & 6.056 & 7.65 & 1.59 & 6.49 & 4.90 & 1.59 & 6.64 & 9.14 & \\
\hline$(\mathrm{C}(\mathrm{C}) \mathrm{C}(\mathrm{C}) \mathrm{C}(\mathrm{C}) \mathrm{C}$ & & 6.963 & & 0.36 & 6.00 & 5.64 & 0.36 & 6.38 & 310.80 & \\
\hline $\mathrm{Cr} \mathrm{C}$ & & & & 2.05 & 6.22 & 4.18 & 2.05 & 50 & 7.98 & \\
\hline & & & & & & 5.91 & 0. & & 510.85 & \\
\hline & & & & & & 5.52 & 0.54 & 6.41 & 10.53 & \\
\hline & & 101 & & & & 3.56 & 1. & 6.05 & 7.38 & \\
\hline & & 432 & & 1.03 & 4.72 & 3.69 & 1.03 & 5.72 & 7.99 & \\
\hline & $\mathrm{C} 12 \mathrm{H}$ & 604 & & 2.27 & 5.33 & 3.06 & 2.27 & 6.04 & 6.47 & -0 . \\
\hline & & & & 0.28 & & 5.01 & 0.2 & $6 .($ & 210.07 & \\
\hline $\mathrm{C}(\mathrm{C}(\mathrm{C}$ & $\mathrm{C} 12 \mathrm{H}^{\circ}$ & 6.336 & 7.85 & 1.51 & 6.79 & 5.28 & 1.51 & 6.79 & 9.65 & \\
\hline $\mathrm{C}(\mathrm{C}) \mathrm{C}(\mathrm{C}) \mathrm{C}(\mathrm{C})$ & & & & 0.76 & 7.25 & 6.49 & 0.76 & 7.03 & 311.60 & -4 . \\
\hline & & & & 29 & 4.49 & 3.20 & 1.29 & 5.61 & 7.22 & \\
\hline & & & & & 6.09 & 6.03 & 0. & 6.43 & 11.46 & -5.0 \\
\hline $\mathrm{C}(\mathrm{C}$ & & 42 & & & 5.2 & 3.46 & 1. & 5.98 & 3.27 & \\
\hline & & & & & & 6.41 & & & 11.66 & \\
\hline & & 7.176 & 7.4 & 0.24 & 6.15 & 5.91 & 0.24 & 6.46 & 511.19 & \\
\hline & & & & & 5.55 & 4.07 & 1.48 & 6. & 8.19 & \\
\hline I) $\mathrm{Br}(\mathrm{F}) \mathrm{H})(\mathrm{H})$ & $\mathrm{C} 12 \mathrm{H} 18 \mathrm{Cl} 3 \mathrm{Br} 2 \mathrm{~F} 3$ & 7.498 & 6.99 & -0.51 & 5.51 & 6.02 & -0.51 & 6.13 & 11.79 & \\
\hline $\mathrm{C}(\mathrm{C}(\mathrm{C}(\mathrm{C}) \mathrm{C}(\mathrm{C}) \mathrm{C}(\mathrm{C}) \mathrm{C}(\mathrm{C}(\mathrm{C}) \mathrm{C}(\mathrm{H})$ & $\mathrm{C} 12 \mathrm{H} 18 \mathrm{Cl} 3 \mathrm{BrF} 4$ & 7.271 & 8 & 0.73 & 7.01 & 6.29 & 0.73 & 6.91 & 11.37 & -4.4 \\
\hline $\mathrm{C}(\mathrm{C}) \mathrm{C}(\mathrm{C}) \mathrm{C}(\mathrm{C}) \mathrm{C}(\mathrm{C}) \mathrm{C}(\mathrm{C}) \mathrm{C}(\mathrm{l})$ & $\mathrm{C} 12 \mathrm{H} 18 \mathrm{Cl} 4 \mathrm{~F} 4$ & 6.095 & 7.31 & 1.21 & 5.99 & 4.77 & 1.21 & 6.38 & 9.21 & \\
\hline ( $\mathrm{C}(\mathrm{C}) \mathrm{C}(\mathrm{C}) \mathrm{C}(\mathrm{C}) \mathrm{C}(\mathrm{C}) \mathrm{C}(\mathrm{C})$ & & 6.427 & 6.89 & 0.46 & 5.36 & 4.90 & 0.46 & 6.05 & 9.82 & \\
\hline & & & & & 4.69 & 3.69 & 1. & 5.71 & 8.01 & \\
\hline & & & & & 5. & 2.96 & & 5.97 & 6.36 & \\
\hline & & & & & 6. & 4.95 & & 6.59 & 9.29 & \\
\hline & & & & & 5. & 4.80 & & 5.88 & 9.86 & \\
\hline & & & & & & 6.40 & -0. & & 511.98 & \\
\hline & & 5.9 & & & 5.75 & 4.56 & 1. & 6. & & \\
\hline $\mathrm{C}(\mathrm{C}(\mathrm{C}) \mathrm{C}(\mathrm{C}) \mathrm{C}(\mathrm{C}) \mathrm{C}(\mathrm{C}) \mathrm{C}(\mathrm{C}) \mathrm{C}(\mathrm{H}$ & $\mathrm{C} 12 \mathrm{H} 19 \mathrm{Cl} 2 \mathrm{~F} 5$ & 4.4 & 6.82 & 2.42 & 5.25 & 2.83 & 2.42 & 6.00 & 6.10 & -0.1 \\
\hline $\mathrm{C}(\mathrm{C}(\mathrm{C}) \mathrm{C}(\mathrm{C}) \mathrm{C}(\mathrm{C}) \mathrm{C}(\mathrm{C}) \mathrm{C}(\mathrm{C}) \mathrm{C}(\mathrm{Cl})$ & $\mathrm{C} 12 \mathrm{H} 19 \mathrm{Cl} 3 \mathrm{BrF} 3$ & 7.03 & 7.46 & 0.43 & 6.21 & 5.78 & 0.43 & 6.49 & 10.93 & -4. \\
\hline$(\mathrm{C}(\mathrm{C}(\mathrm{C}(\mathrm{C}(\mathrm{C}(\mathrm{C}(\mathrm{C}(\mathrm{C}(\mathrm{C}(\mathrm{C}(\mathrm{C}(\mathrm{H})(\mathrm{F}) \mathrm{H})(\mathrm{Cl}) \mathrm{F})(\mathrm{H}) \mathrm{H})(\mathrm{H}) \mathrm{H})(\mathrm{Cl}) \mathrm{H})(\mathrm{H}) \mathrm{H})(\mathrm{H}) \mathrm{H})(\mathrm{H}) \mathrm{F})($ & $\mathrm{C} 12 \mathrm{H} 19 \mathrm{Cl} 3 \mathrm{~F} 4$ & 5.392 & 7.06 & 1.67 & 5.61 & 3.94 & 1.67 & 6.18 & 7.92 & -1.73 \\
\hline$(\mathrm{C}(\mathrm{C}(\mathrm{C}(\mathrm{C}(\mathrm{C}(\mathrm{C}(\mathrm{C}(\mathrm{C}(\mathrm{C}(\mathrm{C}(\mathrm{C}(\mathrm{H})(\mathrm{H}) \mathrm{H})(\mathrm{F}) \mathrm{H})(\mathrm{H}) \mathrm{F})(\mathrm{H}) \mathrm{H})(\mathrm{H}) \mathrm{F})(\mathrm{H}) \mathrm{H})(\mathrm{Cl}) \mathrm{H})(\mathrm{Cl}) \mathrm{H})$ & & 5.713 & 6.63 & 0.92 & 4.97 & 4.05 & 0.92 & 5.85 & 8.51 & \\
\hline & & & & & 6.66 & 6.49 & 0.16 & 6.72 & 211.97 & -5.2 \\
\hline & & & & & 5.99 & 5.29 & & 6.38 & 10.16 & \\
\hline & & & & & & 3.35 & & 6.02 & 7.02 & \\
\hline & & & & & & & & 5.67 & & \\
\hline & & & & & & & & & & \\
\hline & & $1.3 / 5$ & & & 5.55 & 0.91 & & 6.15 & 511.5 & \\
\hline
\end{tabular}


$\mathrm{C}(\mathrm{C}(\mathrm{C}(\mathrm{C}(\mathrm{C}(\mathrm{C}(\mathrm{C}(\mathrm{C}(\mathrm{C}(\mathrm{C}(\mathrm{C}(\mathrm{C}(\mathrm{F})(\mathrm{Cl}) \mathrm{Br})(\mathrm{H}) \mathrm{H})(\mathrm{H}) \mathrm{H})(\mathrm{H}) \mathrm{H})(\mathrm{Cl}) \mathrm{H})(\mathrm{H}) \mathrm{H})(\mathrm{H}) \mathrm{H})(\mathrm{H}) \mathrm{H})(\mathrm{H}) \mathrm{H})(\mathrm{F}) \mathrm{H})(\mathrm{H}) \mathrm{F})(\mathrm{H})(\mathrm{C} 12 \mathrm{H} 20 \mathrm{Cl} 2 \mathrm{BrF} 3$ $\mathrm{C}(\mathrm{C}(\mathrm{C}(\mathrm{C}(\mathrm{C}(\mathrm{C}(\mathrm{C}(\mathrm{C}(\mathrm{C}(\mathrm{C}(\mathrm{C}(\mathrm{C}(\mathrm{F})(\mathrm{F}) \mathrm{H})(\mathrm{H}) \mathrm{H})(\mathrm{H}) \mathrm{H})(\mathrm{F}) \mathrm{F})(\mathrm{H}) \mathrm{H})(\mathrm{H}) \mathrm{H})(\mathrm{H}) \mathrm{H})(\mathrm{H}) \mathrm{H})(\mathrm{H}) \mathrm{H})(\mathrm{Cl}) \mathrm{H})(\mathrm{H}) \mathrm{H})(\mathrm{Cl})(\mathrm{Cl} 2 \mathrm{H} 20 \mathrm{Cl} 2 \mathrm{~F} 4$ $\mathrm{C}(\mathrm{C}(\mathrm{C}(\mathrm{C}(\mathrm{C}(\mathrm{C}(\mathrm{C}(\mathrm{C}(\mathrm{C}(\mathrm{C}(\mathrm{C}(\mathrm{C}(\mathrm{H})(\mathrm{H}) \mathrm{H})(\mathrm{H}) \mathrm{Cl})(\mathrm{H}) \mathrm{H})(\mathrm{H}) \mathrm{H})(\mathrm{F}) \mathrm{H})(\mathrm{Cl}) \mathrm{H})(\mathrm{H}) \mathrm{H})(\mathrm{H}) \mathrm{H})(\mathrm{H}) \mathrm{Cl})(\mathrm{Br}) \mathrm{F})(\mathrm{H}) \mathrm{H})(\mathrm{H}) \mathrm{Cl}_{2} \mathrm{H}_{2} 0 \mathrm{Cl} 3 \mathrm{BrF} 2$ $\mathrm{C}(\mathrm{C}(\mathrm{C}(\mathrm{C}(\mathrm{C}(\mathrm{C}(\mathrm{C}(\mathrm{C}(\mathrm{C}(\mathrm{C}(\mathrm{C}(\mathrm{C}(\mathrm{H})(\mathrm{F}) \mathrm{H})(\mathrm{F}) \mathrm{H})(\mathrm{H}) \mathrm{H})(\mathrm{H}) \mathrm{H})(\mathrm{H}) \mathrm{Cl})(\mathrm{Cl}) \mathrm{H})(\mathrm{H}) \mathrm{H})(\mathrm{Cl}) \mathrm{H})(\mathrm{H}) \mathrm{H})(\mathrm{H}) \mathrm{H})(\mathrm{H}) \mathrm{H})(\mathrm{F})(\mathrm{Cl} 2 \mathrm{H} 20 \mathrm{Cl} 3 \mathrm{~F} 3$ $\mathrm{C}(\mathrm{C}(\mathrm{C}(\mathrm{C}(\mathrm{C}(\mathrm{C}(\mathrm{C}(\mathrm{C}(\mathrm{C}(\mathrm{C}(\mathrm{C}(\mathrm{C}(\mathrm{Cl})(\mathrm{H}) \mathrm{Cl})(\mathrm{H}) \mathrm{H})(\mathrm{H}) \mathrm{H})(\mathrm{H}) \mathrm{H})(\mathrm{H}) \mathrm{H})(\mathrm{H}) \mathrm{H})(\mathrm{F}) \mathrm{H})(\mathrm{H}) \mathrm{H})(\mathrm{H}) \mathrm{H})(\mathrm{Cl}) \mathrm{H})(\mathrm{F}) \mathrm{H})(\mathrm{H})(\mathrm{C} 12 \mathrm{H} 20 \mathrm{Cl} 4 \mathrm{~F} 2$ $\mathrm{C}(\mathrm{C}(\mathrm{C}(\mathrm{C}(\mathrm{C}(\mathrm{C}(\mathrm{C}(\mathrm{C}(\mathrm{C}(\mathrm{C}(\mathrm{C}(\mathrm{C}(\mathrm{H})(\mathrm{H}) \mathrm{H})(\mathrm{H}) \mathrm{H})(\mathrm{H}) \mathrm{F})(\mathrm{Cl}) \mathrm{Br})(\mathrm{H}) \mathrm{H})(\mathrm{H}) \mathrm{H})(\mathrm{H}) \mathrm{H})(\mathrm{H}) \mathrm{H})(\mathrm{F}) \mathrm{H})(\mathrm{H}) \mathrm{Br})(\mathrm{H}) \mathrm{H})(\mathrm{H}) \mathrm{C}_{2} \mathrm{H} 20 \mathrm{ClBr} 2 \mathrm{~F} 3$ $\mathrm{C}(\mathrm{C}(\mathrm{C}(\mathrm{C}(\mathrm{C}(\mathrm{C}(\mathrm{C}(\mathrm{C}(\mathrm{C}(\mathrm{C}(\mathrm{C}(\mathrm{C}(\mathrm{H})(\mathrm{H}) \mathrm{F})(\mathrm{F}) \mathrm{H})(\mathrm{Br}) \mathrm{H})(\mathrm{H}) \mathrm{H})(\mathrm{H}) \mathrm{H})(\mathrm{H}) \mathrm{F})(\mathrm{H}) \mathrm{H})(\mathrm{H}) \mathrm{H})(\mathrm{H}) \mathrm{H})(\mathrm{Cl}) \mathrm{F})(\mathrm{H}) \mathrm{H})(\mathrm{H})\left(\mathrm{C}_{2} 2 \mathrm{H} 20 \mathrm{ClBrF} 4\right.$ $\mathrm{C}(\mathrm{C}(\mathrm{C}(\mathrm{C}(\mathrm{C}(\mathrm{C}(\mathrm{C}(\mathrm{C}(\mathrm{C}(\mathrm{C}(\mathrm{C}(\mathrm{C}(\mathrm{H})(\mathrm{H}) \mathrm{H})(\mathrm{H}) \mathrm{H})(\mathrm{H}) \mathrm{H})(\mathrm{F}) \mathrm{H})(\mathrm{H}) \mathrm{H})(\mathrm{H}) \mathrm{H})(\mathrm{H}) \mathrm{Br})(\mathrm{F}) \mathrm{H})(\mathrm{H}) \mathrm{H})(\mathrm{H}) \mathrm{H})(\mathrm{H}) \mathrm{Br})(\mathrm{H})(\mathrm{C} 12 \mathrm{H} 21 \mathrm{Br} 2 \mathrm{~F} 3$ $\mathrm{C}(\mathrm{C}(\mathrm{C}(\mathrm{C}(\mathrm{C}(\mathrm{C}(\mathrm{C}(\mathrm{C}(\mathrm{C}(\mathrm{C}(\mathrm{C}(\mathrm{C}(\mathrm{H})(\mathrm{H}) \mathrm{Cl})(\mathrm{H}) \mathrm{F})(\mathrm{Cl}) \mathrm{H})(\mathrm{H}) \mathrm{H})(\mathrm{H}) \mathrm{H})(\mathrm{H}) \mathrm{H})(\mathrm{H}) \mathrm{H})(\mathrm{H}) \mathrm{H})(\mathrm{H}) \mathrm{H})(\mathrm{F}) \mathrm{H})(\mathrm{H}) \mathrm{H})(\mathrm{H})(\mathrm{C} 12 \mathrm{H} 21 \mathrm{Cl} 2 \mathrm{BrF} 2$ $\mathrm{C}(\mathrm{C}(\mathrm{C}(\mathrm{C}(\mathrm{C}(\mathrm{C}(\mathrm{C}(\mathrm{C}(\mathrm{C}(\mathrm{C}(\mathrm{C}(\mathrm{C}(\mathrm{H})(\mathrm{H}) \mathrm{H})(\mathrm{F}) \mathrm{H})(\mathrm{H}) \mathrm{H})(\mathrm{H}) \mathrm{Cl})(\mathrm{H}) \mathrm{H})(\mathrm{H}) \mathrm{H})(\mathrm{H}) \mathrm{H})(\mathrm{H}) \mathrm{H})(\mathrm{H}) \mathrm{H})(\mathrm{H}) \mathrm{H})(\mathrm{F}) \mathrm{H})(\mathrm{H})(\mathrm{C} 12 \mathrm{H} 21 \mathrm{Cl} 2 \mathrm{~F} 3$ $\mathrm{C}(\mathrm{C}(\mathrm{C}(\mathrm{C}(\mathrm{C}(\mathrm{C}(\mathrm{C}(\mathrm{C}(\mathrm{C}(\mathrm{C}(\mathrm{C}(\mathrm{C}(\mathrm{H})(\mathrm{H}) \mathrm{H})(\mathrm{Cl}) \mathrm{H})(\mathrm{H}) \mathrm{H})(\mathrm{H}) \mathrm{F})(\mathrm{Br}) \mathrm{H})(\mathrm{H}) \mathrm{Cl})(\mathrm{H}) \mathrm{H})(\mathrm{H}) \mathrm{H})(\mathrm{H}) \mathrm{H})(\mathrm{Cl}) \mathrm{H})(\mathrm{H}) \mathrm{H}) \quad \mathrm{C} 12 \mathrm{H} 21 \mathrm{Cl} 3 \mathrm{BrF}$ $\mathrm{C}(\mathrm{C}(\mathrm{C}(\mathrm{C}(\mathrm{C}(\mathrm{C}(\mathrm{C}(\mathrm{C}(\mathrm{C}(\mathrm{C}(\mathrm{C}(\mathrm{C}(\mathrm{H})(\mathrm{Cl}) \mathrm{H})(\mathrm{H}) \mathrm{H})(\mathrm{H}) \mathrm{H})(\mathrm{H}) \mathrm{H})(\mathrm{H}) \mathrm{H})(\mathrm{H}) \mathrm{H})(\mathrm{Cl}) \mathrm{Cl})(\mathrm{H}) \mathrm{F})(\mathrm{H}) \mathrm{H})(\mathrm{H}) \mathrm{H})(\mathrm{H}) \mathrm{F})(\mathrm{H})(\mathrm{C} 12 \mathrm{H} 21 \mathrm{Cl} 3 \mathrm{~F} 2$ $\mathrm{C}(\mathrm{C}(\mathrm{C}(\mathrm{C}(\mathrm{C}(\mathrm{C}(\mathrm{C}(\mathrm{C}(\mathrm{C}(\mathrm{C}(\mathrm{C}(\mathrm{C}(\mathrm{H})(\mathrm{H}) \mathrm{H})(\mathrm{H}) \mathrm{H})(\mathrm{H}) \mathrm{Cl})(\mathrm{H}) \mathrm{Cl})(\mathrm{H}) \mathrm{H})(\mathrm{H}) \mathrm{Cl})(\mathrm{H}) \mathrm{H})(\mathrm{Cl}) \mathrm{H})(\mathrm{H}) \mathrm{H})(\mathrm{H}) \mathrm{H})(\mathrm{H}) \mathrm{F})(\mathrm{H}) \mathrm{C} 12 \mathrm{H} 21 \mathrm{Cl} 4 \mathrm{~F}$ $\mathrm{C}(\mathrm{C}(\mathrm{C}(\mathrm{C}(\mathrm{C}(\mathrm{C}(\mathrm{C}(\mathrm{C}(\mathrm{C}(\mathrm{C}(\mathrm{C}(\mathrm{C}(\mathrm{H})(\mathrm{H}) \mathrm{H})(\mathrm{H}) \mathrm{Cl})(\mathrm{Cl}) \mathrm{H})(\mathrm{H}) \mathrm{H})(\mathrm{H}) \mathrm{H})(\mathrm{Cl}) \mathrm{H})(\mathrm{H}) \mathrm{H})(\mathrm{Cl}) \mathrm{H})(\mathrm{H}) \mathrm{H})(\mathrm{H}) \mathrm{Cl})(\mathrm{H}) \mathrm{H}) \quad \mathrm{C} 12 \mathrm{H} 21 \mathrm{Cl} 5$ $\mathrm{C}(\mathrm{C}(\mathrm{C}(\mathrm{C}(\mathrm{C}(\mathrm{C}(\mathrm{C}(\mathrm{C}(\mathrm{C}(\mathrm{C}(\mathrm{C}(\mathrm{C}(\mathrm{H})(\mathrm{H}) \mathrm{Br})(\mathrm{H}) \mathrm{H})(\mathrm{H}) \mathrm{F})(\mathrm{H}) \mathrm{H})(\mathrm{H}) \mathrm{H})(\mathrm{H}) \mathrm{F})(\mathrm{H}) \mathrm{H})(\mathrm{H}) \mathrm{Br})(\mathrm{H}) \mathrm{H})(\mathrm{H}) \mathrm{H})(\mathrm{H}) \mathrm{H})(\mathrm{H})(\mathrm{C} 12 \mathrm{H} 21 \mathrm{ClBr} 2 \mathrm{~F} 2$ $\mathrm{C}(\mathrm{C}(\mathrm{C}(\mathrm{C}(\mathrm{C}(\mathrm{C}(\mathrm{C}(\mathrm{C}(\mathrm{C}(\mathrm{C}(\mathrm{C}(\mathrm{C}(\mathrm{F})(\mathrm{H}) \mathrm{H})(\mathrm{H}) \mathrm{H})(\mathrm{H}) \mathrm{H})(\mathrm{H}) \mathrm{H})(\mathrm{H}) \mathrm{H})(\mathrm{Br}) \mathrm{F})(\mathrm{H}) \mathrm{Cl})(\mathrm{H}) \mathrm{F})(\mathrm{H}) \mathrm{H})(\mathrm{H}) \mathrm{H})(\mathrm{H}) \mathrm{H})(\mathrm{H})\left(\mathrm{C} 12 \mathrm{H} 21 \mathrm{ClBrF}^{3}\right.$ $\mathrm{C}(\mathrm{C}(\mathrm{C}(\mathrm{C}(\mathrm{C}(\mathrm{C}(\mathrm{C}(\mathrm{C}(\mathrm{C}(\mathrm{C}(\mathrm{C}(\mathrm{C}(\mathrm{H})(\mathrm{H}) \mathrm{F})(\mathrm{H}) \mathrm{H})(\mathrm{H}) \mathrm{H})(\mathrm{H}) \mathrm{H})(\mathrm{H}) \mathrm{H})(\mathrm{H}) \mathrm{H})(\mathrm{H}) \mathrm{H})(\mathrm{H}) \mathrm{Br})(\mathrm{H}) \mathrm{H})(\mathrm{H}) \mathrm{F})(\mathrm{H}) \mathrm{H})(\mathrm{Br})(\mathrm{C} 12 \mathrm{H} 22 \mathrm{Br} 2 \mathrm{~F} 2$ $\mathrm{C}(\mathrm{C}(\mathrm{C}(\mathrm{C}(\mathrm{C}(\mathrm{C}(\mathrm{C}(\mathrm{C}(\mathrm{C}(\mathrm{C}(\mathrm{C}(\mathrm{C}(\mathrm{H})(\mathrm{H}) \mathrm{H})(\mathrm{H}) \mathrm{Br})(\mathrm{H}) \mathrm{H})(\mathrm{H}) \mathrm{H})(\mathrm{H}) \mathrm{H})(\mathrm{H}) \mathrm{H})(\mathrm{H}) \mathrm{Br})(\mathrm{H}) \mathrm{H})(\mathrm{Br}) \mathrm{H})(\mathrm{H}) \mathrm{F})(\mathrm{H}) \mathrm{H}) \quad \mathrm{C} 12 \mathrm{H} 22 \mathrm{Br} 3 \mathrm{~F}$ $\mathrm{C}(\mathrm{C}(\mathrm{C}(\mathrm{C}(\mathrm{C}(\mathrm{C}(\mathrm{C}(\mathrm{C}(\mathrm{C}(\mathrm{C}(\mathrm{C}(\mathrm{C}(\mathrm{H})(\mathrm{H}) \mathrm{H})(\mathrm{H}) \mathrm{H})(\mathrm{H}) \mathrm{H})(\mathrm{H}) \mathrm{F})(\mathrm{Br}) \mathrm{H})(\mathrm{H}) \mathrm{H})(\mathrm{H}) \mathrm{H})(\mathrm{H}) \mathrm{H})(\mathrm{H}) \mathrm{H})(\mathrm{H}) \mathrm{H})(\mathrm{F}) \mathrm{H})(\mathrm{H})(\mathrm{C} 12 \mathrm{H} 22 \mathrm{BrF} 3$ $\mathrm{C}(\mathrm{C}(\mathrm{C}(\mathrm{C}(\mathrm{C}(\mathrm{C}(\mathrm{C}(\mathrm{C}(\mathrm{C}(\mathrm{C}(\mathrm{C}(\mathrm{C}(\mathrm{H})(\mathrm{H}) \mathrm{H})(\mathrm{H}) \mathrm{H})(\mathrm{H}) \mathrm{H})(\mathrm{F}) \mathrm{H})(\mathrm{H}) \mathrm{H})(\mathrm{H}) \mathrm{H})(\mathrm{H}) \mathrm{H})(\mathrm{H}) \mathrm{Cl})(\mathrm{H}) \mathrm{Cl})(\mathrm{H}) \mathrm{H})(\mathrm{H}) \mathrm{Br})(\mathrm{H}) \mathrm{C} 12 \mathrm{H} 22 \mathrm{Cl} 2 \mathrm{BrF}$ $\mathrm{C}(\mathrm{C}(\mathrm{C}(\mathrm{C}(\mathrm{C}(\mathrm{C}(\mathrm{C}(\mathrm{C}(\mathrm{C}(\mathrm{C}(\mathrm{C}(\mathrm{C}(\mathrm{H})(\mathrm{H}) \mathrm{H})(\mathrm{H}) \mathrm{H})(\mathrm{H}) \mathrm{H})(\mathrm{H}) \mathrm{F})(\mathrm{H}) \mathrm{H})(\mathrm{Cl}) \mathrm{H})(\mathrm{H}) \mathrm{F})(\mathrm{H}) \mathrm{H})(\mathrm{H}) \mathrm{H})(\mathrm{H}) \mathrm{H})(\mathrm{Cl}) \mathrm{H})(\mathrm{H})\left(\mathrm{Cl} 2 \mathrm{H} 22 \mathrm{Cl}_{2} \mathrm{~F} 2\right.$ $\mathrm{C}(\mathrm{C}(\mathrm{C}(\mathrm{C}(\mathrm{C}(\mathrm{C}(\mathrm{C}(\mathrm{C}(\mathrm{C}(\mathrm{C}(\mathrm{C}(\mathrm{C}(\mathrm{F})(\mathrm{H}) \mathrm{H})(\mathrm{H}) \mathrm{H})(\mathrm{H}) \mathrm{H})(\mathrm{H}) \mathrm{H})(\mathrm{H}) \mathrm{H})(\mathrm{Cl}) \mathrm{H})(\mathrm{H}) \mathrm{H})(\mathrm{Cl}) \mathrm{H})(\mathrm{H}) \mathrm{H})(\mathrm{H}) \mathrm{H})(\mathrm{H}) \mathrm{H})(\mathrm{H})(\mathrm{C} 12 \mathrm{H} 22 \mathrm{Cl} 3 \mathrm{~F}$ $\mathrm{C}(\mathrm{C}(\mathrm{C}(\mathrm{C}(\mathrm{C}(\mathrm{C}(\mathrm{C}(\mathrm{C}(\mathrm{C}(\mathrm{C}(\mathrm{C}(\mathrm{C}(\mathrm{H})(\mathrm{H}) \mathrm{H})(\mathrm{Cl}) \mathrm{H})(\mathrm{H}) \mathrm{H})(\mathrm{H}) \mathrm{Cl})(\mathrm{H}) \mathrm{Cl})(\mathrm{Cl}) \mathrm{H})(\mathrm{H}) \mathrm{H})(\mathrm{H}) \mathrm{H})(\mathrm{H}) \mathrm{H})(\mathrm{H}) \mathrm{H})(\mathrm{H}) \mathrm{H}) \quad \mathrm{C} 12 \mathrm{H} 22 \mathrm{Cl} 4$ $\mathrm{C}(\mathrm{C}(\mathrm{C}(\mathrm{C}(\mathrm{C}(\mathrm{C}(\mathrm{C}(\mathrm{C}(\mathrm{C}(\mathrm{C}(\mathrm{C}(\mathrm{C}(\mathrm{H})(\mathrm{Br}) \mathrm{H})(\mathrm{Cl}) \mathrm{H})(\mathrm{Br}) \mathrm{H})(\mathrm{H}) \mathrm{H})(\mathrm{H}) \mathrm{H})(\mathrm{H}) \mathrm{H})(\mathrm{H}) \mathrm{H})(\mathrm{H}) \mathrm{H})(\mathrm{H}) \mathrm{H})(\mathrm{F}) \mathrm{H})(\mathrm{H}) \mathrm{H})(\mathrm{H}) \mathrm{C} 12 \mathrm{H} 22 \mathrm{ClBr} 2 \mathrm{~F}$ $\mathrm{C}(\mathrm{C}(\mathrm{C}(\mathrm{C}(\mathrm{C}(\mathrm{C}(\mathrm{C}(\mathrm{C}(\mathrm{C}(\mathrm{C}(\mathrm{C}(\mathrm{C}(\mathrm{H})(\mathrm{Cl}) \mathrm{H})(\mathrm{H}) \mathrm{H})(\mathrm{H}) \mathrm{H})(\mathrm{H}) \mathrm{H})(\mathrm{H}) \mathrm{H})(\mathrm{H}) \mathrm{H})(\mathrm{H}) \mathrm{H})(\mathrm{Br}) \mathrm{H})(\mathrm{F}) \mathrm{H})(\mathrm{H}) \mathrm{H})(\mathrm{H}) \mathrm{H})(\mathrm{H}) \quad \mathrm{C} 12 \mathrm{H} 22 \mathrm{ClBrF} 2$ $\mathrm{C}(\mathrm{C}(\mathrm{C}(\mathrm{C}(\mathrm{C}(\mathrm{C}(\mathrm{C}(\mathrm{C}(\mathrm{C}(\mathrm{C}(\mathrm{C}(\mathrm{C}(\mathrm{H})(\mathrm{H}) \mathrm{H})(\mathrm{F}) \mathrm{F})(\mathrm{H}) \mathrm{F})(\mathrm{H}) \mathrm{H})(\mathrm{H}) \mathrm{H})(\mathrm{H}) \mathrm{H})(\mathrm{H}) \mathrm{H})(\mathrm{Cl}) \mathrm{H})(\mathrm{H}) \mathrm{H})(\mathrm{H}) \mathrm{H})(\mathrm{H}) \mathrm{H})(\mathrm{H})(\mathrm{C} 12 \mathrm{H} 22 \mathrm{ClF} 3$ $\mathrm{C}(\mathrm{C}(\mathrm{C}(\mathrm{C}(\mathrm{C}(\mathrm{C}(\mathrm{C}(\mathrm{C}(\mathrm{C}(\mathrm{C}(\mathrm{C}(\mathrm{C}(\mathrm{H})(\mathrm{H}) \mathrm{H})(\mathrm{H}) \mathrm{H})(\mathrm{H}) \mathrm{H})(\mathrm{H}) \mathrm{H})(\mathrm{H}) \mathrm{H})(\mathrm{H}) \mathrm{H})(\mathrm{H}) \mathrm{H})(\mathrm{H}) \mathrm{H})(\mathrm{Br}) \mathrm{H})(\mathrm{H}) \mathrm{H})(\mathrm{H}) \mathrm{H})(\mathrm{Br}) \mathrm{C} 12 \mathrm{H} 23 \mathrm{Br} 2 \mathrm{~F}$ $\mathrm{C}(\mathrm{C}(\mathrm{C}(\mathrm{C}(\mathrm{C}(\mathrm{C}(\mathrm{C}(\mathrm{C}(\mathrm{C}(\mathrm{C}(\mathrm{C}(\mathrm{C}(\mathrm{H})(\mathrm{H}) \mathrm{H})(\mathrm{H}) \mathrm{H})(\mathrm{H}) \mathrm{H})(\mathrm{H}) \mathrm{H})(\mathrm{H}) \mathrm{H})(\mathrm{H}) \mathrm{H})(\mathrm{H}) \mathrm{H})(\mathrm{H}) \mathrm{H})(\mathrm{F}) \mathrm{H})(\mathrm{F}) \mathrm{Br})(\mathrm{H}) \mathrm{H})(\mathrm{H})(\mathrm{C} 12 \mathrm{H} 23 \mathrm{BrF} 2$ $\mathrm{C}(\mathrm{C}(\mathrm{C}(\mathrm{C}(\mathrm{C}(\mathrm{C}(\mathrm{C}(\mathrm{C}(\mathrm{C}(\mathrm{C}(\mathrm{C}(\mathrm{C}(\mathrm{H})(\mathrm{H}) \mathrm{H})(\mathrm{H}) \mathrm{H})(\mathrm{H}) \mathrm{H})(\mathrm{H}) \mathrm{Br})(\mathrm{H}) \mathrm{H})(\mathrm{H}) \mathrm{H})(\mathrm{H}) \mathrm{H})(\mathrm{H}) \mathrm{Cl})(\mathrm{H}) \mathrm{H})(\mathrm{H}) \mathrm{H})(\mathrm{H}) \mathrm{Cl}) \quad \mathrm{C} 12 \mathrm{H} 23 \mathrm{Cl} 2 \mathrm{~B}$ $\mathrm{C}(\mathrm{C}(\mathrm{C}(\mathrm{C}(\mathrm{C}(\mathrm{C}(\mathrm{C}(\mathrm{C}(\mathrm{C}(\mathrm{C}(\mathrm{C}(\mathrm{C}(\mathrm{H})(\mathrm{H}) \mathrm{H})(\mathrm{F}) \mathrm{H})(\mathrm{H}) \mathrm{H})(\mathrm{H}) \mathrm{H})(\mathrm{Cl}) \mathrm{H})(\mathrm{H}) \mathrm{H})(\mathrm{H}) \mathrm{H})(\mathrm{H}) \mathrm{H})(\mathrm{H}) \mathrm{Cl})(\mathrm{H}) \mathrm{H})(\mathrm{H}) \mathrm{H})(\mathrm{H})(\mathrm{C} 12 \mathrm{H} 23 \mathrm{Cl} 2 \mathrm{~F}$ $\mathrm{C}(\mathrm{C}(\mathrm{C}(\mathrm{C}(\mathrm{C}(\mathrm{C}(\mathrm{C}(\mathrm{C}(\mathrm{C}(\mathrm{C}(\mathrm{C}(\mathrm{C}(\mathrm{H})(\mathrm{H}) \mathrm{H})(\mathrm{H}) \mathrm{H})(\mathrm{H}) \mathrm{H})(\mathrm{H}) \mathrm{H})(\mathrm{H}) \mathrm{H})(\mathrm{H}) \mathrm{H})(\mathrm{H}) \mathrm{H})(\mathrm{Cl}) \mathrm{H})(\mathrm{H}) \mathrm{Cl})(\mathrm{Cl}) \mathrm{H})(\mathrm{H}) \mathrm{H})(\mathrm{H}) \mathrm{C} 12 \mathrm{H} 23 \mathrm{Cl} 3$ $\mathrm{C}(\mathrm{C}(\mathrm{C}(\mathrm{C}(\mathrm{C}(\mathrm{C}(\mathrm{C}(\mathrm{C}(\mathrm{C}(\mathrm{C}(\mathrm{C}(\mathrm{C}(\mathrm{H})(\mathrm{H}) \mathrm{H})(\mathrm{Br}) \mathrm{H})(\mathrm{H}) \mathrm{H})(\mathrm{Br}) \mathrm{H})(\mathrm{H}) \mathrm{H})(\mathrm{H}) \mathrm{H})(\mathrm{H}) \mathrm{H})(\mathrm{H}) \mathrm{H})(\mathrm{H}) \mathrm{H})(\mathrm{H}) \mathrm{H})(\mathrm{H}) \mathrm{H})(\mathrm{H}) \mathrm{C} 12 \mathrm{H} 23 \mathrm{ClBr} 2$ $\mathrm{C}(\mathrm{C}(\mathrm{C}(\mathrm{C}(\mathrm{C}(\mathrm{C}(\mathrm{C}(\mathrm{C}(\mathrm{C}(\mathrm{C}(\mathrm{C}(\mathrm{C}(\mathrm{H})(\mathrm{H}) \mathrm{H})(\mathrm{H}) \mathrm{H})(\mathrm{H}) \mathrm{Br})(\mathrm{F}) \mathrm{H})(\mathrm{H}) \mathrm{H})(\mathrm{H}) \mathrm{H})(\mathrm{H}) \mathrm{H})(\mathrm{H}) \mathrm{H})(\mathrm{H}) \mathrm{H})(\mathrm{H}) \mathrm{H})(\mathrm{H}) \mathrm{Cl})(\mathrm{H}) \mathrm{Cl}_{2} \mathrm{H} 23 \mathrm{ClBrF}$ $\mathrm{C}(\mathrm{C}(\mathrm{C}(\mathrm{C}(\mathrm{C}(\mathrm{C}(\mathrm{C}(\mathrm{C}(\mathrm{C}(\mathrm{C}(\mathrm{C}(\mathrm{C}(\mathrm{H})(\mathrm{H}) \mathrm{H})(\mathrm{H}) \mathrm{H})(\mathrm{H}) \mathrm{H})(\mathrm{H}) \mathrm{H})(\mathrm{H}) \mathrm{H})(\mathrm{H}) \mathrm{H})(\mathrm{H}) \mathrm{H})(\mathrm{H}) \mathrm{Br})(\mathrm{H}) \mathrm{H})(\mathrm{H}) \mathrm{H})(\mathrm{H}) \mathrm{H})(\mathrm{H}) \mathrm{Cl}_{2} \mathrm{H} 24 \mathrm{Br} 2$ $\mathrm{C}(\mathrm{C}(\mathrm{C}(\mathrm{C}(\mathrm{C}(\mathrm{C}(\mathrm{C}(\mathrm{C}(\mathrm{C}(\mathrm{C}(\mathrm{C}(\mathrm{C}(\mathrm{H})(\mathrm{H}) \mathrm{H})(\mathrm{H}) \mathrm{H})(\mathrm{H}) \mathrm{H})(\mathrm{H}) \mathrm{H})(\mathrm{Br}) \mathrm{H})(\mathrm{H}) \mathrm{H})(\mathrm{H}) \mathrm{H})(\mathrm{F}) \mathrm{H})(\mathrm{H}) \mathrm{H})(\mathrm{H}) \mathrm{H})(\mathrm{H}) \mathrm{H})(\mathrm{H})(\mathrm{C} 12 \mathrm{H} 24 \mathrm{BrF}$ $\mathrm{C}(\mathrm{C}(\mathrm{C}(\mathrm{C}(\mathrm{C}(\mathrm{C}(\mathrm{C}(\mathrm{C}(\mathrm{C}(\mathrm{C}(\mathrm{C}(\mathrm{C}(\mathrm{H})(\mathrm{H}) \mathrm{H})(\mathrm{H}) \mathrm{H})(\mathrm{H}) \mathrm{H})(\mathrm{H}) \mathrm{H})(\mathrm{Cl}) \mathrm{H})(\mathrm{H}) \mathrm{H})(\mathrm{H}) \mathrm{H})(\mathrm{H}) \mathrm{H})(\mathrm{H}) \mathrm{H})(\mathrm{H}) \mathrm{H})(\mathrm{H}) \mathrm{Cl})(\mathrm{H}) \mathrm{Cl}_{2} \mathrm{H} 24 \mathrm{Cl} 2$ $\mathrm{C}(\mathrm{C}(\mathrm{C}(\mathrm{C}(\mathrm{C}(\mathrm{C}(\mathrm{C}(\mathrm{C}(\mathrm{C}(\mathrm{C}(\mathrm{C}(\mathrm{C}(\mathrm{H})(\mathrm{Br}) \mathrm{H})(\mathrm{H}) \mathrm{H})(\mathrm{H}) \mathrm{H})(\mathrm{H}) \mathrm{H})(\mathrm{H}) \mathrm{H})(\mathrm{H}) \mathrm{H})(\mathrm{H}) \mathrm{Cl})(\mathrm{H}) \mathrm{H})(\mathrm{H}) \mathrm{H})(\mathrm{H}) \mathrm{H})(\mathrm{H}) \mathrm{H})(\mathrm{H}) \mathrm{C} 12 \mathrm{H} 24 \mathrm{ClBr}$ $\mathrm{C}(\mathrm{C}(\mathrm{C}(\mathrm{C}(\mathrm{C}(\mathrm{C}(\mathrm{C}(\mathrm{C}(\mathrm{C}(\mathrm{C}(\mathrm{C}(\mathrm{C}(\mathrm{H})(\mathrm{H}) \mathrm{H})(\mathrm{H}) \mathrm{H})(\mathrm{H}) \mathrm{H})(\mathrm{F}) \mathrm{H})(\mathrm{H}) \mathrm{H})(\mathrm{H}) \mathrm{H})(\mathrm{H}) \mathrm{H})(\mathrm{H}) \mathrm{H})(\mathrm{H}) \mathrm{H})(\mathrm{H}) \mathrm{H})(\mathrm{Cl}) \mathrm{H})(\mathrm{H})(\mathrm{C} 12 \mathrm{H} 24 \mathrm{ClF}$ $\mathrm{C}(\mathrm{C}(\mathrm{C}(\mathrm{C}(\mathrm{C}(\mathrm{C}(\mathrm{C}(\mathrm{C}(\mathrm{C}(\mathrm{C}(\mathrm{C}(\mathrm{C}(\mathrm{H})(\mathrm{H}) \mathrm{H})(\mathrm{H}) \mathrm{H})(\mathrm{H}) \mathrm{H})(\mathrm{H}) \mathrm{H})(\mathrm{H}) \mathrm{H})(\mathrm{Br}) \mathrm{H})(\mathrm{H}) \mathrm{H})(\mathrm{H}) \mathrm{H})(\mathrm{H}) \mathrm{H})(\mathrm{H}) \mathrm{H})(\mathrm{H}) \mathrm{H})(\mathrm{H}) \mathrm{Cl}_{2} \mathrm{H} 25 \mathrm{Br}$ $\mathrm{C}(\mathrm{C}(\mathrm{C}(\mathrm{C}(\mathrm{C}(\mathrm{C}(\mathrm{C}(\mathrm{C}(\mathrm{C}(\mathrm{C}(\mathrm{C}(\mathrm{C}(\mathrm{H})(\mathrm{H}) \mathrm{H})(\mathrm{H}) \mathrm{H})(\mathrm{H}) \mathrm{Cl})(\mathrm{H}) \mathrm{H})(\mathrm{H}) \mathrm{H})(\mathrm{H}) \mathrm{H})(\mathrm{H}) \mathrm{H})(\mathrm{H}) \mathrm{H})(\mathrm{H}) \mathrm{H})(\mathrm{H}) \mathrm{H})(\mathrm{H}) \mathrm{H})(\mathrm{H})(\mathrm{C} 12 \mathrm{H} 25 \mathrm{Cl}$ $\mathrm{C}(\mathrm{C}(\mathrm{C}(\mathrm{C}(\mathrm{C}(\mathrm{C}(\mathrm{C}(\mathrm{C}(\mathrm{C}(\mathrm{C}(\mathrm{C}(\mathrm{C}(\mathrm{H})(\mathrm{H}) \mathrm{H})(\mathrm{H}) \mathrm{H})(\mathrm{H}) \mathrm{H})(\mathrm{H}) \mathrm{H})(\mathrm{H}) \mathrm{F})(\mathrm{H}) \mathrm{H})(\mathrm{H}) \mathrm{H})(\mathrm{H}) \mathrm{H})(\mathrm{H}) \mathrm{H})(\mathrm{H}) \mathrm{H})(\mathrm{H}) \mathrm{H})(\mathrm{H})(\mathrm{Cl} 2 \mathrm{H} 25 \mathrm{~F}$ $\mathrm{C}(\mathrm{C}(\mathrm{C}(\mathrm{C}(\mathrm{C}(\mathrm{C}(\mathrm{C}(\mathrm{C}(\mathrm{C}(\mathrm{C}(\mathrm{C}(\mathrm{C}(\mathrm{F})(\mathrm{Br}) \mathrm{F})(\mathrm{F}) \mathrm{F})(\mathrm{F}) \mathrm{H})(\mathrm{F}) \mathrm{H})(\mathrm{F}) \mathrm{H})(\mathrm{F}) \mathrm{H})(\mathrm{F}) \mathrm{F})(\mathrm{Br}) \mathrm{H})(\mathrm{F}) \mathrm{Cl})(\mathrm{F}) \mathrm{F})(\mathrm{F}) \mathrm{F})(\mathrm{Br})(\mathrm{F}) \mathrm{F} \quad \mathrm{C} 12 \mathrm{H} 5 \mathrm{ClBr} 3 \mathrm{~F} 17$ $\mathrm{C}(\mathrm{C}(\mathrm{C}(\mathrm{C}(\mathrm{C}(\mathrm{C}(\mathrm{C}(\mathrm{C}(\mathrm{C}(\mathrm{C}(\mathrm{C}(\mathrm{C}(\mathrm{F})(\mathrm{Br}) \mathrm{F})(\mathrm{F}) \mathrm{H})(\mathrm{F}) \mathrm{F})(\mathrm{H}) \mathrm{F})(\mathrm{F}) \mathrm{Br})(\mathrm{F}) \mathrm{F})(\mathrm{H}) \mathrm{F})(\mathrm{F}) \mathrm{H})(\mathrm{F}) \mathrm{H})(\mathrm{F}) \mathrm{F})(\mathrm{H}) \mathrm{Br})(\mathrm{F})(\mathrm{F}) \mathrm{F} \quad \mathrm{C} 12 \mathrm{H} 6 \mathrm{Br} 3 \mathrm{~F} 17$ $\mathrm{C}(\mathrm{C}(\mathrm{C}(\mathrm{C}(\mathrm{C}(\mathrm{C}(\mathrm{C}(\mathrm{C}(\mathrm{C}(\mathrm{C}(\mathrm{C}(\mathrm{C}(\mathrm{F})(\mathrm{F}) \mathrm{H})(\mathrm{F}) \mathrm{F})(\mathrm{F}) \mathrm{F})(\mathrm{F}) \mathrm{F})(\mathrm{F}) \mathrm{F})(\mathrm{Br}) \mathrm{H})(\mathrm{H}) \mathrm{H})(\mathrm{Br}) \mathrm{H})(\mathrm{F}) \mathrm{Br})(\mathrm{F}) \mathrm{H})(\mathrm{F}) \mathrm{Br})(\mathrm{F})(\mathrm{F}) \mathrm{F}$ C12H6Br4F16 $\mathrm{C}(\mathrm{C}(\mathrm{C}(\mathrm{C}(\mathrm{C}(\mathrm{C}(\mathrm{C}(\mathrm{C}(\mathrm{C}(\mathrm{C}(\mathrm{C}(\mathrm{C}(\mathrm{Cl})(\mathrm{Cl}) \mathrm{F})(\mathrm{F}) \mathrm{H})(\mathrm{F}) \mathrm{F})(\mathrm{F}) \mathrm{F})(\mathrm{F}) \mathrm{F})(\mathrm{F}) \mathrm{H})(\mathrm{F}) \mathrm{F})(\mathrm{F}) \mathrm{F})(\mathrm{F}) \mathrm{H})(\mathrm{Cl}) \mathrm{F})(\mathrm{H}) \mathrm{Br})(\mathrm{H})(\mathrm{F}) \mathrm{H} \quad \mathrm{C} 12 \mathrm{H} 6 \mathrm{Cl} 3 \mathrm{BrF} 16$ $\mathrm{C}(\mathrm{C}(\mathrm{C}(\mathrm{C}(\mathrm{C}(\mathrm{C}(\mathrm{C}(\mathrm{C}(\mathrm{C}(\mathrm{C}(\mathrm{C}(\mathrm{C}(\mathrm{F})(\mathrm{Cl}) \mathrm{Cl})(\mathrm{F}) \mathrm{Cl})(\mathrm{F}) \mathrm{Cl})(\mathrm{H}) \mathrm{F})(\mathrm{F}) \mathrm{H})(\mathrm{F}) \mathrm{F})(\mathrm{F}) \mathrm{H})(\mathrm{Cl}) \mathrm{F})(\mathrm{H}) \mathrm{F})(\mathrm{F}) \mathrm{H})(\mathrm{F}) \mathrm{F})(\mathrm{H})(\mathrm{Cl}) \quad \mathrm{C} 12 \mathrm{H} 6 \mathrm{Cl} 6 \mathrm{~F} 14$ $\mathrm{C}(\mathrm{C}(\mathrm{C}(\mathrm{C}(\mathrm{C}(\mathrm{C}(\mathrm{C}(\mathrm{C}(\mathrm{C}(\mathrm{C}(\mathrm{C}(\mathrm{C}(\mathrm{F})(\mathrm{F}) \mathrm{F})(\mathrm{F}) \mathrm{F})(\mathrm{F}) \mathrm{F})(\mathrm{F}) \mathrm{F})(\mathrm{Br}) \mathrm{H})(\mathrm{H}) \mathrm{Br})(\mathrm{H}) \mathrm{H})(\mathrm{H}) \mathrm{F})(\mathrm{Br}) \mathrm{F})(\mathrm{Br}) \mathrm{H})(\mathrm{F}) \mathrm{F})(\mathrm{H})(\mathrm{F}) \quad \mathrm{C} 12 \mathrm{H} 7 \mathrm{Br} 4 \mathrm{~F} 15$ $\mathrm{C}(\mathrm{C}(\mathrm{C}(\mathrm{C}(\mathrm{C}(\mathrm{C}(\mathrm{C}(\mathrm{C}(\mathrm{C}(\mathrm{C}(\mathrm{C}(\mathrm{C}(\mathrm{Br})(\mathrm{Br}) \mathrm{F})(\mathrm{F}) \mathrm{H})(\mathrm{Cl}) \mathrm{F})(\mathrm{H}) \mathrm{F})(\mathrm{Cl}) \mathrm{F})(\mathrm{H}) \mathrm{F})(\mathrm{F}) \mathrm{H})(\mathrm{F}) \mathrm{F})(\mathrm{F}) \mathrm{F})(\mathrm{H}) \mathrm{F})(\mathrm{H}) \mathrm{F})(\mathrm{H})(\mathrm{F}) \mathrm{F}$ C12H7Cl2 $\mathrm{Br} 2 \mathrm{~F} 15$ $\mathrm{C}(\mathrm{C}(\mathrm{C}(\mathrm{C}(\mathrm{C}(\mathrm{C}(\mathrm{C}(\mathrm{C}(\mathrm{C}(\mathrm{C}(\mathrm{C}(\mathrm{C}(\mathrm{H})(\mathrm{Cl}) \mathrm{F})(\mathrm{H}) \mathrm{F})(\mathrm{F}) \mathrm{F})(\mathrm{H}) \mathrm{F})(\mathrm{F}) \mathrm{H})(\mathrm{F}) \mathrm{H})(\mathrm{H}) \mathrm{F})(\mathrm{F}) \mathrm{F})(\mathrm{Br}) \mathrm{F})(\mathrm{H}) \mathrm{Cl})(\mathrm{Cl}) \mathrm{F})(\mathrm{F})(\mathrm{Br}) \quad \mathrm{C} 12 \mathrm{H} 7 \mathrm{Cl} 3 \mathrm{Br} 2 \mathrm{~F} 14$ $\mathrm{C}(\mathrm{C}(\mathrm{C}(\mathrm{C}(\mathrm{C}(\mathrm{C}(\mathrm{C}(\mathrm{C}(\mathrm{C}(\mathrm{C}(\mathrm{C}(\mathrm{C}(\mathrm{Cl})(\mathrm{Cl}) \mathrm{F})(\mathrm{F}) \mathrm{F})(\mathrm{Cl}) \mathrm{H})(\mathrm{F}) \mathrm{F})(\mathrm{F}) \mathrm{F})(\mathrm{H}) \mathrm{H})(\mathrm{H}) \mathrm{F})(\mathrm{F}) \mathrm{F})(\mathrm{H}) \mathrm{F})(\mathrm{F}) \mathrm{F})(\mathrm{H}) \mathrm{F})(\mathrm{F})(\mathrm{Br}) \mathrm{H} \quad \mathrm{C} 12 \mathrm{H} 7 \mathrm{Cl} 3 \mathrm{BrF} 15$ $\mathrm{C}(\mathrm{C}(\mathrm{C}(\mathrm{C}(\mathrm{C}(\mathrm{C}(\mathrm{C}(\mathrm{C}(\mathrm{C}(\mathrm{C}(\mathrm{C}(\mathrm{C}(\mathrm{Br})(\mathrm{H}) \mathrm{F})(\mathrm{F}) \mathrm{Cl})(\mathrm{F}) \mathrm{F})(\mathrm{F}) \mathrm{Cl})(\mathrm{F}) \mathrm{H})(\mathrm{F}) \mathrm{H})(\mathrm{F}) \mathrm{F})(\mathrm{Cl}) \mathrm{H})(\mathrm{F}) \mathrm{H})(\mathrm{F}) \mathrm{F})(\mathrm{H}) \mathrm{F})(\mathrm{Cl})(\mathrm{F}) \quad \mathrm{C} 12 \mathrm{H} 7 \mathrm{Cl} 1 \mathrm{BrF} 14$ $\mathrm{C}(\mathrm{C}(\mathrm{C}(\mathrm{C}(\mathrm{C}(\mathrm{C}(\mathrm{C}(\mathrm{C}(\mathrm{C}(\mathrm{C}(\mathrm{C}(\mathrm{C}(\mathrm{H})(\mathrm{Cl}) \mathrm{H})(\mathrm{Cl}) \mathrm{F})(\mathrm{F}) \mathrm{F})(\mathrm{F}) \mathrm{F})(\mathrm{H}) \mathrm{H})(\mathrm{F}) \mathrm{Cl})(\mathrm{F}) \mathrm{F})(\mathrm{H}) \mathrm{Cl})(\mathrm{H}) \mathrm{F})(\mathrm{F}) \mathrm{F})(\mathrm{F}) \mathrm{F})(\mathrm{F})(\mathrm{F}) \mathrm{H} \quad \mathrm{C} 12 \mathrm{H} 7 \mathrm{Cl} 4 \mathrm{~F} 15$ $\mathrm{C}(\mathrm{C}(\mathrm{C}(\mathrm{C}(\mathrm{C}(\mathrm{C}(\mathrm{C}(\mathrm{C}(\mathrm{C}(\mathrm{C}(\mathrm{C}(\mathrm{C}(\mathrm{H})(\mathrm{F}) \mathrm{F})(\mathrm{H}) \mathrm{H})(\mathrm{Cl}) \mathrm{F})(\mathrm{Cl}) \mathrm{F})(\mathrm{F}) \mathrm{H})(\mathrm{Cl}) \mathrm{F})(\mathrm{F}) \mathrm{F})(\mathrm{F}) \mathrm{F})(\mathrm{H}) \mathrm{F})(\mathrm{H}) \mathrm{Cl})(\mathrm{F}) \mathrm{Cl})(\mathrm{F})(\mathrm{H}) \mathrm{F} \mathrm{C12H}$ 7Cl5F14 $\mathrm{C}(\mathrm{C}(\mathrm{C}(\mathrm{C}(\mathrm{C}(\mathrm{C}(\mathrm{C}(\mathrm{C}(\mathrm{C}(\mathrm{C}(\mathrm{C}(\mathrm{C}(\mathrm{F})(\mathrm{Cl}) \mathrm{H})(\mathrm{F}) \mathrm{F})(\mathrm{F}) \mathrm{Cl})(\mathrm{Cl}) \mathrm{H})(\mathrm{Cl}) \mathrm{F})(\mathrm{H}) \mathrm{F})(\mathrm{H}) \mathrm{F})(\mathrm{Cl}) \mathrm{Cl})(\mathrm{F}) \mathrm{H})(\mathrm{F}) \mathrm{H})(\mathrm{F}) \mathrm{F})(\mathrm{H})(\mathrm{F}) \mathrm{C} 12 \mathrm{H} 7 \mathrm{Cl}$ F 12 $\mathrm{C}(\mathrm{C}(\mathrm{C}(\mathrm{C}(\mathrm{C}(\mathrm{C}(\mathrm{C}(\mathrm{C}(\mathrm{C}(\mathrm{C}(\mathrm{C}(\mathrm{C}(\mathrm{F})(\mathrm{F}) \mathrm{F})(\mathrm{F}) \mathrm{H})(\mathrm{F}) \mathrm{Br})(\mathrm{H}) \mathrm{F})(\mathrm{F}) \mathrm{F})(\mathrm{F}) \mathrm{H})(\mathrm{F}) \mathrm{H})(\mathrm{F}) \mathrm{Br})(\mathrm{F}) \mathrm{F})(\mathrm{Br}) \mathrm{F})(\mathrm{F}) \mathrm{H})(\mathrm{H})(\mathrm{Cl}) \mathrm{H}$ C12H7ClBr3F15 $\mathrm{C}(\mathrm{C}(\mathrm{C}(\mathrm{C}(\mathrm{C}(\mathrm{C}(\mathrm{C}(\mathrm{C}(\mathrm{C}(\mathrm{C}(\mathrm{C}(\mathrm{C}(\mathrm{H})(\mathrm{F}) \mathrm{F})(\mathrm{F}) \mathrm{H})(\mathrm{H}) \mathrm{F})(\mathrm{H}) \mathrm{H})(\mathrm{F}) \mathrm{F})(\mathrm{F}) \mathrm{F})(\mathrm{Br}) \mathrm{H})(\mathrm{H}) \mathrm{F})(\mathrm{Br}) \mathrm{F})(\mathrm{F}) \mathrm{Br})(\mathrm{F}) \mathrm{F})(\mathrm{F})(\mathrm{H}) \mathrm{F} \quad \mathrm{C} 12 \mathrm{H} 8 \mathrm{Br} 3 \mathrm{~F} 15$ $\mathrm{C}(\mathrm{C}(\mathrm{C}(\mathrm{C}(\mathrm{C}(\mathrm{C}(\mathrm{C}(\mathrm{C}(\mathrm{C}(\mathrm{C}(\mathrm{C}(\mathrm{C}(\mathrm{H})(\mathrm{Cl}) \mathrm{Br})(\mathrm{F}) \mathrm{H})(\mathrm{F}) \mathrm{F})(\mathrm{F}) \mathrm{F})(\mathrm{H}) \mathrm{F})(\mathrm{H}) \mathrm{H})(\mathrm{Cl}) \mathrm{F})(\mathrm{H}) \mathrm{H})(\mathrm{F}) \mathrm{F})(\mathrm{F}) \mathrm{H})(\mathrm{F}) \mathrm{F})(\mathrm{F})(\mathrm{Br}) \mathrm{F} \mathrm{C12H} \mathrm{Cl} \mathrm{Cl} 2 \mathrm{Br} 2 \mathrm{~F} 14$ $\mathrm{C}(\mathrm{C}(\mathrm{C}(\mathrm{C}(\mathrm{C}(\mathrm{C}(\mathrm{C}(\mathrm{C}(\mathrm{C}(\mathrm{C}(\mathrm{C}(\mathrm{C}(\mathrm{H})(\mathrm{H}) \mathrm{Cl})(\mathrm{H}) \mathrm{Br})(\mathrm{F}) \mathrm{Br})(\mathrm{H}) \mathrm{F})(\mathrm{H}) \mathrm{F})(\mathrm{F}) \mathrm{Br})(\mathrm{F}) \mathrm{H})(\mathrm{Cl}) \mathrm{F})(\mathrm{F}) \mathrm{F})(\mathrm{F}) \mathrm{H})(\mathrm{F}) \mathrm{F})(\mathrm{H})(\mathrm{F}) \mathrm{C} 12 \mathrm{H} 8 \mathrm{Cl} 2 \mathrm{Br} 3 \mathrm{~F} 13$ $\mathrm{C}(\mathrm{C}(\mathrm{C}(\mathrm{C}(\mathrm{C}(\mathrm{C}(\mathrm{C}(\mathrm{C}(\mathrm{C}(\mathrm{C}(\mathrm{C}(\mathrm{C}(\mathrm{F})(\mathrm{F}) \mathrm{Cl})(\mathrm{F}) \mathrm{Br})(\mathrm{F}) \mathrm{F})(\mathrm{H}) \mathrm{H})(\mathrm{H}) \mathrm{H})(\mathrm{F}) \mathrm{F})(\mathrm{F}) \mathrm{F})(\mathrm{H}) \mathrm{Cl})(\mathrm{H}) \mathrm{H})(\mathrm{F}) \mathrm{F})(\mathrm{F}) \mathrm{F})(\mathrm{H})(\mathrm{F}) \mathrm{F} \quad \mathrm{C} 12 \mathrm{H} 8 \mathrm{Cl} 2 \mathrm{BrF} 15$ $\mathrm{C}(\mathrm{C}(\mathrm{C}(\mathrm{C}(\mathrm{C}(\mathrm{C}(\mathrm{C}(\mathrm{C}(\mathrm{C}(\mathrm{C}(\mathrm{C}(\mathrm{C}(\mathrm{Br})(\mathrm{F}) \mathrm{F})(\mathrm{F}) \mathrm{F})(\mathrm{H}) \mathrm{F})(\mathrm{H}) \mathrm{Cl})(\mathrm{H}) \mathrm{F})(\mathrm{F}) \mathrm{H})(\mathrm{F}) \mathrm{H})(\mathrm{H}) \mathrm{F})(\mathrm{Cl}) \mathrm{F})(\mathrm{Cl}) \mathrm{F})(\mathrm{H}) \mathrm{Br})(\mathrm{H})(\mathrm{F}) \mathrm{C} 12 \mathrm{H} 8 \mathrm{Cl} 3 \mathrm{Br} 2 \mathrm{~F} 13$ $\mathrm{C}(\mathrm{C}(\mathrm{C}(\mathrm{C}(\mathrm{C}(\mathrm{C}(\mathrm{C}(\mathrm{C}(\mathrm{C}(\mathrm{C}(\mathrm{C}(\mathrm{C}(\mathrm{F})(\mathrm{F}) \mathrm{H})(\mathrm{Br}) \mathrm{F})(\mathrm{Cl}) \mathrm{F})(\mathrm{H}) \mathrm{Cl})(\mathrm{H}) \mathrm{F})(\mathrm{H}) \mathrm{F})(\mathrm{H}) \mathrm{F})(\mathrm{Cl}) \mathrm{H})(\mathrm{F}) \mathrm{F})(\mathrm{Cl}) \mathrm{H})(\mathrm{F}) \mathrm{F})(\mathrm{H})(\mathrm{F}) \quad \mathrm{C} 12 \mathrm{H} 8 \mathrm{Cl} 4 \mathrm{BrF} 13$ $\mathrm{C}(\mathrm{C}(\mathrm{C}(\mathrm{C}(\mathrm{C}(\mathrm{C}(\mathrm{C}(\mathrm{C}(\mathrm{C}(\mathrm{C}(\mathrm{C}(\mathrm{C}(\mathrm{H})(\mathrm{F}) \mathrm{Cl})(\mathrm{Cl}) \mathrm{H})(\mathrm{H}) \mathrm{F})(\mathrm{F}) \mathrm{F})(\mathrm{H}) \mathrm{F})(\mathrm{F}) \mathrm{Cl})(\mathrm{F}) \mathrm{F})(\mathrm{H}) \mathrm{H})(\mathrm{F}) \mathrm{F})(\mathrm{H}) \mathrm{H})(\mathrm{F}) \mathrm{F})(\mathrm{F})(\mathrm{Cl}) \mathrm{C} \mathrm{C} 12 \mathrm{H} 8 \mathrm{Cl} 15 \mathrm{~F} 13$ $\mathrm{C}(\mathrm{C}(\mathrm{C}(\mathrm{C}(\mathrm{C}(\mathrm{C}(\mathrm{C}(\mathrm{C}(\mathrm{C}(\mathrm{C}(\mathrm{C}(\mathrm{C}(\mathrm{F})(\mathrm{H}) \mathrm{F})(\mathrm{F}) \mathrm{H})(\mathrm{F}) \mathrm{H})(\mathrm{F}) \mathrm{F})(\mathrm{Cl}) \mathrm{H})(\mathrm{F}) \mathrm{F})(\mathrm{H}) \mathrm{Br})(\mathrm{F}) \mathrm{Br})(\mathrm{F}) \mathrm{F})(\mathrm{H}) \mathrm{F})(\mathrm{F}) \mathrm{H})(\mathrm{F})(\mathrm{Br}) \quad \mathrm{C} 12 \mathrm{H} 8 \mathrm{ClBr} 3 \mathrm{~F} 14$ $\mathrm{C}(\mathrm{C}(\mathrm{C}(\mathrm{C}(\mathrm{C}(\mathrm{C}(\mathrm{C}(\mathrm{C}(\mathrm{C}(\mathrm{C}(\mathrm{C}(\mathrm{C}(\mathrm{H})(\mathrm{F}) \mathrm{F})(\mathrm{H}) \mathrm{F})(\mathrm{Br}) \mathrm{F})(\mathrm{F}) \mathrm{F})(\mathrm{F}) \mathrm{H})(\mathrm{F}) \mathrm{F})(\mathrm{H}) \mathrm{F})(\mathrm{Br}) \mathrm{F})(\mathrm{H}) \mathrm{H})(\mathrm{H}) \mathrm{F})(\mathrm{F}) \mathrm{F})(\mathrm{H})(\mathrm{H}) \mathrm{Br} \mathrm{C} 12 \mathrm{H} 9 \mathrm{Br} 3 \mathrm{~F} 14$ $\mathrm{C}(\mathrm{C}(\mathrm{C}(\mathrm{C}(\mathrm{C}(\mathrm{C}(\mathrm{C}(\mathrm{C}(\mathrm{C}(\mathrm{C}(\mathrm{C}(\mathrm{C}(\mathrm{F})(\mathrm{H}) \mathrm{F})(\mathrm{H}) \mathrm{F})(\mathrm{F}) \mathrm{H})(\mathrm{H}) \mathrm{Br})(\mathrm{F}) \mathrm{F})(\mathrm{F}) \mathrm{H})(\mathrm{H}) \mathrm{H})(\mathrm{Br}) \mathrm{F})(\mathrm{Br}) \mathrm{F})(\mathrm{F}) \mathrm{F})(\mathrm{H}) \mathrm{Br})(\mathrm{F})(\mathrm{F}) \mathrm{C} 12 \mathrm{H} 9 \mathrm{Br} 4 \mathrm{~F} 13$ $\mathrm{C}(\mathrm{C}(\mathrm{C}(\mathrm{C}(\mathrm{C}(\mathrm{C}(\mathrm{C}(\mathrm{C}(\mathrm{C}(\mathrm{C}(\mathrm{C}(\mathrm{C}(\mathrm{Br})(\mathrm{F}) \mathrm{H})(\mathrm{Cl}) \mathrm{F})(\mathrm{H}) \mathrm{F})(\mathrm{F}) \mathrm{F})(\mathrm{Cl}) \mathrm{H})(\mathrm{F}) \mathrm{H})(\mathrm{F}) \mathrm{H})(\mathrm{H}) \mathrm{Br})(\mathrm{F}) \mathrm{H})(\mathrm{F}) \mathrm{F})(\mathrm{F}) \mathrm{F})(\mathrm{H})(\mathrm{F}) \quad \mathrm{C} 12 \mathrm{H} 9 \mathrm{Cl} 2 \mathrm{Br} 2 \mathrm{~F} 13$ $\mathrm{C}(\mathrm{C}(\mathrm{C}(\mathrm{C}(\mathrm{C}(\mathrm{C}(\mathrm{C}(\mathrm{C}(\mathrm{C}(\mathrm{C}(\mathrm{C}(\mathrm{C}(\mathrm{H})(\mathrm{Br}) \mathrm{F})(\mathrm{Br}) \mathrm{H})(\mathrm{F}) \mathrm{F})(\mathrm{F}) \mathrm{H})(\mathrm{H}) \mathrm{H})(\mathrm{F}) \mathrm{F})(\mathrm{Cl}) \mathrm{F})(\mathrm{F}) \mathrm{H})(\mathrm{F}) \mathrm{H})(\mathrm{Cl}) \mathrm{H})(\mathrm{F}) \mathrm{Cl})(\mathrm{H})(\mathrm{F}) \mathrm{C} 12 \mathrm{H} 9 \mathrm{Cl} 3 \mathrm{Br} 2 \mathrm{~F} 12$ $\mathrm{C}(\mathrm{C}(\mathrm{C}(\mathrm{C}(\mathrm{C}(\mathrm{C}(\mathrm{C}(\mathrm{C}(\mathrm{C}(\mathrm{C}(\mathrm{C}(\mathrm{C}(\mathrm{F})(\mathrm{Cl}) \mathrm{H})(\mathrm{Br}) \mathrm{F})(\mathrm{H}) \mathrm{F})(\mathrm{Cl}) \mathrm{F})(\mathrm{H}) \mathrm{F})(\mathrm{F}) \mathrm{H})(\mathrm{F}) \mathrm{H})(\mathrm{F}) \mathrm{H})(\mathrm{F}) \mathrm{F})(\mathrm{F}) \mathrm{H})(\mathrm{F}) \mathrm{Cl})(\mathrm{H})(\mathrm{F}) \quad \mathrm{C} 12 \mathrm{H} 9 \mathrm{Cl} 3 \mathrm{BrF} 13$ $\mathrm{C}(\mathrm{C}(\mathrm{C}(\mathrm{C}(\mathrm{C}(\mathrm{C}(\mathrm{C}(\mathrm{C}(\mathrm{C}(\mathrm{C}(\mathrm{C}(\mathrm{C}(\mathrm{F})(\mathrm{Br}) \mathrm{Cl})(\mathrm{H}) \mathrm{H})(\mathrm{H}) \mathrm{F})(\mathrm{H}) \mathrm{F})(\mathrm{F}) \mathrm{H})(\mathrm{H}) \mathrm{F})(\mathrm{F}) \mathrm{Cl})(\mathrm{Cl}) \mathrm{F})(\mathrm{H}) \mathrm{H})(\mathrm{F}) \mathrm{F})(\mathrm{F}) \mathrm{Cl})(\mathrm{H})(\mathrm{F}) \mathrm{C} 12 \mathrm{H}$ ) Cl4BrF12 $\mathrm{C}(\mathrm{C}(\mathrm{C}(\mathrm{C}(\mathrm{C}(\mathrm{C}(\mathrm{C}(\mathrm{C}(\mathrm{C}(\mathrm{C}(\mathrm{C}(\mathrm{C}(\mathrm{F})(\mathrm{H}) \mathrm{H})(\mathrm{F}) \mathrm{Cl})(\mathrm{Cl}) \mathrm{H})(\mathrm{H}) \mathrm{F})(\mathrm{H}) \mathrm{Cl})(\mathrm{F}) \mathrm{F})(\mathrm{H}) \mathrm{F})(\mathrm{Cl}) \mathrm{Cl})(\mathrm{F}) \mathrm{F})(\mathrm{H}) \mathrm{F})(\mathrm{F}) \mathrm{H})(\mathrm{F})(\mathrm{F}) \quad \mathrm{C} 12 \mathrm{H} 9 \mathrm{Cl} 5 \mathrm{~F} 12$ $\mathrm{C}(\mathrm{C}(\mathrm{C}(\mathrm{C}(\mathrm{C}(\mathrm{C}(\mathrm{C}(\mathrm{C}(\mathrm{C}(\mathrm{C}(\mathrm{C}(\mathrm{C}(\mathrm{H})(\mathrm{F}) \mathrm{F})(\mathrm{H}) \mathrm{Cl})(\mathrm{Cl}) \mathrm{F})(\mathrm{F}) \mathrm{Cl})(\mathrm{H}) \mathrm{F})(\mathrm{H}) \mathrm{F})(\mathrm{Cl}) \mathrm{H})(\mathrm{F}) \mathrm{H})(\mathrm{F}) \mathrm{F})(\mathrm{F}) \mathrm{H})(\mathrm{Cl}) \mathrm{H})(\mathrm{H}) \quad \mathrm{C} 12 \mathrm{H} 9 \mathrm{Cl} 6 \mathrm{BrF} 10$ $\mathrm{C}(\mathrm{C}(\mathrm{C}(\mathrm{C}(\mathrm{C}(\mathrm{C}(\mathrm{C}(\mathrm{C}(\mathrm{C}(\mathrm{C}(\mathrm{C}(\mathrm{C}(\mathrm{Cl})(\mathrm{Cl}) \mathrm{F})(\mathrm{F}) \mathrm{F})(\mathrm{F}) \mathrm{F})(\mathrm{H}) \mathrm{F})(\mathrm{Cl}) \mathrm{H})(\mathrm{H}) \mathrm{H})(\mathrm{F}) \mathrm{H})(\mathrm{H}) \mathrm{H})(\mathrm{Cl}) \mathrm{Cl})(\mathrm{H}) \mathrm{F})(\mathrm{F}) \mathrm{F})(\mathrm{H}) \quad \mathrm{C} 12 \mathrm{H} 9 \mathrm{Cl} 6 \mathrm{~F} 11$ $\mathrm{C}(\mathrm{C}(\mathrm{C}(\mathrm{C}(\mathrm{C}(\mathrm{C}(\mathrm{C}(\mathrm{C}(\mathrm{C}(\mathrm{C}(\mathrm{C}(\mathrm{C}(\mathrm{C}(\mathrm{F})(\mathrm{H}) \mathrm{F})(\mathrm{F}) \mathrm{F})(\mathrm{F}) \mathrm{Br})(\mathrm{Br}) \mathrm{F})(\mathrm{H}) \mathrm{Br})(\mathrm{F}) \mathrm{H})(\mathrm{H}) \mathrm{H})(\mathrm{H}) \mathrm{F})(\mathrm{F}) \mathrm{H})(\mathrm{H}) \mathrm{H})(\mathrm{H}) \mathrm{F}) \quad \mathrm{C} 13 \mathrm{H} 10 \mathrm{Br} 3 \mathrm{~F} 15$ (F)F)(F)(F)F

$\mathrm{C}(\mathrm{C}(\mathrm{C}(\mathrm{C}(\mathrm{C}(\mathrm{C}(\mathrm{C}(\mathrm{C}(\mathrm{C}(\mathrm{C}(\mathrm{C}(\mathrm{C}(\mathrm{C}(\mathrm{H})(\mathrm{H}) \mathrm{H})(\mathrm{H}) \mathrm{F})(\mathrm{F}) \mathrm{F})(\mathrm{H}) \mathrm{Br})(\mathrm{F}) \mathrm{F})(\mathrm{H}) \mathrm{Br})(\mathrm{F}) \mathrm{F})(\mathrm{H}) \mathrm{Br})(\mathrm{F}) \mathrm{H})(\mathrm{F}) \mathrm{F})(\mathrm{F}) \mathrm{H})(\mathrm{Br})$ $\mathrm{F})(\mathrm{F})(\mathrm{F}) \mathrm{H}$

$\mathrm{C}(\mathrm{C}(\mathrm{C}(\mathrm{C}(\mathrm{C}(\mathrm{C}(\mathrm{C}(\mathrm{C}(\mathrm{C}(\mathrm{C}(\mathrm{C}(\mathrm{C}(\mathrm{C}(\mathrm{F})(\mathrm{F}) \mathrm{Cl})(\mathrm{F}) \mathrm{H})(\mathrm{F}) \mathrm{Cl})(\mathrm{Br}) \mathrm{H})(\mathrm{H}) \mathrm{F})(\mathrm{F}) \mathrm{H})(\mathrm{F}) \mathrm{F})(\mathrm{F}) \mathrm{H})(\mathrm{Br}) \mathrm{H})(\mathrm{H}) \mathrm{F})(\mathrm{F}) \mathrm{H})$ $(\mathrm{F}) \mathrm{H})(\mathrm{F})(\mathrm{H}) \mathrm{F}$ $\mathrm{C}(\mathrm{C}(\mathrm{C}(\mathrm{C}(\mathrm{C}(\mathrm{C}(\mathrm{C}(\mathrm{C}(\mathrm{C}(\mathrm{C}(\mathrm{C}(\mathrm{C}(\mathrm{C}(\mathrm{H})(\mathrm{H}) \mathrm{F})(\mathrm{H}) \mathrm{F})(\mathrm{F}) \mathrm{F})(\mathrm{Cl}) \mathrm{Br})(\mathrm{H}) \mathrm{F})(\mathrm{F}) \mathrm{H})(\mathrm{H}) \mathrm{F})(\mathrm{H}) \mathrm{Cl})(\mathrm{H}) \mathrm{F})(\mathrm{F}) \mathrm{F})(\mathrm{H}) \mathrm{Cl})$ (F)F)(F)(Br)H

$\mathrm{C}(\mathrm{C}(\mathrm{C}(\mathrm{C}(\mathrm{C}(\mathrm{C}(\mathrm{C}(\mathrm{C}(\mathrm{C}(\mathrm{C}(\mathrm{C}(\mathrm{C}(\mathrm{C}(\mathrm{H})(\mathrm{Br}) \mathrm{F})(\mathrm{H}) \mathrm{Cl})(\mathrm{F}) \mathrm{F})(\mathrm{H}) \mathrm{H})(\mathrm{H}) \mathrm{H})(\mathrm{Cl}) \mathrm{F})(\mathrm{H}) \mathrm{F})(\mathrm{F}) \mathrm{F})(\mathrm{F}) \mathrm{F})(\mathrm{H}) \mathrm{F})(\mathrm{Cl}) \mathrm{H})$ (F)F)(F)(H)F

$\mathrm{C}(\mathrm{C}(\mathrm{C}(\mathrm{C}(\mathrm{C}(\mathrm{C}(\mathrm{C}(\mathrm{C}(\mathrm{C}(\mathrm{C}(\mathrm{C}(\mathrm{C}(\mathrm{C}(\mathrm{H})(\mathrm{F}) \mathrm{F})(\mathrm{F}) \mathrm{F})(\mathrm{Cl}) \mathrm{H})(\mathrm{F}) \mathrm{H})(\mathrm{F}) \mathrm{H})(\mathrm{H}) \mathrm{Cl})(\mathrm{H}) \mathrm{F})(\mathrm{F}) \mathrm{F})(\mathrm{H}) \mathrm{H})(\mathrm{F}) \mathrm{Br})(\mathrm{H}) \mathrm{F})$ $(\mathrm{Cl}) \mathrm{F})(\mathrm{H})(\mathrm{F}) \mathrm{Cl}$

$\mathrm{C} 13 \mathrm{H} 10 \mathrm{Br} 4 \mathrm{~F} 14$

$\mathrm{C} 13 \mathrm{H} 10 \mathrm{Cl} 2 \mathrm{Br} 2 \mathrm{~F} 1$ C13H10Cl3Br2F1 3

$\mathrm{C} 13 \mathrm{H} 10 \mathrm{Cl} 3 \mathrm{BrF} 14$

C13H10Cl4BrF13
gKoa lgKow lgKaw lgKow lgKoa lgKa lgKow lgKoa lgKaw EPISuit_EPI_EPI__Exp__Exp w__FT__DFT_DFT $\begin{array}{llllllllll}4.829 & 6.95 & 2.12 & 5.45 & 3.33 & 2.12 & 6.10 & 6.88 & -0.78\end{array}$ $\begin{array}{lllllllllll}7.389 & 7.52 & 0.13 & 6.30 & 6.17 & 0.13 & 6.54 & 11.59 & -5.05\end{array}$

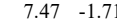
$\begin{array}{lllllll}0.62 & 5.28 & 4.67 & 0.62 & 6.02 & 9.45 & -3.43\end{array}$ $\begin{array}{llllllllll}6.971 & 7.37 & 0.40 & 6.07 & 5.68 & 0.40 & 6.42 & 10.82 & -4.40\end{array}$ $\begin{array}{lllllllll}5.333 & 6.97 & 1.64 & 5.48 & 3.84 & 1.64 & 6.12 & 7.81 & -1.69\end{array}$

$\begin{array}{lllllllll}5.598 & 6.45 & 0.85 & 4.70 & 3.85 & 0.85 & 5.72 & 8.30 & -2.58\end{array}$

$\begin{array}{llllllllll}6.165 & 6.75 & 0.59 & 5.15 & 4.56 & 0.59 & 5.95 & 9.34 & -3.39\end{array}$

$\begin{array}{lllllllll}4.449 & 6.27 & 1.82 & 4.43 & 2.61 & 1.82 & 5.58 & 6.19 & -0.61\end{array}$

$\begin{array}{lllllllll}7.076 & 6.91 & -0.17 & 5.39 & 5.55 & -0.17 & 6.07 & 11.01 & -4.94\end{array}$

$\begin{array}{lllllllll}6.249 & 7.32 & 1.07 & 6.00 & 4.93 & 1.07 & 6.38 & 9.49 & -3.11\end{array}$

$\begin{array}{lllllllll}6.502 & 6.82 & 0.32 & 5.25 & 4.94 & 0.32 & 6.00 & 9.96 & -3.96\end{array}$

$\begin{array}{llllllllll}6.502 & 6.82 & 0.32 & 5.25 & 4.94 & 0.32 & 6.00 & 9.96 & -3.96\end{array}$

$7.573 \quad 7.14$

$\begin{array}{rrrrrrrrrr}6.74 & 6.84 & 0.10 & 5.28 & 5.18 & 0.10 & 6.02 & 10.39 & -4.38\end{array}$

$\begin{array}{lllllllll}5.763 & 7.1 & 1.34 & 5.67 & 4.34 & 1.34 & 6.21 & 8.60 & -2.38\end{array}$

$\begin{array}{llllllllll}6.107 & 6.66 & 0.55 & 5.01 & 4.46 & 0.55 & 5.88 & 9.23 & -3.35\end{array}$

$\begin{array}{llllllllll}7.594 & 6.91 & -0.68 & 5.39 & 6.07 & -0.68 & 6.07 & 11.96 & -5.89\end{array}$

$\begin{array}{lllllllll}4.389 & 6.18 & 1.79 & 4.30 & 2.51 & 1.79 & 5.51 & 6.07 & -0.57\end{array}$

$\begin{array}{lllllllll}6.444 & 6.73 & 0.29 & 5.12 & 4.83 & 0.29 & 5.93 & 9.85 & -3.92\end{array}$

$\begin{array}{lllllllll}4.807 & 6.33 & 1.52 & 4.52 & 3.00 & 1.52 & 5.62 & 6.84 & -1.22\end{array}$

$\begin{array}{lllllllll}6.017 & 6.79 & 0.77 & 5.21 & 4.44 & 0.77 & 5.98 & 9.07 & -3.09\end{array}$

$\begin{array}{llllllllll}6.94 & 6.96 & 0.02 & 5.46 & 5.44 & 0.02 & 6.11 & 10.76 & -4.65\end{array}$

$\begin{array}{rrrrrrrrrr}6.94 & 6.96 & 0.02 & 5.46 & 5.44 & 0.02 & 6.11 & 10.76 & -4.65\end{array}$

$\begin{array}{rrrrrrrrrr}7.098 & 6.9 & -0.20 & 5.37 & 5.57 & -0.20 & 6.06 & 11.05 & -4.99 \\ 5.532 & 6.57 & 1.04 & 4.88 & 3.84 & 1.04 & 5.81 & 8.17 & -2.37\end{array}$

$\begin{array}{lllllllll}4.485 & 6.76 & 2.28 & 5.16 & 2.89 & 2.28 & 5.95 & 6.25 & -0.30\end{array}$

$\begin{array}{lllllllll}6.466 & 6.72 & 0.25 & 5.10 & 4.85 & 0.25 & 5.92 & 9.89 & -3.97\end{array}$

$\begin{array}{rrrrrrr}-0.49 & 5.49 & 4.00 & 1.49 & 6.12 & 8.10 & -1.97\end{array}$

$\begin{array}{llllllllll}5.236 & 6.46 & 1.22 & 4.72 & 3.49 & 1.22 & 5.72 & 7.63 & -1.91\end{array}$

$\begin{array}{lllllllll}6.307 & 6.78 & 0.47 & 5.19 & 4.72 & 0.47 & 5.97 & 9.60 & -3.63\end{array}$

$\begin{array}{lllllllll}7.527 & 7.03 & -0.50 & 5.57 & 6.06 & -0.50 & 6.16 & 11.84 & -5.68\end{array}$

$\begin{array}{llllllllll}5.811 & 6.55 & 0.74 & 4.85 & 4.11 & 0.74 & 5.79 & 8.69 & -2.89\end{array}$

$\begin{array}{lllllllll}6.894 & 6.85 & -0.04 & 5.30 & 5.34 & -0.04 & 6.02 & 10.68 & -4.65\end{array}$

$\begin{array}{llllllllll}5.178 & 6.37 & 1.19 & 4.58 & 3.39 & 1.19 & 5.65 & 7.52 & -1.87\end{array}$

$\begin{array}{lllllllll}5.675 & 6.6 & 0.93 & 4.93 & 4.00 & 0.93 & 5.83 & 8.44 & -2.61\end{array}$

$\begin{array}{lllllllll}6.319 & 6.76 & 0.44 & 5.16 & 4.72 & 0.44 & 5.95 & 9.62 & -3.67\end{array}$

$\begin{array}{llllllll}- & 1.68 & 4.45 & 2.77 & 1.68 & 5.58 & 6.46 & -0.88\end{array}$

$\begin{array}{llllllllll}5.605 & 6.5 & 0.89 & 4.78 & 3.88 & 0.89 & 5.75 & 8.31 & -2.55\end{array}$

$\begin{array}{lllllllll}5.541 & 6.42 & 0.88 & 4.66 & 3.78 & 0.88 & 5.69 & 8.19 & -2.50\end{array}$

$\begin{array}{lllllllll}4.919 & 6.1 & 1.18 & 4.18 & 3.00 & 1.18 & 5.45 & 7.05 & -1.60\end{array}$

$\begin{array}{lllllllll}6.359 & 10 & 3.64 & 10.00 & 6.36 & 3.64 & 8.44 & 9.69 & -1.25\end{array}$

$\begin{array}{lllllllll}-4.64 & 0.00 & 4.98 & 4.10 & 7.97 & 7.72 & 0.25\end{array}$

$\begin{array}{llllllllll}6.77 & 9.63 & 2.86 & 9.45 & 6.59 & 2.86 & 8.16 & 10.45 & -2.29\end{array}$

$\begin{array}{llllllllll}5.645 & 9.96 & 4.31 & 9.94 & 5.63 & 4.31 & 8.41 & 8.38 & 0.03\end{array}$

$\begin{array}{llllllllll}6.754 & 10.05 & 3.30 & 10.07 & 6.78 & 3.30 & 8.48 & 10.42 & -1.94\end{array}$

$\begin{array}{lllllllll}6.76 & 9.32 & 2.56 & 8.99 & 6.43 & 2.56 & 7.92 & 10.43 & -2.51\end{array}$

$\begin{array}{llllllllll}5.459 & 8.99 & 3.53 & 8.49 & 4.96 & 3.53 & 7.67 & 8.04 & -0.37\end{array}$

$\begin{array}{llllllllll}6.531 & 9.31 & 2.78 & 8.97 & 6.19 & 2.78 & 7.91 & 10.01 & -2.10\end{array}$

$\begin{array}{lllllllll}5.624 & 9.64 & 4.02 & 9.46 & 5.45 & 4.02 & 8.17 & 8.34 & -0.18\end{array}$

$\begin{array}{llllllllll}5.956 & 9.22 & 3.26 & 8.84 & 5.57 & 3.26 & 7.84 & 8.95 & -1.11\end{array}$

$\begin{array}{llllllllll}5.499 & 10 & 4.50 & 10.00 & 5.50 & 4.50 & 8.44 & 8.11 & 0.33\end{array}$

$\begin{array}{lllllllll}6.122 & 9.87 & 3.75 & 9.81 & 6.06 & 3.75 & 8.34 & 9.26 & -0.92\end{array}$

$\begin{array}{llllllllll}7.505 & 9.75 & 2.24 & 9.63 & 7.38 & 2.24 & 8.25 & 11.80 & -3.55\end{array}$

$\begin{array}{lllllllll}6.774 & 9.82 & 3.05 & 9.73 & 6.69 & 3.05 & 8.30 & 10.46 & -2.15\end{array}$

$\begin{array}{lllllllll}5.401 & 8.9 & 3.50 & 8.36 & 4.86 & 3.50 & 7.60 & 7.93 & -0.34\end{array}$

$\begin{array}{lllllllll}6.638 & 9.87 & 3.23 & 9.81 & 6.57 & 3.23 & 8.34 & 10.21 & -1.86\end{array}$

$\begin{array}{lllllllll}7.535 & 9.53 & 2.00 & 9.30 & 7.30 & 2.00 & 8.08 & 11.85 & -3.77\end{array}$

$\begin{array}{llllllllll}5.441 & 9.91 & 4.47 & 9.87 & 5.40 & 4.47 & 8.37 & 8.01 & 0.37\end{array}$

$\begin{array}{lllllllll}6.22 & 8.7 & 2.48 & 8.06 & 5.58 & 2.48 & 7.44 & 9.44 & -1.99\end{array}$

$\begin{array}{lllllllll}5.644 & 8.61 & 2.97 & 7.93 & 4.96 & 2.97 & 7.38 & 8.38 & -1.01\end{array}$

$\begin{array}{lllllllll}6.55 & 10 & 3.45 & 10.00 & 6.55 & 3.45 & 8.44 & 10.04 & -1.60\end{array}$

$\begin{array}{llllllllll}5.735 & 8.48 & 2.74 & 7.73 & 4.99 & 2.74 & 7.28 & 8.55 & -1.27\end{array}$

$\begin{array}{llllllllll}5.841 & 9.04 & 3.20 & 8.57 & 5.37 & 3.20 & 7.71 & 8.74 & -1.04\end{array}$

$\begin{array}{llllllllll}6.738 & 8.7 & 1.96 & 8.06 & 6.10 & 1.96 & 7.44 & 10.39 & -2.95\end{array}$

$\begin{array}{llllllllll}5.586 & 8.52 & 2.93 & 7.79 & 4.86 & 2.93 & 7.31 & 8.27 & -0.97\end{array}$

$\begin{array}{lllllllll}6.649 & 8.83 & 2.18 & 8.25 & 6.07 & 2.18 & 7.54 & 10.23 & -2.68\end{array}$

$\begin{array}{llllllllll}5.012 & 8.43 & 3.42 & 7.66 & 4.24 & 3.42 & 7.24 & 7.22 & 0.02\end{array}$

$\begin{array}{lllllllll}6.815 & 9.48 & 2.66 & 9.22 & 6.56 & 2.66 & 8.04 & 10.53 & -2.49\end{array}$

$\begin{array}{lllllllll}5.498 & 8.65 & 3.15 & 7.99 & 4.83 & 3.15 & 7.41 & 8.11 & -0.71\end{array}$

$\begin{array}{lllllllll}7.467 & 8.63 & 1.16 & 7.96 & 6.79 & 1.16 & 7.39 & 11.73 & -4.34\end{array}$

$\begin{array}{llllllllll}7.31 & 9.71 & 2.40 & 9.57 & 7.17 & 2.40 & 8.22 & 11.44 & -3.22\end{array}$

$\begin{array}{llllllllll}5.77 & 9.39 & 3.62 & 9.09 & 5.47 & 3.62 & 7.97 & 8.61 & -0.64\end{array}$

$\begin{array}{lllllllll}7.335 & 9.72 & 2.38 & 9.58 & 7.20 & 2.38 & 8.23 & 11.49 & -3.26\end{array}$

$\begin{array}{lllllllll}4.785 & 8.14 & 3.35 & 7.22 & 3.87 & 3.35 & 7.01 & 6.80 & 0.21\end{array}$

$\begin{array}{lllllllll}6.587 & 9.19 & 2.60 & 8.79 & 6.19 & 2.60 & 7.82 & 10.11 & -2.29\end{array}$

$\begin{array}{lllllllll}5.691 & 9.53 & 3.84 & 9.30 & 5.46 & 3.84 & 8.08 & 8.47 & -0.38\end{array}$

$\begin{array}{lllllllll}6.011 & 9.1 & 3.09 & 8.66 & 5.57 & 3.09 & 7.75 & 9.05 & -1.30\end{array}$ 
SMILE Generated

$\mathrm{C}(\mathrm{C}(\mathrm{C}(\mathrm{C}(\mathrm{C}(\mathrm{C}(\mathrm{C}(\mathrm{C}(\mathrm{C}(\mathrm{C}(\mathrm{C}(\mathrm{C}(\mathrm{C}(\mathrm{F})(\mathrm{F}) \mathrm{H})(\mathrm{F}) \mathrm{Cl})(\mathrm{F}) \mathrm{H})(\mathrm{Cl}) \mathrm{F})(\mathrm{H}) \mathrm{F})(\mathrm{F}) \mathrm{F})(\mathrm{F}) \mathrm{F})(\mathrm{Cl}) \mathrm{H})(\mathrm{F}) \mathrm{Cl})(\mathrm{F}) \mathrm{H})(\mathrm{H}) \mathrm{H})$ $(\mathrm{Cl}) \mathrm{H})(\mathrm{H})(\mathrm{H}) \mathrm{Cl}$

$\mathrm{C}(\mathrm{C}(\mathrm{C}(\mathrm{C}(\mathrm{C}(\mathrm{C}(\mathrm{C}(\mathrm{C}(\mathrm{C}(\mathrm{C}(\mathrm{C}(\mathrm{C}(\mathrm{C}(\mathrm{Cl})(\mathrm{H}) \mathrm{Cl})(\mathrm{H}) \mathrm{F})(\mathrm{F}) \mathrm{F})(\mathrm{H}) \mathrm{F})(\mathrm{F}) \mathrm{F})(\mathrm{Cl}) \mathrm{F})(\mathrm{F}) \mathrm{Cl})(\mathrm{F}) \mathrm{H})(\mathrm{H}) \mathrm{F})(\mathrm{H}) \mathrm{Cl})(\mathrm{H}) \mathrm{F})(\mathrm{Cl})$ $\mathrm{H})(\mathrm{Cl})(\mathrm{H}) \mathrm{H}$

$\mathrm{C}\left(\mathrm{C}(\mathrm{C}(\mathrm{C}(\mathrm{C}(\mathrm{C}(\mathrm{C}(\mathrm{C}(\mathrm{C}(\mathrm{C}(\mathrm{C}(\mathrm{C}(\mathrm{C}(\mathrm{F})(\mathrm{Br}) \mathrm{F})(\mathrm{H}) \mathrm{Br})(\mathrm{F}) \mathrm{F})(\mathrm{H}) \mathrm{F})(\mathrm{H}) \mathrm{F})(\mathrm{H}) \mathrm{H})(\mathrm{F}) \mathrm{F})(\mathrm{H}) \mathrm{H})(\mathrm{F}) \mathrm{H})(\mathrm{F}) \mathrm{F})(\mathrm{H}) \mathrm{Br})(\mathrm{F}) \mathrm{C}{ }_{\mathrm{C} 13 \mathrm{H} 10 \mathrm{ClBr} 3 \mathrm{~F} 14}\right.$ 1)(F)(F)H

$\mathrm{C}(\mathrm{C}(\mathrm{C}(\mathrm{C}(\mathrm{C}(\mathrm{C}(\mathrm{C}(\mathrm{C}(\mathrm{C}(\mathrm{C}(\mathrm{C}(\mathrm{C}(\mathrm{C}(\mathrm{F})(\mathrm{H}) \mathrm{H})(\mathrm{H}) \mathrm{Br})(\mathrm{H}) \mathrm{F})(\mathrm{H}) \mathrm{H})(\mathrm{Br}) \mathrm{H})(\mathrm{H}) \mathrm{F})(\mathrm{F}) \mathrm{F})(\mathrm{F}) \mathrm{F})(\mathrm{H}) \mathrm{F})(\mathrm{F}) \mathrm{F})(\mathrm{F}) \mathrm{H})(\mathrm{F}) \mathrm{H}){ }^{\mathrm{C}}{ }^{2} 13 \mathrm{H} 11 \mathrm{Br} 3 \mathrm{~F} 14$

(F)(F)Br

$\mathrm{C}(\mathrm{C}(\mathrm{C}(\mathrm{C}(\mathrm{C}(\mathrm{C}(\mathrm{C}(\mathrm{C}(\mathrm{C}(\mathrm{C}(\mathrm{C}(\mathrm{C}(\mathrm{C}(\mathrm{H})(\mathrm{H}) \mathrm{F})(\mathrm{F}) \mathrm{Cl})(\mathrm{F}) \mathrm{F})(\mathrm{F}) \mathrm{Cl})(\mathrm{F}) \mathrm{F})(\mathrm{H}) \mathrm{F})(\mathrm{F}) \mathrm{H})(\mathrm{H}) \mathrm{H})(\mathrm{Br}) \mathrm{H})(\mathrm{F}) \mathrm{F})(\mathrm{H}) \mathrm{H})(\mathrm{H}) \mathrm{F}) \mathrm{C} 13 \mathrm{H} 11 \mathrm{Cl} 2 \mathrm{Br} 2 \mathrm{~F} 1$

$(\mathrm{H})(\mathrm{Br}) \mathrm{F}$

$\begin{array}{ll}(\mathrm{H})(\mathrm{Br}) \mathrm{F} & 3 \\ \mathrm{C}(\mathrm{C}(\mathrm{C}(\mathrm{C}(\mathrm{C}(\mathrm{C}(\mathrm{C}(\mathrm{C}(\mathrm{C}(\mathrm{C}(\mathrm{C}(\mathrm{C}(\mathrm{C}(\mathrm{Cl})(\mathrm{H}) \mathrm{F})(\mathrm{H}) \mathrm{F})(\mathrm{F}) \mathrm{Br})(\mathrm{F}) \mathrm{F})(\mathrm{Br}) \mathrm{F})(\mathrm{F}) \mathrm{H})(\mathrm{H}) \mathrm{H})(\mathrm{Br}) \mathrm{H})(\mathrm{F}) \mathrm{H})(\mathrm{H}) \mathrm{F})(\mathrm{F}) \mathrm{Cl})(\mathrm{F}) & \mathrm{C} 13 \mathrm{H} 11 \mathrm{Cl} 2 \mathrm{Br} 3 \mathrm{~F} 1\end{array}$

$\mathrm{H})(\mathrm{H})(\mathrm{F}) \mathrm{H}$

$\mathrm{C}(\mathrm{C}(\mathrm{C}(\mathrm{C}(\mathrm{C}(\mathrm{C}(\mathrm{C}(\mathrm{C}(\mathrm{C}(\mathrm{C}(\mathrm{C}(\mathrm{C}(\mathrm{C}(\mathrm{H})(\mathrm{F}) \mathrm{F})(\mathrm{F}) \mathrm{H})(\mathrm{F}) \mathrm{F})(\mathrm{Cl}) \mathrm{H})(\mathrm{H}) \mathrm{F})(\mathrm{F}) \mathrm{H})(\mathrm{H}) \mathrm{F})(\mathrm{F}) \mathrm{H})(\mathrm{F}) \mathrm{Cl})(\mathrm{H}) \mathrm{Cl})(\mathrm{H}) \mathrm{Br})(\mathrm{H})$
$\mathrm{Cl})(\mathrm{F})(\mathrm{F}) \mathrm{H}$

C(C(C(C(C(C(C(C(C(C(C(C(C(F)(F)H)(H)F)(F)H)(F)H)(F)H)(H)Cl)(F)H)(H)Cl)(F)Cl)(F)Cl)(Cl)Cl)(H) ${ }_{C} 13 H 11 C l 6 F 11$

$\mathrm{H})(\mathrm{H})(\mathrm{F}) \mathrm{F}$

$\mathrm{C}\left(\mathrm{C}(\mathrm{C}(\mathrm{C}(\mathrm{C}(\mathrm{C}(\mathrm{C}(\mathrm{C}(\mathrm{C}(\mathrm{C}(\mathrm{C}(\mathrm{C}(\mathrm{C}(\mathrm{H})(\mathrm{F}) \mathrm{F})(\mathrm{F}) \mathrm{Cl})(\mathrm{H}) \mathrm{F})(\mathrm{H}) \mathrm{Cl})(\mathrm{F}) \mathrm{Cl})(\mathrm{F}) \mathrm{H})(\mathrm{F}) \mathrm{F})(\mathrm{F}) \mathrm{H})(\mathrm{H}) \mathrm{Cl})(\mathrm{H}) \mathrm{Cl})(\mathrm{H}) \mathrm{Cl})(\mathrm{H}){ }_{\mathrm{C} 13 \mathrm{H} 11 \mathrm{Cl} 7 \mathrm{~F} 10}\right.$

$\mathrm{Cl})(\mathrm{F})(\mathrm{H}) \mathrm{H}$

$\mathrm{C}(\mathrm{C}(\mathrm{C}(\mathrm{C}(\mathrm{C}(\mathrm{C}(\mathrm{C}(\mathrm{C}(\mathrm{C}(\mathrm{C}(\mathrm{C}(\mathrm{C}(\mathrm{C}(\mathrm{H})(\mathrm{Cl}) \mathrm{H})(\mathrm{H}) \mathrm{F})(\mathrm{H}) \mathrm{H})(\mathrm{F}) \mathrm{F})(\mathrm{F}) \mathrm{F})(\mathrm{Br}) \mathrm{H})(\mathrm{F}) \mathrm{H})(\mathrm{Br}) \mathrm{F})(\mathrm{H}) \mathrm{F})(\mathrm{H}) \mathrm{F})(\mathrm{F}) \mathrm{H}) \quad \mathrm{C} 13 \mathrm{H} 11 \mathrm{ClBr} 2 \mathrm{~F} 14$

(F)F)(F)(F)H

$\mathrm{C}(\mathrm{C}(\mathrm{C}(\mathrm{C}(\mathrm{C}(\mathrm{C}(\mathrm{C}(\mathrm{C}(\mathrm{C}(\mathrm{C}(\mathrm{C}(\mathrm{C}(\mathrm{C}(\mathrm{F})(\mathrm{F}) \mathrm{Br})(\mathrm{H}) \mathrm{F})(\mathrm{F}) \mathrm{F})(\mathrm{F}) \mathrm{F})(\mathrm{H}) \mathrm{H})(\mathrm{F}) \mathrm{H})(\mathrm{F}) \mathrm{H})(\mathrm{H}) \mathrm{F})(\mathrm{Cl}) \mathrm{F})(\mathrm{H}) \mathrm{H})(\mathrm{H}) \mathrm{Br})(\mathrm{F}) \mathrm{F})$
$(\mathrm{Br})(\mathrm{H}) \mathrm{H}$

$(\mathrm{Br})(\mathrm{H}) \mathrm{H}$

$\mathrm{C}(\mathrm{C}(\mathrm{C}(\mathrm{C}(\mathrm{C}(\mathrm{C})$

$\begin{array}{ll}\mathrm{F})(\mathrm{H})(\mathrm{F}) \mathrm{F} & \\ \mathrm{C}(\mathrm{C}(\mathrm{C}(\mathrm{C}(\mathrm{C}(\mathrm{C}(\mathrm{C}(\mathrm{C}(\mathrm{C}(\mathrm{C}(\mathrm{C}(\mathrm{C}(\mathrm{C}(\mathrm{F})(\mathrm{H}) \mathrm{H})(\mathrm{F}) \mathrm{H})(\mathrm{Br}) \mathrm{H})(\mathrm{H}) \mathrm{F})(\mathrm{H}) \mathrm{F})(\mathrm{H}) \mathrm{Cl})(\mathrm{F}) \mathrm{H})(\mathrm{H}) \mathrm{F})(\mathrm{F}) \mathrm{H})(\mathrm{F}) \mathrm{Cl})(\mathrm{H}) \mathrm{F}) & \mathrm{C} 13 \mathrm{H} 12 \mathrm{Cl} 2 \mathrm{Br} 2 \mathrm{~F} 1\end{array}$

(F)H)(F)(Br)F

$\mathrm{C} 13 \mathrm{H} 12 \mathrm{Cl} 2 \mathrm{Br} 2 \mathrm{~F} 1$

$\mathrm{C}(\mathrm{C}(\mathrm{C}(\mathrm{C}(\mathrm{C}(\mathrm{C}(\mathrm{C}(\mathrm{C}(\mathrm{C}(\mathrm{C}(\mathrm{C}(\mathrm{C}(\mathrm{C}(\mathrm{H})(\mathrm{Cl}) \mathrm{F})(\mathrm{H}) \mathrm{F})(\mathrm{H}) \mathrm{H})(\mathrm{F}) \mathrm{F})(\mathrm{F}) \mathrm{H})(\mathrm{Br}) \mathrm{Cl})(\mathrm{F}) \mathrm{H})(\mathrm{Cl}) \mathrm{H})(\mathrm{H}) \mathrm{H})(\mathrm{H}) \mathrm{H})(\mathrm{F}) \mathrm{H})(\mathrm{F})$

$\mathrm{F})(\mathrm{F})(\mathrm{F}) \mathrm{F}$

$\mathrm{C} 13 \mathrm{H} 12 \mathrm{Cl} 3 \mathrm{BrF} 12$

$\mathrm{C}(\mathrm{C}(\mathrm{C}(\mathrm{C}(\mathrm{C}(\mathrm{C}(\mathrm{C}(\mathrm{C}(\mathrm{C}(\mathrm{C}(\mathrm{C}(\mathrm{C}(\mathrm{C}(\mathrm{H})(\mathrm{F}) \mathrm{H})(\mathrm{Cl}) \mathrm{H})(\mathrm{F}) \mathrm{F})(\mathrm{Br}) \mathrm{H})(\mathrm{F}) \mathrm{H})(\mathrm{F}) \mathrm{Cl})(\mathrm{H}) \mathrm{Cl})(\mathrm{F}) \mathrm{F})(\mathrm{H}) \mathrm{F})(\mathrm{H}) \mathrm{F})(\mathrm{H}) \mathrm{H})(\mathrm{H})$

$\mathrm{Cl})(\mathrm{F})(\mathrm{H}) \mathrm{F}$

$\mathrm{C}(\mathrm{C}(\mathrm{C}(\mathrm{C}(\mathrm{C}(\mathrm{C}(\mathrm{C}(\mathrm{C}(\mathrm{C}(\mathrm{C}(\mathrm{C}(\mathrm{C}(\mathrm{C}(\mathrm{H})(\mathrm{H}) \mathrm{Cl})(\mathrm{H}) \mathrm{Cl})(\mathrm{F}) \mathrm{F})(\mathrm{H}) \mathrm{F})(\mathrm{F}) \mathrm{F})(\mathrm{H}) \mathrm{H})(\mathrm{H}) \mathrm{Cl})(\mathrm{F}) \mathrm{F})(\mathrm{H}) \mathrm{H})(\mathrm{Cl}) \mathrm{H})(\mathrm{F}) \mathrm{F})(\mathrm{F}) \quad \mathrm{C} 13 \mathrm{H} 12 \mathrm{Cl} 4 \mathrm{~F} 12$

$\mathrm{H})(\mathrm{H})(\mathrm{F}) \mathrm{F}$

C13H12C14F12

$\mathrm{H}) \mathrm{F})(\mathrm{F})(\mathrm{H}) \mathrm{F}$

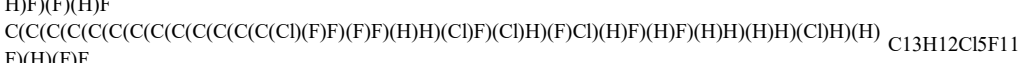

$\begin{array}{ll}\mathrm{F})(\mathrm{H})(\mathrm{F}) \mathrm{F} & \\ \mathrm{C}(\mathrm{C}(\mathrm{C}(\mathrm{C}(\mathrm{C}(\mathrm{C}(\mathrm{C}(\mathrm{C}(\mathrm{C}(\mathrm{C}(\mathrm{C}(\mathrm{C}(\mathrm{C}(\mathrm{F})(\mathrm{Cl}) \mathrm{H})(\mathrm{H}) \mathrm{Cl})(\mathrm{H}) \mathrm{H})(\mathrm{Cl}) \mathrm{F})(\mathrm{F}) \mathrm{F})(\mathrm{H}) \mathrm{F})(\mathrm{F}) \mathrm{H})(\mathrm{H}) \mathrm{F})(\mathrm{F}) \mathrm{H})(\mathrm{Cl}) \mathrm{F})(\mathrm{Cl}) \mathrm{H})(\mathrm{H}) & \mathrm{C} 13 \mathrm{H} 12 \mathrm{Cl} 6 \mathrm{~F} 10\end{array}$

$\mathrm{F})(\mathrm{H})(\mathrm{H}) \mathrm{Cl}$

$\mathrm{C} 13 \mathrm{H} 12 \mathrm{Cl6F} 10$

$\mathrm{C}(\mathrm{C}(\mathrm{C}(\mathrm{C}(\mathrm{C}(\mathrm{C}(\mathrm{C}(\mathrm{C}(\mathrm{C}(\mathrm{C}(\mathrm{C}(\mathrm{C}(\mathrm{C}(\mathrm{H})(\mathrm{F}) \mathrm{Cl})(\mathrm{Cl}) \mathrm{F})(\mathrm{H}) \mathrm{Cl})(\mathrm{Cl}) \mathrm{F})(\mathrm{H}) \mathrm{F})(\mathrm{Cl}) \mathrm{H})(\mathrm{H}) \mathrm{Cl})(\mathrm{H}) \mathrm{H})(\mathrm{H}) \mathrm{F})(\mathrm{H}) \mathrm{F})(\mathrm{H}) \mathrm{F})$

(F)H)(H)(F)Cl

$\mathrm{C}(\mathrm{C}(\mathrm{C}(\mathrm{C}(\mathrm{C}(\mathrm{C}(\mathrm{C}(\mathrm{C}(\mathrm{C}(\mathrm{C}(\mathrm{C}(\mathrm{C}(\mathrm{C}(\mathrm{H})(\mathrm{H}) \mathrm{F})(\mathrm{F}) \mathrm{F})(\mathrm{F}) \mathrm{H})(\mathrm{Cl}) \mathrm{F})(\mathrm{Br}) \mathrm{F})(\mathrm{H}) \mathrm{H})(\mathrm{F}) \mathrm{Br})(\mathrm{F}) \mathrm{H})(\mathrm{H}) \mathrm{F})(\mathrm{F}) \mathrm{F})(\mathrm{H}) \mathrm{H})$

$(\mathrm{H}) \mathrm{F})(\mathrm{F})(\mathrm{H}) \mathrm{H}$

C13H12Cl7F9

$\mathrm{C} 13 \mathrm{H} 12 \mathrm{ClBr} 2 \mathrm{~F} 13$

$\mathrm{C}(\mathrm{C}(\mathrm{C}(\mathrm{C}(\mathrm{C}(\mathrm{C}(\mathrm{C}(\mathrm{C}(\mathrm{C}(\mathrm{C}(\mathrm{C}(\mathrm{C}(\mathrm{C}(\mathrm{F})(\mathrm{F}) \mathrm{H})(\mathrm{H}) \mathrm{H})(\mathrm{H}) \mathrm{H})(\mathrm{F}) \mathrm{H})(\mathrm{Br}) \mathrm{F})(\mathrm{Br}) \mathrm{F})(\mathrm{H}) \mathrm{H})(\mathrm{H}) \mathrm{H})(\mathrm{F}) \mathrm{F})(\mathrm{H}) \mathrm{F})(\mathrm{H}) \mathrm{F})(\mathrm{F}) \mathrm{B}$

$\mathrm{r})(\mathrm{F})(\mathrm{H}) \mathrm{F}$

$\mathrm{C}(\mathrm{C}(\mathrm{C}(\mathrm{C}(\mathrm{C}(\mathrm{C}(\mathrm{C}(\mathrm{C}(\mathrm{C}(\mathrm{C}(\mathrm{C}(\mathrm{C}(\mathrm{C}(\mathrm{H})(\mathrm{H}) \mathrm{Cl})(\mathrm{Br}) \mathrm{F})(\mathrm{F}) \mathrm{H})(\mathrm{H}) \mathrm{F})(\mathrm{F}) \mathrm{F})(\mathrm{H}) \mathrm{F})(\mathrm{H}) \mathrm{F})(\mathrm{F}) \mathrm{F})(\mathrm{F}) \mathrm{H})(\mathrm{H}) \mathrm{F})(\mathrm{H}) \mathrm{Cl})$

$(\mathrm{H}) \mathrm{H})(\mathrm{Br})(\mathrm{H}) \mathrm{H}$

C(C(C(C(C(C(C(C(C(C(C(C(C(H)(H)H)(H)H)(H)F)(F)F)(F)H)(F)H)(Cl)Cl)(F)H)(H)H)(F)Br)(F)F

(H)F)(F)(F)H

$\mathrm{C}(\mathrm{C}(\mathrm{C}(\mathrm{C}(\mathrm{C}(\mathrm{C}(\mathrm{C}(\mathrm{C}(\mathrm{C}(\mathrm{C}(\mathrm{C}(\mathrm{C}(\mathrm{C}(\mathrm{F})(\mathrm{Br}) \mathrm{F})(\mathrm{F}) \mathrm{H})(\mathrm{H}) \mathrm{F})(\mathrm{H}) \mathrm{F})(\mathrm{Cl}) \mathrm{H})(\mathrm{H}) \mathrm{H})(\mathrm{H}) \mathrm{H})(\mathrm{F}) \mathrm{Cl})(\mathrm{H}) \mathrm{H})(\mathrm{F}) \mathrm{F})(\mathrm{F}) \mathrm{H})$

$(\mathrm{H}) \mathrm{F})(\mathrm{Cl})(\mathrm{H}) \mathrm{Br}$

$\mathrm{C}\left(\mathrm{C}(\mathrm{C}(\mathrm{C}(\mathrm{C}(\mathrm{C}(\mathrm{C}(\mathrm{C}(\mathrm{C}(\mathrm{C}(\mathrm{C}(\mathrm{C}(\mathrm{C}(\mathrm{H})(\mathrm{F}) \mathrm{F})(\mathrm{F}) \mathrm{H})(\mathrm{Br}) \mathrm{Cl})(\mathrm{Cl}) \mathrm{F})(\mathrm{H}) \mathrm{H})(\mathrm{Cl}) \mathrm{F})(\mathrm{F}) \mathrm{H})(\mathrm{H}) \mathrm{F})(\mathrm{F}) \mathrm{H})(\mathrm{F}) \mathrm{H})(\mathrm{H}) \mathrm{H})(\mathrm{H}){ }_{\mathrm{C} 13 \mathrm{H} 13 \mathrm{Cl} 3 \mathrm{BrF} 11}\right.$ $\mathrm{F})(\mathrm{F})(\mathrm{H}) \mathrm{H}$

$\mathrm{C}\left(\mathrm{C}(\mathrm{C}(\mathrm{C}(\mathrm{C}(\mathrm{C}(\mathrm{C}(\mathrm{C}(\mathrm{C}(\mathrm{C}(\mathrm{C}(\mathrm{C}(\mathrm{C}(\mathrm{H})(\mathrm{Br}) \mathrm{H})(\mathrm{Cl}) \mathrm{Cl})(\mathrm{H}) \mathrm{F})(\mathrm{F}) \mathrm{H})(\mathrm{F}) \mathrm{H})(\mathrm{H}) \mathrm{Cl})(\mathrm{H}) \mathrm{F})(\mathrm{H}) \mathrm{H})(\mathrm{H}) \mathrm{Cl})(\mathrm{F}) \mathrm{H})(\mathrm{F}) \mathrm{F})(\mathrm{F}){ }_{\mathrm{C} 13 \mathrm{H} 13 \mathrm{Cl} 4 \mathrm{BrF} 10}\right.$

$\mathrm{F})(\mathrm{H})(\mathrm{F}) \mathrm{H}$

$\mathrm{C}(\mathrm{C}(\mathrm{C}(\mathrm{C}(\mathrm{C}(\mathrm{C}(\mathrm{C}(\mathrm{C}(\mathrm{C}(\mathrm{C}(\mathrm{C}(\mathrm{C}(\mathrm{C}(\mathrm{Cl})(\mathrm{H}) \mathrm{H})(\mathrm{F}) \mathrm{Cl})(\mathrm{H}) \mathrm{Cl})(\mathrm{H}) \mathrm{H})(\mathrm{H}) \mathrm{F})(\mathrm{H}) \mathrm{H})(\mathrm{H}) \mathrm{H})(\mathrm{F}) \mathrm{F})(\mathrm{F}) \mathrm{F})(\mathrm{H}) \mathrm{F})(\mathrm{F}) \mathrm{F}) \quad \mathrm{C} 13 \mathrm{H} 13 \mathrm{Cl} 4 \mathrm{~F} 11$

$(\mathrm{F}) \mathrm{H})(\mathrm{Cl})(\mathrm{H}) \mathrm{F}$

$\mathrm{C}\left(\mathrm{C}(\mathrm{C}(\mathrm{C}(\mathrm{C}(\mathrm{C}(\mathrm{C}(\mathrm{C}(\mathrm{C}(\mathrm{C}(\mathrm{C}(\mathrm{C}(\mathrm{C}(\mathrm{Cl})(\mathrm{H}) \mathrm{H})(\mathrm{F}) \mathrm{F})(\mathrm{H}) \mathrm{H})(\mathrm{H}) \mathrm{H})(\mathrm{H}) \mathrm{F})(\mathrm{F}) \mathrm{Cl})(\mathrm{H}) \mathrm{F})(\mathrm{F}) \mathrm{H})(\mathrm{Cl}) \mathrm{F})(\mathrm{H}) \mathrm{H})(\mathrm{H}) \mathrm{F})(\mathrm{Cl}){ }_{\mathrm{Cl}}{ }^{2} \mathrm{H} 13 \mathrm{Cl} 15 \mathrm{~F} 10\right.$

$\mathrm{H})(\mathrm{Cl})(\mathrm{F}) \mathrm{F}$

$\mathrm{C}\left(\mathrm{C}(\mathrm{C}(\mathrm{C}(\mathrm{C}(\mathrm{C}(\mathrm{C}(\mathrm{C}(\mathrm{C}(\mathrm{C}(\mathrm{C}(\mathrm{C}(\mathrm{C}(\mathrm{H})(\mathrm{H}) \mathrm{Cl})(\mathrm{Cl}) \mathrm{H})(\mathrm{F}) \mathrm{Cl})(\mathrm{F}) \mathrm{Cl})(\mathrm{H}) \mathrm{H})(\mathrm{F}) \mathrm{H})(\mathrm{H}) \mathrm{F})(\mathrm{H}) \mathrm{Cl})(\mathrm{H}) \mathrm{F})(\mathrm{H}) \mathrm{F})(\mathrm{F}) \mathrm{F})(\mathrm{H}){ }^{\mathrm{C}} \mathrm{C} 13 \mathrm{H} 13 \mathrm{Cl} 6 \mathrm{~F} 9\right.$

$\mathrm{F})(\mathrm{H})(\mathrm{Cl}) \mathrm{H}$

$\mathrm{C}(\mathrm{C}(\mathrm{C}(\mathrm{C}(\mathrm{C}(\mathrm{C}(\mathrm{C}(\mathrm{C}(\mathrm{C}(\mathrm{C}(\mathrm{C}(\mathrm{C}(\mathrm{C}(\mathrm{H})(\mathrm{H}) \mathrm{F})(\mathrm{F}) \mathrm{Br})(\mathrm{H}) \mathrm{F})(\mathrm{H}) \mathrm{F})(\mathrm{F}) \mathrm{F})(\mathrm{H}) \mathrm{H})(\mathrm{F}) \mathrm{H})(\mathrm{H}) \mathrm{F})(\mathrm{F}) \mathrm{F})(\mathrm{H}) \mathrm{H})(\mathrm{Br}) \mathrm{Cl})(\mathrm{H}) \quad \mathrm{C} 13 \mathrm{H} 13 \mathrm{ClBr} 2 \mathrm{~F} 12$
$\mathrm{H})(\mathrm{F})(\mathrm{F}) \mathrm{H}$

$\mathrm{H})(\mathrm{F})(\mathrm{F}) \mathrm{H}$

$\mathrm{C}(\mathrm{C}(\mathrm{C}(\mathrm{C}(\mathrm{C}(\mathrm{C}(\mathrm{C}(\mathrm{C}(\mathrm{C}(\mathrm{C}(\mathrm{C}(\mathrm{C}(\mathrm{C}(\mathrm{F})(\mathrm{F}) \mathrm{Br})(\mathrm{H}) \mathrm{F})(\mathrm{F}) \mathrm{H})(\mathrm{F}) \mathrm{H})(\mathrm{F}) \mathrm{H})(\mathrm{H}) \mathrm{F})(\mathrm{F}) \mathrm{H})(\mathrm{H}) \mathrm{F})(\mathrm{H}) \mathrm{H})(\mathrm{Br}) \mathrm{H})(\mathrm{Br}) \mathrm{H})(\mathrm{F})$

$\mathrm{H})(\mathrm{F})(\mathrm{H}) \mathrm{H}$

$\mathrm{C}\left(\mathrm{C}(\mathrm{C}(\mathrm{C}(\mathrm{C}(\mathrm{C}(\mathrm{C}(\mathrm{C}(\mathrm{C}(\mathrm{C}(\mathrm{C}(\mathrm{C}(\mathrm{C}(\mathrm{Cl})(\mathrm{H}) \mathrm{H})(\mathrm{H}) \mathrm{F})(\mathrm{H}) \mathrm{F})(\mathrm{Cl}) \mathrm{F})(\mathrm{H}) \mathrm{F})(\mathrm{H}) \mathrm{H})(\mathrm{H}) \mathrm{H})(\mathrm{F}) \mathrm{H})(\mathrm{H}) \mathrm{H})(\mathrm{Br}) \mathrm{F})(\mathrm{F}) \mathrm{F})(\mathrm{H}) \mathrm{Cl} \mathrm{C}^{2} \mathrm{H} 14 \mathrm{Cl} 2 \mathrm{Br} 2 \mathrm{~F}\right.$

$\mathrm{Br})(\mathrm{H})(\mathrm{F}) \mathrm{F}$

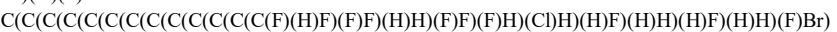

$(\mathrm{Cl}) \mathrm{H})(\mathrm{H})(\mathrm{H}) \mathrm{F}$

$\mathrm{C}(\mathrm{C}(\mathrm{C}(\mathrm{C}(\mathrm{C}(\mathrm{C}(\mathrm{C}(\mathrm{C}(\mathrm{C}(\mathrm{C}(\mathrm{C}(\mathrm{C}(\mathrm{C}(\mathrm{F})(\mathrm{Cl}) \mathrm{Cl})(\mathrm{Cl}) \mathrm{H})(\mathrm{F}) \mathrm{H})(\mathrm{F}) \mathrm{Br})(\mathrm{H}) \mathrm{F})(\mathrm{H}) \mathrm{H})(\mathrm{H}) \mathrm{Br})(\mathrm{F}) \mathrm{H})(\mathrm{H}) \mathrm{F})(\mathrm{F}) \mathrm{H})(\mathrm{H}) \mathrm{H})$

$(\mathrm{H}) \mathrm{H})(\mathrm{F})(\mathrm{H}) \mathrm{F}$

C(C(C(C(C(C(C(C(C(C(C(C(C(H)(F)F)(F)F)(Cl)F)(H)Cl)(Cl)Br)(H)H)(H)F)(F)H)(H)H)(H)F)(F)H)(H)

$\mathrm{F})(\mathrm{H})(\mathrm{H}) \mathrm{H}$
$\mathrm{C}(\mathrm{C}(\mathrm{C}(\mathrm{C}(\mathrm{C}(\mathrm{C}(\mathrm{C}(\mathrm{C}(\mathrm{C}(\mathrm{C}(\mathrm{C}(\mathrm{C}(\mathrm{C}(\mathrm{H})(\mathrm{H}) \mathrm{F})(\mathrm{F}) \mathrm{H})(\mathrm{F}) \mathrm{H})(\mathrm{H}) \mathrm{H})(\mathrm{H}) \mathrm{Cl})(\mathrm{F}) \mathrm{Cl})(\mathrm{Cl}) \mathrm{F})(\mathrm{H}) \mathrm{H})(\mathrm{F}) \mathrm{H})(\mathrm{H}) \mathrm{H})(\mathrm{F}) \mathrm{F})(\mathrm{Cl})$

$\mathrm{F})(\mathrm{H})(\mathrm{F}) \mathrm{H}$

$\mathrm{C}(\mathrm{C}(\mathrm{C}(\mathrm{C}(\mathrm{C}(\mathrm{C}(\mathrm{C}(\mathrm{C}(\mathrm{C}(\mathrm{C}(\mathrm{C}(\mathrm{C}(\mathrm{C}(\mathrm{Cl})(\mathrm{H}) \mathrm{Cl})(\mathrm{H}) \mathrm{F})(\mathrm{H}) \mathrm{F})(\mathrm{H}) \mathrm{H})(\mathrm{H}) \mathrm{F})(\mathrm{H}) \mathrm{F})(\mathrm{F}) \mathrm{H})(\mathrm{F}) \mathrm{F})(\mathrm{H}) \mathrm{F})(\mathrm{H}) \mathrm{H})(\mathrm{Cl}) \mathrm{H})(\mathrm{Cl})$

$\mathrm{Cl})(\mathrm{H})(\mathrm{H}) \mathrm{Br}$

$\mathrm{C}(\mathrm{C}(\mathrm{C}(\mathrm{C}(\mathrm{C}(\mathrm{C}(\mathrm{C}(\mathrm{C}(\mathrm{C}(\mathrm{C}(\mathrm{C}(\mathrm{C}(\mathrm{C}(\mathrm{H})(\mathrm{H}) \mathrm{Cl})(\mathrm{F}) \mathrm{H})(\mathrm{H}) \mathrm{F})(\mathrm{F}) \mathrm{Cl})(\mathrm{H}) \mathrm{F})(\mathrm{H}) \mathrm{H})(\mathrm{H}) \mathrm{F})(\mathrm{H}) \mathrm{F})(\mathrm{Cl}) \mathrm{H})(\mathrm{H}) \mathrm{H})(\mathrm{F}) \mathrm{H})(\mathrm{H})$

$\mathrm{F})(\mathrm{F})(\mathrm{Cl}) \mathrm{Cl}$

$\mathrm{C}(\mathrm{C}(\mathrm{C}(\mathrm{C}(\mathrm{C}(\mathrm{C}(\mathrm{C}(\mathrm{C}(\mathrm{C}(\mathrm{C}(\mathrm{C}(\mathrm{C}(\mathrm{C}(\mathrm{H})(\mathrm{H}) \mathrm{H})(\mathrm{F}) \mathrm{H})(\mathrm{H}) \mathrm{F})(\mathrm{H}) \mathrm{F})(\mathrm{F}) \mathrm{Br})(\mathrm{F}) \mathrm{H})(\mathrm{F}) \mathrm{F})(\mathrm{F}) \mathrm{H})(\mathrm{H}) \mathrm{H})(\mathrm{Cl}) \mathrm{H})(\mathrm{F}) \mathrm{F})(\mathrm{H}) \mathrm{B}$

r) $(\mathrm{F})(\mathrm{H}) \mathrm{H}$

C(C(C(C(C(C(C(C(C(C(C(C(C(F)(H)H)(F)F)(H)F)(H)H)(H)H)(Br)H)(F)H)(F)Br)(F)F)(F)H)(H)F)

(F)H)(H)(H)H

$\mathrm{C}(\mathrm{C}(\mathrm{C}(\mathrm{C}(\mathrm{C}(\mathrm{C}(\mathrm{C}(\mathrm{C}(\mathrm{C}(\mathrm{C}(\mathrm{C}(\mathrm{C}(\mathrm{C}(\mathrm{H})(\mathrm{F}) \mathrm{F})(\mathrm{F}) \mathrm{F})(\mathrm{H}) \mathrm{H})(\mathrm{H}) \mathrm{H})(\mathrm{Br}) \mathrm{Br})(\mathrm{Br}) \mathrm{F})(\mathrm{H}) \mathrm{H})(\mathrm{F}) \mathrm{H})(\mathrm{F}) \mathrm{F})(\mathrm{H}) \mathrm{H})(\mathrm{H}) \mathrm{H})(\mathrm{H})$

$\mathrm{H})(\mathrm{F})(\mathrm{H}) \mathrm{F}$
lgKoa lgKow lgKaw lgKow lgKoa lgKa lgKow lgKoa lgKaw EPISuit_EPI_EPI__Exp__Exp w_ DFT_ DFT DFT e Suite Suite corr_corr_Exp corr__corr_corr $\begin{array}{lllllllll}7.249 & 10.07 & 2.82 & 10.10 & 7.28 & 2.82 & 8.50 & 11.33 & -2.83\end{array}$ $\begin{array}{lllllllll}7.571 & 9.64 & 2.07 & 9.46 & 7.39 & 2.07 & 8.17 & 11.92 & -3.75\end{array}$ $\begin{array}{lllllllll}6.841 & 9.71 & 2.87 & 9.57 & 6.70 & 2.87 & 8.22 & 10.58 & -2.36\end{array}$ $\begin{array}{lllllllll}5.467 & 8.79 & 3.32 & 8.19 & 4.87 & 3.32 & 7.51 & 8.06 & -0.54\end{array}$ $\begin{array}{lllllllll}6.694 & 9.75 & 3.06 & 9.63 & 6.57 & 3.06 & 8.25 & 10.31 & -2.06\end{array}$ $\begin{array}{lllllllll}7.592 & 9.41 & 1.82 & 9.12 & 7.30 & 1.82 & 7.99 & 11.96 & -3.97\end{array}$ $\begin{array}{lllllllll}4.959 & 7.75 & 2.79 & 6.64 & 3.85 & 2.79 & 6.71 & 7.12 & -0.41\end{array}$ $\begin{array}{lllllllll}6.197 & 8.72 & 2.52 & 8.09 & 5.57 & 2.52 & 7.46 & 9.40 & -1.94\end{array}$ $\begin{array}{lllllllll}7.26 & 9.03 & 1.77 & 8.55 & 6.78 & 1.77 & 7.70 & 11.35 & -3.65\end{array}$ $\begin{array}{lllllllll}4.893 & 8.7 & 3.81 & 8.06 & 4.25 & 3.81 & 7.44 & 7.00 & 0.44\end{array}$ $\begin{array}{lllllllll}7.269 & 9.84 & 2.57 & 9.76 & 7.19 & 2.57 & 8.32 & 11.37 & -3.05\end{array}$ $\begin{array}{lllllllll}6.635 & 9.66 & 3.02 & 9.49 & 6.47 & 3.02 & 8.18 & 10.20 & -2.02\end{array}$ $\begin{array}{lllllllll}4.902 & 7.66 & 2.76 & 6.51 & 3.75 & 2.76 & 6.65 & 7.02 & -0.37\end{array}$ $\begin{array}{lllllllll}5.807 & 9.05 & 3.24 & 8.58 & 5.34 & 3.24 & 7.71 & 8.68 & -0.97\end{array}$ $\begin{array}{lllllllll}6.139 & 8.63 & 2.49 & 7.96 & 5.46 & 2.49 & 7.39 & 9.29 & -1.90\end{array}$ $\begin{array}{lllllllll}5.231 & 8.96 & 3.73 & 8.45 & 4.72 & 3.73 & 7.64 & 7.62 & 0.02\end{array}$ $\begin{array}{lllllllll}7.201 & 8.94 & 1.74 & 8.42 & 6.68 & 1.74 & 7.63 & 11.24 & -3.61\end{array}$ $\begin{array}{lllllllll}6.305 & 9.28 & 2.98 & 8.93 & 5.95 & 2.98 & 7.89 & 9.59 & -1.70\end{array}$ $\begin{array}{lllllllll}6.626 & 8.85 & 2.22 & 8.28 & 6.06 & 2.22 & 7.56 & 10.18 & -2.62\end{array}$ $\begin{array}{lllllllll}6.948 & 8.42 & 1.47 & 7.64 & 6.17 & 1.47 & 7.23 & 10.78 & -3.55\end{array}$ $\begin{array}{lllllllll}6.061 & 9.57 & 3.51 & 9.36 & 5.85 & 3.51 & 8.11 & 9.15 & -1.03\end{array}$ $\begin{array}{lllllllll}6.325 & 9.05 & 2.73 & 8.58 & 5.86 & 2.73 & 7.71 & 9.63 & -1.92\end{array}$ $\begin{array}{lllllllll}6.072 & 8.53 & 2.46 & 7.81 & 5.35 & 2.46 & 7.31 & 9.17 & -1.85\end{array}$ $\begin{array}{lllllllll}5.106 & 8.8 & 3.69 & 8.21 & 4.51 & 3.69 & 7.52 & 7.39 & 0.13\end{array}$ $\begin{array}{lllllllll}7.142 & 8.85 & 1.71 & 8.28 & 6.58 & 1.71 & 7.56 & 11.13 & -3.57\end{array}$ $\begin{array}{lllllllll}5.506 & 8.45 & 2.94 & 7.69 & 4.74 & 2.94 & 7.25 & 8.13 & -0.87\end{array}$ $\begin{array}{lllllllll}6.568 & 8.76 & 2.19 & 8.15 & 5.96 & 2.19 & 7.49 & 10.08 & -2.59\end{array}$ $\begin{array}{lllllllll}5.671 & 9.1 & 3.43 & 8.66 & 5.23 & 3.43 & 7.75 & 8.43 & -0.68\end{array}$ $\begin{array}{lllllllll}6.734 & 9.41 & 2.68 & 9.12 & 6.44 & 2.68 & 7.99 & 10.38 & -2.39\end{array}$ $\begin{array}{lllllllll}7.055 & 8.98 & 1.93 & 8.48 & 6.55 & 1.93 & 7.66 & 10.97 & -3.31\end{array}$ $\begin{array}{lllllllll}5.75 & 8.96 & 3.21 & 8.45 & 5.24 & 3.21 & 7.64 & 8.57 & -0.93\end{array}$ $\begin{array}{lllllllll}4.534 & 6.96 & 2.43 & 5.46 & 3.04 & 2.43 & 6.11 & 6.34 & -0.23\end{array}$ $\begin{array}{lllllllll}6.511 & 8.67 & 2.16 & 8.01 & 5.86 & 2.16 & 7.42 & 9.97 & -2.55\end{array}$ $\begin{array}{lllllllll}4.863 & 8.26 & 3.40 & 7.40 & 4.01 & 3.40 & 7.11 & 6.95 & 0.16\end{array}$ $\begin{array}{lllllllll}6.832 & 8.24 & 1.41 & 7.37 & 5.97 & 1.41 & 7.09 & 10.56 & -3.47\end{array}$ $\begin{array}{lllllllll}5.855 & 8.5 & 2.64 & 7.76 & 5.12 & 2.64 & 7.29 & 8.77 & -1.48\end{array}$ $\begin{array}{lllllllll}6.1 & 9.23 & 3.13 & 8.85 & 5.72 & 3.13 & 7.85 & 9.22 & -1.37\end{array}$ $\begin{array}{lllllllll}7.318 & 8.46 & 1.14 & 7.70 & 6.56 & 1.14 & 7.26 & 11.46 & -4.20\end{array}$ $\begin{array}{lllllllll}5.681 & 8.06 & 2.38 & 7.10 & 4.73 & 2.38 & 6.95 & 8.45 & -1.50\end{array}$ $\begin{array}{lllllllll}5.367 & 8.28 & 2.91 & 7.43 & 4.52 & 2.91 & 7.12 & 7.87 & -0.75\end{array}$ $\begin{array}{lllllllll}4.735 & 8.1 & 3.37 & 7.16 & 3.80 & 3.37 & 6.98 & 6.71 & 0.27\end{array}$ $\begin{array}{lllllllll}7.193 & 9.32 & 2.13 & 8.99 & 6.86 & 2.13 & 7.92 & 11.23 & -3.31\end{array}$ 
SMILE Generated

$\mathrm{C}(\mathrm{C}(\mathrm{C}(\mathrm{C}(\mathrm{C}(\mathrm{C}(\mathrm{C}(\mathrm{C}(\mathrm{C}(\mathrm{C}(\mathrm{C}(\mathrm{C}(\mathrm{C}(\mathrm{H})(\mathrm{Br}) \mathrm{Br})(\mathrm{H}) \mathrm{H})(\mathrm{F}) \mathrm{H})(\mathrm{F}) \mathrm{H})(\mathrm{Br}) \mathrm{H})(\mathrm{H}) \mathrm{F})(\mathrm{Br}) \mathrm{H})(\mathrm{F}) \mathrm{F})(\mathrm{H}) \mathrm{H})(\mathrm{F}) \mathrm{F})(\mathrm{H}) \mathrm{F})$ $(\mathrm{H}) \mathrm{F})(\mathrm{H})(\mathrm{H}) \mathrm{H}$

$\mathrm{C}(\mathrm{C}(\mathrm{C}(\mathrm{C}(\mathrm{C}(\mathrm{C}(\mathrm{C}(\mathrm{C}(\mathrm{C}(\mathrm{C}(\mathrm{C}(\mathrm{C}(\mathrm{C}(\mathrm{F})(\mathrm{H}) \mathrm{F})(\mathrm{H}) \mathrm{H})(\mathrm{F}) \mathrm{Br})(\mathrm{F}) \mathrm{F})(\mathrm{H}) \mathrm{Br})(\mathrm{H}) \mathrm{F})(\mathrm{H}) \mathrm{H})(\mathrm{H}) \mathrm{H})(\mathrm{H}) \mathrm{H})(\mathrm{Cl}) \mathrm{H})(\mathrm{F}) \mathrm{Cl})(\mathrm{F})$ $\mathrm{H})(\mathrm{H})(\mathrm{F}) \mathrm{H}$

$\mathrm{C}\left(\mathrm{C}(\mathrm{C}(\mathrm{C}(\mathrm{C}(\mathrm{C}(\mathrm{C}(\mathrm{C}(\mathrm{C}(\mathrm{C}(\mathrm{C}(\mathrm{C}(\mathrm{C}(\mathrm{Br})(\mathrm{H}) \mathrm{Cl})(\mathrm{F}) \mathrm{F})(\mathrm{H}) \mathrm{F})(\mathrm{H}) \mathrm{H})(\mathrm{H}) \mathrm{F})(\mathrm{H}) \mathrm{F})(\mathrm{Cl}) \mathrm{F})(\mathrm{H}) \mathrm{H})(\mathrm{F}) \mathrm{H})(\mathrm{Cl}) \mathrm{H})(\mathrm{H}) \mathrm{H})(\mathrm{H}){ }_{\mathrm{C} 13 \mathrm{H} 15 \mathrm{Cl} 3 \mathrm{BrF}}\right.$ $\mathrm{F})(\mathrm{H})(\mathrm{F}) \mathrm{H}$

$\mathrm{C}(\mathrm{C}(\mathrm{C}(\mathrm{C}(\mathrm{C}(\mathrm{C}(\mathrm{C}(\mathrm{C}(\mathrm{C}(\mathrm{C}(\mathrm{C}(\mathrm{C}(\mathrm{C}(\mathrm{H})(\mathrm{F}) \mathrm{H})(\mathrm{H}) \mathrm{H})(\mathrm{F}) \mathrm{F})(\mathrm{H}) \mathrm{H})(\mathrm{F}) \mathrm{H})(\mathrm{F}) \mathrm{F})(\mathrm{F}) \mathrm{Cl})(\mathrm{H}) \mathrm{Cl})(\mathrm{Cl}) \mathrm{H})(\mathrm{F}) \mathrm{H})(\mathrm{F}) \mathrm{H})(\mathrm{H})$

$\mathrm{H})(\mathrm{H})(\mathrm{H}) \mathrm{F}$

$\mathrm{C}(\mathrm{C}(\mathrm{C}(\mathrm{C}(\mathrm{C}(\mathrm{C}(\mathrm{C}(\mathrm{C}(\mathrm{C}(\mathrm{C}(\mathrm{C}(\mathrm{C}(\mathrm{C}(\mathrm{F})(\mathrm{H}) \mathrm{Cl})(\mathrm{Cl}) \mathrm{F})(\mathrm{H}) \mathrm{F})(\mathrm{H}) \mathrm{Cl})(\mathrm{Br}) \mathrm{H})(\mathrm{H}) \mathrm{H})(\mathrm{H}) \mathrm{F})(\mathrm{F}) \mathrm{F})(\mathrm{H}) \mathrm{Cl})(\mathrm{F}) \mathrm{H})(\mathrm{H}) \mathrm{H})$

$(\mathrm{H}) \mathrm{H})(\mathrm{F})(\mathrm{H}) \mathrm{H}$

$\mathrm{C}(\mathrm{C}(\mathrm{C}(\mathrm{C}(\mathrm{C}(\mathrm{C}(\mathrm{C}(\mathrm{C}(\mathrm{C}(\mathrm{C}(\mathrm{C}(\mathrm{C}(\mathrm{C}(\mathrm{Cl})(\mathrm{F}) \mathrm{H})(\mathrm{H}) \mathrm{H})(\mathrm{H}) \mathrm{Cl})(\mathrm{H}) \mathrm{F})(\mathrm{H}) \mathrm{H})(\mathrm{F}) \mathrm{F})(\mathrm{H}) \mathrm{Cl})(\mathrm{F}) \mathrm{F})(\mathrm{F}) \mathrm{H})(\mathrm{Cl}) \mathrm{F})(\mathrm{F}) \mathrm{H})(\mathrm{H})$ $\mathrm{H})(\mathrm{H})(\mathrm{H}) \mathrm{H}$

$\mathrm{C}(\mathrm{C}(\mathrm{C}(\mathrm{C}(\mathrm{C}(\mathrm{C}(\mathrm{C}(\mathrm{C}(\mathrm{C}(\mathrm{C}(\mathrm{C}(\mathrm{C}(\mathrm{C}(\mathrm{F})(\mathrm{H}) \mathrm{H})(\mathrm{F}) \mathrm{H})(\mathrm{H}) \mathrm{Cl})(\mathrm{H}) \mathrm{H})(\mathrm{H}) \mathrm{Cl})(\mathrm{F}) \mathrm{F})(\mathrm{H}) \mathrm{Cl})(\mathrm{F}) \mathrm{H})(\mathrm{F}) \mathrm{H})(\mathrm{F}) \mathrm{Cl})(\mathrm{H}) \mathrm{H})(\mathrm{H})$ $\mathrm{H})(\mathrm{F})(\mathrm{H}) \mathrm{Cl}$

$\mathrm{C}(\mathrm{C}(\mathrm{C}(\mathrm{C}(\mathrm{C}(\mathrm{C}(\mathrm{C}(\mathrm{C}(\mathrm{C}(\mathrm{C}(\mathrm{C}(\mathrm{C}(\mathrm{C}(\mathrm{H})(\mathrm{H}) \mathrm{H})(\mathrm{H}) \mathrm{F})(\mathrm{H}) \mathrm{F})(\mathrm{Cl}) \mathrm{F})(\mathrm{Cl}) \mathrm{H})(\mathrm{F}) \mathrm{H})(\mathrm{Cl}) \mathrm{H})(\mathrm{H}) \mathrm{Cl})(\mathrm{F}) \mathrm{H})(\mathrm{F}) \mathrm{Cl})(\mathrm{H}) \mathrm{Cl})$

(F)H $(\mathrm{H})(\mathrm{H}) \mathrm{H}$

$\mathrm{C}(\mathrm{C}(\mathrm{C}(\mathrm{C}(\mathrm{C}(\mathrm{C}(\mathrm{C}(\mathrm{C}(\mathrm{C}(\mathrm{C}(\mathrm{C}(\mathrm{C}(\mathrm{C}(\mathrm{F})(\mathrm{H}) \mathrm{H})(\mathrm{Br}) \mathrm{H})(\mathrm{F}) \mathrm{F})(\mathrm{H}) \mathrm{F})(\mathrm{H}) \mathrm{H})(\mathrm{Br}) \mathrm{F})(\mathrm{H}) \mathrm{Cl})(\mathrm{H}) \mathrm{F})(\mathrm{F}) \mathrm{H})(\mathrm{H}) \mathrm{H})(\mathrm{F}) \mathrm{H})(\mathrm{F})$

$\mathrm{F})(\mathrm{H})(\mathrm{H}) \mathrm{H}$

$\mathrm{C}(\mathrm{C}(\mathrm{C}(\mathrm{C}(\mathrm{C}(\mathrm{C}(\mathrm{C}(\mathrm{C}(\mathrm{C}(\mathrm{C}(\mathrm{C}(\mathrm{C}(\mathrm{C}(\mathrm{F})(\mathrm{F}) \mathrm{H})(\mathrm{Cl}) \mathrm{F})(\mathrm{H}) \mathrm{H})(\mathrm{F}) \mathrm{H})(\mathrm{H}) \mathrm{H})(\mathrm{Br}) \mathrm{H})(\mathrm{Br}) \mathrm{H})(\mathrm{H}) \mathrm{F})(\mathrm{H}) \mathrm{F})(\mathrm{H}) \mathrm{F})(\mathrm{H}) \mathrm{Br})$

$(\mathrm{H}) \mathrm{H})(\mathrm{F})(\mathrm{F}) \mathrm{H}$

$\mathrm{C}(\mathrm{C}(\mathrm{C}(\mathrm{C}(\mathrm{C}(\mathrm{C}(\mathrm{C}(\mathrm{C}(\mathrm{C}(\mathrm{C}(\mathrm{C}(\mathrm{C}(\mathrm{C}(\mathrm{F})(\mathrm{F}) \mathrm{H})(\mathrm{H}) \mathrm{H})(\mathrm{H}) \mathrm{Br})(\mathrm{F}) \mathrm{H})(\mathrm{F}) \mathrm{H})(\mathrm{F}) \mathrm{F})(\mathrm{F}) \mathrm{F})(\mathrm{H}) \mathrm{H})(\mathrm{H}) \mathrm{H})(\mathrm{H}) \mathrm{F})(\mathrm{H}) \mathrm{H})$

$(\mathrm{H}) \mathrm{H})(\mathrm{Br})(\mathrm{H}) \mathrm{F}$

$\mathrm{C}(\mathrm{C}(\mathrm{C}(\mathrm{C}(\mathrm{C}(\mathrm{C}(\mathrm{C}(\mathrm{C}(\mathrm{C}(\mathrm{C}(\mathrm{C}(\mathrm{C}(\mathrm{C}(\mathrm{F})(\mathrm{F}) \mathrm{H})(\mathrm{F}) \mathrm{H})(\mathrm{H}) \mathrm{Br})(\mathrm{H}) \mathrm{F})(\mathrm{H}) \mathrm{H})(\mathrm{H}) \mathrm{F})(\mathrm{H}) \mathrm{H})(\mathrm{H}) \mathrm{F})(\mathrm{Br}) \mathrm{H})(\mathrm{H}) \mathrm{H})(\mathrm{H}) \mathrm{F})(\mathrm{F})$ $\mathrm{F})(\mathrm{H})(\mathrm{H}) \mathrm{Br}$

$\mathrm{C}(\mathrm{C}(\mathrm{C}(\mathrm{C}(\mathrm{C}(\mathrm{C}(\mathrm{C}(\mathrm{C}(\mathrm{C}(\mathrm{C}(\mathrm{C}(\mathrm{C}(\mathrm{C}(\mathrm{H})(\mathrm{Br}) \mathrm{F})(\mathrm{Br}) \mathrm{H})(\mathrm{H}) \mathrm{F})(\mathrm{H}) \mathrm{H})(\mathrm{H}) \mathrm{H})(\mathrm{H}) \mathrm{H})(\mathrm{H}) \mathrm{F})(\mathrm{F}) \mathrm{Cl})(\mathrm{H}) \mathrm{F})(\mathrm{H}) \mathrm{F})(\mathrm{H}) \mathrm{F})(\mathrm{F})$

$\mathrm{H})(\mathrm{Cl})(\mathrm{H}) \mathrm{H}$

$\mathrm{C}(\mathrm{C}(\mathrm{C}(\mathrm{C}(\mathrm{C}(\mathrm{C}(\mathrm{C}(\mathrm{C}(\mathrm{C}(\mathrm{C}(\mathrm{C}(\mathrm{C}(\mathrm{C}(\mathrm{Cl})(\mathrm{Cl}) \mathrm{H})(\mathrm{F}) \mathrm{H})(\mathrm{H}) \mathrm{H})(\mathrm{H}) \mathrm{F})(\mathrm{F}) \mathrm{H})(\mathrm{H}) \mathrm{F})(\mathrm{H}) \mathrm{Br})(\mathrm{H}) \mathrm{F})(\mathrm{F}) \mathrm{H})(\mathrm{H}) \mathrm{Cl})(\mathrm{Br}) \mathrm{H})($

$\mathrm{H}) \mathrm{H})(\mathrm{F})(\mathrm{H}) \mathrm{H}$

$\mathrm{C}(\mathrm{C}(\mathrm{C}(\mathrm{C}(\mathrm{C}(\mathrm{C}(\mathrm{C}(\mathrm{C}(\mathrm{C}(\mathrm{C}(\mathrm{C}(\mathrm{C}(\mathrm{C}(\mathrm{H})(\mathrm{H}) \mathrm{H})(\mathrm{H}) \mathrm{Cl})(\mathrm{Cl}) \mathrm{F})(\mathrm{H}) \mathrm{Cl})(\mathrm{H}) \mathrm{H})(\mathrm{F}) \mathrm{H})(\mathrm{Br}) \mathrm{H})(\mathrm{H}) \mathrm{H})(\mathrm{F}) \mathrm{H})(\mathrm{H}) \mathrm{F})(\mathrm{H}) \mathrm{F})$

(F)F)(F)(H)H

$\mathrm{F})(\mathrm{Cl})(\mathrm{H}) \mathrm{F}$

$\mathrm{C}(\mathrm{C}(\mathrm{C}(\mathrm{C}(\mathrm{C}(\mathrm{C}(\mathrm{C}(\mathrm{C}(\mathrm{C}(\mathrm{C}(\mathrm{C}(\mathrm{C}(\mathrm{C}(\mathrm{H})(\mathrm{Cl}) \mathrm{Cl})(\mathrm{Cl}) \mathrm{H})(\mathrm{H}) \mathrm{Br})(\mathrm{H}) \mathrm{H})(\mathrm{F}) \mathrm{H})(\mathrm{H}) \mathrm{H})(\mathrm{H}) \mathrm{F})(\mathrm{H}) \mathrm{F})(\mathrm{Cl}) \mathrm{H})(\mathrm{H}) \mathrm{H})(\mathrm{F}) \mathrm{F})($

$\mathrm{H}) \mathrm{Cl}(\mathrm{F})(\mathrm{H}) \mathrm{H}$

$\mathrm{C}(\mathrm{C}(\mathrm{C}(\mathrm{C}(\mathrm{C}(\mathrm{C}(\mathrm{C}(\mathrm{C}(\mathrm{C}(\mathrm{C}(\mathrm{C}(\mathrm{C}(\mathrm{C}(\mathrm{H})(\mathrm{H}) \mathrm{F})(\mathrm{H}) \mathrm{F})(\mathrm{H}) \mathrm{H})(\mathrm{H}) \mathrm{H})(\mathrm{H}) \mathrm{Cl})(\mathrm{H}) \mathrm{Cl})(\mathrm{H}) \mathrm{H})(\mathrm{H}) \mathrm{F})(\mathrm{H}) \mathrm{Cl})(\mathrm{F}) \mathrm{H})(\mathrm{H}) \mathrm{F})$

$(\mathrm{Cl}) \mathrm{Cl})(\mathrm{F})(\mathrm{F}) \mathrm{H}$

$\mathrm{C}(\mathrm{C}(\mathrm{C}(\mathrm{C}(\mathrm{C}(\mathrm{C}(\mathrm{C}(\mathrm{C}(\mathrm{C}(\mathrm{C}(\mathrm{C}(\mathrm{C}(\mathrm{C}(\mathrm{H})(\mathrm{H}) \mathrm{F})(\mathrm{H}) \mathrm{H})(\mathrm{H}) \mathrm{Cl})(\mathrm{Cl}) \mathrm{H})(\mathrm{F}) \mathrm{H})(\mathrm{H}) \mathrm{H})(\mathrm{H}) \mathrm{Cl})(\mathrm{F}) \mathrm{Cl})(\mathrm{Cl}) \mathrm{H})(\mathrm{H}) \mathrm{H})(\mathrm{F}) \mathrm{H})($

$\mathrm{Cl}) \mathrm{H})(\mathrm{F})(\mathrm{F}) \mathrm{H}$

$\mathrm{C}(\mathrm{C}(\mathrm{C}(\mathrm{C}(\mathrm{C}(\mathrm{C}(\mathrm{C}(\mathrm{C}(\mathrm{C}(\mathrm{C}(\mathrm{C}(\mathrm{C}(\mathrm{C}(\mathrm{F})(\mathrm{H}) \mathrm{Br})(\mathrm{H}) \mathrm{H})(\mathrm{H}) \mathrm{F})(\mathrm{H}) \mathrm{H})(\mathrm{H}) \mathrm{F})(\mathrm{H}) \mathrm{F})(\mathrm{H}) \mathrm{H})(\mathrm{H}) \mathrm{H})(\mathrm{F}) \mathrm{F})(\mathrm{F}) \mathrm{H})(\mathrm{Br}) \mathrm{F})(\mathrm{H})$ $\mathrm{F})(\mathrm{H})(\mathrm{Cl}) \mathrm{H}$

$\mathrm{C}(\mathrm{C}(\mathrm{C}(\mathrm{C}(\mathrm{C}(\mathrm{C}(\mathrm{C}(\mathrm{C}(\mathrm{C}(\mathrm{C}(\mathrm{C}(\mathrm{C}(\mathrm{C}(\mathrm{Br})(\mathrm{H}) \mathrm{H})(\mathrm{H}) \mathrm{F})(\mathrm{H}) \mathrm{H})(\mathrm{H}) \mathrm{H})(\mathrm{Cl}) \mathrm{H})(\mathrm{F}) \mathrm{H})(\mathrm{H}) \mathrm{H})(\mathrm{Br}) \mathrm{H})(\mathrm{H}) \mathrm{F})(\mathrm{H}) \mathrm{Br})(\mathrm{H}) \mathrm{F})($ $\mathrm{F}) \mathrm{H})(\mathrm{F})(\mathrm{F}) \mathrm{F}$

$\mathrm{C}(\mathrm{C}(\mathrm{C}(\mathrm{C}(\mathrm{C}(\mathrm{C}(\mathrm{C}(\mathrm{C}(\mathrm{C}(\mathrm{C}(\mathrm{C}(\mathrm{C}(\mathrm{C}(\mathrm{H})(\mathrm{H}) \mathrm{F})(\mathrm{H}) \mathrm{H})(\mathrm{Br}) \mathrm{F})(\mathrm{H}) \mathrm{H})(\mathrm{H}) \mathrm{F})(\mathrm{H}) \mathrm{F})(\mathrm{F}) \mathrm{H})(\mathrm{H}) \mathrm{H})(\mathrm{H}) \mathrm{Br})(\mathrm{F}) \mathrm{F})(\mathrm{Br}) \mathrm{H})$

$(\mathrm{H}) \mathrm{H})(\mathrm{H})(\mathrm{F}) \mathrm{H}$

$\mathrm{C}(\mathrm{C}(\mathrm{C}(\mathrm{C}(\mathrm{C}(\mathrm{C}(\mathrm{C}(\mathrm{C}(\mathrm{C}(\mathrm{C}(\mathrm{C}(\mathrm{C}(\mathrm{C}(\mathrm{F})(\mathrm{H}) \mathrm{H})(\mathrm{H}) \mathrm{Br})(\mathrm{H}) \mathrm{F})(\mathrm{H}) \mathrm{H})(\mathrm{H}) \mathrm{Br})(\mathrm{F}) \mathrm{H})(\mathrm{H}) \mathrm{H})(\mathrm{F}) \mathrm{H})(\mathrm{H}) \mathrm{Br})(\mathrm{F}) \mathrm{H})(\mathrm{H}) \mathrm{H})($

$\mathrm{H}) \mathrm{F})(\mathrm{F})(\mathrm{H}) \mathrm{Br}$

$\mathrm{C}(\mathrm{C}(\mathrm{C}(\mathrm{C}(\mathrm{C}(\mathrm{C}(\mathrm{C}(\mathrm{C}(\mathrm{C}(\mathrm{C}(\mathrm{C}(\mathrm{C}(\mathrm{C}(\mathrm{H})(\mathrm{F}) \mathrm{Br})(\mathrm{F}) \mathrm{H})(\mathrm{H}) \mathrm{H})(\mathrm{H}) \mathrm{Cl})(\mathrm{H}) \mathrm{H})(\mathrm{H}) \mathrm{H})(\mathrm{H}) \mathrm{Br})(\mathrm{H}) \mathrm{H})(\mathrm{H}) \mathrm{F})(\mathrm{F}) \mathrm{F})(\mathrm{H}) \mathrm{H})$

$(\mathrm{F}) \mathrm{H})(\mathrm{F})(\mathrm{H}) \mathrm{Cl}$

$\mathrm{C}(\mathrm{C}(\mathrm{C}(\mathrm{C}(\mathrm{C}(\mathrm{C}(\mathrm{C}(\mathrm{C}(\mathrm{C}(\mathrm{C}(\mathrm{C}(\mathrm{C}(\mathrm{C}(\mathrm{H})(\mathrm{H}) \mathrm{F})(\mathrm{F}) \mathrm{H})(\mathrm{Cl}) \mathrm{H})(\mathrm{F}) \mathrm{F})(\mathrm{H}) \mathrm{H})(\mathrm{H}) \mathrm{Br})(\mathrm{F}) \mathrm{Cl})(\mathrm{H}) \mathrm{H})(\mathrm{H}) \mathrm{F})(\mathrm{F}) \mathrm{H})(\mathrm{F}) \mathrm{H})(\mathrm{H})$ $\mathrm{H})(\mathrm{H})(\mathrm{H}) \mathrm{H}$

$\mathrm{C}(\mathrm{C}(\mathrm{C}(\mathrm{C}(\mathrm{C}(\mathrm{C}(\mathrm{C}(\mathrm{C}(\mathrm{C}(\mathrm{C}(\mathrm{C}(\mathrm{C}(\mathrm{C}(\mathrm{F})(\mathrm{F}) \mathrm{H})(\mathrm{H}) \mathrm{F})(\mathrm{H}) \mathrm{Br})(\mathrm{F}) \mathrm{H})(\mathrm{H}) \mathrm{Cl})(\mathrm{H}) \mathrm{H})(\mathrm{Cl}) \mathrm{H})(\mathrm{F}) \mathrm{H})(\mathrm{H}) \mathrm{Cl})(\mathrm{H}) \mathrm{H})(\mathrm{H}) \mathrm{H})$

$(\mathrm{H}) \mathrm{H})(\mathrm{Br})(\mathrm{F}) \mathrm{H}$

$\mathrm{C}(\mathrm{C}(\mathrm{C}(\mathrm{C}(\mathrm{C}(\mathrm{C}(\mathrm{C}(\mathrm{C}(\mathrm{C}(\mathrm{C}(\mathrm{C}(\mathrm{C}(\mathrm{C}(\mathrm{F})(\mathrm{F}) \mathrm{H})(\mathrm{H}) \mathrm{F})(\mathrm{H}) \mathrm{H})(\mathrm{H}) \mathrm{F})(\mathrm{H}) \mathrm{H})(\mathrm{Cl}) \mathrm{F})(\mathrm{Cl}) \mathrm{H})(\mathrm{H}) \mathrm{Cl})(\mathrm{H}) \mathrm{Br})(\mathrm{H}) \mathrm{H})(\mathrm{H}) \mathrm{H})$

$(\mathrm{F}) \mathrm{H})(\mathrm{H})(\mathrm{F}) \mathrm{H}$

$\mathrm{C}(\mathrm{C}(\mathrm{C}(\mathrm{C}(\mathrm{C}(\mathrm{C}(\mathrm{C}(\mathrm{C}(\mathrm{C}(\mathrm{C}(\mathrm{C}(\mathrm{C}(\mathrm{C}(\mathrm{H})(\mathrm{H}) \mathrm{H})(\mathrm{F}) \mathrm{Cl})(\mathrm{H}) \mathrm{H})(\mathrm{H}) \mathrm{F})(\mathrm{H}) \mathrm{H})(\mathrm{H}) \mathrm{Cl})(\mathrm{H}) \mathrm{F})(\mathrm{F}) \mathrm{H})(\mathrm{Cl}) \mathrm{F})(\mathrm{H}) \mathrm{H})(\mathrm{F}) \mathrm{H})(\mathrm{H})$

$\mathrm{F})(\mathrm{H})(\mathrm{F}) \mathrm{H}$

$\mathrm{C}(\mathrm{C}(\mathrm{C}(\mathrm{C}(\mathrm{C}(\mathrm{C}(\mathrm{C}(\mathrm{C}(\mathrm{C}(\mathrm{C}(\mathrm{C}(\mathrm{C}(\mathrm{C}(\mathrm{Cl})(\mathrm{H}) \mathrm{H})(\mathrm{Cl}) \mathrm{H})(\mathrm{H}) \mathrm{F})(\mathrm{Cl}) \mathrm{H})(\mathrm{F}) \mathrm{H})(\mathrm{H}) \mathrm{Cl})(\mathrm{F}) \mathrm{H})(\mathrm{F}) \mathrm{H})(\mathrm{F}) \mathrm{H})(\mathrm{F}) \mathrm{H})(\mathrm{H}) \mathrm{H})$

$(\mathrm{H}) \mathrm{Br})(\mathrm{H})(\mathrm{H}) \mathrm{H}$

$\mathrm{C}(\mathrm{C}(\mathrm{C}(\mathrm{C}(\mathrm{C}(\mathrm{C}(\mathrm{C}(\mathrm{C}(\mathrm{C}(\mathrm{C}(\mathrm{C}(\mathrm{C}(\mathrm{C}(\mathrm{H})(\mathrm{F}) \mathrm{H})(\mathrm{H}) \mathrm{H})(\mathrm{H}) \mathrm{F})(\mathrm{H}) \mathrm{F})(\mathrm{H}) \mathrm{H})(\mathrm{H}) \mathrm{Cl})(\mathrm{Cl}) \mathrm{H})(\mathrm{F}) \mathrm{H})(\mathrm{H}) \mathrm{H})(\mathrm{H}) \mathrm{F})(\mathrm{Cl}) \mathrm{Cl})$

$(\mathrm{F}) \mathrm{H})(\mathrm{H})(\mathrm{F}) \mathrm{H}$

$\mathrm{C}(\mathrm{C}(\mathrm{C}(\mathrm{C}(\mathrm{C}(\mathrm{C}(\mathrm{C}(\mathrm{C}(\mathrm{C}(\mathrm{C}(\mathrm{C}(\mathrm{C}(\mathrm{C}(\mathrm{H})(\mathrm{H}) \mathrm{F})(\mathrm{H}) \mathrm{H})(\mathrm{Cl}) \mathrm{Cl})(\mathrm{H}) \mathrm{Cl})(\mathrm{H}) \mathrm{Cl})(\mathrm{H}) \mathrm{H})(\mathrm{H}) \mathrm{H})(\mathrm{H}) \mathrm{Cl})(\mathrm{H}) \mathrm{F})(\mathrm{F}) \mathrm{F})(\mathrm{H}) \mathrm{F})($

$\mathrm{H}) \mathrm{H})(\mathrm{F})(\mathrm{H}) \mathrm{H}$

$\mathrm{C}(\mathrm{C}(\mathrm{C}(\mathrm{C}(\mathrm{C}(\mathrm{C}(\mathrm{C}(\mathrm{C}(\mathrm{C}(\mathrm{C}(\mathrm{C}(\mathrm{C}(\mathrm{C}(\mathrm{H})(\mathrm{Br}) \mathrm{H})(\mathrm{H}) \mathrm{F})(\mathrm{H}) \mathrm{F})(\mathrm{F}) \mathrm{H})(\mathrm{H}) \mathrm{F})(\mathrm{H}) \mathrm{H})(\mathrm{H}) \mathrm{F})(\mathrm{Br}) \mathrm{H})(\mathrm{H}) \mathrm{H})(\mathrm{F}) \mathrm{H})(\mathrm{F}) \mathrm{H})(\mathrm{Cl})$

$\mathrm{H})(\mathrm{H})(\mathrm{F}) \mathrm{H}$

$\mathrm{C}(\mathrm{C}(\mathrm{C}(\mathrm{C}(\mathrm{C}(\mathrm{C}(\mathrm{C}(\mathrm{C}(\mathrm{C}(\mathrm{C}(\mathrm{C}(\mathrm{C}(\mathrm{C}(\mathrm{F})(\mathrm{H}) \mathrm{H})(\mathrm{H}) \mathrm{H})(\mathrm{H}) \mathrm{H})(\mathrm{H}) \mathrm{H})(\mathrm{H}) \mathrm{F})(\mathrm{H}) \mathrm{H})(\mathrm{Br}) \mathrm{F})(\mathrm{H}) \mathrm{H})(\mathrm{H}) \mathrm{F})(\mathrm{F}) \mathrm{F})(\mathrm{H}) \mathrm{Br})(\mathrm{F})$

$\mathrm{H})(\mathrm{H})(\mathrm{H}) \mathrm{F}$

$\mathrm{C}(\mathrm{C}(\mathrm{C}(\mathrm{C}(\mathrm{C}(\mathrm{C}(\mathrm{C}(\mathrm{C}(\mathrm{C}(\mathrm{C}(\mathrm{C}(\mathrm{C}(\mathrm{C}(\mathrm{H})(\mathrm{H}) \mathrm{F})(\mathrm{H}) \mathrm{H})(\mathrm{Br}) \mathrm{H})(\mathrm{H}) \mathrm{Br})(\mathrm{F}) \mathrm{H})(\mathrm{F}) \mathrm{H})(\mathrm{H}) \mathrm{H})(\mathrm{H}) \mathrm{F})(\mathrm{F}) \mathrm{Br})(\mathrm{H}) \mathrm{F})(\mathrm{H}) \mathrm{H})$

$(\mathrm{H}) \mathrm{H})(\mathrm{F})(\mathrm{H}) \mathrm{H}$

C(C(C(C(C(C(C(C(C(C(C(C(C(F)(H)H)(H)F)(F)H)(H)F)(H)H)(Br)H)(F)H)(Cl)H)(H)H)(Cl)H)(H)H)(B $\mathrm{r}) \mathrm{H})(\mathrm{H})(\mathrm{H}) \mathrm{F}$

$\mathrm{C}(\mathrm{C}(\mathrm{C}(\mathrm{C}(\mathrm{C}(\mathrm{C}(\mathrm{C}(\mathrm{C}(\mathrm{C}(\mathrm{C}(\mathrm{C}(\mathrm{C}(\mathrm{C}(\mathrm{H})(\mathrm{H}) \mathrm{Cl})(\mathrm{H}) \mathrm{H})(\mathrm{H}) \mathrm{H})(\mathrm{H}) \mathrm{H})(\mathrm{H}) \mathrm{H})(\mathrm{H}) \mathrm{F})(\mathrm{Cl}) \mathrm{F})(\mathrm{F}) \mathrm{H})(\mathrm{Br}) \mathrm{H})(\mathrm{H}) \mathrm{H})(\mathrm{H}) \mathrm{H})($

$\mathrm{H}) \mathrm{F})(\mathrm{F})(\mathrm{F}) \mathrm{F}$

$\mathrm{C}(\mathrm{C}(\mathrm{C}(\mathrm{C}(\mathrm{C}(\mathrm{C}(\mathrm{C}(\mathrm{C}(\mathrm{C}(\mathrm{C}(\mathrm{C}(\mathrm{C}(\mathrm{C}(\mathrm{H})(\mathrm{H}) \mathrm{H})(\mathrm{H}) \mathrm{Cl})(\mathrm{H}) \mathrm{H})(\mathrm{F}) \mathrm{F})(\mathrm{H}) \mathrm{H})(\mathrm{H}) \mathrm{Cl})(\mathrm{F}) \mathrm{F})(\mathrm{H}) \mathrm{H})(\mathrm{H}) \mathrm{H})(\mathrm{Br}) \mathrm{H})(\mathrm{H}) \mathrm{Cl})$

(F)H)(H)(H)F

$\mathrm{C}(\mathrm{C}(\mathrm{C}(\mathrm{C}(\mathrm{C}(\mathrm{C}(\mathrm{C}(\mathrm{C}(\mathrm{C}(\mathrm{C}(\mathrm{C}(\mathrm{C}(\mathrm{C}(\mathrm{H})(\mathrm{H}) \mathrm{H})(\mathrm{Cl}) \mathrm{H})(\mathrm{F}) \mathrm{F})(\mathrm{F}) \mathrm{F})(\mathrm{H}) \mathrm{Cl})(\mathrm{H}) \mathrm{H})(\mathrm{H}) \mathrm{H})(\mathrm{H}) \mathrm{H})(\mathrm{H}) \mathrm{H})(\mathrm{Cl}) \mathrm{F})(\mathrm{H}) \mathrm{H})(\mathrm{F})$

$\mathrm{F})(\mathrm{H})(\mathrm{H}) \mathrm{H}$

$\mathrm{C}(\mathrm{C}(\mathrm{C}(\mathrm{C}(\mathrm{C}(\mathrm{C}(\mathrm{C}(\mathrm{C}(\mathrm{C}(\mathrm{C}(\mathrm{C}(\mathrm{C}(\mathrm{C}(\mathrm{H})(\mathrm{H}) \mathrm{H})(\mathrm{Cl}) \mathrm{F})(\mathrm{H}) \mathrm{F})(\mathrm{F}) \mathrm{Cl})(\mathrm{Cl}) \mathrm{H})(\mathrm{H}) \mathrm{H})(\mathrm{H}) \mathrm{F})(\mathrm{H}) \mathrm{H})(\mathrm{Cl}) \mathrm{H})(\mathrm{F}) \mathrm{H})(\mathrm{H}) \mathrm{F})$

$(\mathrm{H}) \mathrm{H})(\mathrm{H})(\mathrm{H}) \mathrm{H}$

$\mathrm{C}(\mathrm{C}(\mathrm{C}(\mathrm{C}(\mathrm{C}(\mathrm{C}(\mathrm{C}(\mathrm{C}(\mathrm{C}(\mathrm{C}(\mathrm{C}(\mathrm{C}(\mathrm{C}(\mathrm{H})(\mathrm{Cl}) \mathrm{F})(\mathrm{F}) \mathrm{H})(\mathrm{H}) \mathrm{Cl})(\mathrm{H}) \mathrm{Cl})(\mathrm{H}) \mathrm{F})(\mathrm{H}) \mathrm{Cl})(\mathrm{H}) \mathrm{H})(\mathrm{F}) \mathrm{H})(\mathrm{H}) \mathrm{F})(\mathrm{H}) \mathrm{H})(\mathrm{Cl}) \mathrm{H})($

$\mathrm{H}) \mathrm{H})(\mathrm{H})(\mathrm{H}) \mathrm{H}$

$\mathrm{C}(\mathrm{C}(\mathrm{C}(\mathrm{C}(\mathrm{C}(\mathrm{C}(\mathrm{C}(\mathrm{C}(\mathrm{C}(\mathrm{C}(\mathrm{C}(\mathrm{C}(\mathrm{C}(\mathrm{H})(\mathrm{F}) \mathrm{H})(\mathrm{Cl}) H)(\mathrm{H}) \mathrm{H})(\mathrm{Br}) \mathrm{H})(\mathrm{H}) \mathrm{H})(\mathrm{F}) \mathrm{F})(\mathrm{H}) \mathrm{H})(\mathrm{Br}) \mathrm{F})(\mathrm{H}) \mathrm{H})(\mathrm{F}) \mathrm{H})(\mathrm{H}) \mathrm{F})(\mathrm{F})$

$\mathrm{H})(\mathrm{H})(\mathrm{H}) \mathrm{H}$

$\mathrm{C}(\mathrm{C}(\mathrm{C}(\mathrm{C}(\mathrm{C}(\mathrm{C}(\mathrm{C}(\mathrm{C}(\mathrm{C}(\mathrm{C}(\mathrm{C}(\mathrm{C}(\mathrm{C}(\mathrm{H})(\mathrm{F}) \mathrm{H})(\mathrm{H}) \mathrm{H})(\mathrm{F}) \mathrm{H})(\mathrm{H}) \mathrm{H})(\mathrm{F}) \mathrm{H})(\mathrm{Br}) \mathrm{H})(\mathrm{H}) \mathrm{H})(\mathrm{F}) \mathrm{H})(\mathrm{F}) \mathrm{H})(\mathrm{H}) \mathrm{Cl})(\mathrm{Br}) \mathrm{F})$ $(\mathrm{H}) \mathrm{H})(\mathrm{H})(\mathrm{Br}) \mathrm{H}$

Formula

lgKoa lgKow lgKaw loKow lgKoa lgKa lgKow lgKoa lgKaw EPISuit EPI EPI Exp Exp w DFT DFT DFT e Suite Suite corr _corr_Exp corr _corr _corr $\begin{array}{lllllllllll}7.28 & 8.17 & 0.89 & 7.27 & 6.38 & 0.89 & 7.04 & 11.39 & -4.35\end{array}$ $\begin{array}{lllllllll}6.938 & 8.8 & 1.86 & 8.21 & 6.35 & 1.86 & 7.52 & 10.76 & -3.24\end{array}$ $\begin{array}{lllllllll}5.624 & 7.97 & 2.35 & 6.97 & 4.62 & 2.35 & 6.88 & 8.34 & -1.46\end{array}$ $\begin{array}{lllllllll}4.727 & 8.31 & 3.58 & 7.48 & 3.89 & 3.58 & 7.14 & 6.70 & 0.45\end{array}$ $\begin{array}{lllllllll}6.686 & 8.28 & 1.59 & 7.43 & 5.84 & 1.59 & 7.12 & 10.29 & -3.17\end{array}$ $\begin{array}{lllllllll}5.718 & 8.55 & 2.83 & 7.84 & 5.00 & 2.83 & 7.33 & 8.52 & -1.19\end{array}$ $\begin{array}{lllllllll}6.11 & 8.19 & 2.08 & 7.30 & 5.22 & 2.08 & 7.05 & 9.24 & -2.18\end{array}$ $\begin{array}{lllllllll}7.032 & 8.36 & 1.33 & 7.55 & 6.22 & 1.33 & 7.18 & 10.93 & -3.75\end{array}$ $\begin{array}{lllllllll}5.798 & 8.41 & 2.61 & 7.63 & 5.02 & 2.61 & 7.22 & 8.66 & -1.44\end{array}$ $\begin{array}{lllllllll}6.034 & 7.41 & 1.38 & 6.13 & 4.76 & 1.38 & 6.45 & 9.10 & -2.64\end{array}$ $\begin{array}{lllllllll}4.504 & 7.57 & 3.07 & 6.37 & 3.31 & 3.07 & 6.58 & 6.29 & 0.29\end{array}$ $\begin{array}{lllllllll}5.401 & 7.23 & 1.83 & 5.87 & 4.04 & 1.83 & 6.31 & 7.93 & -1.62\end{array}$ $\begin{array}{lllllllll}5.888 & 7.45 & 1.56 & 6.19 & 4.63 & 1.56 & 6.48 & 8.83 & -2.34\end{array}$ $\begin{array}{lllllllll}6.21 & 7.02 & 0.81 & 5.55 & 4.74 & 0.81 & 6.15 & 9.42 & -3.27\end{array}$ $\begin{array}{lllllllll}5.982 & 8.03 & 2.05 & 7.06 & 5.01 & 2.05 & 6.93 & 9.00 & -2.07\end{array}$ $\begin{array}{lllllllll}5.407 & 7.94 & 2.53 & 6.93 & 4.39 & 2.53 & 6.86 & 7.94 & -1.08\end{array}$ $\begin{array}{lllllllll}7.446 & 7.99 & 0.54 & 7.00 & 6.46 & 0.54 & 6.90 & 11.69 & -4.79\end{array}$ $\begin{array}{lllllllll}5.808 & 7.59 & 1.78 & 6.40 & 4.62 & 1.78 & 6.59 & 8.68 & -2.09\end{array}$ $\begin{array}{lllllllll}6.87 & 7.9 & 1.03 & 6.87 & 5.84 & 1.03 & 6.83 & 10.63 & -3.80\end{array}$ 
SMILE Generated

$\mathrm{C}(\mathrm{C}(\mathrm{C}(\mathrm{C}(\mathrm{C}(\mathrm{C}(\mathrm{C}(\mathrm{C}(\mathrm{C}(\mathrm{C}(\mathrm{C}(\mathrm{C}(\mathrm{C}(\mathrm{H})(\mathrm{H}) \mathrm{H})(\mathrm{F}) \mathrm{H})(\mathrm{H}) \mathrm{H})(\mathrm{Br}) \mathrm{F})(\mathrm{H}) \mathrm{F})(\mathrm{H}) \mathrm{H})(\mathrm{H}) \mathrm{H})(\mathrm{F}) \mathrm{H})(\mathrm{H}) \mathrm{F})(\mathrm{H}) \mathrm{H})(\mathrm{Br}) \mathrm{H})$ $(\mathrm{H}) \mathrm{F})(\mathrm{H})(\mathrm{H}) \mathrm{F}$

$\mathrm{C}(\mathrm{C}(\mathrm{C}(\mathrm{C}(\mathrm{C}(\mathrm{C}(\mathrm{C}(\mathrm{C}(\mathrm{C}(\mathrm{C}(\mathrm{C}(\mathrm{C}(\mathrm{C}(\mathrm{F})(\mathrm{H}) \mathrm{H})(\mathrm{H}) \mathrm{Br})(\mathrm{F}) \mathrm{H})(\mathrm{H}) \mathrm{H})(\mathrm{F}) \mathrm{H})(\mathrm{H}) \mathrm{H})(\mathrm{F}) \mathrm{Br})(\mathrm{H}) \mathrm{H})(\mathrm{F}) \mathrm{F})(\mathrm{H}) \mathrm{H})(\mathrm{H}) \mathrm{H})(\mathrm{H})$ $\mathrm{H})(\mathrm{Br})(\mathrm{H}) \mathrm{H}$

$\mathrm{C}(\mathrm{C}(\mathrm{C}(\mathrm{C}(\mathrm{C}(\mathrm{C}(\mathrm{C}(\mathrm{C}(\mathrm{C}(\mathrm{C}(\mathrm{C}(\mathrm{C}(\mathrm{C}(\mathrm{H})(\mathrm{H}) \mathrm{H})(\mathrm{F}) \mathrm{H})(\mathrm{H}) \mathrm{H})(\mathrm{F}) \mathrm{H})(\mathrm{H}) \mathrm{F})(\mathrm{Cl}) \mathrm{H})(\mathrm{H}) \mathrm{H})(\mathrm{H}) \mathrm{F})(\mathrm{Br}) \mathrm{H})(\mathrm{H}) \mathrm{H})(\mathrm{H}) \mathrm{Cl})(\mathrm{B}$ r)F)(H)(H)H

$\mathrm{C}(\mathrm{C}(\mathrm{C}(\mathrm{C}(\mathrm{C}(\mathrm{C}(\mathrm{C}(\mathrm{C}(\mathrm{C}(\mathrm{C}(\mathrm{C}(\mathrm{C}(\mathrm{C}(\mathrm{H})(\mathrm{F}) \mathrm{H})(\mathrm{F}) \mathrm{H})(\mathrm{H}) \mathrm{H})(\mathrm{H}) \mathrm{H})(\mathrm{F}) \mathrm{Br})(\mathrm{H}) \mathrm{H})(\mathrm{H}) \mathrm{F})(\mathrm{H}) \mathrm{H})(\mathrm{F}) \mathrm{Cl})(\mathrm{H}) \mathrm{H})(\mathrm{H}) \mathrm{H})$

$(\mathrm{Cl}) \mathrm{H})(\mathrm{H})(\mathrm{F}) \mathrm{H}$

$\mathrm{C}(\mathrm{C}(\mathrm{C}(\mathrm{C}(\mathrm{C}(\mathrm{C}(\mathrm{C}(\mathrm{C}(\mathrm{C}(\mathrm{C}(\mathrm{C}(\mathrm{C}(\mathrm{C}(\mathrm{H})(\mathrm{H}) \mathrm{H})(\mathrm{H}) \mathrm{H})(\mathrm{F}) \mathrm{H})(\mathrm{Cl}) \mathrm{H})(\mathrm{H}) \mathrm{H})(\mathrm{H}) \mathrm{H})(\mathrm{F}) \mathrm{F})(\mathrm{H}) \mathrm{H})(\mathrm{F}) \mathrm{H})(\mathrm{F}) \mathrm{F})(\mathrm{F}) \mathrm{H})(\mathrm{Cl}) \quad \mathrm{C} 13 \mathrm{H} 19 \mathrm{Cl} 2 \mathrm{~F} 7$

$\mathrm{H})(\mathrm{H})(\mathrm{H}) \mathrm{H}$

C(C(C(C(C(C(C(C(C(C(C(C(C(Br)(H)H)(H)H)(H)H)(H)H)(H)H)(Cl)H)(H)H)(F)H)(Cl)H)(F)H)(Cl)H)( $\mathrm{H}) \mathrm{Br})(\mathrm{H})(\mathrm{F}) \mathrm{F}$

$\mathrm{C}(\mathrm{C}(\mathrm{C}(\mathrm{C}(\mathrm{C}(\mathrm{C}(\mathrm{C}(\mathrm{C}(\mathrm{C}(\mathrm{C}(\mathrm{C}(\mathrm{C}(\mathrm{C}(\mathrm{Cl})(\mathrm{H}) \mathrm{F})(\mathrm{H}) \mathrm{H})(\mathrm{Br}) \mathrm{H})(\mathrm{H}) \mathrm{H})(\mathrm{H}) \mathrm{H})(\mathrm{H}) \mathrm{F})(\mathrm{H}) \mathrm{H})(\mathrm{H}) \mathrm{H})(\mathrm{F}) \mathrm{H})(\mathrm{H}) \mathrm{H})(\mathrm{Cl}) \mathrm{F})$ $(\mathrm{H}) \mathrm{F})(\mathrm{H})(\mathrm{Cl}) \mathrm{H}$

$\mathrm{C}(\mathrm{C}(\mathrm{C}(\mathrm{C}(\mathrm{C}(\mathrm{C}(\mathrm{C}(\mathrm{C}(\mathrm{C}(\mathrm{C}(\mathrm{C}(\mathrm{C}(\mathrm{C}(\mathrm{F})(\mathrm{F}) \mathrm{F})(\mathrm{H}) \mathrm{H})(\mathrm{H}) \mathrm{H})(\mathrm{F}) \mathrm{H})(\mathrm{H}) \mathrm{H})(\mathrm{H}) \mathrm{H})(\mathrm{H}) \mathrm{H})(\mathrm{Cl}) \mathrm{H})(\mathrm{Cl}) \mathrm{H})(\mathrm{H}) \mathrm{F})(\mathrm{H}) \mathrm{H})(\mathrm{H})$ $\mathrm{H})(\mathrm{H})(\mathrm{F}) \mathrm{Cl}$

$\mathrm{C}(\mathrm{C}(\mathrm{C}(\mathrm{C}(\mathrm{C}(\mathrm{C}(\mathrm{C}(\mathrm{C}(\mathrm{C}(\mathrm{C}(\mathrm{C}(\mathrm{C}(\mathrm{C}(\mathrm{H})(\mathrm{H}) \mathrm{Cl})(\mathrm{Cl}) \mathrm{H})(\mathrm{H}) \mathrm{H})(\mathrm{H}) \mathrm{F})(\mathrm{H}) \mathrm{H})(\mathrm{F}) \mathrm{H})(\mathrm{H}) \mathrm{H})(\mathrm{H}) \mathrm{H})(\mathrm{H}) \mathrm{F})(\mathrm{H}) \mathrm{H})(\mathrm{F}) \mathrm{H})$

$(\mathrm{Cl}) \mathrm{H})(\mathrm{F})(\mathrm{H}) \mathrm{Cl}$

$\mathrm{C}\left(\mathrm{C}(\mathrm{C}(\mathrm{C}(\mathrm{C}(\mathrm{C}(\mathrm{C}(\mathrm{C}(\mathrm{C}(\mathrm{C}(\mathrm{C}(\mathrm{C}(\mathrm{C}(\mathrm{H})(\mathrm{F}) \mathrm{H})(\mathrm{H}) \mathrm{H})(\mathrm{H}) \mathrm{H})(\mathrm{H}) \mathrm{H})(\mathrm{H}) \mathrm{Cl})(\mathrm{H}) \mathrm{F})(\mathrm{H}) \mathrm{Cl})(\mathrm{H}) \mathrm{F})(\mathrm{H}) \mathrm{H})(\mathrm{Cl}) \mathrm{Cl})(\mathrm{Cl}) \mathrm{H})\left(\mathrm{C}^{2}\right.\right.$

$\mathrm{H}) \mathrm{F})(\mathrm{H})(\mathrm{H}) \mathrm{H}$

$\mathrm{C}(\mathrm{C}(\mathrm{C}(\mathrm{C}(\mathrm{C}(\mathrm{C}(\mathrm{C}(\mathrm{C}(\mathrm{C}(\mathrm{C}(\mathrm{C}(\mathrm{C}(\mathrm{C}(\mathrm{H})(\mathrm{H}) \mathrm{H})(\mathrm{H}) \mathrm{H})(\mathrm{H}) \mathrm{H})(\mathrm{F}) \mathrm{Br})(\mathrm{H}) \mathrm{F})(\mathrm{H}) \mathrm{H})(\mathrm{H}) \mathrm{F})(\mathrm{H}) \mathrm{H})(\mathrm{Cl}) \mathrm{H})(\mathrm{F}) \mathrm{Br})(\mathrm{F}) \mathrm{H})$

$(\mathrm{H}) \mathrm{F})(\mathrm{H})(\mathrm{H}) \mathrm{H}$

$\mathrm{C}(\mathrm{C}(\mathrm{C}(\mathrm{C}(\mathrm{C}(\mathrm{C}(\mathrm{C}(\mathrm{C}(\mathrm{C}(\mathrm{C}(\mathrm{C}(\mathrm{C}(\mathrm{C}(\mathrm{H})(\mathrm{Cl}) \mathrm{F})(\mathrm{F}) \mathrm{H})(\mathrm{H}) \mathrm{H})(\mathrm{H}) \mathrm{F})(\mathrm{Br}) \mathrm{H})(\mathrm{Br}) \mathrm{H})(\mathrm{H}) \mathrm{H})(\mathrm{H}) \mathrm{H})(\mathrm{H}) \mathrm{H})(\mathrm{H}) \mathrm{F})(\mathrm{H}) \mathrm{H})($ $\mathrm{H}) \mathrm{F})(\mathrm{H})(\mathrm{Br}) \mathrm{H}$

$\mathrm{C}\left(\mathrm{C}(\mathrm{C}(\mathrm{C}(\mathrm{C}(\mathrm{C}(\mathrm{C}(\mathrm{C}(\mathrm{C}(\mathrm{C}(\mathrm{C}(\mathrm{C}(\mathrm{C}(\mathrm{H})(\mathrm{F}) \mathrm{H})(\mathrm{H}) \mathrm{H})(\mathrm{H}) \mathrm{H})(\mathrm{H}) \mathrm{F})(\mathrm{F}) \mathrm{F})(\mathrm{F}) \mathrm{H})(\mathrm{H}) \mathrm{H})(\mathrm{H}) \mathrm{H})(\mathrm{H}) \mathrm{Cl})(\mathrm{H}) \mathrm{H})(\mathrm{H}) \mathrm{F})(\mathrm{Br}){ }_{\mathrm{C} 13 \mathrm{H} 19 \mathrm{ClBrF} 7}\right.$

$\mathrm{H})(\mathrm{H})(\mathrm{F}) \mathrm{H}$

$\mathrm{C}(\mathrm{C}(\mathrm{C}(\mathrm{C}(\mathrm{C}(\mathrm{C}(\mathrm{C}(\mathrm{C}(\mathrm{C}(\mathrm{C}(\mathrm{C}(\mathrm{C}(\mathrm{C}(\mathrm{H})(\mathrm{Br}) \mathrm{H})(\mathrm{H}) \mathrm{H})(\mathrm{H}) \mathrm{F})(\mathrm{H}) \mathrm{H})(\mathrm{F}) \mathrm{H})(\mathrm{H}) \mathrm{H})(\mathrm{H}) \mathrm{H})(\mathrm{H}) \mathrm{H})(\mathrm{F}) \mathrm{F})(\mathrm{H}) \mathrm{H})(\mathrm{H}) \mathrm{H})(\mathrm{F})$

$\mathrm{F})(\mathrm{H})(\mathrm{H}) \mathrm{Br}$

$\mathrm{C}(\mathrm{C}(\mathrm{C}(\mathrm{C}(\mathrm{C}(\mathrm{C}(\mathrm{C}(\mathrm{C}(\mathrm{C}(\mathrm{C}(\mathrm{C}(\mathrm{C}(\mathrm{C}(\mathrm{F})(\mathrm{F}) \mathrm{H})(\mathrm{H}) \mathrm{H})(\mathrm{H}) \mathrm{F})(\mathrm{H}) \mathrm{H})(\mathrm{Br}) \mathrm{H})(\mathrm{F}) \mathrm{H})(\mathrm{F}) \mathrm{H})(\mathrm{H}) \mathrm{H})(\mathrm{H}) \mathrm{H})(\mathrm{H}) \mathrm{Br})(\mathrm{H}) \mathrm{H})$

$(\mathrm{H}) \mathrm{H})(\mathrm{Br})(\mathrm{H}) \mathrm{H}$

$\mathrm{C}(\mathrm{C}(\mathrm{C}(\mathrm{C}(\mathrm{C}(\mathrm{C}(\mathrm{C}(\mathrm{C}(\mathrm{C}(\mathrm{C}(\mathrm{C}(\mathrm{C}(\mathrm{C}(\mathrm{H})(\mathrm{H}) \mathrm{H})(\mathrm{H}) \mathrm{H})(\mathrm{Cl}) \mathrm{H})(\mathrm{H}) \mathrm{Br})(\mathrm{F}) \mathrm{H})(\mathrm{H}) \mathrm{F})(\mathrm{H}) \mathrm{H})(\mathrm{Br}) \mathrm{H})(\mathrm{H}) \mathrm{H})(\mathrm{H}) \mathrm{H})(\mathrm{H}) \mathrm{H})($

$\mathrm{H}) \mathrm{F})(\mathrm{H})(\mathrm{F}) \mathrm{Cl}$

$\mathrm{C}(\mathrm{C}(\mathrm{C}(\mathrm{C}(\mathrm{C}(\mathrm{C}(\mathrm{C}(\mathrm{C}(\mathrm{C}(\mathrm{C}(\mathrm{C}(\mathrm{C}(\mathrm{C}(\mathrm{H})(\mathrm{H}) \mathrm{H})(\mathrm{H}) \mathrm{H})(\mathrm{H}) \mathrm{H})(\mathrm{H}) \mathrm{H})(\mathrm{H}) \mathrm{H})(\mathrm{H}) \mathrm{H})(\mathrm{H}) \mathrm{H})(\mathrm{F}) \mathrm{Cl})(\mathrm{F}) \mathrm{F})(\mathrm{H}) \mathrm{F})(\mathrm{Cl}) \mathrm{H})$

$(\mathrm{Br}) \mathrm{F})(\mathrm{H})(\mathrm{H}) \mathrm{H}$

$\mathrm{C}(\mathrm{C}(\mathrm{C}(\mathrm{C}(\mathrm{C}(\mathrm{C}(\mathrm{C}(\mathrm{C}(\mathrm{C}(\mathrm{C}(\mathrm{C}(\mathrm{C}(\mathrm{C}(\mathrm{F})(\mathrm{H}) \mathrm{F})(\mathrm{F}) \mathrm{H})(\mathrm{F}) \mathrm{H})(\mathrm{H}) \mathrm{H})(\mathrm{H}) \mathrm{Cl})(\mathrm{Cl}) \mathrm{H})(\mathrm{H}) \mathrm{H})(\mathrm{Cl}) \mathrm{H})(\mathrm{Br}) \mathrm{H})(\mathrm{H}) \mathrm{H})(\mathrm{H}) \mathrm{H})($

$\mathrm{H}) \mathrm{H})(\mathrm{H})(\mathrm{H}) \mathrm{H}$

$\mathrm{C}(\mathrm{C}(\mathrm{C}(\mathrm{C}(\mathrm{C}(\mathrm{C}(\mathrm{C}(\mathrm{C}(\mathrm{C}(\mathrm{C}(\mathrm{C}(\mathrm{C}(\mathrm{C}(\mathrm{F})(\mathrm{H}) \mathrm{H})(\mathrm{H}) \mathrm{Cl})(\mathrm{F}) \mathrm{Cl})(\mathrm{H}) \mathrm{F})(\mathrm{H}) \mathrm{Cl})(\mathrm{H}) \mathrm{F})(\mathrm{H}) \mathrm{H})(\mathrm{F}) \mathrm{H})(\mathrm{H}) \mathrm{H})(\mathrm{H}) \mathrm{H})(\mathrm{H}) \mathrm{H})$

$(\mathrm{H}) \mathrm{H})(\mathrm{H})(\mathrm{H}) \mathrm{H}$

$\mathrm{C}(\mathrm{C}(\mathrm{C}(\mathrm{C}(\mathrm{C}(\mathrm{C}(\mathrm{C}(\mathrm{C}(\mathrm{C}(\mathrm{C}(\mathrm{C}(\mathrm{C}(\mathrm{C}(\mathrm{F})(\mathrm{H}) \mathrm{H})(\mathrm{H}) \mathrm{Cl})(\mathrm{H}) \mathrm{Cl})(\mathrm{F}) \mathrm{H})(\mathrm{H}) \mathrm{H})(\mathrm{F}) \mathrm{F})(\mathrm{H}) \mathrm{H})(\mathrm{H}) \mathrm{H})(\mathrm{H}) \mathrm{Cl})(\mathrm{H}) \mathrm{H})(\mathrm{H}) \mathrm{H})$

$(\mathrm{H}) \mathrm{Cl})(\mathrm{H})(\mathrm{H}) \mathrm{H}$

$\mathrm{C}(\mathrm{C}(\mathrm{C}(\mathrm{C}(\mathrm{C}(\mathrm{C}(\mathrm{C}(\mathrm{C}(\mathrm{C}(\mathrm{C}(\mathrm{C}(\mathrm{C}(\mathrm{C}(\mathrm{H})(\mathrm{H}) \mathrm{H})(\mathrm{H}) \mathrm{H})(\mathrm{H}) \mathrm{H})(\mathrm{H}) \mathrm{F})(\mathrm{H}) \mathrm{F})(\mathrm{F}) \mathrm{H})(\mathrm{Cl}) \mathrm{Cl})(\mathrm{H}) \mathrm{H})(\mathrm{Cl}) \mathrm{H})(\mathrm{H}) \mathrm{H})(\mathrm{H}) \mathrm{H})($

$\mathrm{H}) \mathrm{Cl})(\mathrm{H})(\mathrm{Cl}) \mathrm{H}$

$\mathrm{C}(\mathrm{C}(\mathrm{C}(\mathrm{C}(\mathrm{C}(\mathrm{C}(\mathrm{C}(\mathrm{C}(\mathrm{C}(\mathrm{C}(\mathrm{C}(\mathrm{C}(\mathrm{C}(\mathrm{H})(\mathrm{H}) \mathrm{H})(\mathrm{H}) \mathrm{F})(\mathrm{H}) \mathrm{Br})(\mathrm{H}) \mathrm{H})(\mathrm{H}) \mathrm{Cl})(\mathrm{H}) \mathrm{F})(\mathrm{H}) \mathrm{H})(\mathrm{F}) \mathrm{H})(\mathrm{H}) \mathrm{H})(\mathrm{F}) \mathrm{Br})(\mathrm{F}) \mathrm{H})$

$(\mathrm{H}) \mathrm{H})(\mathrm{H})(\mathrm{H}) \mathrm{H}$

$\mathrm{C}(\mathrm{C}(\mathrm{C}(\mathrm{C}(\mathrm{C}(\mathrm{C}(\mathrm{C}(\mathrm{C}(\mathrm{C}(\mathrm{C}(\mathrm{C}(\mathrm{C}(\mathrm{C}(\mathrm{H})(\mathrm{H}) \mathrm{H})(\mathrm{H}) \mathrm{H})(\mathrm{H}) \mathrm{H})(\mathrm{H}) \mathrm{H})(\mathrm{F}) \mathrm{H})(\mathrm{H}) \mathrm{H})(\mathrm{Br}) \mathrm{H})(\mathrm{H}) \mathrm{H})(\mathrm{H}) \mathrm{Br})(\mathrm{F}) \mathrm{F})(\mathrm{H}) \mathrm{H})$

(F)H $(\mathrm{H})(\mathrm{H}) \mathrm{F}$

$\mathrm{C}(\mathrm{C}(\mathrm{C}(\mathrm{C}(\mathrm{C}(\mathrm{C}(\mathrm{C}(\mathrm{C}(\mathrm{C}(\mathrm{C}(\mathrm{C}(\mathrm{C}(\mathrm{C}(\mathrm{F})(\mathrm{H}) \mathrm{H})(\mathrm{H}) \mathrm{Br})(\mathrm{H}) \mathrm{F})(\mathrm{H}) \mathrm{H})(\mathrm{H}) \mathrm{H})(\mathrm{H}) \mathrm{H})(\mathrm{H}) \mathrm{H})(\mathrm{F}) \mathrm{Br})(\mathrm{H}) \mathrm{H})(\mathrm{H}) \mathrm{H})(\mathrm{H}) \mathrm{H})($

$\mathrm{H}) \mathrm{H})(\mathrm{Br})(\mathrm{F}) \mathrm{H}$

$\mathrm{C}(\mathrm{C}(\mathrm{C}(\mathrm{C}(\mathrm{C}(\mathrm{C}(\mathrm{C}(\mathrm{C}(\mathrm{C}(\mathrm{C}(\mathrm{C}(\mathrm{C}(\mathrm{C}(\mathrm{Cl})(\mathrm{H}) \mathrm{H})(\mathrm{H}) \mathrm{Br})(\mathrm{H}) \mathrm{H})(\mathrm{H}) \mathrm{H})(\mathrm{H}) \mathrm{H})(\mathrm{H}) \mathrm{H})(\mathrm{H}) \mathrm{F})(\mathrm{H}) \mathrm{Br})(\mathrm{H}) \mathrm{F})(\mathrm{H}) \mathrm{F})(\mathrm{H}) \mathrm{Cl})($ $\mathrm{H}) \mathrm{H})(\mathrm{H})(\mathrm{H}) \mathrm{H}$

$\mathrm{C}(\mathrm{C}(\mathrm{C}(\mathrm{C}(\mathrm{C}(\mathrm{C}(\mathrm{C}(\mathrm{C}(\mathrm{C}(\mathrm{C}(\mathrm{C}(\mathrm{C}(\mathrm{C}(\mathrm{H})(\mathrm{H}) \mathrm{H})(\mathrm{H}) \mathrm{H})(\mathrm{H}) \mathrm{F})(\mathrm{Cl}) \mathrm{H})(\mathrm{H}) \mathrm{H})(\mathrm{H}) \mathrm{H})(\mathrm{H}) \mathrm{H})(\mathrm{F}) \mathrm{H})(\mathrm{Br}) \mathrm{H})(\mathrm{H}) \mathrm{H})(\mathrm{H}) \mathrm{F})$

(F) $\mathrm{H})(\mathrm{H})(\mathrm{H}) \mathrm{Cl}$

$\mathrm{C}(\mathrm{C}(\mathrm{C}(\mathrm{C}(\mathrm{C}(\mathrm{C}(\mathrm{C}(\mathrm{C}(\mathrm{C}(\mathrm{C}(\mathrm{C}(\mathrm{C}(\mathrm{C}(\mathrm{F})(\mathrm{H}) \mathrm{H})(\mathrm{H}) \mathrm{H})(\mathrm{H}) \mathrm{Cl})(\mathrm{Cl}) \mathrm{F})(\mathrm{H}) \mathrm{H})(\mathrm{H}) \mathrm{H})(\mathrm{F}) \mathrm{F})(\mathrm{H}) \mathrm{H})(\mathrm{H}) \mathrm{H})(\mathrm{H}) \mathrm{H})(\mathrm{H}) \mathrm{H})$

$(\mathrm{H}) \mathrm{H})(\mathrm{H})(\mathrm{F}) \mathrm{H}$

$\mathrm{C}(\mathrm{C}(\mathrm{C}(\mathrm{C}(\mathrm{C}(\mathrm{C}(\mathrm{C}(\mathrm{C}(\mathrm{C}(\mathrm{C}(\mathrm{C}(\mathrm{C}(\mathrm{C}(\mathrm{H})(\mathrm{H}) \mathrm{H})(\mathrm{H}) \mathrm{Cl})(\mathrm{F}) \mathrm{Cl})(\mathrm{Br}) \mathrm{H})(\mathrm{H}) \mathrm{H})(\mathrm{H}) \mathrm{H})(\mathrm{H}) \mathrm{Cl})(\mathrm{H}) \mathrm{H})(\mathrm{H}) \mathrm{H})(\mathrm{F}) \mathrm{H})(\mathrm{H}) \mathrm{H})($

$\mathrm{H}) \mathrm{H})(\mathrm{H})(\mathrm{F}) \mathrm{H}$

$\mathrm{C}(\mathrm{C}(\mathrm{C}(\mathrm{C}(\mathrm{C}(\mathrm{C}(\mathrm{C}(\mathrm{C}(\mathrm{C}(\mathrm{C}(\mathrm{C}(\mathrm{C}(\mathrm{C}(\mathrm{H})(\mathrm{H}) \mathrm{H})(\mathrm{H}) \mathrm{F})(\mathrm{H}) \mathrm{Cl})(\mathrm{H}) \mathrm{H})(\mathrm{H}) \mathrm{H})(\mathrm{H}) \mathrm{H})(\mathrm{H}) \mathrm{H})(\mathrm{H}) \mathrm{H})(\mathrm{H}) \mathrm{F})(\mathrm{H}) \mathrm{Cl})(\mathrm{H}) \mathrm{H})($

$\mathrm{H}) \mathrm{F})(\mathrm{H})(\mathrm{F}) \mathrm{Cl}$

$\mathrm{C}(\mathrm{C}(\mathrm{C}(\mathrm{C}(\mathrm{C}(\mathrm{C}(\mathrm{C}(\mathrm{C}(\mathrm{C}(\mathrm{C}(\mathrm{C}(\mathrm{C}(\mathrm{C}(\mathrm{H})(\mathrm{F}) \mathrm{H})(\mathrm{H}) \mathrm{H})(\mathrm{F}) \mathrm{F})(\mathrm{H}) \mathrm{H})(\mathrm{H}) \mathrm{Cl})(\mathrm{H}) \mathrm{H})(\mathrm{H}) \mathrm{H})(\mathrm{H}) \mathrm{Cl})(\mathrm{H}) \mathrm{H})(\mathrm{H}) \mathrm{H})(\mathrm{H}) \mathrm{H})$

$(\mathrm{H}) \mathrm{Cl})(\mathrm{Cl})(\mathrm{H}) \mathrm{H}$

$\mathrm{C}\left(\mathrm{C}(\mathrm{C}(\mathrm{C}(\mathrm{C}(\mathrm{C}(\mathrm{C}(\mathrm{C}(\mathrm{C}(\mathrm{C}(\mathrm{C}(\mathrm{C}(\mathrm{C}(\mathrm{Cl})(\mathrm{H}) \mathrm{Cl})(\mathrm{H}) \mathrm{H})(\mathrm{Cl}) \mathrm{H})(\mathrm{H}) \mathrm{H})(\mathrm{H}) \mathrm{H})(\mathrm{H}) \mathrm{H})(\mathrm{H}) \mathrm{H})(\mathrm{H}) \mathrm{H})(\mathrm{H}) \mathrm{H})(\mathrm{H}) \mathrm{Cl})(\mathrm{F}) \mathrm{H})\left({ }_{\mathrm{Cl}} \mathrm{H}_{2} 1 \mathrm{Cl}^{2} \mathrm{~F} 2\right.\right.$

$\mathrm{H}) \mathrm{H})(\mathrm{Cl})(\mathrm{H}) \mathrm{F}$

$\mathrm{C}(\mathrm{C}(\mathrm{C}(\mathrm{C}(\mathrm{C}(\mathrm{C}(\mathrm{C}(\mathrm{C}(\mathrm{C}(\mathrm{C}(\mathrm{C}(\mathrm{C}(\mathrm{C}(\mathrm{H})(\mathrm{H}) \mathrm{H})(\mathrm{H}) \mathrm{H})(\mathrm{H}) \mathrm{Br})(\mathrm{H}) \mathrm{H})(\mathrm{H}) \mathrm{H})(\mathrm{H}) \mathrm{H})(\mathrm{H}) \mathrm{F})(\mathrm{Br}) \mathrm{H})(\mathrm{Cl}) \mathrm{H})(\mathrm{F}) \mathrm{H})(\mathrm{H}) \mathrm{H})($

F) $\mathrm{H})(\mathrm{F})(\mathrm{H}) \mathrm{H}$

$\mathrm{C}(\mathrm{C}(\mathrm{C}(\mathrm{C}(\mathrm{C}(\mathrm{C}(\mathrm{C}(\mathrm{C}(\mathrm{C}(\mathrm{C}(\mathrm{C}(\mathrm{C}(\mathrm{C}(\mathrm{F})(\mathrm{H}) \mathrm{F})(\mathrm{H}) \mathrm{H})(\mathrm{H}) \mathrm{Br})(\mathrm{H}) \mathrm{H})(\mathrm{F}) \mathrm{Cl})(\mathrm{F}) \mathrm{F})(\mathrm{H}) \mathrm{H})(\mathrm{H}) \mathrm{H})(\mathrm{H}) \mathrm{H})(\mathrm{H}) \mathrm{H})(\mathrm{H}) \mathrm{H})(\mathrm{H})$

$\mathrm{H})(\mathrm{H})(\mathrm{H}) \mathrm{H}$

$\mathrm{C}(\mathrm{C}(\mathrm{C}(\mathrm{C}(\mathrm{C}(\mathrm{C}(\mathrm{C}(\mathrm{C}(\mathrm{C}(\mathrm{C}(\mathrm{C}(\mathrm{C}(\mathrm{C}(\mathrm{Br})(\mathrm{H}) \mathrm{H})(\mathrm{Br}) \mathrm{H})(\mathrm{H}) \mathrm{H})(\mathrm{H}) \mathrm{H})(\mathrm{H}) \mathrm{H})(\mathrm{H}) \mathrm{H})(\mathrm{H}) \mathrm{H})(\mathrm{H}) \mathrm{F})(\mathrm{H}) \mathrm{H})(\mathrm{H}) \mathrm{H})(\mathrm{H}) \mathrm{H})($

$\mathrm{F}) \mathrm{H})(\mathrm{F})(\mathrm{F}) \mathrm{H}$

$\mathrm{C}(\mathrm{C}(\mathrm{C}(\mathrm{C}(\mathrm{C}(\mathrm{C}(\mathrm{C}(\mathrm{C}(\mathrm{C}(\mathrm{C}(\mathrm{C}(\mathrm{C}(\mathrm{C}(\mathrm{H})(\mathrm{H}) \mathrm{H})(\mathrm{H}) \mathrm{H})(\mathrm{Cl}) \mathrm{H})(\mathrm{H}) \mathrm{H})(\mathrm{H}) \mathrm{H})(\mathrm{H}) \mathrm{F})(\mathrm{H}) \mathrm{Br})(\mathrm{H}) \mathrm{F})(\mathrm{H}) \mathrm{H})(\mathrm{H}) \mathrm{F})(\mathrm{H}) \mathrm{H})$

$(\mathrm{H}) \mathrm{H})(\mathrm{Cl})(\mathrm{H}) \mathrm{H}$

$\mathrm{C}(\mathrm{C}(\mathrm{C}(\mathrm{C}(\mathrm{C}(\mathrm{C}(\mathrm{C}(\mathrm{C}(\mathrm{C}(\mathrm{C}(\mathrm{C}(\mathrm{C}(\mathrm{C}(\mathrm{H})(\mathrm{H}) \mathrm{Cl})(\mathrm{H}) \mathrm{F})(\mathrm{H}) \mathrm{F})(\mathrm{H}) \mathrm{H})(\mathrm{F}) \mathrm{H})(\mathrm{Cl}) \mathrm{H})(\mathrm{H}) \mathrm{H})(\mathrm{H}) \mathrm{H})(\mathrm{H}) \mathrm{H})(\mathrm{H}) \mathrm{H})(\mathrm{H}) \mathrm{H})$

$(\mathrm{H}) \mathrm{H})(\mathrm{H})(\mathrm{F}) \mathrm{H}$

$\mathrm{C}(\mathrm{C}(\mathrm{C}(\mathrm{C}(\mathrm{C}(\mathrm{C}(\mathrm{C}(\mathrm{C}(\mathrm{C}(\mathrm{C}(\mathrm{C}(\mathrm{C}(\mathrm{C}(\mathrm{H})(\mathrm{H}) \mathrm{H})(\mathrm{Cl}) \mathrm{F})(\mathrm{H}) \mathrm{F})(\mathrm{Cl}) \mathrm{H})(\mathrm{H}) \mathrm{H})(\mathrm{H}) \mathrm{F})(\mathrm{H}) \mathrm{H})(\mathrm{H}) \mathrm{H})(\mathrm{H}) \mathrm{H})(\mathrm{H}) \mathrm{H})(\mathrm{H}) \mathrm{H})$

(H)H)(Cl)(H)H

$\mathrm{C}(\mathrm{C}(\mathrm{C}(\mathrm{C}(\mathrm{C}(\mathrm{C}(\mathrm{C}(\mathrm{C}(\mathrm{C}(\mathrm{C}(\mathrm{C}(\mathrm{C}(\mathrm{C}(\mathrm{H})(\mathrm{H}) \mathrm{H})(\mathrm{H}) \mathrm{H})(\mathrm{H}) \mathrm{H})(\mathrm{F}) \mathrm{H})(\mathrm{H}) \mathrm{Cl})(\mathrm{H}) \mathrm{H})(\mathrm{Cl}) \mathrm{H})(\mathrm{H}) \mathrm{F})(\mathrm{H}) \mathrm{H})(\mathrm{H}) \mathrm{H})(\mathrm{H}) \mathrm{H})(\mathrm{C}$ 1) $\mathrm{H})(\mathrm{Cl})(\mathrm{H}) \mathrm{H}$

$\mathrm{C}(\mathrm{C}(\mathrm{C}(\mathrm{C}(\mathrm{C}(\mathrm{C}(\mathrm{C}(\mathrm{C}(\mathrm{C}(\mathrm{C}(\mathrm{C}(\mathrm{C}(\mathrm{C}(\mathrm{Cl})(\mathrm{H}) \mathrm{F})(\mathrm{H}) \mathrm{H})(\mathrm{H}) \mathrm{H})(\mathrm{H}) \mathrm{H})(\mathrm{Br}) \mathrm{H})(\mathrm{H}) \mathrm{H})(\mathrm{F}) \mathrm{Br})(\mathrm{H}) \mathrm{H})(\mathrm{H}) \mathrm{H})(\mathrm{H}) \mathrm{H})(\mathrm{H}) \mathrm{H})($ $\mathrm{H}) \mathrm{F})(\mathrm{H})(\mathrm{H}) \mathrm{H}$

$\mathrm{C}(\mathrm{C}(\mathrm{C}(\mathrm{C}(\mathrm{C}(\mathrm{C}(\mathrm{C}(\mathrm{C}(\mathrm{C}(\mathrm{C}(\mathrm{C}(\mathrm{C}(\mathrm{C}(\mathrm{H})(\mathrm{H}) \mathrm{H})(\mathrm{H}) \mathrm{H})(\mathrm{H}) \mathrm{F})(\mathrm{Cl}) \mathrm{H})(\mathrm{H}) \mathrm{H})(\mathrm{F}) \mathrm{H})(\mathrm{H}) \mathrm{F})(\mathrm{H}) \mathrm{H})(\mathrm{H}) \mathrm{H})(\mathrm{H}) \mathrm{H})(\mathrm{Br}) \mathrm{F})$

$(\mathrm{H}) \mathrm{H})(\mathrm{H})(\mathrm{H}) \mathrm{H}$

$\mathrm{C}(\mathrm{C}(\mathrm{C}(\mathrm{C}(\mathrm{C}(\mathrm{C}(\mathrm{C}(\mathrm{C}(\mathrm{C}(\mathrm{C}(\mathrm{C}(\mathrm{C}(\mathrm{C}(\mathrm{H})(\mathrm{F}) \mathrm{H})(\mathrm{H}) \mathrm{H})(\mathrm{Br}) \mathrm{H})(\mathrm{H}) \mathrm{Br})(\mathrm{H}) \mathrm{H})(\mathrm{H}) \mathrm{H})(\mathrm{F}) \mathrm{F})(\mathrm{H}) \mathrm{H})(\mathrm{H}) \mathrm{H})(\mathrm{H}) \mathrm{H})(\mathrm{H}) \mathrm{H})($

$\mathrm{H}) \mathrm{H})(\mathrm{H})(\mathrm{H}) \mathrm{H}$

$\mathrm{C}(\mathrm{C}(\mathrm{C}(\mathrm{C}(\mathrm{C}(\mathrm{C}(\mathrm{C}(\mathrm{C}(\mathrm{C}(\mathrm{C}(\mathrm{C}(\mathrm{C}(\mathrm{C}(\mathrm{F})(\mathrm{H}) \mathrm{H})(\mathrm{H}) \mathrm{H})(\mathrm{H}) \mathrm{H})(\mathrm{H}) \mathrm{H})(\mathrm{H}) \mathrm{Cl})(\mathrm{H}) \mathrm{Cl})(\mathrm{H}) \mathrm{H})(\mathrm{Br}) \mathrm{H})(\mathrm{H}) \mathrm{H})(\mathrm{H}) \mathrm{H})(\mathrm{H}) \mathrm{H})($ $\mathrm{H}) \mathrm{H})(\mathrm{H})(\mathrm{H}) \mathrm{F}$
lgKoa lgKow lgKaw lgKow lgKoa lgKa lgKow lgKoa lgKaw EPISuit EPI EPI Exp Exp w DFT DFT DFT e Suite Suite corr_corr_Exp corr_corr _corr $\begin{array}{lllllllll}4.98 & 7.15 & 2.17 & 5.75 & 3.58 & 2.17 & 6.25 & 7.16 & -0.91\end{array}$ $\begin{array}{lllllllll}7.436 & 8.37 & 0.93 & 7.57 & 6.63 & 0.93 & 7.19 & 11.67 & -4.48\end{array}$ $\begin{array}{lllllllll}7.035 & 7.7 & 0.66 & 6.57 & 5.90 & 0.66 & 6.68 & 10.94 & -4.26\end{array}$ $\begin{array}{lllllllll}6.286 & 8.19 & 1.90 & 7.30 & 5.39 & 1.90 & 7.05 & 9.56 & -2.5\end{array}$

$\begin{array}{lllllllll}4.5 & 7.64 & 3.14 & 6.48 & 3.34 & 3.14 & 6.63 & 6.28 & 0.35\end{array}$

$\begin{array}{lllllllll}7.505 & 7.42 & -0.09 & 6.15 & 6.23 & -0.09 & 6.46 & 11.80 & -5.34\end{array}$

$\begin{array}{lllllllll}6.608 & 7.76 & 1.15 & 6.66 & 5.50 & 1.15 & 6.72 & 10.15 & -3.43\end{array}$

$\begin{array}{lllllllll}4.972 & 7.36 & 2.39 & 6.06 & 3.67 & 2.39 & 6.41 & 7.15 & -0.73\end{array}$

$\begin{array}{lllllllll}5.293 & 6.93 & 1.64 & 5.42 & 3.78 & 1.64 & 6.08 & 7.74 & -1.65\end{array}$

$\begin{array}{lllllllll}7.024 & 7.91 & 0.89 & 6.88 & 5.99 & 0.89 & 6.84 & 10.92 & -4.08\end{array}$

$\begin{array}{lllllllll}6.712 & 8.13 & 1.42 & 7.21 & 5.79 & 1.42 & 7.01 & 10.34 & -3.34\end{array}$

$\begin{array}{lllllllll}7.019 & 7.2 & 0.18 & 5.82 & 5.64 & 0.18 & 6.29 & 10.91 & -4.61\end{array}$

$\begin{array}{lllllllll}4.473 & 7.13 & 2.66 & 5.72 & 3.06 & 2.66 & 6.24 & 6.23 & 0.01\end{array}$

$\begin{array}{lllllllll}6.228 & 8.1 & 1.87 & 7.16 & 5.29 & 1.87 & 6.98 & 9.45 & -2.47\end{array}$

$\begin{array}{lllllllll}6.387 & 7.02 & 0.63 & 5.55 & 4.92 & 0.63 & 6.15 & 9.75 & -3.59\end{array}$

$\begin{array}{lllllllll}6.803 & 7.17 & 0.37 & 5.78 & 5.41 & 0.37 & 6.27 & 10.51 & -4.24\end{array}$

$\begin{array}{lllllllll}7.305 & 8.91 & 1.60 & 8.37 & 6.77 & 1.60 & 7.61 & 11.43 & -3.83\end{array}$

$\begin{array}{lllllllll}6.228 & 7.08 & 0.85 & 5.64 & 4.79 & 0.85 & 6.20 & 9.45 & -3.25\end{array}$

$\begin{array}{lllllllll}5.33 & 7.42 & 2.09 & 6.15 & 4.06 & 2.09 & 6.46 & 7.80 & -1.34\end{array}$

$\begin{array}{lllllllll}6.393 & 7.73 & 1.34 & 6.61 & 5.27 & 1.34 & 6.70 & 9.76 & -3.06\end{array}$

$\begin{array}{lllllllll}7.454 & 8.04 & 0.59 & 7.07 & 6.49 & 0.59 & 6.94 & 11.70 & -4.77\end{array}$

$\begin{array}{lllllllll}6.401 & 7.52 & 1.12 & 6.30 & 5.18 & 1.12 & 6.54 & 9.77 & -3.23\end{array}$

$\begin{array}{lllllllll}5.848 & 7.42 & 1.57 & 6.15 & 4.58 & 1.57 & 6.46 & 8.75 & -2.29\end{array}$

$\begin{array}{lllllllll}7.555 & 7.89 & 0.33 & 6.85 & 6.52 & 0.33 & 6.82 & 11.89 & -5.07\end{array}$

$\begin{array}{lllllllll}7.232 & 7.3 & 0.07 & 5.97 & 5.90 & 0.07 & 6.37 & 11.30 & -4.93\end{array}$

$\begin{array}{lllllllll}5.595 & 6.9 & 1.31 & 5.37 & 4.07 & 1.31 & 6.06 & 8.29 & -2.23\end{array}$

$\begin{array}{lllllllll}5.507 & 8.05 & 2.54 & 7.09 & 4.55 & 2.54 & 6.94 & 8.13 & -1.18\end{array}$

$\begin{array}{lllllllll}7.396 & 7.95 & 0.55 & 6.94 & 6.39 & 0.55 & 6.87 & 11.60 & -4.73\end{array}$

$\begin{array}{lllllllll}5.019 & 6.81 & 1.79 & 5.24 & 3.45 & 1.79 & 5.99 & 7.23 & -1.24\end{array}$

$\begin{array}{lllllllll}6.9 & 7.94 & 1.04 & 6.93 & 5.89 & 1.04 & 6.86 & 10.69 & -3.83\end{array}$

$\begin{array}{lllllllll}7.223 & 7.51 & 0.29 & 6.28 & 6.00 & 0.29 & 6.53 & 11.28 & -4.75\end{array}$

$\begin{array}{lllllllll}6.169 & 6.99 & 0.82 & 5.51 & 4.69 & 0.82 & 6.13 & 9.34 & -3.21\end{array}$

$\begin{array}{lllllllll}6.013 & 8.07 & 2.06 & 7.12 & 5.06 & 2.06 & 6.96 & 9.06 & -2.10\end{array}$

$\begin{array}{lllllllll}5.607 & 6.88 & 1.27 & 5.34 & 4.07 & 1.27 & 6.05 & 8.31 & -2.27\end{array}$

$\begin{array}{lllllllll}6.022 & 7.03 & 1.01 & 5.57 & 4.56 & 1.01 & 6.16 & 9.07 & -2.91\end{array}$

$\begin{array}{lllllllll}4.456 & 6.7 & 2.24 & 5.07 & 2.83 & 2.24 & 5.91 & 6.20 & -0.29\end{array}$

$\begin{array}{lllllllll}6.188 & 7.68 & 1.49 & 6.54 & 5.05 & 1.49 & 6.66 & 9.38 & -2.72\end{array}$

$\begin{array}{lllllllll}6.518 & 7.26 & 0.74 & 5.91 & 5.17 & 0.74 & 6.34 & 9.99 & -3.65\end{array}$

$\begin{array}{lllllllll}7.338 & 7.86 & 0.52 & 6.81 & 6.28 & 0.52 & 6.80 & 11.49 & -4.69\end{array}$

$\begin{array}{lllllllll}5.632 & 7.39 & 1.76 & 6.10 & 4.35 & 1.76 & 6.44 & 8.36 & -1.92\end{array}$

$\begin{array}{lllllllll}6.705 & 7.68 & 0.98 & 6.54 & 5.56 & 0.98 & 6.66 & 10.33 & -3.67\end{array}$

$\begin{array}{lllllllll}6.532 & 7.24 & 0.71 & 5.88 & 5.17 & 0.71 & 6.32 & 10.01 & -3.69\end{array}$ 
SMILE Generated

$\mathrm{C}(\mathrm{C}(\mathrm{C}(\mathrm{C}(\mathrm{C}(\mathrm{C}(\mathrm{C}(\mathrm{C}(\mathrm{C}(\mathrm{C}(\mathrm{C}(\mathrm{C}(\mathrm{C}(\mathrm{H})(\mathrm{H}) \mathrm{H})(\mathrm{Cl}) \mathrm{Cl})(\mathrm{H}) \mathrm{H})(\mathrm{H}) \mathrm{H})(\mathrm{H}) \mathrm{H})(\mathrm{H}) \mathrm{H})(\mathrm{F}) \mathrm{F})(\mathrm{H}) \mathrm{F})(\mathrm{H}) \mathrm{H})(\mathrm{H}) \mathrm{H})(\mathrm{H}) \mathrm{H})$ $(\mathrm{H}) \mathrm{H})(\mathrm{H})(\mathrm{H}) \mathrm{H}$

$\mathrm{C}(\mathrm{C}(\mathrm{C}(\mathrm{C}(\mathrm{C}(\mathrm{C}(\mathrm{C}(\mathrm{C}(\mathrm{C}(\mathrm{C}(\mathrm{C}(\mathrm{C}(\mathrm{C}(\mathrm{H})(\mathrm{H}) \mathrm{H})(\mathrm{H}) \mathrm{Cl})(\mathrm{Cl}) \mathrm{H})(\mathrm{H}) \mathrm{H})(\mathrm{H}) \mathrm{H})(\mathrm{H}) \mathrm{H})(\mathrm{H}) \mathrm{H})(\mathrm{H}) \mathrm{H})(\mathrm{H}) \mathrm{Br})(\mathrm{H}) \mathrm{F})(\mathrm{H}) \mathrm{H})($ $\mathrm{H}) \mathrm{H})(\mathrm{Cl})(\mathrm{H}) \mathrm{H}$

$\mathrm{C}(\mathrm{C}(\mathrm{C}(\mathrm{C}(\mathrm{C}(\mathrm{C}(\mathrm{C}(\mathrm{C}(\mathrm{C}(\mathrm{C}(\mathrm{C}(\mathrm{C}(\mathrm{C}(\mathrm{H})(\mathrm{H}) \mathrm{H})(\mathrm{H}) \mathrm{H})(\mathrm{H}) \mathrm{H})(\mathrm{H}) \mathrm{H})(\mathrm{F}) \mathrm{H})(\mathrm{H}) \mathrm{Cl})(\mathrm{H}) \mathrm{H})(\mathrm{F}) \mathrm{H})(\mathrm{H}) \mathrm{H})(\mathrm{H}) \mathrm{H})(\mathrm{H}) \mathrm{H})$ $(\mathrm{H}) \mathrm{Cl})(\mathrm{H})(\mathrm{Cl}) \mathrm{H}$

$\mathrm{C}(\mathrm{C}(\mathrm{C}(\mathrm{C}(\mathrm{C}(\mathrm{C}(\mathrm{C}(\mathrm{C}(\mathrm{C}(\mathrm{C}(\mathrm{C}(\mathrm{C}(\mathrm{C}(\mathrm{H})(\mathrm{H}) \mathrm{H})(\mathrm{Cl}) \mathrm{H})(\mathrm{H}) \mathrm{H})(\mathrm{H}) \mathrm{H})(\mathrm{Cl}) \mathrm{H})(\mathrm{H}) \mathrm{H})(\mathrm{H}) \mathrm{H})(\mathrm{H}) \mathrm{H})(\mathrm{H}) \mathrm{H})(\mathrm{H}) \mathrm{H})(\mathrm{H}) \mathrm{H})($ $\mathrm{H}) \mathrm{Cl}(\mathrm{H})(\mathrm{F}) \mathrm{Cl}$

C(C(C(C(C(C(C(C(C(C(C(C(C(Br)(H)H)(H)H)(H)F)(H)H)(Br)H)(H)H)(H)H)(H)H)(H)H)(Cl)H)(H)H)( F) $\mathrm{H})(\mathrm{H})(\mathrm{H}) \mathrm{H}$

$\mathrm{C}(\mathrm{C}(\mathrm{C}(\mathrm{C}(\mathrm{C}(\mathrm{C}(\mathrm{C}(\mathrm{C}(\mathrm{C}(\mathrm{C}(\mathrm{C}(\mathrm{C}(\mathrm{C}(\mathrm{H})(\mathrm{H}) \mathrm{Cl})(\mathrm{H}) \mathrm{F})(\mathrm{H}) \mathrm{H})(\mathrm{H}) \mathrm{H})(\mathrm{H}) \mathrm{H})(\mathrm{Br}) \mathrm{F})(\mathrm{H}) \mathrm{H})(\mathrm{H}) \mathrm{H})(\mathrm{F}) \mathrm{H})(\mathrm{H}) \mathrm{H})(\mathrm{H}) \mathrm{H})$ $(\mathrm{H}) \mathrm{H})(\mathrm{H})(\mathrm{H}) \mathrm{H}$

$\mathrm{C}(\mathrm{C}(\mathrm{C}(\mathrm{C}(\mathrm{C}(\mathrm{C}(\mathrm{C}(\mathrm{C}(\mathrm{C}(\mathrm{C}(\mathrm{C}(\mathrm{C}(\mathrm{C}(\mathrm{H})(\mathrm{H}) \mathrm{F})(\mathrm{H}) \mathrm{H})(\mathrm{H}) \mathrm{H})(\mathrm{H}) \mathrm{H})(\mathrm{H}) \mathrm{H})(\mathrm{H}) \mathrm{H})(\mathrm{H}) \mathrm{H})(\mathrm{H}) \mathrm{H})(\mathrm{H}) \mathrm{H})(\mathrm{H}) \mathrm{H})(\mathrm{H}) \mathrm{Br})$ $(\mathrm{F}) \mathrm{Br})(\mathrm{H})(\mathrm{H}) \mathrm{H}$

$\mathrm{C}(\mathrm{C}(\mathrm{C}(\mathrm{C}(\mathrm{C}(\mathrm{C}(\mathrm{C}(\mathrm{C}(\mathrm{C}(\mathrm{C}(\mathrm{C}(\mathrm{C}(\mathrm{C}(\mathrm{H})(\mathrm{H}) \mathrm{H})(\mathrm{H}) \mathrm{H})(\mathrm{F}) \mathrm{Br})(\mathrm{H}) \mathrm{H})(\mathrm{H}) \mathrm{H})(\mathrm{F}) \mathrm{H})(\mathrm{H}) \mathrm{H})(\mathrm{H}) \mathrm{H})(\mathrm{H}) \mathrm{H})(\mathrm{H}) \mathrm{H})(\mathrm{H}) \mathrm{H})$ (F)H $(\mathrm{H})(\mathrm{H}) \mathrm{H}$

$\mathrm{C}(\mathrm{C}(\mathrm{C}(\mathrm{C}(\mathrm{C}(\mathrm{C}(\mathrm{C}(\mathrm{C}(\mathrm{C}(\mathrm{C}(\mathrm{C}(\mathrm{C}(\mathrm{C}(\mathrm{H})(\mathrm{H}) \mathrm{H})(\mathrm{H}) \mathrm{H})(\mathrm{F}) \mathrm{Br})(\mathrm{H}) \mathrm{Cl})(\mathrm{H}) \mathrm{H})(\mathrm{H}) \mathrm{H})(\mathrm{H}) \mathrm{H})(\mathrm{H}) \mathrm{H})(\mathrm{Cl}) \mathrm{H})(\mathrm{H}) \mathrm{H})(\mathrm{H}) \mathrm{H})($

$\mathrm{H}) \mathrm{H})(\mathrm{H})(\mathrm{H}) \mathrm{H}$

$\mathrm{C}(\mathrm{C}(\mathrm{C}(\mathrm{C}(\mathrm{C}(\mathrm{C}(\mathrm{C}(\mathrm{C}(\mathrm{C}(\mathrm{C}(\mathrm{C}(\mathrm{C}(\mathrm{C}(\mathrm{H})(\mathrm{H}) \mathrm{H})(\mathrm{H}) \mathrm{H})(\mathrm{F}) \mathrm{H})(\mathrm{H}) \mathrm{Cl})(\mathrm{F}) \mathrm{H})(\mathrm{H}) \mathrm{H})(\mathrm{H}) \mathrm{H})(\mathrm{Cl}) \mathrm{H})(\mathrm{H}) \mathrm{H})(\mathrm{H}) \mathrm{H})(\mathrm{H}) \mathrm{H})($

$\mathrm{H}) \mathrm{H})(\mathrm{H})(\mathrm{H}) \mathrm{H}$

$\mathrm{C}(\mathrm{C}(\mathrm{C}(\mathrm{C}(\mathrm{C}(\mathrm{C}(\mathrm{C}(\mathrm{C}(\mathrm{C}(\mathrm{C}(\mathrm{C}(\mathrm{C}(\mathrm{C}(\mathrm{H})(\mathrm{H}) \mathrm{H})(\mathrm{H}) \mathrm{H})(\mathrm{H}) \mathrm{H})(\mathrm{H}) \mathrm{H})(\mathrm{H}) \mathrm{H})(\mathrm{H}) \mathrm{H})(\mathrm{H}) \mathrm{H})(\mathrm{H}) \mathrm{H})(\mathrm{H}) \mathrm{H})(\mathrm{H}) \mathrm{H})(\mathrm{F}) \mathrm{Cl})($

$\mathrm{H}) \mathrm{Cl})(\mathrm{H})(\mathrm{H}) \mathrm{Cl}$

$\mathrm{C}(\mathrm{C}(\mathrm{C}(\mathrm{C}(\mathrm{C}(\mathrm{C}(\mathrm{C}(\mathrm{C}(\mathrm{C}(\mathrm{C}(\mathrm{C}(\mathrm{C}(\mathrm{C}(\mathrm{H})(\mathrm{H}) \mathrm{Cl})(\mathrm{H}) \mathrm{H})(\mathrm{H}) \mathrm{Cl})(\mathrm{H}) \mathrm{H})(\mathrm{H}) \mathrm{H})(\mathrm{H}) \mathrm{H})(\mathrm{H}) \mathrm{H})(\mathrm{H}) \mathrm{H})(\mathrm{Cl}) \mathrm{H})(\mathrm{Cl}) \mathrm{H})(\mathrm{H}) \mathrm{H})$

$(\mathrm{H}) \mathrm{H})(\mathrm{H})(\mathrm{H}) \mathrm{H}$

$\mathrm{C}(\mathrm{C}(\mathrm{C}(\mathrm{C}(\mathrm{C}(\mathrm{C}(\mathrm{C}(\mathrm{C}(\mathrm{C}(\mathrm{C}(\mathrm{C}(\mathrm{C}(\mathrm{C}(\mathrm{H})(\mathrm{H}) \mathrm{H})(\mathrm{H}) \mathrm{H})(\mathrm{H}) \mathrm{H})(\mathrm{H}) \mathrm{H})(\mathrm{H}) \mathrm{H})(\mathrm{H}) \mathrm{Br})(\mathrm{H}) \mathrm{Cl})(\mathrm{H}) \mathrm{F})(\mathrm{H}) \mathrm{H})(\mathrm{H}) \mathrm{Br})(\mathrm{H}) \mathrm{H})($

$\mathrm{H}) \mathrm{H})(\mathrm{H})(\mathrm{H}) \mathrm{H}$

$\mathrm{C}(\mathrm{C}(\mathrm{C}(\mathrm{C}(\mathrm{C}(\mathrm{C}(\mathrm{C}(\mathrm{C}(\mathrm{C}(\mathrm{C}(\mathrm{C}(\mathrm{C}(\mathrm{C}(\mathrm{H})(\mathrm{H}) \mathrm{H})(\mathrm{H}) \mathrm{H})(\mathrm{Br}) \mathrm{H})(\mathrm{H}) \mathrm{H})(\mathrm{H}) \mathrm{H})(\mathrm{H}) \mathrm{H})(\mathrm{H}) \mathrm{H})(\mathrm{F}) \mathrm{H})(\mathrm{H}) \mathrm{H})(\mathrm{H}) \mathrm{H})(\mathrm{H}) \mathrm{H})($

$\mathrm{Cl}) \mathrm{H})(\mathrm{F})(\mathrm{H}) \mathrm{H}$

$\mathrm{C}(\mathrm{C}(\mathrm{C}(\mathrm{C}(\mathrm{C}(\mathrm{C}(\mathrm{C}(\mathrm{C}(\mathrm{C}(\mathrm{C}(\mathrm{C}(\mathrm{C}(\mathrm{C}(\mathrm{H})(\mathrm{Br}) \mathrm{H})(\mathrm{H}) \mathrm{H})(\mathrm{H}) \mathrm{H})(\mathrm{H}) \mathrm{H})(\mathrm{H}) \mathrm{H})(\mathrm{H}) \mathrm{H})(\mathrm{H}) \mathrm{H})(\mathrm{H}) \mathrm{H})(\mathrm{F}) \mathrm{H})(\mathrm{H}) \mathrm{Br})(\mathrm{H}) \mathrm{H})($

$\mathrm{H}) \mathrm{H})(\mathrm{H})(\mathrm{H}) \mathrm{H}$

$\mathrm{C}(\mathrm{C}(\mathrm{C}(\mathrm{C}(\mathrm{C}(\mathrm{C}(\mathrm{C}(\mathrm{C}(\mathrm{C}(\mathrm{C}(\mathrm{C}(\mathrm{C}(\mathrm{C}(\mathrm{H})(\mathrm{H}) \mathrm{H})(\mathrm{H}) \mathrm{H})(\mathrm{H}) \mathrm{H})(\mathrm{H}) \mathrm{H})(\mathrm{H}) \mathrm{H})(\mathrm{F}) \mathrm{H})(\mathrm{H}) \mathrm{H})(\mathrm{H}) \mathrm{H})(\mathrm{H}) \mathrm{Br})(\mathrm{H}) \mathrm{F})(\mathrm{H}) \mathrm{H})$

$(\mathrm{H}) \mathrm{H})(\mathrm{H})(\mathrm{H}) \mathrm{H}$

$\mathrm{C}(\mathrm{C}(\mathrm{C}(\mathrm{C}(\mathrm{C}(\mathrm{C}(\mathrm{C}(\mathrm{C}(\mathrm{C}(\mathrm{C}(\mathrm{C}(\mathrm{C}(\mathrm{C}(\mathrm{H})(\mathrm{H}) \mathrm{H})(\mathrm{H}) \mathrm{H})(\mathrm{H}) \mathrm{H})(\mathrm{H}) \mathrm{H})(\mathrm{H}) \mathrm{H})(\mathrm{H}) \mathrm{H})(\mathrm{H}) \mathrm{H})(\mathrm{H}) \mathrm{H})(\mathrm{H}) \mathrm{F})(\mathrm{H}) \mathrm{H})(\mathrm{H}) \mathrm{H})$

$(\mathrm{H}) \mathrm{H})(\mathrm{Cl})(\mathrm{H}) \mathrm{Cl}$

$\mathrm{C}\left(\mathrm{C}(\mathrm{C}(\mathrm{C}(\mathrm{C}(\mathrm{C}(\mathrm{C}(\mathrm{C}(\mathrm{C}(\mathrm{C}(\mathrm{C}(\mathrm{C}(\mathrm{C}(\mathrm{H})(\mathrm{H}) \mathrm{H})(\mathrm{H}) \mathrm{H})(\mathrm{Cl}) \mathrm{Cl})(\mathrm{H}) \mathrm{H})(\mathrm{H}) \mathrm{H})(\mathrm{H}) \mathrm{H})(\mathrm{H}) \mathrm{H})(\mathrm{H}) \mathrm{H})(\mathrm{H}) \mathrm{H})(\mathrm{Cl}) \mathrm{H})(\mathrm{H}) \mathrm{H})\left({ }_{\mathrm{C} 13 \mathrm{H} 25 \mathrm{Cl} 3}\right.\right.$

$\mathrm{H}) \mathrm{H})(\mathrm{H})(\mathrm{H}) \mathrm{H}$

$\mathrm{C}(\mathrm{C}(\mathrm{C}(\mathrm{C}(\mathrm{C}(\mathrm{C}(\mathrm{C}(\mathrm{C}(\mathrm{C}(\mathrm{C}(\mathrm{C}(\mathrm{C}(\mathrm{C}(\mathrm{H})(\mathrm{H}) \mathrm{H})(\mathrm{H}) \mathrm{H})(\mathrm{H}) \mathrm{H})(\mathrm{H}) \mathrm{H})(\mathrm{H}) \mathrm{H})(\mathrm{H}) \mathrm{Br})(\mathrm{H}) \mathrm{H})(\mathrm{H}) \mathrm{F})(\mathrm{H}) \mathrm{Cl})(\mathrm{H}) \mathrm{H})(\mathrm{H}) \mathrm{H})($

$\mathrm{H}) \mathrm{H})(\mathrm{H})(\mathrm{H}) \mathrm{H}$

$\mathrm{C}(\mathrm{C}(\mathrm{C}(\mathrm{C}(\mathrm{C}(\mathrm{C}(\mathrm{C}(\mathrm{C}(\mathrm{C}(\mathrm{C}(\mathrm{C}(\mathrm{C}(\mathrm{C}(\mathrm{H})(\mathrm{H}) \mathrm{H})(\mathrm{H}) \mathrm{H})(\mathrm{H}) \mathrm{H})(\mathrm{H}) \mathrm{F})(\mathrm{H}) \mathrm{H})(\mathrm{H}) \mathrm{H})(\mathrm{H}) \mathrm{H})(\mathrm{H}) \mathrm{F})(\mathrm{H}) \mathrm{H})(\mathrm{H}) \mathrm{H})(\mathrm{H}) \mathrm{H})$

$(\mathrm{H}) \mathrm{H})(\mathrm{H})(\mathrm{H}) \mathrm{Cl}$

$\mathrm{C}(\mathrm{C}(\mathrm{C}(\mathrm{C}(\mathrm{C}(\mathrm{C}(\mathrm{C}(\mathrm{C}(\mathrm{C}(\mathrm{C}(\mathrm{C}(\mathrm{C}(\mathrm{C}(\mathrm{H})(\mathrm{H}) \mathrm{H})(\mathrm{H}) \mathrm{H})(\mathrm{H}) \mathrm{H})(\mathrm{H}) \mathrm{H})(\mathrm{Br}) \mathrm{H})(\mathrm{H}) \mathrm{H})(\mathrm{H}) \mathrm{Br})(\mathrm{H}) \mathrm{H})(\mathrm{H}) \mathrm{H})(\mathrm{H}) \mathrm{H})(\mathrm{H}) \mathrm{H})($

$\mathrm{H}) \mathrm{H})(\mathrm{H})(\mathrm{H}) \mathrm{H}$

$\mathrm{C}(\mathrm{C}(\mathrm{C}(\mathrm{C}(\mathrm{C}(\mathrm{C}(\mathrm{C}(\mathrm{C}(\mathrm{C}(\mathrm{C}(\mathrm{C}(\mathrm{C}(\mathrm{C}(\mathrm{H})(\mathrm{H}) \mathrm{H})(\mathrm{H}) \mathrm{H})(\mathrm{H}) \mathrm{H})(\mathrm{H}) \mathrm{H})(\mathrm{H}) \mathrm{H})(\mathrm{H}) \mathrm{H})(\mathrm{H}) \mathrm{H})(\mathrm{H}) \mathrm{H})(\mathrm{H}) \mathrm{F})(\mathrm{H}) \mathrm{H})(\mathrm{H}) \mathrm{H})$

$(\mathrm{H}) \mathrm{Br})(\mathrm{H})(\mathrm{H}) \mathrm{H}$

$\mathrm{C}(\mathrm{C}(\mathrm{C}(\mathrm{C}(\mathrm{C}(\mathrm{C}(\mathrm{C}(\mathrm{C}(\mathrm{C}(\mathrm{C}(\mathrm{C}(\mathrm{C}(\mathrm{C}(\mathrm{Cl})(\mathrm{H}) \mathrm{H})(\mathrm{H}) \mathrm{H})(\mathrm{H}) \mathrm{H})(\mathrm{H}) \mathrm{H})(\mathrm{H}) \mathrm{H})(\mathrm{H}) \mathrm{H})(\mathrm{H}) \mathrm{H})(\mathrm{H}) \mathrm{H})(\mathrm{H}) \mathrm{H})(\mathrm{H}) \mathrm{H})(\mathrm{H}) H)($

(C) $(\mathrm{C}(\mathrm{C})(\mathrm{Cl})$

$\mathrm{C}(\mathrm{C}(\mathrm{C}(\mathrm{C}(\mathrm{C}(\mathrm{C}(\mathrm{C}(\mathrm{C}(\mathrm{C}(\mathrm{C}(\mathrm{C}(\mathrm{C}(\mathrm{C}(\mathrm{H})(\mathrm{H}) \mathrm{H})(\mathrm{H}) \mathrm{H})(\mathrm{H}) \mathrm{H})(\mathrm{H}) \mathrm{H})(\mathrm{H}) \mathrm{H})(\mathrm{H}) \mathrm{Cl})(\mathrm{H}) \mathrm{H})(\mathrm{Br}) \mathrm{H})(\mathrm{H}) \mathrm{H})(\mathrm{H}) \mathrm{H})(\mathrm{H}) \mathrm{H})($

$\mathrm{H}) \mathrm{H})(\mathrm{H})(\mathrm{H}) \mathrm{H}$

$\mathrm{C}(\mathrm{C}(\mathrm{C}(\mathrm{C}(\mathrm{C}(\mathrm{C}(\mathrm{C}(\mathrm{C}(\mathrm{C}(\mathrm{C}(\mathrm{C}(\mathrm{C}(\mathrm{C}(\mathrm{Cl})(\mathrm{F}) \mathrm{H})(\mathrm{H}) \mathrm{H})(\mathrm{H}) \mathrm{H})(\mathrm{H}) \mathrm{H})(\mathrm{H}) \mathrm{H})(\mathrm{H}) \mathrm{H})(\mathrm{H}) \mathrm{H})(\mathrm{H}) \mathrm{H})(\mathrm{H}) \mathrm{H})(\mathrm{H}) \mathrm{H})(\mathrm{H}) \mathrm{H})($

$\mathrm{H}) \mathrm{H})(\mathrm{H})(\mathrm{H}) \mathrm{H}$

$\mathrm{C}(\mathrm{C}(\mathrm{C}(\mathrm{C}(\mathrm{C}(\mathrm{C}(\mathrm{C}(\mathrm{C}(\mathrm{C}(\mathrm{C}(\mathrm{C}(\mathrm{C}(\mathrm{C}(\mathrm{H})(\mathrm{H}) \mathrm{H})(\mathrm{H}) \mathrm{H})(\mathrm{H}) \mathrm{H})(\mathrm{H}) \mathrm{Br})(\mathrm{H}) \mathrm{H})(\mathrm{H}) \mathrm{H})(\mathrm{H}) \mathrm{H})(\mathrm{H}) \mathrm{H})(\mathrm{H}) \mathrm{H})(\mathrm{H}) \mathrm{H})(\mathrm{H}) \mathrm{H})($

$\mathrm{H}) \mathrm{H})(\mathrm{H})(\mathrm{H}) \mathrm{H}$

$\mathrm{C}(\mathrm{C}(\mathrm{C}(\mathrm{C}(\mathrm{C}(\mathrm{C}(\mathrm{C}(\mathrm{C}(\mathrm{C}(\mathrm{C}(\mathrm{C}(\mathrm{C}(\mathrm{C}(\mathrm{H})(\mathrm{H}) \mathrm{H})(\mathrm{H}) \mathrm{H})(\mathrm{H}) \mathrm{H})(\mathrm{H}) \mathrm{H})(\mathrm{H}) \mathrm{H})(\mathrm{H}) \mathrm{H})(\mathrm{Cl}) \mathrm{H})(\mathrm{H}) \mathrm{H})(\mathrm{H}) \mathrm{H})(\mathrm{H}) \mathrm{H})(\mathrm{H}) \mathrm{H})($

$\mathrm{H}) \mathrm{H})(\mathrm{H})(\mathrm{H}) \mathrm{H}$

$\mathrm{C}(\mathrm{C}(\mathrm{C}(\mathrm{C}(\mathrm{C}(\mathrm{C}(\mathrm{C}(\mathrm{C}(\mathrm{C}(\mathrm{C}(\mathrm{C}(\mathrm{C}(\mathrm{C}(\mathrm{H})(\mathrm{H}) \mathrm{H})(\mathrm{H}) \mathrm{H})(\mathrm{H}) \mathrm{H})(\mathrm{H}) \mathrm{H})(\mathrm{H}) \mathrm{F})(\mathrm{H}) \mathrm{H})(\mathrm{H}) \mathrm{H})(\mathrm{H}) \mathrm{H})(\mathrm{H}) \mathrm{H})(\mathrm{H}) \mathrm{H})(\mathrm{H}) \mathrm{H})$

$(\mathrm{H}) \mathrm{H})(\mathrm{H})(\mathrm{H}) \mathrm{H}$

$(\mathrm{H}) \mathrm{H})(\mathrm{H})(\mathrm{H}) \mathrm{H}$
$\mathrm{C}(\mathrm{C}(\mathrm{C}(\mathrm{C}(\mathrm{C}(\mathrm{C}(\mathrm{C}(\mathrm{C}(\mathrm{C}(\mathrm{C}(\mathrm{C}(\mathrm{C}(\mathrm{C}(\mathrm{F})(\mathrm{H}) \mathrm{F})(\mathrm{H}) \mathrm{Cl})(\mathrm{H}) \mathrm{F})(\mathrm{F}) \mathrm{Br})(\mathrm{F}) \mathrm{F})(\mathrm{F}) \mathrm{H})(\mathrm{F}) \mathrm{F})(\mathrm{F}) \mathrm{Br})(\mathrm{H}) \mathrm{F})(\mathrm{F}) \mathrm{F})(\mathrm{F}) \mathrm{F})(\mathrm{H}) \mathrm{Br})$

$(\mathrm{F})(\mathrm{H}) \mathrm{F}$

$\mathrm{C}(\mathrm{C}(\mathrm{C}(\mathrm{C}(\mathrm{C}(\mathrm{C}(\mathrm{C}(\mathrm{C}(\mathrm{C}(\mathrm{C}(\mathrm{C}(\mathrm{C}(\mathrm{C}(\mathrm{Br})(\mathrm{F}) \mathrm{F})(\mathrm{F}) \mathrm{F})(\mathrm{H}) \mathrm{F})(\mathrm{F}) \mathrm{H})(\mathrm{F}) \mathrm{H})(\mathrm{Br}) \mathrm{H})(\mathrm{F}) \mathrm{Br})(\mathrm{H}) \mathrm{Br})(\mathrm{Cl}) \mathrm{F})(\mathrm{H}) \mathrm{F})(\mathrm{F}) \mathrm{H})(\mathrm{F})$

$\mathrm{F})(\mathrm{F})(\mathrm{F}) \mathrm{H}$

$\mathrm{C}(\mathrm{C}(\mathrm{C}(\mathrm{C}(\mathrm{C}(\mathrm{C}(\mathrm{C}(\mathrm{C}(\mathrm{C}(\mathrm{C}(\mathrm{C}(\mathrm{C}(\mathrm{C}(\mathrm{Br})(\mathrm{Br}) \mathrm{Br})(\mathrm{F}) \mathrm{F})(\mathrm{H}) \mathrm{F})(\mathrm{F}) \mathrm{H})(\mathrm{F}) \mathrm{F})(\mathrm{F}) \mathrm{F})(\mathrm{F}) \mathrm{H})(\mathrm{H}) \mathrm{F})(\mathrm{H}) \mathrm{F})(\mathrm{F}) \mathrm{H})(\mathrm{F}) \mathrm{F})(\mathrm{H}) \mathrm{H}){ }_{\mathrm{C} 13 \mathrm{H} 9 \mathrm{Br} 3 \mathrm{~F} 16}$

(H)(F)F

$\mathrm{C}(\mathrm{C}(\mathrm{C}(\mathrm{C}(\mathrm{C}(\mathrm{C}(\mathrm{C}(\mathrm{C}(\mathrm{C}(\mathrm{C}(\mathrm{C}(\mathrm{C}(\mathrm{C}(\mathrm{F})(\mathrm{H}) \mathrm{H})(\mathrm{H}) \mathrm{F})(\mathrm{F}) \mathrm{F})(\mathrm{F}) \mathrm{F})(\mathrm{F}) \mathrm{F})(\mathrm{H}) \mathrm{Br})(\mathrm{F}) \mathrm{F})(\mathrm{F}) \mathrm{H})(\mathrm{Br}) \mathrm{F})(\mathrm{H}) \mathrm{Cl})(\mathrm{F}) \mathrm{F})(\mathrm{H}) \mathrm{H})$

(H)(F)Cl

$\mathrm{C}(\mathrm{C}(\mathrm{C}(\mathrm{C}(\mathrm{C}(\mathrm{C}(\mathrm{C}(\mathrm{C}(\mathrm{C}(\mathrm{C}(\mathrm{C}(\mathrm{C}(\mathrm{C}(\mathrm{F})(\mathrm{F}) \mathrm{Br})(\mathrm{Cl}) \mathrm{H})(\mathrm{F}) \mathrm{H})(\mathrm{F}) \mathrm{F})(\mathrm{F}) \mathrm{F})(\mathrm{H}) \mathrm{F})(\mathrm{F}) \mathrm{F})(\mathrm{Cl}) \mathrm{H})(\mathrm{F}) \mathrm{H})(\mathrm{H}) \mathrm{F})(\mathrm{F}) \mathrm{F})(\mathrm{F}) \mathrm{H})\left({ }_{\mathrm{C} 13 \mathrm{H} 9 \mathrm{Cl} 3 \mathrm{BrF} 15}\right.$

$\mathrm{Cl})(\mathrm{H}) \mathrm{H}$

$\mathrm{C}(\mathrm{C}(\mathrm{C}(\mathrm{C}(\mathrm{C}(\mathrm{C}(\mathrm{C}(\mathrm{C}(\mathrm{C}(\mathrm{C}(\mathrm{C}(\mathrm{C}(\mathrm{C}(\mathrm{H})(\mathrm{F}) \mathrm{F})(\mathrm{Cl}) \mathrm{F})(\mathrm{H}) \mathrm{F})(\mathrm{F}) \mathrm{H})(\mathrm{H}) \mathrm{H})(\mathrm{H}) \mathrm{F})(\mathrm{H}) \mathrm{Br})(\mathrm{F}) \mathrm{F})(\mathrm{F}) \mathrm{F})(\mathrm{Cl}) \mathrm{F})(\mathrm{H}) \mathrm{Cl})(\mathrm{F}) \mathrm{F}){ }_{\mathrm{Cl}}{ }^{3} \mathrm{H}_{9 \mathrm{Cl}} \mathrm{BrF} 14$

$(\mathrm{H})(\mathrm{Cl}) \mathrm{F}$

$\mathrm{C}(\mathrm{C}(\mathrm{C}(\mathrm{C}(\mathrm{C}(\mathrm{C}$

$\mathrm{F})(\mathrm{F})(\mathrm{F}) \mathrm{Br}$

$\mathrm{C}(\mathrm{C}(\mathrm{C}(\mathrm{C}(\mathrm{C}(\mathrm{C}(\mathrm{C}(\mathrm{C}(\mathrm{C}(\mathrm{C}(\mathrm{C}(\mathrm{C}(\mathrm{C}(\mathrm{Cl})(\mathrm{Cl}) \mathrm{Cl})(\mathrm{H}) \mathrm{F})(\mathrm{F}) \mathrm{H})(\mathrm{Cl}) \mathrm{F})(\mathrm{F}) \mathrm{H})(\mathrm{F}) \mathrm{Cl})(\mathrm{F}) \mathrm{H})(\mathrm{F}) \mathrm{F})(\mathrm{H}) \mathrm{H})(\mathrm{H}) \mathrm{H})(\mathrm{F}) \mathrm{F})$

(F)F)(H)(F)F

C(C(C(C(C(C(C(C(C(C(C(C(C(H)(F)Cl)(H)Cl)(F)F)(H)F)(F)F)(H)F)(F)H)(H)Cl)(Cl)F)(Cl)F)(F)H)(Cl)

$\mathrm{H})(\mathrm{F})(\mathrm{Cl}) \mathrm{H}$

$\mathrm{C}(\mathrm{C}(\mathrm{C}(\mathrm{C}(\mathrm{C}(\mathrm{C}(\mathrm{C}(\mathrm{C}(\mathrm{C}(\mathrm{C}(\mathrm{C}(\mathrm{C}(\mathrm{C}(\mathrm{C}(\mathrm{F})(\mathrm{F}) \mathrm{F})(\mathrm{H}) \mathrm{H})(\mathrm{F}) \mathrm{H})(\mathrm{F}) \mathrm{F})(\mathrm{H}) \mathrm{Cl})(\mathrm{F}) \mathrm{F})(\mathrm{Cl}) \mathrm{H})(\mathrm{F}) \mathrm{H})(\mathrm{H}) \mathrm{F})(\mathrm{Br}) \mathrm{F})(\mathrm{F}) \mathrm{H})(\mathrm{F})$

$\mathrm{Cl})(\mathrm{H}) \mathrm{F})(\mathrm{Cl})(\mathrm{F}) \mathrm{H}$

$\mathrm{C}(\mathrm{C}(\mathrm{C}(\mathrm{C}(\mathrm{C}(\mathrm{C}(\mathrm{C}(\mathrm{C}(\mathrm{C}(\mathrm{C}(\mathrm{C}(\mathrm{C}(\mathrm{C}(\mathrm{C}(\mathrm{H})(\mathrm{F}) \mathrm{H})(\mathrm{F}) \mathrm{H})(\mathrm{H}) \mathrm{Cl})(\mathrm{F}) \mathrm{Cl})(\mathrm{H}) \mathrm{F})(\mathrm{F}) \mathrm{F})(\mathrm{H}) \mathrm{F})(\mathrm{F}) \mathrm{F})(\mathrm{F}) \mathrm{F})(\mathrm{H}) \mathrm{Cl})(\mathrm{H}) \mathrm{F})(\mathrm{H})$ $\mathrm{F})(\mathrm{Cl}) \mathrm{Cl})(\mathrm{F})(\mathrm{H}) \mathrm{F}$

$\mathrm{C}(\mathrm{C}(\mathrm{C}(\mathrm{C}(\mathrm{C}(\mathrm{C}(\mathrm{C}(\mathrm{C}(\mathrm{C}(\mathrm{C}(\mathrm{C}(\mathrm{C}(\mathrm{C}(\mathrm{C}(\mathrm{H})(\mathrm{F}) \mathrm{F})(\mathrm{F}) \mathrm{H})(\mathrm{H}) \mathrm{F})(\mathrm{H}) \mathrm{F})(\mathrm{F}) \mathrm{H})(\mathrm{Br}) \mathrm{H})(\mathrm{Br}) \mathrm{F})(\mathrm{H}) \mathrm{F})(\mathrm{Br}) \mathrm{F})(\mathrm{F}) \mathrm{Br})(\mathrm{H}) \mathrm{F})($

F)F)(F)H)(F)(H)H

(H) $(\mathrm{H}) \mathrm{Cl}(\mathrm{F})(\mathrm{F}) \mathrm{H}$

(H)F)(F)F)(F)(H)H
$\mathrm{C} 13 \mathrm{H} 9 \mathrm{Cl} 2 \mathrm{Br} 2 \mathrm{~F} 15$

$\mathrm{C} 13 \mathrm{H} 9 \mathrm{C} 4 \mathrm{BrF} 14$

$\mathrm{C} 13 \mathrm{H} 9 \mathrm{Cl} 5 \mathrm{BrF} 13$

C13H9C15F14

$\mathrm{C} 13 \mathrm{H} 9 \mathrm{Cl} 7 \mathrm{~F} 12$

lgKoa lgKow lgKaw lgKow lgKoa lgKa lgKow lgKoa lgKaw EPISuit EPI EPI Exp Exp w DFT DFT DFT e Suite Suite corr_corr_Exp corr _corr _corr $\begin{array}{lllllllll}6.224 & 8.17 & 1.95 & 7.27 & 5.32 & 1.95 & 7.04 & 9.45 & -2.41\end{array}$ $\begin{array}{lllllllll}7.524 & 7.48 & -0.04 & 6.24 & 6.28 & -0.04 & 6.51 & 11.83 & -5.33\end{array}$ $\begin{array}{lllllllll}5.886 & 7.08 & 1.19 & 5.64 & 4.45 & 1.19 & 6.20 & 8.82 & -2.63\end{array}$ $\begin{array}{lllllllll}6.949 & 7.39 & 0.44 & 6.10 & 5.66 & 0.44 & 6.44 & 10.78 & -4.34\end{array}$ $\begin{array}{lllllllll}7.027 & 7.25 & 0.22 & 5.90 & 5.67 & 0.22 & 6.33 & 10.92 & -4.59\end{array}$ $\begin{array}{lllllllll}6.13 & 7.59 & 1.46 & 6.40 & 4.94 & 1.46 & 6.59 & 9.27 & -2.68\end{array}$ $\begin{array}{lllllllll}7.134 & 7.81 & 0.68 & 6.73 & 6.06 & 0.68 & 6.76 & 11.12 & -4.36\end{array}$ $\begin{array}{lllllllll}5.427 & 7.34 & 1.91 & 6.03 & 4.12 & 1.91 & 6.40 & 7.98 & -1.58\end{array}$ $\begin{array}{lllllllll}7.55 & 7.96 & 0.41 & 6.96 & 6.55 & 0.41 & 6.88 & 11.88 & -5.01\end{array}$ $\begin{array}{lllllll}0.86 & 5.58 & 4.72 & 0.86 & 6.17 & 9.36 & -3.19\end{array}$

$\begin{array}{lllllll}2.10 & 5.09 & 2.99 & 2.10 & 5.92 & 6.48 & -0.57\end{array}$

$\begin{array}{lllllll}0.08 & 5.93 & 5.85 & 0.08 & 6.35 & 11.22 & -4.88\end{array}$

$\begin{array}{lllllll}1.32 & 5.31 & 4.00 & 1.32 & 6.03 & 8.20 & -2.17\end{array}$

$\begin{array}{lllllll}1.05 & 5.76 & 4.71 & 1.05 & 6.26 & 9.24 & -2.98\end{array}$

$\begin{array}{lllllll}0.56 & 5.79 & 5.23 & 0.56 & 6.28 & 10.17 & -3.89\end{array}$

$\begin{array}{lllllll}1.80 & 5.30 & 3.50 & 1.80 & 6.02 & 7.29 & -1.26\end{array}$

$\begin{array}{lllllll}1.02 & 5.52 & 4.51 & 1.02 & 6.14 & 9.00 & -2.87\end{array}$

$\begin{array}{lllllll}1.00 & 5.39 & 4.39 & 1.00 & 6.07 & 8.87 & -2.80\end{array}$

$\begin{array}{lllllll}1.30 & 4.91 & 3.61 & 1.30 & 5.82 & 7.72 & -1.90\end{array}$

$\begin{array}{lllllll}3.77 & 10.07 & 6.31 & 3.77 & 8.48 & 9.55 & -1.07\end{array}$

$\begin{array}{lllllll}2.23 & 9.76 & 7.53 & 2.23 & 8.32 & 11.99 & -3.67\end{array}$

$\begin{array}{lllllll}3.92 & 8.90 & 4.97 & 3.92 & 7.87 & 7.82 & 0.05\end{array}$

$\begin{array}{lllllll}3.65 & 9.90 & 6.24 & 3.65 & 8.39 & 9.54 & -1.15\end{array}$

$\begin{array}{lllllll}4.14 & 9.10 & 4.97 & 4.14 & 7.98 & 7.68 & 0.31\end{array}$

$\begin{array}{lllllll}3.39 & 9.57 & 6.18 & 3.39 & 8.22 & 9.63 & -1.41\end{array}$

$\begin{array}{lllllll}2.64 & 10.03 & 7.39 & 2.64 & 8.46 & 11.57 & -3.12\end{array}$

$\begin{array}{lllllll}3.87 & 10.09 & 6.22 & 3.87 & 8.49 & 9.38 & -0.89\end{array}$

$\begin{array}{lllllll}2.37 & 9.27 & 6.90 & 2.37 & 8.07 & 11.13 & -3.07\end{array}$

$\begin{array}{lllllll}3.81 & 10.10 & 6.29 & 3.81 & 8.50 & 9.51 & -1.01\end{array}$

$\begin{array}{lllllll}4.29 & 9.97 & 5.68 & 4.29 & 8.43 & 8.46 & -0.03\end{array}$

$\begin{array}{lllllll}2.81 & 9.12 & 6.31 & 2.81 & 7.99 & 10.14 & -2.15\end{array}$

$\begin{array}{lllllll}3.74 & 9.82 & 6.08 & 3.74 & 8.35 & 9.28 & -0.93\end{array}$ $\begin{array}{lllllll}3.78 & 9.97 & 6.19 & 3.78 & 8.43 & 9.41 & -0.98\end{array}$ 
$\mathrm{C}\left(\mathrm{C}\left(\mathrm{C}(\mathrm{C}(\mathrm{C}(\mathrm{C}(\mathrm{C}(\mathrm{C}(\mathrm{C}(\mathrm{C}(\mathrm{C}(\mathrm{C}(\mathrm{C}(\mathrm{C}(\mathrm{H})(\mathrm{F}) \mathrm{Br})(\mathrm{F}) \mathrm{F})(\mathrm{H}) \mathrm{Br})(\mathrm{F}) \mathrm{F})(\mathrm{H}) \mathrm{F})(\mathrm{F}) \mathrm{H})(\mathrm{F}) \mathrm{F})(\mathrm{H}) \mathrm{F})(\mathrm{H}) \mathrm{F})(\mathrm{H}) \mathrm{H})(\mathrm{F}) \mathrm{H})(\mathrm{F}){ }_{\mathrm{C}} \mathrm{C} 14 \mathrm{H} 12 \mathrm{Br} 4 \mathrm{~F} 14\right.\right.$

$\mathrm{Br})(\mathrm{F}) \mathrm{H})(\mathrm{H})(\mathrm{Br}) \mathrm{H}$

$\mathrm{C}(\mathrm{C}(\mathrm{C}(\mathrm{C}(\mathrm{C}(\mathrm{C}(\mathrm{C}(\mathrm{C}(\mathrm{C}(\mathrm{C}(\mathrm{C}(\mathrm{C}(\mathrm{C}(\mathrm{C}(\mathrm{H})(\mathrm{F}) \mathrm{H})(\mathrm{H}) \mathrm{Cl})(\mathrm{F}) \mathrm{H})(\mathrm{Br}) \mathrm{F})(\mathrm{Cl}) \mathrm{F})(\mathrm{H}) \mathrm{F})(\mathrm{H}) \mathrm{Br})(\mathrm{F}) \mathrm{F})(\mathrm{F}) \mathrm{F})(\mathrm{H}) \mathrm{F})(\mathrm{H}) \mathrm{F})(\mathrm{C} 14 \mathrm{H} 12 \mathrm{Cl} 2 \mathrm{Br} 3 \mathrm{~F} 1$ $\mathrm{H}) \mathrm{F})(\mathrm{H}) \mathrm{H})(\mathrm{F})(\mathrm{Br}) \mathrm{H}$

$\mathrm{C}(\mathrm{C}(\mathrm{C}(\mathrm{C}(\mathrm{C}(\mathrm{C}(\mathrm{C}(\mathrm{C}(\mathrm{C}(\mathrm{C}(\mathrm{C}(\mathrm{C}(\mathrm{C}(\mathrm{C}(\mathrm{F})(\mathrm{H}) \mathrm{H})(\mathrm{Cl}) \mathrm{H})(\mathrm{F}) \mathrm{F})(\mathrm{F}) \mathrm{Br})(\mathrm{F}) \mathrm{F})(\mathrm{H}) \mathrm{F})(\mathrm{F}) \mathrm{H})(\mathrm{F}) \mathrm{H})(\mathrm{F}) \mathrm{H})(\mathrm{F}) \mathrm{H})(\mathrm{H}) \mathrm{Br}) \quad \mathrm{C} 14 \mathrm{H} 12 \mathrm{Cl} 3 \mathrm{Br} 2 \mathrm{~F} 1$ $(\mathrm{H}) \mathrm{H})(\mathrm{Cl}) \mathrm{F})(\mathrm{H})(\mathrm{F}) \mathrm{Cl}$

3

$\mathrm{F}) \mathrm{F})(\mathrm{F}) \mathrm{F})(\mathrm{F})(\mathrm{H}) \mathrm{H}$

$\mathrm{C}(\mathrm{C}(\mathrm{C}(\mathrm{C}(\mathrm{C}(\mathrm{C}(\mathrm{C}(\mathrm{C}(\mathrm{C}(\mathrm{C}(\mathrm{C}(\mathrm{C}(\mathrm{C}(\mathrm{C}(\mathrm{F})(\mathrm{Cl}) \mathrm{Cl})(\mathrm{Cl}) \mathrm{P})(\mathrm{F}) \mathrm{H})(\mathrm{H}) \mathrm{F})(\mathrm{F}) \mathrm{H})(\mathrm{F}) \mathrm{Cl})(\mathrm{F}) H)(\mathrm{H}) \mathrm{P})(\mathrm{F}) H)(\mathrm{B}) \mathrm{H})(\mathrm{H}) H)(\mathrm{Cl}$

F)F $(\mathrm{F}) \mathrm{H})(\mathrm{H})(\mathrm{H}) \mathrm{F}$

$\mathrm{C}(\mathrm{C}(\mathrm{C}(\mathrm{C}(\mathrm{C}(\mathrm{C}(\mathrm{C}(\mathrm{C}(\mathrm{C}(\mathrm{C}(\mathrm{C}(\mathrm{C}(\mathrm{C}(\mathrm{C}(\mathrm{H})(\mathrm{F}) \mathrm{F})(\mathrm{F}) \mathrm{F})(\mathrm{F}) \mathrm{Br})(\mathrm{H}) \mathrm{H})(\mathrm{F}) \mathrm{H})(\mathrm{H}) \mathrm{Br})(\mathrm{H}) \mathrm{F})(\mathrm{H}) \mathrm{F})(\mathrm{H}) \mathrm{H})(\mathrm{H}) \mathrm{F})(\mathrm{Cl}) \mathrm{H})($

$\mathrm{F}) \mathrm{F})(\mathrm{F}) \mathrm{F})(\mathrm{Br})(\mathrm{F}) \mathrm{H}$

$\mathrm{C}(\mathrm{C}(\mathrm{C}(\mathrm{C}(\mathrm{C}(\mathrm{C}(\mathrm{C}(\mathrm{C}(\mathrm{C}(\mathrm{C}(\mathrm{C}(\mathrm{C}(\mathrm{C}(\mathrm{C}(\mathrm{F})(\mathrm{H}) \mathrm{Br})(\mathrm{H}) \mathrm{F})(\mathrm{H}) \mathrm{F})(\mathrm{F}) \mathrm{H})(\mathrm{F}) \mathrm{F})(\mathrm{F}) \mathrm{F})(\mathrm{H}) \mathrm{H})(\mathrm{F}) \mathrm{F})(\mathrm{H}) \mathrm{H})(\mathrm{Br}) \mathrm{H})(\mathrm{H}) \mathrm{H})$

(F)F)(Br)F)(F)(H)H

$\mathrm{C}(\mathrm{C}(\mathrm{C}(\mathrm{C}(\mathrm{C}(\mathrm{C}(\mathrm{C}(\mathrm{C}(\mathrm{C}(\mathrm{C}(\mathrm{C}(\mathrm{C}(\mathrm{C}(\mathrm{C}(\mathrm{H})(\mathrm{H}) \mathrm{H})(\mathrm{F}) \mathrm{H})(\mathrm{F}) \mathrm{H})(\mathrm{H}) \mathrm{H})(\mathrm{H}) \mathrm{Cl})(\mathrm{F}) \mathrm{H})(\mathrm{F}) \mathrm{F})(\mathrm{F}) \mathrm{F})(\mathrm{H}) \mathrm{F})(\mathrm{F}) \mathrm{F})(\mathrm{Cl}) \mathrm{H})$

$(\mathrm{Br}) \mathrm{H})(\mathrm{F}) \mathrm{Br})(\mathrm{F})(\mathrm{H}) \mathrm{F}$

$\mathrm{H}) \mathrm{F})(\mathrm{H}) \mathrm{H})(\mathrm{F})(\mathrm{H}) \mathrm{Br}$

(F)F)(F)F)(H)(H)H

$\mathrm{C}(\mathrm{C}(\mathrm{C}(\mathrm{C}(\mathrm{C}(\mathrm{C}(\mathrm{C}(\mathrm{C}(\mathrm{C}(\mathrm{C}(\mathrm{C}(\mathrm{C}(\mathrm{C}(\mathrm{C}(\mathrm{H})(\mathrm{H}) \mathrm{F})(\mathrm{F}) \mathrm{F})(\mathrm{F}) \mathrm{Cl})(\mathrm{H}) \mathrm{Cl})(\mathrm{Cl}) \mathrm{H})(\mathrm{H}) \mathrm{H})(\mathrm{F}) \mathrm{H})(\mathrm{F}) \mathrm{H})(\mathrm{F}) \mathrm{H})(\mathrm{H}) \mathrm{F})(\mathrm{H}) \mathrm{Br})(\mathrm{C} 14 \mathrm{H} 13 \mathrm{Cl} 3 \mathrm{Br} 2 \mathrm{~F} 1$

$\mathrm{F}) \mathrm{H})(\mathrm{F}) \mathrm{F})(\mathrm{F})(\mathrm{H}) \mathrm{Br}$

$\mathrm{C}(\mathrm{C}(\mathrm{C}(\mathrm{C}(\mathrm{C}(\mathrm{C}(\mathrm{C}(\mathrm{C}(\mathrm{C}(\mathrm{C}(\mathrm{C}(\mathrm{C}(\mathrm{C}(\mathrm{C}(\mathrm{H})(\mathrm{H}) \mathrm{F})(\mathrm{H}) \mathrm{F})(\mathrm{H}) \mathrm{F})(\mathrm{H}) \mathrm{F})(\mathrm{H}) \mathrm{F})(\mathrm{H}) \mathrm{H})(\mathrm{Cl}) \mathrm{F})(\mathrm{F}) \mathrm{Cl})(\mathrm{F}) \mathrm{H})(\mathrm{F}) \mathrm{F})(\mathrm{F}) \mathrm{Cl})$

$(\mathrm{H}) \mathrm{F})(\mathrm{H}) \mathrm{H})(\mathrm{H})(\mathrm{Br}) \mathrm{F}$

$\mathrm{C}(\mathrm{C}(\mathrm{C}(\mathrm{C}(\mathrm{C}(\mathrm{C}(\mathrm{C}(\mathrm{C}(\mathrm{C}(\mathrm{C}(\mathrm{C}(\mathrm{C}(\mathrm{C}(\mathrm{C}(\mathrm{F})(\mathrm{H}) \mathrm{F})(\mathrm{F}) \mathrm{H})(\mathrm{F}) \mathrm{Cl})(\mathrm{F}) \mathrm{H})(\mathrm{F}) \mathrm{H})(\mathrm{H}) \mathrm{H})(\mathrm{H}) \mathrm{F})(\mathrm{H}) \mathrm{F})(\mathrm{Cl}) \mathrm{F})(\mathrm{H}) \mathrm{F})(\mathrm{H}) \mathrm{F})$

$(\mathrm{Br}) \mathrm{H})(\mathrm{H}) \mathrm{F})(\mathrm{Cl})(\mathrm{H}) \mathrm{Cl}$

$\mathrm{C}(\mathrm{C}(\mathrm{C}(\mathrm{C}(\mathrm{C}(\mathrm{C}(\mathrm{C}(\mathrm{C}(\mathrm{C}(\mathrm{C}(\mathrm{C}(\mathrm{C}(\mathrm{C}(\mathrm{C}(\mathrm{Cl})(\mathrm{F}) \mathrm{H})(\mathrm{Cl}) \mathrm{H})(\mathrm{H}) \mathrm{F})(\mathrm{H}) \mathrm{F})(\mathrm{Cl}) \mathrm{H})(\mathrm{F}) \mathrm{F})(\mathrm{H}) \mathrm{F})(\mathrm{H}) \mathrm{F})(\mathrm{H}) \mathrm{H})(\mathrm{H}) \mathrm{Cl})(\mathrm{F}) \mathrm{F})$

$\mathrm{H}) \mathrm{H})(\mathrm{F}) \mathrm{Cl}(\mathrm{H})(\mathrm{F}) \mathrm{Br}$

$\mathrm{C}(\mathrm{C}(\mathrm{C}(\mathrm{C}(\mathrm{C}(\mathrm{C}(\mathrm{C}(\mathrm{C}(\mathrm{C}(\mathrm{C}(\mathrm{C}(\mathrm{C}(\mathrm{C}(\mathrm{C}(\mathrm{H})(\mathrm{H}) \mathrm{F})(\mathrm{Cl}) \mathrm{H})(\mathrm{F}) \mathrm{F})(\mathrm{H}) \mathrm{H})(\mathrm{Cl}) \mathrm{H})(\mathrm{H}) \mathrm{Cl})(\mathrm{H}) \mathrm{F})(\mathrm{H}) \mathrm{F})(\mathrm{H}) \mathrm{Cl})(\mathrm{F}) \mathrm{F})(\mathrm{F}) \mathrm{F})($

$\mathrm{H}) \mathrm{H})(\mathrm{Cl}) \mathrm{F})(\mathrm{F})(\mathrm{H}) \mathrm{F}$

$\mathrm{C}(\mathrm{C}(\mathrm{C}(\mathrm{C}(\mathrm{C}(\mathrm{C}(\mathrm{C}(\mathrm{C}(\mathrm{C}(\mathrm{C}(\mathrm{C}(\mathrm{C}(\mathrm{C}(\mathrm{C}(\mathrm{H})(\mathrm{F}) \mathrm{Cl})(\mathrm{H}) \mathrm{H})(\mathrm{F}) \mathrm{Cl})(\mathrm{H}) \mathrm{F})(\mathrm{F}) \mathrm{F})(\mathrm{H}) \mathrm{F})(\mathrm{F}) \mathrm{H})(\mathrm{F}) \mathrm{Cl})(\mathrm{H}) \mathrm{H})(\mathrm{H}) \mathrm{H})(\mathrm{Cl}) \mathrm{H})($

$\mathrm{Cl}) \mathrm{F})(\mathrm{H}) \mathrm{F})(\mathrm{Cl})(\mathrm{F}) \mathrm{H}$

$\mathrm{C}(\mathrm{C}(\mathrm{C}(\mathrm{C}(\mathrm{C}(\mathrm{C}(\mathrm{C}(\mathrm{C}(\mathrm{C}(\mathrm{C}(\mathrm{C}(\mathrm{C}(\mathrm{C}(\mathrm{C}(\mathrm{Br})(\mathrm{Cl}) \mathrm{H})(\mathrm{H}) \mathrm{F})(\mathrm{H}) \mathrm{F})(\mathrm{F}) \mathrm{F})(\mathrm{H}) \mathrm{H})(\mathrm{H}) \mathrm{H})(\mathrm{F}) \mathrm{F})(\mathrm{F}) \mathrm{F})(\mathrm{H}) \mathrm{H})(\mathrm{H}) \mathrm{F})(\mathrm{F}) \mathrm{F})$

$(\mathrm{Br}) \mathrm{H})(\mathrm{H}) \mathrm{F})(\mathrm{F})(\mathrm{F}) \mathrm{H}$

$\mathrm{C}(\mathrm{C}(\mathrm{C}(\mathrm{C}(\mathrm{C}(\mathrm{C}(\mathrm{C}(\mathrm{C}(\mathrm{C}(\mathrm{C}(\mathrm{C}(\mathrm{C}(\mathrm{C}(\mathrm{C}(\mathrm{Br})(\mathrm{H}) \mathrm{Br})(\mathrm{F}) \mathrm{F})(\mathrm{H}) \mathrm{H})(\mathrm{H}) \mathrm{H})(\mathrm{F}) \mathrm{Br})(\mathrm{F}) \mathrm{H})(\mathrm{H}) \mathrm{F})(\mathrm{H}) \mathrm{F})(\mathrm{H}) \mathrm{H})(\mathrm{H}) \mathrm{F})(\mathrm{F}) \mathrm{H})($

$\mathrm{F}) \mathrm{H})(\mathrm{F}) \mathrm{F})(\mathrm{F})(\mathrm{H}) \mathrm{F}$

F)F $)(\mathrm{H}) \mathrm{F})(\mathrm{H})(\mathrm{F}) \mathrm{H}(\mathrm{C}(\mathrm{C}(\mathrm{C}(\mathrm{C}(\mathrm{C}(\mathrm{F})(\mathrm{Br}) \mathrm{F})(\mathrm{H}) \mathrm{F})(\mathrm{H}) \mathrm{F})(\mathrm{H}) \mathrm{H})(\mathrm{F}) \mathrm{Br})(\mathrm{H}) \mathrm{F})(\mathrm{H}) \mathrm{H})(\mathrm{H}) \mathrm{H})(\mathrm{H}) \mathrm{F})(\mathrm{Cl}) \mathrm{Cl})(\mathrm{H}) \mathrm{F})($

$\mathrm{C}(\mathrm{C}(\mathrm{C}(\mathrm{C}(\mathrm{C}(\mathrm{C}(\mathrm{C}(\mathrm{C}(\mathrm{C}(\mathrm{C}(\mathrm{C}(\mathrm{C}(\mathrm{C}(\mathrm{C}(\mathrm{H})(\mathrm{F}) \mathrm{Br})(\mathrm{F}) \mathrm{H})(\mathrm{F}) \mathrm{F})(\mathrm{H}) \mathrm{H})(\mathrm{H}) \mathrm{H})(\mathrm{Cl}) \mathrm{H})(\mathrm{F}) \mathrm{H})(\mathrm{H}) \mathrm{H})(\mathrm{H}) \mathrm{Br})(\mathrm{H}) \mathrm{Cl})$

$(\mathrm{Cl}) \mathrm{F})(\mathrm{F}) \mathrm{F})(\mathrm{H}) \mathrm{F})(\mathrm{H})(\mathrm{F}) \mathrm{F}$

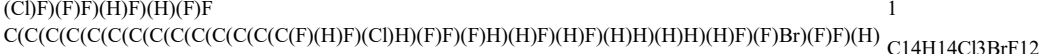

$\mathrm{H})(\mathrm{H}) \mathrm{Cl})(\mathrm{F})(\mathrm{Cl}) \mathrm{H}$

$\mathrm{C}\left(\mathrm{C}\left(\mathrm{C}(\mathrm{C}(\mathrm{C}(\mathrm{C}(\mathrm{C}(\mathrm{C}(\mathrm{C}(\mathrm{C}(\mathrm{C}(\mathrm{C}(\mathrm{C}(\mathrm{C}(\mathrm{F})(\mathrm{F}) \mathrm{H})(\mathrm{H}) \mathrm{H})(\mathrm{H}) \mathrm{F})(\mathrm{H}) \mathrm{H})(\mathrm{Cl}) \mathrm{F})(\mathrm{Cl}) \mathrm{H})(\mathrm{Cl}) \mathrm{Cl})(\mathrm{F}) \mathrm{F})(\mathrm{H}) \mathrm{H})(\mathrm{H}) \mathrm{H})(\mathrm{F}) \mathrm{H})\left({ }_{\mathrm{Cl}}{ }_{4 \mathrm{H} 14 \mathrm{Cl} 5 \mathrm{~F} 11}\right.\right.\right.$

$\mathrm{F}) \mathrm{H})(\mathrm{F}) \mathrm{F})(\mathrm{H})(\mathrm{Cl}) \mathrm{F}$

$\mathrm{C}\left(\mathrm{C}\left(\mathrm{C}(\mathrm{C}(\mathrm{C}(\mathrm{C}(\mathrm{C}(\mathrm{C}(\mathrm{C}(\mathrm{C}(\mathrm{C}(\mathrm{C}(\mathrm{C}(\mathrm{C}(\mathrm{H})(\mathrm{H}) \mathrm{H})(\mathrm{F}) \mathrm{F})(\mathrm{F}) \mathrm{H})(\mathrm{H}) \mathrm{H})(\mathrm{F}) \mathrm{Cl})(\mathrm{Br}) \mathrm{H})(\mathrm{H}) \mathrm{F})(\mathrm{F}) \mathrm{H})(\mathrm{F}) \mathrm{F})(\mathrm{F}) \mathrm{F})(\mathrm{F}) \mathrm{H})(\mathrm{H}){ }_{\mathrm{Cl}} 4 \mathrm{H} 14 \mathrm{ClBr} 2 \mathrm{~F} 13\right.\right.$

$\mathrm{F})(\mathrm{H}) \mathrm{Br})(\mathrm{F})(\mathrm{H}) \mathrm{H}$

$\mathrm{C}\left(\mathrm{C}\left(\mathrm{C}(\mathrm{C}(\mathrm{C}(\mathrm{C}(\mathrm{C}(\mathrm{C}(\mathrm{C}(\mathrm{C}(\mathrm{C}(\mathrm{C}(\mathrm{C}(\mathrm{C}(\mathrm{Br})(\mathrm{H}) \mathrm{F})(\mathrm{H}) \mathrm{H})(\mathrm{H}) \mathrm{F})(\mathrm{H}) \mathrm{F})(\mathrm{F}) \mathrm{F})(\mathrm{Br}) \mathrm{F})(\mathrm{H}) \mathrm{H})(\mathrm{H}) \mathrm{H})(\mathrm{Cl}) \mathrm{Br})(\mathrm{H}) \mathrm{F})(\mathrm{F}) \mathrm{H})\left(\mathrm{Cl}_{4} \mathrm{H} 14 \mathrm{ClBr} 3 \mathrm{~F} 12\right.\right.\right.$

F)F)(F)H)(H)(F)H

$\mathrm{C}(\mathrm{C}(\mathrm{C}(\mathrm{C}(\mathrm{C}(\mathrm{C}(\mathrm{C}(\mathrm{C}(\mathrm{C}(\mathrm{C}(\mathrm{C}(\mathrm{C}(\mathrm{C}(\mathrm{C}(\mathrm{F})(\mathrm{H}) \mathrm{H})(\mathrm{F}) \mathrm{Br})(\mathrm{H}) \mathrm{H})(\mathrm{H}) \mathrm{F})(\mathrm{H}) \mathrm{H})(\mathrm{H}) \mathrm{F})(\mathrm{F}) \mathrm{H})(\mathrm{F}) \mathrm{H})(\mathrm{F}) \mathrm{Br})(\mathrm{F}) \mathrm{F})(\mathrm{F}) \mathrm{F})$ $(\mathrm{H}) \mathrm{H})(\mathrm{F}) \mathrm{H})(\mathrm{H})(\mathrm{H}) \mathrm{F}$

$\mathrm{C}(\mathrm{C}(\mathrm{C}(\mathrm{C}(\mathrm{C}(\mathrm{C}(\mathrm{C}(\mathrm{C}(\mathrm{C}(\mathrm{C}(\mathrm{C}(\mathrm{C}(\mathrm{C}(\mathrm{C}(\mathrm{H})(\mathrm{F}) \mathrm{H})(\mathrm{H}) \mathrm{F})(\mathrm{F}) \mathrm{F})(\mathrm{F}) \mathrm{H})(\mathrm{H}) \mathrm{Br})(\mathrm{F}) \mathrm{H})(\mathrm{H}) \mathrm{H})(\mathrm{H}) \mathrm{F})(\mathrm{F}) \mathrm{H})(\mathrm{H}) \mathrm{F})(\mathrm{F}) \mathrm{H})$

$(\mathrm{Br}) \mathrm{H})(\mathrm{Br}) \mathrm{H})(\mathrm{H})(\mathrm{F}) \mathrm{Br}$

$\mathrm{C} 14 \mathrm{H} 15 \mathrm{Br} 2 \mathrm{~F} 13$

H)F (F)H)(H)(F)Br

$\mathrm{C}(\mathrm{C}(\mathrm{C}(\mathrm{C}(\mathrm{C}(\mathrm{C}(\mathrm{C}(\mathrm{C}(\mathrm{C}(\mathrm{C}(\mathrm{C}(\mathrm{C}(\mathrm{C}(\mathrm{C}(\mathrm{Cl})(\mathrm{F}) \mathrm{H})(\mathrm{H}) \mathrm{H})(\mathrm{H}) \mathrm{Br})(\mathrm{F}) \mathrm{H})(\mathrm{F}) \mathrm{H})(\mathrm{H}) \mathrm{H})(\mathrm{F}) \mathrm{F})(\mathrm{H}) \mathrm{H})(\mathrm{H}) \mathrm{Br})(\mathrm{F}) \mathrm{H})(\mathrm{H}) \mathrm{F})(\mathrm{C} 14 \mathrm{H} 15 \mathrm{Cl} 2 \mathrm{Br} 3 \mathrm{~F} 1$

$\mathrm{Cl}) \mathrm{F})(\mathrm{H}) \mathrm{Br})(\mathrm{F})(\mathrm{F}) \mathrm{H}$
$\mathrm{C}(\mathrm{C}(\mathrm{C}(\mathrm{C}(\mathrm{C}(\mathrm{C}(\mathrm{C}(\mathrm{C}(\mathrm{C}(\mathrm{C}(\mathrm{C}(\mathrm{C}(\mathrm{C}(\mathrm{C}(\mathrm{H})(\mathrm{F}) \mathrm{H})(\mathrm{H}) \mathrm{H})(\mathrm{F}) \mathrm{H})(\mathrm{H}) \mathrm{F})(\mathrm{H}) \mathrm{F})(\mathrm{H}) \mathrm{Cl})(\mathrm{Cl}) \mathrm{H})(\mathrm{H}) \mathrm{F})(\mathrm{H}) \mathrm{H})(\mathrm{Cl}) \mathrm{F})(\mathrm{F}) \mathrm{F})($

$\mathrm{C}(\mathrm{C}(\mathrm{C}(\mathrm{C}(\mathrm{C}(\mathrm{C}(\mathrm{C}(\mathrm{C}(\mathrm{C}(\mathrm{C}(\mathrm{C}(\mathrm{C}(\mathrm{C}(\mathrm{C}(\mathrm{H})(\mathrm{F}) \mathrm{H})(\mathrm{H}) \mathrm{H})(\mathrm{F}) \mathrm{H})(\mathrm{H}) \mathrm{F})(\mathrm{H}) \mathrm{F})(\mathrm{H}) \mathrm{Cl})(\mathrm{Cl}) \mathrm{H})(\mathrm{H}) \mathrm{F})(\mathrm{H}) \mathrm{H})(\mathrm{Cl}) \mathrm{F})(\mathrm{F}) \mathrm{F})($

$\mathrm{F}) \mathrm{H})(\mathrm{Br}) \mathrm{F})(\mathrm{H})(\mathrm{F}) \mathrm{H}$

$\mathrm{C}(\mathrm{C}(\mathrm{C}(\mathrm{C}(\mathrm{C}(\mathrm{C}(\mathrm{C}(\mathrm{C}(\mathrm{C}(\mathrm{C}(\mathrm{C}(\mathrm{C}(\mathrm{C}(\mathrm{C}(\mathrm{H})(\mathrm{F}) \mathrm{F})(\mathrm{H}) \mathrm{F})(\mathrm{H}) \mathrm{F})(\mathrm{F}) \mathrm{F})(\mathrm{H}) \mathrm{H})(\mathrm{H}) \mathrm{Cl})(\mathrm{H}) \mathrm{Cl})(\mathrm{H}) \mathrm{F})(\mathrm{H}) \mathrm{H})(\mathrm{F}) \mathrm{Cl})(\mathrm{H}) \mathrm{H})(\mathrm{C}$

$\mathrm{Br}) \mathrm{Cl})(\mathrm{H}) \mathrm{F})(\mathrm{H})(\mathrm{H}) \mathrm{F}$

$\mathrm{C}(\mathrm{C}(\mathrm{C}(\mathrm{C}(\mathrm{C}(\mathrm{C}(\mathrm{C}(\mathrm{C}(\mathrm{C}(\mathrm{C}(\mathrm{C}(\mathrm{C}(\mathrm{C}(\mathrm{C}(\mathrm{H})(\mathrm{F}) \mathrm{H})(\mathrm{F}) \mathrm{H})(\mathrm{H}) \mathrm{F})(\mathrm{Cl}) \mathrm{F})(\mathrm{F}) \mathrm{H})(\mathrm{F}) \mathrm{H})(\mathrm{F}) \mathrm{H})(\mathrm{H}) \mathrm{F})(\mathrm{H}) \mathrm{H})(\mathrm{H}) \mathrm{H})(\mathrm{Cl}) \mathrm{F})$

$(\mathrm{H}) \mathrm{H})(\mathrm{F}) \mathrm{Cl})(\mathrm{H})(\mathrm{F}) \mathrm{C}$

$\mathrm{C}(\mathrm{C}(\mathrm{C}(\mathrm{C}(\mathrm{C}(\mathrm{C}(\mathrm{C}(\mathrm{C}(\mathrm{C}(\mathrm{C}(\mathrm{C}(\mathrm{C}(\mathrm{C}(\mathrm{C}(\mathrm{F})(\mathrm{H}) \mathrm{H})(\mathrm{F}) \mathrm{H})(\mathrm{Cl}) \mathrm{F})(\mathrm{H}) \mathrm{F})(\mathrm{H}) \mathrm{F})(\mathrm{F}) \mathrm{H})(\mathrm{H}) \mathrm{Cl})(\mathrm{H}) \mathrm{Cl})(\mathrm{F}) \mathrm{H})(\mathrm{Cl}) \mathrm{F})(\mathrm{F}) \mathrm{F})($

$\mathrm{H}) \mathrm{H})(\mathrm{H}) \mathrm{H})(\mathrm{Cl})(\mathrm{H}) \mathrm{H}$

$\mathrm{C}(\mathrm{C}(\mathrm{C}(\mathrm{C}(\mathrm{C}(\mathrm{C}(\mathrm{C}(\mathrm{C}(\mathrm{C}(\mathrm{C}(\mathrm{C}(\mathrm{C}(\mathrm{C}(\mathrm{C}(\mathrm{F})(\mathrm{F}) \mathrm{H})(\mathrm{H}) \mathrm{H})(\mathrm{H}) \mathrm{F})(\mathrm{Cl}) \mathrm{H})(\mathrm{Cl}) \mathrm{H})(\mathrm{H}) \mathrm{F})(\mathrm{H}) \mathrm{H})(\mathrm{F}) \mathrm{H})(\mathrm{H}) \mathrm{H})(\mathrm{Cl}) \mathrm{H})(\mathrm{F}) \mathrm{H})($

$\mathrm{F}) \mathrm{Cl}(\mathrm{H}) \mathrm{F})(\mathrm{Cl})(\mathrm{F}) \mathrm{Cl}$

$\mathrm{C}(\mathrm{C}(\mathrm{C}(\mathrm{C}(\mathrm{C}(\mathrm{C}(\mathrm{C}(\mathrm{C}(\mathrm{C}(\mathrm{C}(\mathrm{C}(\mathrm{C}(\mathrm{C}(\mathrm{C}(\mathrm{F})(\mathrm{F}) \mathrm{F})(\mathrm{H}) \mathrm{H})(\mathrm{H}) \mathrm{Cl})(\mathrm{F}) \mathrm{H})(\mathrm{H}) \mathrm{F})(\mathrm{F}) \mathrm{F})(\mathrm{H}) \mathrm{H})(\mathrm{H}) \mathrm{H})(\mathrm{H}) \mathrm{H})(\mathrm{F}) \mathrm{F})(\mathrm{Br}) \mathrm{F}) \quad \mathrm{C} 14 \mathrm{H} 15 \mathrm{ClBr} 2 \mathrm{~F} 12$

$(\mathrm{H}) \mathrm{Br})(\mathrm{F}) \mathrm{H})(\mathrm{H})(\mathrm{F}) \mathrm{H}$

$\mathrm{C}\left(\mathrm{C}\left(\mathrm{C}(\mathrm{C}(\mathrm{C}(\mathrm{C}(\mathrm{C}(\mathrm{C}(\mathrm{C}(\mathrm{C}(\mathrm{C}(\mathrm{C}(\mathrm{C}(\mathrm{C}(\mathrm{H})(\mathrm{F}) \mathrm{F})(\mathrm{F}) \mathrm{H})(\mathrm{H}) \mathrm{Br})(\mathrm{H}) \mathrm{H})(\mathrm{H}) \mathrm{H})(\mathrm{H}) \mathrm{H})(\mathrm{Br}) \mathrm{H})(\mathrm{H}) \mathrm{F})(\mathrm{H}) \mathrm{Br})(\mathrm{H}) \mathrm{F})(\mathrm{Cl}) \mathrm{F}){ }_{\mathrm{C} 14 \mathrm{H} 15 \mathrm{ClBr} 3 \mathrm{~F} 11}\right.\right.$

(F)H)(F)F)(F)(H)F

$\mathrm{C}\left(\mathrm{C}\left(\mathrm{C}(\mathrm{C}(\mathrm{C}(\mathrm{C}(\mathrm{C}(\mathrm{C}(\mathrm{C}(\mathrm{C}(\mathrm{C}(\mathrm{C}(\mathrm{C}(\mathrm{C}(\mathrm{H})(\mathrm{F}) \mathrm{F})(\mathrm{H}) \mathrm{H})(\mathrm{H}) \mathrm{H})(\mathrm{H}) \mathrm{H})(\mathrm{H}) \mathrm{Br})(\mathrm{H}) \mathrm{F})(\mathrm{F}) \mathrm{H})(\mathrm{F}) \mathrm{H})(\mathrm{H}) \mathrm{Br})(\mathrm{Br}) \mathrm{F})(\mathrm{H}) \mathrm{H}){ }_{\mathrm{C} 14 \mathrm{H} 16 \mathrm{Br} 3 \mathrm{~F} 11}\right.\right.$

(F)F)(F)F)(H)(F)H

$\mathrm{C}(\mathrm{C}(\mathrm{C}(\mathrm{C}(\mathrm{C}(\mathrm{C}(\mathrm{C}(\mathrm{C}(\mathrm{C}(\mathrm{C}(\mathrm{C}(\mathrm{C}(\mathrm{C}(\mathrm{C}(\mathrm{Cl})(\mathrm{H}) \mathrm{H})(\mathrm{F}) \mathrm{F})(\mathrm{Br}) \mathrm{H})(\mathrm{H}) \mathrm{Cl})(\mathrm{F}) \mathrm{H})(\mathrm{F}) \mathrm{H})(\mathrm{H}) \mathrm{F})(\mathrm{H}) \mathrm{H})(\mathrm{H}) \mathrm{H})(\mathrm{H}) \mathrm{F})(\mathrm{Br}) \mathrm{H}) \mathrm{C} 14 \mathrm{H} 16 \mathrm{Cl} 2 \mathrm{Br} 2 \mathrm{~F} 1$

$(\mathrm{H}) \mathrm{F})(\mathrm{F}) \mathrm{H})(\mathrm{H})(\mathrm{F}) \mathrm{F} \quad 0$

(F) r)F $(\mathrm{F}) \mathrm{H})(\mathrm{H})(\mathrm{H}) \mathrm{F}$

$\mathrm{C}(\mathrm{C}(\mathrm{C}(\mathrm{C}(\mathrm{C}(\mathrm{C}(\mathrm{C}(\mathrm{C}(\mathrm{C}(\mathrm{C}(\mathrm{C}(\mathrm{C}(\mathrm{C}(\mathrm{C}(\mathrm{H})(\mathrm{H}) \mathrm{Cl})(\mathrm{H}) \mathrm{H})(\mathrm{F}) \mathrm{H})(\mathrm{F}) \mathrm{F})(\mathrm{F}) \mathrm{H})(\mathrm{Br}) \mathrm{Cl})(\mathrm{H}) \mathrm{Br})(\mathrm{H}) \mathrm{F})(\mathrm{H}) \mathrm{F})(\mathrm{H}) \mathrm{H})$

$(\mathrm{H}) \mathrm{Cl})(\mathrm{H}) \mathrm{F})(\mathrm{F}) \mathrm{H})(\mathrm{F})(\mathrm{H}) \mathrm{H}$

$\mathrm{C}(\mathrm{C}(\mathrm{C}(\mathrm{C}(\mathrm{C}(\mathrm{C}(\mathrm{C}(\mathrm{C}(\mathrm{C}(\mathrm{C}(\mathrm{C}(\mathrm{C}(\mathrm{C}(\mathrm{C}(\mathrm{H})(\mathrm{F}) \mathrm{F})(\mathrm{H}) \mathrm{H})(\mathrm{H}) \mathrm{Cl})(\mathrm{H}) \mathrm{H})(\mathrm{F}) \mathrm{F})(\mathrm{H}) \mathrm{H})(\mathrm{F}) \mathrm{H})(\mathrm{F}) \mathrm{Cl})(\mathrm{F}) \mathrm{F})(\mathrm{F}) \mathrm{F})(\mathrm{Cl}) \mathrm{H})$

$(\mathrm{H}) \mathrm{H})(\mathrm{H}) \mathrm{Br})(\mathrm{H})(\mathrm{H}) \mathrm{H}$

$\mathrm{F}) \mathrm{F})(\mathrm{H}) \mathrm{H})(\mathrm{F})(\mathrm{Cl}) \mathrm{F}$

$\mathrm{C}(\mathrm{C}(\mathrm{C}(\mathrm{C}(\mathrm{C}(\mathrm{C}(\mathrm{C}(\mathrm{C}(\mathrm{C}(\mathrm{C}(\mathrm{C}(\mathrm{C}(\mathrm{C}(\mathrm{C}(\mathrm{H})(\mathrm{H}) \mathrm{H})(\mathrm{F}) \mathrm{H})(\mathrm{H}) \mathrm{F})(\mathrm{H}) \mathrm{F})(\mathrm{F}) \mathrm{H})(\mathrm{H}) \mathrm{H})(\mathrm{F}) \mathrm{Cl})(\mathrm{F}) \mathrm{H})(\mathrm{F}) \mathrm{Cl})(\mathrm{H}) \mathrm{F})(\mathrm{F}) \mathrm{H})(\mathrm{C}$ l) $\mathrm{H})(\mathrm{Cl}) \mathrm{Cl}(\mathrm{H})(\mathrm{H}) \mathrm{H}$
EPISuit EPI EPI Exp Exp w DFT DFT DFT

e Suite Suite corr_corr _Exp corr_corr_corr

$\begin{array}{lllllllll}7.042 & 9.55 & 2.51 & 9.33 & 6.82 & 2.51 & 8.10 & 10.95 & -2.85\end{array}$

$\begin{array}{lllllllll}7.529 & 9.77 & 2.24 & 9.66 & 7.42 & 2.24 & 8.27 & 11.84 & -3.58\end{array}$

$\begin{array}{lllllllll}6.955 & 9.68 & 2.73 & 9.52 & 6.80 & 2.73 & 8.20 & 10.79 & -2.59\end{array}$

$\begin{array}{lllllllll}5.756 & 9.72 & 3.96 & 9.58 & 5.62 & 3.96 & 8.23 & 8.59 & -0.36\end{array}$

$\begin{array}{lllllllll}6.379 & 9.59 & 3.21 & 9.39 & 6.18 & 3.21 & 8.13 & 9.73 & -1.60\end{array}$

$\begin{array}{lllllllll}6.466 & 9.46 & 2.99 & 9.19 & 6.20 & 2.99 & 8.03 & 9.89 & -1.86\end{array}$

$\begin{array}{lllllllll}6.574 & 10.02 & 3.45 & 10.03 & 6.58 & 3.45 & 8.46 & 10.09 & -1.63\end{array}$

$\begin{array}{lllllllll}6.25 & 9.43 & 3.18 & 9.15 & 5.97 & 3.18 & 8.01 & 9.49 & -1.49\end{array}$

$\begin{array}{lllllllll}7.218 & 9.16 & 1.94 & 8.75 & 6.80 & 1.94 & 7.80 & 11.27 & -3.47\end{array}$

$\begin{array}{lllllllll}5.354 & 9.77 & 4.42 & 9.66 & 5.24 & 4.42 & 8.27 & 7.85 & 0.42\end{array}$

$\begin{array}{lllllllll}6.643 & 9.07 & 2.43 & 8.61 & 6.18 & 2.43 & 7.73 & 10.22 & -2.49\end{array}$

$\begin{array}{lllllllll}5.745 & 9.41 & 3.66 & 9.12 & 5.45 & 3.66 & 7.99 & 8.57 & -0.58\end{array}$

$\begin{array}{lllllllll}5.327 & 8.24 & 2.91 & 7.37 & 4.46 & 2.91 & 7.09 & 7.80 & -0.71\end{array}$

$\begin{array}{lllllllll}7.139 & 9.3 & 2.16 & 8.96 & 6.79 & 2.16 & 7.91 & 11.13 & -3.22\end{array}$

$\begin{array}{lllllllll}6.242 & 9.64 & 3.40 & 9.46 & 6.07 & 3.40 & 8.17 & 9.48 & -1.31\end{array}$

$\begin{array}{lllllllll}7.305 & 9.95 & 2.64 & 9.93 & 7.28 & 2.64 & 8.40 & 11.43 & -3.03\end{array}$

$\begin{array}{lllllllll}5.258 & 9.19 & 3.93 & 8.79 & 4.86 & 3.93 & 7.82 & 7.67 & 0.15\end{array}$

$\begin{array}{lllllllll}5.523 & 8.67 & 3.15 & 8.01 & 4.87 & 3.15 & 7.42 & 8.16 & -0.74\end{array}$

$\begin{array}{lllllllll}6.749 & 9.63 & 2.88 & 9.45 & 6.57 & 2.88 & 8.16 & 10.41 & -2.25\end{array}$

$\begin{array}{lllllllll}7.081 & 9.21 & 2.13 & 8.82 & 6.69 & 2.13 & 7.84 & 11.02 & -3.18\end{array}$

$\begin{array}{lllllllll}5.434 & 8.8 & 3.37 & 8.21 & 4.84 & 3.37 & 7.52 & 7.99 & -0.47\end{array}$

$\begin{array}{lllllllll}6.671 & 9.77 & 3.10 & 9.66 & 6.56 & 3.10 & 8.27 & 10.27 & -2.00\end{array}$

$\begin{array}{lllllllll}5.617 & 9.25 & 3.63 & 8.88 & 5.25 & 3.63 & 7.87 & 8.33 & -0.46\end{array}$

$\begin{array}{lllllllll}7.325 & 9.72 & 2.40 & 9.58 & 7.19 & 2.40 & 8.23 & 11.47 & -3.24\end{array}$

$\begin{array}{lllllllll}5.054 & 9.14 & 4.09 & 8.72 & 4.63 & 4.09 & 7.78 & 7.30 & 0.49\end{array}$

$\begin{array}{lllllllll}6.109 & 7.72 & 1.61 & 6.60 & 4.99 & 1.61 & 6.69 & 9.23 & -2.54\end{array}$

$\begin{array}{lllllllll}6.448 & 9.03 & 2.58 & 8.55 & 5.97 & 2.58 & 7.70 & 9.86 & -2.16\end{array}$

$\begin{array}{lllllllll}7.345 & 8.69 & 1.34 & 8.04 & 6.70 & 1.34 & 7.44 & 11.50 & -4.07\end{array}$

$\begin{array}{lllllllll}5.874 & 8.94 & 3.07 & 8.42 & 5.35 & 3.07 & 7.63 & 8.80 & -1.17\end{array}$

$\begin{array}{lllllllll}6.935 & 9.25 & 2.31 & 8.88 & 6.57 & 2.31 & 7.87 & 10.75 & -2.88\end{array}$

$\begin{array}{lllllllll}5.298 & 8.85 & 3.55 & 8.28 & 4.73 & 3.55 & 7.56 & 7.74 & -0.19\end{array}$

$\begin{array}{lllllllll}6.361 & 9.16 & 2.80 & 8.75 & 5.95 & 2.80 & 7.80 & 9.70 & -1.90\end{array}$

$\begin{array}{lllllllll}6.682 & 8.73 & 2.05 & 8.10 & 6.06 & 2.05 & 7.47 & 10.29 & -2.82\end{array}$

$\begin{array}{lllllllll}6.117 & 9.45 & 3.33 & 9.18 & 5.85 & 3.33 & 8.02 & 9.25 & -1.23\end{array}$

$\begin{array}{lllllllll}6.274 & 8.37 & 2.10 & 7.57 & 5.47 & 2.10 & 7.19 & 9.54 & -2.35\end{array}$

$\begin{array}{lllllllll}6.38 & 8.93 & 2.55 & 8.40 & 5.85 & 2.55 & 7.62 & 9.73 & -2.11\end{array}$

$\begin{array}{lllllllll}5.397 & 7.68 & 2.28 & 6.54 & 4.25 & 2.28 & 6.66 & 7.93 & -1.27\end{array}$

$\begin{array}{lllllllll}5.98 & 9.5 & 3.52 & 9.25 & 5.73 & 3.52 & 8.06 & 9.00 & -0.94\end{array}$

$\begin{array}{lllllllll}7.199 & 8.73 & 1.53 & 8.10 & 6.57 & 1.53 & 7.47 & 11.24 & -3.77\end{array}$

$\begin{array}{lllllllll}6.973 & 9.74 & 2.77 & 9.61 & 6.85 & 2.77 & 8.24 & 10.82 & -2.58\end{array}$

$\begin{array}{lllllllll}5.727 & 8.98 & 3.25 & 8.48 & 5.22 & 3.25 & 7.66 & 8.53 & -0.87\end{array}$

$\begin{array}{lllllllll}6.649 & 9.15 & 2.50 & 8.73 & 6.23 & 2.50 & 7.79 & 10.23 & -2.44\end{array}$ 
$\mathrm{C}\left(\mathrm{C}\left(\mathrm{C}(\mathrm{C}(\mathrm{C}(\mathrm{C}(\mathrm{C}(\mathrm{C}(\mathrm{C}(\mathrm{C}(\mathrm{C}(\mathrm{C}(\mathrm{C}(\mathrm{C}(\mathrm{H})(\mathrm{Br}) \mathrm{F})(\mathrm{H}) \mathrm{H})(\mathrm{H}) \mathrm{H})(\mathrm{H}) \mathrm{H})(\mathrm{F}) \mathrm{F})(\mathrm{F}) \mathrm{H})(\mathrm{H}) \mathrm{Br})(\mathrm{H}) \mathrm{H})(\mathrm{Br}) \mathrm{F})(\mathrm{F}) \mathrm{F})(\mathrm{H}) \mathrm{F})\left({ }_{\mathrm{C}}{ }^{2} 4 \mathrm{H} 16 \mathrm{ClBr} 3 \mathrm{~F} 10\right.\right.\right.$ $\mathrm{H}) \mathrm{H})(\mathrm{F}) \mathrm{H})(\mathrm{Cl})(\mathrm{H}) \mathrm{F}$

$\mathrm{C}\left(\mathrm{C}\left(\mathrm{C}(\mathrm{C}(\mathrm{C}(\mathrm{C}(\mathrm{C}(\mathrm{C}(\mathrm{C}(\mathrm{C}(\mathrm{C}(\mathrm{C}(\mathrm{C}(\mathrm{C}(\mathrm{F})(\mathrm{H}) \mathrm{Br})(\mathrm{F}) \mathrm{H})(\mathrm{H}) \mathrm{Br})(\mathrm{H}) \mathrm{F})(\mathrm{H}) \mathrm{H})(\mathrm{Br}) \mathrm{H})(\mathrm{F}) \mathrm{H})(\mathrm{H}) \mathrm{H})(\mathrm{H}) \mathrm{H})(\mathrm{F}) \mathrm{F})(\mathrm{H}) \mathrm{F})\left({ }_{\mathrm{C} 14 \mathrm{H} 16 \mathrm{ClBr} 4 \mathrm{~F} 9}\right.\right.\right.$ $\mathrm{H}) \mathrm{F})(\mathrm{H}) \mathrm{Br})(\mathrm{Cl})(\mathrm{H}) \mathrm{F}$

$\mathrm{C}\left(\mathrm{C}\left(\mathrm{C}(\mathrm{C}(\mathrm{C}(\mathrm{C}(\mathrm{C}(\mathrm{C}(\mathrm{C}(\mathrm{C}(\mathrm{C}(\mathrm{C}(\mathrm{C}(\mathrm{C}(\mathrm{H})(\mathrm{F}) \mathrm{Br})(\mathrm{F}) \mathrm{F})(\mathrm{H}) \mathrm{H})(\mathrm{H}) \mathrm{F})(\mathrm{Br}) \mathrm{H})(\mathrm{H}) \mathrm{F})(\mathrm{H}) \mathrm{H})(\mathrm{H}) \mathrm{Br})(\mathrm{F}) \mathrm{H})(\mathrm{H}) \mathrm{H})(\mathrm{H}) \mathrm{F})\left({ }_{\mathrm{C} 14 \mathrm{H} 17 \mathrm{Br} 3 \mathrm{~F} 10}\right.\right.\right.$ $\mathrm{H}) \mathrm{F})(\mathrm{F}) \mathrm{H})(\mathrm{H})(\mathrm{H}) \mathrm{F}$

$\mathrm{C}\left(\mathrm{C}\left(\mathrm{C}(\mathrm{C}(\mathrm{C}(\mathrm{C}(\mathrm{C}(\mathrm{C}(\mathrm{C}(\mathrm{C}(\mathrm{C}(\mathrm{C}(\mathrm{C}(\mathrm{C}(\mathrm{H})(\mathrm{F}) \mathrm{F})(\mathrm{H}) \mathrm{H})(\mathrm{F}) \mathrm{H})(\mathrm{H}) \mathrm{H})(\mathrm{F}) \mathrm{H})(\mathrm{H}) \mathrm{F})(\mathrm{Br}) \mathrm{H})(\mathrm{Cl}) \mathrm{F})(\mathrm{H}) \mathrm{H})(\mathrm{H}) \mathrm{H})(\mathrm{F}) \mathrm{H})\left({ }_{\mathrm{C}}{ }^{2} \mathrm{H}_{17} \mathrm{Cl} 2 \mathrm{Br} 2 \mathrm{~F} 9\right.\right.\right.$ $\mathrm{H}) \mathrm{Br}(\mathrm{H}) \mathrm{F})(\mathrm{Cl})(\mathrm{H}) \mathrm{F}$ $\mathrm{C}\left(\mathrm{C}\left(\mathrm{C}(\mathrm{C}(\mathrm{C}(\mathrm{C}(\mathrm{C}(\mathrm{C}(\mathrm{C}(\mathrm{C}(\mathrm{C}(\mathrm{C}(\mathrm{C}(\mathrm{C}(\mathrm{Br})(\mathrm{F}) \mathrm{Cl})(\mathrm{H}) \mathrm{F})(\mathrm{H}) \mathrm{H})(\mathrm{H}) \mathrm{F})(\mathrm{F}) \mathrm{F})(\mathrm{H}) \mathrm{H})(\mathrm{H}) \mathrm{H})(\mathrm{H}) \mathrm{F})(\mathrm{H}) \mathrm{Cl})(\mathrm{F}) \mathrm{H})(\mathrm{F}) \mathrm{H})\left({ }_{\mathrm{C}} \mathrm{C}_{4 \mathrm{H} 17 \mathrm{Cl} 2 \mathrm{BrF} 10}\right.\right.\right.$
$\mathrm{H}) \mathrm{H})(\mathrm{H}) \mathrm{H})(\mathrm{F})(\mathrm{F}) \mathrm{H}$

$\mathrm{C}\left(\mathrm{C}\left(\mathrm{C}(\mathrm{C}(\mathrm{C}(\mathrm{C}(\mathrm{C}(\mathrm{C}(\mathrm{C}(\mathrm{C}(\mathrm{C}(\mathrm{C}(\mathrm{C}(\mathrm{C}(\mathrm{F})(\mathrm{F}) \mathrm{Cl})(\mathrm{F}) \mathrm{H})(\mathrm{H}) \mathrm{H})(\mathrm{H}) \mathrm{Br})(\mathrm{F}) \mathrm{H})(\mathrm{F}) \mathrm{Cl})(\mathrm{F}) \mathrm{H})(\mathrm{H}) \mathrm{H})(\mathrm{H}) \mathrm{Cl})(\mathrm{H}) \mathrm{F})(\mathrm{F}) \mathrm{H})\left({ }_{\mathrm{C} 14 \mathrm{H} 17 \mathrm{Cl} 3 \mathrm{BrF} 9}\right.\right.\right.$ $\mathrm{H}) \mathrm{H})(\mathrm{H}) \mathrm{H})(\mathrm{F})(\mathrm{H}) \mathrm{H}$

$\mathrm{C}\left(\mathrm{C}\left(\mathrm{C}(\mathrm{C}(\mathrm{C}(\mathrm{C}(\mathrm{C}(\mathrm{C}(\mathrm{C}(\mathrm{C}(\mathrm{C}(\mathrm{C}(\mathrm{C}(\mathrm{C}(\mathrm{H})(\mathrm{H}) \mathrm{H})(\mathrm{Cl}) \mathrm{H})(\mathrm{H}) \mathrm{F})(\mathrm{H}) \mathrm{F})(\mathrm{H}) \mathrm{H})(\mathrm{Cl}) \mathrm{H})(\mathrm{H}) \mathrm{F})(\mathrm{H}) \mathrm{Cl})(\mathrm{F}) \mathrm{F})(\mathrm{H}) \mathrm{H})(\mathrm{F}) \mathrm{H})\left({ }_{\mathrm{C} 14 \mathrm{H} 17 \mathrm{Cl} 4 \mathrm{BrF} 8}\right.\right.\right.$ $\mathrm{Cl}) \mathrm{H})(\mathrm{H}) \mathrm{Br})(\mathrm{F})(\mathrm{H}) \mathrm{F}$

$\mathrm{C}\left(\mathrm{C}\left(\mathrm{C}(\mathrm{C}(\mathrm{C}(\mathrm{C}(\mathrm{C}(\mathrm{C}(\mathrm{C}(\mathrm{C}(\mathrm{C}(\mathrm{C}(\mathrm{C}(\mathrm{C}(\mathrm{Cl})(\mathrm{H}) \mathrm{H})(\mathrm{Cl}) \mathrm{H})(\mathrm{H}) \mathrm{F})(\mathrm{F}) \mathrm{H})(\mathrm{F}) \mathrm{H})(\mathrm{H}) \mathrm{F})(\mathrm{H}) \mathrm{F})(\mathrm{F}) \mathrm{H})(\mathrm{H}) \mathrm{H})(\mathrm{Cl}) \mathrm{F})(\mathrm{Cl}) \mathrm{H})\left({ }_{\mathrm{C} 14 \mathrm{H} 17 \mathrm{Cl} 4 \mathrm{~F} 9}\right.\right.\right.$ $\mathrm{H}) \mathrm{F})(\mathrm{H}) \mathrm{F})(\mathrm{H})(\mathrm{H}) \mathrm{H}$

$\mathrm{C}\left(\mathrm{C}\left(\mathrm{C}(\mathrm{C}(\mathrm{C}(\mathrm{C}(\mathrm{C}(\mathrm{C}(\mathrm{C}(\mathrm{C}(\mathrm{C}(\mathrm{C}(\mathrm{C}(\mathrm{C}(\mathrm{H})(\mathrm{F}) \mathrm{F})(\mathrm{F}) \mathrm{H})(\mathrm{H}) \mathrm{H})(\mathrm{H}) \mathrm{H})(\mathrm{H}) \mathrm{H})(\mathrm{H}) \mathrm{F})(\mathrm{H}) \mathrm{Cl})(\mathrm{F}) \mathrm{H})(\mathrm{F}) \mathrm{H})(\mathrm{H}) \mathrm{Cl})(\mathrm{Cl}) \mathrm{F})\left({ }_{\mathrm{Cl}} \mathrm{H}_{17} \mathrm{Cl} 5 \mathrm{~F} 8\right.\right.\right.$

$\mathrm{Cl}) \mathrm{H})(\mathrm{H}) \mathrm{F})(\mathrm{Cl})(\mathrm{H}) \mathrm{H}$

$\mathrm{C}\left(\mathrm{C}\left(\mathrm{C}(\mathrm{C}(\mathrm{C}(\mathrm{C}(\mathrm{C}(\mathrm{C}(\mathrm{C}(\mathrm{C}(\mathrm{C}(\mathrm{C}(\mathrm{C}(\mathrm{C}(\mathrm{H})(\mathrm{F}) \mathrm{Br})(\mathrm{F}) \mathrm{Br})(\mathrm{F}) \mathrm{Cl})(\mathrm{H}) \mathrm{F})(\mathrm{H}) \mathrm{H})(\mathrm{F}) \mathrm{F})(\mathrm{H}) \mathrm{F})(\mathrm{F}) \mathrm{F})(\mathrm{H}) \mathrm{F})(\mathrm{H}) \mathrm{H})(\mathrm{H}) \mathrm{H})\left(\mathrm{C}_{44 \mathrm{H} 17 \mathrm{ClBr} 2 \mathrm{~F} 10}\right.\right.\right.$ $\mathrm{H}) \mathrm{H})(\mathrm{H}) \mathrm{H})(\mathrm{H})(\mathrm{H}) \mathrm{H}$

$\mathrm{C}(\mathrm{C}(\mathrm{C}(\mathrm{C}(\mathrm{C}(\mathrm{C}(\mathrm{C}(\mathrm{C}(\mathrm{C}(\mathrm{C}(\mathrm{C}(\mathrm{C}(\mathrm{C}(\mathrm{C}(\mathrm{H})(\mathrm{H}) \mathrm{H})(\mathrm{Br}) \mathrm{F})(\mathrm{F}) \mathrm{F})(\mathrm{H}) \mathrm{H})(\mathrm{F}) \mathrm{H})(\mathrm{H}) \mathrm{H})(\mathrm{H}) \mathrm{H})(\mathrm{H}) \mathrm{H})(\mathrm{H}) \mathrm{H})(\mathrm{F}) \mathrm{Br})(\mathrm{H}) \mathrm{F})($

$\mathrm{F}) \mathrm{H})(\mathrm{F}) \mathrm{H})(\mathrm{H})(\mathrm{F}) \mathrm{F}$

$\mathrm{C}(\mathrm{C}(\mathrm{C}(\mathrm{C}(\mathrm{C}(\mathrm{C}(\mathrm{C}(\mathrm{C}(\mathrm{C}(\mathrm{C}(\mathrm{C}(\mathrm{C}(\mathrm{C}(\mathrm{C}(\mathrm{H})(\mathrm{H}) \mathrm{F})(\mathrm{F}) \mathrm{F})(\mathrm{H}) \mathrm{H})(\mathrm{H}) \mathrm{F})(\mathrm{H}) \mathrm{H})(\mathrm{Br}) \mathrm{H})(\mathrm{F}) \mathrm{H})(\mathrm{H}) \mathrm{F})(\mathrm{F}) \mathrm{H})(\mathrm{H}) \mathrm{Br})(\mathrm{H}) \mathrm{H})($ $\mathrm{Br}) \mathrm{H})(\mathrm{F}) \mathrm{F})(\mathrm{H})(\mathrm{H}) \mathrm{H}$

$\mathrm{C}\left(\mathrm{C}\left(\mathrm{C}(\mathrm{C}(\mathrm{C}(\mathrm{C}(\mathrm{C}(\mathrm{C}(\mathrm{C}(\mathrm{C}(\mathrm{C}(\mathrm{C}(\mathrm{C}(\mathrm{C}(\mathrm{H})(\mathrm{H}) \mathrm{F})(\mathrm{H}) \mathrm{Cl})(\mathrm{H}) \mathrm{F})(\mathrm{H}) \mathrm{F})(\mathrm{H}) \mathrm{Cl})(\mathrm{H}) \mathrm{H})(\mathrm{F}) \mathrm{H})(\mathrm{H}) \mathrm{F})(\mathrm{H}) \mathrm{Br})(\mathrm{H}) \mathrm{H})(\mathrm{F}) \mathrm{H})\left({ }_{\mathrm{C} 14 \mathrm{H} 18 \mathrm{Cl} 2 \mathrm{Br} 2 \mathrm{~F} 8}\right.\right.\right.$

$\mathrm{H}) \mathrm{F})(\mathrm{F}) \mathrm{Br})(\mathrm{H})(\mathrm{H}) \mathrm{H}$

$\mathrm{C}\left(\mathrm{C}\left(\mathrm{C}(\mathrm{C}(\mathrm{C}(\mathrm{C}(\mathrm{C}(\mathrm{C}(\mathrm{C}(\mathrm{C}(\mathrm{C}(\mathrm{C}(\mathrm{C}(\mathrm{C}(\mathrm{H})(\mathrm{H}) \mathrm{H})(\mathrm{Cl}) \mathrm{F})(\mathrm{H}) \mathrm{F})(\mathrm{F}) \mathrm{H})(\mathrm{H}) \mathrm{H})(\mathrm{F}) \mathrm{H})(\mathrm{H}) \mathrm{H})(\mathrm{Cl}) \mathrm{F})(\mathrm{H}) \mathrm{Br})(\mathrm{H}) \mathrm{F})(\mathrm{H}) \mathrm{H})\left({ }_{\mathrm{C} 14 \mathrm{H} 18 \mathrm{Cl} 3 \mathrm{BrF} 8}\right.\right.\right.$

$\mathrm{H}) \mathrm{F})(\mathrm{H}) \mathrm{H})(\mathrm{F})(\mathrm{Cl}) \mathrm{H}$

$\mathrm{C}(\mathrm{C}(\mathrm{C}(\mathrm{C}(\mathrm{C}(\mathrm{C}(\mathrm{C}(\mathrm{C}(\mathrm{C}(\mathrm{C}(\mathrm{C}(\mathrm{C}(\mathrm{C}(\mathrm{C}(\mathrm{F})(\mathrm{F}) \mathrm{H})(\mathrm{H}) \mathrm{H})(\mathrm{H}) \mathrm{H})(\mathrm{H}) \mathrm{Cl})(\mathrm{H}) \mathrm{H})(\mathrm{F}) \mathrm{F})(\mathrm{F}) \mathrm{H})(\mathrm{H}) \mathrm{H})(\mathrm{F}) \mathrm{H})(\mathrm{H}) \mathrm{H})(\mathrm{H}) \mathrm{H})$

$(\mathrm{F}) \mathrm{F})(\mathrm{H}) \mathrm{Cl})(\mathrm{F})(\mathrm{H}) \mathrm{Cl}$

$\mathrm{C}(\mathrm{C}(\mathrm{C}(\mathrm{C}(\mathrm{C}(\mathrm{C}(\mathrm{C}(\mathrm{C}(\mathrm{C}(\mathrm{C}(\mathrm{C}(\mathrm{C}(\mathrm{C}(\mathrm{C}(\mathrm{H})(\mathrm{Cl}) \mathrm{F})(\mathrm{H}) \mathrm{H})(\mathrm{H}) \mathrm{H})(\mathrm{H}) \mathrm{H})(\mathrm{H}) \mathrm{H})(\mathrm{Cl}) \mathrm{Cl})(\mathrm{H}) \mathrm{H})(\mathrm{H}) \mathrm{Br})(\mathrm{F}) \mathrm{H})(\mathrm{Cl}) \mathrm{H})(\mathrm{F}) \quad \mathrm{C} 14 \mathrm{H} 18 \mathrm{Cl} 4 \mathrm{BrF} 7$

$\mathrm{H})(\mathrm{F}) \mathrm{H})(\mathrm{F}) \mathrm{F})(\mathrm{H})(\mathrm{F}) \mathrm{H}$

$\mathrm{C}\left(\mathrm{C}\left(\mathrm{C}(\mathrm{C}(\mathrm{C}(\mathrm{C}(\mathrm{C}(\mathrm{C}(\mathrm{C}(\mathrm{C}(\mathrm{C}(\mathrm{C}(\mathrm{C}(\mathrm{C}(\mathrm{H})(\mathrm{H}) \mathrm{F})(\mathrm{H}) \mathrm{Cl})(\mathrm{H}) \mathrm{H})(\mathrm{H}) \mathrm{F})(\mathrm{Cl}) \mathrm{H})(\mathrm{F}) \mathrm{H})(\mathrm{H}) \mathrm{H})(\mathrm{Cl}) \mathrm{H})(\mathrm{F}) \mathrm{H})(\mathrm{H}) \mathrm{F})(\mathrm{H}) \mathrm{H})\left({ }_{\mathrm{C} 14 \mathrm{H} 18 \mathrm{Cl} 4 \mathrm{~F} 8}\right.\right.\right.$

$\mathrm{H}) \mathrm{Cl}(\mathrm{H}) \mathrm{F})(\mathrm{F})(\mathrm{H}) \mathrm{F}$

$\mathrm{C}(\mathrm{C}(\mathrm{C}(\mathrm{C}(\mathrm{C}(\mathrm{C}(\mathrm{C}(\mathrm{C}(\mathrm{C}(\mathrm{C}(\mathrm{C}(\mathrm{C}(\mathrm{C}(\mathrm{C}(\mathrm{F})(\mathrm{F}) \mathrm{H})(\mathrm{F}) \mathrm{H})(\mathrm{H}) \mathrm{H})(\mathrm{F}) \mathrm{H})(\mathrm{Cl}) \mathrm{H})(\mathrm{H}) \mathrm{F})(\mathrm{Cl}) \mathrm{H})(\mathrm{H}) \mathrm{H})(\mathrm{Cl}) \mathrm{H})(\mathrm{H}) \mathrm{H}) \quad \mathrm{C} 14 \mathrm{H} 18 \mathrm{Cl} 5 \mathrm{~F} 7$

$(\mathrm{Cl}) \mathrm{Cl})(\mathrm{H}) \mathrm{H})(\mathrm{H}) \mathrm{H})(\mathrm{F})(\mathrm{F}) \mathrm{H}$

$\mathrm{C}(\mathrm{C}(\mathrm{C}(\mathrm{C}(\mathrm{C}(\mathrm{C}(\mathrm{C}(\mathrm{C}(\mathrm{C}(\mathrm{C}(\mathrm{C}(\mathrm{C}(\mathrm{C}(\mathrm{C}(\mathrm{F})(\mathrm{H}) \mathrm{F})(\mathrm{H}) \mathrm{F})(\mathrm{F}) \mathrm{H})(\mathrm{H}) \mathrm{H})(\mathrm{Cl}) \mathrm{H})(\mathrm{F}) \mathrm{Br})(\mathrm{H}) \mathrm{F})(\mathrm{H}) \mathrm{F})(\mathrm{H}) \mathrm{H})(\mathrm{H}) \mathrm{H})(\mathrm{H}) \mathrm{H})($

$\mathrm{H}) \mathrm{F})(\mathrm{H}) \mathrm{H})(\mathrm{F})(\mathrm{Br}) \mathrm{H}$

$\mathrm{C}(\mathrm{C}(\mathrm{C}(\mathrm{C}(\mathrm{C}(\mathrm{C}(\mathrm{C}(\mathrm{C}(\mathrm{C}(\mathrm{C}(\mathrm{C}(\mathrm{C}(\mathrm{C}(\mathrm{C}(\mathrm{F})(\mathrm{F}) \mathrm{F})(\mathrm{H}) \mathrm{H})(\mathrm{H}) \mathrm{H})(\mathrm{H}) \mathrm{H})(\mathrm{Cl}) \mathrm{H})(\mathrm{H}) \mathrm{H})(\mathrm{F}) \mathrm{Br})(\mathrm{H}) \mathrm{F})(\mathrm{F}) \mathrm{H})(\mathrm{H}) \mathrm{H})(\mathrm{F}) \mathrm{F})($ $\mathrm{H}) \mathrm{H})(\mathrm{H}) \mathrm{H})(\mathrm{F})(\mathrm{H}) \mathrm{F}$

$\mathrm{C}(\mathrm{C}(\mathrm{C}(\mathrm{C}(\mathrm{C}(\mathrm{C}(\mathrm{C}(\mathrm{C}(\mathrm{C}(\mathrm{C}(\mathrm{C}(\mathrm{C}(\mathrm{C}(\mathrm{C}(\mathrm{H})(\mathrm{F}) \mathrm{F})(\mathrm{F}) \mathrm{H})(\mathrm{H}) \mathrm{H})(\mathrm{F}) \mathrm{F})(\mathrm{F}) \mathrm{H})(\mathrm{H}) \mathrm{H})(\mathrm{H}) \mathrm{F})(\mathrm{H}) \mathrm{H})(\mathrm{Br}) \mathrm{H})(\mathrm{H}) \mathrm{H})(\mathrm{F}) \mathrm{H})$

$(\mathrm{H}) \mathrm{H})(\mathrm{Br}) \mathrm{H})(\mathrm{H})(\mathrm{F}) \mathrm{H}$

$\mathrm{C}(\mathrm{C}(\mathrm{C}(\mathrm{C}(\mathrm{C}(\mathrm{C}(\mathrm{C}(\mathrm{C}(\mathrm{C}(\mathrm{C}(\mathrm{C}(\mathrm{C}(\mathrm{C}(\mathrm{C}(\mathrm{F})(\mathrm{H}) \mathrm{Br})(\mathrm{F}) \mathrm{F})(\mathrm{H}) \mathrm{H})(\mathrm{H}) \mathrm{H})(\mathrm{F}) \mathrm{F})(\mathrm{H}) \mathrm{H})(\mathrm{F}) \mathrm{H})(\mathrm{H}) \mathrm{H})(\mathrm{F}) \mathrm{F})(\mathrm{H}) \mathrm{Br})(\mathrm{H}) \mathrm{H})($

$\mathrm{H}) \mathrm{H})(\mathrm{H}) \mathrm{Br})(\mathrm{H})(\mathrm{H}) \mathrm{H}$

$\mathrm{C}\left(\mathrm{C}\left(\mathrm{C}(\mathrm{C}(\mathrm{C}(\mathrm{C}(\mathrm{C}(\mathrm{C}(\mathrm{C}(\mathrm{C}(\mathrm{C}(\mathrm{C}(\mathrm{C}(\mathrm{C}(\mathrm{H})(\mathrm{H}) \mathrm{H})(\mathrm{H}) \mathrm{H})(\mathrm{H}) \mathrm{H})(\mathrm{Br}) \mathrm{H})(\mathrm{H}) \mathrm{H})(\mathrm{F}) \mathrm{H})(\mathrm{F}) \mathrm{H})(\mathrm{F}) \mathrm{H})(\mathrm{H}) \mathrm{H})(\mathrm{F}) \mathrm{Br})(\mathrm{H}) \mathrm{H}){ }_{\mathrm{Cl}} 4 \mathrm{H} 19 \mathrm{Cl} 2 \mathrm{Br} 2 \mathrm{~F} 7\right.\right.$

(H)F)(F)H $(\mathrm{F})(\mathrm{Cl}) \mathrm{Cl}$

$\mathrm{C}\left(\mathrm{C}\left(\mathrm{C}(\mathrm{C}(\mathrm{C}(\mathrm{C}(\mathrm{C}(\mathrm{C}(\mathrm{C}(\mathrm{C}(\mathrm{C}(\mathrm{C}(\mathrm{C}(\mathrm{C}(\mathrm{Cl})(\mathrm{F}) \mathrm{F})(\mathrm{H}) \mathrm{H})(\mathrm{F}) \mathrm{H})(\mathrm{H}) \mathrm{Cl})(\mathrm{F}) \mathrm{H})(\mathrm{H}) \mathrm{F})(\mathrm{H}) \mathrm{H})(\mathrm{H}) \mathrm{F})(\mathrm{F}) \mathrm{H})(\mathrm{H}) \mathrm{H})(\mathrm{Br}) \mathrm{H})\left({ }_{\mathrm{C} 14 \mathrm{H} 19 \mathrm{Cl} 2 \mathrm{BrF} 8}\right.\right.\right.$

$\mathrm{H}) \mathrm{H})(\mathrm{H}) \mathrm{H})(\mathrm{H})(\mathrm{F}) \mathrm{H}$

$\mathrm{C}(\mathrm{C}(\mathrm{C}(\mathrm{C}(\mathrm{C}(\mathrm{C}(\mathrm{C}(\mathrm{C}(\mathrm{C}(\mathrm{C}(\mathrm{C}(\mathrm{C}(\mathrm{C}(\mathrm{C}(\mathrm{F})(\mathrm{H}) \mathrm{H})(\mathrm{F}) \mathrm{Cl})(\mathrm{H}) \mathrm{Cl})(\mathrm{Br}) \mathrm{H})(\mathrm{H}) \mathrm{H})(\mathrm{H}) \mathrm{H})(\mathrm{F}) \mathrm{H})(\mathrm{H}) \mathrm{H})(\mathrm{F}) \mathrm{H})(\mathrm{Cl}) \mathrm{H})(\mathrm{F}) \mathrm{H})$ (H)F)(H)F)(H)(H)H

$\mathrm{C}\left(\mathrm{C}\left(\mathrm{C}(\mathrm{C}(\mathrm{C}(\mathrm{C}(\mathrm{C}(\mathrm{C}(\mathrm{C}(\mathrm{C}(\mathrm{C}(\mathrm{C}(\mathrm{C}(\mathrm{C}(\mathrm{H})(\mathrm{F}) \mathrm{F})(\mathrm{H}) \mathrm{H})(\mathrm{H}) \mathrm{H})(\mathrm{F}) \mathrm{F})(\mathrm{H}) \mathrm{H})(\mathrm{H}) \mathrm{H})(\mathrm{F}) \mathrm{H})(\mathrm{Cl}) \mathrm{F})(\mathrm{H}) \mathrm{F})(\mathrm{F}) \mathrm{H})(\mathrm{Cl}) \mathrm{H})\left(\mathrm{Cl}_{4} \mathrm{H} 19 \mathrm{Cl} 3 \mathrm{~F} 8\right.\right.\right.$

$\mathrm{H}) \mathrm{H})(\mathrm{Cl}) \mathrm{H})(\mathrm{H})(\mathrm{H}) \mathrm{H}$

$\mathrm{C}\left(\mathrm{C}\left(\mathrm{C}(\mathrm{C}(\mathrm{C}(\mathrm{C}(\mathrm{C}(\mathrm{C}(\mathrm{C}(\mathrm{C}(\mathrm{C}(\mathrm{C}(\mathrm{C}(\mathrm{C}(\mathrm{H})(\mathrm{F}) \mathrm{H})(\mathrm{F}) \mathrm{H})(\mathrm{F}) \mathrm{F})(\mathrm{H}) \mathrm{H})(\mathrm{H}) \mathrm{H})(\mathrm{H}) \mathrm{H})(\mathrm{H}) \mathrm{H})(\mathrm{F}) \mathrm{Cl})(\mathrm{H}) \mathrm{Cl})(\mathrm{H}) \mathrm{F})(\mathrm{H}) \mathrm{Cl})\left({ }_{\mathrm{Cl}} \mathrm{H} 19 \mathrm{Cl} 4 \mathrm{~F} 7\right.\right.\right.$

$\mathrm{H}) \mathrm{H})(\mathrm{H}) \mathrm{Cl})(\mathrm{H})(\mathrm{H}) \mathrm{F}$

$\mathrm{C}\left(\mathrm{C}\left(\mathrm{C}(\mathrm{C}(\mathrm{C}(\mathrm{C}(\mathrm{C}(\mathrm{C}(\mathrm{C}(\mathrm{C}(\mathrm{C}(\mathrm{C}(\mathrm{C}(\mathrm{C}(\mathrm{Cl})(\mathrm{Br}) \mathrm{F})(\mathrm{H}) \mathrm{H})(\mathrm{H}) \mathrm{F})(\mathrm{H}) \mathrm{H})(\mathrm{F}) \mathrm{H})(\mathrm{F}) \mathrm{H})(\mathrm{H}) \mathrm{H})(\mathrm{H}) \mathrm{H})(\mathrm{H}) \mathrm{H})(\mathrm{H}) \mathrm{H})(\mathrm{F}) \mathrm{Br}){ }_{\mathrm{C} 14 \mathrm{H} 19 \mathrm{ClBr} 2 \mathrm{~F} 8}\right.\right.$

(H)F)(H)F)(F)(H)H

$\mathrm{C}(\mathrm{C}(\mathrm{C}(\mathrm{C}(\mathrm{C}(\mathrm{C}(\mathrm{C}(\mathrm{C}(\mathrm{C}(\mathrm{C}(\mathrm{C}(\mathrm{C}(\mathrm{C}(\mathrm{C}(\mathrm{Br})(\mathrm{H}) \mathrm{F})(\mathrm{H}) \mathrm{H})(\mathrm{F}) \mathrm{Br})(\mathrm{H}) \mathrm{H})(\mathrm{H}) \mathrm{Br})(\mathrm{F}) \mathrm{H})(\mathrm{H}) \mathrm{H})(\mathrm{H}) \mathrm{F})(\mathrm{Cl}) \mathrm{H})(\mathrm{H}) \mathrm{F})$

$(\mathrm{H}) \mathrm{H})(\mathrm{H}) \mathrm{H})(\mathrm{F}) \mathrm{H})(\mathrm{F})(\mathrm{H}) \mathrm{H}$

$\mathrm{C}(\mathrm{C}(\mathrm{C}(\mathrm{C}(\mathrm{C}(\mathrm{C}(\mathrm{C}(\mathrm{C}(\mathrm{C}(\mathrm{C}(\mathrm{C}(\mathrm{C}(\mathrm{C}(\mathrm{C}(\mathrm{H})(\mathrm{F}) \mathrm{H})(\mathrm{H}) \mathrm{H})(\mathrm{F}) \mathrm{F})(\mathrm{F}) \mathrm{Cl})(\mathrm{H}) \mathrm{H})(\mathrm{H}) \mathrm{F})(\mathrm{Br}) \mathrm{H})(\mathrm{H}) \mathrm{H})(\mathrm{F}) \mathrm{H})(\mathrm{H}) \mathrm{F})(\mathrm{H}) \mathrm{F})$

(F)H $(\mathrm{H}) \mathrm{H})(\mathrm{H})(\mathrm{H}) \mathrm{H}$

$\mathrm{C}\left(\mathrm{C}\left(\mathrm{C}(\mathrm{C}(\mathrm{C}(\mathrm{C}(\mathrm{C}(\mathrm{C}(\mathrm{C}(\mathrm{C}(\mathrm{C}(\mathrm{C}(\mathrm{C}(\mathrm{C}(\mathrm{H})(\mathrm{H}) \mathrm{H})(\mathrm{F}) \mathrm{H})(\mathrm{F}) \mathrm{F})(\mathrm{Br}) \mathrm{F})(\mathrm{H}) \mathrm{H})(\mathrm{H}) \mathrm{H})(\mathrm{H}) \mathrm{H})(\mathrm{H}) \mathrm{H})(\mathrm{H}) \mathrm{F})(\mathrm{Br}) \mathrm{H})(\mathrm{F}) \mathrm{H})\left(\mathrm{Cl}_{\mathrm{C}} 4 \mathrm{H} 20 \mathrm{Br} 2 \mathrm{~F} 8\right.\right.\right.$

$\mathrm{H}) \mathrm{F})(\mathrm{H}) \mathrm{H})(\mathrm{H})(\mathrm{F}) \mathrm{H}$

$\mathrm{C}(\mathrm{C}(\mathrm{C}(\mathrm{C}(\mathrm{C}(\mathrm{C}(\mathrm{C}(\mathrm{C}(\mathrm{C}(\mathrm{C}(\mathrm{C}(\mathrm{C}(\mathrm{C}(\mathrm{C}(\mathrm{F})(\mathrm{H}) \mathrm{H})(\mathrm{H}) \mathrm{F})(\mathrm{H}) \mathrm{F})(\mathrm{H}) \mathrm{H})(\mathrm{H}) \mathrm{F})(\mathrm{Br}) \mathrm{F})(\mathrm{H}) \mathrm{H})(\mathrm{H}) \mathrm{H})(\mathrm{Br}) \mathrm{H})(\mathrm{H}) \mathrm{H})(\mathrm{H}) \mathrm{Br})$

(H)F)(F)H $(\mathrm{H})(\mathrm{H}) \mathrm{H}$

$\mathrm{C}(\mathrm{C}(\mathrm{C}(\mathrm{C}(\mathrm{C}(\mathrm{C}(\mathrm{C}(\mathrm{C}(\mathrm{C}(\mathrm{C}(\mathrm{C}(\mathrm{C}(\mathrm{C}(\mathrm{C}(\mathrm{Br})(\mathrm{H}) \mathrm{H})(\mathrm{H}) \mathrm{F})(\mathrm{H}) \mathrm{H})(\mathrm{F}) \mathrm{H})(\mathrm{H}) \mathrm{H})(\mathrm{Br}) \mathrm{H})(\mathrm{H}) \mathrm{H})(\mathrm{H}) \mathrm{F})(\mathrm{H}) \mathrm{F})(\mathrm{H}) \mathrm{H})$

$(\mathrm{Br}) \mathrm{H})(\mathrm{H}) \mathrm{H})(\mathrm{H}) \mathrm{F})(\mathrm{F})(\mathrm{H}) \mathrm{Br}$

$\mathrm{C}(\mathrm{C}(\mathrm{C}(\mathrm{C}(\mathrm{C}(\mathrm{C}(\mathrm{C}(\mathrm{C}(\mathrm{C}(\mathrm{C}(\mathrm{C}(\mathrm{C}(\mathrm{C}(\mathrm{C}(\mathrm{F})(\mathrm{H}) \mathrm{H})(\mathrm{H}) \mathrm{H})(\mathrm{H}) \mathrm{F})(\mathrm{H}) \mathrm{H})(\mathrm{H}) \mathrm{H})(\mathrm{H}) \mathrm{H})(\mathrm{F}) \mathrm{H})(\mathrm{F}) \mathrm{Br})(\mathrm{H}) \mathrm{F})(\mathrm{Br}) \mathrm{H})(\mathrm{H}) \mathrm{Cl})$

$(\mathrm{H}) \mathrm{Cl})(\mathrm{H}) \mathrm{H})(\mathrm{H})(\mathrm{H}) \mathrm{F}$

$\mathrm{C}(\mathrm{C}(\mathrm{C}(\mathrm{C}(\mathrm{C}(\mathrm{C}(\mathrm{C}(\mathrm{C}(\mathrm{C}(\mathrm{C}(\mathrm{C}(\mathrm{C}(\mathrm{C}(\mathrm{C}(\mathrm{H})(\mathrm{H}) \mathrm{F})(\mathrm{H}) \mathrm{Cl})(\mathrm{H}) \mathrm{H})(\mathrm{Cl}) \mathrm{F})(\mathrm{F}) \mathrm{H})(\mathrm{H}) \mathrm{F})(\mathrm{H}) \mathrm{H})(\mathrm{H}) \mathrm{H})(\mathrm{H}) \mathrm{H})(\mathrm{H}) \mathrm{H})(\mathrm{H}) \mathrm{F})($

$\mathrm{H}) \mathrm{F})(\mathrm{F}) \mathrm{H})(\mathrm{H})(\mathrm{Br}) \mathrm{H}$

$\mathrm{C}\left(\mathrm{C}\left(\mathrm{C}(\mathrm{C}(\mathrm{C}(\mathrm{C}(\mathrm{C}(\mathrm{C}(\mathrm{C}(\mathrm{C}(\mathrm{C}(\mathrm{C}(\mathrm{C}(\mathrm{C}(\mathrm{H})(\mathrm{H}) \mathrm{F})(\mathrm{H}) \mathrm{F})(\mathrm{H}) \mathrm{H})(\mathrm{H}) \mathrm{F})(\mathrm{H}) \mathrm{H})(\mathrm{F}) \mathrm{H})(\mathrm{H}) \mathrm{Cl})(\mathrm{H}) \mathrm{H})(\mathrm{H}) \mathrm{H})(\mathrm{F}) \mathrm{Cl})(\mathrm{H}) \mathrm{F})\left({ }_{\mathrm{C} 14 \mathrm{H} 20 \mathrm{Cl} 3 \mathrm{BrF} 6}\right.\right.\right.$

$\mathrm{H}) \mathrm{Cl}(\mathrm{H}) \mathrm{H})(\mathrm{H})(\mathrm{Br}) \mathrm{H}$

$\mathrm{C}\left(\mathrm{C}\left(\mathrm{C}(\mathrm{C}(\mathrm{C}(\mathrm{C}(\mathrm{C}(\mathrm{C}(\mathrm{C}(\mathrm{C}(\mathrm{C}(\mathrm{C}(\mathrm{C}(\mathrm{C}(\mathrm{H})(\mathrm{H}) \mathrm{F})(\mathrm{F}) \mathrm{Cl})(\mathrm{H}) \mathrm{F})(\mathrm{H}) \mathrm{H})(\mathrm{H}) \mathrm{H})(\mathrm{H}) \mathrm{F})(\mathrm{Cl}) \mathrm{H})(\mathrm{H}) \mathrm{H})(\mathrm{H}) \mathrm{F})(\mathrm{H}) \mathrm{H})(\mathrm{H}) \mathrm{H})\left({ }_{\mathrm{C} 14 \mathrm{H} 20 \mathrm{Cl} 3 \mathrm{~F} 7}\right.\right.\right.$

$\mathrm{Cl}) \mathrm{H})(\mathrm{F}) \mathrm{H})(\mathrm{H})(\mathrm{F}) \mathrm{H}$

$\mathrm{C}(\mathrm{C}(\mathrm{C}(\mathrm{C}(\mathrm{C}(\mathrm{C}(\mathrm{C}(\mathrm{C}(\mathrm{C}(\mathrm{C}(\mathrm{C}(\mathrm{C}(\mathrm{C}(\mathrm{C}(\mathrm{H})(\mathrm{H}) \mathrm{Cl})(\mathrm{Br}) \mathrm{F})(\mathrm{Cl}) \mathrm{H})(\mathrm{H}) \mathrm{F})(\mathrm{H}) \mathrm{H})(\mathrm{H}) \mathrm{H})(\mathrm{F}) \mathrm{H})(\mathrm{H}) \mathrm{F})(\mathrm{H}) \mathrm{F})(\mathrm{H}) \mathrm{H})(\mathrm{H}) \mathrm{H})$ $(\mathrm{H}) \mathrm{Cl}(\mathrm{H}) \mathrm{Cl})(\mathrm{H})(\mathrm{H}) \mathrm{H}$

$(\mathrm{H}) \mathrm{Cl})(\mathrm{H}) \mathrm{Cl})(\mathrm{H})(\mathrm{H}) \mathrm{H}$
$\mathrm{C}\left(\mathrm{C}\left(\mathrm{C}(\mathrm{C}(\mathrm{C}(\mathrm{C}(\mathrm{C}(\mathrm{C}(\mathrm{C}(\mathrm{C}(\mathrm{C}(\mathrm{C}(\mathrm{C}(\mathrm{C}(\mathrm{H})(\mathrm{H}) \mathrm{Cl})(\mathrm{H}) \mathrm{F})(\mathrm{H}) \mathrm{F})(\mathrm{Cl}) \mathrm{H})(\mathrm{H}) \mathrm{Cl})(\mathrm{H}) \mathrm{F})(\mathrm{H}) \mathrm{Cl})(\mathrm{H}) \mathrm{H})(\mathrm{F}) \mathrm{F})(\mathrm{H}) \mathrm{H})(\mathrm{H}) \mathrm{H}){ }_{\mathrm{Cl}} 4 \mathrm{H} 20 \mathrm{Cl} 4 \mathrm{~F} 6\right.\right.$

$(\mathrm{H}) \mathrm{H})(\mathrm{F}) \mathrm{H})(\mathrm{H})(\mathrm{H}) \mathrm{H}$

$\mathrm{C}\left(\mathrm{C}\left(\mathrm{C}\left(\mathrm{C}(\mathrm{C}(\mathrm{C}(\mathrm{C}(\mathrm{C}(\mathrm{C}(\mathrm{C}(\mathrm{C}(\mathrm{C}(\mathrm{C}(\mathrm{C}(\mathrm{F})(\mathrm{H}) \mathrm{H})(\mathrm{H}) \mathrm{H})(\mathrm{H}) \mathrm{H})(\mathrm{H}) \mathrm{H})(\mathrm{H}) \mathrm{Cl})(\mathrm{H}) \mathrm{H})(\mathrm{F}) \mathrm{H})(\mathrm{H}) \mathrm{Cl})(\mathrm{F}) \mathrm{H})(\mathrm{Cl}) \mathrm{Cl})(\mathrm{H}) \mathrm{C}{ }_{\mathrm{C} 14 \mathrm{H} 20 \mathrm{Cl} 5 \mathrm{~F} 5}\right.\right.\right.$ 1)(H)F)(H)H)(F)(H)H

$\mathrm{C}\left(\mathrm{C}\left(\mathrm{C}(\mathrm{C}(\mathrm{C}(\mathrm{C}(\mathrm{C}(\mathrm{C}(\mathrm{C}(\mathrm{C}(\mathrm{C}(\mathrm{C}(\mathrm{C}(\mathrm{C}(\mathrm{H})(\mathrm{Br}) \mathrm{H})(\mathrm{F}) \mathrm{H})(\mathrm{H}) \mathrm{H})(\mathrm{H}) \mathrm{H})(\mathrm{H}) \mathrm{F})(\mathrm{Br}) \mathrm{F})(\mathrm{H}) \mathrm{F})(\mathrm{F}) \mathrm{H})(\mathrm{H}) \mathrm{H})(\mathrm{H}) \mathrm{F})(\mathrm{F}) \mathrm{H})\left({ }_{\mathrm{C} 14 \mathrm{H} 20 \mathrm{ClBr} 2 \mathrm{~F} 7}\right.\right.\right.$

$\mathrm{Cl}) \mathrm{H})(\mathrm{H}) \mathrm{H})(\mathrm{H})(\mathrm{H}) \mathrm{H}$

$\mathrm{C}(\mathrm{C}(\mathrm{C}(\mathrm{C}(\mathrm{C}(\mathrm{C}(\mathrm{C}(\mathrm{C}(\mathrm{C}(\mathrm{C}(\mathrm{C}(\mathrm{C}(\mathrm{C}(\mathrm{C}(\mathrm{F})(\mathrm{H}) \mathrm{H})(\mathrm{H}) \mathrm{F})(\mathrm{H}) \mathrm{F})(\mathrm{F}) \mathrm{H})(\mathrm{H}) \mathrm{H})(\mathrm{H}) \mathrm{H})(\mathrm{H}) \mathrm{H})(\mathrm{Br}) \mathrm{H})(\mathrm{H}) \mathrm{F})(\mathrm{H}) \mathrm{H})(\mathrm{Br}) \mathrm{H})$ $(\mathrm{H}) \mathrm{F})(\mathrm{H}) \mathrm{H})(\mathrm{H})(\mathrm{H}) \mathrm{F}$

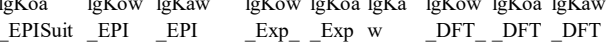

e Suite Suite corr_corr_Exp corr__corr _corr

$\begin{array}{lllllllll}7.451 & 9.25 & 1.80 & 8.88 & 7.08 & 1.80 & 7.87 & 11.70 & -3.83\end{array}$

$\begin{array}{lllllllll}7.61 & 8.17 & 0.56 & 7.27 & 6.71 & 0.56 & 7.04 & 11.99 & -4.95\end{array}$

$\begin{array}{lllllllll}5.339 & 7.59 & 2.25 & 6.40 & 4.15 & 2.25 & 6.59 & 7.82 & -1.23\end{array}$

$\begin{array}{lllllllll}5.826 & 7.81 & 1.98 & 6.73 & 4.75 & 1.98 & 6.76 & 8.71 & -1.95\end{array}$

$\begin{array}{lllllllll}4.929 & 8.15 & 3.22 & 7.24 & 4.02 & 3.22 & 7.02 & 7.07 & -0.05\end{array}$

$\begin{array}{lllllllll}5.991 & 8.46 & 2.47 & 7.70 & 5.23 & 2.47 & 7.26 & 9.02 & -1.76\end{array}$

$\begin{array}{lllllllll}6.241 & 7.96 & 1.72 & 6.96 & 5.24 & 1.72 & 6.88 & 9.48 & -2.60\end{array}$

$\begin{array}{lllllllll}4.606 & 7.56 & 2.95 & 6.36 & 3.40 & 2.95 & 6.57 & 6.47 & 0.09\end{array}$

$\begin{array}{lllllllll}5.737 & 7.94 & 2.20 & 6.93 & 4.72 & 2.20 & 6.86 & 8.55 & -1.69\end{array}$

$\begin{array}{lllllllll}6.915 & 9.65 & 2.74 & 9.48 & 6.74 & 2.74 & 8.17 & 10.71 & -2.54\end{array}$

$\begin{array}{lllllllll}5.531 & 8.72 & 3.19 & 8.09 & 4.90 & 3.19 & 7.46 & 8.17 & -0.71\end{array}$

$\begin{array}{lllllllll}6.438 & 8.39 & 1.95 & 7.60 & 5.65 & 1.95 & 7.21 & 9.84 & -2.63\end{array}$

$\begin{array}{lllllllll}6.183 & 7.87 & 1.69 & 6.82 & 5.13 & 1.69 & 6.81 & 9.37 & -2.56\end{array}$

$\begin{array}{lllllllll}6.35 & 8.52 & 2.17 & 7.79 & 5.62 & 2.17 & 7.31 & 9.68 & -2.37\end{array}$

$\begin{array}{lllllllll}4.782 & 8.19 & 3.41 & 7.30 & 3.89 & 3.41 & 7.05 & 6.80 & 0.26\end{array}$

$\begin{array}{lllllllll}7.491 & 8.91 & 1.42 & 8.37 & 6.95 & 1.42 & 7.61 & 11.77 & -4.17\end{array}$

$\begin{array}{lllllllll}4.363 & 7.02 & 2.66 & 5.55 & 2.90 & 2.66 & 6.15 & 6.03 & 0.13\end{array}$

$\begin{array}{lllllllll}6.176 & 8.08 & 1.90 & 7.13 & 5.23 & 1.90 & 6.97 & 9.36 & -2.39\end{array}$

$\begin{array}{lllllllll}5.192 & 7.63 & 2.44 & 6.46 & 4.03 & 2.44 & 6.62 & 7.55 & -0.93\end{array}$

$\begin{array}{lllllllll}5.034 & 8.71 & 3.68 & 8.07 & 4.40 & 3.68 & 7.45 & 7.26 & 0.19\end{array}$

$\begin{array}{lllllllll}4.56 & 7.45 & 2.89 & 6.19 & 3.30 & 2.89 & 6.48 & 6.39 & 0.09\end{array}$

$\begin{array}{lllllllll}7.607 & 9.26 & 1.65 & 8.90 & 7.24 & 1.65 & 7.87 & 11.99 & -4.11\end{array}$

$\begin{array}{lllllllll}7.353 & 8.74 & 1.39 & 8.12 & 6.73 & 1.39 & 7.47 & 11.52 & -4.04\end{array}$

$\begin{array}{lllllllll}5.046 & 7.67 & 2.62 & 6.52 & 3.90 & 2.62 & 6.65 & 7.28 & -0.63\end{array}$

$\begin{array}{lllllllll}6.038 & 7.91 & 1.87 & 6.88 & 5.01 & 1.87 & 6.84 & 9.10 & -2.27\end{array}$

$\begin{array}{lllllllll}5.142 & 8.25 & 3.11 & 7.39 & 4.28 & 3.11 & 7.10 & 7.46 & -0.36\end{array}$

$\begin{array}{lllllllll}6.283 & 8.64 & 2.36 & 7.97 & 5.61 & 2.36 & 7.40 & 9.55 & -2.16\end{array}$

$\begin{array}{lllllllll}6.361 & 8.5 & 2.14 & 7.76 & 5.62 & 2.14 & 7.29 & 9.70 & -2.41\end{array}$

$\begin{array}{lllllllll}7.268 & 8.17 & 0.90 & 7.27 & 6.37 & 0.90 & 7.04 & 11.36 & -4.33\end{array}$

$\begin{array}{lllllllll}4.654 & 8.03 & 3.38 & 7.06 & 3.68 & 3.38 & 6.93 & 6.56 & 0.37\end{array}$

$\begin{array}{lllllllll}5.658 & 8.25 & 2.59 & 7.39 & 4.80 & 2.59 & 7.10 & 8.41 & -1.31\end{array}$

$\begin{array}{lllllllll}6.556 & 7.91 & 1.35 & 6.88 & 5.53 & 1.35 & 6.84 & 10.06 & -3.22\end{array}$

$\begin{array}{lllllllll}7.532 & 7.65 & 0.12 & 6.49 & 6.37 & 0.12 & 6.64 & 11.85 & -5.21\end{array}$

$\begin{array}{lllllllll}7.123 & 8.21 & 1.09 & 7.33 & 6.24 & 1.09 & 7.07 & 11.10 & -4.03\end{array}$

$\begin{array}{lllllllll}5.485 & 7.81 & 2.32 & 6.73 & 4.41 & 2.32 & 6.76 & 8.09 & -1.33\end{array}$

$\begin{array}{lllllllll}6.547 & 8.12 & 1.57 & 7.19 & 5.62 & 1.57 & 7.00 & 10.04 & -3.04\end{array}$

$\begin{array}{lllllllll}4.91 & 7.72 & 2.81 & 6.60 & 3.79 & 2.81 & 6.69 & 7.03 & -0.34\end{array}$

$\begin{array}{lllllllll}7.539 & 8.36 & 0.82 & 7.55 & 6.73 & 0.82 & 7.18 & 11.86 & -4.68\end{array}$

$\begin{array}{lllllllll}5.901 & 7.96 & 2.06 & 6.96 & 4.90 & 2.06 & 6.88 & 8.85 & -1.98\end{array}$

$\begin{array}{lllllllll}7.034 & 8.34 & 1.31 & 7.52 & 6.22 & 1.31 & 7.17 & 10.93 & -3.77\end{array}$

$\begin{array}{lllllllll}5.981 & 7.82 & 1.84 & 6.75 & 4.91 & 1.84 & 6.77 & 9.00 & -2.23\end{array}$

$\begin{array}{lllllllll}4.677 & 6.97 & 2.29 & 5.48 & 3.18 & 2.29 & 6.12 & 6.60 & -0.49\end{array}$ 
$\mathrm{C}\left(\mathrm{C}\left(\mathrm{C}(\mathrm{C}(\mathrm{C}(\mathrm{C}(\mathrm{C}(\mathrm{C}(\mathrm{C}(\mathrm{C}(\mathrm{C}(\mathrm{C}(\mathrm{C}(\mathrm{C}(\mathrm{F})(\mathrm{F}) \mathrm{Br})(\mathrm{H}) \mathrm{H})(\mathrm{H}) \mathrm{H})(\mathrm{H}) \mathrm{H})(\mathrm{H}) \mathrm{F})(\mathrm{Cl}) \mathrm{F})(\mathrm{H}) \mathrm{H})(\mathrm{H}) \mathrm{H})(\mathrm{Cl}) \mathrm{H})(\mathrm{H}) \mathrm{F})(\mathrm{H}) \mathrm{F})\left({ }_{\mathrm{Cl}}{ }_{\mathrm{H}} 21 \mathrm{Cl} 2 \mathrm{BrF} 6\right.\right.\right.$ $\mathrm{H}) \mathrm{H})(\mathrm{H}) \mathrm{H})(\mathrm{H})(\mathrm{H}) \mathrm{H}$

$\mathrm{C}\left(\mathrm{C}\left(\mathrm{C}(\mathrm{C}(\mathrm{C}(\mathrm{C}(\mathrm{C}(\mathrm{C}(\mathrm{C}(\mathrm{C}(\mathrm{C}(\mathrm{C}(\mathrm{C}(\mathrm{C}(\mathrm{H})(\mathrm{H}) \mathrm{F})(\mathrm{F}) \mathrm{H})(\mathrm{H}) \mathrm{H})(\mathrm{Cl}) \mathrm{H})(\mathrm{F}) \mathrm{H})(\mathrm{F}) \mathrm{H})(\mathrm{H}) \mathrm{H})(\mathrm{Br}) \mathrm{H})(\mathrm{H}) \mathrm{H})(\mathrm{H}) \mathrm{H})(\mathrm{H}) \mathrm{Cl}){ }^{\mathrm{C} 14 \mathrm{H} 21 \mathrm{Cl} 3 \mathrm{BrF} 5}\right.\right.$ $(\mathrm{F}) \mathrm{H})(\mathrm{Cl}) \mathrm{H})(\mathrm{H})(\mathrm{H}) \mathrm{H}$

$\mathrm{C}\left(\mathrm{C}\left(\mathrm{C}(\mathrm{C}(\mathrm{C}(\mathrm{C}(\mathrm{C}(\mathrm{C}(\mathrm{C}(\mathrm{C}(\mathrm{C}(\mathrm{C}(\mathrm{C}(\mathrm{C}(\mathrm{H})(\mathrm{H}) \mathrm{H})(\mathrm{F}) \mathrm{H})(\mathrm{H}) \mathrm{H})(\mathrm{H}) \mathrm{H})(\mathrm{H}) \mathrm{H})(\mathrm{H}) \mathrm{F})(\mathrm{Cl}) \mathrm{H})(\mathrm{H}) \mathrm{H})(\mathrm{H}) \mathrm{H})(\mathrm{F}) \mathrm{F})(\mathrm{Cl}) \mathrm{H})\left({ }_{\mathrm{C} 14 \mathrm{H} 21 \mathrm{Cl} 3 \mathrm{~F} 6}\right.\right.\right.$ $\mathrm{F}) \mathrm{H})(\mathrm{Cl}) \mathrm{H})(\mathrm{H})(\mathrm{F}) \mathrm{H}$

$\mathrm{C}(\mathrm{C}(\mathrm{C}(\mathrm{C}(\mathrm{C}(\mathrm{C}(\mathrm{C}(\mathrm{C}(\mathrm{C}(\mathrm{C}(\mathrm{C}(\mathrm{C}(\mathrm{C}(\mathrm{C}(\mathrm{H})(\mathrm{Cl}) \mathrm{Br})(\mathrm{F}) \mathrm{H})(\mathrm{H}) \mathrm{F})(\mathrm{F}) \mathrm{H})(\mathrm{H}) \mathrm{H})(\mathrm{H}) \mathrm{H})(\mathrm{H}) \mathrm{H})(\mathrm{F}) \mathrm{H})(\mathrm{H}) \mathrm{Cl})(\mathrm{H}) \mathrm{H})$

$(\mathrm{H}) \mathrm{Cl})(\mathrm{H}) \mathrm{H})(\mathrm{H}) \mathrm{H})(\mathrm{H})(\mathrm{Cl}) \mathrm{H}$

$\mathrm{C}(\mathrm{C}(\mathrm{C}(\mathrm{C}(\mathrm{C}(\mathrm{C}) \mathrm{C}(\mathrm{C}(\mathrm{C}(\mathrm{C}(\mathrm{C}(\mathrm{C}(\mathrm{C}(\mathrm{C}(\mathrm{H})(\mathrm{H}) H)(\mathrm{F}) H)(\mathrm{H}) \mathrm{H})(\mathrm{P}) \mathrm{H})(\mathrm{H}) \mathrm{H})(\mathrm{H}) \mathrm{P})(\mathrm{Cl}) H)(\mathrm{Cl}) \mathrm{H})(\mathrm{H}) \mathrm{F})(\mathrm{H}) H)(\mathrm{C}$

$(\mathrm{H}) \mathrm{H})(\mathrm{H}) \mathrm{Cl})(\mathrm{H})(\mathrm{H}) \mathrm{F}$

$\mathrm{C}(\mathrm{C}(\mathrm{C}(\mathrm{C}(\mathrm{C}(\mathrm{C}(\mathrm{C}(\mathrm{C}(\mathrm{C}(\mathrm{C}(\mathrm{C}(\mathrm{C}(\mathrm{C}(\mathrm{C}(\mathrm{H})(\mathrm{Cl}) \mathrm{H})(\mathrm{H}) \mathrm{F})(\mathrm{H}) \mathrm{H})(\mathrm{H}) \mathrm{H})(\mathrm{H}) \mathrm{H})(\mathrm{Cl}) \mathrm{H})(\mathrm{H}) \mathrm{F})(\mathrm{F}) \mathrm{H})(\mathrm{H}) \mathrm{Cl})(\mathrm{H}) \mathrm{H})$

$(\mathrm{H}) \mathrm{H})(\mathrm{H}) \mathrm{Cl})(\mathrm{F}) \mathrm{H})(\mathrm{H})(\mathrm{Cl}) \mathrm{H}$

$\mathrm{C}(\mathrm{C}(\mathrm{C}(\mathrm{C}(\mathrm{C}(\mathrm{C}(\mathrm{C}(\mathrm{C}(\mathrm{C}(\mathrm{C}(\mathrm{C}(\mathrm{C}(\mathrm{C}(\mathrm{C}(\mathrm{H})(\mathrm{H}) \mathrm{H})(\mathrm{H}) \mathrm{Br})(\mathrm{H}) \mathrm{H})(\mathrm{Br}) \mathrm{H})(\mathrm{F}) \mathrm{H})(\mathrm{H}) \mathrm{F})(\mathrm{H}) \mathrm{H})(\mathrm{H}) \mathrm{H})(\mathrm{H}) \mathrm{F})(\mathrm{Cl}) \mathrm{H})$

$(\mathrm{H}) \mathrm{F})(\mathrm{H}) \mathrm{H})(\mathrm{H}) \mathrm{F})(\mathrm{H})(\mathrm{F}) \mathrm{H}$

$\mathrm{C}(\mathrm{C}(\mathrm{C}(\mathrm{C}(\mathrm{C}(\mathrm{C}(\mathrm{C}(\mathrm{C}(\mathrm{C}(\mathrm{C}(\mathrm{C}(\mathrm{C}(\mathrm{C}(\mathrm{C}(\mathrm{H})(\mathrm{H}) \mathrm{H})(\mathrm{H}) \mathrm{Cl})(\mathrm{H}) \mathrm{H})(\mathrm{F}) \mathrm{F})(\mathrm{H}) \mathrm{H})(\mathrm{H}) \mathrm{H})(\mathrm{H}) \mathrm{F})(\mathrm{H}) \mathrm{H})(\mathrm{H}) \mathrm{H})(\mathrm{F}) \mathrm{H})(\mathrm{F}) \mathrm{H})(\mathrm{C} 14 \mathrm{H} 21 \mathrm{ClBrF} 7$

$\mathrm{H}) \mathrm{H})(\mathrm{F}) \mathrm{F})(\mathrm{H})(\mathrm{H}) \mathrm{Br}$

$\mathrm{C}\left(\mathrm{C}\left(\mathrm{C}(\mathrm{C}(\mathrm{C}(\mathrm{C}(\mathrm{C}(\mathrm{C}(\mathrm{C}(\mathrm{C}(\mathrm{C}(\mathrm{C}(\mathrm{C}(\mathrm{C}(\mathrm{H})(\mathrm{H}) \mathrm{H})(\mathrm{H}) \mathrm{H})(\mathrm{F}) \mathrm{H})(\mathrm{H}) \mathrm{H})(\mathrm{F}) \mathrm{F})(\mathrm{F}) \mathrm{Br})(\mathrm{H}) \mathrm{H})(\mathrm{H}) \mathrm{H})(\mathrm{H}) \mathrm{H})(\mathrm{H}) \mathrm{H})(\mathrm{H}) \mathrm{H})\left({ }_{\mathrm{C} 14 \mathrm{H} 22 \mathrm{Br} 2 \mathrm{~F} 6}\right.\right.\right.$

$\mathrm{Br}) \mathrm{H})(\mathrm{F}) \mathrm{H})(\mathrm{F})(\mathrm{H}) \mathrm{H}$

$\mathrm{C}\left(\mathrm{C}\left(\mathrm{C}(\mathrm{C}(\mathrm{C}(\mathrm{C}(\mathrm{C}(\mathrm{C}(\mathrm{C}(\mathrm{C}(\mathrm{C}(\mathrm{C}(\mathrm{C}(\mathrm{C}(\mathrm{H})(\mathrm{H}) \mathrm{H})(\mathrm{H}) \mathrm{F})(\mathrm{F}) \mathrm{F})(\mathrm{H}) \mathrm{H})(\mathrm{H}) \mathrm{F})(\mathrm{H}) \mathrm{H})(\mathrm{H}) \mathrm{H})(\mathrm{H}) \mathrm{H})(\mathrm{Br}) \mathrm{H})(\mathrm{H}) \mathrm{H})(\mathrm{Br}) \mathrm{H}){ }_{\mathrm{C} 14 \mathrm{H} 22 \mathrm{Br} 3 \mathrm{~F} 5}\right.\right.$

$(\mathrm{H}) \mathrm{F})(\mathrm{H}) \mathrm{H})(\mathrm{Br})(\mathrm{H}) \mathrm{H}$

$\mathrm{C}(\mathrm{C}(\mathrm{C}(\mathrm{C}(\mathrm{C}(\mathrm{C}(\mathrm{C}(\mathrm{C}(\mathrm{C}(\mathrm{C}(\mathrm{C}(\mathrm{C}(\mathrm{C}(\mathrm{C}(\mathrm{H})(\mathrm{H}) \mathrm{Br})(\mathrm{H}) \mathrm{H})(\mathrm{H}) \mathrm{F})(\mathrm{H}) \mathrm{H})(\mathrm{F}) \mathrm{H})(\mathrm{H}) \mathrm{H})(\mathrm{H}) \mathrm{Cl})(\mathrm{H}) \mathrm{Br})(\mathrm{H}) \mathrm{H})(\mathrm{H}) \mathrm{H})$

$(\mathrm{H}) \mathrm{F})(\mathrm{H}) \mathrm{H})(\mathrm{F}) \mathrm{H})(\mathrm{Cl})(\mathrm{H}) \mathrm{H}$

$\mathrm{C}(\mathrm{C}(\mathrm{C}(\mathrm{C}(\mathrm{C}(\mathrm{C}(\mathrm{C}(\mathrm{C}(\mathrm{C}(\mathrm{C}(\mathrm{C}(\mathrm{C}(\mathrm{C}(\mathrm{C}(\mathrm{F})(\mathrm{Cl}) \mathrm{H})(\mathrm{H}) \mathrm{H})(\mathrm{H}) \mathrm{H})(\mathrm{H}) \mathrm{H})(\mathrm{H}) \mathrm{H})(\mathrm{H}) \mathrm{F})(\mathrm{Br}) \mathrm{H})(\mathrm{H}) \mathrm{H})(\mathrm{H}) \mathrm{H})(\mathrm{H}) \mathrm{H})(\mathrm{H}) \mathrm{F})$ (F) $\mathrm{H})(\mathrm{H}) \mathrm{Cl})(\mathrm{F})(\mathrm{H}) \mathrm{H}$

$\mathrm{C}(\mathrm{C}(\mathrm{C}(\mathrm{C}(\mathrm{C}(\mathrm{C}(\mathrm{C}(\mathrm{C}(\mathrm{C}(\mathrm{C}(\mathrm{C}(\mathrm{C}(\mathrm{C}(\mathrm{C}(\mathrm{H})(\mathrm{H}) \mathrm{Cl})(\mathrm{H}) \mathrm{Cl})(\mathrm{H}) \mathrm{H})(\mathrm{H}) \mathrm{H})(\mathrm{F}) \mathrm{Cl})(\mathrm{F}) \mathrm{H})(\mathrm{F}) \mathrm{H})(\mathrm{H}) \mathrm{Br})(\mathrm{H}) \mathrm{H})(\mathrm{H}) \mathrm{H})$

$(\mathrm{H}) \mathrm{H})(\mathrm{H}) \mathrm{F})(\mathrm{H}) \mathrm{H})(\mathrm{H})(\mathrm{H}) \mathrm{H}$

$\mathrm{C}(\mathrm{C}(\mathrm{C}(\mathrm{C}(\mathrm{C}(\mathrm{C}(\mathrm{C}(\mathrm{C}(\mathrm{C}(\mathrm{C}(\mathrm{C}(\mathrm{C}(\mathrm{C}(\mathrm{C}(\mathrm{H})(\mathrm{H}) \mathrm{H})(\mathrm{H}) \mathrm{F})(\mathrm{H}) \mathrm{F})(\mathrm{H}) \mathrm{F})(\mathrm{H}) \mathrm{Cl})(\mathrm{H}) \mathrm{H})(\mathrm{H}) \mathrm{H})(\mathrm{Cl}) \mathrm{H})(\mathrm{H}) \mathrm{F})(\mathrm{H}) \mathrm{H})(\mathrm{Cl}) \mathrm{H})$

$(\mathrm{H}) \mathrm{H})(\mathrm{H}) \mathrm{H})(\mathrm{F})(\mathrm{H}) \mathrm{H}$

$\mathrm{C}(\mathrm{C}(\mathrm{C}(\mathrm{C}(\mathrm{C}(\mathrm{C}(\mathrm{C}(\mathrm{C}(\mathrm{C}(\mathrm{C}(\mathrm{C}(\mathrm{C}(\mathrm{C}(\mathrm{C}(\mathrm{F})(\mathrm{H}) \mathrm{H})(\mathrm{H}) \mathrm{H})(\mathrm{Cl}) \mathrm{H})(\mathrm{H}) \mathrm{Cl})(\mathrm{Cl}) \mathrm{F})(\mathrm{H}) \mathrm{H})(\mathrm{H}) \mathrm{H})(\mathrm{H}) \mathrm{F})(\mathrm{H}) \mathrm{H})(\mathrm{H}) \mathrm{Cl})$

$(\mathrm{H}) \mathrm{H})(\mathrm{H}) \mathrm{H})(\mathrm{F}) \mathrm{H})(\mathrm{H})(\mathrm{H}) \mathrm{H}$

$\mathrm{C}(\mathrm{C}(\mathrm{C}(\mathrm{C}(\mathrm{C}(\mathrm{C}(\mathrm{C}(\mathrm{C}(\mathrm{C}(\mathrm{C}(\mathrm{C}(\mathrm{C}(\mathrm{C}(\mathrm{C}(\mathrm{Cl})(\mathrm{H}) \mathrm{H})(\mathrm{H}) \mathrm{Cl})(\mathrm{H}) \mathrm{F})(\mathrm{Cl}) \mathrm{H})(\mathrm{H}) \mathrm{H})(\mathrm{H}) \mathrm{H})(\mathrm{F}) \mathrm{H})(\mathrm{H}) \mathrm{H})(\mathrm{H}) \mathrm{H})(\mathrm{F}) \mathrm{H})$

$(\mathrm{H}) \mathrm{H})(\mathrm{H}) \mathrm{H})(\mathrm{H}) \mathrm{H})(\mathrm{Cl})(\mathrm{Cl}) \mathrm{H}$

$\mathrm{C}(\mathrm{C}(\mathrm{C}(\mathrm{C}(\mathrm{C}) \mathrm{C}(\mathrm{C}(\mathrm{C}(\mathrm{C}(\mathrm{C}) \mathrm{C}$

(H)F)(H)Br)(F)(H)H

$\mathrm{C}\left(\mathrm{C}\left(\mathrm{C}(\mathrm{C}(\mathrm{C}(\mathrm{C}(\mathrm{C}(\mathrm{C}(\mathrm{C}(\mathrm{C}(\mathrm{C}(\mathrm{C}(\mathrm{C}(\mathrm{C}(\mathrm{F})(\mathrm{H}) \mathrm{F})(\mathrm{H}) \mathrm{H})(\mathrm{H}) \mathrm{H})(\mathrm{H}) \mathrm{H})(\mathrm{H}) \mathrm{H})(\mathrm{Br}) \mathrm{H})(\mathrm{H}) \mathrm{F})(\mathrm{F}) \mathrm{H})(\mathrm{H}) \mathrm{H})(\mathrm{H}) \mathrm{H})(\mathrm{Cl}) \mathrm{F})\left({ }_{\mathrm{C} 14 \mathrm{H} 22 \mathrm{ClBrF} 6}\right.\right.\right.$

$\mathrm{H}) \mathrm{H})(\mathrm{F}) \mathrm{H})(\mathrm{H})(\mathrm{H}) \mathrm{H}$

$\mathrm{C}\left(\mathrm{C}\left(\mathrm{C}(\mathrm{C}(\mathrm{C}(\mathrm{C}(\mathrm{C}(\mathrm{C}(\mathrm{C}(\mathrm{C}(\mathrm{C}(\mathrm{C}(\mathrm{C}(\mathrm{C}(\mathrm{H})(\mathrm{Br}) \mathrm{H})(\mathrm{H}) \mathrm{H})(\mathrm{F}) \mathrm{F})(\mathrm{H}) \mathrm{H})(\mathrm{Br}) \mathrm{F})(\mathrm{H}) \mathrm{H})(\mathrm{H}) \mathrm{H})(\mathrm{H}) \mathrm{H})(\mathrm{H}) \mathrm{H})(\mathrm{F}) \mathrm{H})(\mathrm{H}) \mathrm{H}){ }_{\mathrm{C} 14 \mathrm{H} 23 \mathrm{Br} 2 \mathrm{~F} 5}\right.\right.$

$(\mathrm{H}) \mathrm{H})(\mathrm{F}) \mathrm{H})(\mathrm{H})(\mathrm{H}) \mathrm{H}$

$\mathrm{C}(\mathrm{C}(\mathrm{C}(\mathrm{C}(\mathrm{C}(\mathrm{C}(\mathrm{C}(\mathrm{C}(\mathrm{C}(\mathrm{C}(\mathrm{C}(\mathrm{C}(\mathrm{C}(\mathrm{C}(\mathrm{F})(\mathrm{H}) \mathrm{H})(\mathrm{H}) \mathrm{Br})(\mathrm{H}) \mathrm{H})(\mathrm{H}) \mathrm{H})(\mathrm{H}) \mathrm{H})(\mathrm{Br}) \mathrm{H})(\mathrm{F}) \mathrm{H})(\mathrm{H}) \mathrm{F})(\mathrm{H}) \mathrm{H})(\mathrm{H}) \mathrm{H})$

$(\mathrm{H}) \mathrm{H})(\mathrm{Br}) \mathrm{H})(\mathrm{H}) \mathrm{F})(\mathrm{H})(\mathrm{H}) \mathrm{H}$

$\mathrm{C}\left(\mathrm{C}\left(\mathrm{C}(\mathrm{C}(\mathrm{C}(\mathrm{C}(\mathrm{C}(\mathrm{C}(\mathrm{C}(\mathrm{C}(\mathrm{C}(\mathrm{C}(\mathrm{C}(\mathrm{C}(\mathrm{H})(\mathrm{H}) \mathrm{H})(\mathrm{H}) \mathrm{F})(\mathrm{H}) \mathrm{H})(\mathrm{H}) \mathrm{H})(\mathrm{H}) \mathrm{H})(\mathrm{H}) \mathrm{F})(\mathrm{Cl}) \mathrm{H})(\mathrm{H}) \mathrm{Cl})(\mathrm{F}) \mathrm{H})(\mathrm{F}) \mathrm{H})(\mathrm{Br}) \mathrm{H}){ }_{\mathrm{Cl}} \mathrm{H}_{2} 2 \mathrm{Cl}_{2} \mathrm{BrF} 4\right.\right.$

$(\mathrm{H}) \mathrm{H})(\mathrm{H}) \mathrm{H})(\mathrm{H})(\mathrm{H}) \mathrm{H}$

$\mathrm{C}\left(\mathrm{C}\left(\mathrm{C}(\mathrm{C}(\mathrm{C}(\mathrm{C}(\mathrm{C}(\mathrm{C}(\mathrm{C}(\mathrm{C}(\mathrm{C}(\mathrm{C}(\mathrm{C}(\mathrm{C}(\mathrm{H})(\mathrm{H}) \mathrm{H})(\mathrm{H}) \mathrm{H})(\mathrm{H}) \mathrm{H})(\mathrm{F}) \mathrm{H})(\mathrm{H}) \mathrm{H})(\mathrm{H}) \mathrm{Cl})(\mathrm{F}) \mathrm{F})(\mathrm{H}) \mathrm{F})(\mathrm{H}) \mathrm{F})(\mathrm{H}) \mathrm{H})(\mathrm{H}) \mathrm{Cl})\left({ }_{\mathrm{C} 14 \mathrm{H} 23 \mathrm{Cl} 2 \mathrm{~F} 5}\right.\right.\right.$

$\mathrm{H}) \mathrm{H})(\mathrm{H}) \mathrm{H})(\mathrm{H})(\mathrm{H}) \mathrm{H}$

$\mathrm{C}(\mathrm{C}(\mathrm{C}(\mathrm{C}(\mathrm{C}(\mathrm{C}(\mathrm{C}(\mathrm{C}(\mathrm{C}(\mathrm{C}(\mathrm{C}(\mathrm{C}(\mathrm{C}(\mathrm{C}(\mathrm{H})(\mathrm{H}) \mathrm{H})(\mathrm{H}) \mathrm{H})(\mathrm{H}) \mathrm{Cl})(\mathrm{F}) \mathrm{F})(\mathrm{H}) \mathrm{F})(\mathrm{F}) \mathrm{H})(\mathrm{H}) \mathrm{H})(\mathrm{H}) \mathrm{H})(\mathrm{Cl}) \mathrm{Cl}(\mathrm{H}) \mathrm{H})(\mathrm{H}) \mathrm{H})$
$(\mathrm{H}) \mathrm{H})(\mathrm{H}) \mathrm{H})(\mathrm{H})(\mathrm{H}) \mathrm{H} 23 \mathrm{Cl}$ F 4

$\mathrm{C}(\mathrm{C}(\mathrm{C}(\mathrm{C}(\mathrm{C}(\mathrm{C}(\mathrm{C}(\mathrm{C}(\mathrm{C}(\mathrm{C}(\mathrm{C}(\mathrm{C}(\mathrm{C}(\mathrm{C}(\mathrm{H})(\mathrm{F}) \mathrm{H})(\mathrm{F}) \mathrm{H})(\mathrm{Cl}) \mathrm{H})(\mathrm{Cl}) \mathrm{Cl})(\mathrm{H}) \mathrm{H})(\mathrm{H}) \mathrm{H})(\mathrm{H}) \mathrm{H})(\mathrm{H}) \mathrm{H})(\mathrm{H}) \mathrm{H})(\mathrm{F}) \mathrm{H}) \quad \mathrm{C} 14 \mathrm{H} 23 \mathrm{Cl} 4 \mathrm{~F} 3$

$(\mathrm{H}) \mathrm{H})(\mathrm{H}) \mathrm{H})(\mathrm{H}) \mathrm{H})(\mathrm{H})(\mathrm{Cl}) \mathrm{H}$

$\mathrm{C}(\mathrm{C}(\mathrm{C}(\mathrm{C}(\mathrm{C}(\mathrm{C}(\mathrm{C}(\mathrm{C}(\mathrm{C}(\mathrm{C}(\mathrm{C}(\mathrm{C}(\mathrm{C}(\mathrm{C}(\mathrm{H})(\mathrm{H}) \mathrm{H})(\mathrm{H}) \mathrm{Cl})(\mathrm{H}) \mathrm{H})(\mathrm{H}) \mathrm{Cl})(\mathrm{H}) \mathrm{H})(\mathrm{Cl}) \mathrm{H})(\mathrm{H}) \mathrm{H})(\mathrm{Cl}) \mathrm{H})(\mathrm{H}) \mathrm{H})(\mathrm{F}) \mathrm{H})(\mathrm{H})$ $\mathrm{H})(\mathrm{H}) \mathrm{H})(\mathrm{H}) \mathrm{H})(\mathrm{H})(\mathrm{F}) \mathrm{Cl}$

$\mathrm{C}\left(\mathrm{C}\left(\mathrm{C}(\mathrm{C}(\mathrm{C}(\mathrm{C}(\mathrm{C}(\mathrm{C}(\mathrm{C}(\mathrm{C}(\mathrm{C}(\mathrm{C}(\mathrm{C}(\mathrm{C}(\mathrm{F})(\mathrm{F}) \mathrm{H})(\mathrm{H}) \mathrm{H})(\mathrm{H}) \mathrm{H})(\mathrm{H}) \mathrm{H})(\mathrm{H}) \mathrm{Br})(\mathrm{H}) \mathrm{H})(\mathrm{H}) \mathrm{F})(\mathrm{H}) \mathrm{H})(\mathrm{H}) \mathrm{H})(\mathrm{H}) \mathrm{H})(\mathrm{H}) \mathrm{F})\left({ }_{\mathrm{C} 14 \mathrm{H} 23 \mathrm{ClBr} 2 \mathrm{~F} 4}\right.\right.\right.$ $\mathrm{H}) \mathrm{Br})(\mathrm{H}) \mathrm{Cl})(\mathrm{H})(\mathrm{H}) \mathrm{H}$

$\mathrm{C}\left(\mathrm{C}\left(\mathrm{C}(\mathrm{C}(\mathrm{C}(\mathrm{C}(\mathrm{C}(\mathrm{C}(\mathrm{C}(\mathrm{C}(\mathrm{C}(\mathrm{C}(\mathrm{C}(\mathrm{C}(\mathrm{H})(\mathrm{H}) \mathrm{H})(\mathrm{F}) \mathrm{H})(\mathrm{H}) \mathrm{F})(\mathrm{H}) \mathrm{H})(\mathrm{H}) \mathrm{H})(\mathrm{H}) \mathrm{H})(\mathrm{H}) \mathrm{H})(\mathrm{H}) \mathrm{H})(\mathrm{F}) \mathrm{H})(\mathrm{H}) \mathrm{Cl})(\mathrm{H}) \mathrm{H})\left({ }_{\mathrm{C} 14 \mathrm{H} 23 \mathrm{ClBrF} 5}\right.\right.\right.$

$\mathrm{F}) \mathrm{Br})(\mathrm{H}) \mathrm{H})(\mathrm{F})(\mathrm{H}) \mathrm{H}$

$\mathrm{C}(\mathrm{C}(\mathrm{C}(\mathrm{C}(\mathrm{C}(\mathrm{C}(\mathrm{C}(\mathrm{C}(\mathrm{C}(\mathrm{C}(\mathrm{C}(\mathrm{C}(\mathrm{C}(\mathrm{C}(\mathrm{H})(\mathrm{Br}) \mathrm{H})(\mathrm{H}) \mathrm{H})(\mathrm{F}) \mathrm{F})(\mathrm{H}) \mathrm{H})(\mathrm{H}) \mathrm{H})(\mathrm{H}) \mathrm{H})(\mathrm{H}) \mathrm{H})(\mathrm{H}) \mathrm{H})(\mathrm{H}) \mathrm{F})(\mathrm{H}) \mathrm{H})$

$(\mathrm{H}) \mathrm{Br})(\mathrm{H}) \mathrm{H})(\mathrm{H}) \mathrm{H})(\mathrm{H})(\mathrm{F}) \mathrm{H}$

C $(\mathrm{C}(\mathrm{C}(\mathrm{C}(\mathrm{C}(\mathrm{C}(\mathrm{C}(\mathrm{C}(\mathrm{C}(\mathrm{C}(\mathrm{C}(\mathrm{C}(\mathrm{C}(\mathrm{C}(\mathrm{F})(\mathrm{H}) \mathrm{H})(\mathrm{H}) \mathrm{H})(\mathrm{H}) \mathrm{H})(\mathrm{Cl}) \mathrm{H})(\mathrm{H}) \mathrm{H})(\mathrm{F}) \mathrm{Br})(\mathrm{H}) \mathrm{H})(\mathrm{H}) \mathrm{H})(\mathrm{H}) \mathrm{H})(\mathrm{H}) \mathrm{H})$

$(\mathrm{H}) \mathrm{H})(\mathrm{Cl}) \mathrm{H})(\mathrm{H}) \mathrm{H})(\mathrm{H})(\mathrm{H}) \mathrm{F}$

C(C(C(C(C(C(C(C(C(C(C(C(C(C(H)(H)H)(H)Cl)(H)H)(H)H)(H)H)(H)H)(H)H)(H)H)(F)H)(Cl)H)(F)H) $(\mathrm{F}) \mathrm{H})(\mathrm{H}) \mathrm{H})(\mathrm{H})(\mathrm{H}) \mathrm{F}$

$(\mathrm{F}) \mathrm{H})(\mathrm{Cl}) \mathrm{H})(\mathrm{H})(\mathrm{H}) \mathrm{Cl}$

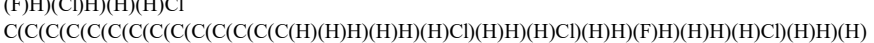

$\mathrm{H})(\mathrm{F}) \mathrm{Cl}(\mathrm{H}) \mathrm{H})(\mathrm{H})(\mathrm{H}) \mathrm{H}$

$\mathrm{C}(\mathrm{C}(\mathrm{C}(\mathrm{C}(\mathrm{C}(\mathrm{C}(\mathrm{C}(\mathrm{C}(\mathrm{C}(\mathrm{C}(\mathrm{C}(\mathrm{C}(\mathrm{C}(\mathrm{C}(\mathrm{H})(\mathrm{H}) \mathrm{H})(\mathrm{H}) \mathrm{H})(\mathrm{H}) \mathrm{H})(\mathrm{H}) \mathrm{F})(\mathrm{H}) \mathrm{Br})(\mathrm{H}) \mathrm{Cl})(\mathrm{H}) \mathrm{Br})(\mathrm{H}) \mathrm{F})(\mathrm{H}) \mathrm{H})(\mathrm{F}) \mathrm{H})$

$(\mathrm{H}) \mathrm{H})(\mathrm{H}) \mathrm{H})(\mathrm{H}) \mathrm{H})(\mathrm{H})(\mathrm{H}) \mathrm{H}$

$\mathrm{C}(\mathrm{C}(\mathrm{C}(\mathrm{C}(\mathrm{C}(\mathrm{C}(\mathrm{C}(\mathrm{C}(\mathrm{C}(\mathrm{C}(\mathrm{C}(\mathrm{C}(\mathrm{C}(\mathrm{C}(\mathrm{H})(\mathrm{H}) \mathrm{H})(\mathrm{H}) \mathrm{F})(\mathrm{H}) \mathrm{F})(\mathrm{H}) \mathrm{H})(\mathrm{H}) \mathrm{Cl})(\mathrm{H}) \mathrm{H})(\mathrm{H}) \mathrm{H})(\mathrm{H}) \mathrm{H})(\mathrm{H}) \mathrm{H})(\mathrm{H}) \mathrm{H})(\mathrm{F}) \mathrm{F})($

$\mathrm{H}) \mathrm{H})(\mathrm{H}) \mathrm{H})(\mathrm{H})(\mathrm{Br}) \mathrm{H}$

$\mathrm{C}(\mathrm{C}(\mathrm{C}(\mathrm{C}(\mathrm{C}(\mathrm{C}(\mathrm{C}(\mathrm{C}(\mathrm{C}(\mathrm{C}(\mathrm{C}(\mathrm{C}(\mathrm{C}(\mathrm{C}(\mathrm{H})(\mathrm{H}) \mathrm{H})(\mathrm{H}) \mathrm{H})(\mathrm{H}) \mathrm{H})(\mathrm{Br}) \mathrm{H})(\mathrm{H}) \mathrm{H})(\mathrm{F}) \mathrm{H})(\mathrm{H}) \mathrm{H})(\mathrm{H}) \mathrm{H})(\mathrm{Br}) \mathrm{H})(\mathrm{F}) \mathrm{H})$

$(\mathrm{H}) \mathrm{H})(\mathrm{F}) \mathrm{H})(\mathrm{H}) \mathrm{H})(\mathrm{H})(\mathrm{H}) \mathrm{H}$

$\mathrm{C}(\mathrm{C}(\mathrm{C}(\mathrm{C}(\mathrm{C}(\mathrm{C}) \mathrm{C}(\mathrm{C}(\mathrm{C}) \mathrm{C}(\mathrm{C}(\mathrm{C}) \mathrm{C}(\mathrm{C}(\mathrm{P})(\mathrm{H}) \mathrm{F})(\mathrm{H})$

$(\mathrm{H}) \mathrm{H})(\mathrm{H}) \mathrm{H})(\mathrm{F})(\mathrm{H}) \mathrm{H}$

$\mathrm{C}(\mathrm{C}(\mathrm{C}(\mathrm{C}(\mathrm{C}(\mathrm{C}(\mathrm{C}(\mathrm{C}(\mathrm{C}(\mathrm{C}(\mathrm{C}(\mathrm{C}(\mathrm{C}(\mathrm{C}(\mathrm{H})(\mathrm{H}) \mathrm{H})(\mathrm{H}) \mathrm{H})(\mathrm{Cl}) \mathrm{H})(\mathrm{H}) \mathrm{H})(\mathrm{H}) \mathrm{H})(\mathrm{H}) \mathrm{H})(\mathrm{H}) \mathrm{H})(\mathrm{H}) \mathrm{Cl})(\mathrm{H}) \mathrm{F})(\mathrm{H}) \mathrm{H})$

$(\mathrm{H}) \mathrm{H})(\mathrm{H}) \mathrm{Br})(\mathrm{H}) \mathrm{H})(\mathrm{H})(\mathrm{H}) \mathrm{F}$

$\mathrm{C}(\mathrm{C}(\mathrm{C}(\mathrm{C}(\mathrm{C}(\mathrm{C}(\mathrm{C}(\mathrm{C}(\mathrm{C}(\mathrm{C}(\mathrm{C}(\mathrm{C}(\mathrm{C}(\mathrm{C}(\mathrm{H})(\mathrm{H}) \mathrm{H})(\mathrm{H}) \mathrm{H})(\mathrm{H}) \mathrm{F})(\mathrm{H}) \mathrm{F})(\mathrm{H}) \mathrm{H})(\mathrm{H}) \mathrm{H})(\mathrm{H}) \mathrm{H})(\mathrm{H}) \mathrm{H})(\mathrm{H}) \mathrm{H})(\mathrm{H}) \mathrm{H})(\mathrm{H}) \mathrm{H})(\mathrm{Cl}$

C(C(C(C(C(C)(C(C)(

$\mathrm{C}\left(\mathrm{C}\left(\mathrm{C}(\mathrm{C}(\mathrm{C}(\mathrm{C}(\mathrm{C}(\mathrm{C}(\mathrm{C}(\mathrm{C}(\mathrm{C}(\mathrm{C}(\mathrm{C}(\mathrm{C}(\mathrm{H})(\mathrm{H}) \mathrm{Cl})(\mathrm{H}) \mathrm{H})(\mathrm{H}) \mathrm{H})(\mathrm{H}) \mathrm{Cl})(\mathrm{H}) \mathrm{H})(\mathrm{H}) \mathrm{F})(\mathrm{H}) \mathrm{H})(\mathrm{F}) \mathrm{H})(\mathrm{H}) \mathrm{H})(\mathrm{H}) \mathrm{H})(\mathrm{H}) \mathrm{H}){ }_{\mathrm{C} 14 \mathrm{H} 25 \mathrm{Cl} 3 \mathrm{~F} 2}\right.\right.$

$(\mathrm{H}) \mathrm{H})(\mathrm{H}) \mathrm{H})(\mathrm{H})(\mathrm{H}) \mathrm{Cl}$

$\mathrm{C}(\mathrm{C}(\mathrm{C}(\mathrm{C}(\mathrm{C}(\mathrm{C}(\mathrm{C}(\mathrm{C}(\mathrm{C}(\mathrm{C}(\mathrm{C}(\mathrm{C}(\mathrm{C}(\mathrm{C}(\mathrm{H})(\mathrm{Cl}) \mathrm{H})(\mathrm{H}) \mathrm{H})(\mathrm{H}) \mathrm{H})(\mathrm{H}) \mathrm{Cl})(\mathrm{H}) \mathrm{H})(\mathrm{H}) \mathrm{H})(\mathrm{H}) \mathrm{H})(\mathrm{Cl}) \mathrm{H})(\mathrm{H}) \mathrm{H})(\mathrm{H}) \mathrm{H})(\mathrm{H})$

$\mathrm{H})(\mathrm{H}) \mathrm{H})(\mathrm{H}) \mathrm{H})(\mathrm{H})(\mathrm{Cl}) \mathrm{F}$

$\mathrm{C}(\mathrm{C}(\mathrm{C}(\mathrm{C}(\mathrm{C}(\mathrm{C}(\mathrm{C}(\mathrm{C}(\mathrm{C}(\mathrm{C}(\mathrm{C}(\mathrm{C}(\mathrm{C}(\mathrm{C}(\mathrm{H})(\mathrm{H}) \mathrm{H})(\mathrm{H}) \mathrm{H})(\mathrm{H}) \mathrm{F})(\mathrm{H}) \mathrm{Cl})(\mathrm{H}) \mathrm{H})(\mathrm{Br}) \mathrm{H})(\mathrm{H}) \mathrm{H})(\mathrm{H}) \mathrm{H})(\mathrm{H}) \mathrm{F})(\mathrm{H}) \mathrm{H})$

$(\mathrm{H}) \mathrm{H})(\mathrm{H}) \mathrm{H})(\mathrm{Br}) \mathrm{H})(\mathrm{H})(\mathrm{H}) \mathrm{H}$

$\mathrm{C}(\mathrm{C}(\mathrm{C}(\mathrm{C}(\mathrm{C}(\mathrm{C}(\mathrm{C}(\mathrm{C}(\mathrm{C}(\mathrm{C}(\mathrm{C}(\mathrm{C}(\mathrm{C}(\mathrm{C}(\mathrm{H})(\mathrm{H}) \mathrm{H})(\mathrm{Br}) \mathrm{H})(\mathrm{H}) \mathrm{H})(\mathrm{H}) \mathrm{H})(\mathrm{H}) \mathrm{Cl})(\mathrm{H}) \mathrm{H})(\mathrm{H}) \mathrm{H})(\mathrm{H}) \mathrm{H})(\mathrm{F}) \mathrm{F})(\mathrm{H}) \mathrm{H})$

$(\mathrm{H}) \mathrm{H})(\mathrm{H}) \mathrm{H})(\mathrm{H}) \mathrm{F})(\mathrm{H})(\mathrm{H}) \mathrm{H}$
$\mathrm{C} 14 \mathrm{H} 21 \mathrm{Cl} 4 \mathrm{BrF} 4$

C14H21C14F5

$\mathrm{C} 14 \mathrm{H} 21 \mathrm{Cl} 5 \mathrm{~F} 4$

$\mathrm{C} 14 \mathrm{H} 21 \mathrm{ClBr} 2 \mathrm{~F} 6$

C14H23Cl4F3

$\mathrm{C} 14 \mathrm{H} 24 \mathrm{Br} 2 \mathrm{~F} 4$

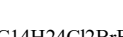

EPISuit_EPI _EPI _Exp__Exp w $\quad$ DFT___DFT_DFT

e Suite Suite corr_corr_Exp corr _corr _corr

$\begin{array}{lllllllll}6.583 & 8.61 & 2.03 & 7.93 & 5.90 & 2.03 & 7.38 & 10.11 & -2.73\end{array}$

$\begin{array}{lllllllll}6.166 & 7.44 & 1.27 & 6.18 & 4.90 & 1.27 & 6.48 & 9.34 & -2.86\end{array}$

$\begin{array}{lllllllll}5.269 & 7.78 & 2.51 & 6.69 & 4.18 & 2.51 & 6.74 & 7.69 & -0.95\end{array}$

$7.297 \quad 7.82$

$5.589 \quad 7.35$

$\begin{array}{lllllll}0.52 & 6.75 & 6.22 & 0.52 & 6.77 & 11.42 & -4.65\end{array}$

$6.732 \quad 7.74$

$\begin{array}{lllllll}1.76 & 6.04 & 4.28 & 1.76 & 6.41 & 8.28 & -1.87\end{array}$

$5.669 \quad 7.21$

$\begin{array}{lllllll}1.01 & 6.63 & 5.62 & 1.01 & 6.71 & 10.38 & -3.67\end{array}$

$5.511 \quad 8.29$

$\begin{array}{lllllll}1.54 & 5.84 & 4.29 & 1.54 & 6.30 & 8.43 & -2.13\end{array}$

$\begin{array}{llllllll}2.78 & 7.45 & 4.67 & 2.78 & 7.13 & 8.14 & -1.01\end{array}$

$6.516 \quad 8.51$

$\begin{array}{lllllll}1.99 & 7.78 & 5.78 & 1.99 & 7.30 & 9.98 & -2.68\end{array}$

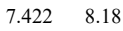

$\begin{array}{lllllll}0.76 & 7.28 & 6.53 & 0.76 & 7.04 & 11.65 & -4.60\end{array}$

$7.239 \quad 7.73$

$\begin{array}{lllllll}0.49 & 6.61 & 6.12 & 0.49 & 6.70 & 11.31 & -4.61\end{array}$

$5.601 \quad 7.33$

$\begin{array}{lllllll}1.73 & 6.01 & 4.29 & 1.73 & 6.39 & 8.30 & -1.91\end{array}$

$7.335 \quad 8.31$

$\begin{array}{lllllll}0.98 & 7.48 & 6.50 & 0.98 & 7.14 & 11.49 & -4.34\end{array}$

$4.957 \quad 7.17$

$\begin{array}{lllllll}2.21 & 5.78 & 3.56 & 2.21 & 6.27 & 7.12 & -0.85\end{array}$

$6.759 \quad 8.22$

$\begin{array}{lllllll}1.46 & 7.34 & 5.88 & 1.46 & 7.08 & 10.43 & -3.35\end{array}$

$\begin{array}{ll}7.162 & 7.87\end{array}$

$\begin{array}{lllllll}0.71 & 6.82 & 6.11 & 0.71 & 6.81 & 11.17 & -4.36\end{array}$

$\begin{array}{ll}7.588 & 8.83\end{array}$

$5.2 \quad 7.68$

$\begin{array}{lllllll}1.24 & 8.25 & 7.01 & 1.24 & 7.54 & 11.95 & -4.41\end{array}$

$\begin{array}{lllllll}2.48 & 6.54 & 4.06 & 2.48 & 6.66 & 7.56 & -0.90\end{array}$

$6.956 \quad 8.65$

$\begin{array}{ll}7.112 & 7.57\end{array}$

$\begin{array}{lllllll}1.69 & 7.99 & 6.29 & 1.69 & 7.41 & 10.79 & -3.38\end{array}$

$5.892 \quad 7.32$

$\begin{array}{lllllll}0.46 & 6.37 & 5.91 & 0.46 & 6.58 & 11.08 & -4.50\end{array}$

$4.985 \quad 7.65$

$6.795 \quad 8.71$

$7.268 \quad 8.43$

$\begin{array}{ll}7.52 & 7.93\end{array}$

$\begin{array}{ll}6.536 & 7.48\end{array}$

$5.639 \quad 7.82$

$6.713 \quad 8.11$

$7.21 \quad 8.34$

$4.753 \quad 7.12$

$5.814 \quad 7.43$

$7.546 \quad 8.41$

$6.895 \quad 7.54$

$6.069 \quad 7.95$

$6.263 \quad 7.36$

$4.765 \quad 7.1$

$6.828 \quad 7.66$

$5.852 \quad 7.92$

$6.323 \quad 7.64$

$\begin{array}{ll}7.386 & 7.95\end{array}$

$\mathrm{C} 14 \mathrm{H} 25 \mathrm{Cl} 4 \mathrm{~F}$

$\mathrm{C} 14 \mathrm{H} 25 \mathrm{ClBr} 2 \mathrm{~F} 2$

$\begin{array}{ll}7.324 & 7.67\end{array}$

$\begin{array}{lllllll}1.43 & 6.00 & 4.57 & 1.43 & 6.38 & 8.84 & -2.45\end{array}$

$\begin{array}{lllllll}2.66 & 6.49 & 3.83 & 2.66 & 6.64 & 7.17 & -0.53\end{array}$

$\begin{array}{lllllll}1.91 & 8.07 & 6.16 & 1.91 & 7.45 & 10.49 & -3.04\end{array}$

$\begin{array}{lllllll}1.16 & 7.66 & 6.50 & 1.16 & 7.24 & 11.36 & -4.13\end{array}$

$\begin{array}{lllllll}0.41 & 6.91 & 6.50 & 0.41 & 6.85 & 11.83 & -4.97\end{array}$

$\begin{array}{lllllll}0.94 & 6.24 & 5.29 & 0.94 & 6.51 & 10.02 & -3.51\end{array}$

$\begin{array}{lllllll}2.18 & 6.75 & 4.57 & 2.18 & 6.77 & 8.37 & -1.60\end{array}$

$\begin{array}{lllllll}1.40 & 7.18 & 5.78 & 1.40 & 6.99 & 10.34 & -3.35\end{array}$

$\begin{array}{lllllll}1.13 & 7.52 & 6.39 & 1.13 & 7.17 & 11.26 & -4.09\end{array}$

$\begin{array}{lllllll}2.37 & 5.70 & 3.33 & 2.37 & 6.23 & 6.74 & -0.51\end{array}$

$\begin{array}{lllllll}1.62 & 6.16 & 4.55 & 1.62 & 6.47 & 8.69 & -2.22\end{array}$

$\begin{array}{lllllll}0.86 & 7.63 & 6.76 & 0.86 & 7.22 & 11.87 & -4.65\end{array}$

$\begin{array}{lllllll}0.64 & 6.33 & 5.68 & 0.64 & 6.55 & 10.68 & -4.13\end{array}$

$\begin{array}{lllllll}1.88 & 6.94 & 5.06 & 1.88 & 6.87 & 9.16 & -2.29\end{array}$

$\begin{array}{lllllll}1.10 & 6.06 & 4.96 & 1.10 & 6.41 & 9.52 & -3.10\end{array}$

$\begin{array}{lllllll}2.33 & 5.67 & 3.34 & 2.33 & 6.21 & 6.77 & -0.55\end{array}$

$\begin{array}{llllllll}0.83 & 6.51 & 5.68 & 0.83 & 6.65 & 10.56 & -3.91\end{array}$

$\begin{array}{lllllll}2.07 & 6.90 & 4.83 & 2.07 & 6.84 & 8.76 & -1.92\end{array}$

$\begin{array}{lllllll}1.32 & 6.48 & 5.16 & 1.32 & 6.63 & 9.63 & -3.00\end{array}$

$\begin{array}{lllllll}0.56 & 6.94 & 6.38 & 0.56 & 6.87 & 11.58 & -4.71\end{array}$

$\begin{array}{lllllll}0.35 & 6.52 & 6.18 & 0.35 & 6.65 & 11.47 & -4.81\end{array}$

$\mathrm{C} 14 \mathrm{H} 25 \mathrm{ClBrF} 3$
$6.427 \quad 8.01$ 
SMILE Generated

$\mathrm{C}(\mathrm{C}(\mathrm{C}(\mathrm{C}(\mathrm{C}(\mathrm{C}(\mathrm{C}(\mathrm{C}(\mathrm{C}(\mathrm{C}(\mathrm{C}(\mathrm{C}(\mathrm{C}(\mathrm{C}(\mathrm{H})(\mathrm{H}) \mathrm{H})(\mathrm{H}) \mathrm{H})(\mathrm{H}) \mathrm{H})(\mathrm{H}) \mathrm{H})(\mathrm{H}) \mathrm{H})(\mathrm{H}) \mathrm{F})(\mathrm{Br}) \mathrm{H})(\mathrm{F}) \mathrm{H})(\mathrm{Br}) \mathrm{H})(\mathrm{H}) \mathrm{H})$ $(\mathrm{H}) \mathrm{H})(\mathrm{H}) \mathrm{H})(\mathrm{H}) \mathrm{H})(\mathrm{H})(\mathrm{H}) \mathrm{H}$

$\mathrm{C}(\mathrm{C}(\mathrm{C}(\mathrm{C}(\mathrm{C}(\mathrm{C}(\mathrm{C}(\mathrm{C}(\mathrm{C}(\mathrm{C}(\mathrm{C}(\mathrm{C}(\mathrm{C}(\mathrm{C}(\mathrm{Br})(\mathrm{F}) \mathrm{H})(\mathrm{H}) \mathrm{H})(\mathrm{H}) \mathrm{H})(\mathrm{H}) \mathrm{H})(\mathrm{F}) \mathrm{H})(\mathrm{H}) \mathrm{H})(\mathrm{H}) \mathrm{H})(\mathrm{H}) \mathrm{H})(\mathrm{H}) \mathrm{H})(\mathrm{H}) \mathrm{H})(\mathrm{H}) \mathrm{H})$ $(\mathrm{H}) \mathrm{F})(\mathrm{H}) \mathrm{H})(\mathrm{H})(\mathrm{H}) \mathrm{H}$

$\mathrm{C}(\mathrm{C}(\mathrm{C}(\mathrm{C}(\mathrm{C}(\mathrm{C}(\mathrm{C}(\mathrm{C}(\mathrm{C}(\mathrm{C}(\mathrm{C}(\mathrm{C}(\mathrm{C}(\mathrm{C}(\mathrm{H})(\mathrm{H}) \mathrm{H})(\mathrm{H}) \mathrm{H})(\mathrm{H}) \mathrm{H})(\mathrm{F}) \mathrm{H})(\mathrm{H}) \mathrm{H})(\mathrm{H}) \mathrm{H})(\mathrm{H}) \mathrm{H})(\mathrm{H}) \mathrm{Br})(\mathrm{H}) \mathrm{H})(\mathrm{H}) \mathrm{H})$ $(\mathrm{H}) \mathrm{H})(\mathrm{H}) \mathrm{Cl}(\mathrm{H}) \mathrm{H})(\mathrm{Cl})(\mathrm{H}) \mathrm{H}$

$\mathrm{C}(\mathrm{C}(\mathrm{C}(\mathrm{C}(\mathrm{C}(\mathrm{C}(\mathrm{C}(\mathrm{C}(\mathrm{C}(\mathrm{C}(\mathrm{C}(\mathrm{C}(\mathrm{C}(\mathrm{C}(\mathrm{H})(\mathrm{H}) \mathrm{H})(\mathrm{H}) \mathrm{H})(\mathrm{H}) \mathrm{Cl})(\mathrm{H}) \mathrm{H})(\mathrm{H}) \mathrm{H})(\mathrm{H}) \mathrm{H})(\mathrm{H}) \mathrm{H})(\mathrm{F}) \mathrm{F})(\mathrm{H}) \mathrm{H})(\mathrm{H}) \mathrm{H})(\mathrm{H}) \mathrm{H})$ $(\mathrm{H}) \mathrm{H})(\mathrm{H}) \mathrm{H})(\mathrm{Cl})(\mathrm{H}) \mathrm{H}$

$\mathrm{C}(\mathrm{C}(\mathrm{C}(\mathrm{C}(\mathrm{C}(\mathrm{C}(\mathrm{C}(\mathrm{C}(\mathrm{C}(\mathrm{C}(\mathrm{C}(\mathrm{C}(\mathrm{C}(\mathrm{C}(\mathrm{H})(\mathrm{H}) \mathrm{H})(\mathrm{H}) \mathrm{H})(\mathrm{H}) \mathrm{H})(\mathrm{H}) \mathrm{H})(\mathrm{H}) \mathrm{H})(\mathrm{Cl}) \mathrm{H})(\mathrm{F}) \mathrm{H})(\mathrm{H}) \mathrm{H})(\mathrm{H}) \mathrm{H})(\mathrm{H}) \mathrm{H}) \quad \mathrm{C} 14 \mathrm{H} 26 \mathrm{Cl} 3 \mathrm{~F}$

$(\mathrm{H}) \mathrm{Cl})(\mathrm{Cl}) \mathrm{H})(\mathrm{H}) \mathrm{H})(\mathrm{H})(\mathrm{H}) \mathrm{H}$

$\mathrm{C}(\mathrm{C}(\mathrm{C}(\mathrm{C}(\mathrm{C}(\mathrm{C}(\mathrm{C}(\mathrm{C}(\mathrm{C}(\mathrm{C}(\mathrm{C}(\mathrm{C}(\mathrm{C}(\mathrm{C}(\mathrm{H})(\mathrm{H}) \mathrm{H})(\mathrm{H}) \mathrm{H})(\mathrm{H}) \mathrm{H})(\mathrm{H}) \mathrm{Br})(\mathrm{F}) \mathrm{H})(\mathrm{H}) \mathrm{F})(\mathrm{H}) \mathrm{H})(\mathrm{H}) \mathrm{H})(\mathrm{H}) \mathrm{H})(\mathrm{H}) \mathrm{H})(\mathrm{H}) \mathrm{H})$

$(\mathrm{H}) \mathrm{H})(\mathrm{Cl}) \mathrm{H})(\mathrm{H})(\mathrm{H}) \mathrm{H}$

$\mathrm{C}(\mathrm{C}(\mathrm{C}(\mathrm{C}(\mathrm{C}(\mathrm{C}(\mathrm{C}(\mathrm{C}(\mathrm{C}(\mathrm{C}(\mathrm{C}(\mathrm{C}(\mathrm{C}(\mathrm{C}(\mathrm{H})(\mathrm{H}) \mathrm{H})(\mathrm{F}) \mathrm{H})(\mathrm{H}) \mathrm{H})(\mathrm{H}) \mathrm{H})(\mathrm{H}) \mathrm{H})(\mathrm{H}) \mathrm{H})(\mathrm{H}) \mathrm{H})(\mathrm{H}) \mathrm{H})(\mathrm{H}) \mathrm{H})(\mathrm{H}) \mathrm{F})(\mathrm{F}) \mathrm{H})($ $\mathrm{H}) \mathrm{H})(\mathrm{H}) \mathrm{H})(\mathrm{H})(\mathrm{H}) \mathrm{Cl}$

$\mathrm{C}(\mathrm{C}(\mathrm{C}(\mathrm{C}(\mathrm{C}(\mathrm{C}(\mathrm{C}(\mathrm{C}(\mathrm{C}(\mathrm{C}(\mathrm{C}(\mathrm{C}(\mathrm{C}(\mathrm{C}(\mathrm{H})(\mathrm{H}) \mathrm{Br})(\mathrm{H}) \mathrm{H})(\mathrm{H}) \mathrm{H})(\mathrm{H}) \mathrm{H})(\mathrm{H}) \mathrm{H})(\mathrm{H}) \mathrm{H})(\mathrm{H}) \mathrm{H})(\mathrm{H}) \mathrm{F})(\mathrm{F}) \mathrm{H})(\mathrm{H}) \mathrm{H})(\mathrm{H}) \mathrm{H})$ $(\mathrm{H}) \mathrm{H})(\mathrm{H}) \mathrm{H})(\mathrm{H})(\mathrm{H}) \mathrm{H}$

$\mathrm{C}(\mathrm{C}(\mathrm{C}(\mathrm{C}(\mathrm{C}(\mathrm{C}(\mathrm{C}(\mathrm{C}(\mathrm{C}(\mathrm{C}(\mathrm{C}(\mathrm{C}(\mathrm{C}(\mathrm{C}(\mathrm{H})(\mathrm{H}) \mathrm{Cl})(\mathrm{H}) \mathrm{Cl})(\mathrm{H}) \mathrm{H})(\mathrm{H}) \mathrm{H})(\mathrm{H}) \mathrm{H})(\mathrm{H}) \mathrm{H})(\mathrm{H}) \mathrm{H})(\mathrm{H}) \mathrm{H})(\mathrm{H}) \mathrm{H})(\mathrm{H}) \mathrm{F})$

$(\mathrm{H}) \mathrm{H})(\mathrm{H}) \mathrm{H})(\mathrm{H}) \mathrm{H})(\mathrm{H})(\mathrm{H}) \mathrm{H}$

$\mathrm{C}(\mathrm{C}(\mathrm{C}(\mathrm{C}(\mathrm{C}(\mathrm{C}(\mathrm{C}(\mathrm{C}(\mathrm{C}(\mathrm{C}(\mathrm{C}(\mathrm{C}(\mathrm{C}(\mathrm{C}(\mathrm{H})(\mathrm{H}) \mathrm{H})(\mathrm{H}) \mathrm{H})(\mathrm{H}) \mathrm{H})(\mathrm{H}) \mathrm{H})(\mathrm{Cl}) \mathrm{H})(\mathrm{H}) \mathrm{H})(\mathrm{H}) \mathrm{H})(\mathrm{H}) \mathrm{H})(\mathrm{H}) \mathrm{Cl})(\mathrm{H}) \mathrm{H})(\mathrm{H})$

$\mathrm{H})(\mathrm{H}) \mathrm{H})(\mathrm{H}) \mathrm{H})(\mathrm{H})(\mathrm{Cl}) \mathrm{H}$

$\mathrm{C}(\mathrm{C}(\mathrm{C}(\mathrm{C}(\mathrm{C}(\mathrm{C}(\mathrm{C}(\mathrm{C}(\mathrm{C}(\mathrm{C}(\mathrm{C}(\mathrm{C}(\mathrm{C}(\mathrm{C}(\mathrm{H})(\mathrm{F}) \mathrm{H})(\mathrm{H}) \mathrm{Cl})(\mathrm{H}) \mathrm{H})(\mathrm{H}) \mathrm{H})(\mathrm{H}) \mathrm{H})(\mathrm{H}) \mathrm{Br})(\mathrm{H}) \mathrm{H})(\mathrm{H}) \mathrm{H})(\mathrm{H}) \mathrm{H})(\mathrm{H}) \mathrm{H})$

$(\mathrm{H}) \mathrm{H})(\mathrm{H}) \mathrm{H})(\mathrm{H}) \mathrm{H})(\mathrm{H})(\mathrm{H}) \mathrm{H}$

$\mathrm{C}(\mathrm{C}(\mathrm{C}(\mathrm{C}(\mathrm{C}(\mathrm{C}(\mathrm{C}(\mathrm{C}(\mathrm{C}(\mathrm{C}(\mathrm{C}(\mathrm{C}(\mathrm{C}(\mathrm{C}(\mathrm{H})(\mathrm{H}) \mathrm{H})(\mathrm{H}) \mathrm{H})(\mathrm{H}) \mathrm{H})(\mathrm{H}) \mathrm{H})(\mathrm{H}) \mathrm{Cl})(\mathrm{H}) \mathrm{H})(\mathrm{H}) \mathrm{F})(\mathrm{H}) \mathrm{H})(\mathrm{H}) \mathrm{H})(\mathrm{H}) \mathrm{F})(\mathrm{H}) \mathrm{H})$ $(\mathrm{H}) \mathrm{H})(\mathrm{H}) \mathrm{H})(\mathrm{H})(\mathrm{H}) \mathrm{H}$

$\mathrm{C}(\mathrm{C}(\mathrm{C}(\mathrm{C}(\mathrm{C}(\mathrm{C}(\mathrm{C}(\mathrm{C}(\mathrm{C}(\mathrm{C}(\mathrm{C}(\mathrm{C}(\mathrm{C}(\mathrm{C}(\mathrm{H})(\mathrm{H}) \mathrm{H})(\mathrm{H}) \mathrm{H})(\mathrm{H}) \mathrm{H})(\mathrm{H}) \mathrm{H})(\mathrm{H}) \mathrm{H})(\mathrm{H}) \mathrm{H})(\mathrm{H}) \mathrm{H})(\mathrm{Br}) \mathrm{H})(\mathrm{H}) \mathrm{H})(\mathrm{H}) \mathrm{H})$

$(\mathrm{H}) \mathrm{H})(\mathrm{H}) \mathrm{Br})(\mathrm{H}) \mathrm{H})(\mathrm{H})(\mathrm{H}) \mathrm{H}$

$\mathrm{C}(\mathrm{C}(\mathrm{C}(\mathrm{C}(\mathrm{C}(\mathrm{C}(\mathrm{C}(\mathrm{C}(\mathrm{C}(\mathrm{C}(\mathrm{C}(\mathrm{C}(\mathrm{C}(\mathrm{C}(\mathrm{H})(\mathrm{H}) \mathrm{H})(\mathrm{H}) \mathrm{Br})(\mathrm{H}) \mathrm{H})(\mathrm{H}) \mathrm{H})(\mathrm{H}) \mathrm{H})(\mathrm{H}) \mathrm{H})(\mathrm{F}) \mathrm{H})(\mathrm{H}) \mathrm{H})(\mathrm{H}) \mathrm{H})(\mathrm{H}) \mathrm{H})$

$(\mathrm{H}) \mathrm{H})(\mathrm{H}) \mathrm{H})(\mathrm{H}) \mathrm{H})(\mathrm{H})(\mathrm{H}) \mathrm{H}$

$\mathrm{C}(\mathrm{C}(\mathrm{C}(\mathrm{C}(\mathrm{C}(\mathrm{C}(\mathrm{C}(\mathrm{C}(\mathrm{C}(\mathrm{C}(\mathrm{C}(\mathrm{C}(\mathrm{C}(\mathrm{C}(\mathrm{H})(\mathrm{H}) \mathrm{H})(\mathrm{Cl}) \mathrm{H})(\mathrm{H}) \mathrm{H})(\mathrm{H}) \mathrm{H})(\mathrm{H}) \mathrm{H})(\mathrm{Cl}) \mathrm{H})(\mathrm{H}) \mathrm{H})(\mathrm{H}) \mathrm{H})(\mathrm{H}) \mathrm{H})(\mathrm{H}) \mathrm{H})(\mathrm{H})$

$\mathrm{H})(\mathrm{H}) \mathrm{H})(\mathrm{H}) \mathrm{H})(\mathrm{H})(\mathrm{H}) \mathrm{H}$

C(C(C(C(C(C(C(C(C(C(C(C(C(C(H)(H)H)(Br)H)(H)H)(H)H)(H)H)(H)H)(H)H)(H)H)(H)H)(H)H)

$(\mathrm{H}) \mathrm{H})(\mathrm{H}) \mathrm{H})(\mathrm{H}) \mathrm{H})(\mathrm{H})(\mathrm{Cl}) \mathrm{H}$

$(\mathrm{H}) \mathrm{H})(\mathrm{H}) \mathrm{H})(\mathrm{H})(\mathrm{H}) \mathrm{H}$

$\mathrm{C}\left(\mathrm{C}\left(\mathrm{C}(\mathrm{C}(\mathrm{C}(\mathrm{C}(\mathrm{C}(\mathrm{C}(\mathrm{C}(\mathrm{C}(\mathrm{C}(\mathrm{C}(\mathrm{C}(\mathrm{C}(\mathrm{H})(\mathrm{H}) \mathrm{H})(\mathrm{H}) \mathrm{H})(\mathrm{H}) \mathrm{H})(\mathrm{H}) \mathrm{H})(\mathrm{H}) \mathrm{H})(\mathrm{H}) \mathrm{H})(\mathrm{H}) \mathrm{H})(\mathrm{H}) \mathrm{H})(\mathrm{H}) \mathrm{H})(\mathrm{H}) \mathrm{H})(\mathrm{H}) \mathrm{H}){ }_{\mathrm{Cl}} \mathrm{H}_{2} 2 \mathrm{Br}\right.\right.$

$(\mathrm{H}) \mathrm{H})(\mathrm{Br}) \mathrm{H})(\mathrm{H})(\mathrm{H}) \mathrm{H}$

$\mathrm{C}\left(\mathrm{C}\left(\mathrm{C}(\mathrm{C}(\mathrm{C}(\mathrm{C}(\mathrm{C}(\mathrm{C}(\mathrm{C}(\mathrm{C}(\mathrm{C}(\mathrm{C}(\mathrm{C}(\mathrm{C}(\mathrm{H})(\mathrm{H}) \mathrm{H})(\mathrm{H}) \mathrm{H})(\mathrm{H}) \mathrm{H})(\mathrm{H}) \mathrm{H})(\mathrm{H}) \mathrm{H})(\mathrm{H}) \mathrm{H})(\mathrm{H}) \mathrm{H})(\mathrm{H}) \mathrm{H})(\mathrm{H}) \mathrm{H})(\mathrm{H}) \mathrm{H})(\mathrm{H}) \mathrm{H}){ }_{\mathrm{Cl}}{ }^{4} \mathrm{H} 29 \mathrm{Cl}\right.\right.$

$(\mathrm{H}) \mathrm{Cl}(\mathrm{H}) \mathrm{H})(\mathrm{H})(\mathrm{H}) \mathrm{H}$

$\mathrm{C}\left(\mathrm{C}\left(\mathrm{C}(\mathrm{C}(\mathrm{C}(\mathrm{C}(\mathrm{C}(\mathrm{C}(\mathrm{C}(\mathrm{C}(\mathrm{C}(\mathrm{C}(\mathrm{C}(\mathrm{C}(\mathrm{H})(\mathrm{H}) \mathrm{H})(\mathrm{H}) \mathrm{H})(\mathrm{H}) \mathrm{H})(\mathrm{H}) \mathrm{H})(\mathrm{H}) \mathrm{H})(\mathrm{H}) \mathrm{H})(\mathrm{H}) \mathrm{H})(\mathrm{H}) \mathrm{H})(\mathrm{H}) \mathrm{H})(\mathrm{H}) \mathrm{H})(\mathrm{H}) \mathrm{H}){ }_{\mathrm{C} 14 \mathrm{H} 29 \mathrm{~F}}\right.\right.$

$(\mathrm{H}) \mathrm{H})(\mathrm{H}) \mathrm{F})(\mathrm{H})(\mathrm{H}) \mathrm{H}$

$\mathrm{C}\left(\mathrm{C}\left(\mathrm{C}(\mathrm{C}(\mathrm{C}(\mathrm{C}(\mathrm{C}(\mathrm{C}(\mathrm{C}(\mathrm{C}(\mathrm{C}(\mathrm{C}(\mathrm{C}(\mathrm{C}(\mathrm{H})(\mathrm{Br}) \mathrm{F})(\mathrm{H}) \mathrm{Br})(\mathrm{F}) \mathrm{H})(\mathrm{F}) \mathrm{H})(\mathrm{F}) \mathrm{Br})(\mathrm{F}) \mathrm{F})(\mathrm{F}) \mathrm{H})(\mathrm{F}) \mathrm{H})(\mathrm{F}) \mathrm{H})(\mathrm{Br}) \mathrm{H})(\mathrm{H}) \mathrm{F})\left({ }_{\mathrm{C} 15 \mathrm{H} 11 \mathrm{ClBr} 4 \mathrm{~F} 16}\right.\right.\right.$

$\mathrm{H}) \mathrm{F})(\mathrm{F}) \mathrm{H})(\mathrm{C}(\mathrm{F})(\mathrm{F}) \mathrm{Cl})(\mathrm{F}) \mathrm{F}$

$\mathrm{C}(\mathrm{C}(\mathrm{C}(\mathrm{C}(\mathrm{C}(\mathrm{C}(\mathrm{C}(\mathrm{C}(\mathrm{C}(\mathrm{C}(\mathrm{C}(\mathrm{C}(\mathrm{C}(\mathrm{C}(\mathrm{Cl})(\mathrm{F}) \mathrm{F})(\mathrm{H}) \mathrm{F})(\mathrm{H}) \mathrm{F})(\mathrm{F}) \mathrm{H})(\mathrm{Br}) \mathrm{F})(\mathrm{F}) \mathrm{H})(\mathrm{F}) \mathrm{H})(\mathrm{H}) \mathrm{F})(\mathrm{H}) \mathrm{Br})(\mathrm{F}) \mathrm{H})(\mathrm{H}) \mathrm{H})$

(F)H $(\mathrm{F}) \mathrm{F})(\mathrm{C}(\mathrm{F})(\mathrm{Br}) \mathrm{F})(\mathrm{H}) \mathrm{F}$

$(\mathrm{F}) \mathrm{H})(\mathrm{F}) \mathrm{F})(\mathrm{C}(\mathrm{F})(\mathrm{Br}) \mathrm{F})(\mathrm{H}) \mathrm{F}$
$\mathrm{C}(\mathrm{C}(\mathrm{C}(\mathrm{C}(\mathrm{C}(\mathrm{C}(\mathrm{C}(\mathrm{C}(\mathrm{C}(\mathrm{C}(\mathrm{C}(\mathrm{C}(\mathrm{C}(\mathrm{C}(\mathrm{F})(\mathrm{H}) \mathrm{F})(\mathrm{H}) \mathrm{F})(\mathrm{H}) \mathrm{Br})(\mathrm{F}) \mathrm{H})(\mathrm{F}) \mathrm{H})(\mathrm{H}) \mathrm{H})(\mathrm{F}) \mathrm{H})(\mathrm{Br}) \mathrm{H})(\mathrm{F}) \mathrm{H})(\mathrm{Cl}) \mathrm{H})(\mathrm{F}) \mathrm{F})(\mathrm{C} 15 \mathrm{H} 13 \mathrm{Cl} 2 \mathrm{Br} 3 \mathrm{~F} 1$

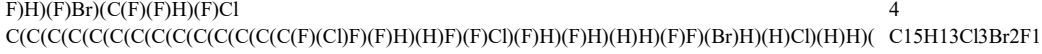

$\mathrm{F}) \mathrm{H})(\mathrm{F}) \mathrm{H})(\mathrm{C}(\mathrm{F})(\mathrm{F}) \mathrm{F})(\mathrm{Br}) \mathrm{H}$

$\mathrm{C}(\mathrm{C}(\mathrm{C}(\mathrm{C}(\mathrm{C}(\mathrm{C}(\mathrm{C}(\mathrm{C}(\mathrm{C}(\mathrm{C}(\mathrm{C}(\mathrm{C}(\mathrm{C}(\mathrm{C}(\mathrm{F})(\mathrm{F}) \mathrm{H})(\mathrm{F}) \mathrm{H})(\mathrm{H}) \mathrm{Cl})(\mathrm{F}) \mathrm{F})(\mathrm{H}) \mathrm{F})(\mathrm{F}) \mathrm{H})(\mathrm{F}) \mathrm{F})(\mathrm{H}) \mathrm{H})(\mathrm{F}) \mathrm{Cl})(\mathrm{F}) \mathrm{H})(\mathrm{Cl}) \mathrm{H})$ $(\mathrm{H}) \mathrm{H})(\mathrm{H}) \mathrm{F})(\mathrm{C}(\mathrm{Cl})(\mathrm{F}) \mathrm{F})(\mathrm{H}) \mathrm{Cl}$

$\mathrm{C}\left(\mathrm{C}\left(\mathrm{C}(\mathrm{C}(\mathrm{C}(\mathrm{C}(\mathrm{C}(\mathrm{C}(\mathrm{C}(\mathrm{C}(\mathrm{C}(\mathrm{C}(\mathrm{C}(\mathrm{C}(\mathrm{H})(\mathrm{F}) \mathrm{F})(\mathrm{Cl}) \mathrm{F})(\mathrm{F}) \mathrm{Cl})(\mathrm{Cl}) \mathrm{H})(\mathrm{H}) \mathrm{Cl})(\mathrm{Cl}) \mathrm{H})(\mathrm{Cl}) \mathrm{H})(\mathrm{F}) \mathrm{H})(\mathrm{F}) \mathrm{H})(\mathrm{H}) \mathrm{F})(\mathrm{H}) \mathrm{H}){ }_{\mathrm{C} 15 \mathrm{H} 13 \mathrm{Cl} 1 \mathrm{~F} 12}\right.\right.$

(F)H $(\mathrm{F}) \mathrm{F})(\mathrm{C}(\mathrm{H})(\mathrm{Cl}) \mathrm{F})(\mathrm{F}) \mathrm{H}$

$\mathrm{C}(\mathrm{C}(\mathrm{C}(\mathrm{C}(\mathrm{C}(\mathrm{C}(\mathrm{C}(\mathrm{C}(\mathrm{C}(\mathrm{C}(\mathrm{C}(\mathrm{C}(\mathrm{C}(\mathrm{C}(\mathrm{F})(\mathrm{F}) \mathrm{H})(\mathrm{H}) \mathrm{F})(\mathrm{F}) \mathrm{H})(\mathrm{H}) \mathrm{F})(\mathrm{F}) \mathrm{Br})(\mathrm{F}) \mathrm{Br})(\mathrm{H}) \mathrm{H})(\mathrm{H}) \mathrm{F})(\mathrm{Cl}) \mathrm{H})(\mathrm{F}) \mathrm{F})(\mathrm{F}) \mathrm{F})$

(H)F $(\mathrm{F}) \mathrm{H})(\mathrm{C}(\mathrm{Br})(\mathrm{H}) \mathrm{H})(\mathrm{F}) \mathrm{H}$

$\mathrm{C}(\mathrm{C}(\mathrm{C}(\mathrm{C}(\mathrm{C}(\mathrm{C}(\mathrm{C}(\mathrm{C}(\mathrm{C}(\mathrm{C}(\mathrm{C}(\mathrm{C}(\mathrm{C}(\mathrm{C}(\mathrm{H})(\mathrm{F}) \mathrm{H})(\mathrm{H}) \mathrm{F})(\mathrm{H}) \mathrm{F})(\mathrm{F}) \mathrm{H})(\mathrm{Br}) \mathrm{F})(\mathrm{F}) \mathrm{Br})(\mathrm{H}) \mathrm{Br})(\mathrm{H}) \mathrm{F})(\mathrm{H}) \mathrm{F})(\mathrm{F}) \mathrm{H})(\mathrm{F}) \mathrm{F})$

$(\mathrm{H}) \mathrm{H})(\mathrm{H}) \mathrm{F})(\mathrm{C}(\mathrm{F})(\mathrm{H}) \mathrm{F})(\mathrm{H}) \mathrm{F}$

C $(C(C(C(C(C(C(C)(C(C(C(C(C(C(F)(H) F)(H) B r)(F) B r)(F) H)(H) F)(B r) H)(H) F)(F) H)(F) H)(F) F)(F) F)$

$(\mathrm{H}) \mathrm{H})(\mathrm{F}) \mathrm{F})(\mathrm{C}(\mathrm{H})(\mathrm{H}) \mathrm{H})(\mathrm{Br}) \mathrm{H}$

$\mathrm{C}(\mathrm{C}(\mathrm{C}(\mathrm{C}(\mathrm{C}(\mathrm{C}(\mathrm{C}(\mathrm{C}(\mathrm{C}(\mathrm{C}(\mathrm{C}(\mathrm{C}(\mathrm{C}(\mathrm{C}(\mathrm{F})(\mathrm{H}) \mathrm{H})(\mathrm{H}) \mathrm{F})(\mathrm{F}) \mathrm{H})(\mathrm{Cl}) \mathrm{Cl})(\mathrm{H}) \mathrm{F})(\mathrm{H}) \mathrm{F})(\mathrm{Cl}) \mathrm{F})(\mathrm{H}) \mathrm{H})(\mathrm{Br}) \mathrm{F})(\mathrm{H}) \mathrm{H})(\mathrm{F}) \mathrm{H})($ F)H $(\mathrm{H}) \mathrm{F})(\mathrm{C}(\mathrm{F})(\mathrm{F}) \mathrm{F})(\mathrm{F}) \mathrm{H}$

$\mathrm{C}(\mathrm{C}(\mathrm{C}(\mathrm{C}(\mathrm{C}(\mathrm{C}(\mathrm{C}(\mathrm{C}(\mathrm{C}(\mathrm{C}(\mathrm{C}(\mathrm{C}(\mathrm{C}(\mathrm{C}(\mathrm{F})(\mathrm{H}) \mathrm{H})(\mathrm{H}) \mathrm{Cl})(\mathrm{F}) \mathrm{H})(\mathrm{F}) \mathrm{F})(\mathrm{H}) \mathrm{F})(\mathrm{H}) \mathrm{F})(\mathrm{H}) \mathrm{F})(\mathrm{H}) \mathrm{F})(\mathrm{Cl}) \mathrm{F})(\mathrm{Cl}) \mathrm{F})(\mathrm{Cl}) \mathrm{H})($

$\mathrm{H}) \mathrm{F})(\mathrm{H}) \mathrm{Cl}(\mathrm{C}(\mathrm{F})(\mathrm{F}) \mathrm{H})(\mathrm{H}) \mathrm{H}$

$\mathrm{C}(\mathrm{C}(\mathrm{C}(\mathrm{C}(\mathrm{C}(\mathrm{C}(\mathrm{C}(\mathrm{C}(\mathrm{C}(\mathrm{C}(\mathrm{C}(\mathrm{C}(\mathrm{C}(\mathrm{C}(\mathrm{H})(\mathrm{F}) \mathrm{H})(\mathrm{F}) \mathrm{F})(\mathrm{H}) \mathrm{F})(\mathrm{F}) \mathrm{H})(\mathrm{H}) \mathrm{Cl})(\mathrm{Cl}) \mathrm{H})(\mathrm{H}) \mathrm{Cl})(\mathrm{H}) \mathrm{Cl})(\mathrm{H}) \mathrm{Cl})(\mathrm{Cl}) \mathrm{F})(\mathrm{F}) \mathrm{H})$

$(\mathrm{H}) \mathrm{F})(\mathrm{F}) \mathrm{H})(\mathrm{C}(\mathrm{F})(\mathrm{H}) \mathrm{F})(\mathrm{H}) \mathrm{Cl}$

$\mathrm{C}(\mathrm{C}(\mathrm{C}(\mathrm{C}(\mathrm{C}(\mathrm{C}(\mathrm{C}(\mathrm{C}(\mathrm{C}(\mathrm{C}(\mathrm{C}(\mathrm{C}(\mathrm{C}(\mathrm{C}(\mathrm{H})(\mathrm{H}) \mathrm{F})(\mathrm{F}) \mathrm{F})(\mathrm{F}) \mathrm{H})(\mathrm{Br}) \mathrm{H})(\mathrm{F}) \mathrm{H})(\mathrm{F}) \mathrm{Br})(\mathrm{H}) \mathrm{F})(\mathrm{F}) \mathrm{Br})(\mathrm{F}) \mathrm{H})(\mathrm{F}) \mathrm{F})(\mathrm{F}) \mathrm{H})$

$(\mathrm{H}) \mathrm{F})(\mathrm{H}) \mathrm{Cl})(\mathrm{C}(\mathrm{H})(\mathrm{H}) \mathrm{H})(\mathrm{F}) \mathrm{H}$

C(C(C(C(C(C(C(C(C(C(C(C(C(C(F)(F)Br)(H)H)(F)H)(H)H)(F)H)(H)H)(H)H)(H)F)(F)F)(H)F)(F)H)(B

$\mathrm{r}) \mathrm{F})(\mathrm{H}) \mathrm{F})(\mathrm{C}(\mathrm{F})(\mathrm{H}) \mathrm{Br})(\mathrm{F}) \mathrm{F}$

$\mathrm{C}(\mathrm{C}(\mathrm{C}(\mathrm{C}(\mathrm{C}(\mathrm{C}(\mathrm{C}(\mathrm{C}(\mathrm{C}(\mathrm{C}(\mathrm{C}(\mathrm{C}(\mathrm{C}(\mathrm{C}(\mathrm{F})(\mathrm{H}) \mathrm{F})(\mathrm{F}) \mathrm{F})(\mathrm{F}) \mathrm{H})(\mathrm{Cl}) \mathrm{H})(\mathrm{H}) \mathrm{H})(\mathrm{H}) \mathrm{F})(\mathrm{F}) \mathrm{Br})(\mathrm{F}) \mathrm{H})(\mathrm{F}) \mathrm{H})(\mathrm{Br}) \mathrm{H})(\mathrm{F}) \mathrm{H})(\mathrm{C} \mathrm{C} 15 \mathrm{H} 15 \mathrm{Cl} 2 \mathrm{Br} 2 \mathrm{~F} 1$

l) $\mathrm{H})(\mathrm{F}) \mathrm{F})(\mathrm{C}(\mathrm{H})(\mathrm{H}) \mathrm{H})(\mathrm{F}) \mathrm{H}$

$\mathrm{C}\left(\mathrm{C}\left(\mathrm{C}(\mathrm{C}(\mathrm{C}(\mathrm{C}(\mathrm{C}(\mathrm{C}(\mathrm{C}(\mathrm{C}(\mathrm{C}(\mathrm{C}(\mathrm{C}(\mathrm{C}(\mathrm{F})(\mathrm{Cl}) \mathrm{H})(\mathrm{F}) \mathrm{F})(\mathrm{H}) \mathrm{F})(\mathrm{F}) \mathrm{H})(\mathrm{H}) \mathrm{H})(\mathrm{H}) \mathrm{F})(\mathrm{H}) \mathrm{H})(\mathrm{Br}) \mathrm{H})(\mathrm{F}) \mathrm{F})(\mathrm{F}) \mathrm{H})(\mathrm{H}) \mathrm{F})(\mathrm{F}) \mathrm{C}^{\mathrm{C}} 15 \mathrm{H} 15 \mathrm{Cl} 3 \mathrm{Br} 2 \mathrm{~F} 1\right.\right.$

$\mathrm{Cl})(\mathrm{H}) \mathrm{Br})(\mathrm{C}(\mathrm{H})(\mathrm{H}) \mathrm{Cl})(\mathrm{F}) \mathrm{H}$

$(\mathrm{F}) \mathrm{H})(\mathrm{F}) \mathrm{F})(\mathrm{C}(\mathrm{F})(\mathrm{H}) \mathrm{F})(\mathrm{H}) \mathrm{H}$

(

$\mathrm{Br})(\mathrm{H}) \mathrm{F})(\mathrm{C} 15 \mathrm{H} 16 \mathrm{Br} 3 \mathrm{~F} 13$

F)F $(\mathrm{F}) \mathrm{H})(\mathrm{C}(\mathrm{H})(\mathrm{F}) \mathrm{F})(\mathrm{H}) \mathrm{F}$

$\mathrm{C}(\mathrm{C}(\mathrm{C}(\mathrm{C}(\mathrm{C}(\mathrm{C}(\mathrm{C}(\mathrm{C}(\mathrm{C}(\mathrm{C}(\mathrm{C}(\mathrm{C}(\mathrm{C}(\mathrm{C}(\mathrm{F})(\mathrm{H}) \mathrm{H})(\mathrm{F}) \mathrm{F})(\mathrm{H}) \mathrm{F})(\mathrm{Cl}) \mathrm{H})(\mathrm{H}) \mathrm{F})(\mathrm{F}) \mathrm{Br})(\mathrm{H}) \mathrm{H})(\mathrm{F}) \mathrm{H})(\mathrm{F}) \mathrm{H})(\mathrm{F}) \mathrm{H})(\mathrm{H}) \mathrm{Cl})(\mathrm{C} 15 \mathrm{H} 16 \mathrm{Cl} 2 \mathrm{Br} 2 \mathrm{~F} 1$ $\mathrm{Br}) \mathrm{H})(\mathrm{H}) \mathrm{H})(\mathrm{C}(\mathrm{F})(\mathrm{H}) \mathrm{H})(\mathrm{F}) \mathrm{F}$

$\mathrm{C}(\mathrm{C}(\mathrm{C}(\mathrm{C}(\mathrm{C}(\mathrm{C}(\mathrm{C}(\mathrm{C}(\mathrm{C}(\mathrm{C}(\mathrm{C}(\mathrm{C}(\mathrm{C}(\mathrm{C}(\mathrm{F})(\mathrm{F}) \mathrm{Cl})(\mathrm{F}) \mathrm{Cl})(\mathrm{F}) \mathrm{F})(\mathrm{F}) \mathrm{H})(\mathrm{H}) \mathrm{H})(\mathrm{H}) \mathrm{H})(\mathrm{H}) \mathrm{H})(\mathrm{H}) \mathrm{H})(\mathrm{F}) \mathrm{H})(\mathrm{H}) \mathrm{F})(\mathrm{Br}) \mathrm{F})(\quad \mathrm{C} 15 \mathrm{H} 16 \mathrm{Cl} 2 \mathrm{BrF} 13$ $\mathrm{H}) \mathrm{H})(\mathrm{H}) \mathrm{F})(\mathrm{C}(\mathrm{F})(\mathrm{F}) \mathrm{H})(\mathrm{H}) \mathrm{F}$

$\mathrm{C}(\mathrm{C}(\mathrm{C}(\mathrm{C}(\mathrm{C}(\mathrm{C}(\mathrm{C}(\mathrm{C}(\mathrm{C}(\mathrm{C}(\mathrm{C}(\mathrm{C}(\mathrm{C}(\mathrm{C}(\mathrm{H})(\mathrm{Br}) \mathrm{F})(\mathrm{H}) \mathrm{H})(\mathrm{H}) \mathrm{F})(\mathrm{H}) \mathrm{F})(\mathrm{F}) \mathrm{H})(\mathrm{H}) \mathrm{F})(\mathrm{H}) \mathrm{H})(\mathrm{Cl}) \mathrm{F})(\mathrm{H}) \mathrm{H})(\mathrm{H}) \mathrm{F})(\mathrm{F}) \mathrm{Cl})(\mathrm{C} 15 \mathrm{H} 16 \mathrm{Cl} 3 \mathrm{Br} 2 \mathrm{~F} 1$

$\mathrm{F}) \mathrm{H})(\mathrm{H}) \mathrm{H})(\mathrm{C}(\mathrm{F})(\mathrm{Br}) \mathrm{Cl})(\mathrm{F}) \mathrm{H}$

$\mathrm{C}(\mathrm{C}(\mathrm{C}(\mathrm{C}(\mathrm{C}(\mathrm{C}(\mathrm{C}(\mathrm{C}(\mathrm{C}(\mathrm{C}(\mathrm{C}(\mathrm{C}(\mathrm{C}(\mathrm{C}(\mathrm{H})(\mathrm{F}) \mathrm{F})(\mathrm{H}) \mathrm{F})(\mathrm{H}) \mathrm{Br})(\mathrm{H}) \mathrm{H})(\mathrm{F}) \mathrm{F})(\mathrm{F}) \mathrm{H})(\mathrm{H}) \mathrm{H})(\mathrm{H}) \mathrm{F})(\mathrm{H}) \mathrm{H})(\mathrm{H}) \mathrm{F})(\mathrm{Cl}) \mathrm{H})($

$\mathrm{H}) \mathrm{F})(\mathrm{Cl}) \mathrm{Cl})(\mathrm{C}(\mathrm{F})(\mathrm{H}) \mathrm{H})(\mathrm{F}) \mathrm{Cl}$

lgKoa lgKow lgKaw lgKow lgKoa lgKa lgKow lgKoa lgKaw EPISuit EPI EPI Exp Exp w DFT DFT DFT e Suite Suite corr_corr_Exp corr__corr_corr $\begin{array}{lllllllll}6.691 & 7.49 & 0.80 & 6.25 & 5.45 & 0.80 & 6.51 & 10.30 & -3.79\end{array}$ $\begin{array}{lllllllll}5.124 & 7.16 & 2.04 & 5.76 & 3.72 & 2.04 & 6.26 & 7.43 & -1.16\end{array}$ $\begin{array}{llllllllll}7.257 & 7.79 & 0.53 & 6.70 & 6.17 & 0.53 & 6.75 & 11.34 & -4.60\end{array}$ $\begin{array}{lllllllll}6.36 & 8.13 & 1.77 & 7.21 & 5.44 & 1.77 & 7.01 & 9.70 & -2.69\end{array}$ $\begin{array}{lllllllll}6.612 & 7.63 & 1.02 & 6.46 & 5.44 & 1.02 & 6.62 & 10.16 & -3.54\end{array}$ $\begin{array}{lllllllll}6.115 & 7.4 & 1.28 & 6.12 & 4.83 & 1.28 & 6.45 & 9.25 & -2.80\end{array}$ $\begin{array}{lllllllll}4.548 & 7.07 & 2.52 & 5.63 & 3.11 & 2.52 & 6.19 & 6.37 & -0.18\end{array}$ $\begin{array}{lllllllll}5.551 & 7.29 & 1.74 & 5.96 & 4.22 & 1.74 & 6.36 & 8.21 & -1.85\end{array}$ $\begin{array}{lllllllll}6.049 & 7.52 & 1.47 & 6.30 & 4.83 & 1.47 & 6.54 & 9.12 & -2.59\end{array}$ $\begin{array}{lllllllll}7.111 & 7.83 & 0.72 & 6.76 & 6.04 & 0.72 & 6.78 & 11.07 & -4.30\end{array}$ $\begin{array}{lllllllll}6.624 & 7.61 & 0.99 & 6.43 & 5.45 & 0.99 & 6.61 & 10.18 & -3.57\end{array}$ 
$\mathrm{C}(\mathrm{C}(\mathrm{C}(\mathrm{C}(\mathrm{C}(\mathrm{C}(\mathrm{C}(\mathrm{C}(\mathrm{C}(\mathrm{C}(\mathrm{C}(\mathrm{C}(\mathrm{C}(\mathrm{C}(\mathrm{Cl})(\mathrm{H}) \mathrm{H})(\mathrm{H}) \mathrm{H})(\mathrm{F}) \mathrm{F})(\mathrm{H}) \mathrm{F})(\mathrm{F}) \mathrm{H})(\mathrm{F}) \mathrm{H})(\mathrm{F}) \mathrm{F})(\mathrm{F}) \mathrm{H})(\mathrm{H}) \mathrm{F})(\mathrm{Cl}) \mathrm{F})(\mathrm{H}) \mathrm{Cl})$ (F)H)(F)H $(\mathrm{C}(\mathrm{H})(\mathrm{H}) \mathrm{H})(\mathrm{H}) \mathrm{Cl}$

$\mathrm{C}(\mathrm{C}(\mathrm{C}(\mathrm{C}(\mathrm{C}(\mathrm{C}(\mathrm{C}(\mathrm{C}(\mathrm{C}(\mathrm{C}(\mathrm{C}(\mathrm{C}(\mathrm{C}(\mathrm{C}(\mathrm{F})(\mathrm{Cl}) \mathrm{F})(\mathrm{H}) \mathrm{H})(\mathrm{Cl}) \mathrm{H})(\mathrm{F}) \mathrm{H})(\mathrm{H}) \mathrm{Cl})(\mathrm{F}) \mathrm{F})(\mathrm{F}) \mathrm{H})(\mathrm{Cl}) \mathrm{H})(\mathrm{H}) \mathrm{H})(\mathrm{H}) \mathrm{H})(\mathrm{H}) \mathrm{F})($ $\mathrm{H}) \mathrm{F})(\mathrm{H}) \mathrm{F})(\mathrm{C}(\mathrm{H})(\mathrm{Cl}) \mathrm{F})(\mathrm{F}) \mathrm{H}$

$\mathrm{C}(\mathrm{C}(\mathrm{C}(\mathrm{C}(\mathrm{C}(\mathrm{C}(\mathrm{C}(\mathrm{C}(\mathrm{C}(\mathrm{C}(\mathrm{C}(\mathrm{C}(\mathrm{C}(\mathrm{C}(\mathrm{F})(\mathrm{F}) \mathrm{H})(\mathrm{F}) \mathrm{H})(\mathrm{H}) \mathrm{H})(\mathrm{H}) \mathrm{F})(\mathrm{H}) \mathrm{F})(\mathrm{Br}) \mathrm{Cl})(\mathrm{H}) \mathrm{H})(\mathrm{F}) \mathrm{F})(\mathrm{H}) \mathrm{F})(\mathrm{H}) \mathrm{H})(\mathrm{F}) \mathrm{H})$ $(\mathrm{F}) \mathrm{H})(\mathrm{Br}) \mathrm{H})(\mathrm{C}(\mathrm{F})(\mathrm{F}) \mathrm{F})(\mathrm{H}) \mathrm{H}$

$\mathrm{C}(\mathrm{C}(\mathrm{C}(\mathrm{C}(\mathrm{C}(\mathrm{C}(\mathrm{C}(\mathrm{C}(\mathrm{C}(\mathrm{C}(\mathrm{C}(\mathrm{C}(\mathrm{C}(\mathrm{C}(\mathrm{F})(\mathrm{F}) \mathrm{Br})(\mathrm{F}) \mathrm{H})(\mathrm{H}) \mathrm{H})(\mathrm{H}) \mathrm{F})(\mathrm{H}) \mathrm{F})(\mathrm{H}) \mathrm{H})(\mathrm{H}) \mathrm{F})(\mathrm{F}) \mathrm{F})(\mathrm{H}) \mathrm{Br})(\mathrm{H}) \mathrm{F})(\mathrm{H}) \mathrm{F})$

$(\mathrm{H}) \mathrm{F})(\mathrm{F}) \mathrm{H})(\mathrm{C}(\mathrm{H})(\mathrm{H}) \mathrm{H})(\mathrm{H}) \mathrm{Br}$

$\mathrm{C}(\mathrm{C}(\mathrm{C}(\mathrm{C}(\mathrm{C}(\mathrm{C}(\mathrm{C}(\mathrm{C}(\mathrm{C}(\mathrm{C}(\mathrm{C}(\mathrm{C}(\mathrm{C}(\mathrm{C}(\mathrm{H})(\mathrm{Br}) \mathrm{Cl})(\mathrm{H}) \mathrm{Br})(\mathrm{H}) \mathrm{F})(\mathrm{H}) \mathrm{H})(\mathrm{F}) \mathrm{H})(\mathrm{F}) \mathrm{H})(\mathrm{F}) H)(\mathrm{F}) \mathrm{Cl})(\mathrm{F}) \mathrm{H})(\mathrm{F}) \mathrm{H})(\mathrm{F}) \mathrm{F})(\mathrm{C} 15 \mathrm{H} 17 \mathrm{Cl2B} 2 \mathrm{Fl}$

$\mathrm{H}) \mathrm{H})(\mathrm{F}) \mathrm{H})(\mathrm{C}$

$\begin{array}{ll}\mathrm{H}) \mathrm{H})(\mathrm{F}) \mathrm{H})(\mathrm{C}(\mathrm{F})(\mathrm{H}) \mathrm{H})(\mathrm{H}) \mathrm{H} & 1 \\ \mathrm{C}(\mathrm{C}(\mathrm{C}(\mathrm{C}(\mathrm{C}(\mathrm{C}(\mathrm{C}(\mathrm{C}(\mathrm{C}(\mathrm{C}(\mathrm{C}(\mathrm{C}(\mathrm{C}(\mathrm{C}(\mathrm{H})(\mathrm{H}) \mathrm{Br})(\mathrm{H}) \mathrm{F})(\mathrm{H}) \mathrm{F})(\mathrm{F}) \mathrm{H})(\mathrm{F}) \mathrm{H})(\mathrm{H}) \mathrm{Br})(\mathrm{F}) \mathrm{H})(\mathrm{F}) \mathrm{H})(\mathrm{F}) \mathrm{H})(\mathrm{Cl}) \mathrm{F})(\mathrm{F}) \mathrm{H})(\mathrm{C} 15 \mathrm{H} 17 \mathrm{Cl} 2 \mathrm{Br} 3 \mathrm{~F} 1\end{array}$

$\mathrm{Br}) \mathrm{H})(\mathrm{Cl}) \mathrm{H})(\mathrm{C}(\mathrm{H})(\mathrm{F}) \mathrm{H})(\mathrm{H}) \mathrm{H}$

$\mathrm{C}(\mathrm{C}(\mathrm{C}(\mathrm{C}(\mathrm{C}(\mathrm{C}(\mathrm{C}(\mathrm{C}(\mathrm{C}(\mathrm{C}(\mathrm{C}(\mathrm{C}(\mathrm{C}(\mathrm{C}(\mathrm{H})(\mathrm{H}) \mathrm{H})(\mathrm{H}) \mathrm{H})(\mathrm{F}) \mathrm{H})(\mathrm{F}) \mathrm{H})(\mathrm{F}) \mathrm{F})(\mathrm{H}) \mathrm{H})(\mathrm{H}) \mathrm{H})(\mathrm{H}) \mathrm{F})(\mathrm{F}) \mathrm{H})(\mathrm{F}) \mathrm{F})(\mathrm{F}) \mathrm{H})(\mathrm{H})$ $\mathrm{F})(\mathrm{Br}) \mathrm{H})(\mathrm{C}(\mathrm{F})(\mathrm{F}) \mathrm{Cl})(\mathrm{H}) \mathrm{Cl}$

$\mathrm{C}\left(\mathrm{C}\left(\mathrm{C}(\mathrm{C}(\mathrm{C}(\mathrm{C}(\mathrm{C}(\mathrm{C}(\mathrm{C}(\mathrm{C}(\mathrm{C}(\mathrm{C}(\mathrm{C}(\mathrm{C}(\mathrm{H})(\mathrm{H}) \mathrm{F})(\mathrm{H}) \mathrm{Cl})(\mathrm{H}) \mathrm{H})(\mathrm{Br}) \mathrm{H})(\mathrm{H}) \mathrm{F})(\mathrm{Cl}) \mathrm{H})(\mathrm{F}) \mathrm{F})(\mathrm{H}) \mathrm{F})(\mathrm{H}) \mathrm{F})(\mathrm{F}) \mathrm{H})(\mathrm{H}) \mathrm{H})\left({ }_{\mathrm{C} 15 \mathrm{H} 17 \mathrm{Cl} 13 \mathrm{BrF} 11}\right.\right.\right.$ $\mathrm{H}) \mathrm{H})(\mathrm{F}) \mathrm{F})(\mathrm{C}(\mathrm{F})(\mathrm{F}) \mathrm{H})(\mathrm{H}) \mathrm{Cl}$

$\mathrm{C}\left(\mathrm{C}\left(\mathrm{C}(\mathrm{C}(\mathrm{C}(\mathrm{C}(\mathrm{C}(\mathrm{C}(\mathrm{C}(\mathrm{C}(\mathrm{C}(\mathrm{C}(\mathrm{C}(\mathrm{C}(\mathrm{F})(\mathrm{H}) \mathrm{F})(\mathrm{H}) \mathrm{Cl})(\mathrm{F}) \mathrm{H})(\mathrm{H}) \mathrm{H})(\mathrm{F}) \mathrm{H})(\mathrm{H}) \mathrm{H})(\mathrm{H}) \mathrm{Cl})(\mathrm{H}) \mathrm{H})(\mathrm{H}) \mathrm{Br})(\mathrm{F}) \mathrm{H})(\mathrm{F}) \mathrm{F})\left({ }_{\mathrm{C} 15 \mathrm{H} 17 \mathrm{Cl} 4 \mathrm{BrF} 10}\right.\right.\right.$ $\mathrm{Cl}) \mathrm{F})(\mathrm{H}) \mathrm{H})(\mathrm{C}(\mathrm{H})(\mathrm{F}) \mathrm{F})(\mathrm{Cl}) \mathrm{H}$

$\mathrm{C}\left(\mathrm{C}\left(\mathrm{C}(\mathrm{C}(\mathrm{C}(\mathrm{C}(\mathrm{C}(\mathrm{C}(\mathrm{C}(\mathrm{C}(\mathrm{C}(\mathrm{C}(\mathrm{C}(\mathrm{C}(\mathrm{F})(\mathrm{H}) \mathrm{Cl})(\mathrm{F}) \mathrm{H})(\mathrm{F}) \mathrm{H})(\mathrm{F}) \mathrm{H})(\mathrm{H}) \mathrm{H})(\mathrm{F}) \mathrm{H})(\mathrm{H}) \mathrm{Cl})(\mathrm{F}) \mathrm{F})(\mathrm{H}) \mathrm{H})(\mathrm{H}) \mathrm{Cl})(\mathrm{F}) \mathrm{Cl})\left({ }_{\mathrm{C} 15 \mathrm{H} 17 \mathrm{Cl} 5 \mathrm{~F} 10}\right.\right.\right.$

$\mathrm{Cl}) \mathrm{H})(\mathrm{H}) \mathrm{H})(\mathrm{C}(\mathrm{F})(\mathrm{F}) \mathrm{H})(\mathrm{H}) \mathrm{H}$

$\mathrm{C}\left(\mathrm{C}\left(\mathrm{C}(\mathrm{C}(\mathrm{C}(\mathrm{C}(\mathrm{C}(\mathrm{C}(\mathrm{C}(\mathrm{C}(\mathrm{C}(\mathrm{C}(\mathrm{C}(\mathrm{C}(\mathrm{Cl})(\mathrm{H}) \mathrm{F})(\mathrm{F}) \mathrm{H})(\mathrm{H}) \mathrm{Cl})(\mathrm{F}) \mathrm{H})(\mathrm{F}) \mathrm{H})(\mathrm{H}) \mathrm{H})(\mathrm{H}) \mathrm{Cl})(\mathrm{H}) \mathrm{F})(\mathrm{Cl}) \mathrm{Cl})(\mathrm{H}) \mathrm{H})(\mathrm{F}) \mathrm{H}){ }_{\mathrm{C} 15 \mathrm{H} 17 \mathrm{Cl} 6 \mathrm{~F} 9}\right.\right.$

$(\mathrm{F}) \mathrm{F})(\mathrm{H}) \mathrm{Cl})(\mathrm{C}(\mathrm{H})(\mathrm{H}) \mathrm{H})(\mathrm{F}) \mathrm{H}$

$\mathrm{C} 15 \mathrm{H} 17 \mathrm{Cl6F} 9$

C(C(C(C(C(C(C(C(C(C(C(C(C(C(F)(F)Cl)(F)H)(H)F)(F)F)(F)H)(F)H)(Br)F)(H)H)(H)H)(H)H)(H)H

$(\mathrm{H}) \mathrm{H})(\mathrm{Br}) \mathrm{H})(\mathrm{C}(\mathrm{F})(\mathrm{H}) \mathrm{H})(\mathrm{F}) \mathrm{F}$

$\mathrm{C}\left(\mathrm{C}\left(\mathrm{C}(\mathrm{C}(\mathrm{C}(\mathrm{C}(\mathrm{C}(\mathrm{C}(\mathrm{C}(\mathrm{C}(\mathrm{C}(\mathrm{C}(\mathrm{C}(\mathrm{C}(\mathrm{H})(\mathrm{Br}) \mathrm{F})(\mathrm{H}) \mathrm{H})(\mathrm{H}) \mathrm{F})(\mathrm{H}) \mathrm{H})(\mathrm{F}) \mathrm{H})(\mathrm{H}) \mathrm{H})(\mathrm{H}) \mathrm{F})(\mathrm{Br}) \mathrm{H})(\mathrm{H}) \mathrm{H})(\mathrm{F}) \mathrm{F})(\mathrm{H}) \mathrm{F})\left({ }_{\mathrm{C} 15 \mathrm{H} 18 \mathrm{Br} 2 \mathrm{~F} 12}\right.\right.\right.$

$\mathrm{F}) \mathrm{F})(\mathrm{H}) \mathrm{H})(\mathrm{C}(\mathrm{H})(\mathrm{H}) \mathrm{F})(\mathrm{F}) \mathrm{F}$

$\mathrm{C}(\mathrm{C}(\mathrm{C}(\mathrm{C}(\mathrm{C}(\mathrm{C}(\mathrm{C}(\mathrm{C}(\mathrm{C}(\mathrm{C}(\mathrm{C}(\mathrm{C}(\mathrm{C}(\mathrm{C}(\mathrm{H})(\mathrm{H}) \mathrm{H})(\mathrm{F}) \mathrm{F})(\mathrm{H}) \mathrm{H})(\mathrm{F}) \mathrm{H})(\mathrm{F}) \mathrm{H})(\mathrm{F}) \mathrm{H})(\mathrm{H}) \mathrm{F})(\mathrm{H}) \mathrm{H})(\mathrm{H}) \mathrm{F})(\mathrm{H}) \mathrm{F})(\mathrm{F}) \mathrm{H}) \quad \mathrm{C} 15 \mathrm{H} 18 \mathrm{Br} 3 \mathrm{~F} 11$

$(\mathrm{Br}) \mathrm{H})(\mathrm{F}) \mathrm{Br})(\mathrm{C}(\mathrm{H})(\mathrm{H}) \mathrm{Br})(\mathrm{F}) \mathrm{H}$

$\mathrm{C}\left(\mathrm{C}\left(\mathrm{C}(\mathrm{C}(\mathrm{C}(\mathrm{C}(\mathrm{C}(\mathrm{C}(\mathrm{C}(\mathrm{C}(\mathrm{C}(\mathrm{C}(\mathrm{C}(\mathrm{C}(\mathrm{H})(\mathrm{H}) \mathrm{F})(\mathrm{F}) \mathrm{H})(\mathrm{H}) \mathrm{H})(\mathrm{Br}) \mathrm{H})(\mathrm{F}) \mathrm{H})(\mathrm{F}) \mathrm{H})(\mathrm{Br}) \mathrm{Br})(\mathrm{F}) \mathrm{H})(\mathrm{Br}) \mathrm{H})(\mathrm{F}) \mathrm{F})(\mathrm{H}) \mathrm{F}){ }_{\mathrm{C} 15 \mathrm{H} 18 \mathrm{Br} 4 \mathrm{~F} 10}\right.\right.$ $(\mathrm{H}) \mathrm{H})(\mathrm{H}) \mathrm{F})(\mathrm{C}(\mathrm{H})(\mathrm{H}) \mathrm{H})(\mathrm{F}) \mathrm{H}$

C(C(C(C(C(C(C(C(C(C(C(C(C(C(Br)(F)H)(H)F)(F)H)(Br)H)(Cl)F)(F)F)(F)Cl)(H)H)(H)H)(H)F)(H)H)( C15H18C12Br2F1 $\mathrm{H}) \mathrm{H})(\mathrm{H}) \mathrm{H})(\mathrm{C}(\mathrm{H})(\mathrm{F}) \mathrm{H})(\mathrm{H}) \mathrm{F}$

$\mathrm{C}(\mathrm{C}(\mathrm{C}(\mathrm{C}(\mathrm{C}(\mathrm{C}(\mathrm{C}(\mathrm{C}(\mathrm{C}(\mathrm{C}(\mathrm{C}(\mathrm{C}(\mathrm{C}(\mathrm{C}(\mathrm{H})(\mathrm{H}) \mathrm{H})(\mathrm{Cl}) \mathrm{H})(\mathrm{H}) \mathrm{H})(\mathrm{F}) \mathrm{H})(\mathrm{H}) \mathrm{H})(\mathrm{Cl}) \mathrm{H})(\mathrm{H}) \mathrm{F})(\mathrm{H}) \mathrm{H})(\mathrm{F}) \mathrm{F})(\mathrm{F}) \mathrm{F})(\mathrm{F}) \mathrm{F})($ $\mathrm{H}) \mathrm{H})(\mathrm{H}) \mathrm{F})(\mathrm{C}(\mathrm{H})(\mathrm{F}) \mathrm{F})(\mathrm{H}) \mathrm{Br}$

$\mathrm{C}(\mathrm{C}(\mathrm{C}(\mathrm{C}(\mathrm{C}(\mathrm{C}(\mathrm{C}(\mathrm{C}(\mathrm{C}(\mathrm{C}(\mathrm{C}(\mathrm{C}(\mathrm{C}(\mathrm{C}(\mathrm{F})(\mathrm{F}) \mathrm{F})(\mathrm{H}) \mathrm{H})(\mathrm{F}) \mathrm{Br})(\mathrm{H}) \mathrm{Cl})(\mathrm{Cl}) \mathrm{H})(\mathrm{H}) \mathrm{H})(\mathrm{H}) \mathrm{F})(\mathrm{F}) \mathrm{H})(\mathrm{F}) \mathrm{H})(\mathrm{H}) \mathrm{F})(\mathrm{F}) \mathrm{H})$

$(\mathrm{F}) \mathrm{H})(\mathrm{H}) \mathrm{H})(\mathrm{C}(\mathrm{Cl})(\mathrm{H}) \mathrm{H})(\mathrm{H}) \mathrm{H}$

$\mathrm{C}(\mathrm{C}(\mathrm{C}(\mathrm{C}(\mathrm{C}(\mathrm{C}(\mathrm{C}(\mathrm{C}(\mathrm{C}(\mathrm{C}(\mathrm{C}(\mathrm{C}(\mathrm{C}(\mathrm{C}(\mathrm{F})(\mathrm{F}) \mathrm{H})(\mathrm{H}) \mathrm{F})(\mathrm{Cl}) \mathrm{H})(\mathrm{H}) \mathrm{Cl})(\mathrm{F}) \mathrm{H})(\mathrm{H}) \mathrm{F})(\mathrm{F}) \mathrm{H})(\mathrm{H}) \mathrm{H})(\mathrm{H}) \mathrm{H})(\mathrm{H}) \mathrm{F})(\mathrm{Cl}) \mathrm{F})($

$\mathrm{H}) \mathrm{Cl})(\mathrm{H}) \mathrm{F})(\mathrm{C}(\mathrm{H})(\mathrm{H}) \mathrm{H})(\mathrm{F}) \mathrm{H}$

$\mathrm{C}(\mathrm{C}(\mathrm{C}(\mathrm{C}(\mathrm{C}(\mathrm{C}(\mathrm{C}(\mathrm{C}(\mathrm{C}(\mathrm{C}(\mathrm{C}(\mathrm{C}(\mathrm{C}(\mathrm{C}(\mathrm{H})(\mathrm{F}) \mathrm{H})(\mathrm{H}) \mathrm{F})(\mathrm{F}) \mathrm{H})(\mathrm{F}) \mathrm{H})(\mathrm{H}) \mathrm{F})(\mathrm{F}) \mathrm{H})(\mathrm{Cl}) \mathrm{F})(\mathrm{H}) \mathrm{H})(\mathrm{Cl}) \mathrm{F})(\mathrm{H}) \mathrm{H})(\mathrm{H}) \mathrm{H})(\mathrm{C}$ 1)F)(H)Cl) $(\mathrm{C}(\mathrm{H})(\mathrm{H}) \mathrm{Cl}(\mathrm{H}) \mathrm{H}$

$\mathrm{C}\left(\mathrm{C}\left(\mathrm{C}(\mathrm{C}(\mathrm{C}(\mathrm{C}(\mathrm{C}(\mathrm{C}(\mathrm{C}(\mathrm{C}(\mathrm{C}(\mathrm{C}(\mathrm{C}(\mathrm{C}(\mathrm{H})(\mathrm{F}) \mathrm{Cl})(\mathrm{Cl}) \mathrm{H})(\mathrm{H}) \mathrm{H})(\mathrm{H}) \mathrm{Cl})(\mathrm{H}) \mathrm{H})(\mathrm{F}) \mathrm{F})(\mathrm{Cl}) \mathrm{Cl})(\mathrm{H}) \mathrm{H})(\mathrm{H}) \mathrm{F})(\mathrm{H}) \mathrm{F})(\mathrm{H}) \mathrm{F}){ }_{\mathrm{C} 15 \mathrm{H} 18 \mathrm{Cl} 6 \mathrm{~F} 8}\right.\right.$

(F)H)(F)H $(\mathrm{C}(\mathrm{H})(\mathrm{Cl}) \mathrm{H})(\mathrm{H}) \mathrm{H}$

$\mathrm{C}(\mathrm{C}(\mathrm{C}(\mathrm{C}(\mathrm{C}(\mathrm{C}(\mathrm{C}(\mathrm{C}(\mathrm{C}(\mathrm{C}(\mathrm{C}(\mathrm{C}(\mathrm{C}(\mathrm{C}(\mathrm{H})(\mathrm{Br}) \mathrm{Cl})(\mathrm{H}) \mathrm{H})(\mathrm{F}) \mathrm{H})(\mathrm{H}) \mathrm{H})(\mathrm{F}) \mathrm{H})(\mathrm{H}) \mathrm{F})(\mathrm{H}) \mathrm{H})(\mathrm{H}) \mathrm{F})(\mathrm{F}) \mathrm{F})(\mathrm{F}) \mathrm{H})(\mathrm{H}) \mathrm{H})($

$\mathrm{H}) \mathrm{F})(\mathrm{Br}) \mathrm{H})(\mathrm{C}(\mathrm{H})(\mathrm{F}) \mathrm{F})(\mathrm{F}) \mathrm{H}$

$\mathrm{C}(\mathrm{C}(\mathrm{C}(\mathrm{C}(\mathrm{C}(\mathrm{C}(\mathrm{C}(\mathrm{C}(\mathrm{C}(\mathrm{C}(\mathrm{C}(\mathrm{C}(\mathrm{C}(\mathrm{C}(\mathrm{Br})(\mathrm{H}) \mathrm{F})(\mathrm{F}) \mathrm{H})(\mathrm{H}) \mathrm{H})(\mathrm{H}) \mathrm{F})(\mathrm{F}) \mathrm{H})(\mathrm{H}) \mathrm{F})(\mathrm{F}) \mathrm{Cl})(\mathrm{H}) \mathrm{F})(\mathrm{H}) \mathrm{F})(\mathrm{H}) \mathrm{H})(\mathrm{F}) \mathrm{H})$

$(\mathrm{H}) \mathrm{H})(\mathrm{H}) \mathrm{Br})(\mathrm{C}(\mathrm{Br})(\mathrm{H}) \mathrm{H})(\mathrm{H}) \mathrm{F}$

$\mathrm{C}(\mathrm{C}(\mathrm{C}(\mathrm{C}(\mathrm{C}(\mathrm{C}(\mathrm{C}(\mathrm{C}(\mathrm{C}(\mathrm{C}(\mathrm{C}(\mathrm{C}(\mathrm{C}(\mathrm{C}(\mathrm{H})(\mathrm{H}) \mathrm{H})(\mathrm{H}) \mathrm{F})(\mathrm{H}) \mathrm{H})(\mathrm{F}) \mathrm{H})(\mathrm{F}) \mathrm{F})(\mathrm{F}) \mathrm{H})(\mathrm{F}) \mathrm{H})(\mathrm{Br}) \mathrm{H})(\mathrm{H}) \mathrm{F})(\mathrm{H}) \mathrm{H})(\mathrm{F}) \mathrm{F})(\mathrm{F})$

$\mathrm{Br})(\mathrm{H}) \mathrm{H})(\mathrm{C}(\mathrm{H})(\mathrm{H}) \mathrm{H})(\mathrm{H}) \mathrm{Br}$

$\mathrm{C}(\mathrm{C}(\mathrm{C}(\mathrm{C}(\mathrm{C}(\mathrm{C}(\mathrm{C}(\mathrm{C}(\mathrm{C}(\mathrm{C}(\mathrm{C}(\mathrm{C}(\mathrm{C}(\mathrm{C}(\mathrm{F})(\mathrm{F}) \mathrm{H})(\mathrm{F}) \mathrm{H})(\mathrm{Br}) \mathrm{H})(\mathrm{H}) \mathrm{F})(\mathrm{H}) \mathrm{H})(\mathrm{H}) \mathrm{H})(\mathrm{F}) \mathrm{H})(\mathrm{F}) \mathrm{F})(\mathrm{H}) \mathrm{Br})(\mathrm{Br}) \mathrm{H})(\mathrm{F}) \mathrm{H})($ $\mathrm{H}) \mathrm{H})(\mathrm{H}) \mathrm{H})(\mathrm{C}(\mathrm{F})(\mathrm{H}) \mathrm{H})(\mathrm{Br}) \mathrm{H}$

$\mathrm{C}(\mathrm{C}(\mathrm{C}(\mathrm{C}(\mathrm{C}(\mathrm{C}(\mathrm{C}(\mathrm{C}(\mathrm{C}(\mathrm{C}(\mathrm{C}(\mathrm{C}(\mathrm{C}(\mathrm{C}(\mathrm{H})(\mathrm{F}) \mathrm{F})(\mathrm{H}) \mathrm{H})(\mathrm{F}) \mathrm{H})(\mathrm{H}) \mathrm{F})(\mathrm{F}) \mathrm{H})(\mathrm{H}) \mathrm{H})(\mathrm{H}) \mathrm{F})(\mathrm{H}) \mathrm{H})(\mathrm{H}) \mathrm{H})(\mathrm{F}) \mathrm{H})(\mathrm{Cl}) \mathrm{H})$ $(\mathrm{H}) \mathrm{F})(\mathrm{Br}) \mathrm{H})(\mathrm{C}(\mathrm{H})(\mathrm{Cl}) \mathrm{F})(\mathrm{Br}) \mathrm{H}$

$\mathrm{C}(\mathrm{C}(\mathrm{C}(\mathrm{C}(\mathrm{C}(\mathrm{C}(\mathrm{C}(\mathrm{C}(\mathrm{C}(\mathrm{C}(\mathrm{C}(\mathrm{C}(\mathrm{C}(\mathrm{C}(\mathrm{H})(\mathrm{H}) \mathrm{Cl})(\mathrm{H}) \mathrm{H})(\mathrm{Br}) \mathrm{F})(\mathrm{H}) \mathrm{H})(\mathrm{H}) \mathrm{F})(\mathrm{H}) \mathrm{H})(\mathrm{F}) \mathrm{H})(\mathrm{F}) \mathrm{H})(\mathrm{H}) \mathrm{F})(\mathrm{H}) \mathrm{H})(\mathrm{H}) \mathrm{F})($

$\mathrm{F}) \mathrm{F})(\mathrm{H}) \mathrm{F})(\mathrm{C}(\mathrm{H})(\mathrm{H}) \mathrm{Cl})(\mathrm{F}) \mathrm{H}$

$\mathrm{C}(\mathrm{C}(\mathrm{C}(\mathrm{C}(\mathrm{C}(\mathrm{C}(\mathrm{C}(\mathrm{C}(\mathrm{C}(\mathrm{C}(\mathrm{C}(\mathrm{C}(\mathrm{C}(\mathrm{C}(\mathrm{F})(\mathrm{H}) \mathrm{H})(\mathrm{F}) \mathrm{Cl})(\mathrm{H}) \mathrm{H})(\mathrm{F}) \mathrm{Cl})(\mathrm{H}) \mathrm{F})(\mathrm{H}) \mathrm{H})(\mathrm{H}) \mathrm{H})(\mathrm{F}) \mathrm{H})(\mathrm{Br}) \mathrm{H})(\mathrm{F}) \mathrm{F})(\mathrm{H}) \mathrm{H})($

$\mathrm{H}) \mathrm{H})(\mathrm{H}) \mathrm{H})(\mathrm{C}(\mathrm{Cl})(\mathrm{F}) \mathrm{H})(\mathrm{F}) \mathrm{H}$

$\mathrm{C}(\mathrm{C}(\mathrm{C}(\mathrm{C}(\mathrm{C}(\mathrm{C}(\mathrm{C}(\mathrm{C}(\mathrm{C}(\mathrm{C}(\mathrm{C}(\mathrm{C}(\mathrm{C}(\mathrm{C}(\mathrm{Cl})(\mathrm{H}) \mathrm{F})(\mathrm{H}) \mathrm{H})(\mathrm{H}) \mathrm{F})(\mathrm{H}) \mathrm{F})(\mathrm{H}) \mathrm{H})(\mathrm{H}) \mathrm{F})(\mathrm{H}) \mathrm{Cl})(\mathrm{Br}) \mathrm{H})(\mathrm{F}) \mathrm{H})(\mathrm{H}) \mathrm{H})(\mathrm{H}) \mathrm{F})($

$\mathrm{F}) \mathrm{H})(\mathrm{H}) \mathrm{F})(\mathrm{C}(\mathrm{Cl})(\mathrm{H}) \mathrm{H})(\mathrm{H}) \mathrm{Cl}$

$\mathrm{C}(\mathrm{C}(\mathrm{C}(\mathrm{C}(\mathrm{C}(\mathrm{C}(\mathrm{C}(\mathrm{C}(\mathrm{C}(\mathrm{C}(\mathrm{C}(\mathrm{C}(\mathrm{C}(\mathrm{C}(\mathrm{F})(\mathrm{F}) \mathrm{H})(\mathrm{H}) \mathrm{H})(\mathrm{Cl}) \mathrm{H})(\mathrm{H}) \mathrm{F})(\mathrm{F}) \mathrm{Cl})(\mathrm{Cl}) \mathrm{H})(\mathrm{F}) \mathrm{H})(\mathrm{H}) \mathrm{F})(\mathrm{H}) \mathrm{H})(\mathrm{H}) \mathrm{F})(\mathrm{Cl}) \mathrm{H})($ $\mathrm{H}) \mathrm{F})(\mathrm{H}) \mathrm{H})(\mathrm{C}(\mathrm{H})(\mathrm{H}) \mathrm{H})(\mathrm{Cl}) \mathrm{H}$

$\mathrm{C}(\mathrm{C}(\mathrm{C}(\mathrm{C}(\mathrm{C}(\mathrm{C}(\mathrm{C}(\mathrm{C}(\mathrm{C}(\mathrm{C}(\mathrm{C}(\mathrm{C}(\mathrm{C}(\mathrm{C}(\mathrm{H})(\mathrm{H}) \mathrm{H})(\mathrm{F}) \mathrm{F})(\mathrm{Br}) \mathrm{H})(\mathrm{H}) \mathrm{F})(\mathrm{H}) \mathrm{F})(\mathrm{H}) \mathrm{H})(\mathrm{F}) \mathrm{Cl})(\mathrm{H}) \mathrm{F})(\mathrm{H}) \mathrm{H})(\mathrm{H}) \mathrm{F})(\mathrm{H}) \mathrm{H})($ $\mathrm{H}) \mathrm{F})(\mathrm{F}) \mathrm{H})(\mathrm{C}(\mathrm{Br})(\mathrm{H}) \mathrm{H})(\mathrm{F}) \mathrm{H}$

$\mathrm{C}(\mathrm{C}(\mathrm{C}(\mathrm{C}(\mathrm{C}(\mathrm{C}(\mathrm{C}(\mathrm{C}(\mathrm{C}(\mathrm{C}(\mathrm{C}(\mathrm{C}(\mathrm{C}(\mathrm{C}(\mathrm{F})(\mathrm{H}) \mathrm{Br})(\mathrm{H}) \mathrm{H})(\mathrm{H}) \mathrm{F})(\mathrm{H}) \mathrm{Cl})(\mathrm{Br}) \mathrm{F})(\mathrm{F}) \mathrm{H})(\mathrm{H}) \mathrm{H})(\mathrm{F}) \mathrm{F})(\mathrm{F}) \mathrm{H})(\mathrm{H}) \mathrm{H})(\mathrm{H}) \mathrm{H})($

$\mathrm{H}) \mathrm{H})(\mathrm{H}) \mathrm{Br})(\mathrm{C}(\mathrm{H})(\mathrm{H}) \mathrm{F})(\mathrm{H}) \mathrm{F}$

$\mathrm{C}(\mathrm{C}(\mathrm{C}(\mathrm{C}(\mathrm{C}(\mathrm{C}(\mathrm{C}(\mathrm{C}(\mathrm{C}(\mathrm{C}(\mathrm{C}(\mathrm{C}(\mathrm{C}(\mathrm{C}(\mathrm{H})(\mathrm{Br}) \mathrm{H})(\mathrm{H}) \mathrm{H})(\mathrm{F}) \mathrm{H})(\mathrm{F}) \mathrm{F})(\mathrm{H}) \mathrm{F})(\mathrm{H}) \mathrm{H})(\mathrm{H}) \mathrm{H})(\mathrm{F}) \mathrm{H})(\mathrm{F}) \mathrm{F})(\mathrm{H}) \mathrm{F})(\mathrm{H}) \mathrm{H})$

$(\mathrm{F}) \mathrm{H})(\mathrm{H}) \mathrm{H})(\mathrm{C}(\mathrm{H})(\mathrm{H}) \mathrm{H})(\mathrm{F}) \mathrm{B}$

$\mathrm{C}(\mathrm{C}(\mathrm{C}(\mathrm{C}(\mathrm{C}(\mathrm{C}(\mathrm{C}(\mathrm{C}(\mathrm{C}(\mathrm{C}(\mathrm{C}(\mathrm{C}(\mathrm{C}(\mathrm{C}(\mathrm{H})(\mathrm{Br}) \mathrm{F})(\mathrm{Br}) \mathrm{F})(\mathrm{H}) \mathrm{H})(\mathrm{H}) \mathrm{H})(\mathrm{F}) \mathrm{H})(\mathrm{F}) \mathrm{Cl})(\mathrm{H}) \mathrm{H})(\mathrm{H}) \mathrm{H})(\mathrm{H}) \mathrm{H})(\mathrm{F}) \mathrm{H})(\mathrm{H}) \mathrm{H})$

$(\mathrm{H}) \mathrm{F})(\mathrm{Cl}) \mathrm{H})(\mathrm{C}(\mathrm{H})(\mathrm{F}) \mathrm{F})(\mathrm{H}) \mathrm{H}$

$\mathrm{C}(\mathrm{C}(\mathrm{C}(\mathrm{C}(\mathrm{C}(\mathrm{C}(\mathrm{C}(\mathrm{C}(\mathrm{C}(\mathrm{C}(\mathrm{C}(\mathrm{C}(\mathrm{C}(\mathrm{C}(\mathrm{H})(\mathrm{H}) \mathrm{H})(\mathrm{Cl}) \mathrm{H})(\mathrm{F}) \mathrm{H})(\mathrm{H}) \mathrm{H})(\mathrm{H}) \mathrm{H})(\mathrm{H}) \mathrm{H})(\mathrm{F}) \mathrm{H})(\mathrm{H}) \mathrm{H})(\mathrm{F}) \mathrm{H})(\mathrm{H}) \mathrm{H})(\mathrm{F}) \mathrm{H})($

$\mathrm{F}) \mathrm{Cl})(\mathrm{Br}) \mathrm{H})(\mathrm{C}(\mathrm{H})(\mathrm{F}) \mathrm{F})(\mathrm{F}) \mathrm{F}$

$\mathrm{C}\left(\mathrm{C}\left(\mathrm{C}(\mathrm{C}(\mathrm{C}(\mathrm{C}(\mathrm{C}(\mathrm{C}(\mathrm{C}(\mathrm{C}(\mathrm{C}(\mathrm{C}(\mathrm{C}(\mathrm{C}(\mathrm{H})(\mathrm{H}) \mathrm{H})(\mathrm{H}) \mathrm{H})(\mathrm{H}) \mathrm{F})(\mathrm{F}) \mathrm{F})(\mathrm{Br}) \mathrm{Cl})(\mathrm{H}) \mathrm{H})(\mathrm{H}) \mathrm{H})(\mathrm{H}) \mathrm{F})(\mathrm{H}) \mathrm{H})(\mathrm{F}) \mathrm{F})(\mathrm{Cl}) \mathrm{H})\left({ }_{\mathrm{C} 15 \mathrm{H} 20 \mathrm{Cl} 3 \mathrm{BrF} 8}\right.\right.\right.$

$\mathrm{H}) \mathrm{F})(\mathrm{H}) \mathrm{H})(\mathrm{C}(\mathrm{F})(\mathrm{H}) \mathrm{H})(\mathrm{H}) \mathrm{Cl}$

$\mathrm{C}\left(\mathrm{C}\left(\mathrm{C}(\mathrm{C}(\mathrm{C}(\mathrm{C}(\mathrm{C}(\mathrm{C}(\mathrm{C}(\mathrm{C}(\mathrm{C}(\mathrm{C}(\mathrm{C}(\mathrm{C}(\mathrm{F})(\mathrm{Cl}) \mathrm{H})(\mathrm{F}) \mathrm{H})(\mathrm{H}) \mathrm{H})(\mathrm{F}) \mathrm{F})(\mathrm{Cl}) \mathrm{Cl})(\mathrm{H}) \mathrm{F})(\mathrm{F}) \mathrm{H})(\mathrm{H}) \mathrm{H})(\mathrm{H}) \mathrm{H})(\mathrm{F}) \mathrm{H})(\mathrm{H}) \mathrm{H})\left({ }_{\mathrm{C} 15 \mathrm{H} 20 \mathrm{Cl} 3 \mathrm{~F}}\right.\right.\right.$

$\mathrm{H}) \mathrm{H})(\mathrm{F}) \mathrm{H})(\mathrm{C}(\mathrm{H})(\mathrm{F}) \mathrm{H})(\mathrm{H}) \mathrm{H}$

C(C(C(C(C)C(C(C(C(C(C(C(C(C(F)(Cl)H)(F)H)(F)H)(F)H)(Br)H)(H)H)(H)H)(F)H)(Cl)H)(H)Cl)(H)F) $(\mathrm{H}) \mathrm{H})(\mathrm{H}) \mathrm{F})(\mathrm{C}(\mathrm{H})(\mathrm{H}) \mathrm{Cl})(\mathrm{H}) \mathrm{H}$

$\mathrm{C}(\mathrm{C}(\mathrm{C}(\mathrm{C}(\mathrm{C}(\mathrm{C}(\mathrm{C}(\mathrm{C}(\mathrm{C}(\mathrm{C}(\mathrm{C}(\mathrm{C}(\mathrm{C}(\mathrm{C}(\mathrm{Cl})(\mathrm{H}) \mathrm{H})(\mathrm{F}) \mathrm{Cl}(\mathrm{H}) \mathrm{H})(\mathrm{H}) \mathrm{F})(\mathrm{H}) \mathrm{F})(\mathrm{H}) \mathrm{F})(\mathrm{H}) \mathrm{Cl})(\mathrm{H}) \mathrm{F})(\mathrm{H}) \mathrm{H})(\mathrm{H}) \mathrm{P})(\mathrm{P}) \mathrm{H})(\mathrm{Cl}$ F)H $)(\mathrm{H}) \mathrm{H})(\mathrm{C}(\mathrm{H})(\mathrm{H}) \mathrm{H})(\mathrm{H}) \mathrm{C}$

$\mathrm{C}\left(\mathrm{C}\left(\mathrm{C}(\mathrm{C}(\mathrm{C}(\mathrm{C}(\mathrm{C}(\mathrm{C}(\mathrm{C}(\mathrm{C}(\mathrm{C}(\mathrm{C}(\mathrm{C}(\mathrm{C}(\mathrm{H})(\mathrm{F}) \mathrm{F})(\mathrm{Cl}) \mathrm{H})(\mathrm{H}) \mathrm{F})(\mathrm{H}) \mathrm{H})(\mathrm{H}) \mathrm{H})(\mathrm{H}) \mathrm{H})(\mathrm{H}) \mathrm{H})(\mathrm{Cl}) \mathrm{H})(\mathrm{H}) \mathrm{F})(\mathrm{F}) \mathrm{Cl})(\mathrm{H}) \mathrm{H})\left({ }^{2} 15 \mathrm{H}^{2} \mathrm{Cl}\right.\right.\right.$

F)F $(\mathrm{H}) \mathrm{H})(\mathrm{C}(\mathrm{H})(\mathrm{H}) \mathrm{Cl})(\mathrm{H}) \mathrm{Cl}$

$\mathrm{C}(\mathrm{C}(\mathrm{C}(\mathrm{C}(\mathrm{C}(\mathrm{C}(\mathrm{C}(\mathrm{C}(\mathrm{C}(\mathrm{C}(\mathrm{C}(\mathrm{C}(\mathrm{C}(\mathrm{C}(\mathrm{H})(\mathrm{H}) \mathrm{F})(\mathrm{H}) \mathrm{H})(\mathrm{H}) \mathrm{H})(\mathrm{F}) \mathrm{H})(\mathrm{H}) \mathrm{Cl})(\mathrm{H}) \mathrm{Cl})(\mathrm{Cl}) \mathrm{H})(\mathrm{H}) \mathrm{H})(\mathrm{F}) \mathrm{H})(\mathrm{Cl}) \mathrm{H})$

$(\mathrm{H}) \mathrm{F})(\mathrm{H}) \mathrm{H})(\mathrm{F}) \mathrm{H})(\mathrm{C}(\mathrm{H})(\mathrm{Cl}) \mathrm{F})(\mathrm{Cl}) \mathrm{H}$

$\mathrm{C}(\mathrm{C}(\mathrm{C}(\mathrm{C}(\mathrm{C}(\mathrm{C}(\mathrm{C}(\mathrm{C}(\mathrm{C}(\mathrm{C}(\mathrm{C}(\mathrm{C}(\mathrm{C}(\mathrm{C}(\mathrm{H})(\mathrm{F}) \mathrm{H})(\mathrm{H}) \mathrm{Br})(\mathrm{H}) \mathrm{H})(\mathrm{H}) \mathrm{H})(\mathrm{F}) \mathrm{H})(\mathrm{F}) \mathrm{F})(\mathrm{H}) \mathrm{H})(\mathrm{H}) \mathrm{Cl})(\mathrm{F}) \mathrm{Br})(\mathrm{H}) \mathrm{H})(\mathrm{H}) \mathrm{H})$ $(\mathrm{H}) \mathrm{H})(\mathrm{H}) \mathrm{F})(\mathrm{C}(\mathrm{F})(\mathrm{F}) \mathrm{F})(\mathrm{H}) \mathrm{H}$

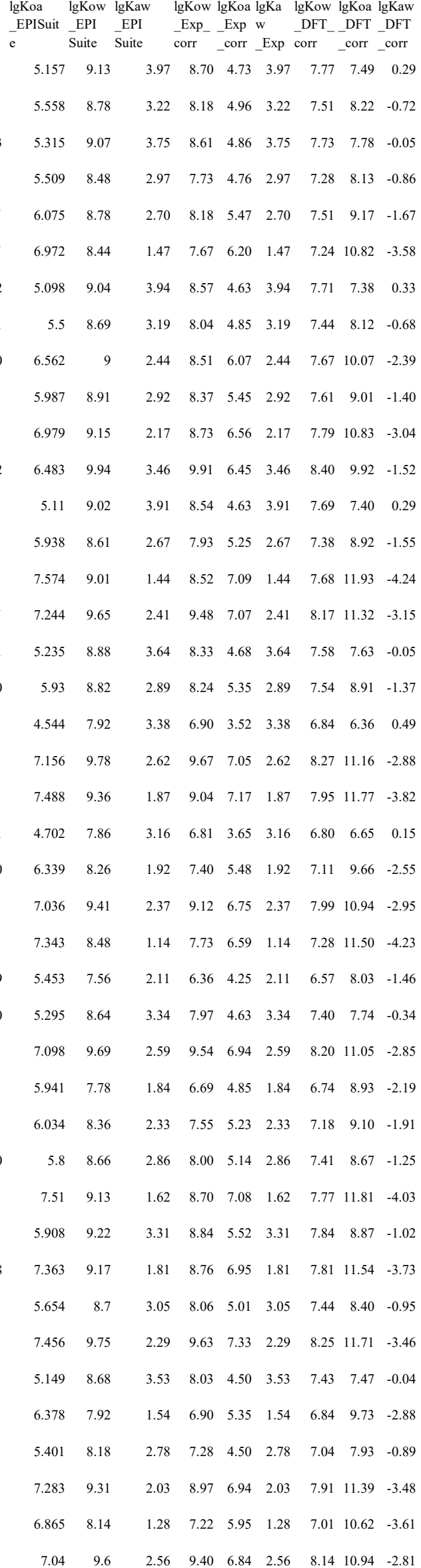


$\mathrm{C}\left(\mathrm{C}\left(\mathrm{C}(\mathrm{C}(\mathrm{C}(\mathrm{C}(\mathrm{C}(\mathrm{C}(\mathrm{C}(\mathrm{C}(\mathrm{C}(\mathrm{C}(\mathrm{C}(\mathrm{C}(\mathrm{F})(\mathrm{F}) \mathrm{H})(\mathrm{H}) \mathrm{H})(\mathrm{F}) \mathrm{Br})(\mathrm{F}) \mathrm{H})(\mathrm{H}) \mathrm{Br})(\mathrm{H}) \mathrm{H})(\mathrm{H}) \mathrm{H})(\mathrm{H}) \mathrm{H})(\mathrm{H}) \mathrm{H})(\mathrm{H}) \mathrm{F})(\mathrm{H}) \mathrm{F})\left({ }_{\mathrm{C} 15 \mathrm{H} 21 \mathrm{Br} 2 \mathrm{~F} 9}\right.\right.\right.$ $\mathrm{H}) \mathrm{F})(\mathrm{H}) \mathrm{H})(\mathrm{C}(\mathrm{F})(\mathrm{H}) \mathrm{H})(\mathrm{F}) \mathrm{H}$

$\mathrm{C}\left(\mathrm{C}\left(\mathrm{C}(\mathrm{C}(\mathrm{C}(\mathrm{C}(\mathrm{C}(\mathrm{C}(\mathrm{C}(\mathrm{C}(\mathrm{C}(\mathrm{C}(\mathrm{C}(\mathrm{C}(\mathrm{H})(\mathrm{F}) \mathrm{H})(\mathrm{F}) \mathrm{H})(\mathrm{F}) \mathrm{H})(\mathrm{H}) \mathrm{H})(\mathrm{H}) \mathrm{F})(\mathrm{H}) \mathrm{H})(\mathrm{H}) \mathrm{H})(\mathrm{F}) \mathrm{Br})(\mathrm{H}) \mathrm{H})(\mathrm{H}) \mathrm{Br})(\mathrm{H}) \mathrm{F})\left({ }_{\mathrm{Cl}}{ }^{2} \mathrm{H} 21 \mathrm{Br} 3 \mathrm{~F} 8\right.\right.\right.$ $\mathrm{H}) \mathrm{F})(\mathrm{H}) \mathrm{H})(\mathrm{C}(\mathrm{Br})(\mathrm{H}) \mathrm{H})(\mathrm{F}) \mathrm{H}$

$\mathrm{C}\left(\mathrm{C}\left(\mathrm{C}(\mathrm{C}(\mathrm{C}(\mathrm{C}(\mathrm{C}(\mathrm{C}(\mathrm{C}(\mathrm{C}(\mathrm{C}(\mathrm{C}(\mathrm{C}(\mathrm{C}(\mathrm{Cl})(\mathrm{H}) \mathrm{F})(\mathrm{H}) \mathrm{F})(\mathrm{Cl}) \mathrm{H})(\mathrm{F}) \mathrm{H})(\mathrm{H}) \mathrm{H})(\mathrm{H}) \mathrm{H})(\mathrm{H}) \mathrm{F})(\mathrm{H}) \mathrm{H})(\mathrm{F}) \mathrm{F})(\mathrm{H}) \mathrm{H})(\mathrm{H}) \mathrm{Br})\left({ }_{\mathrm{C} 15 \mathrm{H} 21 \mathrm{Cl} 2 \mathrm{BrF} 8}\right.\right.\right.$ F)F $(\mathrm{H}) \mathrm{H})(\mathrm{C}(\mathrm{H})(\mathrm{H}) \mathrm{H})(\mathrm{H}) \mathrm{H}$

$\mathrm{C}\left(\mathrm{C}\left(\mathrm{C}(\mathrm{C}(\mathrm{C}(\mathrm{C}(\mathrm{C}(\mathrm{C}(\mathrm{C}(\mathrm{C}(\mathrm{C}(\mathrm{C}(\mathrm{C}(\mathrm{C}(\mathrm{H})(\mathrm{F}) \mathrm{H})(\mathrm{F}) \mathrm{H})(\mathrm{Cl}) \mathrm{F})(\mathrm{H}) \mathrm{F})(\mathrm{Br}) \mathrm{H})(\mathrm{H}) \mathrm{H})(\mathrm{H}) \mathrm{H})(\mathrm{H}) \mathrm{H})(\mathrm{H}) \mathrm{Cl})(\mathrm{H}) \mathrm{F})(\mathrm{Cl}) \mathrm{H}){ }_{\mathrm{C} 15 \mathrm{H} 21 \mathrm{Cl} 3 \mathrm{BrF} 7}\right.\right.$ $(\mathrm{H}) \mathrm{F})(\mathrm{H}) \mathrm{H})(\mathrm{C}(\mathrm{H})(\mathrm{F}) \mathrm{H})(\mathrm{H}) \mathrm{H}$

$\mathrm{C}\left(\mathrm{C}\left(\mathrm{C}(\mathrm{C}(\mathrm{C}(\mathrm{C}(\mathrm{C}(\mathrm{C}(\mathrm{C}(\mathrm{C}(\mathrm{C}(\mathrm{C}(\mathrm{C}(\mathrm{C}(\mathrm{H})(\mathrm{H}) \mathrm{F})(\mathrm{F}) \mathrm{H})(\mathrm{F}) \mathrm{H})(\mathrm{H}) \mathrm{Cl})(\mathrm{H}) \mathrm{F})(\mathrm{H}) \mathrm{H})(\mathrm{F}) \mathrm{F})(\mathrm{H}) \mathrm{Cl})(\mathrm{H}) \mathrm{Cl})(\mathrm{H}) \mathrm{H})(\mathrm{H}) \mathrm{F})\left({ }_{\mathrm{C}}{ }^{2} \mathrm{H} 21 \mathrm{Cl} 3 \mathrm{~F} 8\right.\right.\right.$

$\mathrm{H}) \mathrm{H})(\mathrm{H}) \mathrm{H})(\mathrm{C}(\mathrm{H})(\mathrm{H}) \mathrm{H})(\mathrm{F}) \mathrm{H}$

$\mathrm{C}\left(\mathrm{C}\left(\mathrm{C}(\mathrm{C}(\mathrm{C}(\mathrm{C}(\mathrm{C}(\mathrm{C}(\mathrm{C}(\mathrm{C}(\mathrm{C}(\mathrm{C}(\mathrm{C}(\mathrm{C}(\mathrm{H})(\mathrm{H}) \mathrm{H})(\mathrm{H}) \mathrm{F})(\mathrm{F}) \mathrm{F})(\mathrm{H}) \mathrm{H})(\mathrm{H}) \mathrm{F})(\mathrm{H}) \mathrm{H})(\mathrm{Cl}) \mathrm{H})(\mathrm{F}) \mathrm{H})(\mathrm{H}) \mathrm{Cl})(\mathrm{H}) \mathrm{H})(\mathrm{Cl}) \mathrm{H})\left({ }_{\mathrm{C} 15 \mathrm{H}}{ }^{2} \mathrm{Cl} 4 \mathrm{~F} 7\right.\right.\right.$ $\mathrm{H}) \mathrm{H})(\mathrm{H}) \mathrm{F})(\mathrm{C}(\mathrm{H})(\mathrm{F}) \mathrm{Cl})(\mathrm{H}) \mathrm{H}$

$\mathrm{C}(\mathrm{C}(\mathrm{C}(\mathrm{C}(\mathrm{C}(\mathrm{C}(\mathrm{C}(\mathrm{C}(\mathrm{C}(\mathrm{C}(\mathrm{C}(\mathrm{C}(\mathrm{C}(\mathrm{C}(\mathrm{Cl})(\mathrm{H}) \mathrm{H})(\mathrm{H}) \mathrm{F})(\mathrm{H}) \mathrm{F})(\mathrm{Cl}) \mathrm{H})(\mathrm{Cl}) \mathrm{F})(\mathrm{H}) \mathrm{H})(\mathrm{H}) \mathrm{H})(\mathrm{F}) \mathrm{H})(\mathrm{H}) \mathrm{Cl})(\mathrm{H}) \mathrm{H})$

$(\mathrm{H}) \mathrm{H})(\mathrm{Cl}) \mathrm{H})(\mathrm{F}) \mathrm{H})(\mathrm{C}(\mathrm{H})(\mathrm{H}) \mathrm{H})(\mathrm{F}) \mathrm{H}$

$\mathrm{H}) \mathrm{Cl})(\mathrm{F}) \mathrm{F})(\mathrm{C}(\mathrm{Br})(\mathrm{H}) \mathrm{H})(\mathrm{H}) \mathrm{F}$

$\mathrm{C}(\mathrm{C}(\mathrm{C}(\mathrm{C}(\mathrm{C}(\mathrm{C}(\mathrm{C}(\mathrm{C}(\mathrm{C}(\mathrm{C}(\mathrm{C}(\mathrm{C}(\mathrm{C}(\mathrm{C}(\mathrm{H})(\mathrm{F}) \mathrm{H})(\mathrm{H}) \mathrm{F})(\mathrm{H}) \mathrm{H})(\mathrm{F}) \mathrm{Br})(\mathrm{F}) \mathrm{H})(\mathrm{Cl}) \mathrm{H})(\mathrm{Br}) \mathrm{H})(\mathrm{H}) \mathrm{H})(\mathrm{F}) \mathrm{H})(\mathrm{H}) \mathrm{H})(\mathrm{H}) \mathrm{H})$

$(\mathrm{F}) \mathrm{H})(\mathrm{H}) \mathrm{F})(\mathrm{C}(\mathrm{H})(\mathrm{H}) \mathrm{H})(\mathrm{Br}) \mathrm{H}$

$\mathrm{C}\left(\mathrm{C}\left(\mathrm{C}(\mathrm{C}(\mathrm{C}(\mathrm{C}(\mathrm{C}(\mathrm{C}(\mathrm{C}(\mathrm{C}(\mathrm{C}(\mathrm{C}(\mathrm{C}(\mathrm{C}(\mathrm{H})(\mathrm{H}) \mathrm{H})(\mathrm{H}) \mathrm{H})(\mathrm{H}) \mathrm{H})(\mathrm{H}) \mathrm{F})(\mathrm{H}) \mathrm{H})(\mathrm{H}) \mathrm{H})(\mathrm{H}) \mathrm{H})(\mathrm{F}) \mathrm{F})(\mathrm{Br}) \mathrm{F})(\mathrm{Cl}) \mathrm{H})(\mathrm{H}) \mathrm{F})\left({ }_{\mathrm{C} 15 \mathrm{H} 21 \mathrm{ClBrF} 9}\right.\right.\right.$

$\mathrm{H}) \mathrm{F})(\mathrm{F}) \mathrm{H})(\mathrm{C}(\mathrm{H})(\mathrm{F}) \mathrm{F})(\mathrm{H}) \mathrm{H}$

$\mathrm{C}\left(\mathrm{C}\left(\mathrm{C}(\mathrm{C}(\mathrm{C}(\mathrm{C}(\mathrm{C}(\mathrm{C}(\mathrm{C}(\mathrm{C}(\mathrm{C}(\mathrm{C}(\mathrm{C}(\mathrm{C}(\mathrm{F})(\mathrm{H}) \mathrm{H})(\mathrm{H}) \mathrm{F})(\mathrm{F}) \mathrm{H})(\mathrm{H}) \mathrm{H})(\mathrm{F}) \mathrm{F})(\mathrm{H}) \mathrm{H})(\mathrm{H}) \mathrm{F})(\mathrm{H}) \mathrm{Br})(\mathrm{H}) \mathrm{H})(\mathrm{H}) \mathrm{H})(\mathrm{H}) \mathrm{H})\left({ }_{\mathrm{C} 15 \mathrm{H} 22 \mathrm{Br} 2 \mathrm{~F} 8}\right.\right.\right.$

$\mathrm{Br}) \mathrm{H})(\mathrm{H}) \mathrm{H})(\mathrm{C}(\mathrm{H})(\mathrm{H}) \mathrm{H})(\mathrm{F}) \mathrm{F}$

$\mathrm{C} 15 \mathrm{H} 22 \mathrm{Br} 2 \mathrm{~F}$

C(C) C $(\mathrm{C}(\mathrm{C}(\mathrm{C}(\mathrm{C}(\mathrm{C}(\mathrm{C}(\mathrm{C}(\mathrm{C}(\mathrm{C}(\mathrm{C})$

$\mathrm{C}(\mathrm{C}(\mathrm{C}(\mathrm{C}(\mathrm{C}(\mathrm{C}(\mathrm{C}(\mathrm{C}(\mathrm{C}(\mathrm{C}(\mathrm{C}(\mathrm{C}(\mathrm{C}(\mathrm{C}(\mathrm{H})(\mathrm{H}) \mathrm{F})(\mathrm{F}) \mathrm{H})(\mathrm{F}) \mathrm{H})(\mathrm{H}) \mathrm{H})(\mathrm{H}) \mathrm{F})(\mathrm{Br}) \mathrm{H})(\mathrm{H}) \mathrm{H})(\mathrm{H}) \mathrm{Cl})(\mathrm{H}) \mathrm{Cl})(\mathrm{F}) \mathrm{H}) \quad \mathrm{C} 15 \mathrm{H} 22 \mathrm{Cl} 2 \mathrm{Br} 2 \mathrm{~F} 6$

$(\mathrm{Br}) \mathrm{H})(\mathrm{F}) \mathrm{H})(\mathrm{H}) \mathrm{H})(\mathrm{C}(\mathrm{H})(\mathrm{H}) \mathrm{H})(\mathrm{H}) \mathrm{H}$

$\mathrm{C}\left(\mathrm{C}\left(\mathrm{C}(\mathrm{C}(\mathrm{C}(\mathrm{C}(\mathrm{C}(\mathrm{C}(\mathrm{C}(\mathrm{C}(\mathrm{C}(\mathrm{C}(\mathrm{C}(\mathrm{C}(\mathrm{H})(\mathrm{H}) \mathrm{H})(\mathrm{H}) \mathrm{Cl})(\mathrm{Cl}) \mathrm{H})(\mathrm{H}) \mathrm{H})(\mathrm{H}) \mathrm{H})(\mathrm{H}) \mathrm{F})(\mathrm{F}) \mathrm{H})(\mathrm{F}) \mathrm{H})(\mathrm{H}) \mathrm{H})(\mathrm{F}) \mathrm{H})(\mathrm{H}) \mathrm{H})\left({ }_{\mathrm{C} 15 \mathrm{H} 22 \mathrm{Cl} 2 \mathrm{BrF} 7}\right.\right.\right.$

$\mathrm{H}) \mathrm{H})(\mathrm{H}) \mathrm{F})(\mathrm{C}(\mathrm{H})(\mathrm{Br}) \mathrm{F})(\mathrm{F}) \mathrm{H}$

$\mathrm{C}\left(\mathrm{C}\left(\mathrm{C}(\mathrm{C}(\mathrm{C}(\mathrm{C}(\mathrm{C}(\mathrm{C}(\mathrm{C}(\mathrm{C}(\mathrm{C}(\mathrm{C}(\mathrm{C}(\mathrm{C}(\mathrm{H})(\mathrm{F}) \mathrm{F})(\mathrm{H}) \mathrm{H})(\mathrm{H}) \mathrm{H})(\mathrm{H}) \mathrm{H})(\mathrm{F}) \mathrm{F})(\mathrm{H}) \mathrm{Cl})(\mathrm{H}) \mathrm{H})(\mathrm{H}) \mathrm{H})(\mathrm{F}) \mathrm{Cl})(\mathrm{H}) \mathrm{H})(\mathrm{H}) \mathrm{H})\left(\mathrm{C}_{15 \mathrm{H} 22 \mathrm{Cl} 2 \mathrm{~F} 8}\right.\right.\right.$

$\mathrm{H}) \mathrm{F})(\mathrm{F}) \mathrm{H})(\mathrm{C}(\mathrm{H})(\mathrm{H}) \mathrm{H})(\mathrm{H}) \mathrm{F}$

$\mathrm{C}\left(\mathrm{C}\left(\mathrm{C}(\mathrm{C}(\mathrm{C}(\mathrm{C}(\mathrm{C}(\mathrm{C}(\mathrm{C}(\mathrm{C}(\mathrm{C}(\mathrm{C}(\mathrm{C}(\mathrm{C}(\mathrm{H})(\mathrm{Cl}) \mathrm{H})(\mathrm{F}) \mathrm{H})(\mathrm{H}) \mathrm{F})(\mathrm{F}) \mathrm{H})(\mathrm{H}) \mathrm{H})(\mathrm{H}) \mathrm{F})(\mathrm{Cl}) \mathrm{H})(\mathrm{F}) \mathrm{H})(\mathrm{H}) \mathrm{H})(\mathrm{H}) \mathrm{Br})(\mathrm{H}) \mathrm{H}){ }_{\mathrm{C} 15 \mathrm{H} 22 \mathrm{Cl} 3 \mathrm{BrF} 6}\right.\right.$ $(\mathrm{H}) \mathrm{Cl})(\mathrm{H}) \mathrm{F})(\mathrm{C}(\mathrm{H})(\mathrm{H}) \mathrm{H})(\mathrm{H}) \mathrm{H}$

$\mathrm{C}\left(\mathrm{C}\left(\mathrm{C}(\mathrm{C}(\mathrm{C}(\mathrm{C}(\mathrm{C}(\mathrm{C}(\mathrm{C}(\mathrm{C}(\mathrm{C}(\mathrm{C}(\mathrm{C}(\mathrm{C}(\mathrm{F})(\mathrm{Cl}) \mathrm{H})(\mathrm{H}) \mathrm{H})(\mathrm{H}) \mathrm{H})(\mathrm{H}) \mathrm{H})(\mathrm{F}) \mathrm{H})(\mathrm{F}) \mathrm{F})(\mathrm{H}) \mathrm{H})(\mathrm{Cl}) \mathrm{H})(\mathrm{H}) \mathrm{H})(\mathrm{H}) \mathrm{F})(\mathrm{Cl}) \mathrm{F})\left({ }_{\mathrm{C} 15 \mathrm{H} 22 \mathrm{Cl} 3 \mathrm{~F} 7}\right.\right.\right.$ $\mathrm{H}) \mathrm{F})(\mathrm{H}) \mathrm{H})(\mathrm{C}(\mathrm{H})(\mathrm{H}) \mathrm{H})(\mathrm{H}) \mathrm{H}$

$\mathrm{C}\left(\mathrm{C}\left(\mathrm{C}(\mathrm{C}(\mathrm{C}(\mathrm{C}(\mathrm{C}(\mathrm{C}(\mathrm{C}(\mathrm{C}(\mathrm{C}(\mathrm{C}(\mathrm{C}(\mathrm{C}(\mathrm{Cl})(\mathrm{H}) \mathrm{H})(\mathrm{H}) \mathrm{H})(\mathrm{F}) \mathrm{H})(\mathrm{H}) \mathrm{H})(\mathrm{F}) \mathrm{H})(\mathrm{H}) \mathrm{F})(\mathrm{H}) \mathrm{H})(\mathrm{H}) \mathrm{F})(\mathrm{H}) \mathrm{H})(\mathrm{Cl}) \mathrm{F})(\mathrm{H}) \mathrm{Cl})\left({ }_{\mathrm{C} 15 \mathrm{H} 22 \mathrm{Cl} 4 \mathrm{~F} 6}\right.\right.\right.$

$\mathrm{H}) \mathrm{H})(\mathrm{Cl}) \mathrm{H})(\mathrm{C}(\mathrm{H})(\mathrm{H}) \mathrm{H})(\mathrm{H}) \mathrm{F}$
$\mathrm{C}(\mathrm{C}(\mathrm{C}(\mathrm{C}(\mathrm{C}(\mathrm{C}(\mathrm{C}(\mathrm{C}(\mathrm{C}(\mathrm{C}(\mathrm{C}(\mathrm{C}(\mathrm{C}(\mathrm{C}(\mathrm{H})(\mathrm{H}) \mathrm{H})(\mathrm{H}) \mathrm{F})(\mathrm{H}) \mathrm{F})(\mathrm{Cl}) \mathrm{H})(\mathrm{H}) \mathrm{H})(\mathrm{H}) \mathrm{Cl})(\mathrm{H}) \mathrm{H})(\mathrm{H}) \mathrm{H})(\mathrm{H}) \mathrm{Cl})(\mathrm{H}) \mathrm{H})(\mathrm{Cl}) \quad \mathrm{C} 15 \mathrm{H} 22 \mathrm{Cl} 5 \mathrm{~F} 5$

$\mathrm{H})(\mathrm{H}) \mathrm{F})(\mathrm{F}) \mathrm{H})(\mathrm{C}(\mathrm{H})(\mathrm{H}) \mathrm{H})(\mathrm{F}) \mathrm{C}$

$\mathrm{C} 15 \mathrm{H} 22 \mathrm{Cl} 5 \mathrm{~F} 5$

$\mathrm{C}\left(\mathrm{C}\left(\mathrm{C}(\mathrm{C}(\mathrm{C}(\mathrm{C}(\mathrm{C}(\mathrm{C}(\mathrm{C}(\mathrm{C}(\mathrm{C}(\mathrm{C}(\mathrm{C}(\mathrm{C}(\mathrm{H})(\mathrm{F}) \mathrm{H})(\mathrm{H}) \mathrm{H})(\mathrm{F}) \mathrm{H})(\mathrm{F}) \mathrm{H})(\mathrm{F}) \mathrm{Br})(\mathrm{H}) \mathrm{F})(\mathrm{H}) \mathrm{H})(\mathrm{H}) \mathrm{F})(\mathrm{H}) \mathrm{H})(\mathrm{H}) \mathrm{Br})(\mathrm{H}) \mathrm{F})\left({ }_{\mathrm{C} 15 \mathrm{H} 22 \mathrm{ClBr} 2 \mathrm{~F} 7}\right.\right.\right.$ $\mathrm{H}) \mathrm{H})(\mathrm{H}) \mathrm{H})(\mathrm{C}(\mathrm{H})(\mathrm{H}) \mathrm{H})(\mathrm{Cl}) \mathrm{H}$

$\mathrm{C}\left(\mathrm{C}\left(\mathrm{C}(\mathrm{C}(\mathrm{C}(\mathrm{C}(\mathrm{C}(\mathrm{C}(\mathrm{C}(\mathrm{C}(\mathrm{C}(\mathrm{C}(\mathrm{C}(\mathrm{C}(\mathrm{H})(\mathrm{Br}) \mathrm{F})(\mathrm{F}) \mathrm{H})(\mathrm{H}) \mathrm{Br})(\mathrm{H}) \mathrm{H})(\mathrm{H}) \mathrm{H})(\mathrm{H}) \mathrm{H})(\mathrm{H}) \mathrm{H})(\mathrm{F}) \mathrm{H})(\mathrm{F}) \mathrm{H})(\mathrm{H}) \mathrm{H})(\mathrm{H}) \mathrm{H}){ }_{\mathrm{C} 15 \mathrm{H} 22 \mathrm{ClBr} 3 \mathrm{~F} 6}\right.\right.$ $(\mathrm{H}) \mathrm{F})(\mathrm{H}) \mathrm{Br})(\mathrm{C}(\mathrm{Cl})(\mathrm{H}) \mathrm{H})(\mathrm{F}) \mathrm{H}$

$\mathrm{C}(\mathrm{C}(\mathrm{C}(\mathrm{C}(\mathrm{C}(\mathrm{C}(\mathrm{C}(\mathrm{C}(\mathrm{C}(\mathrm{C}(\mathrm{C}(\mathrm{C}(\mathrm{C}(\mathrm{C}(\mathrm{H})(\mathrm{H}) \mathrm{H})(\mathrm{H}) \mathrm{H})(\mathrm{H}) \mathrm{Br})(\mathrm{F}) \mathrm{H})(\mathrm{Cl}) \mathrm{F})(\mathrm{H}) \mathrm{H})(\mathrm{H}) \mathrm{H})(\mathrm{H}) \mathrm{H})(\mathrm{H}) \mathrm{H})(\mathrm{H}) \mathrm{F})(\mathrm{H}) \mathrm{F}) \quad \mathrm{C} 15 \mathrm{H} 22 \mathrm{ClBrF} 8$

(H)H $(\mathrm{F}) \mathrm{H})(\mathrm{C}(\mathrm{F})(\mathrm{H}) \mathrm{F})(\mathrm{H}) \mathrm{F}$

$\mathrm{C}\left(\mathrm{C}\left(\mathrm{C}(\mathrm{C}(\mathrm{C}(\mathrm{C}(\mathrm{C}(\mathrm{C}(\mathrm{C}(\mathrm{C}(\mathrm{C}(\mathrm{C}(\mathrm{C}(\mathrm{C}(\mathrm{H})(\mathrm{H}) \mathrm{H})(\mathrm{H}) \mathrm{F})(\mathrm{Br}) \mathrm{H})(\mathrm{H}) \mathrm{H})(\mathrm{F}) \mathrm{H})(\mathrm{H}) \mathrm{Br})(\mathrm{H}) \mathrm{H})(\mathrm{H}) \mathrm{H})(\mathrm{F}) \mathrm{F})(\mathrm{H}) \mathrm{H})(\mathrm{H}) \mathrm{F}){ }_{\mathrm{C} 15 \mathrm{H} 23 \mathrm{Br} 2 \mathrm{~F} 7}\right.\right.$

$(\mathrm{H}) \mathrm{H})(\mathrm{F}) \mathrm{H})(\mathrm{C}(\mathrm{H})(\mathrm{F}) \mathrm{H})(\mathrm{H}) \mathrm{H}$

$\mathrm{C}\left(\mathrm{C}\left(\mathrm{C}(\mathrm{C}(\mathrm{C}(\mathrm{C}(\mathrm{C}(\mathrm{C}(\mathrm{C}(\mathrm{C}(\mathrm{C}(\mathrm{C}(\mathrm{C}(\mathrm{C}(\mathrm{H})(\mathrm{F}) \mathrm{H})(\mathrm{H}) \mathrm{H})(\mathrm{H}) \mathrm{F})(\mathrm{H}) \mathrm{F})(\mathrm{H}) \mathrm{H})(\mathrm{H}) \mathrm{H})(\mathrm{H}) \mathrm{Br})(\mathrm{H}) \mathrm{H})(\mathrm{F}) \mathrm{H})(\mathrm{H}) \mathrm{H})(\mathrm{Br}) \mathrm{H}){ }_{\mathrm{C} 15 \mathrm{H} 23 \mathrm{Br} 3 \mathrm{~F} 6}\right.\right.$

$(\mathrm{H}) \mathrm{Br})(\mathrm{H}) \mathrm{H})(\mathrm{C}(\mathrm{H})(\mathrm{H}) \mathrm{H})(\mathrm{F}) \mathrm{F}$

$\mathrm{C} 15 \mathrm{H} 23 \mathrm{Br} 3 \mathrm{~F} 6$

$\mathrm{C}(\mathrm{C}(\mathrm{C}(\mathrm{C}(\mathrm{C}(\mathrm{C}(\mathrm{C}(\mathrm{C}(\mathrm{C}(\mathrm{C}(\mathrm{C}(\mathrm{C}(\mathrm{C}(\mathrm{C}(\mathrm{H})(\mathrm{H}) \mathrm{H})(\mathrm{H}) \mathrm{F})(\mathrm{Br}) \mathrm{H})(\mathrm{H}) \mathrm{Cl})(\mathrm{H}) \mathrm{H})(\mathrm{H}) \mathrm{H})(\mathrm{H}) \mathrm{H})(\mathrm{H}) \mathrm{Br})(\mathrm{H}) \mathrm{H})(\mathrm{H}) \mathrm{F})(\mathrm{H})$ $\mathrm{H})(\mathrm{F}) \mathrm{H})(\mathrm{F}) \mathrm{H})(\mathrm{C}(\mathrm{H})(\mathrm{Cl}) \mathrm{H})(\mathrm{H}) \mathrm{F}$

$\mathrm{C}\left(\mathrm{C}\left(\mathrm{C}(\mathrm{C}(\mathrm{C}(\mathrm{C}(\mathrm{C}(\mathrm{C}(\mathrm{C}(\mathrm{C}(\mathrm{C}(\mathrm{C}(\mathrm{C}(\mathrm{C}(\mathrm{F})(\mathrm{H}) \mathrm{H})(\mathrm{F}) \mathrm{H})(\mathrm{H}) \mathrm{Br})(\mathrm{H}) \mathrm{H})(\mathrm{H}) \mathrm{H})(\mathrm{H}) \mathrm{H})(\mathrm{Cl}) \mathrm{H})(\mathrm{F}) \mathrm{H})(\mathrm{Cl}) \mathrm{H})(\mathrm{H}) \mathrm{F})(\mathrm{F}) \mathrm{H}) \mathrm{Cl}^{5} \mathrm{H} 23 \mathrm{Cl} 2 \mathrm{BrF} 6\right.\right.$ $(\mathrm{H}) \mathrm{H})(\mathrm{H}) \mathrm{H})(\mathrm{C}(\mathrm{F})(\mathrm{H}) \mathrm{H})(\mathrm{H}) \mathrm{H}$

$\mathrm{C}(\mathrm{C}(\mathrm{C}(\mathrm{C}(\mathrm{C}(\mathrm{C}(\mathrm{C}(\mathrm{C}(\mathrm{C}(\mathrm{C}(\mathrm{C}(\mathrm{C}(\mathrm{C}(\mathrm{C}(\mathrm{F})(\mathrm{H}) \mathrm{H})(\mathrm{F}) \mathrm{H})(\mathrm{H}) \mathrm{H})(\mathrm{H}) \mathrm{H})(\mathrm{H}) \mathrm{F})(\mathrm{F}) \mathrm{F})(\mathrm{H}) \mathrm{H})(\mathrm{H}) \mathrm{H})(\mathrm{H}) \mathrm{H})(\mathrm{F}) \mathrm{H})(\mathrm{H}) \mathrm{H}) \quad \mathrm{C} 15 \mathrm{H} 23 \mathrm{Cl} 2 \mathrm{~F} 7$

$(\mathrm{H}) \mathrm{F})(\mathrm{Cl}) \mathrm{H})(\mathrm{C}(\mathrm{H})(\mathrm{H}) \mathrm{H})(\mathrm{Cl}) \mathrm{H}$

$\mathrm{C}\left(\mathrm{C}\left(\mathrm{C}(\mathrm{C}(\mathrm{C}(\mathrm{C}(\mathrm{C}(\mathrm{C}(\mathrm{C}(\mathrm{C}(\mathrm{C}(\mathrm{C}(\mathrm{C}(\mathrm{C}(\mathrm{H})(\mathrm{H}) \mathrm{H})(\mathrm{F}) \mathrm{F})(\mathrm{H}) \mathrm{H})(\mathrm{H}) \mathrm{H})(\mathrm{H}) \mathrm{H})(\mathrm{H}) \mathrm{Cl})(\mathrm{H}) \mathrm{H})(\mathrm{H}) \mathrm{Cl})(\mathrm{F}) \mathrm{H})(\mathrm{H}) \mathrm{Br})(\mathrm{H}) \mathrm{F}){ }_{\mathrm{C} 15 \mathrm{H} 23 \mathrm{Cl} 3 \mathrm{BrF} 5}\right.\right.$

$(\mathrm{H}) \mathrm{H})(\mathrm{H}) \mathrm{F})(\mathrm{C}(\mathrm{H})(\mathrm{H}) \mathrm{Cl})(\mathrm{H}) \mathrm{H}$

$\mathrm{C}\left(\mathrm{C}\left(\mathrm{C}(\mathrm{C}(\mathrm{C}(\mathrm{C}(\mathrm{C}(\mathrm{C}(\mathrm{C}(\mathrm{C}(\mathrm{C}(\mathrm{C}(\mathrm{C}(\mathrm{C}(\mathrm{H})(\mathrm{H}) \mathrm{H})(\mathrm{H}) \mathrm{H})(\mathrm{Cl}) \mathrm{Cl})(\mathrm{F}) \mathrm{F})(\mathrm{H}) \mathrm{H})(\mathrm{H}) \mathrm{F})(\mathrm{H}) \mathrm{H})(\mathrm{H}) \mathrm{H})(\mathrm{H}) \mathrm{H})(\mathrm{F}) \mathrm{H})(\mathrm{F}) \mathrm{H})\left({ }_{\mathrm{C} 15 \mathrm{H} 23 \mathrm{Cl} 3 \mathrm{~F} 6}\right.\right.\right.$

$\mathrm{H}) \mathrm{H})(\mathrm{F}) \mathrm{H})(\mathrm{C}(\mathrm{H})(\mathrm{Cl}) \mathrm{H})(\mathrm{H}) \mathrm{H}$

$\mathrm{C}\left(\mathrm{C}\left(\mathrm{C}(\mathrm{C}(\mathrm{C}(\mathrm{C}(\mathrm{C}(\mathrm{C}(\mathrm{C}(\mathrm{C}(\mathrm{C}(\mathrm{C}(\mathrm{C}(\mathrm{C}(\mathrm{H})(\mathrm{H}) \mathrm{H})(\mathrm{Br}) \mathrm{H})(\mathrm{H}) \mathrm{H})(\mathrm{F}) \mathrm{H})(\mathrm{F}) \mathrm{H})(\mathrm{H}) \mathrm{H})(\mathrm{F}) \mathrm{H})(\mathrm{H}) \mathrm{H})(\mathrm{Cl}) \mathrm{H})(\mathrm{H}) \mathrm{H})(\mathrm{H}) \mathrm{H}){ }^{\mathrm{C} 15 \mathrm{H} 23 \mathrm{ClBr} 2 \mathrm{~F} 6}\right.\right.$ (F) Br) $(\mathrm{F}) \mathrm{H})(\mathrm{C}(\mathrm{H})(\mathrm{H}) \mathrm{H})(\mathrm{H}) \mathrm{F}$

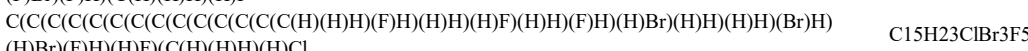

$(\mathrm{H}) \mathrm{Br})(\mathrm{F}) \mathrm{H})(\mathrm{H}) \mathrm{F})(\mathrm{C}(\mathrm{H})(\mathrm{H}) \mathrm{H})(\mathrm{H}) \mathrm{Cl}$

$\mathrm{C}\left(\mathrm{C}\left(\mathrm{C}(\mathrm{C}(\mathrm{C}(\mathrm{C}(\mathrm{C}(\mathrm{C}(\mathrm{C}(\mathrm{C}(\mathrm{C}(\mathrm{C}(\mathrm{C}(\mathrm{C}(\mathrm{H})(\mathrm{H}) \mathrm{H})(\mathrm{H}) \mathrm{H})(\mathrm{Br}) \mathrm{H})(\mathrm{F}) \mathrm{H})(\mathrm{H}) \mathrm{H})(\mathrm{F}) \mathrm{F})(\mathrm{H}) \mathrm{H})(\mathrm{F}) \mathrm{H})(\mathrm{H}) \mathrm{F})(\mathrm{H}) \mathrm{F})(\mathrm{H}) \mathrm{H})\left({ }_{\mathrm{C} 15 \mathrm{H} 23 \mathrm{ClBrF} 7}\right.\right.\right.$

$\mathrm{H}) \mathrm{H})(\mathrm{H}) \mathrm{H})(\mathrm{C}(\mathrm{H})(\mathrm{Cl}) \mathrm{H})(\mathrm{F}) \mathrm{H}$

$\mathrm{C}\left(\mathrm{C}\left(\mathrm{C}(\mathrm{C}(\mathrm{C}(\mathrm{C}(\mathrm{C}(\mathrm{C}(\mathrm{C}(\mathrm{C}(\mathrm{C}(\mathrm{C}(\mathrm{C}(\mathrm{C}(\mathrm{H})(\mathrm{H}) \mathrm{F})(\mathrm{H}) \mathrm{H})(\mathrm{H}) \mathrm{H})(\mathrm{F}) \mathrm{H})(\mathrm{H}) \mathrm{Br})(\mathrm{Br}) \mathrm{F})(\mathrm{H}) \mathrm{H})(\mathrm{H}) \mathrm{H})(\mathrm{H}) \mathrm{F})(\mathrm{H}) \mathrm{F})(\mathrm{F}) \mathrm{H})\left({ }_{\mathrm{C}}\right.\right.\right.$ 15H24Br2F 6

$\mathrm{H}) \mathrm{H})(\mathrm{H}) \mathrm{H})(\mathrm{C}(\mathrm{H})(\mathrm{H}) \mathrm{H})(\mathrm{H}) \mathrm{H}$

$\mathrm{C}\left(\mathrm{C}\left(\mathrm{C}(\mathrm{C}(\mathrm{C}(\mathrm{C}(\mathrm{C}(\mathrm{C}(\mathrm{C}(\mathrm{C}(\mathrm{C}(\mathrm{C}(\mathrm{C}(\mathrm{C}(\mathrm{Br})(\mathrm{H}) \mathrm{H})(\mathrm{H}) \mathrm{H})(\mathrm{F}) \mathrm{F})(\mathrm{H}) \mathrm{H})(\mathrm{F}) \mathrm{H})(\mathrm{H}) \mathrm{H})(\mathrm{H}) \mathrm{H})(\mathrm{H}) \mathrm{H})(\mathrm{H}) \mathrm{F})(\mathrm{H}) \mathrm{H})(\mathrm{H}) \mathrm{H})\left({ }_{\mathrm{C} 15 \mathrm{H} 24 \mathrm{BrF} 7}\right.\right.\right.$

F)H $)(\mathrm{F}) \mathrm{H})(\mathrm{C}(\mathrm{H})(\mathrm{H}) \mathrm{F})(\mathrm{H}) \mathrm{H}$

$\mathrm{C}\left(\mathrm{C}\left(\mathrm{C}(\mathrm{C}(\mathrm{C}(\mathrm{C}(\mathrm{C}(\mathrm{C}(\mathrm{C}(\mathrm{C}(\mathrm{C}(\mathrm{C}(\mathrm{C}(\mathrm{C}(\mathrm{H})(\mathrm{H}) \mathrm{H})(\mathrm{H}) \mathrm{H})(\mathrm{H}) \mathrm{H})(\mathrm{F}) \mathrm{H})(\mathrm{H}) \mathrm{Cl})(\mathrm{H}) \mathrm{H})(\mathrm{H}) \mathrm{H})(\mathrm{H}) \mathrm{H})(\mathrm{H}) \mathrm{H})(\mathrm{Cl}) \mathrm{H})(\mathrm{H}) \mathrm{F}){ }_{\mathrm{C} 15 \mathrm{H} 24 \mathrm{Cl} 2 \mathrm{BrF} 5}\right.\right.$

$\mathrm{C}\left(\mathrm{C}\left(\mathrm{C}(\mathrm{C}(\mathrm{C}(\mathrm{C}(\mathrm{C}(\mathrm{C}(\mathrm{C}(\mathrm{C}(\mathrm{C}(\mathrm{C}(\mathrm{C}(\mathrm{C}(\mathrm{H})(\mathrm{H}) \mathrm{H})(\mathrm{H}) \mathrm{H})(\mathrm{H}) \mathrm{H})(\mathrm{H}) \mathrm{H})(\mathrm{H}) \mathrm{H})(\mathrm{H}) \mathrm{H})(\mathrm{H}) \mathrm{Cl})(\mathrm{F}) \mathrm{H})(\mathrm{Cl}) \mathrm{F})(\mathrm{H}) \mathrm{H})(\mathrm{F}) \mathrm{H}){ }_{\mathrm{C} 15 \mathrm{H} 24 \mathrm{Cl} 2 \mathrm{~F} 6}\right.\right.$

$(\mathrm{H}) \mathrm{H})(\mathrm{H}) \mathrm{H})(\mathrm{C}(\mathrm{F})(\mathrm{H}) \mathrm{F})(\mathrm{H}) \mathrm{F}$

$\mathrm{C}\left(\mathrm{C}\left(\mathrm{C}(\mathrm{C}(\mathrm{C}(\mathrm{C}(\mathrm{C}(\mathrm{C}(\mathrm{C}(\mathrm{C}(\mathrm{C}(\mathrm{C}(\mathrm{C}(\mathrm{C}(\mathrm{H})(\mathrm{H}) \mathrm{Cl})(\mathrm{H}) \mathrm{H})(\mathrm{F}) \mathrm{F})(\mathrm{H}) \mathrm{F})(\mathrm{H}) \mathrm{H})(\mathrm{H}) \mathrm{H})(\mathrm{H}) \mathrm{H})(\mathrm{F}) \mathrm{H})(\mathrm{H}) \mathrm{H})(\mathrm{H}) \mathrm{H})(\mathrm{H}) \mathrm{H})\left(\mathrm{Cl}_{15} \mathrm{H}_{24} \mathrm{Cl}_{3} 5\right.\right.\right.$

F)H $(\mathrm{H}) \mathrm{H})(\mathrm{C}(\mathrm{H})(\mathrm{Cl}) \mathrm{H})(\mathrm{H}) \mathrm{Cl}$

$\mathrm{C}(\mathrm{C}(\mathrm{C}(\mathrm{C}(\mathrm{C}(\mathrm{C}(\mathrm{C}(\mathrm{C}(\mathrm{C}(\mathrm{C}(\mathrm{C}(\mathrm{C}(\mathrm{C}(\mathrm{C}(\mathrm{Cl})(\mathrm{F}) \mathrm{H})(\mathrm{F}) \mathrm{H})(\mathrm{H}) \mathrm{H})(\mathrm{F}) \mathrm{H})(\mathrm{H}) \mathrm{H})(\mathrm{H}) \mathrm{H})(\mathrm{H}) \mathrm{H})(\mathrm{H}) \mathrm{H})(\mathrm{H}) \mathrm{H})(\mathrm{Br}) \mathrm{H})$

$(\mathrm{Br}) \mathrm{F})(\mathrm{H}) \mathrm{H})(\mathrm{H}) \mathrm{H})(\mathrm{C}(\mathrm{H})(\mathrm{H}) \mathrm{H})(\mathrm{H}) \mathrm{F}$

$\mathrm{C}(\mathrm{C}(\mathrm{C}(\mathrm{C}(\mathrm{C}(\mathrm{C}(\mathrm{C}(\mathrm{C}(\mathrm{C}(\mathrm{C}(\mathrm{C}(\mathrm{C}(\mathrm{C}(\mathrm{C}(\mathrm{F})(\mathrm{H}) \mathrm{H})(\mathrm{H}) \mathrm{F})(\mathrm{H}) \mathrm{H})(\mathrm{H}) \mathrm{H})(\mathrm{H}) \mathrm{F})(\mathrm{H}) \mathrm{H})(\mathrm{H}) \mathrm{Cl})(\mathrm{H}) \mathrm{F})(\mathrm{H}) \mathrm{H})(\mathrm{H}) \mathrm{H})(\mathrm{H}) \mathrm{H})($ $\mathrm{H}) \mathrm{F})(\mathrm{H}) \mathrm{H})(\mathrm{C}(\mathrm{H})(\mathrm{F}) \mathrm{Br})(\mathrm{H}) \mathrm{H}$

$\mathrm{C}(\mathrm{C}(\mathrm{C}(\mathrm{C}(\mathrm{C}(\mathrm{C}(\mathrm{C}(\mathrm{C}(\mathrm{C}(\mathrm{C}(\mathrm{C}(\mathrm{C}(\mathrm{C}(\mathrm{C}(\mathrm{F})(\mathrm{H}) \mathrm{H})(\mathrm{F}) \mathrm{F})(\mathrm{H}) \mathrm{H})(\mathrm{H}) \mathrm{Br})(\mathrm{H}) \mathrm{H})(\mathrm{H}) \mathrm{H})(\mathrm{H}) \mathrm{H})(\mathrm{H}) \mathrm{H})(\mathrm{H}) \mathrm{F})(\mathrm{H}) \mathrm{H})(\mathrm{F}) \mathrm{H})($

$\mathrm{H}) \mathrm{H})(\mathrm{H}) \mathrm{H})(\mathrm{C}(\mathrm{H})(\mathrm{H}) \mathrm{H})(\mathrm{Br}) \mathrm{H}$

$\mathrm{C}(\mathrm{C}(\mathrm{C}(\mathrm{C}(\mathrm{C}(\mathrm{C}(\mathrm{C}(\mathrm{C}(\mathrm{C}(\mathrm{C}(\mathrm{C}(\mathrm{C}(\mathrm{C}(\mathrm{C}(\mathrm{H})(\mathrm{H}) \mathrm{H})(\mathrm{H}) \mathrm{H})(\mathrm{H}) \mathrm{H})(\mathrm{F}) \mathrm{H})(\mathrm{F}) \mathrm{F})(\mathrm{H}) \mathrm{H})(\mathrm{Br}) \mathrm{H})(\mathrm{H}) \mathrm{F})(\mathrm{H}) \mathrm{F})(\mathrm{F}) \mathrm{H})(\mathrm{H}) \mathrm{H})($

$\mathrm{H}) \mathrm{H})(\mathrm{H}) \mathrm{H})(\mathrm{C}(\mathrm{H})(\mathrm{H}) \mathrm{H})(\mathrm{H}) \mathrm{H}$

$\mathrm{C}(\mathrm{C}(\mathrm{C}(\mathrm{C}(\mathrm{C}(\mathrm{C}(\mathrm{C}(\mathrm{C}(\mathrm{C}(\mathrm{C}(\mathrm{C}(\mathrm{C}(\mathrm{C}(\mathrm{C}(\mathrm{Cl})(\mathrm{H}) \mathrm{H})(\mathrm{H}) \mathrm{F})(\mathrm{H}) \mathrm{Cl})(\mathrm{H}) \mathrm{H})(\mathrm{H}) \mathrm{H})(\mathrm{Br}) \mathrm{H})(\mathrm{H}) \mathrm{H})(\mathrm{H}) \mathrm{F})(\mathrm{H}) \mathrm{H})(\mathrm{F}) \mathrm{H})$

$(\mathrm{H}) \mathrm{H})(\mathrm{H}) \mathrm{H})(\mathrm{H}) \mathrm{H})(\mathrm{C}(\mathrm{F})(\mathrm{H}) \mathrm{H})(\mathrm{H}) \mathrm{H}$

lgKoa lgKow lgKaw lgKow lgKoa lgKa lgKow lgKoa lgKaw EPISuit_EPI_EPI_Exp__Exp w_ DFT_DFT DFT e Suite Suite corr_corr _Exp corr__corr_corr $\begin{array}{lllllllll}4.927 & 7.94 & 3.01 & 6.93 & 3.91 & 3.01 & 6.86 & 7.06 & -0.20\end{array}$ $\begin{array}{lllllllll}6.564 & 8.34 & 1.78 & 7.52 & 5.75 & 1.78 & 7.17 & 10.07 & -2.90\end{array}$ $\begin{array}{lllllllll}6.082 & 8.83 & 2.75 & 8.25 & 5.51 & 2.75 & 7.54 & 9.18 & -1.64\end{array}$ $\begin{array}{lllllllll}6.485 & 8.48 & 2.00 & 7.73 & 5.74 & 2.00 & 7.28 & 9.93 & -2.65\end{array}$ 
$\mathrm{C}(\mathrm{C}(\mathrm{C}(\mathrm{C}(\mathrm{C}(\mathrm{C}(\mathrm{C}(\mathrm{C}(\mathrm{C}(\mathrm{C}(\mathrm{C}(\mathrm{C}(\mathrm{C}(\mathrm{C}(\mathrm{H})(\mathrm{H}) \mathrm{H})(\mathrm{H}) \mathrm{F})(\mathrm{F}) \mathrm{H})(\mathrm{H}) \mathrm{H})(\mathrm{H}) \mathrm{H})(\mathrm{H}) \mathrm{H})(\mathrm{H}) \mathrm{H})(\mathrm{H}) \mathrm{H})(\mathrm{H}) \mathrm{H})(\mathrm{F}) \mathrm{Cl})(\mathrm{H}) \mathrm{Cl})$ $(\mathrm{H}) \mathrm{H})(\mathrm{H}) \mathrm{H})(\mathrm{C}(\mathrm{H})(\mathrm{F}) \mathrm{F})(\mathrm{H}) \mathrm{H}$

$\mathrm{C}(\mathrm{C}(\mathrm{C}(\mathrm{C}(\mathrm{C}(\mathrm{C}(\mathrm{C}(\mathrm{C}(\mathrm{C}(\mathrm{C}(\mathrm{C}(\mathrm{C}(\mathrm{C}(\mathrm{C}(\mathrm{H})(\mathrm{H}) \mathrm{F})(\mathrm{H}) \mathrm{H})(\mathrm{H}) \mathrm{H})(\mathrm{Br}) \mathrm{H})(\mathrm{F}) \mathrm{H})(\mathrm{Cl}) \mathrm{H})(\mathrm{H}) \mathrm{H})(\mathrm{H}) \mathrm{H})(\mathrm{Cl}) \mathrm{H})(\mathrm{F}) \mathrm{H})$ $(\mathrm{H}) \mathrm{H})(\mathrm{H}) \mathrm{H})(\mathrm{H}) \mathrm{H})(\mathrm{C}(\mathrm{H})(\mathrm{H}) \mathrm{H})(\mathrm{Cl}) \mathrm{H}$

$\mathrm{C}(\mathrm{C}(\mathrm{C}(\mathrm{C}(\mathrm{C}(\mathrm{C}(\mathrm{C}(\mathrm{C}(\mathrm{C}(\mathrm{C}(\mathrm{C}(\mathrm{C}(\mathrm{C}(\mathrm{C}(\mathrm{Cl})(\mathrm{F}) \mathrm{H})(\mathrm{H}) \mathrm{H})(\mathrm{H}) \mathrm{F})(\mathrm{F}) \mathrm{H})(\mathrm{H}) \mathrm{H})(\mathrm{H}) \mathrm{Cl})(\mathrm{H}) \mathrm{H})(\mathrm{H}) \mathrm{H})(\mathrm{H}) \mathrm{H})(\mathrm{H}) \mathrm{Cl})$ $(\mathrm{H}) \mathrm{H})(\mathrm{H}) \mathrm{H})(\mathrm{H}) \mathrm{H})(\mathrm{C}(\mathrm{H})(\mathrm{H}) \mathrm{F})(\mathrm{H}) \mathrm{H}$

$\mathrm{C}(\mathrm{C}(\mathrm{C}(\mathrm{C}(\mathrm{C}(\mathrm{C}(\mathrm{C}(\mathrm{C}(\mathrm{C}(\mathrm{C}(\mathrm{C}(\mathrm{C}(\mathrm{C}(\mathrm{C}(\mathrm{H})(\mathrm{H}) \mathrm{H})(\mathrm{H}) \mathrm{H})(\mathrm{H}) \mathrm{H})(\mathrm{H}) \mathrm{Cl})(\mathrm{H}) \mathrm{H})(\mathrm{H}) \mathrm{H})(\mathrm{H}) \mathrm{H})(\mathrm{H}) \mathrm{H})(\mathrm{F}) \mathrm{H})(\mathrm{H}) \mathrm{Cl})(\mathrm{Cl}) \mathrm{C}$ 1)(F)H $(\mathrm{H}) \mathrm{H})(\mathrm{C}(\mathrm{F})(\mathrm{H}) \mathrm{H})(\mathrm{H}) \mathrm{H}$

$\mathrm{C}\left(\mathrm{C}\left(\mathrm{C}(\mathrm{C}(\mathrm{C}(\mathrm{C}(\mathrm{C}(\mathrm{C}(\mathrm{C}(\mathrm{C}(\mathrm{C}(\mathrm{C}(\mathrm{C}(\mathrm{C}(\mathrm{F})(\mathrm{H}) \mathrm{F})(\mathrm{H}) \mathrm{F})(\mathrm{H}) \mathrm{H})(\mathrm{H}) \mathrm{H})(\mathrm{H}) \mathrm{H})(\mathrm{H}) \mathrm{H})(\mathrm{H}) \mathrm{H})(\mathrm{F}) \mathrm{H})(\mathrm{H}) \mathrm{F})(\mathrm{H}) \mathrm{H})(\mathrm{H}) \mathrm{H})\left({ }_{\mathrm{C}}{ }^{2}\right.\right.\right.$ H $25 \mathrm{ClBrF} 5$

$\mathrm{H}) \mathrm{H})(\mathrm{H}) \mathrm{H})(\mathrm{C}(\mathrm{H})(\mathrm{H}) \mathrm{Br})(\mathrm{H}) \mathrm{Cl}$

$\mathrm{C}(\mathrm{C}(\mathrm{C}(\mathrm{C}(\mathrm{C}(\mathrm{C}(\mathrm{C}(\mathrm{C}(\mathrm{C}(\mathrm{C}(\mathrm{C}(\mathrm{C}(\mathrm{C}(\mathrm{C}(\mathrm{H})(\mathrm{H}) \mathrm{H})(\mathrm{H}) \mathrm{H})(\mathrm{H}) \mathrm{H})(\mathrm{H}) \mathrm{F})(\mathrm{H}) \mathrm{H})(\mathrm{Br}) \mathrm{H})(\mathrm{H}) \mathrm{F})(\mathrm{H}) \mathrm{H})(\mathrm{H}) \mathrm{H})(\mathrm{F}) \mathrm{H})(\mathrm{H}) \mathrm{H})$

$(\mathrm{H}) \mathrm{H})(\mathrm{F}) \mathrm{H})(\mathrm{C}(\mathrm{H})(\mathrm{H}) \mathrm{H})(\mathrm{H}) \mathrm{B}$

$\mathrm{C}(\mathrm{C}(\mathrm{C}(\mathrm{C}(\mathrm{C}(\mathrm{C}(\mathrm{C}(\mathrm{C}(\mathrm{C}(\mathrm{C}(\mathrm{C}(\mathrm{C}(\mathrm{C}(\mathrm{C}(\mathrm{H})(\mathrm{H}) \mathrm{H})(\mathrm{H}) \mathrm{H})(\mathrm{H}) \mathrm{H})(\mathrm{H}) \mathrm{H})(\mathrm{H}) \mathrm{F})(\mathrm{H}) \mathrm{F})(\mathrm{H}) \mathrm{H})(\mathrm{H}) \mathrm{H})(\mathrm{H}) \mathrm{F})(\mathrm{Br}) \mathrm{H})(\mathrm{H}) \mathrm{H})$ $(\mathrm{H}) \mathrm{H})(\mathrm{H}) \mathrm{H})(\mathrm{C}(\mathrm{H})(\mathrm{F}) \mathrm{H})(\mathrm{F}) \mathrm{H}$

$\mathrm{C}(\mathrm{C}(\mathrm{C}(\mathrm{C}(\mathrm{C}(\mathrm{C}(\mathrm{C}(\mathrm{C}(\mathrm{C}(\mathrm{C}(\mathrm{C}(\mathrm{C}(\mathrm{C}(\mathrm{C}(\mathrm{H})(\mathrm{H}) \mathrm{H})(\mathrm{H}) \mathrm{H})(\mathrm{H}) \mathrm{H})(\mathrm{Cl}) \mathrm{H})(\mathrm{H}) \mathrm{F})(\mathrm{H}) \mathrm{H})(\mathrm{H}) \mathrm{F})(\mathrm{F}) \mathrm{Cl})(\mathrm{H}) \mathrm{H})(\mathrm{H}) \mathrm{H})(\mathrm{H}) \mathrm{H})$ $(\mathrm{H}) \mathrm{H})(\mathrm{Br}) \mathrm{H})(\mathrm{C}(\mathrm{H})(\mathrm{H}) \mathrm{H})(\mathrm{H}) \mathrm{H}$

C $(\mathrm{C}(\mathrm{C}(\mathrm{C}(\mathrm{C}(\mathrm{C}(\mathrm{C}(\mathrm{C}(\mathrm{C}(\mathrm{C}(\mathrm{C}(\mathrm{C}(\mathrm{C}(\mathrm{C}(\mathrm{H})(\mathrm{H}) \mathrm{H})(\mathrm{H}) \mathrm{H})(\mathrm{H}) \mathrm{H})(\mathrm{H}) \mathrm{H})(\mathrm{F}) \mathrm{H})(\mathrm{H}) \mathrm{H})(\mathrm{F}) \mathrm{H})(\mathrm{Cl}) \mathrm{H})(\mathrm{H}) \mathrm{H})(\mathrm{H}) \mathrm{F})(\mathrm{H}) \mathrm{H})($

$\mathrm{H}) \mathrm{H})(\mathrm{H}) \mathrm{H})(\mathrm{C}(\mathrm{H})(\mathrm{Cl}) \mathrm{H})(\mathrm{H}) \mathrm{F}$

$\mathrm{C}\left(\mathrm{C}\left(\mathrm{C}(\mathrm{C}(\mathrm{C}(\mathrm{C}(\mathrm{C}(\mathrm{C}(\mathrm{C}(\mathrm{C}(\mathrm{C}(\mathrm{C}(\mathrm{C}(\mathrm{C}(\mathrm{H})(\mathrm{H}) \mathrm{H})(\mathrm{H}) \mathrm{H})(\mathrm{F}) \mathrm{H})(\mathrm{H}) \mathrm{H})(\mathrm{H}) \mathrm{H})(\mathrm{Cl}) \mathrm{H})(\mathrm{H}) \mathrm{Cl})(\mathrm{H}) \mathrm{F})(\mathrm{F}) \mathrm{H})(\mathrm{H}) \mathrm{H})(\mathrm{H}) \mathrm{H}){ }_{\mathrm{C} 15 \mathrm{H} 26 \mathrm{Cl} 3 \mathrm{~F} 3}\right.\right.$

$(\mathrm{H}) \mathrm{H})(\mathrm{H}) \mathrm{H})(\mathrm{C}(\mathrm{Cl})(\mathrm{H}) \mathrm{H})(\mathrm{H}) \mathrm{H}$

$\mathrm{C}(\mathrm{C}(\mathrm{C}(\mathrm{C}(\mathrm{C}(\mathrm{C}(\mathrm{C}(\mathrm{C}(\mathrm{C}(\mathrm{C}(\mathrm{C}(\mathrm{C}(\mathrm{C}(\mathrm{C}(\mathrm{H})(\mathrm{H}) \mathrm{F})(\mathrm{H}) \mathrm{H})(\mathrm{H}) \mathrm{F})(\mathrm{Br}) \mathrm{H})(\mathrm{H}) \mathrm{H})(\mathrm{H}) \mathrm{H})(\mathrm{H}) \mathrm{H})(\mathrm{H}) \mathrm{H})(\mathrm{H}) \mathrm{H})(\mathrm{H}) \mathrm{Br})$

$(\mathrm{H}) \mathrm{H})(\mathrm{H}) \mathrm{H})(\mathrm{H}) \mathrm{Cl}(\mathrm{C}(\mathrm{H})(\mathrm{H}) \mathrm{H})(\mathrm{H}) \mathrm{F}$

$\mathrm{C}(\mathrm{C}(\mathrm{C}(\mathrm{C}(\mathrm{C}(\mathrm{C}(\mathrm{C}(\mathrm{C}(\mathrm{C}(\mathrm{C}(\mathrm{C}(\mathrm{C}(\mathrm{C}(\mathrm{C}(\mathrm{H})(\mathrm{H}) \mathrm{H})(\mathrm{H}) \mathrm{H})(\mathrm{H}) \mathrm{H})(\mathrm{H}) \mathrm{F})(\mathrm{H}) \mathrm{H})(\mathrm{H}) \mathrm{H})(\mathrm{F}) \mathrm{H})(\mathrm{H}) \mathrm{F})(\mathrm{H}) \mathrm{H})(\mathrm{H}) \mathrm{H})(\mathrm{H}) \mathrm{H})($ $\mathrm{H}) \mathrm{H})(\mathrm{F}) \mathrm{Br})(\mathrm{C}(\mathrm{H})(\mathrm{H}) \mathrm{H})(\mathrm{H}) \mathrm{Cl}$

$\mathrm{C}(\mathrm{C}(\mathrm{C}(\mathrm{C}(\mathrm{C}(\mathrm{C}(\mathrm{C}(\mathrm{C}(\mathrm{C}(\mathrm{C}(\mathrm{C}(\mathrm{C}(\mathrm{C}(\mathrm{C}(\mathrm{H})(\mathrm{H}) \mathrm{H})(\mathrm{F}) \mathrm{H})(\mathrm{H}) \mathrm{F})(\mathrm{H}) \mathrm{H})(\mathrm{H}) \mathrm{F})(\mathrm{H}) \mathrm{H})(\mathrm{H}) \mathrm{H})(\mathrm{H}) \mathrm{H})(\mathrm{B}) \mathrm{H})(\mathrm{H}) \mathrm{H})(\mathrm{H}) \mathrm{H}$

$(\mathrm{Br}) \mathrm{H})(\mathrm{H}) \mathrm{H})(\mathrm{C}(\mathrm{H})(\mathrm{H}) \mathrm{H})(\mathrm{H}) \mathrm{H}$

$\mathrm{C}(\mathrm{C}(\mathrm{C}(\mathrm{C}(\mathrm{C}(\mathrm{C}(\mathrm{C}(\mathrm{C}(\mathrm{C}(\mathrm{C}(\mathrm{C}(\mathrm{C}(\mathrm{C}(\mathrm{C}(\mathrm{H})(\mathrm{H}) \mathrm{H})(\mathrm{H}) \mathrm{H})(\mathrm{H}) \mathrm{Br})(\mathrm{H}) \mathrm{F})(\mathrm{H}) \mathrm{H})(\mathrm{F}) \mathrm{H})(\mathrm{H}) \mathrm{H})(\mathrm{H}) \mathrm{H})(\mathrm{H}) \mathrm{H})(\mathrm{H}) \mathrm{H})(\mathrm{H}) \mathrm{H})$

$(\mathrm{H}) \mathrm{H})(\mathrm{H}) \mathrm{F})(\mathrm{C}(\mathrm{H})(\mathrm{H}) \mathrm{H})(\mathrm{F}) \mathrm{H}$

$\mathrm{C}(\mathrm{C}(\mathrm{C}(\mathrm{C}(\mathrm{C}(\mathrm{C}(\mathrm{C}(\mathrm{C}(\mathrm{C}(\mathrm{C}(\mathrm{C}(\mathrm{C}(\mathrm{C}(\mathrm{C}(\mathrm{H})(\mathrm{H}) \mathrm{F})(\mathrm{H}) \mathrm{H})(\mathrm{Cl}) \mathrm{H})(\mathrm{H}) \mathrm{H})(\mathrm{H}) \mathrm{H})(\mathrm{Br}) \mathrm{H})(\mathrm{H}) \mathrm{H})(\mathrm{H}) \mathrm{H})(\mathrm{H}) \mathrm{H})(\mathrm{H}) \mathrm{H})(\mathrm{H}) \mathrm{C}$ 1)(H)F)(H)H)(C(H)(H)H)(H)H

$\mathrm{C}\left(\mathrm{C}\left(\mathrm{C}(\mathrm{C}(\mathrm{C}(\mathrm{C}(\mathrm{C}(\mathrm{C}(\mathrm{C}(\mathrm{C}(\mathrm{C}(\mathrm{C}(\mathrm{C}(\mathrm{C}(\mathrm{H})(\mathrm{H}) \mathrm{H})(\mathrm{H}) \mathrm{F})(\mathrm{H}) \mathrm{H})(\mathrm{H}) \mathrm{H})(\mathrm{H}) \mathrm{H})(\mathrm{H}) \mathrm{H})(\mathrm{H}) \mathrm{H})(\mathrm{Cl}) \mathrm{H})(\mathrm{H}) \mathrm{H})(\mathrm{H}) \mathrm{H})(\mathrm{H}) \mathrm{F}){ }_{\mathrm{C} 15 \mathrm{H} 27 \mathrm{Cl} 2 \mathrm{~F} 3}\right.\right.$

$(\mathrm{H}) \mathrm{H})(\mathrm{H}) \mathrm{F})(\mathrm{C}(\mathrm{H})(\mathrm{H}) \mathrm{Cl}(\mathrm{H}) \mathrm{H}$

$\mathrm{C}(\mathrm{C}(\mathrm{C}(\mathrm{C}(\mathrm{C}(\mathrm{C}(\mathrm{C}(\mathrm{C}(\mathrm{C}(\mathrm{C}(\mathrm{C}(\mathrm{C}(\mathrm{C}(\mathrm{C}(\mathrm{H})(\mathrm{H}) \mathrm{H})(\mathrm{H}) \mathrm{H})(\mathrm{H}) \mathrm{H})(\mathrm{H}) \mathrm{H})(\mathrm{H}) \mathrm{H})(\mathrm{H}) \mathrm{H})(\mathrm{H}) \mathrm{H})(\mathrm{H}) \mathrm{H})(\mathrm{H}) \mathrm{Cl})(\mathrm{Cl}) \mathrm{H})(\mathrm{H})$

$\mathrm{H})(\mathrm{F}) \mathrm{F})(\mathrm{Cl}) \mathrm{H})(\mathrm{C}(\mathrm{H})(\mathrm{H}) \mathrm{H})(\mathrm{H}) \mathrm{H}$

$\mathrm{C}\left(\mathrm{C}\left(\mathrm{C}(\mathrm{C}(\mathrm{C}(\mathrm{C}(\mathrm{C}(\mathrm{C}(\mathrm{C}(\mathrm{C}(\mathrm{C}(\mathrm{C}(\mathrm{C}(\mathrm{C}(\mathrm{H})(\mathrm{H}) \mathrm{Cl})(\mathrm{H}) \mathrm{H})(\mathrm{Br}) \mathrm{H})(\mathrm{H}) \mathrm{F})(\mathrm{F}) \mathrm{H})(\mathrm{H}) \mathrm{H})(\mathrm{H}) \mathrm{H})(\mathrm{F}) \mathrm{H})(\mathrm{H}) \mathrm{H})(\mathrm{H}) \mathrm{H})(\mathrm{H}) \mathrm{H}){ }_{\mathrm{C} 15 \mathrm{H} 27 \mathrm{ClBrF} 3}\right.\right.$

$(\mathrm{H}) \mathrm{H})(\mathrm{H}) \mathrm{H})(\mathrm{C}(\mathrm{H})(\mathrm{H}) \mathrm{H})(\mathrm{H}) \mathrm{H}$

$\mathrm{C}\left(\mathrm{C}\left(\mathrm{C}(\mathrm{C}(\mathrm{C}(\mathrm{C}(\mathrm{C}(\mathrm{C}(\mathrm{C}(\mathrm{C}(\mathrm{C}(\mathrm{C}(\mathrm{C}(\mathrm{C}(\mathrm{H})(\mathrm{H}) \mathrm{F})(\mathrm{F}) \mathrm{H})(\mathrm{H}) \mathrm{H})(\mathrm{H}) \mathrm{H})(\mathrm{H}) \mathrm{F})(\mathrm{H}) \mathrm{H})(\mathrm{H}) \mathrm{H})(\mathrm{H}) \mathrm{Cl})(\mathrm{H}) \mathrm{H})(\mathrm{H}) \mathrm{H})(\mathrm{H}) \mathrm{H})\left({ }_{\mathrm{C} 15 \mathrm{H} 27 \mathrm{ClF} 4}\right.\right.\right.$

$\mathrm{H}) \mathrm{H})(\mathrm{H}) \mathrm{H})(\mathrm{C}(\mathrm{H})(\mathrm{H}) \mathrm{F})(\mathrm{H}) \mathrm{H}$

$\mathrm{C}(\mathrm{C}(\mathrm{C}(\mathrm{C}(\mathrm{C}(\mathrm{C}(\mathrm{C}(\mathrm{C}(\mathrm{C}(\mathrm{C}(\mathrm{C}(\mathrm{C}(\mathrm{C}(\mathrm{C}(\mathrm{H})(\mathrm{H}) \mathrm{F})(\mathrm{H}) \mathrm{H})(\mathrm{H}) \mathrm{H})(\mathrm{H}) \mathrm{H})(\mathrm{Br}) \mathrm{H})(\mathrm{H}) \mathrm{H})(\mathrm{H}) \mathrm{F})(\mathrm{H}) \mathrm{F})(\mathrm{H}) \mathrm{H})(\mathrm{H}) \mathrm{H})(\mathrm{H}) \mathrm{H})$ $(\mathrm{H}) \mathrm{H})(\mathrm{H}) \mathrm{H})(\mathrm{C}(\mathrm{H})(\mathrm{H}) \mathrm{H})(\mathrm{H}) \mathrm{H}$

$\mathrm{C}(\mathrm{C}(\mathrm{C}(\mathrm{C}(\mathrm{C}(\mathrm{C}(\mathrm{C}(\mathrm{C}(\mathrm{C}(\mathrm{C}(\mathrm{C}(\mathrm{C}(\mathrm{C}(\mathrm{C}(\mathrm{H})(\mathrm{Cl}) \mathrm{H})(\mathrm{H}) \mathrm{H})(\mathrm{H}) \mathrm{H})(\mathrm{H}) \mathrm{H})(\mathrm{H}) \mathrm{H})(\mathrm{H}) \mathrm{H})(\mathrm{H}) \mathrm{Cl})(\mathrm{F}) \mathrm{H})(\mathrm{H}) \mathrm{H})(\mathrm{H}) \mathrm{H})$

$(\mathrm{H}) \mathrm{H})(\mathrm{H}) \mathrm{F})(\mathrm{H}) \mathrm{H})(\mathrm{C}(\mathrm{H})(\mathrm{H}) \mathrm{H})(\mathrm{H}) \mathrm{H}$

$\mathrm{C}(\mathrm{C}(\mathrm{C}(\mathrm{C}(\mathrm{C}(\mathrm{C}(\mathrm{C}(\mathrm{C}(\mathrm{C}(\mathrm{C}(\mathrm{C}(\mathrm{C}(\mathrm{C}(\mathrm{C}(\mathrm{H})(\mathrm{H}) \mathrm{H})(\mathrm{H}) \mathrm{H})(\mathrm{F}) \mathrm{H})(\mathrm{H}) \mathrm{H})(\mathrm{H}) \mathrm{H})(\mathrm{F}) \mathrm{Cl})(\mathrm{H}) \mathrm{H})(\mathrm{H}) \mathrm{H})(\mathrm{Br}) \mathrm{H})(\mathrm{H}) \mathrm{H})$

$(\mathrm{H}) \mathrm{H})(\mathrm{H}) \mathrm{H})(\mathrm{H}) \mathrm{H})(\mathrm{C}(\mathrm{H})(\mathrm{H}) \mathrm{H})(\mathrm{H}) \mathrm{H}$

$\mathrm{C}(\mathrm{C}(\mathrm{C}(\mathrm{C}(\mathrm{C}(\mathrm{C}(\mathrm{C}(\mathrm{C}(\mathrm{C}(\mathrm{C}(\mathrm{C}(\mathrm{C}(\mathrm{C}(\mathrm{C}(\mathrm{H})(\mathrm{H}) \mathrm{H})(\mathrm{H}) \mathrm{H})(\mathrm{H}) \mathrm{H})(\mathrm{H}) \mathrm{H})(\mathrm{H}) \mathrm{H})(\mathrm{H}) \mathrm{H})(\mathrm{H}) \mathrm{H})(\mathrm{F}) \mathrm{H})(\mathrm{H}) \mathrm{H})(\mathrm{H}) \mathrm{H})(\mathrm{H}) \mathrm{H})$

$(\mathrm{Cl}) \mathrm{H})(\mathrm{H}) \mathrm{H})(\mathrm{C}(\mathrm{F})(\mathrm{H}) \mathrm{H})(\mathrm{H}) \mathrm{F}$

$\mathrm{C}(\mathrm{C}(\mathrm{C}(\mathrm{C}(\mathrm{C}(\mathrm{C}(\mathrm{C}(\mathrm{C}(\mathrm{C}(\mathrm{C}(\mathrm{C}(\mathrm{C}(\mathrm{C}(\mathrm{C}(\mathrm{H})(\mathrm{H}) \mathrm{H})(\mathrm{H}) \mathrm{Br})(\mathrm{H}) \mathrm{H})(\mathrm{H}) \mathrm{H})(\mathrm{H}) \mathrm{H})(\mathrm{H}) \mathrm{F})(\mathrm{H}) \mathrm{H})(\mathrm{H}) \mathrm{H})(\mathrm{H}) \mathrm{H})(\mathrm{H}) \mathrm{H})$

$(\mathrm{H}) \mathrm{H})(\mathrm{H}) \mathrm{Br})(\mathrm{H}) \mathrm{H})(\mathrm{C}(\mathrm{H})(\mathrm{H}) \mathrm{H})(\mathrm{H}) \mathrm{H}$

$\mathrm{C}(\mathrm{C}(\mathrm{C}(\mathrm{C}(\mathrm{C}(\mathrm{C}(\mathrm{C}(\mathrm{C}(\mathrm{C}(\mathrm{C}(\mathrm{C}(\mathrm{C}(\mathrm{C}(\mathrm{C}(\mathrm{H})(\mathrm{H}) \mathrm{H})(\mathrm{H}) \mathrm{H})(\mathrm{H}) \mathrm{H})(\mathrm{H}) \mathrm{H})(\mathrm{H}) \mathrm{H})(\mathrm{H}) \mathrm{H})(\mathrm{H}) \mathrm{H})(\mathrm{H}) \mathrm{F})(\mathrm{H}) \mathrm{H})(\mathrm{H}) \mathrm{H})(\mathrm{H}) \mathrm{H})$ $(\mathrm{H}) \mathrm{F})(\mathrm{H}) \mathrm{H})(\mathrm{C}(\mathrm{H})(\mathrm{Br}) \mathrm{H})(\mathrm{H}) \mathrm{H}$

$\mathrm{C}(\mathrm{C}(\mathrm{C}(\mathrm{C}(\mathrm{C}(\mathrm{C}(\mathrm{C}(\mathrm{C}(\mathrm{C}(\mathrm{C}(\mathrm{C}(\mathrm{C}(\mathrm{C}(\mathrm{C}(\mathrm{H})(\mathrm{H}) \mathrm{H})(\mathrm{H}) \mathrm{H})(\mathrm{H}) \mathrm{H})(\mathrm{H}) \mathrm{H})(\mathrm{H}) \mathrm{H})(\mathrm{H}) \mathrm{F})(\mathrm{H}) \mathrm{H})(\mathrm{Cl}) \mathrm{H})(\mathrm{H}) \mathrm{H})(\mathrm{H}) \mathrm{H})(\mathrm{H}) \mathrm{H})$ $(\mathrm{Cl}) \mathrm{H})(\mathrm{H}) \mathrm{H})(\mathrm{C}(\mathrm{H})(\mathrm{H}) \mathrm{H})(\mathrm{H}) \mathrm{H}$

$\mathrm{C}(\mathrm{C}(\mathrm{C}(\mathrm{C}(\mathrm{C}(\mathrm{C}(\mathrm{C}(\mathrm{C}(\mathrm{C}(\mathrm{C}(\mathrm{C}(\mathrm{C}(\mathrm{C}(\mathrm{C}(\mathrm{H})(\mathrm{H}) \mathrm{H})(\mathrm{H}) \mathrm{H})(\mathrm{Cl}) \mathrm{H})(\mathrm{H}) \mathrm{H})(\mathrm{H}) \mathrm{H})(\mathrm{H}) \mathrm{H})(\mathrm{H}) \mathrm{H})(\mathrm{H}) \mathrm{H})(\mathrm{H}) \mathrm{H})(\mathrm{H}) \mathrm{H})$

$(\mathrm{H}) \mathrm{H})(\mathrm{H}) \mathrm{H})(\mathrm{H}) \mathrm{H})(\mathrm{C}(\mathrm{H})(\mathrm{H}) \mathrm{Cl})(\mathrm{H}) \mathrm{Cl}$

$\mathrm{C}(\mathrm{C}(\mathrm{C}(\mathrm{C}(\mathrm{C}(\mathrm{C}(\mathrm{C}(\mathrm{C}(\mathrm{C}(\mathrm{C}(\mathrm{C}(\mathrm{C}(\mathrm{C}(\mathrm{C}(\mathrm{H})(\mathrm{H}) \mathrm{H})(\mathrm{H}) \mathrm{H})(\mathrm{H}) \mathrm{H})(\mathrm{H}) \mathrm{H})(\mathrm{H}) \mathrm{H})(\mathrm{Cl}) \mathrm{H})(\mathrm{H}) \mathrm{Br})(\mathrm{H}) \mathrm{H})(\mathrm{H}) \mathrm{H})(\mathrm{H}) \mathrm{H})(\mathrm{H})$

$\mathrm{H})(\mathrm{H}) \mathrm{H})(\mathrm{H}) \mathrm{H})(\mathrm{C}(\mathrm{H})(\mathrm{H}) \mathrm{H})(\mathrm{H}) \mathrm{F}$

$\mathrm{H})(\mathrm{H}) \mathrm{H})(\mathrm{H}) \mathrm{H})(\mathrm{C}(\mathrm{H})(\mathrm{H}) \mathrm{H})(\mathrm{H}) \mathrm{F}$
$\mathrm{C}(\mathrm{C}(\mathrm{C}(\mathrm{C}(\mathrm{C}(\mathrm{C}(\mathrm{C}(\mathrm{C}(\mathrm{C}(\mathrm{C}(\mathrm{C}(\mathrm{C}(\mathrm{C}(\mathrm{C}(\mathrm{H})(\mathrm{H}) \mathrm{H})(\mathrm{H}) \mathrm{H})(\mathrm{H}) \mathrm{F})(\mathrm{H}) \mathrm{H})(\mathrm{H}) \mathrm{H})(\mathrm{H}) \mathrm{H})(\mathrm{F}) \mathrm{H})(\mathrm{H}) \mathrm{H})(\mathrm{H}) \mathrm{H})(\mathrm{Cl}) \mathrm{H})(\mathrm{H}) \mathrm{H})$

$(\mathrm{H}) \mathrm{H})(\mathrm{H}) \mathrm{H})(\mathrm{C}(\mathrm{H})(\mathrm{H}) \mathrm{H})(\mathrm{H}) \mathrm{H}$

$\mathrm{C}(\mathrm{C}(\mathrm{C}(\mathrm{C}(\mathrm{C}(\mathrm{C}(\mathrm{C}(\mathrm{C}(\mathrm{C}(\mathrm{C}(\mathrm{C}(\mathrm{C}(\mathrm{C}(\mathrm{C}(\mathrm{H})(\mathrm{H}) \mathrm{H})(\mathrm{H}) \mathrm{H})(\mathrm{H}) \mathrm{H})(\mathrm{H}) \mathrm{H})(\mathrm{H}) \mathrm{H})(\mathrm{H}) \mathrm{H})(\mathrm{H}) \mathrm{H})(\mathrm{H}) \mathrm{Br})(\mathrm{H}) \mathrm{H})(\mathrm{F}) \mathrm{H})$

$(\mathrm{H}) \mathrm{H})(\mathrm{H}) \mathrm{H})(\mathrm{H}) \mathrm{H})(\mathrm{C}(\mathrm{H})(\mathrm{H}) \mathrm{H})(\mathrm{H}) \mathrm{H}$

$\mathrm{C}(\mathrm{C}(\mathrm{C}(\mathrm{C}(\mathrm{C}(\mathrm{C}(\mathrm{C}(\mathrm{C}(\mathrm{C}(\mathrm{C}(\mathrm{C}(\mathrm{C}(\mathrm{C}(\mathrm{C}(\mathrm{H})(\mathrm{H}) \mathrm{H})(\mathrm{H}) \mathrm{H})(\mathrm{H}) \mathrm{H})(\mathrm{H}) \mathrm{H})(\mathrm{H}) \mathrm{Cl})(\mathrm{H}) \mathrm{H})(\mathrm{H}) \mathrm{H})(\mathrm{H}) \mathrm{H})(\mathrm{H}) \mathrm{H})(\mathrm{Cl}) \mathrm{H})(\mathrm{H})$

$\mathrm{H})(\mathrm{H}) \mathrm{H})(\mathrm{H}) \mathrm{H})(\mathrm{C}(\mathrm{H})(\mathrm{H}) \mathrm{H})(\mathrm{H}) \mathrm{H}$

$\mathrm{C}(\mathrm{C}(\mathrm{C}(\mathrm{C}(\mathrm{C}(\mathrm{C}(\mathrm{C}(\mathrm{C}(\mathrm{C}(\mathrm{C}(\mathrm{C}(\mathrm{C}(\mathrm{C}(\mathrm{C}(\mathrm{H})(\mathrm{H}) \mathrm{H})(\mathrm{Br}) \mathrm{H})(\mathrm{H}) \mathrm{H})(\mathrm{H}) \mathrm{H})(\mathrm{H}) \mathrm{H})(\mathrm{H}) \mathrm{H})(\mathrm{Cl}) \mathrm{H})(\mathrm{H}) \mathrm{H})(\mathrm{H}) \mathrm{H})(\mathrm{H}) \mathrm{H})(\mathrm{H})$

$\mathrm{H})(\mathrm{H}) \mathrm{H})(\mathrm{H}) \mathrm{H})(\mathrm{C}(\mathrm{H})(\mathrm{H}) \mathrm{H})(\mathrm{H}) \mathrm{H}$

$\mathrm{C}(\mathrm{C}(\mathrm{C}(\mathrm{C}(\mathrm{C}(\mathrm{C}(\mathrm{C}(\mathrm{C}(\mathrm{C}(\mathrm{C}(\mathrm{C}(\mathrm{C}(\mathrm{C}(\mathrm{C}(\mathrm{H})(\mathrm{H}) \mathrm{H})(\mathrm{H}) \mathrm{H})(\mathrm{H}) \mathrm{Cl})(\mathrm{H}) \mathrm{H})(\mathrm{H}) \mathrm{H})(\mathrm{H}) \mathrm{H})(\mathrm{F}) \mathrm{H})(\mathrm{H}) \mathrm{H})(\mathrm{H}) \mathrm{H})(\mathrm{H}) \mathrm{H})(\mathrm{H}) \mathrm{H})$

$(\mathrm{H}) \mathrm{H})(\mathrm{H}) \mathrm{H})(\mathrm{C}(\mathrm{H})(\mathrm{H}) \mathrm{H})(\mathrm{H}) \mathrm{H}$

$\mathrm{C}\left(\mathrm{C}\left(\mathrm{C}(\mathrm{C}(\mathrm{C}(\mathrm{C}(\mathrm{C}(\mathrm{C}(\mathrm{C}(\mathrm{C}(\mathrm{C}(\mathrm{C}(\mathrm{C}(\mathrm{C}(\mathrm{H})(\mathrm{H}) \mathrm{H})(\mathrm{H}) \mathrm{H})(\mathrm{H}) \mathrm{H})(\mathrm{H}) \mathrm{H})(\mathrm{H}) \mathrm{H})(\mathrm{H}) \mathrm{H})(\mathrm{H}) \mathrm{H})(\mathrm{H}) \mathrm{H})(\mathrm{H}) \mathrm{H})(\mathrm{H}) \mathrm{F})(\mathrm{F}) \mathrm{H})\left({ }_{\mathrm{Cl}}{ }^{2} \mathrm{H}_{30} \mathrm{~F}_{2}\right.\right.\right.$

$\mathrm{H}) \mathrm{H})(\mathrm{H}) \mathrm{H})(\mathrm{C}(\mathrm{H})(\mathrm{H}) \mathrm{H})(\mathrm{H}) \mathrm{H}$

$\mathrm{C}(\mathrm{C}(\mathrm{C}(\mathrm{C}(\mathrm{C}(\mathrm{C}(\mathrm{C}(\mathrm{C}(\mathrm{C}(\mathrm{C}(\mathrm{C}(\mathrm{C}(\mathrm{C}(\mathrm{C}(\mathrm{H})(\mathrm{H}) \mathrm{H})(\mathrm{H}) \mathrm{H})(\mathrm{H}) \mathrm{H})(\mathrm{H}) \mathrm{H})(\mathrm{H}) \mathrm{H})(\mathrm{H}) \mathrm{H})(\mathrm{Br}) \mathrm{H})(\mathrm{H}) \mathrm{H})(\mathrm{H}) \mathrm{H})(\mathrm{H}) \mathrm{H})$

$(\mathrm{H}) \mathrm{H})(\mathrm{H}) \mathrm{H})(\mathrm{H}) \mathrm{H})(\mathrm{C}(\mathrm{H})(\mathrm{H}) \mathrm{H})(\mathrm{H}) \mathrm{H}$

$\mathrm{C}(\mathrm{C}(\mathrm{C}(\mathrm{C}(\mathrm{C}(\mathrm{C}(\mathrm{C}(\mathrm{C}(\mathrm{C}(\mathrm{C}(\mathrm{C}(\mathrm{C}(\mathrm{C}(\mathrm{C}(\mathrm{H})(\mathrm{H}) \mathrm{H})(\mathrm{H}) \mathrm{H})(\mathrm{H}) \mathrm{H})(\mathrm{H}) \mathrm{H})(\mathrm{H}) \mathrm{H})(\mathrm{H}) \mathrm{H})(\mathrm{H}) \mathrm{H})(\mathrm{H}) \mathrm{H})(\mathrm{H}) \mathrm{Cl})(\mathrm{H}) \mathrm{H}) \quad \mathrm{C} 15 \mathrm{H} 31 \mathrm{Cl}$

$(\mathrm{H}) \mathrm{H})(\mathrm{H}) \mathrm{H})(\mathrm{H}) \mathrm{H})(\mathrm{C}(\mathrm{H})(\mathrm{H}) \mathrm{H})(\mathrm{H}) \mathrm{H}$

$\mathrm{C}\left(\mathrm{C}\left(\mathrm{C}(\mathrm{C}(\mathrm{C}(\mathrm{C}(\mathrm{C}(\mathrm{C}(\mathrm{C}(\mathrm{C}(\mathrm{C}(\mathrm{C}(\mathrm{C}(\mathrm{C}(\mathrm{H})(\mathrm{H}) \mathrm{H})(\mathrm{H}) \mathrm{H})(\mathrm{H}) \mathrm{H})(\mathrm{H}) \mathrm{H})(\mathrm{H}) \mathrm{H})(\mathrm{H}) \mathrm{H})(\mathrm{H}) \mathrm{H})(\mathrm{F}) \mathrm{H})(\mathrm{H}) \mathrm{H})(\mathrm{H}) \mathrm{H})(\mathrm{H}) \mathrm{H}){ }_{\mathrm{C} 15 \mathrm{H} 31 \mathrm{~F}}\right.\right.$

$(\mathrm{H}) \mathrm{H})(\mathrm{H}) \mathrm{H})(\mathrm{C}(\mathrm{H})(\mathrm{H}) \mathrm{H})(\mathrm{H}) \mathrm{H}$

$\mathrm{C}(\mathrm{C}(\mathrm{C}(\mathrm{C}(\mathrm{C}(\mathrm{C}(\mathrm{C}(\mathrm{C}(\mathrm{C}(\mathrm{C}(\mathrm{C}(\mathrm{C}(\mathrm{C}(\mathrm{C}(\mathrm{C}(\mathrm{C}(\mathrm{F})(\mathrm{F}) \mathrm{H})(\mathrm{H}) \mathrm{F})(\mathrm{F}) \mathrm{H})(\mathrm{F}) \mathrm{F})(\mathrm{F}) \mathrm{F})(\mathrm{F}) \mathrm{H})(\mathrm{Br}) \mathrm{H})(\mathrm{H}) \mathrm{Br})(\mathrm{F}) \mathrm{F})(\mathrm{H}) \mathrm{H})(\mathrm{Cl})$

$\mathrm{F})(\mathrm{H}) \mathrm{F})(\mathrm{H}) \mathrm{Br})(\mathrm{H}) \mathrm{F})(\mathrm{F}) \mathrm{H})(\mathrm{H})(\mathrm{F}) \mathrm{F}$

$\mathrm{C}\left(\mathrm{C}\left(\mathrm{C}\left(\mathrm{C}\left(\mathrm{C}\left(\mathrm{C}(\mathrm{C}(\mathrm{C}(\mathrm{C}(\mathrm{C}(\mathrm{C}(\mathrm{C}(\mathrm{C}(\mathrm{C}(\mathrm{C}(\mathrm{C}(\mathrm{H})(\mathrm{F}) \mathrm{F})(\mathrm{F}) \mathrm{F})(\mathrm{H}) \mathrm{H})(\mathrm{F}) \mathrm{H})(\mathrm{Br}) \mathrm{H})(\mathrm{F}) \mathrm{H})(\mathrm{F}) \mathrm{H})(\mathrm{F}) \mathrm{F})(\mathrm{Br}) \mathrm{H})(\mathrm{F}) \mathrm{H})(\mathrm{H}){ }_{\mathrm{C} 16 \mathrm{H} 15 \mathrm{Br} 3 \mathrm{~F} 16}\right.\right.\right.\right.\right.$ $\mathrm{H})(\mathrm{F}) \mathrm{F})(\mathrm{F}) \mathrm{F})(\mathrm{H}) \mathrm{H})(\mathrm{F}) \mathrm{H})(\mathrm{H})(\mathrm{F}) \mathrm{Br}$

$\mathrm{C}(\mathrm{C}(\mathrm{C}(\mathrm{C}(\mathrm{C}(\mathrm{C}(\mathrm{C}(\mathrm{C}(\mathrm{C}(\mathrm{C}(\mathrm{C}(\mathrm{C}(\mathrm{C}(\mathrm{C}(\mathrm{C}(\mathrm{C}(\mathrm{Cl})(\mathrm{H}) \mathrm{H})(\mathrm{H}) \mathrm{Cl})(\mathrm{F}) \mathrm{F})(\mathrm{H}) \mathrm{F})(\mathrm{F}) \mathrm{H})(\mathrm{F}) \mathrm{H})(\mathrm{H}) \mathrm{Br})(\mathrm{F}) \mathrm{H})(\mathrm{F}) \mathrm{H})(\mathrm{F}) \mathrm{H})$

$(\mathrm{H}) \mathrm{H})(\mathrm{F}) \mathrm{H})(\mathrm{F}) \mathrm{F})(\mathrm{F}) \mathrm{H})(\mathrm{H}) \mathrm{Cl})(\mathrm{F})(\mathrm{Cl}) \mathrm{Cl}$

$\mathrm{C}(\mathrm{C}(\mathrm{C}(\mathrm{C}(\mathrm{C}(\mathrm{C}(\mathrm{C}(\mathrm{C}(\mathrm{C}(\mathrm{C}(\mathrm{C}(\mathrm{C}(\mathrm{C}(\mathrm{C}(\mathrm{C}(\mathrm{C}(\mathrm{F})(\mathrm{F}) \mathrm{H})(\mathrm{F}) \mathrm{H})(\mathrm{H}) \mathrm{F})(\mathrm{H}) \mathrm{F})(\mathrm{Br}) \mathrm{H})(\mathrm{F}) \mathrm{H})(\mathrm{F}) \mathrm{F})(\mathrm{H}) \mathrm{H})(\mathrm{F}) \mathrm{F})(\mathrm{F}) \mathrm{H})(\mathrm{H}) \mathrm{B}$

r) $(\mathrm{F}) \mathrm{H})(\mathrm{F}) \mathrm{F})(\mathrm{H}) \mathrm{H})(\mathrm{F}) \mathrm{H})(\mathrm{Br})(\mathrm{H}) \mathrm{H}$

$\mathrm{C}(\mathrm{C}(\mathrm{C}(\mathrm{C}(\mathrm{C}(\mathrm{C}(\mathrm{C}(\mathrm{C}(\mathrm{C}(\mathrm{C}(\mathrm{C}(\mathrm{C}(\mathrm{C}(\mathrm{C}(\mathrm{C}(\mathrm{C}(\mathrm{F})(\mathrm{H}) \mathrm{F})(\mathrm{F}) \mathrm{H})(\mathrm{F}) \mathrm{H})(\mathrm{H}) \mathrm{H})(\mathrm{F}) \mathrm{H})(\mathrm{H}) \mathrm{F})(\mathrm{F}) \mathrm{Br})(\mathrm{H}) \mathrm{H})(\mathrm{F}) \mathrm{F})(\mathrm{H}) \mathrm{H})(\mathrm{H}) \quad \mathrm{C} 16 \mathrm{H} 16 \mathrm{Cl} 2 \mathrm{Br} 3 \mathrm{~F} 1$ $\mathrm{Cl})(\mathrm{H}) \mathrm{Br})(\mathrm{F}) \mathrm{H})(\mathrm{F}) \mathrm{H})(\mathrm{Br}) \mathrm{F})(\mathrm{Cl})(\mathrm{H}) \mathrm{F}$

lgKoa lgKow lgKaw lgKow lgKoa lgKa lgKow lgKoa lgKaw EPISuit EPI EPI Exp Exp w DFT DFT DFT e Suite Suite corr_corr_Exp corr__corr_corr $\begin{array}{lllllllll}5.432 & 8.22 & 2.79 & 7.34 & 4.56 & 2.79 & 7.08 & 7.99 & -0.92\end{array}$ $\begin{array}{lllllllll}7.391 & 8.19 & 0.80 & 7.30 & 6.50 & 0.80 & 7.05 & 11.59 & -4.54\end{array}$ $\begin{array}{lllllllll}5.834 & 7.87 & 2.04 & 6.82 & 4.78 & 2.04 & 6.81 & 8.73 & -1.92\end{array}$ $\begin{array}{lllllllll}7.565 & 8.85 & 1.29 & 8.28 & 7.00 & 1.29 & 7.56 & 11.91 & -4.35\end{array}$ 
$\mathrm{C}(\mathrm{C}(\mathrm{C}(\mathrm{C}(\mathrm{C}(\mathrm{C}(\mathrm{C}(\mathrm{C}(\mathrm{C}(\mathrm{C}(\mathrm{C}(\mathrm{C}(\mathrm{C}(\mathrm{C}(\mathrm{C}(\mathrm{C}(\mathrm{H})(\mathrm{H}) \mathrm{Cl})(\mathrm{F}) \mathrm{Cl})(\mathrm{F}) \mathrm{F})(\mathrm{H}) \mathrm{H})(\mathrm{Br}) \mathrm{H})(\mathrm{H}) \mathrm{H})(\mathrm{H}) \mathrm{F})(\mathrm{F}) \mathrm{H})(\mathrm{Cl}) \mathrm{H})(\mathrm{F}) \mathrm{H})(\mathrm{C} 16 \mathrm{H} 16 \mathrm{Cl} 3 \mathrm{Br} 2 \mathrm{~F} 1$ $\mathrm{H}) \mathrm{F})(\mathrm{F}) \mathrm{F})(\mathrm{F}) \mathrm{H})(\mathrm{H}) \mathrm{Br})(\mathrm{F}) \mathrm{H})(\mathrm{F})(\mathrm{H}) \mathrm{F}$

$\mathrm{C}(\mathrm{C}(\mathrm{C}(\mathrm{C}(\mathrm{C}(\mathrm{C}(\mathrm{C}(\mathrm{C}(\mathrm{C}(\mathrm{C}(\mathrm{C}(\mathrm{C}(\mathrm{C}(\mathrm{C}(\mathrm{C}(\mathrm{C}(\mathrm{F})(\mathrm{Cl}) \mathrm{F})(\mathrm{H}) \mathrm{H})(\mathrm{F}) \mathrm{F})(\mathrm{H}) \mathrm{F})(\mathrm{F}) \mathrm{H})(\mathrm{H}) \mathrm{H})(\mathrm{H}) \mathrm{F})(\mathrm{H}) \mathrm{F})(\mathrm{F}) \mathrm{H})(\mathrm{H}) \mathrm{Cl})(\mathrm{F})$ $\mathrm{H})(\mathrm{H}) \mathrm{F})(\mathrm{H}) \mathrm{H})(\mathrm{B}$

$\mathrm{C}\left(\mathrm{C}\left(\mathrm{C}\left(\mathrm{C}\left(\mathrm{C}\left(\mathrm{C}(\mathrm{C}(\mathrm{C}(\mathrm{C}(\mathrm{C}(\mathrm{C}(\mathrm{C}(\mathrm{C}(\mathrm{C}(\mathrm{C}(\mathrm{C}(\mathrm{H})(\mathrm{Cl}) \mathrm{Cl})(\mathrm{F}) \mathrm{H})(\mathrm{H}) \mathrm{H})(\mathrm{H}) \mathrm{Cl})(\mathrm{F}) \mathrm{F})(\mathrm{Cl}) \mathrm{H})(\mathrm{H}) \mathrm{Cl})(\mathrm{H}) \mathrm{H})(\mathrm{F}) \mathrm{F})(\mathrm{F}) \mathrm{H})\left({ }_{\mathrm{C}} 16 \mathrm{H} 16 \mathrm{Cl} 5 \mathrm{~F} 13\right.\right.\right.\right.\right.\right.$ F)H $(\mathrm{H}) \mathrm{F})(\mathrm{F}) \mathrm{F})(\mathrm{H}) \mathrm{F})(\mathrm{H}) \mathrm{H})(\mathrm{H})(\mathrm{F}) \mathrm{F}$

$\mathrm{C}(\mathrm{C}(\mathrm{C}(\mathrm{C}(\mathrm{C}(\mathrm{C}(\mathrm{C}(\mathrm{C}(\mathrm{C}(\mathrm{C}(\mathrm{C}(\mathrm{C}(\mathrm{C}(\mathrm{C}(\mathrm{C}(\mathrm{C}(\mathrm{F})(\mathrm{H}) \mathrm{H})(\mathrm{Cl}) \mathrm{H})(\mathrm{F}) \mathrm{H})(\mathrm{Cl}) \mathrm{H})(\mathrm{F}) \mathrm{H})(\mathrm{F}) \mathrm{H})(\mathrm{H}) \mathrm{Cl})(\mathrm{Br}) \mathrm{F})(\mathrm{H}) \mathrm{F})(\mathrm{H}) \mathrm{F})($ $\mathrm{H}) \mathrm{F})(\mathrm{H}) \mathrm{Cl}(\mathrm{H}) \mathrm{Cl})(\mathrm{H}) \mathrm{F})(\mathrm{H}) \mathrm{Cl}(\mathrm{H})(\mathrm{F}) \mathrm{F}$

$\mathrm{C}(\mathrm{C}(\mathrm{C}(\mathrm{C}(\mathrm{C}(\mathrm{C}(\mathrm{C}(\mathrm{C}(\mathrm{C}(\mathrm{C}(\mathrm{C}(\mathrm{C}(\mathrm{C}(\mathrm{C}(\mathrm{C}(\mathrm{C}(\mathrm{F})(\mathrm{F}) \mathrm{F})(\mathrm{H}) \mathrm{F})(\mathrm{F}) \mathrm{H})(\mathrm{H}) \mathrm{H})(\mathrm{Cl}) \mathrm{Cl})(\mathrm{Cl}) \mathrm{H})(\mathrm{F}) \mathrm{H})(\mathrm{H}) \mathrm{Cl})(\mathrm{F}) \mathrm{H})(\mathrm{H}) \mathrm{H})($

$\mathrm{Cl}) \mathrm{H})(\mathrm{H}) \mathrm{F})(\mathrm{F}) \mathrm{H})(\mathrm{F}) \mathrm{F})(\mathrm{H}) \mathrm{Cl}(\mathrm{F})(\mathrm{H}) \mathrm{H}$

$\mathrm{C}(\mathrm{C}(\mathrm{C}(\mathrm{C}(\mathrm{C}(\mathrm{C}(\mathrm{C}(\mathrm{C}(\mathrm{C}(\mathrm{C}(\mathrm{C}(\mathrm{C}(\mathrm{C}(\mathrm{C}(\mathrm{C}(\mathrm{C}(\mathrm{F})(\mathrm{F}) \mathrm{H})(\mathrm{H}) \mathrm{F})(\mathrm{F}) \mathrm{F})(\mathrm{F}) \mathrm{F})(\mathrm{F}) \mathrm{H})(\mathrm{F}) \mathrm{F})(\mathrm{H}) \mathrm{H})(\mathrm{Cl}) \mathrm{H})(\mathrm{F}) \mathrm{F})(\mathrm{H}) \mathrm{H})(\mathrm{F}) \mathrm{H})$ $(\mathrm{H}) \mathrm{Br})(\mathrm{H}) \mathrm{F})(\mathrm{H}) \mathrm{F})(\mathrm{H}) \mathrm{Br})(\mathrm{H})(\mathrm{H}) \mathrm{H}$

$\mathrm{C}(\mathrm{C}(\mathrm{C}(\mathrm{C}(\mathrm{C}(\mathrm{C}(\mathrm{C}(\mathrm{C}(\mathrm{C}(\mathrm{C}(\mathrm{C}(\mathrm{C}(\mathrm{C}(\mathrm{C}(\mathrm{C}(\mathrm{C}(\mathrm{H})(\mathrm{H}) \mathrm{Cl})(\mathrm{Br}) \mathrm{F})(\mathrm{H}) \mathrm{F})(\mathrm{Br}) \mathrm{H})(\mathrm{F}) \mathrm{F})(\mathrm{H}) \mathrm{Br})(\mathrm{H}) \mathrm{F})(\mathrm{H}) \mathrm{H})(\mathrm{F}) \mathrm{H})(\mathrm{H}) \mathrm{H})($ $\mathrm{H}) \mathrm{F})(\mathrm{F}) \mathrm{F})(\mathrm{F}) \mathrm{H})(\mathrm{H}) \mathrm{F})(\mathrm{H}) \mathrm{F})(\mathrm{F})(\mathrm{F}) \mathrm{H}$

C16H16ClBr3F14

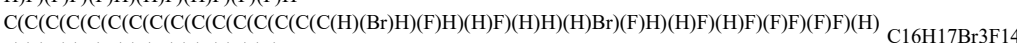

$\mathrm{F})(\mathrm{F}) \mathrm{H})(\mathrm{Br}) \mathrm{H})(\mathrm{H}) \mathrm{H})(\mathrm{F}) \mathrm{F})(\mathrm{H})(\mathrm{H}) \mathrm{F}$

$\mathrm{C}(\mathrm{C}(\mathrm{C}(\mathrm{C}(\mathrm{C}(\mathrm{C}(\mathrm{C}(\mathrm{C}(\mathrm{C}(\mathrm{C}(\mathrm{C}(\mathrm{C}(\mathrm{C}(\mathrm{C}(\mathrm{C}(\mathrm{C}(\mathrm{H})(\mathrm{F}) \mathrm{H})(\mathrm{H}) \mathrm{F})(\mathrm{F}) \mathrm{H})(\mathrm{Br}) \mathrm{H})(\mathrm{H}) \mathrm{F})(\mathrm{H}) \mathrm{H})(\mathrm{Br}) \mathrm{F})(\mathrm{F}) \mathrm{H})(\mathrm{H}) \mathrm{H})(\mathrm{Br}) \mathrm{F})($

$\mathrm{F}) \mathrm{F})(\mathrm{Br}) \mathrm{H})(\mathrm{H}) \mathrm{H})(\mathrm{F}) \mathrm{H})(\mathrm{H}) \mathrm{F})(\mathrm{F})(\mathrm{H}) \mathrm{F}$

$\mathrm{C}(\mathrm{C}(\mathrm{C}(\mathrm{C}(\mathrm{C}(\mathrm{C}(\mathrm{C}(\mathrm{C}(\mathrm{C}(\mathrm{C}(\mathrm{C}(\mathrm{C}(\mathrm{C}(\mathrm{C}(\mathrm{C}(\mathrm{C}(\mathrm{H})(\mathrm{F}) \mathrm{H})(\mathrm{F}) \mathrm{H})(\mathrm{Cl}) \mathrm{H})(\mathrm{H}) \mathrm{F})(\mathrm{H}) \mathrm{H})(\mathrm{H}) \mathrm{F})(\mathrm{Cl}) \mathrm{H})(\mathrm{F}) \mathrm{H})(\mathrm{H}) \mathrm{H})(\mathrm{H}) \mathrm{F})$

$(\mathrm{F}) \mathrm{Cl})(\mathrm{H}) \mathrm{H})(\mathrm{H}) \mathrm{F})(\mathrm{H}) \mathrm{F})(\mathrm{F}) \mathrm{F})(\mathrm{Br})(\mathrm{Cl}) \mathrm{F}$

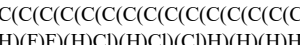

(C) $(\mathrm{C}(\mathrm{C}(\mathrm{C}(\mathrm{C}(\mathrm{C}(\mathrm{C}(\mathrm{C}(\mathrm{C}(\mathrm{C}(\mathrm{C}(\mathrm{C}(\mathrm{C}(\mathrm{C}(\mathrm{C}(\mathrm{F})(\mathrm{F}) \mathrm{F})(\mathrm{F}) \mathrm{H})(\mathrm{H}) \mathrm{H})(\mathrm{F}) \mathrm{H})(\mathrm{Br}) \mathrm{Cl})(\mathrm{H}) \mathrm{F})(\mathrm{Br}) \mathrm{F})(\mathrm{F}) \mathrm{H})(\mathrm{F}) \mathrm{H})(\mathrm{H}) \mathrm{F})(\mathrm{H})$

$\mathrm{F})(\mathrm{H}) \mathrm{H})(\mathrm{F}) \mathrm{H})(\mathrm{H}) \mathrm{F})(\mathrm{H}) \mathrm{H})(\mathrm{F})(\mathrm{H}) \mathrm{H}$

$\mathrm{C}\left(\mathrm{C}\left(\mathrm{C}\left(\mathrm{C}\left(\mathrm{C}\left(\mathrm{C}(\mathrm{C}(\mathrm{C}(\mathrm{C}(\mathrm{C}(\mathrm{C}(\mathrm{C}(\mathrm{C}(\mathrm{C}(\mathrm{C}(\mathrm{C}(\mathrm{Cl})(\mathrm{Br}) \mathrm{H})(\mathrm{F}) \mathrm{H})(\mathrm{F}) \mathrm{F})(\mathrm{H}) \mathrm{H})(\mathrm{F}) \mathrm{H})(\mathrm{Br}) \mathrm{F})(\mathrm{H}) \mathrm{F})(\mathrm{F}) \mathrm{F})(\mathrm{F}) \mathrm{H})(\mathrm{H}) \mathrm{F})(\mathrm{F}){ }_{\mathrm{C} 16 \mathrm{H} 17 \mathrm{ClBr} 3 \mathrm{~F} 13}\right.\right.\right.\right.\right.$ $\mathrm{H})(\mathrm{H}) \mathrm{H})(\mathrm{H}) \mathrm{H})(\mathrm{F}) \mathrm{H})(\mathrm{Br}) \mathrm{H})(\mathrm{H})(\mathrm{H}) \mathrm{F}$

$\mathrm{C}(\mathrm{C}(\mathrm{C}(\mathrm{C}(\mathrm{C}(\mathrm{C}(\mathrm{C}(\mathrm{C}(\mathrm{C}(\mathrm{C}(\mathrm{C}(\mathrm{C}(\mathrm{C}(\mathrm{C}(\mathrm{C}(\mathrm{C}(\mathrm{F})(\mathrm{H}) \mathrm{F})(\mathrm{H}) \mathrm{F})(\mathrm{H}) \mathrm{Cl})(\mathrm{F}) \mathrm{H})(\mathrm{F}) \mathrm{Br})(\mathrm{H}) \mathrm{H})(\mathrm{H}) \mathrm{H})(\mathrm{H}) \mathrm{Br})(\mathrm{H}) \mathrm{Cl})(\mathrm{H}) \mathrm{F})(\mathrm{C} 16 \mathrm{H} 18 \mathrm{Cl} 3 \mathrm{Br} 2 \mathrm{~F} 1$

$\mathrm{H}) \mathrm{H})(\mathrm{F}) \mathrm{Cl}(\mathrm{F}) \mathrm{H})(\mathrm{H}) \mathrm{F})(\mathrm{H}) \mathrm{H})(\mathrm{F})(\mathrm{F}) \mathrm{H}$

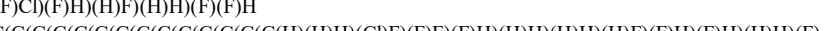

$\mathrm{H})(\mathrm{H}) \mathrm{F})(\mathrm{H}) \mathrm{F})(\mathrm{Cl}) \mathrm{F})(\mathrm{H}) \mathrm{F})(\mathrm{Cl})(\mathrm{H}) \mathrm{Cl}$

$\mathrm{C}(\mathrm{C}(\mathrm{C}(\mathrm{C}(\mathrm{C}(\mathrm{C}(\mathrm{C}(\mathrm{C}(\mathrm{C}(\mathrm{C}(\mathrm{C}(\mathrm{C}(\mathrm{C}(\mathrm{C}(\mathrm{C}(\mathrm{C}(\mathrm{F})(\mathrm{F}) \mathrm{F})(\mathrm{H}) \mathrm{H})(\mathrm{H}) \mathrm{F})(\mathrm{H}) \mathrm{H})(\mathrm{H}) \mathrm{F})(\mathrm{Br}) \mathrm{H})(\mathrm{F}) \mathrm{F})(\mathrm{H}) \mathrm{H})(\mathrm{H}) \mathrm{H})(\mathrm{Br}) \mathrm{H}) \quad \mathrm{C} 16 \mathrm{H} 18 \mathrm{ClBr} 2 \mathrm{~F} 13$

$(\mathrm{F}) \mathrm{H})(\mathrm{F}) \mathrm{F})(\mathrm{H}) \mathrm{F})(\mathrm{H}) \mathrm{H})(\mathrm{Cl}) \mathrm{H})(\mathrm{F})(\mathrm{F}) \mathrm{H}$

$\mathrm{C}\left(\mathrm{C}\left(\mathrm{C}\left(\mathrm{C}\left(\mathrm{C}\left(\mathrm{C}(\mathrm{C}(\mathrm{C}(\mathrm{C}(\mathrm{C}(\mathrm{C}(\mathrm{C}(\mathrm{C}(\mathrm{C}(\mathrm{C}(\mathrm{C}(\mathrm{F})(\mathrm{F}) \mathrm{H})(\mathrm{F}) \mathrm{H})(\mathrm{H}) \mathrm{H})(\mathrm{H}) \mathrm{Br})(\mathrm{F}) \mathrm{H})(\mathrm{Br}) \mathrm{H})(\mathrm{H}) \mathrm{H})(\mathrm{F}) \mathrm{H})(\mathrm{F}) \mathrm{H})(\mathrm{F}) \mathrm{F})\left(\mathrm{B}{ }_{\mathrm{C} 16 \mathrm{H} 18 \mathrm{ClBr} 3 \mathrm{~F} 12}\right.\right.\right.\right.\right.\right.$ r)F)(F)H $(\mathrm{H}) \mathrm{H})(\mathrm{Cl}) \mathrm{F})(\mathrm{H}) \mathrm{H})(\mathrm{H})(\mathrm{H}) \mathrm{F}$

$\mathrm{C}\left(\mathrm{C}\left(\mathrm{C}\left(\mathrm{C}\left(\mathrm{C}\left(\mathrm{C}(\mathrm{C}(\mathrm{C}(\mathrm{C}(\mathrm{C}(\mathrm{C}(\mathrm{C}(\mathrm{C}(\mathrm{C}(\mathrm{C}(\mathrm{C}(\mathrm{F})(\mathrm{F}) \mathrm{H})(\mathrm{F}) \mathrm{H})(\mathrm{Br}) \mathrm{F})(\mathrm{F}) \mathrm{H})(\mathrm{F}) \mathrm{F})(\mathrm{H}) \mathrm{H})(\mathrm{H}) \mathrm{H})(\mathrm{F}) \mathrm{Br})(\mathrm{H}) \mathrm{H})(\mathrm{H}) \mathrm{H})(\mathrm{F}){ }_{\mathrm{C} 16 \mathrm{H} 19 \mathrm{Br} 3 \mathrm{~F} 12}\right.\right.\right.\right.\right.$

$\mathrm{H})(\mathrm{H}) \mathrm{F})(\mathrm{H}) \mathrm{H})(\mathrm{H}) \mathrm{H})(\mathrm{F}) \mathrm{H})(\mathrm{F})(\mathrm{H}) \mathrm{Br}$

$\mathrm{C}\left(\mathrm{C}\left(\mathrm{C}\left(\mathrm{C}\left(\mathrm{C}\left(\mathrm{C}(\mathrm{C}(\mathrm{C}(\mathrm{C}(\mathrm{C}(\mathrm{C}(\mathrm{C}(\mathrm{C}(\mathrm{C}(\mathrm{C}(\mathrm{C}(\mathrm{Br})(\mathrm{H}) \mathrm{H})(\mathrm{F}) \mathrm{H})(\mathrm{F}) \mathrm{H})(\mathrm{H}) \mathrm{F})(\mathrm{H}) \mathrm{H})(\mathrm{F}) \mathrm{H})(\mathrm{H}) \mathrm{H})(\mathrm{F}) \mathrm{H})(\mathrm{F}) \mathrm{H})(\mathrm{H}) \mathrm{H})\left(\mathrm{B}{ }_{\mathrm{C} 16 \mathrm{H} 19 \mathrm{Br} 4 \mathrm{~F} 11}\right.\right.\right.\right.\right.\right.$

r)H)(F)F)(F)H $(\mathrm{H}) \mathrm{Br})(\mathrm{H}) \mathrm{F})(\mathrm{H})(\mathrm{F}) \mathrm{Br}$

$\mathrm{C}\left(\mathrm{C}\left(\mathrm{C}\left(\mathrm{C}\left(\mathrm{C}\left(\mathrm{C}(\mathrm{C}(\mathrm{C}(\mathrm{C}(\mathrm{C}(\mathrm{C}(\mathrm{C}(\mathrm{C}(\mathrm{C}(\mathrm{C}(\mathrm{C}(\mathrm{Br})(\mathrm{F}) \mathrm{H})(\mathrm{F}) \mathrm{F})(\mathrm{F}) \mathrm{H})(\mathrm{F}) \mathrm{H})(\mathrm{H}) \mathrm{F})(\mathrm{H}) \mathrm{H})(\mathrm{F}) \mathrm{H})(\mathrm{H}) \mathrm{H})(\mathrm{Cl}) \mathrm{F})(\mathrm{H}) \mathrm{F})(\mathrm{H}) \mathrm{Cl}^{2}\right.\right.\right.\right.\right.$ H $19 \mathrm{Cl} 2 \mathrm{Br} 2 \mathrm{~F} 1$ $\mathrm{Cl}(\mathrm{H}) \mathrm{Br})(\mathrm{H}) \mathrm{F})(\mathrm{H}) \mathrm{H})(\mathrm{H}) \mathrm{H})(\mathrm{F})(\mathrm{H}) \mathrm{H}$

$\mathrm{C}\left(\mathrm{C}\left(\mathrm{C}\left(\mathrm{C}\left(\mathrm{C}\left(\mathrm{C}(\mathrm{C}(\mathrm{C}(\mathrm{C}(\mathrm{C}(\mathrm{C}(\mathrm{C}(\mathrm{C}(\mathrm{C}(\mathrm{C}(\mathrm{C}(\mathrm{F})(\mathrm{H}) \mathrm{Cl})(\mathrm{F}) \mathrm{F})(\mathrm{F}) \mathrm{H})(\mathrm{Br}) \mathrm{H})(\mathrm{H}) \mathrm{H})(\mathrm{H}) \mathrm{H})(\mathrm{H}) \mathrm{F})(\mathrm{H}) \mathrm{H})(\mathrm{H}) \mathrm{H})(\mathrm{H}) \mathrm{H})\left({ }_{\mathrm{C}} 16 \mathrm{H} 19 \mathrm{Cl} 2 \mathrm{BrF} 12\right.\right.\right.\right.\right.\right.$ $\mathrm{H}) \mathrm{F})(\mathrm{Cl}) \mathrm{F})(\mathrm{F}) \mathrm{F})(\mathrm{H}) \mathrm{F})(\mathrm{H}) \mathrm{H})(\mathrm{F})(\mathrm{F}) \mathrm{H}$

$\mathrm{C}\left(\mathrm{C}\left(\mathrm{C}\left(\mathrm{C}\left(\mathrm{C}\left(\mathrm{C}(\mathrm{C}(\mathrm{C}(\mathrm{C}(\mathrm{C}(\mathrm{C}(\mathrm{C}(\mathrm{C}(\mathrm{C}(\mathrm{C}(\mathrm{C}(\mathrm{Cl})(\mathrm{H}) \mathrm{H})(\mathrm{F}) \mathrm{Cl})(\mathrm{H}) \mathrm{H})(\mathrm{H}) \mathrm{H})(\mathrm{H}) \mathrm{F})(\mathrm{H}) \mathrm{F})(\mathrm{F}) \mathrm{H})(\mathrm{F}) \mathrm{F})(\mathrm{F}) \mathrm{H})(\mathrm{H}) \mathrm{F})(\mathrm{H}){ }_{\mathrm{C} 16 \mathrm{H} 19 \mathrm{Cl} 3 \mathrm{BrF} 11}\right.\right.\right.\right.\right.$

$\mathrm{F})(\mathrm{Cl}) \mathrm{Br})(\mathrm{H}) \mathrm{F})(\mathrm{H}) \mathrm{H})(\mathrm{H}) \mathrm{H})(\mathrm{F})(\mathrm{H}) \mathrm{H}$

$\mathrm{C}(\mathrm{C}(\mathrm{C}(\mathrm{C}(\mathrm{C}(\mathrm{C}(\mathrm{C}(\mathrm{C}(\mathrm{C}(\mathrm{C}(\mathrm{C}(\mathrm{C}(\mathrm{C}(\mathrm{C}(\mathrm{C}(\mathrm{C}(\mathrm{H})(\mathrm{H}) \mathrm{Cl})(\mathrm{F}) \mathrm{F})(\mathrm{F}) \mathrm{H})(\mathrm{F}) \mathrm{Cl})(\mathrm{H}) \mathrm{H})(\mathrm{H}) \mathrm{F})(\mathrm{H}) \mathrm{H})(\mathrm{F}) \mathrm{F})(\mathrm{H}) \mathrm{F})(\mathrm{H}) \mathrm{H}) \quad \mathrm{C} 16 \mathrm{H} 19 \mathrm{Cl} 4 \mathrm{~F} 11$

$(\mathrm{Cl}) \mathrm{H})(\mathrm{H}) \mathrm{Cl})(\mathrm{F}) \mathrm{H})(\mathrm{H}) \mathrm{H})(\mathrm{H}) \mathrm{H})(\mathrm{F})(\mathrm{F}) \mathrm{H}$

$\mathrm{C}\left(\mathrm{C}\left(\mathrm{C}\left(\mathrm{C}\left(\mathrm{C}\left(\mathrm{C}(\mathrm{C}(\mathrm{C}(\mathrm{C}(\mathrm{C}(\mathrm{C}(\mathrm{C}(\mathrm{C}(\mathrm{C}(\mathrm{C}(\mathrm{C}(\mathrm{F})(\mathrm{H}) \mathrm{F})(\mathrm{H}) \mathrm{H})(\mathrm{H}) \mathrm{F})(\mathrm{F}) \mathrm{H})(\mathrm{F}) \mathrm{Br})(\mathrm{F}) \mathrm{H})(\mathrm{H}) \mathrm{H})(\mathrm{H}) \mathrm{F})(\mathrm{H}) \mathrm{F})(\mathrm{H}) \mathrm{F})(\mathrm{F}) \quad{ }^{\mathrm{C}} 16 \mathrm{H} 19 \mathrm{ClBr} 2 \mathrm{~F} 12\right.\right.\right.\right.\right.$

$\mathrm{H})(\mathrm{H}) \mathrm{H})(\mathrm{Cl}) \mathrm{H})(\mathrm{H}) \mathrm{H})(\mathrm{H}) \mathrm{H})(\mathrm{Br})(\mathrm{F}) \mathrm{F}$

$\mathrm{C}(\mathrm{C}(\mathrm{C}(\mathrm{C}(\mathrm{C}(\mathrm{C}(\mathrm{C}(\mathrm{C}(\mathrm{C}(\mathrm{C}(\mathrm{C}(\mathrm{C}(\mathrm{C}(\mathrm{C}(\mathrm{C}(\mathrm{C}(\mathrm{H})(\mathrm{H}) \mathrm{H})(\mathrm{Br}) \mathrm{H})(\mathrm{H}) \mathrm{H})(\mathrm{H}) \mathrm{F})(\mathrm{Br}) \mathrm{F})(\mathrm{F}) \mathrm{H})(\mathrm{F}) \mathrm{Cl})(\mathrm{H}) \mathrm{F})(\mathrm{H}) \mathrm{H})(\mathrm{F}) \mathrm{H})($ $\mathrm{H}) \mathrm{F})(\mathrm{H}) \mathrm{F})(\mathrm{H}) \mathrm{H})(\mathrm{F}) \mathrm{H})(\mathrm{H}) \mathrm{F})(\mathrm{F})(\mathrm{Br}) \mathrm{H}$

$\mathrm{C}(\mathrm{C}(\mathrm{C}(\mathrm{C}(\mathrm{C}(\mathrm{C}(\mathrm{C}(\mathrm{C}(\mathrm{C}(\mathrm{C}(\mathrm{C}(\mathrm{C}(\mathrm{C}(\mathrm{C}(\mathrm{C}(\mathrm{C}(\mathrm{F})(\mathrm{H}) \mathrm{F})(\mathrm{F}) \mathrm{H})(\mathrm{F}) \mathrm{F})(\mathrm{H}) \mathrm{F})(\mathrm{H}) \mathrm{H})(\mathrm{Br}) \mathrm{Br})(\mathrm{H}) \mathrm{H})(\mathrm{H}) \mathrm{H})(\mathrm{H}) \mathrm{H})(\mathrm{H}) \mathrm{F})$

$(\mathrm{F}) \mathrm{H})(\mathrm{H}) \mathrm{H})(\mathrm{H}) \mathrm{H})(\mathrm{H}) \mathrm{H})(\mathrm{F}) \mathrm{F})(\mathrm{F})(\mathrm{F}) \mathrm{H}$

$\mathrm{C}(\mathrm{C}(\mathrm{C}(\mathrm{C}(\mathrm{C}(\mathrm{C}(\mathrm{C}(\mathrm{C}(\mathrm{C}(\mathrm{C}(\mathrm{C}(\mathrm{C}(\mathrm{C}(\mathrm{C}(\mathrm{C}(\mathrm{C}(\mathrm{F})(\mathrm{F}) \mathrm{H})(\mathrm{F}) \mathrm{F})(\mathrm{Br}) \mathrm{Br})(\mathrm{H}) \mathrm{F})(\mathrm{H}) \mathrm{F})(\mathrm{H}) \mathrm{H})(\mathrm{H}) \mathrm{F})(\mathrm{H}) \mathrm{F})(\mathrm{H}) \mathrm{F})(\mathrm{Br}) \mathrm{H})$

$(\mathrm{H}) \mathrm{F})(\mathrm{H}) \mathrm{H})(\mathrm{F}) \mathrm{H})(\mathrm{H}) \mathrm{H})(\mathrm{H}) \mathrm{H})(\mathrm{H})(\mathrm{H}) \mathrm{H}$

$\mathrm{C}(\mathrm{C}(\mathrm{C}(\mathrm{C}(\mathrm{C}(\mathrm{C}(\mathrm{C}(\mathrm{C}(\mathrm{C}(\mathrm{C}(\mathrm{C}(\mathrm{C}(\mathrm{C}(\mathrm{C}(\mathrm{C}(\mathrm{C}(\mathrm{F})(\mathrm{H}) \mathrm{Cl})(\mathrm{Cl}) \mathrm{H})(\mathrm{F}) \mathrm{F})(\mathrm{F}) \mathrm{H})(\mathrm{H}) \mathrm{F})(\mathrm{H}) \mathrm{F})(\mathrm{H}) \mathrm{H})(\mathrm{F}) \mathrm{H})(\mathrm{H}) \mathrm{H})(\mathrm{F}) \mathrm{Br})(\mathrm{F})$

$\mathrm{H})(\mathrm{H}) \mathrm{H})(\mathrm{H}) \mathrm{H})(\mathrm{H}) \mathrm{H})(\mathrm{H}) \mathrm{H})(\mathrm{H})(\mathrm{F}) \mathrm{Cl}$

C(C(C(C(C(C(C(C)(C(C(C(C(C)(C(C(C(Br)(H)H)(F)H)(H)H)(H)H)(H)F)(F)H)(F)H)(H)F)(H)H)(H)F

$(\mathrm{Cl}) \mathrm{H})(\mathrm{F}) \mathrm{H})(\mathrm{Cl}) \mathrm{H})(\mathrm{H}) \mathrm{F})(\mathrm{Cl}) \mathrm{Cl})(\mathrm{H})(\mathrm{H}) \mathrm{F}$

$\mathrm{C}(\mathrm{C}(\mathrm{C}(\mathrm{C}(\mathrm{C}(\mathrm{C}(\mathrm{C}(\mathrm{C}(\mathrm{C}(\mathrm{C}(\mathrm{C}(\mathrm{C}(\mathrm{C}(\mathrm{C}(\mathrm{C}(\mathrm{C}(\mathrm{Cl})(\mathrm{F}) \mathrm{H})(\mathrm{H}) \mathrm{H})(\mathrm{H}) \mathrm{F})(\mathrm{H}) \mathrm{F})(\mathrm{H}) \mathrm{H})(\mathrm{F}) \mathrm{H})(\mathrm{F}) \mathrm{H})(\mathrm{H}) \mathrm{H})(\mathrm{H}) \mathrm{H})(\mathrm{H}) \mathrm{H})$ $(\mathrm{F}) \mathrm{H})(\mathrm{H}) \mathrm{H})(\mathrm{Cl}) \mathrm{F})(\mathrm{H}) \mathrm{H})(\mathrm{F}) \mathrm{F})(\mathrm{Cl})(\mathrm{F}) \mathrm{Cl}$

$\mathrm{C}(\mathrm{C}(\mathrm{C}(\mathrm{C}(\mathrm{C}(\mathrm{C}(\mathrm{C}(\mathrm{C}(\mathrm{C}(\mathrm{C}(\mathrm{C}(\mathrm{C}(\mathrm{C}(\mathrm{C}(\mathrm{C}(\mathrm{C}(\mathrm{H})(\mathrm{H}) \mathrm{F})(\mathrm{F}) \mathrm{H})(\mathrm{Cl}) \mathrm{H})(\mathrm{H}) \mathrm{H})(\mathrm{F}) \mathrm{H})(\mathrm{F}) \mathrm{F})(\mathrm{H}) \mathrm{H})(\mathrm{H}) \mathrm{H})(\mathrm{F}) \mathrm{F})(\mathrm{H}) \mathrm{F})(\mathrm{H})$ $\mathrm{F})(\mathrm{H}) \mathrm{Br})(\mathrm{F}) \mathrm{H})(\mathrm{H}) \mathrm{H})(\mathrm{Br}) \mathrm{F})(\mathrm{H})(\mathrm{H}) \mathrm{H}$

$\mathrm{C}(\mathrm{C}(\mathrm{C}(\mathrm{C}(\mathrm{C}(\mathrm{C}(\mathrm{C}(\mathrm{C}(\mathrm{C}(\mathrm{C}(\mathrm{C}(\mathrm{C}(\mathrm{C}(\mathrm{C}(\mathrm{C}(\mathrm{C}(\mathrm{H})(\mathrm{F}) \mathrm{F})(\mathrm{F}) \mathrm{H})(\mathrm{H}) \mathrm{F})(\mathrm{H}) \mathrm{H})(\mathrm{F}) \mathrm{H})(\mathrm{H}) \mathrm{H})(\mathrm{H}) \mathrm{Cl})(\mathrm{F}) \mathrm{Br})(\mathrm{H}) \mathrm{F})(\mathrm{F}) \mathrm{H})(\mathrm{H})$

$\mathrm{Br})(\mathrm{H}) \mathrm{H})(\mathrm{H}) \mathrm{H})(\mathrm{H}) \mathrm{Br})(\mathrm{F}) \mathrm{H})(\mathrm{F})(\mathrm{H}) \mathrm{H}$

$\mathrm{C}(\mathrm{C}(\mathrm{C}(\mathrm{C}(\mathrm{C}(\mathrm{C}(\mathrm{C}(\mathrm{C}(\mathrm{C}(\mathrm{C}(\mathrm{C}(\mathrm{C}(\mathrm{C}(\mathrm{C}(\mathrm{C}(\mathrm{C}(\mathrm{H})(\mathrm{H}) \mathrm{H})(\mathrm{H}) \mathrm{H})(\mathrm{H}) \mathrm{H})(\mathrm{H}) \mathrm{Br})(\mathrm{F}) \mathrm{F})(\mathrm{F}) \mathrm{H})(\mathrm{Br}) \mathrm{F})(\mathrm{H}) \mathrm{F})(\mathrm{H}) \mathrm{H})(\mathrm{H}) \mathrm{H})($

$\mathrm{H}) \mathrm{H})(\mathrm{F}) \mathrm{H})(\mathrm{H}) \mathrm{F})(\mathrm{H}) \mathrm{F})(\mathrm{F}) \mathrm{H})(\mathrm{F})(\mathrm{H}) \mathrm{F}$

$\mathrm{C}(\mathrm{C}(\mathrm{C}(\mathrm{C}(\mathrm{C}(\mathrm{C}(\mathrm{C}(\mathrm{C}(\mathrm{C}(\mathrm{C}(\mathrm{C}(\mathrm{C}(\mathrm{C}(\mathrm{C}(\mathrm{C}(\mathrm{C}(\mathrm{H})(\mathrm{Cl}) \mathrm{H})(\mathrm{Br}) \mathrm{H})(\mathrm{F}) \mathrm{H})(\mathrm{F}) \mathrm{F})(\mathrm{H}) \mathrm{H})(\mathrm{H}) \mathrm{H})(\mathrm{H}) \mathrm{H})(\mathrm{H}) \mathrm{F})(\mathrm{H}) \mathrm{H})(\mathrm{H}) \mathrm{Br})($

$\mathrm{H}) \mathrm{H})(\mathrm{H}) \mathrm{F})(\mathrm{F}) \mathrm{F})(\mathrm{H}) \mathrm{Cl}(\mathrm{F}) \mathrm{H})(\mathrm{F})(\mathrm{H}) \mathrm{H}$

$\mathrm{C}(\mathrm{C}(\mathrm{C}(\mathrm{C}(\mathrm{C}(\mathrm{C}(\mathrm{C}(\mathrm{C}(\mathrm{C}(\mathrm{C}(\mathrm{C}(\mathrm{C}(\mathrm{C}(\mathrm{C}(\mathrm{C}(\mathrm{C}(\mathrm{H})(\mathrm{H}) \mathrm{H})(\mathrm{F}) \mathrm{H})(\mathrm{H}) \mathrm{H})(\mathrm{F}) \mathrm{Cl})(\mathrm{F}) \mathrm{H})(\mathrm{H}) \mathrm{Cl})(\mathrm{H}) \mathrm{H})(\mathrm{F}) \mathrm{H})(\mathrm{F}) \mathrm{F})(\mathrm{H}) \mathrm{F})(\mathrm{F})$ $\mathrm{H})(\mathrm{H}) \mathrm{H})(\mathrm{F}) \mathrm{H})(\mathrm{H}) \mathrm{H})(\mathrm{H}) \mathrm{H})(\mathrm{Cl})(\mathrm{F}) \mathrm{H}$

$\mathrm{C}(\mathrm{C}(\mathrm{C}(\mathrm{C}(\mathrm{C}(\mathrm{C}(\mathrm{C}(\mathrm{C}(\mathrm{C}(\mathrm{C}(\mathrm{C}(\mathrm{C}(\mathrm{C}(\mathrm{C}(\mathrm{C}(\mathrm{C}(\mathrm{F})(\mathrm{H}) \mathrm{F})(\mathrm{H}) \mathrm{F})(\mathrm{H}) \mathrm{H})(\mathrm{H}) \mathrm{H})(\mathrm{H}) \mathrm{H})(\mathrm{H}) \mathrm{H})(\mathrm{H}) \mathrm{F})(\mathrm{H}) \mathrm{F})(\mathrm{Cl}) \mathrm{H})(\mathrm{Cl}) \mathrm{H})$

$(\mathrm{F}) \mathrm{H})(\mathrm{H}) \mathrm{H})(\mathrm{Cl}) \mathrm{H})(\mathrm{H}) \mathrm{F})(\mathrm{H}) \mathrm{Cl})(\mathrm{F})(\mathrm{F}) \mathrm{H}$

$\mathrm{C}(\mathrm{C}(\mathrm{C}(\mathrm{C}(\mathrm{C}(\mathrm{C}(\mathrm{C}(\mathrm{C}(\mathrm{C}(\mathrm{C}(\mathrm{C}(\mathrm{C}(\mathrm{C}(\mathrm{C}(\mathrm{C}(\mathrm{C}(\mathrm{F})(\mathrm{Cl}) \mathrm{H})(\mathrm{H}) \mathrm{H})(\mathrm{Cl}) \mathrm{F})(\mathrm{H}) \mathrm{F})(\mathrm{H}) \mathrm{F})(\mathrm{H}) \mathrm{H})(\mathrm{Cl}) \mathrm{H})(\mathrm{H}) \mathrm{F})(\mathrm{H}) \mathrm{Cl})(\mathrm{H}) \mathrm{F})($

$\mathrm{H}) \mathrm{H})(\mathrm{H}) \mathrm{Cl}(\mathrm{F}) \mathrm{H})(\mathrm{F}) \mathrm{H})(\mathrm{H}) \mathrm{H})(\mathrm{H})(\mathrm{H}) \mathrm{H}$

$\mathrm{C}(\mathrm{C}(\mathrm{C}(\mathrm{C}(\mathrm{C}(\mathrm{C}(\mathrm{C}(\mathrm{C}(\mathrm{C}(\mathrm{C}(\mathrm{C}(\mathrm{C}(\mathrm{C}(\mathrm{C}(\mathrm{C}(\mathrm{C}(\mathrm{F})(\mathrm{H}) \mathrm{H})(\mathrm{H}) \mathrm{F})(\mathrm{H}) \mathrm{H})(\mathrm{H}) \mathrm{H})(\mathrm{H}) \mathrm{H})(\mathrm{H}) \mathrm{F})(\mathrm{F}) \mathrm{F})(\mathrm{F}) \mathrm{H})(\mathrm{H}) \mathrm{F})(\mathrm{H}) \mathrm{Cl})$

$(\mathrm{Br}) \mathrm{F})(\mathrm{F}) \mathrm{Br})(\mathrm{H}) \mathrm{H})(\mathrm{H}) \mathrm{F})(\mathrm{H}) \mathrm{H})(\mathrm{H})(\mathrm{H}) \mathrm{H}$

C(C(C(C(C(C(C(C(C(C(C(C(C(C(C(C(F)(H)H)(H)H)(H)F)(H)H)(F)H)(H)H)(F)H)(F)H)(H)H)(H)H

$(\mathrm{H}) \mathrm{H})(\mathrm{F}) \mathrm{F})(\mathrm{F}) \mathrm{Br})(\mathrm{H}) \mathrm{F})(\mathrm{H}) \mathrm{H})(\mathrm{H})(\mathrm{Br}) \mathrm{F}$

$\mathrm{C}(\mathrm{C}(\mathrm{C}(\mathrm{C}(\mathrm{C}(\mathrm{C}(\mathrm{C}(\mathrm{C}(\mathrm{C}(\mathrm{C}(\mathrm{C}(\mathrm{C}(\mathrm{C}(\mathrm{C}(\mathrm{C}(\mathrm{C}(\mathrm{H})(\mathrm{Br}) \mathrm{F})(\mathrm{H}) \mathrm{H})(\mathrm{H}) \mathrm{H})(\mathrm{H}) \mathrm{H})(\mathrm{H}) \mathrm{F})(\mathrm{F}) \mathrm{F})(\mathrm{H}) \mathrm{H})(\mathrm{F}) \mathrm{Br})(\mathrm{F}) \mathrm{H})(\mathrm{H}) \mathrm{H})$

$(\mathrm{F}) \mathrm{H})(\mathrm{H}) \mathrm{H})(\mathrm{F}) \mathrm{H})(\mathrm{H}) \mathrm{H})(\mathrm{H}) \mathrm{H})(\mathrm{H})(\mathrm{Br}) \mathrm{F}$

$\mathrm{C}(\mathrm{C}(\mathrm{C}(\mathrm{C}(\mathrm{C}(\mathrm{C}(\mathrm{C}(\mathrm{C}(\mathrm{C}(\mathrm{C}(\mathrm{C}(\mathrm{C}(\mathrm{C}(\mathrm{C}(\mathrm{C}(\mathrm{C}(\mathrm{Br})(\mathrm{H}) \mathrm{H})(\mathrm{H}) \mathrm{F})(\mathrm{F}) \mathrm{H})(\mathrm{F}) \mathrm{F})(\mathrm{H}) \mathrm{Cl})(\mathrm{H}) \mathrm{Cl})(\mathrm{H}) \mathrm{H})(\mathrm{H}) \mathrm{F})(\mathrm{H}) \mathrm{H})(\mathrm{H}) \mathrm{Br})($

$\mathrm{H}) \mathrm{F})(\mathrm{H}) \mathrm{H})(\mathrm{H}) \mathrm{H})(\mathrm{F}) \mathrm{H})(\mathrm{H}) \mathrm{H})(\mathrm{H})(\mathrm{H}) \mathrm{F}$

$\mathrm{C}(\mathrm{C}(\mathrm{C}(\mathrm{C}(\mathrm{C}(\mathrm{C}(\mathrm{C}(\mathrm{C}(\mathrm{C}(\mathrm{C}(\mathrm{C}(\mathrm{C}(\mathrm{C}(\mathrm{C}(\mathrm{C}(\mathrm{C}(\mathrm{F})(\mathrm{H}) \mathrm{H})(\mathrm{H}) \mathrm{H})(\mathrm{H}) \mathrm{H})(\mathrm{H}) \mathrm{H})(\mathrm{F}) \mathrm{H})(\mathrm{H}) \mathrm{H})(\mathrm{H}) \mathrm{H})(\mathrm{F}) \mathrm{F})(\mathrm{Cl}) \mathrm{H})(\mathrm{F}) \mathrm{Cl})($ $\mathrm{Br}) \mathrm{H})(\mathrm{H}) \mathrm{H})(\mathrm{F}) \mathrm{F})(\mathrm{H}) \mathrm{H})(\mathrm{H}) \mathrm{F})(\mathrm{F})(\mathrm{H}) \mathrm{H}$
Suite Suite corr_corr_Exp corr__corr_corr

$\begin{array}{lllllllll}6.949 & 9.92 & 2.97 & 9.88 & 6.91 & 2.97 & 8.38 & 10.78 & -2.40\end{array}$

$\begin{array}{lllllllll}6.373 & 9.83 & 3.46 & 9.75 & 6.29 & 3.46 & 8.31 & 9.72 & -1.41\end{array}$

$\begin{array}{lllllllll}5.798 & 9.74 & 3.94 & 9.61 & 5.67 & 3.94 & 8.24 & 8.66 & -0.42\end{array}$

$\begin{array}{lllllllll}7.026 & 8.98 & 1.95 & 8.48 & 6.52 & 1.95 & 7.66 & 10.92 & -3.26\end{array}$

$\begin{array}{lllllllll}6.87 & 10.06 & 3.19 & 10.09 & 6.90 & 3.19 & 8.49 & 10.63 & -2.14\end{array}$

$\begin{array}{lllllllll}5.484 & 9.96 & 4.48 & 9.94 & 5.46 & 4.48 & 8.41 & 8.09 & 0.33\end{array}$

$\begin{array}{lllllllll}6.461 & 9.7 & 3.24 & 9.55 & 6.31 & 3.24 & 8.21 & 9.88 & -1.67\end{array}$

$\begin{array}{lllllllll}5.829 & 9.52 & 3.69 & 9.28 & 5.59 & 3.69 & 8.07 & 8.72 & -0.65\end{array}$

$\begin{array}{lllllllll}7.465 & 9.92 & 2.45 & 9.88 & 7.43 & 2.45 & 8.38 & 11.73 & -3.34\end{array}$

$\begin{array}{lllllllll}6.812 & 9.97 & 3.16 & 9.96 & 6.80 & 3.16 & 8.42 & 10.53 & -2.11\end{array}$

$\begin{array}{lllllllll}6.487 & 9.38 & 2.89 & 9.07 & 6.18 & 2.89 & 7.97 & 9.93 & -1.96\end{array}$

$\begin{array}{lllllllll}5.253 & 9.43 & 4.18 & 9.15 & 4.97 & 4.18 & 8.01 & 7.66 & 0.34\end{array}$

$\begin{array}{lllllllll}6.89 & 9.83 & 2.94 & 9.75 & 6.81 & 2.94 & 8.31 & 10.67 & -2.36\end{array}$

$\begin{array}{lllllllll}7.075 & 9.45 & 2.37 & 9.18 & 6.80 & 2.37 & 8.02 & 11.01 & -2.99\end{array}$

$\begin{array}{lllllllll}5.523 & 9.62 & 4.10 & 9.43 & 5.34 & 4.10 & 8.15 & 8.16 & -0.01\end{array}$

$\begin{array}{lllllllll}5.681 & 9.56 & 3.88 & 9.34 & 5.46 & 3.88 & 8.10 & 8.45 & -0.34\end{array}$

$\begin{array}{lllllllll}7.319 & 9.96 & 2.64 & 9.94 & 7.30 & 2.64 & 8.41 & 11.46 & -3.04\end{array}$

$\begin{array}{lllllllll}6.686 & 9.78 & 3.09 & 9.67 & 6.58 & 3.09 & 8.27 & 10.29 & -2.02\end{array}$

$\begin{array}{lllllllll}6.853 & 8.71 & 1.86 & 8.07 & 6.22 & 1.86 & 7.45 & 10.60 & -3.15\end{array}$

$\begin{array}{lllllllll}6.441 & 9.27 & 2.83 & 8.91 & 6.08 & 2.83 & 7.88 & 9.84 & -1.96\end{array}$

$\begin{array}{lllllllll}5.545 & 9.61 & 4.06 & 9.42 & 5.35 & 4.06 & 8.14 & 8.20 & -0.06\end{array}$

$\begin{array}{lllllllll}6.607 & 9.92 & 3.31 & 9.88 & 6.57 & 3.31 & 8.38 & 10.15 & -1.77\end{array}$

$\begin{array}{lllllllll}6.031 & 9.83 & 3.80 & 9.75 & 5.95 & 3.80 & 8.31 & 9.09 & -0.78\end{array}$

$\begin{array}{lllllllll}5.37 & 8.95 & 3.58 & 8.43 & 4.85 & 3.58 & 7.64 & 7.88 & -0.24\end{array}$

$\begin{array}{lllllllll}6.938 & 9.28 & 2.34 & 8.93 & 6.58 & 2.34 & 7.89 & 10.76 & -2.87\end{array}$

$\begin{array}{lllllllll}5.477 & 9.51 & 4.03 & 9.27 & 5.24 & 4.03 & 8.07 & 8.07 & -0.01\end{array}$

$\begin{array}{lllllllll}6.304 & 9.1 & 2.80 & 8.66 & 5.86 & 2.80 & 7.75 & 9.59 & -1.84\end{array}$

$\begin{array}{lllllllll}6.295 & 9.31 & 3.01 & 8.97 & 5.96 & 3.01 & 7.91 & 9.58 & -1.66\end{array}$

$\begin{array}{lllllllll}6.617 & 8.88 & 2.26 & 8.33 & 6.07 & 2.26 & 7.58 & 10.17 & -2.59\end{array}$

$\begin{array}{lllllllll}6.46 & 9.96 & 3.50 & 9.94 & 6.44 & 3.50 & 8.41 & 9.88 & -1.47\end{array}$

$\begin{array}{lllllllll}6.469 & 9.75 & 3.28 & 9.63 & 6.35 & 3.28 & 8.25 & 9.90 & -1.64\end{array}$

$\begin{array}{lllllllll}6.705 & 8.75 & 2.04 & 8.13 & 6.09 & 2.04 & 7.48 & 10.33 & -2.85\end{array}$

$\begin{array}{lllllllll}5.095 & 8.83 & 3.74 & 8.25 & 4.52 & 3.74 & 7.54 & 7.37 & 0.17\end{array}$

$7.299 \quad 9.53$

$\begin{array}{llllllll}2.23 & 9.30 & 7.07 & 2.23 & 8.08 & 11.42 & -3.34\end{array}$

$\begin{array}{lllllllll}5.018 & 8.97 & 3.95 & 8.46 & 4.51 & 3.95 & 7.65 & 7.23 & 0.42\end{array}$

$\begin{array}{lllllllll}4.67 & 7.87 & 3.20 & 6.82 & 3.62 & 3.20 & 6.81 & 6.59 & 0.22\end{array}$

$\begin{array}{lllllllll}6.401 & 8.85 & 2.45 & 8.28 & 5.83 & 2.45 & 7.56 & 9.77 & -2.21\end{array}$

$\begin{array}{lllllllll}6.907 & 9.89 & 2.98 & 9.84 & 6.85 & 2.98 & 8.36 & 10.70 & -2.34\end{array}$

$\begin{array}{lllllllll}5.605 & 9.04 & 3.43 & 8.57 & 5.13 & 3.43 & 7.71 & 8.31 & -0.60\end{array}$

$\begin{array}{lllllllll}7.242 & 9.44 & 2.20 & 9.16 & 6.97 & 2.20 & 8.01 & 11.32 & -3.30\end{array}$

$\begin{array}{lllllllll}6.998 & 8.93 & 1.93 & 8.40 & 6.47 & 1.93 & 7.62 & 10.87 & -3.25\end{array}$

$\begin{array}{lllllllll}6.831 & 10 & 3.17 & 10.00 & 6.83 & 3.17 & 8.44 & 10.56 & -2.12\end{array}$ 
SMILE Generated

$\mathrm{C}(\mathrm{C}(\mathrm{C}(\mathrm{C}(\mathrm{C}(\mathrm{C}(\mathrm{C}(\mathrm{C}(\mathrm{C}(\mathrm{C}(\mathrm{C}(\mathrm{C}(\mathrm{C}(\mathrm{C}(\mathrm{C}(\mathrm{C}(\mathrm{H})(\mathrm{F}) \mathrm{H})(\mathrm{F}) \mathrm{H})(\mathrm{F}) \mathrm{H})(\mathrm{H}) \mathrm{H})(\mathrm{Cl}) \mathrm{F})(\mathrm{H}) \mathrm{F})(\mathrm{H}) \mathrm{H})(\mathrm{Cl}) \mathrm{F})(\mathrm{H}) \mathrm{H})(\mathrm{H}) \mathrm{H})$ (F)H)(F)H $(\mathrm{H}) \mathrm{Cl})(\mathrm{H}) \mathrm{H})(\mathrm{F}) \mathrm{H})(\mathrm{H})(\mathrm{H}) \mathrm{H}$

$\mathrm{C}(\mathrm{C}(\mathrm{C}(\mathrm{C}(\mathrm{C}(\mathrm{C}(\mathrm{C}(\mathrm{C}(\mathrm{C}(\mathrm{C}(\mathrm{C}(\mathrm{C}(\mathrm{C}(\mathrm{C}(\mathrm{C}(\mathrm{C}(\mathrm{H})(\mathrm{H}) \mathrm{H})(\mathrm{F}) \mathrm{H})(\mathrm{H}) \mathrm{Cl})(\mathrm{Br}) \mathrm{H})(\mathrm{H}) \mathrm{Cl})(\mathrm{H}) \mathrm{H})(\mathrm{F}) \mathrm{Cl})(\mathrm{H}) \mathrm{H})(\mathrm{H}) \mathrm{H})$ (H)H $(\mathrm{F}) \mathrm{H})(\mathrm{H}) \mathrm{F})(\mathrm{H}) \mathrm{F})(\mathrm{H}) \mathrm{F})(\mathrm{H}) \mathrm{H})(\mathrm{Cl})(\mathrm{F}) \mathrm{H}$

$\mathrm{C}(\mathrm{C}(\mathrm{C}(\mathrm{C}(\mathrm{C}(\mathrm{C}(\mathrm{C}(\mathrm{C}(\mathrm{C}(\mathrm{C}(\mathrm{C}(\mathrm{C}(\mathrm{C}(\mathrm{C}(\mathrm{C}(\mathrm{C}(\mathrm{H})(\mathrm{H}) \mathrm{Cl})(\mathrm{H}) \mathrm{H})(\mathrm{H}) \mathrm{Cl})(\mathrm{H}) \mathrm{F})(\mathrm{H}) \mathrm{H})(\mathrm{H}) \mathrm{H})(\mathrm{H}) \mathrm{H})(\mathrm{F}) \mathrm{F})(\mathrm{F}) \mathrm{H})(\mathrm{H}) \mathrm{H})$ $\mathrm{H}) \mathrm{H})(\mathrm{H}) \mathrm{H})(\mathrm{H}) \mathrm{F})(\mathrm{H}) \mathrm{Cl}(\mathrm{F}) \mathrm{F})(\mathrm{F})(\mathrm{H}) \mathrm{Cl}$

$\mathrm{C}(\mathrm{C}(\mathrm{C}(\mathrm{C}(\mathrm{C}(\mathrm{C}(\mathrm{C}(\mathrm{C}(\mathrm{C}(\mathrm{C}(\mathrm{C}(\mathrm{C}(\mathrm{C}(\mathrm{C}(\mathrm{C}(\mathrm{C}(\mathrm{Cl})(\mathrm{H}) \mathrm{H})(\mathrm{H}) \mathrm{F})(\mathrm{H}) \mathrm{F})(\mathrm{H}) \mathrm{H})(\mathrm{F}) \mathrm{H})(\mathrm{F}) \mathrm{H})(\mathrm{H}) \mathrm{H})(\mathrm{F}) \mathrm{H})(\mathrm{F}) \mathrm{H})(\mathrm{H}) \mathrm{H})$

$(\mathrm{H}) \mathrm{Cl}(\mathrm{H}) \mathrm{H})(\mathrm{H}) \mathrm{H})(\mathrm{H}) \mathrm{Cl})(\mathrm{Cl}) \mathrm{Cl})(\mathrm{H})(\mathrm{F}) \mathrm{H}$

$\mathrm{C}(\mathrm{C}(\mathrm{C}(\mathrm{C}(\mathrm{C}(\mathrm{C}(\mathrm{C}(\mathrm{C}(\mathrm{C}(\mathrm{C}(\mathrm{C}(\mathrm{C}(\mathrm{C}(\mathrm{C}(\mathrm{C}(\mathrm{C}(\mathrm{F})(\mathrm{H}) \mathrm{H})(\mathrm{H}) \mathrm{Cl})(\mathrm{Br}) \mathrm{H})(\mathrm{H}) \mathrm{H})(\mathrm{H}) \mathrm{H})(\mathrm{Br}) \mathrm{F})(\mathrm{H}) \mathrm{H})(\mathrm{H}) \mathrm{H})(\mathrm{H}) \mathrm{H})(\mathrm{H}) \mathrm{H})$

(F)H)(F)F)(F)F)(F)H $(\mathrm{F}) \mathrm{H})(\mathrm{H})(\mathrm{H}) \mathrm{H}$

$\mathrm{C}(\mathrm{C}(\mathrm{C}(\mathrm{C}(\mathrm{C}(\mathrm{C}(\mathrm{C}(\mathrm{C}(\mathrm{C}(\mathrm{C}(\mathrm{C}(\mathrm{C}(\mathrm{C}(\mathrm{C}(\mathrm{C}(\mathrm{C}(\mathrm{H})(\mathrm{H}) \mathrm{F})(\mathrm{H}) \mathrm{F})(\mathrm{F}) \mathrm{F})(\mathrm{H}) \mathrm{H})(\mathrm{H}) \mathrm{H})(\mathrm{H}) \mathrm{F})(\mathrm{H}) \mathrm{H})(\mathrm{H}) \mathrm{F})(\mathrm{H}) \mathrm{F})(\mathrm{H}) \mathrm{H})(\mathrm{H})$ $\mathrm{H})(\mathrm{H}) \mathrm{H})(\mathrm{H}) \mathrm{Br})(\mathrm{H}) \mathrm{H})(\mathrm{H}) \mathrm{F})(\mathrm{F})(\mathrm{H}) \mathrm{Br}$

$\mathrm{C}(\mathrm{C}(\mathrm{C}(\mathrm{C}(\mathrm{C}(\mathrm{C}(\mathrm{C}(\mathrm{C}(\mathrm{C}(\mathrm{C}(\mathrm{C}(\mathrm{C}(\mathrm{C}(\mathrm{C}(\mathrm{C}(\mathrm{C}(\mathrm{F})(\mathrm{H}) \mathrm{H})(\mathrm{Br}) \mathrm{H})(\mathrm{H}) \mathrm{F})(\mathrm{H}) \mathrm{H})(\mathrm{H}) \mathrm{Cl})(\mathrm{H}) \mathrm{H})(\mathrm{H}) \mathrm{H})(\mathrm{H}) \mathrm{F})(\mathrm{Cl}) \mathrm{H})(\mathrm{H}) \mathrm{H})($ $\mathrm{Br}) \mathrm{H})(\mathrm{F}) \mathrm{F})(\mathrm{H}) \mathrm{H})(\mathrm{H}) \mathrm{H})(\mathrm{F}) \mathrm{H})(\mathrm{H})(\mathrm{F}) \mathrm{H}$

$\mathrm{C}(\mathrm{C}(\mathrm{C}(\mathrm{C}(\mathrm{C}(\mathrm{C}(\mathrm{C}(\mathrm{C}(\mathrm{C}(\mathrm{C}(\mathrm{C}(\mathrm{C}(\mathrm{C}(\mathrm{C}(\mathrm{C}(\mathrm{C}(\mathrm{H})(\mathrm{F}) \mathrm{F})(\mathrm{H}) \mathrm{H})(\mathrm{H}) \mathrm{F})(\mathrm{H}) \mathrm{F})(\mathrm{F}) \mathrm{H})(\mathrm{H}) \mathrm{H})(\mathrm{F}) \mathrm{F})(\mathrm{H}) \mathrm{Br})(\mathrm{H}) \mathrm{H})(\mathrm{H}) \mathrm{Cl})$ $(\mathrm{H}) \mathrm{H})(\mathrm{Cl}) \mathrm{H})(\mathrm{H}) \mathrm{H})(\mathrm{H}) \mathrm{H})(\mathrm{F}) \mathrm{H})(\mathrm{H})(\mathrm{H}) \mathrm{H}$

$\mathrm{C}(\mathrm{C}(\mathrm{C}(\mathrm{C}(\mathrm{C}(\mathrm{C}(\mathrm{C}(\mathrm{C}(\mathrm{C}(\mathrm{C}(\mathrm{C}(\mathrm{C}(\mathrm{C}(\mathrm{C}(\mathrm{C}(\mathrm{C}(\mathrm{H})(\mathrm{H}) \mathrm{H})(\mathrm{H}) \mathrm{F})(\mathrm{H}) \mathrm{Cl})(\mathrm{Br}) \mathrm{H})(\mathrm{H}) \mathrm{F})(\mathrm{F}) \mathrm{H})(\mathrm{H}) \mathrm{H})(\mathrm{Cl}) \mathrm{F})(\mathrm{H}) \mathrm{H})(\mathrm{H}) \mathrm{H})($ $\mathrm{F}) \mathrm{H})(\mathrm{H}) \mathrm{Cl}(\mathrm{H}) \mathrm{H})(\mathrm{F}) \mathrm{H})(\mathrm{H}) \mathrm{F})(\mathrm{H})(\mathrm{H}) \mathrm{H}$

$\mathrm{C}(\mathrm{C}(\mathrm{C}(\mathrm{C}(\mathrm{C}(\mathrm{C}(\mathrm{C}(\mathrm{C}(\mathrm{C}(\mathrm{C}(\mathrm{C}(\mathrm{C}(\mathrm{C}(\mathrm{C}(\mathrm{C}(\mathrm{C}(\mathrm{F})(\mathrm{H}) \mathrm{H})(\mathrm{H}) \mathrm{H})(\mathrm{H}) \mathrm{F})(\mathrm{H}) \mathrm{H})(\mathrm{H}) \mathrm{H})(\mathrm{H}) \mathrm{F})(\mathrm{Cl}) \mathrm{F})(\mathrm{H}) \mathrm{H})(\mathrm{H}) \mathrm{H})(\mathrm{Cl}) \mathrm{H})($

$\mathrm{H}) \mathrm{H})(\mathrm{F}) \mathrm{H})(\mathrm{Cl}) \mathrm{H})(\mathrm{H}) \mathrm{H})(\mathrm{F}) \mathrm{F})(\mathrm{H})(\mathrm{F}) \mathrm{H}$

$\mathrm{H}) \mathrm{H})(\mathrm{F}) \mathrm{H})(\mathrm{Cl}) \mathrm{H})(\mathrm{H}) \mathrm{H})(\mathrm{F}) \mathrm{F})(\mathrm{H})(\mathrm{F}) \mathrm{H}$
$\mathrm{C}(\mathrm{C}(\mathrm{C}(\mathrm{C}(\mathrm{C}(\mathrm{C}(\mathrm{C}(\mathrm{C}(\mathrm{C}(\mathrm{C}(\mathrm{C}(\mathrm{C}(\mathrm{C}(\mathrm{C}(\mathrm{C}(\mathrm{C}(\mathrm{H})(\mathrm{F}) \mathrm{H})(\mathrm{F}) \mathrm{H})(\mathrm{H}) \mathrm{F})(\mathrm{F}) \mathrm{H})(\mathrm{Cl}) \mathrm{H})(\mathrm{H}) \mathrm{H})(\mathrm{H}) \mathrm{H})(\mathrm{H}) \mathrm{Cl})(\mathrm{Cl}) \mathrm{H})(\mathrm{H}) \mathrm{F})(\mathrm{Cl}$ $\mathrm{H}) \mathrm{H})(\mathrm{H}) \mathrm{F})(\mathrm{H}) \mathrm{H})(\mathrm{H}) \mathrm{H})(\mathrm{H}) \mathrm{H})(\mathrm{H})(\mathrm{Cl}) \mathrm{F}$

$\mathrm{C}(\mathrm{C}(\mathrm{C}(\mathrm{C}(\mathrm{C}(\mathrm{C}(\mathrm{C}(\mathrm{C}(\mathrm{C}(\mathrm{C}(\mathrm{C}(\mathrm{C}(\mathrm{C}(\mathrm{C}(\mathrm{C}(\mathrm{C}(\mathrm{F})(\mathrm{H}) \mathrm{H})(\mathrm{F}) \mathrm{H})(\mathrm{H}) \mathrm{Cl})(\mathrm{H}) \mathrm{H})(\mathrm{F}) \mathrm{H})(\mathrm{F}) \mathrm{H})(\mathrm{H}) \mathrm{Cl})(\mathrm{H}) \mathrm{Cl})(\mathrm{H}) \mathrm{H})(\mathrm{Cl}) \mathrm{H})($ $\mathrm{H}) \mathrm{H})(\mathrm{F}) \mathrm{F})(\mathrm{Cl}) \mathrm{H})(\mathrm{H}) \mathrm{H})(\mathrm{H}) \mathrm{H})(\mathrm{H})(\mathrm{H}) \mathrm{H}$

$\mathrm{C}(\mathrm{C}(\mathrm{C}(\mathrm{C}(\mathrm{C}(\mathrm{C}(\mathrm{C}(\mathrm{C}(\mathrm{C}(\mathrm{C}(\mathrm{C}(\mathrm{C}(\mathrm{C}(\mathrm{C}(\mathrm{C}(\mathrm{C}(\mathrm{H})(\mathrm{H}) \mathrm{H})(\mathrm{H}) \mathrm{H})(\mathrm{F}) \mathrm{F})(\mathrm{H}) \mathrm{H})(\mathrm{H}) \mathrm{H})(\mathrm{Cl}) \mathrm{H})(\mathrm{H}) \mathrm{H})(\mathrm{F}) \mathrm{H})(\mathrm{F}) \mathrm{F})(\mathrm{H}) \mathrm{F})$

$(\mathrm{Br}) \mathrm{H})(\mathrm{H}) \mathrm{Br})(\mathrm{H}) \mathrm{H})(\mathrm{F}) \mathrm{H})(\mathrm{H}) \mathrm{F})(\mathrm{H})(\mathrm{H}) \mathrm{H}$

C $(\mathrm{C}(\mathrm{C}(\mathrm{C}(\mathrm{C}(\mathrm{C}(\mathrm{C}(\mathrm{C}(\mathrm{C}(\mathrm{C}(\mathrm{C}(\mathrm{C}(\mathrm{C}(\mathrm{C}(\mathrm{C}(\mathrm{C}(\mathrm{H})(\mathrm{H}) \mathrm{H})(\mathrm{H}) \mathrm{H})(\mathrm{H}) \mathrm{F})(\mathrm{F}) \mathrm{F})(\mathrm{H}) \mathrm{H})(\mathrm{H}) \mathrm{F})(\mathrm{F}) \mathrm{H})(\mathrm{H}) \mathrm{H})(\mathrm{Br}) \mathrm{F})(\mathrm{H}) \mathrm{H})$

$(\mathrm{H}) \mathrm{Cl})(\mathrm{H}) \mathrm{H})(\mathrm{H}) \mathrm{F})(\mathrm{H}) \mathrm{H})(\mathrm{H}) \mathrm{H})(\mathrm{F})(\mathrm{H}) \mathrm{F}$

$\mathrm{C}(\mathrm{C}(\mathrm{C}(\mathrm{C}(\mathrm{C}(\mathrm{C}(\mathrm{C}(\mathrm{C}(\mathrm{C}(\mathrm{C}(\mathrm{C}(\mathrm{C}(\mathrm{C}(\mathrm{C}(\mathrm{C}(\mathrm{C}(\mathrm{F})(\mathrm{H}) \mathrm{F})(\mathrm{F}) \mathrm{F})(\mathrm{H}) \mathrm{H})(\mathrm{H}) \mathrm{F})(\mathrm{H}) \mathrm{F})(\mathrm{H}) \mathrm{H})(\mathrm{H}) \mathrm{H})(\mathrm{Br}) \mathrm{H})(\mathrm{H}) \mathrm{H})(\mathrm{F}) \mathrm{Br})$

$(\mathrm{F}) \mathrm{H})(\mathrm{H}) \mathrm{H})(\mathrm{H}) \mathrm{H})(\mathrm{H}) \mathrm{H})(\mathrm{H}) \mathrm{H})(\mathrm{H})(\mathrm{H}) \mathrm{H}$

$\mathrm{C}(\mathrm{C}(\mathrm{C}(\mathrm{C}(\mathrm{C}(\mathrm{C}(\mathrm{C}(\mathrm{C}(\mathrm{C}(\mathrm{C}(\mathrm{C}(\mathrm{C}(\mathrm{C}(\mathrm{C}(\mathrm{C}(\mathrm{C}(\mathrm{H})(\mathrm{H}) \mathrm{F})(\mathrm{Br}) \mathrm{H})(\mathrm{H}) \mathrm{H})(\mathrm{H}) \mathrm{H})(\mathrm{H}) \mathrm{H})(\mathrm{F}) \mathrm{H})(\mathrm{H}) \mathrm{F})(\mathrm{H}) \mathrm{H})(\mathrm{H}) \mathrm{H})(\mathrm{F}) \mathrm{F})$

$(\mathrm{H}) \mathrm{H})(\mathrm{H}) \mathrm{F})(\mathrm{H}) \mathrm{Br})(\mathrm{F}) \mathrm{H})(\mathrm{H}) \mathrm{H})(\mathrm{Br})(\mathrm{H}) \mathrm{H}$

$\mathrm{C}(\mathrm{C}(\mathrm{C}(\mathrm{C}(\mathrm{C}(\mathrm{C}(\mathrm{C}(\mathrm{C}(\mathrm{C}(\mathrm{C}(\mathrm{C}(\mathrm{C}(\mathrm{C}(\mathrm{C}(\mathrm{C}(\mathrm{C}(\mathrm{H})(\mathrm{H}) \mathrm{H})(\mathrm{F}) \mathrm{H})(\mathrm{F}) \mathrm{H})(\mathrm{H}) \mathrm{H})(\mathrm{F}) \mathrm{H})(\mathrm{H}) \mathrm{Br})(\mathrm{H}) \mathrm{H})(\mathrm{H}) \mathrm{F})(\mathrm{F}) \mathrm{H})(\mathrm{Cl}) \mathrm{H})($ $\mathrm{H}) \mathrm{H})(\mathrm{H}) \mathrm{F})(\mathrm{H}) \mathrm{H})(\mathrm{H}) \mathrm{H})(\mathrm{H}) \mathrm{H})(\mathrm{H})(\mathrm{Cl}) \mathrm{Br}$

$\mathrm{C}(\mathrm{C}(\mathrm{C}(\mathrm{C}(\mathrm{C}(\mathrm{C}(\mathrm{C}(\mathrm{C}(\mathrm{C}(\mathrm{C}(\mathrm{C}(\mathrm{C}(\mathrm{C}(\mathrm{C}(\mathrm{C}(\mathrm{C}(\mathrm{H})(\mathrm{F}) \mathrm{H})(\mathrm{H}) \mathrm{Cl})(\mathrm{H}) \mathrm{H})(\mathrm{H}) \mathrm{H})(\mathrm{H}) \mathrm{H})(\mathrm{F}) \mathrm{H})(\mathrm{H}) \mathrm{F})(\mathrm{H}) \mathrm{H})(\mathrm{H}) \mathrm{Cl})(\mathrm{F}) \mathrm{Br})($ $\mathrm{H}) \mathrm{H})(\mathrm{H}) \mathrm{H})(\mathrm{F}) \mathrm{H})(\mathrm{H}) \mathrm{H})(\mathrm{H}) \mathrm{F})(\mathrm{H})(\mathrm{F}) \mathrm{H}$

$\mathrm{C}(\mathrm{C}(\mathrm{C}(\mathrm{C}(\mathrm{C}(\mathrm{C}(\mathrm{C}(\mathrm{C}(\mathrm{C}(\mathrm{C}(\mathrm{C}(\mathrm{C}(\mathrm{C}(\mathrm{C}(\mathrm{C}(\mathrm{C}(\mathrm{H})(\mathrm{H}) \mathrm{H})(\mathrm{F}) \mathrm{F})(\mathrm{H}) \mathrm{H})(\mathrm{H}) \mathrm{H})(\mathrm{Cl}) \mathrm{F})(\mathrm{F}) \mathrm{H})(\mathrm{H}) \mathrm{H})(\mathrm{H}) \mathrm{H})(\mathrm{H}) \mathrm{Cl})(\mathrm{F}) \mathrm{F})$ $(\mathrm{H}) \mathrm{H})(\mathrm{H}) \mathrm{H})(\mathrm{H}) \mathrm{H})(\mathrm{H}) \mathrm{F})(\mathrm{H}) \mathrm{F})(\mathrm{H})(\mathrm{H}) \mathrm{H}$

$\mathrm{C}(\mathrm{C}(\mathrm{C}(\mathrm{C}(\mathrm{C}(\mathrm{C}(\mathrm{C}(\mathrm{C}(\mathrm{C}(\mathrm{C}(\mathrm{C}(\mathrm{C}(\mathrm{C}(\mathrm{C}(\mathrm{C}(\mathrm{C}(\mathrm{F})(\mathrm{Cl}) \mathrm{F})(\mathrm{H}) \mathrm{Br})(\mathrm{F}) \mathrm{H})(\mathrm{H}) \mathrm{H})(\mathrm{H}) \mathrm{H})(\mathrm{H}) \mathrm{H})(\mathrm{F}) \mathrm{H})(\mathrm{Cl}) \mathrm{H})(\mathrm{H}) \mathrm{H})(\mathrm{F}) \mathrm{H})($ $\mathrm{H}) \mathrm{H})(\mathrm{H}) \mathrm{H})(\mathrm{F}) \mathrm{H})(\mathrm{H}) \mathrm{H})(\mathrm{H}) \mathrm{Cl}(\mathrm{H})(\mathrm{H}) \mathrm{H}$

$\mathrm{C}(\mathrm{C}(\mathrm{C}(\mathrm{C}(\mathrm{C}(\mathrm{C}(\mathrm{C}(\mathrm{C}(\mathrm{C}(\mathrm{C}(\mathrm{C}(\mathrm{C}(\mathrm{C}(\mathrm{C}(\mathrm{C}(\mathrm{C}(\mathrm{H})(\mathrm{H}) \mathrm{H})(\mathrm{H}) \mathrm{H})(\mathrm{H}) \mathrm{H})(\mathrm{H}) \mathrm{F})(\mathrm{H}) \mathrm{H})(\mathrm{Cl}) \mathrm{H})(\mathrm{H}) \mathrm{H})(\mathrm{H}) \mathrm{F})(\mathrm{H}) \mathrm{F})(\mathrm{F}) \mathrm{H})($ $\mathrm{H}) \mathrm{Cl}(\mathrm{H}) \mathrm{F})(\mathrm{F}) \mathrm{H})(\mathrm{F}) \mathrm{H})(\mathrm{H}) \mathrm{H})(\mathrm{Cl})(\mathrm{H}) \mathrm{H}$

$\mathrm{C}(\mathrm{C}(\mathrm{C}(\mathrm{C}(\mathrm{C}(\mathrm{C}(\mathrm{C}(\mathrm{C}(\mathrm{C}(\mathrm{C}(\mathrm{C}(\mathrm{C}(\mathrm{C}(\mathrm{C}(\mathrm{C}(\mathrm{C}(\mathrm{F})(\mathrm{H}) \mathrm{H})(\mathrm{H}) \mathrm{H})(\mathrm{H}) \mathrm{H})(\mathrm{F}) \mathrm{F})(\mathrm{H}) \mathrm{H})(\mathrm{F}) \mathrm{H})(\mathrm{H}) \mathrm{H})(\mathrm{H}) \mathrm{F})(\mathrm{F}) \mathrm{H})(\mathrm{H}) \mathrm{H})(\mathrm{H})$ $\mathrm{H})(\mathrm{Cl}) \mathrm{H})(\mathrm{H}) \mathrm{H})(\mathrm{Cl}) \mathrm{H})(\mathrm{Cl}) \mathrm{H})(\mathrm{H})(\mathrm{Cl}) \mathrm{H}$

$\mathrm{C}(\mathrm{C}(\mathrm{C}(\mathrm{C}(\mathrm{C}(\mathrm{C}(\mathrm{C}(\mathrm{C}(\mathrm{C}(\mathrm{C}(\mathrm{C}(\mathrm{C}(\mathrm{C}(\mathrm{C}(\mathrm{C}(\mathrm{C}(\mathrm{H})(\mathrm{H}) \mathrm{F})(\mathrm{H}) \mathrm{H})(\mathrm{H}) \mathrm{F})(\mathrm{F}) \mathrm{F})(\mathrm{H}) \mathrm{Br})(\mathrm{H}) \mathrm{H})(\mathrm{H}) \mathrm{H})(\mathrm{H}) \mathrm{F})(\mathrm{H}) \mathrm{F})(\mathrm{H}) \mathrm{F})(\mathrm{H})$

$\mathrm{H})(\mathrm{Br}) \mathrm{H})(\mathrm{H}) \mathrm{H})(\mathrm{H}) \mathrm{H})(\mathrm{H}) \mathrm{Cl})(\mathrm{H})(\mathrm{H}) \mathrm{H}$

$\mathrm{C}(\mathrm{C}(\mathrm{C}(\mathrm{C}(\mathrm{C}(\mathrm{C}(\mathrm{C}(\mathrm{C}(\mathrm{C}(\mathrm{C}(\mathrm{C}(\mathrm{C}(\mathrm{C}(\mathrm{C}(\mathrm{C}(\mathrm{C}(\mathrm{H})(\mathrm{F}) \mathrm{H})(\mathrm{F}) \mathrm{F})(\mathrm{Br}) \mathrm{H})(\mathrm{H}) \mathrm{H})(\mathrm{F}) \mathrm{H})(\mathrm{H}) \mathrm{H})(\mathrm{H}) \mathrm{H})(\mathrm{H}) \mathrm{H})(\mathrm{F}) \mathrm{H})(\mathrm{F}) \mathrm{H})$

$(\mathrm{H}) \mathrm{H})(\mathrm{Br}) \mathrm{F})(\mathrm{H}) \mathrm{H})(\mathrm{H}) \mathrm{H})(\mathrm{H}) \mathrm{H})(\mathrm{H})(\mathrm{H}) \mathrm{H}$

$\mathrm{C}(\mathrm{C}(\mathrm{C}(\mathrm{C}(\mathrm{C}(\mathrm{C}(\mathrm{C}(\mathrm{C}(\mathrm{C}(\mathrm{C}(\mathrm{C}(\mathrm{C}(\mathrm{C}(\mathrm{C}(\mathrm{C}(\mathrm{C}(\mathrm{H})(\mathrm{H}) \mathrm{F})(\mathrm{F}) \mathrm{H})(\mathrm{H}) \mathrm{F})(\mathrm{H}) \mathrm{H})(\mathrm{Br}) \mathrm{H})(\mathrm{H}) \mathrm{F})(\mathrm{Cl}) \mathrm{H})(\mathrm{H}) \mathrm{H})(\mathrm{Br}) \mathrm{H})(\mathrm{H}) \mathrm{F})($ $\mathrm{H}) \mathrm{H})(\mathrm{Cl}) \mathrm{H})(\mathrm{H}) \mathrm{H})(\mathrm{H}) \mathrm{H})(\mathrm{H}) \mathrm{H})(\mathrm{H})(\mathrm{H}) \mathrm{H}$

$\mathrm{C}(\mathrm{C}(\mathrm{C}(\mathrm{C}(\mathrm{C}(\mathrm{C}(\mathrm{C}(\mathrm{C}(\mathrm{C}(\mathrm{C}(\mathrm{C}(\mathrm{C}(\mathrm{C}(\mathrm{C}(\mathrm{C}(\mathrm{C}(\mathrm{H})(\mathrm{H}) \mathrm{H})(\mathrm{F}) \mathrm{F})(\mathrm{H}) \mathrm{H})(\mathrm{F}) \mathrm{H})(\mathrm{H}) \mathrm{H})(\mathrm{H}) \mathrm{H})(\mathrm{H}) \mathrm{F})(\mathrm{H}) \mathrm{H})(\mathrm{H}) \mathrm{F})(\mathrm{Br}) \mathrm{H})$ $(\mathrm{H}) \mathrm{Cl})(\mathrm{H}) \mathrm{H})(\mathrm{H}) \mathrm{F})(\mathrm{Cl}) \mathrm{H})(\mathrm{H}) \mathrm{H})(\mathrm{H})(\mathrm{H}) \mathrm{H}$

$\mathrm{C}(\mathrm{C}(\mathrm{C}(\mathrm{C}(\mathrm{C}(\mathrm{C}(\mathrm{C}(\mathrm{C}(\mathrm{C}(\mathrm{C}(\mathrm{C}(\mathrm{C}(\mathrm{C}(\mathrm{C}(\mathrm{C}(\mathrm{C}(\mathrm{H})(\mathrm{H}) \mathrm{H})(\mathrm{H}) \mathrm{H})(\mathrm{H}) \mathrm{H})(\mathrm{F}) \mathrm{F})(\mathrm{H}) \mathrm{H})(\mathrm{Cl}) \mathrm{H})(\mathrm{H}) \mathrm{H})(\mathrm{F}) \mathrm{H})(\mathrm{F}) \mathrm{F})(\mathrm{H}) \mathrm{H})$

$(\mathrm{H}) \mathrm{H})(\mathrm{F}) \mathrm{H})(\mathrm{H}) \mathrm{H})(\mathrm{F}) \mathrm{H})(\mathrm{H}) \mathrm{H})(\mathrm{Cl})(\mathrm{H}) \mathrm{H}$

$\mathrm{C}(\mathrm{C}(\mathrm{C}(\mathrm{C}(\mathrm{C}(\mathrm{C}(\mathrm{C}(\mathrm{C}(\mathrm{C}(\mathrm{C}(\mathrm{C}(\mathrm{C}(\mathrm{C}(\mathrm{C}(\mathrm{C}(\mathrm{C}(\mathrm{H})(\mathrm{H}) \mathrm{H})(\mathrm{H}) \mathrm{F})(\mathrm{Cl}) \mathrm{H})(\mathrm{H}) \mathrm{H})(\mathrm{H}) \mathrm{F})(\mathrm{H}) \mathrm{Cl})(\mathrm{F}) \mathrm{F})(\mathrm{H}) \mathrm{H})(\mathrm{H}) \mathrm{H})(\mathrm{H}) \mathrm{F})($

$\mathrm{Br}) \mathrm{H})(\mathrm{Cl}) \mathrm{H})(\mathrm{H}) \mathrm{H})(\mathrm{H}) \mathrm{H})(\mathrm{H}) \mathrm{H})(\mathrm{H})(\mathrm{H}) \mathrm{H}$

$\mathrm{C}(\mathrm{C}(\mathrm{C}(\mathrm{C}(\mathrm{C}(\mathrm{C}(\mathrm{C}(\mathrm{C}(\mathrm{C}(\mathrm{C}(\mathrm{C}(\mathrm{C}(\mathrm{C}(\mathrm{C}(\mathrm{C}(\mathrm{C}(\mathrm{F})(\mathrm{H}) \mathrm{H})(\mathrm{H}) \mathrm{Cl})(\mathrm{H}) \mathrm{H})(\mathrm{H}) \mathrm{H})(\mathrm{H}) \mathrm{H})(\mathrm{H}) \mathrm{Cl})(\mathrm{H}) \mathrm{F})(\mathrm{F}) \mathrm{H})(\mathrm{H}) \mathrm{F})(\mathrm{H}) \mathrm{F})($ $\mathrm{H}) \mathrm{H})(\mathrm{H}) \mathrm{Cl}(\mathrm{H}) \mathrm{H})(\mathrm{H}) \mathrm{H})(\mathrm{H}) \mathrm{H})(\mathrm{H})(\mathrm{F}) \mathrm{H}$

$\mathrm{C}(\mathrm{C}(\mathrm{C}(\mathrm{C}(\mathrm{C}(\mathrm{C}(\mathrm{C}(\mathrm{C}(\mathrm{C}(\mathrm{C}(\mathrm{C}(\mathrm{C}(\mathrm{C}(\mathrm{C}(\mathrm{C}(\mathrm{C}(\mathrm{H})(\mathrm{H}) \mathrm{H})(\mathrm{H}) \mathrm{H})(\mathrm{H}) \mathrm{Cl})(\mathrm{H}) \mathrm{F})(\mathrm{H}) \mathrm{H})(\mathrm{H}) \mathrm{H})(\mathrm{H}) \mathrm{H})(\mathrm{H}) \mathrm{H})(\mathrm{F}) \mathrm{H})(\mathrm{H}) \mathrm{H})($ $\mathrm{F}) \mathrm{H})(\mathrm{H}) \mathrm{F})(\mathrm{H}) \mathrm{Cl})(\mathrm{Cl}) \mathrm{F})(\mathrm{H}) \mathrm{H})(\mathrm{H})(\mathrm{Cl}) \mathrm{H}$

$\mathrm{C}(\mathrm{C}(\mathrm{C}(\mathrm{C}(\mathrm{C}(\mathrm{C}(\mathrm{C}(\mathrm{C}(\mathrm{C}(\mathrm{C}(\mathrm{C}(\mathrm{C}(\mathrm{C}(\mathrm{C}(\mathrm{C}(\mathrm{C}(\mathrm{F})(\mathrm{H}) \mathrm{H})(\mathrm{H}) \mathrm{H})(\mathrm{Br}) \mathrm{H})(\mathrm{H}) \mathrm{H})(\mathrm{F}) \mathrm{H})(\mathrm{F}) \mathrm{H})(\mathrm{H}) \mathrm{H})(\mathrm{H}) \mathrm{F})(\mathrm{H}) \mathrm{H})(\mathrm{Cl}) \mathrm{F})($

$\mathrm{H}) \mathrm{H})(\mathrm{H}) \mathrm{H})(\mathrm{H}) \mathrm{H})(\mathrm{H}) \mathrm{H})(\mathrm{Br}) \mathrm{H})(\mathrm{F})(\mathrm{H}) \mathrm{H}$

$\mathrm{C}(\mathrm{C}(\mathrm{C}(\mathrm{C}(\mathrm{C}(\mathrm{C}(\mathrm{C}(\mathrm{C}(\mathrm{C}(\mathrm{C}(\mathrm{C}(\mathrm{C}(\mathrm{C}(\mathrm{C}(\mathrm{C}(\mathrm{C}(\mathrm{H})(\mathrm{H}) \mathrm{H})(\mathrm{H}) \mathrm{H})(\mathrm{H}) \mathrm{H})(\mathrm{F}) \mathrm{H})(\mathrm{H}) \mathrm{H})(\mathrm{H}) \mathrm{H})(\mathrm{F}) \mathrm{H})(\mathrm{H}) \mathrm{F})(\mathrm{F}) \mathrm{H})(\mathrm{H}) \mathrm{Br})$

$(\mathrm{F}) \mathrm{H})(\mathrm{H}) \mathrm{H})(\mathrm{H}) \mathrm{F})(\mathrm{H}) \mathrm{H})(\mathrm{F}) \mathrm{H})(\mathrm{H})(\mathrm{Cl}) \mathrm{H}$

$\mathrm{C}(\mathrm{C}(\mathrm{C}(\mathrm{C}(\mathrm{C}(\mathrm{C}(\mathrm{C}(\mathrm{C}(\mathrm{C}(\mathrm{C}(\mathrm{C}(\mathrm{C}(\mathrm{C}(\mathrm{C}(\mathrm{C}(\mathrm{C}(\mathrm{F})(\mathrm{F}) \mathrm{H})(\mathrm{H}) \mathrm{F})(\mathrm{H}) \mathrm{H})(\mathrm{H}) \mathrm{Br})(\mathrm{H}) \mathrm{H})(\mathrm{H}) \mathrm{H})(\mathrm{H}) \mathrm{H})(\mathrm{F}) \mathrm{H})(\mathrm{H}) \mathrm{H})(\mathrm{H}) \mathrm{H})($ $\mathrm{H}) \mathrm{H})(\mathrm{Br}) \mathrm{H})(\mathrm{F}) \mathrm{H})(\mathrm{H}) \mathrm{F})(\mathrm{H}) \mathrm{H})(\mathrm{H})(\mathrm{H}) \mathrm{H}$

$\mathrm{C}(\mathrm{C}(\mathrm{C}(\mathrm{C}(\mathrm{C}(\mathrm{C}(\mathrm{C}(\mathrm{C}(\mathrm{C}(\mathrm{C}(\mathrm{C}(\mathrm{C}(\mathrm{C}(\mathrm{C}(\mathrm{C}(\mathrm{C}(\mathrm{F})(\mathrm{H}) \mathrm{H})(\mathrm{Br}) \mathrm{H})(\mathrm{H}) \mathrm{H})(\mathrm{H}) \mathrm{Br})(\mathrm{H}) \mathrm{H})(\mathrm{H}) \mathrm{H})(\mathrm{H}) \mathrm{H})(\mathrm{H}) \mathrm{F})(\mathrm{Br}) \mathrm{H})$

$(\mathrm{H}) \mathrm{H})(\mathrm{H}) \mathrm{H})(\mathrm{H}) \mathrm{H})(\mathrm{H}) \mathrm{H})(\mathrm{H}) \mathrm{H})(\mathrm{H}) \mathrm{F})(\mathrm{H})(\mathrm{F}) \mathrm{F}$

$\mathrm{C}(\mathrm{C}(\mathrm{C}(\mathrm{C}(\mathrm{C}(\mathrm{C}(\mathrm{C}(\mathrm{C}(\mathrm{C}(\mathrm{C}(\mathrm{C}(\mathrm{C}(\mathrm{C}(\mathrm{C}(\mathrm{C}(\mathrm{C}(\mathrm{Cl})(\mathrm{H}) \mathrm{H})(\mathrm{H}) \mathrm{F})(\mathrm{H}) \mathrm{H})(\mathrm{H}) \mathrm{H})(\mathrm{H}) \mathrm{H})(\mathrm{H}) \mathrm{H})(\mathrm{H}) \mathrm{H})(\mathrm{Br}) \mathrm{H})(\mathrm{H}) \mathrm{H})(\mathrm{Cl}) \mathrm{H})$ $(\mathrm{H}) \mathrm{H})(\mathrm{H}) \mathrm{H})(\mathrm{H}) \mathrm{H})(\mathrm{H}) \mathrm{F})(\mathrm{F}) \mathrm{F})(\mathrm{F})(\mathrm{H}) \mathrm{H}$

$\mathrm{C}(\mathrm{C}(\mathrm{C}(\mathrm{C}(\mathrm{C}(\mathrm{C}(\mathrm{C}(\mathrm{C}(\mathrm{C}(\mathrm{C}(\mathrm{C}(\mathrm{C}(\mathrm{C}(\mathrm{C}(\mathrm{C}(\mathrm{C}(\mathrm{H})(\mathrm{F}) \mathrm{H})(\mathrm{H}) \mathrm{H})(\mathrm{F}) \mathrm{F})(\mathrm{F}) \mathrm{H})(\mathrm{H}) \mathrm{H})(\mathrm{H}) \mathrm{H})(\mathrm{H}) \mathrm{H})(\mathrm{H}) \mathrm{H})(\mathrm{F}) \mathrm{H})(\mathrm{H}) \mathrm{H})$

$(\mathrm{Cl}) \mathrm{H})(\mathrm{Cl}) \mathrm{F})(\mathrm{H}) \mathrm{H})(\mathrm{H}) \mathrm{H})(\mathrm{H}) \mathrm{H})(\mathrm{H})(\mathrm{H}) \mathrm{H}$

$\mathrm{C}(\mathrm{C}(\mathrm{C}(\mathrm{C}(\mathrm{C}(\mathrm{C}(\mathrm{C}(\mathrm{C}(\mathrm{C}(\mathrm{C}(\mathrm{C}(\mathrm{C}(\mathrm{C}(\mathrm{C}(\mathrm{C}(\mathrm{C}(\mathrm{H})(\mathrm{H}) \mathrm{H})(\mathrm{H}) \mathrm{H})(\mathrm{Cl}) \mathrm{H})(\mathrm{H}) \mathrm{H})(\mathrm{H}) \mathrm{F})(\mathrm{H}) \mathrm{H})(\mathrm{F}) \mathrm{H})(\mathrm{H}) \mathrm{F})(\mathrm{H}) \mathrm{H})(\mathrm{F}) \mathrm{H})($

$\mathrm{H}) \mathrm{H})(\mathrm{H}) \mathrm{H})(\mathrm{H}) \mathrm{H})(\mathrm{Cl}) \mathrm{H})(\mathrm{H}) \mathrm{Cl}(\mathrm{F})(\mathrm{H}) \mathrm{H}$

$\mathrm{C}(\mathrm{C}(\mathrm{C}(\mathrm{C}(\mathrm{C}(\mathrm{C}(\mathrm{C}(\mathrm{C}(\mathrm{C}(\mathrm{C}(\mathrm{C}(\mathrm{C}(\mathrm{C}(\mathrm{C}(\mathrm{C}(\mathrm{C}(\mathrm{H})(\mathrm{H}) \mathrm{H})(\mathrm{H}) \mathrm{H})(\mathrm{H}) \mathrm{H})(\mathrm{H}) \mathrm{H})(\mathrm{H}) \mathrm{H})(\mathrm{Br}) \mathrm{H})(\mathrm{H}) \mathrm{H})(\mathrm{H}) \mathrm{H})(\mathrm{H}) \mathrm{F})(\mathrm{F}) \mathrm{H})($ $\mathrm{H}) \mathrm{H})(\mathrm{F}) \mathrm{H})(\mathrm{H}) \mathrm{Br})(\mathrm{H}) \mathrm{H})(\mathrm{H}) \mathrm{F})(\mathrm{H})(\mathrm{Cl}) \mathrm{F}$

$\mathrm{C}(\mathrm{C}(\mathrm{C}(\mathrm{C}(\mathrm{C}(\mathrm{C}(\mathrm{C}(\mathrm{C}(\mathrm{C}(\mathrm{C}(\mathrm{C}(\mathrm{C}(\mathrm{C}(\mathrm{C}(\mathrm{C}(\mathrm{C}(\mathrm{H})(\mathrm{H}) \mathrm{F})(\mathrm{H}) \mathrm{H})(\mathrm{H}) \mathrm{H})(\mathrm{H}) \mathrm{H})(\mathrm{H}) \mathrm{Br})(\mathrm{H}) \mathrm{H})(\mathrm{H}) \mathrm{H})(\mathrm{H}) \mathrm{H})(\mathrm{F}) \mathrm{H})(\mathrm{F}) \mathrm{H})($ $\mathrm{H}) \mathrm{H})(\mathrm{H}) \mathrm{H})(\mathrm{F}) \mathrm{F})(\mathrm{H}) \mathrm{Cl})(\mathrm{H}) \mathrm{H})(\mathrm{F})(\mathrm{H}) \mathrm{H}$

$\mathrm{C}(\mathrm{C}(\mathrm{C}(\mathrm{C}(\mathrm{C}(\mathrm{C}(\mathrm{C}(\mathrm{C}(\mathrm{C}(\mathrm{C}(\mathrm{C}(\mathrm{C}(\mathrm{C}(\mathrm{C}(\mathrm{C}(\mathrm{C}(\mathrm{H})(\mathrm{H}) \mathrm{H})(\mathrm{H}) \mathrm{H})(\mathrm{H}) \mathrm{H})(\mathrm{F}) \mathrm{H})(\mathrm{H}) \mathrm{H})(\mathrm{H}) \mathrm{Br})(\mathrm{H}) \mathrm{F})(\mathrm{H}) \mathrm{H})(\mathrm{H}) \mathrm{H})(\mathrm{H}) \mathrm{Br})$ $(\mathrm{H}) \mathrm{H})(\mathrm{H}) \mathrm{F})(\mathrm{H}) \mathrm{F})(\mathrm{H}) \mathrm{F})(\mathrm{H}) \mathrm{H})(\mathrm{H})(\mathrm{H}) \mathrm{H}$

C(C $(\mathrm{C}(\mathrm{C}(\mathrm{C}(\mathrm{C}(\mathrm{C}(\mathrm{C}(\mathrm{C}(\mathrm{C}(\mathrm{C}(\mathrm{C}(\mathrm{C}(\mathrm{C}(\mathrm{C}(\mathrm{C}(\mathrm{Br})(\mathrm{H}) \mathrm{H})(\mathrm{H}) \mathrm{H})(\mathrm{H}) \mathrm{H})(\mathrm{H}) \mathrm{H})(\mathrm{H}) \mathrm{F})(\mathrm{H}) \mathrm{H})(\mathrm{H}) \mathrm{H})(\mathrm{F}) \mathrm{H})(\mathrm{H}) \mathrm{H})(\mathrm{H}) \mathrm{H})(\mathrm{C}$

$\mathrm{F}) \mathrm{F})(\mathrm{H}) \mathrm{H})(\mathrm{F}) \mathrm{H})(\mathrm{H}) \mathrm{H})(\mathrm{H}) \mathrm{F})(\mathrm{H})(\mathrm{H}) \mathrm{H}$

$\mathrm{C}(\mathrm{C}(\mathrm{C}(\mathrm{C}(\mathrm{C}(\mathrm{C}(\mathrm{C}(\mathrm{C}(\mathrm{C}(\mathrm{C}(\mathrm{C}(\mathrm{C}(\mathrm{C}(\mathrm{C}(\mathrm{C}(\mathrm{C}(\mathrm{H})(\mathrm{H}) \mathrm{F})(\mathrm{H}) \mathrm{H})(\mathrm{H}) \mathrm{H})(\mathrm{H}) \mathrm{H})(\mathrm{H}) \mathrm{H})(\mathrm{Cl}) \mathrm{H})(\mathrm{H}) \mathrm{Br})(\mathrm{H}) \mathrm{H})(\mathrm{F}) \mathrm{Cl})(\mathrm{H}) \mathrm{H})$ $(\mathrm{H}) \mathrm{F})(\mathrm{H}) \mathrm{H})(\mathrm{H}) \mathrm{H})(\mathrm{F}) \mathrm{H})(\mathrm{H}) \mathrm{H})(\mathrm{H})(\mathrm{H}) \mathrm{H}$
$\mathrm{C} 16 \mathrm{H} 22 \mathrm{Cl} 3 \mathrm{~F} 9$

lgKoa lgKow lgKaw lgKow lgKoa lgKa lgKow lgKoa lgKaw EPISuit EPI EPI Exp Exp w DFT DFT DFT e Suite Suite corr_corr_Exp corr_corr_corr $\begin{array}{lllllllll}5.447 & 9.1 & 3.65 & 8.66 & 5.00 & 3.65 & 7.75 & 8.02 & -0.27\end{array}$

$\mathrm{C} 16 \mathrm{H} 22 \mathrm{Cl} 4 \mathrm{BrF} 7$

$$
7.41
$$

$6.588 \quad 9.49$

$\begin{array}{lllllll}1.66 & 8.63 & 6.96 & 1.66 & 7.74 & 11.63 & -3.90\end{array}$

$\mathrm{C} 16 \mathrm{H} 22 \mathrm{Cl} 4 \mathrm{~F} 8$

$\mathrm{C} 16 \mathrm{H} 22 \mathrm{Cl} 5 \mathrm{~F} 7$

$\mathrm{C} 16 \mathrm{H} 22 \mathrm{ClBr} 2 \mathrm{Fg}$

$\mathrm{C} 16 \mathrm{H} 23 \mathrm{Br} 2 \mathrm{~F} 9$

$\mathrm{C} 16 \mathrm{H} 23 \mathrm{Cl} 2 \mathrm{Br} 2 \mathrm{~F} 7$

C16H23Cl2BrF8

$\mathrm{C} 16 \mathrm{H} 23 \mathrm{Cl} 3 \mathrm{BrF} 7$

$\mathrm{C} 16 \mathrm{H} 23 \mathrm{Cl} 3 \mathrm{~F} 8$

C16H23Cl4F7

$\mathrm{C} 16 \mathrm{H} 23 \mathrm{Cl} 5 \mathrm{~F} 6$

$\mathrm{C} 16 \mathrm{H} 23 \mathrm{ClBr} 2 \mathrm{~F} 8$

C16H23ClBrF9

$\mathrm{C} 16 \mathrm{H} 24 \mathrm{Br} 2 \mathrm{~F} 8$

$\mathrm{C} 16 \mathrm{H} 24 \mathrm{Br} 3 \mathrm{~F} 7$

16H24Cl2Br2F6

$\mathrm{C} 16 \mathrm{H} 24 \mathrm{Cl} 2 \mathrm{BrF} 7$

$\mathrm{C} 16 \mathrm{H} 24 \mathrm{Cl} 2 \mathrm{~F} 8$

$\mathrm{C} 16 \mathrm{H} 24 \mathrm{Cl} 3 \mathrm{BrF} 6$

$\mathrm{C} 16 \mathrm{H} 24 \mathrm{Cl} 3 \mathrm{~F} 7$

$\mathrm{C} 16 \mathrm{H} 24 \mathrm{Cl} 4 \mathrm{~F} 6$

$\mathrm{C} 16 \mathrm{H} 24 \mathrm{ClBr} 2 \mathrm{~F} 7$

$\mathrm{C} 16 \mathrm{H} 25 \mathrm{Cl} 2 \mathrm{Br} 2 \mathrm{~F} 5$

$\mathrm{C} 16 \mathrm{H} 25 \mathrm{Cl} 2 \mathrm{BrF} 6$

$\mathrm{C} 16 \mathrm{H} 25 \mathrm{Cl} 2 \mathrm{~F} 7$

$\mathrm{C} 16 \mathrm{H} 25 \mathrm{Cl} 3 \mathrm{BrF}$

C16H25Cl3F6

$\mathrm{C} 16 \mathrm{H} 25 \mathrm{Cl} 4 \mathrm{~F} 5$

$\mathrm{C} 16 \mathrm{H} 25 \mathrm{ClBr} 2 \mathrm{~F} 6$

$\mathrm{C} 16 \mathrm{H} 25 \mathrm{ClBrF} 7$

$\mathrm{C} 16 \mathrm{H} 26 \mathrm{Br} 2 \mathrm{~F} 6$

$\mathrm{C} 16 \mathrm{H} 26 \mathrm{Br} 3 \mathrm{~F} 5$

$\mathrm{C} 16 \mathrm{H} 26 \mathrm{Cl} 2 \mathrm{BrF}$

C16H26Cl2F6

$\mathrm{C} 16 \mathrm{H} 26 \mathrm{Cl} 3 \mathrm{~F} 5$

$\mathrm{C} 16 \mathrm{H} 26 \mathrm{ClBr} 2 \mathrm{~F}$

$\mathrm{C} 16 \mathrm{H} 26 \mathrm{ClBrF} 6$

$\mathrm{C} 16 \mathrm{H} 27 \mathrm{Br} 2 \mathrm{~F} 5$

$\mathrm{C} 16 \mathrm{H} 27 \mathrm{BrF} 6$

$\mathrm{Cl} 16 \mathrm{H} 27 \mathrm{Cl} 2 \mathrm{BrF}$

$\begin{array}{lllllllll}6.909 & 9.06 & 2.15 & 8.60 & 6.45 & 2.15 & 7.72 & 10.70 & -2.98\end{array}$

$\begin{array}{lllllllll}7.337 & 10.02 & 2.68 & 10.03 & 7.35 & 2.68 & 8.46 & 11.49 & -3.03\end{array}$

$\begin{array}{lllllllll}5.293 & 8.43 & 3.14 & 7.66 & 4.52 & 3.14 & 7.24 & 7.74 & -0.50\end{array}$

$\begin{array}{lllllllll}7.427 & 9.06 & 1.63 & 8.60 & 6.96 & 1.63 & 7.72 & 11.66 & -3.93\end{array}$

$\begin{array}{lllllllll}5.711 & 8.58 & 2.87 & 7.88 & 5.01 & 2.87 & 7.35 & 8.50 & -1.15\end{array}$

$\begin{array}{lllllllll}6.702 & 8.82 & 2.12 & 8.24 & 6.12 & 2.12 & 7.54 & 10.32 & -2.79\end{array}$

$\begin{array}{lllllllll}5.955 & 9.31 & 3.35 & 8.97 & 5.62 & 3.35 & 7.91 & 8.95 & -1.04\end{array}$

$\begin{array}{lllllllll}5.537 & 8.14 & 2.60 & 7.22 & 4.62 & 2.60 & 7.01 & 8.18 & -1.17\end{array}$

$\begin{array}{lllllllll}7.268 & 9.12 & 1.85 & 8.69 & 6.83 & 1.85 & 7.77 & 11.36 & -3.60\end{array}$

$\begin{array}{lllllllll}6.955 & 9.34 & 2.38 & 9.01 & 6.63 & 2.38 & 7.94 & 10.79 & -2.85\end{array}$

$\begin{array}{lllllllll}5.39 & 9.01 & 3.62 & 8.52 & 4.90 & 3.62 & 7.68 & 7.91 & -0.23\end{array}$

$\begin{array}{lllllllll}6.393 & 9.23 & 2.84 & 8.85 & 6.01 & 2.84 & 7.85 & 9.76 & -1.90\end{array}$

$\begin{array}{lllllllll}7.369 & 8.97 & 1.60 & 8.46 & 6.86 & 1.60 & 7.65 & 11.55 & -3.90\end{array}$

$\begin{array}{lllllllll}7.046 & 8.38 & 1.33 & 7.58 & 6.25 & 1.33 & 7.20 & 10.96 & -3.76\end{array}$

$\begin{array}{lllllllll}6.219 & 8.79 & 2.57 & 8.19 & 5.62 & 2.57 & 7.51 & 9.44 & -1.92\end{array}$

$\begin{array}{lllllllll}5.913 & 9.72 & 3.81 & 9.58 & 5.77 & 3.81 & 8.23 & 8.87 & -0.65\end{array}$

$\begin{array}{lllllllll}7.212 & 9.03 & 1.82 & 8.55 & 6.73 & 1.82 & 7.70 & 11.26 & -3.56\end{array}$

$\begin{array}{lllllllll}4.824 & 7.88 & 3.06 & 6.84 & 3.78 & 3.06 & 6.81 & 6.87 & -0.06\end{array}$

$\begin{array}{lllllllll}6.706 & 9.01 & 2.30 & 8.52 & 6.22 & 2.30 & 7.68 & 10.33 & -2.65\end{array}$

$\begin{array}{lllllllll}6.714 & 8.8 & 2.09 & 8.21 & 6.12 & 2.09 & 7.52 & 10.35 & -2.82\end{array}$

$\begin{array}{lllllllll}6.821 & 9.36 & 2.54 & 9.04 & 6.51 & 2.54 & 7.95 & 10.54 & -2.59\end{array}$

$\begin{array}{lllllllll}7.475 & 8.51 & 1.03 & 7.78 & 6.74 & 1.03 & 7.30 & 11.74 & -4.45\end{array}$

$\begin{array}{lllllllll}6.498 & 8.77 & 2.27 & 8.16 & 5.89 & 2.27 & 7.50 & 9.95 & -2.45\end{array}$

$\begin{array}{lllllllll}5.68 & 9.19 & 3.51 & 8.79 & 5.28 & 3.51 & 7.82 & 8.45 & -0.63\end{array}$

$\begin{array}{lllllllll}7.569 & 9.09 & 1.52 & 8.64 & 7.12 & 1.52 & 7.74 & 11.92 & -4.17\end{array}$

$\begin{array}{lllllllll}5.332 & 8.09 & 2.76 & 7.15 & 4.39 & 2.76 & 6.98 & 7.81 & -0.83\end{array}$

$\begin{array}{lllllllll}7.064 & 9.07 & 2.01 & 8.61 & 6.61 & 2.01 & 7.73 & 10.99 & -3.26\end{array}$

$\begin{array}{lllllllll}7.222 & 9.01 & 1.79 & 8.52 & 6.73 & 1.79 & 7.68 & 11.28 & -3.60\end{array}$

$\begin{array}{lllllllll}4.765 & 7.79 & 3.02 & 6.70 & 3.68 & 3.02 & 6.75 & 6.77 & -0.02\end{array}$

$\begin{array}{lllllllll}5.78 & 8.02 & 2.24 & 7.04 & 4.80 & 2.24 & 6.92 & 8.63 & -1.71\end{array}$

$\begin{array}{lllllllll}7.488 & 8.49 & 1.00 & 7.75 & 6.74 & 1.00 & 7.28 & 11.77 & -4.48\end{array}$

$\begin{array}{lllllllll}7.077 & 9.05 & 1.97 & 8.58 & 6.61 & 1.97 & 7.71 & 11.01 & -3.30\end{array}$

$\begin{array}{lllllllll}6.11 & 9.32 & 3.21 & 8.99 & 5.77 & 3.21 & 7.92 & 9.24 & -1.32\end{array}$

$\begin{array}{lllllllll}5.691 & 8.15 & 2.46 & 7.24 & 4.78 & 2.46 & 7.02 & 8.47 & -1.44\end{array}$

$\begin{array}{lllllllll}6.842 & 8.33 & 1.49 & 7.51 & 6.02 & 1.49 & 7.16 & 10.58 & -3.42\end{array}$

$\begin{array}{lllllllll}6.015 & 8.74 & 2.73 & 8.12 & 5.39 & 2.73 & 7.47 & 9.06 & -1.59\end{array}$

$\begin{array}{lllllllll}6.128 & 8.07 & 1.94 & 7.12 & 5.18 & 1.94 & 6.96 & 9.27 & -2.31\end{array}$

$\begin{array}{lllllllll}5.311 & 8.49 & 3.18 & 7.75 & 4.57 & 3.18 & 7.28 & 7.77 & -0.49\end{array}$

$\begin{array}{lllllllll}7.434 & 9.11 & 1.68 & 8.67 & 7.00 & 1.68 & 7.76 & 11.67 & -3.91\end{array}$ 
$\mathrm{C}(\mathrm{C}(\mathrm{C}(\mathrm{C}(\mathrm{C}(\mathrm{C}(\mathrm{C}(\mathrm{C}(\mathrm{C}(\mathrm{C}(\mathrm{C}(\mathrm{C}(\mathrm{C}(\mathrm{C}(\mathrm{C}(\mathrm{C}(\mathrm{H})(\mathrm{H}) \mathrm{H})(\mathrm{H}) \mathrm{H})(\mathrm{Cl}) \mathrm{H})(\mathrm{F}) \mathrm{H})(\mathrm{H}) \mathrm{H})(\mathrm{H}) \mathrm{H})(\mathrm{F}) \mathrm{F})(\mathrm{H}) \mathrm{H})(\mathrm{H}) \mathrm{Cl})(\mathrm{H}) \mathrm{F})(\mathrm{C} 16 \mathrm{H} 27 \mathrm{Cl} 2 \mathrm{~F} 5$
$\mathrm{H}) \mathrm{H})(\mathrm{H}) \mathrm{H})(\mathrm{H}) \mathrm{H})(\mathrm{H}) \mathrm{H})(\mathrm{H}) \mathrm{H})(\mathrm{H})(\mathrm{F}) \mathrm{H}$ $\mathrm{H}) \mathrm{H})(\mathrm{H}) \mathrm{H})(\mathrm{H}) \mathrm{H})(\mathrm{H}) \mathrm{H})(\mathrm{H}) \mathrm{H})(\mathrm{H})(\mathrm{F}) \mathrm{H}$

$\mathrm{C}\left(\mathrm{C}\left(\mathrm{C}\left(\mathrm{C}\left(\mathrm{C}\left(\mathrm{C}(\mathrm{C}(\mathrm{C}(\mathrm{C}(\mathrm{C}(\mathrm{C}(\mathrm{C}(\mathrm{C}(\mathrm{C}(\mathrm{C}(\mathrm{C}(\mathrm{Cl})(\mathrm{H}) \mathrm{H})(\mathrm{H}) \mathrm{F})(\mathrm{H}) \mathrm{H})(\mathrm{F}) \mathrm{Cl})(\mathrm{H}) \mathrm{H})(\mathrm{H}) \mathrm{H})(\mathrm{H}) \mathrm{H})(\mathrm{H}) \mathrm{H})(\mathrm{H}) \mathrm{H})(\mathrm{H}) \mathrm{H})\left({ }_{\mathrm{C} 16 \mathrm{H} 27 \mathrm{Cl} 3 \mathrm{~F}}\right.\right.\right.\right.\right.\right.$ $\mathrm{H}) \mathrm{H})(\mathrm{Cl}) \mathrm{H})(\mathrm{H}) \mathrm{H})(\mathrm{H}) \mathrm{F})(\mathrm{H}) \mathrm{H})(\mathrm{F})(\mathrm{H}) \mathrm{H}$

$\mathrm{C}(\mathrm{C}(\mathrm{C}(\mathrm{C}(\mathrm{C}(\mathrm{C}(\mathrm{C}(\mathrm{C}(\mathrm{C}(\mathrm{C}(\mathrm{C}(\mathrm{C}(\mathrm{C}(\mathrm{C}(\mathrm{C}(\mathrm{C}(\mathrm{F})(\mathrm{H}) \mathrm{H})(\mathrm{H}) \mathrm{H})(\mathrm{H}) \mathrm{H})(\mathrm{Br}) \mathrm{F})(\mathrm{F}) \mathrm{H})(\mathrm{H}) \mathrm{H})(\mathrm{F}) \mathrm{H})(\mathrm{H}) \mathrm{H})(\mathrm{H}) \mathrm{H})(\mathrm{H}) \mathrm{H})(\mathrm{C}$ 6 $6 \mathrm{H} 27 \mathrm{ClBrF} 5$ $\mathrm{H}) \mathrm{H})(\mathrm{Cl}) \mathrm{H})(\mathrm{H}) \mathrm{H})(\mathrm{H}) \mathrm{H})(\mathrm{H}) \mathrm{H})(\mathrm{H})(\mathrm{F}) \mathrm{H}$

$\mathrm{C}\left(\mathrm{C}\left(\mathrm{C}\left(\mathrm{C}\left(\mathrm{C}\left(\mathrm{C}(\mathrm{C}(\mathrm{C}(\mathrm{C}(\mathrm{C}(\mathrm{C}(\mathrm{C}(\mathrm{C}(\mathrm{C}(\mathrm{C}(\mathrm{C}(\mathrm{H})(\mathrm{H}) \mathrm{F})(\mathrm{H}) \mathrm{Cl})(\mathrm{H}) \mathrm{H})(\mathrm{H}) \mathrm{H})(\mathrm{H}) \mathrm{H})(\mathrm{H}) \mathrm{H})(\mathrm{F}) \mathrm{H})(\mathrm{H}) \mathrm{H})(\mathrm{H}) \mathrm{H})(\mathrm{H}) \mathrm{H})\left({ }_{\mathrm{C} 16 \mathrm{H} 27 \mathrm{ClF} 6}\right.\right.\right.\right.\right.\right.$ $\mathrm{H}) \mathrm{H}(\mathrm{H}) \mathrm{H})(\mathrm{F}) \mathrm{F})(\mathrm{H}) \mathrm{H})(\mathrm{F}) \mathrm{H})(\mathrm{F})(\mathrm{H}) \mathrm{H}$

$\mathrm{C}\left(\mathrm{C}\left(\mathrm{C}\left(\mathrm{C}\left(\mathrm{C}\left(\mathrm{C}(\mathrm{C}(\mathrm{C}(\mathrm{C}(\mathrm{C}(\mathrm{C}(\mathrm{C}(\mathrm{C}(\mathrm{C}(\mathrm{C}(\mathrm{C}(\mathrm{H})(\mathrm{H}) \mathrm{H})(\mathrm{H}) \mathrm{H})(\mathrm{F}) \mathrm{H})(\mathrm{Br}) \mathrm{H})(\mathrm{H}) \mathrm{H})(\mathrm{H}) \mathrm{H})(\mathrm{F}) \mathrm{H})(\mathrm{H}) \mathrm{H})(\mathrm{Br}) \mathrm{H})(\mathrm{H}) \mathrm{H}){ }_{\mathrm{C} 16 \mathrm{H} 28 \mathrm{Br} 2 \mathrm{~F} 4}\right.\right.\right.\right.\right.$ $(\mathrm{H}) \mathrm{H})(\mathrm{H}) \mathrm{H})(\mathrm{H}) \mathrm{H})(\mathrm{H}) \mathrm{H})(\mathrm{F}) \mathrm{H})(\mathrm{H})(\mathrm{F}) \mathrm{H}$

$\mathrm{C}(\mathrm{C}(\mathrm{C}(\mathrm{C}(\mathrm{C}(\mathrm{C}(\mathrm{C}(\mathrm{C}(\mathrm{C}(\mathrm{C}(\mathrm{C}(\mathrm{C}(\mathrm{C}(\mathrm{C}(\mathrm{C}(\mathrm{C}(\mathrm{H})(\mathrm{H}) \mathrm{F})(\mathrm{H}) \mathrm{H})(\mathrm{H}) \mathrm{H})(\mathrm{H}) \mathrm{H})(\mathrm{H}) \mathrm{H})(\mathrm{F}) \mathrm{H})(\mathrm{Br}) \mathrm{H})(\mathrm{H}) \mathrm{H})(\mathrm{H}) \mathrm{H})(\mathrm{H}) \mathrm{H})(\mathrm{C} 16 \mathrm{H} 28 \mathrm{BrF} 5$ $\mathrm{H}) \mathrm{H})(\mathrm{H}) \mathrm{H})(\mathrm{H}) \mathrm{F})(\mathrm{H}) \mathrm{H})(\mathrm{H}) \mathrm{F})(\mathrm{F})(\mathrm{H}) \mathrm{H}$

$\mathrm{C}(\mathrm{C}(\mathrm{C}(\mathrm{C}(\mathrm{C}(\mathrm{C}(\mathrm{C}(\mathrm{C}(\mathrm{C}(\mathrm{C}(\mathrm{C}(\mathrm{C}(\mathrm{C}(\mathrm{C}(\mathrm{C}(\mathrm{C}(\mathrm{H})(\mathrm{H}) \mathrm{F})(\mathrm{Cl}) \mathrm{H})(\mathrm{H}) \mathrm{H})(\mathrm{H}) \mathrm{H})(\mathrm{H}) \mathrm{H})(\mathrm{H}) \mathrm{H})(\mathrm{Br}) \mathrm{H})(\mathrm{H}) \mathrm{H})(\mathrm{F}) \mathrm{H})(\mathrm{H}) \mathrm{Cl})$ $(\mathrm{H}) \mathrm{H})(\mathrm{H}) \mathrm{H})(\mathrm{H}) \mathrm{H})(\mathrm{H}) \mathrm{H})(\mathrm{F}) \mathrm{H})(\mathrm{H})(\mathrm{H}) \mathrm{H}$

$\mathrm{Cl}) \mathrm{F})(\mathrm{H}) \mathrm{H})(\mathrm{H}) \mathrm{H})(\mathrm{H}) \mathrm{H})(\mathrm{H}) \mathrm{H})(\mathrm{H})(\mathrm{H}) \mathrm{H}$

$\mathrm{C}(\mathrm{C}(\mathrm{C}(\mathrm{C}(\mathrm{C}(\mathrm{C}(\mathrm{C}(\mathrm{C}(\mathrm{C}(\mathrm{C}(\mathrm{C}(\mathrm{C}(\mathrm{C}(\mathrm{C}(\mathrm{C}(\mathrm{C}(\mathrm{H})(\mathrm{Cl}) \mathrm{H})(\mathrm{H}) \mathrm{H})(\mathrm{H}) \mathrm{H})(\mathrm{F}) \mathrm{H})(\mathrm{H}) \mathrm{Cl})(\mathrm{H}) \mathrm{H})(\mathrm{F}) \mathrm{H})(\mathrm{H}) \mathrm{H})(\mathrm{Cl}) \mathrm{H})(\mathrm{H}) \mathrm{H})$

$(\mathrm{F}) \mathrm{H})(\mathrm{H}) \mathrm{H})(\mathrm{H}) \mathrm{H})(\mathrm{H}) \mathrm{H})(\mathrm{H}) \mathrm{H})(\mathrm{H})(\mathrm{H}) \mathrm{H}$

$\mathrm{C}\left(\mathrm{C}\left(\mathrm{C}\left(\mathrm{C}\left(\mathrm{C}\left(\mathrm{C}(\mathrm{C}(\mathrm{C}(\mathrm{C}(\mathrm{C}(\mathrm{C}(\mathrm{C}(\mathrm{C}(\mathrm{C}(\mathrm{C}(\mathrm{C}(\mathrm{F})(\mathrm{H}) \mathrm{H})(\mathrm{H}) \mathrm{H})(\mathrm{H}) \mathrm{H})(\mathrm{H}) \mathrm{H})(\mathrm{Cl}) \mathrm{H})(\mathrm{H}) \mathrm{H})(\mathrm{H}) \mathrm{H})(\mathrm{H}) \mathrm{Br})(\mathrm{F}) \mathrm{H})(\mathrm{H}) \mathrm{H})\left({ }_{\mathrm{C} 16 \mathrm{H} 28 \mathrm{ClBrF} 4}\right.\right.\right.\right.\right.\right.$

$\mathrm{H}) \mathrm{H})(\mathrm{H}) \mathrm{F})(\mathrm{H}) \mathrm{H})(\mathrm{F}) \mathrm{H})(\mathrm{H}) \mathrm{H})(\mathrm{H})(\mathrm{H}) \mathrm{H}$

$\mathrm{C}\left(\mathrm{C}\left(\mathrm{C}\left(\mathrm{C}\left(\mathrm{C}\left(\mathrm{C}(\mathrm{C}(\mathrm{C}(\mathrm{C}(\mathrm{C}(\mathrm{C}(\mathrm{C}(\mathrm{C}(\mathrm{C}(\mathrm{C}(\mathrm{C}(\mathrm{H})(\mathrm{H}) \mathrm{Cl})(\mathrm{F}) \mathrm{F})(\mathrm{F}) \mathrm{H})(\mathrm{H}) \mathrm{F})(\mathrm{H}) \mathrm{H})(\mathrm{H}) \mathrm{H})(\mathrm{H}) \mathrm{H})(\mathrm{H}) \mathrm{H})(\mathrm{H}) \mathrm{H})(\mathrm{H}) \mathrm{H})\left(\mathrm{C}_{16 \mathrm{H} 28 \mathrm{ClF} 5}\right.\right.\right.\right.\right.\right.$

$\mathrm{H}) \mathrm{H})(\mathrm{H}) \mathrm{H})(\mathrm{H}) \mathrm{H})(\mathrm{F}) \mathrm{H})(\mathrm{H}) \mathrm{H})(\mathrm{H})(\mathrm{H}) \mathrm{H}$

$\mathrm{C}(\mathrm{C}(\mathrm{C}(\mathrm{C}(\mathrm{C}(\mathrm{C}(\mathrm{C}(\mathrm{C}(\mathrm{C}(\mathrm{C}(\mathrm{C}(\mathrm{C}(\mathrm{C}(\mathrm{C}(\mathrm{C}(\mathrm{C}(\mathrm{H})(\mathrm{H}) \mathrm{H})(\mathrm{H}) \mathrm{H})(\mathrm{H}) \mathrm{H})(\mathrm{Br}) \mathrm{H})(\mathrm{H}) \mathrm{H})(\mathrm{H}) \mathrm{H})(\mathrm{H}) \mathrm{H})(\mathrm{H}) \mathrm{H})(\mathrm{H}) \mathrm{H})(\mathrm{H}) \mathrm{H})$ $(\mathrm{F}) \mathrm{H})(\mathrm{H}) \mathrm{F})(\mathrm{Br}) \mathrm{H})(\mathrm{H}) \mathrm{H})(\mathrm{F}) \mathrm{H})(\mathrm{H})(\mathrm{H}) \mathrm{H}$

(C) $(\mathrm{C}(\mathrm{C}(\mathrm{C}(\mathrm{C}$

$\mathrm{C}(\mathrm{C}(\mathrm{C}(\mathrm{C}(\mathrm{C}(\mathrm{C}(\mathrm{C}(\mathrm{C}(\mathrm{C}(\mathrm{C}(\mathrm{C}(\mathrm{C}(\mathrm{C}(\mathrm{C}(\mathrm{C}(\mathrm{C}(\mathrm{H})(\mathrm{H}) \mathrm{H})(\mathrm{H}) \mathrm{H})(\mathrm{H}) \mathrm{H})(\mathrm{H}) \mathrm{H})(\mathrm{H}) \mathrm{H})(\mathrm{H}) \mathrm{H})(\mathrm{H}) \mathrm{H})(\mathrm{Cl}) \mathrm{H})(\mathrm{H}) \mathrm{H})(\mathrm{H}) \mathrm{H}) \quad \mathrm{C} 16 \mathrm{H} 29 \mathrm{Cl} 2 \mathrm{~F} 3$

$(\mathrm{H}) \mathrm{H})(\mathrm{H}) \mathrm{F})(\mathrm{F}) \mathrm{F})(\mathrm{Cl}) \mathrm{H})(\mathrm{H}) \mathrm{H})(\mathrm{H})(\mathrm{H}) \mathrm{H}$

$\mathrm{C}\left(\mathrm{C}\left(\mathrm{C}\left(\mathrm{C}\left(\mathrm{C}\left(\mathrm{C}(\mathrm{C}(\mathrm{C}(\mathrm{C}(\mathrm{C}(\mathrm{C}(\mathrm{C}(\mathrm{C}(\mathrm{C}(\mathrm{C}(\mathrm{C}(\mathrm{H})(\mathrm{H}) \mathrm{H})(\mathrm{H}) \mathrm{H})(\mathrm{H}) \mathrm{H})(\mathrm{H}) \mathrm{H})(\mathrm{H}) \mathrm{H})(\mathrm{H}) \mathrm{H})(\mathrm{H}) \mathrm{H})(\mathrm{Cl}) \mathrm{H})(\mathrm{H}) \mathrm{H})(\mathrm{H}) \mathrm{H}) \quad \mathrm{Cl}_{6 \mathrm{H}} 29 \mathrm{Cl3F} 2\right.\right.\right.\right.\right.$

$(\mathrm{H}) \mathrm{F})(\mathrm{Cl}) \mathrm{H})(\mathrm{H}) \mathrm{H})(\mathrm{H}) \mathrm{H})(\mathrm{H}) \mathrm{H})(\mathrm{H})(\mathrm{Cl}) \mathrm{F}$

$\mathrm{C}\left(\mathrm{C}\left(\mathrm{C}\left(\mathrm{C}\left(\mathrm{C}\left(\mathrm{C}(\mathrm{C}(\mathrm{C}(\mathrm{C}(\mathrm{C}(\mathrm{C}(\mathrm{C}(\mathrm{C}(\mathrm{C}(\mathrm{C}(\mathrm{C}(\mathrm{H})(\mathrm{H}) \mathrm{F})(\mathrm{F}) \mathrm{H})(\mathrm{H}) \mathrm{Br})(\mathrm{H}) \mathrm{H})(\mathrm{H}) \mathrm{H})(\mathrm{Cl}) \mathrm{H})(\mathrm{H}) \mathrm{H})(\mathrm{H}) \mathrm{H})(\mathrm{H}) \mathrm{H})(\mathrm{H}) \mathrm{H})\left({ }_{\mathrm{C} 16 \mathrm{H} 29 \mathrm{ClBrF} 3}\right.\right.\right.\right.\right.\right.$

F)H $(\mathrm{H}) \mathrm{H})(\mathrm{H}) \mathrm{H})(\mathrm{H}) \mathrm{H})(\mathrm{H}) \mathrm{H})(\mathrm{H})(\mathrm{H}) \mathrm{H}$

$\mathrm{C}(\mathrm{C}(\mathrm{C}(\mathrm{C}(\mathrm{C}(\mathrm{C}(\mathrm{C}(\mathrm{C}(\mathrm{C}(\mathrm{C}(\mathrm{C}(\mathrm{C}(\mathrm{C}(\mathrm{C}(\mathrm{C}(\mathrm{C}(\mathrm{H})(\mathrm{H}) \mathrm{H})(\mathrm{H}) \mathrm{H})(\mathrm{H}) \mathrm{H})(\mathrm{H}) \mathrm{H})(\mathrm{F}) \mathrm{F})(\mathrm{H}) \mathrm{H})(\mathrm{H}) \mathrm{H})(\mathrm{H}) \mathrm{H})(\mathrm{H}) \mathrm{H})(\mathrm{H}) \mathrm{H})($ $\mathrm{H}) \mathrm{H})(\mathrm{H}) \mathrm{Cl})(\mathrm{F}) \mathrm{H})(\mathrm{H}) \mathrm{H})(\mathrm{H}) \mathrm{H})(\mathrm{F})(\mathrm{H}) \mathrm{H}$

$\mathrm{C}(\mathrm{C}(\mathrm{C}(\mathrm{C}(\mathrm{C}(\mathrm{C}(\mathrm{C}(\mathrm{C}(\mathrm{C}(\mathrm{C}(\mathrm{C}(\mathrm{C}(\mathrm{C}(\mathrm{C}(\mathrm{C}(\mathrm{C}(\mathrm{H})(\mathrm{H}) \mathrm{H})(\mathrm{H}) \mathrm{H})(\mathrm{H}) \mathrm{H})(\mathrm{H}) \mathrm{H})(\mathrm{H}) \mathrm{H})(\mathrm{H}) \mathrm{H})(\mathrm{H}) \mathrm{H})(\mathrm{F}) \mathrm{F})(\mathrm{H}) \mathrm{H})(\mathrm{H}) \mathrm{H})(\mathrm{C}$

$\mathrm{H}) \mathrm{H})(\mathrm{H}) \mathrm{H})(\mathrm{H}) \mathrm{H})(\mathrm{H}) \mathrm{H})(\mathrm{H}) \mathrm{H})(\mathrm{H})(\mathrm{Br}) \mathrm{F}$

$\mathrm{C}\left(\mathrm{C}\left(\mathrm{C}\left(\mathrm{C}\left(\mathrm{C}\left(\mathrm{C}(\mathrm{C}(\mathrm{C}(\mathrm{C}(\mathrm{C}(\mathrm{C}(\mathrm{C}(\mathrm{C}(\mathrm{C}(\mathrm{C}(\mathrm{C}(\mathrm{H})(\mathrm{H}) \mathrm{H})(\mathrm{H}) \mathrm{H})(\mathrm{H}) \mathrm{Cl})(\mathrm{H}) \mathrm{H})(\mathrm{H}) \mathrm{H})(\mathrm{H}) \mathrm{F})(\mathrm{H}) \mathrm{H})(\mathrm{H}) \mathrm{H})(\mathrm{H}) \mathrm{H})(\mathrm{H}) \mathrm{H})\left({ }_{\mathrm{C}} 6 \mathrm{H} 30 \mathrm{Cl} 2 \mathrm{~F} 2\right.\right.\right.\right.\right.\right.$

$\mathrm{H}) \mathrm{H})(\mathrm{H}) \mathrm{H})(\mathrm{H}) \mathrm{H})(\mathrm{F}) \mathrm{Cl}(\mathrm{H}) \mathrm{H})(\mathrm{H})(\mathrm{H}) \mathrm{H}$

$\mathrm{C}(\mathrm{C}(\mathrm{C}(\mathrm{C}(\mathrm{C}(\mathrm{C}(\mathrm{C}(\mathrm{C}(\mathrm{C}(\mathrm{C}(\mathrm{C}(\mathrm{C}(\mathrm{C}(\mathrm{C}(\mathrm{C}(\mathrm{C}(\mathrm{H})(\mathrm{H}) \mathrm{H})(\mathrm{H}) \mathrm{H})(\mathrm{F}) \mathrm{H})(\mathrm{H}) \mathrm{H})(\mathrm{H}) \mathrm{H})(\mathrm{H}) \mathrm{H})(\mathrm{H}) \mathrm{H})(\mathrm{H}) \mathrm{H})(\mathrm{H}) \mathrm{H})(\mathrm{H}) \mathrm{H})($ $\mathrm{Br}) \mathrm{H})(\mathrm{H}) \mathrm{H})(\mathrm{H}) \mathrm{H})(\mathrm{H}) \mathrm{Cl})(\mathrm{H}) \mathrm{H})(\mathrm{F})(\mathrm{H}) \mathrm{H}$

$\mathrm{C}\left(\mathrm{C}\left(\mathrm{C}\left(\mathrm{C}\left(\mathrm{C}\left(\mathrm{C}(\mathrm{C}(\mathrm{C}(\mathrm{C}(\mathrm{C}(\mathrm{C}(\mathrm{C}(\mathrm{C}(\mathrm{C}(\mathrm{C}(\mathrm{C}(\mathrm{F})(\mathrm{H}) \mathrm{H})(\mathrm{H}) \mathrm{H})(\mathrm{H}) \mathrm{H})(\mathrm{H}) \mathrm{H})(\mathrm{H}) \mathrm{H})(\mathrm{H}) \mathrm{H})(\mathrm{H}) \mathrm{H})(\mathrm{H}) \mathrm{H})(\mathrm{H}) \mathrm{H})(\mathrm{H}) \mathrm{H})\left(\mathrm{C}_{\mathrm{C}} 6 \mathrm{H}_{30} \mathrm{ClF}^{3}\right.\right.\right.\right.\right.\right.$

F)H $(\mathrm{H}) \mathrm{H})(\mathrm{H}) \mathrm{H})(\mathrm{H}) \mathrm{H})(\mathrm{F}) \mathrm{H})(\mathrm{H})(\mathrm{H}) \mathrm{Cl}$

$\mathrm{C}\left(\mathrm{C}\left(\mathrm{C}\left(\mathrm{C}\left(\mathrm{C}\left(\mathrm{C}(\mathrm{C}(\mathrm{C}(\mathrm{C}(\mathrm{C}(\mathrm{C}(\mathrm{C}(\mathrm{C}(\mathrm{C}(\mathrm{C}(\mathrm{C}(\mathrm{H})(\mathrm{H}) \mathrm{H})(\mathrm{H}) \mathrm{H})(\mathrm{H}) \mathrm{H})(\mathrm{H}) \mathrm{F})(\mathrm{H}) \mathrm{H})(\mathrm{H}) \mathrm{H})(\mathrm{H}) \mathrm{H})(\mathrm{H}) \mathrm{H})(\mathrm{H}) \mathrm{H})(\mathrm{H}) \mathrm{H})\left({ }_{\mathrm{C} 16 \mathrm{H} 31 \mathrm{BrF} 2}\right.\right.\right.\right.\right.\right.$

$\mathrm{H}) \mathrm{H})(\mathrm{F}) \mathrm{H})(\mathrm{H}) \mathrm{H})(\mathrm{H}) \mathrm{H})(\mathrm{H}) \mathrm{H})(\mathrm{H})(\mathrm{Br}) \mathrm{H}$

$\mathrm{C}\left(\mathrm{C}\left(\mathrm{C}\left(\mathrm{C}\left(\mathrm{C}\left(\mathrm{C}(\mathrm{C}(\mathrm{C}(\mathrm{C}(\mathrm{C}(\mathrm{C}(\mathrm{C}(\mathrm{C}(\mathrm{C}(\mathrm{C}(\mathrm{C}(\mathrm{H})(\mathrm{F}) \mathrm{H})(\mathrm{H}) \mathrm{H})(\mathrm{H}) \mathrm{H})(\mathrm{H}) \mathrm{H})(\mathrm{H}) \mathrm{H})(\mathrm{H}) \mathrm{H})(\mathrm{H}) \mathrm{H})(\mathrm{H}) \mathrm{H})(\mathrm{H}) \mathrm{H})(\mathrm{H}) \mathrm{H})\left({ }_{\mathrm{Cl}}{ }_{6 \mathrm{H}} 31 \mathrm{Cl} 2 \mathrm{~F}\right.\right.\right.\right.\right.\right.$

$\mathrm{Cl}) \mathrm{H})(\mathrm{H}) \mathrm{H})(\mathrm{H}) \mathrm{H})(\mathrm{H}) \mathrm{H})(\mathrm{H}) \mathrm{H})(\mathrm{H})(\mathrm{Cl}) \mathrm{H}$

$\mathrm{C}\left(\mathrm{C}\left(\mathrm{C}\left(\mathrm{C}\left(\mathrm{C}\left(\mathrm{C}(\mathrm{C}(\mathrm{C}(\mathrm{C}(\mathrm{C}(\mathrm{C}(\mathrm{C}(\mathrm{C}(\mathrm{C}(\mathrm{C}(\mathrm{C}(\mathrm{H})(\mathrm{H}) \mathrm{H})(\mathrm{H}) \mathrm{H})(\mathrm{H}) \mathrm{H})(\mathrm{H}) \mathrm{H})(\mathrm{H}) \mathrm{H})(\mathrm{H}) \mathrm{H})(\mathrm{H}) \mathrm{H})(\mathrm{H}) \mathrm{H})(\mathrm{H}) \mathrm{H})(\mathrm{H}) \mathrm{H})\left({ }_{\mathrm{C}}{ }_{16 \mathrm{H}} 31 \mathrm{ClBrF}\right.\right.\right.\right.\right.\right.$

$\mathrm{H}) \mathrm{H})(\mathrm{Cl}) \mathrm{H})(\mathrm{H}) \mathrm{H})(\mathrm{H}) \mathrm{H})(\mathrm{H}) \mathrm{H})(\mathrm{F})(\mathrm{Br}) \mathrm{H}$

$\mathrm{C}\left(\mathrm{C}\left(\mathrm{C}\left(\mathrm{C}\left(\mathrm{C}\left(\mathrm{C}(\mathrm{C}(\mathrm{C}(\mathrm{C}(\mathrm{C}(\mathrm{C}(\mathrm{C}(\mathrm{C}(\mathrm{C}(\mathrm{C}(\mathrm{C}(\mathrm{H})(\mathrm{H}) \mathrm{H})(\mathrm{Cl}) \mathrm{H})(\mathrm{H}) \mathrm{H})(\mathrm{H}) \mathrm{H})(\mathrm{H}) \mathrm{H})(\mathrm{H}) \mathrm{H})(\mathrm{H}) \mathrm{H})(\mathrm{H}) \mathrm{H})(\mathrm{H}) \mathrm{H})(\mathrm{H}) \mathrm{H}){ }^{\mathrm{C}}{ }^{2} 6 \mathrm{H} 31 \mathrm{ClF} 2\right.\right.\right.\right.\right.$ $(\mathrm{H}) \mathrm{H})(\mathrm{F}) \mathrm{H})(\mathrm{H}) \mathrm{H})(\mathrm{H}) \mathrm{H})(\mathrm{H}) \mathrm{H}(\mathrm{H})(\mathrm{H}) \mathrm{F}$

$\mathrm{C}\left(\mathrm{C}\left(\mathrm{C}\left(\mathrm{C}\left(\mathrm{C}\left(\mathrm{C}(\mathrm{C}(\mathrm{C}(\mathrm{C}(\mathrm{C}(\mathrm{C}(\mathrm{C}(\mathrm{C}(\mathrm{C}(\mathrm{C}(\mathrm{C}(\mathrm{H})(\mathrm{H}) \mathrm{H})(\mathrm{H}) \mathrm{F})(\mathrm{H}) \mathrm{H})(\mathrm{H}) \mathrm{H})(\mathrm{H}) \mathrm{H})(\mathrm{H}) \mathrm{H})(\mathrm{H}) \mathrm{H})(\mathrm{H}) \mathrm{H})(\mathrm{H}) \mathrm{H})(\mathrm{H}) \mathrm{H})\left({ }_{\mathrm{C} 16 \mathrm{H} 31 \mathrm{~F}^{3}}\right.\right.\right.\right.\right.\right.$

F)H)(H)H)(H)H)(H)H)(H)H)(H)(F)H

$\mathrm{C}\left(\mathrm{C}\left(\mathrm{C}\left(\mathrm{C}\left(\mathrm{C}\left(\mathrm{C}(\mathrm{C}(\mathrm{C}(\mathrm{C}(\mathrm{C}(\mathrm{C}(\mathrm{C}(\mathrm{C}(\mathrm{C}(\mathrm{C}(\mathrm{C}(\mathrm{H})(\mathrm{H}) \mathrm{H})(\mathrm{H}) \mathrm{Br})(\mathrm{H}) \mathrm{H})(\mathrm{H}) \mathrm{H})(\mathrm{H}) \mathrm{H})(\mathrm{H}) \mathrm{H})(\mathrm{H}) \mathrm{H})(\mathrm{H}) \mathrm{H})(\mathrm{F}) \mathrm{H})(\mathrm{H}) \mathrm{H})\left({ }_{\mathrm{C} 16 \mathrm{H} 32 \mathrm{BrF}}\right.\right.\right.\right.\right.\right.$

$\mathrm{H}) \mathrm{H})(\mathrm{H}) \mathrm{H})(\mathrm{H}) \mathrm{H})(\mathrm{H}) \mathrm{H})(\mathrm{H}) \mathrm{H})(\mathrm{H})(\mathrm{H}) \mathrm{H}$

$\mathrm{C}\left(\mathrm{C}\left(\mathrm{C}\left(\mathrm{C}\left(\mathrm{C}\left(\mathrm{C}(\mathrm{C}(\mathrm{C}(\mathrm{C}(\mathrm{C}(\mathrm{C}(\mathrm{C}(\mathrm{C}(\mathrm{C}(\mathrm{C}(\mathrm{C}(\mathrm{H})(\mathrm{H}) \mathrm{H})(\mathrm{H}) \mathrm{Cl})(\mathrm{Cl}) \mathrm{H})(\mathrm{H}) \mathrm{H})(\mathrm{H}) \mathrm{H})(\mathrm{H}) \mathrm{H})(\mathrm{H}) \mathrm{H})(\mathrm{H}) \mathrm{H})(\mathrm{H}) \mathrm{H})(\mathrm{H}) \mathrm{H}){ }_{\mathrm{Cl}}{ }^{6 \mathrm{H}} 32 \mathrm{Cl} 2\right.\right.\right.\right.\right.$

$(\mathrm{H}) \mathrm{H})(\mathrm{H}) \mathrm{H})(\mathrm{H}) \mathrm{H})(\mathrm{H}) \mathrm{H})(\mathrm{H}) \mathrm{H})(\mathrm{H})(\mathrm{H}) \mathrm{H}$

$\mathrm{C}\left(\mathrm{C}\left(\mathrm{C}\left(\mathrm{C}\left(\mathrm{C}\left(\mathrm{C}(\mathrm{C}(\mathrm{C}(\mathrm{C}(\mathrm{C}(\mathrm{C}(\mathrm{C}(\mathrm{C}(\mathrm{C}(\mathrm{C}(\mathrm{C}(\mathrm{H})(\mathrm{H}) \mathrm{H})(\mathrm{H}) \mathrm{H})(\mathrm{H}) \mathrm{H})(\mathrm{H}) \mathrm{H})(\mathrm{H}) \mathrm{H})(\mathrm{H}) \mathrm{H})(\mathrm{H}) \mathrm{H})(\mathrm{H}) \mathrm{H})(\mathrm{H}) \mathrm{H})(\mathrm{H}) \mathrm{H})\left({ }_{\mathrm{C} 16 \mathrm{H} 32 \mathrm{ClF}}\right.\right.\right.\right.\right.\right.$

$\mathrm{H}) \mathrm{H})(\mathrm{H}) \mathrm{H})(\mathrm{H}) \mathrm{H})(\mathrm{H}) \mathrm{Cl}(\mathrm{H}) \mathrm{H})(\mathrm{H})(\mathrm{F}) \mathrm{H}$

$\mathrm{C}\left(\mathrm{C}\left(\mathrm{C}\left(\mathrm{C}\left(\mathrm{C}\left(\mathrm{C}(\mathrm{C}(\mathrm{C}(\mathrm{C}(\mathrm{C}(\mathrm{C}(\mathrm{C}(\mathrm{C}(\mathrm{C}(\mathrm{C}(\mathrm{C}(\mathrm{H})(\mathrm{H}) \mathrm{H})(\mathrm{H}) \mathrm{F})(\mathrm{H}) \mathrm{H})(\mathrm{H}) \mathrm{H})(\mathrm{H}) \mathrm{H})(\mathrm{H}) \mathrm{H})(\mathrm{H}) \mathrm{H})(\mathrm{F}) \mathrm{H})(\mathrm{H}) \mathrm{H})(\mathrm{H}) \mathrm{H})\left(\mathrm{Cl}_{6 \mathrm{H}} 32 \mathrm{~F} 2\right.\right.\right.\right.\right.\right.$

$\mathrm{H}) \mathrm{H})(\mathrm{H}) \mathrm{H})(\mathrm{H}) \mathrm{H})(\mathrm{H}) \mathrm{H})(\mathrm{H}) \mathrm{H})(\mathrm{H})(\mathrm{H}) \mathrm{H}$

$\mathrm{C}\left(\mathrm{C}\left(\mathrm{C}\left(\mathrm{C}\left(\mathrm{C}\left(\mathrm{C}(\mathrm{C}(\mathrm{C}(\mathrm{C}(\mathrm{C}(\mathrm{C}(\mathrm{C}(\mathrm{C}(\mathrm{C}(\mathrm{C}(\mathrm{C}(\mathrm{Br})(\mathrm{H}) \mathrm{H})(\mathrm{H}) \mathrm{H})(\mathrm{H}) \mathrm{H})(\mathrm{H}) \mathrm{H})(\mathrm{H}) \mathrm{H})(\mathrm{H}) \mathrm{H})(\mathrm{H}) \mathrm{H})(\mathrm{H}) \mathrm{H})(\mathrm{H}) \mathrm{H})(\mathrm{H}) \mathrm{H}){ }_{\mathrm{C} 16 \mathrm{H} 33 \mathrm{Br}}\right.\right.\right.\right.\right.$

$(\mathrm{H}) \mathrm{H})(\mathrm{H}) \mathrm{H})(\mathrm{H}) \mathrm{H})(\mathrm{H}) \mathrm{H})(\mathrm{H}) \mathrm{H})(\mathrm{H})(\mathrm{H}) \mathrm{H}$

$\mathrm{C}\left(\mathrm{C}\left(\mathrm{C}\left(\mathrm{C}\left(\mathrm{C}\left(\mathrm{C}(\mathrm{C}(\mathrm{C}(\mathrm{C}(\mathrm{C}(\mathrm{C}(\mathrm{C}(\mathrm{C}(\mathrm{C}(\mathrm{C}(\mathrm{C}(\mathrm{H})(\mathrm{H}) \mathrm{H})(\mathrm{H}) \mathrm{H})(\mathrm{H}) \mathrm{H})(\mathrm{H}) \mathrm{H})(\mathrm{H}) \mathrm{H})(\mathrm{H}) \mathrm{H})(\mathrm{H}) \mathrm{H})(\mathrm{H}) \mathrm{H})(\mathrm{H}) \mathrm{H})(\mathrm{H}) \mathrm{H})\left({ }_{\mathrm{Cl}}{ }^{6} \mathrm{H}_{33} \mathrm{Cl}\right.\right.\right.\right.\right.\right.$

$\mathrm{H}) \mathrm{H})(\mathrm{H}) \mathrm{H})(\mathrm{H}) \mathrm{H})(\mathrm{H}) \mathrm{H})(\mathrm{H}) \mathrm{H})(\mathrm{H})(\mathrm{H}) \mathrm{Cl}$

$\mathrm{C}\left(\mathrm{C}\left(\mathrm{C}\left(\mathrm{C}\left(\mathrm{C}\left(\mathrm{C}(\mathrm{C}(\mathrm{C}(\mathrm{C}(\mathrm{C}(\mathrm{C}(\mathrm{C}(\mathrm{C}(\mathrm{C}(\mathrm{C}(\mathrm{C}(\mathrm{H})(\mathrm{H}) \mathrm{H})(\mathrm{H}) \mathrm{H})(\mathrm{H}) \mathrm{H})(\mathrm{H}) \mathrm{H})(\mathrm{H}) \mathrm{H})(\mathrm{H}) \mathrm{H})(\mathrm{H}) \mathrm{H})(\mathrm{H}) \mathrm{H})(\mathrm{H}) \mathrm{H})(\mathrm{H}) \mathrm{H})\left({ }_{\mathrm{Cl}}{ }^{6 \mathrm{H}} 33 \mathrm{~F}\right.\right.\right.\right.\right.\right.$
$\mathrm{H}) \mathrm{H})(\mathrm{H}) \mathrm{H})(\mathrm{H}) \mathrm{H})(\mathrm{H}) \mathrm{H})(\mathrm{F}) \mathrm{H})(\mathrm{H})(\mathrm{H}) \mathrm{H}$

C $(\mathrm{C}(\mathrm{C}(\mathrm{C}(\mathrm{C}(\mathrm{C}(\mathrm{C}(\mathrm{C}(\mathrm{C}(\mathrm{C}(\mathrm{C}(\mathrm{C}(\mathrm{C}(\mathrm{C}(\mathrm{C}(\mathrm{C}(\mathrm{C}(\mathrm{H})(\mathrm{H}) \mathrm{H})(\mathrm{H}) \mathrm{H})(\mathrm{H}) \mathrm{H})(\mathrm{F}) \mathrm{F})(\mathrm{F}) \mathrm{H})(\mathrm{H}) \mathrm{F})(\mathrm{F}) \mathrm{H})(\mathrm{H}) \mathrm{Br})(\mathrm{H}) \mathrm{F})(\mathrm{F}) \mathrm{Br}) \mathrm{C} 17 \mathrm{H} 18 \mathrm{Cl} 2 \mathrm{Br} 2 \mathrm{~F} 1$ (F)F)(F)H)(F)H)(F)H)(F)H)(F)H)(Cl)(Cl)H

$\mathrm{C}\left(\mathrm{C}\left(\mathrm{C}\left(\mathrm{C}\left(\mathrm{C}\left(\mathrm{C}\left(\mathrm{C}(\mathrm{C}(\mathrm{C}(\mathrm{C}(\mathrm{C}(\mathrm{C}(\mathrm{C}(\mathrm{C}(\mathrm{C}(\mathrm{C}(\mathrm{C}(\mathrm{H})(\mathrm{F}) \mathrm{H})(\mathrm{Cl}) \mathrm{H})(\mathrm{H}) \mathrm{F})(\mathrm{F}) \mathrm{H})(\mathrm{H}) \mathrm{F})(\mathrm{F}) \mathrm{H})(\mathrm{H}) \mathrm{F})(\mathrm{H}) \mathrm{Br})(\mathrm{H}) \mathrm{F})(\mathrm{F}) \mathrm{Br}) \mathrm{C}_{3}\right.\right.\right.\right.\right.\right.$ 7H $18 \mathrm{Cl} 3 \mathrm{Br} 2 \mathrm{~F} 1$ $(\mathrm{H}) \mathrm{H})(\mathrm{F}) \mathrm{F})(\mathrm{Cl}) \mathrm{H})(\mathrm{F}) \mathrm{H})(\mathrm{H}) \mathrm{Cl})(\mathrm{H}) \mathrm{H})(\mathrm{F})(\mathrm{H}) \mathrm{F}$

(

$\mathrm{C}\left(\mathrm{C}\left(\mathrm{C}\left(\mathrm{C}\left(\mathrm{C}\left(\mathrm{C}\left(\mathrm{C}(\mathrm{C}(\mathrm{C}(\mathrm{C}(\mathrm{C}(\mathrm{C}(\mathrm{C}(\mathrm{C}(\mathrm{C}(\mathrm{C}(\mathrm{C}(\mathrm{H})(\mathrm{F}) \mathrm{F})(\mathrm{H}) \mathrm{F})(\mathrm{H}) \mathrm{H})(\mathrm{F}) \mathrm{F})(\mathrm{H}) \mathrm{H})(\mathrm{F}) \mathrm{Br})(\mathrm{H}) \mathrm{F})(\mathrm{H}) \mathrm{F})(\mathrm{H}) \mathrm{H})(\mathrm{F}) \mathrm{H})\left({ }_{\mathrm{C} 17 \mathrm{H} 18 \mathrm{Cl} 3 \mathrm{BrF} 14}\right.\right.\right.\right.\right.\right.\right.$

F)H $(\mathrm{H}) \mathrm{Cl})(\mathrm{F}) \mathrm{F})(\mathrm{H}) \mathrm{H})(\mathrm{H}) \mathrm{F})(\mathrm{H}) \mathrm{Cl}(\mathrm{H})(\mathrm{F}) \mathrm{Cl}$

$\mathrm{C}(\mathrm{C}(\mathrm{C}(\mathrm{C}(\mathrm{C}(\mathrm{C}(\mathrm{C}(\mathrm{C}(\mathrm{C}(\mathrm{C}(\mathrm{C}(\mathrm{C}(\mathrm{C}(\mathrm{C}(\mathrm{C}(\mathrm{C}(\mathrm{C}(\mathrm{F})(\mathrm{H}) \mathrm{F})(\mathrm{H}) \mathrm{F})(\mathrm{F}) \mathrm{H})(\mathrm{F}) \mathrm{H})(\mathrm{H}) \mathrm{F})(\mathrm{H}) \mathrm{F})(\mathrm{H}) \mathrm{H})(\mathrm{H}) \mathrm{H})(\mathrm{H}) \mathrm{F})(\mathrm{H}) \mathrm{F})($

$\mathrm{H}) \mathrm{Cl}(\mathrm{Br}) \mathrm{F})(\mathrm{F}) \mathrm{F})(\mathrm{H}) \mathrm{H})(\mathrm{Cl}) \mathrm{H})(\mathrm{H}) \mathrm{Cl})(\mathrm{Cl})(\mathrm{F}) \mathrm{H}$

$\mathrm{C} 17 \mathrm{H} 18 \mathrm{C} 14 \mathrm{BrF} 13$

$\mathrm{C}(\mathrm{C}(\mathrm{C}(\mathrm{C}(\mathrm{C}(\mathrm{C}(\mathrm{C}(\mathrm{C}(\mathrm{C}(\mathrm{C}(\mathrm{C}(\mathrm{C}(\mathrm{C}(\mathrm{C}(\mathrm{C}(\mathrm{C}(\mathrm{C}(\mathrm{H})(\mathrm{Cl}) \mathrm{H})(\mathrm{F}) \mathrm{F})(\mathrm{Cl}) \mathrm{H})(\mathrm{H}) \mathrm{Cl})(\mathrm{H}) \mathrm{F})(\mathrm{H}) \mathrm{Cl})(\mathrm{Cl}) \mathrm{H})(\mathrm{F}) \mathrm{H})(\mathrm{H}) \mathrm{F})(\mathrm{F})$

$\mathrm{H})(\mathrm{H}) \mathrm{F})(\mathrm{H}) \mathrm{H})(\mathrm{H}) \mathrm{H})(\mathrm{F}) \mathrm{H})(\mathrm{H}) \mathrm{F})(\mathrm{F}) \mathrm{F})(\mathrm{H})(\mathrm{F}) \mathrm{F}$

(

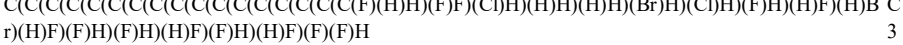

$\mathrm{C}(\mathrm{C}(\mathrm{C}(\mathrm{C}(\mathrm{C}(\mathrm{C}(\mathrm{C}(\mathrm{C}(\mathrm{C}(\mathrm{C}(\mathrm{C}(\mathrm{C}(\mathrm{C}(\mathrm{C}(\mathrm{C}(\mathrm{C}(\mathrm{C}(\mathrm{F})(\mathrm{H}) \mathrm{Br})(\mathrm{F}) \mathrm{H})(\mathrm{H}) \mathrm{F})(\mathrm{F}) \mathrm{F})(\mathrm{H}) \mathrm{F})(\mathrm{H}) \mathrm{H})(\mathrm{Br}) \mathrm{H})(\mathrm{H}) \mathrm{F})(\mathrm{Br}) \mathrm{H}) \quad \mathrm{C} 17 \mathrm{H} 19 \mathrm{Cl} 2 \mathrm{Br} 3 \mathrm{~F} 1$ $(\mathrm{H}) \mathrm{H})(\mathrm{F}) \mathrm{H})(\mathrm{H}) \mathrm{H})(\mathrm{H}) \mathrm{F})(\mathrm{Cl}) \mathrm{H})(\mathrm{H}) \mathrm{H})(\mathrm{Cl}) \mathrm{F})(\mathrm{H})(\mathrm{F}) \mathrm{F}$

2

$\mathrm{C}\left(\mathrm{C}\left(\mathrm{C}\left(\mathrm{C}\left(\mathrm{C}\left(\mathrm{C}\left(\mathrm{C}(\mathrm{C}(\mathrm{C}(\mathrm{C}(\mathrm{C}(\mathrm{C}(\mathrm{C}(\mathrm{C}(\mathrm{C}(\mathrm{C}(\mathrm{C}(\mathrm{H})(\mathrm{F}) \mathrm{F})(\mathrm{Cl}) \mathrm{H})(\mathrm{F}) \mathrm{H})(\mathrm{F}) \mathrm{F})(\mathrm{H}) \mathrm{F})(\mathrm{H}) \mathrm{F})(\mathrm{Cl}) \mathrm{H})(\mathrm{H}) \mathrm{H})(\mathrm{H}) \mathrm{H})(\mathrm{F}) \mathrm{F})\left({ }_{\mathrm{C} 17 \mathrm{H} 19 \mathrm{Cl} 3 \mathrm{BrF} 13}\right.\right.\right.\right.\right.\right.\right.$ $\mathrm{H}) \mathrm{F})(\mathrm{H}) \mathrm{F})(\mathrm{Cl}) \mathrm{H})(\mathrm{F}) \mathrm{H})(\mathrm{H}) \mathrm{H})(\mathrm{H}) \mathrm{Br})(\mathrm{H})(\mathrm{H}) \mathrm{F}$

$\mathrm{C}(\mathrm{C}(\mathrm{C}(\mathrm{C}(\mathrm{C}(\mathrm{C}(\mathrm{C}(\mathrm{C}(\mathrm{C}(\mathrm{C}(\mathrm{C}(\mathrm{C}(\mathrm{C}(\mathrm{C}(\mathrm{C}(\mathrm{C}(\mathrm{C}(\mathrm{H})(\mathrm{H}) \mathrm{H})(\mathrm{F}) \mathrm{Cl})(\mathrm{H}) \mathrm{H})(\mathrm{F}) \mathrm{H})(\mathrm{F}) \mathrm{H})(\mathrm{H}) \mathrm{F})(\mathrm{H}) \mathrm{F})(\mathrm{Br}) \mathrm{H})(\mathrm{F}) \mathrm{H})(\mathrm{H}) \mathrm{F})$

$(\mathrm{F}) \mathrm{F})(\mathrm{H}) \mathrm{F})(\mathrm{F}) \mathrm{H})(\mathrm{H}) \mathrm{H})(\mathrm{Br}) \mathrm{F})(\mathrm{H}) \mathrm{F})(\mathrm{H})(\mathrm{F}) \mathrm{H}$
lgKoa lgKow lgKaw lgKow lgKoa lgKa lgKow lgKoa lgKaw EPISuit_EPI_EPI_Exp__Exp w DFT_ DFT DFT e Suite Suite corr_corr _Exp corr_corr_corr $\begin{array}{lllllllll}5.797 & 8.71 & 2.91 & 8.07 & 5.16 & 2.91 & 7.45 & 8.66 & -1.21\end{array}$

$\begin{array}{lllllllll}6.939 & 9.1 & 2.16 & 8.66 & 6.50 & 2.16 & 7.75 & 10.76 & -3.01\end{array}$

$\begin{array}{lllllllll}6.444 & 8.87 & 2.43 & 8.31 & 5.89 & 2.43 & 7.57 & 9.85 & -2.27\end{array}$

$\begin{array}{lllllllll}4.805 & 8.47 & 3.66 & 7.72 & 4.05 & 3.66 & 7.27 & 6.84 & 0.43\end{array}$

$\begin{array}{lllllllll}6.639 & 8.28 & 1.64 & 7.43 & 5.79 & 1.64 & 7.12 & 10.21 & -3.09\end{array}$

$\begin{array}{lllllllll}5.069 & 7.95 & 2.88 & 6.94 & 4.06 & 2.88 & 6.87 & 7.32 & -0.46\end{array}$

$\begin{array}{lllllllll}7.134 & 8.51 & 1.38 & 7.78 & 6.40 & 1.38 & 7.30 & 11.12 & -3.82\end{array}$

$\begin{array}{lllllllll}6.158 & 8.77 & 2.61 & 8.16 & 5.55 & 2.61 & 7.50 & 9.32 & -1.83\end{array}$

$\begin{array}{lllllllll}6.558 & 8.42 & 1.86 & 7.64 & 5.78 & 1.86 & 7.23 & 10.06 & -2.83\end{array}$

$\begin{array}{lllllllll}6.063 & 8.19 & 2.13 & 7.30 & 5.17 & 2.13 & 7.05 & 9.15 & -2.10\end{array}$

$\begin{array}{lllllllll}5.165 & 8.53 & 3.37 & 7.81 & 4.44 & 3.37 & 7.31 & 7.50 & -0.19\end{array}$

$\begin{array}{lllllllll}6.996 & 8.34 & 1.34 & 7.52 & 6.18 & 1.34 & 7.17 & 10.86 & -3.70\end{array}$

$\begin{array}{lllllllll}5.429 & 8.01 & 2.58 & 7.03 & 4.45 & 2.58 & 6.91 & 7.99 & -1.07\end{array}$

$\begin{array}{lllllllll}6.585 & 8.9 & 2.31 & 8.36 & 6.04 & 2.31 & 7.60 & 10.11 & -2.51\end{array}$

$\begin{array}{lllllllll}6.988 & 8.55 & 1.56 & 7.84 & 6.27 & 1.56 & 7.33 & 10.85 & -3.52\end{array}$

$\begin{array}{lllllllll}6.491 & 8.32 & 1.83 & 7.49 & 5.66 & 1.83 & 7.15 & 9.94 & -2.78\end{array}$

$\begin{array}{lllllllll}5.594 & 8.66 & 3.07 & 8.00 & 4.93 & 3.07 & 7.41 & 8.29 & -0.87\end{array}$

$\begin{array}{lllllllll}6.597 & 8.88 & 2.28 & 8.33 & 6.05 & 2.28 & 7.58 & 10.13 & -2.55\end{array}$

$\begin{array}{lllllllll}7.014 & 9.03 & 2.02 & 8.55 & 6.54 & 2.02 & 7.70 & 10.90 & -3.20\end{array}$

$\begin{array}{lllllllll}6.929 & 8.46 & 1.53 & 7.70 & 6.17 & 1.53 & 7.26 & 10.74 & -3.48\end{array}$

$\begin{array}{lllllllll}5.363 & 8.13 & 2.77 & 7.21 & 4.44 & 2.77 & 7.01 & 7.86 & -0.86\end{array}$

$\begin{array}{lllllllll}6.296 & 8.28 & 1.98 & 7.43 & 5.45 & 1.98 & 7.12 & 9.58 & -2.46\end{array}$

$\begin{array}{lllllllll}6.855 & 8.57 & 1.72 & 7.87 & 6.15 & 1.72 & 7.34 & 10.60 & -3.26\end{array}$

$\begin{array}{lllllllll}7.358 & 8.59 & 1.23 & 7.90 & 6.66 & 1.23 & 7.36 & 11.53 & -4.17\end{array}$

$\begin{array}{lllllllll}5.721 & 8.19 & 2.47 & 7.30 & 4.83 & 2.47 & 7.05 & 8.52 & -1.47\end{array}$

$\begin{array}{lllllllll}4.649 & 7.87 & 3.22 & 6.82 & 3.60 & 3.22 & 6.81 & 6.55 & 0.25\end{array}$

$\begin{array}{lllllllll}6.657 & 8.34 & 1.68 & 7.52 & 5.84 & 1.68 & 7.17 & 10.24 & -3.07\end{array}$

$\begin{array}{lllllllll}7.142 & 8.56 & 1.42 & 7.85 & 6.43 & 1.42 & 7.34 & 11.13 & -3.80\end{array}$

$6.15 \quad 8.32$

$\begin{array}{lllllll}2.17 & 7.49 & 5.32 & 2.17 & 7.15 & 9.31 & -2.16\end{array}$

$5.009 \quad 7.93$

$7.154 \quad 8.54$

$\begin{array}{lllllll}2.92 & 6.91 & 3.99 & 2.92 & 6.85 & 7.21 & -0.36\end{array}$

$7.079 \quad 8.45$

$\begin{array}{lllllll}1.39 & 7.82 & 6.43 & 1.39 & 7.32 & 11.15 & -3.83\end{array}$

$6.398 \quad 8.07$

$\begin{array}{lllllll}1.37 & 7.69 & 6.32 & 1.37 & 7.25 & 11.02 & -3.76\end{array}$

$6.183 \quad 10.03$

$\begin{array}{lllllll}1.67 & 7.12 & 5.45 & 1.67 & 6.96 & 9.77 & -2.81\end{array}$

$6.574 \quad 9.67$

$\begin{array}{lllllll}3.85 & 10.04 & 6.20 & 3.85 & 8.47 & 9.37 & -0.90\end{array}$

$5.677 \quad 10.01$

$\begin{array}{lllllll}3.10 & 9.51 & 6.41 & 3.10 & 8.19 & 10.09 & -1.90\end{array}$

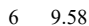

$\begin{array}{lllllll}4.33 & 10.01 & 5.68 & 4.33 & 8.45 & 8.44 & 0.01\end{array}$

$\begin{array}{lllllllll}5.424 & 9.49 & 4.07 & 9.24 & 5.17 & 4.07 & 8.05 & 7.98 & 0.08\end{array}$

$\begin{array}{lllllllll}5.201 & 8.75 & 3.55 & 8.13 & 4.59 & 3.55 & 7.48 & 7.57 & -0.08\end{array}$

$\begin{array}{lllllllll}7.589 & 9.9 & 2.31 & 9.85 & 7.54 & 2.31 & 8.37 & 11.95 & -3.59\end{array}$

$\begin{array}{lllllllll}5.367 & 9.4 & 4.03 & 9.10 & 5.07 & 4.03 & 7.98 & 7.87 & 0.11\end{array}$

$\begin{array}{lllllllll}5.55 & 9.85 & 4.30 & 9.78 & 5.48 & 4.30 & 8.33 & 8.21 & 0.12\end{array}$ 
$\mathrm{C}(\mathrm{C}(\mathrm{C}(\mathrm{C}(\mathrm{C}(\mathrm{C}(\mathrm{C}(\mathrm{C}(\mathrm{C}(\mathrm{C}(\mathrm{C}(\mathrm{C}(\mathrm{C}(\mathrm{C}(\mathrm{C}(\mathrm{C}(\mathrm{C}(\mathrm{H})(\mathrm{H}) \mathrm{H})(\mathrm{H}) \mathrm{H})(\mathrm{H}) \mathrm{F})(\mathrm{H}) \mathrm{H})(\mathrm{F}) \mathrm{H})(\mathrm{F}) \mathrm{H})(\mathrm{F}) \mathrm{H})(\mathrm{H}) \mathrm{F})(\mathrm{H}) \mathrm{F})(\mathrm{F}) \mathrm{H})($ $\mathrm{F}) \mathrm{F})(\mathrm{H}) \mathrm{H})(\mathrm{H}) \mathrm{H})(\mathrm{H}) \mathrm{Br})(\mathrm{Br}) \mathrm{H})(\mathrm{F}) \mathrm{Br})(\mathrm{F})(\mathrm{F}) \mathrm{F}$

$\mathrm{C} 17 \mathrm{H} 20 \mathrm{Br} 3 \mathrm{~F} 13$

$\mathrm{C}(\mathrm{C}(\mathrm{C}(\mathrm{C}(\mathrm{C}(\mathrm{C}(\mathrm{C}(\mathrm{C}(\mathrm{C}(\mathrm{C}(\mathrm{C}(\mathrm{C}(\mathrm{C}(\mathrm{C}(\mathrm{C}(\mathrm{C}(\mathrm{C}(\mathrm{F})(\mathrm{H}) \mathrm{F})(\mathrm{H}) \mathrm{F})(\mathrm{F}) \mathrm{F})(\mathrm{H}) \mathrm{H})(\mathrm{Br}) \mathrm{H})(\mathrm{H}) \mathrm{F})(\mathrm{F}) \mathrm{H})(\mathrm{H}) \mathrm{H})(\mathrm{F}) \mathrm{H})(\mathrm{H}) \mathrm{H})(\mathrm{C} 17 \mathrm{H} 20 \mathrm{Cl} 3 \mathrm{Br} 2 \mathrm{~F} 1$ $\mathrm{H}) \mathrm{Cl}(\mathrm{F}) \mathrm{Cl})(\mathrm{H}) \mathrm{F})(\mathrm{H}) \mathrm{H})(\mathrm{H}) \mathrm{Cl})(\mathrm{H}) \mathrm{F})(\mathrm{H})(\mathrm{H}) \mathrm{Br}$ $\mathrm{C}(\mathrm{C}(\mathrm{C}(\mathrm{C}(\mathrm{C}(\mathrm{C}(\mathrm{C}(\mathrm{C}(\mathrm{C}(\mathrm{C}(\mathrm{C})$

$\mathrm{C}(\mathrm{C}(\mathrm{C}(\mathrm{C}(\mathrm{C}(\mathrm{C}(\mathrm{C}(\mathrm{C}(\mathrm{C}(\mathrm{C}(\mathrm{C}(\mathrm{C}(\mathrm{C}(\mathrm{C}(\mathrm{C}(\mathrm{C}(\mathrm{C}(\mathrm{F})(\mathrm{H}) \mathrm{F})(\mathrm{Cl}) \mathrm{H})(\mathrm{H}) \mathrm{F})(\mathrm{F}) \mathrm{H})(\mathrm{H}) \mathrm{H})(\mathrm{H}) \mathrm{F})(\mathrm{Cl}) \mathrm{H})(\mathrm{Cl}) \mathrm{H})(\mathrm{H}) \mathrm{H})$

$(\mathrm{H}) \mathrm{H})(\mathrm{F}) \mathrm{H})(\mathrm{H}) \mathrm{H})(\mathrm{Cl}) \mathrm{F})(\mathrm{H}) \mathrm{H})(\mathrm{H}) \mathrm{F})(\mathrm{F}) \mathrm{Cl}(\mathrm{F})(\mathrm{Cl}) \mathrm{H}$

$\mathrm{C}(\mathrm{C}(\mathrm{C}(\mathrm{C}(\mathrm{C}(\mathrm{C}(\mathrm{C}(\mathrm{C}(\mathrm{C}(\mathrm{C}(\mathrm{C}(\mathrm{C}(\mathrm{C}(\mathrm{C}(\mathrm{C}(\mathrm{C}(\mathrm{C}(\mathrm{H})(\mathrm{H}) \mathrm{F})(\mathrm{F}) \mathrm{H})(\mathrm{BH}) \mathrm{F})(\mathrm{H}) \mathrm{F})(\mathrm{F}) \mathrm{Br})(\mathrm{H}) \mathrm{H})(\mathrm{F}) \mathrm{H})(\mathrm{H}) \mathrm{H})(\mathrm{F}) \mathrm{L}$

$\mathrm{H}) \mathrm{Cl})(\mathrm{F}) \mathrm{H})(\mathrm{H}) \mathrm{H})(\mathrm{F}) \mathrm{H})(\mathrm{H}) \mathrm{H})(\mathrm{H}) \mathrm{F})(\mathrm{H})(\mathrm{H}) \mathrm{F}$

$\mathrm{C}(\mathrm{C}(\mathrm{C}(\mathrm{C}(\mathrm{C}(\mathrm{C}(\mathrm{C}(\mathrm{C}(\mathrm{C}(\mathrm{C}(\mathrm{C}(\mathrm{C}(\mathrm{C}(\mathrm{C}(\mathrm{C}(\mathrm{C}(\mathrm{C}(\mathrm{H})(\mathrm{F}) \mathrm{F})(\mathrm{F}) \mathrm{H})(\mathrm{Br}) \mathrm{H})(\mathrm{H}) \mathrm{H})(\mathrm{F}) \mathrm{F})(\mathrm{H}) \mathrm{F})(\mathrm{Br}) \mathrm{F})(\mathrm{H}) \mathrm{H})(\mathrm{F}) \mathrm{H})(\mathrm{H}) \mathrm{H})$

$(\mathrm{H}) \mathrm{H})(\mathrm{H}) \mathrm{H})(\mathrm{Br}) \mathrm{H})(\mathrm{H}) \mathrm{F})(\mathrm{F}) \mathrm{H})(\mathrm{F}) \mathrm{H})(\mathrm{H})(\mathrm{H}) \mathrm{F}$

$\mathrm{C}(\mathrm{C}(\mathrm{C}(\mathrm{C}(\mathrm{C}(\mathrm{C}(\mathrm{C}(\mathrm{C}(\mathrm{C}(\mathrm{C}(\mathrm{C}(\mathrm{C}(\mathrm{C}(\mathrm{C}(\mathrm{C}(\mathrm{C}(\mathrm{C}(\mathrm{F})(\mathrm{Cl}) \mathrm{H})(\mathrm{H}) \mathrm{H})(\mathrm{H}) \mathrm{H})(\mathrm{H}) \mathrm{H})(\mathrm{H}) \mathrm{F})(\mathrm{F}) \mathrm{H})(\mathrm{H}) \mathrm{H})(\mathrm{F}) \mathrm{H})(\mathrm{H}) \mathrm{F})(\mathrm{H}) \mathrm{F})(\mathrm{Cl}$ $\mathrm{F}) \mathrm{Cl}(\mathrm{H}) \mathrm{F})(\mathrm{Cl}) \mathrm{H})(\mathrm{H}) \mathrm{Cl})(\mathrm{H}) \mathrm{H})(\mathrm{F}) \mathrm{H})(\mathrm{H})(\mathrm{F}) \mathrm{Cl}$

$\mathrm{C}(\mathrm{C}(\mathrm{C}(\mathrm{C}(\mathrm{C}(\mathrm{C}(\mathrm{C}(\mathrm{C}(\mathrm{C}(\mathrm{C}(\mathrm{C}(\mathrm{C}(\mathrm{C}(\mathrm{C}(\mathrm{C}(\mathrm{C}(\mathrm{C}(\mathrm{F})(\mathrm{H}) \mathrm{H})(\mathrm{H}) \mathrm{H})(\mathrm{Br}) \mathrm{H})(\mathrm{F}) \mathrm{H})(\mathrm{F}) \mathrm{H})(\mathrm{H}) \mathrm{H})(\mathrm{H}) \mathrm{F})(\mathrm{H}) \mathrm{H})(\mathrm{Br}) \mathrm{F})$

$(\mathrm{H}) \mathrm{F})(\mathrm{H}) \mathrm{H})(\mathrm{H}) \mathrm{F})(\mathrm{F}) \mathrm{Br})(\mathrm{H}) \mathrm{H})(\mathrm{F}) \mathrm{H})(\mathrm{H}) \mathrm{F})(\mathrm{H})(\mathrm{F}) \mathrm{H}$

$\mathrm{C}(\mathrm{C}(\mathrm{C}(\mathrm{C}(\mathrm{C}(\mathrm{C}(\mathrm{C}(\mathrm{C}(\mathrm{C}(\mathrm{C}(\mathrm{C}(\mathrm{C}(\mathrm{C}(\mathrm{C}(\mathrm{C}(\mathrm{C}(\mathrm{C}(\mathrm{H})(\mathrm{Cl}) \mathrm{H})(\mathrm{Br}) \mathrm{H})(\mathrm{H}) \mathrm{H})(\mathrm{F}) \mathrm{F})(\mathrm{H}) \mathrm{H})(\mathrm{H}) \mathrm{H})(\mathrm{F}) \mathrm{H})(\mathrm{H}) \mathrm{Cl})(\mathrm{F}) \mathrm{H})$

$(\mathrm{F}) \mathrm{H})(\mathrm{H}) \mathrm{F})(\mathrm{H}) \mathrm{H})(\mathrm{F}) \mathrm{H})(\mathrm{Cl}) \mathrm{H})(\mathrm{F}) \mathrm{H})(\mathrm{Cl}) \mathrm{H})(\mathrm{F})(\mathrm{H}) \mathrm{H}$

$\mathrm{C}(\mathrm{C}(\mathrm{C}(\mathrm{C}(\mathrm{C}(\mathrm{C}(\mathrm{C}(\mathrm{C}(\mathrm{C}(\mathrm{C}(\mathrm{C}(\mathrm{C}(\mathrm{C}(\mathrm{C}(\mathrm{C}(\mathrm{C}(\mathrm{C}(\mathrm{Cl})(\mathrm{H}) \mathrm{Cl})(\mathrm{H}) \mathrm{H})(\mathrm{H}) \mathrm{Cl})(\mathrm{H}) \mathrm{F})(\mathrm{H}) \mathrm{F})(\mathrm{H}) \mathrm{H})(\mathrm{F}) \mathrm{H})(\mathrm{F}) \mathrm{H})(\mathrm{H}) \mathrm{H})(\mathrm{Cl})$

$\mathrm{H})(\mathrm{H}) \mathrm{Cl})(\mathrm{H}) \mathrm{H})(\mathrm{H}) \mathrm{F})(\mathrm{H}) \mathrm{F})(\mathrm{H}) \mathrm{H})(\mathrm{H}) \mathrm{F})(\mathrm{F})(\mathrm{Br}) \mathrm{H}$

$\mathrm{C}(\mathrm{C}(\mathrm{C}(\mathrm{C}(\mathrm{C}(\mathrm{C}(\mathrm{C}(\mathrm{C}(\mathrm{C}(\mathrm{C}(\mathrm{C}(\mathrm{C}(\mathrm{C}(\mathrm{C}(\mathrm{C}(\mathrm{C}(\mathrm{C}(\mathrm{H})(\mathrm{H}) \mathrm{Cl})(\mathrm{H}) \mathrm{F})(\mathrm{H}) \mathrm{F})(\mathrm{H}) \mathrm{F})(\mathrm{H}) \mathrm{H})(\mathrm{H}) \mathrm{Cl})(\mathrm{Cl}) \mathrm{H})(\mathrm{Cl}) \mathrm{H})(\mathrm{H}) \mathrm{F})(\mathrm{H})$

$\mathrm{H})(\mathrm{Cl}) \mathrm{F})(\mathrm{H}) \mathrm{H})(\mathrm{F}) \mathrm{H})(\mathrm{H}) \mathrm{F})(\mathrm{H}) \mathrm{F})(\mathrm{H}) \mathrm{H})(\mathrm{H})(\mathrm{F}) \mathrm{H}$

$\mathrm{C}(\mathrm{C}(\mathrm{C}(\mathrm{C}(\mathrm{C}(\mathrm{C}(\mathrm{C}(\mathrm{C}(\mathrm{C}(\mathrm{C}(\mathrm{C}(\mathrm{C}(\mathrm{C}(\mathrm{C}(\mathrm{C}(\mathrm{C}(\mathrm{C}(\mathrm{H})(\mathrm{F}) \mathrm{H})(\mathrm{F}) \mathrm{F})(\mathrm{H}) \mathrm{H})(\mathrm{H}) \mathrm{F})(\mathrm{H}) \mathrm{H})(\mathrm{H}) \mathrm{H})(\mathrm{H}) \mathrm{H})(\mathrm{F}) \mathrm{F})(\mathrm{H}) \mathrm{H})(\mathrm{H}) \mathrm{F})($ $\mathrm{H}) \mathrm{H})(\mathrm{H}) \mathrm{Br})(\mathrm{H}) \mathrm{F})(\mathrm{H}) \mathrm{F})(\mathrm{H}) \mathrm{Br})(\mathrm{F}) \mathrm{H})(\mathrm{F})(\mathrm{H}) \mathrm{H}$

$\mathrm{C}(\mathrm{C}(\mathrm{C}(\mathrm{C}(\mathrm{C}(\mathrm{C}(\mathrm{C}(\mathrm{C}(\mathrm{C}(\mathrm{C}(\mathrm{C}(\mathrm{C}(\mathrm{C}(\mathrm{C}(\mathrm{C}(\mathrm{C}(\mathrm{C}(\mathrm{H})(\mathrm{H}) \mathrm{F})(\mathrm{H}) \mathrm{H})(\mathrm{F}) \mathrm{H})(\mathrm{F}) \mathrm{H})(\mathrm{H}) \mathrm{F})(\mathrm{H}) \mathrm{H})(\mathrm{F}) \mathrm{H})(\mathrm{H}) \mathrm{Br})(\mathrm{Br}) \mathrm{H})$

$(\mathrm{H}) \mathrm{H})(\mathrm{Br}) \mathrm{H})(\mathrm{H}) \mathrm{F})(\mathrm{H}) \mathrm{H})(\mathrm{H}) \mathrm{H})(\mathrm{F}) \mathrm{F})(\mathrm{H}) \mathrm{H})(\mathrm{F})(\mathrm{H}) \mathrm{F}$

$\mathrm{C}\left(\mathrm{C}\left(\mathrm{C}\left(\mathrm{C}\left(\mathrm{C}\left(\mathrm{C}\left(\mathrm{C}(\mathrm{C}(\mathrm{C}(\mathrm{C}(\mathrm{C}(\mathrm{C}(\mathrm{C}(\mathrm{C}(\mathrm{C}(\mathrm{C}(\mathrm{C}(\mathrm{F})(\mathrm{H}) \mathrm{F})(\mathrm{H}) \mathrm{F})(\mathrm{H}) \mathrm{H})(\mathrm{H}) \mathrm{H})(\mathrm{H}) \mathrm{F})(\mathrm{H}) \mathrm{H})(\mathrm{F}) \mathrm{H})(\mathrm{H}) \mathrm{H})(\mathrm{H}) \mathrm{H})(\mathrm{H}) \mathrm{H})\left(\mathrm{C} 17 \mathrm{H}^{2} \mathrm{C}\right.\right.\right.\right.\right.\right.\right.$

$\mathrm{H}) \mathrm{Cl}(\mathrm{F}) \mathrm{Cl})(\mathrm{H}) \mathrm{H})(\mathrm{H}) \mathrm{F})(\mathrm{F}) \mathrm{H})(\mathrm{Br}) \mathrm{H})(\mathrm{H})(\mathrm{F}) \mathrm{Cl}$

$\mathrm{C}\left(\mathrm{C}\left(\mathrm{C}\left(\mathrm{C}\left(\mathrm{C}\left(\mathrm{C}\left(\mathrm{C}(\mathrm{C}(\mathrm{C}(\mathrm{C}(\mathrm{C}(\mathrm{C}(\mathrm{C}(\mathrm{C}(\mathrm{C}(\mathrm{C}(\mathrm{C}(\mathrm{H})(\mathrm{F}) \mathrm{Cl})(\mathrm{H}) \mathrm{H})(\mathrm{H}) \mathrm{H})(\mathrm{H}) \mathrm{F})(\mathrm{F}) \mathrm{H})(\mathrm{H}) \mathrm{H})(\mathrm{F}) \mathrm{H})(\mathrm{H}) \mathrm{H})(\mathrm{F}) \mathrm{F})(\mathrm{F}) \mathrm{F})\left({ }_{\mathrm{C} 17 \mathrm{H} 23 \mathrm{Cl} 4 \mathrm{~F} 9}\right.\right.\right.\right.\right.\right.\right.$

F) $\mathrm{H})(\mathrm{H}) \mathrm{H})(\mathrm{Cl}) \mathrm{H})(\mathrm{Cl}) \mathrm{H})(\mathrm{H}) \mathrm{H})(\mathrm{H}) \mathrm{H})(\mathrm{H})(\mathrm{Cl}) \mathrm{H}$

$\mathrm{C}(\mathrm{C}(\mathrm{C}(\mathrm{C}(\mathrm{C}(\mathrm{C}(\mathrm{C}(\mathrm{C}(\mathrm{C}(\mathrm{C}(\mathrm{C}(\mathrm{C}(\mathrm{C}(\mathrm{C}(\mathrm{C}(\mathrm{C}(\mathrm{C}(\mathrm{H})(\mathrm{F}) \mathrm{H})(\mathrm{H}) \mathrm{F})(\mathrm{H}) \mathrm{H})(\mathrm{F}) \mathrm{H})(\mathrm{Br}) \mathrm{H})(\mathrm{H}) \mathrm{F})(\mathrm{H}) \mathrm{Br})(\mathrm{H}) \mathrm{H})(\mathrm{F}) \mathrm{H}) \quad \mathrm{C} 17 \mathrm{H} 23 \mathrm{ClBr} 3 \mathrm{~F} 9$

$(\mathrm{H}) \mathrm{F})(\mathrm{H}) \mathrm{F})(\mathrm{F}) \mathrm{H})(\mathrm{H}) \mathrm{H})(\mathrm{H}) \mathrm{Cl}(\mathrm{H}) \mathrm{H})(\mathrm{H}) \mathrm{H})(\mathrm{F})(\mathrm{H}) \mathrm{Br}$

H) $(\mathrm{H}) \mathrm{H}(\mathrm{H}) \mathrm{H}(\mathrm{H}) \mathrm{F})(\mathrm{H}) \mathrm{H})(\mathrm{H}) \mathrm{F})(\mathrm{Br})(\mathrm{H}) \mathrm{H}$

$\mathrm{C}\left(\mathrm{C}\left(\mathrm{C}\left(\mathrm{C}\left(\mathrm{C}\left(\mathrm{C}\left(\mathrm{C}(\mathrm{C}(\mathrm{C}(\mathrm{C}(\mathrm{C}(\mathrm{C}(\mathrm{C}(\mathrm{C}(\mathrm{C}(\mathrm{C}(\mathrm{C}(\mathrm{F})(\mathrm{F}) \mathrm{H})(\mathrm{H}) \mathrm{F})(\mathrm{H}) \mathrm{H})(\mathrm{H}) \mathrm{F})(\mathrm{H}) \mathrm{H})(\mathrm{H}) \mathrm{H})(\mathrm{H}) \mathrm{Br})(\mathrm{F}) \mathrm{H})(\mathrm{H}) \mathrm{F})(\mathrm{H}) \mathrm{H}){ }_{\mathrm{C}} 17 \mathrm{H} 24 \mathrm{Br} 3 \mathrm{~F} 9\right.\right.\right.\right.\right.\right.$

$(\mathrm{Br}) \mathrm{Br})(\mathrm{H}) \mathrm{H})(\mathrm{H}) \mathrm{H})(\mathrm{H}) \mathrm{H})(\mathrm{F}) \mathrm{H})(\mathrm{H}) \mathrm{H})(\mathrm{F})(\mathrm{H}) \mathrm{F}$

$\mathrm{C}(\mathrm{C}(\mathrm{C}(\mathrm{C}(\mathrm{C}(\mathrm{C}(\mathrm{C}(\mathrm{C}(\mathrm{C}(\mathrm{C}(\mathrm{C}(\mathrm{C}(\mathrm{C}(\mathrm{C}(\mathrm{C}(\mathrm{C}(\mathrm{C}(\mathrm{H})(\mathrm{F}) \mathrm{Br})(\mathrm{H}) \mathrm{F})(\mathrm{Cl}) \mathrm{H})(\mathrm{H}) \mathrm{F})(\mathrm{H}) \mathrm{H})(\mathrm{H}) \mathrm{H})(\mathrm{F}) \mathrm{H})(\mathrm{H}) \mathrm{F})(\mathrm{H}) \mathrm{H})$

$(\mathrm{H}) \mathrm{H})(\mathrm{Cl}) \mathrm{H})(\mathrm{F}) \mathrm{Br})(\mathrm{F}) \mathrm{H})(\mathrm{H}) \mathrm{H})(\mathrm{H}) \mathrm{H})(\mathrm{F}) \mathrm{H})(\mathrm{H})(\mathrm{H}) \mathrm{H}$

$\mathrm{C}(\mathrm{C}(\mathrm{C}(\mathrm{C}(\mathrm{C}(\mathrm{C}(\mathrm{C}(\mathrm{C}(\mathrm{C}(\mathrm{C}(\mathrm{C}(\mathrm{C}(\mathrm{C}(\mathrm{C}(\mathrm{C}(\mathrm{C}(\mathrm{C}(\mathrm{H})(\mathrm{H}) \mathrm{H})(\mathrm{H}) \mathrm{Br})(\mathrm{F}) \mathrm{Cl})(\mathrm{Cl}) \mathrm{H})(\mathrm{H}) \mathrm{H})(\mathrm{H}) \mathrm{H})(\mathrm{F}) \mathrm{H})(\mathrm{F}) \mathrm{H})(\mathrm{F}) \mathrm{H})$

$(\mathrm{H}) \mathrm{F})(\mathrm{H}) \mathrm{H})(\mathrm{H}) \mathrm{F})(\mathrm{H}) \mathrm{H})(\mathrm{H}) \mathrm{H})(\mathrm{H}) \mathrm{H})(\mathrm{F}) \mathrm{H})(\mathrm{F})(\mathrm{F}) \mathrm{H}$

$\mathrm{C}(\mathrm{C}(\mathrm{C}(\mathrm{C}(\mathrm{C}(\mathrm{C}(\mathrm{C}(\mathrm{C}(\mathrm{C}(\mathrm{C}(\mathrm{C}(\mathrm{C}(\mathrm{C}(\mathrm{C}(\mathrm{C}(\mathrm{C}(\mathrm{C}(\mathrm{H})(\mathrm{H}) \mathrm{H})(\mathrm{F}) \mathrm{H})(\mathrm{Cl}) \mathrm{F})(\mathrm{F}) \mathrm{H})(\mathrm{F}) \mathrm{Cl})(\mathrm{H}) \mathrm{H})(\mathrm{H}) \mathrm{H})(\mathrm{H}) \mathrm{H})(\mathrm{H}) \mathrm{H})(\mathrm{F}) \mathrm{F})$ $(\mathrm{H}) \mathrm{F})(\mathrm{H}) \mathrm{H})(\mathrm{H}) \mathrm{F})(\mathrm{F}) \mathrm{H})(\mathrm{H}) \mathrm{H})(\mathrm{H}) \mathrm{H})(\mathrm{F})(\mathrm{H}) \mathrm{H}$

$\mathrm{C}(\mathrm{C}(\mathrm{C}(\mathrm{C}(\mathrm{C}(\mathrm{C}(\mathrm{C}(\mathrm{C}(\mathrm{C}(\mathrm{C}(\mathrm{C}(\mathrm{C}(\mathrm{C}(\mathrm{C}(\mathrm{C}(\mathrm{C}(\mathrm{C}(\mathrm{H})(\mathrm{H}) \mathrm{F})(\mathrm{Cl}) \mathrm{H})(\mathrm{H}) \mathrm{H})(\mathrm{H}) \mathrm{H})(\mathrm{H}) \mathrm{H})(\mathrm{H}) \mathrm{F})(\mathrm{H}) \mathrm{H})(\mathrm{Cl}) \mathrm{F})(\mathrm{H}) \mathrm{H})(\mathrm{H})$ $\mathrm{H})(\mathrm{H}) \mathrm{H})(\mathrm{H}) \mathrm{F})(\mathrm{H}) \mathrm{Cl})(\mathrm{F}) \mathrm{F})(\mathrm{H}) \mathrm{F})(\mathrm{H}) \mathrm{F})(\mathrm{F})(\mathrm{H}) \mathrm{H}$

$\mathrm{C}(\mathrm{C}(\mathrm{C}(\mathrm{C}(\mathrm{C}(\mathrm{C}(\mathrm{C}(\mathrm{C}(\mathrm{C}(\mathrm{C}(\mathrm{C}(\mathrm{C}(\mathrm{C}(\mathrm{C}(\mathrm{C}(\mathrm{C}(\mathrm{C}(\mathrm{H})(\mathrm{H}) \mathrm{F})(\mathrm{H}) \mathrm{H})(\mathrm{F}) \mathrm{H})(\mathrm{Cl}) \mathrm{F})(\mathrm{H}) \mathrm{H})(\mathrm{H}) \mathrm{H})(\mathrm{H}) \mathrm{F})(\mathrm{H}) \mathrm{Cl})(\mathrm{Cl}) \mathrm{H})(\mathrm{H})$

$\mathrm{H})(\mathrm{H}) \mathrm{F})(\mathrm{F}) \mathrm{F})(\mathrm{H}) \mathrm{H})(\mathrm{H}) \mathrm{F})(\mathrm{Cl}) \mathrm{H})(\mathrm{H}) \mathrm{H})(\mathrm{H})(\mathrm{H}) \mathrm{H}$

(H)(H)(H) $(\mathrm{H}) \mathrm{H})(\mathrm{F}) \mathrm{H})(\mathrm{H}) \mathrm{H})(\mathrm{H}) \mathrm{Cl})(\mathrm{H}) \mathrm{H})(\mathrm{H}) \mathrm{H})(\mathrm{F}$

$\mathrm{H})(\mathrm{F}) \mathrm{H})(\mathrm{F}) \mathrm{Cl}(\mathrm{H}) \mathrm{H})(\mathrm{H}) \mathrm{H})(\mathrm{Cl}) \mathrm{H})(\mathrm{Cl}) \mathrm{H})(\mathrm{F})(\mathrm{F}) \mathrm{H}$

$\mathrm{C}(\mathrm{C}(\mathrm{C}(\mathrm{C}(\mathrm{C}(\mathrm{C}(\mathrm{C}(\mathrm{C}(\mathrm{C}(\mathrm{C}(\mathrm{C}(\mathrm{C}(\mathrm{C}(\mathrm{C}(\mathrm{C}(\mathrm{C}(\mathrm{C}(\mathrm{H})(\mathrm{F}) \mathrm{H})(\mathrm{H}) \mathrm{H})(\mathrm{F}) \mathrm{H})(\mathrm{F}) \mathrm{H})(\mathrm{H}) \mathrm{H})(\mathrm{H}) \mathrm{F})(\mathrm{Cl}) \mathrm{F})(\mathrm{F}) \mathrm{F})(\mathrm{F}) \mathrm{H})(\mathrm{H}) \mathrm{Br})($ $\mathrm{H}) \mathrm{H})(\mathrm{H}) \mathrm{H})(\mathrm{H}) \mathrm{H})(\mathrm{H}) \mathrm{F})(\mathrm{H}) \mathrm{H})(\mathrm{H}) \mathrm{Br})(\mathrm{H})(\mathrm{H}) \mathrm{H}$

$\mathrm{C}\left(\mathrm{C}\left(\mathrm{C}\left(\mathrm{C}\left(\mathrm{C}\left(\mathrm{C}\left(\mathrm{C}(\mathrm{C}(\mathrm{C}(\mathrm{C}(\mathrm{C}(\mathrm{C}(\mathrm{C}(\mathrm{C}(\mathrm{C}(\mathrm{C}(\mathrm{C}(\mathrm{H})(\mathrm{F}) \mathrm{F})(\mathrm{H}) \mathrm{H})(\mathrm{H}) \mathrm{F})(\mathrm{H}) \mathrm{H})(\mathrm{H}) \mathrm{F})(\mathrm{H}) \mathrm{H})(\mathrm{F}) \mathrm{H})(\mathrm{F}) \mathrm{H})(\mathrm{H}) \mathrm{F})(\mathrm{Cl}) \mathrm{F})\left({ }_{\mathrm{C} 17 \mathrm{H} 24 \mathrm{ClBrF} 10}\right.\right.\right.\right.\right.\right.\right.$ $\mathrm{H}) \mathrm{H})(\mathrm{H}) \mathrm{H})(\mathrm{F}) \mathrm{Br})(\mathrm{H}) \mathrm{F})(\mathrm{H}) \mathrm{H})(\mathrm{H}) \mathrm{H})(\mathrm{H})(\mathrm{H}) \mathrm{H}$

$\mathrm{C}\left(\mathrm{C}\left(\mathrm{C}\left(\mathrm{C}\left(\mathrm{C}\left(\mathrm{C}\left(\mathrm{C}(\mathrm{C}(\mathrm{C}(\mathrm{C}(\mathrm{C}(\mathrm{C}(\mathrm{C}(\mathrm{C}(\mathrm{C}(\mathrm{C}(\mathrm{C}(\mathrm{F})(\mathrm{H}) \mathrm{H})(\mathrm{H}) \mathrm{H})(\mathrm{H}) \mathrm{F})(\mathrm{H}) \mathrm{H})(\mathrm{H}) \mathrm{F})(\mathrm{H}) \mathrm{H})(\mathrm{H}) \mathrm{H})(\mathrm{F}) \mathrm{H})(\mathrm{H}) \mathrm{F})(\mathrm{H}) \mathrm{F})\left({ }_{\mathrm{C} 17 \mathrm{H} 25 \mathrm{Br} 3 \mathrm{~F} 8}\right.\right.\right.\right.\right.\right.\right.$

$\mathrm{F}) \mathrm{H})(\mathrm{Br}) \mathrm{H})(\mathrm{H}) \mathrm{H})(\mathrm{H}) \mathrm{F})(\mathrm{H}) \mathrm{H})(\mathrm{Br}) \mathrm{H})(\mathrm{Br})(\mathrm{H}) \mathrm{H}$

$\mathrm{C}\left(\mathrm{C}\left(\mathrm{C}\left(\mathrm{C}\left(\mathrm{C}\left(\mathrm{C}\left(\mathrm{C}(\mathrm{C}(\mathrm{C}(\mathrm{C}(\mathrm{C}(\mathrm{C}(\mathrm{C}(\mathrm{C}(\mathrm{C}(\mathrm{C}(\mathrm{C}(\mathrm{H})(\mathrm{H}) \mathrm{H})(\mathrm{H}) \mathrm{F})(\mathrm{F}) \mathrm{H})(\mathrm{F}) \mathrm{H})(\mathrm{Cl}) \mathrm{H})(\mathrm{H}) \mathrm{F})(\mathrm{H}) \mathrm{F})(\mathrm{H}) \mathrm{F})(\mathrm{H}) \mathrm{H})(\mathrm{H}) \mathrm{H})\left({ }_{\mathrm{C} 17 \mathrm{H} 25 \mathrm{Cl} 2 \mathrm{BrF}}\right.\right.\right.\right.\right.\right.\right.$

$\mathrm{H}) \mathrm{H})(\mathrm{H}) \mathrm{H})(\mathrm{H}) \mathrm{H})(\mathrm{Cl}) \mathrm{F})(\mathrm{F}) \mathrm{Br})(\mathrm{H}) \mathrm{H})(\mathrm{H})(\mathrm{H}) \mathrm{H}$

$\mathrm{C}(\mathrm{C}(\mathrm{C}(\mathrm{C}(\mathrm{C}(\mathrm{C}(\mathrm{C}(\mathrm{C}(\mathrm{C}(\mathrm{C}(\mathrm{C}(\mathrm{C}(\mathrm{C}(\mathrm{C}(\mathrm{C}(\mathrm{C}(\mathrm{C}(\mathrm{H})(\mathrm{F}) \mathrm{H})(\mathrm{H}) \mathrm{H})(\mathrm{H}) \mathrm{H})(\mathrm{F}) \mathrm{H})(\mathrm{H}) \mathrm{H})(\mathrm{H}) \mathrm{H})(\mathrm{H}) \mathrm{H})(\mathrm{F}) \mathrm{H})(\mathrm{Cl}) \mathrm{F}) \quad \mathrm{C} 17 \mathrm{H} 25 \mathrm{Cl} 3 \mathrm{~F} 8$

$(\mathrm{Cl}) \mathrm{H})(\mathrm{H}) \mathrm{F})(\mathrm{H}) \mathrm{H})(\mathrm{H}) \mathrm{H})(\mathrm{H}) \mathrm{H})(\mathrm{F}) \mathrm{H})(\mathrm{Cl}) \mathrm{H})(\mathrm{F})(\mathrm{F}) \mathrm{H}$

$\mathrm{C} 17 \mathrm{H} 25 \mathrm{Cl} 3 \mathrm{~F} 8$

$\mathrm{C}(\mathrm{C}(\mathrm{C}(\mathrm{C}(\mathrm{C}(\mathrm{C}(\mathrm{C}(\mathrm{C}(\mathrm{C}(\mathrm{C}(\mathrm{C}(\mathrm{C}(\mathrm{C}(\mathrm{C}(\mathrm{C}(\mathrm{C}(\mathrm{C}(\mathrm{H})$

$\mathrm{C}(\mathrm{C}(\mathrm{C}(\mathrm{C}(\mathrm{C}(\mathrm{C}(\mathrm{C}(\mathrm{C}(\mathrm{C}(\mathrm{C}(\mathrm{C}(\mathrm{C}(\mathrm{C}(\mathrm{C}(\mathrm{C}(\mathrm{C}(\mathrm{C}(\mathrm{H})(\mathrm{H}) \mathrm{H})(\mathrm{H}) \mathrm{Cl})(\mathrm{Cl}) \mathrm{H})(\mathrm{F}) \mathrm{H})(\mathrm{H}) \mathrm{H})(\mathrm{H}) \mathrm{H})(\mathrm{H}) \mathrm{H})(\mathrm{F}) \mathrm{H})(\mathrm{H}) \mathrm{Cl})(\mathrm{H}) \quad \mathrm{C} 17 \mathrm{H} 25 \mathrm{Cl} 5 \mathrm{~F} 6$

$\mathrm{F})(\mathrm{H}) \mathrm{H})(\mathrm{H}) \mathrm{F})(\mathrm{H}) \mathrm{H})(\mathrm{H}) \mathrm{H})(\mathrm{H}) \mathrm{F})(\mathrm{Cl}) \mathrm{H})(\mathrm{F})(\mathrm{H}) \mathrm{Cl}$

$\mathrm{C}\left(\mathrm{C}\left(\mathrm{C}\left(\mathrm{C}\left(\mathrm{C}\left(\mathrm{C}\left(\mathrm{C}(\mathrm{C}(\mathrm{C}(\mathrm{C}(\mathrm{C}(\mathrm{C}(\mathrm{C}(\mathrm{C}(\mathrm{C}(\mathrm{C}(\mathrm{C}(\mathrm{H})(\mathrm{Br}) \mathrm{H})(\mathrm{H}) \mathrm{H})(\mathrm{H}) \mathrm{H})(\mathrm{H}) \mathrm{F})(\mathrm{F}) \mathrm{H})(\mathrm{H}) \mathrm{H})(\mathrm{F}) \mathrm{H})(\mathrm{F}) \mathrm{H})(\mathrm{F}) \mathrm{H})(\mathrm{H}) \mathrm{H}){ }_{\mathrm{C} 17 \mathrm{H} 25 \mathrm{ClBr} 2 \mathrm{~F} 8}\right.\right.\right.\right.\right.\right.$

$(\mathrm{H}) \mathrm{H})(\mathrm{H}) \mathrm{F})(\mathrm{H}) \mathrm{F})(\mathrm{H}) \mathrm{H})(\mathrm{H}) \mathrm{H})(\mathrm{Cl}) \mathrm{Br})(\mathrm{H})(\mathrm{H}) \mathrm{F}$

$\mathrm{C}\left(\mathrm{C}\left(\mathrm{C}\left(\mathrm{C}\left(\mathrm{C}\left(\mathrm{C}\left(\mathrm{C}\left(\mathrm{C}(\mathrm{C}(\mathrm{C}(\mathrm{C}(\mathrm{C}(\mathrm{C}(\mathrm{C}(\mathrm{C}(\mathrm{C}(\mathrm{C}(\mathrm{H})(\mathrm{H}) \mathrm{H})(\mathrm{F}) \mathrm{H})(\mathrm{H}) \mathrm{F})(\mathrm{H}) \mathrm{H})(\mathrm{H}) \mathrm{H})(\mathrm{H}) \mathrm{H})(\mathrm{H}) \mathrm{H})(\mathrm{H}) \mathrm{Cl})(\mathrm{Br}) \mathrm{H})(\mathrm{H}) \quad{ }_{\mathrm{C} 17 \mathrm{H} 25 \mathrm{ClBr} 3 \mathrm{~F} 7}\right.\right.\right.\right.\right.\right.\right.$

$\mathrm{F})(\mathrm{H}) \mathrm{Br})(\mathrm{H}) \mathrm{F})(\mathrm{H}) \mathrm{H})(\mathrm{H}) \mathrm{H})(\mathrm{Br}) \mathrm{H})(\mathrm{H}) \mathrm{F})(\mathrm{H})(\mathrm{F}) \mathrm{F}$

C(C(C(C(C(C(C(C(C(C(C(C(C(C(C(C(C(H)(F)H)(H)H)(H)H)(H)F)(H)F)(F)H)(H)H)(F)H)(Br)F)(H)H $(\mathrm{Cl}) \mathrm{F})(\mathrm{H}) \mathrm{H})(\mathrm{F}) \mathrm{H})(\mathrm{H}) \mathrm{H})(\mathrm{H}) \mathrm{H})(\mathrm{H}) \mathrm{H})(\mathrm{H})(\mathrm{H}) \mathrm{F}$

$\mathrm{C}(\mathrm{C}(\mathrm{C}(\mathrm{C}(\mathrm{C}(\mathrm{C}(\mathrm{C}(\mathrm{C}(\mathrm{C}(\mathrm{C}(\mathrm{C}(\mathrm{C}(\mathrm{C}(\mathrm{C}(\mathrm{C}(\mathrm{C}(\mathrm{C}(\mathrm{F})(\mathrm{H}) \mathrm{H})(\mathrm{H}) \mathrm{H})(\mathrm{H}) \mathrm{H})(\mathrm{H}) \mathrm{H})(\mathrm{F}) \mathrm{H})(\mathrm{H}) \mathrm{H})(\mathrm{H}) \mathrm{H})(\mathrm{H}) \mathrm{Br})(\mathrm{H}) \mathrm{H})$

$(\mathrm{H}) \mathrm{F})(\mathrm{H}) \mathrm{Br})(\mathrm{F}) \mathrm{H})(\mathrm{H}) \mathrm{F})(\mathrm{F}) \mathrm{H})(\mathrm{F}) \mathrm{H})(\mathrm{H}) \mathrm{F})(\mathrm{H})(\mathrm{H}) \mathrm{H}$

$\mathrm{C}(\mathrm{C}(\mathrm{C}(\mathrm{C}(\mathrm{C}(\mathrm{C}(\mathrm{C}(\mathrm{C}(\mathrm{C}(\mathrm{C}(\mathrm{C}(\mathrm{C}(\mathrm{C}(\mathrm{C}(\mathrm{C}(\mathrm{C}(\mathrm{C}(\mathrm{H})(\mathrm{H}) \mathrm{H})(\mathrm{F}) \mathrm{H})(\mathrm{H}) \mathrm{H})(\mathrm{H}) \mathrm{H})(\mathrm{H}) \mathrm{F})(\mathrm{H}) \mathrm{H})(\mathrm{H}) \mathrm{F})(\mathrm{H}) \mathrm{H})(\mathrm{H}) \mathrm{F})(\mathrm{H}) \mathrm{H})$

$(\mathrm{H}) \mathrm{H})(\mathrm{H}) \mathrm{H})(\mathrm{H}) \mathrm{H})(\mathrm{H}) \mathrm{Br})(\mathrm{F}) \mathrm{F})(\mathrm{F}) \mathrm{F})(\mathrm{H})(\mathrm{F}) \mathrm{H}$

$\mathrm{C}(\mathrm{C}(\mathrm{C}(\mathrm{C}(\mathrm{C}(\mathrm{C}(\mathrm{C}(\mathrm{C}(\mathrm{C}(\mathrm{C}(\mathrm{C}(\mathrm{C}(\mathrm{C}(\mathrm{C}(\mathrm{C}(\mathrm{C}(\mathrm{C}(\mathrm{H})(\mathrm{H}) \mathrm{H})(\mathrm{F}) \mathrm{H})(\mathrm{H}) \mathrm{Br})(\mathrm{H}) \mathrm{H})(\mathrm{H}) \mathrm{H})(\mathrm{F}) \mathrm{H})(\mathrm{H}) \mathrm{H})(\mathrm{H}) \mathrm{H})(\mathrm{F}) \mathrm{H})$

$(\mathrm{H}) \mathrm{H})(\mathrm{H}) \mathrm{Cl}(\mathrm{H}) \mathrm{H})(\mathrm{H}) \mathrm{Br})(\mathrm{F}) \mathrm{H})(\mathrm{H}) \mathrm{H})(\mathrm{H}) \mathrm{F})(\mathrm{H})(\mathrm{Cl}) \mathrm{F}$

$\mathrm{C}(\mathrm{C}(\mathrm{C}(\mathrm{C}(\mathrm{C}(\mathrm{C}(\mathrm{C}(\mathrm{C}(\mathrm{C}(\mathrm{C}(\mathrm{C}(\mathrm{C}(\mathrm{C}(\mathrm{C}(\mathrm{C}(\mathrm{C}(\mathrm{C}(\mathrm{H})(\mathrm{H}) \mathrm{H})(\mathrm{H}) \mathrm{Br})(\mathrm{H}) \mathrm{H})(\mathrm{H}) \mathrm{H})(\mathrm{Cl}) \mathrm{H})(\mathrm{H}) \mathrm{H})(\mathrm{F}) \mathrm{H})(\mathrm{H}) \mathrm{H})(\mathrm{F}) \mathrm{F})$

$(\mathrm{H}) \mathrm{F})(\mathrm{H}) \mathrm{Cl}(\mathrm{H}) \mathrm{H})(\mathrm{H}) \mathrm{H})(\mathrm{F}) \mathrm{H})(\mathrm{F}) \mathrm{H})(\mathrm{H}) \mathrm{H})(\mathrm{H})(\mathrm{H}) \mathrm{F}$

$\mathrm{C}(\mathrm{C}(\mathrm{C}(\mathrm{C}(\mathrm{C}(\mathrm{C}(\mathrm{C}(\mathrm{C}(\mathrm{C}(\mathrm{C}(\mathrm{C}(\mathrm{C}(\mathrm{C}(\mathrm{C}(\mathrm{C}(\mathrm{C}(\mathrm{C}(\mathrm{H})(\mathrm{F}) \mathrm{F})(\mathrm{H}) \mathrm{Cl})(\mathrm{F}) \mathrm{F})(\mathrm{H}) \mathrm{H})(\mathrm{H}) \mathrm{H})(\mathrm{H}) \mathrm{H})(\mathrm{H}) \mathrm{F})(\mathrm{H}) \mathrm{H})(\mathrm{F}) \mathrm{H})(\mathrm{H}) \mathrm{H})($ $\mathrm{H}) \mathrm{H})(\mathrm{H}) \mathrm{H})(\mathrm{H}) \mathrm{F})(\mathrm{H}) \mathrm{H})(\mathrm{F}) \mathrm{H})(\mathrm{H}) \mathrm{H})(\mathrm{H})(\mathrm{H}) \mathrm{Cl}$

$\mathrm{C}(\mathrm{C}(\mathrm{C}(\mathrm{C}(\mathrm{C}(\mathrm{C}(\mathrm{C}(\mathrm{C}(\mathrm{C}(\mathrm{C}(\mathrm{C}(\mathrm{C}(\mathrm{C}(\mathrm{C}(\mathrm{C}(\mathrm{C}(\mathrm{C}(\mathrm{H})(\mathrm{H}) \mathrm{H})(\mathrm{H}) \mathrm{F})(\mathrm{H}) \mathrm{H})(\mathrm{H}) \mathrm{H})(\mathrm{H}) \mathrm{H})(\mathrm{H}) \mathrm{H})(\mathrm{H}) \mathrm{H})(\mathrm{H}) \mathrm{H})(\mathrm{H}) \mathrm{H})(\mathrm{Cl})$

$\mathrm{H})(\mathrm{H}) \mathrm{F})(\mathrm{Cl}) \mathrm{F})(\mathrm{F}) \mathrm{H})(\mathrm{H}) \mathrm{H})(\mathrm{Br}) \mathrm{H})(\mathrm{H}) \mathrm{F})(\mathrm{H})(\mathrm{F}) \mathrm{Cl}$

$\mathrm{C}(\mathrm{C}(\mathrm{C}(\mathrm{C}(\mathrm{C}(\mathrm{C}(\mathrm{C}(\mathrm{C}(\mathrm{C}(\mathrm{C}(\mathrm{C}(\mathrm{C}(\mathrm{C}(\mathrm{C}(\mathrm{C}(\mathrm{C}(\mathrm{C}(\mathrm{H})(\mathrm{H}) \mathrm{H})(\mathrm{H}) \mathrm{H})(\mathrm{H}) \mathrm{Cl})(\mathrm{H}) \mathrm{H})(\mathrm{H}) \mathrm{H})(\mathrm{H}) \mathrm{H})(\mathrm{H}) \mathrm{H})(\mathrm{H}) \mathrm{F})(\mathrm{H}) \mathrm{F})(\mathrm{Cl})$

$\mathrm{F})(\mathrm{H}) \mathrm{H})(\mathrm{F}) \mathrm{H})(\mathrm{H}) \mathrm{F})(\mathrm{F}) \mathrm{F})(\mathrm{H}) \mathrm{H})(\mathrm{H}) \mathrm{H})(\mathrm{H})(\mathrm{H}) \mathrm{Cl}$

$\mathrm{C}(\mathrm{C}(\mathrm{C}(\mathrm{C}(\mathrm{C}(\mathrm{C}(\mathrm{C}(\mathrm{C}(\mathrm{C}(\mathrm{C}(\mathrm{C}(\mathrm{C}(\mathrm{C}(\mathrm{C}(\mathrm{C}(\mathrm{C}(\mathrm{C}(\mathrm{H})(\mathrm{H}) \mathrm{H})(\mathrm{Br}) \mathrm{H})(\mathrm{H}) \mathrm{H})(\mathrm{H}) \mathrm{Br})(\mathrm{H}) \mathrm{H})(\mathrm{H}) \mathrm{H})(\mathrm{H}) \mathrm{H})(\mathrm{Cl}) \mathrm{H})(\mathrm{H}) \mathrm{H})$

$(\mathrm{F}) \mathrm{F})(\mathrm{H}) \mathrm{F})(\mathrm{H}) \mathrm{F})(\mathrm{H}) \mathrm{F})(\mathrm{H}) \mathrm{H})(\mathrm{H}) \mathrm{H})(\mathrm{H}) \mathrm{H})(\mathrm{F})(\mathrm{H}) \mathrm{F}$

loKoa lgKow lgKaw loKow lgKoa lgKa loKow lgKoa lgKaw EPISuit EPI EPI Exp Exp w DFT DFT DFT e Suite Suite corr_corr_Exp corr__corr_corr $\begin{array}{lllllllll}6.554 & 10.07 & 3.52 & 10.10 & 6.59 & 3.52 & 8.50 & 10.05 & -1.56\end{array}$

$7.443 \quad 9.94$
-10

$5.23 \quad 9.45$

$7.355 \quad 10.07$

$6.049 \quad 10.05$

$6.312 \quad 9.53$

$5.981 \quad 9.15$

$6.751 \quad 9.67$

$6.985 \quad 9.37$

$7.317 \quad 8.95$

$6.418 \quad 9.29$

$5.543 \quad 9.4$

$6.44 \quad 9.06$

$6.351 \quad 9.19$

$6.526 \quad 9.85$

$6.761 \quad 8.63$

$5.972 \quad 9.53$

$6.868 \quad 9.19$

$7.286 \quad 9.34$

$5.648 \quad 8.94$

$5.491 \quad 10.02$

$5.884 \quad 9.66$

$6.875 \quad 9.9$

$7.277 \quad 9.55$

$6.963 \quad 9.77$

$5.327 \quad 9.37$

$6.557 \quad 8.58$

$6.746 \quad 9.74$

$5.582 \quad 9.06$

$6.575 \quad 9.3$

$6.895 \quad 8.87$

$6.732 \quad 9.24$

$7.549 \quad 8.82$

$5.825 \quad 9.57$

$5.278 \quad 8.24$

$5.122 \quad 9.32$

$7.413 \quad 8.87$
-12

$6.516 \quad 9.21$
0

$4.948 \quad 8.88$

$7.578 \quad 9.52$

$6.68 \quad 9.86$

$7.091 \quad 9.3$ $\begin{array}{lllllll}2.50 & 9.91 & 7.41 & 2.50 & 8.40 & 11.68 & -3.29\end{array}$

$\begin{array}{lllllll}4.22 & 9.18 & 4.96 & 4.22 & 8.02 & 7.62 & 0.40\end{array}$

$\begin{array}{lllllll}2.72 & 10.10 & 7.39 & 2.72 & 8.50 & 11.52 & -3.03\end{array}$

$\begin{array}{lllllll}4.00 & 10.07 & 6.07 & 4.00 & 8.48 & 9.12 & -0.64\end{array}$

$\begin{array}{lllllll}3.22 & 9.30 & 6.08 & 3.22 & 8.08 & 9.61 & -1.53\end{array}$

$\begin{array}{lllllll}3.17 & 8.73 & 5.56 & 3.17 & 7.79 & 9.00 & -1.2\end{array}$

$\begin{array}{lllllll}2.92 & 9.51 & 6.59 & 2.92 & 8.19 & 10.41 & -2.22\end{array}$

$\begin{array}{lllllll}2.39 & 9.06 & 6.67 & 2.39 & 7.96 & 10.84 & -2.88\end{array}$

$\begin{array}{lllllll}1.63 & 8.43 & 6.80 & 1.63 & 7.64 & 11.45 & -3.82\end{array}$

$\begin{array}{lllllll}2.87 & 8.94 & 6.07 & 2.87 & 7.90 & 9.80 & -1.90\end{array}$

$\begin{array}{lllllll}3.86 & 9.10 & 5.25 & 3.86 & 7.98 & 8.19 & -0.21\end{array}$

$\begin{array}{lllllll}2.62 & 8.60 & 5.98 & 2.62 & 7.72 & 9.84 & -2.12\end{array}$

$\begin{array}{lllllll}2.84 & 8.79 & 5.95 & 2.84 & 7.82 & 9.68 & -1.86\end{array}$

$\begin{array}{lllllll}3.32 & 9.78 & 6.45 & 3.32 & 8.33 & 10.00 & -1.67\end{array}$

$\begin{array}{lllllll}1.87 & 7.96 & 6.09 & 1.87 & 7.39 & 10.43 & -3.04\end{array}$

$\begin{array}{lllllll}3.56 & 9.30 & 5.74 & 3.56 & 8.08 & 8.98 & -0.90\end{array}$

$\begin{array}{lllllll}2.32 & 8.79 & 6.47 & 2.32 & 7.82 & 10.63 & -2.81\end{array}$

$\begin{array}{lllllll}2.05 & 9.01 & 6.96 & 2.05 & 7.94 & 11.40 & -3.46\end{array}$

$\begin{array}{lllllll}3.29 & 8.42 & 5.13 & 3.29 & 7.63 & 8.39 & -0.76\end{array}$

$\begin{array}{lllllll}4.53 & 10.03 & 5.50 & 4.53 & 8.46 & 8.10 & 0.36\end{array}$

$\begin{array}{lllllll}3.78 & 9.49 & 5.72 & 3.78 & 8.18 & 8.82 & -0.64\end{array}$

$\begin{array}{lllllll}3.02 & 9.85 & 6.83 & 3.02 & 8.37 & 10.64 & -2.28\end{array}$

$\begin{array}{lllllll}2.27 & 9.33 & 7.06 & 2.27 & 8.10 & 11.38 & -3.28\end{array}$

$\begin{array}{lllllll}2.81 & 9.66 & 6.85 & 2.81 & 8.27 & 10.80 & -2.54\end{array}$

$\begin{array}{lllllll}4.04 & 9.06 & 5.02 & 4.04 & 7.96 & 7.80 & 0.16\end{array}$

$\begin{array}{lllllll}2.02 & 7.88 & 5.86 & 2.02 & 7.35 & 10.06 & -2.71\end{array}$

$\begin{array}{lllllll}2.99 & 9.61 & 6.62 & 2.99 & 8.24 & 10.40 & -2.16\end{array}$

$\begin{array}{lllllll}3.48 & 8.60 & 5.12 & 3.48 & 7.72 & 8.27 & -0.55\end{array}$

$\begin{array}{lllllll}2.73 & 8.96 & 6.23 & 2.73 & 7.91 & 10.09 & -2.19\end{array}$

$\begin{array}{lllllll}1.98 & 8.31 & 6.34 & 1.98 & 7.57 & 10.68 & -3.10\end{array}$

$\begin{array}{lllllll}2.51 & 8.87 & 6.36 & 2.51 & 7.86 & 10.38 & -2.52\end{array}$

$\begin{array}{lllllll}1.27 & 8.24 & 6.97 & 1.27 & 7.54 & 11.88 & -4.34\end{array}$

$\begin{array}{lllllll}3.74 & 9.36 & 5.61 & 3.74 & 8.11 & 8.71 & -0.60\end{array}$

$\begin{array}{lllllll}2.96 & 7.37 & 4.41 & 2.96 & 7.09 & 7.71 & -0.62\end{array}$

$\begin{array}{lllllll}4.20 & 8.99 & 4.79 & 4.20 & 7.92 & 7.42 & 0.50\end{array}$

$\begin{array}{lllllll}1.46 & 8.31 & 6.86 & 1.46 & 7.57 & 11.63 & -4.05\end{array}$

$\begin{array}{lllllll}2.69 & 8.82 & 6.13 & 2.69 & 7.84 & 9.98 & -2.15\end{array}$

$\begin{array}{lllllll}3.93 & 8.33 & 4.40 & 3.93 & 7.58 & 7.10 & 0.48\end{array}$

$\begin{array}{lllllll}1.94 & 9.28 & 7.34 & 1.94 & 8.07 & 11.93 & -3.86\end{array}$

$\begin{array}{lllllll}3.18 & 9.79 & 6.61 & 3.18 & 8.34 & 10.28 & -1.95\end{array}$

$\begin{array}{lllllll}2.21 & 8.96 & 6.75 & 2.21 & 7.91 & 11.04 & -3.13\end{array}$ 
$\mathrm{C}\left(\mathrm{C}\left(\mathrm{C}\left(\mathrm{C}\left(\mathrm{C}\left(\mathrm{C}\left(\mathrm{C}(\mathrm{C}(\mathrm{C}(\mathrm{C}(\mathrm{C}(\mathrm{C}(\mathrm{C}(\mathrm{C}(\mathrm{C}(\mathrm{C}(\mathrm{C}(\mathrm{H})(\mathrm{H}) \mathrm{H})(\mathrm{F}) \mathrm{H})(\mathrm{F}) \mathrm{H})(\mathrm{H}) \mathrm{H})(\mathrm{F}) \mathrm{H})(\mathrm{H}) \mathrm{H})(\mathrm{F}) \mathrm{H})(\mathrm{H}) \mathrm{H})(\mathrm{H}) \mathrm{H})(\mathrm{F}) \mathrm{H})\left({ }_{\mathrm{C} 17 \mathrm{H} 26 \mathrm{ClBrF} 8}\right.\right.\right.\right.\right.\right.\right.$ $\mathrm{H}) \mathrm{F})(\mathrm{H}) \mathrm{H})(\mathrm{H}) \mathrm{F})(\mathrm{H}) \mathrm{H})(\mathrm{F}) \mathrm{H})(\mathrm{H}) \mathrm{Cl})(\mathrm{H})(\mathrm{H}) \mathrm{B}$

\section{$\mathrm{C} 17 \mathrm{H} 26 \mathrm{ClBrF} 8$}

$\mathrm{C}(\mathrm{C}(\mathrm{C}(\mathrm{C}(\mathrm{C}(\mathrm{C}(\mathrm{C}(\mathrm{C}(\mathrm{C}(\mathrm{C}(\mathrm{C}(\mathrm{C}(\mathrm{C}(\mathrm{C}(\mathrm{C}(\mathrm{C}(\mathrm{C}(\mathrm{H})(\mathrm{H}) \mathrm{Cl})(\mathrm{F}) \mathrm{H})(\mathrm{H}) \mathrm{Cl})(\mathrm{H}) \mathrm{H})(\mathrm{H}) \mathrm{H})(\mathrm{H}) \mathrm{H})(\mathrm{H}) \mathrm{H})(\mathrm{H}) \mathrm{H})(\mathrm{F}) \mathrm{H})(\mathrm{H})$ $\mathrm{H})(\mathrm{F}) \mathrm{H})(\mathrm{H}) \mathrm{F})(\mathrm{H}) \mathrm{H})(\mathrm{H}) \mathrm{H})(\mathrm{H}) \mathrm{F})(\mathrm{F}) \mathrm{H})(\mathrm{Br})(\mathrm{H}) \mathrm{H}$

$\mathrm{C}\left(\mathrm{C}\left(\mathrm{C}\left(\mathrm{C}\left(\mathrm{C}\left(\mathrm{C}\left(\mathrm{C}(\mathrm{C}(\mathrm{C}(\mathrm{C}(\mathrm{C}(\mathrm{C}(\mathrm{C}(\mathrm{C}(\mathrm{C}(\mathrm{C}(\mathrm{C}(\mathrm{H})(\mathrm{H}) \mathrm{H})(\mathrm{H}) \mathrm{H})(\mathrm{H}) \mathrm{F})(\mathrm{H}) \mathrm{H})(\mathrm{H}) \mathrm{H})(\mathrm{H}) \mathrm{H})(\mathrm{H}) \mathrm{F})(\mathrm{H}) \mathrm{H})(\mathrm{F}) \mathrm{H})(\mathrm{H}) \mathrm{H}){ }_{\mathrm{C} 17 \mathrm{H} 27 \mathrm{Cl} 2 \mathrm{~F} 7}\right.\right.\right.\right.\right.\right.$ $(\mathrm{H}) \mathrm{F})(\mathrm{H}) \mathrm{H})(\mathrm{H}) \mathrm{H})(\mathrm{H}) \mathrm{H})(\mathrm{Cl}) \mathrm{F})(\mathrm{H}) \mathrm{H})(\mathrm{F})(\mathrm{F}) \mathrm{Cl}$

$\mathrm{C}(\mathrm{C}(\mathrm{C}(\mathrm{C}(\mathrm{C}(\mathrm{C}(\mathrm{C}(\mathrm{C}(\mathrm{C}(\mathrm{C}(\mathrm{C}(\mathrm{C}(\mathrm{C}(\mathrm{C}(\mathrm{C}(\mathrm{C}(\mathrm{C}(\mathrm{H})(\mathrm{H}) \mathrm{H})(\mathrm{H}) \mathrm{H})(\mathrm{H}) \mathrm{F})(\mathrm{H}) \mathrm{H})(\mathrm{H}) \mathrm{H})(\mathrm{F}) \mathrm{H})(\mathrm{F}) \mathrm{H})(\mathrm{F}) \mathrm{H})(\mathrm{Cl}) \mathrm{Cl})$

$(\mathrm{F}) \mathrm{H})(\mathrm{H}) \mathrm{H})(\mathrm{F}) \mathrm{H})(\mathrm{H}) \mathrm{Cl})(\mathrm{H}) \mathrm{H})(\mathrm{H}) \mathrm{H})(\mathrm{H}) \mathrm{H})(\mathrm{H})(\mathrm{H}) \mathrm{H}$

$\mathrm{C}\left(\mathrm{C}\left(\mathrm{C}\left(\mathrm{C}\left(\mathrm{C}\left(\mathrm{C}\left(\mathrm{C}(\mathrm{C}(\mathrm{C}(\mathrm{C}(\mathrm{C}(\mathrm{C}(\mathrm{C}(\mathrm{C}(\mathrm{C}(\mathrm{C}(\mathrm{C}(\mathrm{H})(\mathrm{H}) \mathrm{H})(\mathrm{H}) \mathrm{H})(\mathrm{H}) \mathrm{H})(\mathrm{H}) \mathrm{H})(\mathrm{H}) \mathrm{H})(\mathrm{H}) \mathrm{H})(\mathrm{F}) \mathrm{F})(\mathrm{F}) \mathrm{H})(\mathrm{F}) \mathrm{H})(\mathrm{F}) \mathrm{H})\left({ }_{\mathrm{C} 17 \mathrm{H} 27 \mathrm{Cl} 4 \mathrm{~F} 5}\right.\right.\right.\right.\right.\right.\right.$

$\mathrm{Cl}) \mathrm{H})(\mathrm{H}) \mathrm{H})(\mathrm{H}) \mathrm{Cl}(\mathrm{Cl}) \mathrm{H})(\mathrm{H}) \mathrm{H})(\mathrm{H}) \mathrm{Cl})(\mathrm{H})(\mathrm{H}) \mathrm{H}$

$\mathrm{C}(\mathrm{C}(\mathrm{C}(\mathrm{C}(\mathrm{C}(\mathrm{C}(\mathrm{C}(\mathrm{C}(\mathrm{C}(\mathrm{C}(\mathrm{C}(\mathrm{C}(\mathrm{C}(\mathrm{C}(\mathrm{C}(\mathrm{C}(\mathrm{C}(\mathrm{H})(\mathrm{H}) \mathrm{H})(\mathrm{Cl}) \mathrm{F})(\mathrm{F}) \mathrm{H})(\mathrm{H}) \mathrm{H})(\mathrm{H}) \mathrm{H})(\mathrm{F}) \mathrm{H})(\mathrm{H}) \mathrm{H})(\mathrm{H}) \mathrm{H})(\mathrm{H}) \mathrm{H})$

$(\mathrm{H}) \mathrm{H})(\mathrm{H}) \mathrm{H})(\mathrm{F}) \mathrm{H})(\mathrm{H}) \mathrm{F})(\mathrm{F}) \mathrm{H})(\mathrm{H}) \mathrm{H})(\mathrm{F}) \mathrm{Br})(\mathrm{H})(\mathrm{H}) \mathrm{H}$

$\mathrm{C}(\mathrm{C}(\mathrm{C}(\mathrm{C}(\mathrm{C}(\mathrm{C}(\mathrm{C}(\mathrm{C}(\mathrm{C}(\mathrm{C}(\mathrm{C}(\mathrm{C}(\mathrm{C}(\mathrm{C}(\mathrm{C}(\mathrm{C}(\mathrm{C}(\mathrm{F})(\mathrm{H}) \mathrm{F})(\mathrm{H}) \mathrm{H})(\mathrm{H}) \mathrm{H})(\mathrm{H}) \mathrm{H})(\mathrm{H}) \mathrm{H})(\mathrm{H}) \mathrm{F})(\mathrm{F}) \mathrm{H})(\mathrm{H}) \mathrm{H})(\mathrm{H}) \mathrm{H})(\mathrm{H}) \mathrm{H})$ $(\mathrm{H}) \mathrm{H})(\mathrm{H}) \mathrm{H})(\mathrm{H}) \mathrm{Br})(\mathrm{F}) \mathrm{H})(\mathrm{H}) \mathrm{H})(\mathrm{F}) \mathrm{H})(\mathrm{Br})(\mathrm{H}) \mathrm{H}$

$\mathrm{C}(\mathrm{C}(\mathrm{C}(\mathrm{C}(\mathrm{C}(\mathrm{C}(\mathrm{C}(\mathrm{C}(\mathrm{C}(\mathrm{C}(\mathrm{C}(\mathrm{C}(\mathrm{C}(\mathrm{C}(\mathrm{C}(\mathrm{C}(\mathrm{C}(\mathrm{F})(\mathrm{H}) \mathrm{H})(\mathrm{H}) \mathrm{H})(\mathrm{F}) \mathrm{H})(\mathrm{F}) \mathrm{H})(\mathrm{H}) \mathrm{H})(\mathrm{H}) \mathrm{H})(\mathrm{H}) \mathrm{H})(\mathrm{H}) \mathrm{H})(\mathrm{H}) \mathrm{H})$

$(\mathrm{Cl}) \mathrm{H})(\mathrm{H}) \mathrm{H})(\mathrm{Cl}) \mathrm{H})(\mathrm{H}) \mathrm{H})(\mathrm{H}) \mathrm{H})(\mathrm{F}) \mathrm{H})(\mathrm{F}) \mathrm{F})(\mathrm{H})(\mathrm{H}) \mathrm{H}$

$\mathrm{C}(\mathrm{C}(\mathrm{C}(\mathrm{C}(\mathrm{C}(\mathrm{C}(\mathrm{C}(\mathrm{C}(\mathrm{C}(\mathrm{C}(\mathrm{C}(\mathrm{C}(\mathrm{C}(\mathrm{C}(\mathrm{C}(\mathrm{C}(\mathrm{C}(\mathrm{H})(\mathrm{H}) \mathrm{F})(\mathrm{H}) \mathrm{H})(\mathrm{H}) \mathrm{H})(\mathrm{F}) \mathrm{H})(\mathrm{H}) \mathrm{H})(\mathrm{F}) \mathrm{H})(\mathrm{H}) \mathrm{H})(\mathrm{H}) \mathrm{H})(\mathrm{Cl}) \mathrm{Cl})(\mathrm{H})$ $\mathrm{H})(\mathrm{F}) \mathrm{H})(\mathrm{F}) \mathrm{H})(\mathrm{H}) \mathrm{H})(\mathrm{H}) \mathrm{H})(\mathrm{H}) \mathrm{H})(\mathrm{H}) \mathrm{H})(\mathrm{H})(\mathrm{H}) \mathrm{Cl}$

$\mathrm{C}(\mathrm{C}(\mathrm{C}(\mathrm{C}(\mathrm{C}(\mathrm{C}(\mathrm{C}(\mathrm{C}(\mathrm{C}(\mathrm{C}(\mathrm{C}(\mathrm{C}(\mathrm{C}(\mathrm{C}(\mathrm{C}(\mathrm{C}(\mathrm{C}(\mathrm{H})(\mathrm{H}) \mathrm{H})(\mathrm{H}) \mathrm{H})(\mathrm{Cl}) \mathrm{H})(\mathrm{H}) \mathrm{F})(\mathrm{Cl}) \mathrm{H})(\mathrm{H}) \mathrm{H})(\mathrm{H}) \mathrm{Cl})(\mathrm{H}) \mathrm{H})(\mathrm{H}) \mathrm{F})(\mathrm{H})$

$\mathrm{H})(\mathrm{H}) \mathrm{H})(\mathrm{Cl}) \mathrm{H})(\mathrm{H}) \mathrm{H})(\mathrm{F}) \mathrm{H})(\mathrm{F}) \mathrm{H})(\mathrm{H}) \mathrm{H})(\mathrm{H})(\mathrm{H}) \mathrm{H}$

$\mathrm{C}(\mathrm{C}(\mathrm{C}(\mathrm{C}(\mathrm{C}(\mathrm{C}(\mathrm{C}(\mathrm{C}(\mathrm{C}(\mathrm{C}(\mathrm{C}(\mathrm{C}(\mathrm{C}(\mathrm{C}(\mathrm{C}(\mathrm{C}(\mathrm{C}(\mathrm{H})(\mathrm{H}) \mathrm{F})(\mathrm{F}) \mathrm{Cl})(\mathrm{H}) \mathrm{H})(\mathrm{H}) \mathrm{H})(\mathrm{H}) \mathrm{H})(\mathrm{H}) \mathrm{H})(\mathrm{Br}) \mathrm{H})(\mathrm{H}) \mathrm{H})(\mathrm{H}) \mathrm{H})(\mathrm{F})$

$\mathrm{H})(\mathrm{H}) \mathrm{H})(\mathrm{F}) \mathrm{H})(\mathrm{H}) \mathrm{H})(\mathrm{H}) \mathrm{H})(\mathrm{H}) \mathrm{H})(\mathrm{F}) \mathrm{H})(\mathrm{H})(\mathrm{F}) \mathrm{H}$

$\mathrm{C}(\mathrm{C}(\mathrm{C}(\mathrm{C}(\mathrm{C}(\mathrm{C}(\mathrm{C}(\mathrm{C}(\mathrm{C}(\mathrm{C}(\mathrm{C}(\mathrm{C}(\mathrm{C}(\mathrm{C}(\mathrm{C}(\mathrm{C}(\mathrm{C}(\mathrm{H})(\mathrm{H}) \mathrm{H})(\mathrm{F}) \mathrm{H})(\mathrm{H}) \mathrm{H})(\mathrm{H}) \mathrm{H})(\mathrm{H}) \mathrm{H})(\mathrm{H}) \mathrm{H})(\mathrm{H}) \mathrm{Br})(\mathrm{F}) \mathrm{H})(\mathrm{F}) \mathrm{H})$

$(\mathrm{H}) \mathrm{H})(\mathrm{H}) \mathrm{H})(\mathrm{H}) \mathrm{H})(\mathrm{H}) \mathrm{H})(\mathrm{H}) \mathrm{H})(\mathrm{F}) \mathrm{H})(\mathrm{F}) \mathrm{H})(\mathrm{H})(\mathrm{Br}) \mathrm{H}$

$\mathrm{C}(\mathrm{C}(\mathrm{C}(\mathrm{C}(\mathrm{C}(\mathrm{C}(\mathrm{C}(\mathrm{C}(\mathrm{C}(\mathrm{C}(\mathrm{C}(\mathrm{C}(\mathrm{C}(\mathrm{C}(\mathrm{C}(\mathrm{C}(\mathrm{C}(\mathrm{F})(\mathrm{H}) \mathrm{F})(\mathrm{H}) \mathrm{H})(\mathrm{H}) \mathrm{H})(\mathrm{F}) \mathrm{H})(\mathrm{H}) \mathrm{H})(\mathrm{H}) \mathrm{H})(\mathrm{F}) \mathrm{H})(\mathrm{H}) \mathrm{H})(\mathrm{H}) \mathrm{H})$

$(\mathrm{Br}) \mathrm{H})(\mathrm{H}) \mathrm{H})(\mathrm{H}) \mathrm{H})(\mathrm{H}) \mathrm{H})(\mathrm{H}) \mathrm{H})(\mathrm{F}) \mathrm{F})(\mathrm{H}) \mathrm{H})(\mathrm{H})(\mathrm{H}) \mathrm{H}$

$\mathrm{C}(\mathrm{C}(\mathrm{C}(\mathrm{C}(\mathrm{C}(\mathrm{C}(\mathrm{C}(\mathrm{C}(\mathrm{C}(\mathrm{C}(\mathrm{C}(\mathrm{C}(\mathrm{C}(\mathrm{C}(\mathrm{C}(\mathrm{C}(\mathrm{C}(\mathrm{H})(\mathrm{H}) \mathrm{F})(\mathrm{H}) \mathrm{H})(\mathrm{H}) \mathrm{H})(\mathrm{H}) \mathrm{H})(\mathrm{H}) \mathrm{H})(\mathrm{H}) \mathrm{F})(\mathrm{H}) \mathrm{H})(\mathrm{H}) \mathrm{F})(\mathrm{H}) \mathrm{Br})(\mathrm{Cl})$

$\mathrm{H})(\mathrm{H}) \mathrm{H})(\mathrm{H}) \mathrm{H})(\mathrm{H}) \mathrm{H})(\mathrm{H}) \mathrm{F})(\mathrm{H}) \mathrm{H})(\mathrm{H}) \mathrm{H})(\mathrm{Cl})(\mathrm{H}) \mathrm{H}$

$\mathrm{C}(\mathrm{C}(\mathrm{C}(\mathrm{C}(\mathrm{C}(\mathrm{C}(\mathrm{C}(\mathrm{C}(\mathrm{C}(\mathrm{C}(\mathrm{C}(\mathrm{C}(\mathrm{C}(\mathrm{C}(\mathrm{C}(\mathrm{C}(\mathrm{C}(\mathrm{H})(\mathrm{H}) \mathrm{H})(\mathrm{F}) \mathrm{H})(\mathrm{H}) \mathrm{H})(\mathrm{H}) \mathrm{H})(\mathrm{F}) \mathrm{H})(\mathrm{F}) \mathrm{H})(\mathrm{H}) \mathrm{H})(\mathrm{Cl}) \mathrm{H})(\mathrm{H}) \mathrm{H})$

$(\mathrm{H}) \mathrm{H})(\mathrm{H}) \mathrm{H})(\mathrm{H}) \mathrm{H})(\mathrm{H}) \mathrm{H})(\mathrm{H}) \mathrm{H})(\mathrm{H}) \mathrm{H})(\mathrm{Cl}) \mathrm{F})(\mathrm{H})(\mathrm{F}) \mathrm{H}$

$\mathrm{C}(\mathrm{C}(\mathrm{C}(\mathrm{C}(\mathrm{C}(\mathrm{C}(\mathrm{C}(\mathrm{C}(\mathrm{C}(\mathrm{C}(\mathrm{C}(\mathrm{C}(\mathrm{C}(\mathrm{C}(\mathrm{C}(\mathrm{C}(\mathrm{C}(\mathrm{H})(\mathrm{H}) \mathrm{H})(\mathrm{H}) \mathrm{H})(\mathrm{H}) \mathrm{H})(\mathrm{H}) \mathrm{H})(\mathrm{H}) \mathrm{H})(\mathrm{Cl}) \mathrm{H})(\mathrm{H}) \mathrm{H})(\mathrm{H}) \mathrm{H})(\mathrm{H}) \mathrm{H})(\mathrm{H})$ $\mathrm{H})(\mathrm{H}) \mathrm{H})(\mathrm{H}) \mathrm{F})(\mathrm{F}) \mathrm{F})(\mathrm{H}) \mathrm{Cl})(\mathrm{H}) \mathrm{F})(\mathrm{H}) \mathrm{H})(\mathrm{Cl})(\mathrm{H}) \mathrm{H}$

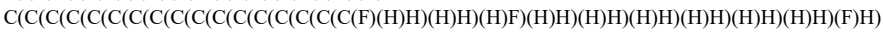
$(\mathrm{H}) \mathrm{H})(\mathrm{H}) \mathrm{H})(\mathrm{H}) \mathrm{H})(\mathrm{F}) \mathrm{H})(\mathrm{H}) \mathrm{Br})(\mathrm{Cl}) \mathrm{F})(\mathrm{H})(\mathrm{H}) \mathrm{H}$

$\mathrm{C}(\mathrm{C}(\mathrm{C}(\mathrm{C}(\mathrm{C}(\mathrm{C}(\mathrm{C}(\mathrm{C}(\mathrm{C}(\mathrm{C}(\mathrm{C}(\mathrm{C}(\mathrm{C}(\mathrm{C}(\mathrm{C}(\mathrm{C}(\mathrm{C}(\mathrm{H})(\mathrm{H}) \mathrm{F})(\mathrm{H}) \mathrm{H})(\mathrm{Br}) \mathrm{H})(\mathrm{H}) \mathrm{F})(\mathrm{H}) \mathrm{H})(\mathrm{H}) \mathrm{H})(\mathrm{H}) \mathrm{F})(\mathrm{Br}) \mathrm{H})(\mathrm{H}) \mathrm{H})(\mathrm{H})$

$\mathrm{H})(\mathrm{H}) \mathrm{H})(\mathrm{H}) \mathrm{H})(\mathrm{H}) \mathrm{H})(\mathrm{H}) \mathrm{H})(\mathrm{H}) \mathrm{H})(\mathrm{H}) \mathrm{H})(\mathrm{H})(\mathrm{F}) \mathrm{H}$

$\mathrm{C}(\mathrm{C}(\mathrm{C}(\mathrm{C}(\mathrm{C}(\mathrm{C}(\mathrm{C}(\mathrm{C}(\mathrm{C}(\mathrm{C}(\mathrm{C}(\mathrm{C}(\mathrm{C}(\mathrm{C}(\mathrm{C}(\mathrm{C}(\mathrm{C}(\mathrm{F})(\mathrm{F}) \mathrm{H})(\mathrm{H}) \mathrm{H})(\mathrm{H}) \mathrm{H})(\mathrm{H}) \mathrm{H})(\mathrm{H}) \mathrm{H})(\mathrm{H}) \mathrm{H})(\mathrm{H}) \mathrm{H})(\mathrm{H}) \mathrm{H})(\mathrm{H}) \mathrm{H})$

$(\mathrm{H}) \mathrm{H})(\mathrm{F}) \mathrm{F})(\mathrm{H}) \mathrm{H})(\mathrm{H}) \mathrm{H})(\mathrm{H}) \mathrm{Br})(\mathrm{H}) \mathrm{H})(\mathrm{H}) \mathrm{H})(\mathrm{H})(\mathrm{F}) \mathrm{H}$

$\mathrm{C}(\mathrm{C}(\mathrm{C}(\mathrm{C}(\mathrm{C}(\mathrm{C}(\mathrm{C}(\mathrm{C}(\mathrm{C}(\mathrm{C}(\mathrm{C}(\mathrm{C}(\mathrm{C}(\mathrm{C}(\mathrm{C}(\mathrm{C}(\mathrm{C}(\mathrm{Cl})(\mathrm{H}) \mathrm{H})(\mathrm{H}) \mathrm{H})(\mathrm{H}) \mathrm{H})(\mathrm{H}) \mathrm{F})(\mathrm{H}) \mathrm{H})(\mathrm{H}) \mathrm{H})(\mathrm{H}) \mathrm{H})(\mathrm{H}) \mathrm{H})(\mathrm{H}) \mathrm{Cl})(\mathrm{H})$ $\mathrm{H})(\mathrm{H}) \mathrm{F})(\mathrm{H}) \mathrm{H})(\mathrm{H}) \mathrm{H})(\mathrm{F}) \mathrm{H})(\mathrm{H}) \mathrm{H})(\mathrm{H}) \mathrm{F})(\mathrm{H})(\mathrm{H}) \mathrm{H}$

$\mathrm{C}(\mathrm{C}(\mathrm{C}(\mathrm{C}(\mathrm{C}(\mathrm{C}(\mathrm{C}(\mathrm{C}(\mathrm{C}(\mathrm{C}(\mathrm{C}(\mathrm{C}(\mathrm{C}(\mathrm{C}(\mathrm{C}(\mathrm{C}(\mathrm{C}(\mathrm{H})(\mathrm{H}) \mathrm{H})(\mathrm{H}) \mathrm{H})(\mathrm{H}) \mathrm{H})(\mathrm{H}) \mathrm{F})(\mathrm{H}) \mathrm{H})(\mathrm{F}) \mathrm{H})(\mathrm{H}) \mathrm{H})(\mathrm{H}) \mathrm{H})(\mathrm{H}) \mathrm{H})$

$(\mathrm{H}) \mathrm{H})(\mathrm{Cl}) \mathrm{H})(\mathrm{H}) \mathrm{Cl})(\mathrm{H}) \mathrm{H})(\mathrm{H}) \mathrm{Cl})(\mathrm{H}) \mathrm{H})(\mathrm{H}) \mathrm{H})(\mathrm{F})(\mathrm{H}) \mathrm{H}$

$\mathrm{C}(\mathrm{C}(\mathrm{C}(\mathrm{C}(\mathrm{C}(\mathrm{C}(\mathrm{C}(\mathrm{C}(\mathrm{C}(\mathrm{C}(\mathrm{C}(\mathrm{C}(\mathrm{C}(\mathrm{C}(\mathrm{C}(\mathrm{C}(\mathrm{C}(\mathrm{Cl})(\mathrm{H}) \mathrm{H})(\mathrm{H}) \mathrm{H})(\mathrm{Br}) \mathrm{H})(\mathrm{H}) \mathrm{F})(\mathrm{H}) \mathrm{H})(\mathrm{H}) \mathrm{H})(\mathrm{H}) \mathrm{H})(\mathrm{H}) \mathrm{H})(\mathrm{H}) \mathrm{H})(\mathrm{H})$

$\mathrm{H})(\mathrm{F}) \mathrm{H})(\mathrm{H}) \mathrm{H})(\mathrm{H}) \mathrm{H})(\mathrm{H}) \mathrm{H})(\mathrm{H}) \mathrm{F})(\mathrm{H}) \mathrm{H})(\mathrm{H})(\mathrm{F}) \mathrm{H}$

$\mathrm{C}(\mathrm{C}(\mathrm{C}(\mathrm{C}(\mathrm{C}(\mathrm{C}(\mathrm{C}(\mathrm{C}(\mathrm{C}(\mathrm{C}(\mathrm{C}(\mathrm{C}(\mathrm{C}(\mathrm{C}(\mathrm{C}(\mathrm{C}(\mathrm{C}(\mathrm{H})(\mathrm{H}) \mathrm{F})(\mathrm{H}) \mathrm{H})(\mathrm{H}) \mathrm{H})(\mathrm{H}) \mathrm{H})(\mathrm{H}) \mathrm{H})(\mathrm{H}) \mathrm{H})(\mathrm{Cl}) \mathrm{H})(\mathrm{H}) \mathrm{F})(\mathrm{H}) \mathrm{H})(\mathrm{H})$

$\mathrm{H})(\mathrm{H}) \mathrm{F})(\mathrm{H}) \mathrm{H})(\mathrm{F}) \mathrm{H})(\mathrm{H}) \mathrm{H})(\mathrm{H}) \mathrm{H})(\mathrm{F}) \mathrm{H})(\mathrm{H})(\mathrm{H}) \mathrm{H}$

$\mathrm{C}(\mathrm{C}(\mathrm{C}(\mathrm{C}(\mathrm{C}(\mathrm{C}(\mathrm{C}(\mathrm{C}(\mathrm{C}(\mathrm{C}(\mathrm{C}(\mathrm{C}(\mathrm{C}(\mathrm{C}(\mathrm{C}(\mathrm{C}(\mathrm{C}(\mathrm{H})(\mathrm{H}) \mathrm{H})(\mathrm{F}) \mathrm{H})(\mathrm{H}) \mathrm{H})(\mathrm{F}) \mathrm{H})(\mathrm{H}) \mathrm{Br})(\mathrm{H}) \mathrm{H})(\mathrm{H}) \mathrm{H})(\mathrm{F}) \mathrm{H})(\mathrm{H}) \mathrm{H})$

$(\mathrm{H}) \mathrm{H})(\mathrm{Br}) \mathrm{H})(\mathrm{H}) \mathrm{H})(\mathrm{H}) \mathrm{H})(\mathrm{H}) \mathrm{H})(\mathrm{H}) \mathrm{H})(\mathrm{H}) \mathrm{H})(\mathrm{H})(\mathrm{H}) \mathrm{H}$

$\mathrm{C}(\mathrm{C}(\mathrm{C}(\mathrm{C}(\mathrm{C}(\mathrm{C}(\mathrm{C}(\mathrm{C}(\mathrm{C}(\mathrm{C}(\mathrm{C}(\mathrm{C}(\mathrm{C}(\mathrm{C}(\mathrm{C}(\mathrm{C}(\mathrm{C}(\mathrm{H})(\mathrm{H}) \mathrm{H})(\mathrm{F}) \mathrm{H})(\mathrm{H}) \mathrm{H})(\mathrm{H}) \mathrm{H})(\mathrm{H}) \mathrm{H})(\mathrm{H}) \mathrm{H})(\mathrm{H}) \mathrm{H})(\mathrm{Br}) \mathrm{H})(\mathrm{F}) \mathrm{H})$

$(\mathrm{H}) \mathrm{F})(\mathrm{H}) \mathrm{H})(\mathrm{F}) \mathrm{H})(\mathrm{H}) \mathrm{H})(\mathrm{H}) \mathrm{H})(\mathrm{H}) \mathrm{H})(\mathrm{H}) \mathrm{H})(\mathrm{H})(\mathrm{H}) \mathrm{H}$

$\mathrm{C}(\mathrm{C}(\mathrm{C}(\mathrm{C}(\mathrm{C}(\mathrm{C}(\mathrm{C}(\mathrm{C}(\mathrm{C}(\mathrm{C}(\mathrm{C}(\mathrm{C}(\mathrm{C}(\mathrm{C}(\mathrm{C}(\mathrm{C}(\mathrm{C}(\mathrm{H})(\mathrm{H}) \mathrm{H})(\mathrm{H}) \mathrm{Cl})(\mathrm{H}) \mathrm{H})(\mathrm{H}) \mathrm{H})(\mathrm{H}) \mathrm{H})(\mathrm{H}) \mathrm{H})(\mathrm{H}) \mathrm{H})(\mathrm{H}) \mathrm{H})(\mathrm{H}) \mathrm{H})(\mathrm{H})$ $\mathrm{Cl}(\mathrm{H}) \mathrm{H})(\mathrm{H}) \mathrm{F})(\mathrm{H}) \mathrm{H})(\mathrm{F}) \mathrm{H})(\mathrm{F}) \mathrm{H})(\mathrm{H}) \mathrm{H})(\mathrm{H})(\mathrm{H}) \mathrm{H}$

$\mathrm{C}(\mathrm{C}(\mathrm{C}(\mathrm{C}(\mathrm{C}(\mathrm{C}(\mathrm{C}(\mathrm{C}(\mathrm{C}(\mathrm{C}(\mathrm{C}(\mathrm{C}(\mathrm{C}(\mathrm{C}(\mathrm{C}(\mathrm{C}(\mathrm{C}(\mathrm{H})(\mathrm{H}) \mathrm{H})(\mathrm{H}) \mathrm{H})(\mathrm{H}) \mathrm{H})(\mathrm{F}) \mathrm{H})(\mathrm{H}) \mathrm{H})(\mathrm{H}) \mathrm{H})(\mathrm{Cl}) \mathrm{H})(\mathrm{H}) \mathrm{Cl})(\mathrm{Cl}) \mathrm{H})(\mathrm{H})$ $\mathrm{H})(\mathrm{F}) \mathrm{H})(\mathrm{H}) \mathrm{H})(\mathrm{H}) \mathrm{H})(\mathrm{H}) \mathrm{H})(\mathrm{H}) \mathrm{H})(\mathrm{H}) \mathrm{H})(\mathrm{H})(\mathrm{H}) \mathrm{H}$

$\mathrm{C}(\mathrm{C}(\mathrm{C}(\mathrm{C}(\mathrm{C}(\mathrm{C}(\mathrm{C}(\mathrm{C}(\mathrm{C}(\mathrm{C}(\mathrm{C}(\mathrm{C}(\mathrm{C}(\mathrm{C}(\mathrm{C}(\mathrm{C}(\mathrm{C}(\mathrm{Cl})(\mathrm{H}) \mathrm{H})(\mathrm{H}) \mathrm{Br})(\mathrm{H}) \mathrm{H})(\mathrm{H}) \mathrm{H})(\mathrm{H}) \mathrm{H})(\mathrm{H}) \mathrm{H})(\mathrm{H}) \mathrm{H})(\mathrm{H}) \mathrm{H})(\mathrm{H}) \mathrm{H})(\mathrm{F})$

$\mathrm{H})(\mathrm{F}) \mathrm{H})(\mathrm{H}) \mathrm{H})(\mathrm{H}) \mathrm{H})(\mathrm{H}) \mathrm{H})(\mathrm{H}) \mathrm{H})(\mathrm{H}) \mathrm{F})(\mathrm{H})(\mathrm{H}) \mathrm{H}$

$\mathrm{C}(\mathrm{C}(\mathrm{C}(\mathrm{C}(\mathrm{C}(\mathrm{C}(\mathrm{C}(\mathrm{C}(\mathrm{C}(\mathrm{C}(\mathrm{C}(\mathrm{C}(\mathrm{C}(\mathrm{C}(\mathrm{C}(\mathrm{C}(\mathrm{C}(\mathrm{H})(\mathrm{H}) \mathrm{H})(\mathrm{F}) \mathrm{H})(\mathrm{H}) \mathrm{H})(\mathrm{H}) \mathrm{H})(\mathrm{H}) \mathrm{H})(\mathrm{H}) \mathrm{H})(\mathrm{H}) \mathrm{H})(\mathrm{F}) \mathrm{H})(\mathrm{H}) \mathrm{H})$

$(\mathrm{H}) \mathrm{H})(\mathrm{H}) \mathrm{H})(\mathrm{F}) \mathrm{H})(\mathrm{Cl}) \mathrm{H})(\mathrm{H}) \mathrm{H})(\mathrm{H}) \mathrm{H})(\mathrm{H}) \mathrm{H})(\mathrm{F})(\mathrm{H}) \mathrm{H}$

$\mathrm{C}(\mathrm{C}(\mathrm{C}(\mathrm{C}(\mathrm{C}(\mathrm{C}(\mathrm{C}(\mathrm{C}(\mathrm{C}(\mathrm{C}(\mathrm{C}(\mathrm{C}(\mathrm{C}(\mathrm{C}(\mathrm{C}(\mathrm{C}(\mathrm{C}(\mathrm{H})(\mathrm{H}) \mathrm{H})(\mathrm{H}) \mathrm{H})(\mathrm{H}) \mathrm{H})(\mathrm{H}) \mathrm{H})(\mathrm{H}) \mathrm{H})(\mathrm{H}) \mathrm{H})(\mathrm{H}) \mathrm{H})(\mathrm{H}) \mathrm{H})(\mathrm{H}) \mathrm{H})(\mathrm{H})$ $\mathrm{H})(\mathrm{H}) \mathrm{F})(\mathrm{H}) \mathrm{H})(\mathrm{H}) \mathrm{H})(\mathrm{F}) \mathrm{Br})(\mathrm{H}) \mathrm{F})(\mathrm{H}) \mathrm{H})(\mathrm{H})(\mathrm{H}) \mathrm{H}$

$\mathrm{C}(\mathrm{C}(\mathrm{C}(\mathrm{C}(\mathrm{C}(\mathrm{C}(\mathrm{C}(\mathrm{C}(\mathrm{C}(\mathrm{C}(\mathrm{C}(\mathrm{C}(\mathrm{C}(\mathrm{C}(\mathrm{C}(\mathrm{C}(\mathrm{C}(\mathrm{H})(\mathrm{H}) \mathrm{H})(\mathrm{H}) \mathrm{H})(\mathrm{H}) \mathrm{H})(\mathrm{H}) \mathrm{H})(\mathrm{H}) \mathrm{H})(\mathrm{H}) \mathrm{H})(\mathrm{H}) \mathrm{H})(\mathrm{H}) \mathrm{H})(\mathrm{H}) \mathrm{H})(\mathrm{H})$

$\mathrm{H})(\mathrm{H}) \mathrm{H})(\mathrm{H}) \mathrm{H})(\mathrm{H}) \mathrm{Cl}(\mathrm{H}) \mathrm{F})(\mathrm{H}) \mathrm{F})(\mathrm{H}) \mathrm{H})(\mathrm{Cl})(\mathrm{H}) \mathrm{H}$

$\mathrm{C}(\mathrm{C}(\mathrm{C}(\mathrm{C}(\mathrm{C}(\mathrm{C}(\mathrm{C}(\mathrm{C}(\mathrm{C}(\mathrm{C}(\mathrm{C}(\mathrm{C}(\mathrm{C}(\mathrm{C}(\mathrm{C}(\mathrm{C}(\mathrm{C}(\mathrm{H})(\mathrm{F}) \mathrm{H})(\mathrm{H}) \mathrm{H})(\mathrm{H}) \mathrm{H})(\mathrm{F}) \mathrm{H})(\mathrm{H}) \mathrm{H})(\mathrm{H}) \mathrm{H})(\mathrm{H}) \mathrm{H})(\mathrm{H}) \mathrm{Cl})(\mathrm{H}) \mathrm{H})(\mathrm{H})$

$\mathrm{H})(\mathrm{H}) \mathrm{H})(\mathrm{H}) \mathrm{H})(\mathrm{H}) \mathrm{H})(\mathrm{H}) \mathrm{H})(\mathrm{Br}) \mathrm{H})(\mathrm{H}) \mathrm{H})(\mathrm{H})(\mathrm{H}) \mathrm{H}$

$\mathrm{C}(\mathrm{C}(\mathrm{C}(\mathrm{C}(\mathrm{C}(\mathrm{C}(\mathrm{C}(\mathrm{C}(\mathrm{C}(\mathrm{C}(\mathrm{C}(\mathrm{C}(\mathrm{C}(\mathrm{C}(\mathrm{C}(\mathrm{C}(\mathrm{C}(\mathrm{H})(\mathrm{F}) \mathrm{H})(\mathrm{H}) \mathrm{H})(\mathrm{H}) \mathrm{H})(\mathrm{H}) \mathrm{H})(\mathrm{H}) \mathrm{H})(\mathrm{Cl}) \mathrm{H})(\mathrm{H}) \mathrm{H})(\mathrm{H}) \mathrm{H})(\mathrm{H}) \mathrm{H})$

$(\mathrm{F}) \mathrm{F})(\mathrm{H}) \mathrm{H})(\mathrm{H}) \mathrm{H})(\mathrm{H}) \mathrm{H})(\mathrm{H}) \mathrm{H})(\mathrm{H}) \mathrm{H})(\mathrm{H}) \mathrm{H})(\mathrm{H})(\mathrm{H}) \mathrm{H}$

$\mathrm{C}(\mathrm{C}(\mathrm{C}(\mathrm{C}(\mathrm{C}(\mathrm{C}(\mathrm{C}(\mathrm{C}(\mathrm{C}(\mathrm{C}(\mathrm{C}(\mathrm{C}(\mathrm{C}(\mathrm{C}(\mathrm{C}(\mathrm{C}(\mathrm{C}(\mathrm{H})(\mathrm{H}) \mathrm{H})(\mathrm{H}) \mathrm{H})(\mathrm{H}) \mathrm{H})(\mathrm{F}) \mathrm{H})(\mathrm{H}) \mathrm{H})(\mathrm{H}) \mathrm{H})(\mathrm{F}) \mathrm{H})(\mathrm{H}) \mathrm{H})(\mathrm{H}) \mathrm{H})(\mathrm{Br})$ $\mathrm{H})(\mathrm{H}) \mathrm{H})(\mathrm{H}) \mathrm{H})(\mathrm{H}) \mathrm{H})(\mathrm{H}) \mathrm{H})(\mathrm{H}) \mathrm{H})(\mathrm{H}) \mathrm{H})(\mathrm{H})(\mathrm{H}) \mathrm{H}$

$\mathrm{C}(\mathrm{C}(\mathrm{C}(\mathrm{C}(\mathrm{C}(\mathrm{C}(\mathrm{C}(\mathrm{C}(\mathrm{C}(\mathrm{C}(\mathrm{C}(\mathrm{C}(\mathrm{C}(\mathrm{C}(\mathrm{C}(\mathrm{C}(\mathrm{C}(\mathrm{H})(\mathrm{H}) \mathrm{H})(\mathrm{H}) \mathrm{H})(\mathrm{H}) \mathrm{H})(\mathrm{F}) \mathrm{H})(\mathrm{H}) \mathrm{H})(\mathrm{H}) \mathrm{H})(\mathrm{H}) \mathrm{H})(\mathrm{H}) \mathrm{H})(\mathrm{H}) \mathrm{H})(\mathrm{H}) \mathrm{C}$ l) $(\mathrm{H}) \mathrm{H})(\mathrm{H}) \mathrm{H})(\mathrm{H}) \mathrm{H})(\mathrm{H}) \mathrm{H})(\mathrm{H}) \mathrm{H})(\mathrm{H}) \mathrm{Cl})(\mathrm{H})(\mathrm{H}) \mathrm{H}$

$\mathrm{C}(\mathrm{C}(\mathrm{C}(\mathrm{C}(\mathrm{C}(\mathrm{C}(\mathrm{C}(\mathrm{C}(\mathrm{C}(\mathrm{C}(\mathrm{C}(\mathrm{C}(\mathrm{C}(\mathrm{C}(\mathrm{C}(\mathrm{C}(\mathrm{C}(\mathrm{Cl})(\mathrm{H}) \mathrm{H})(\mathrm{H}) \mathrm{H})(\mathrm{H}) \mathrm{H})(\mathrm{H}) \mathrm{H})(\mathrm{H}) \mathrm{H})(\mathrm{H}) \mathrm{H})(\mathrm{H}) \mathrm{H})(\mathrm{H}) \mathrm{H})(\mathrm{H}) \mathrm{H})(\mathrm{F}) \quad \mathrm{Cl} 17 \mathrm{H} 33 \mathrm{ClF} 2$

$\mathrm{H})(\mathrm{H}) \mathrm{H})(\mathrm{H}) \mathrm{F})(\mathrm{H}) \mathrm{H})(\mathrm{H}) \mathrm{H})(\mathrm{H}) \mathrm{H})(\mathrm{H}) \mathrm{H})(\mathrm{H})(\mathrm{H}) \mathrm{H}$

$\mathrm{C}\left(\mathrm{C}\left(\mathrm{C}\left(\mathrm{C}\left(\mathrm{C}\left(\mathrm{C}\left(\mathrm{C}\left(\mathrm{C}(\mathrm{C}(\mathrm{C}(\mathrm{C}(\mathrm{C}(\mathrm{C}(\mathrm{C}(\mathrm{C}(\mathrm{C}(\mathrm{C}(\mathrm{H})(\mathrm{H}) \mathrm{H})(\mathrm{H}) \mathrm{H})(\mathrm{H}) \mathrm{H})(\mathrm{H}) \mathrm{H})(\mathrm{H}) \mathrm{H})(\mathrm{H}) \mathrm{H})(\mathrm{H}) \mathrm{H})(\mathrm{H}) \mathrm{H})(\mathrm{H}) \mathrm{H})(\mathrm{H}) \quad \mathrm{Cl}_{7 \mathrm{H}} 33 \mathrm{~F} 3\right.\right.\right.\right.\right.\right.\right.$

$\mathrm{H})(\mathrm{H}) \mathrm{H})(\mathrm{H}) \mathrm{F})(\mathrm{F}) \mathrm{H})(\mathrm{H}) \mathrm{H})(\mathrm{H}) \mathrm{H})(\mathrm{H}) \mathrm{F})(\mathrm{H})(\mathrm{H}) \mathrm{H}$

$\mathrm{C}(\mathrm{C}(\mathrm{C}(\mathrm{C}(\mathrm{C}(\mathrm{C}(\mathrm{C}(\mathrm{C}(\mathrm{C}(\mathrm{C}(\mathrm{C}(\mathrm{C}(\mathrm{C}(\mathrm{C}(\mathrm{C}(\mathrm{C}(\mathrm{C}(\mathrm{H})(\mathrm{H}) \mathrm{H})(\mathrm{H}) \mathrm{H})(\mathrm{H}) \mathrm{H})(\mathrm{H}) \mathrm{F})(\mathrm{H}) \mathrm{H})(\mathrm{H}) \mathrm{H})(\mathrm{H}) \mathrm{H})(\mathrm{H}) \mathrm{H})(\mathrm{H}) \mathrm{H})(\mathrm{H})$ $\mathrm{H})(\mathrm{H}) \mathrm{H})(\mathrm{H}) \mathrm{H})(\mathrm{H}) \mathrm{H})(\mathrm{H}) \mathrm{H})(\mathrm{Br}) \mathrm{H})(\mathrm{H}) \mathrm{H})(\mathrm{H})(\mathrm{H}) \mathrm{H}$ $\mathrm{C}(\mathrm{C}(\mathrm{C}(\mathrm{C}(\mathrm{C}(\mathrm{C}(\mathrm{C}(\mathrm{C}(\mathrm{C}(\mathrm{C}(\mathrm{C}(\mathrm{C}(\mathrm{C}(\mathrm{C}(\mathrm{C}(\mathrm{C}(\mathrm{C}(\mathrm{H})(\mathrm{H}) \mathrm{H})(\mathrm{H}) \mathrm{H})(\mathrm{H}) \mathrm{H})(\mathrm{H}) \mathrm{H})(\mathrm{H}) \mathrm{H})(\mathrm{H}) \mathrm{H})(\mathrm{H}) \mathrm{H})(\mathrm{H}) \mathrm{H})(\mathrm{H}) \mathrm{H})(\mathrm{H})$
$\mathrm{H})(\mathrm{H}) \mathrm{H})(\mathrm{H}) \mathrm{Cl})(\mathrm{H}) \mathrm{H})(\mathrm{Cl}) \mathrm{H} 34 \mathrm{H})(\mathrm{H}) \mathrm{H})(\mathrm{H}) \mathrm{H})(\mathrm{H})(\mathrm{H}) \mathrm{H}$

$\mathrm{C}\left(\mathrm{C}\left(\mathrm{C}\left(\mathrm{C}\left(\mathrm{C}\left(\mathrm{C}\left(\mathrm{C}\left(\mathrm{C}(\mathrm{C}(\mathrm{C}(\mathrm{C}(\mathrm{C}(\mathrm{C}(\mathrm{C}(\mathrm{C}(\mathrm{C}(\mathrm{C}(\mathrm{H})(\mathrm{H}) \mathrm{H})(\mathrm{H}) \mathrm{H})(\mathrm{H}) \mathrm{H})(\mathrm{H}) \mathrm{H})(\mathrm{H}) \mathrm{H})(\mathrm{H}) \mathrm{H})(\mathrm{H}) \mathrm{F})(\mathrm{H}) \mathrm{H})(\mathrm{H}) \mathrm{H})(\mathrm{H}) \mathrm{C}{ }_{\mathrm{C} 17 \mathrm{H} 34 \mathrm{ClF}}\right.\right.\right.\right.\right.\right.\right.$ l)(H)H $(\mathrm{H}) \mathrm{H})(\mathrm{H}) \mathrm{H})(\mathrm{H}) \mathrm{H})(\mathrm{H}) \mathrm{H})(\mathrm{H}) \mathrm{H})(\mathrm{H})(\mathrm{H}) \mathrm{H}$

$\mathrm{C}(\mathrm{C}(\mathrm{C}(\mathrm{C}(\mathrm{C}(\mathrm{C}(\mathrm{C}(\mathrm{C}(\mathrm{C}(\mathrm{C}(\mathrm{C}(\mathrm{C}(\mathrm{C}(\mathrm{C}(\mathrm{C}(\mathrm{C}(\mathrm{C}(\mathrm{H})(\mathrm{H}) \mathrm{H})(\mathrm{H}) \mathrm{H})(\mathrm{H}) \mathrm{H})(\mathrm{H}) \mathrm{H})(\mathrm{H}) \mathrm{H})(\mathrm{H}) \mathrm{H})(\mathrm{H}) \mathrm{H})(\mathrm{H}) \mathrm{H})(\mathrm{H}) \mathrm{H})(\mathrm{H}) \quad \mathrm{C} 17 \mathrm{H} 34 \mathrm{~F} 2$

$\mathrm{H})(\mathrm{H}) \mathrm{H})(\mathrm{H}) \mathrm{H})(\mathrm{H}) \mathrm{H})(\mathrm{H}) \mathrm{F})(\mathrm{H}) \mathrm{H})(\mathrm{H}) \mathrm{H})(\mathrm{F})(\mathrm{H}) \mathrm{H}$

$\mathrm{C}(\mathrm{C}(\mathrm{C}(\mathrm{C}(\mathrm{C}(\mathrm{C}(\mathrm{C}(\mathrm{C}(\mathrm{C}(\mathrm{C}(\mathrm{C}(\mathrm{C}(\mathrm{C}(\mathrm{C}(\mathrm{C}(\mathrm{C}(\mathrm{C}(\mathrm{H})(\mathrm{H}) \mathrm{H})(\mathrm{H}) \mathrm{H})(\mathrm{H}) \mathrm{H})(\mathrm{H}) \mathrm{H})(\mathrm{H}) \mathrm{H})(\mathrm{H}) \mathrm{H})(\mathrm{H}) \mathrm{H})(\mathrm{H}) \mathrm{H})(\mathrm{H}) \mathrm{H})(\mathrm{H})$

$\mathrm{H})(\mathrm{H}) \mathrm{H})(\mathrm{H}) \mathrm{H})(\mathrm{H}) \mathrm{H})(\mathrm{H}) \mathrm{H})(\mathrm{H}) \mathrm{H})(\mathrm{H}) \mathrm{H})(\mathrm{H})(\mathrm{H}) \mathrm{B}$

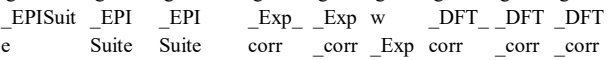

$\begin{array}{lllllllll}4.704 & 8.15 & 3.45 & 7.24 & 3.79 & 3.45 & 7.02 & 6.65 & 0.37\end{array}$

$\begin{array}{lllllllll}6.275 & 8.67 & 2.40 & 8.01 & 5.62 & 2.40 & 7.42 & 9.54 & -2.12\end{array}$

$\begin{array}{lllllllll}6.047 & 9.68 & 3.63 & 9.52 & 5.89 & 3.63 & 8.20 & 9.12 & -0.92\end{array}$

$\begin{array}{lllllllll}6.299 & 9.18 & 2.88 & 8.78 & 5.90 & 2.88 & 7.81 & 9.58 & -1.77\end{array}$

$\begin{array}{lllllllll}7.361 & 9.49 & 2.13 & 9.24 & 7.11 & 2.13 & 8.05 & 11.53 & -3.48\end{array}$

$\begin{array}{lllllllll}6.543 & 9.69 & 3.15 & 9.54 & 6.39 & 3.15 & 8.20 & 10.03 & -1.83\end{array}$

$\begin{array}{lllllllll}6.216 & 8.58 & 2.36 & 7.88 & 5.52 & 2.36 & 7.35 & 9.43 & -2.08\end{array}$

$\begin{array}{lllllllll}5.736 & 9.07 & 3.33 & 8.61 & 5.28 & 3.33 & 7.73 & 8.55 & -0.82\end{array}$

$\begin{array}{llllllllll}6.878 & 9.46 & 2.58 & 9.19 & 6.61 & 2.58 & 8.03 & 10.65 & -2.62\end{array}$

$\begin{array}{lllllllll}7.051 & 8.88 & 1.83 & 8.33 & 6.50 & 1.83 & 7.58 & 10.96 & -3.38\end{array}$

$\begin{array}{lllllllll}6.38 & 9.23 & 2.85 & 8.85 & 6.00 & 2.85 & 7.85 & 9.73 & -1.88\end{array}$

$\begin{array}{lllllllll}6.575 & 8.64 & 2.06 & 7.97 & 5.91 & 2.06 & 7.40 & 10.09 & -2.69\end{array}$

$\begin{array}{lllllllll}5.678 & 8.98 & 3.30 & 8.48 & 5.18 & 3.30 & 7.66 & 8.44 & -0.78\end{array}$

$\begin{array}{lllllllll}7.141 & 8.94 & 1.80 & 8.42 & 6.62 & 1.80 & 7.63 & 11.13 & -3.50\end{array}$

$\begin{array}{lllllllll}6.165 & 9.2 & 3.03 & 8.81 & 5.77 & 3.03 & 7.83 & 9.34 & -1.51\end{array}$

$\begin{array}{lllllllll}7.227 & 9.51 & 2.28 & 9.27 & 6.99 & 2.28 & 8.07 & 11.29 & -3.22\end{array}$

$\begin{array}{lllllllll}6.74 & 9.29 & 2.55 & 8.94 & 6.39 & 2.55 & 7.90 & 10.39 & -2.50\end{array}$

$\begin{array}{lllllllll}7.083 & 8.85 & 1.77 & 8.28 & 6.52 & 1.77 & 7.56 & 11.02 & -3.46\end{array}$

$\begin{array}{lllllllll}6.178 & 9.18 & 3.00 & 8.78 & 5.77 & 3.00 & 7.81 & 9.36 & -1.55\end{array}$

$\begin{array}{lllllllll}5.855 & 8.59 & 2.74 & 7.90 & 5.16 & 2.74 & 7.36 & 8.77 & -1.41\end{array}$

$\begin{array}{lllllllll}6.926 & 8.91 & 1.98 & 8.37 & 6.39 & 1.98 & 7.61 & 10.74 & -3.13\end{array}$

$\begin{array}{lllllllll}6.509 & 8.76 & 2.25 & 8.15 & 5.90 & 2.25 & 7.49 & 9.97 & -2.48\end{array}$

$\begin{array}{lllllllll}4.792 & 8.28 & 3.49 & 7.43 & 3.94 & 3.49 & 7.12 & 6.82 & 0.31\end{array}$

$\begin{array}{lllllllll}7.363 & 8.83 & 1.47 & 8.25 & 6.79 & 1.47 & 7.54 & 11.54 & -3.99\end{array}$

$\begin{array}{lllllllll}5.725 & 8.43 & 2.70 & 7.66 & 4.95 & 2.70 & 7.24 & 8.53 & -1.29\end{array}$

$\begin{array}{lllllllll}6.212 & 8.65 & 2.44 & 7.99 & 5.55 & 2.44 & 7.41 & 9.42 & -2.02\end{array}$

$\begin{array}{lllllllll}7.283 & 8.97 & 1.69 & 8.46 & 6.78 & 1.69 & 7.65 & 11.39 & -3.74\end{array}$

$\begin{array}{lllllllll}6.868 & 8.82 & 1.95 & 8.24 & 6.29 & 1.95 & 7.54 & 10.63 & -3.09\end{array}$

$\begin{array}{lllllllll}5.221 & 8.41 & 3.19 & 7.63 & 4.44 & 3.19 & 7.22 & 7.60 & -0.38\end{array}$

$\begin{array}{lllllllll}6.895 & 9.3 & 2.41 & 8.96 & 6.55 & 2.41 & 7.91 & 10.68 & -2.77\end{array}$

$\begin{array}{lllllllll}6.721 & 8.86 & 2.14 & 8.30 & 6.16 & 2.14 & 7.57 & 10.36 & -2.79\end{array}$

$\begin{array}{lllllllll}7.297 & 8.95 & 1.65 & 8.43 & 6.78 & 1.65 & 7.64 & 11.42 & -3.78\end{array}$

$\begin{array}{lllllllll}6.4 & 9.29 & 2.89 & 8.94 & 6.05 & 2.89 & 7.90 & 9.77 & -1.87\end{array}$

$\begin{array}{lllllllll}6.583 & 8.69 & 2.11 & 8.04 & 5.94 & 2.11 & 7.44 & 10.11 & -2.67\end{array}$

$\begin{array}{lllllllll}7.081 & 8.92 & 1.84 & 8.39 & 6.55 & 1.84 & 7.61 & 11.02 & -3.41\end{array}$

$\begin{array}{lllllllll}6.088 & 8.68 & 2.59 & 8.03 & 5.44 & 2.59 & 7.43 & 9.20 & -1.77\end{array}$

$\begin{array}{lllllllll}4.946 & 8.29 & 3.34 & 7.45 & 4.10 & 3.34 & 7.13 & 7.10 & 0.03\end{array}$

$\begin{array}{lllllllll}7.023 & 8.83 & 1.81 & 8.25 & 6.45 & 1.81 & 7.54 & 10.91 & -3.37\end{array}$

$\begin{array}{lllllllll}7.509 & 9.05 & 1.54 & 8.58 & 7.04 & 1.54 & 7.71 & 11.81 & -4.09\end{array}$

$\begin{array}{lllllllll}6.447 & 8.74 & 2.29 & 8.12 & 5.83 & 2.29 & 7.47 & 9.86 & -2.38\end{array}$

$\begin{array}{lllllllll}5.455 & 8.5 & 3.04 & 7.76 & 4.72 & 3.04 & 7.29 & 8.03 & -0.74\end{array}$

$\begin{array}{llllllllll}7.521 & 9.03 & 1.51 & 8.55 & 7.04 & 1.51 & 7.70 & 11.83 & -4.13\end{array}$ 
$\mathrm{C}\left(\mathrm{C}\left(\mathrm{C}\left(\mathrm{C}\left(\mathrm{C}\left(\mathrm{C}\left(\mathrm{C}\left(\mathrm{C}(\mathrm{C}(\mathrm{C}(\mathrm{C}(\mathrm{C}(\mathrm{C}(\mathrm{C}(\mathrm{C}(\mathrm{C}(\mathrm{C}(\mathrm{H})(\mathrm{H}) \mathrm{H})(\mathrm{H}) \mathrm{H})(\mathrm{H}) \mathrm{Cl})(\mathrm{H}) \mathrm{H})(\mathrm{H}) \mathrm{H})(\mathrm{H}) \mathrm{H})(\mathrm{H}) \mathrm{H})(\mathrm{H}) \mathrm{H})(\mathrm{H}) \mathrm{H})(\mathrm{H}){ }_{\mathrm{Cl}}{ }^{2} \mathrm{H} 35 \mathrm{Cl}\right.\right.\right.\right.\right.\right.\right.$ $\mathrm{H})(\mathrm{H}) \mathrm{H})(\mathrm{H}) \mathrm{H})(\mathrm{H}) \mathrm{H})(\mathrm{H}) \mathrm{H})(\mathrm{H}) \mathrm{H})(\mathrm{H}) \mathrm{H})(\mathrm{H})(\mathrm{H}) \mathrm{H}$

$\mathrm{C} 17 \mathrm{H} 35 \mathrm{C}$

C $(\mathrm{C}(\mathrm{C}(\mathrm{C}(\mathrm{C}(\mathrm{C}(\mathrm{C}(\mathrm{C}(\mathrm{C}(\mathrm{C}(\mathrm{C}(\mathrm{C}(\mathrm{C}(\mathrm{C}(\mathrm{C}(\mathrm{C}(\mathrm{C}(\mathrm{H})(\mathrm{H}) \mathrm{H})(\mathrm{H}) \mathrm{H})(\mathrm{H}) \mathrm{H})(\mathrm{H}) \mathrm{H})(\mathrm{H}) \mathrm{H})(\mathrm{H}) \mathrm{H})(\mathrm{H}) \mathrm{H})(\mathrm{H}) \mathrm{H})(\mathrm{H}) \mathrm{H})(\mathrm{H})$ F)(H)H $(\mathrm{H}) \mathrm{H})(\mathrm{H}) \mathrm{H})(\mathrm{H}) \mathrm{H})(\mathrm{H}) \mathrm{H})(\mathrm{H}) \mathrm{H})(\mathrm{H})(\mathrm{H}) \mathrm{H}$

$\mathrm{C}(\mathrm{C}(\mathrm{C}(\mathrm{C}(\mathrm{C}(\mathrm{C}(\mathrm{C}(\mathrm{C}(\mathrm{C}(\mathrm{C}(\mathrm{C}(\mathrm{C}(\mathrm{C}(\mathrm{C}(\mathrm{C}(\mathrm{C}(\mathrm{C}(\mathrm{C}(\mathrm{H})(\mathrm{Br}) \mathrm{F})(\mathrm{Cl}) \mathrm{Br})(\mathrm{H}) \mathrm{F})(\mathrm{H}) \mathrm{H})(\mathrm{H}) \mathrm{H})(\mathrm{Cl}) \mathrm{F})(\mathrm{F}) \mathrm{H})(\mathrm{H}) \mathrm{F})(\mathrm{H}) \mathrm{F})($ $\mathrm{H}) \mathrm{F})(\mathrm{Cl}) \mathrm{H})(\mathrm{H}) \mathrm{F})(\mathrm{F}) \mathrm{H})(\mathrm{H}) \mathrm{F})(\mathrm{H}) \mathrm{F})(\mathrm{F}) \mathrm{H})(\mathrm{F}) \mathrm{H})(\mathrm{F})(\mathrm{H}) \mathrm{F}$

$\mathrm{C}(\mathrm{C}(\mathrm{C}(\mathrm{C}(\mathrm{C}(\mathrm{C}(\mathrm{C}(\mathrm{C}(\mathrm{C}(\mathrm{C}(\mathrm{C}(\mathrm{C}(\mathrm{C}(\mathrm{C}(\mathrm{C}(\mathrm{C}(\mathrm{C}(\mathrm{C}(\mathrm{Cl})(\mathrm{F}) \mathrm{H})(\mathrm{H}) \mathrm{F})(\mathrm{F}) \mathrm{H})(\mathrm{H}) \mathrm{H})(\mathrm{H}) \mathrm{F})(\mathrm{H}) \mathrm{F})(\mathrm{H}) \mathrm{F})(\mathrm{H}) \mathrm{F})(\mathrm{H}) \mathrm{F})$

$(\mathrm{F}) \mathrm{H})(\mathrm{Br}) \mathrm{H})(\mathrm{F}) \mathrm{H})(\mathrm{F}) \mathrm{F})(\mathrm{F}) \mathrm{H})(\mathrm{F}) \mathrm{Cl})(\mathrm{H}) \mathrm{H})(\mathrm{F}) \mathrm{H})(\mathrm{Br})(\mathrm{H}) \mathrm{H}$

$\mathrm{C} 17 \mathrm{H} 35 \mathrm{~F}$

$\mathrm{C} 18 \mathrm{H} 18 \mathrm{Cl} 3 \mathrm{Br} 2 \mathrm{~F} 1$ 5 $\mathrm{C} 18 \mathrm{H} 19 \mathrm{C} 12 \mathrm{Br} 2 \mathrm{~F} 1$ 5

$\mathrm{C}\left(\mathrm{C}\left(\mathrm{C}\left(\mathrm{C}\left(\mathrm{C}\left(\mathrm{C}\left(\mathrm{C}\left(\mathrm{C}\left(\mathrm{C}(\mathrm{C}(\mathrm{C}(\mathrm{C}(\mathrm{C}(\mathrm{C}(\mathrm{C}(\mathrm{C}(\mathrm{C}(\mathrm{C}(\mathrm{Cl})(\mathrm{H}) \mathrm{Cl})(\mathrm{H}) \mathrm{H})(\mathrm{H}) \mathrm{Br})(\mathrm{Cl}) \mathrm{Cl})(\mathrm{H}) \mathrm{H})(\mathrm{F}) \mathrm{H})(\mathrm{F}) \mathrm{H})(\mathrm{F}) \mathrm{H})(\mathrm{H}) \mathrm{H})\left({ }_{\mathrm{C} 18 \mathrm{H} 21 \mathrm{Cl} 5 \mathrm{BrF} 11}\right.\right.\right.\right.\right.\right.\right.\right.\right.$ $\mathrm{Cl}) \mathrm{H})(\mathrm{H}) \mathrm{H})(\mathrm{H}) \mathrm{F})(\mathrm{H}) \mathrm{F})(\mathrm{H}) \mathrm{F})(\mathrm{F}) \mathrm{H})(\mathrm{F}) \mathrm{H})(\mathrm{H}) \mathrm{F})(\mathrm{F})(\mathrm{H}) \mathrm{F}$

$\mathrm{C}(\mathrm{C}(\mathrm{C}(\mathrm{C}(\mathrm{C}(\mathrm{C}(\mathrm{C}(\mathrm{C}(\mathrm{C}(\mathrm{C}(\mathrm{C}(\mathrm{C}(\mathrm{C}(\mathrm{C}(\mathrm{C}(\mathrm{C}(\mathrm{C}(\mathrm{C}(\mathrm{F})(\mathrm{Br}) \mathrm{H})(\mathrm{H}) \mathrm{F})(\mathrm{F}) \mathrm{F})(\mathrm{F}) \mathrm{F})(\mathrm{H}) \mathrm{H})(\mathrm{H}) \mathrm{H})(\mathrm{H}) \mathrm{H})(\mathrm{F}) \mathrm{H})(\mathrm{H}) \mathrm{H})(\mathrm{H})$ $\mathrm{H})(\mathrm{H}) \mathrm{Br})(\mathrm{H}) \mathrm{Br})(\mathrm{H}) \mathrm{F})(\mathrm{H}) \mathrm{F})(\mathrm{H}) \mathrm{H})(\mathrm{H}) \mathrm{H})(\mathrm{F}) \mathrm{H})(\mathrm{F})(\mathrm{H}) \mathrm{F}$

$\mathrm{C} 18 \mathrm{H} 23 \mathrm{Br} 3 \mathrm{~F} 12$

$\mathrm{C}(\mathrm{C}(\mathrm{C}(\mathrm{C}(\mathrm{C}(\mathrm{C}(\mathrm{C}(\mathrm{C}(\mathrm{C}(\mathrm{C}(\mathrm{C}(\mathrm{C}(\mathrm{C}(\mathrm{C}(\mathrm{C}(\mathrm{C}(\mathrm{C}(\mathrm{C}(\mathrm{F})(\mathrm{H}) \mathrm{Br})(\mathrm{H}) \mathrm{H})(\mathrm{H}) \mathrm{F})(\mathrm{H}) \mathrm{H})(\mathrm{H}) \mathrm{H})(\mathrm{F}) \mathrm{H})(\mathrm{F}) \mathrm{H})(\mathrm{F}) \mathrm{H})(\mathrm{F}) \mathrm{H})(\mathrm{H}) \quad \mathrm{C} 18 \mathrm{H} 23 \mathrm{Cl} 2 \mathrm{Br} 2 \mathrm{~F} 1$ $\mathrm{F})(\mathrm{H}) \mathrm{H})(\mathrm{H}) \mathrm{H})(\mathrm{H}) \mathrm{H})(\mathrm{H}) \mathrm{F})(\mathrm{H}) \mathrm{Cl})(\mathrm{H}) \mathrm{Br})(\mathrm{F}) \mathrm{H})(\mathrm{F})(\mathrm{F}) \mathrm{Cl}$

$\mathrm{C}(\mathrm{C}(\mathrm{C}(\mathrm{C}(\mathrm{C}(\mathrm{C}(\mathrm{C}(\mathrm{C}(\mathrm{C}(\mathrm{C}(\mathrm{C}(\mathrm{C}(\mathrm{C}(\mathrm{C}(\mathrm{C}(\mathrm{C}(\mathrm{C}(\mathrm{C}(\mathrm{F})(\mathrm{H}) \mathrm{F})(\mathrm{Cl}) \mathrm{H})(\mathrm{H}) \mathrm{F})(\mathrm{H}) \mathrm{F})(\mathrm{H}) \mathrm{Cl})(\mathrm{H}) \mathrm{F})(\mathrm{F}) \mathrm{H})(\mathrm{Br}) \mathrm{H})(\mathrm{F}) \mathrm{H})(\mathrm{H}) \mathrm{C} 18 \mathrm{H} 24 \mathrm{Cl} 2 \mathrm{Br} 2 \mathrm{~F} 1$ $\mathrm{H})(\mathrm{H}) \mathrm{H})(\mathrm{H}) \mathrm{H})(\mathrm{H}) \mathrm{F})(\mathrm{Br}) \mathrm{F})(\mathrm{H}) \mathrm{H})(\mathrm{H}) \mathrm{H})(\mathrm{H}) \mathrm{H})(\mathrm{H})(\mathrm{F}) \mathrm{H}$

$\mathrm{C}(\mathrm{C}(\mathrm{C}(\mathrm{C}(\mathrm{C}(\mathrm{C}(\mathrm{C}(\mathrm{C}(\mathrm{C}(\mathrm{C}(\mathrm{C}(\mathrm{C}(\mathrm{C}(\mathrm{C}(\mathrm{C}(\mathrm{C}(\mathrm{C}(\mathrm{C}(\mathrm{H})(\mathrm{F}) \mathrm{H})(\mathrm{F}) \mathrm{H})(\mathrm{H}) \mathrm{Br})(\mathrm{H}) \mathrm{F})(\mathrm{H}) \mathrm{F})(\mathrm{H}) \mathrm{F})(\mathrm{F}) \mathrm{H})(\mathrm{H}) \mathrm{H})(\mathrm{H}) \mathrm{H})(\mathrm{F})$

$\mathrm{H})(\mathrm{H}) \mathrm{H})(\mathrm{H}) \mathrm{F})(\mathrm{F}) \mathrm{H})(\mathrm{Cl}) \mathrm{H})(\mathrm{H}) \mathrm{H})(\mathrm{Cl}) \mathrm{F})(\mathrm{H}) \mathrm{H})(\mathrm{H})(\mathrm{F}) \mathrm{H}$

$\mathrm{C}(\mathrm{C}(\mathrm{C}(\mathrm{C}(\mathrm{C}(\mathrm{C}(\mathrm{C}(\mathrm{C}(\mathrm{C}(\mathrm{C}(\mathrm{C}(\mathrm{C}(\mathrm{C}(\mathrm{C}(\mathrm{C}(\mathrm{C}(\mathrm{C}(\mathrm{C}(\mathrm{F})(\mathrm{F}) \mathrm{F})(\mathrm{H}) \mathrm{F})(\mathrm{H}) \mathrm{H})(\mathrm{H}) \mathrm{H})(\mathrm{F}) \mathrm{H})(\mathrm{F}) \mathrm{H})(\mathrm{H}) \mathrm{H})(\mathrm{F}) \mathrm{H})(\mathrm{H}) \mathrm{F})$

$(\mathrm{H}) \mathrm{H})(\mathrm{H}) \mathrm{H})(\mathrm{F}) \mathrm{H})(\mathrm{Br}) \mathrm{F})(\mathrm{H}) \mathrm{H})(\mathrm{H}) \mathrm{H})(\mathrm{H}) \mathrm{H})(\mathrm{Br}) \mathrm{H})(\mathrm{F})(\mathrm{H}) \mathrm{H}$

$\mathrm{C}(\mathrm{C}(\mathrm{C}(\mathrm{C}(\mathrm{C}(\mathrm{C}(\mathrm{C}(\mathrm{C}(\mathrm{C}(\mathrm{C}(\mathrm{C}(\mathrm{C}(\mathrm{C}(\mathrm{C}(\mathrm{C}(\mathrm{C}(\mathrm{C}(\mathrm{C}(\mathrm{H})(\mathrm{Br}) \mathrm{H})(\mathrm{H}) \mathrm{F})(\mathrm{Br}) \mathrm{H})(\mathrm{F}) \mathrm{F})(\mathrm{F}) \mathrm{H})(\mathrm{F}) \mathrm{H})(\mathrm{H}) \mathrm{H})(\mathrm{F}) \mathrm{H})(\mathrm{H}) \mathrm{H})(\mathrm{H})$ $\mathrm{H})(\mathrm{H}) \mathrm{F})(\mathrm{F}) \mathrm{H})(\mathrm{H}) \mathrm{H})(\mathrm{F}) \mathrm{H})(\mathrm{H}) \mathrm{Br})(\mathrm{H}) \mathrm{F})(\mathrm{H}) \mathrm{H})(\mathrm{H})(\mathrm{H}) \mathrm{H}$

$\mathrm{C}(\mathrm{C}(\mathrm{C}(\mathrm{C}(\mathrm{C}(\mathrm{C}(\mathrm{C}(\mathrm{C}(\mathrm{C}(\mathrm{C}(\mathrm{C}(\mathrm{C}(\mathrm{C}(\mathrm{C}(\mathrm{C}(\mathrm{C}(\mathrm{C}(\mathrm{C}(\mathrm{Cl})(\mathrm{F}) \mathrm{Br})(\mathrm{H}) \mathrm{H})(\mathrm{H}) \mathrm{F})(\mathrm{H}) \mathrm{F})(\mathrm{H}) \mathrm{H})(\mathrm{H}) \mathrm{F})(\mathrm{H}) \mathrm{H})(\mathrm{H}) \mathrm{H})(\mathrm{F}) \mathrm{H})$ $(\mathrm{H}) \mathrm{H})(\mathrm{F}) \mathrm{H})(\mathrm{Cl}) \mathrm{H})(\mathrm{F}) \mathrm{H})(\mathrm{F}) \mathrm{H})(\mathrm{H}) \mathrm{H})(\mathrm{H}) \mathrm{H})(\mathrm{F}) \mathrm{H})(\mathrm{H})(\mathrm{F}) \mathrm{H}$

$\mathrm{C}(\mathrm{C}(\mathrm{C}(\mathrm{C}(\mathrm{C}(\mathrm{C}(\mathrm{C}(\mathrm{C}(\mathrm{C}(\mathrm{C}(\mathrm{C}(\mathrm{C}(\mathrm{C}(\mathrm{C}(\mathrm{C}(\mathrm{C}(\mathrm{C}(\mathrm{C}(\mathrm{H})(\mathrm{H}) \mathrm{H})(\mathrm{F}) \mathrm{H})(\mathrm{H}) \mathrm{Cl})(\mathrm{H}) \mathrm{F})(\mathrm{H}) \mathrm{F})(\mathrm{Cl}) \mathrm{H})(\mathrm{H}) \mathrm{H})(\mathrm{H}) \mathrm{F})(\mathrm{H}) \mathrm{H})$

$(\mathrm{H}) \mathrm{F})(\mathrm{F}) \mathrm{H})(\mathrm{H}) \mathrm{H})(\mathrm{H}) \mathrm{Br})(\mathrm{F}) \mathrm{H})(\mathrm{H}) \mathrm{H})(\mathrm{H}) \mathrm{F})(\mathrm{H}) \mathrm{Cl})(\mathrm{H})(\mathrm{H}) \mathrm{F}$

$\mathrm{C}(\mathrm{C}(\mathrm{C}(\mathrm{C}(\mathrm{C}(\mathrm{C}(\mathrm{C}(\mathrm{C}(\mathrm{C}(\mathrm{C}(\mathrm{C}(\mathrm{C}(\mathrm{C}(\mathrm{C}(\mathrm{C}(\mathrm{C}(\mathrm{C}(\mathrm{C}(\mathrm{H})(\mathrm{H}) \mathrm{H})(\mathrm{H}) \mathrm{F})(\mathrm{H}) \mathrm{H})(\mathrm{H}) \mathrm{H})(\mathrm{H}) \mathrm{F})(\mathrm{F}) \mathrm{F})(\mathrm{H}) \mathrm{H})(\mathrm{F}) \mathrm{H})(\mathrm{H}) \mathrm{Cl})(\mathrm{H})$

$\mathrm{H})(\mathrm{H}) \mathrm{Cl})(\mathrm{F}) \mathrm{H})(\mathrm{F}) \mathrm{H})(\mathrm{H}) \mathrm{H})(\mathrm{H}) \mathrm{F})(\mathrm{F}) \mathrm{F})(\mathrm{H}) \mathrm{Cl})(\mathrm{H})(\mathrm{H}) \mathrm{H}$

$\mathrm{C}(\mathrm{C}(\mathrm{C}(\mathrm{C}(\mathrm{C}(\mathrm{C}(\mathrm{C}(\mathrm{C}(\mathrm{C}(\mathrm{C}(\mathrm{C}(\mathrm{C}(\mathrm{C}(\mathrm{C}(\mathrm{C}(\mathrm{C}(\mathrm{C}(\mathrm{C}(\mathrm{H})(\mathrm{H}) \mathrm{H})(\mathrm{H}) \mathrm{F})(\mathrm{H}) \mathrm{H})(\mathrm{H}) \mathrm{H})(\mathrm{F}) \mathrm{H})(\mathrm{H}) \mathrm{F})(\mathrm{H}) \mathrm{F})(\mathrm{H}) \mathrm{Cl})(\mathrm{H}) \mathrm{H})(\mathrm{F})$ $\mathrm{H})(\mathrm{H}) \mathrm{H})(\mathrm{H}) \mathrm{H})(\mathrm{Cl}) \mathrm{Cl}(\mathrm{Cl}) \mathrm{H})(\mathrm{F}) \mathrm{H})(\mathrm{H}) \mathrm{F})(\mathrm{Cl}) \mathrm{H})(\mathrm{H})(\mathrm{H}) \mathrm{F}$

$\mathrm{C}(\mathrm{C}(\mathrm{C}(\mathrm{C}(\mathrm{C}(\mathrm{C}(\mathrm{C}(\mathrm{C}(\mathrm{C}(\mathrm{C}(\mathrm{C}(\mathrm{C}(\mathrm{C}(\mathrm{C}(\mathrm{C}(\mathrm{C}(\mathrm{C}(\mathrm{C}(\mathrm{H})(\mathrm{H}) \mathrm{H})(\mathrm{F}) \mathrm{F})(\mathrm{F}) \mathrm{H})(\mathrm{F}) \mathrm{Br})(\mathrm{H}) \mathrm{H})(\mathrm{H}) \mathrm{F})(\mathrm{F}) \mathrm{H})(\mathrm{Cl}) \mathrm{H})(\mathrm{H}) \mathrm{F})(\mathrm{F})$ $\mathrm{H})(\mathrm{H}) \mathrm{H})(\mathrm{H}) \mathrm{H})(\mathrm{H}) \mathrm{H})(\mathrm{H}) \mathrm{F})(\mathrm{H}) \mathrm{H})(\mathrm{H}) \mathrm{F})(\mathrm{Br}) \mathrm{H})(\mathrm{H})(\mathrm{H}) \mathrm{H}$

$\mathrm{C}(\mathrm{C}(\mathrm{C}(\mathrm{C}(\mathrm{C}(\mathrm{C}(\mathrm{C}(\mathrm{C}(\mathrm{C}(\mathrm{C}(\mathrm{C}(\mathrm{C}(\mathrm{C}(\mathrm{C}(\mathrm{C}(\mathrm{C}(\mathrm{C}(\mathrm{C}(\mathrm{H})(\mathrm{H}) \mathrm{H})(\mathrm{H}) \mathrm{H})(\mathrm{H}) \mathrm{H})(\mathrm{H}) \mathrm{H})(\mathrm{H}) \mathrm{H})(\mathrm{H}) \mathrm{Cl})(\mathrm{H}) \mathrm{F})(\mathrm{F}) \mathrm{H})(\mathrm{H}) \mathrm{H})$ $(\mathrm{H}) \mathrm{F})(\mathrm{H}) \mathrm{F})(\mathrm{F}) \mathrm{H})(\mathrm{H}) \mathrm{Br})(\mathrm{F}) \mathrm{F})(\mathrm{H}) \mathrm{H})(\mathrm{H}) \mathrm{H})(\mathrm{H}) \mathrm{Cl})(\mathrm{F})(\mathrm{F}) \mathrm{H}$

$\mathrm{C}(\mathrm{C}(\mathrm{C}(\mathrm{C}(\mathrm{C}(\mathrm{C}(\mathrm{C}(\mathrm{C}(\mathrm{C}(\mathrm{C}(\mathrm{C}(\mathrm{C}(\mathrm{C}(\mathrm{C}(\mathrm{C}(\mathrm{C}(\mathrm{C}(\mathrm{C}(\mathrm{Cl})(\mathrm{H}) \mathrm{F})(\mathrm{H}) \mathrm{F})(\mathrm{H}) \mathrm{F})(\mathrm{Cl}) \mathrm{F})(\mathrm{F}) \mathrm{H})(\mathrm{H}) \mathrm{H})(\mathrm{H}) \mathrm{F})(\mathrm{H}) \mathrm{H})(\mathrm{F}) \mathrm{H})(\mathrm{H})$

F)(H)H $(\mathrm{H}) \mathrm{H})(\mathrm{F}) \mathrm{H})(\mathrm{H}) \mathrm{Cl})(\mathrm{H}) \mathrm{H})(\mathrm{H}) \mathrm{H})(\mathrm{H}) \mathrm{H})(\mathrm{H})(\mathrm{H}) \mathrm{H}$

$\mathrm{C}(\mathrm{C}(\mathrm{C}(\mathrm{C}(\mathrm{C}(\mathrm{C}(\mathrm{C}(\mathrm{C}(\mathrm{C}(\mathrm{C}(\mathrm{C}(\mathrm{C}(\mathrm{C}(\mathrm{C}(\mathrm{C}(\mathrm{C}(\mathrm{C}(\mathrm{C}(\mathrm{H})(\mathrm{F}) \mathrm{H})(\mathrm{Cl}) \mathrm{H})(\mathrm{F}) \mathrm{H})(\mathrm{H}) \mathrm{H})(\mathrm{H}) \mathrm{F})(\mathrm{H}) \mathrm{H})(\mathrm{F}) \mathrm{H})(\mathrm{Br}) \mathrm{H})(\mathrm{F}) \mathrm{H})$

$(\mathrm{Br}) \mathrm{H})(\mathrm{H}) \mathrm{H})(\mathrm{F}) \mathrm{H})(\mathrm{H}) \mathrm{H})(\mathrm{H}) \mathrm{H})(\mathrm{F}) \mathrm{H})(\mathrm{H}) \mathrm{H})(\mathrm{H}) \mathrm{H})(\mathrm{H})(\mathrm{F}) \mathrm{Br}$

$\mathrm{C}(\mathrm{C}(\mathrm{C}(\mathrm{C}(\mathrm{C}(\mathrm{C}(\mathrm{C}(\mathrm{C}(\mathrm{C}(\mathrm{C}(\mathrm{C}(\mathrm{C}(\mathrm{C}(\mathrm{C}(\mathrm{C}(\mathrm{C}(\mathrm{C}(\mathrm{C}(\mathrm{F})(\mathrm{H}) \mathrm{Br})(\mathrm{F}) \mathrm{H})(\mathrm{H}) \mathrm{H})(\mathrm{H}) \mathrm{H})(\mathrm{H}) \mathrm{F})(\mathrm{H}) \mathrm{H})(\mathrm{H}) \mathrm{H})(\mathrm{H}) \mathrm{H})(\mathrm{F}) \mathrm{H})$ $(\mathrm{H}) \mathrm{H})(\mathrm{F}) \mathrm{H})(\mathrm{H}) \mathrm{H})(\mathrm{H}) \mathrm{F})(\mathrm{H}) \mathrm{H})(\mathrm{H}) \mathrm{F})(\mathrm{F}) \mathrm{Br})(\mathrm{H}) \mathrm{H})(\mathrm{F})(\mathrm{H}) \mathrm{H}$

$\mathrm{C}(\mathrm{C}(\mathrm{C}(\mathrm{C}(\mathrm{C}(\mathrm{C}(\mathrm{C}(\mathrm{C}(\mathrm{C}(\mathrm{C}(\mathrm{C}(\mathrm{C}(\mathrm{C}(\mathrm{C}(\mathrm{C}(\mathrm{C}(\mathrm{C}(\mathrm{C}(\mathrm{F})(\mathrm{H}) \mathrm{F})(\mathrm{F}) \mathrm{H})(\mathrm{H}) \mathrm{Br})(\mathrm{F}) \mathrm{H})(\mathrm{H}) \mathrm{H})(\mathrm{Br}) \mathrm{H})(\mathrm{H}) \mathrm{H})(\mathrm{F}) \mathrm{H})(\mathrm{H}) \mathrm{H})$ $(\mathrm{H}) \mathrm{H})(\mathrm{Br}) \mathrm{H})(\mathrm{H}) \mathrm{H})(\mathrm{H}) \mathrm{H})(\mathrm{H}) \mathrm{H})(\mathrm{H}) \mathrm{F})(\mathrm{F}) \mathrm{H})(\mathrm{H}) \mathrm{H})(\mathrm{H})(\mathrm{F}) \mathrm{H}$

$\mathrm{C}(\mathrm{C}(\mathrm{C}(\mathrm{C}(\mathrm{C}(\mathrm{C}(\mathrm{C}(\mathrm{C}(\mathrm{C}(\mathrm{C}(\mathrm{C}(\mathrm{C}(\mathrm{C}(\mathrm{C}(\mathrm{C}(\mathrm{C}(\mathrm{C}(\mathrm{C}(\mathrm{H})(\mathrm{F}) \mathrm{H})(\mathrm{H}) \mathrm{F})(\mathrm{F}) \mathrm{H})(\mathrm{Cl}) \mathrm{H})(\mathrm{H}) \mathrm{H})(\mathrm{Cl}) \mathrm{F})(\mathrm{H}) \mathrm{H})(\mathrm{Br}) \mathrm{H})(\mathrm{F}) \mathrm{H})$

$(\mathrm{F}) \mathrm{H})(\mathrm{H}) \mathrm{F})(\mathrm{H}) \mathrm{H})(\mathrm{F}) \mathrm{H})(\mathrm{H}) \mathrm{H})(\mathrm{H}) \mathrm{H})(\mathrm{H}) \mathrm{H})(\mathrm{H}) \mathrm{H})(\mathrm{H})(\mathrm{H}) \mathrm{H}$

$\mathrm{C}(\mathrm{C}(\mathrm{C}(\mathrm{C}(\mathrm{C}(\mathrm{C}(\mathrm{C}(\mathrm{C}(\mathrm{C}(\mathrm{C}(\mathrm{C}(\mathrm{C}(\mathrm{C}(\mathrm{C}(\mathrm{C}(\mathrm{C}(\mathrm{C}(\mathrm{C}(\mathrm{H})(\mathrm{H}) \mathrm{H})(\mathrm{H}) \mathrm{F})(\mathrm{H}) \mathrm{H})(\mathrm{H}) \mathrm{H})(\mathrm{F}) \mathrm{H})(\mathrm{F}) \mathrm{Cl})(\mathrm{H}) \mathrm{F})(\mathrm{F}) \mathrm{Cl})(\mathrm{F}) \mathrm{H})(\mathrm{F})$

$\mathrm{H})(\mathrm{H}) \mathrm{H})(\mathrm{H}) \mathrm{H})(\mathrm{H}) \mathrm{H})(\mathrm{H}) \mathrm{H})(\mathrm{H}) \mathrm{H})(\mathrm{H}) \mathrm{H})(\mathrm{H}) \mathrm{F})(\mathrm{F})(\mathrm{H}) \mathrm{H}$

$\mathrm{C}(\mathrm{C}(\mathrm{C}(\mathrm{C}(\mathrm{C}(\mathrm{C}(\mathrm{C}(\mathrm{C}(\mathrm{C}(\mathrm{C}(\mathrm{C}(\mathrm{C}(\mathrm{C}(\mathrm{C}(\mathrm{C}(\mathrm{C}(\mathrm{C}(\mathrm{C}(\mathrm{H})(\mathrm{H}) \mathrm{H})(\mathrm{F}) \mathrm{H})(\mathrm{F}) \mathrm{H})(\mathrm{H}) \mathrm{F})(\mathrm{H}) \mathrm{H})(\mathrm{H}) \mathrm{H})(\mathrm{H}) \mathrm{Cl})(\mathrm{H}) \mathrm{H})(\mathrm{H}) \mathrm{Cl})$ $(\mathrm{F}) \mathrm{H})(\mathrm{H}) \mathrm{F})(\mathrm{Cl}) \mathrm{H})(\mathrm{H}) \mathrm{F})(\mathrm{F}) \mathrm{H})(\mathrm{H}) \mathrm{H})(\mathrm{H}) \mathrm{H})(\mathrm{H}) \mathrm{H})(\mathrm{H})(\mathrm{H}) \mathrm{F}$

$\mathrm{C}(\mathrm{C}(\mathrm{C}(\mathrm{C}(\mathrm{C}(\mathrm{C}(\mathrm{C}(\mathrm{C}(\mathrm{C}(\mathrm{C}(\mathrm{C}(\mathrm{C}(\mathrm{C}(\mathrm{C}(\mathrm{C}(\mathrm{C}(\mathrm{C}(\mathrm{C}(\mathrm{H})(\mathrm{H}) \mathrm{H})(\mathrm{H}) \mathrm{H})(\mathrm{H}) \mathrm{Cl})(\mathrm{H}) \mathrm{H})(\mathrm{H}) \mathrm{H})(\mathrm{H}) \mathrm{H})(\mathrm{H}) \mathrm{H})(\mathrm{F}) \mathrm{F})(\mathrm{H}) \mathrm{H})(\mathrm{C}$ l)H $(\mathrm{H}) \mathrm{F})(\mathrm{H}) \mathrm{H})(\mathrm{F}) \mathrm{H})(\mathrm{H}) \mathrm{Cl}(\mathrm{F}) \mathrm{H})(\mathrm{F}) \mathrm{H})(\mathrm{H}) \mathrm{F})(\mathrm{Cl})(\mathrm{H}) \mathrm{H}$

$\mathrm{C}(\mathrm{C}(\mathrm{C}(\mathrm{C}(\mathrm{C}(\mathrm{C}(\mathrm{C}(\mathrm{C}(\mathrm{C}(\mathrm{C}(\mathrm{C}(\mathrm{C}(\mathrm{C}(\mathrm{C}(\mathrm{C}(\mathrm{C}(\mathrm{C}(\mathrm{C}(\mathrm{Cl})(\mathrm{F}) \mathrm{H})(\mathrm{H}) \mathrm{H})(\mathrm{H}) \mathrm{H})(\mathrm{H}) \mathrm{H})(\mathrm{H}) \mathrm{F})(\mathrm{H}) \mathrm{F})(\mathrm{H}) \mathrm{H})(\mathrm{F}) \mathrm{H})(\mathrm{F}) \mathrm{Br})$ $(\mathrm{H}) \mathrm{H})(\mathrm{H}) \mathrm{H})(\mathrm{H}) \mathrm{Br})(\mathrm{H}) \mathrm{F})(\mathrm{H}) \mathrm{F})(\mathrm{H}) \mathrm{H})(\mathrm{H}) \mathrm{H})(\mathrm{F}) \mathrm{H})(\mathrm{H})(\mathrm{H}) \mathrm{H}$

$\mathrm{C}(\mathrm{C}(\mathrm{C}(\mathrm{C}(\mathrm{C}(\mathrm{C}(\mathrm{C}(\mathrm{C}(\mathrm{C}(\mathrm{C}(\mathrm{C}(\mathrm{C}(\mathrm{C}(\mathrm{C}(\mathrm{C}(\mathrm{C}(\mathrm{C}(\mathrm{C}(\mathrm{H})(\mathrm{H}) \mathrm{H})(\mathrm{F}) \mathrm{H})(\mathrm{H}) \mathrm{H})(\mathrm{H}) \mathrm{H})(\mathrm{F}) \mathrm{H})(\mathrm{H}) \mathrm{H})(\mathrm{H}) \mathrm{H})(\mathrm{H}) \mathrm{F})(\mathrm{H}) \mathrm{H})(\mathrm{H})$ $\mathrm{Br})(\mathrm{F}) \mathrm{H})(\mathrm{F}) \mathrm{H})(\mathrm{H}) \mathrm{F})(\mathrm{Cl}) \mathrm{F})(\mathrm{H}) \mathrm{H})(\mathrm{H}) \mathrm{F})(\mathrm{F}) \mathrm{H})(\mathrm{H})(\mathrm{H}) \mathrm{H}$

$\mathrm{C}(\mathrm{C}(\mathrm{C}(\mathrm{C}(\mathrm{C}(\mathrm{C}(\mathrm{C}(\mathrm{C}(\mathrm{C}(\mathrm{C}(\mathrm{C}(\mathrm{C}(\mathrm{C}(\mathrm{C}(\mathrm{C}(\mathrm{C}(\mathrm{C}(\mathrm{C}(\mathrm{H})(\mathrm{H}) \mathrm{H})(\mathrm{H}) \mathrm{H})(\mathrm{F}) \mathrm{F})(\mathrm{H}) \mathrm{H})(\mathrm{H}) \mathrm{F})(\mathrm{F}) \mathrm{H})(\mathrm{H}) \mathrm{H})(\mathrm{H}) \mathrm{H})(\mathrm{F}) \mathrm{H})(\mathrm{F})$ $\mathrm{H})(\mathrm{H}) \mathrm{F})(\mathrm{Br}) \mathrm{H})(\mathrm{H}) \mathrm{H})(\mathrm{H}) \mathrm{H})(\mathrm{H}) \mathrm{H})(\mathrm{Br}) \mathrm{H})(\mathrm{H}) \mathrm{H})(\mathrm{H})(\mathrm{H}) \mathrm{F}$

$\mathrm{C}(\mathrm{C}(\mathrm{C}(\mathrm{C}(\mathrm{C}(\mathrm{C}(\mathrm{C}(\mathrm{C}(\mathrm{C}(\mathrm{C}(\mathrm{C}(\mathrm{C}(\mathrm{C}(\mathrm{C}(\mathrm{C}(\mathrm{C}(\mathrm{C}(\mathrm{C}(\mathrm{H})(\mathrm{H}) \mathrm{H})(\mathrm{H}) \mathrm{Cl})(\mathrm{Br}) \mathrm{H})(\mathrm{H}) \mathrm{H})(\mathrm{H}) \mathrm{F})(\mathrm{H}) \mathrm{H})(\mathrm{H}) \mathrm{H})(\mathrm{H}) \mathrm{H})(\mathrm{F}) \mathrm{F})($ $\mathrm{H}) \mathrm{F})(\mathrm{H}) \mathrm{Cl}(\mathrm{H}) \mathrm{F})(\mathrm{F}) \mathrm{H})(\mathrm{H}) \mathrm{H})(\mathrm{H}) \mathrm{H})(\mathrm{H}) \mathrm{H})(\mathrm{H}) \mathrm{F})(\mathrm{H})(\mathrm{H}) \mathrm{H}$

$\mathrm{C}(\mathrm{C}(\mathrm{C}(\mathrm{C}(\mathrm{C}(\mathrm{C}(\mathrm{C}(\mathrm{C}(\mathrm{C}(\mathrm{C}(\mathrm{C}(\mathrm{C}(\mathrm{C}(\mathrm{C}(\mathrm{C}(\mathrm{C}(\mathrm{C}(\mathrm{C}(\mathrm{H})(\mathrm{H}) \mathrm{H})(\mathrm{H}) \mathrm{H})(\mathrm{H}) \mathrm{H})(\mathrm{H}) \mathrm{F})(\mathrm{H}) \mathrm{H})(\mathrm{H}) \mathrm{H})(\mathrm{H}) \mathrm{F})(\mathrm{H}) \mathrm{H})(\mathrm{H}) \mathrm{F})(\mathrm{H})$ $\mathrm{H})(\mathrm{Cl}) \mathrm{H})(\mathrm{F}) \mathrm{F})(\mathrm{H}) \mathrm{H})(\mathrm{H}) \mathrm{H})(\mathrm{H}) \mathrm{Cl})(\mathrm{H}) \mathrm{F})(\mathrm{H}) \mathrm{F})(\mathrm{H})(\mathrm{F}) \mathrm{H}$

$\mathrm{C}(\mathrm{C}(\mathrm{C}(\mathrm{C}(\mathrm{C}(\mathrm{C}(\mathrm{C}(\mathrm{C}(\mathrm{C}(\mathrm{C}(\mathrm{C}(\mathrm{C}(\mathrm{C}(\mathrm{C}(\mathrm{C}(\mathrm{C}(\mathrm{C}(\mathrm{C}(\mathrm{H})(\mathrm{F}) \mathrm{H})(\mathrm{H}) \mathrm{H})(\mathrm{H}) \mathrm{Cl})(\mathrm{H}) \mathrm{H})(\mathrm{F}) \mathrm{H})(\mathrm{H}) \mathrm{H})(\mathrm{H}) \mathrm{H})(\mathrm{Cl}) \mathrm{H})(\mathrm{H}) \mathrm{F})$ $(\mathrm{H}) \mathrm{H})(\mathrm{H}) \mathrm{H})(\mathrm{H}) \mathrm{F})(\mathrm{H}) \mathrm{H})(\mathrm{Cl}) \mathrm{H})(\mathrm{F}) \mathrm{H})(\mathrm{H}) \mathrm{F})(\mathrm{H}) \mathrm{H})(\mathrm{F})(\mathrm{H}) \mathrm{H}$

$\mathrm{C}(\mathrm{C}(\mathrm{C}(\mathrm{C}(\mathrm{C}(\mathrm{C}(\mathrm{C}(\mathrm{C}(\mathrm{C}(\mathrm{C}(\mathrm{C}(\mathrm{C}(\mathrm{C}(\mathrm{C}(\mathrm{C}(\mathrm{C}(\mathrm{C}(\mathrm{C}(\mathrm{H})(\mathrm{F}) \mathrm{H})(\mathrm{H}) \mathrm{H})(\mathrm{H}) \mathrm{H})(\mathrm{H}) \mathrm{F})(\mathrm{H}) \mathrm{Cl})(\mathrm{F}) \mathrm{F})(\mathrm{H}) \mathrm{H})(\mathrm{H}) \mathrm{H})(\mathrm{H}) \mathrm{H})(\mathrm{H})$

$\mathrm{H})(\mathrm{H}) \mathrm{Cl}(\mathrm{H}) \mathrm{H})(\mathrm{H}) \mathrm{H})(\mathrm{H}) \mathrm{F})(\mathrm{H}) \mathrm{H})(\mathrm{H}) \mathrm{H})(\mathrm{Cl}) \mathrm{H})(\mathrm{Cl})(\mathrm{H}) \mathrm{F}$

$\mathrm{C}(\mathrm{C}(\mathrm{C}(\mathrm{C}(\mathrm{C}(\mathrm{C}(\mathrm{C}(\mathrm{C}(\mathrm{C}(\mathrm{C}(\mathrm{C}(\mathrm{C}(\mathrm{C}(\mathrm{C}(\mathrm{C}(\mathrm{C}(\mathrm{C}(\mathrm{C}(\mathrm{H})(\mathrm{H}) \mathrm{H})(\mathrm{F}) \mathrm{H})(\mathrm{F}) \mathrm{H})(\mathrm{H}) \mathrm{H})(\mathrm{H}) \mathrm{H})(\mathrm{F}) \mathrm{H})(\mathrm{F}) \mathrm{H})(\mathrm{H}) \mathrm{H})(\mathrm{H}) \mathrm{H})(\mathrm{H})$ $\mathrm{H})(\mathrm{H}) \mathrm{F})(\mathrm{H}) \mathrm{H})(\mathrm{H}) \mathrm{H})(\mathrm{H}) \mathrm{H})(\mathrm{H}) \mathrm{F})(\mathrm{F}) \mathrm{H})(\mathrm{Br}) \mathrm{H})(\mathrm{H})(\mathrm{Cl}) \mathrm{F}$

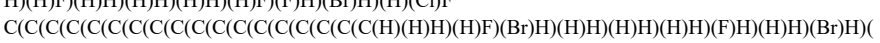
$\mathrm{H}) \mathrm{H})(\mathrm{H}) \mathrm{F})(\mathrm{H}) \mathrm{H})(\mathrm{H}) \mathrm{H})(\mathrm{F}) \mathrm{H})(\mathrm{H}) \mathrm{H})(\mathrm{F}) \mathrm{H})(\mathrm{F}) \mathrm{H})(\mathrm{H})(\mathrm{H}) \mathrm{F}$

$\mathrm{C}(\mathrm{C}(\mathrm{C}(\mathrm{C}(\mathrm{C}(\mathrm{C}(\mathrm{C}(\mathrm{C}(\mathrm{C}(\mathrm{C}(\mathrm{C}(\mathrm{C}(\mathrm{C}(\mathrm{C}(\mathrm{C}(\mathrm{C}(\mathrm{C}(\mathrm{C}(\mathrm{H})(\mathrm{H}) \mathrm{H})(\mathrm{H}) \mathrm{F})(\mathrm{H}) \mathrm{H})(\mathrm{H}) \mathrm{Br})(\mathrm{H}) \mathrm{F})(\mathrm{H}) \mathrm{H})(\mathrm{H}) \mathrm{H})(\mathrm{F}) \mathrm{F})(\mathrm{H}) \mathrm{H})$ $(\mathrm{H}) \mathrm{F})(\mathrm{H}) \mathrm{H})(\mathrm{H}) \mathrm{H})(\mathrm{H}) \mathrm{H})(\mathrm{H}) \mathrm{H})(\mathrm{F}) \mathrm{H})(\mathrm{H}) \mathrm{H})(\mathrm{F}) \mathrm{F})(\mathrm{H})(\mathrm{H}) \mathrm{H}$

$\mathrm{C}(\mathrm{C}(\mathrm{C}(\mathrm{C}(\mathrm{C}(\mathrm{C}(\mathrm{C}(\mathrm{C}(\mathrm{C}(\mathrm{C}(\mathrm{C}(\mathrm{C}(\mathrm{C}(\mathrm{C}(\mathrm{C}(\mathrm{C}(\mathrm{C}(\mathrm{C}(\mathrm{H})(\mathrm{F}) \mathrm{H})(\mathrm{H}) \mathrm{F})(\mathrm{H}) \mathrm{H})(\mathrm{H}) \mathrm{H})(\mathrm{Br}) \mathrm{H})(\mathrm{F}) \mathrm{H})(\mathrm{H}) \mathrm{F})(\mathrm{F}) \mathrm{H})(\mathrm{Cl}) \mathrm{H})$

$(\mathrm{H}) \mathrm{H})(\mathrm{H}) \mathrm{H})(\mathrm{H}) \mathrm{H})(\mathrm{H}) \mathrm{H})(\mathrm{Cl}) \mathrm{F})(\mathrm{H}) \mathrm{H})(\mathrm{H}) \mathrm{H})(\mathrm{H}) \mathrm{H})(\mathrm{H})(\mathrm{H}) \mathrm{H}$

$\mathrm{C}(\mathrm{C}(\mathrm{C}(\mathrm{C}(\mathrm{C}(\mathrm{C}(\mathrm{C}(\mathrm{C}(\mathrm{C}(\mathrm{C}(\mathrm{C}(\mathrm{C}(\mathrm{C}(\mathrm{C}(\mathrm{C}(\mathrm{C}(\mathrm{C}(\mathrm{C}(\mathrm{H})(\mathrm{H}) \mathrm{H})(\mathrm{H}) \mathrm{H})(\mathrm{H}) \mathrm{F})(\mathrm{H}) \mathrm{H})(\mathrm{H}) \mathrm{Cl})(\mathrm{H}) \mathrm{H})(\mathrm{H}) \mathrm{H})(\mathrm{H}) \mathrm{H})(\mathrm{H}) \mathrm{H})($

$\mathrm{H}) \mathrm{H})(\mathrm{F}) \mathrm{H})(\mathrm{H}) \mathrm{F})(\mathrm{Cl}) \mathrm{H})(\mathrm{H}) \mathrm{F})(\mathrm{H}) \mathrm{Cl}(\mathrm{H}) \mathrm{F})(\mathrm{H}) \mathrm{Cl})(\mathrm{H})(\mathrm{H}) \mathrm{H}$

$\mathrm{C}(\mathrm{C}(\mathrm{C}(\mathrm{C}(\mathrm{C}(\mathrm{C}(\mathrm{C}(\mathrm{C}(\mathrm{C}(\mathrm{C}(\mathrm{C}(\mathrm{C}(\mathrm{C}(\mathrm{C}(\mathrm{C}(\mathrm{C}(\mathrm{C}(\mathrm{C}(\mathrm{F})(\mathrm{H}) \mathrm{F})(\mathrm{H}) \mathrm{H})(\mathrm{H}) \mathrm{H})(\mathrm{H}) \mathrm{H})(\mathrm{H}) \mathrm{H})(\mathrm{H}) \mathrm{Cl})(\mathrm{H}) \mathrm{F})(\mathrm{H}) \mathrm{F})(\mathrm{H}) \mathrm{H})(\mathrm{H})$ F) $(\mathrm{H}) \mathrm{H})(\mathrm{Br}) \mathrm{H})(\mathrm{H}) \mathrm{H})(\mathrm{H}) \mathrm{H})(\mathrm{F}) \mathrm{H})(\mathrm{H}) \mathrm{Br})(\mathrm{H}) \mathrm{H})(\mathrm{H})(\mathrm{H}) \mathrm{H}$

C $(\mathrm{C}(\mathrm{C}(\mathrm{C}(\mathrm{C}(\mathrm{C}(\mathrm{C}(\mathrm{C}(\mathrm{C}(\mathrm{C}(\mathrm{C}(\mathrm{C}(\mathrm{C}(\mathrm{C}(\mathrm{C}(\mathrm{C}(\mathrm{C}(\mathrm{C}(\mathrm{H})(\mathrm{H}) \mathrm{H})(\mathrm{H}) \mathrm{Br})(\mathrm{H}) \mathrm{F})(\mathrm{H}) \mathrm{H})(\mathrm{F}) \mathrm{H})(\mathrm{H}) \mathrm{H})(\mathrm{H}) \mathrm{H})(\mathrm{H}) \mathrm{F})(\mathrm{H}) \mathrm{H})$ $(\mathrm{H}) \mathrm{H})(\mathrm{H}) \mathrm{H})(\mathrm{F}) \mathrm{H})(\mathrm{H}) \mathrm{H})(\mathrm{F}) \mathrm{F})(\mathrm{H}) \mathrm{Cl}(\mathrm{F}) \mathrm{H})(\mathrm{H}) \mathrm{H})(\mathrm{H})(\mathrm{H}) \mathrm{H}$

$\mathrm{C}(\mathrm{C}(\mathrm{C}(\mathrm{C}(\mathrm{C}(\mathrm{C}(\mathrm{C}(\mathrm{C}(\mathrm{C}(\mathrm{C}(\mathrm{C}(\mathrm{C}(\mathrm{C}(\mathrm{C}(\mathrm{C}(\mathrm{C}(\mathrm{C}(\mathrm{C}(\mathrm{H})(\mathrm{H}) \mathrm{H})(\mathrm{H}) \mathrm{H})(\mathrm{H}) \mathrm{H})(\mathrm{H}) \mathrm{H})(\mathrm{F}) \mathrm{H})(\mathrm{H}) \mathrm{H})(\mathrm{F}) \mathrm{H})(\mathrm{F}) \mathrm{F})(\mathrm{F}) \mathrm{H})(\mathrm{F})$ $\mathrm{H})(\mathrm{H}) \mathrm{Br})(\mathrm{H}) \mathrm{H})(\mathrm{H}) \mathrm{H})(\mathrm{H}) \mathrm{H})(\mathrm{H}) \mathrm{H})(\mathrm{H}) \mathrm{F})(\mathrm{H}) \mathrm{H})(\mathrm{H})(\mathrm{H}) \mathrm{H}$

$\mathrm{C}(\mathrm{C}(\mathrm{C}(\mathrm{C}(\mathrm{C}(\mathrm{C}(\mathrm{C}(\mathrm{C}(\mathrm{C}(\mathrm{C}(\mathrm{C}(\mathrm{C}(\mathrm{C}(\mathrm{C}(\mathrm{C}(\mathrm{C}(\mathrm{C}(\mathrm{C}(\mathrm{H})(\mathrm{F}) \mathrm{F})(\mathrm{Br}) \mathrm{H})(\mathrm{H}) \mathrm{H})(\mathrm{H}) \mathrm{H})(\mathrm{H}) \mathrm{H})(\mathrm{H}) \mathrm{F})(\mathrm{H}) \mathrm{H})(\mathrm{H}) \mathrm{H})(\mathrm{H}) \mathrm{Cl})$

$\mathrm{H}) \mathrm{H})(\mathrm{H}) \mathrm{H})(\mathrm{H}) \mathrm{H})(\mathrm{H}) \mathrm{H})(\mathrm{Cl}) \mathrm{H})(\mathrm{H}) \mathrm{H})(\mathrm{H}) \mathrm{H})(\mathrm{F}) \mathrm{H})(\mathrm{H})(\mathrm{H}) \mathrm{F}$

$\mathrm{C}(\mathrm{C}(\mathrm{C}(\mathrm{C}(\mathrm{C}(\mathrm{C}(\mathrm{C}(\mathrm{C}(\mathrm{C}(\mathrm{C}(\mathrm{C}(\mathrm{C}(\mathrm{C}(\mathrm{C}(\mathrm{C}(\mathrm{C}(\mathrm{C}(\mathrm{C}(\mathrm{H})(\mathrm{F}) \mathrm{H})(\mathrm{F}) \mathrm{H})(\mathrm{H}) \mathrm{H})(\mathrm{Cl}) \mathrm{H})(\mathrm{F}) \mathrm{H})(\mathrm{H}) \mathrm{H})(\mathrm{H}) \mathrm{F})(\mathrm{H}) \mathrm{H})(\mathrm{H}) \mathrm{H})(\mathrm{H})$ $\mathrm{H})(\mathrm{H}) \mathrm{H})(\mathrm{H}) \mathrm{F})(\mathrm{H}) \mathrm{H})(\mathrm{H}) \mathrm{H})(\mathrm{Cl}) \mathrm{H})(\mathrm{H}) \mathrm{H})(\mathrm{H}) \mathrm{H})(\mathrm{H})(\mathrm{F}) \mathrm{H}$
lgKoa lgKow lgKaw lgKow lgKoa lgKa lgKow lgKoa lgKaw EPISuit EPI EPI Exp Exp w DFT DFT DFT e Suite Suite corr_corr _Exp corr__corr_corr $\begin{array}{lllllllll}7.375 & 8.87 & 1.49 & 8.31 & 6.82 & 1.49 & 7.57 & 11.56 & -3.99\end{array}$

$\begin{array}{lllllllll}6.764 & 8.56 & 1.80 & 7.85 & 6.05 & 1.80 & 7.34 & 10.44 & -3.10\end{array}$

$\begin{array}{lllllllll}6.084 & 9.9 & 3.82 & 9.85 & 6.04 & 3.82 & 8.37 & 9.19 & -0.82\end{array}$

$\begin{array}{lllllllll}5.451 & 9.72 & 4.27 & 9.58 & 5.31 & 4.27 & 8.23 & 8.03 & 0.20\end{array}$

$\begin{array}{ll}7.127 & 9.78\end{array}$

$\begin{array}{lllllll}2.65 & 9.67 & 7.02 & 2.65 & 8.27 & 11.10 & -2.83\end{array}$

$6.689 \quad 10.03$

$\begin{array}{lllllll}3.34 & 10.04 & 6.70 & 3.34 & 8.47 & 10.30 & -1.83\end{array}$

$6.436 \quad 9.51$

$\begin{array}{lllllll}3.07 & 9.27 & 6.19 & 3.07 & 8.07 & 9.84 & -1.77\end{array}$

$6.864 \quad 9.64$

$\begin{array}{lllllll}2.78 & 9.46 & 6.69 & 2.78 & 8.17 & 10.62 & -2.45\end{array}$

$5.227 \quad 9.24$

$\begin{array}{lllllll}4.01 & 8.87 & 4.85 & 4.01 & 7.86 & 7.61 & 0.24\end{array}$

$\mathrm{C} 18 \mathrm{H} 25 \mathrm{Br} 2 \mathrm{~F} 11$

$\begin{array}{lllllll}3.98 & 9.84 & 5.86 & 3.98 & 8.36 & 8.87 & -0.51\end{array}$

$6.738 \quad 9.48$

$\begin{array}{lllllll}2.74 & 9.22 & 6.48 & 2.74 & 8.04 & 10.39 & -2.35\end{array}$

$\mathrm{C} 18 \mathrm{H} 25 \mathrm{Cl} 2 \mathrm{BrF} 10$

$5.658 \quad 9.37$

$\begin{array}{lllllll}3.71 & 9.06 & 5.35 & 3.71 & 7.96 & 8.41 & -0.45\end{array}$

$5.908 \quad 8.87$

$\begin{array}{lllllll}2.96 & 8.31 & 5.35 & 2.96 & 7.57 & 8.87 & -1.29\end{array}$

$5.681 \quad 9.88$

$\begin{array}{lllllll}4.20 & 9.82 & 5.62 & 4.20 & 8.35 & 8.45 & -0.10\end{array}$

$7.146 \quad 9.84$

$\begin{array}{lllllll}2.69 & 9.76 & 7.07 & 2.69 & 8.32 & 11.14 & -2.82\end{array}$

$6.821 \quad 10.05$

$\begin{array}{lllllll}3.23 & 10.07 & 6.85 & 3.23 & 8.48 & 10.54 & -2.06\end{array}$

$6.015 \quad 9.43$

$\begin{array}{lllllll}3.41 & 9.15 & 5.73 & 3.41 & 8.01 & 9.06 & -1.06\end{array}$

$5.441 \quad 9.34$

$\begin{array}{lllllll}3.90 & 9.01 & 5.12 & 3.90 & 7.94 & 8.01 & -0.07\end{array}$

$7.569 \quad 9.26$

$\begin{array}{lllllll}1.69 & 8.90 & 7.20 & 1.69 & 7.87 & 11.92 & -4.04\end{array}$

$6.028 \quad 9.41$

$\begin{array}{lllllll}3.38 & 9.12 & 5.74 & 3.38 & 7.99 & 9.09 & -1.10\end{array}$

$6.934 \quad 9.08$

$\begin{array}{lllllll}2.15 & 8.63 & 6.48 & 2.15 & 7.74 & 10.75 & -3.01\end{array}$

$6.445 \quad 9.56$

$\begin{array}{lllllll}3.12 & 9.34 & 6.23 & 3.12 & 8.10 & 9.85 & -1.75\end{array}$

$5.547 \quad 9.9$

$\begin{array}{lllllll}4.35 & 9.85 & 5.50 & 4.35 & 8.37 & 8.20 & 0.16\end{array}$

$5.129 \quad 8.73$

$\begin{array}{lllllll}3.60 & 8.10 & 4.50 & 3.60 & 7.47 & 7.43 & 0.03\end{array}$

$6.94 \quad 9.79$

$\begin{array}{lllllll}2.85 & 9.69 & 6.84 & 2.85 & 8.28 & 10.76 & -2.48\end{array}$

$7.017 \quad 9.65$

$\begin{array}{lllllll}2.63 & 9.48 & 6.84 & 2.63 & 8.17 & 10.90 & -2.73\end{array}$

$5.313 \quad 9.18$

$\begin{array}{lllllll}3.87 & 8.78 & 4.91 & 3.87 & 7.81 & 7.77 & 0.04\end{array}$

$\begin{array}{ll}6.386 & 9.47\end{array}$

$\begin{array}{lllllll}3.08 & 9.21 & 6.12 & 3.08 & 8.04 & 9.74 & -1.71\end{array}$

$6.802 \quad 9.62$

$\begin{array}{lllllll}2.82 & 9.43 & 6.61 & 2.82 & 8.15 & 10.51 & -2.36\end{array}$

$5.236 \quad 9.29$

$\begin{array}{lllllll}4.05 & 8.94 & 4.89 & 4.05 & 7.90 & 7.63 & 0.27\end{array}$

$5.637 \quad 8.94$

$\begin{array}{lllllll}3.30 & 8.42 & 5.12 & 3.30 & 7.63 & 8.37 & -0.74\end{array}$

$7.439 \quad 9.99$

$\begin{array}{lllllll}2.55 & 9.99 & 7.43 & 2.55 & 8.44 & 11.68 & -3.24\end{array}$

$5.071 \quad 8.64$

$\begin{array}{lllllll}3.57 & 7.97 & 4.40 & 3.57 & 7.40 & 7.33 & 0.07\end{array}$

$6.085 \quad 8.87$

$\begin{array}{lllllll}2.78 & 8.31 & 5.53 & 2.78 & 7.57 & 9.19 & -1.62\end{array}$

$5.849 \quad 9.87$

$\begin{array}{lllllll}4.02 & 9.81 & 5.78 & 4.02 & 8.34 & 8.76 & -0.41\end{array}$

$7.312 \quad 9.83$

$\begin{array}{lllllll}2.52 & 9.75 & 7.23 & 2.52 & 8.31 & 11.44 & -3.13\end{array}$

$6.988 \quad 9.24$

$\begin{array}{lllllll}2.25 & 8.87 & 6.61 & 2.25 & 7.86 & 10.85 & -2.99\end{array}$

\begin{tabular}{ll}
$7.147 \quad 9.18$ \\
\hline
\end{tabular}

$\begin{array}{lllllll}2.03 & 8.78 & 6.74 & 2.03 & 7.81 & 11.14 & -3.33\end{array}$

$6.169 \quad 9.44$

$\begin{array}{lllllll}3.27 & 9.16 & 5.89 & 3.27 & 8.01 & 9.34 & -1.33\end{array}$

$5.538 \quad 9.26$

$\begin{array}{lllllll}3.72 & 8.90 & 5.17 & 3.72 & 7.87 & 8.19 & -0.31\end{array}$

$\begin{array}{ll}7.08 & 9.3\end{array}$

$\begin{array}{lllllll}2.22 & 8.96 & 6.74 & 2.22 & 7.91 & 11.02 & -3.11\end{array}$

$5.433 \quad 8.89$

$\begin{array}{lllllll}3.46 & 8.34 & 4.89 & 3.46 & 7.59 & 7.99 & -0.40\end{array}$ 
$\mathrm{C}\left(\mathrm{C}\left(\mathrm{C}\left(\mathrm{C}\left(\mathrm{C}\left(\mathrm{C}\left(\mathrm{C}\left(\mathrm{C}\left(\mathrm{C}(\mathrm{C}(\mathrm{C}(\mathrm{C}(\mathrm{C}(\mathrm{C}(\mathrm{C}(\mathrm{C}(\mathrm{C}(\mathrm{C}(\mathrm{H})(\mathrm{H}) \mathrm{H})(\mathrm{H}) \mathrm{F})(\mathrm{H}) \mathrm{H})(\mathrm{F}) \mathrm{H})(\mathrm{F}) \mathrm{H})(\mathrm{Cl}) \mathrm{H})(\mathrm{H}) \mathrm{H})(\mathrm{H}) \mathrm{H})(\mathrm{F}) \mathrm{H})(\mathrm{H}){ }_{\mathrm{C} 18 \mathrm{H} 30 \mathrm{Cl} 3 \mathrm{~F} 5}\right.\right.\right.\right.\right.\right.\right.\right.$ $\mathrm{H})(\mathrm{H}) \mathrm{H})(\mathrm{H}) \mathrm{F})(\mathrm{H}) \mathrm{H})(\mathrm{H}) \mathrm{H})(\mathrm{H}) \mathrm{H})(\mathrm{Cl}) \mathrm{H})(\mathrm{Cl}) \mathrm{H})(\mathrm{H})(\mathrm{H}) \mathrm{H}$

$\mathrm{C} 18 \mathrm{H} 30 \mathrm{Cl} 3 \mathrm{~F}$

$\mathrm{C}(\mathrm{C}(\mathrm{C}(\mathrm{C}(\mathrm{C}(\mathrm{C}(\mathrm{C}(\mathrm{C}(\mathrm{C}(\mathrm{C}(\mathrm{C}(\mathrm{C}(\mathrm{C}(\mathrm{C}(\mathrm{C}(\mathrm{C}(\mathrm{C}(\mathrm{C}(\mathrm{H})(\mathrm{H}) \mathrm{F})(\mathrm{H}) \mathrm{H})(\mathrm{H}) \mathrm{H})(\mathrm{H}) \mathrm{H})(\mathrm{H}) \mathrm{H})(\mathrm{H}) \mathrm{H})(\mathrm{H}) \mathrm{Cl})(\mathrm{H}) \mathrm{F})(\mathrm{H}) \mathrm{Cl})($ $\mathrm{H}) \mathrm{H})(\mathrm{H}) \mathrm{H})(\mathrm{H}) \mathrm{F})(\mathrm{Cl}) \mathrm{H})(\mathrm{H}) \mathrm{H})(\mathrm{F}) \mathrm{H})(\mathrm{H}) \mathrm{H})(\mathrm{H}) \mathrm{Cl})(\mathrm{H})(\mathrm{H}) \mathrm{H}$

$\mathrm{C}\left(\mathrm{C}\left(\mathrm{C}\left(\mathrm{C}\left(\mathrm{C}\left(\mathrm{C}\left(\mathrm{C}\left(\mathrm{C}\left(\mathrm{C}(\mathrm{C}(\mathrm{C}(\mathrm{C}(\mathrm{C}(\mathrm{C}(\mathrm{C}(\mathrm{C}(\mathrm{C}(\mathrm{C}(\mathrm{F})(\mathrm{H}) \mathrm{H})(\mathrm{H}) \mathrm{H})(\mathrm{H}) \mathrm{H})(\mathrm{Br}) \mathrm{H})(\mathrm{Cl}) \mathrm{H})(\mathrm{H}) \mathrm{H})(\mathrm{H}) \mathrm{H})(\mathrm{H}) \mathrm{H})(\mathrm{H}) \mathrm{H})\left(\mathrm{C}_{\mathrm{C}} 18 \mathrm{H} 30 \mathrm{ClBr} 2 \mathrm{~F}\right.\right.\right.\right.\right.\right.\right.\right.\right.$ $\mathrm{H}) \mathrm{F})(\mathrm{H}) \mathrm{H})(\mathrm{H}) \mathrm{H})(\mathrm{F}) \mathrm{H})(\mathrm{F}) \mathrm{H})(\mathrm{H}) \mathrm{H})(\mathrm{Br}) \mathrm{H})(\mathrm{F}) \mathrm{H})(\mathrm{H})(\mathrm{H}) \mathrm{H}$

$\mathrm{C}(\mathrm{C}(\mathrm{C}(\mathrm{C}(\mathrm{C}(\mathrm{C}(\mathrm{C}(\mathrm{C}(\mathrm{C}(\mathrm{C}(\mathrm{C}(\mathrm{C}(\mathrm{C}(\mathrm{C}(\mathrm{C}(\mathrm{C}(\mathrm{C}(\mathrm{C}(\mathrm{H})(\mathrm{H}) \mathrm{H})(\mathrm{H}) \mathrm{H})(\mathrm{Cl}) \mathrm{H})(\mathrm{H}) \mathrm{H})(\mathrm{H}) \mathrm{F})(\mathrm{H}) \mathrm{H})(\mathrm{H}) \mathrm{H})(\mathrm{H}) \mathrm{Br})(\mathrm{H}) \mathrm{H})($ $\mathrm{H}) \mathrm{H})(\mathrm{H}) \mathrm{F})(\mathrm{H}) \mathrm{H})(\mathrm{F}) \mathrm{H})(\mathrm{H}) \mathrm{H})(\mathrm{H}) \mathrm{H})(\mathrm{H}) \mathrm{H})(\mathrm{H}) \mathrm{H})(\mathrm{F})(\mathrm{F}) \mathrm{F}$

C $(\mathrm{C}(\mathrm{C}(\mathrm{C}(\mathrm{C}(\mathrm{C}(\mathrm{C}(\mathrm{C}(\mathrm{C}(\mathrm{C}(\mathrm{C}(\mathrm{C}(\mathrm{C}(\mathrm{C}(\mathrm{C}(\mathrm{C}(\mathrm{C}(\mathrm{C}(\mathrm{H})(\mathrm{H}) \mathrm{H})(\mathrm{H}) \mathrm{F})(\mathrm{F}) \mathrm{H})(\mathrm{H}) \mathrm{H})(\mathrm{Br}) \mathrm{H})(\mathrm{H}) \mathrm{H})(\mathrm{H}) \mathrm{H})(\mathrm{H}) \mathrm{H})(\mathrm{H}) \mathrm{H})($

$\mathrm{H}) \mathrm{H})(\mathrm{H}) \mathrm{H})(\mathrm{H}) \mathrm{H})(\mathrm{F}) \mathrm{F})(\mathrm{Br}) \mathrm{H})(\mathrm{H}) \mathrm{F})(\mathrm{H}) \mathrm{H})(\mathrm{H}) \mathrm{H})(\mathrm{H})(\mathrm{H}) \mathrm{H}$

$\mathrm{C}(\mathrm{C}(\mathrm{C}(\mathrm{C}(\mathrm{C}(\mathrm{C}(\mathrm{C}(\mathrm{C}(\mathrm{C}(\mathrm{C}(\mathrm{C}(\mathrm{C}(\mathrm{C}(\mathrm{C}(\mathrm{C}(\mathrm{C}(\mathrm{C}(\mathrm{C}(\mathrm{F})(\mathrm{H}) \mathrm{F})(\mathrm{Br}) \mathrm{H})(\mathrm{H}) \mathrm{H})(\mathrm{H}) \mathrm{H})(\mathrm{H}) \mathrm{H})(\mathrm{F}) \mathrm{H})(\mathrm{H}) \mathrm{H})(\mathrm{H}) \mathrm{H})(\mathrm{H}) \mathrm{H})$

$(\mathrm{H}) \mathrm{H})(\mathrm{H}) \mathrm{H})(\mathrm{H}) \mathrm{H})(\mathrm{H}) \mathrm{H})(\mathrm{F}) \mathrm{H})(\mathrm{H}) \mathrm{H})(\mathrm{H}) \mathrm{H})(\mathrm{F}) \mathrm{H})(\mathrm{F})(\mathrm{H}) \mathrm{H}$

$\mathrm{C}(\mathrm{C}(\mathrm{C}(\mathrm{C}(\mathrm{C}(\mathrm{C}(\mathrm{C}(\mathrm{C}(\mathrm{C}(\mathrm{C}(\mathrm{C}(\mathrm{C}(\mathrm{C}(\mathrm{C}(\mathrm{C}(\mathrm{C}(\mathrm{C}(\mathrm{C}(\mathrm{H})(\mathrm{H}) \mathrm{H})(\mathrm{H}) \mathrm{Cl})(\mathrm{H}) \mathrm{H})(\mathrm{H}) \mathrm{H})(\mathrm{H}) \mathrm{H})(\mathrm{H}) \mathrm{F})(\mathrm{H}) \mathrm{H})(\mathrm{H}) \mathrm{H})(\mathrm{H}) \mathrm{H})($ $\mathrm{H}) \mathrm{F})(\mathrm{H}) \mathrm{H})(\mathrm{F}) \mathrm{H}(\mathrm{C}) \mathrm{C})(\mathrm{H}) \mathrm{H})(\mathrm{H}) \mathrm{H})(\mathrm{Cl}) \mathrm{H})(\mathrm{H}) \mathrm{B})(\mathrm{H})(\mathrm{H}) \mathrm{H}$

$\mathrm{C}\left(\mathrm{C}\left(\mathrm{C}\left(\mathrm{C}\left(\mathrm{C}\left(\mathrm{C}\left(\mathrm{C}\left(\mathrm{C}\left(\mathrm{C}(\mathrm{C}(\mathrm{C}(\mathrm{C}(\mathrm{C}(\mathrm{C}(\mathrm{C}(\mathrm{C}(\mathrm{C}(\mathrm{C}(\mathrm{H})(\mathrm{H}) \mathrm{H})(\mathrm{H}) \mathrm{H})(\mathrm{H}) \mathrm{H})(\mathrm{H}) \mathrm{H})(\mathrm{H}) \mathrm{H})(\mathrm{H}) \mathrm{H})(\mathrm{H}) \mathrm{H})(\mathrm{Cl}) \mathrm{H})(\mathrm{H}) \mathrm{Cl})\left({ }_{\mathrm{Cl}} \mathrm{H}_{3} \mathrm{Cl}_{2} \mathrm{~F}_{5}\right.\right.\right.\right.\right.\right.\right.\right.\right.$ F)H $(\mathrm{F}) \mathrm{H})(\mathrm{H}) \mathrm{H})(\mathrm{H}) \mathrm{H})(\mathrm{F}) \mathrm{H})(\mathrm{H}) \mathrm{H})(\mathrm{H}) \mathrm{H})(\mathrm{H}) \mathrm{H})(\mathrm{F})(\mathrm{F}) \mathrm{H}$

$\mathrm{C}\left(\mathrm{C}\left(\mathrm{C}\left(\mathrm{C}\left(\mathrm{C}\left(\mathrm{C}\left(\mathrm{C}\left(\mathrm{C}\left(\mathrm{C}(\mathrm{C}(\mathrm{C}(\mathrm{C}(\mathrm{C}(\mathrm{C}(\mathrm{C}(\mathrm{C}(\mathrm{C}(\mathrm{C}(\mathrm{H})(\mathrm{H}) \mathrm{H})(\mathrm{H}) \mathrm{Cl})(\mathrm{H}) \mathrm{H})(\mathrm{H}) \mathrm{H})(\mathrm{Cl}) \mathrm{H})(\mathrm{Cl}) \mathrm{H})(\mathrm{H}) \mathrm{H})(\mathrm{F}) \mathrm{H})(\mathrm{H}) \mathrm{H})\left({ }_{\mathrm{C}} \mathrm{C} 18 \mathrm{H} 31 \mathrm{Cl} 3 \mathrm{~F} 4\right.\right.\right.\right.\right.\right.\right.\right.\right.$ $\mathrm{H}) \mathrm{F})(\mathrm{H}) \mathrm{H})(\mathrm{H}) \mathrm{H})(\mathrm{H}) \mathrm{H})(\mathrm{H}) \mathrm{H})(\mathrm{H}) \mathrm{F})(\mathrm{F}) \mathrm{H})(\mathrm{H}) \mathrm{H})(\mathrm{H})(\mathrm{H}) \mathrm{H}$

$\mathrm{C}\left(\mathrm{C}\left(\mathrm{C}\left(\mathrm{C}\left(\mathrm{C}\left(\mathrm{C}\left(\mathrm{C}\left(\mathrm{C}\left(\mathrm{C}(\mathrm{C}(\mathrm{C}(\mathrm{C}(\mathrm{C}(\mathrm{C}(\mathrm{C}(\mathrm{C}(\mathrm{C}(\mathrm{C}(\mathrm{H})(\mathrm{H}) \mathrm{H})(\mathrm{H}) \mathrm{F})(\mathrm{F}) \mathrm{H})(\mathrm{H}) \mathrm{H})(\mathrm{H}) \mathrm{H})(\mathrm{H}) \mathrm{H})(\mathrm{H}) \mathrm{H})(\mathrm{H}) \mathrm{F})(\mathrm{H}) \mathrm{H})(\mathrm{F}){ }_{\mathrm{C} 18 \mathrm{H} 31 \mathrm{ClBrF} 5}\right.\right.\right.\right.\right.\right.\right.\right.$ $\mathrm{H})(\mathrm{H}) \mathrm{F})(\mathrm{H}) \mathrm{H})(\mathrm{H}) \mathrm{H})(\mathrm{H}) \mathrm{H})(\mathrm{Cl}) \mathrm{H})(\mathrm{H}) \mathrm{H})(\mathrm{H}) \mathrm{Br})(\mathrm{H})(\mathrm{H}) \mathrm{H}$

$\mathrm{C}\left(\mathrm{C}\left(\mathrm{C}\left(\mathrm{C}\left(\mathrm{C}\left(\mathrm{C}\left(\mathrm{C}\left(\mathrm{C}\left(\mathrm{C}(\mathrm{C}(\mathrm{C}(\mathrm{C}(\mathrm{C}(\mathrm{C}(\mathrm{C}(\mathrm{C}(\mathrm{C}(\mathrm{C}(\mathrm{H})(\mathrm{H}) \mathrm{H})(\mathrm{H}) \mathrm{H})(\mathrm{F}) \mathrm{F})(\mathrm{H}) \mathrm{H})(\mathrm{F}) \mathrm{F})(\mathrm{F}) \mathrm{H})(\mathrm{H}) \mathrm{H})(\mathrm{H}) \mathrm{H})(\mathrm{H}) \mathrm{H})(\mathrm{H}){ }_{\mathrm{C} 18 \mathrm{H} 31 \mathrm{ClF} 6}\right.\right.\right.\right.\right.\right.\right.\right.$

$\mathrm{H})(\mathrm{H}) \mathrm{H})(\mathrm{H}) \mathrm{H})(\mathrm{H}) \mathrm{H})(\mathrm{H}) \mathrm{H})(\mathrm{H}) \mathrm{Cl})(\mathrm{H}) \mathrm{H})(\mathrm{H}) \mathrm{F})(\mathrm{H})(\mathrm{H}) \mathrm{H}$

$\mathrm{C}\left(\mathrm{C}\left(\mathrm{C}\left(\mathrm{C}\left(\mathrm{C}\left(\mathrm{C}\left(\mathrm{C}\left(\mathrm{C}\left(\mathrm{C}(\mathrm{C}(\mathrm{C}(\mathrm{C}(\mathrm{C}(\mathrm{C}(\mathrm{C}(\mathrm{C}(\mathrm{C}(\mathrm{C}(\mathrm{F})(\mathrm{H}) \mathrm{H})(\mathrm{H}) \mathrm{H})(\mathrm{H}) \mathrm{F})(\mathrm{H}) \mathrm{H})(\mathrm{H}) \mathrm{H})(\mathrm{H}) \mathrm{H})(\mathrm{H}) \mathrm{H})(\mathrm{F}) \mathrm{H})(\mathrm{H}) \mathrm{H})(\mathrm{H}){ }^{\mathrm{C}}{ }^{2} 18 \mathrm{H} 32 \mathrm{Br} 2 \mathrm{~F} 4\right.\right.\right.\right.\right.\right.\right.\right.$ $\mathrm{F})(\mathrm{H}) \mathrm{H})(\mathrm{H}) \mathrm{H})(\mathrm{H}) \mathrm{H})(\mathrm{H}) \mathrm{H})(\mathrm{H}) \mathrm{H})(\mathrm{Br}) \mathrm{H})(\mathrm{H}) \mathrm{Br})(\mathrm{H})(\mathrm{H}) \mathrm{H}$

$\mathrm{C}\left(\mathrm{C}\left(\mathrm{C}\left(\mathrm{C}\left(\mathrm{C}\left(\mathrm{C}\left(\mathrm{C}\left(\mathrm{C}\left(\mathrm{C}(\mathrm{C}(\mathrm{C}(\mathrm{C}(\mathrm{C}(\mathrm{C}(\mathrm{C}(\mathrm{C}(\mathrm{C}(\mathrm{C}(\mathrm{H})(\mathrm{H}) \mathrm{H})(\mathrm{H}) \mathrm{H})(\mathrm{H}) \mathrm{H})(\mathrm{F}) \mathrm{F})(\mathrm{H}) \mathrm{H})(\mathrm{H}) \mathrm{H})(\mathrm{H}) \mathrm{H})(\mathrm{H}) \mathrm{H})(\mathrm{F}) \mathrm{H})(\mathrm{H}){ }_{\mathrm{C} 18 \mathrm{H} 32 \mathrm{BrF} 5}\right.\right.\right.\right.\right.\right.\right.\right.$ $\mathrm{Br})(\mathrm{H}) \mathrm{H})(\mathrm{H}) \mathrm{H})(\mathrm{H}) \mathrm{H})(\mathrm{H}) \mathrm{H})(\mathrm{H}) \mathrm{H})(\mathrm{H}) \mathrm{F})(\mathrm{H}) \mathrm{H})(\mathrm{H})(\mathrm{F}) \mathrm{H}$

$\mathrm{C}(\mathrm{C}(\mathrm{C}(\mathrm{C}(\mathrm{C}(\mathrm{C}(\mathrm{C}(\mathrm{C}(\mathrm{C}(\mathrm{C}(\mathrm{C}(\mathrm{C}(\mathrm{C}(\mathrm{C}(\mathrm{C}(\mathrm{C}(\mathrm{C}(\mathrm{C}(\mathrm{H})(\mathrm{H}) \mathrm{Cl})(\mathrm{H}) \mathrm{H})(\mathrm{H}) \mathrm{H})(\mathrm{F}) \mathrm{H})(\mathrm{H}) \mathrm{H})(\mathrm{H}) \mathrm{H})(\mathrm{H}) \mathrm{Cl})(\mathrm{F}) \mathrm{H})(\mathrm{H}) \mathrm{H})($

$\mathrm{H}) \mathrm{H})(\mathrm{H}) \mathrm{H})(\mathrm{H}) \mathrm{H})(\mathrm{H}) \mathrm{H})(\mathrm{F}) \mathrm{H})(\mathrm{H}) \mathrm{F})(\mathrm{H}) \mathrm{H})(\mathrm{H}) \mathrm{H})(\mathrm{H})(\mathrm{H}) \mathrm{H}$

$\mathrm{C}(\mathrm{C}(\mathrm{C}(\mathrm{C}(\mathrm{C}(\mathrm{C}(\mathrm{C}(\mathrm{C}(\mathrm{C}(\mathrm{C}(\mathrm{C}(\mathrm{C}(\mathrm{C}(\mathrm{C}(\mathrm{C}(\mathrm{C}(\mathrm{C}(\mathrm{C}(\mathrm{H})(\mathrm{Cl}) \mathrm{F})(\mathrm{H}) \mathrm{H})(\mathrm{H}) \mathrm{H})(\mathrm{H}) \mathrm{H})(\mathrm{H}) \mathrm{H})(\mathrm{H}) \mathrm{H})(\mathrm{H}) \mathrm{F})(\mathrm{H}) \mathrm{H})(\mathrm{H}) \mathrm{H})$

$(\mathrm{H}) \mathrm{H})(\mathrm{H}) \mathrm{H})(\mathrm{H}) \mathrm{H})(\mathrm{Cl}) \mathrm{H})(\mathrm{H}) \mathrm{H})(\mathrm{F}) \mathrm{H})(\mathrm{H}) \mathrm{Cl}(\mathrm{H}) \mathrm{H})(\mathrm{H})(\mathrm{H}) \mathrm{H}$

$\mathrm{C}\left(\mathrm{C}\left(\mathrm{C}\left(\mathrm{C}\left(\mathrm{C}\left(\mathrm{C}\left(\mathrm{C}\left(\mathrm{C}\left(\mathrm{C}(\mathrm{C}(\mathrm{C}(\mathrm{C}(\mathrm{C}(\mathrm{C}(\mathrm{C}(\mathrm{C}(\mathrm{C}(\mathrm{C}(\mathrm{H})(\mathrm{H}) \mathrm{H})(\mathrm{H}) \mathrm{F})(\mathrm{H}) \mathrm{H})(\mathrm{H}) \mathrm{H})(\mathrm{H}) \mathrm{H})(\mathrm{H}) \mathrm{F})(\mathrm{H}) \mathrm{H})(\mathrm{H}) \mathrm{F})(\mathrm{H}) \mathrm{H})(\mathrm{H}){ }_{\mathrm{C} 18 \mathrm{H} 32 \mathrm{ClBrF} 4}\right.\right.\right.\right.\right.\right.\right.\right.$ $\mathrm{H})(\mathrm{H}) \mathrm{H})(\mathrm{H}) \mathrm{Br})(\mathrm{H}) \mathrm{F})(\mathrm{H}) \mathrm{H})(\mathrm{H}) \mathrm{Cl})(\mathrm{H}) \mathrm{H})(\mathrm{H}) \mathrm{H})(\mathrm{H})(\mathrm{H}) \mathrm{H}$

$\mathrm{C}(\mathrm{C}(\mathrm{C}(\mathrm{C}(\mathrm{C}(\mathrm{C}(\mathrm{C}(\mathrm{C}(\mathrm{C}(\mathrm{C}(\mathrm{C}(\mathrm{C}(\mathrm{C}(\mathrm{C}(\mathrm{C}(\mathrm{C}(\mathrm{C}(\mathrm{C}(\mathrm{H})(\mathrm{H}) \mathrm{H})(\mathrm{H}) \mathrm{F})(\mathrm{H}) \mathrm{H})(\mathrm{F}) \mathrm{H})(\mathrm{H}) \mathrm{H})(\mathrm{H}) \mathrm{H})(\mathrm{H}) \mathrm{H})(\mathrm{H}) \mathrm{H})(\mathrm{H}) \mathrm{H})$ $(\mathrm{H}) \mathrm{H})(\mathrm{H}) \mathrm{H})(\mathrm{H}) \mathrm{Cl}(\mathrm{H}) \mathrm{H})(\mathrm{F}) \mathrm{H})(\mathrm{F}) \mathrm{F})(\mathrm{H}) \mathrm{H})(\mathrm{H}) \mathrm{H})(\mathrm{H})(\mathrm{H}) \mathrm{H}$

$\mathrm{C}\left(\mathrm{C}\left(\mathrm{C}\left(\mathrm{C}\left(\mathrm{C}\left(\mathrm{C}\left(\mathrm{C}\left(\mathrm{C}\left(\mathrm{C}(\mathrm{C}(\mathrm{C}(\mathrm{C}(\mathrm{C}(\mathrm{C}(\mathrm{C}(\mathrm{C}(\mathrm{C}(\mathrm{C}(\mathrm{H})(\mathrm{H}) \mathrm{H})(\mathrm{H}) \mathrm{F})(\mathrm{H}) \mathrm{H})(\mathrm{H}) \mathrm{F})(\mathrm{H}) \mathrm{H})(\mathrm{H}) \mathrm{H})(\mathrm{F}) \mathrm{H})(\mathrm{H}) \mathrm{H})(\mathrm{H}) \mathrm{H})(\mathrm{H}){ }_{\mathrm{C} 18 \mathrm{H} 33 \mathrm{BrF}}\right.\right.\right.\right.\right.\right.\right.\right.$

$\mathrm{H})(\mathrm{H}) \mathrm{H})(\mathrm{H}) \mathrm{H})(\mathrm{H}) \mathrm{H})(\mathrm{Br}) \mathrm{H})(\mathrm{H}) \mathrm{H})(\mathrm{H}) \mathrm{H})(\mathrm{H}) \mathrm{H})(\mathrm{H})(\mathrm{F}) \mathrm{H}$

$\mathrm{C}\left(\mathrm{C}\left(\mathrm{C}\left(\mathrm{C}\left(\mathrm{C}\left(\mathrm{C}\left(\mathrm{C}\left(\mathrm{C}\left(\mathrm{C}(\mathrm{C}(\mathrm{C}(\mathrm{C}(\mathrm{C}(\mathrm{C}(\mathrm{C}(\mathrm{C}(\mathrm{C}(\mathrm{C}(\mathrm{H})(\mathrm{H}) \mathrm{H})(\mathrm{H}) \mathrm{H})(\mathrm{H}) \mathrm{H})(\mathrm{H}) \mathrm{H})(\mathrm{H}) \mathrm{H})(\mathrm{H}) \mathrm{H})(\mathrm{Cl}) \mathrm{H})(\mathrm{H}) \mathrm{F})(\mathrm{F}) \mathrm{Cl})\left({ }_{\mathrm{C}} \mathrm{C}_{8 \mathrm{H}} 33 \mathrm{Cl} 2 \mathrm{~F} 3\right.\right.\right.\right.\right.\right.\right.\right.\right.$

$\mathrm{H}) \mathrm{H})(\mathrm{H}) \mathrm{H})(\mathrm{H}) \mathrm{H})(\mathrm{H}) \mathrm{H})(\mathrm{H}) \mathrm{F})(\mathrm{H}) \mathrm{H})(\mathrm{H}) \mathrm{H})(\mathrm{H}) \mathrm{H})(\mathrm{H})(\mathrm{H}) \mathrm{H}$

$\mathrm{C}(\mathrm{C}(\mathrm{C}(\mathrm{C}(\mathrm{C}(\mathrm{C}(\mathrm{C}(\mathrm{C}(\mathrm{C}(\mathrm{C}(\mathrm{C}(\mathrm{C}(\mathrm{C}(\mathrm{C}(\mathrm{C}(\mathrm{C}(\mathrm{C}(\mathrm{C}(\mathrm{H})(\mathrm{Br}) \mathrm{H})(\mathrm{H}) \mathrm{Cl})(\mathrm{H}) \mathrm{H})(\mathrm{H}) \mathrm{H})(\mathrm{F}) \mathrm{H})(\mathrm{F}) \mathrm{H})(\mathrm{H}) \mathrm{H})(\mathrm{H}) \mathrm{H})(\mathrm{H}) \mathrm{H})(\mathrm{C}$ $\mathrm{H}) \mathrm{H}(\mathrm{H}) \mathrm{H})(\mathrm{H}) \mathrm{H})(\mathrm{H}) \mathrm{H}(\mathrm{H}) \mathrm{H}(\mathrm{H}) \mathrm{H})(\mathrm{H}) \mathrm{H}(\mathrm{F}) \mathrm{H})(\mathrm{H})(\mathrm{H}) \mathrm{H}$

$\mathrm{C}\left(\mathrm{C}\left(\mathrm{C}\left(\mathrm{C}\left(\mathrm{C}\left(\mathrm{C}\left(\mathrm{C}\left(\mathrm{C}\left(\mathrm{C}(\mathrm{C}(\mathrm{C}(\mathrm{C}(\mathrm{C}(\mathrm{C}(\mathrm{C}(\mathrm{C}(\mathrm{C}(\mathrm{C}(\mathrm{F})(\mathrm{H}) \mathrm{H})(\mathrm{H}) \mathrm{H})(\mathrm{F}) \mathrm{H})(\mathrm{H}) \mathrm{H})(\mathrm{H}) \mathrm{H})(\mathrm{H}) \mathrm{H})(\mathrm{H}) \mathrm{F})(\mathrm{F}) \mathrm{Cl})(\mathrm{H}) \mathrm{H})(\mathrm{H}) \mathrm{C}^{2} 8 \mathrm{H} 33 \mathrm{ClF} 4\right.\right.\right.\right.\right.\right.\right.\right.$

$\mathrm{H})(\mathrm{H}) \mathrm{H})(\mathrm{H}) \mathrm{H})(\mathrm{H}) \mathrm{H})(\mathrm{H}) \mathrm{H})(\mathrm{H}) \mathrm{H})(\mathrm{H}) \mathrm{H})(\mathrm{H}) \mathrm{H})(\mathrm{H})(\mathrm{H}) \mathrm{H}$

$\mathrm{C}(\mathrm{C}(\mathrm{C}(\mathrm{C}(\mathrm{C}(\mathrm{C}(\mathrm{C}(\mathrm{C}(\mathrm{C}(\mathrm{C}(\mathrm{C}(\mathrm{C}(\mathrm{C}(\mathrm{C}(\mathrm{C}(\mathrm{C}(\mathrm{C}(\mathrm{C}(\mathrm{H})(\mathrm{H}) \mathrm{H})(\mathrm{H}) \mathrm{H})(\mathrm{H}) \mathrm{H})(\mathrm{H}) \mathrm{H})(\mathrm{H}) \mathrm{F})(\mathrm{F}) \mathrm{Br})(\mathrm{H}) \mathrm{H})(\mathrm{H}) \mathrm{H})(\mathrm{H}) \mathrm{H})($

$\mathrm{H}) \mathrm{H})(\mathrm{H}) \mathrm{H})(\mathrm{H}) \mathrm{H})(\mathrm{F}) \mathrm{H})(\mathrm{H}) \mathrm{H})(\mathrm{H}) \mathrm{H})(\mathrm{H}) \mathrm{H})(\mathrm{H}) \mathrm{H})(\mathrm{H})(\mathrm{H}) \mathrm{H}$

$\mathrm{C}(\mathrm{C}(\mathrm{C}(\mathrm{C}(\mathrm{C}(\mathrm{C}(\mathrm{C}(\mathrm{C}(\mathrm{C}(\mathrm{C}(\mathrm{C}(\mathrm{C}(\mathrm{C}(\mathrm{C}(\mathrm{C}(\mathrm{C}(\mathrm{C}(\mathrm{C}(\mathrm{H})(\mathrm{H}) \mathrm{H})(\mathrm{H}) \mathrm{H})(\mathrm{H}) \mathrm{H})(\mathrm{H}) \mathrm{H})(\mathrm{H}) \mathrm{Cl})(\mathrm{H}) \mathrm{F})(\mathrm{H}) \mathrm{H})(\mathrm{H}) \mathrm{H})(\mathrm{H}) \mathrm{H})$

$\mathrm{H}) \mathrm{H})(\mathrm{H}) \mathrm{H})(\mathrm{H}) \mathrm{H})(\mathrm{H}) \mathrm{H})(\mathrm{H}) \mathrm{H})(\mathrm{H}) \mathrm{H})(\mathrm{H}) \mathrm{H})(\mathrm{H}) \mathrm{Cl})(\mathrm{H})(\mathrm{H}) \mathrm{F}$

$\mathrm{C}(\mathrm{C}(\mathrm{C}(\mathrm{C}(\mathrm{C}(\mathrm{C}(\mathrm{C}(\mathrm{C}(\mathrm{C}(\mathrm{C}(\mathrm{C}(\mathrm{C}(\mathrm{C}(\mathrm{C}(\mathrm{C}(\mathrm{C}(\mathrm{C}(\mathrm{C}(\mathrm{H})(\mathrm{H}) \mathrm{H})(\mathrm{H}) \mathrm{Br})(\mathrm{H}) \mathrm{H})(\mathrm{H}) \mathrm{H})(\mathrm{H}) \mathrm{H})(\mathrm{H}) \mathrm{F})(\mathrm{H}) \mathrm{H})(\mathrm{F}) \mathrm{H})(\mathrm{H}) \mathrm{H})($

$\mathrm{H}) \mathrm{H})(\mathrm{H}) \mathrm{H})(\mathrm{Cl}) \mathrm{H})(\mathrm{H}) \mathrm{H})(\mathrm{H}) \mathrm{H})(\mathrm{H}) \mathrm{H})(\mathrm{H}) \mathrm{H})(\mathrm{H}) \mathrm{H})(\mathrm{H})(\mathrm{H}) \mathrm{H}$

$\mathrm{C}(\mathrm{C}(\mathrm{C}(\mathrm{C}(\mathrm{C}(\mathrm{C}(\mathrm{C}(\mathrm{C}(\mathrm{C}(\mathrm{C}(\mathrm{C}(\mathrm{C}(\mathrm{C}(\mathrm{C}(\mathrm{C}(\mathrm{C}(\mathrm{C}(\mathrm{C}(\mathrm{F})(\mathrm{H}) \mathrm{H})(\mathrm{F}) \mathrm{H})(\mathrm{H}) \mathrm{H})(\mathrm{H}) \mathrm{H})(\mathrm{H}) \mathrm{Cl})(\mathrm{H}) \mathrm{H})(\mathrm{H}) \mathrm{H})(\mathrm{H}) \mathrm{H})(\mathrm{H}) \mathrm{H})$ $(\mathrm{H}) \mathrm{H})(\mathrm{H}) \mathrm{H})(\mathrm{H}) \mathrm{H})(\mathrm{H}) \mathrm{H})(\mathrm{H}) \mathrm{H})(\mathrm{H}) \mathrm{F})(\mathrm{H}) \mathrm{H})(\mathrm{H}) \mathrm{H})(\mathrm{H})(\mathrm{H}) \mathrm{H}$

$\mathrm{C}(\mathrm{C}(\mathrm{C}(\mathrm{C}(\mathrm{C}(\mathrm{C}(\mathrm{C}(\mathrm{C}(\mathrm{C}(\mathrm{C}(\mathrm{C}(\mathrm{C}(\mathrm{C}(\mathrm{C}(\mathrm{C}(\mathrm{C}(\mathrm{C}(\mathrm{C}(\mathrm{H})(\mathrm{H}) \mathrm{H})(\mathrm{H}) \mathrm{H})(\mathrm{F}) \mathrm{H})(\mathrm{H}) \mathrm{H})(\mathrm{F}) \mathrm{H})(\mathrm{H}) \mathrm{H})(\mathrm{H}) \mathrm{F})(\mathrm{H}) \mathrm{H})(\mathrm{F}) \mathrm{H})(\mathrm{H})$ $\mathrm{H})(\mathrm{H}) \mathrm{H})(\mathrm{H}) \mathrm{H})(\mathrm{H}) \mathrm{H})(\mathrm{H}) \mathrm{H})(\mathrm{H}) \mathrm{H})(\mathrm{H}) \mathrm{H})(\mathrm{H}) \mathrm{H})(\mathrm{H})(\mathrm{H}) \mathrm{H}$

$\mathrm{C}(\mathrm{C}(\mathrm{C}(\mathrm{C}(\mathrm{C}(\mathrm{C}(\mathrm{C}(\mathrm{C}(\mathrm{C}(\mathrm{C}(\mathrm{C}(\mathrm{C}(\mathrm{C}(\mathrm{C}(\mathrm{C}(\mathrm{C}(\mathrm{C}(\mathrm{C}(\mathrm{H})(\mathrm{H}) \mathrm{H})(\mathrm{H}) \mathrm{H})(\mathrm{Br}) \mathrm{H})(\mathrm{H}) \mathrm{H})(\mathrm{F}) \mathrm{H})(\mathrm{F}) \mathrm{H})(\mathrm{H}) \mathrm{H})(\mathrm{H}) \mathrm{H})(\mathrm{H}) \mathrm{H})($ $\mathrm{H}) \mathrm{H}(\mathrm{H}) \mathrm{H})(\mathrm{H}) \mathrm{H})(\mathrm{H}) \mathrm{H})(\mathrm{H}) \mathrm{H})(\mathrm{H}) \mathrm{H})(\mathrm{H}) \mathrm{H})(\mathrm{H}) \mathrm{H})(\mathrm{H})(\mathrm{H}) \mathrm{H}$

$\mathrm{C}(\mathrm{C}(\mathrm{C}(\mathrm{C}(\mathrm{C}(\mathrm{C}(\mathrm{C}(\mathrm{C}(\mathrm{C}(\mathrm{C}(\mathrm{C}(\mathrm{C}(\mathrm{C}(\mathrm{C}(\mathrm{C}(\mathrm{C}(\mathrm{C}(\mathrm{C}(\mathrm{H})(\mathrm{H}) \mathrm{H})(\mathrm{H}) \mathrm{H})(\mathrm{H}) \mathrm{H})(\mathrm{H}) \mathrm{H})(\mathrm{H}) \mathrm{H})(\mathrm{F}) \mathrm{H})(\mathrm{H}) \mathrm{H})(\mathrm{H}) \mathrm{H})(\mathrm{H}) \mathrm{H})$

$(\mathrm{H}) \mathrm{Cl}(\mathrm{H}) \mathrm{H})(\mathrm{H}) \mathrm{H})(\mathrm{H}) \mathrm{H})(\mathrm{H}) \mathrm{H})(\mathrm{Cl}) \mathrm{H})(\mathrm{H}) \mathrm{H})(\mathrm{H}) \mathrm{H})(\mathrm{H})(\mathrm{H}) \mathrm{H}$

$\mathrm{C}(\mathrm{C}(\mathrm{C}(\mathrm{C}(\mathrm{C}(\mathrm{C}(\mathrm{C}(\mathrm{C}(\mathrm{C}(\mathrm{C}(\mathrm{C}(\mathrm{C}(\mathrm{C}(\mathrm{C}(\mathrm{C}(\mathrm{C}(\mathrm{C}(\mathrm{C}(\mathrm{H})(\mathrm{H}) \mathrm{H})(\mathrm{H}) \mathrm{H})(\mathrm{H}) \mathrm{H})(\mathrm{F}) \mathrm{H})(\mathrm{H}) \mathrm{H})(\mathrm{H}) \mathrm{H})(\mathrm{H}) \mathrm{H})(\mathrm{Cl}) \mathrm{H})(\mathrm{H}) \mathrm{H})($

$\mathrm{H}) \mathrm{H})(\mathrm{H}) \mathrm{H})(\mathrm{H}) \mathrm{H})(\mathrm{F}) \mathrm{H})(\mathrm{H}) \mathrm{H})(\mathrm{H}) \mathrm{H})(\mathrm{H}) \mathrm{H})(\mathrm{H}) \mathrm{H})(\mathrm{H})(\mathrm{H}) \mathrm{H}$

$\mathrm{C}(\mathrm{C}(\mathrm{C}(\mathrm{C}(\mathrm{C}(\mathrm{C}(\mathrm{C}(\mathrm{C}(\mathrm{C}(\mathrm{C}(\mathrm{C}(\mathrm{C}(\mathrm{C}(\mathrm{C}(\mathrm{C}(\mathrm{C}(\mathrm{C}(\mathrm{C}(\mathrm{F})(\mathrm{H}) \mathrm{H})(\mathrm{H}) \mathrm{H})(\mathrm{H}) \mathrm{H})(\mathrm{F}) \mathrm{H})(\mathrm{H}) \mathrm{H})(\mathrm{H}) \mathrm{H})(\mathrm{H}) \mathrm{H})(\mathrm{H}) \mathrm{H})(\mathrm{H}) \mathrm{H})$

$(\mathrm{H}) \mathrm{H})(\mathrm{H}) \mathrm{H})(\mathrm{H}) \mathrm{H})(\mathrm{F}) \mathrm{H})(\mathrm{H}) \mathrm{H})(\mathrm{H}) \mathrm{H})(\mathrm{H}) \mathrm{H})(\mathrm{H}) \mathrm{H})(\mathrm{H})(\mathrm{H}) \mathrm{H}$

$\mathrm{C}(\mathrm{C}(\mathrm{C}(\mathrm{C}(\mathrm{C}(\mathrm{C}(\mathrm{C}(\mathrm{C}(\mathrm{C}(\mathrm{C}(\mathrm{C}(\mathrm{C}(\mathrm{C}(\mathrm{C}(\mathrm{C}(\mathrm{C}(\mathrm{C}(\mathrm{C}(\mathrm{H})(\mathrm{H}) \mathrm{H})(\mathrm{H}) \mathrm{H})(\mathrm{H}) \mathrm{H})(\mathrm{H}) \mathrm{H})(\mathrm{H}) \mathrm{H})(\mathrm{H}) \mathrm{H})(\mathrm{H}) \mathrm{H})(\mathrm{H}) \mathrm{Br})(\mathrm{H}) \mathrm{H})($

$\mathrm{H}) \mathrm{H})(\mathrm{H}) \mathrm{H})(\mathrm{H}) \mathrm{F})(\mathrm{H}) \mathrm{H})(\mathrm{H}) \mathrm{H})(\mathrm{H}) \mathrm{H})(\mathrm{H}) \mathrm{H})(\mathrm{H}) \mathrm{H})(\mathrm{H})(\mathrm{H}) \mathrm{H}$

$\mathrm{C}(\mathrm{C}(\mathrm{C}(\mathrm{C}(\mathrm{C}(\mathrm{C}(\mathrm{C}(\mathrm{C}(\mathrm{C}(\mathrm{C}(\mathrm{C}(\mathrm{C}(\mathrm{C}(\mathrm{C}(\mathrm{C}(\mathrm{C}(\mathrm{C}(\mathrm{C}(\mathrm{H})(\mathrm{H}) \mathrm{H})(\mathrm{H}) \mathrm{H})(\mathrm{H}) \mathrm{F})(\mathrm{H}) \mathrm{H})(\mathrm{H}) \mathrm{H})(\mathrm{H}) \mathrm{H})(\mathrm{H}) \mathrm{H})(\mathrm{H}) \mathrm{H})(\mathrm{H}) \mathrm{H})$

$(\mathrm{H}) \mathrm{H})(\mathrm{H}) \mathrm{H})(\mathrm{H}) \mathrm{Cl})(\mathrm{H}) \mathrm{H})(\mathrm{H}) \mathrm{H})(\mathrm{H}) \mathrm{H})(\mathrm{H}) \mathrm{H})(\mathrm{H}) \mathrm{H})(\mathrm{H})(\mathrm{H}) \mathrm{H}$

$\mathrm{C}(\mathrm{C}(\mathrm{C}(\mathrm{C}(\mathrm{C}(\mathrm{C}(\mathrm{C}(\mathrm{C}(\mathrm{C}(\mathrm{C}(\mathrm{C}(\mathrm{C}(\mathrm{C}(\mathrm{C}(\mathrm{C}(\mathrm{C}(\mathrm{C}(\mathrm{C}(\mathrm{H})(\mathrm{H}) \mathrm{H})(\mathrm{H}) \mathrm{H})(\mathrm{H}) \mathrm{H})(\mathrm{H}) \mathrm{H})(\mathrm{H}) \mathrm{H})(\mathrm{H}) \mathrm{H})(\mathrm{H}) \mathrm{H})(\mathrm{H}) \mathrm{H})(\mathrm{H}) \mathrm{H})$

$\mathrm{H}) \mathrm{H})(\mathrm{H}) \mathrm{H})(\mathrm{H}) \mathrm{H})(\mathrm{H}) \mathrm{H})(\mathrm{H}) \mathrm{H})(\mathrm{H}) \mathrm{H})(\mathrm{F}) \mathrm{H})(\mathrm{F}) \mathrm{H})(\mathrm{H})(\mathrm{H}) \mathrm{H}$

$\mathrm{C}(\mathrm{C}(\mathrm{C}(\mathrm{C}(\mathrm{C}(\mathrm{C}(\mathrm{C}(\mathrm{C}(\mathrm{C}(\mathrm{C}(\mathrm{C}(\mathrm{C}(\mathrm{C}(\mathrm{C}(\mathrm{C}(\mathrm{C}(\mathrm{C}(\mathrm{C}(\mathrm{H})(\mathrm{H}) \mathrm{H})(\mathrm{H}) \mathrm{H})(\mathrm{H}) \mathrm{H})(\mathrm{H}) \mathrm{H})(\mathrm{F}) \mathrm{H})(\mathrm{H}) \mathrm{H})(\mathrm{H}) \mathrm{H})(\mathrm{H}) \mathrm{H})(\mathrm{H}) \mathrm{H})$ $(\mathrm{H}) \mathrm{H})(\mathrm{H}) \mathrm{H})(\mathrm{H}) \mathrm{H})(\mathrm{H}) \mathrm{H})(\mathrm{H}) \mathrm{H})(\mathrm{H}) \mathrm{H})(\mathrm{H}) \mathrm{H})(\mathrm{H}) \mathrm{H})(\mathrm{H})(\mathrm{H}) \mathrm{H}$

$\mathrm{C} 18 \mathrm{H} 34 \mathrm{BrF} 3$

$\mathrm{C} 18 \mathrm{H} 34 \mathrm{Cl} 2 \mathrm{~F}$

$\mathrm{C} 18 \mathrm{H} 34 \mathrm{ClBrF} 2$

$\mathrm{C} 18 \mathrm{H} 34 \mathrm{ClF} 3$

C18H34F4

$\mathrm{C} 18 \mathrm{H} 35 \mathrm{BrF} 2$

$\mathrm{C} 18 \mathrm{H} 35 \mathrm{Cl} 2 \mathrm{~F}$

$\mathrm{C} 18 \mathrm{H} 35 \mathrm{ClF} 2$

$\mathrm{C} 18 \mathrm{H} 35 \mathrm{~F} 3$

$\mathrm{C} 18 \mathrm{H} 36 \mathrm{BrF}$

$\mathrm{C} 18 \mathrm{H} 36 \mathrm{ClF}$

$\mathrm{C} 18 \mathrm{H} 36 \mathrm{~F} 2$

$\mathrm{C} 18 \mathrm{H} 37 \mathrm{~F}$

年

H)F $(\mathrm{H}) \mathrm{H})(\mathrm{Cl}) \mathrm{H})(\mathrm{H}) \mathrm{H})(\mathrm{F}) \mathrm{H})(\mathrm{H}) \mathrm{H})(\mathrm{F}) \mathrm{H})(\mathrm{H}) \mathrm{Cl})(\mathrm{H}) \mathrm{F})(\mathrm{Br})(\mathrm{F}) \mathrm{H}$

$\mathrm{C}(\mathrm{C}(\mathrm{C}(\mathrm{C}(\mathrm{C}(\mathrm{C}(\mathrm{C}(\mathrm{C}(\mathrm{C}(\mathrm{C}(\mathrm{C}(\mathrm{C}(\mathrm{C}(\mathrm{C}(\mathrm{C}(\mathrm{C}(\mathrm{C}(\mathrm{C}(\mathrm{C}(\mathrm{Cl})(\mathrm{H}) \mathrm{H})(\mathrm{H}) \mathrm{Br})(\mathrm{H}) \mathrm{F})(\mathrm{H}) \mathrm{H})(\mathrm{F}) \mathrm{H})(\mathrm{H}) \mathrm{Cl})(\mathrm{H}) \mathrm{F})(\mathrm{H}) \mathrm{F})(\mathrm{H}) \mathrm{F})$

$(\mathrm{H}) \mathrm{H})(\mathrm{Cl}) \mathrm{H})(\mathrm{H}) \mathrm{F})(\mathrm{H}) \mathrm{F})(\mathrm{F}) \mathrm{H})(\mathrm{F}) \mathrm{H})(\mathrm{H}) \mathrm{Cl})(\mathrm{F}) \mathrm{F})(\mathrm{H}) \mathrm{H})(\mathrm{H})(\mathrm{H}) \mathrm{F}$

$\mathrm{C}\left(\mathrm{C}\left(\mathrm{C}\left(\mathrm{C}\left(\mathrm{C}\left(\mathrm{C}\left(\mathrm{C}\left(\mathrm{C}\left(\mathrm{C}\left(\mathrm{C}(\mathrm{C}(\mathrm{C}(\mathrm{C}(\mathrm{C}(\mathrm{C}(\mathrm{C}(\mathrm{C}(\mathrm{C}(\mathrm{C}(\mathrm{H})(\mathrm{H}) \mathrm{F})(\mathrm{H}) \mathrm{H})(\mathrm{Cl}) \mathrm{H})(\mathrm{F}) \mathrm{H})(\mathrm{F}) \mathrm{H})(\mathrm{H}) \mathrm{Br})(\mathrm{F}) \mathrm{H})(\mathrm{F}) \mathrm{H})(\mathrm{H}) \mathrm{H})\left({ }_{\mathrm{C} 19 \mathrm{H} 23 \mathrm{ClBr} 3 \mathrm{~F} 13}\right.\right.\right.\right.\right.\right.\right.\right.\right.\right.$

$\mathrm{Br}) \mathrm{H})(\mathrm{Br}) \mathrm{F})(\mathrm{H}) \mathrm{F})(\mathrm{F}) \mathrm{H})(\mathrm{H}) \mathrm{F})(\mathrm{H}) \mathrm{F})(\mathrm{H}) \mathrm{H})(\mathrm{H}) \mathrm{H})(\mathrm{F}) \mathrm{H})(\mathrm{H})(\mathrm{F}) \mathrm{F}$

$\mathrm{C}\left(\mathrm{C}\left(\mathrm{C}\left(\mathrm{C}\left(\mathrm{C}\left(\mathrm{C}\left(\mathrm{C}\left(\mathrm{C}\left(\mathrm{C}\left(\mathrm{C}(\mathrm{C}(\mathrm{C}(\mathrm{C}(\mathrm{C}(\mathrm{C}(\mathrm{C}(\mathrm{C}(\mathrm{C}(\mathrm{C}(\mathrm{H})(\mathrm{H}) \mathrm{Br})(\mathrm{H}) \mathrm{F})(\mathrm{Cl}) \mathrm{F})(\mathrm{H}) \mathrm{H})(\mathrm{H}) \mathrm{H})(\mathrm{F}) \mathrm{H})(\mathrm{F}) \mathrm{H})(\mathrm{H}) \mathrm{F})(\mathrm{Br}) \mathrm{H}){ }_{\mathrm{C} 19 \mathrm{H} 25 \mathrm{ClBr} 2 \mathrm{~F} 12}\right.\right.\right.\right.\right.\right.\right.\right.\right.$ $(\mathrm{H}) \mathrm{F})(\mathrm{H}) \mathrm{F})(\mathrm{F}) \mathrm{H})(\mathrm{H}) \mathrm{H})(\mathrm{F}) \mathrm{H})(\mathrm{H}) \mathrm{H})(\mathrm{H}) \mathrm{H})(\mathrm{F}) \mathrm{H})(\mathrm{H}) \mathrm{F})(\mathrm{H})(\mathrm{F}) \mathrm{H}$

$\mathrm{C}\left(\mathrm{C}\left(\mathrm{C}\left(\mathrm{C}\left(\mathrm{C}\left(\mathrm{C}\left(\mathrm{C}\left(\mathrm{C}\left(\mathrm{C}\left(\mathrm{C}(\mathrm{C}(\mathrm{C}(\mathrm{C}(\mathrm{C}(\mathrm{C}(\mathrm{C}(\mathrm{C}(\mathrm{C}(\mathrm{C}(\mathrm{H})(\mathrm{H}) \mathrm{F})(\mathrm{Cl}) \mathrm{H})(\mathrm{F}) \mathrm{H})(\mathrm{H}) \mathrm{F})(\mathrm{H}) \mathrm{F})(\mathrm{Br}) \mathrm{F})(\mathrm{H}) \mathrm{H})(\mathrm{H}) \mathrm{F})(\mathrm{H}) \mathrm{H})\left({ }_{\mathrm{C} 19 \mathrm{H} 26 \mathrm{Cl} 2 \mathrm{BrF} 11}\right.\right.\right.\right.\right.\right.\right.\right.\right.\right.$ $\mathrm{H}) \mathrm{H})(\mathrm{Cl}) \mathrm{H})(\mathrm{H}) \mathrm{H})(\mathrm{H}) \mathrm{H})(\mathrm{H}) \mathrm{H})(\mathrm{H}) \mathrm{H})(\mathrm{H}) \mathrm{F})(\mathrm{H}) \mathrm{F})(\mathrm{F}) \mathrm{H})(\mathrm{F})(\mathrm{F}) \mathrm{H}$

$\mathrm{C}\left(\mathrm{C}\left(\mathrm{C}\left(\mathrm{C}\left(\mathrm{C}\left(\mathrm{C}\left(\mathrm{C}\left(\mathrm{C}\left(\mathrm{C}\left(\mathrm{C}(\mathrm{C}(\mathrm{C}(\mathrm{C}(\mathrm{C}(\mathrm{C}(\mathrm{C}(\mathrm{C}(\mathrm{C}(\mathrm{C}(\mathrm{F})(\mathrm{H}) \mathrm{F})(\mathrm{F}) \mathrm{H})(\mathrm{F}) \mathrm{F})(\mathrm{H}) \mathrm{F})(\mathrm{Cl}) \mathrm{H})(\mathrm{F}) \mathrm{H})(\mathrm{Br}) \mathrm{H})(\mathrm{H}) \mathrm{H})(\mathrm{H}) \mathrm{H})\left({ }_{\mathrm{C} 19 \mathrm{H} 26 \mathrm{ClBr} 2 \mathrm{~F} 11}\right.\right.\right.\right.\right.\right.\right.\right.\right.\right.$ $\mathrm{H}) \mathrm{H})(\mathrm{F}) \mathrm{H})(\mathrm{H}) \mathrm{H})(\mathrm{H}) \mathrm{Br})(\mathrm{H}) \mathrm{H})(\mathrm{H}) \mathrm{H})(\mathrm{H}) \mathrm{H})(\mathrm{H}) \mathrm{H})(\mathrm{F}) \mathrm{H})(\mathrm{F})(\mathrm{F}) \mathrm{H}$

$\mathrm{C}\left(\mathrm{C}\left(\mathrm{C}\left(\mathrm{C}\left(\mathrm{C}\left(\mathrm{C}\left(\mathrm{C}\left(\mathrm{C}\left(\mathrm{C}\left(\mathrm{C}(\mathrm{C}(\mathrm{C}(\mathrm{C}(\mathrm{C}(\mathrm{C}(\mathrm{C}(\mathrm{C}(\mathrm{C}(\mathrm{C}(\mathrm{H})(\mathrm{F}) \mathrm{H})(\mathrm{H}) \mathrm{H})(\mathrm{H}) \mathrm{H})(\mathrm{H}) \mathrm{H})(\mathrm{F}) \mathrm{H})(\mathrm{F}) \mathrm{F})(\mathrm{F}) \mathrm{H})(\mathrm{H}) \mathrm{F})(\mathrm{H}) \mathrm{Br})\left({ }_{\mathrm{C} 19 \mathrm{H} 27 \mathrm{Br} 2 \mathrm{~F} 11}\right.\right.\right.\right.\right.\right.\right.\right.\right.\right.$

$\mathrm{H}) \mathrm{H})(\mathrm{H}) \mathrm{F})(\mathrm{F}) \mathrm{H})(\mathrm{H}) \mathrm{F})(\mathrm{H}) \mathrm{H})(\mathrm{H}) \mathrm{Br})(\mathrm{H}) \mathrm{H})(\mathrm{H}) \mathrm{H})(\mathrm{F}) \mathrm{H})(\mathrm{H})(\mathrm{F}) \mathrm{H}$

$\mathrm{C}(\mathrm{C}(\mathrm{C}(\mathrm{C}(\mathrm{C}(\mathrm{C}(\mathrm{C}(\mathrm{C}(\mathrm{C}(\mathrm{C}(\mathrm{C}(\mathrm{C}(\mathrm{C}(\mathrm{C}(\mathrm{C}(\mathrm{C}(\mathrm{C}(\mathrm{C}(\mathrm{C}(\mathrm{H})(\mathrm{H}) \mathrm{Cl})(\mathrm{H}) \mathrm{H})(\mathrm{H}) \mathrm{F})(\mathrm{H}) \mathrm{H})(\mathrm{H}) \mathrm{H})(\mathrm{F}) \mathrm{H})(\mathrm{H}) \mathrm{H})(\mathrm{F}) \mathrm{H})(\mathrm{F}) \mathrm{H})($

$\mathrm{H}) \mathrm{H})(\mathrm{F}) \mathrm{H})(\mathrm{Cl}) \mathrm{H})(\mathrm{F}) \mathrm{H})(\mathrm{H}) \mathrm{H})(\mathrm{F}) \mathrm{H})(\mathrm{H}) \mathrm{F})(\mathrm{F}) \mathrm{F})(\mathrm{H}) \mathrm{H})(\mathrm{H})(\mathrm{Cl}) \mathrm{H}$
lgKoa lgKow lgKaw lgKow lgKoa lgKa lgKow lgKoa lgKaw EPISuit EPI EPI Exp Exp w DFT DFT DFT e Suite Suite corr_corr_Exp corr__corr_corr $\begin{array}{lllllllll}6.355 & 9.06 & 2.70 & 8.60 & 5.89 & 2.70 & 7.72 & 9.69 & -1.97\end{array}$

$\begin{array}{lllllllll}7.496 & 9.45 & 1.95 & 9.18 & 7.23 & 1.95 & 8.02 & 11.78 & -3.76\end{array}$

$\begin{array}{lllllllll}7.575 & 9.31 & 1.74 & 8.97 & 7.23 & 1.74 & 7.91 & 11.93 & -4.01\end{array}$

$\begin{array}{lllllllll}6.679 & 9.65 & 2.97 & 9.48 & 6.51 & 2.97 & 8.17 & 10.28 & -2.11\end{array}$

$\begin{array}{lllllllll}7.612 & 9.8 & 2.19 & 9.70 & 7.51 & 2.19 & 8.29 & 12.00 & -3.71\end{array}$

$\begin{array}{lllllllll}5.376 & 8.8 & 3.42 & 8.21 & 4.78 & 3.42 & 7.52 & 7.89 & -0.37\end{array}$

$\begin{array}{lllllllll}7.359 & 9.28 & 1.92 & 8.93 & 7.00 & 1.92 & 7.89 & 11.53 & -3.64\end{array}$

$\begin{array}{lllllllll}5.792 & 8.95 & 3.16 & 8.43 & 5.27 & 3.16 & 7.64 & 8.65 & -1.02\end{array}$

$\begin{array}{lllllllll}6.784 & 9.19 & 2.41 & 8.79 & 6.39 & 2.41 & 7.82 & 10.47 & -2.65\end{array}$

$\begin{array}{lllllllll}6.298 & 8.97 & 2.67 & 8.46 & 5.79 & 2.67 & 7.65 & 9.58 & -1.93\end{array}$

$6.14 \quad 10.05$

$\begin{array}{lllllll}3.91 & 10.07 & 6.16 & 3.91 & 8.48 & 9.29 & -0.81\end{array}$

$7.372 \quad 9.26$

$\begin{array}{lllllll}1.89 & 8.90 & 7.01 & 1.89 & 7.87 & 11.55 & -3.68\end{array}$

$6.474 \quad 9.6$

$\begin{array}{lllllll}3.13 & 9.40 & 6.28 & 3.13 & 8.14 & 9.90 & -1.77\end{array}$

$6.22 \quad 9.08$

$7.293 \quad 9.4$

$\begin{array}{lllllll}2.86 & 8.63 & 5.77 & 2.86 & 7.74 & 9.44 & -1.70\end{array}$

$6.726 \quad 9.1$

$5.829 \quad 9.44$

$6.164 \quad 8.99$

$7.32 \quad 9.88$

$7.235 \quad 9.31$

$6.328 \quad 9.64$

$\begin{array}{lllllll}2.37 & 8.66 & 6.28 & 2.37 & 7.75 & 10.37 & -2.62\end{array}$

$\begin{array}{lllllll}3.61 & 9.16 & 5.55 & 3.61 & 8.01 & 8.72 & -0.71\end{array}$

$\begin{array}{lllllll}2.83 & 8.49 & 5.67 & 2.83 & 7.67 & 9.34 & -1.67\end{array}$

$\begin{array}{lllllll}2.56 & 9.82 & 7.26 & 2.56 & 8.35 & 11.46 & -3.11\end{array}$

$\begin{array}{lllllll}2.08 & 8.97 & 6.89 & 2.08 & 7.91 & 11.30 & -3.39\end{array}$

$\begin{array}{lllllll}3.31 & 9.46 & 6.15 & 3.31 & 8.17 & 9.64 & -1.47\end{array}$

$7.261 \quad 9.79$

$\begin{array}{ll}7.088 & 9.35\end{array}$

$\begin{array}{lllllll}2.53 & 9.69 & 7.16 & 2.53 & 8.28 & 11.35 & -3.07\end{array}$

$\begin{array}{lllllll}2.26 & 9.03 & 6.77 & 2.26 & 7.94 & 11.03 & -3.09\end{array}$

$7.594 \quad 9.37$

$\begin{array}{lllllll}1.78 & 9.06 & 7.28 & 1.78 & 7.96 & 11.96 & -4.00\end{array}$

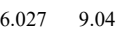

$\begin{array}{lllllll}3.01 & 8.57 & 5.55 & 3.01 & 7.71 & 9.08 & -1.38\end{array}$

$4.883 \quad 8.65$

$\begin{array}{lllllll}3.77 & 7.99 & 4.22 & 3.77 & 7.41 & 6.98 & 0.42\end{array}$

$6.96 \quad 9.19$

$\begin{array}{lllllll}2.23 & 8.79 & 6.56 & 2.23 & 7.82 & 10.80 & -2.98\end{array}$

$\begin{array}{ll}7.446 & 9.41\end{array}$

$\begin{array}{lllllll}1.96 & 9.12 & 7.16 & 1.96 & 7.99 & 11.69 & -3.70\end{array}$

$6.385 \quad 9.1$

$\begin{array}{lllllll}2.72 & 8.66 & 5.94 & 2.72 & 7.75 & 9.74 & -1.99\end{array}$

$5.393 \quad 8.86$

$\begin{array}{lllllll}3.47 & 8.30 & 4.83 & 3.47 & 7.57 & 7.92 & -0.35\end{array}$

$7.388 \quad 9.32$

$\begin{array}{lllllll}1.93 & 8.99 & 7.05 & 1.93 & 7.92 & 11.58 & -3.66\end{array}$

$6.814 \quad 9.23$

$\begin{array}{lllllll}2.42 & 8.85 & 6.43 & 2.42 & 7.85 & 10.53 & -2.68\end{array}$

$5.752 \quad 8.92$

$\begin{array}{lllllll}3.17 & 8.39 & 5.22 & 3.17 & 7.61 & 8.58 & -0.97\end{array}$

$7.131 \quad 9.05$

$\begin{array}{lllllll}1.92 & 8.58 & 6.66 & 1.92 & 7.71 & 11.11 & -3.40\end{array}$

$5.937 \quad 9.73$

$\begin{array}{lllllll}3.79 & 9.60 & 5.80 & 3.79 & 8.24 & 8.92 & -0.68\end{array}$

$6.432 \quad 9.96$

$\begin{array}{lllllll}3.53 & 9.94 & 6.41 & 3.53 & 8.41 & 9.83 & -1.42\end{array}$

$6.51 \quad 9.82$

$\begin{array}{lllllll}3.31 & 9.73 & 6.42 & 3.31 & 8.30 & 9.97 & -1.67\end{array}$

$5.742 \quad 9.69$

$\begin{array}{lllllll}3.95 & 9.54 & 5.59 & 3.95 & 8.20 & 8.56 & -0.36\end{array}$

$5.595 \quad 9.73$

$\begin{array}{lllllll}4.14 & 9.60 & 5.46 & 4.14 & 8.24 & 8.29 & -0.05\end{array}$

$6.171 \quad 9.82$

$\begin{array}{lllllll}3.65 & 9.73 & 6.08 & 3.65 & 8.30 & 9.35 & -1.04\end{array}$

$5.537 \quad 9.64$

$\begin{array}{lllllll}4.10 & 9.46 & 5.36 & 4.10 & 8.17 & 8.18 & -0.02\end{array}$

$5.448 \quad 9.77$ 
$\mathrm{C}(\mathrm{C}(\mathrm{C}(\mathrm{C}(\mathrm{C}(\mathrm{C}(\mathrm{C}(\mathrm{C}(\mathrm{C}(\mathrm{C}(\mathrm{C}(\mathrm{C}(\mathrm{C}(\mathrm{C}(\mathrm{C}(\mathrm{C}(\mathrm{C}(\mathrm{C}(\mathrm{C}(\mathrm{H})(\mathrm{H}) \mathrm{F})(\mathrm{F}) \mathrm{H})(\mathrm{H}) \mathrm{H})(\mathrm{H}) \mathrm{Br})(\mathrm{H}) \mathrm{H})(\mathrm{H}) \mathrm{Cl})(\mathrm{H}) \mathrm{H})(\mathrm{H}) \mathrm{H})$ $(\mathrm{H}) \mathrm{F})(\mathrm{H}) \mathrm{H})(\mathrm{F}) \mathrm{H})(\mathrm{H}) \mathrm{F})(\mathrm{H}) \mathrm{H})(\mathrm{H}) \mathrm{F})(\mathrm{F}) \mathrm{F})(\mathrm{F}) \mathrm{H})(\mathrm{H}) \mathrm{Cl}(\mathrm{H}) \mathrm{H})(\mathrm{H})(\mathrm{H}) \mathrm{H}$

$\mathrm{C}(\mathrm{C}(\mathrm{C}(\mathrm{C}(\mathrm{C}(\mathrm{C}(\mathrm{C}(\mathrm{C}(\mathrm{C}(\mathrm{C}(\mathrm{C}(\mathrm{C}(\mathrm{C}(\mathrm{C}(\mathrm{C}(\mathrm{C}(\mathrm{C}(\mathrm{C}(\mathrm{C}(\mathrm{F})(\mathrm{H}) \mathrm{H})(\mathrm{F}) \mathrm{H})(\mathrm{H}) \mathrm{F})(\mathrm{Cl}) \mathrm{H})(\mathrm{F}) \mathrm{H})(\mathrm{F}) \mathrm{H})(\mathrm{H}) \mathrm{H})(\mathrm{H}) \mathrm{Cl})(\mathrm{H}) \mathrm{Cl})$ $(\mathrm{H}) \mathrm{H})(\mathrm{Br}) \mathrm{H})(\mathrm{H}) \mathrm{H})(\mathrm{H}) \mathrm{H})(\mathrm{H}) \mathrm{H})(\mathrm{H}) \mathrm{H})(\mathrm{F}) \mathrm{H})(\mathrm{H}) \mathrm{H})(\mathrm{H}) \mathrm{H})(\mathrm{F})(\mathrm{H}) \mathrm{F}$

$\mathrm{C}(\mathrm{C}(\mathrm{C}(\mathrm{C}(\mathrm{C}(\mathrm{C}(\mathrm{C}(\mathrm{C}(\mathrm{C}(\mathrm{C}(\mathrm{C}(\mathrm{C}(\mathrm{C}(\mathrm{C}(\mathrm{C}(\mathrm{C}(\mathrm{C}(\mathrm{C}(\mathrm{C}(\mathrm{F})(\mathrm{Cl}) \mathrm{H})(\mathrm{H}) \mathrm{H})(\mathrm{F}) \mathrm{H})(\mathrm{H}) \mathrm{H})(\mathrm{H}) \mathrm{H})(\mathrm{H}) \mathrm{H})(\mathrm{Cl}) \mathrm{H})(\mathrm{H}) \mathrm{F})$ $(\mathrm{H}) \mathrm{Cl}(\mathrm{H}) \mathrm{Cl})(\mathrm{F}) \mathrm{H})(\mathrm{F}) \mathrm{H})(\mathrm{H}) \mathrm{F})(\mathrm{H}) \mathrm{F})(\mathrm{H}) \mathrm{H})(\mathrm{Cl}) \mathrm{H})(\mathrm{H}) \mathrm{H})(\mathrm{H}) \mathrm{H})(\mathrm{H})(\mathrm{H}) \mathrm{H}$

C $(\mathrm{C}(\mathrm{C}(\mathrm{C}(\mathrm{C}(\mathrm{C}(\mathrm{C}(\mathrm{C}(\mathrm{C}(\mathrm{C}(\mathrm{C}(\mathrm{C}(\mathrm{C}(\mathrm{C}(\mathrm{C}(\mathrm{C}(\mathrm{C}(\mathrm{C}(\mathrm{C}(\mathrm{F})(\mathrm{H}) \mathrm{H})(\mathrm{H}) \mathrm{H})(\mathrm{F}) \mathrm{H})(\mathrm{H}) \mathrm{F})(\mathrm{H}) \mathrm{F})(\mathrm{H}) \mathrm{F})(\mathrm{H}) \mathrm{H})(\mathrm{H}) \mathrm{H})(\mathrm{H}) \mathrm{H}) \mathrm{C}$ $\mathrm{H}) \mathrm{H})(\mathrm{H}) \mathrm{Br})(\mathrm{H}) \mathrm{H})(\mathrm{F}) \mathrm{H})(\mathrm{H}) \mathrm{F})(\mathrm{H}) \mathrm{H})(\mathrm{H}) \mathrm{H})(\mathrm{F}) \mathrm{H})(\mathrm{H}) \mathrm{F})(\mathrm{H})(\mathrm{Br}) \mathrm{H}$

$\mathrm{C}(\mathrm{C}(\mathrm{C}(\mathrm{C}(\mathrm{C}(\mathrm{C}(\mathrm{C}(\mathrm{C}(\mathrm{C}(\mathrm{C}(\mathrm{C}(\mathrm{C}(\mathrm{C}(\mathrm{C}(\mathrm{C}(\mathrm{C}(\mathrm{C}(\mathrm{C}(\mathrm{C}(\mathrm{F})(\mathrm{F}) \mathrm{H})(\mathrm{H}) \mathrm{H})(\mathrm{H}) \mathrm{H})(\mathrm{H}) \mathrm{H})(\mathrm{F}) \mathrm{H})(\mathrm{H}) \mathrm{F})(\mathrm{H}) \mathrm{H})(\mathrm{Cl}) \mathrm{H})(\mathrm{Cl}) \mathrm{H})$ $(\mathrm{H}) \mathrm{Cl}(\mathrm{H}) \mathrm{H})(\mathrm{H}) \mathrm{H})(\mathrm{H}) \mathrm{H})(\mathrm{F}) \mathrm{H})(\mathrm{H}) \mathrm{F})(\mathrm{H}) \mathrm{H})(\mathrm{F}) \mathrm{H})(\mathrm{H}) \mathrm{H})(\mathrm{H})(\mathrm{Cl}) \mathrm{H}$

$\mathrm{C}(\mathrm{C}(\mathrm{C}(\mathrm{C}(\mathrm{C}(\mathrm{C}(\mathrm{C}(\mathrm{C}(\mathrm{C}(\mathrm{C}(\mathrm{C}(\mathrm{C}(\mathrm{C}(\mathrm{C}(\mathrm{C}(\mathrm{C}(\mathrm{C}(\mathrm{C}(\mathrm{C}(\mathrm{H})(\mathrm{H}) \mathrm{H})(\mathrm{H}) \mathrm{H})(\mathrm{H}) \mathrm{F})(\mathrm{H}) \mathrm{H})(\mathrm{F}) \mathrm{H})(\mathrm{H}) \mathrm{F})(\mathrm{F}) \mathrm{H})(\mathrm{F}) \mathrm{H})(\mathrm{F}) \mathrm{H})($ $\mathrm{H}) \mathrm{H})(\mathrm{Br}) \mathrm{H})(\mathrm{H}) \mathrm{H})(\mathrm{H}) \mathrm{H})(\mathrm{H}) \mathrm{H})(\mathrm{H}) \mathrm{Cl})(\mathrm{H}) \mathrm{H})(\mathrm{H}) \mathrm{F})(\mathrm{F}) \mathrm{H})(\mathrm{H})(\mathrm{F}) \mathrm{H}$

$\mathrm{C}(\mathrm{C}(\mathrm{C}(\mathrm{C}(\mathrm{C}(\mathrm{C}(\mathrm{C}(\mathrm{C}(\mathrm{C}(\mathrm{C}(\mathrm{C}(\mathrm{C}(\mathrm{C}(\mathrm{C}(\mathrm{C}(\mathrm{C}(\mathrm{C}(\mathrm{C}(\mathrm{C}(\mathrm{F})(\mathrm{H}) \mathrm{H})(\mathrm{H}) \mathrm{H})(\mathrm{H}) \mathrm{Br})(\mathrm{H}) \mathrm{H})(\mathrm{F}) \mathrm{H})(\mathrm{H}) \mathrm{H})(\mathrm{H}) \mathrm{F})(\mathrm{H}) \mathrm{H})(\mathrm{H}) \mathrm{H})$ $(\mathrm{H}) \mathrm{F})(\mathrm{F}) \mathrm{Br})(\mathrm{H}) \mathrm{F})(\mathrm{H}) \mathrm{H})(\mathrm{H}) \mathrm{F})(\mathrm{H}) \mathrm{H})(\mathrm{H}) \mathrm{H})(\mathrm{H}) \mathrm{F})(\mathrm{H}) \mathrm{H})(\mathrm{H})(\mathrm{H}) \mathrm{H}$

$\mathrm{C}(\mathrm{C}(\mathrm{C}(\mathrm{C}(\mathrm{C}(\mathrm{C}(\mathrm{C}(\mathrm{C}(\mathrm{C}(\mathrm{C}(\mathrm{C}(\mathrm{C}(\mathrm{C}(\mathrm{C}(\mathrm{C}(\mathrm{C}(\mathrm{C}(\mathrm{C}(\mathrm{C}(\mathrm{F})(\mathrm{H}) \mathrm{H})(\mathrm{Cl}) \mathrm{H})(\mathrm{H}) \mathrm{F})(\mathrm{H}) \mathrm{H})(\mathrm{H}) \mathrm{H})(\mathrm{H}) \mathrm{H})(\mathrm{H}) \mathrm{Br})(\mathrm{H}) \mathrm{H})$

$(\mathrm{H}) \mathrm{F})(\mathrm{H}) \mathrm{Cl}(\mathrm{H}) \mathrm{H})(\mathrm{H}) \mathrm{H})(\mathrm{H}) \mathrm{Cl})(\mathrm{F}) \mathrm{H})(\mathrm{H}) \mathrm{H})(\mathrm{F}) \mathrm{H})(\mathrm{H}) \mathrm{F})(\mathrm{H}) \mathrm{H})(\mathrm{H})(\mathrm{H}) \mathrm{H}$

$\mathrm{C}(\mathrm{C}(\mathrm{C}(\mathrm{C}(\mathrm{C}(\mathrm{C}(\mathrm{C}(\mathrm{C}(\mathrm{C}(\mathrm{C}(\mathrm{C}(\mathrm{C}(\mathrm{C}(\mathrm{C}(\mathrm{C}(\mathrm{C}(\mathrm{C}(\mathrm{C}(\mathrm{C}(\mathrm{H})(\mathrm{H}) \mathrm{H})(\mathrm{Br}) \mathrm{H})(\mathrm{H}) \mathrm{Br})(\mathrm{H}) \mathrm{H})(\mathrm{H}) \mathrm{H})(\mathrm{F}) \mathrm{H})(\mathrm{H}) \mathrm{F})(\mathrm{H}) \mathrm{F})(\mathrm{H}) \mathrm{F})$

$(\mathrm{H}) \mathrm{H})(\mathrm{H}) \mathrm{H})(\mathrm{H}) \mathrm{H})(\mathrm{H}) \mathrm{H})(\mathrm{H}) \mathrm{H})(\mathrm{F}) \mathrm{H})(\mathrm{F}) \mathrm{H})(\mathrm{H}) \mathrm{H})(\mathrm{H}) \mathrm{H})(\mathrm{H})(\mathrm{F}) \mathrm{H}$

$\mathrm{C}(\mathrm{C}(\mathrm{C}(\mathrm{C}(\mathrm{C}(\mathrm{C}(\mathrm{C}(\mathrm{C}(\mathrm{C}(\mathrm{C}(\mathrm{C}(\mathrm{C}(\mathrm{C}(\mathrm{C}(\mathrm{C}(\mathrm{C}(\mathrm{C}(\mathrm{C}(\mathrm{C}(\mathrm{H})(\mathrm{H}) \mathrm{H})(\mathrm{H}) \mathrm{H})(\mathrm{H}) \mathrm{H})(\mathrm{H}) \mathrm{F})(\mathrm{F}) \mathrm{F})(\mathrm{H}) \mathrm{F})(\mathrm{H}) \mathrm{H})(\mathrm{H}) \mathrm{H})(\mathrm{H}) \mathrm{H})($

$\mathrm{H}) \mathrm{H})(\mathrm{H}) \mathrm{H})(\mathrm{H}) \mathrm{H})(\mathrm{H}) \mathrm{H})(\mathrm{H}) \mathrm{H})(\mathrm{H}) \mathrm{F})(\mathrm{H}) \mathrm{H})(\mathrm{Br}) \mathrm{H})(\mathrm{F}) \mathrm{H})(\mathrm{H})(\mathrm{F}) \mathrm{F}$

$\mathrm{H}) \mathrm{H})(\mathrm{H}) \mathrm{H})(\mathrm{H}) \mathrm{H})(\mathrm{H}) \mathrm{H})(\mathrm{H}) \mathrm{H})(\mathrm{H}) \mathrm{F})(\mathrm{H}) \mathrm{H})(\mathrm{Br}) \mathrm{H})(\mathrm{F}) \mathrm{H})(\mathrm{H})(\mathrm{F}) \mathrm{F}$
$\mathrm{C}(\mathrm{C}(\mathrm{C}(\mathrm{C}(\mathrm{C}(\mathrm{C}(\mathrm{C}(\mathrm{C}(\mathrm{C}(\mathrm{C}(\mathrm{C}(\mathrm{C}(\mathrm{C}(\mathrm{C}(\mathrm{C}(\mathrm{C}(\mathrm{C}(\mathrm{C}(\mathrm{C}(\mathrm{H})(\mathrm{H}) \mathrm{H})(\mathrm{H}) \mathrm{F})(\mathrm{Cl}) \mathrm{H})(\mathrm{H}) \mathrm{H})(\mathrm{F}) \mathrm{H})(\mathrm{H}) \mathrm{H})(\mathrm{H}) \mathrm{F})(\mathrm{H}) \mathrm{H})(\mathrm{H}) \mathrm{H})$ $(\mathrm{H}) \mathrm{H})(\mathrm{H}) \mathrm{H})(\mathrm{H}) \mathrm{H})(\mathrm{H}) \mathrm{H})(\mathrm{H}) \mathrm{H})(\mathrm{H}) \mathrm{F})(\mathrm{F}) \mathrm{H})(\mathrm{F}) \mathrm{F})(\mathrm{H}) \mathrm{H})(\mathrm{Cl})(\mathrm{H}) \mathrm{H}$

$\mathrm{C}(\mathrm{C}(\mathrm{C}(\mathrm{C}(\mathrm{C}(\mathrm{C}(\mathrm{C}(\mathrm{C}(\mathrm{C}(\mathrm{C}(\mathrm{C}(\mathrm{C}(\mathrm{C}(\mathrm{C}(\mathrm{C}(\mathrm{C}(\mathrm{C}(\mathrm{C}(\mathrm{C}(\mathrm{H})(\mathrm{H}) \mathrm{H})(\mathrm{H}) \mathrm{H})(\mathrm{H}) \mathrm{H})(\mathrm{Cl}) \mathrm{H})(\mathrm{H}) \mathrm{H})(\mathrm{H}) \mathrm{H})(\mathrm{H}) \mathrm{Cl})(\mathrm{H}) \mathrm{H})(\mathrm{H})$ $\mathrm{H})(\mathrm{H}) \mathrm{H})(\mathrm{F}) \mathrm{H})(\mathrm{H}) \mathrm{H})(\mathrm{F}) \mathrm{H})(\mathrm{H}) \mathrm{F})(\mathrm{H}) \mathrm{F})(\mathrm{H}) \mathrm{H})(\mathrm{F}) \mathrm{H})(\mathrm{Cl}) \mathrm{H})(\mathrm{H})(\mathrm{H}) \mathrm{F}$

$\mathrm{C}(\mathrm{C}(\mathrm{C}(\mathrm{C}(\mathrm{C}(\mathrm{C}(\mathrm{C}(\mathrm{C}(\mathrm{C}(\mathrm{C}(\mathrm{C}(\mathrm{C}(\mathrm{C}(\mathrm{C}(\mathrm{C}(\mathrm{C}(\mathrm{C}(\mathrm{C}(\mathrm{C}(\mathrm{H})(\mathrm{Cl}) \mathrm{H})(\mathrm{H}) \mathrm{H})(\mathrm{H}) \mathrm{H})(\mathrm{H}) \mathrm{H})(\mathrm{H}) \mathrm{Cl})(\mathrm{H}) \mathrm{H})(\mathrm{H}) \mathrm{H})(\mathrm{H}) \mathrm{H})(\mathrm{H})$ $\mathrm{H})(\mathrm{H}) \mathrm{F})(\mathrm{H}) \mathrm{H})(\mathrm{H}) \mathrm{F})(\mathrm{H}) \mathrm{H})(\mathrm{H}) \mathrm{F})(\mathrm{H}) \mathrm{H})(\mathrm{H}) \mathrm{F})(\mathrm{H}) \mathrm{H})(\mathrm{F}) \mathrm{H})(\mathrm{Cl})(\mathrm{Cl}) \mathrm{H}$

$\mathrm{C}(\mathrm{C}(\mathrm{C}(\mathrm{C}(\mathrm{C}(\mathrm{C}(\mathrm{C}(\mathrm{C}(\mathrm{C}(\mathrm{C}(\mathrm{C}(\mathrm{C}(\mathrm{C}(\mathrm{C}(\mathrm{C}(\mathrm{C}(\mathrm{C}(\mathrm{C}(\mathrm{C}(\mathrm{H})(\mathrm{F}) \mathrm{H})(\mathrm{H}) \mathrm{F})(\mathrm{H}) \mathrm{H})(\mathrm{H}) \mathrm{H})(\mathrm{H}) \mathrm{H})(\mathrm{H}) \mathrm{F})(\mathrm{H}) \mathrm{F})(\mathrm{F}) \mathrm{H})(\mathrm{H}) \mathrm{F})$

$(\mathrm{F}) \mathrm{H})(\mathrm{H}) \mathrm{H})(\mathrm{H}) \mathrm{H})(\mathrm{H}) \mathrm{H})(\mathrm{H}) \mathrm{H})(\mathrm{H}) \mathrm{H})(\mathrm{H}) \mathrm{H})(\mathrm{Br}) \mathrm{H})(\mathrm{Cl}) \mathrm{H})(\mathrm{H})(\mathrm{H}) \mathrm{H}$

$\mathrm{C}(\mathrm{C}(\mathrm{C}(\mathrm{C}(\mathrm{C}(\mathrm{C}(\mathrm{C}(\mathrm{C}(\mathrm{C}(\mathrm{C}(\mathrm{C}(\mathrm{C}(\mathrm{C}(\mathrm{C}(\mathrm{C}(\mathrm{C}(\mathrm{C}(\mathrm{C}(\mathrm{C}(\mathrm{Br})(\mathrm{H}) \mathrm{F})(\mathrm{H}) \mathrm{H})(\mathrm{H}) \mathrm{H})(\mathrm{H}) \mathrm{F})(\mathrm{H}) \mathrm{H})(\mathrm{H}) \mathrm{H})(\mathrm{H}) \mathrm{H})(\mathrm{H}) \mathrm{H})(\mathrm{F}) \mathrm{H})$ $(\mathrm{H}) \mathrm{H})(\mathrm{H}) \mathrm{H})(\mathrm{H}) \mathrm{H})(\mathrm{F}) \mathrm{H})(\mathrm{F}) \mathrm{H})(\mathrm{Br}) \mathrm{H})(\mathrm{H}) \mathrm{H})(\mathrm{H}) \mathrm{H})(\mathrm{H}) \mathrm{H})(\mathrm{H})(\mathrm{F}) \mathrm{H}$

$\mathrm{C}(\mathrm{C}(\mathrm{C}(\mathrm{C}(\mathrm{C}(\mathrm{C}(\mathrm{C}(\mathrm{C}(\mathrm{C}(\mathrm{C}(\mathrm{C}(\mathrm{C}(\mathrm{C}(\mathrm{C}(\mathrm{C}(\mathrm{C}(\mathrm{C}(\mathrm{C}(\mathrm{C}(\mathrm{H})(\mathrm{H}) \mathrm{H})(\mathrm{H}) \mathrm{H})(\mathrm{H}) \mathrm{H})(\mathrm{H}) \mathrm{H})(\mathrm{H}) \mathrm{H})(\mathrm{H}) \mathrm{H})(\mathrm{H}) \mathrm{F})(\mathrm{H}) \mathrm{H})(\mathrm{F}) \mathrm{H})$ $(\mathrm{F}) \mathrm{F})(\mathrm{H}) \mathrm{H})(\mathrm{H}) \mathrm{H})(\mathrm{H}) \mathrm{F})(\mathrm{H}) \mathrm{H})(\mathrm{H}) \mathrm{Br})(\mathrm{F}) \mathrm{H})(\mathrm{H}) \mathrm{H})(\mathrm{H}) \mathrm{H})(\mathrm{H})(\mathrm{F}) \mathrm{H}$

$\mathrm{C}(\mathrm{C}(\mathrm{C}(\mathrm{C}(\mathrm{C}(\mathrm{C}(\mathrm{C}(\mathrm{C}(\mathrm{C}(\mathrm{C}(\mathrm{C}(\mathrm{C}(\mathrm{C}(\mathrm{C}(\mathrm{C}(\mathrm{C}(\mathrm{C}(\mathrm{C}(\mathrm{C}(\mathrm{F})(\mathrm{H}) \mathrm{F})(\mathrm{H}) \mathrm{H})(\mathrm{Cl}) \mathrm{H})(\mathrm{F}) \mathrm{H})(\mathrm{H}) \mathrm{H})(\mathrm{F}) \mathrm{H})(\mathrm{H}) \mathrm{H})(\mathrm{H}) \mathrm{Br})(\mathrm{H}) \mathrm{H})$ $(\mathrm{H}) \mathrm{H})(\mathrm{H}) \mathrm{H})(\mathrm{H}) \mathrm{H})(\mathrm{H}) \mathrm{H})(\mathrm{H}) \mathrm{H})(\mathrm{H}) \mathrm{H})(\mathrm{H}) \mathrm{F})(\mathrm{H}) \mathrm{H})(\mathrm{H}) \mathrm{H})(\mathrm{Cl})(\mathrm{H}) \mathrm{H}$

$\mathrm{C}(\mathrm{C}(\mathrm{C}(\mathrm{C}(\mathrm{C}(\mathrm{C}(\mathrm{C}(\mathrm{C}(\mathrm{C}(\mathrm{C}(\mathrm{C}(\mathrm{C}(\mathrm{C}(\mathrm{C}(\mathrm{C}(\mathrm{C}(\mathrm{C}(\mathrm{C}(\mathrm{C}(\mathrm{H})(\mathrm{H}) \mathrm{H})(\mathrm{H}) \mathrm{H})(\mathrm{H}) \mathrm{H})(\mathrm{H}) \mathrm{H})(\mathrm{H}) \mathrm{H})(\mathrm{H}) \mathrm{H})(\mathrm{H}) \mathrm{Cl})(\mathrm{Cl}) \mathrm{H})(\mathrm{H})$

$\mathrm{H})(\mathrm{H}) \mathrm{F})(\mathrm{F}) \mathrm{H})(\mathrm{H}) \mathrm{H})(\mathrm{H}) \mathrm{H})(\mathrm{H}) \mathrm{H})(\mathrm{H}) \mathrm{H})(\mathrm{F}) \mathrm{F})(\mathrm{F}) \mathrm{H})(\mathrm{F}) \mathrm{H})(\mathrm{H})(\mathrm{H}) \mathrm{H}$

$\mathrm{C}\left(\mathrm{C}\left(\mathrm{C}\left(\mathrm{C}\left(\mathrm{C}\left(\mathrm{C}\left(\mathrm{C}\left(\mathrm{C}\left(\mathrm{C}\left(\mathrm{C}(\mathrm{C}(\mathrm{C}(\mathrm{C}(\mathrm{C}(\mathrm{C}(\mathrm{C}(\mathrm{C}(\mathrm{C}(\mathrm{C}(\mathrm{F})(\mathrm{H}) \mathrm{H})(\mathrm{H}) \mathrm{H})(\mathrm{H}) \mathrm{H})(\mathrm{H}) \mathrm{H})(\mathrm{H}) \mathrm{F})(\mathrm{H}) \mathrm{H})(\mathrm{H}) \mathrm{H})(\mathrm{H}) \mathrm{Cl})(\mathrm{H}) \mathrm{H}){ }_{\mathrm{C} 19 \mathrm{H} 32 \mathrm{Cl} 3 \mathrm{~F} 5}\right.\right.\right.\right.\right.\right.\right.\right.\right.$

$(\mathrm{F}) \mathrm{H})(\mathrm{H}) \mathrm{H})(\mathrm{H}) \mathrm{F})(\mathrm{H}) \mathrm{H})(\mathrm{Cl}) \mathrm{H})(\mathrm{F}) \mathrm{H})(\mathrm{H}) \mathrm{H})(\mathrm{H}) \mathrm{H})(\mathrm{H}) \mathrm{H})(\mathrm{Cl})(\mathrm{H}) \mathrm{H}$

$\mathrm{C}(\mathrm{C}(\mathrm{C}(\mathrm{C}(\mathrm{C}(\mathrm{C}(\mathrm{C}(\mathrm{C}(\mathrm{C}(\mathrm{C}(\mathrm{C}(\mathrm{C}(\mathrm{C}(\mathrm{C}(\mathrm{C}(\mathrm{C}(\mathrm{C}(\mathrm{C}(\mathrm{C}(\mathrm{H})(\mathrm{F}) \mathrm{H})(\mathrm{H}) \mathrm{H})(\mathrm{H}) \mathrm{H})(\mathrm{Cl}) \mathrm{H})(\mathrm{H}) \mathrm{H})(\mathrm{H}) \mathrm{F})(\mathrm{H}) \mathrm{H})(\mathrm{F}) \mathrm{H})(\mathrm{H}) \mathrm{H})$ $(\mathrm{H}) \mathrm{H})(\mathrm{Br}) \mathrm{H})(\mathrm{H}) \mathrm{H})(\mathrm{H}) \mathrm{H})(\mathrm{H}) \mathrm{H})(\mathrm{H}) \mathrm{F})(\mathrm{H}) \mathrm{F})(\mathrm{H}) \mathrm{H})(\mathrm{F}) \mathrm{H})(\mathrm{H})(\mathrm{H}) \mathrm{H}$

$\mathrm{C}(\mathrm{C}(\mathrm{C}(\mathrm{C}(\mathrm{C}(\mathrm{C}(\mathrm{C}(\mathrm{C}(\mathrm{C}(\mathrm{C}(\mathrm{C}(\mathrm{C}(\mathrm{C}(\mathrm{C}(\mathrm{C}(\mathrm{C}(\mathrm{C}(\mathrm{C}(\mathrm{C}(\mathrm{H})(\mathrm{H}) \mathrm{H})(\mathrm{Br}) \mathrm{H})(\mathrm{H}) \mathrm{H})(\mathrm{H}) \mathrm{H})(\mathrm{H}) \mathrm{H})(\mathrm{H}) \mathrm{H})(\mathrm{H}) \mathrm{H})(\mathrm{H}) \mathrm{H})(\mathrm{H}) \quad \mathrm{C} 19 \mathrm{H} 33 \mathrm{Br} 2 \mathrm{~F} 5$

$\mathrm{H})(\mathrm{H}) \mathrm{H})(\mathrm{H}) \mathrm{H})(\mathrm{F}) \mathrm{H})(\mathrm{H}) \mathrm{H})(\mathrm{H}) \mathrm{F})(\mathrm{F}) \mathrm{H})(\mathrm{F}) \mathrm{H})(\mathrm{H}) \mathrm{H})(\mathrm{H}) \mathrm{H})(\mathrm{H})(\mathrm{Br}) \mathrm{F}$

$\mathrm{C}\left(\mathrm{C}\left(\mathrm{C}\left(\mathrm{C}\left(\mathrm{C}\left(\mathrm{C}\left(\mathrm{C}\left(\mathrm{C}\left(\mathrm{C}\left(\mathrm{C}(\mathrm{C}(\mathrm{C}(\mathrm{C}(\mathrm{C}(\mathrm{C}(\mathrm{C}(\mathrm{C}(\mathrm{C}(\mathrm{C}(\mathrm{H})(\mathrm{H}) \mathrm{H})(\mathrm{H}) \mathrm{F})(\mathrm{F}) \mathrm{H})(\mathrm{H}) \mathrm{H})(\mathrm{H}) \mathrm{F})(\mathrm{H}) \mathrm{H})(\mathrm{H}) \mathrm{F})(\mathrm{Br}) \mathrm{H})(\mathrm{H}) \mathrm{H})\left({ }_{\mathrm{C} 19 \mathrm{H} 33 \mathrm{BrF} 6}\right.\right.\right.\right.\right.\right.\right.\right.\right.\right.$

$\mathrm{H}) \mathrm{H})(\mathrm{H}) \mathrm{H})(\mathrm{H}) \mathrm{H})(\mathrm{H}) \mathrm{H})(\mathrm{H}) \mathrm{H})(\mathrm{H}) \mathrm{H})(\mathrm{H}) \mathrm{H})(\mathrm{H}) \mathrm{F})(\mathrm{H}) \mathrm{H})(\mathrm{H})(\mathrm{F}) \mathrm{H}$

$\mathrm{C}(\mathrm{C}(\mathrm{C}(\mathrm{C}(\mathrm{C}(\mathrm{C}(\mathrm{C}(\mathrm{C}(\mathrm{C}(\mathrm{C}(\mathrm{C}(\mathrm{C}(\mathrm{C}(\mathrm{C}(\mathrm{C}(\mathrm{C}(\mathrm{C}(\mathrm{C}(\mathrm{C}(\mathrm{H})(\mathrm{H}) \mathrm{H})(\mathrm{H}) \mathrm{H})(\mathrm{H}) \mathrm{Cl})(\mathrm{H}) \mathrm{H})(\mathrm{H}) \mathrm{Cl})(\mathrm{H}) \mathrm{F})(\mathrm{Cl}) \mathrm{H})(\mathrm{H}) \mathrm{F}) \quad \mathrm{C} 19 \mathrm{H} 33 \mathrm{Cl} 3 \mathrm{~F} 4$

$(\mathrm{F}) \mathrm{H})(\mathrm{H}) \mathrm{H})(\mathrm{F}) \mathrm{H})(\mathrm{H}) \mathrm{H})(\mathrm{H}) \mathrm{H})(\mathrm{H}) \mathrm{H})(\mathrm{H}) \mathrm{H})(\mathrm{H}) \mathrm{H})(\mathrm{H}) \mathrm{H})(\mathrm{H}) \mathrm{H})(\mathrm{H})(\mathrm{H}) \mathrm{H}$

$\mathrm{C}(\mathrm{C}(\mathrm{C}(\mathrm{C}(\mathrm{C}(\mathrm{C}(\mathrm{C}(\mathrm{C}(\mathrm{C}(\mathrm{C}(\mathrm{C}(\mathrm{C}(\mathrm{C}(\mathrm{C}(\mathrm{C}(\mathrm{C}(\mathrm{C}(\mathrm{C}(\mathrm{C}(\mathrm{H})(\mathrm{H}) \mathrm{H})(\mathrm{H}) \mathrm{H})(\mathrm{H}) \mathrm{H})(\mathrm{H}) \mathrm{H})(\mathrm{H}) \mathrm{H})(\mathrm{Br}) \mathrm{H})(\mathrm{H}) \mathrm{H})(\mathrm{Cl}) \mathrm{H})(\mathrm{H}) \quad \mathrm{C} 19 \mathrm{H} 34 \mathrm{ClBrF} 4$

$\mathrm{F})(\mathrm{H}) \mathrm{H})(\mathrm{H}) \mathrm{H})(\mathrm{H}) \mathrm{H})(\mathrm{H}) \mathrm{F})(\mathrm{H}) \mathrm{H})(\mathrm{H}) \mathrm{H})(\mathrm{F}) \mathrm{H})(\mathrm{H}) \mathrm{H})(\mathrm{H}) \mathrm{H})(\mathrm{H})(\mathrm{F}) \mathrm{H}$

$\mathrm{C}(\mathrm{C}(\mathrm{C}(\mathrm{C}(\mathrm{C}(\mathrm{C}(\mathrm{C}(\mathrm{C}(\mathrm{C}(\mathrm{C}(\mathrm{C}(\mathrm{C}(\mathrm{C}(\mathrm{C}(\mathrm{C}(\mathrm{C}(\mathrm{C}(\mathrm{C}(\mathrm{C}(\mathrm{H})(\mathrm{H}) \mathrm{F})(\mathrm{H}) \mathrm{H})(\mathrm{H}) \mathrm{H})(\mathrm{H}) \mathrm{H})(\mathrm{H}) \mathrm{H})(\mathrm{H}) \mathrm{H})(\mathrm{H}) \mathrm{H})(\mathrm{H}) \mathrm{H})(\mathrm{H}) \mathrm{H})$ $(\mathrm{H}) \mathrm{H})(\mathrm{H}) \mathrm{F})(\mathrm{F}) \mathrm{H})(\mathrm{H}) \mathrm{H})(\mathrm{H}) \mathrm{H})(\mathrm{H}) \mathrm{H})(\mathrm{H}) \mathrm{F})(\mathrm{Cl}) \mathrm{H})(\mathrm{H}) \mathrm{H})(\mathrm{H})(\mathrm{H}) \mathrm{F}$

$\mathrm{C}\left(\mathrm{C}\left(\mathrm{C}\left(\mathrm{C}\left(\mathrm{C}\left(\mathrm{C}\left(\mathrm{C}\left(\mathrm{C}\left(\mathrm{C}\left(\mathrm{C}(\mathrm{C}(\mathrm{C}(\mathrm{C}(\mathrm{C}(\mathrm{C}(\mathrm{C}(\mathrm{C}(\mathrm{C}(\mathrm{C}(\mathrm{F})(\mathrm{H}) \mathrm{H})(\mathrm{H}) \mathrm{H})(\mathrm{H}) \mathrm{H})(\mathrm{H}) \mathrm{H})(\mathrm{H}) \mathrm{H})(\mathrm{H}) \mathrm{H})(\mathrm{H}) \mathrm{Br})(\mathrm{H}) \mathrm{H})(\mathrm{H}) \mathrm{F}){ }_{\mathrm{C} 19 \mathrm{H} 35 \mathrm{BrF}}\right.\right.\right.\right.\right.\right.\right.\right.\right.$ $(\mathrm{H}) \mathrm{H})(\mathrm{H}) \mathrm{H})(\mathrm{H}) \mathrm{F})(\mathrm{H}) \mathrm{H})(\mathrm{H}) \mathrm{F})(\mathrm{H}) \mathrm{H})(\mathrm{H}) \mathrm{H})(\mathrm{H}) \mathrm{H})(\mathrm{H}) \mathrm{H})(\mathrm{H})(\mathrm{H}) \mathrm{H}$

$\mathrm{C}(\mathrm{C}(\mathrm{C}(\mathrm{C}(\mathrm{C}(\mathrm{C}(\mathrm{C}(\mathrm{C}(\mathrm{C}(\mathrm{C}(\mathrm{C}(\mathrm{C}(\mathrm{C}(\mathrm{C}(\mathrm{C}(\mathrm{C}(\mathrm{C}(\mathrm{C}(\mathrm{C}(\mathrm{H})(\mathrm{H}) \mathrm{H})(\mathrm{H}) \mathrm{H})(\mathrm{F}) \mathrm{H})(\mathrm{Cl}) \mathrm{H})(\mathrm{H}) \mathrm{H})(\mathrm{H}) \mathrm{H})(\mathrm{H}) \mathrm{H})(\mathrm{Cl}) \mathrm{H}) \quad \mathrm{C} 19 \mathrm{H} 35 \mathrm{Cl} 2 \mathrm{~F} 3$

$(\mathrm{H}) \mathrm{H})(\mathrm{H}) \mathrm{H})(\mathrm{F}) \mathrm{H})(\mathrm{H}) \mathrm{H})(\mathrm{H}) \mathrm{H})(\mathrm{F}) \mathrm{H})(\mathrm{H}) \mathrm{H})(\mathrm{H}) \mathrm{H})(\mathrm{H}) \mathrm{H})(\mathrm{H}) \mathrm{H})(\mathrm{H})(\mathrm{H}) \mathrm{H}$

$\mathrm{C}\left(\mathrm{C}\left(\mathrm{C}\left(\mathrm{C}\left(\mathrm{C}\left(\mathrm{C}\left(\mathrm{C}\left(\mathrm{C}\left(\mathrm{C}\left(\mathrm{C}(\mathrm{C}(\mathrm{C}(\mathrm{C}(\mathrm{C}(\mathrm{C}(\mathrm{C}(\mathrm{C}(\mathrm{C}(\mathrm{C}(\mathrm{H})(\mathrm{H}) \mathrm{H})(\mathrm{H}) \mathrm{H})(\mathrm{F}) \mathrm{H})(\mathrm{H}) \mathrm{H})(\mathrm{H}) \mathrm{H})(\mathrm{H}) \mathrm{F})(\mathrm{H}) \mathrm{H})(\mathrm{H}) \mathrm{H})(\mathrm{F}) \mathrm{H})\left({ }_{\mathrm{C} 19 \mathrm{H} 35 \mathrm{ClBrF} 3}\right.\right.\right.\right.\right.\right.\right.\right.\right.\right.$
$\mathrm{H}) \mathrm{H})(\mathrm{H}) \mathrm{H})(\mathrm{H}) \mathrm{H})(\mathrm{H}) \mathrm{H})(\mathrm{H}) \mathrm{H})(\mathrm{Br}) \mathrm{H})(\mathrm{H}) \mathrm{H})(\mathrm{H}) \mathrm{H})(\mathrm{H}) \mathrm{H})(\mathrm{H})(\mathrm{H}) \mathrm{Cl}$

$\mathrm{C}(\mathrm{C}(\mathrm{C}(\mathrm{C}(\mathrm{C}(\mathrm{C}(\mathrm{C}(\mathrm{C}(\mathrm{C}(\mathrm{C}(\mathrm{C}(\mathrm{C}(\mathrm{C}(\mathrm{C}(\mathrm{C}(\mathrm{C}(\mathrm{C}(\mathrm{C}(\mathrm{C}(\mathrm{H})(\mathrm{H}) \mathrm{H})(\mathrm{H}) \mathrm{H})(\mathrm{H}) \mathrm{H})(\mathrm{H}) \mathrm{F})(\mathrm{H}) \mathrm{H})(\mathrm{H}) \mathrm{H})(\mathrm{H}) \mathrm{Cl})(\mathrm{H}) \mathrm{H}) \quad \mathrm{C} 19 \mathrm{H} 35 \mathrm{ClF} 4$

$(\mathrm{H}) \mathrm{H})(\mathrm{H}) \mathrm{H})(\mathrm{H}) \mathrm{H})(\mathrm{H}) \mathrm{H})(\mathrm{H}) \mathrm{H})(\mathrm{H}) \mathrm{H})(\mathrm{H}) \mathrm{F})(\mathrm{H}) \mathrm{F})(\mathrm{H}) \mathrm{H})(\mathrm{H}) \mathrm{H})(\mathrm{H})(\mathrm{H}) \mathrm{F}$

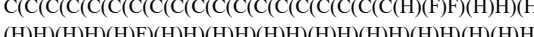

$\mathrm{C}(\mathrm{C}(\mathrm{C}(\mathrm{C}(\mathrm{C}(\mathrm{C}(\mathrm{C}(\mathrm{C}(\mathrm{C}(\mathrm{C}(\mathrm{C}(\mathrm{C}(\mathrm{C}(\mathrm{C}(\mathrm{C}(\mathrm{C}(\mathrm{C}(\mathrm{C}(\mathrm{C}(\mathrm{H})(\mathrm{H}) \mathrm{H})(\mathrm{H}) \mathrm{H})(\mathrm{H}) \mathrm{H})(\mathrm{Cl}) \mathrm{H})(\mathrm{H}) \mathrm{F})(\mathrm{H}) \mathrm{Cl})(\mathrm{H}) \mathrm{H})(\mathrm{H}) \mathrm{H})$

$(\mathrm{H}) \mathrm{H})(\mathrm{H}) \mathrm{H})(\mathrm{H}) \mathrm{H})(\mathrm{H}) \mathrm{H})(\mathrm{H}) \mathrm{H})(\mathrm{H}) \mathrm{H})(\mathrm{H}) \mathrm{H})(\mathrm{H}) \mathrm{H})(\mathrm{H}) \mathrm{H})(\mathrm{H}) \mathrm{H})(\mathrm{H})(\mathrm{F}) \mathrm{H}$

$\mathrm{C}(\mathrm{C}(\mathrm{C}(\mathrm{C}(\mathrm{C}(\mathrm{C}(\mathrm{C}(\mathrm{C}(\mathrm{C}(\mathrm{C}(\mathrm{C}(\mathrm{C}(\mathrm{C}(\mathrm{C}(\mathrm{C}(\mathrm{C}(\mathrm{C}(\mathrm{C}(\mathrm{C}(\mathrm{H})(\mathrm{H}) \mathrm{H})(\mathrm{Cl}) \mathrm{H})(\mathrm{F}) \mathrm{H})(\mathrm{F}) \mathrm{H})(\mathrm{H}) \mathrm{H})(\mathrm{H}) \mathrm{H})(\mathrm{H}) \mathrm{H})(\mathrm{H}) \mathrm{H})(\mathrm{H}) \mathrm{H})$

$(\mathrm{H}) \mathrm{H})(\mathrm{H}) \mathrm{H})(\mathrm{H}) \mathrm{H})(\mathrm{H}) \mathrm{H})(\mathrm{H}) \mathrm{H})(\mathrm{H}) \mathrm{H})(\mathrm{H}) \mathrm{H})(\mathrm{H}) \mathrm{H})(\mathrm{H}) \mathrm{H})(\mathrm{H})(\mathrm{H}) \mathrm{F}$

$\mathrm{C}(\mathrm{C}(\mathrm{C}(\mathrm{C}(\mathrm{C}(\mathrm{C}(\mathrm{C}(\mathrm{C}(\mathrm{C}(\mathrm{C}(\mathrm{C}(\mathrm{C}(\mathrm{C}(\mathrm{C}(\mathrm{C}(\mathrm{C}(\mathrm{C}(\mathrm{C}(\mathrm{C}(\mathrm{H})(\mathrm{H}) \mathrm{H})(\mathrm{H}) \mathrm{H})(\mathrm{H}) \mathrm{H})(\mathrm{H}) \mathrm{F})(\mathrm{H}) \mathrm{F})(\mathrm{H}) \mathrm{H})(\mathrm{H}) \mathrm{F})(\mathrm{H}) \mathrm{H})(\mathrm{H}) \mathrm{H})($

$\mathrm{H}) \mathrm{H})(\mathrm{H}) \mathrm{H})(\mathrm{H}) \mathrm{H})(\mathrm{H}) \mathrm{H})(\mathrm{H}) \mathrm{H})(\mathrm{H}) \mathrm{H})(\mathrm{H}) \mathrm{H})(\mathrm{H}) \mathrm{F})(\mathrm{H}) \mathrm{H})(\mathrm{H})(\mathrm{H}) \mathrm{H}$

$\mathrm{C}(\mathrm{C}(\mathrm{C}(\mathrm{C}(\mathrm{C}(\mathrm{C}(\mathrm{C}(\mathrm{C}(\mathrm{C}(\mathrm{C}(\mathrm{C}(\mathrm{C}(\mathrm{C}(\mathrm{C}(\mathrm{C}(\mathrm{C}(\mathrm{C}(\mathrm{C}(\mathrm{C}(\mathrm{H})(\mathrm{H}) \mathrm{H})(\mathrm{H}) \mathrm{H})(\mathrm{H}) \mathrm{H})(\mathrm{Br}) \mathrm{H})(\mathrm{H}) \mathrm{H})(\mathrm{H}) \mathrm{H})(\mathrm{H}) \mathrm{H})(\mathrm{H}) \mathrm{F}) \quad \mathrm{C} 19 \mathrm{H} 37 \mathrm{BrF} 2$

$(\mathrm{H}) \mathrm{H})(\mathrm{H}) \mathrm{H})(\mathrm{H}) \mathrm{H})(\mathrm{H}) \mathrm{H})(\mathrm{H}) \mathrm{H})(\mathrm{H}) \mathrm{H})(\mathrm{H}) \mathrm{H})(\mathrm{F}) \mathrm{H})(\mathrm{H}) \mathrm{H})(\mathrm{H}) \mathrm{H})(\mathrm{H})(\mathrm{H}) \mathrm{H}$

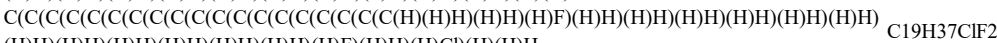

$(\mathrm{H}) \mathrm{H})(\mathrm{H}) \mathrm{H})(\mathrm{H}) \mathrm{H})(\mathrm{H}) \mathrm{H})(\mathrm{H}) \mathrm{H})(\mathrm{H}) \mathrm{H})(\mathrm{H}) \mathrm{F})(\mathrm{H}) \mathrm{H})(\mathrm{H}) \mathrm{Cl})(\mathrm{H})(\mathrm{H}) \mathrm{H}$

$\mathrm{C}\left(\mathrm{C}\left(\mathrm{C}\left(\mathrm{C}\left(\mathrm{C}\left(\mathrm{C}\left(\mathrm{C}\left(\mathrm{C}\left(\mathrm{C}\left(\mathrm{C}(\mathrm{C}(\mathrm{C}(\mathrm{C}(\mathrm{C}(\mathrm{C}(\mathrm{C}(\mathrm{C}(\mathrm{C}(\mathrm{C}(\mathrm{H})(\mathrm{H}) \mathrm{H})(\mathrm{H}) \mathrm{H})(\mathrm{H}) \mathrm{H})(\mathrm{H}) \mathrm{H})(\mathrm{H}) \mathrm{H})(\mathrm{H}) \mathrm{H})(\mathrm{H}) \mathrm{H})(\mathrm{H}) \mathrm{H})(\mathrm{F}) \mathrm{H}){ }_{\mathrm{Cl} 19 \mathrm{H} 37 \mathrm{~F} 3}\right.\right.\right.\right.\right.\right.\right.\right.\right.$

$(\mathrm{H}) \mathrm{H})(\mathrm{H}) \mathrm{H})(\mathrm{F}) \mathrm{H})(\mathrm{H}) \mathrm{H})(\mathrm{H}) \mathrm{H})(\mathrm{H}) \mathrm{H})(\mathrm{H}) \mathrm{H})(\mathrm{H}) \mathrm{H})(\mathrm{H}) \mathrm{H})(\mathrm{H})(\mathrm{F}) \mathrm{H}$

$\mathrm{C}(\mathrm{C}(\mathrm{C}(\mathrm{C}(\mathrm{C}(\mathrm{C}(\mathrm{C}(\mathrm{C}(\mathrm{C}(\mathrm{C}(\mathrm{C}(\mathrm{C}(\mathrm{C}(\mathrm{C}(\mathrm{C}(\mathrm{C}(\mathrm{C}(\mathrm{C}(\mathrm{C}(\mathrm{H})(\mathrm{H}) \mathrm{H})(\mathrm{H}) \mathrm{H})(\mathrm{H}) \mathrm{H})(\mathrm{Cl}) \mathrm{H})(\mathrm{H}) \mathrm{H})(\mathrm{H}) \mathrm{H})(\mathrm{H}) \mathrm{H})(\mathrm{H}) \mathrm{H})$

$(\mathrm{H}) \mathrm{F})(\mathrm{H}) \mathrm{H})(\mathrm{H}) \mathrm{H})(\mathrm{H}) \mathrm{H})(\mathrm{H}) \mathrm{H})(\mathrm{H}) \mathrm{H})(\mathrm{H}) \mathrm{H})(\mathrm{H}) \mathrm{H})(\mathrm{H}) \mathrm{H})(\mathrm{H}) \mathrm{H})(\mathrm{H})(\mathrm{H}) \mathrm{H}$

$\mathrm{C}(\mathrm{C}(\mathrm{C}(\mathrm{C}(\mathrm{C}(\mathrm{C}(\mathrm{C}(\mathrm{C}(\mathrm{C}(\mathrm{C}(\mathrm{C}(\mathrm{C}(\mathrm{C}(\mathrm{C}(\mathrm{C}(\mathrm{C}(\mathrm{C}(\mathrm{C}(\mathrm{C}(\mathrm{H})(\mathrm{H}) \mathrm{H})(\mathrm{H}) \mathrm{F})(\mathrm{H}) \mathrm{H})(\mathrm{H}) \mathrm{H})(\mathrm{H}) \mathrm{H})(\mathrm{H}) \mathrm{H})(\mathrm{H}) \mathrm{H})(\mathrm{H}) \mathrm{F})(\mathrm{H}) \mathrm{H})$ $(\mathrm{H}) \mathrm{H})(\mathrm{H}) \mathrm{H})(\mathrm{H}) \mathrm{H})(\mathrm{H}) \mathrm{H})(\mathrm{H}) \mathrm{H})(\mathrm{H}) \mathrm{H})(\mathrm{H}) \mathrm{H})(\mathrm{H}) \mathrm{H})(\mathrm{H}) \mathrm{H})(\mathrm{H})(\mathrm{H}) \mathrm{H}$

$\mathrm{C}\left(\mathrm{C}\left(\mathrm{C}\left(\mathrm{C}\left(\mathrm{C}\left(\mathrm{C}\left(\mathrm{C}\left(\mathrm{C}\left(\mathrm{C}\left(\mathrm{C}(\mathrm{C}(\mathrm{C}(\mathrm{C}(\mathrm{C}(\mathrm{C}(\mathrm{C}(\mathrm{C}(\mathrm{C}(\mathrm{C}(\mathrm{H})(\mathrm{H}) \mathrm{H})(\mathrm{H}) \mathrm{H})(\mathrm{H}) \mathrm{H})(\mathrm{F}) \mathrm{H})(\mathrm{H}) \mathrm{H})(\mathrm{H}) \mathrm{H})(\mathrm{H}) \mathrm{H})(\mathrm{H}) \mathrm{H})(\mathrm{H}) \mathrm{H}){ }_{\mathrm{Cl}}{ }^{2} \mathrm{H}_{39 \mathrm{~F}}\right.\right.\right.\right.\right.\right.\right.\right.\right.$ $(\mathrm{H}) \mathrm{H})(\mathrm{H}) \mathrm{H})(\mathrm{H}) \mathrm{H})(\mathrm{H}) \mathrm{H})(\mathrm{H}) \mathrm{H})(\mathrm{H}) \mathrm{H})(\mathrm{H}) \mathrm{H})(\mathrm{H}) \mathrm{H})(\mathrm{H}) \mathrm{H})(\mathrm{H})(\mathrm{H}) \mathrm{H}$

$\mathrm{C}(\mathrm{C}(\mathrm{C}(\mathrm{C}(\mathrm{C}(\mathrm{C}(\mathrm{C}(\mathrm{C}(\mathrm{C}(\mathrm{C}(\mathrm{C}(\mathrm{C}(\mathrm{C}(\mathrm{C}(\mathrm{C}(\mathrm{C}(\mathrm{C}(\mathrm{C}(\mathrm{C}(\mathrm{C}(\mathrm{Cl})(\mathrm{H}) \mathrm{F})(\mathrm{H}) \mathrm{F})(\mathrm{H}) \mathrm{H})(\mathrm{H}) \mathrm{F})(\mathrm{H}) \mathrm{H})(\mathrm{H}) \mathrm{H})(\mathrm{F}) \mathrm{H})(\mathrm{H}) \mathrm{H})(\mathrm{H})$ $\mathrm{H})(\mathrm{H}) \mathrm{H})(\mathrm{Br}) \mathrm{H})(\mathrm{H}) \mathrm{F})(\mathrm{H}) \mathrm{H})(\mathrm{F}) \mathrm{H})(\mathrm{H}) \mathrm{H})(\mathrm{F}) \mathrm{H})(\mathrm{F}) \mathrm{H})(\mathrm{H}) \mathrm{Cl})(\mathrm{F}) \mathrm{H})(\mathrm{H})(\mathrm{F}) \mathrm{H}$

$\mathrm{C}(\mathrm{C}(\mathrm{C}(\mathrm{C}(\mathrm{C}(\mathrm{C}(\mathrm{C}(\mathrm{C}(\mathrm{C}(\mathrm{C}(\mathrm{C}(\mathrm{C}(\mathrm{C}(\mathrm{C}(\mathrm{C}(\mathrm{C}(\mathrm{C}(\mathrm{C}(\mathrm{C}(\mathrm{C}(\mathrm{H})(\mathrm{F}) \mathrm{H})(\mathrm{H}) \mathrm{F})(\mathrm{H}) \mathrm{F})(\mathrm{F}) \mathrm{H})(\mathrm{H}) \mathrm{H})(\mathrm{H}) \mathrm{F})(\mathrm{Br}) \mathrm{H})(\mathrm{H}) \mathrm{H})$

$(\mathrm{F}) \mathrm{H})(\mathrm{H}) \mathrm{H})(\mathrm{H}) \mathrm{H})(\mathrm{H}) \mathrm{H})(\mathrm{H}) \mathrm{H})(\mathrm{F}) \mathrm{H})(\mathrm{F}) \mathrm{H})(\mathrm{F}) \mathrm{H})(\mathrm{H}) \mathrm{F})(\mathrm{Br}) \mathrm{H})(\mathrm{H}) \mathrm{H})(\mathrm{H})(\mathrm{H}) \mathrm{Cl}$

$\mathrm{C}(\mathrm{C}(\mathrm{C}(\mathrm{C}(\mathrm{C}(\mathrm{C}(\mathrm{C}(\mathrm{C}(\mathrm{C}(\mathrm{C}(\mathrm{C}(\mathrm{C}(\mathrm{C}(\mathrm{C}(\mathrm{C}(\mathrm{C}(\mathrm{C}(\mathrm{C}(\mathrm{C}(\mathrm{C}(\mathrm{F})(\mathrm{F}) \mathrm{H})(\mathrm{H}) \mathrm{H})(\mathrm{F}) \mathrm{H})(\mathrm{H}) \mathrm{H})(\mathrm{H}) \mathrm{H})(\mathrm{H}) \mathrm{H})(\mathrm{H}) \mathrm{H})(\mathrm{H}) \mathrm{H})(\mathrm{F})$ $\mathrm{H})(\mathrm{Br}) \mathrm{H})(\mathrm{F}) \mathrm{H})(\mathrm{F}) \mathrm{H})(\mathrm{H}) \mathrm{Cl}(\mathrm{H}) \mathrm{F})(\mathrm{H}) \mathrm{H})(\mathrm{H}) \mathrm{H})(\mathrm{H}) \mathrm{F})(\mathrm{Br}) \mathrm{H})(\mathrm{H}) \mathrm{H})(\mathrm{H})(\mathrm{H}) \mathrm{F}$
lgKoa lgKow lgKaw lgKow lgKoa lgKa lgKow lgKoa lgKaw

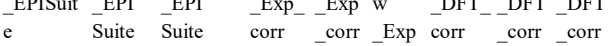
$\begin{array}{lllllllll}6.382 & 9.92 & 3.54 & 9.88 & 6.34 & 3.54 & 8.38 & 9.74 & -1.35\end{array}$

$\begin{array}{lllllllll}6.785 & 9.57 & 2.78 & 9.36 & 6.57 & 2.78 & 8.11 & 10.48 & -2.36\end{array}$

$\begin{array}{lllllllll}7.201 & 9.72 & 2.52 & 9.58 & 7.06 & 2.52 & 8.23 & 11.24 & -3.01\end{array}$

$\begin{array}{lllllllll}5.654 & 9.16 & 3.51 & 8.75 & 5.24 & 3.51 & 7.80 & 8.40 & -0.60\end{array}$

$\begin{array}{lllllllll}6.637 & 9.61 & 2.97 & 9.42 & 6.44 & 2.97 & 8.14 & 10.20 & -2.06\end{array}$

$\begin{array}{lllllllll}5.008 & 9 & 3.99 & 8.51 & 4.52 & 3.99 & 7.67 & 7.21 & 0.46\end{array}$

$\begin{array}{lllllllll}6.753 & 9.96 & 3.21 & 9.94 & 6.73 & 3.21 & 8.41 & 10.42 & -2.01\end{array}$

$\begin{array}{lllllllll}7.572 & 9.76 & 2.19 & 9.64 & 7.45 & 2.19 & 8.26 & 11.92 & -3.66\end{array}$

$\begin{array}{lllllllll}6.452 & 9.36 & 2.91 & 9.04 & 6.14 & 2.91 & 7.95 & 9.86 & -1.91\end{array}$

$\begin{array}{lllllllll}5.544 & 9.69 & 4.15 & 9.54 & 5.39 & 4.15 & 8.20 & 8.20 & 0.01\end{array}$

$\begin{array}{lllllllll}6.041 & 9.92 & 3.88 & 9.88 & 6.00 & 3.88 & 8.38 & 9.11 & -0.73\end{array}$

$\begin{array}{lllllllll}6.364 & 9.49 & 3.13 & 9.24 & 6.11 & 3.13 & 8.05 & 9.70 & -1.65\end{array}$

$\begin{array}{lllllllll}7.505 & 9.88 & 2.37 & 9.82 & 7.45 & 2.37 & 8.35 & 11.80 & -3.45\end{array}$

$\begin{array}{lllllllll}5.877 & 9.27 & 3.39 & 8.91 & 5.52 & 3.39 & 7.88 & 8.81 & -0.93\end{array}$

$\begin{array}{lllllllll}6.951 & 9.56 & 2.61 & 9.34 & 6.73 & 2.61 & 8.10 & 10.78 & -2.68\end{array}$

$\begin{array}{lllllllll}5.983 & 9.83 & 3.85 & 9.75 & 5.90 & 3.85 & 8.31 & 9.00 & -0.69\end{array}$

$\begin{array}{lllllllll}7.447 & 9.79 & 2.34 & 9.69 & 7.34 & 2.34 & 8.28 & 11.69 & -3.41\end{array}$

$\begin{array}{lllllllll}6.4 & 9.98 & 3.58 & 9.97 & 6.39 & 3.58 & 8.43 & 9.77 & -1.34\end{array}$

$\begin{array}{lllllllll}6.871 & 9.7 & 2.83 & 9.55 & 6.72 & 2.83 & 8.21 & 10.63 & -2.42\end{array}$

$\begin{array}{lllllllll}6.306 & 9.4 & 3.09 & 9.10 & 6.01 & 3.09 & 7.98 & 9.60 & -1.61\end{array}$

$\begin{array}{lllllllll}7.309 & 9.62 & 2.31 & 9.43 & 7.12 & 2.31 & 8.15 & 11.44 & -3.29\end{array}$

$\begin{array}{lllllllll}5.672 & 9.22 & 3.55 & 8.84 & 5.29 & 3.55 & 7.84 & 8.43 & -0.59\end{array}$

$\begin{array}{lllllllll}7.151 & 9.68 & 2.53 & 9.52 & 6.99 & 2.53 & 8.20 & 11.15 & -2.95\end{array}$

$7.173 \quad 9.67$

$\begin{array}{lllllll}2.50 & 9.51 & 7.01 & 2.50 & 8.19 & 11.19 & -3.00\end{array}$

$5.605 \quad 9.34$

$\begin{array}{lllllll}3.74 & 9.01 & 5.28 & 3.74 & 7.94 & 8.31 & -0.37\end{array}$

$6.53 \quad 9.48$

$\begin{array}{lllllll}2.95 & 9.22 & 6.27 & 2.95 & 8.04 & 10.01 & -1.96\end{array}$

$6.947 \quad 9.63$

$\begin{array}{ll}7.602 & 9.8\end{array}$

$\begin{array}{lllllll}2.68 & 9.45 & 6.76 & 2.68 & 8.16 & 10.77 & -2.61\end{array}$

$5.964 \quad 9.4$

$\begin{array}{lllllll}2.20 & 9.70 & 7.50 & 2.20 & 8.29 & 11.98 & -3.69\end{array}$

$6.967 \quad 9.62$

$\begin{array}{lllllll}3.44 & 9.10 & 5.67 & 3.44 & 7.98 & 8.97 & -0.99\end{array}$

$7.455 \quad 9.84$

$\begin{array}{lllllll}2.65 & 9.43 & 6.78 & 2.65 & 8.15 & 10.81 & -2.66\end{array}$

$6.393 \quad 9.53$

$\begin{array}{lllllll}2.38 & 9.76 & 7.38 & 2.38 & 8.32 & 11.71 & -3.39\end{array}$

$5.252 \quad 9.14$

$\begin{array}{lllllll}3.14 & 9.30 & 6.16 & 3.14 & 8.08 & 9.76 & -1.67\end{array}$

\begin{tabular}{ll}
$7.327 \quad 9.68$ \\
\hline
\end{tabular}

$\begin{array}{lllllll}3.89 & 8.72 & 4.83 & 3.89 & 7.78 & 7.66 & 0.12\end{array}$

$6.753 \quad 9.59$

$\begin{array}{lllllll}2.35 & 9.52 & 7.17 & 2.35 & 8.20 & 11.47 & -3.27\end{array}$

$5.76 \quad 9.35$

$7.181 \quad 9.72$

$\begin{array}{lllllll}3.59 & 9.03 & 5.44 & 3.59 & 7.94 & 8.59 & -0.65\end{array}$

$6.119 \quad 9.41$

$\begin{array}{lllllll}2.54 & 9.58 & 7.04 & 2.54 & 8.23 & 11.20 & -2.98\end{array}$

$7.497 \quad 9.54$

$\begin{array}{lllllll}3.29 & 9.12 & 5.83 & 3.29 & 7.99 & 9.25 & -1.26\end{array}$

$\begin{array}{lllllll}2.04 & 9.31 & 7.27 & 2.04 & 8.09 & 11.78 & -3.69\end{array}$

\begin{tabular}{ll}
$5.65 \quad 9.61$ \\
\hline
\end{tabular}

$\begin{array}{lllllll}3.96 & 9.42 & 5.46 & 3.96 & 8.14 & 8.39 & -0.25\end{array}$

$\begin{array}{lllllllll}6.226 & 9.7 & 3.47 & 9.55 & 6.08 & 3.47 & 8.21 & 9.45 & -1.24\end{array}$

$\begin{array}{lllllllll}6.664 & 9.84 & 3.18 & 9.76 & 6.59 & 3.18 & 8.32 & 10.25 & -1.93\end{array}$ 
lgKoa lgKow lgKaw lgKow lgKoa lgKa lgKow lgKoa lgKaw

$\mathrm{C}(\mathrm{C}(\mathrm{C}(\mathrm{C}(\mathrm{C}(\mathrm{C}(\mathrm{C}(\mathrm{C}(\mathrm{C}(\mathrm{C}(\mathrm{C}(\mathrm{C}(\mathrm{C}(\mathrm{C}(\mathrm{C}(\mathrm{C}(\mathrm{C}(\mathrm{C}(\mathrm{C}(\mathrm{C}(\mathrm{H})(\mathrm{H}) \mathrm{H})(\mathrm{H}) \mathrm{H})(\mathrm{H}) \mathrm{H})(\mathrm{F}) \mathrm{H})(\mathrm{H}) \mathrm{F})(\mathrm{F}) \mathrm{H})(\mathrm{H}) \mathrm{H})(\mathrm{F}) \mathrm{H})(\mathrm{H})$ $\mathrm{H})(\mathrm{H}) \mathrm{H})(\mathrm{F}) \mathrm{H})(\mathrm{F}) \mathrm{H})(\mathrm{H}) \mathrm{Cl}(\mathrm{H}) \mathrm{H})(\mathrm{Cl}) \mathrm{H})(\mathrm{H}) \mathrm{F})(\mathrm{Cl}) \mathrm{H})(\mathrm{H}) \mathrm{F})(\mathrm{H}) \mathrm{H})(\mathrm{H})(\mathrm{H}) \mathrm{H}$

$\mathrm{C} 20 \mathrm{H} 31 \mathrm{Cl} 3 \mathrm{~F} 8$

EPISuit_EPI_EPI

EPI Exp Exp w DFT DFT DFT

$\mathrm{C}(\mathrm{C}(\mathrm{C}(\mathrm{C}(\mathrm{C}(\mathrm{C}(\mathrm{C}(\mathrm{C}(\mathrm{C}(\mathrm{C}(\mathrm{C}(\mathrm{C}(\mathrm{C}(\mathrm{C}(\mathrm{C}(\mathrm{C}(\mathrm{C}(\mathrm{C}(\mathrm{C}(\mathrm{C}(\mathrm{H})(\mathrm{H}) \mathrm{H})(\mathrm{F}) \mathrm{H})(\mathrm{H}) \mathrm{H})(\mathrm{H}) \mathrm{H})(\mathrm{H}) \mathrm{H})(\mathrm{H}) \mathrm{H})(\mathrm{F}) \mathrm{H})(\mathrm{H}) \mathrm{H})(\mathrm{F})$ $\mathrm{H})(\mathrm{H}) \mathrm{H})(\mathrm{H}) \mathrm{H})(\mathrm{Cl}) \mathrm{H})(\mathrm{H}) \mathrm{H})(\mathrm{H}) \mathrm{F})(\mathrm{H}) \mathrm{Br})(\mathrm{H}) \mathrm{F})(\mathrm{H}) \mathrm{Br})(\mathrm{H}) \mathrm{F})(\mathrm{H}) \mathrm{H})(\mathrm{F})(\mathrm{H}) \mathrm{H}$

$\mathrm{C}\left(\mathrm{C}\left(\mathrm{C}\left(\mathrm{C}\left(\mathrm{C}\left(\mathrm{C}\left(\mathrm{C}\left(\mathrm{C}\left(\mathrm{C}\left(\mathrm{C}\left(\mathrm{C}\left(\mathrm{C}(\mathrm{C}(\mathrm{C}(\mathrm{C}(\mathrm{C}(\mathrm{C}(\mathrm{C}(\mathrm{C}(\mathrm{C}(\mathrm{Cl})(\mathrm{H}) \mathrm{H})(\mathrm{H}) \mathrm{H})(\mathrm{F}) \mathrm{H})(\mathrm{H}) \mathrm{H})(\mathrm{H}) \mathrm{H})(\mathrm{H}) \mathrm{F})(\mathrm{F}) \mathrm{H})(\mathrm{H}) \mathrm{H})(\mathrm{Br}){ }_{\mathrm{C} 20 \mathrm{H} 32 \mathrm{ClBrF} 8}\right.\right.\right.\right.\right.\right.\right.\right.\right.\right.\right.$ $\mathrm{H})(\mathrm{F}) \mathrm{H})(\mathrm{H}) \mathrm{H})(\mathrm{H}) \mathrm{F})(\mathrm{H}) \mathrm{H})(\mathrm{F}) \mathrm{H})(\mathrm{H}) \mathrm{H})(\mathrm{H}) \mathrm{H})(\mathrm{H}) \mathrm{H})(\mathrm{F}) \mathrm{H})(\mathrm{H}) \mathrm{F})(\mathrm{H})(\mathrm{H}) \mathrm{H}$

$\mathrm{C} 2 \mathrm{H} 32 \mathrm{ClBr} 2 \mathrm{~F} 7$

$\begin{array}{lllllllll}5.793 & 9.64 & 3.85 & 9.46 & 5.62 & 3.85 & 8.17 & 8.65 & -0.49\end{array}$

corr_corr_Exp corr_corr_corr

$\begin{array}{ll}7.452 & 10.03\end{array}$

$\begin{array}{lllllll}2.58 & 10.04 & 7.47 & 2.58 & 8.47 & 11.70 & -3.24\end{array}$

$5.814 \quad 9.63$

$\begin{array}{lllllll}3.82 & 9.45 & 5.63 & 3.82 & 8.16 & 8.69 & -0.53\end{array}$

刑

$(\mathrm{H}) \mathrm{H})(\mathrm{Br}) \mathrm{H})(\mathrm{H}) \mathrm{F})(\mathrm{Cl}) \mathrm{H})(\mathrm{H}) \mathrm{H})(\mathrm{H}) \mathrm{F})(\mathrm{H}) \mathrm{H})(\mathrm{H}) \mathrm{F})(\mathrm{H}) \mathrm{F})(\mathrm{H}) \mathrm{H})(\mathrm{H}) \mathrm{H})(\mathrm{F})(\mathrm{H}) \mathrm{H}$

$\mathrm{C} 20 \mathrm{H} 33 \mathrm{Cl} 2 \mathrm{BrF} 6$

$7.306 \quad 10.07$
-10

$\begin{array}{lllllll}2.76 & 10.10 & 7.34 & 2.76 & 8.50 & 11.43 & -2.94\end{array}$

$\mathrm{C}(\mathrm{C}(\mathrm{C}(\mathrm{C}(\mathrm{C}(\mathrm{C}(\mathrm{C}(\mathrm{C}(\mathrm{C}(\mathrm{C}(\mathrm{C}(\mathrm{C}(\mathrm{C}(\mathrm{C}(\mathrm{C}(\mathrm{C}(\mathrm{C}(\mathrm{C}(\mathrm{C}(\mathrm{C}(\mathrm{F})(\mathrm{H}) \mathrm{H})(\mathrm{H}) \mathrm{F})(\mathrm{H}) \mathrm{H})(\mathrm{H}) \mathrm{H})(\mathrm{Cl}) \mathrm{H})(\mathrm{H}) \mathrm{H})(\mathrm{H}) \mathrm{H})(\mathrm{H}) \mathrm{F})(\mathrm{H}) \quad \mathrm{C} 20 \mathrm{H} 33 \mathrm{Cl} 2 \mathrm{~F} 7$

F)(H)H $(\mathrm{H}) \mathrm{F})(\mathrm{H}) \mathrm{H})(\mathrm{H}) \mathrm{H})(\mathrm{H}) \mathrm{H})(\mathrm{F}) \mathrm{H})(\mathrm{H}) \mathrm{H})(\mathrm{F}) \mathrm{H})(\mathrm{H}) \mathrm{H})(\mathrm{H}) \mathrm{Cl})(\mathrm{H})(\mathrm{H}) \mathrm{H}$

C $(\mathrm{C}(\mathrm{C}(\mathrm{C}(\mathrm{C}(\mathrm{C}(\mathrm{C}(\mathrm{C}(\mathrm{C}(\mathrm{C}(\mathrm{C}(\mathrm{C}(\mathrm{C}(\mathrm{C}(\mathrm{C}(\mathrm{C}(\mathrm{C}(\mathrm{C}(\mathrm{C}(\mathrm{C}(\mathrm{Cl})(\mathrm{H}) \mathrm{H})(\mathrm{F}) \mathrm{H})(\mathrm{H}) \mathrm{H})(\mathrm{H}) \mathrm{H})(\mathrm{F}) \mathrm{H})(\mathrm{H}) \mathrm{H})(\mathrm{H}) \mathrm{H})(\mathrm{Cl}) \mathrm{H})$

$(\mathrm{H}) \mathrm{H})(\mathrm{H}) \mathrm{H})(\mathrm{H}) \mathrm{F})(\mathrm{H}) \mathrm{H})(\mathrm{H}) \mathrm{H})(\mathrm{H}) \mathrm{H})(\mathrm{H}) \mathrm{F})(\mathrm{H}) \mathrm{H})(\mathrm{H}) \mathrm{F})(\mathrm{F}) \mathrm{H})(\mathrm{H}) \mathrm{H})(\mathrm{H})(\mathrm{Cl}) \mathrm{H}$

$\mathrm{C} 20 \mathrm{H} 33 \mathrm{Cl} 3 \mathrm{~F} 6$

$\mathrm{C}(\mathrm{C}(\mathrm{C}(\mathrm{C}(\mathrm{C}(\mathrm{C}(\mathrm{C}(\mathrm{C}(\mathrm{C}(\mathrm{C}(\mathrm{C}(\mathrm{C}(\mathrm{C}(\mathrm{C}(\mathrm{C}(\mathrm{C}(\mathrm{C}(\mathrm{C}(\mathrm{C}(\mathrm{C}(\mathrm{H})(\mathrm{H}) \mathrm{H})(\mathrm{F}) \mathrm{H})(\mathrm{H}) \mathrm{H})(\mathrm{H}) \mathrm{H})(\mathrm{H}) \mathrm{F})(\mathrm{F}) \mathrm{H})(\mathrm{H}) \mathrm{Cl})(\mathrm{H}) \mathrm{H})(\mathrm{H})$ $\mathrm{F})(\mathrm{H}) \mathrm{H})(\mathrm{F}) \mathrm{H})(\mathrm{H}) \mathrm{F})(\mathrm{H}) \mathrm{H})(\mathrm{Br}) \mathrm{H})(\mathrm{H}) \mathrm{H})(\mathrm{H}) \mathrm{H})(\mathrm{H}) \mathrm{H})(\mathrm{H}) \mathrm{H})(\mathrm{H}) \mathrm{F})(\mathrm{H})(\mathrm{H}) \mathrm{H}$

$\mathrm{C} 20 \mathrm{H} 33 \mathrm{ClBrF} 7$

$\mathrm{C}(\mathrm{C}(\mathrm{C}(\mathrm{C}(\mathrm{C}(\mathrm{C}(\mathrm{C}(\mathrm{C}(\mathrm{C}(\mathrm{C}(\mathrm{C}(\mathrm{C}(\mathrm{C}(\mathrm{C}(\mathrm{C}(\mathrm{C}(\mathrm{C}(\mathrm{C}(\mathrm{C}(\mathrm{C}(\mathrm{F})(\mathrm{H}) \mathrm{H})(\mathrm{H}) \mathrm{H})(\mathrm{H}) \mathrm{F})(\mathrm{H}) \mathrm{H})(\mathrm{H}) \mathrm{H})(\mathrm{H}) \mathrm{F})(\mathrm{H}) \mathrm{H})(\mathrm{H}) \mathrm{H})(\mathrm{H})$

$\mathrm{H})(\mathrm{F}) \mathrm{H})(\mathrm{F}) \mathrm{H})(\mathrm{H}) \mathrm{H})(\mathrm{H}) \mathrm{F})(\mathrm{H}) \mathrm{H})(\mathrm{H}) \mathrm{H})(\mathrm{H}) \mathrm{Br})(\mathrm{H}) \mathrm{H})(\mathrm{H}) \mathrm{H})(\mathrm{H}) \mathrm{F})(\mathrm{H})(\mathrm{H}) \mathrm{H}$

$\mathrm{C} 20 \mathrm{H} 34 \mathrm{BrF} 7$

$\mathrm{C}(\mathrm{C}(\mathrm{C}(\mathrm{C}(\mathrm{C}(\mathrm{C}(\mathrm{C}(\mathrm{C}(\mathrm{C}(\mathrm{C}(\mathrm{C}(\mathrm{C}(\mathrm{C}(\mathrm{C}(\mathrm{C}(\mathrm{C}(\mathrm{C}(\mathrm{C}(\mathrm{C}(\mathrm{C}(\mathrm{H})(\mathrm{H}) \mathrm{F})(\mathrm{H}) \mathrm{H})(\mathrm{F}) \mathrm{H})(\mathrm{Br}) \mathrm{H})(\mathrm{H}) \mathrm{F})(\mathrm{H}) \mathrm{H})(\mathrm{F}) \mathrm{H})(\mathrm{H}) \mathrm{H})(\mathrm{H})$

$\mathrm{H})(\mathrm{H}) \mathrm{H})(\mathrm{H}) \mathrm{H})(\mathrm{Cl}) \mathrm{H})(\mathrm{H}) \mathrm{H})(\mathrm{H}) \mathrm{H})(\mathrm{H}) \mathrm{H})(\mathrm{H}) \mathrm{H})(\mathrm{H}) \mathrm{H})(\mathrm{F}) \mathrm{H})(\mathrm{F}) \mathrm{H})(\mathrm{H})(\mathrm{H}) \mathrm{H}$

$\mathrm{C} 20 \mathrm{H} 34 \mathrm{ClBrF} 6$

$\mathrm{C}\left(\mathrm{C}\left(\mathrm{C}\left(\mathrm{C}\left(\mathrm{C}\left(\mathrm{C}\left(\mathrm{C}\left(\mathrm{C}\left(\mathrm{C}\left(\mathrm{C}\left(\mathrm{C}\left(\mathrm{C}(\mathrm{C}(\mathrm{C}(\mathrm{C}(\mathrm{C}(\mathrm{C}(\mathrm{C}(\mathrm{C}(\mathrm{C}(\mathrm{F})(\mathrm{H}) \mathrm{F})(\mathrm{H}) \mathrm{H})(\mathrm{H}) \mathrm{H})(\mathrm{H}) \mathrm{H})(\mathrm{H}) \mathrm{H})(\mathrm{H}) \mathrm{H})(\mathrm{H}) \mathrm{H})(\mathrm{H}) \mathrm{H})(\mathrm{H}){ }_{\mathrm{C} 20 \mathrm{H} 35 \mathrm{BrF} 6}\right.\right.\right.\right.\right.\right.\right.\right.\right.\right.\right.$

$\mathrm{H})(\mathrm{H}) \mathrm{F})(\mathrm{H}) \mathrm{H})(\mathrm{H}) \mathrm{F})(\mathrm{H}) \mathrm{H})(\mathrm{H}) \mathrm{H})(\mathrm{H}) \mathrm{H})(\mathrm{F}) \mathrm{H})(\mathrm{H}) \mathrm{H})(\mathrm{F}) \mathrm{H})(\mathrm{H}) \mathrm{H})(\mathrm{H})(\mathrm{H}) \mathrm{Br}$

$\mathrm{C} 20 \mathrm{H} 35 \mathrm{BrF} 6$

$\mathrm{C}(\mathrm{C}(\mathrm{C}(\mathrm{C}(\mathrm{C}(\mathrm{C}(\mathrm{C}(\mathrm{C}(\mathrm{C}(\mathrm{C}(\mathrm{C}(\mathrm{C}(\mathrm{C}(\mathrm{C}(\mathrm{C}(\mathrm{C}(\mathrm{C}(\mathrm{C}(\mathrm{C}(\mathrm{C}(\mathrm{H})(\mathrm{H}) \mathrm{F})(\mathrm{H}) \mathrm{H})(\mathrm{F}) \mathrm{H})(\mathrm{H}) \mathrm{H})(\mathrm{H}) \mathrm{H})(\mathrm{H}) \mathrm{H})(\mathrm{H}) \mathrm{H})(\mathrm{F}) \mathrm{H})(\mathrm{Cl})$

$\mathrm{H})(\mathrm{H}) \mathrm{H})(\mathrm{H}) \mathrm{H})(\mathrm{H}) \mathrm{F})(\mathrm{H}) \mathrm{H})(\mathrm{H}) \mathrm{H})(\mathrm{H}) \mathrm{H})(\mathrm{H}) \mathrm{H})(\mathrm{H}) \mathrm{Br})(\mathrm{H}) \mathrm{H})(\mathrm{F}) \mathrm{H})(\mathrm{H})(\mathrm{H}) \mathrm{H}$

C20H35C6

$\mathrm{C}(\mathrm{C}(\mathrm{C}(\mathrm{C}(\mathrm{C}(\mathrm{C}(\mathrm{C}(\mathrm{C}(\mathrm{C}(\mathrm{C}(\mathrm{C}(\mathrm{C}(\mathrm{C}(\mathrm{C}(\mathrm{C}(\mathrm{C}(\mathrm{C}(\mathrm{C}(\mathrm{C}(\mathrm{C}(\mathrm{H})(\mathrm{H}) \mathrm{H})(\mathrm{Cl}) \mathrm{H})(\mathrm{H}) \mathrm{H})(\mathrm{H})$
$\mathrm{H})(\mathrm{H}) \mathrm{H})(\mathrm{F}) \mathrm{H})(\mathrm{F}) \mathrm{H})(\mathrm{F}) \mathrm{H})(\mathrm{H}) \mathrm{H})(\mathrm{H}) \mathrm{H})(\mathrm{H}) \mathrm{H}(\mathrm{H}) \mathrm{H})(\mathrm{H}) \mathrm{H})(\mathrm{H}) \mathrm{H})(\mathrm{H})(\mathrm{H}) \mathrm{F}$

$\mathrm{C} 20 \mathrm{H} 35 \mathrm{ClF} 6$

$\mathrm{C}\left(\mathrm{C}\left(\mathrm{C}\left(\mathrm{C}\left(\mathrm{C}\left(\mathrm{C}\left(\mathrm{C}\left(\mathrm{C}\left(\mathrm{C}\left(\mathrm{C}\left(\mathrm{C}\left(\mathrm{C}(\mathrm{C}(\mathrm{C}(\mathrm{C}(\mathrm{C}(\mathrm{C}(\mathrm{C}(\mathrm{C}(\mathrm{C}(\mathrm{H})(\mathrm{H}) \mathrm{H})(\mathrm{H}) \mathrm{F})(\mathrm{H}) \mathrm{H})(\mathrm{H}) \mathrm{H})(\mathrm{H}) \mathrm{H})(\mathrm{F}) \mathrm{H})(\mathrm{H}) \mathrm{H})(\mathrm{H}) \mathrm{H})(\mathrm{H}) \quad{ }_{\mathrm{C} 20 \mathrm{H}} 36 \mathrm{BrF} 5\right.\right.\right.\right.\right.\right.\right.\right.\right.\right.\right.$

$\mathrm{H})(\mathrm{H}) \mathrm{F})(\mathrm{H}) \mathrm{H})(\mathrm{H}) \mathrm{H})(\mathrm{H}) \mathrm{F})(\mathrm{H}) \mathrm{H})(\mathrm{H}) \mathrm{Br})(\mathrm{H}) \mathrm{H})(\mathrm{H}) \mathrm{H})(\mathrm{F}) \mathrm{H})(\mathrm{H}) \mathrm{H})(\mathrm{H})(\mathrm{H}) \mathrm{H}$

$\mathrm{C} 20 \mathrm{H} 36 \mathrm{BrF} 5$

$\mathrm{H})(\mathrm{H}) \mathrm{H})(\mathrm{F}) \mathrm{H})(\mathrm{H}) \mathrm{H})(\mathrm{H}) \mathrm{H})(\mathrm{H}) \mathrm{H})(\mathrm{F}) \mathrm{H})(\mathrm{H}) \mathrm{H})(\mathrm{H}) \mathrm{H})(\mathrm{H}) \mathrm{H})(\mathrm{Br}) \mathrm{H})(\mathrm{H})(\mathrm{H}) \mathrm{H}$

$\mathrm{C} 20 \mathrm{H} 37 \mathrm{BrF} 4$

$\mathrm{C}\left(\mathrm{C}\left(\mathrm{C}\left(\mathrm{C}\left(\mathrm{C}\left(\mathrm{C}\left(\mathrm{C}\left(\mathrm{C}\left(\mathrm{C}\left(\mathrm{C}\left(\mathrm{C}\left(\mathrm{C}(\mathrm{C}(\mathrm{C}(\mathrm{C}(\mathrm{C}(\mathrm{C}(\mathrm{C}(\mathrm{C}(\mathrm{C}(\mathrm{F})(\mathrm{H}) \mathrm{F})(\mathrm{H}) \mathrm{H})(\mathrm{H}) \mathrm{H})(\mathrm{H}) \mathrm{H})(\mathrm{H}) \mathrm{H})(\mathrm{Cl}) \mathrm{H})(\mathrm{H}) \mathrm{H})(\mathrm{H}) \mathrm{H})(\mathrm{H}){ }^{\mathrm{C}} 20 \mathrm{H} 37 \mathrm{ClF} 4\right.\right.\right.\right.\right.\right.\right.\right.\right.\right.\right.$

$\mathrm{H})(\mathrm{H}) \mathrm{H})(\mathrm{F}) \mathrm{H})(\mathrm{H}) \mathrm{H})(\mathrm{H}) \mathrm{H})(\mathrm{H}) \mathrm{H})(\mathrm{H}) \mathrm{F})(\mathrm{H}) \mathrm{H})(\mathrm{H}) \mathrm{H})(\mathrm{H}) \mathrm{H})(\mathrm{H}) \mathrm{H})(\mathrm{H})(\mathrm{H}) \mathrm{H}$

C20H37F5

$\mathrm{C}(\mathrm{C}(\mathrm{C}(\mathrm{C}(\mathrm{C}(\mathrm{C}(\mathrm{C}(\mathrm{C}(\mathrm{C}(\mathrm{C}(\mathrm{C}(\mathrm{C}(\mathrm{C}(\mathrm{C}(\mathrm{C}(\mathrm{C}(\mathrm{C}(\mathrm{C}(\mathrm{C}(\mathrm{C}(\mathrm{H})(\mathrm{H}) \mathrm{F})(\mathrm{F}) \mathrm{H})(\mathrm{H}) \mathrm{H})(\mathrm{H}) \mathrm{H})(\mathrm{H}) \mathrm{H})(\mathrm{F}) \mathrm{H})(\mathrm{H}) \mathrm{F})(\mathrm{H}) \mathrm{H})(\mathrm{H})$

$\mathrm{H})(\mathrm{H}) \mathrm{H})(\mathrm{H}) \mathrm{H})(\mathrm{H}) \mathrm{H})(\mathrm{H}) \mathrm{H})(\mathrm{H}) \mathrm{H})(\mathrm{H}) \mathrm{H})(\mathrm{H}) \mathrm{H})(\mathrm{H}) \mathrm{H})(\mathrm{H}) \mathrm{H})(\mathrm{H}) \mathrm{H})(\mathrm{H})(\mathrm{H}) \mathrm{F}$

C20

$\mathrm{H})(\mathrm{H}) \mathrm{H})(\mathrm{H}) \mathrm{H})(\mathrm{H}) \mathrm{H})(\mathrm{H}) \mathrm{H})(\mathrm{H}) \mathrm{H})(\mathrm{H}) \mathrm{H})(\mathrm{H}) \mathrm{H})(\mathrm{H}) \mathrm{H})(\mathrm{F}) \mathrm{H})(\mathrm{H}) \mathrm{H})(\mathrm{H})(\mathrm{H}) \mathrm{H}$

$\mathrm{C}(\mathrm{C}(\mathrm{C}(\mathrm{C}(\mathrm{C}(\mathrm{C}(\mathrm{C}(\mathrm{C}(\mathrm{C}(\mathrm{C}(\mathrm{C}(\mathrm{C}(\mathrm{C}(\mathrm{C}(\mathrm{C}(\mathrm{C}(\mathrm{C}(\mathrm{C}(\mathrm{C}(\mathrm{C}(\mathrm{H})(\mathrm{H}) \mathrm{H})(\mathrm{H}) \mathrm{H})(\mathrm{F}) \mathrm{H})(\mathrm{H}) \mathrm{H})(\mathrm{H}) \mathrm{H})(\mathrm{Cl}) \mathrm{H})(\mathrm{H}) \mathrm{H})(\mathrm{H}) \mathrm{H})$

$(\mathrm{H}) \mathrm{H})(\mathrm{H}) \mathrm{H})(\mathrm{H}) \mathrm{H})(\mathrm{H}) \mathrm{H})(\mathrm{H}) \mathrm{H})(\mathrm{H}) \mathrm{H})(\mathrm{F}) \mathrm{H})(\mathrm{H}) \mathrm{H})(\mathrm{H}) \mathrm{F})(\mathrm{H}) \mathrm{H})(\mathrm{H}) \mathrm{H})(\mathrm{H})(\mathrm{H}) \mathrm{H}$

$\mathrm{C}(\mathrm{C}(\mathrm{C}(\mathrm{C}(\mathrm{C}(\mathrm{C}(\mathrm{C}(\mathrm{C}(\mathrm{C}(\mathrm{C}(\mathrm{C}(\mathrm{C}(\mathrm{C}(\mathrm{C}(\mathrm{C}(\mathrm{C}(\mathrm{C}(\mathrm{C}(\mathrm{C}(\mathrm{C}(\mathrm{H})(\mathrm{F}) \mathrm{H})(\mathrm{H}) \mathrm{H})(\mathrm{H}) \mathrm{H})(\mathrm{H}) \mathrm{H})(\mathrm{F}) \mathrm{H})(\mathrm{H}) \mathrm{H})(\mathrm{H}) \mathrm{H})(\mathrm{H}) \mathrm{H})(\mathrm{F})$

$\mathrm{H})(\mathrm{H}) \mathrm{H})(\mathrm{H}) \mathrm{F})(\mathrm{H}) \mathrm{H})(\mathrm{H}) \mathrm{H})(\mathrm{H}) \mathrm{H})(\mathrm{H}) \mathrm{H})(\mathrm{H}) \mathrm{H})(\mathrm{H}) \mathrm{H})(\mathrm{H}) \mathrm{H})(\mathrm{H}) \mathrm{H})(\mathrm{H})(\mathrm{H}) \mathrm{H}$

$\mathrm{C} 20 \mathrm{H} 38 \mathrm{ClF} 3$

$\mathrm{C}(\mathrm{C}(\mathrm{C}(\mathrm{C}(\mathrm{C}(\mathrm{C}(\mathrm{C}(\mathrm{C}(\mathrm{C}(\mathrm{C}(\mathrm{C}(\mathrm{C}(\mathrm{C}(\mathrm{C}(\mathrm{C}(\mathrm{C}(\mathrm{C}(\mathrm{C}(\mathrm{C}(\mathrm{C}(\mathrm{H})(\mathrm{H}) \mathrm{H})(\mathrm{H}) \mathrm{H})(\mathrm{H}) \mathrm{F})(\mathrm{H}) \mathrm{F})(\mathrm{H}) \mathrm{H})(\mathrm{H}) \mathrm{H})(\mathrm{H}) \mathrm{H})(\mathrm{H}) \mathrm{H})(\mathrm{H})$

$\mathrm{H})(\mathrm{H}) \mathrm{H})(\mathrm{H}) \mathrm{H})(\mathrm{H}) \mathrm{H})(\mathrm{H}) \mathrm{H})(\mathrm{H}) \mathrm{H})(\mathrm{H}) \mathrm{H})(\mathrm{H}) \mathrm{H})(\mathrm{H}) \mathrm{H})(\mathrm{H}) \mathrm{H})(\mathrm{H}) \mathrm{H})(\mathrm{F})(\mathrm{H}) \mathrm{H}$

$\mathrm{C} 2 \mathrm{OH} 38 \mathrm{~F} 4$

$\mathrm{C}\left(\mathrm{C}\left(\mathrm{C}\left(\mathrm{C}\left(\mathrm{C}\left(\mathrm{C}\left(\mathrm{C}\left(\mathrm{C}\left(\mathrm{C}\left(\mathrm{C}\left(\mathrm{C}\left(\mathrm{C}(\mathrm{C}(\mathrm{C}(\mathrm{C}(\mathrm{C}(\mathrm{C}(\mathrm{C}(\mathrm{C}(\mathrm{C}(\mathrm{H})(\mathrm{H}) \mathrm{H})(\mathrm{H}) \mathrm{H})(\mathrm{H}) \mathrm{F})(\mathrm{H}) \mathrm{H})(\mathrm{H}) \mathrm{H})(\mathrm{H}) \mathrm{H})(\mathrm{H}) \mathrm{H})(\mathrm{H}) \mathrm{H})(\mathrm{H}){ }_{\mathrm{C} 20 \mathrm{H} 40 \mathrm{~F} 2}\right.\right.\right.\right.\right.\right.\right.\right.\right.\right.\right.$

$\mathrm{H})(\mathrm{H}) \mathrm{H})(\mathrm{H}) \mathrm{H})(\mathrm{H}) \mathrm{H})(\mathrm{H}) \mathrm{H})(\mathrm{H}) \mathrm{H})(\mathrm{H}) \mathrm{H})(\mathrm{H}) \mathrm{H})(\mathrm{H}) \mathrm{H})(\mathrm{H}) \mathrm{H})(\mathrm{H}) \mathrm{H})(\mathrm{H})(\mathrm{F}) \mathrm{H}$

等

$(\mathrm{H}) \mathrm{H})(\mathrm{H}) \mathrm{H})(\mathrm{F}) \mathrm{H})(\mathrm{H}) \mathrm{H})(\mathrm{H}) \mathrm{F})(\mathrm{H}) \mathrm{F})(\mathrm{H}) \mathrm{H})(\mathrm{H}) \mathrm{H})(\mathrm{Cl}) \mathrm{H})(\mathrm{Cl}) \mathrm{H})(\mathrm{H}) \mathrm{F})(\mathrm{H}) \mathrm{H})(\mathrm{H})(\mathrm{H}) \mathrm{H}$

$\mathrm{C}(\mathrm{C}(\mathrm{C}(\mathrm{C}(\mathrm{C}(\mathrm{C}(\mathrm{C}(\mathrm{C}(\mathrm{C}(\mathrm{C}(\mathrm{C}(\mathrm{C}(\mathrm{C}(\mathrm{C}(\mathrm{C}(\mathrm{C}(\mathrm{C}(\mathrm{C}(\mathrm{C}(\mathrm{C}(\mathrm{C}(\mathrm{H})(\mathrm{H}) \mathrm{H})(\mathrm{H}) \mathrm{H})(\mathrm{H}) \mathrm{H})(\mathrm{H}) \mathrm{H})(\mathrm{H}) \mathrm{H})(\mathrm{H}) \mathrm{F})(\mathrm{H}) \mathrm{F})(\mathrm{F}) \mathrm{H})($

$\mathrm{H}) \mathrm{H})(\mathrm{H}) \mathrm{H})(\mathrm{H}) \mathrm{H})(\mathrm{F}) \mathrm{H})(\mathrm{H}) \mathrm{Cl}(\mathrm{H}) \mathrm{H})(\mathrm{H}) \mathrm{H})(\mathrm{H}) \mathrm{H})(\mathrm{H}) \mathrm{H})(\mathrm{H}) \mathrm{H})(\mathrm{F}) \mathrm{H})(\mathrm{H}) \mathrm{H})(\mathrm{F})(\mathrm{F}) \mathrm{H}$

$\mathrm{C} 21 \mathrm{H} 31 \mathrm{Cl} 2 \mathrm{BrF} 10$

$\mathrm{C}(\mathrm{C}(\mathrm{C}(\mathrm{C}(\mathrm{C}(\mathrm{C}(\mathrm{C}(\mathrm{C}(\mathrm{C}(\mathrm{C}(\mathrm{C}(\mathrm{C}(\mathrm{C}(\mathrm{C}(\mathrm{C}(\mathrm{C}(\mathrm{C}(\mathrm{C}(\mathrm{C}(\mathrm{C}(\mathrm{C}(\mathrm{H})(\mathrm{H}) \mathrm{H})(\mathrm{H}) \mathrm{H})(\mathrm{H}) \mathrm{H})(\mathrm{H}) \mathrm{H})(\mathrm{H}) \mathrm{H})(\mathrm{H}) \mathrm{H})(\mathrm{H}) \mathrm{F})(\mathrm{H}) \mathrm{H})($

$\mathrm{H}) \mathrm{H})(\mathrm{F}) \mathrm{H})(\mathrm{H}) \mathrm{H})(\mathrm{H}) \mathrm{Cl}(\mathrm{H}) \mathrm{F})(\mathrm{F}) \mathrm{H})(\mathrm{F}) \mathrm{H})(\mathrm{H}) \mathrm{H})(\mathrm{H}) \mathrm{H})(\mathrm{F}) \mathrm{H})(\mathrm{H}) \mathrm{H})(\mathrm{H}) \mathrm{H})(\mathrm{H})(\mathrm{H}) \mathrm{H}$

$\mathrm{C} 21 \mathrm{H} 36 \mathrm{ClF} 7$

$\mathrm{C}(\mathrm{C}(\mathrm{C}(\mathrm{C}(\mathrm{C}(\mathrm{C}(\mathrm{C}(\mathrm{C}(\mathrm{C}(\mathrm{C}(\mathrm{C}(\mathrm{C}(\mathrm{C}(\mathrm{C}(\mathrm{C}(\mathrm{C}(\mathrm{C}(\mathrm{C}(\mathrm{C}(\mathrm{C}(\mathrm{C}(\mathrm{H})(\mathrm{H}) \mathrm{H})(\mathrm{H}) \mathrm{H})(\mathrm{H}) \mathrm{H})(\mathrm{H}) \mathrm{H})(\mathrm{H}) \mathrm{H})(\mathrm{H}) \mathrm{H})(\mathrm{F}) \mathrm{H})(\mathrm{H}) \mathrm{H})($

$\mathrm{H}) \mathrm{H})(\mathrm{F}) \mathrm{H})(\mathrm{F}) \mathrm{H})(\mathrm{H}) \mathrm{F})(\mathrm{H}) \mathrm{H})(\mathrm{H}) \mathrm{H})(\mathrm{H}) \mathrm{H})(\mathrm{H}) \mathrm{H})(\mathrm{H}) \mathrm{F})(\mathrm{H}) \mathrm{H})(\mathrm{H}) \mathrm{H})(\mathrm{H}) \mathrm{H})(\mathrm{H})(\mathrm{H}) \mathrm{H}$

$\begin{array}{lllllllll}6.81 & 10.06 & 3.25 & 10.09 & 6.84 & 3.25 & 8.49 & 10.52 & -2.03\end{array}$

$\begin{array}{lllllllll}6.164 & 9.68 & 3.52 & 9.52 & 6.01 & 3.52 & 8.20 & 9.34 & -1.14\end{array}$

$\begin{array}{lllllllll}5.611 & 9.58 & 3.97 & 9.37 & 5.40 & 3.97 & 8.12 & 8.32 & -0.20\end{array}$

$\begin{array}{lllllllll}6.672 & 9.89 & 3.22 & 9.84 & 6.62 & 3.22 & 8.36 & 10.27 & -1.91\end{array}$

$\begin{array}{lllllllll}6.108 & 9.78 & 3.67 & 9.67 & 6.00 & 3.67 & 8.27 & 9.23 & -0.96\end{array}$

$\begin{array}{lllllllll}7.101 & 10.02 & 2.92 & 10.03 & 7.11 & 2.92 & 8.46 & 11.06 & -2.60\end{array}$

$\begin{array}{lllllllll}5.464 & 9.62 & 4.16 & 9.43 & 5.28 & 4.16 & 8.15 & 8.05 & 0.10\end{array}$

$\begin{array}{lllllllll}6.398 & 9.77 & 3.37 & 9.66 & 6.28 & 3.37 & 8.27 & 9.77 & -1.50\end{array}$

$\begin{array}{llllllllll}6.906 & 9.98 & 3.07 & 9.97 & 6.90 & 3.07 & 8.43 & 10.70 & -2.27\end{array}$

$\begin{array}{lllllllll}6.332 & 9.89 & 3.56 & 9.84 & 6.28 & 3.56 & 8.36 & 9.64 & -1.29\end{array}$

$\begin{array}{lllllllll}5.339 & 9.65 & 4.31 & 9.48 & 5.17 & 4.31 & 8.17 & 7.82 & 0.35\end{array}$

$\begin{array}{lllllllll}7.254 & 10.03 & 2.78 & 10.04 & 7.27 & 2.78 & 8.47 & 11.34 & -2.87\end{array}$

$\begin{array}{lllllllll}6.69 & 9.95 & 3.26 & 9.93 & 6.67 & 3.26 & 8.40 & 10.30 & -1.90\end{array}$

$\begin{array}{lllllllll}5.699 & 9.71 & 4.01 & 9.57 & 5.56 & 4.01 & 8.22 & 8.48 & -0.26\end{array}$

$\begin{array}{lllllllll}6.128 & 9.84 & 3.71 & 9.76 & 6.05 & 3.71 & 8.32 & 9.27 & -0.95\end{array}$

$\begin{array}{lllllllll}6.556 & 9.97 & 3.41 & 9.96 & 6.54 & 3.41 & 8.42 & 10.06 & -1.64\end{array}$

$\begin{array}{lllllllll}5.947 & 10.03 & 4.08 & 10.04 & 5.96 & 4.08 & 8.47 & 8.94 & -0.47\end{array}$

$\begin{array}{lllllllll}5.402 & 9.98 & 4.58 & 9.97 & 5.39 & 4.58 & 8.43 & 7.94 & 0.49\end{array}$

$\begin{array}{lllllllll}5.761 & 10.04 & 4.28 & 10.06 & 5.78 & 4.28 & 8.47 & 8.60 & -0.12\end{array}$

$\begin{array}{lllllllll}5.556 & 9.99 & 4.43 & 9.99 & 5.55 & 4.43 & 8.44 & 8.22 & 0.22\end{array}$ 


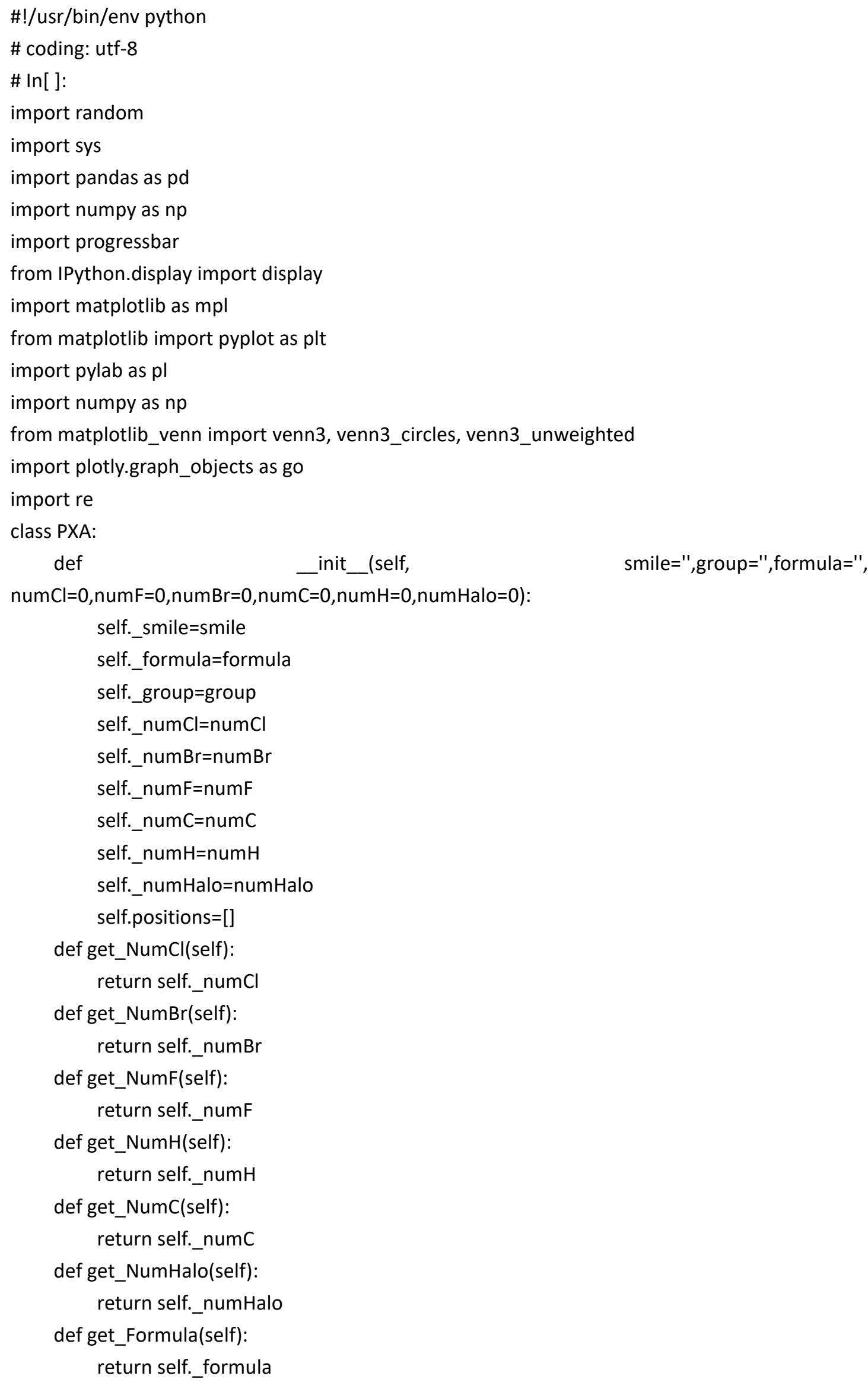


def split(self,word):

return [char for char in word]

\# This section contains functions needed to generate the SMILES structures of all linear isomers of a compound

\#Generates all permutations of a string without repetitions

def permutation(self, $\mathrm{nCl}=0, \mathrm{nF}=0, \mathrm{nBr}=0$ ):

elementsList=[]

numHalo=nCl $+n F+n B r$

for $\mathrm{i}$ in range(0,self._numH): elementsList.append('H')

if $\mathrm{nCl}>0$ :

for $\mathrm{x}$ in range $(0, \mathrm{nCl})$ : elementsList.append(' $\mathrm{C}$ ')

if $\mathrm{nF}>0$ :

for $\mathrm{x}$ in range $(0, \mathrm{nF})$ : elementsList.append('F')

if $\mathrm{nBr}>0$ :

for $x$ in range $(0, n B r)$ : elementsList.append('B')

perms $=[[]]$

for $\mathrm{n}$ in elementsList:

new_perm $=$ []

for perm in perms:

for $\mathrm{i}$ in range $($ len $($ perm $)+1)$ :

new_perm.append(perm[:i] + [n] + perm[i:])

\# handle duplication

if $\mathrm{i}<$ len(perm) and perm $[\mathrm{i}]==\mathrm{n}$ : break

perms $=$ new_perm

return perms

\#Searches for positions in a string which a specific character appears

def duplicates(self,seq,item):

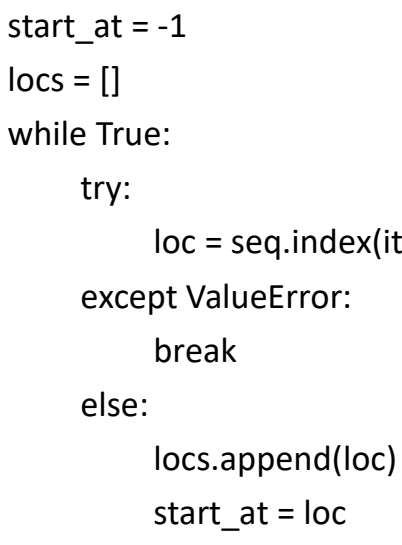

return locs

\# Replaces a hydrogen from the C-H SMILES structure with a halogen, guided by a permutation

def replaceSmileFromPermutation(self,positions_1=[],positions_2=[], positions_3=[], maxH=0, halo_1="',halo_2="", halo_3="',smile="",cont=0):

cont $=0$

smile=self.split(smile) 
for index in range(0,len(smile)):

if smile[index] != 'H':

continue

else:

cont $+=1$

if positions_1:

if (cont-1) in positions_1:

smile[index]=halo_1

if positions_2:

if (cont-1) in positions_2:

smile[index]=halo_2

if positions_3:

if (cont-1) in positions_3:

smile[index]=halo_3

smile="".join(smile)

return smile

\# Generates all linear isomers of a compound which group corresponds to a single halogen

def generateGroupOfOne(self,group="'"):

numH=self._numH

allPossibleSmiles=[]

elementToLook="

halo="'"

if group=="Cl":

perms=self.permutation( $\mathrm{nCl}=$ self._numCl)

elementToLook=' $\mathrm{C}^{\prime}$

halo="Cl"

if group=="F":

perms=self.permutation( $\mathrm{nF}=$ self._numF)

elementToLook=' $F$ '

halo="F"

if group=="Br":

perms=self.permutation( $\mathrm{nBr}=$ self._numBr)

elementToLook='B'

halo="Br"

for $p$ in perms:

smile=self._smile

elementInPerms=".join( $p$ )

positions=self.duplicates(elementInPerms,elementToLook)

smile=self.replaceSmileFromPermutation(positions_1=positions, maxH=numH,halo_1=halo,smile= smile)

allPossibleSmiles.append(smile)

return allPossibleSmiles

\# Generates all linear isomers of a compound which group corresponds to two halogens def generateGroupOfTwo(self,group="): 


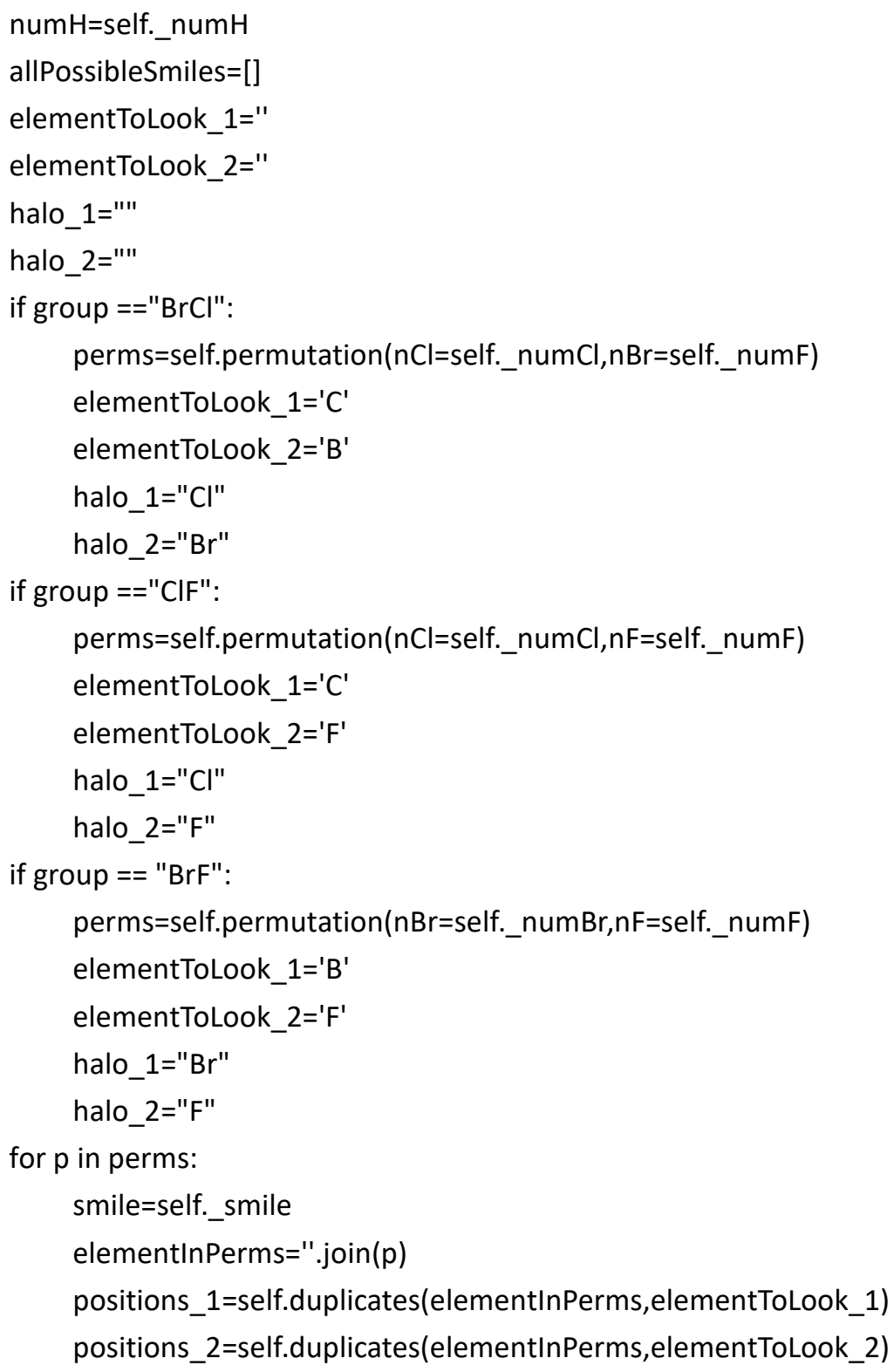

smile=self.replaceSmileFromPermutation(positions_1=positions_1,positions_2=positions_2,maxH =numH,halo_1=halo_1,halo_2=halo_2,smile=smile)

allPossibleSmiles.append(smile)

return allPossibleSmiles

\# Generates all linear isomers of a compound which group corresponds to three halogens def generateGroupOfThree(self,group=""):

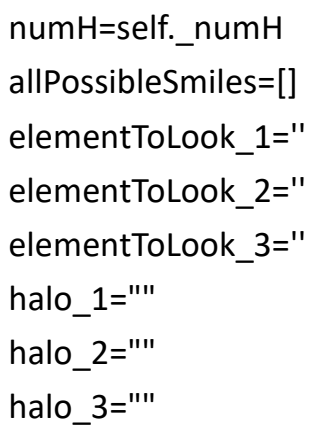




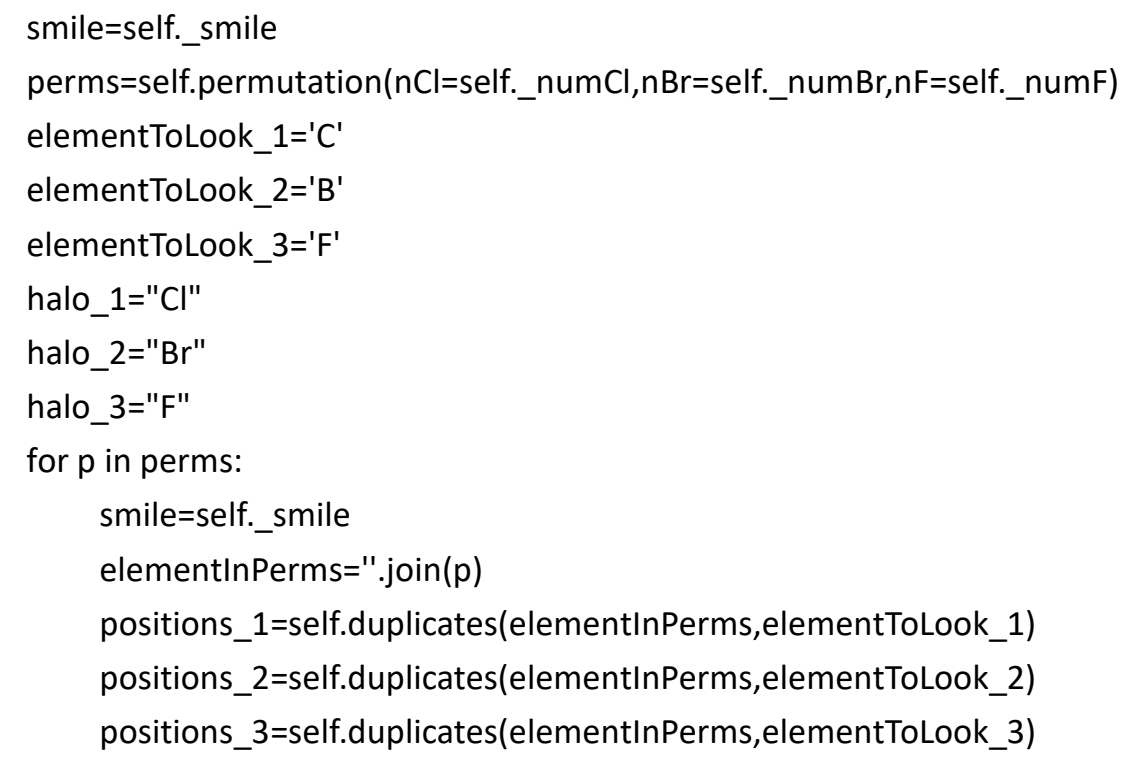

smile=self.replaceSmileFromPermutation(positions_1=positions_1,positions_2=positions_2,positi ons_3=positions_3,maxH=numH,halo_1=halo_1,halo_2=halo_2,halo_3=halo_3,smile=smile)

allPossibleSmiles.append(smile)

return allPossibleSmiles

def generateAllPossible(self):

allPossibleSmiles $=[]$

self._smile=self.generate_CH_Smile()

if self._group =="Cl" :

allPossibleSmiles=self.generateGroupOfOne(self._group)

elif self._group =="Br":

allPossibleSmiles=self.generateGroupOfOne(self._group)

elif self._group =="F":

allPossibleSmiles=self.generateGroupOfOne(self._group)

elif self._group =="BrCl":

allPossibleSmiles=self.generateGroupOfTwo(self._group)

elif self._group =="CIF":

allPossibleSmiles=self.generateGroupOfTwo(self._group)

elif self._group == "BrF":

allPossibleSmiles=self.generateGroupOfTwo(self._group)

elif self._group == "BrClF":

allPossibleSmiles=self.generateGroupOfThree(self._group)

else:

print("Group not recognized")

return

return allPossibleSmiles

\# Replaces multiple strings at a time

def replaceMultiple(self, mainString, toBeReplaced, newString):

for elem in toBeReplaced : 
if elem in mainString :

mainString = mainString $\cdot$ replace(elem, newString)

return mainString

\#Generates a SMILES structure in a format containing just carbon and hydrogen by reading a chemical formula $\left(\mathrm{CnH} 2{ }^{*} \mathrm{n}+2\right)$.

\# Example: For the chemical formula: $\mathrm{C1OH} 22$, the SMILES: ' $\mathrm{C}(\mathrm{C}(\mathrm{C}(\mathrm{C}(\mathrm{C}(\mathrm{C}(\mathrm{C}(\mathrm{C}(\mathrm{C}(\mathrm{C}(\mathrm{H})(\mathrm{H}) \mathrm{H})(\mathrm{H}) \mathrm{H})(\mathrm{H}) \mathrm{H})(\mathrm{H}) \mathrm{H})(\mathrm{H}) \mathrm{H})(\mathrm{H}) \mathrm{H})(\mathrm{H}) \mathrm{H})(\mathrm{H}) \mathrm{H})(\mathrm{H}) \mathrm{H})(\mathrm{H})(\mathrm{H}) \mathrm{H}^{\prime}$ is generated.

\# A second option is added, where the SMILES can be generated by inputing the number of carbons and hydrogens instead of the chemical formula.

def generate_CH_Smile(self):

if self._numH $>0$ and self._numC $>0$ :

total_H=self._numH+self._numCl+self._numBr+self._numF

mult_H=int((total_H - 2)/2)

str_carbon= "C("*self._numC

str_H="H)(H)"*mult_H

newSmile=str_carbon+str_H+" $(\mathrm{H}) \mathrm{H} "$

else:

arr_formula=re.sub( r"([A-Z])", r" \1", self._formula).split()

numC=int(arr_formula[0].replace('C',"))

numH=int(arr_formula[1].replace('H',"))

total_H=numH

mult_H=int((total_H - 2)/2)

str_carbon= "C("*numC

str_H="H)(H)"*mult_H

newSmile=str_carbon+str_H+" $(H) H "$

return newSmile

\#Generates a halogenated SMILES structure by replacing a hydrogen ('H') with a halogen ('Cl','Br', or 'F')

\# When a carboxylic acid is added to the original structure, it replaces the string ' $\mathrm{X}$ ' with halogen instead of ' $\mathrm{H}$ ', this way the hydrogen corresponding to the acid is not edited

def generate(self,smile, num, halogen, toBeReplaced $\left.={ }^{\prime} H^{\prime}\right)$ :

smileStr=list(smile)

if num > len(smileStr):

smileStr=[halogen for $i$ in smileStr]

else:

$\mathrm{i}=0$

while i in range(num):

position=random.randrange( 0 ,len(smileStr))

if smileStr[position] == toBeReplaced:

while smileStr[position]==halogen:

position=random .randrange $(0$,len(smileStr) $)$

smileStr[position]=halogen

self.positions.append(position)

$\mathrm{i}=\mathrm{i}+1$ 
smileStr="'".join(smileStr)

return smilestr

\#Creates a halogenated structure containing just one halogen, i.e. Groups= " $\mathrm{Cl}$ ","Br",or "F"

\# Two options: 1) Manipulates a SMILES structure containing a carboxylic acid (Change variable 'carboxylic=True')

\#

2) Creates a new congener (Default, i.e 'carboxylic=False' )

def add_Group_Of_One(self,smile,x,numC,numH,group,halo,carboxylic=False):

non="

if carboxylic:

\# Returns new information of new structure with added Carboxylic acid

newSmile=self.generate(smile, $(x-1)$ if numH $==0$ else $x$,halo," $X ")$

num_halo $=(x-1)$ if numH $==0$ else $x$

numH $=($ numH +1$)$ if numH $==0$ else numH

numHalo $=x$

formula=f"C\{self._numC $\}$ H\{self._numH $\{$ halo $\}\{x$ if $x>1$ else non\}O2"

return newSmile, num_halo, numH, numHalo, formula

else:

\# Creates an individual row in dataframe for each new congener with columns ["SMILE","Group","Formula","Cl","F","Br","C","H","Halo"]

individualList=[]

individualList.extend([self.generate(smile, $x$, halo),group,f"C\{numC\}\{'H'if numH-x >

0 else " $\}$ numH-x if numH- $x>1$ else non $\}\{$ halo $\}\{x$ if $x>1$ else non $\} ", x$ if group $=={ }^{\prime} C l$ ' else $0, x$ if group $==' F$ else $0, x$ if group $==' B r$ else 0, numC,numH-x, $x$ ])

return individualList

\#Creates a halogenated structure containing two halogens, i.e. Groups= "ClF","BrCl",or "BrF"

\# Two options: 1) Manipulates a SMILES structure containing a carboxylic acid (Change variable 'carboxylic=True')

$\#$

2) Creates a new congener (Default, i.e 'carboxylic=False' )

def add_Group_Of_Two(self,smile,h1,h2,numC,numH,group,halo1, halo2,carboxylic=False):

non="

if carboxylic:

\# Returns new information of new structure with added Carboxylic acid newSmile=self.generate(smile,(h1-1) if numH == 0 else h1,halo1," $X ")$

newSmile=self.generate(newSmile,h2, halo2," $\mathrm{X}$ ")

num_halo1 $=($ h1-1) if self._numH $==0$ else $h 1$

numH $=($ numH +1$)$ if numH $==0$ else numH

numHalo=h1+h2

formula=f"C\{numC $\}$ HnumH $\}\{$ halo1 $\}\{$ h1 if h1 $>1$ else non $\}$ halo2 $\}$ h2 if h2 $>1$ else

non\}O2"

return newSmile, num_halo1, numH, numHalo, formula else:

\# Creates and individual row in dataframe for each congener with columns 


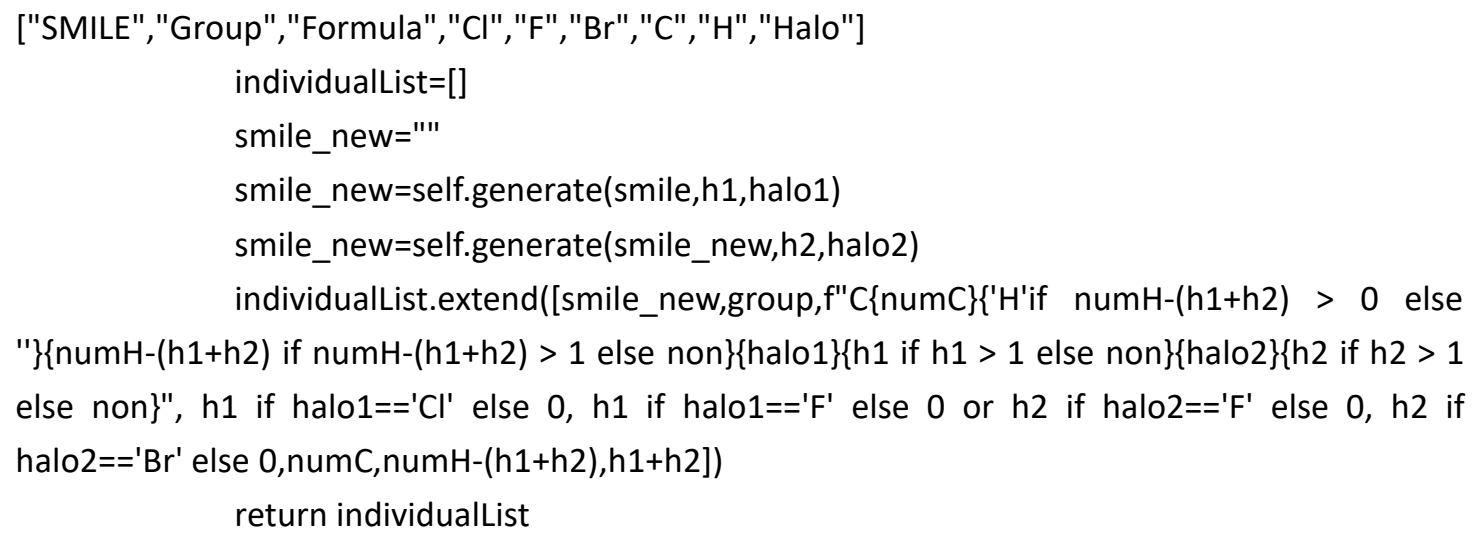

\# Generates all halogenated congeners' SMILES for a corresponding chemical formula read from a dataframe

def generate_Congeners(self,smile_CH,numH,numC):

all_Possible=[]

\#Generates all halogenated SMILES containing one halogen, i.e. Groups= "Cl","Br",and "F"

for $x$ in range $(1, \mathrm{numH}+1)$ :

individualList_Cl=self.add_Group_Of_One(smile_CH,x,numC,numH,'Cl','Cl')

individualList_F=self.add_Group_Of_One(smile_CH,x,numC,numH,'F','F')

individualList_Br=self.add_Group_Of_One(smile_CH,x,numC,numH,'Br','Br')

all_Possible.extend([individualList_Cl,individualList_F,individualList_Br])

\#Generates all halogenated SMILES containing two halogens, i.e. Groups= "ClF","BrCl",and "BrF"

for h1 in range(1,numH+2):

for $\mathrm{h} 2$ in range(1,(numH+1)-h1):

individualList_ClF=self.add_Group_Of_Two(smile_CH,h1,h2,numC,numH,'ClF',"Cl","F")

individualList_BrCl=self.add_Group_Of_Two(smile_CH,h1,h2,numC,numH,' $\mathrm{BrCl}$, "Cl", "Br")

individualList_BrF=self.add_Group_Of_Two(smile_CH,h1,h2, numC,numH, 'BrF',"F","Br")

all_Possible.extend([individualList_ClF,individualList_BrCl,individualList_BrF])

smile=""

individualList=[]

non=""

\#Generates all halogenated SMILES containing three halogen, i.e. Group= "BrCIF"

for $\mathrm{h} 1$ in range(1,numH+2):

for $\mathrm{h} 2$ in range(1,(numH+1)-h1):

for h3 in range $(1,($ num $H+1)-(h 1+h 2))$ :

individualList $=[]$

smile=self.generate(smile_CH,h1,"Cl")

smile=self.generate(smile,h2,"F")

smile=self.generate(smile,h3,"Br")

individualList.extend([smile,"BrClF",f"C\{numC $\}\{$ 'H'if numH-(h1+h2+h3) >

0 else " $\}\{$ numH-(h1+h2+h3) if numH-(h1+h2+h3) $>1$ else non $\} \operatorname{Br}\{h 3$ if h3 $>1$ else non $\} \mathrm{Cl}\{\mathrm{h} 1$ if $h 1>$ 
1 else non\}F\{h2 if h2 > 1 else non\}",h1,h2,h3,numC,numH-(h1+h2+h3),h1+h2+h3])

all_Possible.append(individualList)

return all_Possible

\# Generates a new random SMILES structure for existent congener, i.e. generates a new SMILES with the same amount of carbons, hydrogens, chlorines, flourines, and bromines. def generateRandomSMILE(self):

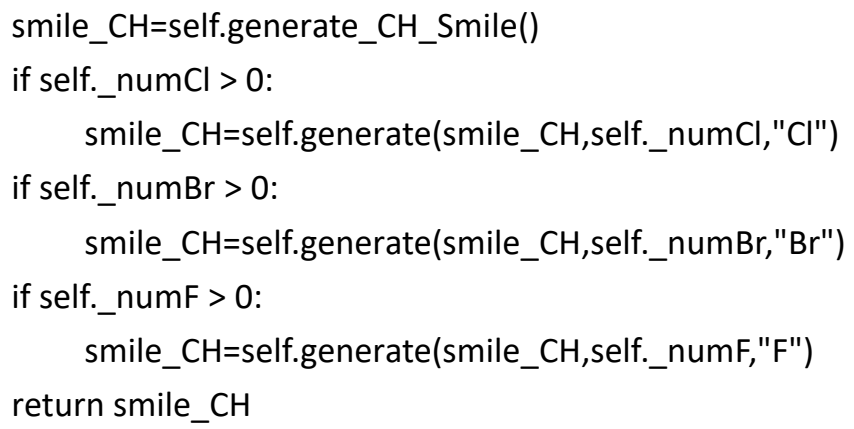

\# Generates a new SMILES structure with an added carboxylic acid for each congener, updating all the information of each compound, i.e. ["SMILE","Group","Formula","Cl","F","Br","C","H","Halo"]

def add_CarboxylicAcid(self):

newSmile=None

str_carbon= "C("*(self._numC +1$)$

str_carboxylic='=O)OH)'

str_X="(X)X)"*(self._numC-1)

newSmile=str_carbon+str_carboxylic+str_X+"(X)(X)X"

non="

self._numC+=1

if self._group $==$ 'Cl':

newSmile, self._numCl, self._numH, self._numHalo, self._formula =self.add_Group_Of_One(newSmile,self._numCl,self._numC,self._numH,self._group,"Cl",carboxyli $c=$ True)

if self._group $==$ ' $F$ ':

newSmile, self._numF, self._numH, self._numHalo, self._formula =self.add_Group_Of_One(newSmile,self._numF,self._numC,self._numH,self._group,"F",carboxylic $=$ True)

if self._group $==$ ' $B r$ ':

newSmile, self._numBr, self._numH, self._numHalo, self._formula =self.add_Group_Of_One(newSmile,self._numBr,self._numC,self._numH,self._group,"Br",carboxyl ic=True)

if self._group == 'BrCl':

newSmile, self._numBr, self._numH, self._numHalo,

self._formula=self.add_Group_Of_Two(newSmile,self._numBr,self._numCl,self._numC,self._numH, self._group,"Br","Cl",carboxylic=True)

if self._group == 'ClF':

newSmile, self._numCl, self._numH, self._numHalo, 
self._formula=self.add_Group_Of_Two(newSmile,self._numCl,self._numF,self._numC,self._numH, self._group,"Cl","F",carboxylic=True)

if self._group $==$ 'BrF':

newSmile, self._numBr, self._numH, self._numHalo,

self._formula=self.add_Group_Of_Two(newSmile,self._numBr,self._numF,self._numC,self._numH, self._group,"Br","F",carboxylic=True)

if self._group $==$ 'BrClF':

newSmile=self.generate(newSmile,(self._numBr-1) if self._numH $=0$ else

self._numBr,"Br","X")

newSmile=self.generate(newSmile,self._numF,"F","X")

newSmile=self.generate(newSmile,self._numCl,"Cl","X")

self._num $B r=$ self._numBr-1 if self._numH $==0$ else self._numBr

self._numH=self._numH +1 if self._numH $==0$ else self._numH

self._numHalo=self._numBr + self._numCl+self._numF

self._formula=f"C\{self._numC $\}$ H\{self._numH\}\{'Br' if self._numBr $>0$ else

non \}\{self._numBr if self._numBr $>1$ else non\}\{'Cl' if self._numCl $>0$ else non \}\{self._numCl if self._numCl $>1$ else non\} $\left\{{ }^{\prime}\right.$ ' if self._numF $>0$ else non $\}\{$ self._numF if self._numF $>1$ else non\}O2"

if self._numH $>0$ :

newSmile=self.generate(newSmile,(self._numH-1),"H","X")

return newSmile

\# Functions used in main function for generating SMILES structures \#

\# Generates all linear isomers of a single compound

\# Must enter the compound's chemical formula as a parameter

def

getlsomers(compound_formula):

num_C,num_H,num_Cl,num_F,num_Br,compound_group=getCompound_Information(compoun d_formula)

pxa=PXA(group=compound_group,numC=num_C,numH=num_H,numCl=num_Cl,numF=num_F,n umBr=num_Br)

all_isomers=pxa.generateAllPossible()

isomers_df $=$ pd.DataFrame (all_isomers,columns=['SMILE'])

return isomers $d f$

def getGroup(numCl,numF,numBr):

group $="$

if numCl $>0$ and numF $==0$ and numBr= $=0$ :

group="Cl"

if numF $>0$ and numCl= $=0$ and $n u m B r==0$ :

group="F"

if numBr $>0$ and numCl= $=0$ and numF $==0$ :

group="Br"

if numBr $>0$ and numCl>0 and numF $==0$ :

group $=" \mathrm{ClBr} "$ 


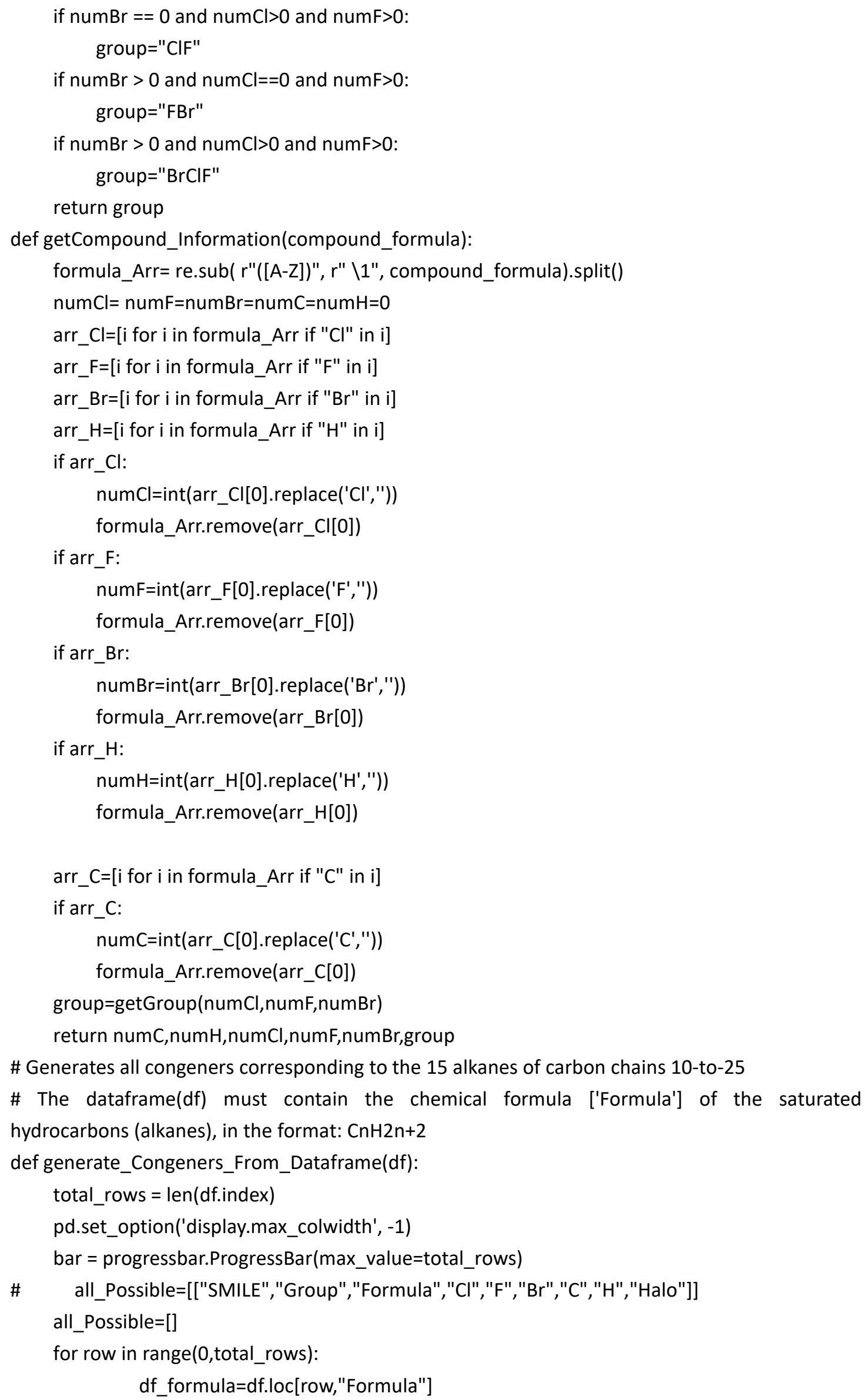




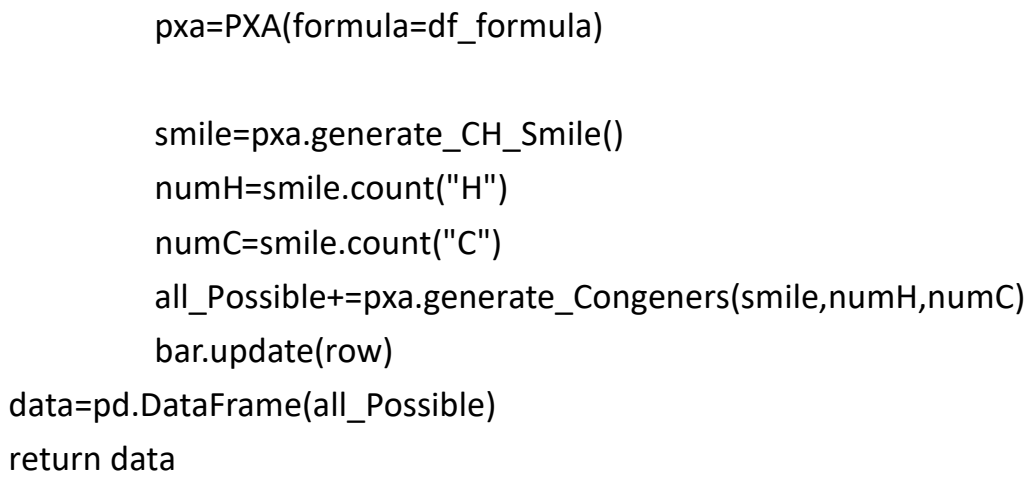




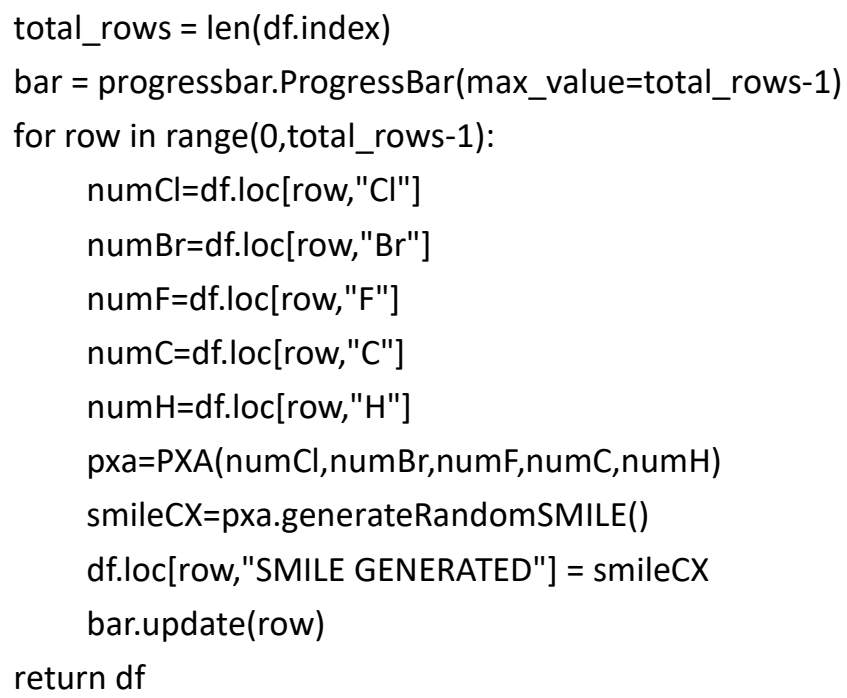

return $\mathrm{df}$

\# Generates a new random SMILES for one structure read as an input def individual_Input():

smile=input("\nEnter the SMILE structure: ")

numCl=int(input("\nEnter the number of Chlorines: "))

numBr=int(input("Enter the number of Bromines: "))

numF=int(input("Enter the number of Florines: "))

pxa=PXA(smile,numCl,numBr,numF)

print("\n"+pxa.generateRandomSMILE())

\# Generates a new random SMILES for group of structure read as inputs def group_Input():

num=int(input("Enter the amount of structures:"))

for $x$ in range $(0$, num $)$ :

smile=input("\nEnter the SMILE structure: ")

numCl=int(input("\nEnter the number of Chlorines: "))

numBr=int(input("Enter the number of Bromines: "))

numF=int(input("Enter the number of Florines: "))

pxa $=P X A($ smile, numCl,numBr,numF)

print("\n"+pxa.generateRandomSMILE())

\# Ths section contains the main function \#

def main():

\#STEP 1: Create a dataframe with the chemical formulas of the alkanes (carbon chain 10-to-25) $\mathrm{df}=$ pd.DataFrame $(\{' F o r m u l a ':[]\})$

numC $=10$

numH $=2$ *numC +2

for row in range $(0,4)$ :

df.loc[row,"Formula"]= f"C\{numC $\} \mathrm{H}\{$ numH $\} "$

numC $+=1$

numH=2*numC+2

total_rows=len(df.index)

pd.set_option('display.max_colwidth', -1)

bar $=$ progressbar.ProgressBar(max_value=total_rows) 
\# \#STEP 2: Generate all the possible linear congeners SMILES

\# congeners=generate_Congeners_From_Dataframe(df)

\# congeners_dataframe=pd.DataFrame(congeners)

["SMILE","Group","Formula","Cl","F","Br","C","H","Halo"]

\# \# $\quad$ congeners_dataframe.to_csv("Your-File.csv", index=False) \#-------------If wanted to save the dataframe as a CSV file

\# \#STEP 3: Add a carboxylic acid to each congener created above

\# congeners_carboxylic_dataframe=all_generateWithCarboxylic(congeners_dataframe) \#congeners_carboxylic_dataframe.to_csv("Your-File-Carboxylic.csv", index=False) ----------If wanted to save the dataframe as a CSV file

\#STEP 4: Generate all linear isomers of a compound for $x$ in range(row,total_rows):

formula=df.loc[row,"Formula"]

formula_Arr= re.sub( $r^{\prime \prime}([A-Z]) ", r^{\prime \prime} \backslash 1 "$, formula).split()

all_possible=[]

num $\mathrm{C}=$ num $\mathrm{H}=0$

arr_C=[i for $\mathrm{i}$ in formula_Arr if " $\mathrm{C}$ " in i]

arr_H=[i for i in formula_Arr if " $\mathrm{H}$ " in i]

if arr_C:

numC=int(arr_C[0].replace('C',"))

formula_Arr.remove(arr_C[0])

if arr_H:

numH=int(arr_H[0].replace('H',"))

formula_Arr.remove(arr_H[0])

bar.update(row)

for h1 in range(1,numH+1):

compound_isomers_dataframe=getlsomers(compound_formula=f'C $\{$ numC $\}\{" H$ " if numH-h1>0 else "' $\}\{$ numH-h1\}Cl\{h1\}')

all_possible.append(compound_isomers_dataframe)

\# bar.update(row)

result $=$ pd.concat(all_possible)

return results

\#compound_isomers_dataframe.to_csv("Your-File-Isomers.csv",

index=False)

$\# \ln []$ :

main() 